\title{
Wilson-Leonard An 11,000-year Archeological Record of Hunter- Gatherers in Central Texas Volume V: Special Studies
}

Michael B. Collins

Texas Archeological Research Laboratory

Barry Balinsky

Texas Archeological Research Laboratory

Joy Becker

Texas Archeological Research Laboratory

C. Britt Bousman

Department of Anthropology, Texas State University

Susan Decker

Texas Archeological Research Laboratory

See next page for additional authors

Follow this and additional works at: https://scholarworks.sfasu.edu/ita

Part of the American Material Culture Commons, Archaeological Anthropology Commons, Environmental Studies Commons, Other American Studies Commons, Other Arts and Humanities Commons, Other History of Art, Architecture, and Archaeology Commons, and the United States History Commons

Tell us how this article helped you.

This Article is brought to you for free and open access by the Center for Regional Heritage Research at SFA ScholarWorks. It has been accepted for inclusion in Index of Texas Archaeology: Open Access Gray Literature from the Lone Star State by an authorized editor of SFA ScholarWorks. For more information, please contact cdsscholarworks@sfasu.edu. 


\section{Wilson-Leonard An 11,000-year Archeological Record of Hunter-Gatherers in Central Texas Volume V: Special Studies}

\section{Authors}

Michael B. Collins, Barry Balinsky, Joy Becker, C. Britt Bousman, Susan Decker, J. Phillip Dering, Glen Fredlund, Marion J. Henry, Mervin Kontrovitz, Raymond W. Neck, Leslie C. Shaw, Jerry Marie Slack, D. Gentry Steele, James L. Theler, Larry L. Tiezen, Diane Wilson, and Barbara Winsborough

\section{Creative Commons License}

\section{(c) (i) () $\odot$}

This work is licensed under a Creative Commons Attribution-NonCommercial-No Derivative Works 4.0 International License. 


\title{
WILSON-LEONARD
}

\section{An 11,000-year Archeological Record of Hunter-Gatherers in Central Texas}

\author{
Volume V: Special Studies
}

Assembled and Edited by Michael B. Collins

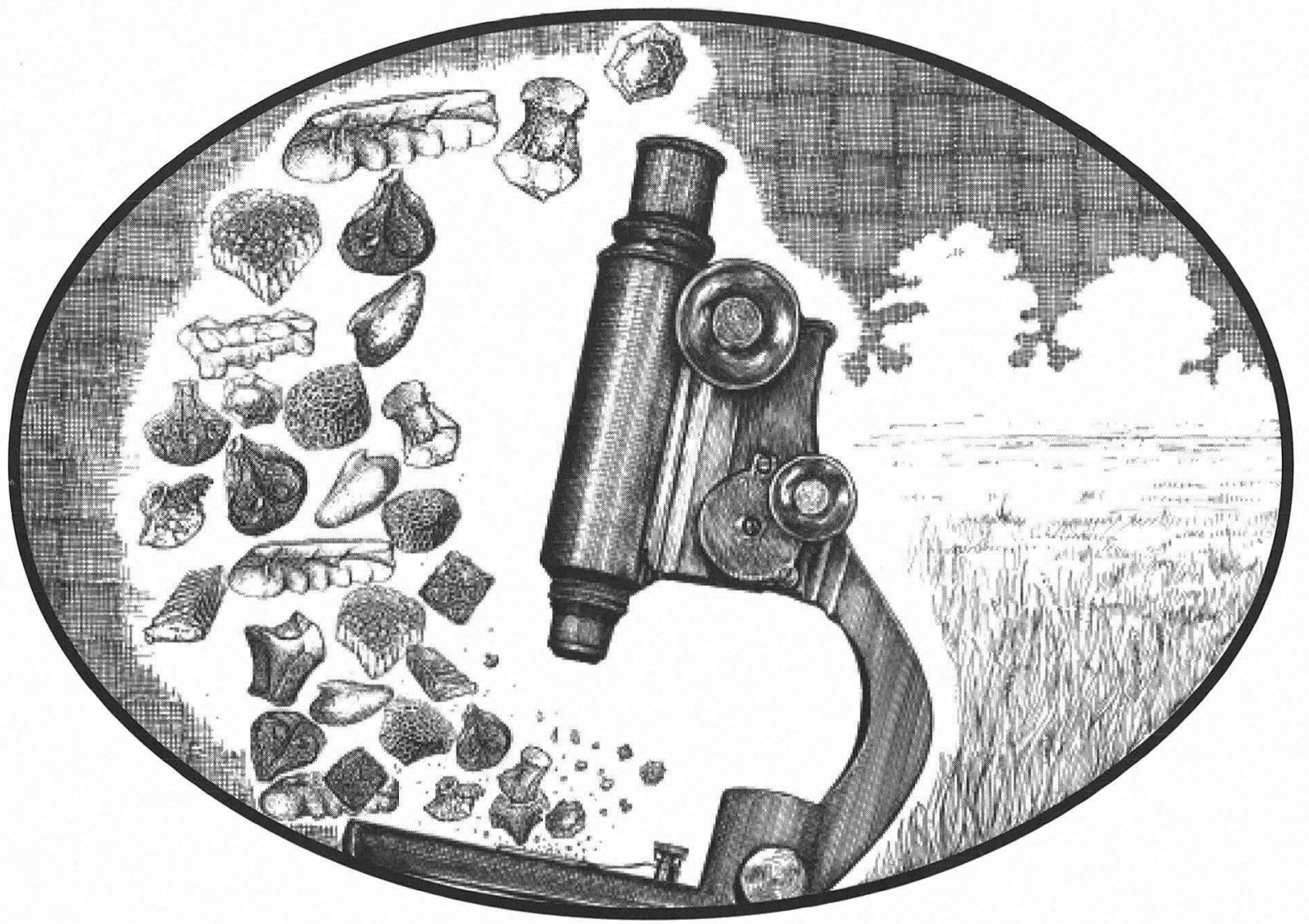

Studies in Archeology 31

Texas Archeological Research Laboratory

The University of Texas at Austin
Archeology Studies Program, Report 10

Texas Department of Transportation

Environmental Affairs Division 


\title{
WILSON-LEONARD
}

\section{An 11,000-year Archeological Record of Hunter-Gatherers in Central Texas}

\author{
Volume V: Special Studies
}

assembled and edited by

Michael B. Collins

with contributions by

Barry W. Baker

Robin Balinsky

Joy Becker

C. Britt Bousman

Michael B. Collins

Susan Decker

J. Philip Dering

Glen Fredlund

Marion J. Henry
Mervin Kontrovitz Raymond W. Neck Leslie C. Shaw Jerry Marie Slack D. Gentry Steele James L. Theler Larry L. Tiezen Diane Wilson Barbara Winsborough

Principal Investigator: Nancy Kenmotsu Frank Weir

Texas Antiquities Committee Permit No. 300

Studies in Archeology 31

Texas Archeological Research Laboratory

The University of Texas at Austin

Archeology Studies Program, Report 10

Texas Department of Transportation

Environmental Affairs Division 
Cover drawing by Frank Weir

The University of Texas at Austin Texas Archeological Research Laboratory J. J. Pickle Research Campus 5

Austin, Texas 78712-1100

Printed 1998, on acid-free, 60-pound paper

ISBN 1-887072-29-2 (Volume V)

ISBN 1-887072-24-1 (5-Volume Set) 


\section{TABLE OF CONTENTS \\ Volume $\mathbf{V}$}

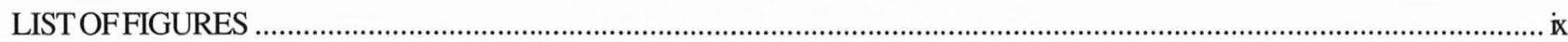

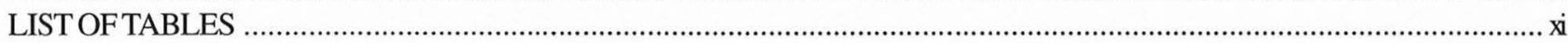

CHAPTER 30: INTRODUCTIONTO VOLUME V

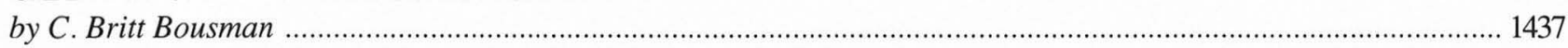

\section{CHAPTER 31: HUMANBIOLOGICAL REMAINS}

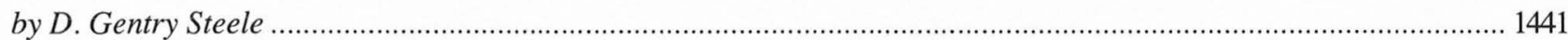

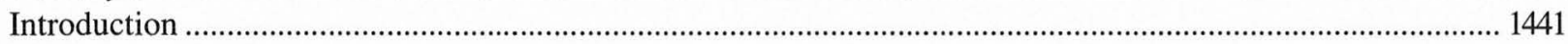

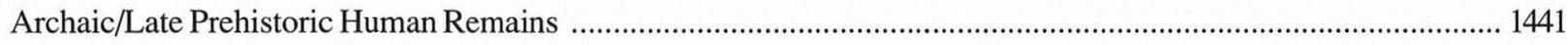

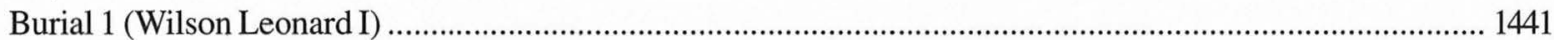

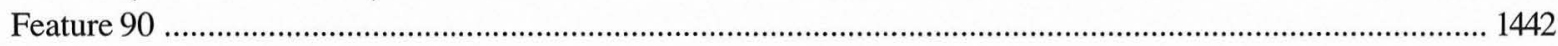

Miscellaneous Human Bone Fragments ............................................................................................ 1443

Summary of Archaic/Late Prehistoric Human Remains ........................................................................... 1443

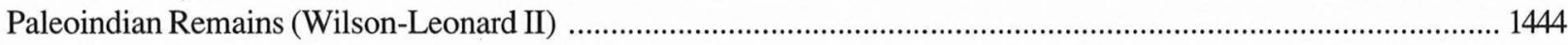

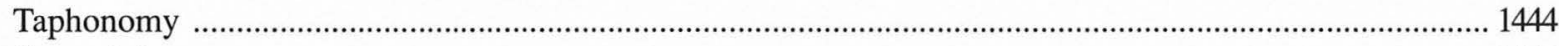

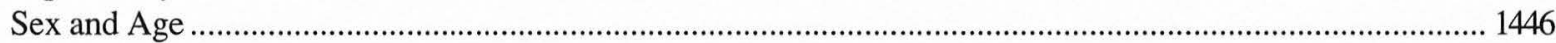

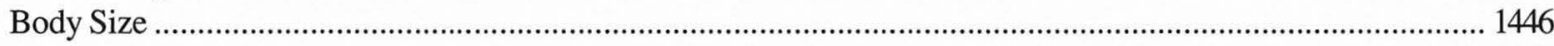

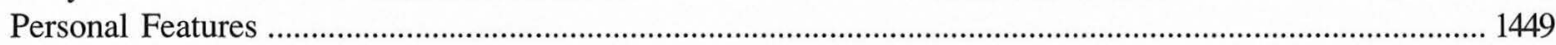

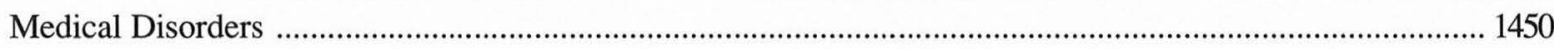

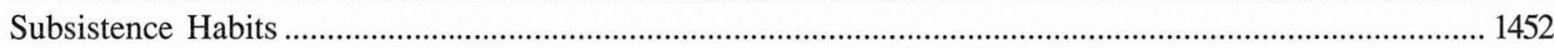

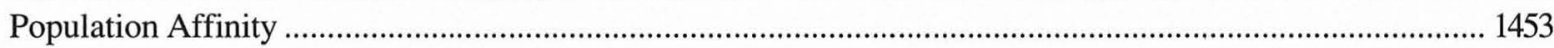

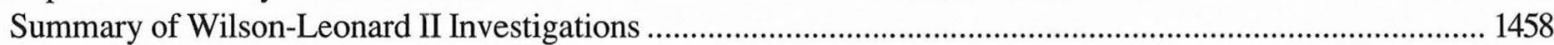

CHAPTER 32: STABLEISOTOPICRESULTS FOR BURIALS 1 AND 2

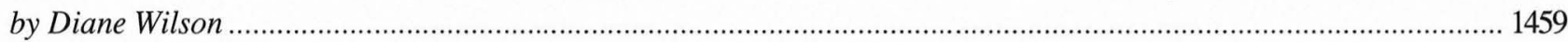

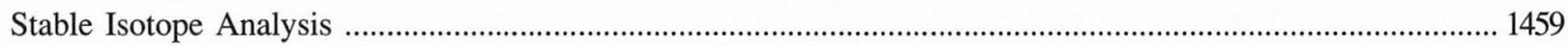

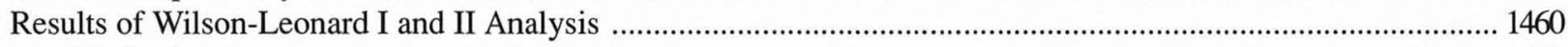

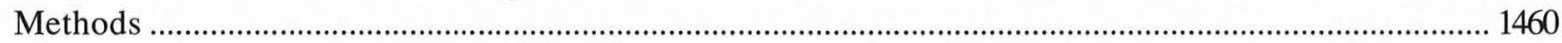

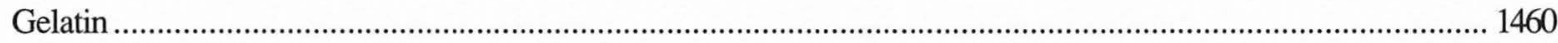

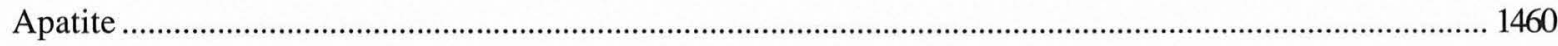

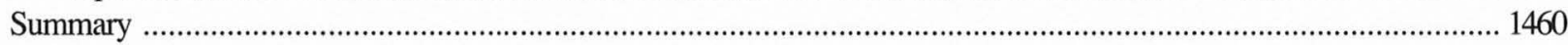

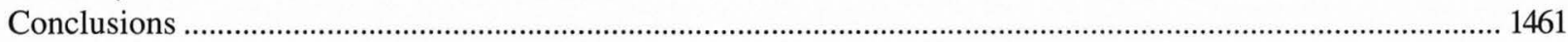

CHAPTER 33: VERTEBRATE FAUNAL REMAINS FROM THE 1/4-INCH AND 1/8-INCH SCREENS

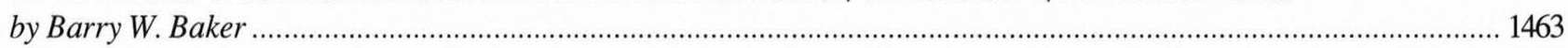

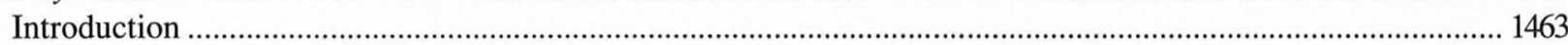

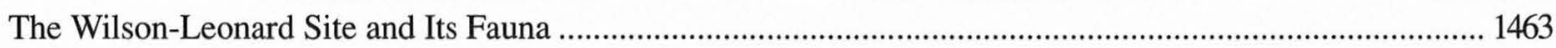

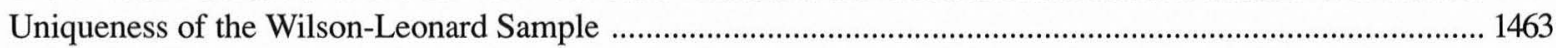

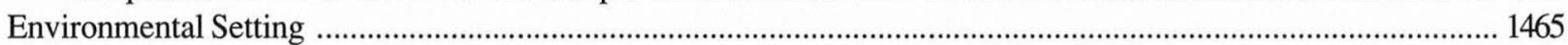

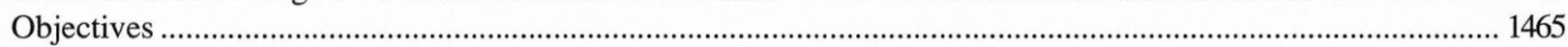

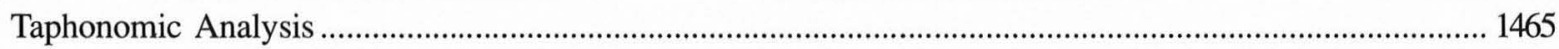

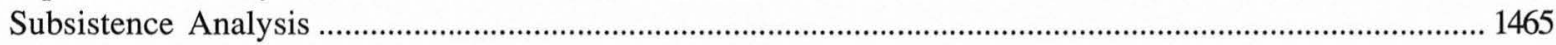

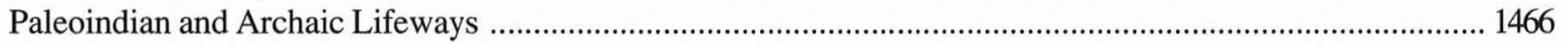

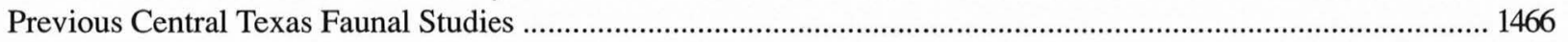

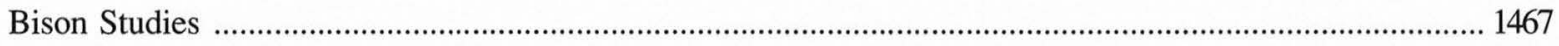

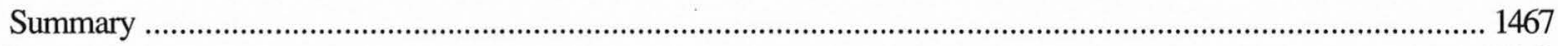

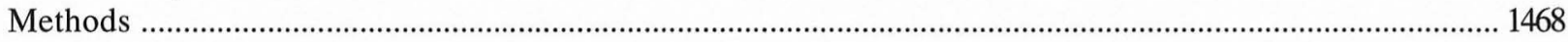

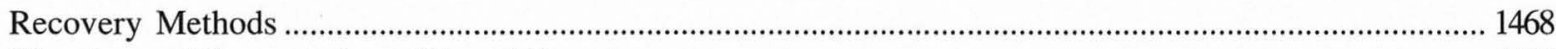

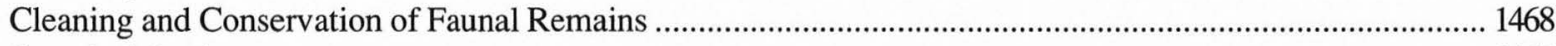

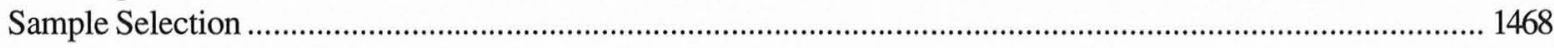




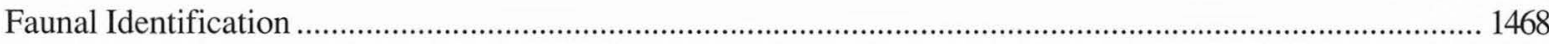

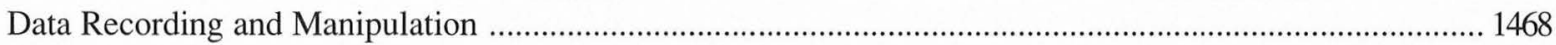

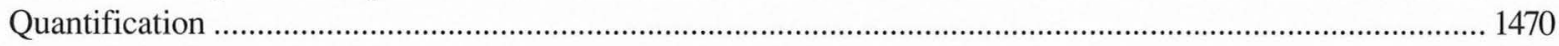

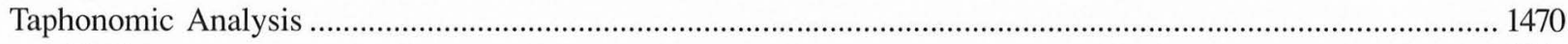

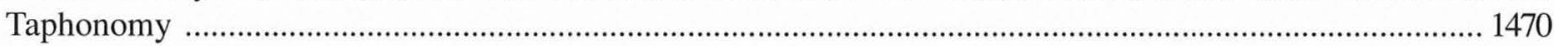

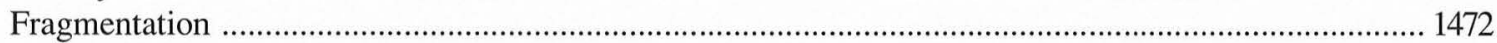

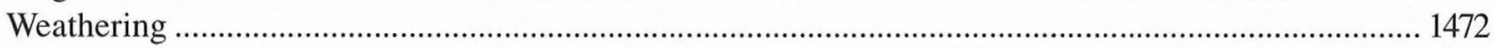

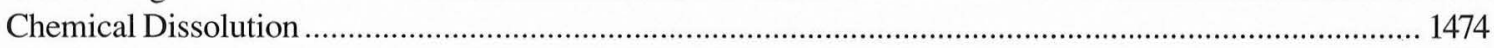

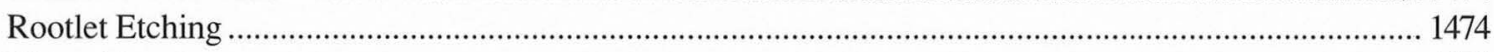

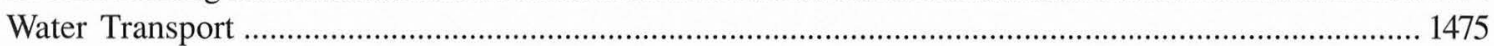

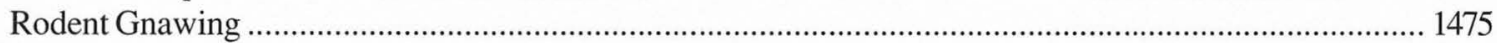

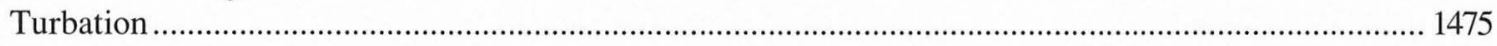

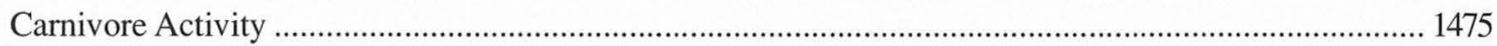

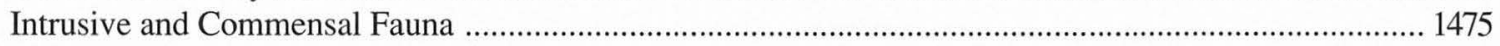

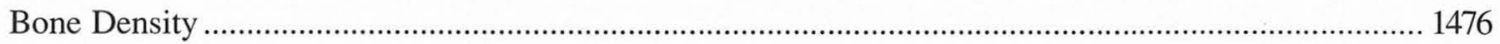

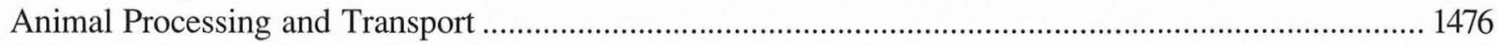

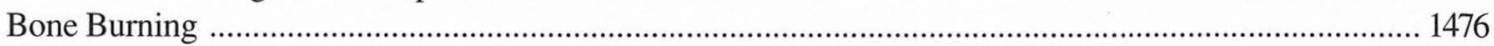

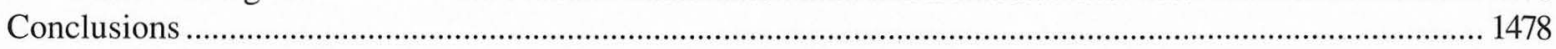

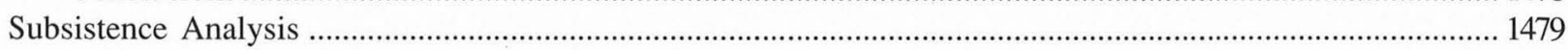

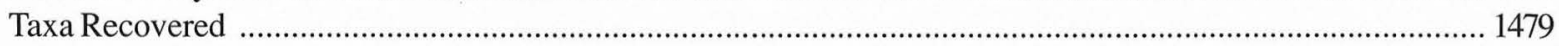

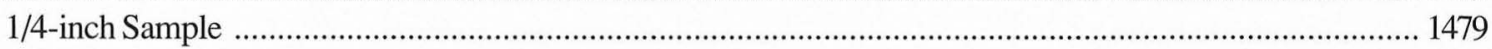

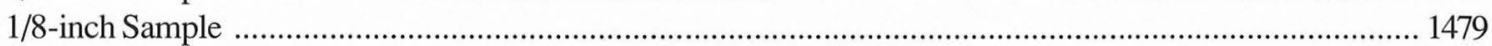

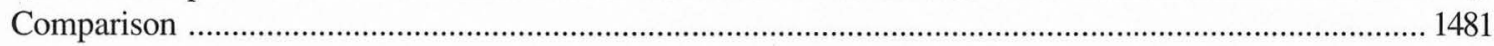

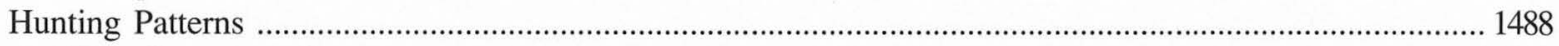

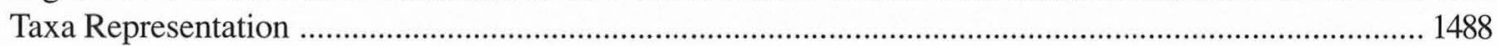

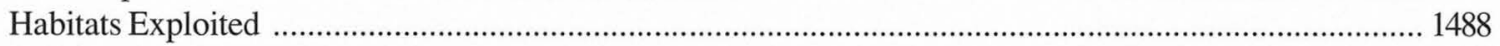

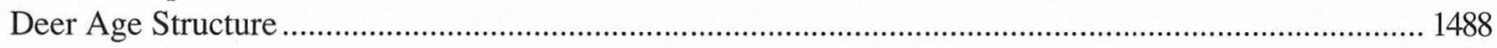

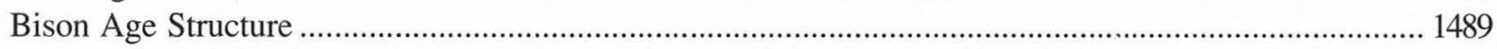

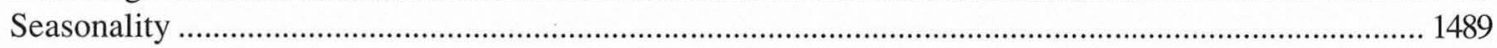

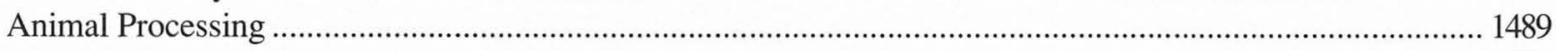

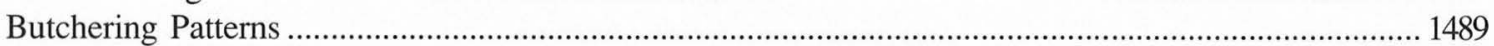

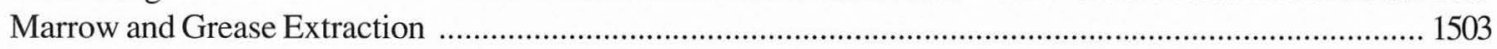

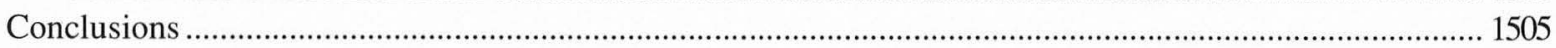

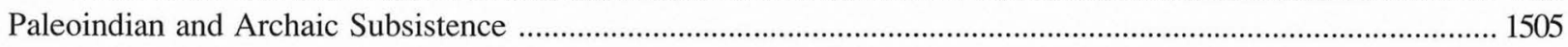

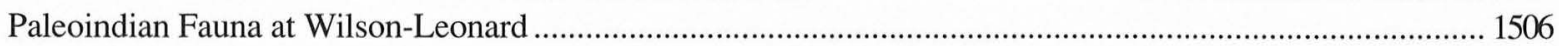

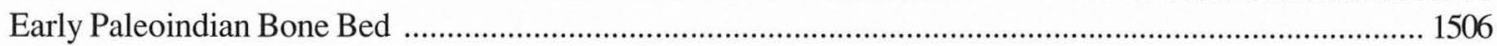

Late Paleoindian (Golandrina, Barber, St. Mary's Hall Components) ...................................................... 1506

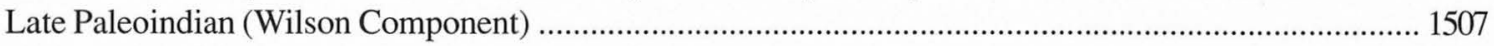

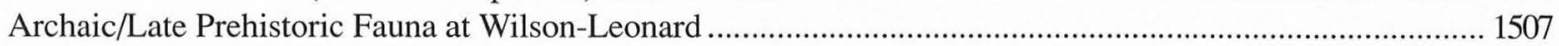

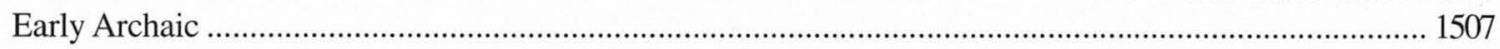

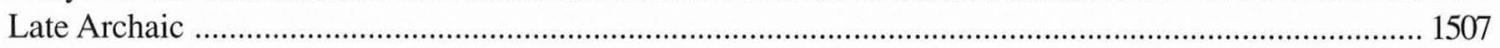

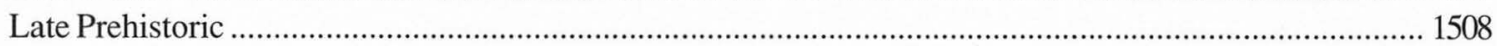

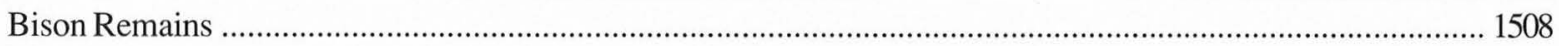

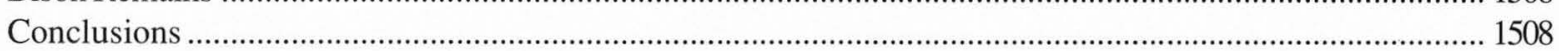

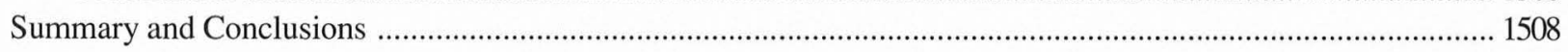

CHAPTER 34: FINE SCREENING METHODS

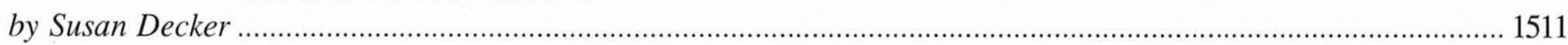

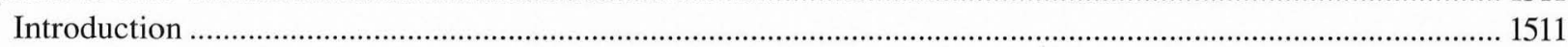

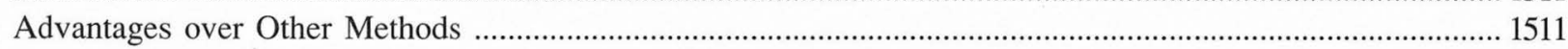

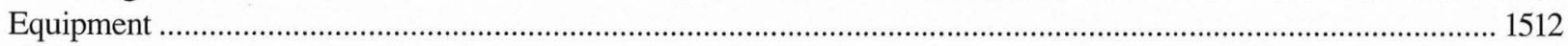

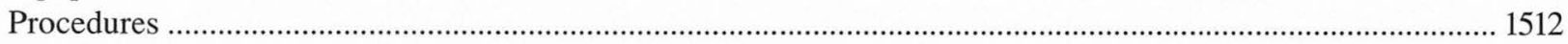

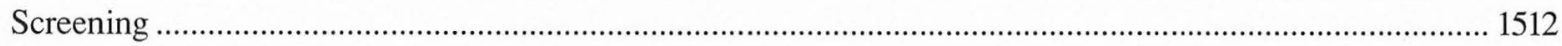

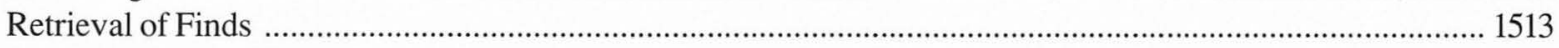

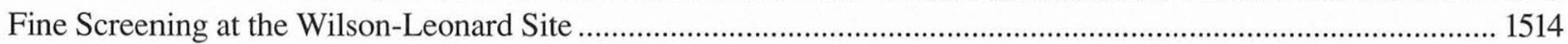


CHAPTER 35: PLEISTOCENETOHOLOCENE WILSON-LEONARD MICROVERTEBRATEFAUNA ANDITS PALEOENVIRONMENTAL SIGNIFICANCE

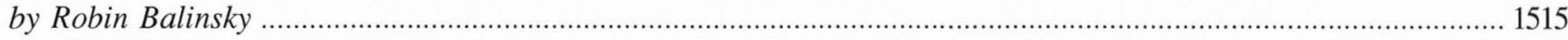

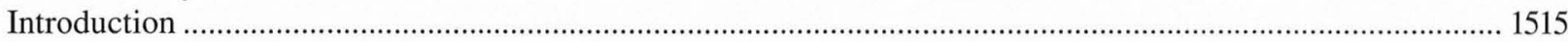

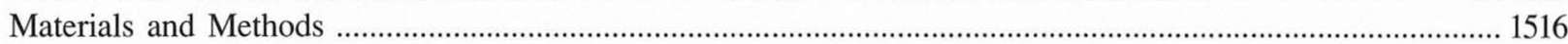

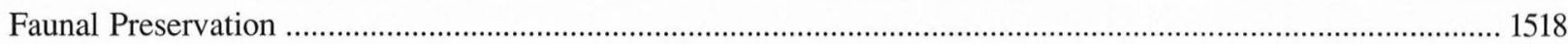

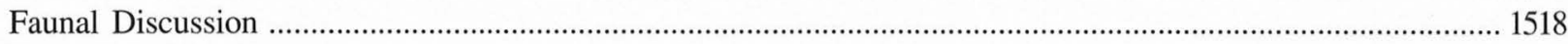

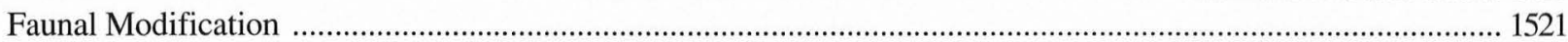

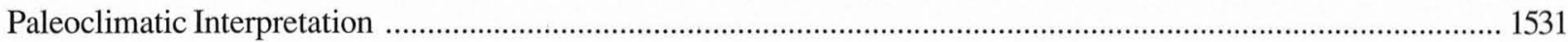

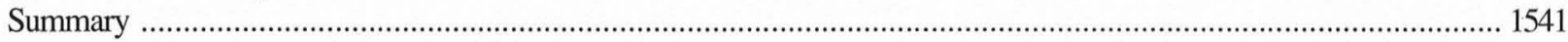

CHAPTER 36: EGGSHELL ANALYSIS

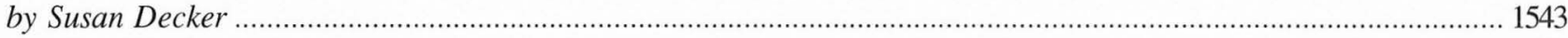

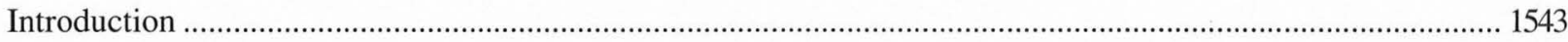

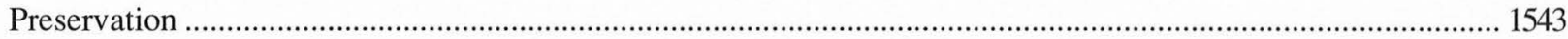

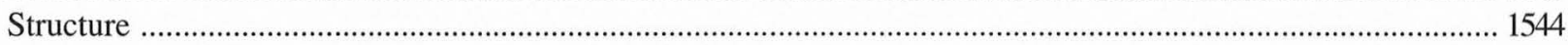

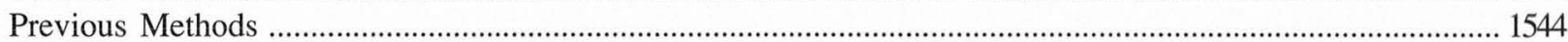

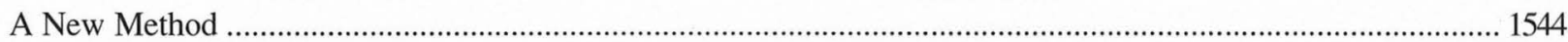

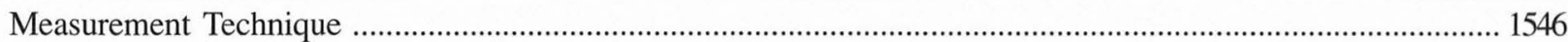

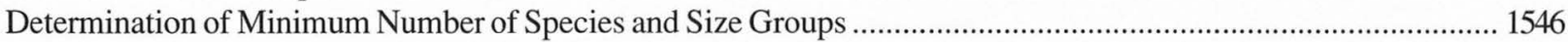

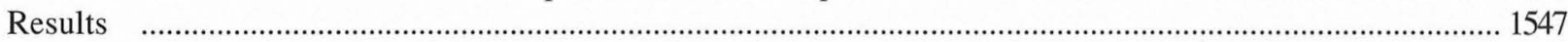

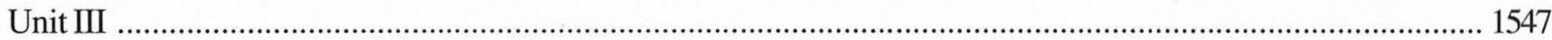

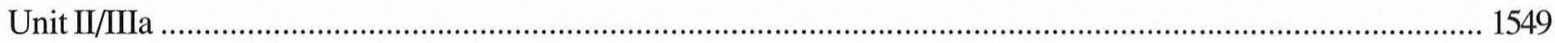

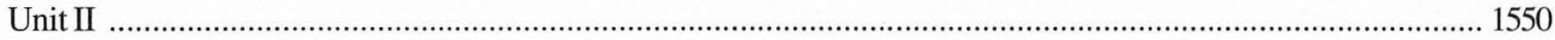

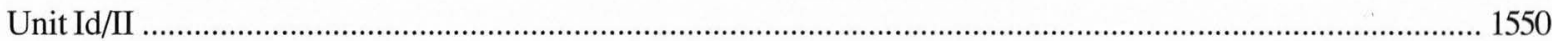

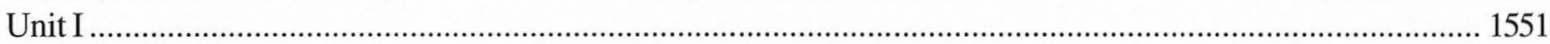

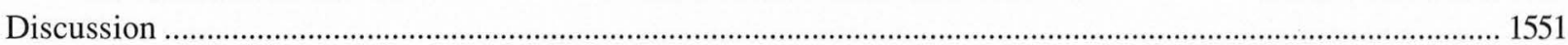

CHAPTER 37: THE MOLLUSCANPALEOASSEMBLAGE

by Leslie C. Shaw, Raymond W. Neck, James L. Theler, and Michael B. Collins ................................................... 1555

Introduction

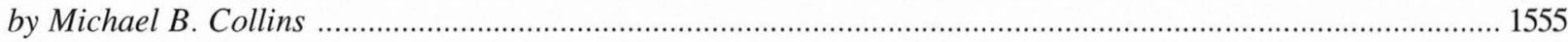

Analysis of a Gastropoda Assemblage

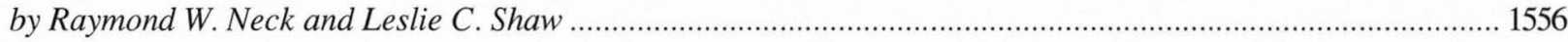

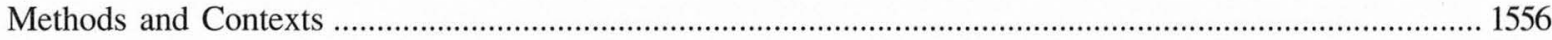

Zoogeographical Setting ..................................................................................................................... 1557

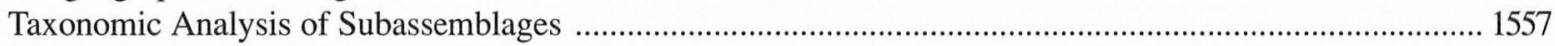

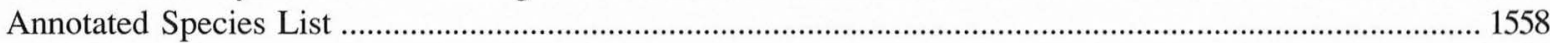

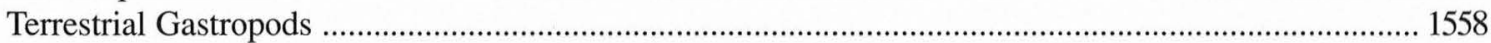

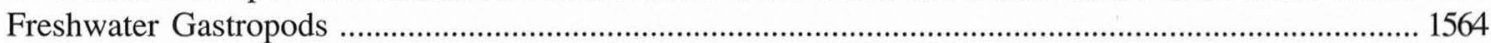

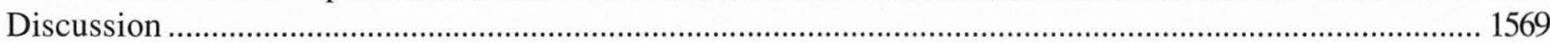

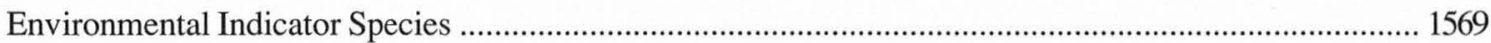

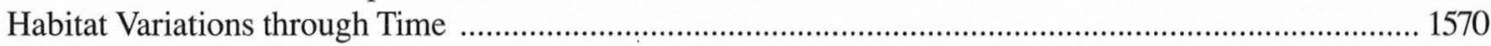

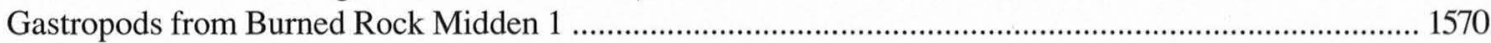

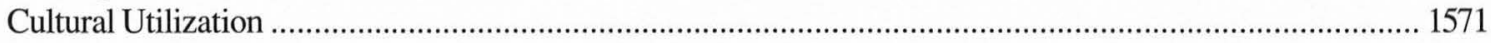

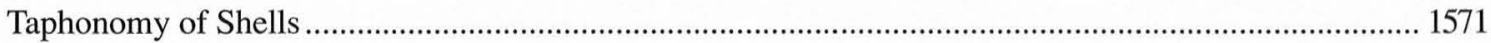

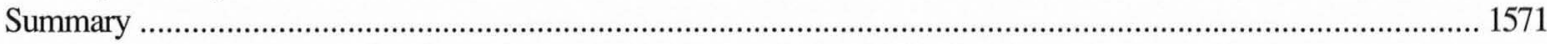

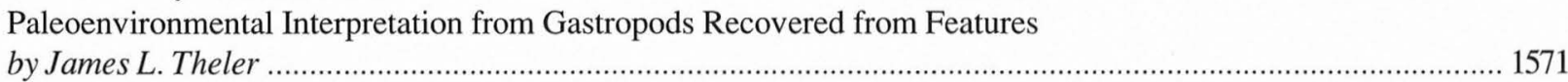

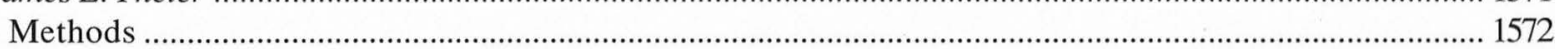

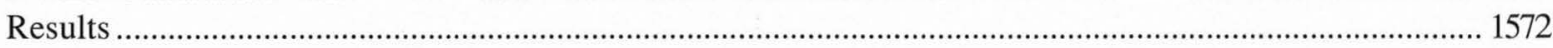

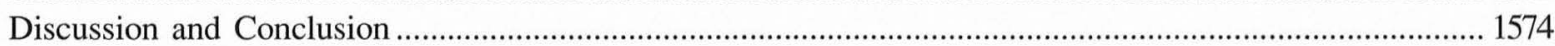

An Analysis of the Freshwater Mollusk (Unionid) Paleoassemblage
by Leslie C. Shaw

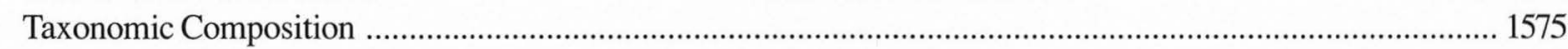

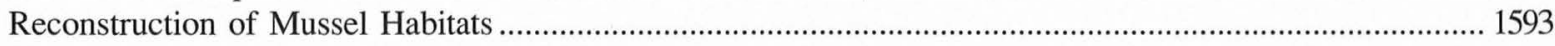




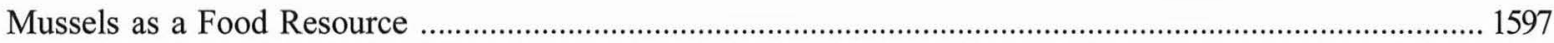

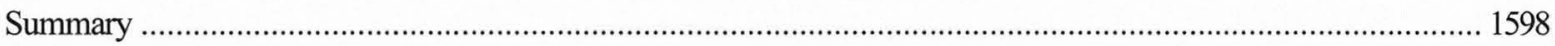

Integrating Results of the Mollusk Studies

by Leslie C. Shaw

CHAPTER 38: Diatom Analysis

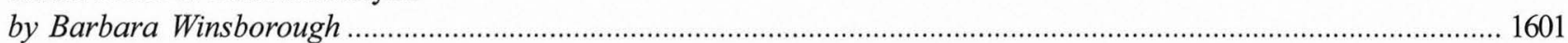

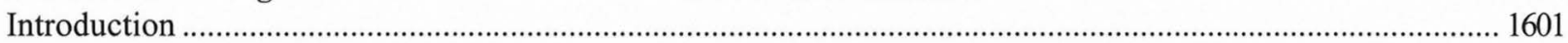

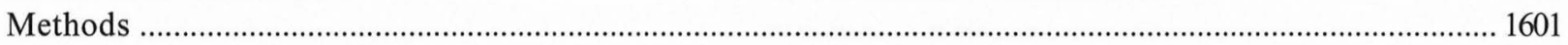

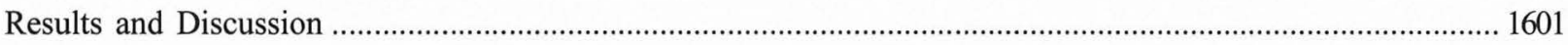

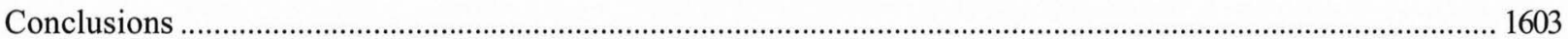

CHAPTER 39: Analysis of Ostracode Remains

by Marion J. Henry, Mervin Kontrovitz, and Jerry Marie Slack ..................................................................... 1605

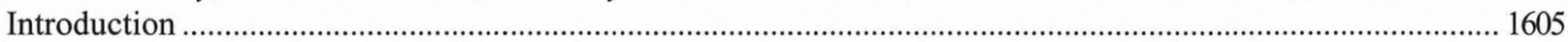

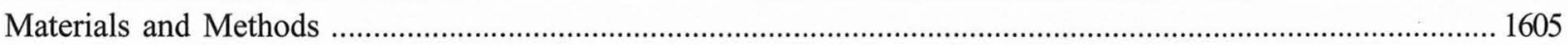

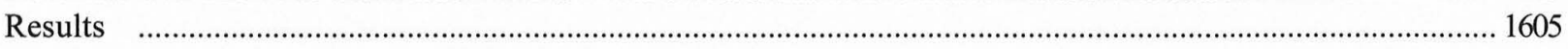

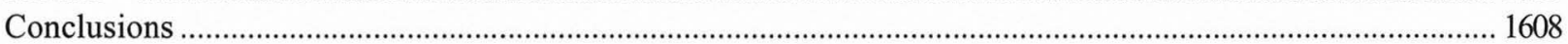

CHAPTER 40: Carbonized Plant Remains

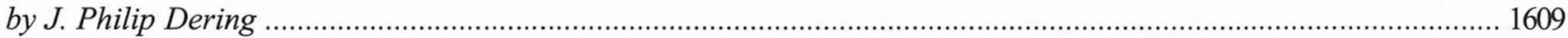

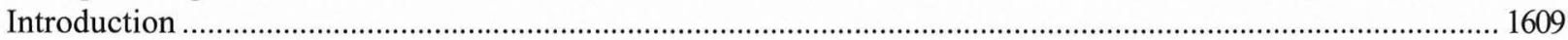

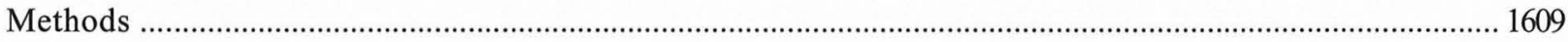

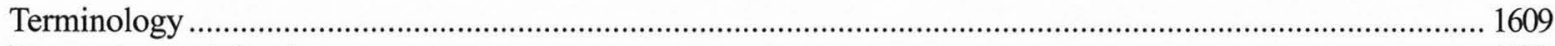

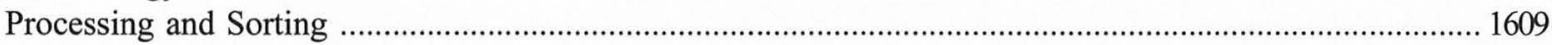

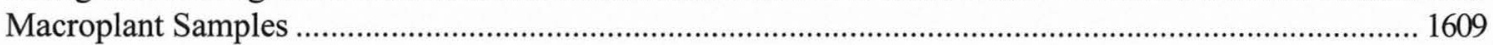

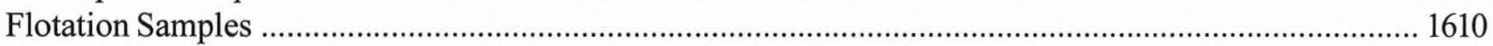

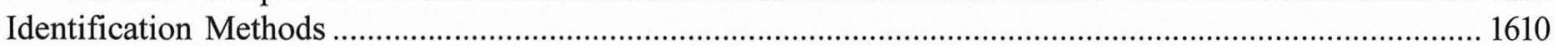

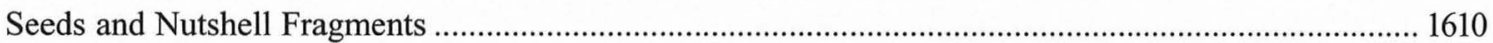

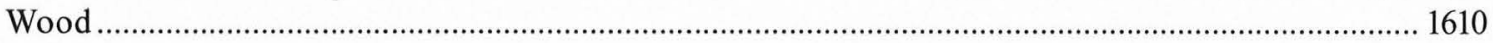

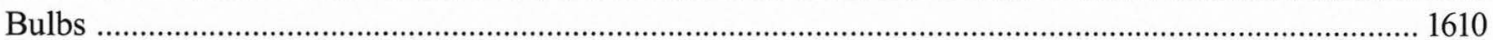

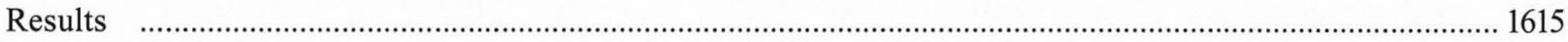

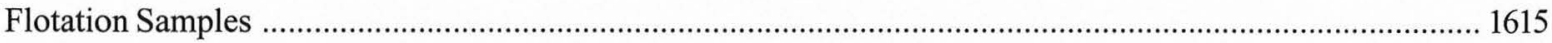

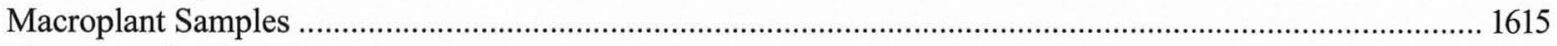

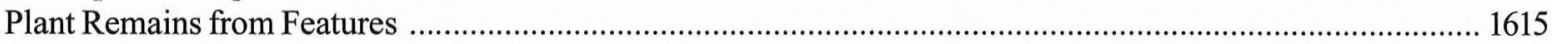

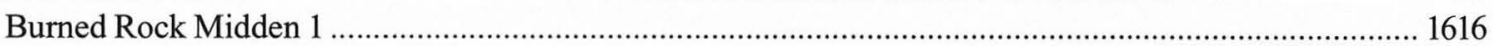

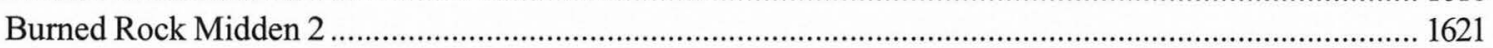

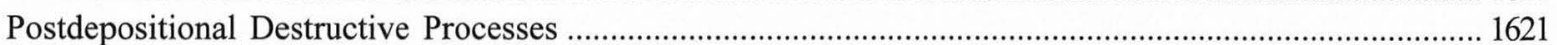

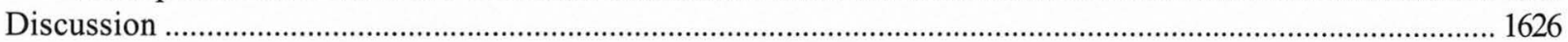

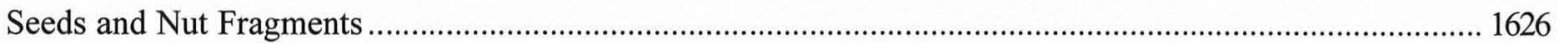

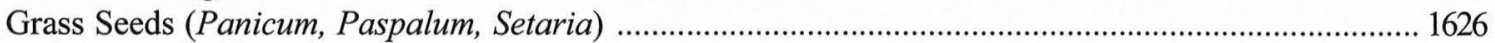

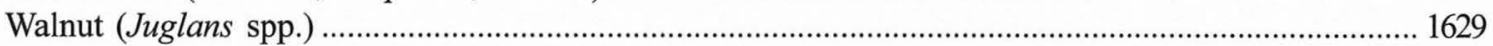

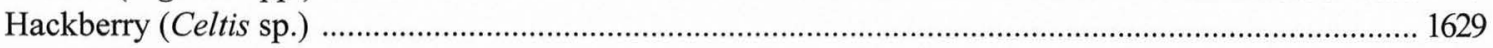

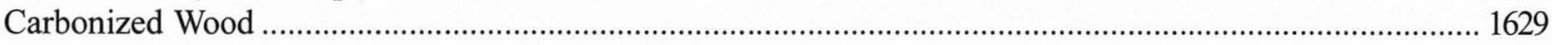

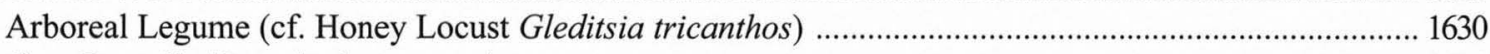

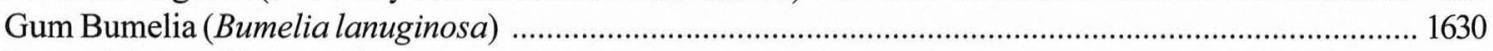

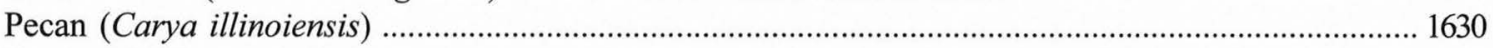

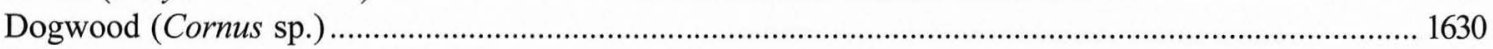

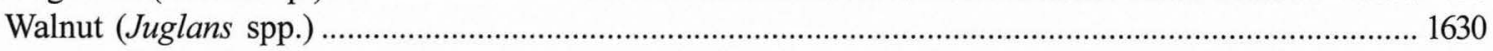

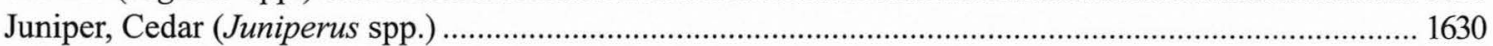

Mulberry Family and Red Mulberry (Moraceae and Morus rubra) …................................................. 1630

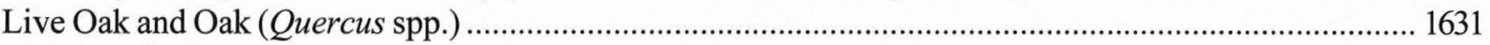

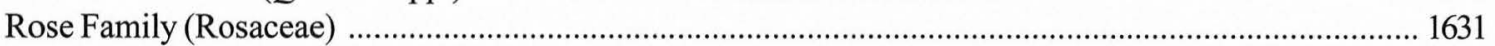

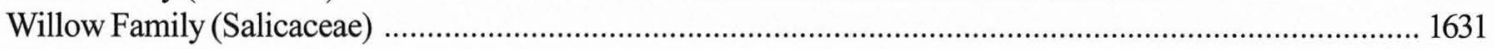

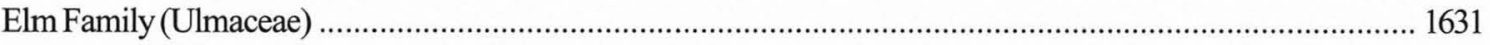

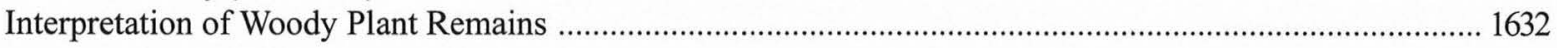




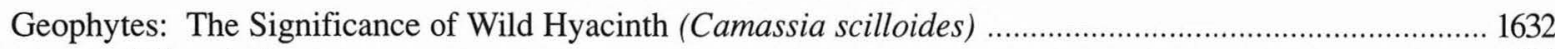

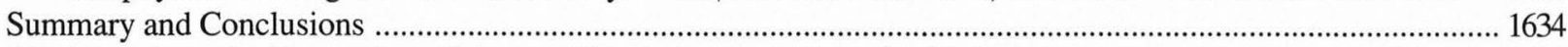

The Macrobotanical Record and Plant and Land Use throughout the Holocene ................................................. 1635

\section{CHAPTER 41: PHYTOLITH ANALYSIS}

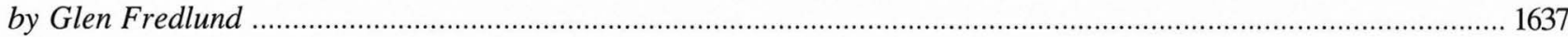

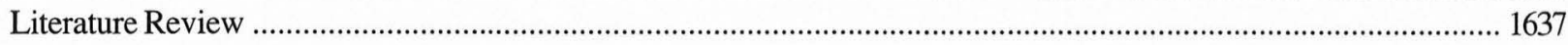

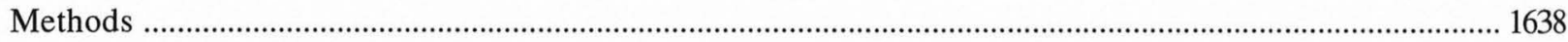

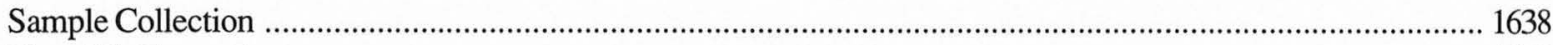

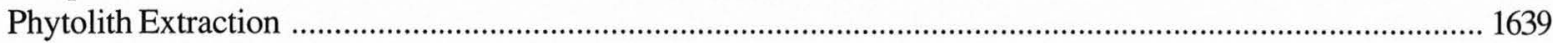

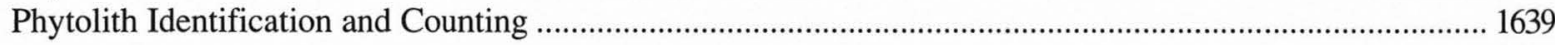

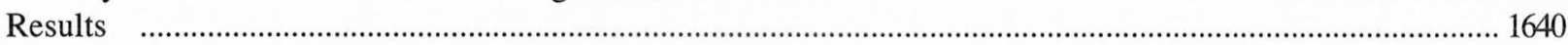

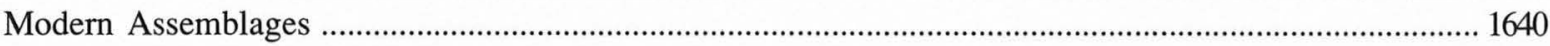

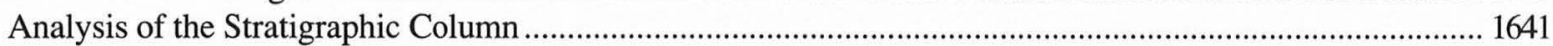

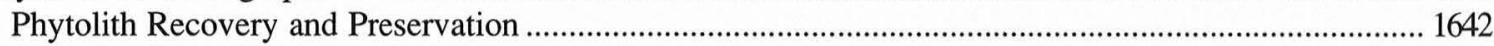

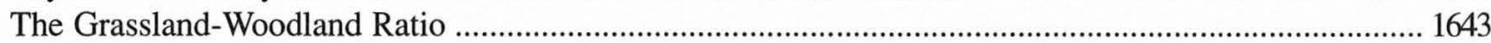

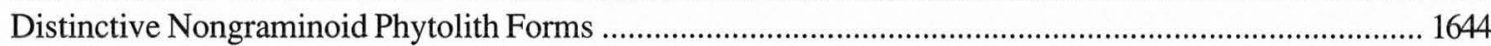

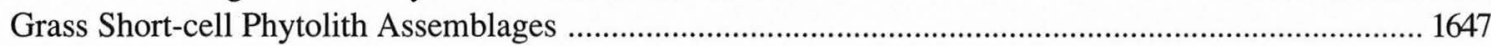

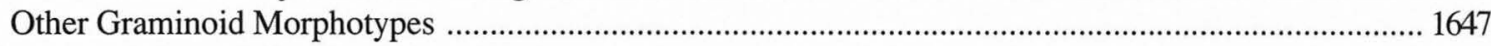

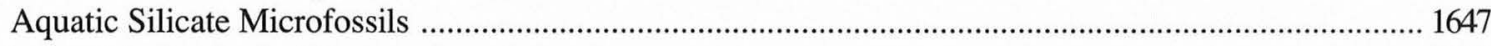

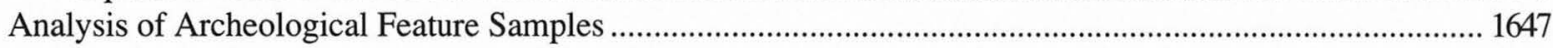

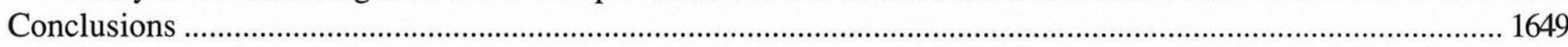

CHAPTER 42: STABLE CARBON ISOTOPE ANALYSIS OF SOIL ORGANIC MATTER

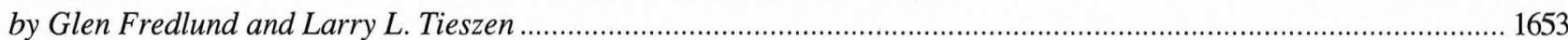

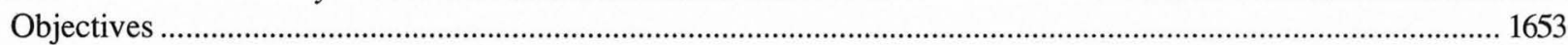

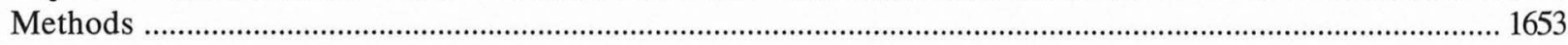

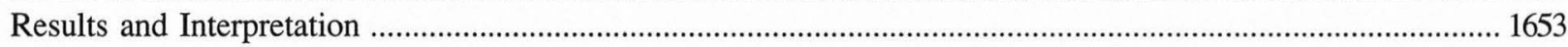

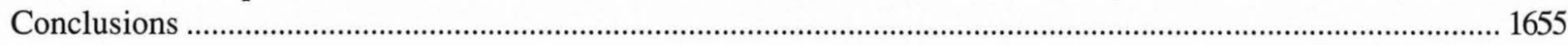

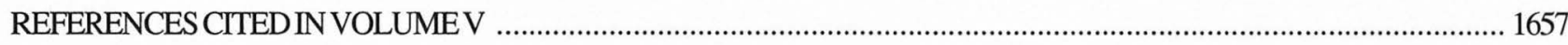

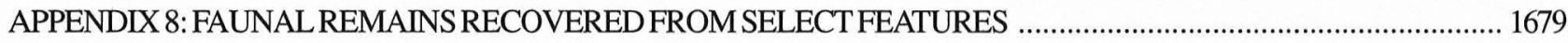

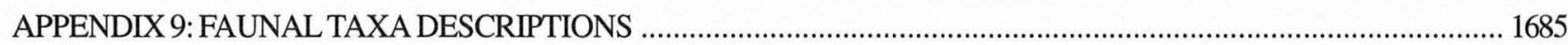

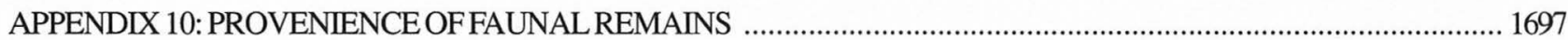




\section{LIST OFFIGURES \\ Volume V}

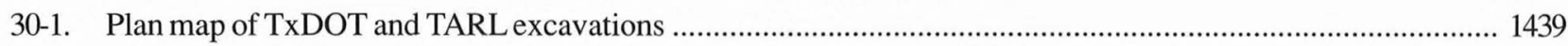

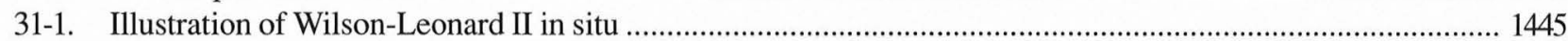

31-2. Left and right lateral and frontal views of Wilson-Leonard II cranium ..................................................... 1446

31-3. Occlusal views of the maxillary and mandibular teeth of Wilson-Leonard II ................................................ 1447

31-4. Sequence of photographs illustrating the reconstruction of Wilson-Leonard II ............................................. 1451

31-5. Lateral view of right mandible of Wilson-Leonard II .............................................................................. 1452

31-6. Bivariate plots of mean cranial lengths and widths of Paleoindian males and females compared with prehistoric and modern populations ........................................................................... 1454

31-7. Bivariate plots of mean facial lengths and widths of Paleoindian males and females compared with prehistoric and modern populations ................................................................................. 1455

31-8. Plot of principal component analysis of size-corrected data for Paleoindian males and females compared with prehistoric and modern populations ............................................................... 1457

32-1. Stable isotope data from Wilson-Leonard I and II compared with values from other

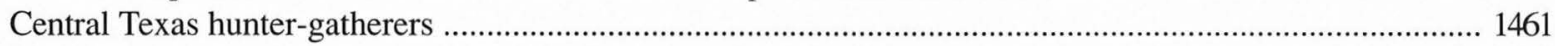

34-1. Nesting screens and water tanks used for fine screening of soil samples ............................................... 1512

34-2. Agitation of nesting screens in water tank during fine screening ........................................................... 1513

34-3. Fine-screened samples drying in the sun in separated top and bottom screens .......................................... 1514

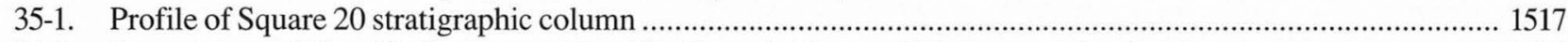

35-2. Percentages of identified versus unidentified bone in Square 20 by excavation level ................................. 1519

35-3. Percentages of rodent from the total amount of identified bone in Square 20 …......................................... 1528

35-4. Percentages of burning for identified and unidentified bone from Square 20 ............................................ 1529

35-5. Percentages of fish and turtle from the total amount of identified bone in Square 20 ................................... 1530

35-6. Percentages of large mammals from the total amount of identified bone in Square 20 .................................. 1532

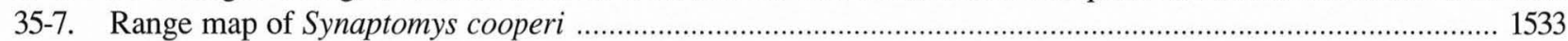

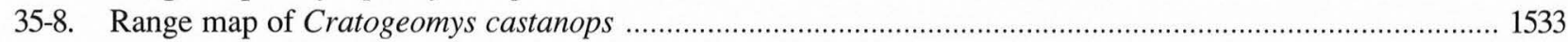

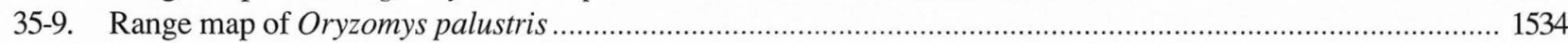

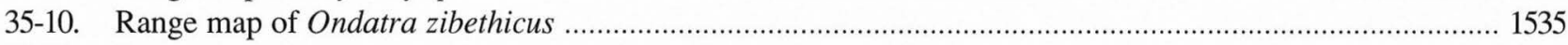

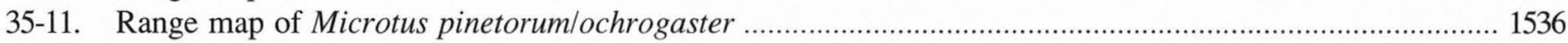

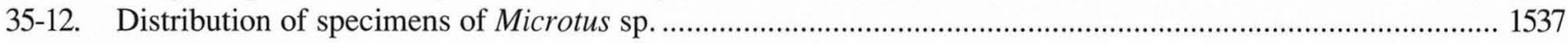

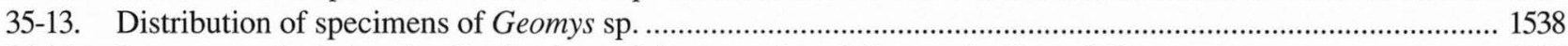

35-14. Range map depicting the distributions of three species of Geomys in Central Texas .................................. 1539

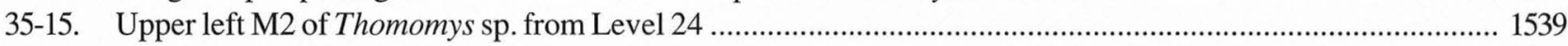

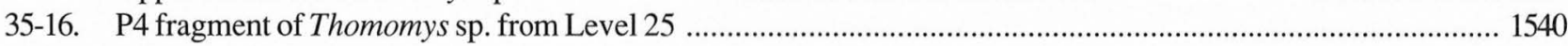

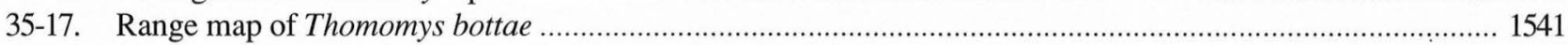

37-1. Comparison of water-body type rankings for Units II, IIIa, and IIIc ….................................................... 1596

37-2. Comparison of water depth rankings for Units II, IIIa, and IIIc ................................................................. 1597

37-3. Comparison of current velocity for Units II, IIIa, and IIIc ........................................................................ 1597

37-4. Comparison of substrate composition rankings for Units II, IIIa, and IIIc .................................................. 1597

39-1. Scanning electron photomicrographs of ostracodes from the Wilson-Leonard site ..................................... 1606

39-2. Estimate of water temperatures based on ostracode remains from early stratigraphic units ........................... 1608

40-1. SEM photographs of archeological and comparative bulbs .................................................................. 1633

41-1. Percent weight of extracted phytoliths by depth ................................................................................. 1643

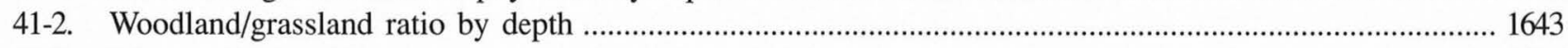

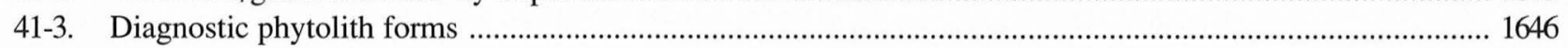

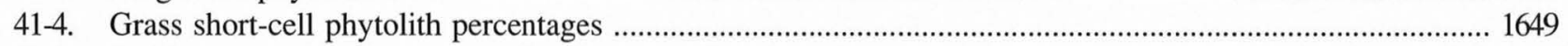

42-1. Stable carbon isotope analysis results by depth ....................................................................................... 1655 


\section{LIST OF TABLES}

Volume $\mathbf{V}$

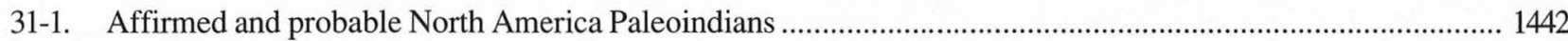

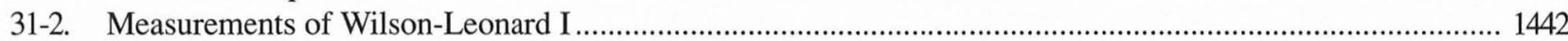

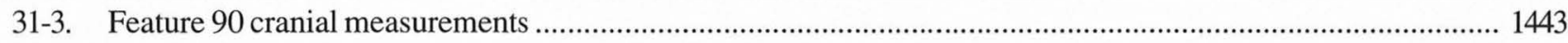

31-4. Provenience and cultural affiliation of miscellaneous human bone fragments .............................................. 1444

31-5. List of Wilson-Leonard II skeletal elements recovered ............................................................................. 1445

31-6. Cranial measurements of Wilson-Leonard II and compared Paleoindians ..................................................... 1447

31-7. Postcranial measurements of Wilson-Leonard II and Gordon Creek females ............................................... 1448

31-8. Crown and neck measurements of maxillary teeth of Paleoindian females .................................................... 1449

31-9. Crown and neck measurements of mandibular teeth of Paleoindian females ................................................ 1450

31-10. Comparative human stature estimates of prehistoric samples .................................................................. 1451

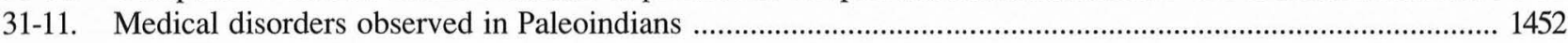

32-1. Delta ${ }^{13} \mathrm{C}$ apatite and gelatin values for Wilson-Leonard I and II ......................................................... 1461

33-1. Selected Central Texas archeological sites or site complexes with vertebrate faunal remains ......................... 1464

33-2. Faunal recovery from 1/4-inch screens by cultural period and stratigraphic unit ........................................ 1469

33-3. Faunal recovery from 1/8-inch screens by cultural period and stratigraphic unit ........................................ 1471

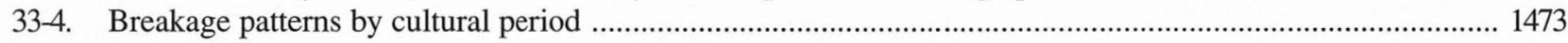

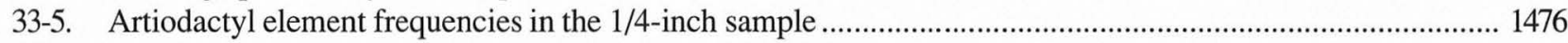

33-6. Burned bone by cultural period .................................................................................................... 1478

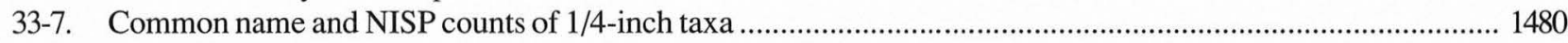

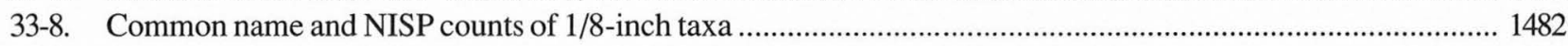

33-9. Taxa by cultural period and major vertebrate group from the $1 / 4$-inch recovery ............................................ 1484

33-10. Taxa by cultural period and major vertebrate group from the $1 / 8$-inch recovery ........................................... 1486

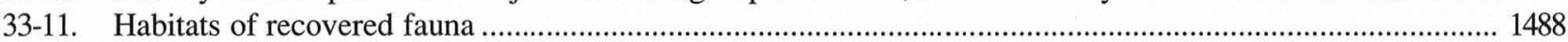

33-12. Faunal recovery by archeological feature, 1/4-inch screens .................................................................... 1490

33-13. Faunal recovery by archeological feature, $1 / 8$-inch screens .................................................................... 1497

33-14. Bison and Bison-sized elements from 1/8-inch and 1/4-inch recovery ..................................................... 1502

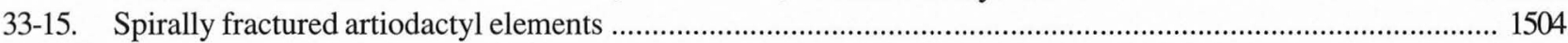

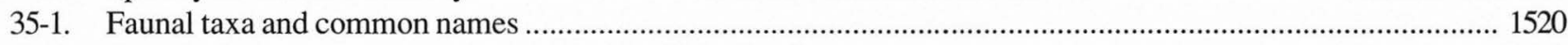

35-2. Distribution of nonmammal taxa in Square 20, by level ........................................................................ 1522

35-3. Distribution of mammalian taxa in Square 20, by level ........................................................................... 1524

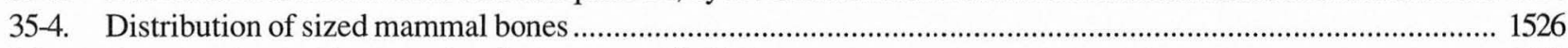

36-1. Comparative modern species list by eggshell thickness ......................................................................... 1548

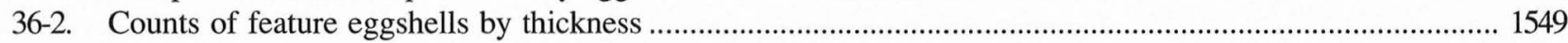

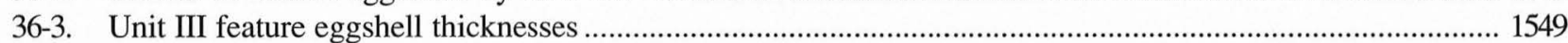

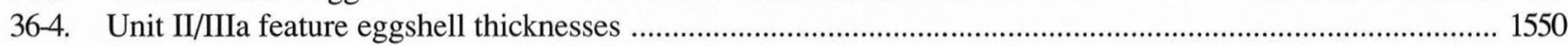

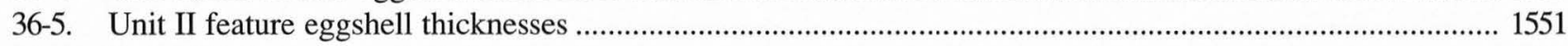

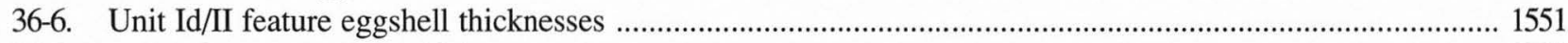

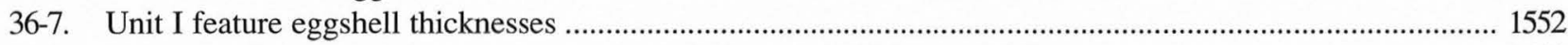

37-1. Habitat preferences of the terrestrial gastropods from TxDOT Unit E28/S78 …...................................... 1558

37-2. Terrestrial gastropod taxa frequencies by level, E28/S78 ….................................................................... 1559

37-3. Terrestrial gastropod taxa frequencies by level, TxDOT Square E20/S78 …................................................ 1561

37-4. Terrestrial gastropod taxa frequencies by level, TxDOT Square E22/S88 …................................................. 1561

37-5. Terrestrial gastropod taxa frequencies by level, TxDOT Square E22/S78 ….............................................. 1562

37-6. Freshwater gastropod taxa frequencies by square and level ................................................................... 1563

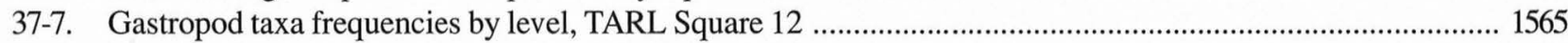

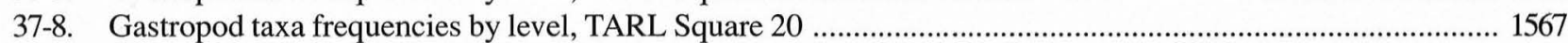

37-9. Gastropod taxa frequencies for selected features ..................................................................................... 1568

37-10. Gastropod taxa frequencies in Burned Rock Midden 1 ............................................................................ 1568

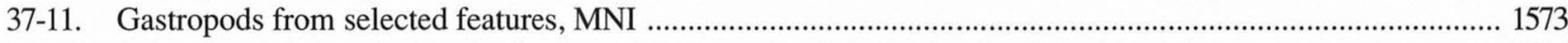

37-12. Scientific and common names for the freshwater mussel shells, family Unionidae ....................................... 1575

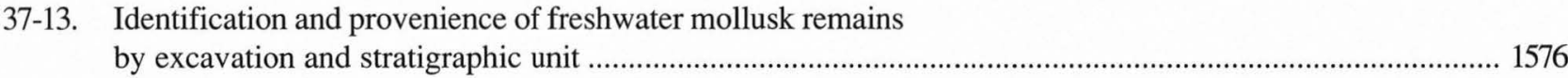




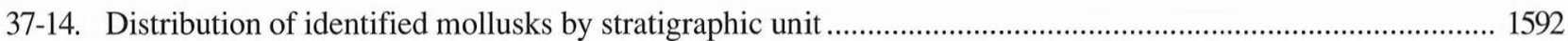

37-15. Distribution of thin-, medium-, and thick-walled shells by stratigraphic unit .............................................. 1594

37-16. Rankings of environmental characteristics for the Wilson-Leonard taxa ….............................................. 1595

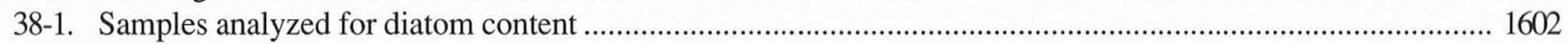

38-2. Diatom abundance in sediments from the Wilson-Leonard site .................................................................. 1603

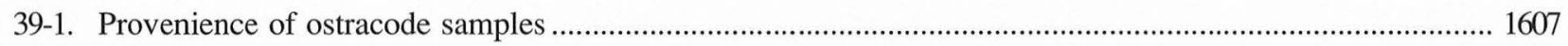

39-2. Ostracode valve count by species ...................................................................................................... 1607

39-3. Approximate maximum water depth and temperature for ostracodes by sample ............................................ 1608

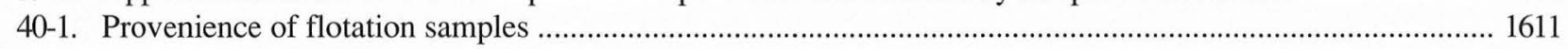

40-2. Key to the potentially economic bulbs of the study area …................................................................... 1615

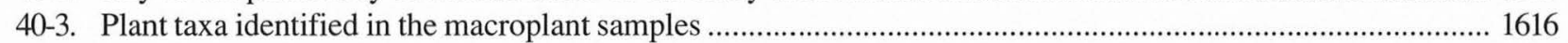

40-4. Carbonized remains from Wilson-Leonard flotation samples ................................................................. 1616

40-5. Identification of macroplant samples from the TxDOT excavations ............................................................. 1617

40-6. Identification of macroplant samples from the TARL excavations .............................................................. 1622

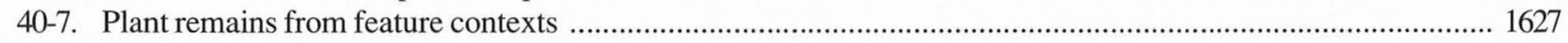

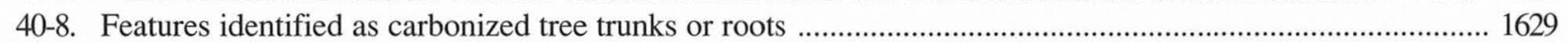

40-9. Provenience of Camassia scilloides by feature ................................................................................... 1634

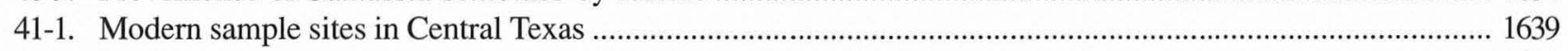

41-2. Modern sample data: percent weight recovered and woodland/grassland ratio ............................................. 1640

41-3. Modern plant sample data: percentage of grass short cells by phytolith morphotype ................................... 1641

41-4. Phytolith recovery, preservation and woodland-grassland ratios for the excavation Square 12 profile and exploratory deeper samples ................................................................ 1642

41-5. Occurrence of distinctive arboreal and other diagnostic morphotypes ...................................................... 1645

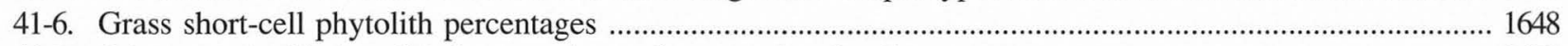

41-7. Other graminoid phytolith forms and aquatic-type microfossils ................................................................. 1650

41-8. Phytolith recovery and preservation in feature samples .............................................................................. 1651

41-9. Grass short-cell percentages in the feature samples .................................................................................... 1651

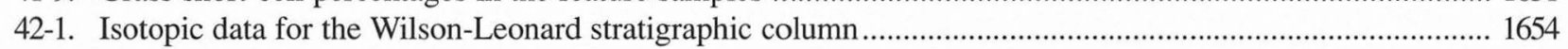

A8-1. Number and percentage of faunal remains by class for select features ...................................................... 1681

A10-1. Provenience of faunal remains recovered from 1/4-inch screens, TxDOT excavations .................................. 1699

A10-2. Provenience of faunal remains recovered from 1/8-inch screens, TARL excavations ...................................... 1777 


\section{Chapter 30}

\section{INTRODUCTION TO VOLUME V}

by C. Britt Bousman

One of the primary research objectives of the WilsonLeonard project was to investigate the interactions between hunter-gatherers and their natural environment. This type of analysis is also known as hunter-gatherer paleoecology. Recent research suggests that past environments in Central Texas fluctuated substantially during the 11,000 years since Wilson-Leonard was first occupied (Bousman 1994, in review; Collins 1995; Collins and Bousman 1993; Nordt et al. 1994; Toomey 1993). An archeological site with an extensive sequence of human occupations, such as Wilson-Leonard, provides one of the best opportunities for investigating hunter-gatherer paleoecology over this time span if ecologically sensitive data are present. Sites with such a long sequence of human occupations are rare; Lubbock Lake (Johnson 1987) and Arenosa Shelter (Collins 1996; Dibble 1967) are the only other sites in Texas with as comprehensive an archeological record.

The purpose of the investigations reported in this volume is to compare the paleoenvironmental data to the evidence of past human behavior and identify correlations between the two records. A single site, rather than multiple sites, is preferred because a single site remains roughly stationary through time in relation to many off-site resources and the general landscape. From this single-site perspective, major patterns of resource exploitation can be seen fundamentally as a response to altering biotic resources that change their spatial distribution through time, or perhaps as independent shifts in human exploitation strategies. When multiple sites are combined in a single synthetic analysis, it is very difficult to unravel the two above effects from differential responses to the distribution of resources in multiple spatial settings. Furthermore, relative chronology is more secure for events in the sequence at a single site than that reconstructed through cross-dating of multiple sites.

Eight topics are identified in Chapter 5 (Research Objectives) to address the larger subject of hunter-gatherer paleoecology. Among these eight topics are the specific issues of paleoenvironmental reconstruction, resource exploitation, and bioarcheology. The 12 contributions in this volume present detailed data on these three specific topics. These contributions present evidence collected during both phases of excavation (TxDOT and TARL), and the sources of evidence are highly varied. Also, even though WilsonLeonard does contain a remarkably complete archeological record in good geological context, as discussions on site formation suggest, the site does not represent a unique setting in terms of organic preservation. In fact, the preservation of organic remains is probably no better than average for the region, and the preservation of organic materials cannot be compared to that seen in dry shelters and caves in the Lower Pecos region or in the bogs of east-central Texas (Chelf 1946). Nevertheless, multiple sources of evidence were preserved and collected, and they all contribute to a markedly better understanding of past environments, human adaptations, and exploitation of past environments by the prehistoric inhabitants of the Wilson-Leonard site and presumably Central Texas.

Two papers, by Steele and Wilson, provide an archive of the bioarchaeology of the human remains at the WilsonLeonard site. Steele (Chapter 31) undertakes a description and analysis of the human physical remains. These are limited primarily to two burials excavated by TxDOT, and he focuses most of his analytical effort on Burial 2. Burial 2 is one of the oldest interred humans in North America excavated by scientific methods. Any human remains from this period (ca. 10,000 B.P.) are extremely rare and highly significant. The physical record imprinted on these remains and interpreted by Steele provides a direct and detailed glimpse of one person who occupied the site in this very early period. Due to the fragmentary and poorly preserved nature of the remains, unfortunately this picture is incomplete. Wilson's stable isotope analysis of the human remains (Chapter 32) provides a reflection of the dietary habits of the two human burials. Regrettably, Burial 2 suffers from 
postdepositional chemical diagensis, and not all stable isotope analyses were reliable or even possible. Nevertheless, the stable isotope analysis does show a measurable shift in diets between the two burials.

Selected columns excavated for enhanced data recovery were employed by both TxDOT and TARL investigators. The earlier excavators fine-screened Square E28/S78 (the "fine-screen unit"); the later excavators dug Squares 12 and 20 from surface to bedrock and extracted matrix samples for multiple kinds of analyses (Figure 30-1). Much of the analytical effort reflected in the chapters of this volume derive from these three columns (see Chapter 3 ).

Resource exploitation was documented by analyses of mammalian fauna, microfauna, molluscan fauna, and macrobotanical remains. Baker (Chapter 33) documents exploitation shifts evidenced in the faunal remains recovered by 1/4-inch screens of the TxDOT excavations and the 1/8inch screens of the TARL excavations. Most of these remains are mammalian species. In addition, Baker provides a detailed assessment of archeological faunal taphonomy, and this represents a significant advancement in our understanding of the formation processes that help mold and bias archeological faunal assemblages in Central Texas. Balinsky (Chapter 35) reports the results of the TARL fine-screening efforts, and Decker (Chapter 34) describes the unique methods used to secure the TARL fine-screen sample. The resulting microfaunal findings expand those published earlier (Winkler 1990). Balinsky's analysis provides new data on the microfauna, and it appears that a significant proportion of these remains were introduced into the site as food items by the prehistoric human inhabitants. An additional contribution by Decker (Chapter 36) provides an analysis of bird eggshell remains. Bird eggshell is rarely recovered in archeological excavations because of the coarse screens in common use, but as Decker demonstrates, throughout the Holocene bird eggs were a food resource and numerous species were exploited. Shaw's analysis (Chapter 37) of the freshwater unionid assemblages demonstrates the prehistoric exploitation of these as food resources. However, most of the molluscan remains are better indicators of past environments. Dering's study (Chapter 40) of the botanical materials recovered from the site provides the first indication that wild hyacinth (Camassia scilloides) was a food item utilized by Early and Late Archaic hunter-gatherers, and other possible plant foods include walnuts (Juglans spp.), at least three species of grass seed (Panicum, Paspalum, and Setaria), and hackberry fruit (Celtis sp.). Dering also discusses the fluctuating use of different fire woods.

Materials that provide evidence of past environments include the mollusks, vertebrate fauna, diatoms, ostracods, phytoliths, and sediment stable isotopes. Pollen samples were also taken by Vaughn Bryant during the TxDOT excavations, but these efforts failed due to poor preservation
(Holloway and Bryant n.d.). Paleoenvironmental data must always be interpreted with caution, but a number of independent lines of evidence have been analyzed from WilsonLeonard, and these can be compared to one another and other nearby sources (see Bousman in review; Nordt et al. 1994; Toomey 1993).

Shaw, Neck, and Theler (Chapter 37) analyzed snails and unionids recovered from TxDOT and TARL sediment columns and features. These data are used to suggest that significant environmental shifts are indicated by changes in the frequencies of snails and mussels. The gastropods suggest that more open environments were present in the middle Holocene. Similar to other sources of evidence, mollusks are rare in Unit I and are probably lost through decomposition. Winsborough's (Chapter 38) discovery that diatoms are only present when encrusted by calcium carbonate nodules even though the specific depositional environment should have diatoms, clearly demonstrates that diatoms have been destroyed by geochemical processes. This is supported by the vertical distribution of phytoliths and mollusks as well as the absence of pollen. Henry, Kontrovitz, and Slack's study (Chapter 39) of ostracodes from Unit I sediments provides rare evidence of paleoenvironments at that period of site formation. The ostracode evidence suggests that conditions were more moist during the accumulation of Unit I sediments than during most of the Holocene. Fredlund's analysis (Chapter 41) of phytoliths provides a continuous record of biotic changes over the last 10,000 years. He documents changes in phytolith mass as well as woodland/grassland ratios and grass short-cell assemblages that reflect paleoenvironmental changes in the phytolith record. Fredlund uses these data to suggest that the biotic composition shifted from woodlands to grasslands and then back to woodlands. The phytoliths and gastropods provide a consistent record of environmental change. Fredlund and Tieszen (Chapter 42) provide an analysis of stable isotopes from a stratified column of sediment samples. These data do not show the dramatic change in past environments indicated by the phytoliths and gastropods, or data from other nearby studies (Bousman in review; Nordt et al. 1994). Fredlund and Tieszen suggest that the organic matter in the sediments is a reflection of highly local biotic communities in the valley setting with similar isotopic signals. Individual sources of paleoenvironmental evidence can be interpreted in a number of ways, but when combined the independent lines of evidence appear to suggest similar trends in past environmental changes even though taphonomic factors such as preservation and local versus regional catchments clearly skew taxa representation in samples.

There is no effort to integrate these separate paleoecological investigations in this volume. However, these diverse findings are addressed in the interpretive chapters in Volume I. 


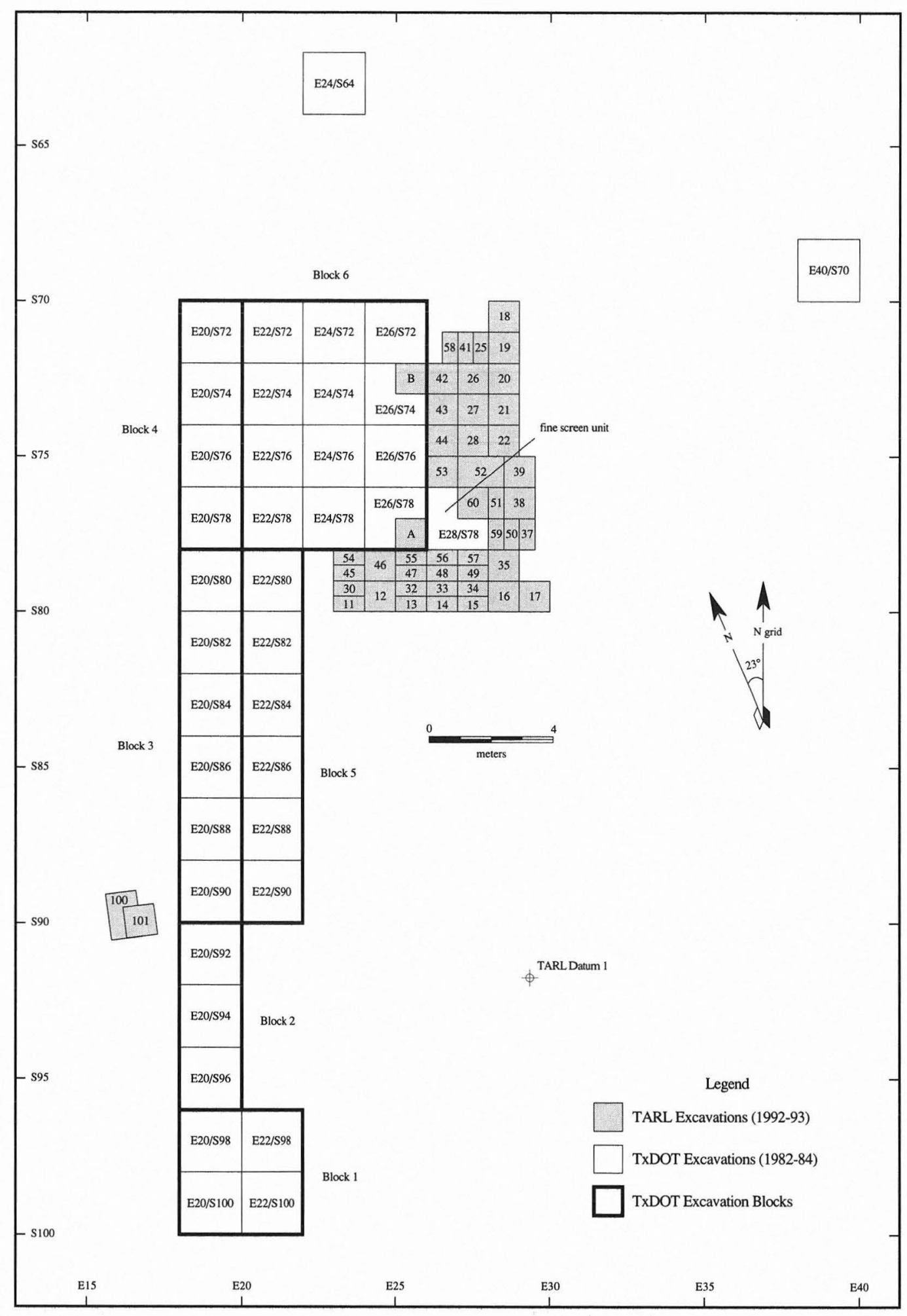

FIGURE 30-1. Plan map of TxDOT and TARL excavations. 


\section{Chapter 31}

\section{HUMAN BIOLOGICAL REMAINS}

by D. Gentry Steele

\section{INTRODUCTION}

In many respects the Wilson-Leonard site has gained its fame and much of its publicity because of the recovery of the ancient human remains identified as Wilson-Leonard II (or Burial 2) from one of the deeper cultural deposits at the site. These remains of a young adult female believed to have died around 10,000 B.P. are worthy of this attention for they represent one of the very few individuals of that antiquity recovered from the Americas. For example, within North America only two adult females represented by very fragmentary and incomplete remains from White Water Draw, Arizona and one adult female from Gordon Creek, Colorado are of equivalent confirmed antiquity. In addition to these individuals, incomplete and fragmentary remains of an adult female from Midland, Texas, an adolescent female from Pelican Rapids, Michigan, and an adolescent female from La Brea, California have been considered of similar or slightly more recent antiquity. If the remains of males are considered, as well as skeletal remains from sites whose antiquity is not as firmly established or sites where only traces of human remains have been found, the database for interpreting the biological history of the earliest Americans increases slightly but is still truly minuscule (Table 31-1).

While Wilson-Leonard II represents the most significant human remains recovered from the site, at least one other individual, and probably more, have been recovered from Archaic/Late Prehistoric levels at the site as well. Burial 1 , represented by very fragmentary and incomplete postcranial remains, was recovered from Late Archaic deposits. In addition to Burial 1, a portion of a braincase was recovered from Feature 90 and six isolated fragments of human bone and one human tooth fragment were recovered from the site. The isolated tooth fragment was found in the TARL excavations and all other human remains were recovered in the TxDOT excavations. All human remains recovered from 41WM235 are reported in this chapter, but given the signifi- cance of the Wilson-Leonard II female, the focus is upon the biological interpretation of the remains of this individual. This follows two earlier efforts at other laboratories to stabilize and conserve the remains constituting Burial 2.

\section{ARCHAIC/LATE PREHISTORIC HUMANREMAINS Burial 1 (Wilson-Leonard I)}

Burial 1 was found in the lower portion of Burned Rock Midden 1 (E20/S92, Level 6) in stratigraphic Unit IIIc. It is probably Late Archaic in age and includes the highly fragmented and incomplete postcranial remains of one individual (see Chapter 26). Identifiable elements recovered were two fragments, side indeterminate, of an ilium; portions of the shafts of a right femur and left tibia; and small fragments of the shaft of a fibula, side indeterminate. In addition to these larger skeletal pieces, approximately 130 additional postcranial fragments were recovered, but their small size, lack of diagnostic features, and eroded surfaces made it impossible to reconstruct these into larger, more analyzable fragments.

Wilson-Leonard I was buried in a flexed position, apparently on the individual's back with the lower legs flexed under the upper legs. The skeleton suffered extensive postmortem destruction while the burial was in situ. Compaction of the overlying soils, probably associated with their intermittent expansion and contraction through time, caused multiple right angle and spiral breaks of the preserved elements. The cortical surfaces of the bones were extensively eroded with marked evidence of root etching and more generalized leaching of the bone minerals. Smaller and thinner bones, such as those of the scapulae and hand and foot bones appear to have been completely reduced, with only the thickest postcranial elements left to represent the individual. It is also possible that burrowing animals and other unspecified forms of bioturbation could have removed some of the smaller elements. No evidence of rodent gnawing, however, was found on the bones of Wilson-Leonard I to 
TABLE 31-1

Affirmed and Probable North America Paleoindians

\begin{tabular}{|c|c|c|c|c|}
\hline Locality & Remains & $\begin{array}{l}\text { Age at } \\
\text { Death }\end{array}$ & $\begin{array}{c}\text { Antiquity } \\
\text { (years B.P.) }\end{array}$ & Reference \\
\hline
\end{tabular}

Female

Wilson-Leonard II, TX

Midland, TX

Whitewater Draw I, AZ

Whitewater Draw II, AZ

Pelican Rapids, MI

La Brea, CA
Gordon Creek, CO

$\begin{array}{lc}\text { Skeleton } & 20-25 \\ \text { Skeleton } & \text { adult } \\ \text { Skeleton } & 25-40 \\ \text { Skeleton } & 30-50 \\ \text { Skeleton } & 35-50 \\ \text { Skeleton } & 15-20\end{array}$

Skeleton
Male

$\begin{array}{cc}\text { Skeleton } & 35-45 \\ \text { Skeleton } & \\ \text { Skeleton } & 20-30 \\ \text { Skeleton } & 25-40 \\ \text { Cranial fragments } & -\end{array}$

$35-45$

20-30

$-$

\author{
9800- 10,000 \\ 9700 \\ 8390- 10,420 \\ 8390-10,420 \\ $7840 \pm 70$ \\ $9000 \pm 80$ \\ Breternitz et al. 1971 \\ Waters 1986 \\ Jenks 1936 \\ Berger 1975; Kroeber 1962
}

\author{
Horn Shelter, TX \\ Horn Shelter adolescent \\ Browns Valley, MI
}

\section{Sex Indeterminate}

Arlington Springs, CA

Mostin, CA

Fishbone Cave, NE

Anzick (Wilsal), MT

Shifting Sands, TX

Warm Mineral Springs, FL

$\begin{array}{cc}- & 10,000 \\ - & 10,000-11,000 \\ - & 10,900-11,200 \\ - & 10,600 \\ 15-20 & 8500-10,000 \\ - & 10,620 \pm 190\end{array}$

Young 1986, 1988

Jenks 1937

Jenks and Wilford 1938

Fryxell et al. 1968

* The estimated antiquity of Sauk Valley at time of research was $8000-10,000$ B.P. It has been recently redated to $4360 \pm 60$ B.P. (Tom Stafford, personal communication).

suggest that burrowing rodents had disturbed the skeleton. In addition to reduction of the bone in situ, it is also possible that the burial was disturbed through human activities for the torso is represented by only two small fragments of the ilium, and the skull is completely missing. Since Burial 1 was located within Burned Rock Midden 1, it may have been disturbed by either modern relict collectors or by the prehistoric inhabitants who utilized the midden.

Very little information could be ascertained about the size, physical features, or biological affinity of Wilson-Leonard I. Only three measurements could be taken to assess the dimensions of the femur shaft (Table 31-2), and none of these measures provided any diagnostic information. Subjectively, the shaft of the femur appears to be short although relatively robust, the dimensions falling within the range of variation for either a male or female. Also, subjectively, size of the diaphysis fragment and the thickness of the cortex suggests the individual was an adolescent or adult.
TABLE 31-2

Measurements of Wilson-Leonard I

\begin{tabular}{l|c}
\hline Element & $\begin{array}{c}\text { Measurement } \\
(\mathrm{cm})\end{array}$ \\
\hline Femur anterior-posterior diameter, midshaft & 3.0 \\
Femur, transverse diameter, midshaft & 2.5 \\
Femur, circumference, midshaft & 8.5 \\
\hline \hline
\end{tabular}

\section{Feature 90}

Feature 90 was found about $1 \mathrm{~m}$ northeast of Burial 1 and about $50 \mathrm{~cm}$ below it (E22/S90, Level 12). It was located in stratigraphic Unit Y, about $20-30 \mathrm{~cm}$ below the base of Burned Rock Midden 1. Feature 90 was judged in the field to be part of the displaced skull missing from Wilson-Leonard I. Its stratigraphic position suggests it may represent an earlier burial (Early Archaic?) although a possible Burial 1 association cannot be definitively ruled out. Recovered from 
the feature were the fragments of a human calotte comprised of portions of the frontal, parietal, and the squamous portion of the occipital, and approximately 60 cranial fragments too small and eroded to be reconstructed into larger, identifiable fragments. No other human skeletal remains were recovered from the feature, nor was there evidence of a burial pit. Like Wilson-Leonard I, the cranial fragments of Feature 90 are incomplete, fragmented, and eroded.

Based upon the gracile nature of the occipital protuberance and supraorbital brow ridges of the calotte, the individual appears to have been a female. The early stages of fusion of the coronal, sagittal, and lambdoid sutures suggest the individual was a young adult. Nothing could be determined about the size or biological affinity of the individual, and only two nondiagnostic measurements could be determined from the frontal bone (Table 31-3). No pathological disorders were observed on the recovered cranial elements.

TABLE $31-3$

Feature 90 Cranial Measurements

\begin{tabular}{l|c}
\hline Element & Measurement $(\mathrm{cm})$ \\
\hline Frontal chord length & 11.1 \\
Frontal arch length & 12.0 \\
\hline \hline
\end{tabular}

\section{Miscellaneous Human Bone Fragments}

In addition to Burial 1 and Feature 90 , six bone and one tooth fragment were recovered (Table 31-4). When the bone fragments were recovered during the initial excavations of the Wilson-Leonard site, they were not recognized as human and were included with the faunal remains. They were first identified as human during the laboratory phase of the faunal analysis by Barry W. Baker and their identification as human was confirmed by this author.

All six bone fragments have highly degraded cortical surfaces with extensive evidence of chemical erosion and some weather checking. The bones were broken prior to recovery, and some of the broken edges exhibit rounding and polishing suggestive of abrasion by sediment-loaded waters or by minor movement within the soil after breakage. One ulna fragment (Lot 20I) exhibits extensive rodent gnawing as well as chemical erosion of the cortex. The one recovered tooth shows a similar degree of degradation by mechanical breakage and chemical erosion of the preserved portion of the root mass and the recovered portion of the enamel crown.

It appears that these fragments have been subjected to multiple destructive processes, probably have been moved from their initial burial location, and could represent fragments from Burial 1 or another individual or individuals not preserved in total or not exposed during the two periods of excavation. Two femur fragments (Lot 36B) recovered 25-30 m northeast of Burial 1 and Feature 90 in Unit IIIc probably represent either adventicious elements or dislocated bones from a different burial. The isolated tooth fragment and one radius fragment (Lot 23I) found 10$12 \mathrm{~m}$ northeast of Burial 1 in Unit IIIb may represent a separate individual (or individuals) as well. Two left ulna fragments (Lot 20I) and a radius fragment (Lot 8I) were recovered in closer proximity to Burial 1 and Feature 90 and could more plausibly be remains from these individuals. These fragments were found 1 to $5 \mathrm{~m}$ north of Burial 1 at the very base of Unit IIIc (IIIb/c and Y/IIIc).

Nothing informative could be gleaned from the five bone and one tooth fragment concerning the biological nature of the individual or individuals represented. The upper left molar fragment includes portions of the two mesial cusps which are worn flat but have not been worn to the degree that dentin is exposed. While this suggests the individual is a young adult, or possibly an adolescent, the age cannot be more precisely determined since it cannot be determined whether the fragment represents a first, second, or third molar. No other biological information could be determined from this bit of tooth.

\section{Summary of Archaic/Late Prehistoric Human Remains}

In summary, the remains of at least one individual (if all remains are from Burial 1), and possibly as many as seven individuals (if Burial 1, Feature 90, and Lots 651, 36B, 23I, $8 \mathrm{I}$, and 20I each represent a separate individual) have been recovered from Archaic and possibly Late Prehistoric deposits at $41 \mathrm{WN} 235$. A more conservative estimate of the minimum number of individuals represented, based on the assessment of the biological remains and where they were recovered from the site, however, is three to five individuals. Burial 1, an adolescent or adult of undetermined sex, is the only individual recovered from a recognized burial context from this time period. Based on the stratigraphic context of Feature 90, this calotte most plausibly represents a second individual, an adolescent or young adult female. Bone fragments of a radius and ulna (Lots $8 \mathrm{I}$ and 20I) because of their proximity to Burial 1 and Feature 90 could be associated with either of these individuals although there is no biological evidence to suggest that they are. A third individual represented by the remains of the two femur shaft fragments (Lot 36B) is probably represented in the assemblage, considering the more than $25-\mathrm{m}$ distance these fragments were from Burial 1 and Feature 90. The isolated tooth fragment (Lot 65I) and the two radius fragments (Lots 8I and 23I) may or may not represent a fourth and possibly a fifth individual. The only information that can be determined about these last one to three individuals is that the femur fragments appear to be from an adolescent or adult of undetermined sex, and the molar fragment appears to be from an adolescent or young adult of undetermined sex. 
TABLE 31-4

Provenience and Cultural Affiliation of Miscellaneous Human Bone Fragments

\begin{tabular}{l|c|c|c|c}
\hline \multicolumn{1}{c|}{ Biological Material } & Unit & Lot Number & Provenience & Cultural Affiliation \\
\hline Left upper molar $(\mathrm{N}=1)$ & IIIb & $65 \mathrm{I}$ & TARL Square 16, Level 12 & Archaic (Early/Middle?) \\
Left femur (N=2) & IIIc & $36 \mathrm{~B}$ & E40/S70, Level 2 & Late Archaic/Late Prehistoric? \\
Radius, side (indeterminate) $(\mathrm{N}=1)$ & IIIb & $23 \mathrm{I}$ & E22/S80, Level 9 & Archaic (Early/Middle?) \\
Radius, side (indeterminate) $(\mathrm{N}=1)$ & Y/IIIc & $8 \mathrm{I}$ & E20/S90, Level 9 & Archaic (Middle/Late?) \\
Ulna, left (N=2) & IIIb/c & 20I & E22/S86, Level 9 & Archaic (Middle/Late?) \\
\hline \hline
\end{tabular}

\section{PALEOINDIAN REMAINS(WILSON-LEONARD II)}

Wilson-Leonard II, also identified as Burial 2, was excavated from a burial pit that originated in the lower portion of the Leanne soil and extended into the underlying sediments (E20/S74 and E20/S72, Levels 31A-34B). Based on the chronostratigraphic position of the burial pit, the individual appears date between 10,000 and 10,500 B.P.

Wilson-Leonard II was placed in an oval burial pit, approximately $1.04-\mathrm{x}-0.52 \mathrm{~m}$ in dimensions and at least $22 \mathrm{~cm}$ deep. The burial pit was detected at a depth of approximately $3.1 \mathrm{~m}$ below surface (although it may have originated slightly above this). The individual was lying on her right side, with her head resting on her right hand, the left hand resting on the right wrist. Wilson-Leonard II's legs were flexed with the left leg crossing the right. The knees were drawn more than half way to the chest. She was generally in a northeast/southwest direction with the head to the north and facing west (Figure 31-1). Elements recovered include portions of the cranium, trunk, pelvic region, and upper and lower limbs (Table 31-5).

Field notes prepared by the excavators of the burial have been used to provide the following distillation of the exposure and removal of Wilson-Leonard II. The burial was exposed as a single unit, leaving skeletal material in situ to aid documentation. After the majority of the skeletal remains had been exposed, a detailed drawing of the burial was prepared. The location of the left hand was in the upper centimeters of the burial pit, and once the map of the burial was completed, these disarticulated bones as well as those of the feet were removed to aid the further excavation of the skeleton. Some hand and foot elements were dislocated due to postmortem movement within the soil. The larger long bone elements were then removed individually. Prior to removing the skull, four coats of a thin Elmer's glue solution were applied to the fragments. Then the consolidated cranium and underlying sediments were removed as a block for cleaning and restoration in the laboratory. The rib cage and pelvis were also removed as block units with underlying matrix for further excavation and conservation in the laboratory.

\section{Taphonomy}

While Wilson-Leonard II is represented by more skeletal remains than were recovered of the more-recent
Wilson-Leonard I, significant postmortem degradation occurred while the burial was in situ. Excavators noted that some of the bones, particularly the small bones of the hands and feet, had been dislocated either during the natural disintegration of the soft tissues or by bioturbation sometime later, although very little evidence of rodent activity in the burial pit was observed. One of the excavators noted that while much of the skeletal material was present, the bone preserved was very fragile. Most notable, however, were the multiple postmortem fractures found on all of the bones, with many of the fractures being complete breaks. The skull, in particular was crushed to approximately one-third its normal width (Figure 31-2). Excavators also noted that ends of the long bones were badly eroded. Because of this extensive fracturing, most of the bones were removed in fragments.

The currently reported examination of the skeletal remains under laboratory conditions generally substantiates the excavators' observations. Virtually all bones preserved and examined were extensively fractured, in many cases with complete fractures that had been reconstructed during conservation by another laboratory. In many cases, even though the surface details were obscured by a stabilizing medium, further erosion of the edges of the fractures after breakage could be seen. The ends of most of the long bones, which in life are covered with a thin cortex, were completely destroyed in situ, or the very friable material that remained could not be consolidated for preservation.

This destruction of the fragile bone was most apparent by the absence of many of the small bones of the wrists, hands, and feet. For example, of the 106 bones that comprise the wrists, hands, and feet, only 9 were recovered, preserved, and available for analysis. Upon analysis of the remains, the cause of this destruction could be attributed for the most part to mechanical breakage into smaller and smaller elements and to chemical erosion. On the larger fragments of the preserved bone, the effects of chemical dissolution of the cortical surface could be seen under magnification as pitting and generalized etching. None of the cortical bone examined under magnification was near the smoothness of cortical bone of dissection room comparative specimens.

Shortly after removal from the field, the skeletal remains, the skull in particular, were cleaned and stabilized, and for some of the bones, reconstruction was undertaken. 


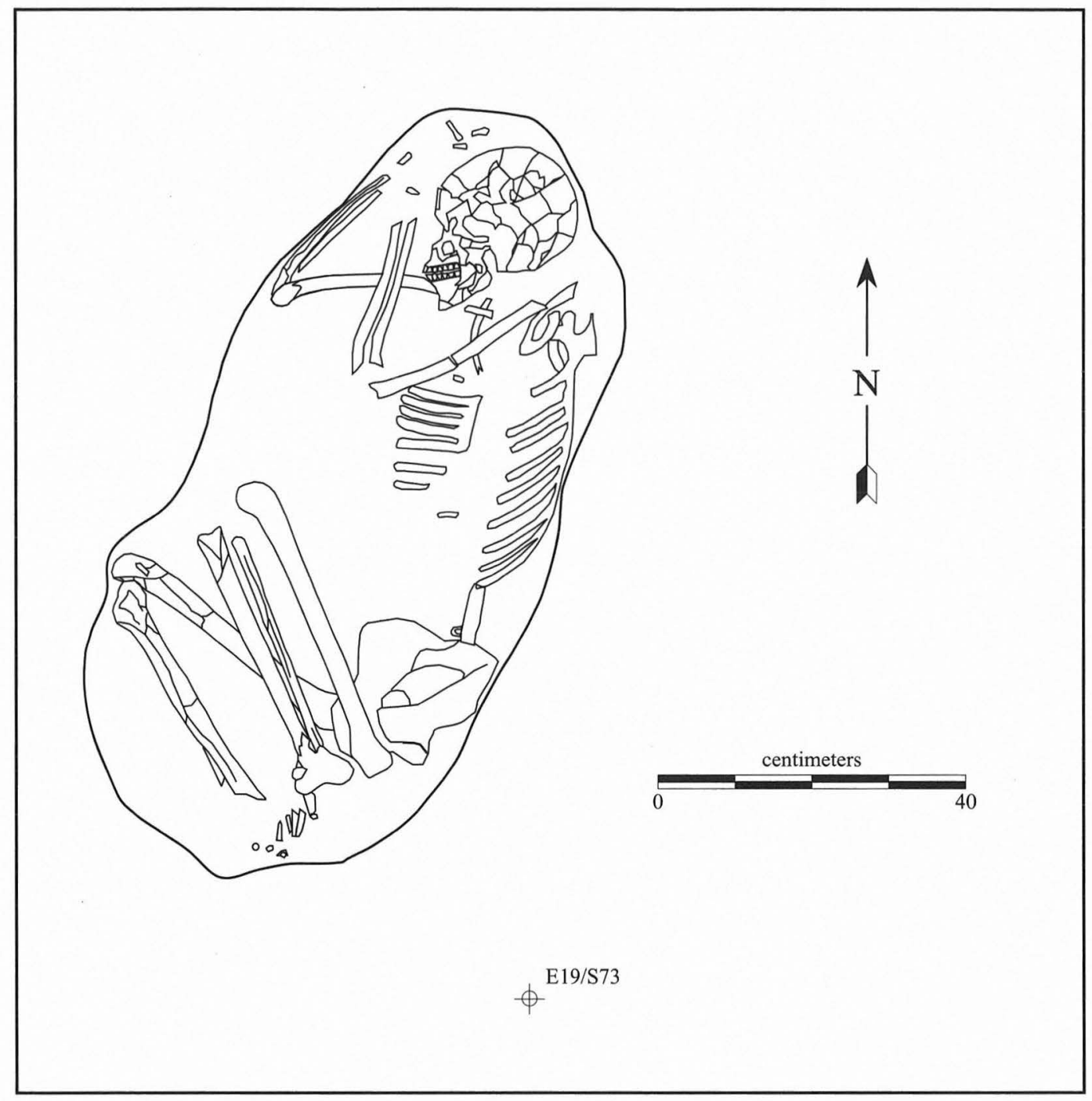

FIGURE 31-1. Illustration of Wilson-Leonard II in situ.

TABLE $31-5$

List of Wilson-Leonard II Skeletal Elements Recovered

\begin{tabular}{l|l}
\hline Anatomical Region & Skeletal Elements \\
\hline Cranium & $\begin{array}{l}\text { All or portions of the frontal, both parietals, occipital, both temporals, sphenoid, both zygomatics, both } \\
\text { maxillae, both palatines, and the mandible }\end{array}$ \\
\hline Vertebral Column & Axis, atlas, and portions of other unidentified vertebrae, and sacrum \\
\hline Thorax & Portions of most ribs and sternum \\
\hline $\begin{array}{l}\text { Pectoral Girdle and Upper } \\
\text { Limb }\end{array}$ & $\begin{array}{l}\text { Portions of both clavicles, left scapula, both humeri, both radii, right ulna, and four metacarpal } \\
\text { fragments }\end{array}$ \\
$\begin{array}{l}\text { Pelvic Girdle and Lower } \\
\text { Limb }\end{array}$ & $\begin{array}{l}\text { Portions of both ilia, right ischium, both femora, both tibiae, both fibulae, left talus, and fragments of } \\
\text { four metatarsals }\end{array}$ \\
\hline \hline
\end{tabular}

Conservators at that time elected not to dismantle the fragmented skull. Instead, the skull was cleaned and stabilized with polyvinyl acetate and plaster in its crushed condition. A later attempt at some reconstructive work of the skull undertaken at a second laboratory separated the mandible from the upper face and removed adhering matrix from the cranium. Sometime during these two periods of conservation, the right second and third maxillary molars were reversed. No attempt was made during the present analysis to reposition the teeth. 
FIGURE 31-2. Wilson-Leonard II cranium (left and right lateral and frontal views).

\section{Sex and Age}

Wilson-Leonard II was identified as a female by archeologists as she was being excavated and this assessment has been substantiated by the more-detailed laboratory examination. The cranium is noteworthy for its gracile nature. The supraorbital brow ridges are slight as are the zygomatic arches and the muscle markings in the occipital region. The mastoid processes are slight. Though the mandible is broken and slightly crushed, the chin is still recognizably pointed, as typical of females. The body of the mandible is slight and the gonial angles are not everted, again, features typical of females. Although little of the pelvis is preserved, the sciatic notches are open as they more commonly are in females. A slight preauricular sulcus is apparent on the left ilial fragment but not on the right. The long bones are relatively gracile, particularly noticeable in the moderate muscle markings of the linea aspera of the femora, again, a condition more commonly seen in females than males. Although the heads of the femora are eroded and too poorly preserved for measurement, subjectively they appear relatively small in diameter. The left talus, also too poorly preserved for measurement, appears to be relatively small, again indicative of a female.

The age of the individual is estimated to be a late adolescent or young adult, probably in her early twenties at the time of death. Although few ends of the long bones remain, the proximal ends of the femora and the distal end of the right radius are preserved and their epiphyses are fused to the diaphyses. While the cranial sutures are damaged by erosion or obliterated by matrix or preservative materials, where they can be seen, it is apparent that they were under active fusion at time of death. The third molars (Figure 31-3), which would have erupted sometime around the eighteenth year, are erupted, in occlusion, and exhibit moderate wear. The first molars, which would have erupted sometime around six years of age, are worn to the point that windows of secondary dentin are exposed, but there is still enamel left on the occlusal surface of these teeth. One of the first molars had been lost during life. This degree of dental wear is typical of more-recent prehistoric hunter and gatherer populations recovered from Central Texas. Considering this degree of wear as well as the state of fusion of the cranial and longbone elements, Wilson-Leonard II was probably older than 18 years but little more than 25 years at time of death.

\section{Body Size}

Wilson-Leonard II is estimated to have been slight and relatively short. Table $31-6$ presents the few measurements that could be determined from the mandible. Table 31-7 presents the postcranial measurements, and Tables 31-8 and 31-9 present the dental measurements.

The stature of Wilson-Leonard II is estimated to have been approximately $158 \mathrm{~cm}$. Because the long bones are all incomplete, it was necessary to determine stature on the basis of the incomplete left femur. An estimate of femur length based upon Segment 1 was calculated using a discriminant function derived for American white females:

$$
0.62(7.4)+38.21=42.80+2.15 \mathrm{~cm}
$$

The calculated femur length was then used to estimate living stature based upon Genovese's (1967) formula derived for Mesoamerican females:

$$
2.59(42.8)+49.742=160.60+3.816 \mathrm{~cm}
$$

Since Genovese's estimation of stature was based upon a cadaveral sample, it is necessary following Trotter and Gleser (1952) to reduce the stature estimate by $2.5 \mathrm{~cm}$ to obtain the estimate of $158.1 \mathrm{~cm}+5.15 \mathrm{~cm}$ for the living stature of the Wilson-Leonard II female. The increased estimate of variation takes into consideration that femur length was estimated following Steele (1970).

Considering the femur is incomplete and that Wilson-Leonard II was not a member of the two referent populations upon which the discriminant functions were 
FIGURE REDACTED

FIGURE 31-3. Occlusal views of the maxillary and mandibular teeth of Wilson-Leonard II.

TABLE 31-6

Cranial Measurements $(\mathrm{cm})$ of Wilson-Leonard II and Compared Paleoindians

\begin{tabular}{|c|c|c|c|c|c|c|c|c|}
\hline \multirow[b]{2}{*}{ Measure } & \multicolumn{5}{|c|}{ Female } & \multicolumn{3}{|c|}{ Male } \\
\hline & $\begin{array}{c}\text { Wilson- } \\
\text { Leonard II }\end{array}$ & $\begin{array}{c}\text { Gordon } \\
\text { Creek }\end{array}$ & $\begin{array}{l}\text { Pelican } \\
\text { Rapids }\end{array}$ & Midland & $\begin{array}{c}\text { Whitewater } \\
\text { Draw I }\end{array}$ & $\begin{array}{c}\text { Horn } \\
\text { Shelter }\end{array}$ & $\begin{array}{c}\text { Browns } \\
\text { Valley }\end{array}$ & $\begin{array}{l}\text { Sauk } \\
\text { Valley }\end{array}$ \\
\hline Maximum cranial length & & 17.3 & 17.9 & 18.0 & 17.0 & 18.7 & 19.3 & 18.6 \\
\hline Maximum cranial breadth & & 13.8 & 13.8 & 12.6 & 13.0 & 14.0 & 14.2 & 13.7 \\
\hline Cranial height (Basion-Bregma) & & & 12.7 & & & & 14.2 & 13.8 \\
\hline Auricular height & & 10.0 & 11.6 & & & 13.8 & 12.4 & \\
\hline Mininum frontal breadth & & & 9.3 & & & 9.5 & 9.2 & 10.7 \\
\hline Basion-Nasion length & & & 10.2 & & & & & 10.2 \\
\hline Bizygomatic breadth & & & 12.7 & & & & 14.0 & 13.5 \\
\hline Upper facial height & & 5.7 & 6.7 & & & & 6.6 & \\
\hline Total facial height & & 10.8 & 11.4 & & & & 11.0 & \\
\hline Nasal height & & 4.7 & 4.7 & & & & 5.1 & \\
\hline Nasal breadth & & & 2.1 & & & 2.4 & 2.4 & 2.8 \\
\hline Orbital height & & 2.9 & 3.4 & & & & 3.6 & 3.2 \\
\hline Orbital breadth & & 3.7 & 3.8 & & & & 3.8 & 4.5 \\
\hline Exterior palate breadth & & & 6.5 & & & & 6.6 & \\
\hline Estimated palate length & & & & & & & 5.3 & \\
\hline Symphsial height & & & & & & 3.4 & 3.2 & \\
\hline Mandibular body length & & & & & & 7.9 & & 9.5 \\
\hline Mandibular body height & 3.0 & & & & & & & 3.9 \\
\hline Mandibular body breadth & 1.2 & & & & & & & 1.6 \\
\hline Minimum ramus breadth & 3.6 & & & & & & 3.5 & \\
\hline Maximum ramus breadth & & & & & & & & \\
\hline Coronoid height & 6.6 & & & & & & & \\
\hline
\end{tabular}


TABLE 31-7

Postcranial Measurements (cm) of Wilson-Leonard II and Gordon Creek Females

\begin{tabular}{|c|c|c|c|c|c|}
\hline Measurement & $\begin{array}{c}\text { Wilson- } \\
\text { Leonard II }\end{array}$ & $\begin{array}{c}\text { Gordon } \\
\text { Creek }\end{array}$ & Measurement & $\begin{array}{c}\text { Wilson- } \\
\text { Leonard II }\end{array}$ & $\begin{array}{c}\text { Gordon } \\
\text { Creek }\end{array}$ \\
\hline Humerus & & & Clavicle & & \\
\hline Maximum length & & 27.5 & Anterior/posterior diameter midshaft & 1.0 & 0.9 \\
\hline Maximum diameter midshaft & 2.0 & 1.9 & Vertical diameter midshaft & 0.9 & 0.8 \\
\hline Minimum diameter midshaft & 1.5 & 1.3 & Middle circumference & 3.5 & 3.5 \\
\hline Minimum circumference & 5.9 & 5.8 & Femur & & \\
\hline Middle circumference & 6.3 & 5.8 & Segment 1 & 7.4 & \\
\hline Vertical diameter of head & & 4.0 & Segment 2 & 21.4 & \\
\hline Transverse diameter of head & & 3.8 & Anterior/posterior diameter midshaft & 2.6 & \\
\hline Radius & & & Transverse diameter midshaft & 2.6 & \\
\hline Anterior/posterior diameter midshaft & 1.5 & & Anterior subtrochanteric diameter & 2.6 & \\
\hline Trans. diameter midshaft & 1.4 & & Transverse subtrochanteric diameter & 3.6 & \\
\hline Middle circumference & 4.5 & & Maximum head diameter & 4.3 & \\
\hline Minimum circumference & 3.5 & & Circumference midshaft & 8.3 & \\
\hline Head diameter & & 1.8 & Tibia & & \\
\hline Neck circumference & & 4.1 & Segment 3 & 14.0 & 11.2 \\
\hline Ulna & & & Segment 4 & & 10.0 \\
\hline Maximum length & & 23.3 & Anterior/posterior diameter nutrient foramen & 2.9 & 3.0 \\
\hline Pysiological length & & 21.1 & Transverse diameter nutrient foramen & 1.9 & 2.0 \\
\hline Middle circumference & & 4.5 & Circumference midshaft & 7.8 & 7.8 \\
\hline Minimum circumference & & 4.0 & Minimum circumference & 7.0 & 7.0 \\
\hline Maximum diameter & & 1.3 & Fibula & & \\
\hline Minimum diameter & & 1.3 & Maximum length & & 31.5 \\
\hline Dorso-volar diameter & & 1.2 & Maximum diameter midshaft & & 1.3 \\
\hline Transverse diameter & & 1.3 & Anterior/posterior diameter & & 1.3 \\
\hline Maximum breadth olecranon & & 1.8 & Transverse diameter & & 1.0 \\
\hline Minimum breadth olecranon & & 1.6 & Middle circumference & & 4.0 \\
\hline Olecranon-radial notch & & 2.5 & & & \\
\hline Olecranon-coronoid length & & 2.1 & & & \\
\hline
\end{tabular}

based, the estimate is at best a crude assessment of stature. There are several points worth noting, however. The estimate is comparable to the mean stature of Genovese's Mesoamerican female sample $(152.3 \mathrm{~cm}$, a sample selected to be as close to an indigenous America population as Genovese could obtain). The estimate is also comparable to estimated statures for similar prehistoric American samples of huntergatherers (Table 31-10).

The only other female Paleoindian individual for which stature could be estimated is the Gordon Creek burial from Colorado. This individual is of comparable antiquity but is from a different geographical region. For this report, the Gordon Creek stature estimate was based on reconstructing the tibia length from a fragment from which Segments 3 and 4 could be measured following Steele (1970). Obtaining an estimated tibia length of $31.76 \mathrm{~cm}+0.99 \mathrm{~cm}$, a living stature estimate for the Gordon Creek female of $147.6+6.21 \mathrm{~cm}$ was calculated utilizing Genovese's discriminant function for Mesoamerican females and calculating the standard error following Steele (1970). This is comparable to the stature estimate of $149.5 \mathrm{~cm}$, based on fragments of the humerus and ulna and the complete fibula reported by Breternitz et al. (1971). Based on these calculated statures, the Gordon Creek female is smaller than the Wilson-Leonard female and smaller than the reported samples of hunters and gatherers and Genovese's Mesoamerican cadaveral sample. The small size of the Gordon Creek female is born out by a subjective assessment of the rest of the skeleton as well. Whether the size difference between Wilson-Leonard II and the Gordon Creek female reflect regional differences or just variants of similar-sized populations is impossible to say. The author has noted, however, that the Whitewater Draw I and II females from Arizona, which are of comparable antiquity, also appear to be small like Gordon Creek. 
TABLE 31-8

Crown and Neck Measurements ( $\mathrm{mm}$ ) of Maxillary Teeth of Paleoindian Females

\begin{tabular}{|c|c|c|c|c|c|c|c|c|}
\hline Measurement & Incisor 1 & Incisor 2 & Canine & Premolar 3 & Premolar 4 & Molar 1 & Molar 2 & Molar 3 \\
\hline \multicolumn{9}{|l|}{ Wilson-Leonard II: } \\
\hline Crown MD & 8.6 & 8.1 & 7.9 & 7.8 & 7.2 & 10.8 & 10.6 & 10.5 \\
\hline Crown BL & 8.1 & 6.8 & 8.6 & 10.8 & 10.7 & 12.2 & 11.4 & 11.7 \\
\hline Crown HT & 8.4 & 8.4 & 8.3 & 7.8 & 7.8 & 8.2 & 9.4 & 7.9 \\
\hline Neck MD & 5.5 & 5.1 & 5.8 & 4.8 & 4.7 & 7.4 & 7.2 & 7.0 \\
\hline Neck BL & 6.8 & 6.7 & 8.0 & 9.4 & 8.0 & 11.0 & 10.8 & 10.0 \\
\hline \multicolumn{9}{|l|}{ Gordon Creek: } \\
\hline Crown MD & 6.8 & 5.3 & 7.2 & 6.7 & 5.9 & 9.5 & 9.5 & 9.4 \\
\hline Crown BL & 7.5 & 6.5 & 8.2 & 9.4 & 8.5 & 11.2 & 11.2 & 10.3 \\
\hline Crown HT & 4.0 & 4.0 & 5.8 & 5.7 & 5.1 & 5.0 & 5.8 & 5.6 \\
\hline Neck MD & 5.7 & 4.6 & 5.7 & 4.5 & 4.1 & 7.6 & 7.4 & 7.2 \\
\hline Neck BL & 6.8 & 6.5 & 7.5 & 8.7 & 8.1 & 10.6 & 10.6 & 9.9 \\
\hline \multicolumn{9}{|l|}{ Whitewater Draw II: } \\
\hline Crown MD & 8.0 & 6.4 & 7.7 & 7.0 & 6.2 & 10.5 & 10.5 & 8.5 \\
\hline Crown BL & 7.3 & 6.5 & 8.3 & 9.5 & 9.2 & 11.4 & 10.9 & 9.5 \\
\hline \multicolumn{9}{|l|}{ Crown HT } \\
\hline \multicolumn{9}{|l|}{ Neck MD } \\
\hline \multicolumn{9}{|l|}{ Neck BL } \\
\hline \multicolumn{9}{|l|}{ Pelican Rapids: } \\
\hline Crown MD & 8.0 & 7.5 & 8.5 & 7.5 & 7.5 & 12.0 & 10.0 & \\
\hline Crown BL & 8.0 & 7.0 & 10.0 & 10.5 & 10.5 & 12.5 & 12.5 & \\
\hline \multicolumn{9}{|l|}{ Crown HT } \\
\hline \multicolumn{9}{|l|}{ Neck MD } \\
\hline Neck BL & & & & & & & & \\
\hline
\end{tabular}

To get some sense of the amount of sexual dimorphism (male stature/female stature $\mathrm{x} 100$ ) that may have been present in the early Holocene population of Texas, the Wilson-Leonard female was compared to the Horn Shelter male, an individual of comparable antiquity who was also recovered from Central Texas. Comparing these two provided a sexual dimorphic ratio of $102.7 \%$. This estimate falls close to the typical degree of sexual dimorphism for humans. When the average of the two Paleoindian females (WilsonLeonard and Gordon Creek) was compared to the two Paleoindian males (Horn Shelter and Sauk Valley), a larger sexual dimorphic ratio of $107.9 \%$ was obtained. This second assessment probably suggests too great of a degree of sexual dimorphism because the small size of the Gordon Creek female skews the female sample.

\section{Personal Features}

The personal features of Wilson-Leonard II are difficult to determine because of the extensive crushing that the skull has undergone and the degree of postmortem destruction of the rest of the skeleton. The shape of the cranium can only be estimated since the conserved skull is about one-third its natural width. Given this caveat, however, this author, working in conjunction with B. P. Gatliff, estimated the natural dimension of the cranium to assist Gatliff in preparing a facial reconstruction of the WilsonLeonard II female (Phelps et al. 1994; Steele and Powell 1993). The dimensions estimated to assist in the facial reconstruction were: maximum cranial width, $12.5 \mathrm{~cm}$; maximum cranial length, $17.5 \mathrm{~cm}$; bizygomatic width, $12.2 \mathrm{~cm}$; palate width, $5.6-6.0 \mathrm{~cm}$; total facial height (nasion gnathion), $115 \mathrm{~cm}$; gonion - gonion, $9.5 \mathrm{~cm}$.; and nasospinale - gnathion, $6.6 \mathrm{~cm}$. These dimensions are listed here to document the author's interpretation of the cranial shape of Wilson-Leonard II but are not included in Table 31-6 because these are not accurate measurements but dimensional inferences only. Based on these dimensions, the braincase and face of Wilson-Leonard II is believed to have been relatively narrow. This reconstruction also suggests that the face was distinguished by a moderate degree of alveolar prognathism (Figure 31-4). A second attempt to reconstruct the facial features of the Burial 2 female is currently underway in collaboration with Denis $\mathrm{C}$. Lee of the 
TABLE 31-9

Crown and Neck Measurements (mm) of Mandibular Teeth of Paleoindian Females

\begin{tabular}{|c|c|c|c|c|c|c|c|c|}
\hline Measurement & Incisor 1 & Incisor 2 & Canine & Premolar 3 & Premolar 4 & Molar 1 & Molar 2 & Molar 3 \\
\hline \multicolumn{9}{|l|}{ Wilson-Leonard II: } \\
\hline Crown MD & 4.9 & 6.8 & 7.6 & 7.6 & 7.4 & 11.2 & 12.2 & 12.2 \\
\hline Crown BL & 5.3 & 6.3 & 8.6 & 8.5 & 8.5 & 11.0 & 11.7 & 11.4 \\
\hline Crown HT & 7.4 & 7.4 & 9.4 & 7.7 & 6.5 & 7.4 & 7.5 & 6.7 \\
\hline Neck MD & 3.1 & 4.4 & 4.6 & 4.4 & 4.9 & 9.4 & 10.0 & 9.9 \\
\hline Neck BL & 5.0 & 5.9 & 8.2 & 7.5 & 6.6 & 8.4 & 8.5 & 8.5 \\
\hline \multicolumn{9}{|l|}{ Gordon Creek: } \\
\hline Crown MD & & 5.1 & 6.3 & 7.6 & 6.7 & 11.0 & 11.0 & 11.7 \\
\hline Crown BL & & 6.5 & 7.5 & 8.4 & & 11.3 & 10.9 & 11.4 \\
\hline Crown HT & & 4.8 & 5.7 & & & 3.7 & 5.0 & 5.0 \\
\hline Neck MD & & 3.8 & 4.8 & 5.1 & 5.0 & 9.0 & 8.8 & \\
\hline Neck BL & & 6.4 & 7.4 & 7.6 & 7.3 & 9.6 & 9.1 & \\
\hline \multicolumn{9}{|l|}{ Whitewater Draw II: } \\
\hline Crown MD & 5.8 & 5.7 & 6.8 & 6.2 & 6.2 & 11.6 & 11.1 & 10.6 \\
\hline Crown BL & 5.8 & 6.3 & 7.4 & 7.5 & 8.0 & 11.9 & 10.8 & 10.3 \\
\hline Crown HT & & & & & & & & \\
\hline Neck MD & & & & & & & & \\
\hline Neck BL & & & & & & & & \\
\hline \multicolumn{9}{|l|}{ Pelican Rapids: } \\
\hline Crown MD & 5.5 & 6.5 & 7.5 & 8.5 & 7.5 & 13.0 & 11.5 & 12.5 \\
\hline Crown BL & 6.0 & 6.5 & 8.5 & & 9.5 & 12.5 & 12.0 & 12.0 \\
\hline Crown HT & & & & & & & & \\
\hline Neck MD & & & & & & & & \\
\hline Neck BL & & & & & & & & \\
\hline
\end{tabular}

Department of Medical Illustration and Sculpture at the University of Michigan.

Few of the infrequently occurring discrete traits were noted on the Wilson-Leonard II skeleton. For the cranium, the sutures of the calotte are relatively simple, particularly the lambdoid suture, which has no large ossicles and only a very few small ones. Considering the face, the supraorbital foramina are notched with less than one-half of the notch being bounded inferiorly by a spicule of bone, and the mandible exhibits a single mental foramen on each side. No lessfrequently occurring discrete traits were observed postcranially.

\section{Medical Disorders}

Medical disorders observed on Wilson-Leonard II were restricted to the dental arcade (Table 31-11). These include a small caries that had not reached the underlying dentin on the disto-occlusal surface of the right mandibular second molar, a small caries on the distolingual surface of the right mandibular third molar, an apical abscess of the right distal premolar, the antemortem loss of the right mandibular first molar, a cracked left second maxillary molar (the crack extending across the molar separating it into buccal and lingual halves), and alveolar resorption along the complete dental arcade (Figure 31-5). In addition to these disorders, the incisal surfaces of the incisors and canines have been disproportionately worn compared to the occlusal surfaces of the molars and premolars. While this last condition is not necessarily a medical disorder, it is discussed in this section for the sake of convenience.

Several observations can be made by comparing Wilson-Leonard II's disorders to other Paleoindians, and the Paleoindians collectively to more recent hunters and gatherers. Among the Paleoindians with preserved teeth, Wilson-Leonard II is one of two individuals to have caries. She, along with the older Horn Shelter male are the only individuals with identifiable cases of an antemortem tooth loss. On the other hand, three Paleoindians with preserved teeth have at least one abscess. Also, all Paleoindians exhibited moderate to marked alveolar resorption, exposing the roots of the implanted teeth along the dental arcade. In comparison to Archaic assemblages, Paleoindians have a lower frequency of caries but a higher frequency of abscesses (Powell and 
TABLE $31-10$

Comparative Human Stature Estimates (cm) of Prehistoric Samples

\begin{tabular}{|c|c|c|c|c|}
\hline Sample & Number & $\begin{array}{c}\text { Female } \\
\bar{x} \pm \sigma\end{array}$ & Number & $\begin{array}{l}\text { Male } \\
\bar{x} \pm \sigma\end{array}$ \\
\hline Paleoindians $^{1}$ & & & & \\
\hline Wilson-Leonard II & 1 & 158.1 & & \\
\hline Gordon Creek & 1 & 147.6 & & \\
\hline Horn Shelter & & & 1 & 162.4 \\
\hline Sauk Valley & & & 1 & 167.5 \\
\hline West Texas Hunter/Gatherers ${ }^{2}$ & & & & \\
\hline Trans-Pecos & 5 & $158.4 \pm 3.5$ & 6 & $167.4 \pm 2.4$ \\
\hline Lower Pecos & 14 & $158 \pm 4.9$ & 21 & $166.0 \pm 4.2$ \\
\hline Tamaulipas & 3 & $158.1 \pm 5.3$ & 9 & $166.7 \pm 4.8$ \\
\hline Central Texas Hunter/Gatherers ${ }^{3}$ & & & & \\
\hline Loeve-Fox & 5 & 162.0 & 12 & 166.7 \\
\hline Eastern U.S. Hunter/Gatherers ${ }^{4}$ & & & & \\
\hline Indian Knoll & 188 & $156.6 \pm 4.6$ & 163 & $165.2 \pm 4.4$ \\
\hline
\end{tabular}

${ }^{1}$ Measurements made by author

${ }^{2}$ data in Steele and Powell (n.d.)

${ }^{3}$ from Prewitt (1974)

${ }^{4}$ from Snow (1948)

FIGURE REDACTED
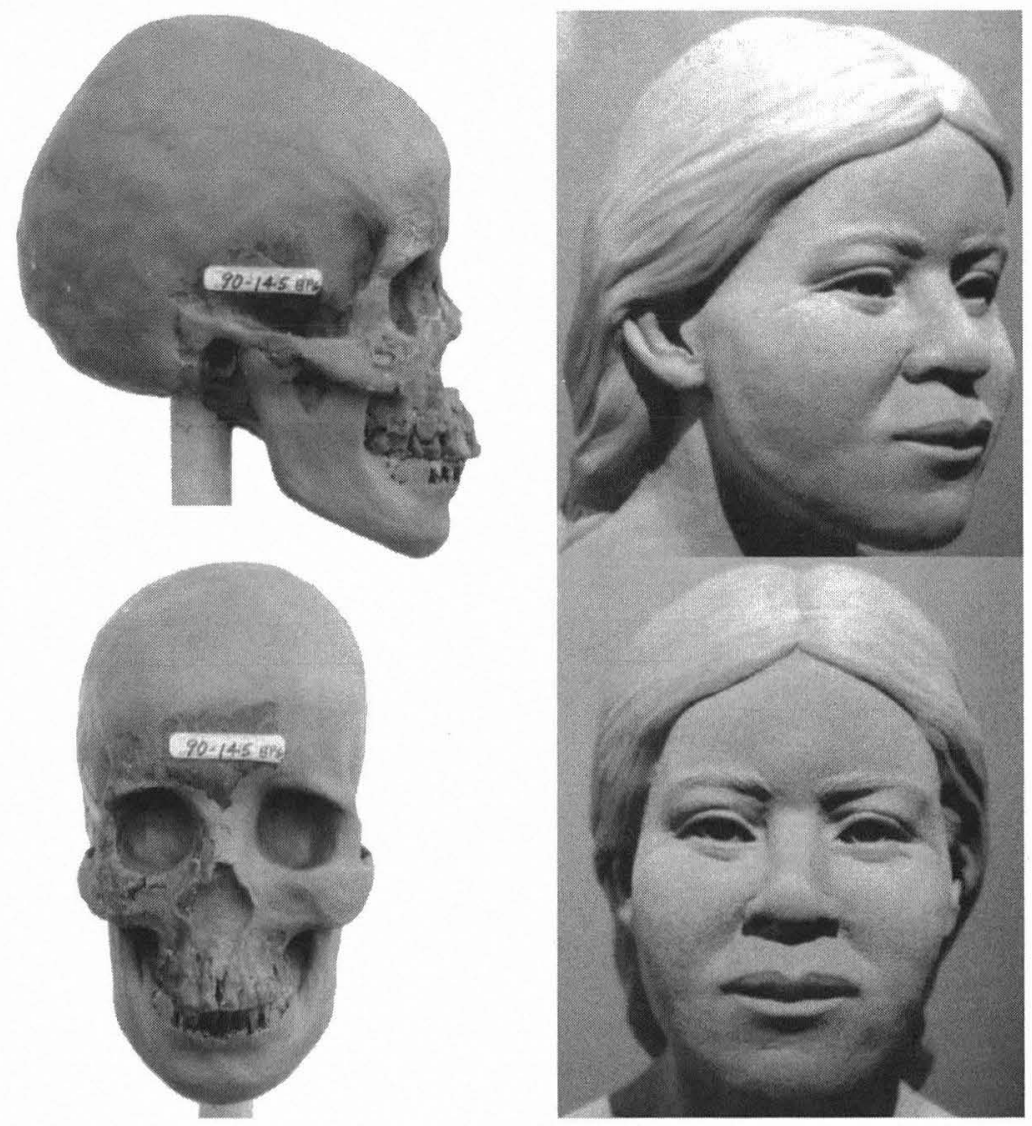

FIGURE 31-4. Sequence of photographs illustrating the reconstruction of Wilson-Leonard II. 
TABLE 31-11

Medical Disorders Observed in Paleoindians

\begin{tabular}{|c|c|c|c|c|c|c|c|c|}
\hline Sample & Age & $\begin{array}{l}\text { Tooth } \\
\text { Loss }\end{array}$ & Abscess & $\begin{array}{l}\text { Degenerative } \\
\text { Joint Disease }\end{array}$ & Fracture & Infection & $\begin{array}{c}\text { Porotic } \\
\text { Hyperostosis }\end{array}$ & $\begin{array}{c}\text { Growth } \\
\text { Arrest Lines }\end{array}$ \\
\hline$\overline{\text { Female }}$ & & & & \multirow{7}{*}{$X$} & \multirow[b]{7}{*}{$\mathrm{X}$} & & \multirow{7}{*}{$\mathrm{X}$} & \multirow[b]{7}{*}{$\mathrm{X}$} \\
\hline Wilson-Leonard II & $20-25$ & $\mathrm{X}$ & $\mathrm{X}$ & & & & & \\
\hline Gordon Creek & $25-30$ & & & & & & & \\
\hline Whitewater Draw I & $30-50$ & & & & & & & \\
\hline Whitewater Draw II & $36-50$ & & & & & & & \\
\hline Midland & & & & & & & & \\
\hline Pelican Rapids & & & & & & & & \\
\hline Male & & \multirow{5}{*}{$\mathrm{X}$} & \multirow{4}{*}{$\mathrm{X}$} & \multirow{4}{*}{$\mathrm{X}$} & \multirow{5}{*}{$\mathrm{X}$} & & & \multirow{5}{*}{$\mathrm{X}$} \\
\hline Horn Shelter I & $35-40$ & & & & & $\mathrm{X}$ & & \\
\hline Horn Shelter II & $12-18$ & & & & & $\mathrm{X}$ & & \\
\hline Browns Valley & $20-30$ & & & & & $\mathrm{X}$ & & \\
\hline Sauk Valley & $25-40$ & & $\mathrm{X}$ & $\mathrm{X}$ & & & & \\
\hline
\end{tabular}

FIGURE REDACTED

FiguRE 31-5. Lateral view of right mandible of Wilson-Leonard II illustrating abscess, antemortem loss of first molar, and alveolar resorption.

Steele 1994). This degree of alveolar resorption is akin to Archaic assemblages.

In examining the remains of the Paleoindian assemblage, Steele and Powell (1993) and Powell and Steele (1994) found that Paleoindians, again like more-recent hunters and gatherers, were afflicted by a variety of pathological conditions typical of physically active individuals (see Table 31-11). Three Paleoindian adults exhibited vertebral osteophytoses typical of degenerative joint disease, two of these individuals exhibited similar degenerative damage in the shoulder, and one individual had degenerative changes in one bone of the foot. One adult male (Horn Shelter I), exhibited a healed fracture of the fifth metatarsal of the foot, and one adolescent female (Pelican Rapids), had sustained a rib fracture. Infectious bone deposition was observed in the sinus cavity of one adult and one adolescent (Horn Shelter I and II), and one individual exhibited a small patch of subperiosteal bone growth on the right clavicle (Browns Valley). There was one possible case of a healed condition of porotic hyperostosis (Whitewater Draw). In addition, Powell and Steele (1994) reported growth arrest lines in the tibiae of two Paleoindians, and four Paleoindians exhibited growth arrest lines in the teeth (dental hypoplasias).

In addition to these disorders, Powell and Steele (1994) described the disproportionate wear of the anterior teeth

compared to the molars in Paleoindians (noted in the Wilson-Leonard II, Gordon Creek, and Midland females). They documented that the extent of anterior tooth wear in the Paleoindians approached that seen in Upper Paleolithic hunters and gatherers of Europe and exceeded that reported for Eskimos, a population noted for the use of anterior teeth as tools. While they expressed a note of caution about the small sample size, Powell and Steele suggested that this condition in the Paleoindians may reflect a pattern of heavy use of the anterior teeth as tools as well. This condition also has been noted for an Archaic assemblage from Texas (Marks et al. 1988).

\section{Subsistence Habits}

Two broad subsistence models have been proposed for Paleoindians. The traditional perspective has been that Paleoindians were big-game hunters who spread downward through the Americas in search of new hunting territories. In this model, big game was abundant and easy prey for the newly arrived predator (Funk 1978; Kelly and Todd 1988; Stoltman 1978). With the ready access to game, it was unnecessary to forage for less nutritive and more difficult to procure, process, or digest smaller game or plants. With the demise of the megafauna at the end of the Pleistocene, Paleoindian hunters were forced to adapt to less game-enriched habitats and became the foragers of the Archaic. 
The alternative view to this big-game model is the moregeneralized dietary model (Dent 1985; Dincauze 1981; Kornfeld 1988; Meltzer and Smith 1986; Olsen 1990; Smith 1986). This model sees the ecological changes that occurred between the Pleistocene and the Holocene as occurring more gradually and having less impact on the subsistence patterns of humans. Because the transition between the Pleistocene and Holocene may have been less marked, many of the Paleoindian populations may have had a more-generalized diet akin to their Archaic descendants. As there were big-game hunting specialists in some regions among the Archaic and Late Prehistoric American populations, there were big-game specialists among the Paleoindians, but within the broader scope of the Americas, the Paleoindians followed generalized foraging patterns as did their Holocene descendants.

To address this issue, Powell and Steele (1994) conducted a macro- and microscopic examination of dental disorders and occlusal wear of the teeth of Wilson-Leonard II and other Paleoindian remains. They reported a slightly lower frequency of developmental interruption lines (hypoplasias) among the Paleoindians than Archaic populations, a lower caries rate per individual and per tooth, but a higher frequency of abscesses than seen in most Archaic assemblages. Alveolar resorption was also reported for Paleoindians, a condition associated with infected gums and plaque deposition.

In evaluating dental wear, they found that the tooth cusps of most Paleoindians tended to be worn flat in a pattern typical of later hunters and gatherers. Gordon Creek, the exception, exhibited a cupped type of wear of the molars. Microscopic examination of the teeth of Wilson Leonard II, Gordon Creek, and Whitewater Draw II females documented a range of abrasive patterns. Wilson Leonard II had frequent pits and some evidence of moderate to large striations, Whitewater Draw II exhibited extensive polishing and fine striations, and Gordon Creek had larger, more frequent striations and gouges. The generally flattened wear on the teeth suggests either the long-term use of the teeth, or the mastication of hard and/or gritty foods. The pattern is typically seen in later hunters and gatherers. The cupped pattern of wear seen in the Gordon Creek female has been attributed by Smith (1983:126) to the consumption of ground grain or nuts or the ingestion of grit such as sand or opaline phytoliths from plant foods. The enamel pitting and compression fracturing observed on the Paleoindians resembled the sort of damage seen on the teeth on a variety of Archaic individuals (Bement 1991; Harmon and Rose 1988; Hartnady and Rose 1991; Marks et al. 1988). The cause proposed by Harmon and Rose (1988) for the damage to the teeth is the consumption of hard foods such as hull or hard seeds. Powell and Steele (1994) note, however, that the consumption of bone cannot be ruled out as another possible cause of the damage.

In summary, the evidence provided by the dental examination of Wilson-Leonard II and other Paleoindian remains suggests that the dietary patterns may not have been very different between Paleoindians and later hunters and gatherers. What cannot be determined is the relative amounts of meats and vegetal matters consumed by these prehistoric peoples, a point discussed by Wilson (see Chapter 32) as well.

\section{Population Affinity}

Assessing the biological affinity of Wilson-Leonard II is more an issue of assessing that of the population of which she is a representative rather than her individual biological affinity. In the most general sense, Wilson-Leonard II and the population of which she is a member can be assigned to the populations of North American Indians. This self-evident assessment, based upon the location of the remains and the cultural context, can be corroborated by an examination of the dentition.

One of the most notable dental characteristics of Native Americans and their biological relatives is the shoveling of the upper incisors. This feature is relatively uncommon among European and African populations and is quite common among Asian and Native Americans. Documenting this distribution, Turner (1985a, 1985b) reports the frequency of shoveling of the upper central incisors to be less than 35\% for Northwest Europeans (1985a) and in excess of $90 \%$ for American Indians (1985b). Although the anterior teeth of Wilson-Leonard II are worn, enough of the crown is left to document that the tooth was shoveled. The second incisors were shoveled as well.

Being more specific in assessing biological affinity of Wilson-Leonard II's population is fraught with difficulties, not the least of which is the extent of postmortem crushing of the cranium. On a subjective basis, the shape of the cranium appears to be relatively narrow and long and the face relatively short and narrow. Also, the face appears to have had a moderate degree of alveolar prognathism. In these characters, Wilson-Leonard II is similar to the Gordon Creek and Pelican Rapids females and is similar to the Whitewater Draw and Midland females in the relatively narrow dimensions of the braincase. Similar shape of the braincase and face of Paleoindian males has been noted as well (Steele and Powell 1992, 1993, 1994).

Bivariate analyses of these features are illustrated in Figures 31-6 and 31-7. The metrical data for the Paleoindian females is based on the Gordon Creek and Pelican Rapids females, and the data for the Paleoindian males is based on the Browns Valley, Sauk Valley, and Horn Shelter individuals (see Table 31-6). The data of the more-recent populations was derived from the literature. The populations, their locations, antiquity, references, and the means of the measurements utilized are presented in detail in Steele and Powell (1994).

Considering the cranial dimensions, the skulls of the Paleoindian males are on average among the longest of the 


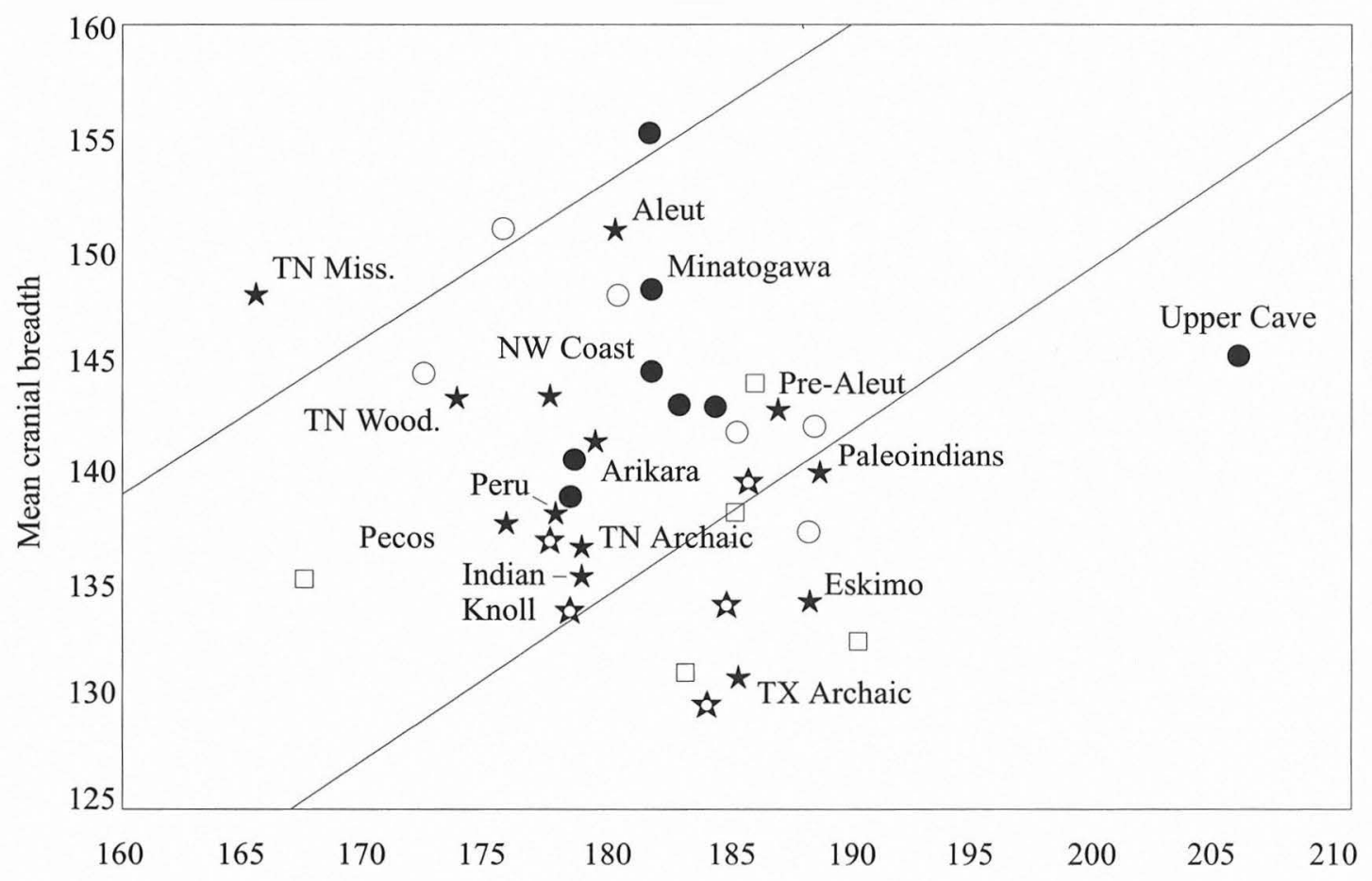

a. Paleoindian males

Mean cranial length

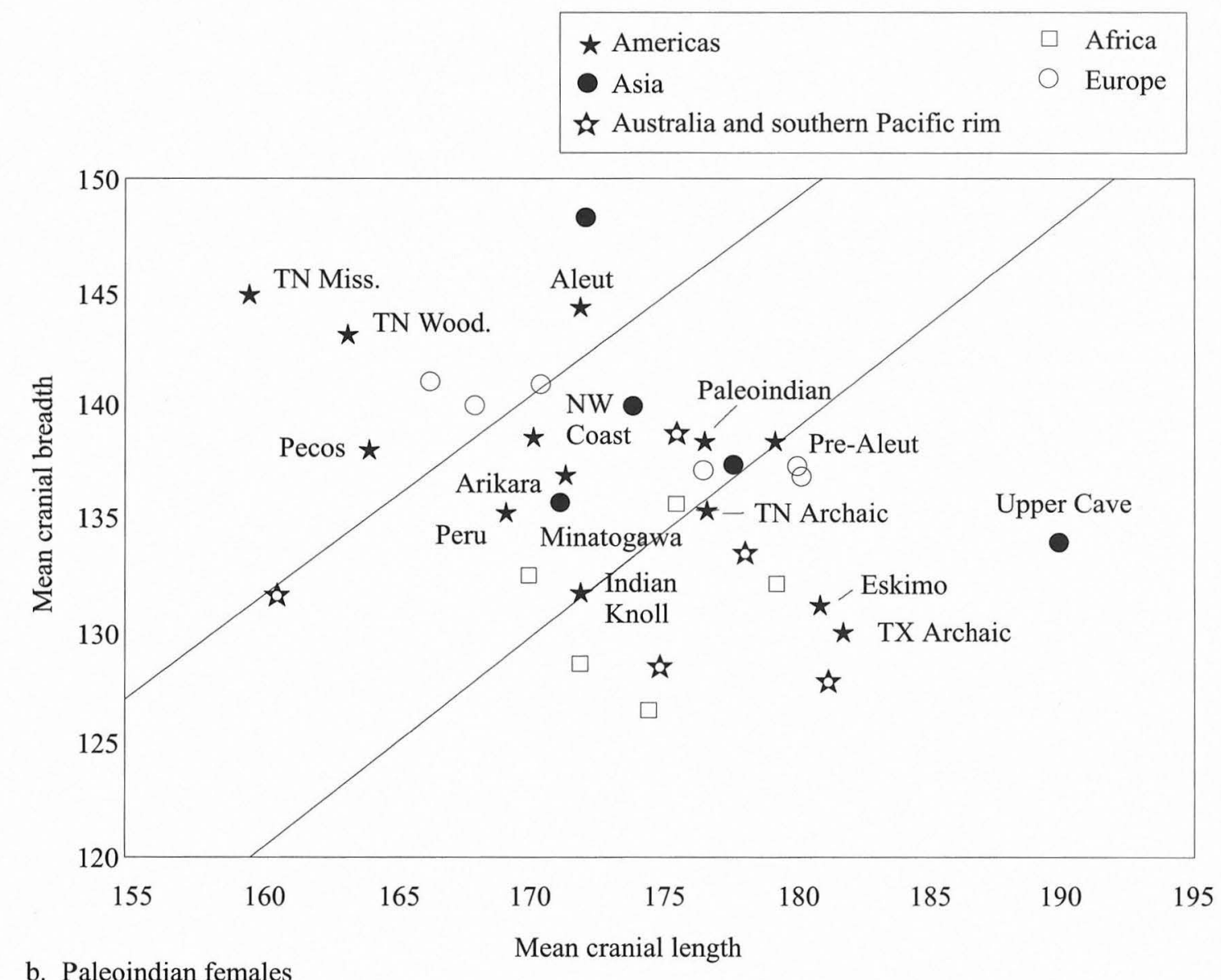

FIGURE 31-6. Bivariate plots of mean cranial lengths and widths of Paleoindian males (a) and females (b) compared with prehistoric and modern populations. Diagonal lines separate brachycranic, mesocranic, and dolichocranic samples, respectively. Selected populations are named in graph. After Steele and Powell (1992). 


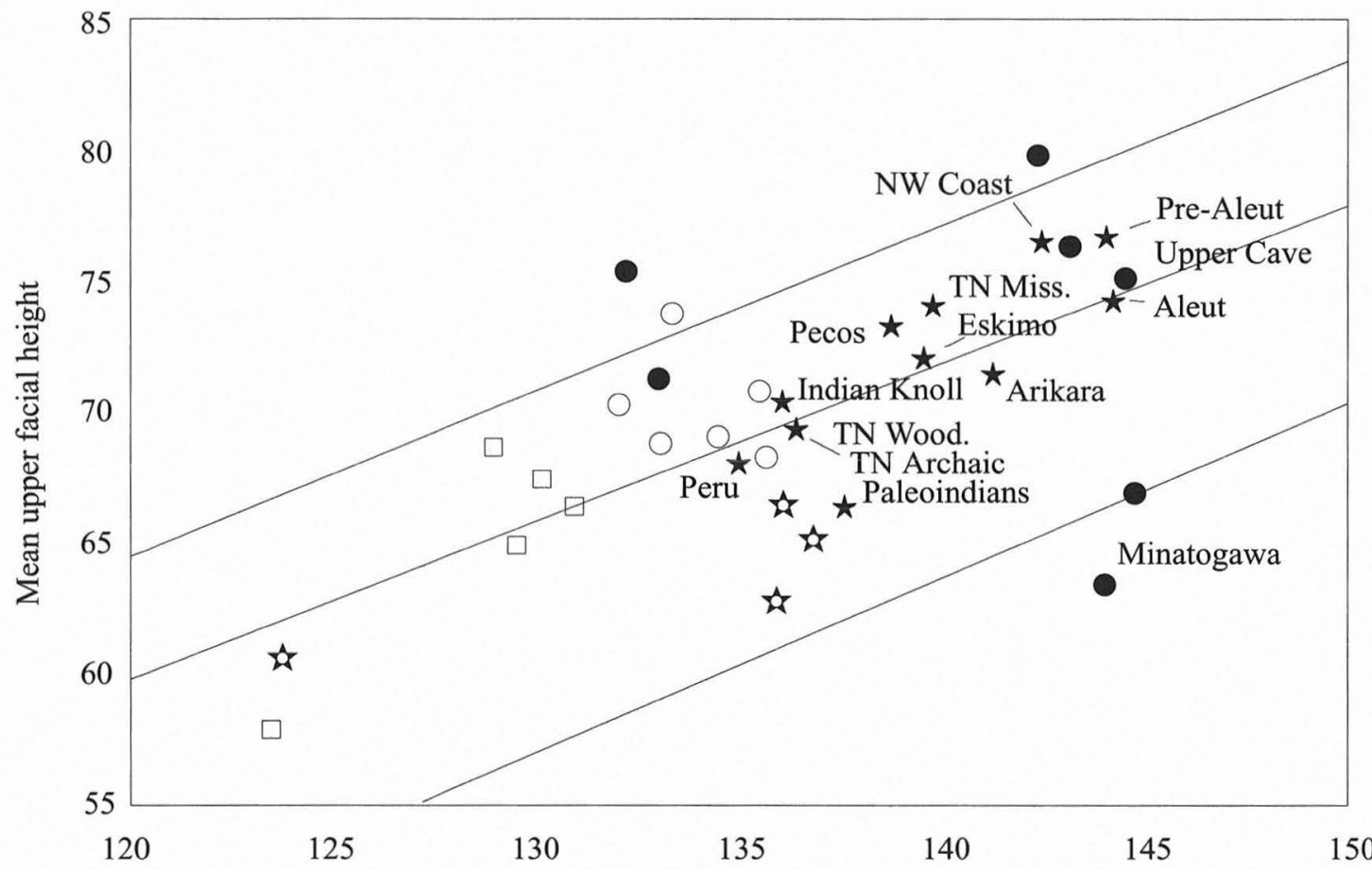

a. Paleoindian males

Mean bizygomatic breadth

Americas

Asia

Australia and southern Pacific rim

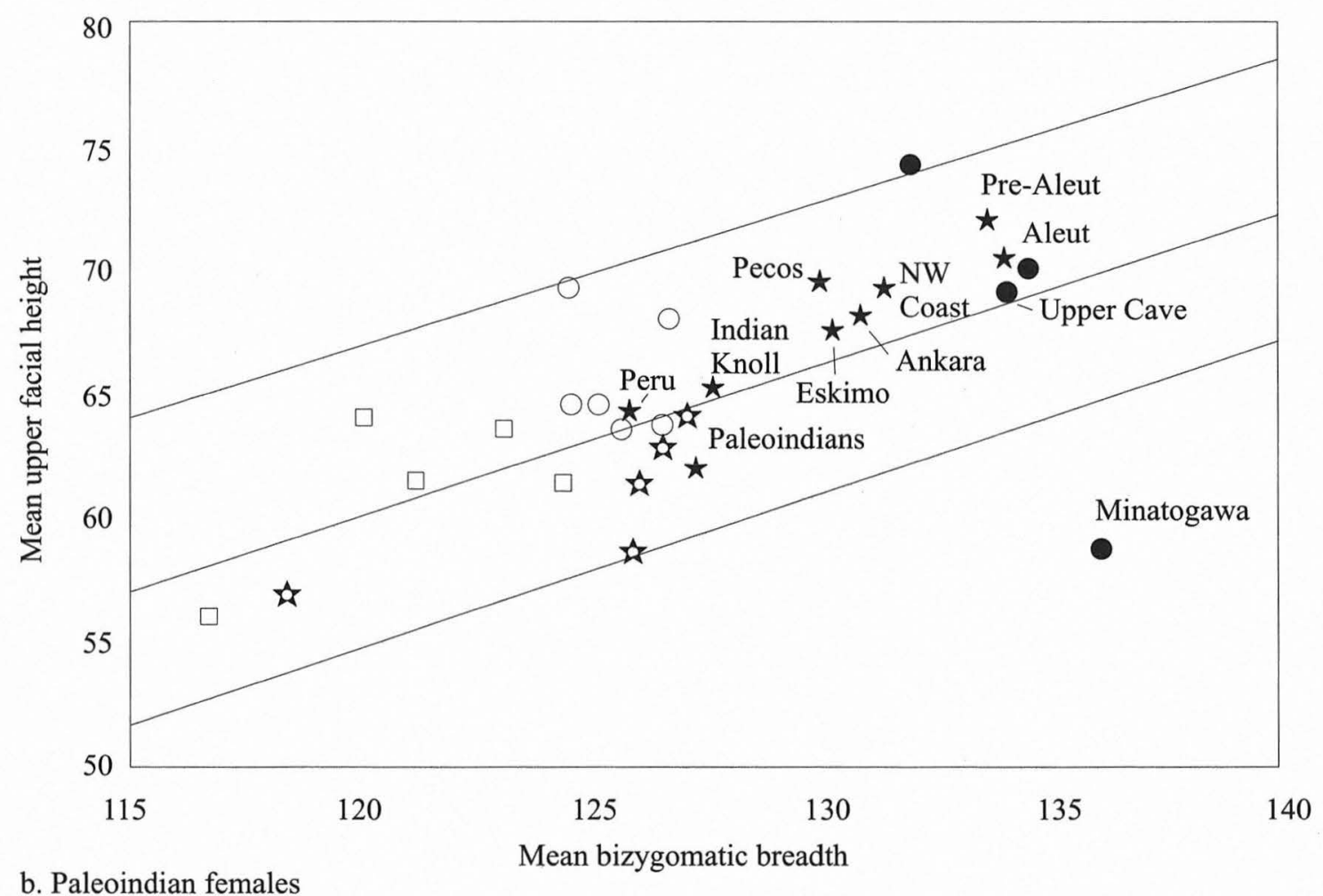

FIGURE 31-7. Bivariate plots of mean facial lengths and widths of Paleoindian males (a) and females (b) compared with prehistoric and modern populations. Diagonal lines separate brachycranic, mesocranic, and dolichocranic samples, respectively. Selected populations are named in graph. After Steele and Powell (1992). 
36 compared samples; only 2 samples, South Australians and Upper Cave at Zhoukoudien (an Upper Pleistocene/ Early Holocene specimen) exceed them. Thirteen of the 36 samples possess significantly shorter cranial lengths, 8 of these being North American Indians. Texas Archaic and Pre-Aleut are 2 other assemblages of early antiquity with long crania. The cranial length of the females is also relatively long but not as dramatically. Of the 34 female samples compared, the Paleoindian females are longer than 21 of the samples but shorter than 12 samples. None of these latter samples, however, is significantly longer than the Paleoindian females. Examining the American assemblages only, the Paleoindian females have longer crania than 8 but shorter than 4 of the samples. Three of the 4 longer samples are temporally early as well (Tennessee Archaic, Texas Archaic, and Pre-Aleut).

Considering the breadth of the cranium, 19 of the samples exceed the Paleoindian male sample, and 4 of these are significantly broader. Evaluating the Paleoindian female sample, 12 of the compared samples are broader ( 3 are significantly broader). When the dimensions of length and breadth are considered in relationship to one another to elucidate shape, the Paleoindian males are documented to have relatively oblong crania (dolichocranic). This tendency toward relatively narrow crania is also seen in the older American assemblages (Tennessee Archaic, Indian Knoll, Pre-Aleut, and Texas Archaic) compared to the temporally more-recent American samples (Pecos, Peru, Arikara, Northwest Coast, Aleut, and Tennessee Mississippian).

The trend of older assemblages having more oblong crania is documented in the female samples as well. The Paleoindian females are relatively narrower than six of the North American Indian samples but relatively broader than four of the North American Indian samples. Three of the four female samples that have narrower mean crania than the Paleoindian females, however, are older assemblages as well. This trend toward older assemblages having relatively narrower crania is seen particularly clearly in the two local temporal sequences, Aleuts and Tennessee populations illustrated in Figures 31-6 and 31-7. In the Tennessee Archaic, Woodland, and Mississippian assemblages, respectively, length decreases $(17.6 \mathrm{~cm}, 16.2 \mathrm{~cm}, 15.9 \mathrm{~cm})$ while breadth increases $(13.6 \mathrm{~cm}, 14.3 \mathrm{~cm}$, and $14.5 \mathrm{~cm})$. There is a strong probability that the very wide crania of the Woodland and Mississippian samples also is a reflection of more frequent and a greater degree of crania modeling than is seen in the Tennessee Archaic. In the Pre-Aleut and Aleut samples, length decreases from $18.7 \mathrm{~cm}$ to $18.0 \mathrm{~cm}$, respectively, and breadth increases from 14.7 to $15.1 \mathrm{~cm}$, respectively.

In facial dimensions, the Asian and American Indian populations are distinguished by the breadth of their faces (see Figure 31-7). Within this general trend, however, both male and female Paleoindian samples are distinctive among American populations by having relatively narrower and shorter faces than is common for American samples. Again, this trend for shorter and narrower faces is seen in the other American assemblages of greater antiquity. For the males, the Tennessee Archaic, Tennessee Woodland, and the Indian Knoll samples cluster closely with the Paleoindian males, and for the females, Indian Knoll clusters closely with the Paleoindian females.

The relationships of the Paleoindian samples to morerecent American Indian, Asian, and other populations have been explored in multivariate analyses as well (Steele and Powell 1992, 1993, 1994). Figure 31-8 illustrates the relationships of these populations based on a principal components analysis of size-correlated data. Note that the Paleoindian samples for both males and females fall at the edge of the distribution of American Indian samples, toward the Australian and southern Pacific rim samples and away from the northeast Asian samples. This pattern of distribution is reflecting the relatively narrower braincase and shorter and narrower face of the Paleoindian males and females, features that they share more closely with Australian and southern Asian samples and that are in contrast to the broader crania and faces of northeast Asians and more-recent North American Indians.

In summary then, the shape of the braincase and face of the Paleoindians used in these metrical analyses and the subjective assessment of Wilson-Leonard II suggest these early samples represent a population that differed from morerecent North American Indians and northeast Asians and resembled a more-generalized Asian stock. This view was proposed as early as the 1920s and has been accepted at least in part by many subsequent scholars (Dixon 1923; Hooten 1933; Hrdlicka 1923; Protsch 1978; Stewart 1960, 1973; Stringer and Andrews 1988). The model in these early studies, based predominantly on Archaic assemblages exhibiting the relatively long and narrow crania, proposed a genetic cause for these differences. The initial colonists of the Americas were descendants of a more-generalized Asian population who inhabited northeastern Asia. This hypothetical ancestral Asian population was identified as either protomongoloid or protocaucasoid. In this model, after the initial colonization of the Americas occurred, the generalized Asian population was replaced in northern Asia by a population distinguished by a broader head and face. Subsequent colonizations of the New World by these peoples replaced the descendants of the earlier long-headed colonizers or displaced them, pushing them into peripheral and less-favorable habitats.

While this model fell into disfavor during the midtwentieth century because of some proponents' reliance upon inadequately dated samples, samples that were too small, or a typological perspective, recent analysts approaching the issue with different assemblages and perspectives have come to the conclusion that an earlier population is indeed distinctive. Neves and Pucciarelli (1989, 1991) found that the earliest authenticated remains from South America are distinguishable from more-recent South 


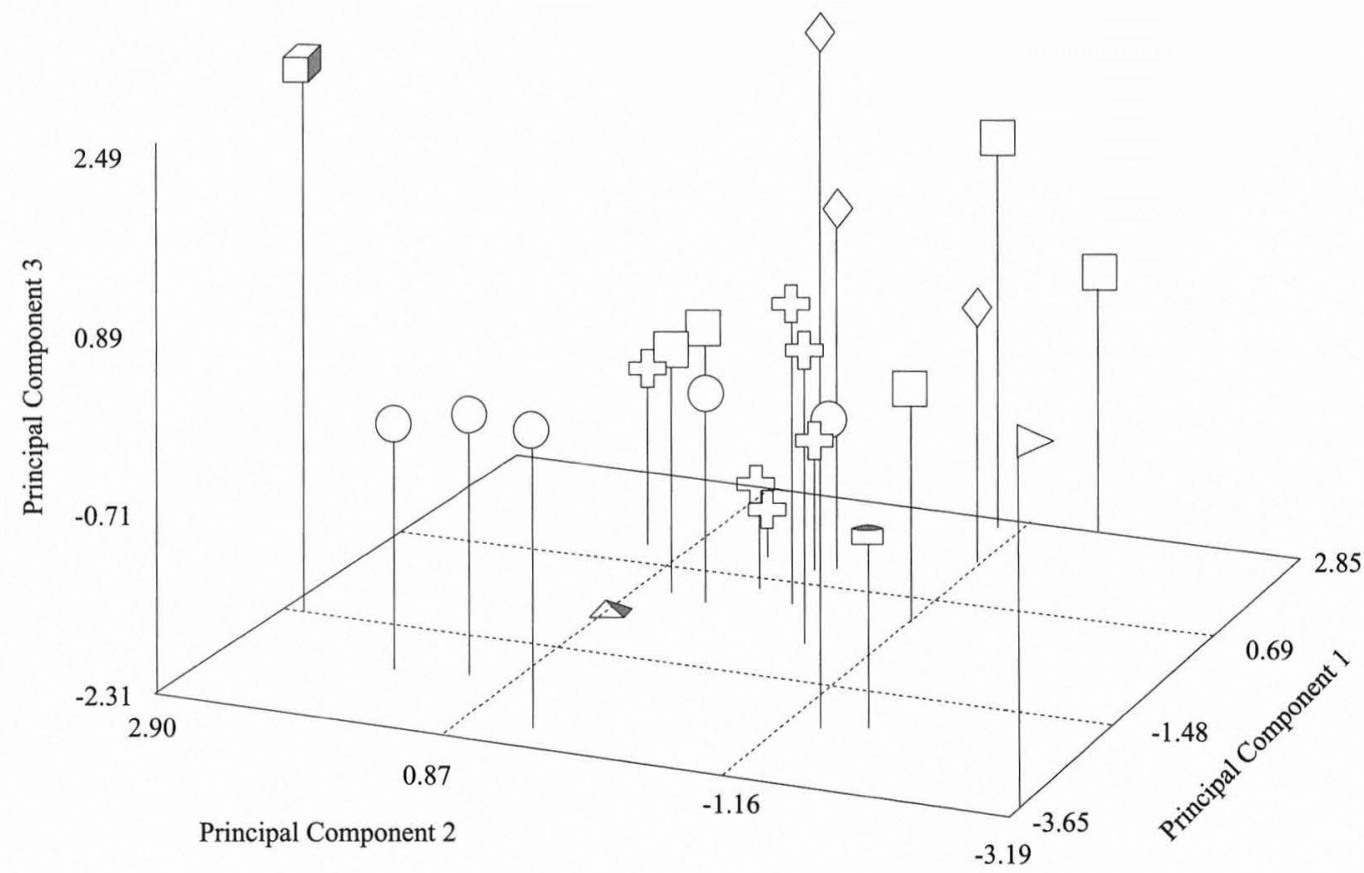

a. Paleoindian males
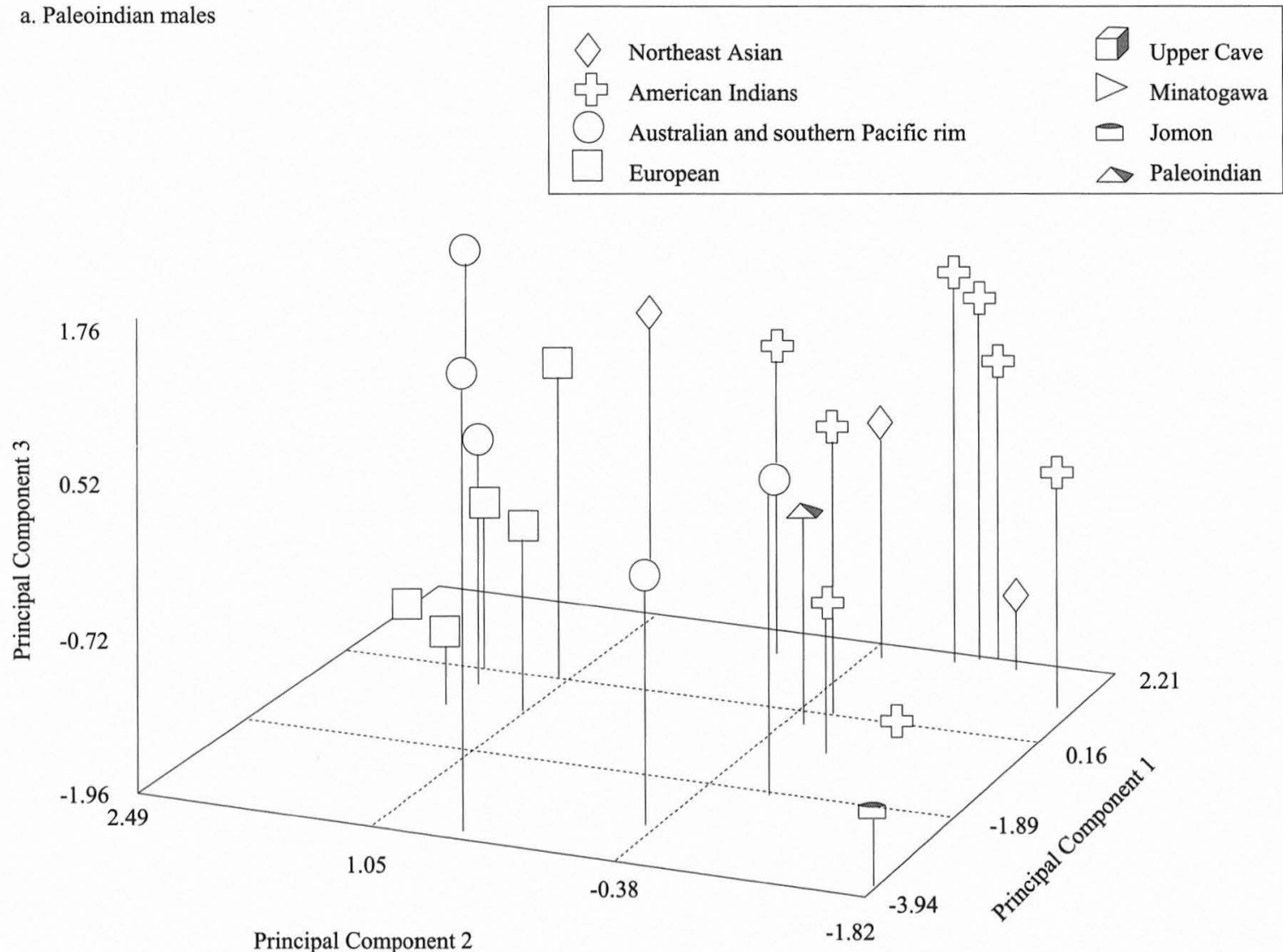

b. Paleoindian Females

FIGURE 31-8. Plot of principal component analysis of size-corrected data for Paleoindian males (Graph A) and females (Graph B) compared with prehistoric and modern populations. After Steele and Powell (1994). 
American populations by their relatively longer and narrower braincase and that they structurally resemble southern Asians and Australians in these features. Neves and Pucciarelli's body of research, using similar anatomical features but analyzing different samples, remarkably parallels the work of Steele and Powell $(1992,1993,1994)$, which is based predominantly on North American assemblages. Brace and Tracer (1992) represent yet a third line of research coming to the same conclusion. Their work, based primarily on measurements of the upper face, documents that North American assemblages can be divided into two basic groups.

While the distinctiveness of the Paleoindians and many of the Archaic assemblages is now confirmed, the underlying biological mechanisms that have created these differences are more difficult to discern. One view accepts the genetic cause, the earliest colonizers from Beringia being a different genetic population than later northern Asians and their North and South American descendants. The alternative view is that these differences reflect a phenotypic adaptation of a single lineage through time, the later populations of this single lineage simply adapting phenotypically, but not genotypically, to a different environment or lifestyle, one possibly associated with the origins of agriculture. At the present time it is difficult to resolve this issue.

\section{Summary of Wilson-Leonard II Investigation}

The Wilson-Leonard II biological remains recovered from a burial pit consist of a relatively complete but badly crushed and eroded skeleton of a young late adolescent/ adult female in her early twenties. The individual was estimated to be $158.1 \pm 5.15 \mathrm{~cm}$ tall during life, a stature compa- rable to more-recent hunting and gathering native American females from the region. Her proportions and muscle markings indicate she was a relatively slight individual. A reconstruction of the head and facial features of Wilson-Leonard II indicates that she had a relatively narrow cranium and face and a face with a moderate alveolar protrusion.

The only medical disorders noted on the skeleton concern the dentition and alveolar margins of the maxillae and mandible. Two small caries were noted on the right second and third mandibular molars, the caries on the second molar not having reached the underlying dentin. In addition to the caries, the right first mandibular molar had been lost antemortem and there was an apical abscess of the right distal premolar. Along the entire margins of the maxillae and the mandible, the alveolar bone surrounding the upper portion of the roots of the teeth has been resorbed. No cause of death is indicated in the skeletal remains.

The biological affinity of Wilson-Leonard II and the other Paleoindians is, in the broadest sense, with more-recent native American Indians and northern Asians. It has been documented, however, that the Paleoindian assemblages share with many of the Archaic hunters and gatherers a narrow cranium and a narrower and shorter face than is found in more-recent Native Americans and northern Asians. These distinctive features may be a reflection of an earlier population with a slightly different genome, or these differences may reflect different phenotypic responses of a single genetic population adapting to different environmental and cultural conditions over time.

Obviously there are too few data to fully characterize the Paleoindian population(s). This paucity makes the Wilson-Leonard II burial of particularly high importance. 


\section{Chapter 32}

\section{STABLE ISOTOPIC RESULTS FOR BURIALS 1 AND 2}

by Diane E. Wilson

\section{STABLE ISOTOPEANALYSIS}

Since 1977, when Nicholas van der Merwe and John Vogel first published their results of stable carbon isotope studies documenting the introduction of maize into eastern North American prehistoric economies, stable carbon isotopic analyses have proliferated in the study of prehistoric diet (Ambrose 1993; Katzenberg et al. 1995; Krueger and Sullivan 1984; Little and Schoeninger 1995; Price 1989; van der Merwe and Vogel 1978; Vogel and van der Merwe 1977). These studies have been successful across much of the United States because the environment generally lacks naturally occurring $\mathrm{C}_{4}$ food plants, such as maize.

Stable carbon isotope analytical technique is based upon the existence of two stable carbon isotopes $\left({ }^{12} \mathrm{C}\right.$ and $\left.{ }^{13} \mathrm{C}\right)$ that occur in abundance in nature. The better known radioactive carbon isotope, ${ }^{14} \mathrm{C}$, is unstable and cannot be used in this type of analysis because it decays and changes form over time. The ratio between ${ }^{13} \mathrm{C}$ and ${ }^{12} \mathrm{C}$ in substances (typically apatite, collagen, hide, hair, soil), measured with a mass spectrometer, is compared against a standard source. In the case of carbon, this source is the Pee Dee Belemnite Formation found in South Carolina, noted as PDB. The ratio of sample to standard yields the final numeric value expressed as $\delta^{13} \mathrm{C}(\%)$. The measured units are expressed in parts per $\operatorname{mil}(\%)$.

Plants are divided into three groups, $\mathrm{C}_{3}, \mathrm{C}_{4}$, and Crassulacean Acid Metabolism (CAM), based on the form of photosynthesis that is used. Most plants including trees, shrubs, and many grasses, use $\mathrm{C}_{3}$ photosynthesis. The $\mathrm{C}_{4}$ plants are generally adapted to more-arid conditions and include many grasses such as maize, sorghum, and millet. The small group of CAM plants have the ability to utilize both $\mathrm{C}_{3}$ and $\mathrm{C}_{4}$ photosynthetic pathways. CAM plants are composed mostly of desert succulents. The three photosynthetic pathways have differing carbon stable isotope ratios in response to fractionation during $\mathrm{CO}_{2}$ fixation. The $\mathrm{C}_{3}$ plants discriminate more aggressively against ${ }^{13} \mathrm{C}$ during photosynthesis than do $\mathrm{C}_{4}$ plants, thus $\mathrm{C}_{3}$ plants yield the lowest $\delta^{13} \mathrm{C}$ values, averaging -26.5\% (van der Merwe 1982), because $\mathrm{C}_{3}$ plants have less ${ }^{13} \mathrm{C}$ in their biomass. The $\mathrm{C}_{4}$ plants discriminate far less against ${ }^{13} \mathrm{C}$ and thus have the highest $\delta^{13} \mathrm{C}$ values, averaging $-12.5 \%$ (Schoeninger 1989:52). CAM plants may mimic either $C_{3}$ or $C_{4}$ isotopic signatures and generally mimic plants in their immediate environment. In Central Texas, CAM plants have $\mathrm{d}^{13} \mathrm{C}$ values similar to those of the $\mathrm{C}_{4}$ plants (Jeffery Huebner, personal communication 1996).

Consumers incorporate carbon into their own biomass through the processes of digestion. Before the carbon source enters specific tissues in the body it undergoes an enrichment factor, often called the fractionation factor. The incremental change from dietary carbon source to consumer's collagen averages $5 \%$; therefore, if an herbivore consumes a purely $\mathrm{C}_{3}$ diet, its $\delta^{13} \mathrm{C}$ collagen will average $-21.5 \%$ ( $(-26.5$ $+5) \%$. In carnivores and omnivores there is further fractionation of approximately 1\% (Chisholm 1989:13).

Bone is composed of two basic components: apatite (bone carbonate) and collagen. Collagen comprises about $90 \%$ of the organic component of bone, while apatite is found in the mineral component. Until recently, the use of apatite had limited application in paleodietary reconstructions, due in part to fear of greater diagenesis in surface apatite which is avoided by the use of structural apatite. Recent testing indicates that $\delta^{13} \mathrm{C}$ collagen values represent the dietary protein source particularly in low protein diets and $\delta^{13} \mathrm{C}$ apatite values represent the dietary whole with a bias of overrepresentation of carbohydrates and fats in low protein diets (Ambrose 1993; Krueger and Sullivan 1984). The difference between collagen and apatite $\delta^{13} \mathrm{C}$ values represents the amount of protein in the diet, while $\delta^{15} \mathrm{~N}$ values may reflect the protein source (Ambrose 1993; Krueger and Sullivan 1984). 
In animals with low protein diets, it is assumed that the consumed protein is allocated to growth and the maintenance of tissues such as collagen rather than to energy metabolism. In these diets, carbohydrates and fats are allocated to energy metabolism. Bone carbonate is thought to be derived mainly from blood bicarbonate which is generated by the metabolism of energy substrates. In herbivores, carbon found in bone carbonate and collagen comes from isotopically similar sources because the difference between plant carbohydrate and protein is small and lipids are only a minor part of the diet. Carnivores and omnivores depend on lipids for some energy metabolism. Since lipids have less $\delta^{13} \mathrm{C}$ than carbohydrates and proteins, carnivores and omnivores have smaller difference (DCA-CO) values than herbivores. Therefore, the $\delta^{13} \mathrm{C}$ collagen value is a function of the growth substrate (protein), while the $\delta^{13} \mathrm{C}$ apatite value is a function of the energy substrate (fats and carbohydrates) (Ambrose 1993; Krueger and Sullivan 1984).

In large mammals such as humans, $\delta^{13} \mathrm{C}$ collagen and apatite values can reflect long-term diets of individuals since apatite and collagen replacement rates are slow. Turnover rates describe the amount of time that an isotopic value indicates an average diet before the bone material is replaced. Collagen seems to have a slow turnover rate, although replacement rates in general have been poorly studied. Harold Krueger (personal communication 1995) believes a turnover rate of approximately 35 years is found in large mammals. Higher rates are seen for infants and children than in adults. Turnover rates are approximately four times higher for trabecular bone compared to cortical bone (Ortner and Putschar 1981).

Although sampled less often than carbon, nitrogen isotopic values $\left(\delta^{15} \mathrm{~N}\right.$, compared against the Atmospheric Nitrogen [AIR] standard) can be used to examine the source of nitrogen-fixing plants and protein (from both animal and plant sources) in the diet (Schoeninger 1989:47). Nitrogen isotopes have also been used with much success to isolate marine dietary sources (Little and Schoeninger 1995). When preservation is poor, nitrogen rarely remains intact.

\section{RESULTS OF WILSON-LEONARD I AND II ANALYSIS}

\section{Methods}

A 5-g sample of cortical bone was removed for analysis from both Wilson-Leonard I and Wilson-Leonard II (see Chapter 31). Both samples were sent to Geochron Laboratories of Krueger Enterprises, Inc., in Cambridge, Massachusetts, for $\delta^{13} \mathrm{C}$ apatite and $\delta^{13} \mathrm{C}$ and $\delta^{15} \mathrm{~N}$ gelatin (the byproduct of laboratory collagen separation) analysis. Upon visual inspection of the human remains, preservation of both samples was determined to be poor.

\section{Gelatin}

Delta ${ }^{15} \mathrm{~N}$ gelatin determinations were not possible on such poorly preserved samples. Additionally, nitrogen gas volumes were very low indicating that the $\mathrm{C} / \mathrm{N}$ ratio was outside the range for unaltered collagen. Nevertheless, $\delta^{13} \mathrm{C}$ gelatin results were obtained but should be considered highly suspect, especially the result for Wilson-Leonard II (Table 32-1). Assuming a fractionation factor of 5\% between the original dietary source and the consumer, it is unlikely in the paleoenvironment of Central Texas to have a consumer's $\delta^{13} \mathrm{C}$ gelatin value of $-25.2 \%$. A consumer ingesting dietary carbon sources entirely from $\mathrm{C}_{3}$ plant sources is expected to produce a $\delta^{13} \mathrm{C}$ signature in the range of $-21.5 \%$. This appears to be the case for Wilson-Leonard I, however, collagen yields for this individual were low and should be considered suspect, despite its falling within the predicted range. The $-25.2 \%$ value for Wilson-Leonard II suggests that preservation is a problem.

\section{Apatite}

Since it is easier to remove contaminants from apatite in the lab, the apatite values presented here are believed to reflect actual dietary signatures rather than diagenic sources (Harold Krueger, personal communication 1995). It is currently believed that apatite values are a better indicator of the dietary whole than gelatin. However, in low protein diets, apatite is biased toward carbohydrate sources in the diet, while gelatin is representative of protein sources. The normal range of $\delta^{13} \mathrm{C}$ apatite values for consumers is $-14 \%$ to $-1 \%,-14 \%$ being the value for a completely $\mathrm{C}_{3}$-based diet and $-1 \%$ for a completely $\mathrm{C}_{4}$-based diet. Apatite values indicate that the majority of the diet originated in $\mathrm{C}_{3}$ photosynthetic pathways. It also appears that at least some of the diet of the individuals buried at the Wilson-Leonard site originated in $\mathrm{C}_{4}$ and/or CAM plants. It is likely that the individuals buried at the Wilson-Leonard site consumed either prickly pear and/or $\mathrm{C}_{4}$ grass seeds, and/or their consumers. Bison, for example, are known to consume both $\mathrm{C}_{3}$ and $\mathrm{C}_{4}$ grasses and some were found at the site.

\section{SUMMARY}

Since gelatin values must be questioned, it is impossible to determine relative amounts of protein consumed by the two individuals tested. Relative amounts of protein consumed can be estimated by comparing the carbon apatite and gelatin difference values. High protein diets tend to have lower difference values than low protein diets. When the natural environment is considered in relation to the stable isotope results, it is clear that the individuals interred at the Wilson-Leonard site had sufficiently high amounts of protein in their diets. 
TABLE 32-1

Delta ${ }^{13} \mathrm{C}$ Apatite and Gelatin Values for Wilson-Leonard I and II

\begin{tabular}{c|c|c|c}
\hline 41WM235 & ${ }^{13} \mathrm{C}$ apatite $(\%)$ & ${ }^{13} \mathrm{C}$ gelatin $(\%)$ & ${ }^{15} \mathrm{~N}$ gelatin \\
\hline Wilson-Leonard I & -9.2 & -21.1 & \\
Wilson-Leonard II & -11.2 & -25.2 & \\
\hline
\end{tabular}

Results are computed by the following formula:

$$
\left.\mathrm{dR}_{\text {sample }} \% \text { o[ } \mathrm{R}_{\text {sample }} / \mathrm{R}_{\text {standard }}-1\right] \times 1000
$$

Where ${ }^{13} \mathrm{C} /{ }^{12} \mathrm{C}$ standard is PDB and ${ }^{15} \mathrm{~N} /{ }^{14} \mathrm{~N}$ standard is AIR.

Note that the ${ }^{13} \mathrm{C}$ gelatin results for burial are not possible without diagenesis.

The results presented here fall within the range of carbon apatite stable isotope values of other Central Texas hunter-gatherers (Figure 32-1). Values indicate a primarily $\mathrm{C}_{3}$ based subsistence economy, with some protein originating in $\mathrm{C}_{4}$ consumers. This is consistent with the natural environment in Central Texas and fits an expected pattern for exploiters of the Central Texas ecozone.

\section{CONCLUSIONS}

Visual inspection of the Wilson-Leonard I and II skeletons revealed fragmentary remains with some surface erosion and suggested that some alteration of the chemical composition of these bones had taken place. The ratio of carbon to nitrogen gas volumes indicates that some of the bone collagen has been altered. The $\mathrm{C} / \mathrm{N}$ values suggest that $\delta^{13} \mathrm{C}$ gelatin values for Wilson-Leonard II should likely be distrusted and Figure 32-1 shows that the $\delta^{13} \mathrm{C}$ gelatin value for Wilson-Leonard II is outside the range of values from other Central texas hunter-gatherers. Results indicate a diet low in protein with exploitation of a food chain based on $\mathrm{C}_{3}$ plants. Likely exploited foods include a subsistence base of nuts, predominately acorns and pecans, supplemented by terrestrial meat sources, probably of deer and rabbit.

While slightly elevated, the $\delta^{13} \mathrm{C}$ gelatin value for Wilson-Leonard I is within the expected range of Central Texas hunter-gatherers. Since $\delta^{13} \mathrm{C}$ gelatin reflects the dietary protein source, particularly in low protein diets, the gelatin signature (s) indicate that the Wilson Leonard population was consuming herbivores with $\mathrm{C}_{3}$ grass and plant diet and/or $\mathrm{C}_{3}$ nuts high in proetin. The low gelatin value(s) suggest that $\mathrm{C}_{4}$ grasses, cacti, and other CAM plants such as the prickly pear common in Central Texas, contributed little to the diet of those buried at the Wilson-Leonard site. The $\delta^{13} \mathrm{C}$ gelatin values confirm a lack of herbivores that consumed $\mathrm{C}_{4}$ grasses that dominate the nearby upland prairies. Likely protein sources in the area include white-tailed deer, eastern cottontail, and nuts, particularly acorns, pecans, and black walnuts. Deer and acorns have low $\delta^{13} \mathrm{C}$ gelatin values (Huebner and Boutton 1992).

Due to poor preservation, $\delta^{15} \mathrm{~N}$ gelatin was not recov-

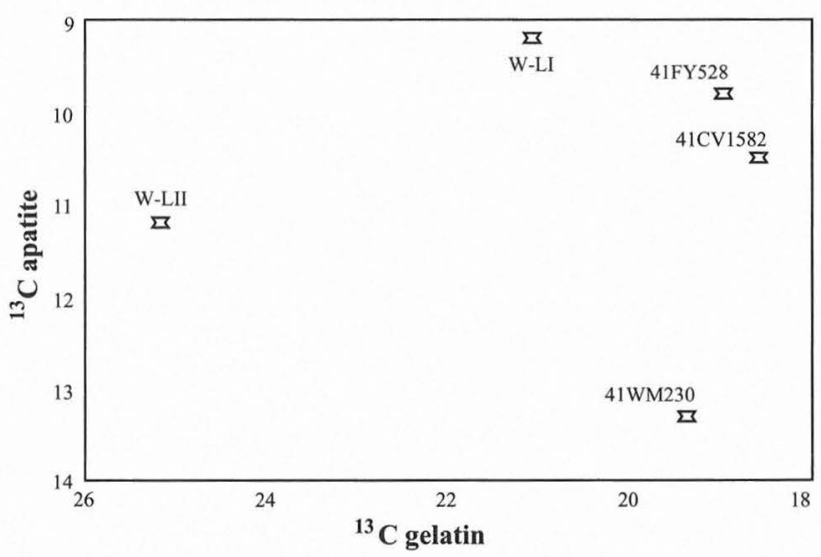

Figure 32-1. Stable isotope data from Wilson-Leonard I and II compared with other values from Central Texas hunter-gatherers. Values are presented with permission from an unpublished database (Jeffery Huebner, personal communication, 1995). Values from the $41 \mathrm{WM} 230$ site are means from 12 individuals sampled.

ered. It was therefore not possible to confirm the origin of protein in the diet of the Wilson-Leonard skeletons using nitrogen isotopes.

Apatite values support the interpretation that $\mathrm{C}_{4}$ grasses and CAM plants contributed little to the Wilson-Leonard diet. Reflective of carbohydrate and fat sources, the $\delta^{13} \mathrm{C}$ apatite values indicate exploitation of a food chain with a $\mathrm{C}_{3}$ plant origin. A diet rich in seeds and nuts would provide a likely $\mathrm{C}_{3}$ carbohydrate and fat source. Of the three common varieties of nuts, black walnuts are higher in protein than most meats, including deer and rabbit, but also higher in fat and carbohydrates than meat sources (Agricultural Research Service 1981). Pecans, on the other hand, are low in protein, very high in fats and carbohydrates (Agricultural Research Service 1981). Acorns are a poorer quality food item, but were likely a more reliable fall crop. Acornshave similar amounts of carbohydrates, fats, and protein, but provide more carbohydrates and fat than protein (Agricultural Research Service 1981). The $\delta^{13} \mathrm{C}$ apatite values for WilsonLeonard I and II are consistent with those reported from other Central Texas populations (see Figure 32-1). Apatite 
values reflect primarily the carbohydrate and fat dietary derivation of low protein diets, while apatite values reflect the dietary whole in higher protein diets. The relative amount of protein in the diet is determined by the difference in $\delta^{13} \mathrm{C}$ apatite and collagen values. High difference values, as those seen in the Wilson-Leonard samples, reflect a low protein diet common to many hunter-gatherer populations and those depicted in Figure 32-1. 


\section{Chapter 33}

\section{VERTEBRATE FAUNAL REMAINS FROM THE 1/4-INCH AND 1/8-INCH SCREENS}

by Barry W. Baker

\section{INTRODUCTION}

The vertebrate faunal remains from Wilson-Leonard presented here were recovered by $1 / 4$-inch and $1 / 8$-inch mesh sampling and provide an opportunity to gain insight into animal use by prehistoric peoples in Central Texas throughout the past 11,000 years. These results provide a base line for understanding the faunal component of prehistoric diet at this long-term, deeply buried, multicomponent site. Topics addressed here include an overview of the sample, a review of previous Central Texas faunal studies, a discussion of research methods, taphonomy, and a subsistence analysis of the sample. Taxa descriptions are presented in Appendix 8. The raw faunal data from the 1/4-inch and 1/8-inch samples are presented in Appendix 10.

\section{The Wilson-Leonard Site and Its Fauna}

Although the Wilson-Leonard faunal sample is degraded and highly fragmented, it represents one of the best preserved, long-term late Pleistocene through Holocene sequences from a Central Texas archeological site. Faunal remains were recovered from the TxDOT excavations with 1/4-inch screens from throughout $4.5 \mathrm{~m}$ of deposits, representing Paleoindian through Late Prehistoric time periods.

The TARL excavations at the site revealed that bedrock lay $6 \mathrm{~m}$ below ground surface, roughly $2 \mathrm{~m}$ below the depth of the previous excavations. Sparse cultural materials were found almost down to bedrock. These later TARL excavations yielded additional faunal samples from both $1 / 8$-inch and fine-screen recovery. The 1/4-inch sample from the TxDOT excavations and the 1/8-inch sample from the TARL excavations are analyzed here. Additional faunal samples from the site are presented elsewhere in this volume (see Chapters 35-37, Appendix 8).

\section{Uniqueness of the Wilson-Leonard Sample}

Unlike the Wilson-Leonard sample, a majority of faunal assemblages from Central Texas have been recovered from cave and rockshelter deposits (Graham 1987:31). While rockshelter and cave settings often protect bone assemblages from alternation of wet and dry cycles, a major factor in bone degradation, these assemblages are often difficult to interpret. Numerous predators, in addition to humans, may inhabit caves and rockshelters, contributing bones or modifying the human-deposited assemblage (Andrews 1990; Brain 1981; McGuire 1980; Steele et al. 1984). In such cases, it is difficult to identify that portion of the assemblage created or modified by humans.

The Wilson-Leonard site, in contrast, reflects an open setting. Although faunal assemblages from open sites are not exempt from taphonomic problems, zooarcheologists generally have greater faith that assemblages from open sites more clearly reflect the use of animals as a human resource (cf. Grayson 1983, 1991; Lyman 1988). Nonhuman taphonomic factors potentially affecting open sites include water transport of bones, commensal animals living and dying at a site, and postoccupation intrusion into a site by burrowing animals. The long time depth, comparatively well-preserved fauna, and open nature of the Wilson-Leonard site is rare for the Central Texas area, and these factors allow for greater control of the taphonomic variables that typically plague cave and rockshelter deposits.

The long-term archeological record at the site is particularly significant. Relatively few sites in Central Texas have yielded faunal assemblages for Paleoindian and Early Archaic time periods (Baker 1992; Baker and Steele 1992; Redder 1985) (Table 33-1). Most of the known archeological sites in the region have produced faunal assemblages reflecting only Late Archaic or Late Prehistoric time periods. 
TABLE 33-1

Selected Central Texas Archeological Sites or Site Complexes with Vertebrate Faunal Remains

\begin{tabular}{|c|c|c|c|c|}
\hline Time Period/Site & No. & $\begin{array}{l}\text { No. of } \\
\text { Taxa }\end{array}$ & County & Reference \\
\hline $\begin{array}{l}\text { Paleoindian: } \\
\text { Richard Beene (41BX831) } \\
\text { Horn Shelter (41BQ46) } \\
\text { Duewall-Newberry (41BZ76) }\end{array}$ & $\begin{array}{r}25 \\
? \\
43\end{array}$ & $\begin{array}{r}6 \\
>5 \\
1\end{array}$ & $\begin{array}{l}\text { Bexar } \\
\text { Bosque } \\
\text { Brazos }\end{array}$ & $\begin{array}{l}\text { Baker and Steele (1992) } \\
\text { Forrester (1985); Redder (1985) } \\
\text { Carlson and Steele (1992); Carlson et al. } \\
\text { (1984); Steele (1990); Steele and Carlson } \\
\text { (1984, 1989a, 1989b) } \\
\text { Alexander (1963) }\end{array}$ \\
\hline $\begin{array}{l}\text { Archaic Indeterminate } \\
\text { Horn Shelter (41BQ46) } \\
\text { Several north-central Texas sites } \\
\text { Greenhaw (41HY29) } \\
\text { John Ischy (41WM49) }\end{array}$ & $\begin{array}{r}? \\
? \\
? \\
>217\end{array}$ & $\begin{array}{r}>6 \\
1 \\
4 \\
7\end{array}$ & $\begin{array}{l}\text { Bosque } \\
\text { Bosque, Hill, Johnson } \\
\text { Hays } \\
\text { Williamson }\end{array}$ & $\begin{array}{l}\text { Forrester (1985); Redder (1985) } \\
\text { Forrester (1965) } \\
\text { Weir (1979:41-43) } \\
\text { Witter (1969) }\end{array}$ \\
\hline $\begin{array}{l}\text { Early Archaic } \\
\text { Panther Springs Creek (41BX228) } \\
\text { Richard Beene (41BX831) } \\
\text { Sleeper site (41BC65) } \\
\end{array}$ & $\begin{array}{r}42 \\
\text { ca. } 4,800 \\
17 \\
\end{array}$ & $\begin{array}{r}9 \\
14 \\
4 \\
\end{array}$ & $\begin{array}{l}\text { Bexar } \\
\text { Bexar } \\
\text { Blanco }\end{array}$ & $\begin{array}{l}\text { Black and McGraw (1985:274) } \\
\text { Baker (1992); Baker and Steele (1992) } \\
\text { Johnson (1991:59-60) }\end{array}$ \\
\hline $\begin{array}{l}\text { Middle Archaic } \\
\text { Panther Springs Creek (41BX228) } \\
\text { Richard Beene (41BX831) } \\
\text { Bear Creek Shelter (41HI17) } \\
\text { McDonald site (41HI105) } \\
\text { 41ML141 } \\
\end{array}$ & $\begin{array}{r}67 \\
229 \\
236 \\
653 \\
7 \\
\end{array}$ & $\begin{array}{r}7 \\
2 \\
23 \\
7 \\
2 \\
\end{array}$ & $\begin{array}{l}\text { Bexar } \\
\text { Bexar } \\
\text { Hill } \\
\text { Hill } \\
\text { McLennan }\end{array}$ & $\begin{array}{l}\text { Black and McGraw (1985:278-280) } \\
\text { Baker (1992); Baker and Steele (1992) } \\
\text { Murry (1978) } \\
\text { Brown (1987, 1989) } \\
\text { Yates }(1985: 316)\end{array}$ \\
\hline $\begin{array}{l}\text { Middle Archaic/Late Archaic } \\
\text { Indeterminate } \\
41 \text { FT200 } \\
41 \text { NV96 }\end{array}$ & $\begin{array}{l}24 \\
10\end{array}$ & $\begin{array}{l}7 \\
1\end{array}$ & $\begin{array}{l}\text { Freestone } \\
\text { Navarrow }\end{array}$ & $\begin{array}{l}\text { McGregor and Bruseth (1987:69) } \\
\text { McGregor and Bruseth (1987:77-78) }\end{array}$ \\
\hline $\begin{array}{l}\text { Late Archaic } \\
\text { Richard Beene (41BX831) } \\
\text { Panther Springs Creek (41BX228) } \\
\text { Hog Creek Reservoir sites (tools) } \\
\text { Bird Point Island (41FT201) } \\
\text { 41FT199 } \\
\text { Bear Creek Shelter (41HI17) } \\
\text { McDonald site (41HI105) } \\
\text { 41ML162 } \\
\text { Adams Ranch site (41NV177) } \\
\text { Hopewell School site (41SV30) } \\
\text { 41SU2 } \\
\text { 41TG91 } \\
\text { Cherry Tree Shelter (41TV933) } \\
\end{array}$ & $\begin{array}{r}1,798 \\
? \\
- \\
\text { ca. } 225 \\
\text { ca. } 45 \\
206 \\
12,560 \\
37 \\
\text { ca. } 300 \\
\text { ca. } 500 \\
? \\
391 \\
?\end{array}$ & $\begin{array}{r}9 \\
7 \\
- \\
21 \\
2 \\
20 \\
11 \\
7 \\
22 \\
13 \\
4 \\
21 \\
?\end{array}$ & $\begin{array}{l}\text { Bexar } \\
\text { Bexar } \\
\text { Bosque, Coryell } \\
\text { Freestone } \\
\text { Freestone } \\
\text { Hill } \\
\text { Hill } \\
\text { McLennan } \\
\text { Navarro } \\
\text { Somervell } \\
\text { Sutton } \\
\text { Tom Green } \\
\text { Travis } \\
\end{array}$ & $\begin{array}{l}\text { Baker and Steele (1992) } \\
\text { Black and McGraw (1985:281) } \\
\text { Harrell (1983) } \\
\text { Murry (1987a) } \\
\text { McGregor and Bruseth (1987:56) } \\
\text { Lynott (1980:230-233); Murry (1978) } \\
\text { Brown (1987, 1989) } \\
\text { Yates (1985:317-318) } \\
\text { Murry (1987b) } \\
\text { Butler (1976:76) } \\
\text { Jarvis and Crawford (1974:25) } \\
\text { Scott (1990); Scott and Creel (1990:173-176) } \\
\text { Kotter (1985:152) }\end{array}$ \\
\hline $\begin{array}{l}\text { Archaic/Late Prehistoric } \\
\text { Indeterminate } \\
\text { Panther Springs Creek (41BX228) } \\
\text { 41BU16 } \\
\text { Several north-central Texas sites }\end{array}$ & $\begin{array}{r}? \\
\text { ca. } 1,000 \\
?\end{array}$ & $\begin{array}{l}11 \\
12 \\
21\end{array}$ & $\begin{array}{l}\text { Bexar } \\
\text { Burleson } \\
\text { Freestone, Navarro }\end{array}$ & $\begin{array}{l}\text { Black and McGraw (1985:283-284) } \\
\text { Hunter (1987) } \\
\text { McGregor and Bruseth }(1987: 23-24,42-46, \\
94-95,119-120,144-145,156-158,164)\end{array}$ \\
\hline $\begin{array}{l}\text { Bear Creek Shelter (41HI17) } \\
\text { Bering Sinkhole (41KR241) } \\
\text { 41ML13 and 41ML150 } \\
\text { Jetta Court (41TV151) } \\
\text { Smith Rockshelter } \\
\text { Kenyon Rockshelter (41TV742) } \\
\text { Loeve-Fox (41WM230) } \\
\text { 41WM130 } \\
\text { 41WM312 }\end{array}$ & $\begin{array}{r}\text { ca. } 400 \\
\text { ca. } 350 \\
17 \\
119 \\
? \\
2,216 \\
163 \\
>4,000 \\
\text { ca. } 15\end{array}$ & $\begin{array}{r}22 \\
6 \\
3 \\
12 \\
12 \\
11 \\
24 \\
14 \\
3\end{array}$ & $\begin{array}{l}\text { Hill } \\
\text { Kerr } \\
\text { McLennan } \\
\text { Travis } \\
\text { Travis } \\
\text { Travis } \\
\text { Williamson } \\
\text { Williamson } \\
\text { Williamson }\end{array}$ & $\begin{array}{l}\text { Lynott (1980:230-233); Murry (1978) } \\
\text { Bement (1991:59-81, 97-104, 187-200) } \\
\text { Yates (1985:316) } \\
\text { Wesolowsky et al. (1976:81) } \\
\text { Suhm (1957:53-54) } \\
\text { Coffman (1986:391) } \\
\text { McDonald (1974) } \\
\text { Bond (1978:198-208, 231-234) } \\
\text { Voellinger and Gearhart (1987:195-203) }\end{array}$ \\
\hline
\end{tabular}


Table 33-1, continued

\begin{tabular}{|c|c|c|c|c|}
\hline Time Period/Site & No. & $\begin{array}{l}\text { No. of } \\
\text { Taxa }\end{array}$ & County & Reference \\
\hline \multicolumn{5}{|l|}{ Late Prehistoric } \\
\hline 41BL670 & 347 & 5 & Bell & Sanchez and Shaffer (1993a) \\
\hline 41BL671 & 3,263 & 19 & Bell & Sanchez and Shaffer (1993a) \\
\hline 41BL495 & 157 & 7 & Bell & Sanchez and Shaffer (1993b) \\
\hline 41BL496 & 56 & 5 & Bell & Sanchez and Shaffer (1993b) \\
\hline 41BL497 & 359 & 8 & Bell & Sanchez and Shaffer (1993b) \\
\hline Richard Beene (41BX831) & 40 & 3 & Bexar & Baker and Steele (1992) \\
\hline Horn Shelter (41BQ46) & $?$ & $>8$ & Bosque & Forrester $(1985: 34)$ \\
\hline Hog Creek Reservoir sites (tools) & - & - & Bosque, Coryell & Harrell (1983) \\
\hline Several north-central Texas sites & $?$ & 3 & Bosque, Hill Johnson & Forrester (1965) \\
\hline Panther Springs Creek (41BX228) & ? & 11 & Bexar & Black and McGraw (1985:286-287) \\
\hline Bird Point Island (41FT201) & ca. 300 & 22 & Freestone & Murry (1987a) \\
\hline Kyle site & 1,192 & 17 & Hill & Lundelius (1962) \\
\hline McDonald site (41HI105) & 4,399 & 11 & Hill & Brown $(1987,1989)$ \\
\hline Pictograph Shelter & ? & 16 & Hill & Stephenson (1970:141-143, 149) \\
\hline Bear Creek Shelter (41HI17) & ca. 1,500 & 34 & Hill & Lynott (1980:230-233); Murry (1978) \\
\hline 41ML161 & 24 & 2 & McLennan & Yates $(1985: 317)$ \\
\hline Adams Ranch (41NV177) & $>342$ & 20 & Navarro & Murry (1987b) \\
\hline $41 \mathrm{RN} 169$ & ? & 3 & Runnels & Griffitts (1992) \\
\hline 41TG91 & ca. & 31 & Tom Green & Scott (1990); Scott and Creel (1990) \\
\hline Cherry Tree Shelter (41TV933) & $\begin{array}{r}10,000 \\
?\end{array}$ & $?$ & Travis & Kotter (1985:152) \\
\hline
\end{tabular}

\section{ENVIRONMENTALSETTING}

Ecologically, the Wilson-Leonard site falls within Blair's (1950:112-115) Balconian biotic province. Balconian vertebrate faunas are composed of a variety of taxa from surrounding regions including the Chihuahuan, Kansan, Tamaulipan, and Texan biotic provinces (Blair 1950:112; Gehlbach 1991). Graham (1987:26) stated that none of the vertebrate fauna of the Balconian province is endemic, though Toomey (1989:3) noted that of roughly 405 terrestrial vertebrates occurring on the Edwards Plateau, 7 salamander species are restricted to the area. Neck (1986:39) reported 5 endemic salamanders and 1 endemic frog. Gehlbach (1991) and Neck (1986) stressed the interaction of the Balcones Escarpment and differing plant communities of evergreen woodlands, tallgrass prairies, and deciduous forests in shaping the biographic distribution of Central Texas vertebrates. Reviews of the modern vertebrate fauna of the area and Texas in general can be found in Bryan et al. (1984), Davis (1978), Dixon (1987), Gehlbach (1991), Hubbs et al. (1991), Jones (1993), Jones and Jones (1992), Owen and Dixon (1989), Peterson (1960), Schmidly (1977, 1983, 1991), Tennant (1985), and Ward et al. (1990).

\section{OBJECTIVES}

The study of animal remains from archeological sites is termed zooarcheology (Olsen and Olsen 1981). Zooarcheologists are interested in a broad range of topics including taphonomy, human subsistence, paleoenvironmental reconstruction, and animal biology (Reitz
1987; Steele 1989). Rather than emphasizing paleoenvironmental reconstruction, the focus of this analysis is on taphonomy and subsistence, the often-neglected topics of Central Texas faunal studies.

\section{Taphonomic Analysis}

Much attention has been focused in recent years on understanding how archeological faunal assemblages are accumulated and preserved (Behrensmeyer and Hill 1980; Binford 1981; Binford and Bertram 1977; Gifford 1981; Koch 1989; Lyman 1984; Shipman 1981). The study of the factors shaping the composition of a faunal assemblage in its transition from the biosphere to the lithosphere is termed taphonomy (Efremov 1940).

Animals pass through numerous stages in their transition from a living biotic community of animals to a sampled fossil assemblage collected for analysis (Gifford 1981; Klein and Cruz-Uribe 1984:3-10). During each of these stages, bones may be added to the sample, removed from the sample, or modified by a myriad of biological and nonbiological forces. Each modification of the assemblage, in turn, makes it more difficult to reconstruct the exact nature of the assemblage that was created and deposited by humans.

\section{Subsistence Analysis}

The term "subsistence" is typically used to refer to a general lifeway including the collecting, processing, and consumption of food items (Lyman 1982a). More narrowly, subsistence reconstruction attempts to identify the exact 
nature of what was consumed, that is, the past diet. The objective of this section is to evaluate the role of animals in human subsistence at the Wilson-Leonard site. Emphasis is placed on (1) identifying taxa that potentially contributed to the diet of the site's occupants; (2) reconstructing prehistoric human hunting patterns represented at the WilsonLeonard site; and (3) identifying how the animal remains were processed and modified by humans.

The primary step in subsistence analysis and diet reconstruction is taxa identification and quantification. Included in this section are discussions of the taxa identified from the site and their relative frequencies. The reconstruction of human hunting patterns focuses on several issues. What taxa appear to have contributed significantly to the diet or were commonly hunted? What habitats were used to procure animal food resources? Were animals of a certain age preferentially harvested? Finally, during what seasons were certain animals hunted? In addressing animal processing, emphasis is placed on butchery reconstruction and marrow and grease production (Binford 1981:87181; Lintz 1976:87-88; Lyman 1987; Peale 1978; Vehik 1977).

\section{Paleoindian and Archaic Lifeways}

A third objective of this study is a comparison of Paleoindian and Archaic faunas from the site. The sample is examined to determine if differences are evident between the Paleoindian and Archaic periods. Bison material from the site is also discussed and summarized.

\section{PREVIOUSCENTRAL TEXAS FAUNALSTUDIES}

The present status of Quaternary faunal studies in Central Texas can be viewed from two broad perspectives: paleontological and archeological. The first centers on assemblages analyzed by paleontologists and biologists with a paleoenvironmental focus. The second perspective is primarily archeological, with emphasis on human diet and animal use. Many of the paleontological assemblages are from noncultural cave or rockshelter deposits and have yielded significant paleoenvironmental vertebrate data for the Quaternary of Central Texas (Dalquest et al. 1969; Evans 1961; Fox et al. 1992; Graham 1976a, 1976b, 1976c, 1984, 1987; Graham and Mead 1987; Hafner 1993; Haynes 1992; Hill 1971; Holman 1966; Holman and Winkler 1987; Hulbert 1979, 1984; Lundelius 1960, 1967, 1974, 1985, 1986, 1992a, 1992b; Lundelius et al. 1983; Marean and Ehrhardt 1995; Martin 1968; Meade 1961; Milstead 1956; Patton 1962, 1963; Pettus 1956; Roth 1972; Semken 1961; Toomey 1989, 1991, 1993; Toomey et al. 1993; Wilkins 1992; Wright and Lundelius 1963). These studies are excellent sources of information on vertebrate systematics, biogeography, and Central Texas paleoenvironments. Authors such as Graham (1987), Lundelius (1967), Toomey (1989), and Wilkins (1992) provide reviews of site locations for Cen- tral Texas paleontological and zooarcheological assemblages.

A second faunal data set for the region comes from archeologically excavated sites, primarily of Holocene, and less frequently, late Pleistocene age (Baker 1992, 1993a, 1993b, 1994, 1996, 1997; Baker and Steele 1992; Bement 1991:59-81, 97-104, 187-200, 1994:43-60; Bond 1978:198-208, 231-234; Brown 1987, 1989; Butler 1976; Carlson and Steele 1992; Carlson et al. 1984; Coffman 1986; Forrester 1965, 1985; Griffitts 1992; Hall 1989; Harrell 1983; Highley 1985; Holman 1966; House 1978; Huebner 1991; Hulbert 1985; Hunter 1987; Jarvis and Crawford 1974; Johnson 1991:59-60; Kotter 1985; Lundelius 1962; Lynott 1979, 1980:230-233; Martin 1987; Masson and Holderby 1994; McDonald 1974; McGraw 1985; Murry 1978, 1982, 1987a, 1987b; Redder 1985; Ricklis 1992; Sanchez and Shaffer 1993a, 1993b; Scott 1990; Scott and Creel 1990; Shaffer 1994, 1995; Sorrow et al. 1967:118-122; Steele 1990; Steele and Carlson 1984, 1989a, 1989b; Stephenson 1970:141-157; Voellinger and Gearhart 1987:195203; Wesolowsky et al. 1976:75-82; Winkler n.d., 1990; Witter 1969; Yates 1982, 1985). Central Texas archeofaunal assemblages (see Table 33-1) are typically from open sites, are comparatively poorly preserved (Black 1989:33), and have been analyzed by a broad range of archeologists, paleontologists, and zooarcheologists. In addition, the majority have been recovered with $1 / 4$-inch mesh screens, which biases these assemblages against systematic recovery of smaller vertebrates (Casteel 1972; DeMarcay and Steele 1986; Gordon 1993; Payne 1972, 1975; Shaffer 1992; Shaffer and Sanchez 1994; Wing and Quitmyer 1985). These sites have yielded a wide range of taxa, though deer (Odocoileus) is most commonly reported (Black 1989:33); there has been varying coverage on issues of taphonomy, subsistence, and paleoecology in the archeological literature (House 1978).

The geographic and biological diversity of the Central Texas area provided a wide variety of resources available for exploitation by prehistoric people. Grassland, forest, and aquatic species of plants and animals were probably all important dietary items. Continued research is required to determine the relative importance of these species and to identify temporal and geographic variation in resource exploitation during Central Texas prehistory, though the WilsonLeonard sample contributes greatly to these questions.

Little is known of prehistoric subsistence patterns in the region for two major reasons. First, relatively little substantive research has been conducted on this topic. Second, organic preservation in open sites in Central Texas is typically poor (Black 1989:18, 33). High soil $\mathrm{pH}$ and high $\mathrm{EH}$ (oxidation) often cause rapid destruction of pollen and other plant remains in the area. The general picture reflected by the Central Texas faunal studies is one in which deer (Odocoileus) dominate in terms of minimum number of individuals (MNI), number of identified specimens (NISP), and meat weight. As Black (1989:33-34) notes, this may in part be due to preservation factors and recovery methods, 
though it is unlikely future research will drastically alter this view.

Marrow and grease processing was probably also an important aspect of deer exploitation, though few studies of marrow and grease processing activities have been conducted on Central Texas assemblages (Masson and Holderby 1994). In addition to deer, taxa identified from Central Texas archeofaunal assemblages include species that inhabit aquatic environments, grassland regions, forested areas, arboreal habitats, and subterranean habitats. All of the taxa represent potential food sources. Assuming these animals accumulated from human activity, the prehistoric peoples of Central Texas exploited a variety of habitats that were easily accessible through diverse local environments and bordering biotic provinces. The range of taxa and prey behaviors represented suggests that numerous hunting, gathering, trapping, and fishing techniques were used to procure animals.

\section{Bison Studies}

One zooarcheological issue that has received continued attention in Central Texas is the question of bison availability, migration, and population fluctuation throughout the Quaternary on the southern plains (Baugh 1986; Creel 1991; Creel et al. 1990; Dillehay 1974; Flynn 1982; Huebner 1991; Hughes 1977; Lynott 1979; Patterson 1992; Scott and Creel 1990). Bison receive wide attention by archeologists because of their influence on human subsistence, technology, mobility, and social organization. Dillehay (1974) initiated much of this regional interest by postulating alternating intervals of bison presence and absence on the southern plains throughout the late Pleistocene and Holocene. Based on faunal data from archeological and paleontological sites, Dillehay (1974) proposed the following bison presence/absence sequence:

Presence Period I - 10,000 to 6,000-5,000 B.C.

Absence Period I - 6,000-5,000 to 2,500 B.C.

Presence Period II - 2,500 B.C. to A.D. 500

Absence Period II - A.D. 500 to 1,200-1,300

Presence Period III - A.D. 1,200-1,300 to 1550

Lynott (1979) critiqued Dillehay's model and felt minimally it was not applicable to north-central Texas. The model was viewed as weak because it ignored the ecological variability of the southern plains, and because bison bone tools (which could be traded from other areas) were included along with scrap bones by Dillehay as evidence of bison presence. While Lynott (1979) viewed bison population densities increasing after 800 B.P. (A.D. 1200) in northcentral Texas, he felt Dillehay's Absence Periods I and II were actually periods of low bison density rather than bison absence.

Flynn (1982) reviewed Dillehay's (1974) periods of Presence I and Absence I and notes that a total "Absence" period was falsified, though the general model was tentatively accepted (Flynn 1982:21). Central and western Oklahoma were used by Baugh (1986) also to test Dillehay's model. She notes the presence of bison in this region for Dillehay's Absence Period II and questions the usefulness of the model. Huebner (1991) later tested the Late Prehistoric interval of Dillehay's (1974) presence/absence periods and argues that Absence Period II and Presence Period III were confirmed. Huebner (1991) relates increased bison availability after ca. 1000 B.P. (ca. A.D. 950 ) to increased xeric conditions on the southern plains which allowed bison to expand in this area. Based on site distribution, Huebner (1991) suggests that bison herds moved through Central Texas into south Texas through a "bison corridor" between the Brazos and Colorado rivers.

Patterson (1992) reviewed bison data from southeast Texas and shows that at least some bison were present in all time periods from the Late Paleoindian through the Late Prehistoric. He suggests it is presently impossible to reconstruct migration routes from the available data (Patterson 1992). Creel et al. (1990) propose using the phrases "high frequency period" and "low frequency period" rather than Dillehay's terms "presence" and "absence" to denote temporal bison population density fluctuations. From site 41TG91 in west-central Texas, Creel et al. (1990) report bison from strata aged to 600 B.C. to A.D. 900 . Bison appeared to be absent or infrequent from ca. A.D. 900-1300. From A.D. 1300 bison were present in large numbers until the late $1800 \mathrm{~s}$ when their populations were decimated through mass killing by humans.

\section{Summary}

One of the major problems limiting a detailed synthesis of zooarcheological data from Central Texas has been that, until the last decade, Central Texas faunal assemblages received relatively little attention (House 1978). This includes a lack of problem orientation. In addition, many early faunal assemblages were treated as single aggregation units, with little regard to site stratigraphy or chronological context. For many sites, little can be said of temporal change in faunal exploitation, since these remains were analyzed and presented as though they were contemporaneous. Exceptions to this include studies by Baker and Steele (1992), Brown (1987, 1989), Creel et al. (1990), Kotter (1985), Masson and Holderby (1994), Murry (1978, 1987a, 1987b), Scott and Creel (1990), and Yates (1982), who include detailed chronological information in their discussions of Central Texas fauna.

Problem-oriented research is also needed to bring these data to the attention of archeologists outside of Texas. Work by Creel and Scott at site 41TG91 in west-central Texas provides an excellent example of bringing Central Texas faunal data to the attention of a broader archeological audience (Creel 1991; Creel et al. 1990; Scott 1990; Scott and Creel 1990). 
Though little formal synthesis of Central Texas archeofaunal studies has been conducted, a general pattern does emerge. Prehistoric inhabitants of the area apparently exploited a diverse range of habitats and taxa of varying size, reflecting a generalized subsistence strategy. In addition to deer, smaller vertebrates of grassland and forest habitats were exploited. Aquatic vertebrates such as fish and turtles also played a role. Only within the past 15 years or so have Central Texas archeologists begun to more fully address these zooarcheological variables.

\section{METHODS}

Research methods employed in the analysis are described here, including archeological recovery methods, cleaning and conservation, sample selection, faunal identification, data recording and manipulation, and quantification. A review of methods is vital to understanding potential biases that can influence bone counts, taxa representation, and subsequent human subsistence interpretations.

\section{Recovery Methods}

Faunal remains from the TxDOT excavations were recovered from six excavation blocks at the Wilson-Leonard site. Forty $2-x-2-m$ squares were excavated to various depths up to $5 \mathrm{~m}$, using arbitrary $5-\mathrm{cm}$ and $10-\mathrm{cm}$ levels. Sediment matrix was dry screened through $1 / 4$-inch-mesh hardware cloth, with the recovered fauna forming the sample for this analysis. One fine-screen 2-x-2-m square (E28/S78) was excavated in $10-\mathrm{cm}$ intervals to a depth of $4.5 \mathrm{~m}$. Using nested 1/4-inch and 1/16-inch screens, material from this unit was water screened in the field. The $1 / 4$-inch faunal material from this fine-screen unit is included in this analysis. The 1/16inch screened vertebrate sample from one of the $1-\mathrm{x}-1-\mathrm{m}$ quads in this square has been previously analyzed and reported (Winkler n.d., 1990).

The more-recent TARL excavations proceeded with smaller $1 / 8$-inch screens to help control for sampling biases at the site. In addition, matrix from two fine-screen squares and some feature contexts was processed in a flotation/matrix separation device at the Vertebrate Paleontology Laboratory, The University of Texas at Austin (see Chapters 34, 35, Appendix 8).

\section{Cleaning and Conservation of Faunal Remains}

The 1/4-inch faunal sample was sorted by lot number by TxDOT and submitted to the Zooarcheological Research Laboratory, Department of Anthropology, Texas A\&M University where it was washed and analyzed. The 1/8-inch sample was washed and sorted by TARL personnel. Many of the bison bones from the lower deposits (1/4-inch sample) were stabilized and conserved by the Vertebrate Paleontology Laboratory, The University of Texas at Austin. Several of the bison bones were jacketed following standard paleontological techniques to reduce breakage in the field. These bones were cleaned with ethanol and variously conserved with gelva, and polyvinyl acetate (PVA). Individual specimen numbers were not assigned, and the sample was recorded by archeological lot number.

\section{Sample Selection}

The analyzed faunal sample consists of all 1/4-inch remains recovered from the 1982-1984 (TxDOT) excavations at the site, with the exception of a shark tooth and rodent mandible recovered from the Paleoindian burial (Burial 2). The other vertebrates recovered from these early excavations include the 1/16-inch sample analyzed by Winkler (n.d., 1990), and the three unsorted and unstudied quads (1/16-inch fraction) from the TxDOT fine-screened square. The 1/8-inch faunas from the more-recent TARL excavations are also included in this analysis. Vertebrates discussed here were recovered from all stratigraphic units at the site. A summary of specimen counts by cultural period and associated stratigraphic unit are presented in Tables 33-2 and 33-3.

\section{Faunal Identification}

Identification of the faunal remains was aided by the use of the Zooarcheological Research Collection (Department of Anthropology) and the Texas Cooperative Wildlife Collection (TCWC) (Department of Wildlife and Fisheries Sciences) at Texas A\&M University. Comparative bison material at The Brazos Valley Museum of Natural History (College Station, Texas) was also referenced. The presence of fossil horse at the Wilson-Leonard site was verified by the Vertebrate Paleontology Laboratory, The University of Texas at Austin.

Specimens were identified as precisely as possible based on structural features and possible animals present in the area. Identification guides used include Auffenberg (1969), Balkwill and Cumbaa (1992), Ford (1990), Gilbert (1980), Gilbert et al. (1985), Hillson (1986), Lawrence (1951), Olsen (1968), Schmid (1972), and an early draft copy of Sobolik and Steele (1996).

\section{Data Recording and Manipulation}

Specimens were coded using a vertebrate faunal analysis coding system developed by Shaffer and Baker (1992). Data were entered into a dBASE (III+) file for error checking, manipulation, and table generation (Carlson and Shaffer 1992). The following information was recorded for each specimen in the 1/4-inch sample where applicable: lot number, quantity, taxon, element, portion of element, side, age, age criteria, sex, sex criteria, degree of weathering, breakage pattern, burning, gnawing, cut marks, and other forms of cultural modification. The $1 / 8$-inch sample was analyzed for the 
TABLE 33-2

Faunal Recovery from 1/4-inch Screens by Cultural Period and Stratigraphic Unit

\begin{tabular}{|c|c|c|}
\hline Cultural Period & Stratigraphic Unit & Totals \\
\hline Unassigned & Unknown & 214 \\
\hline Paleoindian & $\mathrm{X} / \mathrm{Isi}$ & 10 \\
\hline Paleoindian & Isi/Isi-c & 148 \\
\hline Paleoindian & Icl/Isi-c & 373 \\
\hline Paleoindian & Isi/Icl/Isi-c & 203 \\
\hline Paleoindian & I & 209 \\
\hline Paleoindian & Isi/Icl & 14 \\
\hline Early Paleoindian & Icl & 236 \\
\hline Early Paleoindian & $\mathrm{Icl} / \mathrm{D}$ & 21 \\
\hline Early Paleoindian & Isi/Icl/D & 64 \\
\hline Early Paleoindian & Isi/Icl & 1,782 \\
\hline Early Paleoindian & Igl/Isi/Icl & 9 \\
\hline Early Paleoindian & Isi & 512 \\
\hline Early Paleoindian & Isi/D & 17 \\
\hline Early Paleoindian & Isi/D? & 37 \\
\hline Early Paleoindian & $\mathrm{Igl} / \mathrm{Isi}$ & 1,115 \\
\hline Early Paleoindian & Igl & 12 \\
\hline Late Paleoindian & II & 1,542 \\
\hline Late Paleoindian & $\mathrm{Id} / \mathrm{II}$ & 391 \\
\hline Late Paleoindian & $\mathrm{I} / \mathrm{II}$ & 42 \\
\hline Late Paleoindian & Id & 9 \\
\hline Late Paleoindian & Isi-c/II & 293 \\
\hline Late Paleoindian & Isi-c/Id/II & 282 \\
\hline Late Paleoindian & Isi-c/Id & 521 \\
\hline Late Paleoindian & Isi-c & 1,847 \\
\hline Late Paleoindian & Isi/Isi-c & 5 \\
\hline Late Paleoindian & X & 33 \\
\hline Late Paleoindian & $\mathrm{X} / \mathrm{II}$ & 65 \\
\hline Late Paleoindian & $\mathrm{X} / \mathrm{Id} / \mathrm{II}$ & 3 \\
\hline Late Paleoindian & X/Isi-c/Id & 3 \\
\hline Late Paleoindian & $\mathrm{X} / \mathrm{Isi}-\mathrm{c} / \mathrm{Id} / \mathrm{II}$ & 14 \\
\hline Late Paleoindian/Early Archaic & IIIa & 17 \\
\hline Late Paleoindian/Early Archaic & II/IIIa & 585 \\
\hline Late Paleoindian/Early Archaic & II/III & 1 \\
\hline Late Paleoindian/Early Archaic & $\mathrm{X}$ & 139 \\
\hline Late Paleoindian/Early Archaic & $\mathrm{X} / \mathrm{II}$ & 26 \\
\hline Archaic & IIIc/POT & 25 \\
\hline Archaic & IIIc & 41 \\
\hline Archaic & $\mathrm{IIIb} / \mathrm{c}$ & 9 \\
\hline Archaic & III & 9 \\
\hline Archaic & Y/IIIc & 41 \\
\hline Archaic & $\mathrm{Y} / \mathrm{IIIb} / \mathrm{c}$ & 25 \\
\hline Archaic & $\mathrm{Y}$ & 3 \\
\hline Early Archaic & IIIb & 248 \\
\hline Early Archaic & $\mathrm{IIIa} / \mathrm{b}$ & 196 \\
\hline Early Archaic & IIIa & 752 \\
\hline Early Archaic & III & 77 \\
\hline Early Archaic & II/IIIa & 14 \\
\hline Early Archaic & $\mathrm{Y} / \mathrm{III}$ & 1 \\
\hline Early Archaic & $\mathrm{Y} / \mathrm{IIIb}$ & 33 \\
\hline Early Archaic & Y & 50 \\
\hline Early Archaic & $\mathrm{X} / \mathrm{Y} / \mathrm{IIIb}$ & 49 \\
\hline Early Archaic & X/IIIb & 42 \\
\hline Early Archaic & $\mathrm{X} / \mathrm{Y}$ & 80 \\
\hline Early Archaic & $\mathrm{X} / \mathrm{III} / \mathrm{b}$ & 10 \\
\hline Early Archaic & $\mathrm{X} / \mathrm{III}$ & 29 \\
\hline
\end{tabular}


Table 33-2, continued

\begin{tabular}{|c|c|c|}
\hline Cultural Period & Stratigraphic Unit & Totals \\
\hline Early Archaic & $\mathrm{X} / \mathrm{II} / \mathrm{IIIa}$ & 55 \\
\hline Early Archaic & $\mathrm{X}$ & 109 \\
\hline Early Archaic & $\mathrm{X} / \mathrm{II}$ & 19 \\
\hline Early/Middle Archaic & IIIc & 43 \\
\hline Early/Middle Archaic & $\mathrm{IIIb} / \mathrm{c}$ & 433 \\
\hline Early/Middle Archaic & IIIb & 224 \\
\hline Early/Middle Archaic & $\mathrm{IIIa} / \mathrm{b}$ & 9 \\
\hline Early/Middle Archaic & III & 13 \\
\hline Early/Middle Archaic & Y/IIIc & 69 \\
\hline Early/Middle Archaic & $\mathrm{Y} / \mathrm{IIIb} / \mathrm{c}$ & 3 \\
\hline Middle Archaic & IIIC & 172 \\
\hline Middle Archaic & $\mathrm{IIIb} / \mathrm{c}$ & 399 \\
\hline Middle Archaic & IIIb & 32 \\
\hline Middle Archaic & III & 44 \\
\hline Middle/Late Archaic & IIIc & 727 \\
\hline Middle/Late Archaic & $\mathrm{IIIJ} / \mathrm{c}$ & 181 \\
\hline Middle/Late Archaic & Y/IIIc & 5 \\
\hline Late Archaic & IIIc & 3,337 \\
\hline Late Archaic & Unknown & 20 \\
\hline Archaic/Late Prehistoric & IIIc/POT & 748 \\
\hline Late Archaic/Late Prehistoric & IIIc & 1,854 \\
\hline Late Archaic/Late Prehistoric & Unknown & 16 \\
\hline Late Prehistoric & IIIIc & 805 \\
\hline Late Prehistoric & Unknown & 22 \\
\hline Total: & & 21,867 \\
\hline
\end{tabular}

same variables except weathering. The small size of these specimens made an assessment of weathering impractical.

Broken bones that could be fitted together were coded as one specimen. All of these were angular breaks. No spirally fractured bones could be refitted. Terminology for premolars followed a paleontological style of designating the last premolar in a sequence as P4. Although Purdue (1983b, 1986, 1987, 1989, 1991) used bone measurements to address questions of body-size changes in deer throughout the Archaic of the eastern United States, the mixed nature of many of the Middle Archaic, Late Archaic, and Late Prehistoric deposits at the Wilson-Leonard site makes it doubtful that research along these lines would prove insightful.

\section{Quantification}

In recent years, numerous methods of quantifying animal and element abundance from archeological sites have been used (Grayson 1984; Lyman 1994; Reitz 1987; Ringrose 1993, and references therein). Number of Identified Specimens (NISP) and Minimum Number of Individual (MNI) counts are most common methods used to address taxonomic abundance. Recently, Marshall and Pilgram (1993) argued that MNI may be less representative of relative element frequency than NISP in highly fragmented assemblages (such as the Wilson-Leonard sample). The mixed and highly fragmented nature of the Wilson-Leonard sample makes it unlikely that a detailed analysis by MNI would prove accurate, thus NISP counts are emphasized here.

Other quantification measures commonly used by zooarcheologists include Minimum Number of Elements (MNE), and Minimum Animal Units (MAU). The development of these measuring units stemmed from observations by Binford $(1978,1981)$ and others that people do not necessarily use entire carcasses of single animals, but rather segments of animals (e.g., hindquarters, forequarters, etc.). Thus, culturally selected units of animals may become deposited at a site, rather than entire animal carcasses. Knowing how many and what types of various animal units are represented in a site, then, may provide insight into cultural processes that are not provided by NISP or MNI. Though again, the highly fragmented, degraded, and often mixed nature of the Wilson-Leonard sample makes research along these lines less useful (see Grayson 1984:88-90 for a critique of these methods).

\section{TAPHONOMIC ANALYSIS}

\section{Taphonomy}

Before any attempt is made to interpret human subsistence from a faunal assemblage, it is important to understand the forces that may have acted on that assemblage through time. Such information is necessary to ensure that possible biases associated with the data set have been 
TABLE 33-3

Faunal Recovery from 1/8-inch Screens by Cultural Period and Stratigraphic Unit

\begin{tabular}{|c|c|c|}
\hline Period & Stratigraphic Unit & Totals \\
\hline Unassigned & Unknown & 47 \\
\hline Unassigned & FILL & 5 \\
\hline Unassigned & $\mathrm{IIIb} / \mathrm{c} / \mathrm{FILL}$ & 123 \\
\hline Unassigned & IIIc/FILL & 180 \\
\hline Paleoindian & Icl/Isi-c & 528 \\
\hline Paleoindian & Isi/Icl/Isi-c & 168 \\
\hline Paleoindian & Isi/Isi-c & 1,366 \\
\hline Paleoindian & $\mathrm{X}$ & 3 \\
\hline Early Paleoindian & Icl & 269 \\
\hline Early Paleoindian & Igl & 32 \\
\hline Early Paleoindian & $\mathrm{Igl} / \mathrm{Icl}$ & 35 \\
\hline Early Paleoindian & Igl/Isi & 101 \\
\hline Early Paleoindian & Igl/Isi/Icl & 134 \\
\hline Early Paleoindian & Isi & 441 \\
\hline Early Paleoindian & Isi/Icl & 858 \\
\hline Late Paleoindian & II & 4,560 \\
\hline Late Paleoindian & Id & 194 \\
\hline Late Paleoindian & $\mathrm{Id} / \mathrm{II}$ & 790 \\
\hline Late Paleoindian & Isi-c & 1,521 \\
\hline Late Paleoindian & Isi-c/II & 411 \\
\hline Late Paleoindian & Isi-c/Id & 1,138 \\
\hline Late Paleoindian & Isi-c/Id/II & 55 \\
\hline Late Paleoindian/Early Archaic & II & 33 \\
\hline Late Paleoindian/Early Archaic & II/IIIa & 3,148 \\
\hline Late Paleoindian/Early Archaic & $\mathrm{X}$ & 29 \\
\hline Archaic & IIIc & 236 \\
\hline Archaic & Y/IIIc & 93 \\
\hline Early Archaic & Unknown & 1 \\
\hline Early Archaic & IIIa & 3,587 \\
\hline Early Archaic & IIIIa/b & 739 \\
\hline Early Archaic & $\mathrm{X}$ & 69 \\
\hline Early Archaic & $\mathrm{Y}$ & 369 \\
\hline Early/Middle Archaic & $\mathrm{IIIa} / \mathrm{b}$ & 664 \\
\hline Early/Middle Archaic & IIIb & 512 \\
\hline Middle Archaic & $\mathrm{IIIa} / \mathrm{b}$ & 157 \\
\hline Middle Archaic & IIIb & 3,173 \\
\hline Middle Archaic & $\mathrm{IIIb} / \mathrm{c}$ & 610 \\
\hline Middle/Late Archaic & $\mathrm{IIIb}$ & 682 \\
\hline Middle/Late Archaic & $\mathrm{IIIb} / \mathrm{c}$ & 1,764 \\
\hline Middle/Late Archaic & IIIb/c/FILL & 86 \\
\hline Middle/Late Archaic & IIIc & 410 \\
\hline Late Archaic & $\mathrm{IIIb} / \mathrm{c}$ & 1,426 \\
\hline Late Archaic & IIIc & 4,719 \\
\hline Late Archaic/Late Prehistoric & IIIc & 3,152 \\
\hline Total: & & 38,618 \\
\hline
\end{tabular}

considered before dietary conclusions are drawn. Taphonomy is that field of study that attempts to understand those forces that create and modify faunal assemblages through time (Binford 1981; Efremov 1940; Gifford 1981; Koch 1989; Shipman 1981; Steele 1989).

Klein and Cruz-Uribe (1984:3-4) provide an overview of the various stages through which bones pass in their transformation from a living community of animals to an excavated sample for study. This discussion draws primarily from their review. Information loss occurs with each successive taphonomic stage, making it increasingly difficult to reconstruct and characterize the original sample that was exploited by humans (Grayson 1979; Lyman 1982b).

The first stage represented in this taphonomic sequence is the life assemblage. This assemblage represents the entire living community of animals present in their "natural" proportions. The second stage is the death assemblage, representing a subsample of the life assemblage as well as those 
remains that are available for collection by various taphonomic agents. Examples of such agents include humans, carnivores, rodents, and hydraulic activity. The third stage in the sequence is the deposited assemblage, which constitutes those elements that "come to rest at a site" (Klein and Cruz-Uribe 1984:3). The fourth stage through which bones pass is the fossil assemblage, defined as those elements of the deposited assemblage that survive until excavation or collection. The fifth stage is the sample assemblage, referring to remains that are actually collected by the excavator.

In addition to those discussed by Klein and Cruz-Uribe (1984:3-4), two other stages must also be considered. While these are not taphonomic stages in the strict use of the term, they do reflect successive stages of information loss. The first of these is the recorded assemblage (similar to Davis 1987:22 and Gifford 1981:387). This assemblage is composed of those faunal elements that are actually identified and recorded in some manner as the first step in studying the remains. It is often impossible for the zooarcheologist to place all of the faunal remains that were initially recorded within sufficient archeological context for interpretation. Therefore, site interpretations are often made on a subsample of the recorded assemblage. The final stage is the interpreted assemblage, reflecting the actual elements from which site interpretations are made (similar to Davis 1987:22, Gifford 1981:387; Hesse and Wapnish 1985:19).

Two broad approaches can be taken in taphonomy studies (Gifford 1981:366-367). The first is based on contemporary observations used to understand how present-day forces create and modify bone assemblages. Ethnoarcheological and experimental studies are examples of this first approach. A second approach focuses on fossil assemblages to reconstruct their taphonomic histories. Insight from experimental studies is also commonly used in these studies. This second approach, an understanding to the forces that created and modified the Wilson-Leonard sample and ultimately influence any interpretation of the sample, is attempted below. The influence of the following possible taphonomic factors in structuring the WilsonLeonard faunal assemblage are addressed: fragmentation, weathering, chemical dissolution, rootlet etching, water transport, rodent gnawing, turbation, carnivore activity, intrusive and commensal faunal association, bone density, human hunting and animal processing activities, and, finally, bone burning.

\section{Fragmentation}

The 1/4-inch Wilson-Leonard sample includes 21,867 specimens that are, overall, highly fragmented and degraded. Of these, 15,309 (70\%) were small unidentifiable fragments. Only $145(0.7 \%)$ specimens were unbroken. This extremely high degree of fragmentation limited the number of elements that could be identified. The 1/8-inch sample consists of 38,618 specimens, only $246(0.6 \%)$ of which are unbroken. Comparable to the 1/4-inch sample, 26,253 specimens (68\%) could not be identified beyond the taxonomic level Vertebrata.

Breakage patterns at the site show two forms. First, dry bone fractures (a.k.a. angular fractures) dominate the broken bone assemblage ( $82 \%$ of the $1 / 4$-inch sample $[n=17,916]$; $92 \%$ of the $1 / 8$-inch sample [ $n=35,625]$ ) (Table 33-4). These breaks often show a stair-step fracture edge and are common on bones with reduced organic collagen content. Dry bone breakage can result from both mechanical and biological agents (Steele 1989:77). Mechanical forces may include compressive forces from sediment overburden, while biological agents can include root penetration or breakage caused by burrowing animals (Steele 1989:77). The process of archeological excavation and matrix screening can also cause a significant amount of breakage. The high number of dry fractures appears to be the result of postdepositional forces that may have included sediment compaction, turbation (see below), and excavation damage. Many of the bones are fragile and show recent dry fractures that probably occurred during excavation.

In addition to dry bone fractures, spiral fractures are also present on many specimens (17\% of the $1 / 4$-inch sample $[\mathrm{n}=3,806] ; 2 \%$ of the $1 / 8$-inch sample [ $\mathrm{n}=759]$ ) (see Table 334). As indicated here, spirally fractured bones are much more common in the $1 / 4$-inch sample. In part, this is due to differences in the taxa represented in the two samples. The 1/4inch sample is dominated by larger animals whose bones are more conducive to spiral fracturing and to marrow and grease processing. The $1 / 8$-inch is dominated by smaller animals (see subsistence discussion).

Also known as green bone breaks, spiral fractures occur on bones that still retain a large portion of collagen when breakage occurs. Once thought to be definitive of human behavior, spiral breaks are now known to be caused by numerous forces, including carnivore chewing (Johnson 1985). The highly degraded nature of the Wilson-Leonard sample made it difficult to recognize spiral fractures in many cases. The numbers presented above probably underestimate the number of spiral fractures present in the deposited assemblage.

Interestingly, at least $2,434(64 \%)$ of the 3,806 specimens in the 1/4-inch sample that show spiral fractures also show dry bone fractures (see Table 33-4). Of the spirally fractured bones from the 1/8-inch sample, 1,050 specimens (38\%) also exhibit angular fractures. This indicates that much of the assemblage that was fragmented while the bones were relatively fresh was fragmented again much later in time when the bones lost most of their collagen. The spiral fractures in this instance probably represent human activity, since no carnivore damage was noted (see below).

\section{Weathering}

Shipman (1981:115) defined bone weathering as "damage to body parts produced by exposure to elements prior to 
TABLE 33-4

Breakage Patterns by Cultural Period (Angular Only; Spiral Only; Both Angular and Spiral)

\begin{tabular}{|c|c|c|c|c|c|}
\hline & Unbroken & Angular & Spiral & Angular and Spiral & Totals \\
\hline 1/4-inch Sample by Period: & & & & & \\
\hline Unassigned & 3 & 171 & 6 & 34 & 214 \\
\hline Paleoindian & 1 & 932 & 2 & 22 & 957 \\
\hline Early Paleoindian & 6 & 3,763 & 5 & 31 & 3,805 \\
\hline Late Paleoindian & 12 & 4,824 & 22 & 192 & 5,050 \\
\hline Late Paleoindian/Early Archaic & 2 & 699 & 3 & 64 & 768 \\
\hline Archaic & 3 & 127 & 3 & 20 & 153 \\
\hline Early Archaic & 11 & 1,456 & 27 & 270 & 1,764 \\
\hline Early/Middle Archaic & 9 & 648 & 27 & 110 & 794 \\
\hline Middle Archaic & 10 & 533 & 21 & 83 & 647 \\
\hline Middle/Late Archaic & 17 & 658 & 73 & 165 & 913 \\
\hline Late Archaic & 43 & 2,279 & 352 & 683 & 3,357 \\
\hline Archaic/Late Prehistoric & 5 & 363 & 238 & 142 & 748 \\
\hline Late Archaic/Late Prehistoric & 19 & 1,019 & 496 & 336 & 1,870 \\
\hline Late Prehistoric & 4 & 444 & 97 & 282 & 827 \\
\hline Totals: & 145 & 17,916 & 1,372 & 2,434 & 21,867 \\
\hline
\end{tabular}

Spirally fractured total $=3,806$ ( $17.4 \%$ of total specimen count)

Spirally fractured Paleoindian total $=274$ ( $2.3 \%$ of total Paleoindian specimen count)

Spirally fractured Early Archaic - Late Prehistoric total=3,425 (31\% of total Early Archaic - Late Prehistoric specimen count)

\begin{tabular}{|c|c|c|c|c|c|}
\hline \multicolumn{6}{|l|}{ 1/8-inch Sample by Period: } \\
\hline Unassigned & 1 & 259 & 3 & 92 & 355 \\
\hline Paleoindian & 1 & 2,061 & 1 & 2 & 2,065 \\
\hline Early Paleoindian & 1 & 1,864 & 0 & 5 & 1,870 \\
\hline Late Paleoindian & 44 & 8,612 & 1 & 12 & 8,669 \\
\hline Late Paleoindian/Early Archaic & 17 & 3,187 & 0 & 6 & 3,210 \\
\hline Archaic & 5 & 323 & 0 & 1 & 329 \\
\hline Early Archaic & 39 & 4,683 & 0 & 43 & 4,765 \\
\hline Early/Middle Archaic & 10 & 1,154 & 1 & 11 & 1,176 \\
\hline Middle Archaic & 49 & 3,797 & 24 & 70 & 3,940 \\
\hline Middle/Late Archaic & 24 & 2,473 & 234 & 211 & 2,942 \\
\hline Late Archaic & 36 & 4,838 & 969 & 302 & 6,145 \\
\hline Late Archaic/Late Prehistoric & 19 & 2,374 & 464 & 295 & 3,152 \\
\hline Totals: & 246 & 35,625 & 1,697 & 1,050 & 38,618 \\
\hline
\end{tabular}

Spirally fractured total $=2,747$ ( $7.1 \%$ of total specimen count)

Spirally fractured Paleoindian total $=21(0.2 \%$ of total Paleoindian specimen count)

Spirally fractured Early Archaic - Late Prehistoric total=2,625 (11.7\% of total Early Archaic - Late Prehistoric specimen count)

deposition" (by which she apparently means "burial"). While mechanical and chemical degradation continues with postdeposition (White and Hannus 1983), researchers have placed emphasis on the weathering that occurs prior to deposition because these studies provide more information about ground surface landscape, assemblage accumulation, and paleoenvironment. Behrensmeyer (1978) pioneered bone weathering studies and defined six weathering stages for bones in the Amboseli Basin of southern Kenya. These weathering stages have been widely applied to diverse environments and modified by other researchers. Lyman and Fox (1989) provide one of the most recent reviews of bone weathering.

The application of Behrensmeyer's (1978) weathering stages to the Wilson-Leonard sample, however, proved fruit- less. Postdepositional chemical dissolution of the sample was so extensive that no examples of typical bone weathering of the type that occurs on the ground surface (such as the fine line cracking and exfoliation definitive of Behrensmeyer's stages) were consistently observable. Instead, general bone surface texture was assessed for the $1 /$ 4-inch sample and was recorded as one of two stages (heavy or light degradation). The minute size of specimens in the $1 /$ 8-inch sample made it unproductive to assess weathering on this sample.

The term heavy weathering is used here to characterize bones that show extensive surface degradation, which can result particularly from geochemical dissolution, root etching, and burning. Slight weathering was defined as showing only minimal/slight evidence of bone surface degradation, 
regardless of the agent of degradation. This classification is admittedly subjective. Hindsight suggests that in cases where Behrensmeyer's classification is not applicable, a more formal and consistent approach to bone surface degradation quantification should include the recording of specific individual observable characteristics (such as exfoliation, root etching, fine cracking, etc.) on a scale of slight, to moderate, to extreme.

As with fragmentation, analysis shows that bone surfaces are highly degraded. Of the $1 / 4$-sample, $92 \%(n=20,174)$ is heavily weathered as defined above. Burned bones generally show less surface degradation than unburned bones (see below). This high degree of degradation is significant in two respects. First, obliterated morphological features reduce taxa identification rates and also limit interpretations of cut mark frequency, human subsistence, and diet breadth. Because of this extensive degradation, butchering marks on this sample are also probably highly underrepresented. Second, the extensive degradation provides insight into the site formation processes that have modified the assemblage. This is discussed in the following section on chemical dissolution.

\section{Chemical Dissolution}

Chemical dissolution of bones can result from numerous factors. White and Hannus (1983:316) note that, independent of soil properties, the weathering of hydroxyapatite in bone is "probably initiated by organic and carbonic acids formed by the microbial decomposition of collagen." Soil phosphorus may also influence bone preservation and degradation. At a buried Late Prehistoric site in Kansas, Artz (1983) noted that bone preservation tended to be worse in zones of low soil phosphorus. Plant uptake of phosphorus via the root system produced zones of phosphate depletion in the soil. Artz suggested that if bones (a source of calcium phosphate) are present in these depleted zones, increased chemical degradation of the bones may occur through the leaching of phosphates out of the bone.

Biological forms of chemical dissolution and degradation are also known. Acids in plant rootlets may etch bone surfaces leaving recognizable dendritic patterns. Gastrointestinal etching can also occur if bones are digested and then passed or regurgitated by carnivores, humans, or avian predators. The previous discussion of weathering showed that bone surface degradation and chemical dissolution of the Wilson-Leonard sample was extensive. This has important implications for site formation processes at the site.

Soil $\mathrm{pH}$ is another important variable (Gordon and Buikstra 1981; Person et al. 1990). From several Late Woodland burial mounds, Gordon and Buikstra (1981) found that as soil acidity increases, bone destruction increases as well. Person et al. (1990) noted that acidic soils with poor bone preservation are common in tropical environments. In other cases, bone dissolution can occur through interactions with groundwater (Hedges and Millard 1995) .

Winkler (n.d., 1990) also noted degradation and dissolution in her analysis of the small vertebrate fauna from Wilson-Leonard. She reported "pitting" and "corrosion" on the teeth of cottontail rabbits, woodrats, cotton rats, and gophers, and felt these specimens may represent digestion by humans or nonhuman predators (Winkler 1990:203). Clarification of this point is vital, for Winkler's observation calls into question whether or not the small animal assemblage at the site resulted from human or nonhuman site formation processes. The high degree of burning on the small animal sample, however, suggested to Winkler that the remains may represent human food. Further, she cited human coprolite literature supporting the notion of prehistoric consumption of small animals, implying that while corrosion was noted in some cases, it was more likely the result of human than nonhuman digestion.

Corrosion and pitting on the $1 / 4$-inch and 1/8-inch samples is extensive, especially on the unburned bones (as reflected in the previous discussion on bone weathering). The corrosion noted by Winkler probably was produced by the same agent that modified the samples described here. The high frequency of this corrosion, coupled with the fact that no carnivore chewing or nonhuman predator activity was identified in either the $1 / 4$-inch or $1 / 8$-inch sample suggests that the corrosion observed by Winkler did not result from carnivore gastrointestinal digestion but represents a broader pattern of bone dissolution at the site. Winkler's (n.d., 1990) taphonomic observations of the corroded teeth were not detailed enough to test the idea that these resulted from carnivores or owl pellets. However, other lines of evidence discussed in subsequent sections suggest that the small fauna accumulated from human behavior.

Though untested through chemistry and $\mathrm{pH}$ analysis, it is likely that the corrosion noted in both our analyses resulted from some form of geophysical dissolution. Possibilities include carbonic acid dissolution (cf. Andrews 1990:21; Sanchez and Shaffer 1993b), groundwater dissolution (Hedges and Millard 1995), or degradation from organic acids from oak trees or other sources in the soil. This issue deserves continued research, though it is unlikely the extensive degradation seen in many Central Texas faunal assemblages is primarily the result of gastrointestinal digestion.

\section{Rootlet Etching}

As noted above, acids in plant rootlets can degrade bones when in contact with their surfaces. Binford (1981:50, Figures 3.07 and 3.08) illustrates a classic example of rootlet etching showing an extensive, etched, dendritic pattern on the surface of a bone. Though the frequency of rootlet etching on the Wilson-Leonard sample was not quantified, a few specimens did show etching. Extensive geochemical degradation probably reduced the observation of rootlet etching. 
This etching likely played only a minor role in bone degradation at the site.

\section{Water Transport}

Waterborne particle rounding of bones is commonly referred to as abrasion and can be divided into three categories: (1) unabraded, (2) moderately abraded, and (3) heavily abraded (Shipman 1981:114). While no specific evidence of water transport was noted in the samples reported here, Winkler (1990:204) observed rounding on some of her specimens from the site suggesting water transport. Water transport, however, was probably only a minor component of the taphonomic history of the sample. While Stratigraphic Unit I contained gravels indicative of high energy fluvial transport, the bones themselves provide little evidence of water sorting.

\section{Rodent Gnawing}

Rodent gnawing is another potential bone reducing agent, and extensive gnawing can provide evidence of prolonged ground surface exposure prior to site burial. In cases of heavy rodent gnawing, bone morphology and surface modification (such as cut marks) can become obliterated. Chew marks are also indirect evidence of past animal behavior. As such, they are included with ichnofossils (trace fossils) and may be considered a subsample of a faunal assemblage (Gautier 1993). Though gnawed bones represent a small percentage of both the $1 / 4$-inch $(0.6 \%, n=124)$ and $1 / 8$-inch samples $(0.08 \%, \mathrm{n}=32)$, for some specimens gnawing represented a major bone reducing factor. Rodent gnawing usually produces numerous parallel marks perpendicular to the long axis of the bone, and may result in "windows," or holes chewed through the compact bone to expose the medullary cavity or cortical bone (Bonnichsen and Will 1980:10).

\section{Turbation}

Other factors commonly affecting the distribution and reduction of bones at archeological sites include postdepositional turbation processes (Steele 1989:77; Wood and Johnson 1978). Faunalturbation refers to site disturbance by animals, while floralturbation refers to disturbance by plants. Both of these turbation processes can be grouped broadly under bioturbation. Faunalturbation and floralturbation both appear to have affected the site. Evidence that faunalturbation occurred was provided by the identification of animal burrows throughout the site deposits. Rodents are especially well-known for their potential destruction of archeological sites. Evidence of floralturbation was noted at the site in the form of root molds, buried tree stumps and possible tree fall. At the level of the present faunal analysis, though, this disturbance is relatively minor.
Disturbance by prehistoric humans, on the other hand, appears to have been a significant form of site disturbance, especially in Stratigraphic Unit III. This occurred primarily during the construction and use of large burned rock ovens in the Early and Late Archaic periods. Successive construction of prehistoric cooking pits probably mixed the deposits in some areas of the site. This, coupled with a decreased sedimentation rate exacerbated the mixing of Archaic through Late Prehistoric cultural materials in the upper 1-2 $\mathrm{m}$ of the site deposits, especially along the Valley Margin.

\section{Carnivore Activity}

The influence of carnivores in creating and modifying bone assemblages has received wide attention among Old World faunal analysts addressing questions of early hominid behavior, though less emphasis has been placed on canid destruction in studies of North American assemblages (Binford 1981; Haynes 1982; Morey and Klippel 1991; Schmitt and Juell 1994). Carnivores may create assemblages that at first glance appear to be the result of human activity or they can modify and displace bones that were deposited by humans (Binford 1981; Haynes 1980, 1982, 1983; Morey and Klippel 1991).

In chewing bones, carnivores tend to concentrate on long-bone epiphyses, producing distinct puncture marks. Binford (1981) also identified localized pitting and scoring from carnivore chewing in his experimental studies. Spiral fractures, bone chipping, and gastrointestinal pitting may also result. Analysis of the Wilson-Leonard sample showed no specific evidence that could be isolated as carnivore modification. Pitting observed on the sample was interpreted as resulting from geochemical dissolution, though the possibility remains that multiple processes could have yielded similar taphonomic signatures. Spiral fractures occurred in the sample, though based on the absence of other potential carnivore activity, these are believed to have resulted from marrow extraction by humans (see subsistence analysis). Overall, carnivores appear to have had minimal impact on creating or modifying the assemblage.

\section{Intrusive and Commensal Fauna}

In addition to the above variables, the question of fortuitous faunal association must be considered. Intrusive fauna are commonly defined as those that enter a site after deposition, while commensal fauna might include animals that became incorporated into the assemblage through natural death while living in the site area at the time of human occupation. In addition, commensal carnivores can deposit faunal remains onto archeological sites through scats (Andrews and Evans 1983; Schmitt and Juell 1994). The limited animal burrowing noted at the Wilson-Leonard site is insufficient to explain the number and taxonomic diversity of the small animals reported from the site. While 
problematic, the concept of commensal fauna also seems insufficient in explaining the presence of small animals at the site. As noted by Winkler (n.d., 1990) and discussed further below, the high frequency of burning on the sample strongly supports the notion that the small animal assemblage reflects human activity.

\section{Bone Density}

Differential preservation can also bias a faunal assemblage against certain taxa and elements. The bones of fish, birds, reptiles, and amphibians are more fragile than those of mammals and tend to preserve less readily. In addition, the skeletons of reptiles and amphibians contain proportionately more cartilage than do the skeletons of the other vertebrate classes due to their characteristic indeterminate growth. This further hinders their preservation and identification potential and may result in a bias against the presence of their remains at a site.

Detailed work by Lyman (1982b, 1984, 1985, 1993) and others (Kreutzer 1992) has shown that differential preservation of dense skeletal elements can bias faunal samples. Bone density was probably a significant biasing factor at the site. Artiodactyls for example, are represented in the 1/4-inch sample more commonly by dense bones such as carpals, tarsals, and phalanges than by more-fragile bones such as the cranium or scapula (Table 33-5). The recognition of this possible density-mediated attrition greatly complicates any interpretations of carcass transport and butchering. Differences noted in element representation may simply represent a preservation bias, rather than differential carcass transport by humans. This issue is addressed more fully elsewhere in this analysis.

\section{Animal Processing and Transport}

In using the Wilson-Leonard faunal sample to reconstruct prehistoric subsistence, it is important to acknowledge that certain animal resources may have been consumed away from the site, never entering the sample studied here. Entire animals may have been processed and consumed away from the site. Likewise, large animals such as bison or deer may have been killed and butchered elsewhere, with only selective parts returned to the site. It is also possible that some processing occurred at this site but that parts were transported off-site. The high degree of fragmentation of the sample, coupled with the possibility of density-mediated attrition (discussed above) makes the identification of differential processing and transport difficult to access.

\section{Bone Burning}

The issue of burned bones at the site is addressed from three perspectives: (1) burning as a bone-preserving mechanism, (2) burning as a bone-fragmentation and re-
TABLE 33-5

Artiodactyl Element Frequencies in the 1/4-inch Sample

\begin{tabular}{|c|c|}
\hline Element & NISP \\
\hline \multicolumn{2}{|l|}{ Skull (Excluding teeth) (Total=22; 4.9\% NISP) } \\
\hline Cranial fragment & 5 \\
\hline Antler & 9 \\
\hline Mandible & 8 \\
\hline Teeth (14\% NISP): & 63 \\
\hline \multicolumn{2}{|l|}{ Vertebral Column (Total=5; 1.1\% NISP) } \\
\hline Cervical vertebra & 1 \\
\hline Axis & 1 \\
\hline Thoracic vertebra & 1 \\
\hline Lumbar vertebra & 2 \\
\hline Pelvis (1.1\% NISP) & 5 \\
\hline Scapula $(0.4 \%$ NISP $)$ & 2 \\
\hline \multicolumn{2}{|l|}{ Long Bones (Total=168; 37.1\% NISP) } \\
\hline Humerus & 13 \\
\hline Radius & 13 \\
\hline Ulna & 8 \\
\hline Fused 3rd and 4th metacarpal & 15 \\
\hline Femur & 7 \\
\hline Tibia & 19 \\
\hline Fibula & 1 \\
\hline Metapodial indeterminate & 34 \\
\hline Fused 3rd and 4th metatarsal & 58 \\
\hline Phalanges and Paradigits (17\% NISP) & 76 \\
\hline \multicolumn{2}{|l|}{ Podials (Total $=89 ; 20 \%$ NISP) } \\
\hline Carpals & 28 \\
\hline Tarsals & 61 \\
\hline \multicolumn{2}{|l|}{ Sesamoids (Total=22; $4.9 \%$ NISP) } \\
\hline Sesamoid indeterminate & 1 \\
\hline Proximal sesamoid & 17 \\
\hline Proximal abaxial sesamoid & 3 \\
\hline Patella & 1 \\
\hline Total: & 452 \\
\hline $\begin{array}{l}\text { Phalanx, Podial and Sesamoid Total ( } 41 \% \\
\text { NISP) }\end{array}$ & 187 \\
\hline $\begin{array}{l}\text { Skull, Vertebrae, Pelvis, Scapula Total }(7.5 \% \\
\text { NISP) }\end{array}$ & 34 \\
\hline \multicolumn{2}{|c|}{$\begin{array}{l}\text { *Taxa include Odocoileus sp., cf. Odocoileus sp., Antilocapra } \\
\text { Odocoileus genus indeterminate, and cf. Antilocapra/Odocoileus } \\
\text { genus indeterminate. Only three pronghorn elements were } \\
\text { identified from the site; thus, most elements probably represent deer } \\
\text { (Odocoileus sp.). }\end{array}$} \\
\hline
\end{tabular}

ducing agent, and (3) burning as a reflection of human activity. Other researchers have noted that the burning of bones may affect their preservation potential (Buikstra and Swegle 1989:248; Gilchrist and Mytum 1986; Knight 1985). Burning may render certain bones less susceptible to weathering and postburial chemical degradation (Gilchrist and Mytum 1986:30). Gilchrist and Mytum (1986:30) describe an assemblage from acidic soils of gravel and clay in which only burned bones were preserved. Thus, at sites with marginal or reduced preservation, the burned sample may 
be relatively better preserved (Buikstra and Swegle 1989:248).

Gilchrist and Mytum (1986:30) and Knight (1985:82) present conflicting accounts of the direct processes that render burned bones less susceptible to weathering and degradation. According to Gilchrist and Mytum (1985:30),

The major components of bone are the protein collagen, and a mineral - hydroxyapatite in microcrystalline form. Strength and durability are provided by the organic matter and rigidity by the mineral. Although the organic content of bone can be completely destroyed by prolonged heating, incomplete calcination can fortify the bone against other agents of destruction. Before complete calcination occurs, the organic matter chars, but it remains, filling the pores of the bone, and thus cementing the mineral components together. Once carbonized, the organic matter remains stable and resistant to chemical change encountered in the soil.

Knight (1985:82), on the other hand, viewed the removal of bone organics as the contributing factor in burned bone preservation:

Completely calcined bone is preserved for long periods of time in acidic soils because of the chemical and microstructural changes that take place during incineration. The relationship between the organic and inorganic components of bone is critical to its decomposition. Recent work by White and Hannus (1983) strongly suggests that the microbial decomposition of collagen initiates the reactions necessary for the destruction of hydroxyapatite. Because completely calcined bone contains no collagen the initial reactions of bone decomposition do not take place, and preservation potential is increased.

Winkler's (n.d.:13-15, 1990:203-204) previous analyses of the Wilson-Leonard fine-screen fraction show that bone burning was a significant taphonomic factor affecting the small animal sample. She notes that the majority of her sample (89\%) from the upper 16 levels of the site was unburned, while most $(81 \%)$ of the lower material was burned (Winkler 1990:203). The higher frequency of burned bones from the lower levels suggests differential preservation in favor of burned bones (Winkler 1990:203).

Of the 21,867 specimens from the $1 / 4$-inch sample, 8,686 (40\%) were burned. From the 1/8-inch sample, 15,041 specimens (39\%) were burned. These are remarkably similar results. Burned bone frequencies by cultural period are summarized in Table 33-6. These data show a general trend of greater percentages of burned bones in lower portions of the site, similar to Winkler's (n.d., 1990) data discussed above. Fifty-five percent of the 1/4-inch Paleoindian sample (all components) is burned, while $25.4 \%$ of the bones from com- bined Archaic and Late Prehistoric components are burned. The difference for the 1/8-inch sample is even more dramatic. There, $64.7 \%$ of the Paleoindian sample (combined components) is burned, while $21.2 \%$ of the faunal sample from the combined Archaic through Late Prehistoric components is burned. Both data sets, in conjunction with Winkler's and Balinsky's (see Chapter 35) data support the notion of preservation bias at the site through time in favor of burned bones.

While burning may yield bones less susceptible to decay in certain environments, burning can also lead to a great deal of bone fragmentation. At some sites, burning may represent a major bone reducing force, with the burned bones being less identifiable than the nonburned sample. Overall, the biases produced by burning may inflate (through differential burned bone preservation) or decrease (through fragmentation) counts for certain taxa or body parts (Knight 1985) and should be considered in reconstructing past subsistence patterns.

Spiess (1987:16) noted that while calcined bones (burned white) are more resistant to bacterial action and contact with groundwater acid, they are less resistant to stress than are unburned bones and commonly break into very small fragments. Spennemann and Colley (1989:57) suggested that much of the fragmentation of burned bones may result from recovery methods. Buikstra and Swegle (1989:248) additionally commented that zooarcheologists commonly encounter "disproportionately large numbers of burned fragments in counts of unidentifiable faunal remains."

Burned bones from the Wilson-Leonard site are similarly fragmented. Of the burned $1 / 4$-inch vertebrate sample, $71 \%(n=6,199)$ consists of small fragments unidentifiable to the taxonomic level of class. Only 25 burned bones from the 1/4-inch fraction were unbroken. In the 1/8-inch burned sample, $62 \%(\mathrm{n}=9,321)$ was unidentifiable fragments. Only 38 specimens $(0.25 \%)$ in the burned $1 / 8$-inch sample were unbroken. Overall, this suggests that while serving as a preserving mechanism in one sense, burning is also associated with a high degree of bone fragmentation at the site.

The important question remains, however, what agent caused the bones to burn? Possible causes are burning by humans or natural fires. At least seven burned trees have been identified in the site deposits (see Chapters 26 and 40), and these may represent natural fires. Various kinds of fireplaces, in turn, are common archeological features at the site, thus burning could reflect human activity. A further discussion of the burned bone assemblage is presented here in an attempt to determine if it reflects human or nonhuman behavior.

Buikstra and Swegle (1989) conducted experiments to help reconstruct bone condition (fleshed, green, or dry) at the time of burning. Knowing whether the bones were fresh or dry could provide insight into how and when they were burned. Fleshed bones still contain flesh; green bone is recently defleshed or still fresh; while dry bone has lost the 
TABLE 33-6

Burned Bone by Cultural Period

\begin{tabular}{|c|c|c|c|}
\hline & Period Totals & Burned Totals & $\%$ of Period Burned \\
\hline $\begin{array}{l}\text { 1/4-inch Burned Bone: } \\
\text { Unassigned }\end{array}$ & 214 & 50 & 23.4 \\
\hline Paleoindian & 957 & 701 & 73.2 \\
\hline Early Paleoindian & 3,805 & 827 & 21.7 \\
\hline Late Paleoindian & 5,050 & 3,852 & 76.3 \\
\hline Late Paleoindian/Early Archaic & 768 & 439 & 57.2 \\
\hline Archaic & 153 & 30 & 19.6 \\
\hline Early Archaic & 1,764 & 603 & 34.2 \\
\hline Early/Middle Archaic & 794 & 129 & 16.2 \\
\hline Middle Archaic & 647 & 120 & 18.5 \\
\hline Middle/Late Archaic & 913 & 163 & 17.9 \\
\hline Late Archaic & 3,357 & 756 & 22.5 \\
\hline Archaic/Late Prehistoric & 748 & 204 & 27.3 \\
\hline Late Archaic/Late Prehistoric & 1,870 & 609 & 32.6 \\
\hline Late Prehistoric & 827 & 203 & 24.5 \\
\hline Totals: & 21,867 & 8,686 & \\
\hline 1/8-inch Burned Bone: & & & \\
\hline Unassigned & 355 & 49 & 13.8 \\
\hline Paleoindian & 2,065 & 1,243 & 60.2 \\
\hline Early Paleoindian & 1,870 & 902 & 48.2 \\
\hline Late Paleoindian & 8,669 & 6,465 & 74.6 \\
\hline Late Paleoindian/Early Archaic & 3,210 & 1,619 & 50.4 \\
\hline Archaic & 329 & 130 & 39.5 \\
\hline Early Archaic & 4,765 & 1,482 & 31.1 \\
\hline Early/Middle Archaic & 1,176 & 190 & 16.2 \\
\hline Middle Archaic & 3,940 & 488 & 12.4 \\
\hline Middle/Late Archaic & 2,942 & 305 & 10.4 \\
\hline Late Archaic & 6,145 & 1,039 & 16.9 \\
\hline Late Archaic/Late Prehistoric & 3,152 & 1,129 & 35.8 \\
\hline Totals: & 38,618 & 15,041 & \\
\hline
\end{tabular}

majority of its collagen. Factors considered in identifying original bone condition include burned bone color and fracture patterns. Their study showed in part that burned dry bone fails to achieve a wide range of colors and typically shows a tan surface with gray to white areas underneath (Buikstra and Swegle 1989:256). Bones that retain a high degree of collagen, including fleshed and defleshed bones, achieve a broader range of colors (white, blue, gray) when fired at high temperatures.

Few bones from the site appear to have been burned dry. The majority of the sample shows the range of colors (blues and whites) typical of bone that contains a high degree of collagen when it is burned. This suggests the bone was burned relatively shortly after the death of the animal and not after the bone had lost the majority of its organic collagen matrix. Shipman et al. (1984:323) suggests that grass and savanna fires can be eliminated altogether as a cause of noticeably burned bone. These fires produce surface temperatures greater than $65^{\circ} \mathrm{C}$ for a period of less than $10 \mathrm{~min}$ utes (Stinson and Wright 1969). A bone temperature range of $440-800^{\circ} \mathrm{C}$ is required for bone to reach the white and blue colors typical of the Wilson-Leonard sample (Shipman et al. 1984:313; Stage IV). These temperatures can, however, be reached by forest fires or human campfires (Shipman et al. 1984:308, 323).

Since evidence of forest fire was restricted primarily to Stratigraphic Units IIIb and the II/I contact, and since burned bone was noted throughout all time periods at the site (see Table 33-6), it seems likely that burned bone from the site resulted primarily from prehistoric human behavior, rather than natural fires. This further supports the hypothesis that the small animal assemblage from the site, which is highly burned (Winkler 1990:203), reflects human food refuse. It is unlikely that the burned bone resulted directly from cooking, since this extensive burning would have yielded any meat adhering the bone virtually inedible. It is more likely that the bones were either accidentally burned in cultural fires or were burned in hearths as refuse.

\section{Conclusions}

Taphonomic analysis shows that the ratio of identifiable bones is greatly modified by fragmentation and geophysical dissolution in the Wilson-Leonard sample. Heavy chemical degradation eliminated the applicability of Behrensmeyer's weathering stages for understanding site 
formation processes. Rootlet etching probably played only a very minor role in the degradation of the sample. The majority of the site formed under a low-energy sedimentation regime, therefore water transport did not significantly bias the sample. Possible exceptions to this are the gravel lenses in stratigraphic Unit I, which represent higher-energy sedimentary environments. The bone itself shows no significant evidence of abrasion and rounding typical of water-transported assemblages. Rodent gnawing was a relatively minor form of bone reduction at the site. Bioturbation was not a major source of disturbance at the site, though the prehistoric construction of burned rock cooking features in the upper levels did create significant disturbance in affected areas. No specific evidence of carnivore scavenging or scat deposition was identified, though evidence could have been masked by further postdepositional degradation. Analysis of the burned bone suggests that burning served both to differentially preserve and fragment the sample. Evidence indicates that burned bone was probably produced by human activity rather than natural fires. This also supports the idea that the small animal component at the site represents food refuse and not intrusive or commensal animals.

\section{SUBSISTENCE ANALYSIS}

The term subsistence is used to refer to a general lifeway including the collecting, processing, and consumption of food items. Common questions raised by archeologists about a past people's subsistence include what taxa were consumed? Where were they collected? Which parts were consumed and by whom? When and where did these various activities take place? More narrowly, subsistence reconstruction attempts to identify the exact nature of what was consumed, that is, the past diet.

The objective of this section is to evaluate the role of animals from the 1/4-inch and 1/8-inch samples in human subsistence at the Wilson-Leonard site. Emphasis is placed on (1) identifying taxa that potentially contributed to the diet of the site's occupants; (2) reconstructing prehistoric human hunting patterns represented at the Wilson-Leonard site; and (3) identifying how the animal remains were processed and modified by humans.

The primary step in subsistence analysis and diet reconstruction is taxa identification and quantification. As described in the methods section, emphasis is placed on NISP frequencies in characterizing the sample. Here NISP is used to mean the number of specimens assigned to a given taxonomic category. Taxa from the site and their relative frequencies are summarized below and in Tables 33-7 through 33-10. Also see Table 33-2 for a listing of which strata were used for cultural assignments.

The reconstruction of human hunting patterns focuses on several issues. What taxa appear to have contributed significantly to the diet or were commonly hunted? What habitats were used to procure animal food resources? Were animals of a certain age preferentially harvested? Finally, during what seasons were certain animals hunted? In addressing animal processing, emphasis is placed on element and butchery reconstruction and marrow and grease production (Binford 1981:87-181; Lintz 1976:87-88; Lyman 1987; Peale 1978; Vehik 1977).

\section{Taxa Recovered}

\section{1/4-inch Sample}

A total of 21,867 complete or fragmented bones, teeth, and antler fragments was analyzed from the 1/4-inch faunal sample (see Tables 33-7 and 33-9). Specimens identifiable minimally to the taxonomic level of order comprise only $12.1 \%$ $(n=2,637)$ of the total sample. At least 21 species are reflected in the 1/4-inch sample (excluding a fossil shark tooth), representing 4 vertebrate classes. These classes include Osteichthyes (fish), Reptilia (reptiles), Aves (birds), and Mammalia (mammals). No amphibian bones were identified from the $1 / 4$-inch assemblage.

The 21 distinct taxa include indeterminate small fish, Sternotherus sp. (musk turtle), Terrapene sp. (box turtle), Trionyx sp. (softshell turtle), Colubridae (nonpoisonous snake), indeterminate large bird, Odontophorinae (New World quail), Lepus californicus (black-tailed jackrabbit), Sylvilagus sp. (cottontail rabbits), Sciurus sp. (tree squirrels), Geomys sp. (pocket gopher), Sigmodon hispidus (hispid cotton rat), Neotoma sp. (wood rats), Procyon lotor (raccoon), Mephitinae (skunks), Canis sp. (coyote/wolf/dog), Felis rufus (bobcat), Odocoileus sp. (deer), Antilocapra americana (pronghorn), Bison sp. (bison), and Equus sp. (horse).

Overall, the 1/4-inch sample is composed primarily of unidentified fragmented remains. Of the 21,867 elements analyzed, only $0.7 \%$ ( $n=146)$ were complete. Seventy-seven percent of the sample $(n=16,937)$ consists of small fragments unidentifiable to class. This high degree of fragmentation greatly hindered identification.

\section{1/8-inch Sample}

Of the analyzed 1/8-inch faunal sample (see Tables 33-8 and 33-10), most of the specimens were recovered from the Valley Floor $(93 \%, n=35,952)$. Of the remaining 2,666 specimens from the Valley Margin, 1,914 are simply unidentifiable fragments. Specimens identifiable minimally to the taxonomic level of order comprise only $19 \%(n=7,326)$ of the total sample. At least 25 species are represented in the 1/8inch sample (excluding a second fossil shark tooth), representing 5 vertebrate classes. These classes include Osteichthyes, Amphibia, Reptilia, Aves, and Mammalia. The 25 distinct taxa include Ictalurus sp. (catfish), Anura (toad/frog), Kinosternon sp. (mud turtle), Chrysemys sensu lato (water turtle), Trionyx sp. (softshell turtle), Colubridae 
TABLE 33-7

Common Name and NISP Counts of 1/4-inch Taxa

\begin{tabular}{|c|c|c|}
\hline Taxon & Common Name & Totals \\
\hline \multicolumn{3}{|l|}{ Class Indeterminate: } \\
\hline Vertebrata & Vertebrates & 15,309 \\
\hline Small vertebrate, class indeterminate & Small vertebrate & 1 \\
\hline Medium vertebrate, class indeterminate & Medium vertebrate & 3 \\
\hline Large vertebrate, class indeterminate & Large vertebrate & 13 \\
\hline Small/Medium Vertebrata & Small/medium-sized vertebrate & 442 \\
\hline Medium/Large Vertebrata & Medium/large vertebrate & 1,169 \\
\hline \multicolumn{3}{|l|}{ Class Chondrichthyes: } \\
\hline Chondrichthyes & Cartilaginous fish & 1 \\
\hline \multicolumn{3}{|l|}{ Class Osteichthyes: } \\
\hline Osteichthyes (Small) & Small bony fish & 2 \\
\hline Osteichthyes & Bony fish & 2 \\
\hline \multicolumn{3}{|l|}{ Class Reptilia: } \\
\hline Testudinata & Turtles & 129 \\
\hline cf. Testudinata & Turtles & 1 \\
\hline Kinosternidae & Mud and musk turtles & 13 \\
\hline Sternotherus sp. & Musk turtles & 2 \\
\hline Emydidae & Water and box turtles & 4 \\
\hline Terrapene sp. & Box turtles & 1 \\
\hline Trionyx sp. & Softshell turtle & 3 \\
\hline Serpentes & Snakes & 16 \\
\hline Colubridae & Colubrid snakes & 9 \\
\hline \multicolumn{3}{|l|}{ Class Aves: } \\
\hline cf. Aves (Medium) & Medium birds & 1 \\
\hline Aves (Large) & Large birds & 1 \\
\hline Aves & Birds & 1 \\
\hline Phasianidae & Turkeys, grouse, quails, etc. & 1 \\
\hline \multicolumn{3}{|l|}{ Class Mammalia: } \\
\hline Mammalia (Small) & Small mammal & 30 \\
\hline Mammalia (Small/Medium) & Small/medium-sized mammal & 9 \\
\hline Mammalia (Medium) & Medium-sized mammal & 100 \\
\hline Mammalia (Medium/Large) & Medium/large mammal & 3,197 \\
\hline Mammalia (Large) & Large mammal & 543 \\
\hline Mammalia (Large/Very large) & Large/very large mammal & 3 \\
\hline Mammalia (Very large) & Very large mammal & 30 \\
\hline Mammalia & Mammal & 2 \\
\hline Leporidae & Rabbits and hares & 70 \\
\hline cf. Leporidae & Rabbits and hares & 3 \\
\hline Lepus californicus & California jackrabbit & 19 \\
\hline Sylvilagus sp. & Cottontail rabbits & 41 \\
\hline cf. Sylvilagus sp. & Cottontail rabbits & 3 \\
\hline Rodentia (Small) & Small rodent & 2 \\
\hline Rodentia (Small/Medium) & Small/medium-sized rodent & 1 \\
\hline Rodentia (Medium) & Medium rodent & 2 \\
\hline Sciurus sp. & Tree squirrels & 2 \\
\hline Geomys sp. & Pocket gophers & 2 \\
\hline Sigmodon hispidus & Hispid cotton rat & 14 \\
\hline
\end{tabular}


Table 33-7, continued

\begin{tabular}{|c|c|c|}
\hline Taxon & Common Name & Totals \\
\hline cf. Sigmodon hispidus & Hispid cotton rat & 1 \\
\hline Neotoma sp. & Wood rats & 1 \\
\hline Carnivora & Carnivores & 25 \\
\hline Procyon lotor & Raccoon & 2 \\
\hline Mustelidae & Weasels and relatives & 4 \\
\hline cf. Canidae & Dogs and relatives & 1 \\
\hline Canis sp. & Coyote/wolf/dog & 23 \\
\hline cf. Canis sp. & Coyote/wolf/dog & 2 \\
\hline Felis rufus & Bobcat & 1 \\
\hline Artiodactyla & Even-toed ungulates & 106 \\
\hline Artiodactyla (Medium) & Medium even-toed ungulates & 7 \\
\hline Artiodactyla (Large) & Large even-toed ungulates & 5 \\
\hline Odocoileus sp. & Deer & 148 \\
\hline cf. Odocoileus sp. & Deer & 4 \\
\hline Antilocapra americana & Pronghorn antelope & 3 \\
\hline Antilocapra/Odocoileus & Pronghorn/deer & 299 \\
\hline cf. Antilocapra/Odocoileus & Pronghorn/deer & 2 \\
\hline Bison sp. & Bison & 32 \\
\hline cf. Bison & Bison & 3 \\
\hline Equus sp. & Horses and relatives & 1 \\
\hline Total: & & 21,867 \\
\hline
\end{tabular}

(nonpoisonous snakes), Viperidae (pitviper snakes), indeterminate small bird, indeterminate medium-sized bird, indeterminate large bird, Blarina sp. (shrew), Lepus californicus (black-tailed jackrabbit), Sylvilagus sp. (cottontail rabbits), Sciurus sp. (tree squirrels), cf. Spermophilus mexicanus (Mexican ground squirrel), Geomys sp. (pocket gopher), Sigmodon hispidus (hispid cotton rat), Neotoma sp. (wood rats), cf. Microtus sp., Ondatra zibethicus (muskrat), Procyon lotor (raccoon), Canis sp. (coyote/wolf/dog), Odocoileus sp. (deer), Antilocapra americana (pronghorn), and Bison sp. (bison).

Overall, the $1 / 8$-inch sample is composed primarily of unidentified fragmented remains. Of the 38,618 elements analyzed, only $0.64 \%(n=246)$ were complete. Sixty-eight percent of the sample $(n=26,253)$ consists of small fragments unidentifiable to class. As with the $1 / 4$-inch sample, this high degree of fragmentation greatly hindered identification. Both the 1/4-inch and 1/8-inch samples are characterized below in terms of taxa presence by vertebrate class.

\section{Comparison}

Species counts and fragmentation rates between the two samples are generally comparable. However, there is a major difference in terms of artiodactyl frequency. While 606 artiodactyl specimens were identified in the 1/4-inch sample, less than half that many were noted in the $1 / 8$-inch sample $(n=280)$. The use of $1 / 8$-inch screens suggests that their lower recovery rate from the TARL excavations was not the result of recovery method bias. The differences appear to result from the sampling of different activity areas at the site by the TxDOT and TARL excavations and possibly the smaller volume excavated by TARL.

\section{FISH}

Fish from the 1/4-inch sample were rare (see Tables 33-7 and 33-9). Only four vertebrae were identified (see Appendix 10), all from relatively small fish. The 1/8-inch sample yielded 27 fish specimens. This low frequency of fish is undoubtedly the result of archeological recovery methods. One specimen was identifiable as catfish (Ictalurus sp.). Thirty-seven percent $(n=10)$ of the $1 / 8$ inch fish sample is burned. Additional fish were recovered from the fine-screen fraction (see Chapter 35 and Appendix 8). The sparse fish remains from the $1 / 4$-inch and 1/8-inch samples are most likely a reflection of archeological recovery methods, as indicated by higher frequencies in the fine-screen sample.

\section{AMPHIBIANS}

No amphibians were identified from the $1 / 4$-inch sample. This large screen size generally biases against their recovery. Fourteen specimens were recovered from the $1 / 8$-inch sample, and additional examples were noted in the fine-screen 
TABLE 33-8

Common Name and NISP Counts of 1/8-inch Taxa

\begin{tabular}{|c|c|c|}
\hline Taxon & Common Name & Totals \\
\hline \multicolumn{3}{|l|}{ Class Indeterminate: } \\
\hline Vertebrata & Vertebrates & 26,253 \\
\hline Micro vertebrate, class indeterminate & Micro vertebrate & 2 \\
\hline Small vertebrate, class indeterminate & Small vertebrate & 74 \\
\hline Medium vertebrate, class indeterminate & Medium vertebrate & 27 \\
\hline Small/Medium Vertebrata & Small/medium-sized vertebrate & 4,581 \\
\hline Medium/Large Vertebrata & Medium/large vertebrate & 702 \\
\hline \multicolumn{3}{|l|}{ Class Chondrichthyes: } \\
\hline Chondrichthyes & Cartilaginous fish & 1 \\
\hline \multicolumn{3}{|l|}{ Class Osteichthyes: } \\
\hline Osteichthyes (Small) & Small bony fish & 24 \\
\hline Osteichthyes & Bony fish & 2 \\
\hline Ictalurus sp. & Catfish & 1 \\
\hline \multicolumn{3}{|l|}{ Class Amphibia: } \\
\hline Anura & Toads and frogs & 14 \\
\hline \multicolumn{3}{|l|}{ Class Reptilia: } \\
\hline Testudinata & Turtles & 313 \\
\hline Kinosternidae & Mud and musk turtles & 7 \\
\hline Kinosternon sp. & Mud turtles & 2 \\
\hline Emydidae & Water and box turtles & 15 \\
\hline Chrysemys sensu lato & Painted turtles/cooters/sliders & 2 \\
\hline Trionyx sp. & Softshell turtle & 1 \\
\hline Squamata & Lizards and snakes & 9 \\
\hline Serpentes & Snakes & 127 \\
\hline Colubridae & Colubrid snakes & 94 \\
\hline Viperidae & Pitviper snakes & 14 \\
\hline \multicolumn{3}{|l|}{ Class Aves: } \\
\hline Aves (Small) & Small birds & 1 \\
\hline Aves (Medium) & Medium birds & 3 \\
\hline Aves (Large) & Large birds & 2 \\
\hline \multicolumn{3}{|l|}{ Class Mammalia: } \\
\hline Mammalia (Micro) & Micro-mammal & 100 \\
\hline Mammalia (Small) & Small mammal & 384 \\
\hline Mammalia (Small/Medium) & Small/medium-sized mammal & 57 \\
\hline Mammalia (Medium) & Medium-sized mammal & 150 \\
\hline Mammalia (Medium/Large) & Medium/large mammal & 3,934 \\
\hline Mammalia (Large) & Large mammal & 368 \\
\hline Mammalia (Large/Very large) & Large/very large mammal & 3 \\
\hline Mammalia (Very large) & Very large mammal & 11 \\
\hline Blarina sp. & Shrews & 2 \\
\hline Leporidae & Rabbits and hares & 291 \\
\hline cf. Leporidae & Rabbits and hares & 11 \\
\hline Lepus californicus & California jackrabbit & 116 \\
\hline cf. Lepus californicus & California jackrabbit & 5 \\
\hline Sylvilagus sp. & Cottontail rabbits & 347 \\
\hline cf. Sylvilagus sp. & Cottontail rabbits & 5 \\
\hline Rodentia & Rodents & 1 \\
\hline
\end{tabular}


Table 33-8, continued

\begin{tabular}{|c|c|c|}
\hline Taxon & Common Name & Totals \\
\hline Rodentia (Small) & Small rodent & 15 \\
\hline Rodentia (Small/Medium) & Small/medium-sized rodent & 4 \\
\hline Rodentia (Medium) & Medium rodent & 42 \\
\hline Sciurus sp. & Tree squirrels & 1 \\
\hline cf. Spermophilus mexicanus & Mexican ground squirrel & 1 \\
\hline Geomys sp. & Pocket gophers & 101 \\
\hline cf. Geomys sp. & Pocket gophers & 2 \\
\hline Cricetidae & New World rats and mice & 2 \\
\hline Cricetidae (Small) & Small cricetid rodent & 5 \\
\hline Cricetidae (Medium) & Medium cricetid rodent & 7 \\
\hline Sigmodon hispidus & Hispid cotton rat & 22 \\
\hline cf. Sigmodon hispidus & Hispid cotton rat & 1 \\
\hline Neotoma sp. & Wood rats & 46 \\
\hline cf. Microtus sp. & Voles & 2 \\
\hline Ondatra zibethicus & Muskrat & 1 \\
\hline Carnivora & Carnivores & 17 \\
\hline Procyon lotor & Raccoon & 1 \\
\hline cf. Procyon lotor & Raccoon & 1 \\
\hline Canis sp. & Coyote/wolf/dog & 4 \\
\hline cf. Canis sp. & Coyote/wolf/dog & 2 \\
\hline Artiodactyla & Even-toed ungulates & 50 \\
\hline Odocoileus sp. & Deer & 153 \\
\hline cf. Odocoileus sp. & Deer & 3 \\
\hline Antilocapra americana & Pronghorn antelope & 5 \\
\hline Antilocapra/Odocoileus & Pronghorn/deer & 72 \\
\hline Bison sp. & Bison & 2 \\
\hline Total: & & 38,618 \\
\hline
\end{tabular}

fraction (see Chapter 35). None of the specimens from the $1 / 8$-inch sample is burned. The limited taphonomy work that has been conducted on frogs and toads suggests they can enter archeological sites intrusively if they become trapped in pits or similar features (Shaffer and Neely 1992; Whyte 1988, 1991). One specimen was recovered from Burned Rock Midden 1 and a second specimen was noted in Feature 231. Exactly how the anurans entered the site, however, remains unclear.

\section{REPTILES}

Reptiles in the 1/4-inch sample $(\mathrm{N}=178)$ are represented by turtles $(n=153)$ and snakes $(n=25)$. As with fish, reptiles were likely biased against by recovery methods. Turtles from the 1/4-inch sample include musk turtle (Sternotherus sp.), box turtle (Terrapene sp.), and softshell turtle (Trionyx sp.). These reflect both aquatic and terrestrial habitats. Of the snakes, only the nonpoisonous family Colubridae was identified. Roughly $42 \%$ of the $1 / 4$-inch reptile sample is burned.
Reptiles are more frequent in the 1/8-inch sample $(\mathrm{N}=584)$ and are represented by turtles $(n=340)$, snakes $(n=235)$ and fragmented vertebrae indistinguishable between snakes and lizards ( $\mathrm{n}=9$ ). Taxa include mud turtle (Kinosternon $\mathrm{sp}$.), water turtle (Chrysemys sensu lato), softshell turtle (Trionyx sp.), as well as both viperid and colubrid snakes. These animals reflect both aquatic and terrestrial habitats. Roughly $31 \%$ $(n=179)$ of the 1/8-inch reptile sample is burned. Additional reptiles were identified in the fine-screen fraction (see Chapter 35 and Appendix 8).

\section{BIRDS}

Birds are also uncommon in the $1 / 4$-inch sample. One quail bone was identified, and three additional bird bones were noted (see Appendix 8). Three of these are burned. While not identified beyond class, six bird bones were recovered from the 1/8-inch sample, three of which are burned. As discussed in the taphonomy section, the fragile nature of bird bones renders them susceptible to extensive postdepositional fragmentation and degradation. Even in 
TABLE 33-9

Taxa by Cultural Period and Major Vertebrate Group from the 1/4-inch Recovery

\begin{tabular}{|c|c|c|c|}
\hline Period & Vertebrate Group & Totals & Percent \\
\hline Unassigned & Unidentified & 146 & 0.668 \\
\hline Unassigned & Turtle & 2 & 0.009 \\
\hline Unassigned & Unidentified Mammal & 46 & 0.210 \\
\hline Unassigned & Leporid & 2 & 0.009 \\
\hline Unassigned & Artiodactyl & 18 & 0.082 \\
\hline Paleoindian & Unidentified & 810 & 3.704 \\
\hline Paleoindian & Fish & 1 & 0.004 \\
\hline Paleoindian & Turtle & 3 & 0.014 \\
\hline Paleoindian & Unidentified Mammal & 131 & 0.599 \\
\hline Paleoindian & Rodent & 1 & 0.004 \\
\hline Paleoindian & Leporid & 6 & 0.027 \\
\hline Paleoindian & Carnivore & 1 & 0.004 \\
\hline Paleoindian & Artiodactyl & 1 & 0.004 \\
\hline Paleoindian & Bison/Bison-sized & 3 & 0.014 \\
\hline Early Paleoindian & Unidentified & 3,258 & 14.899 \\
\hline Early Paleoindian & Fish & 2 & 0.009 \\
\hline Early Paleoindian & Turtle & 5 & 0.023 \\
\hline Early Paleoindian & Snake & 8 & 0.037 \\
\hline Early Paleoindian & Bird & 1 & 0.004 \\
\hline Early Paleoindian & Unidentified Mammal & 441 & 1.880 \\
\hline Early Paleoindian & Rodent & 2 & 0.009 \\
\hline Early Paleoindian & Leporid & 25 & 0.114 \\
\hline Early Paleoindian & Carnivore & 12 & 0.055 \\
\hline Early Paleoindian & Artiodactyl & 9 & 0.041 \\
\hline Early Paleoindian & Horse & 1 & 0.004 \\
\hline Early Paleoindian & Bison/Bison-sized & 41 & 0.184 \\
\hline Late Paleoindian & Unidentified & 4,090 & 18.704 \\
\hline Late Paleoindian & Shark & 1 & 0.004 \\
\hline Late Paleoindian & Turtle & 28 & 0.128 \\
\hline Late Paleoindian & Bird & 2 & 0.009 \\
\hline Late Paleoindian & Unidentified Mammal & 832 & 3.805 \\
\hline Late Paleoindian & Rodent & 1 & 0.004 \\
\hline Late Paleoindian & Leporid & 30 & 0.137 \\
\hline Late Paleoindian & Carnivore & 13 & 0.059 \\
\hline Late Paleoindian & Artiodactyl & 45 & 0.206 \\
\hline Late Paleoindian & Bison/Bison-sized & 8 & 0.037 \\
\hline Late Paleoindian/Early Archaic & Unidentified & 552 & 2.524 \\
\hline Late Paleoindian/Early Archaic & Turtle & 12 & 0.055 \\
\hline Late Paleoindian/Early Archaic & Unidentified Mammal & 182 & 0.832 \\
\hline Late Paleoindian/Early Archaic & Rodent & 1 & 0.004 \\
\hline Late Paleoindian/Early Archaic & Leporid & 12 & 0.055 \\
\hline Late Paleoindian/Early Archaic & Artiodactyl & 9 & 0.041 \\
\hline Archaic & Unidentified & 95 & 0.434 \\
\hline Archaic & Turtle & 4 & 0.018 \\
\hline Archaic & Snake & 1 & 0.004 \\
\hline Archaic & Unidentified Mammal & 37 & 0.169 \\
\hline Archaic & Leporid & 1 & 0.004 \\
\hline Archaic & Artiodactyl & 15 & 0.069 \\
\hline Early Archaic & Unidentified & 1,238 & 5.661 \\
\hline Early Archaic & Turtle & 29 & 0.133 \\
\hline Early Archaic & Snake & 5 & 0.023 \\
\hline Early Archaic & Unidentified Mammal & 426 & 1.948 \\
\hline Early Archaic & Rodent & 6 & 0.027 \\
\hline Early Archaic & Leporid & 16 & 0.073 \\
\hline Early Archaic & Carnivore & 8 & 0.037 \\
\hline
\end{tabular}


Table 33-9, continued

\begin{tabular}{|c|c|c|c|}
\hline Period & Vertebrate Group & Totals & Percent \\
\hline Early Archaic & Artiodactyl & 36 & 0.165 \\
\hline Early/Middle Archaic & Unidentified & 584 & 2.671 \\
\hline Early/Middle Archaic & Turtle & 13 & 0.059 \\
\hline Early/Middle Archaic & Bird & 1 & 0.004 \\
\hline Early/Middle Archaic & Unidentified Mammal & 145 & 0.663 \\
\hline Early/Middle Archaic & Rodent & 3 & 0.014 \\
\hline Early/Middle Archaic & Leporid & 8 & 0.037 \\
\hline Early/Middle Archaic & Carnivore & 5 & 0.023 \\
\hline Early/Middle Archaic & Artiodactyl & 35 & 0.160 \\
\hline Middle Archaic & Unidentified & 459 & 2.099 \\
\hline Middle Archaic & Turtle & 14 & 0.064 \\
\hline Middle Archaic & Snake & 2 & 0.009 \\
\hline Middle Archaic & Unidentified Mammal & 133 & 0.608 \\
\hline Middle Archaic & Leporid & 13 & 0.059 \\
\hline Middle Archaic & Carnivore & 2 & 0.009 \\
\hline Middle Archaic & Artiodactyl & 24 & 0.110 \\
\hline Middle/Late Archaic & Unidentified & 669 & 3.059 \\
\hline Middle/Late Archaic & Turtle & 8 & 0.037 \\
\hline Middle/Late Archaic & Snake & 2 & 0.009 \\
\hline Middle/Late Archaic & Unidentified Mammal & 163 & 0.745 \\
\hline Middle/Late Archaic & Rodent & 6 & 0.027 \\
\hline Middle/Late Archaic & Leporid & 8 & 0.037 \\
\hline Middle/Late Archaic & Carnivore & 1 & 0.004 \\
\hline Middle/Late Archaic & Artiodactyl & 55 & 0.252 \\
\hline Middle/Late Archaic & Bison/Bison-sized & 1 & 0.004 \\
\hline Late Archaic & Unidentified & 2,481 & 11.346 \\
\hline Late Archaic & Fish & 1 & 0.004 \\
\hline Late Archaic & Turtle & 21 & 0.096 \\
\hline Late Archaic & Snake & 5 & 0.023 \\
\hline Late Archaic & Unidentified Mammal & 638 & 2.918 \\
\hline Late Archaic & Rodent & 5 & 0.023 \\
\hline Late Archaic & Leporid & 14 & 0.064 \\
\hline Late Archaic & Carnivore & 8 & 0.037 \\
\hline Late Archaic & Artiodactyl & 172 & 0.787 \\
\hline Late Archaic & Bison/Bison-sized & 12 & 0.055 \\
\hline Archaic/Late Prehistoric & Unidentified & 573 & 2.620 \\
\hline Archaic/Late Prehistoric & Turtle & 4 & 0.018 \\
\hline Archaic/Late Prehistoric & Snake & 1 & 0.004 \\
\hline Archaic/Late Prehistoric & Unidentified Mammal & 132 & 0.604 \\
\hline Archaic/Late Prehistoric & Artiodactyl & 38 & 0.174 \\
\hline Late Archaic/Late Prehistoric & Unidentified & 1,393 & 6.370 \\
\hline Late Archaic/Late Prehistoric & Turtle & 10 & 0.046 \\
\hline Late Archaic/Late Prehistoric & Snake & 1 & 0.004 \\
\hline Late Archaic/Late Prehistoric & Unidentified Mammal & 365 & 1.669 \\
\hline Late Archaic/Late Prehistoric & Leporid & 1 & 0.004 \\
\hline Late Archaic/Late Prehistoric & Carnivore & 8 & 0.037 \\
\hline Late Archaic/Late Prehistoric & Artiodactyl & 92 & 0.421 \\
\hline Late Prehistoric & Unidentified & 589 & 2.694 \\
\hline Late Prehistoric & Unidentified Mammal & 213 & 0.974 \\
\hline Late Prehistoric & Artiodactyl & 25 & 0.114 \\
\hline Total: & & 21,867 & \\
\hline
\end{tabular}

the fine-screen fraction, bird bones are relatively rare (see Chapter 35). In fact, eggshells appear to be more common in the site than bird bones (see Chapters 35 and 36). Birds likely served as a food source for prehistoric Central Texans, though their dietary contribution remains unclear. Taphonomic variables make it difficult to assess how extensive birds were used, though because of their rarity, their mere presence in a Central Texas archeological site is significant. 
TABLE $33-10$

Taxa by Cultural Period and Major Vertebrate Group from the 1/8-inch Recovery

\begin{tabular}{|c|c|c|c|}
\hline Period & Group & Totals & Percent \\
\hline Unassigned & Unidentified & 240 & 0.621 \\
\hline Unassigned & Unidentified Mammal & 103 & 0.267 \\
\hline Unassigned & Leporid & 2 & 0.005 \\
\hline Unassigned & Artiodactyl & 10 & 0.026 \\
\hline Paleoindian & Unidentified & 1,823 & 4.721 \\
\hline Paleoindian & Shark & 1 & 0.003 \\
\hline Paleoindian & Turtle & 21 & 0.054 \\
\hline Paleoindian & Snake & 21 & 0.054 \\
\hline Paleoindian & Bird & 2 & 0.005 \\
\hline Paleoindian & Unidentified Mammal & 142 & 0.368 \\
\hline Paleoindian & Rodent & 16 & 0.041 \\
\hline Paleoindian & Leporid & 35 & 0.091 \\
\hline Paleoindian & Artiodactyl & 4 & 0.010 \\
\hline Early Paleoindian & Unidentified & 1,381 & 3.576 \\
\hline Early Paleoindian & Turtle & 13 & 0.034 \\
\hline Early Paleoindian & Snake & 3 & 0.008 \\
\hline Early Paleoindian & Unidentified Mammal & 397 & 1.028 \\
\hline Early Paleoindian & Rodent & 7 & 0.018 \\
\hline Early Paleoindian & Leporid & 64 & 0.166 \\
\hline Early Paleoindian & Bison/Bison-sized & 5 & 0.013 \\
\hline Late Paleoindian & Unidentified & 7,709 & 19.962 \\
\hline Late Paleoindian & Fish & 11 & 0.028 \\
\hline Late Paleoindian & Lizard/snake & 5 & 0.013 \\
\hline Late Paleoindian & Turtle & 47 & 0.122 \\
\hline Late Paleoindian & Snake & 30 & 0.078 \\
\hline Late Paleoindian & Bird & 1 & 0.003 \\
\hline Late Paleoindian & Unidentified Mammal & 574 & 1.486 \\
\hline Late Paleoindian & Insectivore & 2 & 0.005 \\
\hline Late Paleoindian & Rodent & 55 & 0.142 \\
\hline Late Paleoindian & Leporid & 223 & 0.577 \\
\hline Late Paleoindian & Carnivore & 4 & 0.010 \\
\hline Late Paleoindian & Artiodactyl & 6 & 0.015 \\
\hline Late Paleoindian & Bison/Bison-sized & 2 & 0.005 \\
\hline Late Paleoindian/Early Archaic & Unidentified & 2,808 & 7.271 \\
\hline Late Paleoindian/Early Archaic & Fish & 6 & 0.015 \\
\hline Late Paleoindian/Early Archaic & Frog/toad & 1 & 0.003 \\
\hline Late Paleoindian/Early Archaic & Lizard/snake & 1 & 0.003 \\
\hline Late Paleoindian/Early Archaic & Turtle & 29 & 0.075 \\
\hline Late Paleoindian/Early Archaic & Snake & 15 & 0.039 \\
\hline Late Paleoindian/Early Archaic & Unidentified Mammal & 247 & 0.640 \\
\hline Late Paleoindian/Early Archaic & Rodent & 21 & 0.054 \\
\hline Late Paleoindian/Early Archaic & Leporid & 75 & 0.194 \\
\hline Late Paleoindian/Early Archaic & Carnivore & 5 & 0.013 \\
\hline Late Paleoindian/Early Archaic & Artiodactyl & 2 & 0.005 \\
\hline Archaic & Unidentified & 299 & 0.774 \\
\hline Archaic & Fish & 1 & 0.003 \\
\hline Archaic & Frog/toad & 1 & 0.003 \\
\hline Archaic & Turtle & 6 & 0.015 \\
\hline Archaic & Snake & 2 & 0.005 \\
\hline Archaic & Unidentified Mammal & 16 & 0.041 \\
\hline Archaic & Leporid & 2 & 0.005 \\
\hline Archaic & Carnivore & 1 & 0.003 \\
\hline Archaic & Artiodactyl & 1 & 0.003 \\
\hline Early Archaic & Unidentified & 4,054 & 10.498 \\
\hline Early Archaic & Fish & 5 & 0.013 \\
\hline Early Archaic & Lizard/snake & 3 & 0.008 \\
\hline
\end{tabular}


Table 33-10, continued

\begin{tabular}{|c|c|c|c|}
\hline$\overline{\text { Period }}$ & Group & Totals & Percent \\
\hline Early Archaic & Turtle & 79 & 0.205 \\
\hline Early Archaic & Snake & 39 & 0.101 \\
\hline Early Archaic & Bird & 1 & 0.003 \\
\hline Early Archaic & Unidentified Mammal & 463 & 1.199 \\
\hline Early Archaic & Rodent & 33 & 0.085 \\
\hline Early Archaic & Leporid & 74 & 0.192 \\
\hline Early Archaic & Carnivore & 2 & 0.005 \\
\hline Early Archaic & Artiodactyl & 12 & 0.031 \\
\hline Early/Middle Archaic & Unidentified & 944 & 2.444 \\
\hline Early/Middle Archaic & Frog/toad & 7 & 0.018 \\
\hline Early/Middle Archaic & Turtle & 15 & 0.039 \\
\hline Early/Middle Archaic & Snake & 15 & 0.039 \\
\hline Early/Middle Archaic & Unidentified Mammal & 141 & 0.365 \\
\hline Early/Middle Archaic & Rodent & 12 & 0.031 \\
\hline Early/Middle Archaic & Leporid & 25 & 0.065 \\
\hline Early/Middle Archaic & Carnivore & 2 & 0.005 \\
\hline Early/Middle Archaic & Artiodactyl & 15 & 0.039 \\
\hline Middle Archaic & Unidentified & 3,111 & 8.056 \\
\hline Middle Archaic & Fish & 1 & 0.003 \\
\hline Middle Archaic & Frog/toad & 3 & 0.008 \\
\hline Middle Archaic & Turtle & 42 & 0.109 \\
\hline Middle Archaic & Snake & 46 & 0.119 \\
\hline Middle Archaic & Unidentified Mammal & 502 & 1.300 \\
\hline Middle Archaic & Rodent & 45 & 0.117 \\
\hline Middle Archaic & Leporid & 154 & 0.399 \\
\hline Middle Archaic & Carnivore & 4 & 0.010 \\
\hline Middle Archaic & Artiodactyl & 32 & 0.083 \\
\hline Middle/Late Archaic & Unidentified & 2,380 & 6.163 \\
\hline Middle/Late Archaic & Frog/toad & 1 & 0.003 \\
\hline Middle/Late Archaic & Turtle & 19 & 0.049 \\
\hline Middle/Late Archaic & Snake & 21 & 0.054 \\
\hline Middle/Late Archaic & Bird & 1 & 0.003 \\
\hline Middle/Late Archaic & Unidentified Mammal & 397 & 1.028 \\
\hline Middle/Late Archaic & Rodent & 27 & 0.070 \\
\hline Middle/Late Archaic & Leporid & 63 & 0.163 \\
\hline Middle/Late Archaic & Carnivore & 1 & 0.003 \\
\hline Middle/Late Archaic & Artiodactyl & 32 & 0.083 \\
\hline Late Archaic & Unidentified & 4,704 & 12.181 \\
\hline Late Archaic & Fish & 3 & 0.008 \\
\hline Late Archaic & Frog/toad & 1 & 0.003 \\
\hline Late Archaic & Turtle & 52 & 0.135 \\
\hline Late Archaic & Snake & 28 & 0.073 \\
\hline Late Archaic & Bird & 1 & 0.003 \\
\hline Late Archaic & Unidentified Mammal & 1,168 & 3.024 \\
\hline Late Archaic & Rodent & 31 & 0.080 \\
\hline Late Archaic & Leporid & 50 & 0.129 \\
\hline Late Archaic & Carnivore & 6 & 0.016 \\
\hline Late Archaic & Artiodactyl & 95 & 0.246 \\
\hline Late Archaic & Bison/Bison-sized & 6 & 0.016 \\
\hline Late Archaic/Late Prehistoric & Unidentified & 2,186 & 5.661 \\
\hline Late Archaic/Late Prehistoric & Turtle & 17 & 0.044 \\
\hline Late Archaic/Late Prehistoric & Snake & 15 & 0.039 \\
\hline Late Archaic/Late Prehistoric & Unidentified Mammal & 846 & 2.191 \\
\hline Late Archaic/Late Prehistoric & Rodent & 6 & 0.016 \\
\hline Late Archaic/Late Prehistoric & Leporid & 8 & 0.021 \\
\hline Late Archaic/Late Prehistoric & Artiodactyl & 74 & 0.192 \\
\hline Total: & & 38,618 & \\
\hline
\end{tabular}




\section{MAMMALS}

Mammals are much more common at the site and dominate the vertebrates from both the $1 / 4$-inch and $1 / 8$-inch samples. Twenty-two percent of the $1 / 4$-inch sample was identified as mammal $(n=4,743)$. In turn, mammals form $97 \%$ of the total 1/4-inch sample identifiable to class. Almost 30\% of the mammal sample is burned. Mammalian taxa include jackrabbit, cottontail rabbit, tree squirrel, pocket gopher, hispid cotton rat, woodrat, raccoon, skunk, canid, bobcat, pronghorn, deer, bison, and horse. Artiodactyls dominate the 1/4inch mammal assemblage.

Sixteen percent of the $1 / 8$-inch sample was identified as mammal $(n=6,347)$. Mammals form $91 \%$ of the total $1 / 8$-inch sample identifiable to class $(n=6,979)$. Almost $35 \%(n=2,175)$ of the mammal sample is burned. Mammalian taxa include shrew, jackrabbit, cottontail rabbit, tree squirrel, ground squirrel, pocket gopher, hispid cotton rat, woodrat, vole, muskrat, raccoon, canid, pronghorn, deer, and bison. Leporids (rabbits and hares) dominate the identifiable 1/8-inch mammal assemblage. This is in stark contrast to the artiodactyl dominated 1/4-inch sample.

\section{Hunting Patterns}

\section{Taxa Representation}

Overall, a diverse range of taxa is represented in the assemblage, though taxa counts for many genera are comparatively low. At least 21 species are reflected in the 1/4inch assemblage, with 25 in the $1 / 8$-inch sample. When the various classes of vertebrates are examined, it can be seen that mammals dominate. Artiodactyls dominate the 1/4-inch sample and leporids (rabbits and hares) dominate the 1/8inch sample.

\section{Habitats Exploited}

Many animal species have very specific habitat preferences. It may be possible, then, to infer habitat types based on the presence of certain species within a given faunal assemblage. Assuming that the recovered fauna was exploited by humans within the vicinity of the site, one may also infer that the associated habitats existed in the site area.

The identification of fish, musk turtle, water turtle, softshell turtle and muskrat from the Wilson-Leonard site (1/ 4-inch and 1/8-inch samples) suggests the exploitation of riverine environments (Table 33-11). This is not surprising given that the site is located on Brushy Creek. A riverine adaptation is also supported by further paleoenvironmental data from the site. Faunal procurement from forest/woodland and forest edge habitats is indicated by the presence of squirrel, raccoon, skunk, bobcat, and deer. Well-drained areas are reflected by the presence of pocket gopher and
TABLE 33-11

Habitats of Recovered Fauna

\begin{tabular}{|c|c|}
\hline Taxon & Habitat \\
\hline Fish & Riverine/aquatic \\
\hline Musk turtle & Riverine/aquatic \\
\hline Box turtle & Diverse terrestrial habitats \\
\hline Softshell turtle & Riverine/aquatic \\
\hline New World quail & $\begin{array}{l}\text { Grassland/scrubland/woodlands/brushy } \\
\text { areas }\end{array}$ \\
\hline Black-tailed jackrabbit & Dry scrublands \\
\hline Cottontail rabbit & Diverse terrestrial habitats \\
\hline Tree squirrel & Arboreal \\
\hline Pocket gopher & Subterranean/loose, sandy soil \\
\hline Ground squirrel & Brushy, grassy habitats \\
\hline Hispid cotton rat & $\begin{array}{l}\text { Well drained areas with dense ground } \\
\text { cover }\end{array}$ \\
\hline Wood rat & Diverse terrestrial habitats \\
\hline Muskrat & Riverine/aquatic \\
\hline Raccoon & Forest/forest edge \\
\hline Skunk & Woodlands/forest edge/open fields \\
\hline Canid & Diverse terrestrial habitats \\
\hline Bobcat & $\begin{array}{l}\text { Heavily wooded uplands and bottomland } \\
\text { forests }\end{array}$ \\
\hline Deer & Grassland/forest/forest edge \\
\hline Pronghorn & Grassland/scrubland/forest edge \\
\hline Bison & Grassland/scrubland/forest edge \\
\hline Horse & Grassland \\
\hline
\end{tabular}

hispid cotton rat. Pronghorn, bison, horse, and jackrabbit reflect the presence of grassland or scrubland areas. However, few pronghorn elements were recovered from the site (see Appendix 10), while bison was largely restricted to the Paleoindian period. Thus, grasslands appear to reflect only a minor portion of the exploited habitats. Forest, forest edge, and riverine/riparian environments seem to have been most commonly exploited.

\section{Deer Age Structure}

Tooth wear for deer from the 1/4-inch sample was grossly assessed to determine if certain age groups of these animals were hunted. Deer teeth were comparatively rare in the $1 / 8$ inch sample. Dental wear for deer was recorded as one of the following categories: slight or no wear (subadult), moderate wear (adult), and heavy wear (old adult). Specific chronometric age intervals were not assessed (Severinghaus 1949). Fifty-six deer teeth were recovered, 11 of which were fragments and could not be assessed for wear. Specimens showing moderate wear dominate the assemblage $(82.2 \% ; n=37)$, followed by slight wear $(11.1 \% ; n=5)$, and heavy wear $(6.7 \%$; $\mathrm{n}=3$ ). While the sample proved too small for detailed analysis, it does show that deer from all age groups (subadult, adult, and old adult) were killed. 
Bone fusion data were also broadly reviewed to see if they could provide age-related insight. Data for deer and pronghorn/deer indeterminate $(n=447)$ from the $1 / 4$-inch sample are summarized here. Long-bone portions showing fused epiphyses were considered adult, while unfused epiphyses reflect subadults. Specimens showing fused epiphyses $(n=52 ; 11.6 \%$ of total sample) dominate the assemblage, followed by unfused epiphyses $(n=20 ; 4.5 \%)$.

Comparative bone fusion data of deer from modern wildlife studies show that reconstructions of chronometric age intervals are problematic. Low nutrition levels in deer can delay epiphyseal fusion (Lewall and Cowan 1963), while different fusion rates occur between males and females (Purdue 1983a). Most deer elements, in fact, do not begin fusing until 20 months of age and continue fusing over a range of months (Purdue 1983a:1210). Overall, however, the fusion data for deer support the teeth wear data in that both adult and subadult deer were hunted by the Wilson-Leonard site's inhabitants.

\section{Bison Age Structure}

None of the bison or bison-sized bone from the 1/4-inch sample show unfused epiphyses suggestive of subadult individuals. Specimens showing fused epiphyses include the distal end of a left tibia (Bison sp.; Unit Igl/Isi; Early Paleoindian; Lot 30LL2a), the distal end of a right tibia ( $\mathrm{Bi}$ son sp.; Unit Isi//si-c; Paleoindian; Lot 28EE2d), and the distal end of a right humerus (Bison sp.; Unit IIIc; Late Archaic; Lot 36D). All of these specimens are suggestive of individuals at least four years old (Duffield 1973). An upper left M1 or M2 (Bison sp.) recovered from Unit Igl/Isi (Early Paleoindian; Lot 31MM1b) has an unformed root and slight wear, reflecting a young animal. A right mandible retaining M3 (Bison sp.; Unit Isi/Icl; Early Paleoindian; Lot 32OO1\&2a) falls within Frison and Reher's (1970) Age Group V, suggesting an animal between 4.5-5.5 years old. No bison or bisonsized bone from the $1 / 8$-inch sample yielded insightful age data.

\section{Seasonality}

Taxa identified from the site could have been available throughout the year. No specific indicators of seasonal occupation were observed. In Texas, turtles may be active throughout the year. While previously used by many archeologists as seasonal indicators, many turtles are now recognized as cold-tolerant and remain active year-round (Holman and Andrews 1994). An examination of deer teeth proved inconclusive in distinguishing between winter and summer occupation. By six months of age, mandibular tooth eruption for $\mathrm{Pm}_{2}$ through $\mathrm{M}_{1}$ is complete (Ramsey and Shult n.d.:2). All mandibular deer specimens recovered from the site exhibit at least this much eruption. Therefore, based on deer dental evidence, a seasonal distinction could not be made.
Bone fusion data also proved inconclusive as a seasonal indicator. Overall, no specific indicators of seasonal use of the site were observed in these samples.

Bison from the site also proved inconclusive as a seasonal indicator. As discussed above, no fusion or age data were available from the $1 / 8$-inch bison sample. The majority of bison from the 1/4-inch sample was at least four years of age and could not be used as a seasonal indicator. While a tooth from a relatively young bison was identified from the Early Paleoindian bone bed component (Unit Igl/Isi; Lot $31 \mathrm{MM} 1 \mathrm{~b}$ ), it is not clear if this maxillary tooth represents a first or second molar. Since these teeth have differing eruption sequences, a seasonal interpretation cannot be made.

\section{Animal Processing}

The high degree of sample fragmentation and lack of detailed primary contextual control (resulting from prehistoric human disturbance at the site) prevent a thorough spatial study of animal processing and deposition at the Wilson-Leonard site, though a few observations can be made. Fauna from archeological feature contexts are reported by taxon in Tables 33-12 and 33-13.

\section{Butchering Patterns}

Butchering is defined as the disarticulation of an animal carcass once the animal has been procured. The reconstruction of animal butchering usually focuses on two broad issues. The first centers on element and body part representation, the second on culturally induced modifications of the remains, including cut marks. Much of the impetus for studies of body part representation in archeological assemblages stems from observations by Binford (1978) that people do not typically use entire animals, but rather, specific animal segments.

In this vein, an animal may be butchered at a kill site, with only select portions returned to a habitation site for consumption. Thus, element representation may shed light on butchering practices and/or site function. Artiodactyl elements commonly interpreted as high utility (in terms of meat, marrow, and grease), and therefore likely to be transported from kill sites, include the femur, tibia, sternum, ribs, and vertebrae (Binford 1978; Metcalfe and Jones 1988). Antler, carpals, tarsals, skulls, and metapodials generally rank lowest (Metcalfe and Jones 1988).

Zooarcheologists, then, have commonly interpreted sites that consist primarily of high meat yielding bones as reflecting a gourmet butchering strategy in which only choice meat cuts were returned to camp. Sites yielding only low utility items have often been interpreted as representing butchering sites, where low choice items were left behind, while higher utility items were transported elsewhere. Sites showing a mixture of low and high utility portions are often considered to reflect the extensive use of carcasses. Recent 
TABLE 33-12

Faunal Recovery by Archeological Feature, 1/4-inch Screens

\begin{tabular}{|c|c|c|c|c|}
\hline Feature & Unit & Cultural Period & Taxon & Totals \\
\hline BRM 1 & IIIC & Archaic & Anura & 1 \\
\hline BRM 1 & IIIC & Archaic & Carnivora & 1 \\
\hline BRM 1 & IIIC & Archaic & Colubridae & 1 \\
\hline BRM 1 & IIII & Archaic & Mammalia (Medium) & 2 \\
\hline BRM 1 & IIIc & Archaic & Mammalia (Medium/Large) & 9 \\
\hline BRM 1 & IIIC & Archaic & Mammalia (Micro) & 2 \\
\hline BRM 1 & IIIC & Archaic & Serpentes & 1 \\
\hline BRM 1 & IIIIc & Archaic & Small/Medium Vertebrata & 48 \\
\hline BRM 1 & IIIC & Archaic & Sylvilagus sp. & 2 \\
\hline BRM 1 & IIIIC & Archaic & Testudinata & 3 \\
\hline BRM 1 & IIIC & Archaic & Vertebrata & 166 \\
\hline BRM 1 & IIIc & Late Archaic & Antilocapra/Odocoileus & 5 \\
\hline BRM 1 & IIIIc & Late Archaic & Colubridae & 2 \\
\hline BRM 1 & IIIIc & Late Archaic & Geomys sp. & 1 \\
\hline BRM 1 & IIIIc & Late Archaic & Lepus californicus & 1 \\
\hline BRM 1 & IIIIc & Late Archaic & Mammalia (Large) & 4 \\
\hline BRM 1 & IIIIc & Late Archaic & Mammalia (Medium) & 3 \\
\hline BRM 1 & IIIC & Late Archaic & Mammalia (Medium/Large) & 242 \\
\hline BRM 1 & IIIIc & Late Archaic & Mammalia (Micro) & 2 \\
\hline BRM 1 & IIIc & Late Archaic & Mammalia (Small) & 1 \\
\hline BRM 1 & IIIIc & Late Archaic & Medium/Large Vertebrata & 2 \\
\hline BRM 1 & IIIIc & Late Archaic & Odocoileus sp. & 7 \\
\hline BRM 1 & IIIc & Late Archaic & Serpentes & 1 \\
\hline BRM 1 & IIIIc & Late Archaic & Small vertebrate, class indeterminate & 2 \\
\hline BRM 1 & IIIc & Late Archaic & Small/Medium Vertebrata & 53 \\
\hline BRM 1 & IIIIc & Late Archaic & Sylvilagus sp. & 2 \\
\hline BRM 1 & IIIc & Late Archaic & Testudinata & 8 \\
\hline BRM 1 & IIIIc & Late Archaic & Vertebrata & 473 \\
\hline BRM 1 & IIIC & Late Archaic & Viperidae & 2 \\
\hline BRM 1 & IIIIc & Late Archaic/Late Prehistoric & Antilocapra/Odocoileus & 5 \\
\hline BRM 1 & IIIc & Late Archaic/Late Prehistoric & Colubridae & 2 \\
\hline BRM 1 & IIIc & Late Archaic/Late Prehistoric & Geomys sp. & 1 \\
\hline BRM 1 & IIIc & Late Archaic/Late Prehistoric & Leporidae & 1 \\
\hline BRM 1 & IIIc & Late Archaic/Late Prehistoric & Lepus californicus & 1 \\
\hline BRM 1 & IIIc & Late Archaic/Late Prehistoric & Mammalia (Large) & 5 \\
\hline BRM 1 & IIIc & Late Archaic/Late Prehistoric & Mammalia (Medium) & 1 \\
\hline BRM 1 & IIIIc & Late Archaic/Late Prehistoric & Mammalia (Medium/Large) & 146 \\
\hline BRM 1 & IIIIc & Late Archaic/Late Prehistoric & Mammalia (Micro) & 1 \\
\hline BRM 1 & IIIIc & Late Archaic/Late Prehistoric & Mammalia (Small) & 2 \\
\hline BRM 1 & IIIc & Late Archaic/Late Prehistoric & Odocoileus sp. & 16 \\
\hline BRM 1 & IIIIc & Late Archaic/Late Prehistoric & Small/Medium Vertebrata & 10 \\
\hline BRM 1 & IIIIc & Late Archaic/Late Prehistoric & Sylvilagus sp. & 2 \\
\hline BRM 1 & IIIc & Late Archaic/Late Prehistoric & Testudinata & 3 \\
\hline BRM 1 & IIIIc & Late Archaic/Late Prehistoric & Vertebrata & 860 \\
\hline 184 & II & Late Paleoindian & Small/Medium Vertebrata & 6 \\
\hline 184 & II & Late Paleoindian & Vertebrata & 12 \\
\hline
\end{tabular}


Table 33-12, continued

\begin{tabular}{|c|c|c|c|c|}
\hline Feature & Unit & Cultural Period & Taxon & Totals \\
\hline 201 & IIIc & Late Archaic & Mammalia (Medium) & 1 \\
\hline 201 & IIIIc & Late Archaic & Mammalia (Medium/Large) & 49 \\
\hline 201 & IIIIc & Late Archaic & Mammalia (Small/Medium) & 1 \\
\hline 201 & IIIIc & Late Archaic & Neotoma sp. & 1 \\
\hline 201 & IIIc & Late Archaic & Odocoileus sp. & 2 \\
\hline 201 & IIIC & Late Archaic & Rodentia (Medium) & 3 \\
\hline 201 & IIIC & Late Archaic & Small/Medium Vertebrata & 14 \\
\hline 201 & IIIIc & Late Archaic & Testudinata & 2 \\
\hline 201 & IIIIc & Late Archaic & Vertebrata & 172 \\
\hline 201 & IIIc/FILL & Unassigned & Mammalia (Large) & 1 \\
\hline 201 & IIIc/FILL & Unassigned & Mammalia (Medium/Large) & 1 \\
\hline $201 / \mathrm{NON}-$ & IIIc/FILL & Unassigned & Mammalia (Large) & 1 \\
\hline $201 / \mathrm{NON}-$ & IIIc/FILL & Unassigned & Mammalia (Medium/Large) & 9 \\
\hline 201/NON- & IIIc/FILL & Unassigned & Vertebrata & 27 \\
\hline 202 & IIII & Late Archaic/Late Prehistoric & Antilocapra/Odocoileus & 2 \\
\hline 202 & IIIC & Late Archaic/Late Prehistoric & Colubridae & 1 \\
\hline 202 & IIIC & Late Archaic/Late Prehistoric & Mammalia (Large) & 1 \\
\hline 202 & IIIIc & Late Archaic/Late Prehistoric & Mammalia (Medium/Large) & 36 \\
\hline 202 & IIIIc & Late Archaic/Late Prehistoric & Mammalia (Small) & 1 \\
\hline 202 & IIIC & Late Archaic/Late Prehistoric & Odocoileus sp. & 9 \\
\hline 202 & IIIIc & Late Archaic/Late Prehistoric & Serpentes & 1 \\
\hline 202 & IIIc & Late Archaic/Late Prehistoric & Small/Medium Vertebrata & 7 \\
\hline 202 & IIIC & Late Archaic/Late Prehistoric & Testudinata & 1 \\
\hline 202 & IIIc & Late Archaic/Late Prehistoric & Vertebrata & 84 \\
\hline 203 & $\mathrm{IIIJ} / \mathrm{c}$ & Middle/Late Archaic & Mammalia (Medium/Large) & 1 \\
\hline 203 & $\mathrm{IIIb} / \mathrm{c}$ & Middle/Late Archaic & Odocoileus sp. & 2 \\
\hline 203 & $\mathrm{IIIb} / \mathrm{c}$ & Middle/Late Archaic & Small/Medium Vertebrata & 2 \\
\hline 203 & IIIb/c & Middle/Late Archaic & Vertebrata & 21 \\
\hline 205 & $\mathrm{IIIb} / \mathrm{c}$ & Late Archaic & Antilocapra americana & 1 \\
\hline 205 & $\mathrm{IIIJ} / \mathrm{c}$ & Late Archaic & Antilocapra/Odocoileus & 1 \\
\hline 205 & IIIb/c & Late Archaic & Leporidae & 1 \\
\hline 205 & $\mathrm{IIIb} / \mathrm{c}$ & Late Archaic & Mammalia (Large) & 2 \\
\hline 205 & IIIb/c & Late Archaic & Mammalia (Medium/Large) & 32 \\
\hline 205 & IIIJ $/ \mathrm{c}$ & Late Archaic & Mammalia (Small) & 1 \\
\hline 205 & $\mathrm{IIIb} / \mathrm{c}$ & Late Archaic & Mammalia (Small/Medium) & 3 \\
\hline 205 & IIIJ/c & Late Archaic & Odocoileus sp. & 4 \\
\hline 205 & IIIb/c & Late Archaic & Rodentia & 1 \\
\hline 205 & IIIIb/c & Late Archaic & Small/Medium Vertebrata & 17 \\
\hline 205 & IIIb/c & Late Archaic & Vertebrata & 283 \\
\hline 206 & IIIIc & Late Archaic & Odocoileus sp. & 3 \\
\hline 206 & IIIIc & Middle/Late Archaic & Mammalia (Medium/Large) & 1 \\
\hline 206 & IIIIc & Middle/Late Archaic & Medium/Large Vertebrata & 1 \\
\hline 207 & IIIIc & Late Archaic & Mammalia (Large) & 8 \\
\hline 207 & IIIc & Late Archaic & Mammalia (Medium/Large) & 5 \\
\hline 207 & IIIc & Late Archaic & Odocoileus sp. & 1 \\
\hline 210 & IIIb & Middle/Late Archaic & Leporidae & 1 \\
\hline 210 & IIIb & Middle/Late Archaic & Lepus californicus & 1 \\
\hline
\end{tabular}


Table 33-12, continued

\begin{tabular}{|c|c|c|c|c|}
\hline Feature & Unit & Cultural Period & Taxon & Totals \\
\hline 210 & $\mathrm{IIIb}$ & Middle/Late Archaic & Mammalia (Small) & 1 \\
\hline 210 & IIIb & Middle/Late Archaic & Medium/Large Vertebrata & 1 \\
\hline 210 & IIIb & Middle/Late Archaic & Small/Medium Vertebrata & 10 \\
\hline 210 & IIIb & Middle/Late Archaic & Sylvilagus sp. & 1 \\
\hline 210 & IIIb & Middle/Late Archaic & Vertebrata & 43 \\
\hline 210 & $\mathrm{IIIb} / \mathrm{c}$ & Middle/Late Archaic & Leporidae & 1 \\
\hline 210 & $\mathrm{IIIb} / \mathrm{c}$ & Middle/Late Archaic & Mammalia (Large) & 1 \\
\hline 210 & $\mathrm{IIIb} / \mathrm{c}$ & Middle/Late Archaic & Medium/Large Vertebrata & 3 \\
\hline 210 & $\mathrm{IIIb} / \mathrm{c}$ & Middle/Late Archaic & Serpentes & 1 \\
\hline 210 & $\mathrm{IIIb} / \mathrm{c}$ & Middle/Late Archaic & Vertebrata & 20 \\
\hline 212 & IIIb & Middle Archaic & Artiodactyla & 4 \\
\hline 212 & IIIb & Middle Archaic & Mammalia (Medium) & 1 \\
\hline 212 & IIIb & Middle Archaic & Mammalia (Medium/Large) & 2 \\
\hline 212 & IIIlb & Middle Archaic & Mammalia (Small) & 1 \\
\hline 212 & IIIb & Middle Archaic & Medium/Large Vertebrata & 7 \\
\hline 212 & IIIb & Middle Archaic & Neotoma sp. & 1 \\
\hline 212 & IIIlb & Middle Archaic & Vertebrata & 41 \\
\hline 213 & IIIa/b & Early Archaic & Lepus californicus & 1 \\
\hline 213 & IIIb & Early/Middle Archaic & Lepus californicus & 1 \\
\hline 213 & IIIb & Early/Middle Archaic & Small/Medium Vertebrata & 2 \\
\hline 213 & IIIb & Early/Middle Archaic & Vertebrata & 9 \\
\hline 213 & IIIb & Middle Archaic & Colubridae & 1 \\
\hline 213 & IIIb & Middle Archaic & Lepus californicus & 1 \\
\hline 213 & IIIb & Middle Archaic & Mammalia (Medium) & 1 \\
\hline 213 & IIIb & Middle Archaic & Medium/Large Vertebrata & 1 \\
\hline 213 & IIIb & Middle Archaic & Vertebrata & 2 \\
\hline 214 & IIIb & Middle Archaic & Geomys sp. & 1 \\
\hline 214 & IIIb & Middle Archaic & Leporidae & 2 \\
\hline 214 & IIIb & Middle Archaic & Lepus californicus & 3 \\
\hline 214 & IIIb & Middle Archaic & Mammalia (Medium) & 2 \\
\hline 214 & IIIb & Middle Archaic & Mammalia (Medium/Large) & 2 \\
\hline 214 & IIIb & Middle Archaic & Mammalia (Small) & 2 \\
\hline 214 & IIIb & Middle Archaic & Mammalia (Small/Medium) & 1 \\
\hline 214 & IIIb & Middle Archaic & Neotoma sp. & 4 \\
\hline 214 & IIIb & Middle Archaic & Serpentes & 2 \\
\hline 214 & IIIb & Middle Archaic & Small/Medium Vertebrata & 3 \\
\hline 214 & IIIb & Middle Archaic & Sylvilagus sp. & 1 \\
\hline 214 & IIIb & Middle Archaic & Testudinata & 3 \\
\hline 214 & IIIb & Middle Archaic & Vertebrata & 51 \\
\hline $214 ?$ & $\mathrm{IIIb}$ & Middle Archaic & Mammalia (Medium) & 1 \\
\hline $214 ?$ & IIIb & Middle Archaic & Serpentes & 1 \\
\hline $214 ?$ & IIIb & Middle Archaic & Small/Medium Vertebrata & 2 \\
\hline $214 ?$ & IIIb & Middle Archaic & Vertebrata & 14 \\
\hline 217 & IIIa & Early Archaic & Leporidae & 1 \\
\hline 217 & IIIa & Early Archaic & Mammalia (Medium/Large) & 6 \\
\hline 217 & IIIa & Early Archaic & Mammalia (Small) & 1 \\
\hline 217 & IIIa & Early Archaic & Odocoileus sp. & 1 \\
\hline
\end{tabular}


Table 33-12, continued

\begin{tabular}{|c|c|c|c|c|}
\hline Feature & Unit & Cultural Period & Taxon & Totals \\
\hline 217 & IIIa & Early Archaic & Serpentes & 1 \\
\hline 217 & IIIa & Early Archaic & Small/Medium Vertebrata & 3 \\
\hline 217 & IIIa & Early Archaic & Sylvilagus sp. & 1 \\
\hline 217 & IIIa & Early Archaic & Vertebrata & 27 \\
\hline 220 & $\mathrm{IIIa} / \mathrm{b}$ & Early Archaic & Small/Medium Vertebrata & 1 \\
\hline 220 & IIIa/b & Early Archaic & Sylvilagus sp. & 1 \\
\hline 220 & $\mathrm{IIIa} / \mathrm{b}$ & Early Archaic & Vertebrata & 4 \\
\hline 221 & $\mathrm{IIIa} / \mathrm{b}$ & Early Archaic & Small/Medium Vertebrata & 1 \\
\hline 222 & IIIa & Early Archaic & Vertebrata & 1 \\
\hline 223 & IIIa & Early Archaic & Leporidae & 1 \\
\hline 223 & IIIa & Early Archaic & Medium/Large Vertebrata & 4 \\
\hline 223 & IIIa & Early Archaic & Small/Medium Vertebrata & 2 \\
\hline 223 & IIIa & Early Archaic & Testudinata & 3 \\
\hline 223 & IIIa & Early Archaic & Vertebrata & 24 \\
\hline 225 & IIIa & Early Archaic & Mammalia (Medium/Large) & 1 \\
\hline 225 & IIIa & Early Archaic & Small/Medium Vertebrata & 7 \\
\hline 225 & IIIa & Early Archaic & Vertebrata & 3 \\
\hline 226 & II/IIIa & Late Paleoindian/Early Archaic & Sylvilagus sp. & 1 \\
\hline 226 & II/IIIa & Late Paleoindian/Early Archaic & Vertebrata & 1 \\
\hline 227 & II & Late Paleoindian & Leporidae & 1 \\
\hline 227 & II & Late Paleoindian & Lepus californicus & 1 \\
\hline 227 & II & Late Paleoindian & Mammalia (Micro) & 2 \\
\hline 227 & II & Late Paleoindian & Medium/Large Vertebrata & 2 \\
\hline 227 & II & Late Paleoindian & Serpentes & 1 \\
\hline 227 & II & Late Paleoindian & Small vertebrate, class indeterminate & 2 \\
\hline 227 & II & Late Paleoindian & Small/Medium Vertebrata & 10 \\
\hline 227 & II & Late Paleoindian & Sylvilagus sp. & 1 \\
\hline 227 & II & Late Paleoindian & Vertebrata & 49 \\
\hline 228 & IIIa & Early Archaic & Lepus californicus & 1 \\
\hline 228 & IIIa & Early Archaic & Vertebrata & 10 \\
\hline 230 & IIIa & Early Archaic & Mammalia (Medium/Large) & 1 \\
\hline 230 & IIIa & Early Archaic & Medium/Large Vertebrata & 1 \\
\hline 230 & IIIa & Early Archaic & Vertebrata & 4 \\
\hline 231 & II & Late Paleoindian & Mammalia (Medium/Large) & 1 \\
\hline 231 & II & Late Paleoindian & Small/Medium Vertebrata & 3 \\
\hline 231 & II & Late Paleoindian & Vertebrata & 4 \\
\hline 231 & II/IIIa & Late Paleoindian/Early Archaic & Anura & 1 \\
\hline 231 & II/IIIa & Late Paleoindian/Early Archaic & Carnivora & 1 \\
\hline 231 & II/IIIa & Late Paleoindian/Early Archaic & cf. Lepus californicus & 1 \\
\hline 231 & II/IIIa & Late Paleoindian/Early Archaic & Colubridae & 1 \\
\hline 231 & II/IIIa & Late Paleoindian/Early Archaic & Leporidae & 1 \\
\hline 231 & II/IIIa & Late Paleoindian/Early Archaic & Lepus californicus & 4 \\
\hline 231 & II/IIIa & Late Paleoindian/Early Archaic & Mammalia (Large) & 3 \\
\hline 231 & II/IIIa & Late Paleoindian/Early Archaic & Mammalia (Medium) & 5 \\
\hline 231 & II/IIIa & Late Paleoindian/Early Archaic & Mammalia (Medium/Large) & 20 \\
\hline 231 & II/IIIa & Late Paleoindian/Early Archaic & Mammalia (Micro) & 3 \\
\hline 231 & II/IIIa & Late Paleoindian/Early Archaic & Mammalia (Small) & 5 \\
\hline 231 & II/IIIa & Late Paleoindian/Early Archaic & Medium/Large Vertebrata & 8 \\
\hline
\end{tabular}


Table 33-12, continued

\begin{tabular}{|c|c|c|c|c|}
\hline Feature & Unit & Cultural Period & Taxon & Total \\
\hline 231 & II/IIIa & Late Paleoindian/Early Archaic & Mammalia (Small/Medium) & 1 \\
\hline 231 & II/IIIa & Late Paleoindian/Early Archaic & Osteichthyes (Small) & 1 \\
\hline 231 & II/IIIa & Late Paleoindian/Early Archaic & Serpentes & 1 \\
\hline 231 & ПI/IIIa & Late Paleoindian/Early Archaic & Small/Medium Vertebrata & 124 \\
\hline 231 & II/IIIa & Late Paleoindian/Early Archaic & Sylvilagus sp. & 7 \\
\hline 231 & II/IIIa & Late Paleoindian/Early Archaic & Testudinata & 3 \\
\hline 231 & II/IIIa & Late Paleoindian/Early Archaic & Vertebrata & 347 \\
\hline 231 & IIIa & Early Archaic & AntilocapralOdocoileus & 1 \\
\hline 231 & IIIa & Early Archaic & Carnivora & 1 \\
\hline 231 & IIIa & Early Archaic & Colubridae & 5 \\
\hline 231 & IIIa & Early Archaic & Cricetidae (Medium) & 1 \\
\hline 231 & IIIa & Early Archaic & Geomys sp. & 7 \\
\hline 231 & IIIa & Early Archaic & Kinosternidae & 1 \\
\hline 231 & IIIIa & Early Archaic & Kinosternon sp. & 1 \\
\hline 231 & IIIa & Early Archaic & Leporidae & 13 \\
\hline 231 & IIIa & Early Archaic & Lepus californicus & 2 \\
\hline 231 & IIIa & Early Archaic & Mammalia (Large) & 7 \\
\hline 231 & IIIa & Early Archaic & Mammalia (Medium) & 10 \\
\hline 231 & IIIa & Early Archaic & Mammalia (Medium/Large) & 84 \\
\hline 231 & IIIa & Early Archaic & Mammalia (Micro) & 4 \\
\hline 231 & IIIa & Early Archaic & Mammalia (Small) & 15 \\
\hline 231 & IIIIa & Early Archaic & Medium vertebrate, class indeterminate & 2 \\
\hline 231 & IIIIa & Early Archaic & Medium/Large Vertebrata & 28 \\
\hline 231 & IIIIa & Early Archaic & Neotoma sp. & 5 \\
\hline 231 & IIIa & Early Archaic & Odocoileus sp. & 1 \\
\hline 231 & IIIIa & Early Archaic & Osteichthyes (Small) & 1 \\
\hline 231 & IIIa & Early Archaic & Rodentia (Medium) & 1 \\
\hline 231 & IIIa & Early Archaic & Serpentes & 1 \\
\hline 231 & IIIa & Early Archaic & Small vertebrate, class indeterminate & 7 \\
\hline 231 & IIIla & Early Archaic & Small/Medium Vertebrata & 235 \\
\hline 231 & IIIa & Early Archaic & Sylvilagus sp. & 5 \\
\hline 231 & IIIIa & Early Archaic & Testudinata & 12 \\
\hline 231 & IIIIa & Early Archaic & Vertebrata & 1064 \\
\hline $231 / 245$ & II/IIIa & Late Paleoindian/Early Archaic & Colubridae & 1 \\
\hline $231 / 245$ & II/IIIa & Late Paleoindian/Early Archaic & Geomys sp. & 2 \\
\hline $231 / 245$ & II/IIIa & Late Paleoindian/Early Archaic & Leporidae & 1 \\
\hline $231 / 245$ & II/IIIa & Late Paleoindian/Early Archaic & Mammalia (Large) & 1 \\
\hline $231 / 245$ & IIIIIIa & Late Paleoindian/Early Archaic & Mammalia (Medium) & 2 \\
\hline $231 / 245$ & II/IIIa & Late Paleoindian/Early Archaic & Mammalia (Medium/Large) & 7 \\
\hline $231 / 245$ & II/IIIa & Late Paleoindian/Early Archaic & Mammalia (Small) & 3 \\
\hline $231 / 245$ & II/IIIa & Late Paleoindian/Early Archaic & Rodentia (Small/Medium) & 1 \\
\hline $231 / 245$ & III/IIIa & Late Paleoindian/Early Archaic & Serpentes & 1 \\
\hline $231 / 245$ & II/IIIa & Late Paleoindian/Early Archaic & Small/Medium Vertebrata & 59 \\
\hline $231 / 245$ & II/IIIa & Late Paleoindian/Early Archaic & Sylvilagus sp. & 3 \\
\hline $231 / 245$ & II/IIIa & Late Paleoindian/Early Archaic & Testudinata & 4 \\
\hline $231 / 245$ & II/IIIa & Late Paleoindian/Early Archaic & Vertebrata & 160 \\
\hline $231 / 245$ & IIIIa & Early Archaic & Leporidae & 1 \\
\hline
\end{tabular}


Table 33-12, continued

\begin{tabular}{|c|c|c|c|c|}
\hline Feature & Unit & Cultural Period & Taxon & Totals \\
\hline $231 / 245$ & IIIa & Early Archaic & Lepus californicus & 1 \\
\hline $231 / 245$ & IIIa & Early Archaic & Mammalia (Medium) & 2 \\
\hline $231 / 245$ & IIIa & Early Archaic & Mammalia (Medium/Large) & 10 \\
\hline $231 / 245$ & IIIa & Early Archaic & Mammalia (Small) & 4 \\
\hline $231 / 245$ & IIIa & Early Archaic & Medium/Large Vertebrata & 6 \\
\hline $231 / 245$ & ШІа & Early Archaic & Neotoma sp. & 1 \\
\hline $231 / 245$ & IIIa & Early Archaic & Osteichthyes (Small) & 3 \\
\hline $231 / 245$ & IIIa & Early Archaic & Sigmodon hispidus & 2 \\
\hline $231 / 245$ & IIIa & Early Archaic & Small vertebrate, class indeterminate & 3 \\
\hline $231 / 245$ & IIIa & Early Archaic & Small/Medium Vertebrata & 33 \\
\hline $231 / 245$ & IIIa & Early Archaic & Sylvilagus sp. & 1 \\
\hline $231 / 245$ & ШІІа & Early Archaic & Testudinata & 4 \\
\hline $231 / 245$ & IIIIa & Early Archaic & Vertebrata & 199 \\
\hline 234 & Isi-c/II & Late Paleoindian & Geomys sp. & 1 \\
\hline 234 & Isi-c/II & Late Paleoindian & Mammalia (Large) & 1 \\
\hline 234 & Isi-c/II & Late Paleoindian & Mammalia (Medium/Large) & 1 \\
\hline 234 & Isi-c/II & Late Paleoindian & Mammalia (Small) & 2 \\
\hline 234 & Isi-c/II & Late Paleoindian & Small vertebrate, class indeterminate & 1 \\
\hline 234 & Isi-c/II & Late Paleoindian & Small/Medium Vertebrata & 16 \\
\hline 234 & Isi-c/II & Late Paleoindian & Vertebrata & 65 \\
\hline 235 & Isi-c/II & Late Paleoindian & Small/Medium Vertebrata & 5 \\
\hline 235 & Isi-c/II & Late Paleoindian & Vertebrata & 3 \\
\hline 236 & II & Late Paleoindian & Small/Medium Vertebrata & 5 \\
\hline 236 & II & Late Paleoindian & Vertebrata & 7 \\
\hline 238 & Isi-c & Late Paleoindian & Mammalia (Large) & 1 \\
\hline 238 & Isi-c & Late Paleoindian & Medium/Large Vertebrata & 1 \\
\hline 238 & Isi-c & Late Paleoindian & Small/Medium Vertebrata & 6 \\
\hline 238 & Isi-c & Late Paleoindian & Vertebrata & 27 \\
\hline 239 & II & Late Paleoindian & Leporidae & 1 \\
\hline 239 & II & Late Paleoindian & Medium/Large Vertebrata & 5 \\
\hline 239 & II & Late Paleoindian & Small/Medium Vertebrata & 7 \\
\hline 239 & II & Late Paleoindian & Sylvilagus sp. & 1 \\
\hline 239 & II & Late Paleoindian & Vertebrata & 31 \\
\hline 240 & II & Late Paleoindian & Small/Medium Vertebrata & 6 \\
\hline 240 & II & Late Paleoindian & Vertebrata & 16 \\
\hline 240 & Ш/ШІа & Late Paleoindian/Early Archaic & Mammalia (Medium/Large) & 1 \\
\hline 240 & II/IIIa & Late Paleoindian/Early Archaic & Small/Medium Vertebrata & 1 \\
\hline 240 & II/IIIa & Late Paleoindian/Early Archaic & Vertebrata & 16 \\
\hline 245 & II/IIIa & Late Paleoindian/Early Archaic & Geomys sp. & 1 \\
\hline 245 & II/IIIa & Late Paleoindian/Early Archaic & Leporidae & 8 \\
\hline 245 & Ш/IIIa & Late Paleoindian/Early Archaic & Mammalia (Medium/Large) & 1 \\
\hline 245 & II/IIIa & Late Paleoindian/Early Archaic & Mammalia (Small) & 3 \\
\hline 245 & II/IIIa & Late Paleoindian/Early Archaic & Medium/Large Vertebrata & 4 \\
\hline 245 & II/IIIa & Late Paleoindian/Early Archaic & Osteichthyes (Small) & 1 \\
\hline 245 & ПI/IIIa & Late Paleoindian/Early Archaic & Small/Medium Vertebrata & 33 \\
\hline 245 & II/IIIa & Late Paleoindian/Early Archaic & Sylvilagus sp. & 1 \\
\hline 245 & II/IIIa & Late Paleoindian/Early Archaic & Testudinata & 2 \\
\hline
\end{tabular}


Table 33-12, continued

\begin{tabular}{|c|c|c|c|c|}
\hline Feature & Unit & Cultural Period & Taxon & Totals \\
\hline 245 & II/IIIa & Late Paleoindian/Early Archaic & Vertebrata & 78 \\
\hline 245 & IIIa & Early Archaic & Artiodactyla & 1 \\
\hline 245 & IIIa & Early Archaic & Geomys sp. & 1 \\
\hline 245 & IIIa & Early Archaic & Leporidae & 2 \\
\hline 245 & IIIa & Early Archaic & Lepus californicus & 1 \\
\hline 245 & IIIa & Early Archaic & Mammalia (Medium) & 1 \\
\hline 245 & IIIa & Early Archaic & Mammalia (Medium/Large) & 6 \\
\hline 245 & IIIa & Early Archaic & Mammalia (Small) & 1 \\
\hline 245 & IIIa & Early Archaic & Sciurus sp. & 1 \\
\hline 245 & IIIa & Early Archaic & Small/Medium Vertebrata & 27 \\
\hline 245 & IIIa & Early Archaic & Sylvilagus sp. & 1 \\
\hline 245 & IIIa & Early Archaic & Testudinata & 3 \\
\hline 245 & IIIa & Early Archaic & Vertebrata & 61 \\
\hline 247 & II & Late Paleoindian & Small/Medium Vertebrata & 2 \\
\hline 247 & II & Late Paleoindian & Vertebrata & 2 \\
\hline 248 & II & Late Paleoindian & Mammalia (Micro) & 1 \\
\hline 248 & II & Late Paleoindian & Mammalia (Small) & 1 \\
\hline 248 & II & Late Paleoindian & Vertebrata & 8 \\
\hline 248 & II/IIIa & Late Paleoindian/Early Archaic & Mammalia (Medium/Large) & 1 \\
\hline 248 & II/IIIa & Late Paleoindian/Early Archaic & Small/Medium Vertebrata & 1 \\
\hline 248 & II/IIIa & Late Paleoindian/Early Archaic & Vertebrata & 3 \\
\hline 249 & II & Late Paleoindian & Osteichthyes (Small) & 1 \\
\hline 249 & II & Late Paleoindian & Small/Medium Vertebrata & 7 \\
\hline 249 & II & Late Paleoindian & Sylvilagus sp. & 1 \\
\hline 249 & II & Late Paleoindian & Testudinata & 1 \\
\hline 249 & II & Late Paleoindian & Vertebrata & 13 \\
\hline 249 & II/IIIa & Late Paleoindian/Early Archaic & Artiodactyla & 1 \\
\hline 249 & ПI/IIIa & Late Paleoindian/Early Archaic & Carnivora & 1 \\
\hline 249 & ПI/IIa & Late Paleoindian/Early Archaic & Mammalia (Medium/Large) & 1 \\
\hline 249 & II/IIa & Late Paleoindian/Early Archaic & Small/Medium Vertebrata & 1 \\
\hline 249 & II/IIIa & Late Paleoindian/Early Archaic & Vertebrata & 8 \\
\hline 254 & II & Late Paleoindian & Mammalia (Medium/Large) & 4 \\
\hline 254 & II & Late Paleoindian & Small/Medium Vertebrata & 5 \\
\hline 254 & II & Late Paleoindian & Vertebrata & 8 \\
\hline 258 & ПI/IIIa & Late Paleoindian/Early Archaic & Vertebrata & 3 \\
\hline 259 & Isi/Icl & Early Paleoindian & Vertebrata & 8 \\
\hline 260 & Isi-c & Late Paleoindian & Mammalia (Large) & 1 \\
\hline 260 & Isi-c & Late Paleoindian & Small/Medium Vertebrata & 1 \\
\hline 262 & Isi/Icl & Early Paleoindian & Leporidae & 3 \\
\hline 262 & Isi/Icl & Early Paleoindian & Mammalia (Large) & 2 \\
\hline 262 & Isi//cl & Early Paleoindian & Mammalia (Medium/Large) & 8 \\
\hline 262 & Isi/Icl & Early Paleoindian & Medium/Large Vertebrata & 11 \\
\hline 262 & Isi/Icl & Early Paleoindian & Small/Medium Vertebrata & 1 \\
\hline 262 & Isi/Icl & Early Paleoindian & Vertebrata & 25 \\
\hline
\end{tabular}


TABLE 33-13

Faunal Recovery by Archeological Feature, 1/8-inch Screens

\begin{tabular}{|c|c|c|c|c|}
\hline Feature & Unit & Cultural Period & Taxon & Totals \\
\hline BRM1 & $\mathrm{IIIb} / \mathrm{c}$ & Early/Middle Archaic & Antilocapra/Odocoileus & 4 \\
\hline BRM1 & $\mathrm{IIIb} / \mathrm{c}$ & Early/Middle Archaic & Artiodactyla & 1 \\
\hline BRM1 & $\mathrm{IIIb} / \mathrm{c}$ & Early/Middle Archaic & Artiodactyla (Large) & 1 \\
\hline BRM1 & $\mathrm{IIIb} / \mathrm{c}$ & Early/Middle Archaic & Leporidae & 1 \\
\hline BRM1 & $\mathrm{IIIb} / \mathrm{c}$ & Early/Middle Archaic & Mammalia (Large) & 11 \\
\hline BRM1 & $\mathrm{IIIb} / \mathrm{c}$ & Early/Middle Archaic & Mammalia (Medium) & 1 \\
\hline BRM1 & $\mathrm{IIIb} / \mathrm{c}$ & Early/Middle Archaic & Mammalia (Medium/Large) & 20 \\
\hline BRM1 & $\mathrm{IIIb} / \mathrm{c}$ & Early/Middle Archaic & Odocoileus sp. & 1 \\
\hline BRM1 & $\mathrm{IIIb} / \mathrm{c}$ & Early/Middle Archaic & Small/Medium Vertebrata & 3 \\
\hline BRM1 & $\mathrm{IIIb} / \mathrm{c}$ & Early/Middle Archaic & Testudinata & 5 \\
\hline BRM1 & $\mathrm{IIIb} / \mathrm{c}$ & Early/Middle Archaic & Vertebrata & 36 \\
\hline BRM1 & IIIc & Archaic & AntilocapralOdocoileus & 3 \\
\hline BRM1 & IIIc & Archaic & Colubridae & 1 \\
\hline BRM1 & IIIc & Archaic & Mammalia (Large) & 2 \\
\hline BRM1 & IIIc & Archaic & Mammalia (Medium/Large) & 6 \\
\hline BRM1 & IIIc & Archaic & Vertebrata & 15 \\
\hline BRM1 & IIIc & Early/Middle Archaic & AntilocapralOdocoileus & 1 \\
\hline BRM1 & IIIc & Early/Middle Archaic & Mammalia (Large) & 1 \\
\hline BRM1 & IIIc & Early/Middle Archaic & Mammalia (Medium/Large) & 2 \\
\hline BRM1 & IIIc & Early/Middle Archaic & Odocoileus sp. & 1 \\
\hline BRM1 & IIIC & Early/Middle Archaic & Vertebrata & 6 \\
\hline BRM1 & IIIC & Late Archaic & Antilocapra americana & 1 \\
\hline BRM1 & IIIc & Late Archaic & Antilocapra/Odocoileus & 13 \\
\hline BRM1 & IIIc & Late Archaic & Artiodactyla & 3 \\
\hline BRM1 & IIIc & Late Archaic & cf. AntilocapralOdocoileus & 1 \\
\hline BRM1 & IIIc & Late Archaic & Emydidae & 1 \\
\hline BRM1 & IIIc & Late Archaic & Leporidae & 1 \\
\hline BRM1 & IIIc & Late Archaic & Mammalia (Large) & 18 \\
\hline BRM1 & IIIc & Late Archaic & Mammalia (Medium) & 1 \\
\hline BRM1 & IIIc & Late Archaic & Mammalia (Medium/Large) & 48 \\
\hline BRM1 & IIIc & Late Archaic & Medium/Large Vertebrata & 8 \\
\hline BRM1 & IIIc & Late Archaic & Odocoileus sp. & 3 \\
\hline BRM1 & IIIc & Late Archaic & Testudinata & 1 \\
\hline BRM1 & IIIc & Late Archaic & Vertebrata & 316 \\
\hline BRM1 & IIIc & Late Archaic/Late Prehistoric & Antilocapra/Odocoileus & 10 \\
\hline BRM1 & IIIC & Late Archaic/Late Prehistoric & Artiodactyla & 3 \\
\hline BRM1 & IIIC & Late Archaic/Late Prehistoric & Kinosternidae & 1 \\
\hline BRM1 & IIIc & Late Archaic/Late Prehistoric & Mammalia (Large) & 47 \\
\hline BRM1 & IIIc & Late Archaic/Late Prehistoric & Mammalia (Medium) & 3 \\
\hline BRM1 & IIIc & Late Archaic/Late Prehistoric & Mammalia (Medium/Large) & 69 \\
\hline BRM1 & IIIIc & Late Archaic/Late Prehistoric & Mustelidae & 4 \\
\hline BRM1 & IIIc & Late Archaic/Late Prehistoric & Odocoileus sp. & 11 \\
\hline BRM1 & IIIc & Late Archaic/Late Prehistoric & Testudinata & 4 \\
\hline BRM1 & IIIc & Late Archaic/Late Prehistoric & Vertebrata & 491 \\
\hline BRM1 & IIIC & Middle/Late Archaic & Antilocapra/Odocoileus & 1 \\
\hline BRM1 & IIIC & Middle/Late Archaic & cf. Odocoileus sp. & 1 \\
\hline BRM1 & IIIc & Middle/Late Archaic & Leporidae & 1 \\
\hline
\end{tabular}


Table 33-13, continued

\begin{tabular}{|c|c|c|c|c|}
\hline Feature & Unit & Cultural Period & Taxon & Totals \\
\hline BRM1 & IIIC & Middle/Late Archaic & Lepus californicus & 1 \\
\hline BRM1 & IIIC & Middle/Late Archaic & Mammalia (Large) & 1 \\
\hline BRM1 & IIIC & Middle/Late Archaic & Mammalia (Medium/Large) & 21 \\
\hline BRM1 & IIIC & Middle/Late Archaic & Medium/Large Vertebrata & 7 \\
\hline BRM1 & IIIc & Middle/Late Archaic & Sigmodon hispidus & 5 \\
\hline BRM1 & IIIC & Middle/Late Archaic & Testudinata & 1 \\
\hline BRM1 & IIIIc & Middle/Late Archaic & Vertebrata & 73 \\
\hline BRM1 & IIIc/POT & Archaic & Antilocapra/Odocoileus & 1 \\
\hline BRM1 & IIIc/POT & Archaic & cf. Odocoileus sp. & 1 \\
\hline BRM1 & IIIc/POT & Archaic & Mammalia (Large) & 1 \\
\hline BRM1 & IIIc/POT & Archaic & Mammalia (Medium/Large) & 4 \\
\hline BRM1 & IIIc/POT & Archaic & Medium/Large Vertebrata & 1 \\
\hline BRM1 & IIIc/POT & Archaic & Testudinata & 2 \\
\hline BRM1 & IIIc/POT & Archaic & Vertebrata & 14 \\
\hline BRM1 & IIIc/POT & Archaic/Late Prehistoric & Antilocapra/Odocoileus & 12 \\
\hline BRM1 & IIIc/POT & Archaic/Late Prehistoric & Artiodactyla & 7 \\
\hline BRM1 & IIIc/POT & Archaic/Late Prehistoric & Mammalia (Large) & 10 \\
\hline BRM1 & IIII/POT & Archaic/Late Prehistoric & Mammalia (Medium) & 1 \\
\hline BRM1 & IIIc/POT & Archaic/Late Prehistoric & Mammalia (Medium/Large) & 31 \\
\hline BRM1 & IIIc/POT & Archaic/Late Prehistoric & Odocoileus sp. & 2 \\
\hline BRM1 & IIIc/POT & Archaic/Late Prehistoric & Serpentes & 1 \\
\hline BRM1 & IIIc/POT & Archaic/Late Prehistoric & Testudinata & 2 \\
\hline BRM1 & IIIc/POT & Archaic/Late Prehistoric & Vertebrata & 172 \\
\hline BRM1 & Y/IIIb/c & Archaic & Artiodactyla & 2 \\
\hline BRM1 & $\mathrm{Y} / \mathrm{IIb} / \mathrm{c}$ & Archaic & Mammalia (Medium) & 1 \\
\hline BRM1 & $\mathrm{Y} / \mathrm{IIIb} / \mathrm{c}$ & Archaic & Mammalia (Medium/Large) & 3 \\
\hline BRM1 & $\mathrm{Y} / \mathrm{II} \mathrm{b} / \mathrm{c}$ & Archaic & Odocoileus sp. & 5 \\
\hline BRM1 & $\mathrm{Y} / \mathrm{II} \mathrm{lb} / \mathrm{c}$ & Archaic & Testudinata & 2 \\
\hline BRM1 & $\mathrm{Y} / \mathrm{IIIb} / \mathrm{c}$ & Archaic & Vertebrata & 12 \\
\hline BRM1 & $\mathrm{Y} / \mathrm{IIIb} / \mathrm{c}$ & Early/Middle Archaic & Sylvilagus sp. & 1 \\
\hline BRM1 & $\mathrm{Y} / \mathrm{IIIb} / \mathrm{c}$ & Early/Middle Archaic & Vertebrata & 2 \\
\hline BRM1 & $\mathrm{Y} / \mathrm{IIIc}$ & Archaic & Mammalia (Medium/Large) & 4 \\
\hline BRM1 & Y/IIIc & Archaic & Odocoileus sp. & 2 \\
\hline BRM1 & Y/IIIc & Archaic & Vertebrata & 8 \\
\hline BRM1 & $\mathrm{Y} / \mathrm{IIIc}$ & Early/Middle Archaic & Antilocapra/Odocoileus & 1 \\
\hline BRM1 & Y/IIIc & Early/Middle Archaic & Artiodactyla & 1 \\
\hline BRM1 & Y/IIIc & Early/Middle Archaic & Canis sp. & 1 \\
\hline BRM1 & Y/IIIc & Early/Middle Archaic & cf. Aves (Medium) & 1 \\
\hline BRM1 & $\mathrm{Y} / \mathrm{IIIc}$ & Early/Middle Archaic & Lepus californicus & 1 \\
\hline BRM1 & Y/IIlc & Early/Middle Archaic & Mammalia (Large) & 4 \\
\hline BRM1 & $\mathrm{Y} / \mathrm{IIIC}$ & Early/Middle Archaic & Mammalia (Medium/Large) & 13 \\
\hline BRM1 & $\mathrm{Y} / \mathrm{IIIC}$ & Early/Middle Archaic & Medium/Large Vertebrata & 13 \\
\hline BRM1 & Y/IIIc & Early/Middle Archaic & Small/Medium Vertebrata & 1 \\
\hline BRM1 & Y/IIIc & Early/Middle Archaic & Vertebrata & 33 \\
\hline BRM1 & Y/IIIc & Middle/Late Archaic & Mammalia (Medium/Large) & 1 \\
\hline BRM1 & $\mathrm{Y} / \mathrm{IIIC}$ & Middle/Late Archaic & Vertebrata & 4 \\
\hline BRM2 & IIIIc & Early/Middle Archaic & Mammalia (Large) & 1 \\
\hline BRM2 & IIIc & Early/Middle Archaic & Mammalia (Medium/Large) & 2 \\
\hline
\end{tabular}


Table 33-13, continued

\begin{tabular}{|c|c|c|c|c|}
\hline Feature & Unit & Cultural Period & Taxon & Total \\
\hline BRM2 & IIIc & Early/Middle Archaic & Odocoileus sp. & 1 \\
\hline BRM2 & IIIC & Early/Middle Archaic & Testudinata & 3 \\
\hline BRM2 & IIIc & Early/Middle Archaic & Vertebrata & 25 \\
\hline BRM2 & IIIc & Middle Archaic & Antilocapra/Odocoileus & 2 \\
\hline BRM2 & IIIc & Middle Archaic & Leporidae & 8 \\
\hline BRM2 & IIIIc & Middle Archaic & Mammalia (Large) & 5 \\
\hline BRM2 & IIIIc & Middle Archaic & Mammalia (Medium) & 1 \\
\hline BRM2 & IIIc & Middle Archaic & Mammalia (Medium/Large) & 15 \\
\hline BRM2 & IIIC & Middle Archaic & Odocoileus sp. & 2 \\
\hline BRM2 & IIIC & Middle Archaic & Small/Medium Vertebrata & 1 \\
\hline BRM2 & IIIc & Middle Archaic & Testudinata & 1 \\
\hline BRM2 & IIIc & Middle Archaic & Vertebrata & 56 \\
\hline BRM2 & IIIc & Middle/Late Archaic & Mammalia (Medium/Large) & 1 \\
\hline BRM2 & IIIC & Middle/Late Archaic & Vertebrata & 3 \\
\hline 104 & $\mathrm{X}$ & Early Archaic & Mammalia (Medium/Large) & 1 \\
\hline 104 & $\mathrm{X}$ & Early Archaic & Medium/Large Vertebrata & 1 \\
\hline 104 & $\mathrm{X}$ & Early Archaic & Vertebrata & 2 \\
\hline 104 & $\mathrm{X}$ & Late Paleoindian/Early Archaic & Antilocapra/Odocoileus & 1 \\
\hline 104 & $\mathrm{X}$ & Late Paleoindian/Early Archaic & Mammalia (Medium/Large) & 2 \\
\hline 104 & $\mathrm{X}$ & Late Paleoindian/Early Archaic & Medium/Large Vertebrata & 2 \\
\hline 104 & $\mathrm{X}$ & Late Paleoindian/Early Archaic & Small/Medium Vertebrata & 1 \\
\hline 104 & $\mathrm{X}$ & Late Paleoindian/Early Archaic & Testudinata & 1 \\
\hline 104 & $\mathrm{X}$ & Late Paleoindian/Early Archaic & Vertebrata & 5 \\
\hline 123 & IIIIa & Early Archaic & Mammalia (Medium/Large) & 1 \\
\hline 124 & IIIa & Early Archaic & Mammalia (Medium/Large) & 7 \\
\hline 124 & IIIa & Early Archaic & Medium/Large Vertebrata & 2 \\
\hline 124 & IIIa & Early Archaic & Small/Medium Vertebrata & 1 \\
\hline 124 & IIIa & Early Archaic & Testudinata & 1 \\
\hline 124 & IIIIa & Early Archaic & Vertebrata & 14 \\
\hline 140 & IIIIa & Early Archaic & Vertebrata & 1 \\
\hline 146 & II & Late Paleoindian & Vertebrata & 2 \\
\hline 146 & II/IIIa & Late Paleoindian/Early Archaic & Mammalia (Medium/Large) & 2 \\
\hline 146 & II/IIIa & Late Paleoindian/Early Archaic & Medium/Large Vertebrata & 1 \\
\hline 150 & II/IIIa & Early Archaic & Vertebrata & 1 \\
\hline 154 & I & Paleoindian & Vertebrata & 2 \\
\hline 155 & II & Late Paleoindian & Mammalia (Large) & 8 \\
\hline 157 & II & Late Paleoindian & Carnivora & 1 \\
\hline 157 & II & Late Paleoindian & Mammalia (Medium/Large) & 4 \\
\hline 157 & II & Late Paleoindian & Small/Medium Vertebrata & 1 \\
\hline 157 & II & Late Paleoindian & Vertebrata & 5 \\
\hline 161 & $\mathrm{Id} / \mathrm{II}$ & Late Paleoindian & Medium/Large Vertebrata & 1 \\
\hline 163 & Isi-c/Id & Late Paleoindian & Antilocapra/Odocoileus & 1 \\
\hline 163 & Isi-c/Id & Late Paleoindian & Mammalia (Medium) & 1 \\
\hline 163 & Isi-c/Id & Late Paleoindian & Mammalia (Medium/Large) & 2 \\
\hline 163 & Isi-c/Id & Late Paleoindian & Medium/Large Vertebrata & 8 \\
\hline 163 & Isi-c/Id & Late Paleoindian & Small/Medium Vertebrata & 4 \\
\hline 163 & Isi-c/Id & Late Paleoindian & Sylvilagus sp. & 1 \\
\hline 163 & Isi-c/Id & Late Paleoindian & Testudinata & 2 \\
\hline
\end{tabular}


Table 33-13, continued

\begin{tabular}{|c|c|c|c|c|}
\hline Feature & Unit & Cultural Period & Taxon & Totals \\
\hline 163 & Isi-c/Id & Late Paleoindian & Vertebrata & 34 \\
\hline 164 & II & Late Paleoindian & Vertebrata & 1 \\
\hline 166 & I & Paleoindian & Medium/Large Vertebrata & 1 \\
\hline 166 & I & Paleoindian & Small/Medium Vertebrata & 1 \\
\hline 166 & I & Paleoindian & Vertebrata & 19 \\
\hline 168 & Isi-c & Late Paleoindian & Vertebrata & 1 \\
\hline 169 & Isi-c & Late Paleoindian & Vertebrata & 1 \\
\hline 169 & Isi/Isi-c & Paleoindian & Mammalia (Medium) & 1 \\
\hline 169 & Isi/Isi-c & Paleoindian & Vertebrata & 1 \\
\hline 17 & $\mathrm{X}$ & Early Archaic & Mammalia (Medium) & 1 \\
\hline 17 & $\mathrm{X}$ & Early Archaic & Mammalia (Medium/Large) & 4 \\
\hline 17 & $\mathrm{X}$ & Early Archaic & Rodentia (Small/Medium) & 1 \\
\hline 17 & $\mathrm{X}$ & Early Archaic & Vertebrata & 2 \\
\hline 170 & Isi & Early Paleoindian & Large vertebrate, class indeterminate & 2 \\
\hline 170 & Isi & Early Paleoindian & Mammalia (Medium/Large) & 30 \\
\hline 170 & Isi & Early Paleoindian & Mammalia (Very large) & 2 \\
\hline 170 & Isi & Early Paleoindian & Vertebrata & 29 \\
\hline 173 & IIIc & Late Archaic & Antilocapra/Odocoileus & 6 \\
\hline 173 & IIIIc & Late Archaic & Artiodactyla & 1 \\
\hline 173 & IIIC & Late Archaic & Artiodactyla (Medium) & 4 \\
\hline 173 & IIIC & Late Archaic & Carnivora & 1 \\
\hline 173 & IIIC & Late Archaic & cf. Canidae & 1 \\
\hline 173 & IIIc & Late Archaic & Leporidae & 2 \\
\hline 173 & IIIC & Late Archaic & Mammalia (Large) & 14 \\
\hline 173 & IIIc & Late Archaic & Mammalia (Medium/Large) & 71 \\
\hline 173 & IIIc & Late Archaic & Medium/Large Vertebrata & 16 \\
\hline 173 & IIIc & Late Archaic & Odocoileus sp. & 3 \\
\hline 173 & IIIc & Late Archaic & Sigmodon hispidus & 3 \\
\hline 173 & IIIC & Late Archaic & Small/Medium Vertebrata & 1 \\
\hline 173 & IIIIc & Late Archaic & Vertebrata & 140 \\
\hline 175 & $\mathrm{IcI} / \mathrm{Isi}$ & Paleoindian & Vertebrata & 14 \\
\hline 175 & $\mathrm{Icl} / \mathrm{D}$ & Early Paleoindian & Vertebrata & 6 \\
\hline 177 & $\mathrm{IIIb} / \mathrm{c}$ & Middle Archaic & Mammalia (Medium/Large) & 2 \\
\hline 181 & ПІ/ІІа & Late Paleoindian/Early Archaic & Lepus californicus & 1 \\
\hline 181 & IIIIa & Early Archaic & Mammalia (Medium/Large) & 5 \\
\hline 181 & IIIa & Early Archaic & Small/Medium Vertebrata & 3 \\
\hline 181 & IIIa & Early Archaic & Vertebrata & 13 \\
\hline $181 ?$ & IIIa & Early Archaic & Medium/Large Vertebrata & 1 \\
\hline $181 ? 185 ?$ & II/IIIa & Late Paleoindian/Early Archaic & Mammalia (Medium/Large) & 1 \\
\hline 186 & II & Late Paleoindian & Mammalia (Medium) & 1 \\
\hline 187 & Icl/Isi-c & Paleoindian & Vertebrata & 1 \\
\hline $188 ?$ & Isi & Early Paleoindian & Mammalia (Large) & 1 \\
\hline 4 & $\mathrm{X} / \mathrm{Y}$ & Early Archaic & Vertebrata & 4 \\
\hline 4 & Y & Early Archaic & Vertebrata & 5 \\
\hline 50 & IIIb & Early Archaic & Medium/Large Vertebrata & 4 \\
\hline 50 & IIIb & Early Archaic & Small/Medium Vertebrata & 1 \\
\hline 50 & IIIIb & Early Archaic & Vertebrata & 2 \\
\hline 7 & IIIc & Late Archaic/Late Prehistoric & Antilocapra/Odocoileus & 1 \\
\hline
\end{tabular}


Table 33-13, continued

\begin{tabular}{|c|c|c|c|c|}
\hline Feature & Unit & Cultural Period & Taxon & Total \\
\hline 7 & IIIc & Late Archaic/Late Prehistoric & Artiodactyla & 2 \\
\hline 7 & IIIc & Late Archaic/Late Prehistoric & Mammalia (Large) & 1 \\
\hline 7 & IIIc & Late Archaic/Late Prehistoric & Mammalia (Medium/Large) & 4 \\
\hline 7 & IIIc & Late Archaic/Late Prehistoric & Vertebrata & 57 \\
\hline 8 & $\mathrm{X} / \mathrm{IIIb}$ & Early Archaic & Leporidae & 1 \\
\hline 8 & $\mathrm{X} / \mathrm{IIIb}$ & Early Archaic & Mammalia (Large) & 1 \\
\hline 8 & $\mathrm{X} / \mathrm{IIIb}$ & Early Archaic & Mammalia (Medium/Large) & 1 \\
\hline 8 & $\mathrm{X} / \mathrm{IIIb}$ & Early Archaic & Medium/Large Vertebrata & 1 \\
\hline 8 & $\mathrm{X} / \mathrm{IIIb}$ & Early Archaic & Serpentes & 1 \\
\hline 8 & $\mathrm{X} / \mathrm{IIIb}$ & Early Archaic & Small/Medium Vertebrata & 2 \\
\hline 8 & $\mathrm{X} / \mathrm{IIIb}$ & Early Archaic & Testudinata & 3 \\
\hline 8 & $\mathrm{X} / \mathrm{IIIb}$ & Early Archaic & Vertebrata & 12 \\
\hline 8 & $\mathrm{X} / \mathrm{Y}$ & Early Archaic & Mammalia (Medium/Large) & 1 \\
\hline 8 & $\mathrm{X} / \mathrm{Y}$ & Early Archaic & Vertebrata & 4 \\
\hline 8 & $\mathrm{X} / \mathrm{Y} / \mathrm{IIIb}$ & Early Archaic & Antilocapra/Odocoileus & 1 \\
\hline 8 & $\mathrm{X} / \mathrm{Y} / \mathrm{IIIb}$ & Early Archaic & cf. Antilocapra/Odocoileus & 1 \\
\hline 8 & $\mathrm{X} / \mathrm{Y} / \mathrm{IIIb}$ & Early Archaic & Leporidae & 1 \\
\hline 8 & $\mathrm{X} / \mathrm{Y} / \mathrm{IIIb}$ & Early Archaic & Mammalia (Large) & 1 \\
\hline 8 & $\mathrm{X} / \mathrm{Y} / \mathrm{IIIb}$ & Early Archaic & Mammalia (Medium/Large) & 4 \\
\hline 8 & $\mathrm{X} / \mathrm{Y} / \mathrm{IIIb}$ & Early Archaic & Medium/Large Vertebrata & 7 \\
\hline 8 & $\mathrm{X} / \mathrm{Y} / \mathrm{IIIb}$ & Early Archaic & Vertebrata & 27 \\
\hline
\end{tabular}

taphonomic research, however, has questioned these assumptions.

Zooarcheologists, then, have commonly interpreted sites that consist primarily of high meat yielding bones as reflecting a gourmet butchering strategy in which only choice meat cuts were returned to camp. Sites yielding only low utility items have often been interpreted as representing butchering sites, where low choice items were left behind, while higher utility items were transported elsewhere. Sites showing a mixture of low and high utility portions are often considered to reflect the extensive use of carcasses. Recent taphonomic research, however, has questioned these assumptions.

Lyman (1982b, 1984, 1985, 1993) and Kreutzer (1992) have shown that differential preservation of dense skeletal elements can create assemblages that are dominated by low utility elements in both deer and bison bone assemblages. Lyman noted that skeletal elements with high food value tend to have low structural density, while low food value elements have high structural density. Since low food value elements tend to preserve better than high food value elements, assemblages with numerous low utility bones may reflect preservation factors more so than butchering practices.

Thus, from sites where preservation is a clear biasing factor, like Wilson-Leonard, a reconstruction of butchering practices from element representation is problematic. As previously discussed, the 1/4-inch sample yielded the largest artiodactyl counts from the site, with an entire range of elements present (see Table 33-5). The only elements conspicu- ously absent from the sample are ribs. Mammal ribs were present at the site, but were highly fragmented. Thus, artiodactyl ribs probably fall within the counts for medium/large mammal indeterminate. Interestingly, low utility elements dominate the assemblage. Phalanges, podials, and sesamoids alone constitute $41 \%(n=187)$ of the artiodactyl elements in the 1/4-inch assemblage. These are the thick dense bones of the lower forelimbs and hindlimbs. From the range of elements present, it appears that entire carcasses of at least some artiodactyls were returned to the site. However, the high frequency of dense, low food utility elements suggests that density-mediated attrition may have biased the assemblage.

A second line of evidence for animal processing strategies usually comes from cut marks on bones. Cut marks are caused by stone tools during animal dismemberment and disarticulation. Butchering practices could not be interpreted through cut mark evidence on the Wilson-Leonard sample since few examples were noted. Only 21 were noted in the $1 / 4-$ inch sample. These include cuts on indeterminate vertebrate $(n=5)$, indeterminate mammal $(n=8)$, indeterminate artiodactyl $(n=1)$, pronghorn/deer $(n=5)$, and deer $(n=2)$. These cut marks are typical of carcass disarticulation, though the small cut mark sample prevents a detailed analysis of the disarticulation sequence. Only two cut marks were observed in the 1/8inch sample. Both were on indeterminate mammal fragments.

Though not extensive, the best bison butchering data from the site come from the Early Paleoindian bone bed (Table 33-14). At least two individual bison are represented in the 
TABLE 33-14

Bison and Bison-sized Elements from 1/8-inch and 1/4-inch Recovery

\begin{tabular}{|c|c|c|c|c|c|c|}
\hline Lot & Unit & No. & Taxon & Element & Portion & Period \\
\hline \multicolumn{7}{|c|}{ 1/8-inch Sample: } \\
\hline 386 & |IIIc & 1 & Mammalia (very large) & Long bone & Diaphyseal fragment & Late Archaic \\
\hline 431 & $\mathrm{IIIb} / \mathrm{c}$ & 4 & Mammalia (very large) & Long bone & Diaphyseal fragment & Late Archaic \\
\hline 437 & IIIc & 1 & Mammalia (very large) & Long bone & Diaphyseal fragment & Late Archaic \\
\hline 1314 & Isi-c & 1 & Mammalia (very large) & Long bone & Diaphyseal fragment & Late Paleoindian \\
\hline 1665 & Id & 1 & Mammalia (very large) & $\begin{array}{l}\text { Tooth, permanent/deciduous } \\
\text { indeterminate }\end{array}$ & Enamel fragment & Late Paleoindian \\
\hline 2270 & Isi & 1 & Bison sp. & Permanent tooth & Cheek tooth & Early Paleoindian \\
\hline 2516 & Igl/Isi/Icl & 1 & Bison sp. & Permanent tooth & Upper M & Early Paleoindian \\
\hline 2569 & $\mathrm{Igl} / \mathrm{Isi} / \mathrm{Icl}$ & 1 & Mammalia (very large) & $\begin{array}{l}\text { Tooth, permanent/deciduous } \\
\text { indeterminate }\end{array}$ & Tooth & Early Paleoindian \\
\hline 2570 & $\mathrm{Igl} / \mathrm{Isi} / \mathrm{Icl}$ & 1 & Mammalia (very large) & $\begin{array}{l}\text { Tooth, permanent/deciduous } \\
\text { indeterminate }\end{array}$ & Cheek tooth & Early Paleoindian \\
\hline $\begin{array}{l}2648 \\
\text { Total: }\end{array}$ & Isi & $\begin{array}{r}1 \\
13\end{array}$ & Mammalia (very large) & Long bone & Diaphyseal fragment & Early Paleoindian \\
\hline \multicolumn{7}{|c|}{ 1/4-inch Sample: } \\
\hline $15 \mathrm{U} 2$ & |I & 2 & Mammalia (very large) & $\begin{array}{l}\text { Tooth, permanent/deciduous } \\
\text { indeterminate }\end{array}$ & Enamel fragment & Late Paleoindian \\
\hline $30 \times 1 c$ & III & 2 & Mammalia (very large) & Long bone & Diaphyseal fragment & Late Paleoindian \\
\hline $10 \mathrm{E}$ & IIIIc & 1 & Bison sp. & Fused 3rd and 4th metacarpal & Proximal anterior lateral end & Late Archaic \\
\hline $10 \mathrm{E}$ & IIIc & 2 & Mammalia (very large) & Rib & Shaft fragment & Late Archaic \\
\hline $12 \mathrm{D}$ & IIIIc & 1 & Bison sp. & Radial carpal bone & Complete or nearly complete & Late Archaic \\
\hline $13 \mathrm{~F}$ & IIIc & 1 & Bison sp. & Proximal axial sesamoid & Complete or nearly complete & Late Archaic \\
\hline $15 \mathrm{D}$ & IIIlc & 1 & Bison sp. & Proximal sesamoid & Anterior aspect & Late Archaic \\
\hline $15 \mathrm{D}$ & IIIc & 1 & Mammalia (very large) & Long bone & Diaphyseal fragment & Late Archaic \\
\hline $16 \mathrm{~F}$ & IIIc & 1 & Bison sp. & Permanent tooth & Lower I & Middle/Late Archaic \\
\hline 17D & IIIIc & 1 & Bison sp. & Fused second and third tarsal & Complete or nearly complete & Late Archaic \\
\hline $36 \mathrm{D}$ & IIIc & 1 & Bison sp. & Humerus & Distal medial end & Late Archaic \\
\hline 37DC & IIIlc & 1 & Bison sp. & Mandible & Horizontal ramus with diastema & Late Archaic \\
\hline 37DC & IIIc & 1 & Bison sp. & Permanent tooth & Lower M3 & Late Archaic \\
\hline 37FB & IIIc & 1 & Mammalia (very large) & Long bone & Diaphyseal fragment & Late Archaic \\
\hline $15 \times 1$ & $\mathrm{Id} / \mathrm{II}$ & 1 & Mammalia (very large) & Long bone & Diaphyseal fragment & Late Paleoindian \\
\hline 29LL2a & $\mathrm{Ig} 1 / \mathrm{Isi}$ & 1 & Bison sp. & Scapula & $\begin{array}{l}\text { Glenoid fossa and incomplete } \\
\text { blade }\end{array}$ & Early Paleoindian \\
\hline 30LL2a & $\mathrm{Igl} / \mathrm{Isi}$ & 1 & Bison sp. & Tibia & Distal end & Early Paleoindian \\
\hline 31LL2/MM1c & $\mathrm{Igl} / \mathrm{Isi}$ & 1 & Bison sp. & Proximal phalanx & Complete or nearly complete & Early Paleoindian \\
\hline 31MM1b & Igl/Isi & 1 & Bison sp. & Permanent tooth & Upper M1 or 2 & Early Paleoindian \\
\hline $31 \mathrm{MM} 2 \mathrm{a}$ & $\mathrm{Ig} 1 / \mathrm{Isi}$ & 1 & Bison sp. & Calcaneus & Lateral aspect & Early Paleoindian \\
\hline 31MM2b & $\mathrm{Igl} / \mathrm{Isi}$ & 1 & Bison sp. & Rib & Vertebral end & Early Paleoindian \\
\hline $34001 \& 2 b$ & $\mathrm{Igl} / \mathrm{Isi}$ & 1 & Bison sp. & Astragalus & Complete or nearly complete & Early Paleoindian \\
\hline $35002 \mathrm{a}$ & Igl/Isi & 5 & Mammalia (very large) & Indeterminate & Fragment & Early Paleoindian \\
\hline $35002 b$ & $\mathrm{Ig} 1 / \mathrm{Isi}$ & 1 & Bison sp. & Cervical vertebra & Centrum and neural area & Early Paleoindian \\
\hline $25 \mathrm{II} 2 \mathrm{c}$ & Isi & 1 & Mammalia (very large) & Indeterminate & Fragment & Early Paleoindian \\
\hline $34 N N 2 b$ & Isi & 1 & cf. Bison & Vertebra & Neural area only & Early Paleoindian \\
\hline $15 \mathrm{AA} 2$ & Isi-c & 1 & Bison sp. & Cranium & Petrosal & Late Paleoindian \\
\hline 29AA1 & Isi-c/Id/II & 1 & Bison sp. & Lumbar vertebra & Centrum and neural area & Late Paleoindian \\
\hline 17JJ2/KK1 & Isi/Icl & 1 & Bison sp. & Astragalus & Complete or nearly complete & Early Paleoindian \\
\hline 29LL1b & Isi/Icl & 1 & Mammalia (very large) & Indeterminate & Fragment & Early Paleoindian \\
\hline 30KK1\&2 & Isi/Icl & 1 & Bison sp. & Humerus & $\begin{array}{l}\text { Complete minus proximal } \\
\text { epiphysis }\end{array}$ & Early Paleoindian \\
\hline 31LL1d & Isi/Icl & 1 & Bison sp. & Permanent tooth & Upper M1 or 2 & Early Paleoindian \\
\hline 32MM1b & Isi/Icl & 1 & Bison sp. & $\begin{array}{l}\text { Tooth, permanent/deciduous } \\
\text { indeterminate }\end{array}$ & Cheek tooth & Early Paleoindian \\
\hline $32 \mathrm{MM} 2 \mathrm{~b}$ & Isi/Icl & 1 & Bison sp. & Astragalus & Lateral aspect & Early Paleoindian \\
\hline $32 \mathrm{MM} 2 \mathrm{~b}$ & Isi/Icl & 1 & Bison sp. & Astragalus & Medial aspect & Early Paleoindian \\
\hline 32MM2c & Isi/Icl & 1 & Mammalia (very large) & Indeterminate & Fragment & Early Paleoindian \\
\hline $32001 \& 2 a$ & Isi/Icl & 1 & Bison sp. & Mandible & $\begin{array}{l}\text { Ascending ramus w/part } \\
\text { horizongtal ramus }\end{array}$ & Early Paleoindian \\
\hline $32001 \& 2 a$ & Isi/Icl & 1 & Bison sp. & Permanent tooth & Lower M3 & Early Paleoindian \\
\hline 32002/PP1a & Isi/Icl & 1 & cf. Bison & Metacarpal & Proximal lateral end & Early Paleoindian \\
\hline 3300 & Isi/Icl & 2 & Mammalia (very large) & Indeterminate & Fragment & Early Paleoindian \\
\hline $35 \mathrm{NN} 1 \& 2 \mathrm{~b}$ & Isi/Icl & 1 & Mammalia (very large) & Long bone & Diaphyseal fragment & Early Paleoindian \\
\hline $35 \mathrm{NN} 1 \& 2 \mathrm{~d}$ & Isi/Icl & 1 & Bison sp. & Fused central/fourth tarsal & Complete or nearly complete & Early Paleoindian \\
\hline $35 \mathrm{NN} 1 \& 2 \mathrm{~d}$ & Isi/Icl & 1 & cf. Bison & Rib & Shaft fragment & Early Paleoindian \\
\hline
\end{tabular}


Table 13-14, continued

\begin{tabular}{|c|c|c|c|c|c|c|}
\hline Lot & Unit & No. & Taxon & Element & Portion & Period \\
\hline 37MM1c & Isi/Icl & 1 & Bison sp. & Permanent tooth & Lower M2 & Early Paleoindian \\
\hline $37001 / 2 a$ & Isi/Icl & 1 & Mammalia (very large) & Vertebra & Articular facet & Early Paleoindian \\
\hline $37001 / 2 \mathrm{a}$ & Isi/Icl & 1 & Mammalia (very large) & Vertebra & Centrum & Early Paleoindian \\
\hline $37001 / 2 a$ & Isi/Icl & 1 & Mammalia (very large) & Vertebra & Neural area only & Early Paleoindian \\
\hline $37002 a$ & Isi/Icl & 1 & Bison sp. & Fused 3rd and 4th metacarpal & Proximal end & Early Paleoindian \\
\hline 37PP2a & Isi/Icl & 1 & Mammalia (very large) & Indeterminate & Fragment & Early Paleoindian \\
\hline 37PP2a & Isi/Icl & 1 & Mammalia (very large) & Indeterminate & Fragment & Early Paleoindian \\
\hline 37PP2a & Isi/Icl & 1 & Mammalia (very large) & Vertebra & Neural area only & Early Paleoindian \\
\hline 24DD1d & Isi/Isi-c & 1 & Bison sp. & Astragalus & Complete or nearly complete & Paleoindian \\
\hline 24DD2d & Isi/Isi-c & 1 & Mammalia (very large) & Indeterminate & Fragment & Paleoindian \\
\hline 28EE2d & Isi/Isi-c & 1 & Bison sp. & Tibia & Distal end & Paleoindian \\
\hline $32 \mathrm{~W} 2$ & II & 1 & Mammalia (very large) & Long bone & Diaphyseal fragment & Late Paleoindian \\
\hline 170 & Isi & 2 & Mammalia (very large) & Long bone & Diaphyseal fragment & Early Paleoindian \\
\hline \multicolumn{7}{|c|}{65} \\
\hline
\end{tabular}

bone bed, including an adult and a one young animal. While no cut marks were identified, elements include those of the cranium (maxillary and mandibular teeth), the pectoral girdle (scapula), vertebral column (cervical and lumbar vertebrae, ribs), forelimbs (humerus, metacarpal), hindlimbs (tibia), and feet (astragalus, calcaneus, phalanx). A metacarpal is spirally fractured. The assemblage of elements within the bone bed implies that these individuals were partially butchered at this locality and that the animals were killed at the site or close to it. Elements such as teeth and foot bones are generally low utility elements that are typically discarded at the kill location. The bison elements attest to the butchering of an adult and juvenile bison within the excavated portion of the site.

\section{Marrow and Grease Extraction}

In addition to the use of animals for meat, humans are known to process animals for both bone marrow and bone grease (Binford 1981; DeMarcay 1986; Lintz 1976; Peale 1978; Zierhut 1967). Bone marrow extraction involves breaking open long-bone shafts for the removal of marrow. Marrow extraction can be identified archeologically by a high degree of spirally fractured long-bone ends, fragmented long-bone shafts, and the presence of impact marks on long bones (DeMarcay 1986:70; Noe-Nygaard 1977). Impact marks are areas of conchoidal fractures where bones were hit with objects such as hammerstones to break open the medullary cavity for access to bone marrow.

Bone grease extraction, in contrast, involves extensive bone fragmentation and boiling for grease removal. Assemblages reflecting grease processing typically consist of extensive, small-sized, unidentifiable, unburned, spirally fractured accumulations of bone (Leechman 1951; Lintz 1976; Vehik 1977). Though detailed spatial analysis was not possible, the 1/4-inch Wilson-Leonard sample was evaluated to determine if marrow or grease processing could be identified.

At least some marrow processing seems evident at the site. Spiral fracture summary data for artiodactyls (deer and pronghorn/deer indeterminate) is presented in Table 33-15. Of the 397 elements (count excludes teeth) assigned to deer or pronghorn/deer in the $1 / 4$-inch sample, 123 (31\%) are spirally fractured. Table 33-15 shows that a broad range of longbone elements is spirally fractured. Sixty-six of these (53.7\%) are articular ends of long bones. This pattern of a high frequency of spirally fractured long-bone articular ends conforms to the predictions of marrow processing discussed above. The other predictions include highly fragmented long-bone shafts and the presence of impact marks. No impact marks were observed on any bones from the site, although this may simply be a reflection of postdepositional degradation. A large proportion of spirally fractured shaft fragments, however, was observed.

In addition to these data, 3,197 specimens were recorded from the 1/4-inch as medium/large mammal indeterminate. Of this sample, $38.2 \%(n=1,222)$ consist of spirally fractured bone fragments. In all likelihood, these indeterminate mammal bones represent deer. Thus, the high frequency of spirally fractured shaft fragments and long-bone articular ends suggests that marrow processing of artiodactyls was taking place at the site. The picture for grease processing, however, is less clear.

As discussed above, assemblages reflecting grease processing should show extensive, small-sized, unidentifiable, unburned, spirally fractured accumulations of bone. Numerous small, unidentifiable, spirally fractured bones, in fact, were identified in the $1 / 4$-inch sample $(n=2,150)$. These counts are in addition to the 1,222 medium/large mammal bones noted above that show spiral fractures. On first appearance, these numerous, spirally broken bones would appear to reflect grease processing. However, many of these fragments are burned. From the ethnographic model predictions, grease-yielding bone should remain unburned. After grease processing occurs, bones are typically discarded in piles away from the fire. In addition, bones that have been processed extensively for grease have less collagen and organics than required to produce the vitrified blue and white burned bone typical of the sample. Thus it 
TABLE 33-15

Spirally Fractured Artiodactyl Elements (Deer and Deer/Pronghorn Indeterminate)

\begin{tabular}{|c|c|c|}
\hline Element & Portion & Totals \\
\hline Mandible & Ascending ramus complete & 1 \\
\hline Mandible & Alveolar ridge fragment & 2 \\
\hline Humerus & Distal portion of shaft & 2 \\
\hline Humerus & Distal posterior part of shaft & 1 \\
\hline Humerus & Distal lateral part of shaft & 1 \\
\hline Humerus & Distal end & 6 \\
\hline Humerus* & Distal end & $* 2$ \\
\hline Radius & Proximal end & 2 \\
\hline Radius & Proximal posterior end & 1 \\
\hline Radius & Proximal lateral end & 1 \\
\hline Radius & Proximal medial end & 4 \\
\hline Radius & Distal end & 2 \\
\hline Femur & Proximal end & 1 \\
\hline Femur & Distal end & 2 \\
\hline Femur & Diaphyseal fragment & 1 \\
\hline Tibia & Proximal portion of shaft & 1 \\
\hline Tibia & Prox. lateral portion of shaft & 1 \\
\hline Tibia & Distal end & 9 \\
\hline Tibia & Distal lateral end & 1 \\
\hline Tibia & Diaphyseal fragment & 1 \\
\hline Fibula & Diaphyseal fragment & 1 \\
\hline Metapodial & Posterior portion of shaft & 1 \\
\hline Metapodial & Diaphyseal fragment & 3 \\
\hline Fused 3rd and 4th metacarpal & Proximal end & 1 \\
\hline Fused 3rd and 4th metacarpal & Proximal anterior end & 1 \\
\hline Fused 3rd and 4th metacarpal & Proximal anterior medial end & 1 \\
\hline Fused 3rd and 4th metacarpal & Proximal lateral end & 1 \\
\hline Fused 3rd and 4th metacarpal & Proximal medial end & 1 \\
\hline Fused 3rd and 4th metacarpal & Distal portion of shaft & 1 \\
\hline Fused 3rd and 4th metacarpal & Distal end & 3 \\
\hline Fused 3rd and 4th metacarpal & Diaphyseal fragment & 1 \\
\hline Fused 3rd and 4th metatarsal & Proximal end & 1 \\
\hline Fused 3rd and 4th metatarsal & Proximal anterior end & 3 \\
\hline Fused 3rd and 4th metatarsal & Proximal anterior medial end & 1 \\
\hline Fused 3 rd and 4 th metatarsal & Proximal posterior end & 1 \\
\hline Fused 3rd and 4th metatarsal & Proximal posterior medial end & 1 \\
\hline Fused 3rd and 4th metatarsal & Proximal lateral end & 1 \\
\hline Fused 3rd and 4th metatarsal & Prox. post. portion of shaft & 1 \\
\hline Fused 3rd and 4th metatarsal & Anterior portion of shaft & 3 \\
\hline Fused 3rd and 4th metatarsal & Distal portion of shaft & 1 \\
\hline Fused 3rd and 4th metatarsal & Distal end & 1 \\
\hline Fused 3rd and 4th metatarsal & Diaphyseal fragment & 31 \\
\hline Phalanx & Distal portion of shaft & 1 \\
\hline Phalanx & Distal end & 1 \\
\hline Phalanx* & Distal end & *1 \\
\hline Proximal phalanx & Proximal end & 3 \\
\hline Proximal phalanx* & Proximal end & $* 1$ \\
\hline Proximal phalanx* & Proximal anterior end & *1 \\
\hline Proximal phalanx & Distal end & 5 \\
\hline Proximal phalanx & Distal anterior end & \\
\hline Middle phalanx & Distal end & 5 \\
\hline Calcaneus & Medial aspect & 1 \\
\hline Total: & & 123 \\
\hline
\end{tabular}

seems unlikely that these small, burned, spirally fractured bones reflect grease processing.

It is suggested here that these fragments may, instead, be associated with marrow processing. Following long-bone breakage and marrow extraction, shaft fragments could have been discarded in fires where they were burned; or some of this material could have been burned during subsequent episodes of midden or hearth use. As the taphonomic analysis 
shows, burning can lead to extensive bone fragmentation. Thus, long-bone shaft fragments with spiral fractures from marrow processing could have been further reduced through discard by burning. However, the burned bone data for artiodactyl long-bone articular portions (see Table 33-15) complicates this interpretation. Only four of these articular ends are burned. If the interpretation of the small, burned, spirally fractured bone is correct and these bones were tossed in fires after marrow processing, it suggests that ends of long bones were discarded differentially since so few are burned.

\section{Conclusions}

The faunal sample from the Wilson-Leonard site is highly fragmented. The majority of the sample consists of unidentifiable fragments. For specimens that could be identified to class, mammals dominate. Artiodactyls were most frequently identified in the 1/4-inch sample, followed by turtle, rabbit, carnivore, bison, rodent, snake, bird, and fish elements. The 1/8-inch sample is dominated by rabbits, turtles, rodents and snakes. Forest, forest edge, and riparian taxa are most commonly represented. Tooth wear and epiphyseal fusion data for deer show that a range of subadult, adult, and old adult cervids were hunted. No specific seasonal indicators were identified in the assemblage.

Only 21 cut marks were identified in the 1/4-inch sample, while 2 were observed from the 1/8-inch sample. Specific butchering patterns and disarticulation sequences could not be reconstructed. The range of artiodactyl elements present at the site, however, suggests that at least some deer were brought back to the site whole. Differential preservation in favor of dense, low utility elements likely biased the sample. The high frequency of spiral fractures is believed to reflect marrow processing, though whether grease processing occurred remains unresolved.

\section{PALEOINDIAN AND ARCHAICSUBSISTENCE}

This section reviews the broader issue of animal exploitation by Paleoindian and Archaic peoples and compares relevant data from the Wilson-Leonard site. The initial portion of this review is drawn from Steele and Powell (1993:142144) and Powell and Steele (1994). The traditional view of Paleoindians is that they were big-game hunters. In this model, small animals and plants are generally considered to have been unimportant in Paleoindian diet. Similarities in projectile point styles throughout North America and their association with megafaunal kills are used as evidence in support of this specialized subsistence economy. Following megafaunal extinctions by $10,000-8,000$ B.P., Early to Middle Archaic peoples are seen as having shifted to a more-generalized diet, including a broader range of plants and small fauna. With the onset of the Early Archaic, more regional diversity is evident in North American projectile point styles. These varying tool kits suggest that more diverse food- getting strategies began to appear in the Early Archaic. Plant remains also occur more frequently at post-Pleistocene North American archeological sites.

More recently, this model of specialized Paleoindian subsistence has been challenged. Johnson (1977) questioned the stereotypical view that all Paleoindians were systematic big-game hunters. She reviewed Paleoindian sites showing a range of small- and medium-sized taxa, in addition to large game animals. Increasingly, researchers are suggesting that not all Paleoindians were specialized big-game hunters (Olsen 1990). This alternative model proposes that Paleoindians, like Archaic peoples, exploited a wide range of plants and animals. While it is recognized by proponents of this model that some Paleoindian groups focused on big game hunting, these occurrences are seen as localized adaptations within a broader sphere of Paleoindian subsistence strategies. Examples of additional data sets potentially supporting this view of Paleoindians as generalized hunter-gatherers are provided below.

Powell and Steele (1994) recently examined North American Paleoindian skeletal material and showed that dental microwear defects were comparable to those identified in Early and Middle Archaic populations, suggesting continuity in subsistence strategies. Meltzer and Smith (1986) also questioned the assumption that all Paleoindians and early Holocene groups were specialized big-game hunters. They argued that Paleoindian and early Holocene site distributions, tool assemblages, and projectile point functions and distributions are consistent with a generalized subsistence economy (Meltzer and Smith 1986:3). In sum, they suggested that Paleoindian and Archaic subsistence were relatively continuous. Meltzer (1988) stressed this point further in his continued research in eastern North America. He suggested that tundra and tundra-forest dwelling Paleoindians in this area were possibly specialized caribou hunters, while forest dwelling Paleoindians were generalists.

Other researchers have also supported the generalized Paleoindian subsistence model. From the Levi site in Central Texas, Alexander (1963) suggested a generalized economy associated with Plainview occupations dated to 9300 B.P. Evidence of small game exploitation and seed grinding suggested that an "Archaic pattern of life was developing as early as 9000 to 7000 years ago" (Alexander 1963:527). Perttula (1989:21), in reviewing Paleoindian evidence from East Texas stated, "there is no clear evidence in northeast Texas for the association of Paleoindian components with the remains of extinct late Pleistocene megafauna....Instead, it is more likely...that the Paleoindian groups were characterized by a generalized forest-based hunting and gathering strategy comparable to the Southeastern North American Paleoindian populations."

From the Aubry site, in north-central Texas, Ferring (1989) reported Clovis material in association with bison, deer, rabbit, pocket gopher, vole, squirrel, bird, turtle, snake. Though research on this site is ongoing, Ferring (1989:11) states 
"the well-preserved faunas will shed light on Clovis subsistence." A Paleoindian sample from Montana also included small animals - "utilized taxa... include cottontail rabbit, mink, and deer....Numerous calcined bone fragments reflect food preparation and detrital discard" Davis et al. (1989:9). From Kincaid Shelter in Texas, Collins et al. (1989) report Clovis material in association with both small and large animals, and Yesner et al. (1992) imply that late Pleistocene Paleoindians exploited a broad range of animals, including water fowl and small mammals.

Most recently, Storck and Spiess (1994) argue that evidence from the Udora site in south-central Ontario, Canada suggests that subsistence strategies for late Pleistocene Paleoindians in this area included a mix of both large and small animals (caribou, hare, and arctic fox). Though much of the research discussed here is ongoing, these recent studies increasingly support the model that at least some Paleoindians emphasized a generalized foraging strategy. This appears increasingly evident for forest dwelling Paleoindians. With this review in mind, data are presented below from the 1/4- and 1/8-inch Wilson-Leonard samples for Paleoindian and post-Paleoindian intervals at the site.

\section{Paleoindian Fauna at Wilson-Leonard}

Taxa identified from Paleoindian components at the Wilson-Leonard site include musk turtle, emydid turtle, snake, bird, rodent, jackrabbit, cottontail rabbit, canid, deer, bison, and horse (see Tables 33-9 and 33-10). Deer and pronghorn/ deer indeterminate dominate the 1/4-inch Paleoindian assemblage, though bison is most common in the Early Paleoindian component. These artiodactyls are followed in decreasing frequency by rabbit, turtle, carnivore, rodent, and bird. In the 1/8-inch sample, small taxa such as leporids, turtles, and snakes are most common during the Paleoindian intervals. Among the leporids, cottontails dominate over jackrabbits during the Paleoindian periods. By the Middle Archaic, cottontails are less frequent, while jackrabbits are relatively more common. This may be related to climatic differences, with xeric jackrabbit habitats established following a more mesic early Holocene period. While bison is present at the site, it represents only a small portion of the total faunal sample, which is dominated by a diverse range of smaller animals.

\section{Early Paleoindian Bone Bed}

The Early Paleoindian bone bed consists of materials recovered from Units Igl/Isi and $\mathrm{Igl} / \mathrm{Isi} / \mathrm{lll}$, plus all bison and bison-sized bone recovered from Early Paleoindian context. A total of 1,167 specimens was recovered from the 1/4-inch sample. The sample is dominated by indeterminate fragments $(\mathrm{n}=971 ; 83.2 \%)$. Other taxa include indeterminate turtle $(n=2)$, musk turtle $(n=1)$, indeterminate small mammal $(\mathrm{n}=8)$, medium/large-sized mammal $(\mathrm{n}=101)$, large mammal
( $n=11)$, bison-sized mammal ( $n=19)$, rabbit/hare $(n=16)$, indeterminate artiodactyl $(n=1)$, large artiodactyl $(n=5)$, and bison $(n=32)$. Burned bone comprises $11.5 \%(n=134)$ of the sample, while $8(0.69 \%)$ spirally fractured bones were identified. Burned specimens include the 2 unidentified turtle elements and 3 bison elements. Spiral fractures were identified on a large artiodactyl fragment and a bison humerus and metacarpal.

At least two individual bison are represented in the bone bed, including an adult and a juvenile animal. The bison MNI is based on the presence of two right astragali. Age structure, as discussed previously, was based on dentition and epiphyseal fusion. The wide range of elements present (including low utility elements) suggests the bison were killed and butchered at or near the site.

A total of 236 bone bed specimens was recovered from the $1 / 8$-inch sample. The sample is dominated by indeterminate fragments $(\mathrm{n}=121 ; 51.27 \%)$. Other taxa include indeterminate turtle $(n=2)$, indeterminate small mammal $(n=3)$, medium-sized mammal ( $\mathrm{n}=2)$, medium/large-sized mammal ( $\mathrm{n}=85)$, large mammal $(n=6)$, bison-sized mammal $(n=2)$, rabbit/hare $(n=10)$, jackrabbit $(n=1)$, cottontail $(n=2)$, and bison $(n=2)$. Burned bone comprises $45.34 \%$ ( $n=107$ ) of the sample, while $3(1.27 \%)$ spirally fractured mammal bones were identified. Burned taxa include turtle, small mammal, medium-sized mammal, jackrabbit, and cottontail.

\section{Late Paleoindian (Golandrina, Barber, St. Mary's Hall Components)}

The Late Paleoindian lanceolate point component consists of materials from Unit II. A total of 1,542 specimens was recovered from the 1/4-inch sample. The sample is dominated by indeterminate fragments $(\mathrm{n}=1,177 ; 76.33 \%)$. Other taxa include cf. turtle $(\mathrm{n}=1)$, indeterminate turtle $(\mathrm{n}=2)$, large bird $(n=1)$, indeterminate small mammal $(n=2)$, small/mediumsized mammal ( $\mathrm{n}=1)$, medium-sized mammal $(\mathrm{n}=14)$, medium/ large-sized mammal ( $\mathrm{n}=288)$, large mammal $(\mathrm{n}=24)$, bison-sized mammal ( $\mathrm{n}=5)$, rabbit/hare $(\mathrm{n}=3)$, jackrabbit $(\mathrm{n}=1)$, cf. cottontail $(n=1)$, cottontail $(n=7)$, carnivore $(n=3)$, canid $(n=1)$, indeterminate artiodactyl $(n=1)$, and pronghorn/deer $(n=10)$. Burned bone comprises $70.69 \%(n=1,090)$ of the sample, while $78(5.06 \%)$ spirally fractured bones were identified. Burned taxa include turtle, bird, jackrabbit, cottontail, carnivore, canid, and pronghorn/deer. Spiral fractures were identified on various fragments, as well as on bison-sized mammal and pronghorn/deer.

A total of 4,592 specimens was recovered from the 1/8inch sample. The sample is dominated by indeterminate fragments $(n=4,127 ; 89.85 \%)$. Other taxa include fish $(n=85)$ indeterminate turtle $(n=16)$, lizard/snake $(n=2)$, snake $(n=13)$, indeterminate small mammal ( $\mathrm{n}=69$ ), small/medium-sized mammal ( $n=4)$, medium-sized mammal ( $n=21$ ), medium/large-sized mammal ( $n=168)$, large mammal ( $n=6)$, cf. rabbit/hare $(n=3)$, rabbit/hare ( $n=31)$, cf. jackrabbit $(n=1)$, jackrabbit $(n=9)$, cf. 
cottontail $(n=3)$, small rodent $(n=4)$, medium-sized rodent $(n=8)$, gopher $(n=16)$, woodrat $(n=1)$, carnivore $(n=3)$, indeterminate artiodactyl $(\mathrm{n}=1)$, and deer $(\mathrm{n}=1)$. Burned bone comprises $77.29 \%(n=3,550)$ of the sample, while $5(0.11 \%)$ spirally fractured bones were identified. Burned taxa include fish, turtle, snake, jackrabbit, cottontail, gopher, woodrat, carnivore, and deer.

\section{Late Paleoindian (Wilson Component)}

The Late Paleoindian Wilson component consists of materials from Unit Isi-c. A total of 1,846 specimens was recovered from the $1 / 4$-inch sample. The sample is dominated by indeterminate fragments $(n=1,565 ; 84.73 \%)$. Other taxa include indeterminate turtle $(n=12)$, kinosternid turtle $(n=1)$, water turtle $(n=1)$, indeterminate bird $(n=1)$, indeterminate mammal $(n=1)$, indeterminate small mammal $(n=2)$, small to medium-sized mammal ( $\mathrm{n}=1)$, medium-sized mammal $(\mathrm{n}=21)$, medium/large-sized mammal ( $n=194)$, large mammal $(n=7)$, medium-sized rodent $(n=1)$, rabbit/hare $(n=5)$, jackrabbit $(n=1)$, cottontail $(n=8)$, carnivore $(n=2)$, cf. Canis $\mathrm{sp} .(\mathrm{n}=1)$, indeterminate artiodactyl $(n=6)$, deer $(n=6)$, pronghorn/deer $(n=9)$, and bison $(n=1)$. The sample is extensively burned $(\mathrm{n}=1,509 ; 81.70 \%)$. Burned taxa include turtle, bird, jackrabbit, cottontail, rodent, carnivore, canid, and deer. Fifty-five $(2.98 \%)$ spirally fractured bones were identified. Spiral fractures were identified on numerous fragments and pronghorn/deer.

A total of 1,521 specimens was recovered from the $1 / 8$ inch sample. The sample is dominated by indeterminate fragments $(n=1,312 ; 86.26 \%)$. Other taxa include indeterminate turtle $(n=12)$, kinosternid turtle $(n=1)$, lizard/snake $(n=2)$, snake $(n=12)$, large bird $(n=1)$, indeterminate small mammal $(n=22)$, small/medium-sized mammal $(n=1)$, medium-sized mammal ( $n=5)$, medium/large-sized mammal $(n=95)$, large mammal $(n=4)$, bison-sized mammal $(n=1)$, shrew $(n=2)$, rabbit/hare $(n=11)$, jackrabbit $(n=4)$, cf. cottontail $(n=1)$, cottontail $(n=22)$, small rodent $(n=1)$, medium-sized rodent $(n=2)$, cf. ground squirrel $(n=1)$, cf. gopher $(n=1)$, gopher $(n=5)$, woodrat $(n=2)$, and indeterminate artiodactyl $(n=1)$. Burned bone comprises $70.02 \%(n=1,065)$ of the sample, while only 6 $(0.39 \%)$ spirally fractured bones were identified. Burned taxa include snake, bird, jackrabbit, cottontail, and woodrat. Spiral fractures were identified on various indeterminate mammal fragments.

\section{Archaic/Late Prehistoric Fauna at Wilson-Leonard}

As with the Paleoindian sample, deer and pronghorn/ deer dominate the Archaic through Late Prehistoric assemblage at the site. These artiodactyls are followed in decreasing frequency by turtle, rabbit, carnivore, bison, and rodent. Overall, the general trend reflected by the Archaic/Late Prehistoric sample is similar to that reflected by the Paleoindian sample. Both 1/4-inch samples for these time periods are dominated by deer or pronghorn/deer, and both show a wide range of taxa. The major difference between the time periods is a higher frequency of bison and cottontail rabbit in the Paleoindian intervals.

\section{Early Archaic}

The best Early Archaic context from the site comes from Unit IIIa. A total of 769 specimens was recovered from the $1 / 4$-inch sample. The sample is dominated by indeterminate fragments $(\mathrm{n}=580 ; 75.42 \%)$. Other taxa include indeterminate turtle $(n=19)$, small/medium-sized mammal $(n=2)$, mediumsized mammal $(n=3)$, medium/large-sized mammal $(n=133)$, large mammal $(n=11)$, cf. rabbit/hare $(n=1)$, rabbit/hare $(n=2)$, cottontail $(n=2)$, carnivore $(n=1)$, canid $(n=1)$, indeterminate artiodactyl $(n=3)$, and pronghorn/deer $(n=11)$. Burned bone comprises $50.85 \%(n=391)$ of the sample, while $110(14.30 \%)$ spirally fractured bones were identified. Burned taxa include turtle, rabbit/hare, and carnivore. Spiral fractures were identified on various fragments and on pronghorn/deer.

A total of 3,580 specimens was recovered from the $1 / 8$ inch sample. The sample is dominated by indeterminate fragments $(n=3,108 ; 86.65 \%)$. Other taxa include fish $(n=5)$, indeterminate turtle $(n=53)$, kinosternid turtle $(n=3)$, mud turtle $(n=2)$, softshell turtle $(n=1)$, lizard/snake $(n=3)$, snake $(n=19)$, small bird $(n=1)$, small mammal $(n=14)$, indeterminate small mammal $(n=39)$, medium-sized mammal $(n=22)$, medium/largesized mammal $(n=216)$, large mammal $(n=10)$, rabbit/hare $(n=32)$, jackrabbit $(n=8)$, cottontail $(n=17)$, medium-sized rodent $(n=3)$, tree squirrel $(n=1)$, gopher $(n=12)$, medium-sized cricetid rodent $(n=1)$, woodrat $(n=2)$, carnivore $(n=1)$, indeterminate artiodactyl $(\mathrm{n}=1)$, deer $(\mathrm{n}=3)$, and pronghorn/deer $(n=3)$. Burned bone comprises $35.07 \%(n=1,258)$ of the sample, while only $25(0.70 \%)$ spirally fractured mammal bones were identified. Burned taxa include turtle, snake, jackrabbit, cottontail rabbit, tree squirrel, and deer.

\section{Late Archaic}

The best Late Archaic context from the site comes from Unit IIIc. A total of 3,337 specimens was recovered from the 1/4-inch sample. The sample is dominated by indeterminate fragments $(n=2,476 ; 74.20 \%)$. Other taxa include fish $(n=1)$, indeterminate turtle $(n=16)$, kinosternid turtle $(n=4)$, water turtle $(n=1)$, snake $(n=5)$, indeterminate small mammal $(n=1)$, small/medium-sized mammal $(n=2)$, medium-sized mammal $(n=6)$, medium/large-sized mammal $(n=477)$, large mammal $(n=137)$, large/very large mammal $(n=1)$, bison-sized mammal $(n=4)$, rabbit/hare $(n=9)$, jackrabbit $(n=1)$, cottontail $(n=4)$, tree squirrel $(n=2)$, cotton rat $(n=3)$, carnivore $(n=4)$, raccoon $(n=2)$, cf. canid $(n=1)$, canid $(n=1)$, indeterminate artiodactyl $(n=44)$, cf. deer $(n=1)$, deer $(n=40)$, pronghorn $(n=2)$, cf. pronghorn/deer $(n=1)$, pronghorn/deer $(n=83)$, and bison $(n=8)$. Burned bone comprises $22.60 \%(n=754)$ of the sample, while 
$1,020(30.57 \%)$ spirally fractured bones were identified. Burned taxa include jackrabbit, cottontail, carnivore, deer, pronghorn/deer, and bison. Spiral fractures were identified on carnivore, deer, pronghorn, pronghorn/deer, and bison.

A total of 4,719 specimens was recovered from the $1 / 8$ inch sample. The sample is dominated by indeterminate fragments ( $n=3,580 ; 75.86 \%)$. Other taxa include fish ( $n=3)$, frog/ toad $(n=1)$, indeterminate turtle $(n=37)$, kinosternid turtle $(n=1)$, water turtle $(n=11)$, snake $(n=24)$, large bird $(n=1)$, small mammal $(n=3)$, indeterminate small mammal $(n=13)$, small/ medium-sized mammal ( $n=11)$, medium-sized mammal $(n=9)$, medium/large-sized mammal $(\mathrm{n}=824)$, large mammal $(\mathrm{n}=68)$, bison-sized mammal ( $n=2)$, cf. rabbit/hare $(n=2)$, rabbit/hare $(n=8)$, jackrabbit $(n=10)$, cottontail $(n=14)$, small rodent $(n=1)$, medium-sized rodent $(n=7)$, gopher $(n=5)$, medium-sized cricetid rodent $(n=3)$, cotton rat $(n=2)$, woodrat $(n=6)$, carnivore $(\mathrm{n}=1)$, indeterminate artiodactyl $(\mathrm{n}=18), \mathrm{cf}$. deer $(\mathrm{n}=2)$, deer $(n=31)$, pronghorn $(n=1)$, and pronghorn/deer $(n=20)$. Burned bone comprises $18.48 \%(\mathrm{n}=872)$ of the sample, while 952 (20.17\%) spirally fractured bones were identified on various deer and deer-sized fragments. Burned taxa include turtle, snake, rodent, deer, and pronghorn/deer.

\section{Late Prehistoric}

The best Late Prehistoric context from the site comes from Unit IIIc. A total of 805 specimens was recovered from the 1/4-inch sample. A well-defined Late Prehistoric context was not available from the 1/8-inch sample. The 1/4-inch Late Prehistoric sample from Unit IIIc is dominated by indeterminate fragments $(\mathrm{n}=581 ; 72.17 \%)$. Other taxa include medium/ large-sized mammal $(n=175)$, large mammal $(n=24)$, indeterminate artiodactyl $(n=3)$, deer $(n=7)$, and pronghorn/deer $(n=15)$. Burned bone comprises $24.60 \%$ ( $n=198)$ of the sample, while $373(46.34 \%)$ spirally fractured bones were identified.

\section{Bison Remains}

As previously discussed, the question of bison availability throughout the Holocene represents one of the most widely addressed zooarcheological issues in Central Texas. Only 78 specimens from the Wilson-Leonard site fall within the size-range of bison (see Table 33-14). Specimens are present in the following intervals: Paleoindian, Early Paleoindian, Late Paleoindian, Middle/Late Archaic, and Late Archaic. No bison were identified from the Early Archaic, corresponding roughly with the onset of Dillehay's (1974) Absence Period I. Bison is also absent in the Late Prehistoric components, and no specimens were recovered from definite Middle Archaic deposits.

\section{Conclusions}

Increasingly, the traditional view of all Paleoindians as specialized big-game hunters is being challenged. Many sites excavated in the past few years show a range of both large and small fauna, interpreted by archeologists as representing food refuse. Data from the 1/4-inch Wilson-Leonard fauna show that Paleoindian and Archaic/Late Prehistoric assemblages are comparable in many respects. Both periods also show a range of smaller taxa including rabbits, turtles, and carnivores. Bison appear more important during the Paleoindian period, though smaller taxa were apparently used as well.

\section{SUMMARY AND CONCLUSIONS}

The Wilson-Leonard site is significant in containing a well-preserved late Pleistocene and Holocene faunal sequence from the eastern Edwards Plateau of Central Texas. Approximately 11,000 years of intermittent human occupation is reflected at this deeply buried open site. The site is unique for this area in containing discrete Paleoindian and Early Archaic components. The majority of archeological sites in the area contain primarily Late Archaic and Late Prehistoric materials. Little opportunity has existed for the study of early Holocene human adaptation in Central Texas. The long-term sequence, open-air nature, and archeological context of the site is significant for our understanding of this region's prehistory.

The taphonomic analysis shows that the faunal sample is highly fragmented and consists primarily of unidentifiable fragments. Bone surfaces are extensively corroded and pitted. Plant rootlet etching does not appear to have significantly modified the assemblage. Geoarcheological investigations at the site showed that the site formed primarily under a low-energy sedimentation regime. No abrasion or rounding was evident on the 1/4-inch sample, suggesting that water transport did not significantly bias the sample.

In addition, rodent gnawing was not a significant form of bone degradation. Only $0.6 \%$ of the sample shows rodent gnaw marks. While faunal- and floralturbation at the site was minimal, the prehistoric construction of burned rock ovens during the Early and Late Archaic periods may have mixed cultural deposits of different ages in some areas of the site. The lower deposits of Paleoindian materials, however, remained relatively intact.

This analysis produced no evidence suggesting that carnivores either modified or deposited bone at the site. No carnivore gnaw marks or breakage was identified. Likewise, no specific intrusive taxa were identified in the assemblage. As additional taphonomic and subsistence analysis show, high frequencies of the small animal component of the site are burned, suggesting they reflect human food refuse.

Bone-density-mediated attrition, however, may have biased the artiodactyl sample toward dense elements such as carpals, tarsals, sesamoids, and phalanges. The recognition of this makes it difficult to address more fully the issue of differential carcass transport by humans at the site. While burned bone is relatively better preserved at the 
site, burning can also lead to a high degree of bone fragmentation. The extensive nature of burned bone throughout the site, and the conclusion that the majority of the bone was burned while it retained its organic collagen matrix, suggests that the burning is the result of cultural activity and not natural fire.

Though a broad range of classes and genera are present, artiodactyls (presumably deer), rabbits, and turtles dominate the assemblage. Fish and birds were rarely encountered in the 1/4-inch and 1/8-inch samples. Habitats exploited, as reflected in taxa presence, include riverine, forest and forest edge, scrubland, and grassland areas. Forest and forest edge environments are most commonly represented. Additional insight into human hunting is provided by deer tooth wear and epiphyseal fusion data. Tooth wear and bone fusion data suggest that a broad range of subadult, adult, and old adult deer were hunted. No specific indicators of seasonal site occupation or hunting were evident in the faunal assemblage.

Detailed butchering patterns for animals at the site could not be reconstructed. As the taphonomic analysis showed, the sample is heavily biased by bone fragmentation and differential preservation. Based on a broad (though skewed) range of deer and deer/pronghorn elements, it appears that at least some animals were returned to the site whole. Few specimens showed cut marks, thus they could not be used to reconstruct butchering patterns at the site. High frequencies of spirally fractured long-bone shaft fragments and articular ends are interpreted as reflecting marrow processing. The burned nature of many of these shaft fragments suggests they were not used in grease manufacture but may have been burned following marrow extraction.

A review of the Paleoindian and Archaic/Late Prehistoric faunas from the site suggests that both time periods show a range of diverse animals of varying size. Though counts are low and must be treated with caution, artiodactyls, rabbits, and turtles dominate the assemblages. The major difference between the Paleoindian and Archaic intervals is a greater number of bison bones during the Paleoindian period, and the fluctuating rabbit frequencies throughout the Holocene. Overall, the Wilson-Leonard site has yielded an important faunal data set that should continue to be the focus of future research. As one of the best preserved and sampled Quaternary faunal sequences on eastern Edwards Plateau, the Wilson-Leonard faunal sample has the potential to provide important insight for years to come. 


\title{
Chapter 34
}

\section{FINE-SCREENING METHODS}

\author{
by Susan Decker
}

\section{INTRODUCTION}

The process of fine screening refers to the technique of washing excavated matrix samples through nested mesh screens to recover microartifacts. It is similar to water screening or wet screening but is referred to as fine screening because of key differences in technique from traditional water-screening methods. The method of fine screening used by the Wilson-Leonard project was derived from the discipline of vertebrate paleontology (VP), where the technique has been employed for over a century to recover microfossils. McKenna (1965) provides a brief history of the method, from the earliest large-scale screening by Charles Moore in the nineteenth century to C. W. Hibbard's extensive use of screening as the primary retrieval method in the 1930s. McKenna improved screen construction in the 1960s and adapted the technique to suit a uniform particle size and a river water source but made it clear that the method is flexible and can be used under a variety of conditions.

Ernest L. Lundelius, Professor of Geological Sciences at The University of Texas at Austin, has long advocated the use of this technique to retrieve microfauna from archeological contexts and has refined it further. Lundelius employs nested screens having graded mesh sizes in order to handle matrix with various particle sizes, a common matter of concern for archeologists. The nested screens are immersed in stock tanks which can be set up near any water supply.

The VP method was selected for the TARL excavations for processing $100 \%$ of the matrix from two vertical columns (Squares 12 and 20), each a 1-x-1-m square. The procedure proved effective in processing a large amount of matrix composed of a wide range of particle sizes. Multiple bags of sediment were recovered from each $10-\mathrm{cm}$ level of a total of 131 levels (67 in Square 12, 64 in Square 20). Of 1,355 paired coarse and fine bags of concentrate, the archeological and faunal materials from all 1,355 coarse bags and from 405 fine bags were sorted and recovered. The 950 unsorted fine concentrate bags are available for future research.

Because the screening of the columns yielded such a valuable data set, a number of TxDOT and TARL samples from feature contexts in other squares were fine screened to aid in the feature analysis. A total of 116 samples, 42 of which were from the TARL excavations and 74 from the TxDOT excavations (including 25 from Burial 2) were processed. These represent 31 features in all three stratigraphic units. Some of these samples were the matrix left over from flotation; the fine screening process added another level of data without requiring a separate matrix sample. All of the TARL fine screening was accomplished with equipment and advice generously provided by Lundelius.

\section{ADVANTAGESOVER OTHER METHODS}

The VP method allows the recovery of the skeletal remains of many small species of animals that are valuable paleoenvironmental and economic indicators. Many such taxa are not recovered with standard 1/4-inch-mesh screens in traditional archeological wet and dry screening procedures. Similarly, otoliths of larger fish species are frequently retrieved with other methods, but the VP method recovers the otoliths of even very small species. By fine screening the matrix, a more-complete recovery of the aquatic and terrestrial species deposited at the site is possible.

The VP method inflicts minimal damage on the microfaunal remains, because it involves only a gentle agitation of the sample in water tanks. In contrast, the popular archeological practice of washing away sediment by spraying it with a pressured-nozzle hose breaks bones, especially when the clumps of dirt are broken apart between screeners' fingers or pushed through the screen. In addition, it is common practice to screen the matrix in the field 
and simultaneously pick out the visible bone by hand. Many bones are overlooked under these less than optimal conditions. In the VP method, bones are not handled until after they have been separated from the concentrate with wax tools and have been turned over to the faunal analyst. This method makes possible $100 \%$ recovery because the matrix is not hurriedly picked in the field during screening but rather is picked in a laboratory with the aid of magnifying lenses (see Retrieval of Finds, below). The advantages are that fewer of the VP-fine-screened bones are lost through the screen, fewer are broken into unidentifiable fragments, and more are recovered from the concentrate.

Rarely recovered bird eggshells were retrieved by using the VP method of fine screening. Bird eggshells provide supplementary evidence for avian species, which are often not well represented in the skeletal remains recovered from archeological sites. The study of eggshells is fairly new to archeology, but as the analysis in Chapter 36 shows, the eggs can easily be classified into general size categories, and with scanning electron microscopes they can be identified to species. Also, large assemblages of microdebitage were retrieved from the fine screens, from complete flakes to tiny potlids and notching flakes. Identifiable charred macrobotanical remains were valuable complements to the flotation samples, and the large quantity of microfauna recovered has allowed an extensive analysis of the paleoenvironment, the paleoeconomy, and related cultural activities.

\section{EQUIPMENT}

Fine screening uses inexpensive equipment consisting of a large galvanized metal stock tank and pairs of wooden nested screens. Twenty screen pairs and three tanks were used. The large number of screens was optional, but it allowed the residue to dry in the screens themselves while other samples were being washed, thus reducing the amount of handling. The screens were designed and built by Gorden Bell and Robert Rainey of the Vertebrate Paleontology Lab, The University of Texas at Austin.

Each set of nested screens consisted of two rectangular wood-framed screens, the top one of which had an 1/8-inch mesh and the bottom one had a 1/16-inch mesh. The concentrate that was caught in the $1 / 8$-inch mesh is referred to here as the coarse fraction, while the concentrate from the 1/16-inch mesh is called the fine fraction. The top screen had a stepped base which allowed it to fit snugly on top of the bottom screen so that the two would not come apart in the water tank. Since the bottom screen stayed under water during washing, the snug fit was necessary to prevent the matrix from escaping into the tank. The bottom screen had handles for lifting the screens and agitating the sample.

There were two reasons for separating the concentrate into two mesh sizes. First, the 1/8-inch mesh caught the larger pieces including rocks, while the very small microfauna passed through to the 1/16-inch screen; in this way the microfauna were saved from being crushed by the rocks while in the screens. Second, the concentrate from the two mesh sizes was analyzed separately; the 1/8-inch fraction was sorted without a magnifying lens, and the 1/16inch fraction was sorted under a microscope.

\section{PROCEDURES}

\section{Screening}

The following steps for the fine-screening process apply to all of the column samples. The feature samples underwent a slightly different procedure. The methods specific to the feature samples are indicated as such.

Step 1. The sample was dried in the sun on a plastic tarp. Drying caused clays in the sediment to contract. Once immersed in water, they expanded, causing the matrix to break apart and pass through the screens. The feature samples were already dry and did not require this step.

Step 2. The clean, empty nested screens were set in a tank of water (Figure 34-1). The bottom screen stayed below the water line, and the mesh of the top screen was at the water line. For the column samples, the same water was used for each sample until the tank had to be emptied of sediment; the samples were not slated to be used for any chemical analysis, so contamination from the water was not a problem. However, the tank was emptied, rinsed, and filled with clean water after washing every feature sample to eliminate contamination in anticipation of analyses that might be performed on the bone or charcoal at a later date.

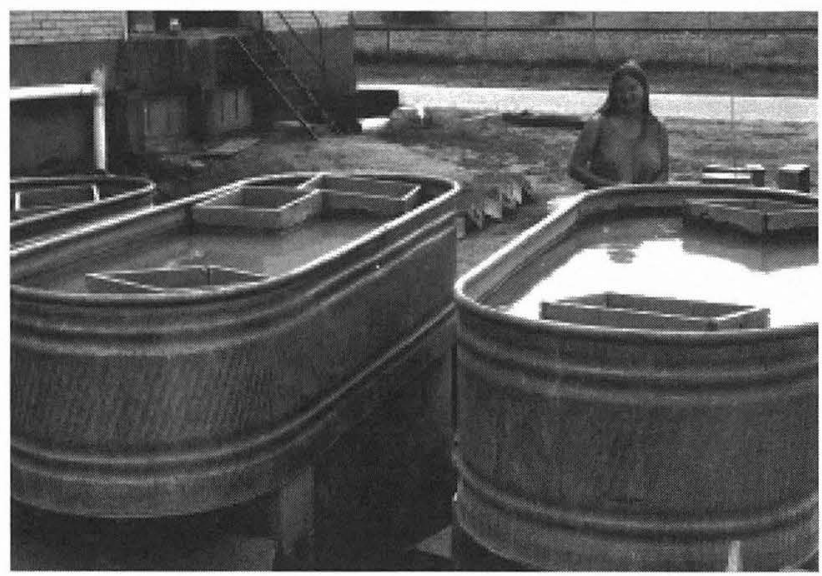

FIGURE 34-1. Nesting screens and water tanks used for fine screening of soil samples.

The dried sediment sample was poured into the first screen. Up to three sets of screens were used for each sample, depending on the sample size. For example, three sets were required for a ca. 20-liter sample. Care was taken to ensure that the screens did not tip over and that the 
matrix was poured evenly over the mesh. The weight of the matrix caused the top screen's mesh to be submerged, along with the matrix.

Step 4. Waterproof identification tags were placed in each top screen. At this point, the larger rocks were cleaned of matrix and removed from the screen so that they would not crush fragile materials during the agitation step. The rocks were set aside with an identification tag and were later cataloged.

Step 5. Each set of screens was gently agitated up and down under the water line to allow the sediment and any material less than 1/16-inch in diameter to pass through both screens (Figure 34-2). The sediment was never pushed through the mesh by hand or squeezed between the fingers to break it down, since that would have damaged the microfaunal remains. Whenever the soil did not immediately pass through the screens, it was allowed to soak in the tank and was agitated at intervals until it deflocculated.

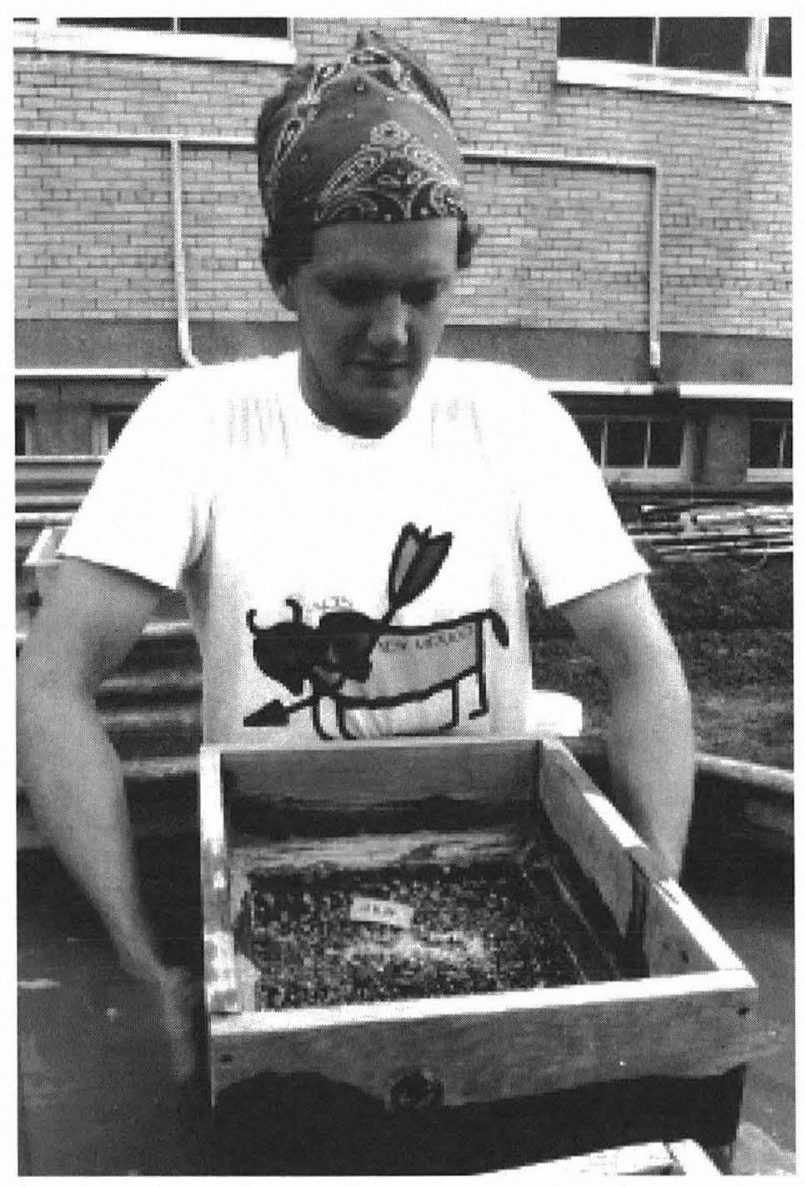

FIGURE 34-2. Agitation of nesting screens in water tank during fine screening.

Step 6. Auxiliary techniques were employed, following Lundelius's directions, in cases where soaking and agitation did not result in the complete deflocculation of the clays in the matirx. Intermediate drying between multiple washings helped in many cases for both the column and feature samples, because the wet-dry-wet cycle induced disintegration of aggregated sediment. An acid bath was used for those column samples that still did not break down; acid baths were not used for feature samples. A solution of water and hydrochloric acid from ordinary swimming pool cleaner was used for the acid bath. The screens were immersed for about 30 minutes in a $27 \% \mathrm{HCl}$ solution (to include the carbonates); they were then rinsed thoroughly in a water tank.

Special samples: An additional step was added for the first four Burial 2 samples that were processed. After fine screening, the water was skimmed with a $.710-\mathrm{mm}$ geological screen, and the contents were backwashed into a clean, labeled cloth for examination. When hair fibers were discovered in the cloths, it was decided that the rest of the burial samples would be floated immediately before fine screening (it was later determined that the "hair" was from brushes used in excavation). "Floating" here means that the sample was stirred in a bucket of water to allow the release of the floating particles. The water was then poured into another bucket through a .425-mm geological screen, which caught the floating items. Only the water was poured out, while all of the residue was held back in the first bucket. It is this residue that was poured into the nested screens. For nonburial feature samples, any floating charcoal or seeds were skimmed off the water surface with a .710-mm geologic screen and saved for analysis before the tank was emptied.

Step 7. After washing, each sample was air dried in a sunny location while still in the screens (Figure 34-3), since removing the residue from the mesh while it is still wet is difficult to do without damaging the bones. During inclement weather, the samples were air dried indoors with oscillating fans. Once completely dry, each sample was bagged and labeled; the coarse and fine fractions were bagged separately.

\section{Retrieval of Finds}

One hundred percent of the bones, eggshells, otoliths, seeds, and debitage was retrieved from the column sample fine-screened concentrate by picking successive trays of matrix until all of the above materials had been removed. The coarse fraction, that greater than 1/8inch, was picked without magnification or with a lamp fitted with a magnifying lens. The fine fraction, that between $1 / 8$ - and 1/16-inch, was picked under a $10 \mathrm{X}$ binocular microscope illuminated by a dual fiber optic light.

Both the coarse and the fine fractions from the feature samples were picked under the microscope so that the exact composition of the residue could be described. Four features (Features 168, 169, and 262 and Burial 2) were picked for $100 \%$ of the bones, eggshells, otoliths, charcoal, snails, debitage, burned limestone, ochre, unidentified minerals, quartz, quartzite, and other grains that 


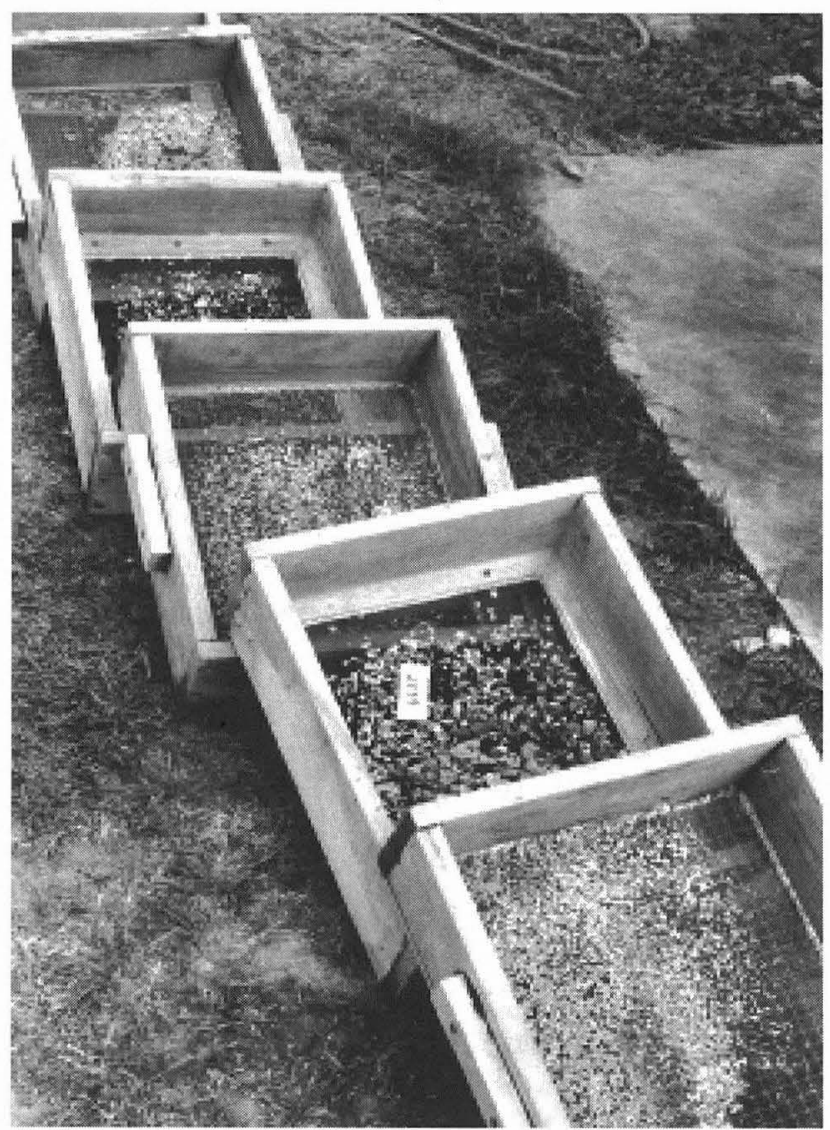

FIGURE 34-3. Fine-screened samples drying in the sun in separated top and bottom screens. were not limestone. The rest of the features were picked for $100 \%$ of the bones, eggshells, otoliths, and debitage in some cases. The composition of the feature matrix was compared with the composition of nonfeature matrix that had been fine screened in the same manner so that anomalies such as evidence for burning of the feature matrix could be identified. The bone densities per unit volume of excavated sediment were calculated, along with the proportions of burned to unburned bone.

\section{FINE SCREENING AT THE WILSON-LEONARD SITE}

As a multicomponent site, Wilson-Leonard benefited from an intensive program of fine screening. Because the site had several distinct cultural components spanning a long period of time, it both required and allowed a diachronic analysis of comparative data retrieved by a standardized method for all artifact categories, from the top of the site to the bottom. This objective was achieved by fine screening two complete vertical 1-x-1-m columns within the site using the same mesh sizes and recovery techniques for all of the matrix. The adoption of a screening method designed for the retrieval of delicate bones with a minimum of damage allowed large faunal assemblages to be recovered. Microfauna is especially sensitive to environmental and economic changes. By studying the changes in microfaunal assemblages through time, a clearer understanding is possible of the distinctions between cultural components. 


\section{Chapter 35}

\section{PLEISTOCENE TO HOLOCENE WILSON-LEONARD MICROVERTEBRATE FAUNA AND ITS PALEOENVIRONMENTAL SIGNIFICANCE}

by Robin Balinsky

\section{INTRODUCTION}

The microvertebrate fauna of the Wilson-Leonard site is reported here on the basis of approximately 36,000 specimens of identifiable and unidentifiable bone, teeth, otoliths, and eggshell from a 6.5 -m continuous stratigraphic sequence dated from approximately 1,000 to 12,000 years before present. Materials for this study were collected from Square 20, a 1-m square located along the east wall of the TARL excavation block. This square was one of two fine-screen squares excavated during the TARL excavations (see Chapters 3 and 34), but due to time constraints, only the fauna recovered from Square 20 is included in this analysis. Material from Square 12 is curated at the University of Texas Vertebrate Paleontology Laboratory (UTVPL) for future analysis under site number TMM43157. Specimens from Square 20 were identified to the lowest taxonomic level possible using the modern comparative collection at the UTVPL, resulting in a total of 45 taxa, including 29 taxa identifiable to genus and 8 identifiable to species.

The identification of seven extralimital rodent taxa supports a paleoenvironmental interpretation of fluctuating wet and dry climatic intervals and overall deeper soil depths over the past 12,000 years. These taxa are the bog lemming (Synaptomys cooperi), the yellow-faced pocket gopher (Cratogeomys castanops), the marsh rice rat (Oryzomys palustris), the muskrat (Ondatra zibethicus), the pine/prairie vole (Microtus sp.), the eastern pocket gopher (Geomys sp.), and the smooth-toothed pocket gopher (cf. Thomomys sp.).

The recovery of these extralimital taxa in the context of a well-dated stratigraphic sequence is congruent with similar faunal records from the 1982-1984 Wilson-Leonard excavations, Hall's Cave in Kerr County, and other sites around the Edwards Plateau, as well as pollen data from Boriack Bog in eastern Central Texas. An effort was made to closely compare the Wilson-Leonard microfauna with the Hall's Cave faunal record, because it is the closest well-dated and extensively analyzed in Central Texas. Although the WilsonLeonard microvertebrate fauna1 sample is small, fragmentary and, for the most part, poorly preserved, its diversity, long stratigraphic continuity, and location relative to other microvertebrate sites in Central Texas make Wilson-Leonard an important microvertebrate locality. The presence of Cratogeomys castanops and Thomomys sp. also records the extension of their previously known past ranges an additional $100 \mathrm{~km}$ eastward.

The primary objective of this study is to identify and describe the microvertebrate faunal sequence at WilsonLeonard and interpret that sequence in paleoenvironmental terms. It was determined in an earlier study (Winkler 1990) that environmentally sensitive microvertebrate remains are present at the site, but their representation is very low owing to poor preservation. In assessing the status of the database TxDOT excavators provided for Winkler's study, Collins et al. $(1991: 14,63)$ questioned the effectiveness of the faunal recovery techniques used for the TxDOT excavation. Winkler studied the microvertebrates recovered by "water screening" the fill from the northwest quadrant of TxDOT Square E28/S78 (the "fine-screen unit") on 1/16-inch wire mesh. Photographs taken during the 1984 water screening of that unit clearly show matrix being pushed through the screen by hand, a method that could potentially damage small bone. It was recommended, therefore, that an additional column taken from the surface to the bedrock be dug by TARL and processed using the less-destructive and more-consistent screening techniques described briefly in this chapter and in detail in Chapter 34.

In evaluating the results of this later effort, it is notable that of 3,493 identifiable pieces of bone from the TxDOT fine-screen unit, $365(10.4 \%)$ were identifiable as fish; of the 365 , only 18 (4.9\%) could be identified to family; of 4,575 identifiable pieces of bone from TARL Square 
$20,591(12.9 \%)$ were identified as fish; of the 591,100 (16.9\%) could be identified to family. Improved faunal resolution is also demonstrated by the recovery and identification of larger numbers of postcranial elements and teeth of the smaller cricetine rodents, particularly Peromyscus sp.; 10 specimens of Peromyscus sp. were recovered from the latest excavation as compared to a single specimen from the TxDOT excavation. These results are interpreted as reflecting the reduced breakage of fragile bone achieved by the present study.

Matrix from Square 20 was collected from a total of 64 levels beginning at the top with Level 6 (Levels 1-5 were discarded without screening because they consisted of disturbed fill) continuing through Level 19 and Levels 24 through 73 (numbers 20-23 were skipped but no actual matrix was skipped or discarded). Levels 12, 13, 16, 25, 26, and 5456 were divided horizontally into " $\mathrm{A}$ " and " $\mathrm{B}$ " subsets to separate materials associated with cultural features (the "B" subset) found in those levels. Most of the levels were $10 \mathrm{~cm}$ thick, although Levels $24-31$ were $5 \mathrm{~cm}$ thick.

The faunal column of Square 20 spans nearly the full range of the three major stratigraphic units (I-III) present at the Wilson-Leonard site, reaching a depth of approximately $6.5 \mathrm{~m}$ (Figure 35-1). The column cuts through an area with considerable interfingering of the different stratigraphic subunits, particularly within the lowermost, Unit I. The base of Unit I, subunit Igl, consists of gravel deposits overlying Comanche Peak Limestone bedrock. Bone recovered from subunit Igl (Levels 55-73) is sparse, consisting mostly of tooth fragments or burned bone. In contrast, an abrupt abundance of scrap bone occurs in the lower Icl and Isi/Icl transition (Levels 51-53). This corresponds to the Early Paleoindian bison bone bed. Unburned bone appears to be slightly decalcified with a soft, chalky texture and a whole or partial coating of carbonate precipitates. This is particularly noticeable in a large amount of cancellous scrap bone from Level 52. Bone is slightly more plentiful in subunit Isic (the Leanne soil), and some of the unburned bone is better preserved, although carbonate coated.

Unit II consists of fluvial and colluvial deposits overlying Unit I. Bone from Unit II is more abundant, and abundance continues and increases toward the top of the column with no apparent reversals. It is likely that this pattern is a function of decreasing preservation over time caused by leaching and organic loss (Hare 1980). While bone from Unit II shows less evidence of leaching than that from Unit I, there is a considerable amount of etching and pitting in both burned and unburned bone from Unit II, particularly affecting the fine fraction. This may result from one or more causes including acids in groundwater or soil or digestive processes of animals and/or human occupants.

Bone is considerably more abundant in Unit III and retains the etched appearance noticeable in Unit II. The bone from the uppermost levels has an extremely dirty appearance. It is difficult to tell whether the dark discolorations evident on more than $50 \%$ of the bone are oxides or stains and/or coatings of thin layers of humic soil. Because the discoloration is extensive, it seems to both mask and at times enhance the visible effects of burning or charring, causing problems in determining that attribute. Consequently, the percentages of burning in Unit III should be viewed as probably having a greater error margin than the two lower units.

\section{MATERIALSAND METHODS}

Approximately $1,500 \mathrm{~kg}$ of matrix was collected from Square 20 in 691 bags with bag numbers correlated to square and level provenience. The bags were transported to the UTVPL where the matrix was first dried on large plastic-covered flats and then screenwashed. The screenwashing setup consisted of three large water tanks and nested sets of 1/8- and 1/16-inch-mesh screens. Matrix was poured into the floating screens and allowed to soak for up to several hours depending on the clay content and calcification. The matrix was then intermittently gently agitated and allowed to soak until soil and clays had broken down, leaving a coarse and fine concentrate. Larger rock fragments were removed at this point, if present, and the washed concentrate was allowed to dry in the sun. Matrix with heavy clay content required more than one stage of washing and drying in order to break down the clays (see Chapter 34 for more details).

After drying, the concentrate was rebagged, labeled, and transferred inside the UTVPL where it was hand picked. Fine concentrate was picked under a binocular microscope while coarse concentrate could be picked with an unaided eye. All bone, snails, small lithic fragments, shells, and seeds were separated out at this point, placed in 5-dram vials or in gelatin capsules within vials, labeled with the original bag number, and stored on a table awaiting final identification. All (691 bags) of the coarse concentrate and 307 of the 691 bags of fine concentrate were picked from Square 20. Of these, faunal remains from 419 coarse bags and 234 fine bags were identified for this study.

The final step involved identification of the bone using an optic light, an Olympus SZ30 microscope (9-40X magnification) and the modern comparative collection the UTVPL. Specimens were identified to their lowest possible taxonomic level and were numbered and catalogued denoting taxon, element, number of specimens, provenience, and any additional comments such as burning, preservation, or notation of a unique characteristic. All bags from Levels 35-72 were fully analyzed. A minimum number of three bags of coarse concentrate and two bags of fine concentrate were analyzed for each level above 35 (only one bag of fine concentrate was recovered from Levels $12 \mathrm{~A}, 13 \mathrm{~B}$, and 25A and $\mathrm{B}$ ). Based on personal observation, this provided a broad enough sampling distribution to include a wide range of taxa. 


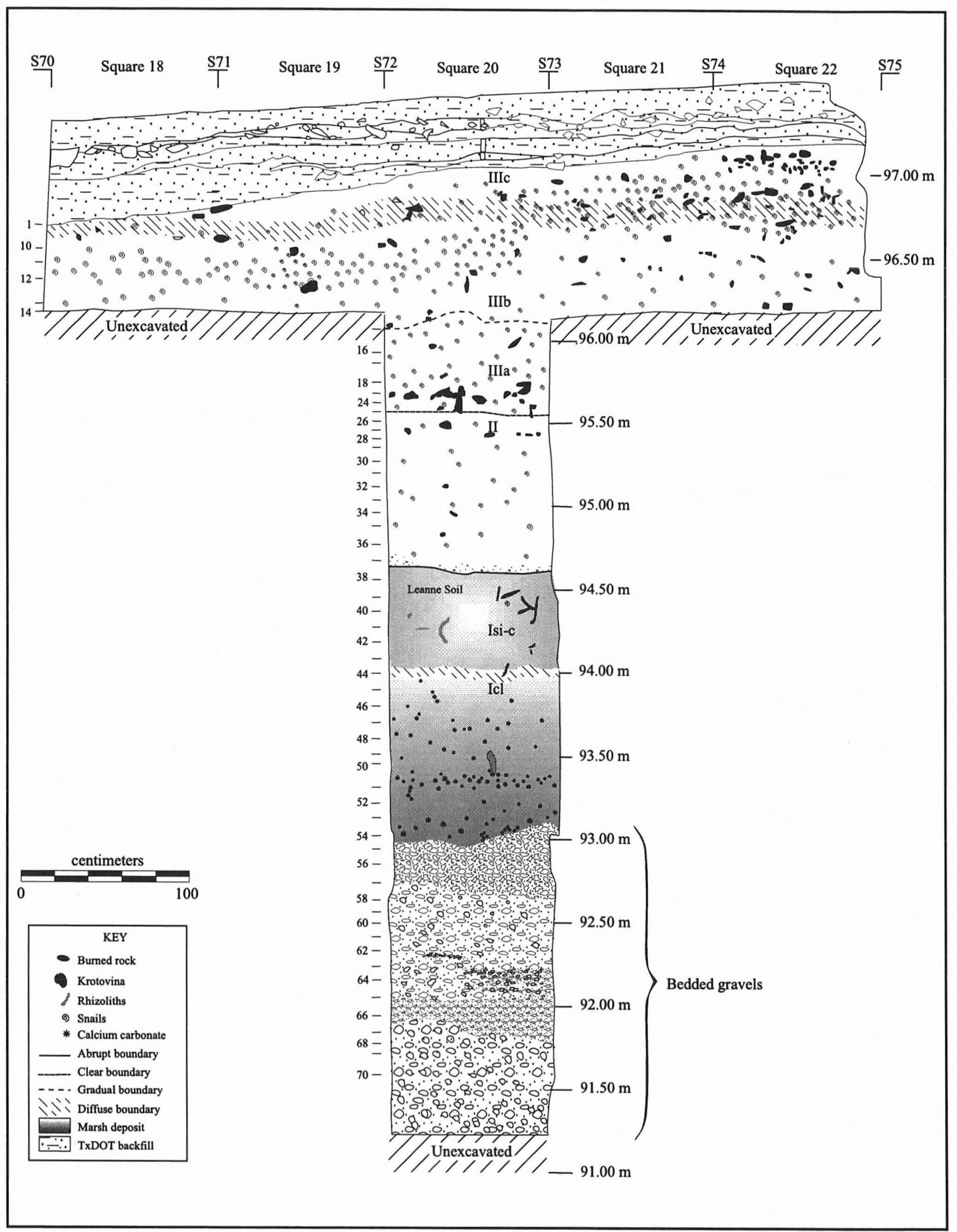

FIGURE 35-1. Profile of Square 20 stratigraphic column. 


\section{FAUNAL PRESERVATION}

Faunal preservation in the entire column ranged from poor to very poor with both preservation quality and faunal abundance decreasing rapidly toward the base of the column. The surface erosion, pitting, and highly fractured nature of the bone often limited specimen identification. This resulted in a high percentage of bone that was unidentifiable, averaging $87 \%$ for the entire column (Figure 35-2). The identifiable percentage was limited to mostly higher or more general taxonomic levels such as Teleost, Chelonia, small mammal, etc. Only the rodents and other taxa such as Phrynosoma sp. or Trionyx sp., which exhibit highly distinctive tooth patterns, elements, or bone textures were exceptions to this. Taxa were identified primarily by teeth or tooth fragments, as well as epiphyseal postcranial fragments, metapodial fragments, and carpal/tarsal elements. Very few whole bones of any taxon of any size were recovered.

\section{FAUNAL DISCUSSION}

Analysis of the fauna from Square 20 resulted in a fairly diverse representation of small taxa and a modest diversity of medium and larger animals from rabbit to bison size. Forty-four taxa were identified including 27 identifiable to genus and 9 identifiable to species from a total number of 4,575 specimens of bone, teeth, otoliths, and eggshell (Tables 35-1 through 35-4). Of the 45 identifiable taxa, 24 are represented by less than 10 specimens each, making sample sizes small and inappropriate for statistical manipulation or determination of minimum number of individuals. Although fish, snakes, and turtles were abundant in numbers of specimens, rodents were by far the best represented both in numbers of specimens and in numbers of taxa, comprising one-third of the total taxonomic diversity and $27 \%$ of the total number of identifiable specimens (Figure 35-3). Birds, amphibians, insectivores, and medium mammals, particularly carnivores, are poorly represented at Wilson-Leonard, most likely due to either their fragility or low representation in the area.

Although there is an abundance of fish specimens, particularly in the upper third of the column, most can be classified only as unidentified teleost based on bone texture and coloration. Centrarchids are represented by pharyngeal fragments and otoliths, both of which have diagnostic textures and shapes even when poorly preserved or burned. Several specimens of otoliths were originally tentatively identified to the genus, Lepomis, but this could not be verified based on the condition of the otolith collection at the UTVPL. A small number of ictalurids could be identified from spine fragments and a single otolith.

Amphibians are represented largely by postcranial elements of anurans including humeri, ilia, and vertebrae. Of a total of 38 specimens of amphibians, only 5 could be identified to the genus Rana, $2 R$. catesbiana based on a pair of large, relatively well-preserved ilia. Based on size alone, several of the smaller specimens of anura may include one or more species of Hyla. Four specimens exhibiting bone texture and shape attributable to Caudata could be determined, but identification to a lower taxonomic level was not possible.

Reptilian diversity at Wilson-Leonard is moderate and is represented by 10 taxa including 1 genus of turtle (Trionyx sp.), 2 genera of snakes (Elaphe sp. and Sonora sp.), and 2 genera of lizards (Phrynosoma sp. and Ophisaurus attenuatus). Turtle carapace and/or plastron fragments are abundant in the upper part of the column and may be referable to the family Kinosternidae. While snake vertebrae were fairly abundant, the difficulty associated with identifying snakes based solely on vertebrae or vertebral fragments severely limits their classification. Several specimens may be referable to the genera Crotalis, Masticophis, and Thamnophis. Lizard specimens that were identifiable to genus or species include 2 horns belonging to the genus Phrynosoma and 11 scales of the glass lizard Ophisaurus attenuatus. Several well-preserved but unidentifiable specimens of lizard jaws recovered from the fine concentrate may be identifiable at a later time.

Birds are represented in small numbers by both postcranial fragments and eggshell fragments. All bird material identified can be attributed to passerine-sized birds. Greater abundance of eggshell is particularly noticeable in Levels 7 and 8 and also in Level 38 (see Table 35-2). Additional data on eggshell abundance and characteristics are presented in Chapters 29 and 36.

Small mammals are the most diverse group of animals present at Wilson-Leonard and are represented by lagomorphs, rodents, and a single insectivore, Cryptotis parva (see Table 35-1 for complete listing and Figure 35-3 for vertical distribution). Sigmodon sp. and Neotoma sp. are the most common identifiable rodents present, followed by Geomys sp. and Microtus sp. Other rodents are represented by fewer specimens. Most rodent identifications are based on isolated tooth fragments, but some postcranial fragments, particularly tarsal bones, were very useful in diagnosing taxa and tended to preserve better than other elements. Although medium mammals were certainly present, very few could be identified based on the specimens recovered. Lepus specimens are uncommon and may be underrepresented. Carnivores are represented by several specimens of Canis $\mathrm{cf}$. latrans and two specimens of Procyon lotor. No mustelids or felids were identified. A single medium-sized, low-crowned tooth fragment from Level 24 may be assignable to either Castor sp. or Erethizon sp. but could not be verified based on the incompleteness of the specimen. Large mammal specimens are also uncommon and the highly fragmentary nature of the material made identification difficult. 


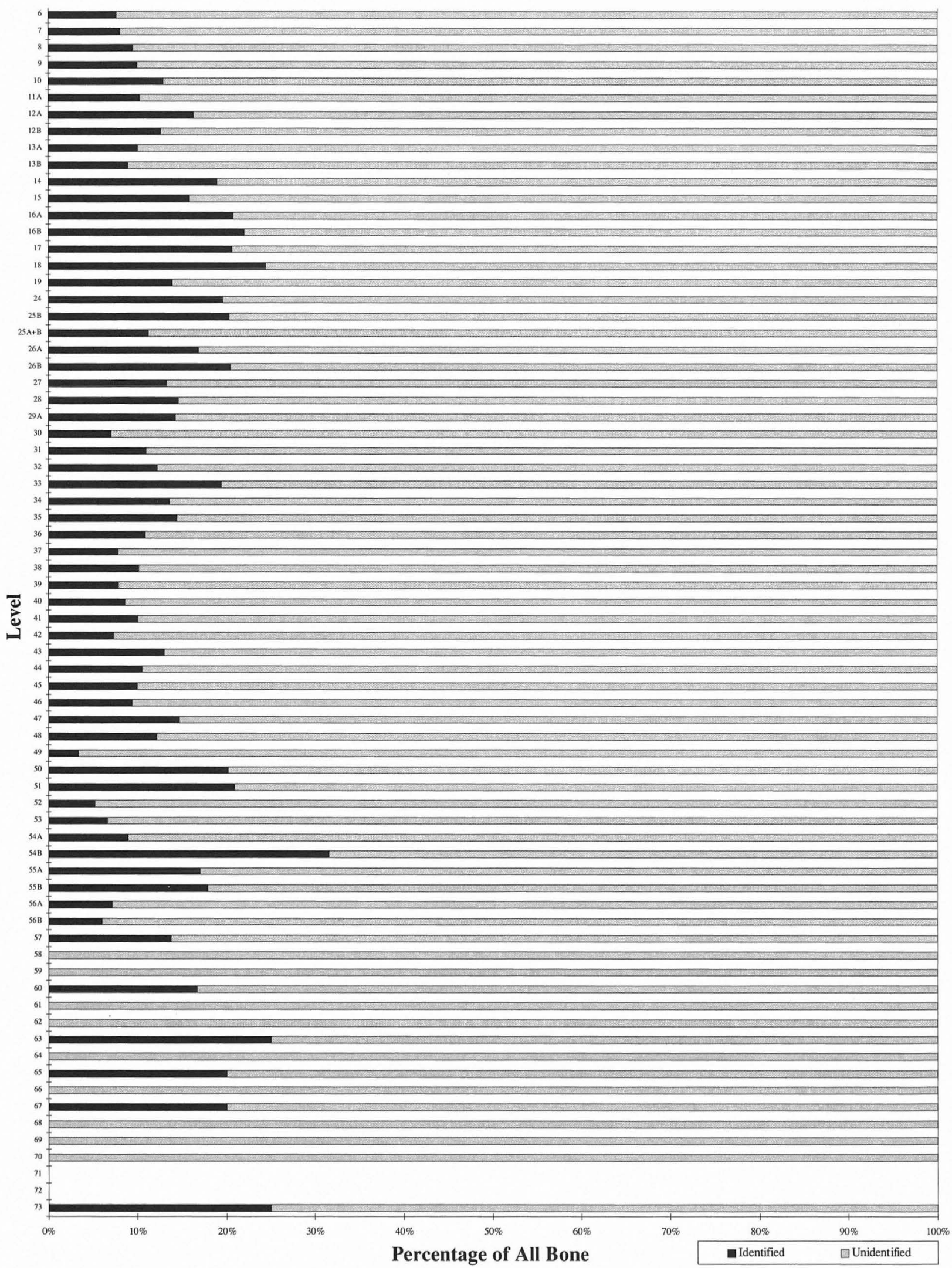

FIGURE 35-2. Percentages of identified versus unidentified bone in Square 20 by excavation level. 
TABLE 35-1

Faunal Taxa and Common Names

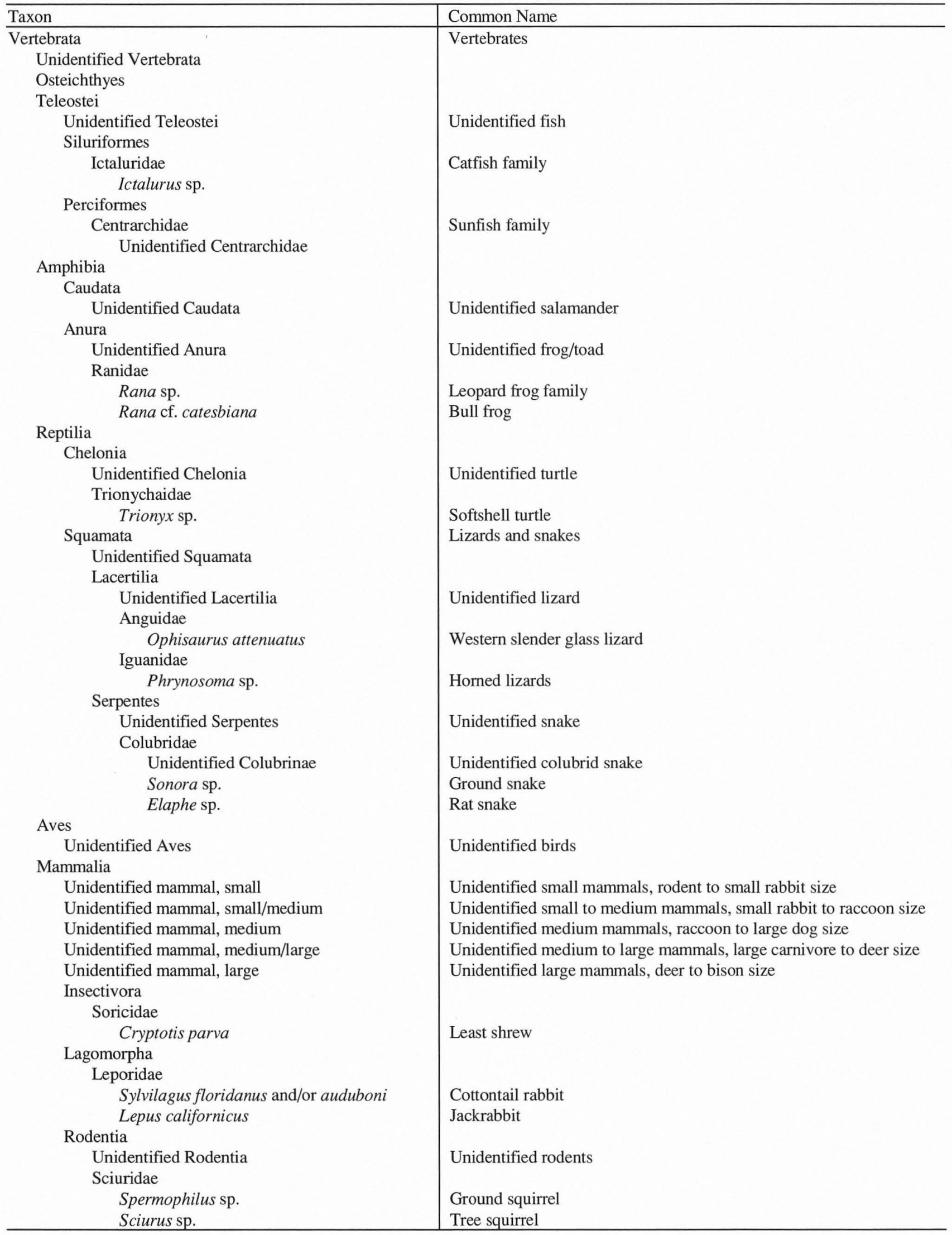




\begin{tabular}{|c|c|}
\hline Taxon & Common Name \\
\hline Rodentia (continued) & \\
\hline Geomyidae & \\
\hline Geomys sp.* & Grooved-tooth pocket gophers \\
\hline Cratogeomys castanops* & Yellow-faced pocket gopher \\
\hline Thomomys sp.* & Smooth-toothed pocket gophers \\
\hline Heteromyida & \\
\hline Perognathus sp. & Pocket mice \\
\hline Muridae & \\
\hline Reithrodontomys sp. & Harvest mice \\
\hline Peromyscus sp. & White-footed deer and field mice \\
\hline Sigmodon hispidus & Hispid cotton rat \\
\hline Neotoma sp. & Wood rats \\
\hline Microtus ochrogaster or M. pinetorum* & Voles \\
\hline Synaptomys cooperi* & Bog lemming \\
\hline Oryzomys palustris* & Marsh rice rat \\
\hline Ondatra zibethicus* & Muskrat \\
\hline Carnivora & \\
\hline Unidentified Carnivora & Unidentified carnivores \\
\hline Canidae & \\
\hline Canis latrans or $C$. familiaris & Coyote or domestic dog \\
\hline Procyonidae & \\
\hline Procyon lotor & Raccoon \\
\hline Artiodactyla & \\
\hline Unidentified Artiodactyla & Unidentified even-toed ungulates \\
\hline Cervidae & \\
\hline Odocoileus sp. & White-tailed deer \\
\hline Bovidae & \\
\hline Bison sp. & Bison \\
\hline
\end{tabular}

\section{FAUNALMODIFICATION}

Aside from a high degree of specimen incompleteness, several other biases potentially affect the preservation of the faunal record at Wilson-Leonard. These include burning, human or animal processing and/or trampling, and groundwater alteration. Burning is a notable characteristic of the bone from this column affecting $25.4 \%$ of that recovered. Any specimens exhibiting minimum characteristics of slight charring or subtle bluish gray discoloration were identified as burned. The extent of burning ranged from these minimum stages to total blackening or removal of all color, resulting in a pale gray to white color. Burned white bone was easily distinguishable from bleached or leached white bone by possessing a higher level of surface textural preservation and by not having a soft, friable appearance in comparison. Less-burned bone also show better preservation than unburned bone regardless of stratigraphic level or the particular soil type from which the bone was recovered.

Percentages of burning differ across the column (Figure 35-4). In Levels 6-37 (Units IIIc through II), 24.7\% of the total bone is burned with individual level percentages ranging from $8.6 \%$ to $68.1 \%$ (averaging $30.8 \%$ ). From Levels 38 through 73 (Unit I) burning accounts for $31.3 \%$ of the total number of specimens, with individual level percentages ranging from $0 \%$ to $91.0 \%$ burned (averaging $35.8 \%$ ). The higher percentage of burned bone in the lower levels is more likely attributable to the preservational aspects of burning rather than an increased level of cultural or natural burning.

While percentages of burning do not differ significantly between identifiable and unidentifiable bone, patterns of burning within the identifiable bone fraction tend to be taxon specific. This suggests that human occupation may have served as a bias and influence on the faunal record in the selection and introduction of certain taxa as food items to the site. Although the faunal record at Wilson-Leonard is fairly diverse and compatible with other noncultural sites in Central Texas (Lundelius 1967), there are particular quantitative and burning patterns evident in the lagomorph, fish, and turtle specimens that indicate those taxa may have been used as food items by humans occupying the site. Lagomorph, specifically Sylvilagus sp., is consistently present in Levels 6-36 (Units IIIc-II) and somewhat more sporadic in Levels 37-55 (lower Unit II through Isl/Isi/Icl). Below these levels, very few specimens of either identified or unidentified bone are present. While its presence in Levels 37-73 is more sporadic, it accounts for a higher percentage of the total fauna in the levels where it does occur, averaging about one-third of the total identifiable fauna for that particular level. Sylvilagus sp. accounts for 338 specimens from the fine fraction, $38.8 \%$ of which are burned, and 100 specimens from the coarse fraction, $23.0 \%$ of which are 
TABLE 35-2

Distribution of Nonmammal Taxa in Square 20, by Level

\begin{tabular}{|c|c|c|c|c|c|c|c|c|c|c|c|c|c|c|c|c|c|c|c|c|}
\hline Level & Unit & 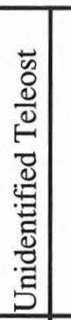 & 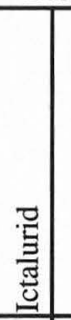 & 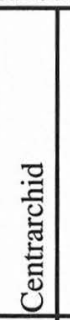 & 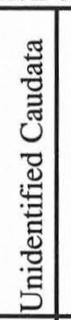 & 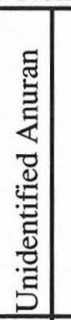 & $\begin{array}{l}\dot{2} \\
\vdots \\
\vdots \\
\vdots \\
\Omega\end{array}$ & 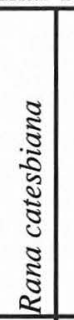 & 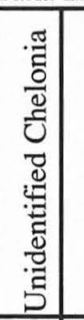 & 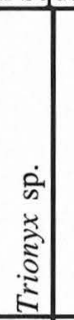 & 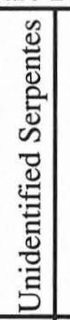 & 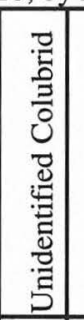 & \begin{tabular}{c}
$\dot{2}$ \\
2 \\
\multirow{2}{5}{} \\
$\frac{3}{10}$
\end{tabular} & $\begin{array}{l}\dot{0} \\
\vdots \\
\vdots \\
\vdots \\
\vdots \\
\vdots\end{array}$ & 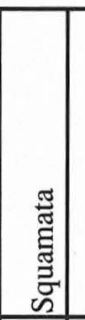 & 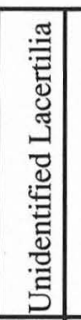 & 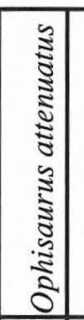 & $\begin{array}{l}0 \\
0 \\
\vdots \\
\vdots \\
0 \\
\vdots \\
\vdots \\
\vdots \\
0\end{array}$ & 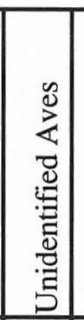 & 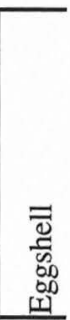 \\
\hline 6 & fill/IIIc & 10 & 0 & 1 & 0 & 1 & 0 & 0 & 30 & 0 & 9 & 0 & 0 & 0 & 0 & 1 & 1 & 0 & 1 & 0 \\
\hline 7 (F201) & IIIIc & 14 & 0 & 4 & 0 & 4 & 0 & 0 & 36 & 1 & 30 & 0 & 0 & 0 & 0 & 1 & 5 & 0 & 0 & 58 \\
\hline 8 (F201) & $\mathrm{IIIb} / \mathrm{c}$ & 17 & 0 & 2 & 1 & 1 & 0 & 0 & 51 & 0 & 28 & 0 & 0 & 0 & 1 & 0 & 2 & 0 & 1 & 67 \\
\hline 9 (F201) & $\mathrm{IIIb} / \mathrm{c}$ & 13 & 0 & 5 & 0 & 2 & 0 & 0 & 90 & 0 & 39 & 0 & 0 & 0 & 0 & 0 & 1 & 0 & 0 & 2 \\
\hline 10 & IIIlb & 14 & 0 & 1 & 0 & 3 & 1 & 0 & 42 & 1 & 32 & 0 & 0 & 0 & 0 & 1 & 0 & 1 & 0 & 18 \\
\hline $11 \mathrm{~A}$ & IIIl & 16 & 0 & 2 & 0 & 3 & 0 & 0 & 11 & 0 & 38 & 0 & 0 & 0 & 0 & 5 & 1 & 0 & 0 & 14 \\
\hline $12 \mathrm{~A}$ & IIIlb & 6 & 1 & 2 & 0 & 2 & 0 & 2 & 17 & 0 & 12 & 0 & 0 & 0 & 1 & 0 & 0 & 0 & 0 & 0 \\
\hline 12B (F204) & IIII & 2 & 0 & 0 & 0 & 0 & 0 & 0 & 8 & 1 & 7 & 0 & 0 & 0 & 0 & 0 & 0 & 0 & 0 & 0 \\
\hline $13 \mathrm{~A}$ & IIIl & 5 & 0 & 5 & 0 & 1 & 0 & 0 & 8 & 0 & 16 & 2 & 0 & 0 & 0 & 2 & 0 & 0 & 0 & 1 \\
\hline 13B (F209) & IIIb & 1 & 0 & 0 & 0 & 1 & 0 & 0 & 4 & 0 & 3 & 0 & 0 & 0 & 0 & 0 & 0 & 0 & 0 & 0 \\
\hline 14 & IIIlb & 7 & 1 & 5 & 0 & 3 & 0 & 0 & 6 & 0 & 6 & 0 & 0 & 0 & 0 & 1 & 0 & 0 & 1 & 5 \\
\hline 15 & IIIa/b & 4 & 0 & 3 & 0 & 1 & 0 & 0 & 75 & 0 & 22 & 0 & 0 & 0 & 0 & 0 & 0 & 0 & 1 & 0 \\
\hline $16 \mathrm{~A}$ & III a/b & 16 & 2 & 2 & 0 & 0 & 0 & 0 & 80 & 0 & 14 & 0 & 0 & 0 & 0 & 0 & 0 & 0 & 0 & 9 \\
\hline 16B (F215) & IIIIa/b & 11 & 0 & 0 & 0 & 0 & 0 & 0 & 56 & 0 & 6 & 0 & 0 & 0 & 0 & 1 & 0 & 0 & 0 & 0 \\
\hline 17 & IIIIa & 30 & 1 & 1 & 1 & 0 & 0 & 0 & 128 & 2 & 19 & 0 & 0 & 0 & 0 & 0 & 0 & 0 & 0 & 0 \\
\hline 18 & IIIIa & 25 & 0 & 4 & 0 & 0 & 0 & 0 & 91 & 0 & 9 & 0 & 0 & 0 & 0 & 0 & 0 & 0 & 0 & 0 \\
\hline 19 & IIIIa & 14 & 0 & 3 & 0 & 0 & 0 & 0 & 42 & 0 & 5 & 0 & 0 & 0 & 0 & 0 & 0 & 0 & 0 & 6 \\
\hline 24 & IIIIa & 65 & 0 & 11 & 2 & 0 & 0 & 0 & 49 & 0 & 13 & 0 & 0 & 0 & 0 & 0 & 0 & 0 & 1 & 4 \\
\hline 25B (F233) & |II/IIIa & 75 & 5 & 8 & 0 & 1 & 0 & 0 & 24 & 0 & 4 & 0 & 0 & 0 & 0 & 0 & 0 & 0 & 0 & 0 \\
\hline $25 \mathrm{~A}+\mathrm{B}(\mathrm{F} 233)$ & II/IIIa & 21 & 0 & 2 & 0 & 0 & 1 & 0 & 15 & 0 & 2 & 0 & 0 & 0 & 0 & 1 & 0 & 0 & 0 & 0 \\
\hline $26 \mathrm{~A}$ & II/IIIa & 33 & 4 & 0 & 0 & 1 & 0 & 0 & 17 & 0 & 11 & 0 & 0 & 0 & 0 & 0 & 0 & 1 & 0 & 0 \\
\hline 26B (F233) & |II/IIIa & 9 & 2 & 3 & 0 & 0 & 0 & 0 & 10 & 0 & 0 & 0 & 0 & 0 & 0 & 0 & 0 & 0 & 0 & 0 \\
\hline 27 & |II/IIIa & 28 & 0 & 5 & 0 & 0 & 0 & 0 & 16 & 0 & 5 & 0 & 0 & 0 & 0 & 1 & 0 & 0 & 0 & 0 \\
\hline 28 & |II/IIIa & 25 & 0 & 0 & 0 & 0 & 0 & 0 & 18 & 0 & 8 & 0 & 0 & 0 & 0 & 0 & 0 & 0 & 1 & 0 \\
\hline $29 \mathrm{~A}$ & II & 8 & 0 & 1 & 0 & 2 & 0 & 0 & 3 & 0 & 3 & 0 & 0 & 0 & 0 & 0 & 0 & 0 & 2 & 3 \\
\hline 30 & II & 5 & 0 & 3 & 0 & 0 & 0 & 0 & 1 & 0 & 0 & 0 & 0 & 0 & 0 & 0 & 0 & 0 & 0 & 2 \\
\hline 31 & II & 2 & 2 & 2 & 0 & 0 & 0 & 0 & 2 & 0 & 2 & 0 & 0 & 0 & 0 & 0 & 0 & 0 & 3 & 5 \\
\hline 32 & II & 2 & 1 & 0 & 0 & 0 & 0 & 0 & 0 & 0 & 2 & 0 & 0 & 0 & 0 & 0 & 0 & 0 & 1 & 5 \\
\hline 33 & II & 3 & 0 & 0 & 0 & 0 & 0 & 0 & 7 & 0 & 1 & 0 & 0 & 0 & 0 & 0 & 0 & 0 & 0 & 0 \\
\hline 34 & II & 2 & 0 & 0 & 0 & 1 & 0 & 0 & 1 & 0 & 0 & 0 & 0 & 0 & 0 & 0 & 0 & 0 & 1 & 6 \\
\hline 35 & II & 1 & 2 & 0 & 0 & 0 & 0 & 0 & 8 & 1 & 2 & 0 & 0 & 0 & 0 & 0 & 0 & 0 & 0 & 3 \\
\hline 36 & II & 1 & 0 & 1 & 0 & 2 & 0 & 0 & 2 & 0 & 3 & 0 & 0 & 0 & 0 & 0 & 1 & 0 & 0 & 2 \\
\hline 37 & III & 0 & 0 & 1 & 0 & 0 & 0 & 0 & 5 & 0 & 3 & 0 & 0 & 0 & 0 & 0 & 0 & 0 & 0 & 0 \\
\hline 38 & Isi-c/II & 3 & 0 & 0 & 0 & 0 & 0 & 0 & 0 & 0 & 4 & 0 & 1 & 0 & 0 & 0 & 0 & 0 & 1 & 12 \\
\hline 39 & Isi-c & 0 & 0 & 0 & 0 & 0 & 0 & 0 & 0 & 0 & 2 & 0 & 0 & 0 & 0 & 1 & 0 & 0 & 0 & 2 \\
\hline 40 & Isi-c & 0 & 0 & 1 & 0 & 0 & 0 & 0 & 1 & 0 & 3 & 0 & 0 & 0 & 0 & 0 & 0 & 0 & 0 & 0 \\
\hline 41 & Isi-c & 0 & 0 & 0 & 0 & 0 & 0 & 0 & 0 & 0 & 1 & 0 & 0 & 1 & 0 & 0 & 0 & 0 & 0 & 1 \\
\hline 42 & Isi-c & 0 & 0 & 1 & 0 & 0 & 0 & 0 & 0 & 0 & 0 & 0 & 0 & 0 & 0 & 0 & 0 & 0 & 0 & 0 \\
\hline 43 & Isi-c & 0 & 0 & 0 & 0 & 0 & 0 & 0 & 0 & 0 & 2 & 0 & 0 & 0 & 0 & 0 & 0 & 0 & 0 & 0 \\
\hline 44 & Icl/Isi-c & 0 & 0 & 0 & 0 & 0 & 0 & 0 & 0 & 0 & 0 & 0 & 0 & 0 & 0 & 0 & 0 & 0 & 0 & 0 \\
\hline 45 & Icl/Isi-c & 1 & 0 & 0 & 0 & 0 & 0 & 0 & 0 & 0 & 2 & 0 & 0 & 0 & 0 & 0 & 0 & 0 & 0 & 0 \\
\hline 46 & Icl/Isi-c & 0 & 0 & 0 & 0 & 0 & 0 & 0 & 0 & 0 & 0 & 0 & 0 & 0 & 0 & 0 & 0 & 0 & 0 & 0 \\
\hline 47 & Icl & 0 & 0 & 0 & 0 & 0 & 0 & 0 & 0 & 0 & 0 & 0 & 0 & 0 & 0 & 0 & 0 & 0 & 0 & 1 \\
\hline 48 & Icl & 0 & 0 & 0 & 0 & 0 & 0 & 0 & 0 & 0 & 1 & 0 & 0 & 0 & 0 & 0 & 0 & 0 & 0 & 0 \\
\hline 49 & Icl & 0 & $0]$ & 0 & 0 & 0 & 0 & 0 & 0 & 0 & $0]$ & 0 & 0 & 0 & 0 & 0 & 0 & 0 & 0 & 0 \\
\hline
\end{tabular}


Table 35-2, continued

\begin{tabular}{|c|c|c|c|c|c|c|c|c|c|c|c|c|c|c|c|c|c|c|c|c|}
\hline Level & Unit & 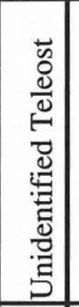 & 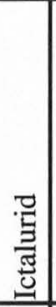 & 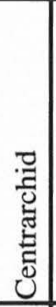 & 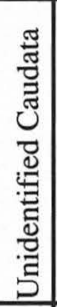 & 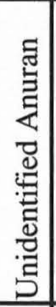 & 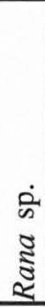 & 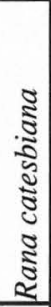 & 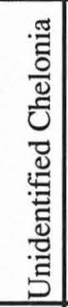 & 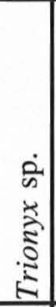 & 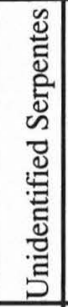 & 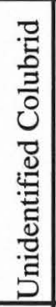 & $\begin{array}{l}\dot{2} \\
2 \\
\frac{2}{3} \\
\frac{2}{5}\end{array}$ & $\begin{array}{l}\dot{0} \\
0 \\
0 \\
\vdots \\
\vdots \\
\vdots \\
5\end{array}$ & 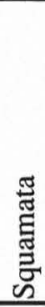 & 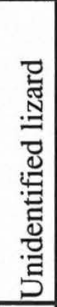 & 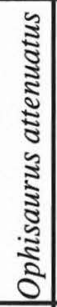 & 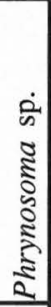 & 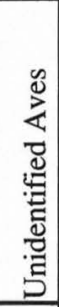 & 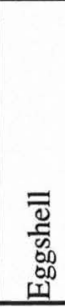 \\
\hline 50 & Icl & 0 & 0 & 0 & 0 & 0 & 0 & 0 & 0 & 0 & 0 & 0 & 0 & 0 & 0 & 0 & 0 & 0 & 0 & 0 \\
\hline 51 & Icl & 0 & 0 & 0 & 0 & 0 & 0 & 0 & 0 & 0 & 0 & 0 & 0 & 0 & 0 & 0 & 0 & 0 & 1 & 0 \\
\hline 52 & Icl & 0 & 0 & 0 & 0 & 0 & 0 & 0 & 1 & 0 & 0 & 0 & 0 & 0 & 0 & 0 & 0 & 0 & 0 & 0 \\
\hline 53 & Isi/Icl & 0 & 0 & 0 & 0 & 0 & 0 & 0 & 0 & 0 & 0 & 0 & 0 & 0 & 0 & 0 & 0 & 0 & 0 & 0 \\
\hline $54 \mathrm{~A}$ & Igl/Isi/Icl & 1 & 0 & 0 & 0 & 0 & 0 & 0 & 0 & 0 & 0 & 0 & 0 & 0 & 0 & 0 & 0 & 0 & 0 & 0 \\
\hline $54 \mathrm{~B}$ & Igl/Isi/Icl & 0 & 0 & 0 & 0 & 0 & 0 & 0 & 0 & 0 & 0 & 0 & 0 & 0 & 0 & 0 & 0 & 0 & 0 & 0 \\
\hline $55 \mathrm{~A}$ & Igl/Isi/Icl & 0 & 0 & 0 & 0 & 0 & 0 & 0 & 0 & 0 & 0 & 0 & 0 & 0 & 0 & 2 & 0 & 0 & 0 & 0 \\
\hline $55 \mathrm{~B}$ & $\mathrm{Igl} / \mathrm{Isi} / \mathrm{Icl}$ & 0 & 0 & 0 & 0 & 0 & 0 & 0 & 0 & 0 & 0 & 0 & 0 & 0 & 0 & 0 & 0 & 0 & 0 & 0 \\
\hline $56 \mathrm{~A}$ & Igl & 0 & 0 & 0 & 0 & 0 & 0 & 0 & 0 & 0 & 0 & 0 & 0 & 0 & 0 & 0 & 0 & 0 & 0 & 0 \\
\hline $56 \mathrm{~B}$ & Igl & 1 & 0 & 0 & 0 & 0 & 0 & 0 & 0 & 0 & 0 & 0 & 0 & 0 & 0 & 0 & 0 & 0 & 1 & 0 \\
\hline 57 & Igl & 0 & 0 & 0 & 0 & 0 & 0 & 0 & 0 & 0 & 0 & 0 & 0 & 0 & 0 & 0 & 0 & 0 & 0 & 0 \\
\hline 58 & Igl & 0 & 0 & 0 & 0 & 0 & 0 & 0 & 0 & 0 & 0 & 0 & 0 & 0 & 0 & 0 & 0 & 0 & 0 & 0 \\
\hline 59 & Igl & 0 & 0 & 0 & 0 & 0 & 0 & 0 & 0 & 0 & 0 & 0 & 0 & 0 & 0 & 0 & 0 & 0 & 0 & 0 \\
\hline 60 & Igl & 0 & 0 & 0 & 0 & 0 & 0 & 0 & 0 & 0 & 0 & 0 & 0 & 0 & 0 & 0 & 0 & 0 & 0 & 0 \\
\hline 61 & Igl & 0 & 0 & 0 & 0 & 0 & 0 & 0 & 0 & 0 & 0 & 0 & 0 & 0 & 0 & 0 & 0 & 0 & 0 & 0 \\
\hline 62 & Igl & 0 & 0 & 0 & 0 & 0 & 0 & 0 & 0 & 0 & 0 & 0 & 0 & 0 & 0 & 0 & 0 & 0 & 0 & 0 \\
\hline 63 & Igl & 0 & 0 & 0 & 0 & 0 & 0 & 0 & 0 & 0 & 0 & 0 & 0 & 0 & 0 & 0 & 0 & 0 & 0 & 0 \\
\hline 64 & Igl & 0 & 0 & 0 & 0 & 0 & 0 & 0 & 0 & 0 & 0 & 0 & 0 & 0 & 0 & 0 & 0 & 0 & 0 & 0 \\
\hline 65 & Igl & 0 & 0 & 0 & 0 & 0 & 0 & 0 & 0 & 0 & 0 & 0 & 0 & 0 & 0 & 0 & 0 & 0 & 0 & 0 \\
\hline 66 & Igl & 0 & 0 & 0 & 0 & 0 & 0 & 0 & 0 & 0 & 0 & 0 & 0 & 0 & 0 & 0 & 0 & 0 & 0 & 0 \\
\hline 67 & Igl & 0 & 0 & 0 & 0 & 0 & 0 & 0 & 0 & 0 & 0 & 0 & 0 & 0 & 0 & 0 & 0 & 0 & 0 & 0 \\
\hline 68 & Igl & 0 & 0 & 0 & 0 & 0 & 0 & 0 & 0 & 0 & 0 & 0 & 0 & 0 & 0 & 0 & 0 & 0 & 0 & 0 \\
\hline 69 & Igl & 0 & 0 & 0 & 0 & 0 & 0 & 0 & 0 & 0 & 0 & 0 & 0 & 0 & 0 & 0 & 0 & 0 & 0 & 0 \\
\hline 70 & Igl & 0 & 0 & 0 & 0 & 0 & 0 & 0 & 0 & 0 & 0 & 0 & 0 & 0 & 0 & 0 & 0 & 0 & 0 & 0 \\
\hline 71 & Igl & 0 & 0 & 0 & 0 & 0 & 0 & 0 & 0 & 0 & 0 & 0 & 0 & 0 & 0 & 0 & 0 & 0 & 0 & 0 \\
\hline 72 & Igl & 0 & 0 & 0 & 0 & 0 & 0 & 0 & 0 & 0 & 0 & 0 & 0 & 0 & 0 & 0 & 0 & 0 & 0 & 0 \\
\hline 73 & Igl & 0 & 0 & 0 & 0 & 0 & 1 & 0 & 0 & 0 & 0 & 0 & 0 & 0 & 0 & 0 & 0 & 0 & 0 & 0 \\
\hline Totals: & & 491 & 21 & 79 & 4 & 29 & 3 & 2 & 955 & 6 & 369 & 2 & 1 & 1 & 2 & 17 & 11 & 2 & 16 & 226 \\
\hline
\end{tabular}

burned. Although Sylvilagus sp. is a common animal living in the fields and brushlands around Wilson-Leonard today, the consistency with which it is found in nearly every level of the Square 20 column and the higher than average level of burning in the fine fraction indicates that they were probably utilized as a significant food resource (Davis 1974).

The distributional pattern of fish and turtle remains from the upper half of the column also supports the use of these two taxa as significant food items. Fish specimens are present consistently in the upper half of the column and form a notable spike in abundance between Levels 24 and 28 (lower Units IIIa and IIIa/II, Figure 35-5). Percentages of fish specimens from the total of identifiable specimens in this interval reach as high as $51 \%$ in Level $25 \mathrm{~B}$ and average $53.9 \%$ burned compared to $45.4 \%$ burned from the entire column. In general, fish have a higher percentage of burned specimens than any other sizable faunal group re- covered from the column. This spike is also centered on Levels 25 and 26 which are associated with a burned rock feature (Feature 233) that may represent an Early Archaic hearth (see Chapter 26). Although some of the burned bone may have resulted from wildfires or the placement of hearths over naturally deposited animal remains, a large percentage can be inferred as cultural burning of animal bone either from cooking or possibly disposal. Based on the presence of cultural features and the high percentage of burning in fish specimens, fish were most likely an important food resource, particularly during the Early Archaic occupations represented in Levels 24 through 28 (ca. $8700-8000$ в.P.). Regional data indicate that by 8000 B.P., significantly drier conditions had begun to characterize the climate of Central Texas (Collins 1995:Table 2), and it is likely that low water levels at streams like Brushy Creek made conditions unsuitable for fish by that time. 
TABLE 35-3

Distribution of Mammalian Taxa in Square 20, by Level

\begin{tabular}{|c|c|c|c|c|c|c|c|c|c|c|c|c|c|c|c|c|c|c|c|c|c|c|c|c|c|c|}
\hline Level & Unit & 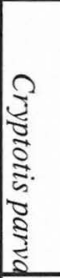 & $\begin{array}{l}5 \\
8 \\
5 \\
5 \\
0 \\
0\end{array}$ & 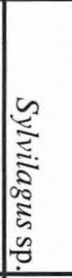 & 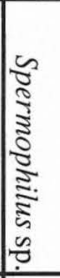 & $\mid \begin{array}{c}\tilde{2} \\
\vdots \\
\vdots \\
\vdots \\
\vdots \\
\vdots \\
0 \\
0\end{array}$ & 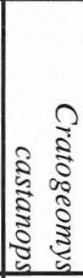 & 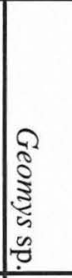 & 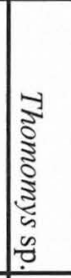 & \begin{tabular}{|c|}
0 \\
0 \\
0 \\
0 \\
0 \\
0 \\
0 \\
0 \\
0 \\
0 \\
0 \\
0
\end{tabular} & 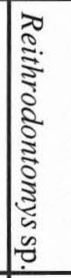 & 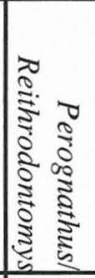 & 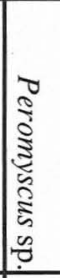 & 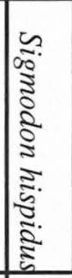 & \begin{tabular}{|c|}
0 \\
0 \\
0 \\
0 \\
0 \\
0 \\
0 \\
0 \\
0 \\
0
\end{tabular} & 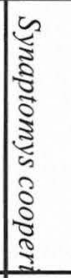 & 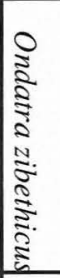 & 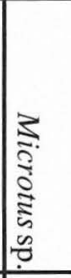 & 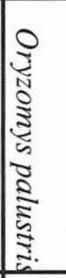 & 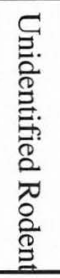 & 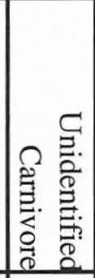 & 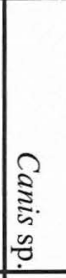 & 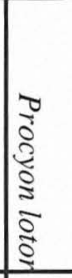 & 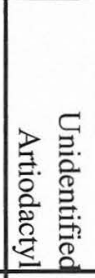 & $\begin{array}{l}0 \\
0 \\
0 \\
0 \\
0 \\
2 \\
2 \\
5 \\
0 \\
0 \\
0\end{array}$ & 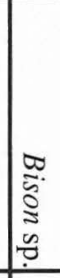 \\
\hline 6 & fill/IIIc & 0 & 0 & 9 & 0 & 0 & 0 & 5 & 0 & 0 & 0 & 0 & 0 & 2 & 0 & 0 & 0 & 0 & 0 & 3 & 0 & 0 & 0 & 0 & 0 & 0 \\
\hline 7 & IIIC & 0 & 2 & 16 & 0 & 0 & 0 & 22 & 0 & 2 & 0 & 0 & 1 & 9 & 2 & 0 & 0 & 1 & 0 & 49 & 0 & 0 & 0 & 2 & 1 & 0 \\
\hline 8 & IIIIb/c & 0 & 0 & 19 & 2 & 1 & 0 & 15 & 0 & 0 & 1 & 0 & 2 & 5 & 4 & 0 & 0 & 0 & 0 & 39 & 2 & 1 & 0 & 10 & 0 & 0 \\
\hline 9 & IIIIb/c & 0 & 0 & 21 & 0 & 1 & 0 & 11 & 0 & 0 & 0 & 0 & 0 & 11 & 5 & 0 & 0 & 0 & 0 & 40 & 0 & 0 & 0 & 7 & 5 & 0 \\
\hline 10 & IIIl & 0 & 2 & 19 & 1 & 0 & 0 & 11 & 0 & 1 & 0 & 0 & 0 & 2 & 2 & 0 & 0 & 0 & 0 & 41 & 1 & 0 & 0 & 2 & 4 & 0 \\
\hline $11 \mathrm{~A}$ & IIIb & 0 & 4 & 20 & 0 & 0 & 0 & 21 & 0 & 0 & 0 & 0 & 1 & 8 & 6 & 0 & 0 & 1 & 0 & 16 & 0 & 0 & 0 & 2 & 0 & 0 \\
\hline $12 \mathrm{~A}$ & IIIb & 0 & 5 & 16 & 0 & 0 & 0 & 6 & 0 & 0 & 0 & 0 & 0 & 2 & 2 & 0 & 0 & 0 & 0 & 18 & 1 & 0 & 0 & 4 & 0 & 0 \\
\hline $12 B$ & IIIlb & 0 & 0 & 4 & 1 & 0 & 0 & 5 & 0 & 0 & 0 & 0 & 0 & 1 & 1 & 0 & 0 & 0 & 0 & 11 & 0 & 0 & 0 & 3 & 0 & 0 \\
\hline $13 \mathrm{~A}$ & IIIb & 1 & 0 & 5 & 0 & 0 & 0 & 9 & 0 & 0 & 1 & 0 & 0 & 8 & 3 & 0 & 0 & 0 & 0 & 16 & 0 & 0 & 0 & 4 & 0 & 0 \\
\hline $13 B$ & IIIlb & 0 & 0 & 2 & 0 & 0 & 0 & 1 & 0 & 0 & 0 & 0 & 0 & 0 & 0 & 0 & 0 & 0 & 0 & 5 & 0 & 0 & 0 & 0 & 0 & 0 \\
\hline 14 & IIIIb & 0 & 1 & 2 & 0 & 0 & 0 & 4 & 0 & 0 & 0 & 0 & 2 & 0 & 1 & 0 & 0 & 0 & 0 & 1 & 0 & 0 & 0 & 1 & 0 & 0 \\
\hline 15 & IIIa/b & 0 & 1 & 6 & 0 & 0 & 0 & 7 & 0 & 0 & 0 & 0 & 0 & 2 & 5 & 0 & 0 & 0 & 0 & 29 & 0 & 0 & 0 & 2 & 0 & 0 \\
\hline $16 \mathrm{~A}$ & IIIa/b & 0 & 0 & 16 & 0 & 0 & 0 & 4 & 0 & 0 & 0 & 0 & 0 & 3 & 3 & 0 & 0 & 1 & 0 & 22 & 0 & 0 & 0 & 1 & 0 & 0 \\
\hline $16 \mathrm{~B}$ & IIIa/b & 0 & 1 & 5 & 0 & 0 & 0 & 6 & 0 & 0 & 0 & 0 & 0 & 5 & 6 & 0 & 0 & 0 & 0 & 7 & 0 & 0 & 0 & 0 & 0 & 0 \\
\hline 17 & IIIa & 0 & 0 & 21 & 0 & 0 & 0 & 12 & 0 & 2 & 0 & 0 & 0 & 3 & 8 & 0 & 0 & 1 & 0 & 20 & 0 & 0 & 0 & 4 & 0 & 0 \\
\hline 18 & IIIa & 0 & 0 & 8 & 0 & 0 & 0 & 3 & 0 & 0 & 0 & 0 & 0 & 2 & 1 & 0 & 0 & 0 & 0 & 14 & 0 & 2 & 1 & 0 & 0 & 0 \\
\hline 19 & IIIa & 0 & 0 & 7 & 0 & 0 & 0 & 6 & 0 & 0 & 0 & 0 & 1 & 3 & 3 & 0 & 0 & 0 & 0 & 27 & 0 & 0 & 0 & 3 & 0 & 0 \\
\hline 24 & IIIa & 0 & 0 & 23 & 0 & 0 & 0 & 6 & 1 & 0 & 0 & 0 & 0 & 6 & 6 & 0 & 0 & 1 & 0 & 28 & 0 & 0 & 0 & 0 & 0 & 0 \\
\hline $25 \mathrm{~B}$ & II/IIIa & 0 & 0 & 9 & 0 & 0 & 0 & 7 & 1 & 0 & 0 & 0 & 0 & 6 & 3 & 0 & 0 & 0 & 0 & 14 & 0 & 0 & 0 & 0 & 0 & 0 \\
\hline $25 \mathrm{~A}+\mathrm{B}$ & II/IIIа & 0 & 0 & 7 & 0 & 0 & 0 & 4 & 0 & 0 & 0 & 0 & 0 & 1 & 0 & 0 & 0 & 2 & 0 & 15 & 0 & 0 & 0 & 0 & 0 & 0 \\
\hline $26 \mathrm{~A}$ & II/III & 0 & 2 & 8 & 0 & 0 & 0 & 1 & 0 & 0 & 0 & 0 & 1 & 4 & 1 & 0 & 0 & 1 & 0 & 16 & 0 & 0 & 0 & 0 & 0 & 0 \\
\hline $26 \mathrm{~B}$ & II/III & 0 & 0 & 2 & 0 & 0 & 0 & 1 & 0 & 0 & 0 & 0 & 0 & 0 & 0 & 0 & 0 & 0 & 0 & 5 & 0 & 0 & 0 & 0 & 0 & 0 \\
\hline 27 & ПI/ІШа & 0 & 1 & 9 & 0 & 0 & 0 & 0 & 0 & 0 & 0 & 0 & 0 & 10 & 1 & 0 & 0 & 0 & 0 & 18 & 0 & 0 & 0 & 0 & 0 & 0 \\
\hline 28 & II/IIIa & 0 & 0 & 19 & 0 & 0 & 0 & 6 & 0 & 0 & 0 & 1 & 0 & 3 & 0 & 0 & 0 & 2 & 0 & 24 & 0 & 0 & 0 & 0 & 0 & 0 \\
\hline $29 \mathrm{~A}$ & II & 0 & 0 & 6 & 0 & 0 & 0 & 3 & 0 & 0 & 0 & 0 & 1 & 2 & 0 & 0 & 0 & 1 & 0 & 14 & 0 & 0 & 0 & 0 & 0 & 0 \\
\hline 30 & III & 0 & 0 & 6 & 0 & 0 & 0 & 2 & 0 & 0 & 0 & 0 & 0 & 4 & 2 & 0 & 0 & 1 & 0 & 14 & 0 & 0 & 0 & 0 & 0 & 0 \\
\hline 31 & II & 0 & 0 & 11 & 0 & 0 & 0 & 3 & 0 & 0 & 0 & 0 & 0 & 8 & 0 & 0 & 0 & 2 & 0 & 23 & 0 & 0 & 0 & 0 & 0 & 0 \\
\hline 32 & II & 0 & 0 & 7 & 1 & 0 & 0 & 11 & 0 & 0 & 0 & 0 & 0 & 7 & 2 & 0 & 0 & 2 & 0 & 16 & 0 & 0 & 0 & 1 & 0 & 0 \\
\hline 33 & III & 0 & 0 & 18 & 0 & 0 & 0 & 2 & 0 & 0 & 0 & 1 & 1 & 4 & 2 & 0 & 0 & 7 & 0 & 15 & 0 & 0 & 0 & 0 & 0 & 0 \\
\hline 34 & II & 0 & 0 & 19 & 0 & 0 & 0 & 1 & 0 & 0 & 0 & 0 & 0 & 2 & 0 & 0 & 0 & 3 & 0 & 15 & 0 & 0 & 0 & 0 & 0 & 0 \\
\hline 35 & III & 0 & 0 & 12 & 0 & 0 & 0 & 4 & 0 & 0 & 0 & 0 & 0 & 9 & 1 & 0 & 0 & 5 & 0 & 24 & 1 & 0 & 0 & 0 & 0 & 0 \\
\hline 36 & II & 0 & 0 & 5 & 0 & 0 & 0 & 7 & 0 & 1 & 0 & 0 & 0 & 1 & 0 & 0 & 1 & 2 & 0 & 33 & 0 & 0 & 0 & 0 & 0 & 0 \\
\hline 37 & III & 0 & 0 & 2 & 0 & 0 & 0 & 3 & 0 & 0 & 0 & 0 & 0 & 0 & 1 & 0 & 0 & 0 & 0 & 6 & 0 & 0 & 0 & 0 & 0 & 0 \\
\hline 38 & Isi-c/II & 0 & 0 & 7 & 0 & 1 & 0 & 3 & 0 & 0 & 0 & 0 & 0 & 0 & 0 & 0 & 0 & 2 & 0 & 8 & 0 & 1 & 0 & 0 & 0 & 0 \\
\hline 39 & Isi-c & 0 & 0 & 2 & 0 & 0 & 0 & 1 & 0 & 0 & 0 & 0 & 0 & 0 & 0 & 0 & 0 & 0 & 0 & 7 & 0 & 0 & 0 & 0 & 0 & 0 \\
\hline 40 & Isi-c & 0 & 0 & 2 & 0 & 0 & 0 & 0 & 0 & 0 & 0 & 0 & 0 & 1 & 0 & 0 & 0 & 1 & 1 & 2 & 0 & 0 & 0 & 0 & 0 & 0 \\
\hline 41 & Isi-c & 0 & 0 & 4 & 0 & 0 & 0 & 0 & 0 & 0 & 0 & 0 & 0 & 1 & 2 & 0 & 0 & 0 & 0 & 8 & 0 & 0 & 0 & 0 & 0 & 0 \\
\hline
\end{tabular}




\begin{tabular}{|c|c|c|c|c|c|c|c|c|c|c|c|c|c|c|c|c|c|c|c|c|c|c|c|c|c|c|}
\hline Level & Unit & 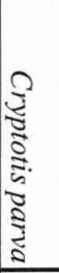 & $\begin{array}{l}5 \\
3 \\
5 \\
0 \\
0 \\
0\end{array}$ & 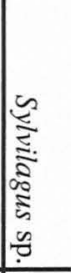 & 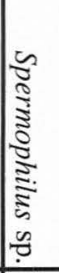 & 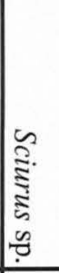 & 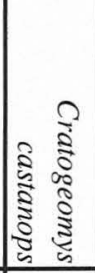 & 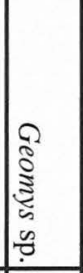 & 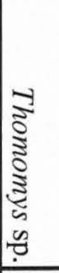 & 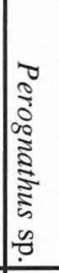 & 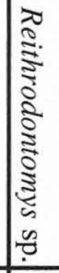 & 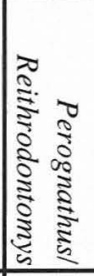 & 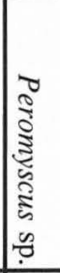 & 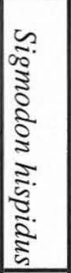 & 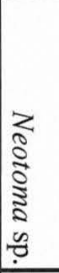 & 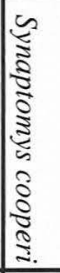 & 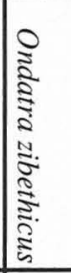 & 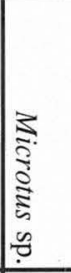 & 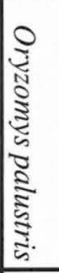 & 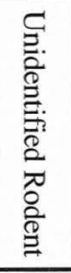 & 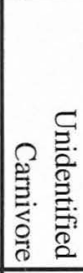 & $\begin{array}{l}2 \\
\vdots \\
\vdots \\
\vdots \\
0 \\
0\end{array}$ & 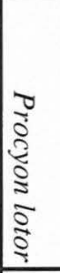 & 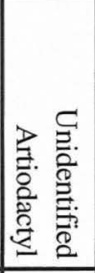 & 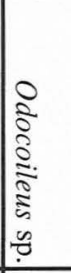 & 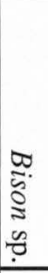 \\
\hline 42 & Isi-c & 0 & 0 & 2 & 0 & 0 & 0 & 3 & 0 & 0 & 0 & 0 & 0 & 0 & 0 & 0 & 0 & 0 & 0 & 6 & 0 & 0 & 0 & 0 & 0 & 0 \\
\hline 43 & Isi-c & 0 & 0 & 1 & 0 & 0 & 0 & 1 & 0 & 0 & 0 & 0 & 0 & 0 & 0 & 0 & 0 & 0 & 0 & 6 & 0 & 0 & 0 & 0 & 0 & 0 \\
\hline 44 & Icl/Isi-c & 0 & 0 & 1 & 0 & 0 & 0 & 1 & 0 & 0 & 0 & 0 & 0 & 0 & 0 & 0 & 0 & 0 & 0 & 1 & 0 & 0 & 1 & 0 & 0 & 0 \\
\hline 45 & Icl/Isi-c & 0 & 0 & 0 & 0 & 0 & 0 & 0 & 0 & 0 & 0 & 0 & 0 & 0 & 0 & 0 & 0 & 0 & 0 & 3 & 0 & 0 & 0 & 0 & 0 & 0 \\
\hline 46 & Icl/Isi-c & 0 & 0 & 1 & 0 & 0 & 0 & 0 & 0 & 0 & 0 & 0 & 0 & 0 & 0 & 0 & 0 & 0 & 0 & 2 & 0 & 0 & 0 & 0 & 0 & 0 \\
\hline 47 & Icl & 0 & 0 & 2 & 0 & 0 & 0 & 0 & 0 & 0 & 0 & 0 & 0 & 0 & 1 & 0 & 0 & 0 & 0 & 1 & 0 & 0 & 0 & 1 & 0 & 0 \\
\hline 48 & Icl & 0 & 0 & 2 & 0 & 0 & 0 & 0 & 0 & 0 & 0 & 0 & 0 & 0 & 0 & 0 & 0 & 0 & 0 & 4 & 0 & 0 & 0 & 0 & 0 & 0 \\
\hline 49 & Icl & 0 & 0 & 0 & 0 & 0 & 0 & 0 & 0 & 0 & 0 & 0 & 0 & 0 & 0 & 0 & 0 & 0 & 0 & 3 & 0 & 0 & 0 & 0 & 0 & 0 \\
\hline 50 & Icl & 0 & 0 & 10 & 0 & 0 & 0 & 0 & 0 & 0 & 0 & 0 & 0 & 0 & 0 & 0 & 0 & 0 & 0 & 5 & 0 & 0 & 0 & 1 & 0 & 0 \\
\hline 51 & Icl & 0 & 0 & 16 & 0 & 0 & 0 & 0 & 0 & 0 & 0 & 0 & 0 & 0 & 0 & 0 & 0 & 1 & 0 & 4 & 0 & 0 & 0 & 0 & 0 & 0 \\
\hline 52 & Icl & 0 & 0 & 6 & 0 & 0 & 0 & 0 & 0 & 0 & 0 & 0 & 0 & 0 & 0 & 0 & 0 & 0 & 0 & 4 & 0 & 0 & 0 & 3 & 0 & 4 \\
\hline 53 & Isi/Icl & 0 & 0 & 1 & 0 & 0 & 1 & 0 & 0 & 0 & 0 & 0 & 0 & 0 & 0 & 0 & 0 & 0 & 0 & 4 & 0 & 0 & 0 & 0 & 0 & 4 \\
\hline $54 \mathrm{~A}$ & Igl/Isi/Icl & 0 & 0 & 9 & 0 & 0 & 0 & 0 & 0 & 0 & 0 & 0 & 0 & 0 & 0 & 0 & 0 & 0 & 0 & 3 & 0 & 0 & 0 & 0 & 0 & 0 \\
\hline $54 \mathrm{~B}$ & Igl/Isi/Icl & 0 & 0 & 3 & 0 & 0 & 0 & 0 & 0 & 0 & 0 & 1 & 0 & 0 & 0 & 0 & 0 & 0 & 0 & 1 & 0 & 0 & 0 & 0 & 0 & 0 \\
\hline $55 \mathrm{~A}$ & Igl/Isi/Icl & 0 & 0 & 2 & 0 & 0 & 0 & 1 & 0 & 0 & 0 & 0 & 0 & 0 & 0 & 0 & 0 & 0 & 0 & 4 & 0 & 0 & 0 & 0 & 0 & 0 \\
\hline $55 \mathrm{~B}$ & Igl/Isi/Icl & 0 & 0 & 5 & 0 & 0 & 0 & 0 & 0 & 0 & 0 & 0 & 0 & 0 & 0 & 0 & 0 & 0 & 0 & 0 & 0 & 0 & 0 & 0 & 0 & 0 \\
\hline $56 \mathrm{~A}$ & Igl & 0 & 0 & 0 & 0 & 0 & 0 & 0 & 0 & 0 & 0 & 0 & 0 & 0 & 1 & 0 & 0 & 0 & 0 & 0 & 0 & 0 & 0 & 0 & 0 & 0 \\
\hline $56 \mathrm{~B}$ & Ig1 & 0 & 0 & 0 & 0 & 0 & 0 & 0 & 0 & 0 & 0 & 0 & 0 & 0 & 0 & 0 & 0 & 0 & 0 & 0 & 0 & 0 & 0 & 0 & 0 & 0 \\
\hline 57 & Igl & 0 & 0 & 3 & 0 & 0 & 0 & 0 & 0 & 0 & 0 & 0 & 0 & 0 & 0 & 0 & 0 & 0 & 0 & 1 & 0 & 0 & 0 & 0 & 0 & 0 \\
\hline 58 & Igl & 0 & 0 & 0 & 0 & 0 & 0 & 0 & 0 & 0 & 0 & 0 & 0 & 0 & 0 & 0 & 0 & 0 & 0 & 0 & 0 & 0 & 0 & 0 & 0 & 0 \\
\hline 59 & Igl & 0 & 0 & 0 & 0 & 0 & 0 & 0 & 0 & 0 & 0 & 0 & 0 & 0 & 0 & 0 & 0 & 0 & 0 & 0 & 0 & 0 & 0 & 0 & 0 & 0 \\
\hline 60 & Ig1 & 0 & 0 & 0 & 0 & 0 & 0 & 0 & 0 & 0 & 0 & 0 & 0 & 0 & 0 & 0 & 0 & 0 & 0 & 0 & 0 & 0 & 0 & 0 & 0 & 0 \\
\hline 61 & Igl & 0 & 0 & 0 & 0 & 0 & 0 & 0 & 0 & 0 & 0 & 0 & 0 & 0 & 0 & 0 & 0 & 0 & 0 & 0 & 0 & 0 & 0 & 0 & 0 & 0 \\
\hline 62 & Igl & 0 & 0 & 0 & 0 & 0 & 0 & 0 & 0 & 0 & 0 & 0 & 0 & 0 & 0 & 0 & 0 & 0 & 0 & 0 & 0 & 0 & 0 & 0 & 0 & 0 \\
\hline 63 & Igl & 0 & 0 & 0 & 0 & 0 & 0 & 0 & 0 & 0 & 0 & 0 & 0 & 0 & 0 & 0 & 0 & 0 & 0 & 0 & 0 & 0 & 0 & 0 & 0 & 0 \\
\hline 64 & Igl & 0 & 0 & 0 & 0 & 0 & 0 & 0 & 0 & 0 & 0 & 0 & 0 & 0 & 0 & 0 & 0 & 0 & 0 & 0 & 0 & 0 & 0 & 0 & 0 & 0 \\
\hline 65 & Igl & 0 & 0 & 0 & 0 & 0 & 0 & 0 & 0 & 0 & 0 & 0 & 0 & 0 & 0 & 2 & 0 & 0 & 0 & 1 & 0 & 0 & 0 & 0 & 0 & 0 \\
\hline 66 & Igl & 0 & 0 & 0 & 0 & 0 & 0 & 0 & 0 & 0 & 0 & 0 & 0 & 0 & 0 & 0 & 0 & 0 & 0 & 0 & 0 & 0 & 0 & 0 & 0 & 0 \\
\hline 67 & Igl & 0 & 0 & 0 & 0 & 0 & 0 & 0 & 0 & 0 & 0 & 0 & 0 & 0 & 0 & 0 & 0 & 0 & 0 & 0 & 0 & 0 & 0 & 1 & 0 & 0 \\
\hline 68 & Igl & 0 & 0 & 0 & 0 & 0 & 0 & 0 & 0 & 0 & 0 & 0 & 0 & 0 & 0 & 0 & 0 & 0 & 0 & 0 & 0 & 0 & 0 & 0 & 0 & 0 \\
\hline 69 & Igl & 0 & 0 & 0 & 0 & 0 & 0 & 0 & 0 & 0 & 0 & 0 & 0 & 0 & 0 & 0 & 0 & 0 & 0 & 0 & 0 & 0 & 0 & 0 & 0 & 0 \\
\hline 70 & Igl & 0 & 0 & 0 & 0 & 0 & 0 & 0 & 0 & 0 & 0 & 0 & 0 & 0 & 0 & 0 & 0 & 0 & 0 & 0 & 0 & 0 & 0 & 0 & 0 & 0 \\
\hline 71 & Ig1 & 0 & 0 & 0 & 0 & 0 & 0 & 0 & 0 & 0 & 0 & 0 & 0 & 0 & 0 & 0 & 0 & 0 & 0 & 0 & 0 & 0 & 0 & 0 & 0 & 0 \\
\hline 72 & Igl & 0 & 0 & 0 & 0 & 0 & 0 & 0 & 0 & 0 & 0 & 0 & 0 & 0 & 0 & 0 & 0 & 0 & 0 & 0 & 0 & 0 & 0 & 0 & 0 & 0 \\
\hline 73 & Igl & 0 & 0 & 0 & 0 & 0 & 0 & 0 & 0 & 0 & 0 & 0 & 0 & 0 & 0 & 0 & 0 & 0 & 0 & 0 & 0 & 0 & 0 & 0 & 0 & 0 \\
\hline Totals & & 1 & 19 & 438 & 5 & 3 & 1 & 219 & 2 & 6 & 2 & 3 & 10 & 135 & 75 & 2 & 1 & 37 & 1 & 716 & 5 & 4 & 2 & 52 & 10 & 8 \\
\hline
\end{tabular}


TABLE $35-4$

Distribution of Sized Mammal Bones

\begin{tabular}{|c|c|c|c|c|c|c|c|c|c|}
\hline Level & Unit & $\begin{array}{l}\text { Small } \\
\text { Mammal }\end{array}$ & $\begin{array}{l}\text { Small- } \\
\text { Medium } \\
\text { Mammal }\end{array}$ & $\begin{array}{l}\text { Medium } \\
\text { Mammal }\end{array}$ & $\begin{array}{l}\text { Medium- } \\
\text { Large } \\
\text { Mammal }\end{array}$ & $\begin{array}{l}\text { Large } \\
\text { Mammal }\end{array}$ & $\begin{array}{c}\text { Total Sized } \\
\text { Mammal }\end{array}$ & $\begin{array}{l}\text { Unidentified } \\
\text { Vertebrate }\end{array}$ & Total Bones \\
\hline 6 & fill/IIIc & 0 & 0 & 0 & 7 & 11 & 18 & 1,102 & 1,193 \\
\hline 7 & IIIc & 1 & 0 & 1 & 36 & 16 & 54 & 3,597 & 3,911 \\
\hline 8 & $\mathrm{IIIb} / \mathrm{c}$ & 7 & 0 & 4 & 13 & 21 & 45 & 3,015 & 3,332 \\
\hline 9 & $\mathrm{IIIb} / \mathrm{c}$ & 7 & 3 & 14 & 0 & 12 & 36 & 2,604 & 2,893 \\
\hline 10 & IIIb & 1 & 0 & 5 & 0 & 5 & 11 & 1,423 & 1,634 \\
\hline $11 \mathrm{~A}$ & IIIb & 38 & 0 & 1 & 10 & 1 & 50 & 1,824 & 2,043 \\
\hline $12 \mathrm{~A}$ & IIIb & 7 & 0 & 3 & 0 & 0 & 10 & 550 & 657 \\
\hline $12 \mathrm{~B}$ & IIIl & 5 & 0 & 3 & 0 & 1 & 9 & 367 & 420 \\
\hline $13 \mathrm{~A}$ & IIIb & 3 & 0 & 4 & 0 & 7 & 14 & 903 & 1,004 \\
\hline $13 B$ & IIIb & 0 & 0 & 0 & 0 & 0 & 0 & 174 & 191 \\
\hline 14 & IIIb & 8 & 0 & 3 & 1 & 6 & 18 & 283 & 348 \\
\hline 15 & IIIa/b & 3 & 0 & 1 & 0 & 1 & 5 & 867 & 1,030 \\
\hline $16 \mathrm{~A}$ & IIIa/b & 4 & 0 & 4 & 0 & 0 & 8 & 692 & 873 \\
\hline $16 \mathrm{~B}$ & IIIa/b & 9 & 0 & 2 & 0 & 2 & 13 & 415 & 532 \\
\hline 17 & IIIa & 29 & 0 & 6 & 0 & 7 & 42 & 1,136 & 1,431 \\
\hline 18 & IIIa & 7 & 0 & 7 & 0 & 1 & 15 & 546 & 721 \\
\hline 19 & IIIIa & 1 & 0 & 10 & 0 & 0 & 11 & 808 & 939 \\
\hline 24 & IIIa & 7 & 0 & 9 & 0 & 3 & 19 & 966 & 1,201 \\
\hline $25 \mathrm{~B}$ & II/IIIa & 12 & 0 & 6 & 0 & 0 & 18 & 683 & 858 \\
\hline $25 \mathrm{~A}+\mathrm{B}$ & II/IIIa & 0 & 0 & 1 & 0 & 0 & 1 & 569 & 641 \\
\hline $26 \mathrm{~A}$ & II/IIIa & 10 & 0 & 1 & 0 & 0 & 11 & 554 & 666 \\
\hline $26 \mathrm{~B}$ & II/IIIa & 1 & 0 & 1 & 0 & 0 & 2 & 132 & 166 \\
\hline 27 & II/IIIa & 10 & 0 & 1 & 0 & 0 & 11 & 686 & 791 \\
\hline 28 & II/IIIa & 0 & 0 & 4 & 0 & 0 & 4 & 649 & 760 \\
\hline $29 \mathrm{~A}$ & II & 0 & 0 & 1 & 0 & 2 & 3 & 312 & 364 \\
\hline 30 & II & 1 & 0 & 0 & 0 & 0 & 1 & 543 & 584 \\
\hline 31 & II & 0 & 0 & 0 & 0 & 1 & 1 & 536 & 602 \\
\hline 32 & II & 9 & 0 & 11 & 0 & 0 & 20 & 558 & 636 \\
\hline 33 & II & 12 & 0 & 1 & 0 & 2 & 15 & 316 & 392 \\
\hline 34 & II & 1 & 0 & 5 & 0 & 1 & 7 & 369 & 427 \\
\hline 35 & II & 3 & 0 & 2 & 0 & 0 & 5 & 462 & 540 \\
\hline 36 & II & 13 & 0 & 0 & 0 & 0 & 13 & 616 & 691 \\
\hline 37 & II & 1 & 0 & 0 & 0 & 0 & 1 & 260 & 282 \\
\hline 38 & Isi-c/II & 2 & 0 & 5 & 0 & 1 & 8 & 470 & 521 \\
\hline 39 & Isi-c & 1 & 0 & 0 & 0 & 0 & 1 & 188 & 204 \\
\hline 40 & Isi-c & 5 & 0 & 0 & 0 & 0 & 5 & 171 & 188 \\
\hline 41 & Isi-c & 0 & 0 & 0 & 0 & 0 & 0 & 161 & 179 \\
\hline 42 & Isi-c & 4 & 0 & 0 & 0 & 0 & 4 & 203 & 219 \\
\hline 43 & Isi-c & 0 & 0 & 0 & 0 & 0 & 0 & 67 & 77 \\
\hline 44 & Icl/Isi-c & 4 & 0 & 0 & 0 & 0 & 4 & 68 & 76 \\
\hline 45 & $\mathrm{Icl} / \mathrm{Isi}-\mathrm{c}$ & 0 & 0 & 0 & 0 & 0 & 0 & 54 & 60 \\
\hline 46 & Icl/Isi-c & 0 & 0 & 0 & 0 & 0 & 0 & 29 & 32 \\
\hline 47 & Icl & 0 & 3 & 0 & 1 & 0 & 4 & 58 & 68 \\
\hline 48 & Icl & 0 & 1 & 0 & 0 & 1 & 2 & 65 & 74 \\
\hline 49 & Icl & 0 & 0 & 0 & 0 & 0 & 0 & 87 & 90 \\
\hline 50 & Icl & 0 & 0 & 0 & 0 & 3 & 3 & 75 & 94 \\
\hline 51 & Icl & 0 & 0 & 0 & 0 & 2 & 2 & 91 & 115 \\
\hline 52 & Icl & 5 & 0 & 0 & 1 & 36 & 42 & 1,094 & 1,154 \\
\hline 53 & Isi/Icl & 1 & 0 & 0 & 0 & 9 & 10 & 284 & 304 \\
\hline $54 \mathrm{~A}$ & Igl/Isi/Icl & 0 & 0 & 0 & 0 & 0 & 0 & 133 & 146 \\
\hline
\end{tabular}


Table 35-4, continued

\begin{tabular}{|c|c|c|c|c|c|c|c|c|c|}
\hline Level & Unit & $\begin{array}{l}\text { Small } \\
\text { Mammal }\end{array}$ & $\begin{array}{l}\text { Small- } \\
\text { Medium } \\
\text { Mammal }\end{array}$ & $\begin{array}{l}\text { Medium } \\
\text { Mammal }\end{array}$ & $\begin{array}{l}\text { Medium- } \\
\text { Large } \\
\text { Mammal }\end{array}$ & $\begin{array}{l}\text { Large } \\
\text { Mammal }\end{array}$ & $\begin{array}{l}\text { Total Sized } \\
\text { Mammal }\end{array}$ & $\begin{array}{l}\text { Unidentified } \\
\text { Vertebrate }\end{array}$ & Total Bones \\
\hline $54 \mathrm{~B}$ & Igl/Isi/Icl & 1 & 0 & 0 & 0 & 0 & 1 & 13 & 19 \\
\hline $55 \mathrm{~A}$ & Igl/Isi/Icl & 0 & 0 & 0 & 0 & 0 & 0 & 44 & 53 \\
\hline $55 \mathrm{~B}$ & Igl/Isi/Icl & 0 & 0 & 0 & 0 & 0 & 0 & 23 & 28 \\
\hline $56 \mathrm{~A}$ & Igl & 0 & 0 & 0 & 0 & 0 & 0 & 13 & 14 \\
\hline $56 \mathrm{~B}$ & Igl & 0 & 1 & 0 & 1 & 0 & 2 & 63 & 67 \\
\hline 57 & Igl & 0 & 0 & 0 & 0 & 0 & 0 & 25 & 29 \\
\hline 58 & Igl & 0 & 0 & 0 & 0 & 0 & 0 & 11 & 11 \\
\hline 59 & Igl & 0 & 0 & 0 & 0 & 0 & 0 & 12 & 12 \\
\hline 60 & Igl & 1 & 0 & 0 & 0 & 0 & 1 & 5 & 6 \\
\hline 61 & Igl & 0 & 0 & 0 & 0 & 0 & 0 & 3 & 3 \\
\hline 62 & Igl & 0 & 0 & 0 & 0 & 0 & 0 & 2 & 2 \\
\hline 63 & Igl & 0 & 0 & 0 & 0 & 1 & 1 & 3 & 4 \\
\hline 64 & Igl & 0 & 0 & 0 & 0 & 0 & 0 & 3 & 3 \\
\hline 65 & Igl & 0 & 0 & 0 & 0 & 0 & 0 & 12 & 15 \\
\hline 66 & Igl & 0 & 0 & 0 & 0 & 0 & 0 & 1 & 1 \\
\hline 67 & Igl & 0 & 0 & 0 & 0 & 0 & 0 & 4 & 5 \\
\hline 68 & Igl & 0 & 0 & 0 & 0 & 0 & 0 & 1 & 1 \\
\hline 69 & Igl & 0 & 0 & 0 & 0 & 0 & 0 & 2 & 2 \\
\hline 70 & Igl & 0 & 0 & 0 & 0 & 0 & 0 & 1 & 1 \\
\hline 71 & Igl & 0 & 0 & 0 & 0 & 0 & 0 & 0 & 0 \\
\hline 72 & Igl & 0 & 0 & 0 & 0 & 0 & 0 & 0 & 0 \\
\hline 73 & Igl & 0 & 0 & 0 & 0 & 0 & 0 & 3 & 4 \\
\hline \multicolumn{2}{|c|}{ Totals: } & 234 & 8 & 116 & 70 & 153 & 581 & 32,059 & 36,634 \\
\hline
\end{tabular}

The abundance of turtle material from Levels 13-25 (Units IIIb-IIIa/II) echoes and partially overlaps the fish spike (see Figure 35-5). The turtle spike, which is centered between Levels 15 and 18 (Units IIIa/b-upper IIIa), consists of up to $53 \%$ of the total identifiable specimens per level and averages $23.1 \%$ burning for these levels as compared to $21.4 \%$ burning of turtle specimens in the entire column. While the percentage of burning in these levels is not much higher than the average percentage of burned turtle for the entire column, the sheer abundance of turtle specimens in this interval suggests a nonnatural factor, most likely human influence. If cultural behavior is indeed responsible for the successive high abundances of fish and turtle remains in the Wilson-Leonard fauna, we can speculate that turtle may have become a more important food resource after fish was either overexploited or became less available as a food resource.

Effects of cultural activities at Wilson-Leonard are less apparent in other taxa or faunal groupings, although most taxa in which there is more than one identifiable specimen tend to have at least one specimen that exhibits burning. This is true for snake, amphibian, lizard, avian, and mammalian specimens, and in particular, for the rodents that make up a large percentage of the total identifiable fauna. Although there is a wide variety of rodent specimens, many of which occur naturally in and around the site area presently, it can be inferred from the higher amount of burning in specimens of the larger rodents such as Neotoma sp., Geomys sp., and possibly Sigmodon hispidus that some rodents and other small animals also may have been utilized as food sources.

Aside from burning, other characteristics of the bone from the Square 20 column such as high fragmentation, pitting, and etching could be the result of several mechanical or chemical alterations by animals and/or humans. Even though not all of the bone from all levels was analyzed, an effort was made to sample an equivalent and often greater number of coarse bags to fine bags of concentrate per level. Of the 36,634 bones analyzed, 30,814 or $84.1 \%$ of the total were recovered from the fine fraction of less than 1/8-inch fragments. Even considering that many of the animals from which these bones were derived were small, most of the small bones are also broken, resulting in a very high level of fragmentation. Although it is difficult to define what is considered a "normal" level of fragmentation, the levels seen in Square 20 suggest mechanical breakdown such as would be expected from mastication or possibly severe trampling. Pitting and etching of a large portion further suggests that the bone underwent digestive processes, although soil acids or groundwater could also produce similar characteristics. There is little evidence of cutting or deliberate shaping of any recovered bone material as might be expected based on the very small specimen size. Only a single specimen of scrap bone from Level 9 (Unit IIIc) shows evidence of gnawing by a small animal. It has been suggested that marrow extraction 


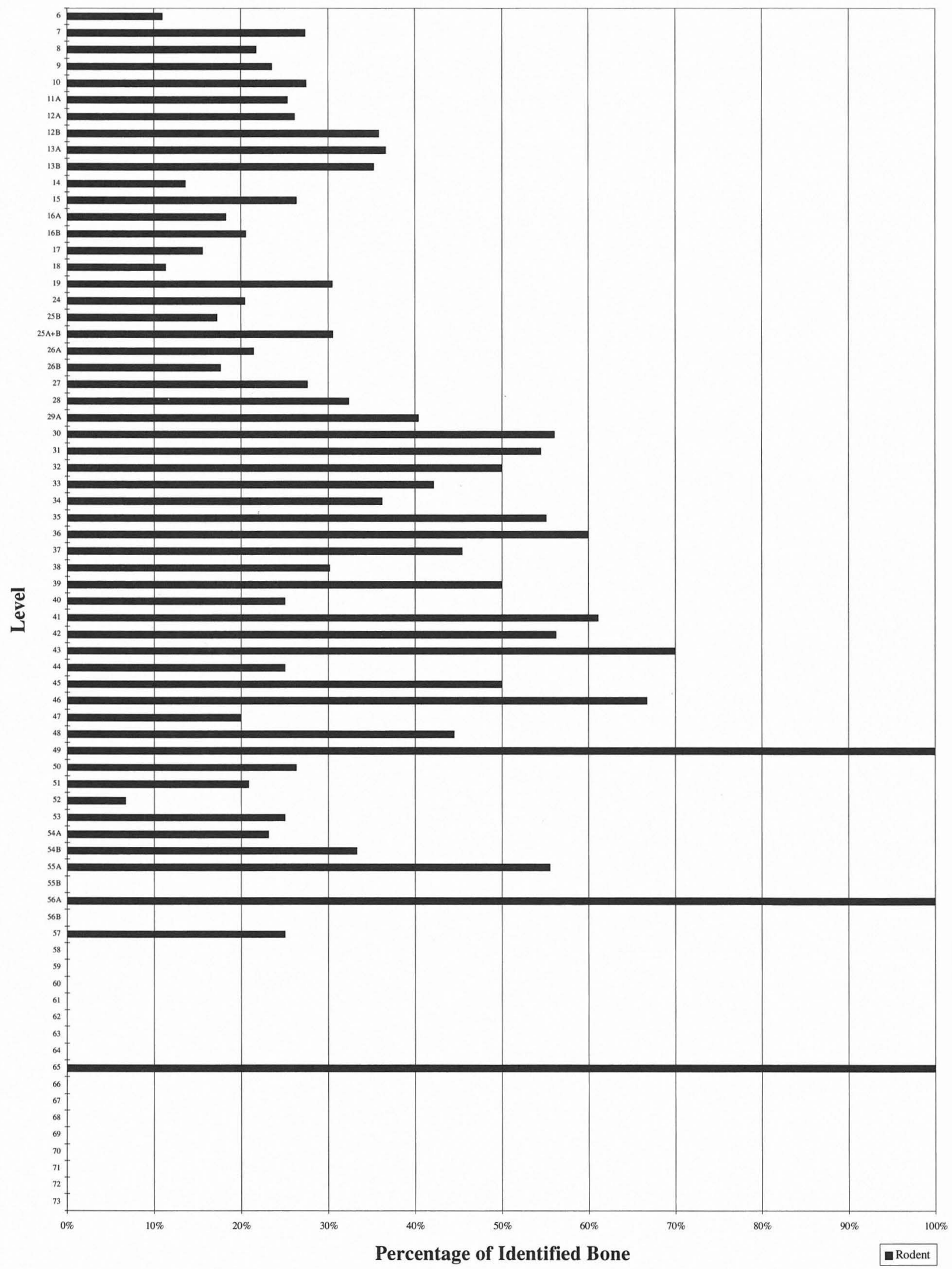

FIGURE 35-3. Percentages of rodent from the total amount of identified bone in Square 20. 


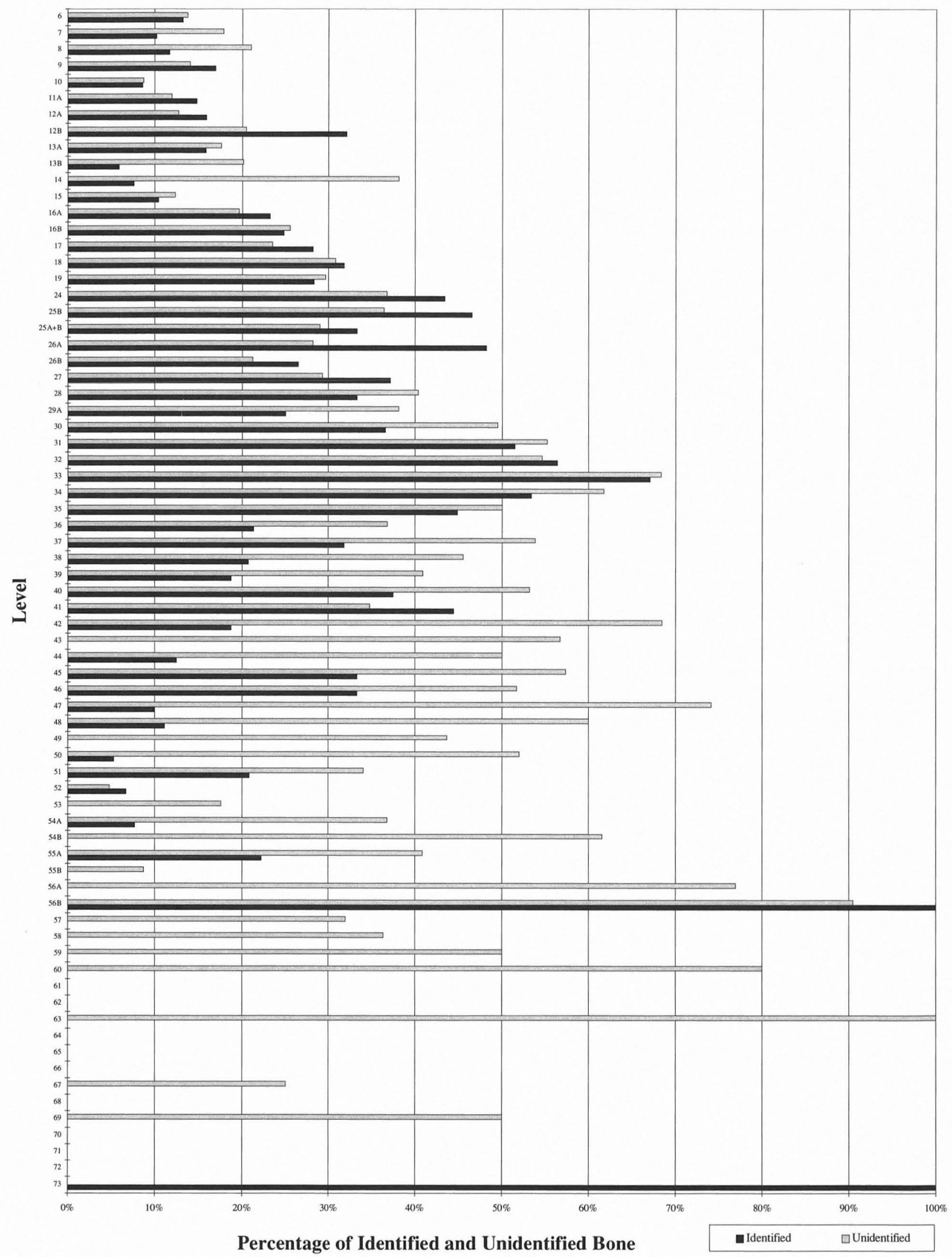

Figure 35-4. Percentages of burning for identified and unidentified bone from Square 20. 


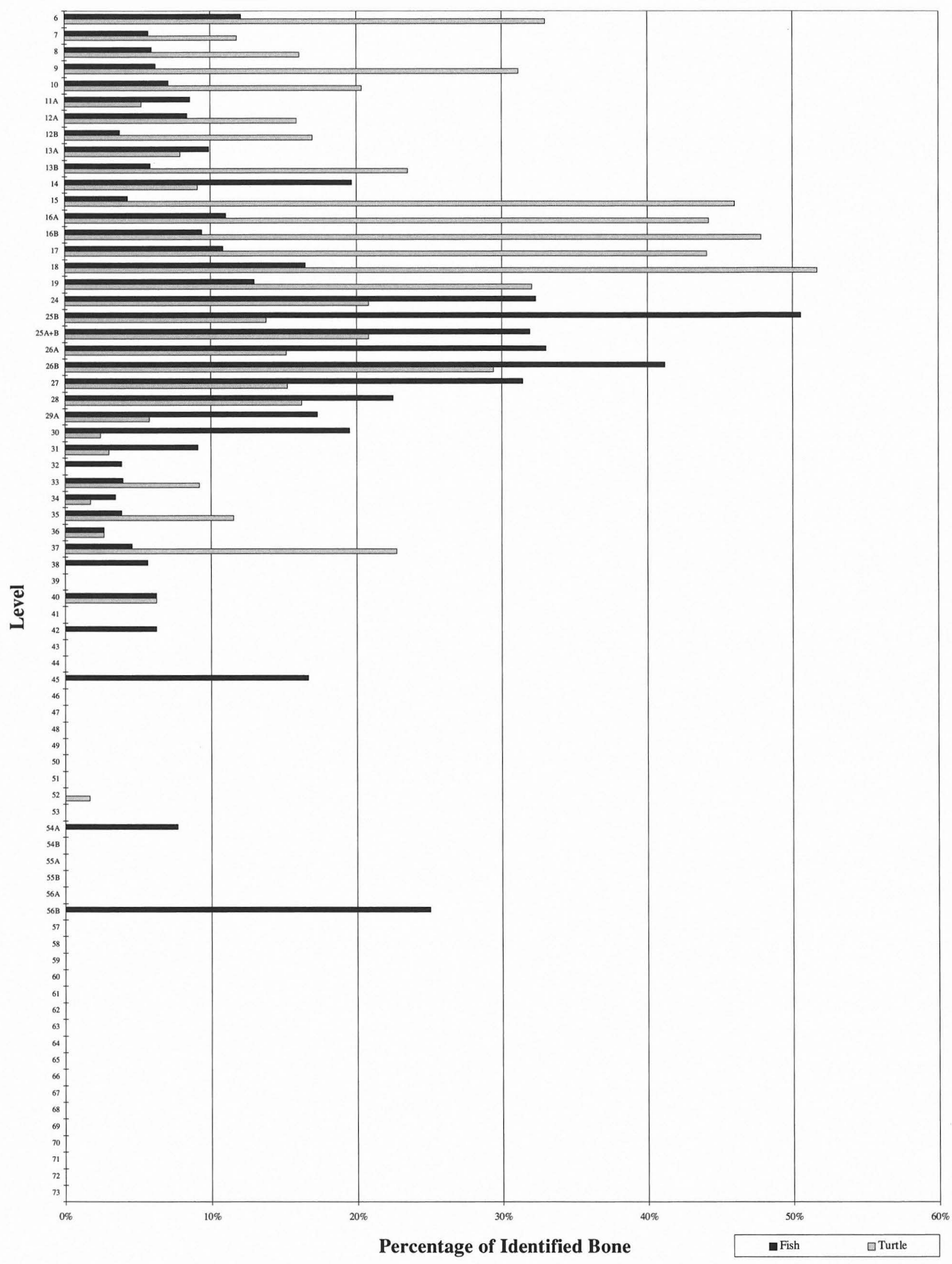

FIGURE 35-5. Percentages of fish and turtle from the total amount of identified bone in Square 20. 
from larger vertebrate bones might have been a common practice and would also provide a plausible explanation for the extremely fractured and fragmentary nature of a large percentage of the bone (see Chapter 33).

In contrast to Baker's analysis of the macrofauna (see Chapter 33), large mammals, notably artiodactyls, are not a significant component of the microfauna. With the exception of Levels 52 and 53, which are inferred to be the remains of a bison bone bed, large mammals account for less than $5 \%$ of the total identifiable fauna in the column, $80 \%$ of which are from the coarse fraction (Figure 35-6). This probably is not a result of a sampling error or misidentification since all bone present in the column was collected, and no larger bone fragments were omitted from this study. This is simply the total amount of material present in the column that could be identified as belonging to the large mammal category with a reasonable level of confidence. It is probable that a larger part of the fauna may be attributable to large mammals, but identification of large mammal specimens based on the highly fragmented nature of the sample is extremely difficult even in the coarse fraction. Consequently, identifiable large mammals are not present in significant amounts in the preserved faunal record of Square 20.

\section{PALEOCLIMATIC INTERPRETION}

The extralimital presence of seven different rodent taxa in the faunal record at Wilson-Leonard indicates a fairly complex and varied history of fluctuating climates and deeper soil levels between approximately 1000 and 12,000 в.P. These taxa include the bog lemming, Synaptomys cooperi; the yellow faced pocket gopher, Cratogeomys castanops; the marsh rice rat, Oryzomys palustris; the muskrat, Ondatra zibethicus; the pine/prairie vole, Microtus sp.; the eastern pocket gopher, Geomys sp.; and the smooth-toothed pocket gopher, Thomomys sp.

Two specimens of Synaptomys cooperi were recovered from the fine fraction of Level 65 (mid Unit Igl). Identification was based on two unrooted tooth fragments consistent in size and angulation of the enamel triangles of specimens recovered from Hall's Cave in Kerr County (Toomey 1993) and Miller's Cave in Llano County (Patton 1962). Specimens of $S$. cooperi have also been recovered from other Pleistocene sites in Texas and as far south as San Josecito Cave near Aramberri, southern Nuevo Leon, Mexico (Cushing 1945). The current range of S. cooperi includes the southeastern part of Canada south to Tennessee, North Carolina, and northeastern Arkansas and west from Minnesota to northeastern Kansas (Figure 35-7). S. cooperi occupies a diverse variety of habitats ranging from wet shrubby grasslands and heavily forested areas to sphagnum bogs or grassy, rocky clearings (Linzey 1983).

The presence of Synaptomys cooperi from sites on the Edwards Plateau is usually interpreted as representing a moister and cooler climate in Central Texas prior to approximately 12,000 B.P. Although the specimens from WilsonLeonard are inferred to be late Pleistocene in age, their presence in Level 65 must be viewed in the context of the gravel beds in which they were found. The exact period over which the gravel beds were deposited is unknown, but it is likely that deposition took place, at least in part, during the "Clovis Drought" that was ending by ca. 11,000 B.P. This period of dry conditions and low water tables is well documented by stratigraphic and paleohydrological details from various sites in the western United States (Haynes 1991). If this is the case, the presence of $S$. cooperi in the gravels may be the result of redeposition of the specimens from older beds. This scenario would explain the apparent temporal proximity of a specimen of Cratogeomys castanops (known from warmer, drier climates) from a slightly higher level.

It has also been suggested by Hibbard (1960) that associations of currently extant allopatric species that were sympatric during the Pleistocene may indicate less-seasonal climates during that time. Although the specimens of Synaptomys cooperi and Cratogeomys castanops are not exactly sympatric at Wilson-Leonard, they are located close to one another in time. This may indicate that the climate around 12,000 B.P. was more equable and seasonal changes during this time may have been less extreme. Taxa such as $S$. cooperi may be restricted to more northeastern climates because of summer extremes in both temperature and aridity (Lundelius 1992c). If the climate during the Pleistocene was less seasonal with more constant temperatures and moisture, Synaptomys may have been able to exist for a longer time at Wilson-Leonard in relict or small populations because of the available water supply and higher levels of localized moisture created by Brushy Creek (Lundelius 1993).

A single specimen of Cratogeomys castanops was recovered from the coarse concentrate slightly higher in the section from Level 53 near the base of the transition between Units Isi and Icl. The specimen consists of the right posterior half of an upper P4 with a connected small medial anterior fragment of the tooth. The only other sites in Texas that have produced fossil specimens of $C$. castanops are Hall's Cave in Kerr County and Kincaid Shelter in Uvalde County (Toomey 1993). The specimens at Hall's Cave are much younger than the specimen from Wilson-Leonard (25002750 B.P. and 3250-3500 B.P. for Hall's Cave specimens [Toomey 1993] as compared to ca. 11,000-11,500 B.P. for the WilsonLeonard specimen). A precise age on the $C$. castanops specimen from Kincaid Shelter could not be determined. It is from disturbed fill and has a modern appearance. The current range for $C$. castanops includes northeastern Mexico and most of the Arkansas River drainage in southeastern Colorado and eastern New Mexico as well as the greater part of the Texas-Oklahoma panhandle region and Trans-Pecos Texas (Davidow-Henry et al. 1989) (Figure 35-8). 


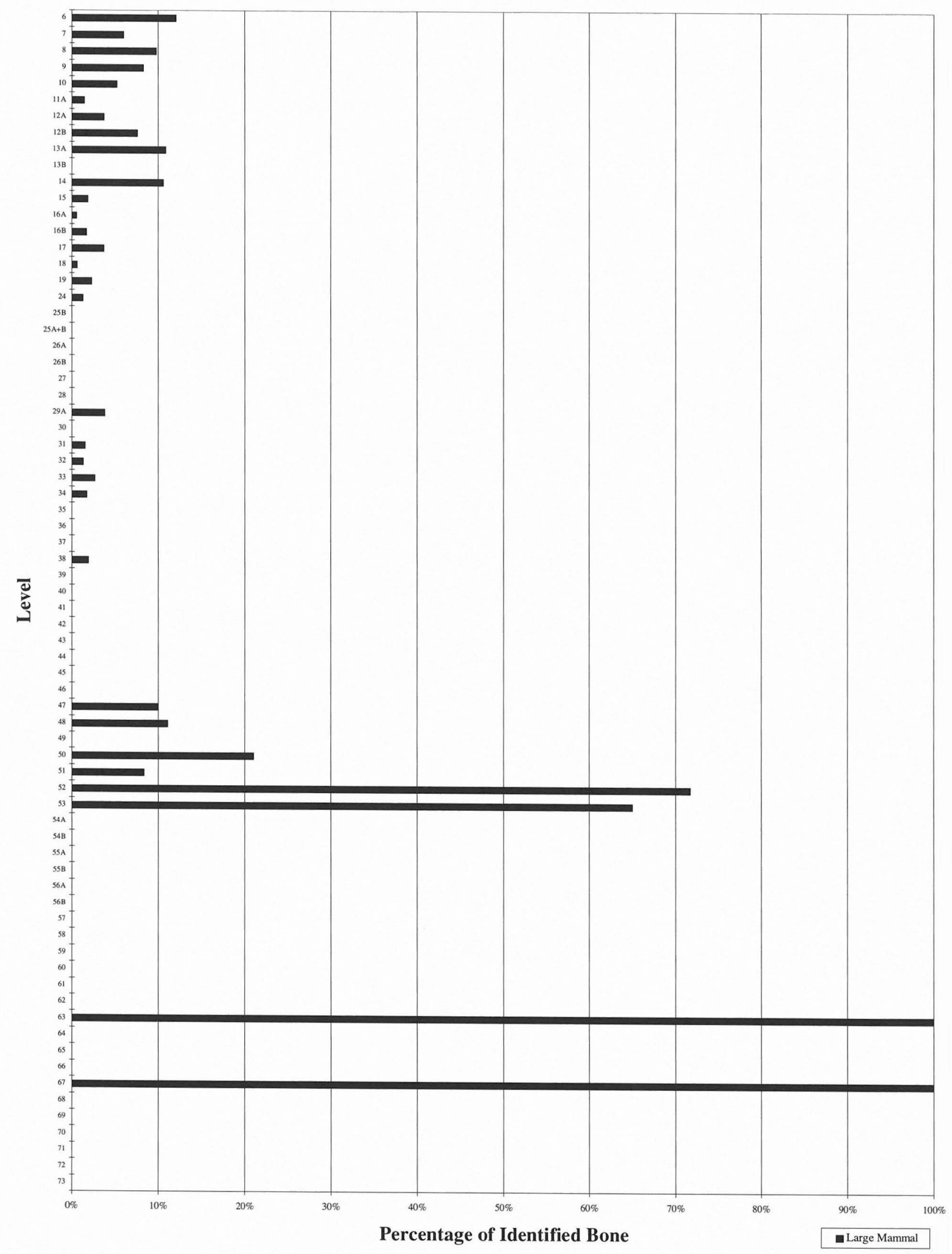

FIGURE 35-6. Percentages of large mammals from the total amount of identified bone in Square 20. 


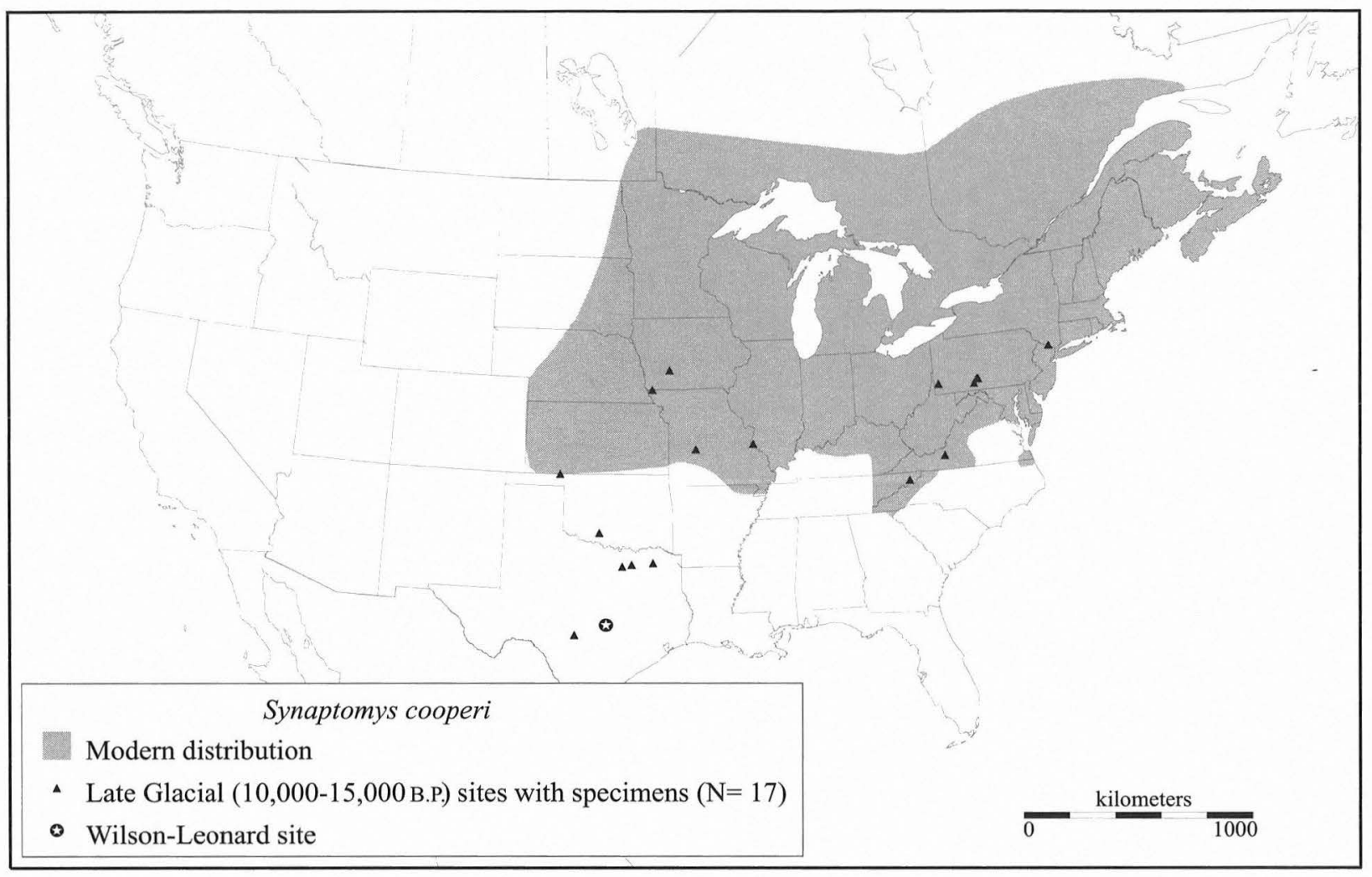

FIGURE 35-7. Range map of Synaptomys cooperi.

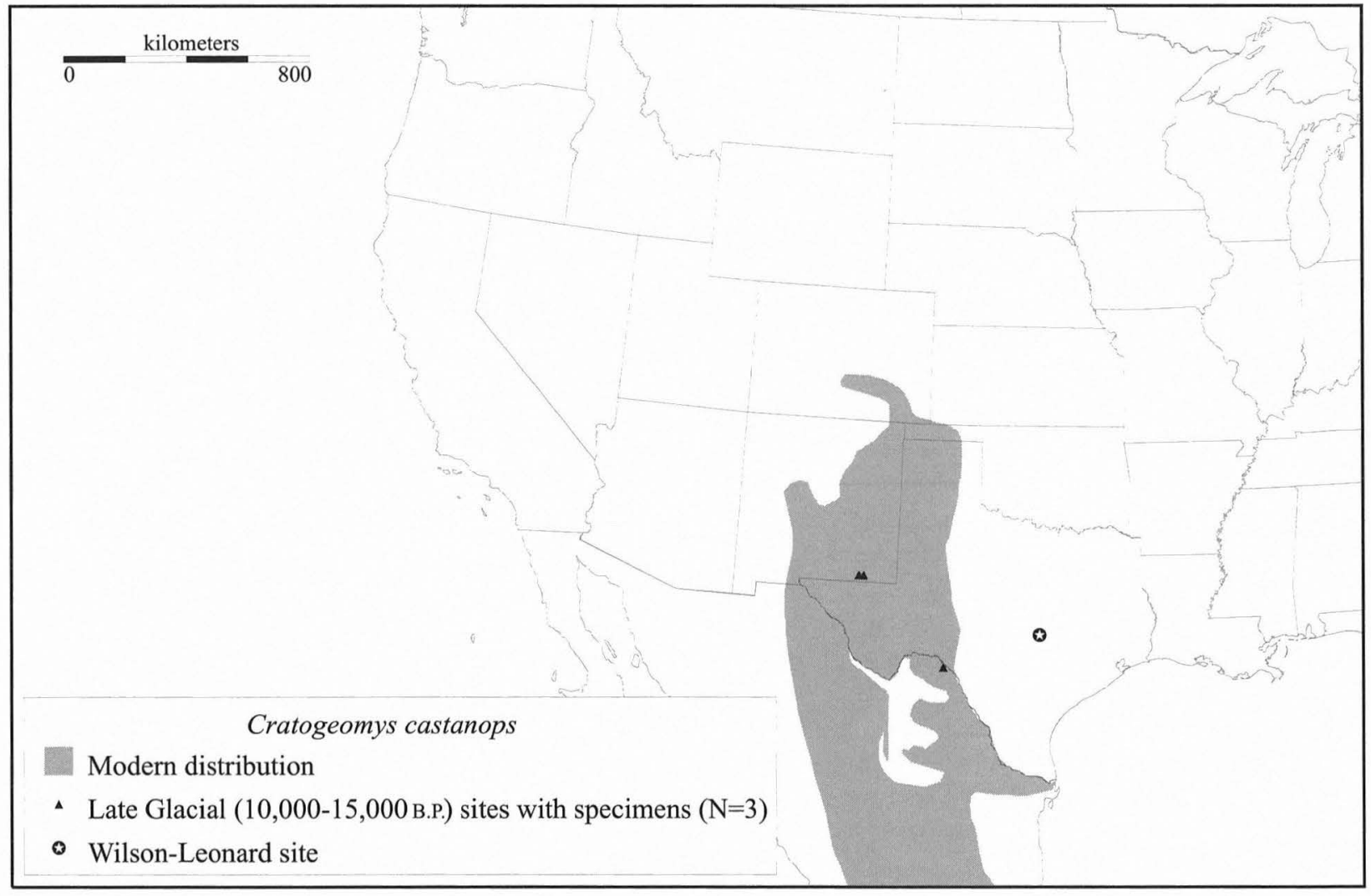

FIGURE 35-8. Range map of Cratogeomys castanops. 


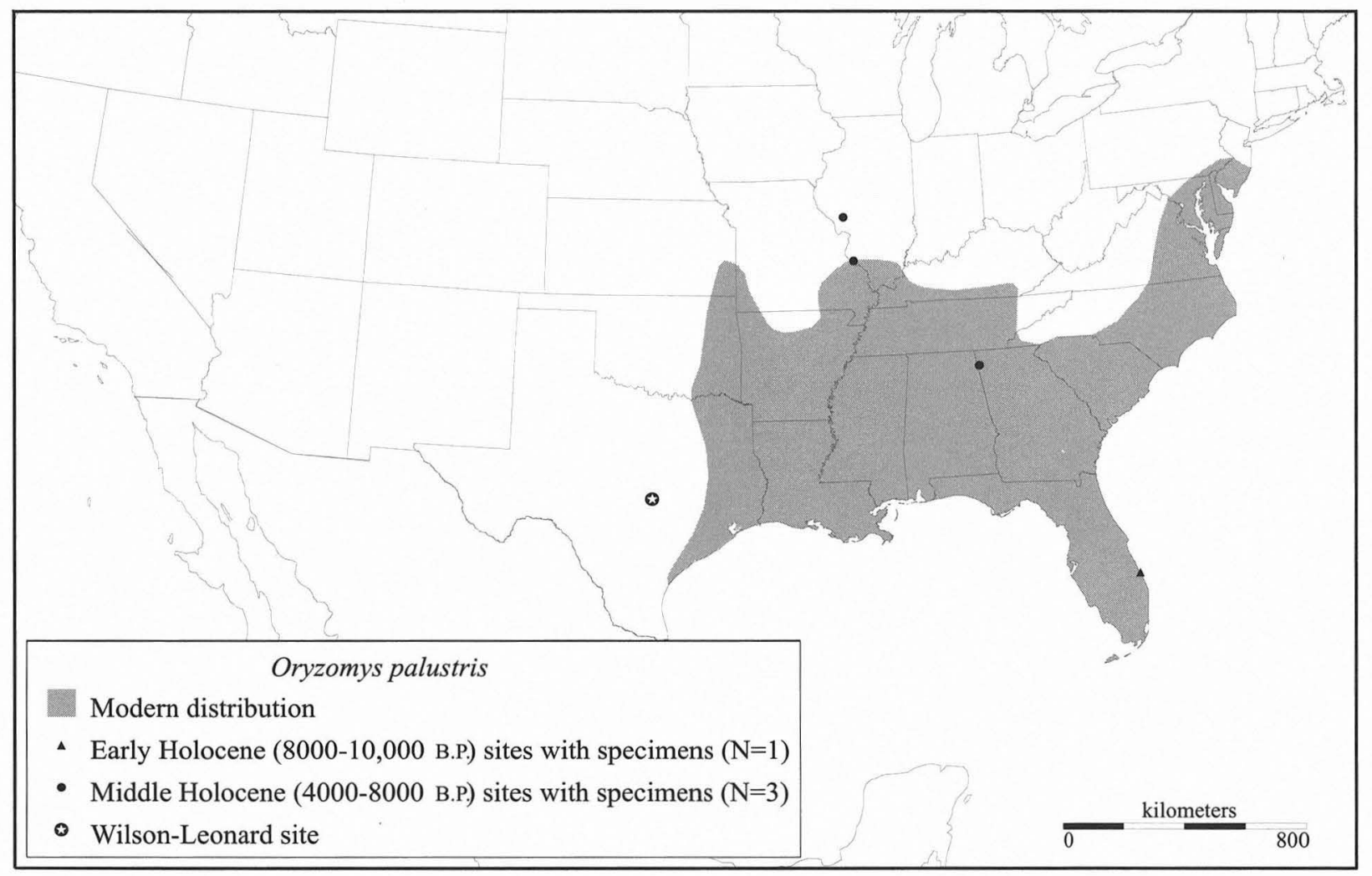

FIGURE 35-9. Range map of Oryzomys palustris.

As one of the larger gopher species, C. castanops requires relatively deep and rockfree soils and tends to be mutually exclusive from other gopher species in its distribution (Davis 1974). Although no Geomys or Thomomys were recovered from the two levels immediately preceding or following Level 53, the low diversity of taxa and very small sample sizes from these levels precludes any intrepretations based on the absences of certain taxa. Although there are no similarly aged specimens of Cratogeomys castanops from other sites in Central Texas, its presence at Wilson-Leonard is not disharmonious considering the time period in which it occurred (near the end of the "Clovis Drought"). Dry and possibly xeric conditions at this time are also known from decreases in arboreal pollen and increases in the grass pollen record documented from Boriack Bog in east-central Texas (Bryant and Holloway 1985). Therefore, the presence of Cratogeomys castanops from Level 53 further supports the existing evidence for a change from moister and cooler conditions in Central Texas prior to ca. 12,000 B.P. to drier and possibly xeric climatic conditions during approximately 11,000 to 11,500 B.P.

A single specimen of the marsh rice rat, Oryzomys palustris, was identified from Level 40 of stratigraphic Unit Isi-c (the Leanne soil). An additional specimen identified by Winkler (1990) was recovered from Level 26 (Unit Id/II) in the previous TxDOT fine-screened square. It dates to ca. 9500 в.P., and is proximal both stratigraphically and temporally to the TARL Level 40 specimen. Other fossil occur- rences of $O$. palustris in Texas include a partial maxilla from Schulze Cave in Edwards County reported by Dalquest et al. (1969) and an occurrence from Montell Shelter, Uvalde County (Lundelius 1967). Both are Late Pleistocene in age. Marsh rice rats currently inhabit coastal wetland and marshy areas but may also occupy areas where sedges and grass supply sufficient cover (Davis 1974). Their range includes most of the Atlantic coast from southern New Jersey to the tip of Florida and westward to eastern Kansas south to the coastal plain of Texas (Wolfe 1982) (Figure 35-9). Based on the current southeastern distribution of this species, the presence of $O$. palustris at Wilson-Leonard suggests a return to moister conditions between approximately 10,000 and 9500 B.P.

Paleoclimatic conditions based on faunal material above Level 36 or after ca. 9500 в.P. become more difficult to interpret because of the lack of strong paleoclimatic faunal signals. Some conclusions can be drawn, however, from the fairly constant presence of Geomys sp. and Microtus sp. in Levels 6-39 (Units IIIc through Isi-c). These taxa, as well as Ondatra zibethicus (a specimen of that was recovered from Level 36), are present either around or northeast of the Edwards Plateau today but are not found in the immediate area around Wilson-Leonard because of moisture or soil depth limitations.

Ondatra zibethicus, the muskrat, identified by a wellpreserved lower left M3, is widely distributed throughout North America and occupies a wide variety of aquatic habitats (Willner et al. 1980) (Figure 35-10). Its only major 


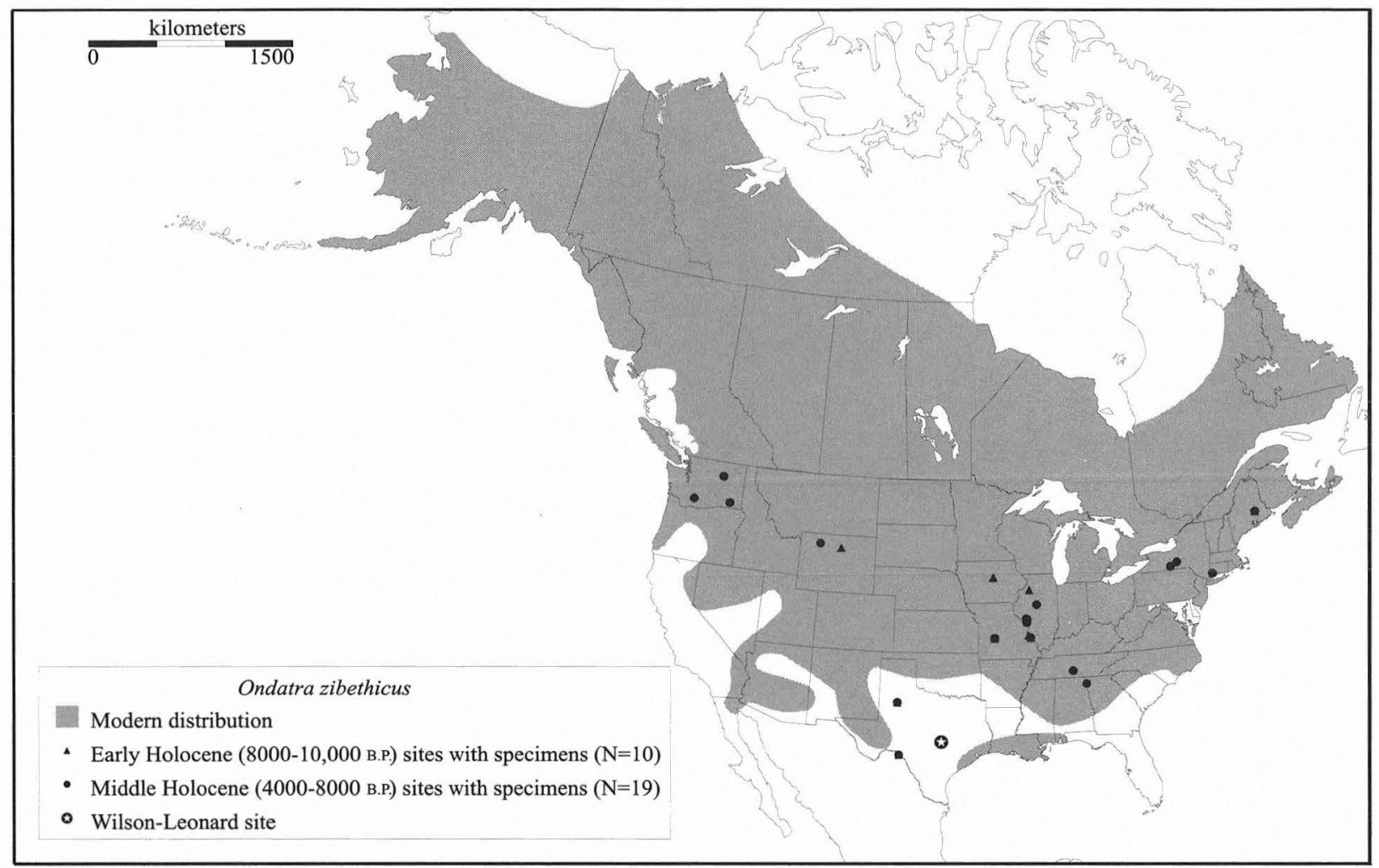

FIGURE 35-10. Range map of Ondatra zibethicus.

requirement is a permanent source of water and this was most likely Brushy Creek (Semken 1970). Although $O$. zibethicus was not widely distributed in Central Texas during or after the Wisconsin, it is known from several Wisconsin-age sites including Montell Shelter, Uvalde County; Miller's Cave, Llano County; and from a more-recent unit in Damp Cave, Val Verde County. All three of these sites have a permanent source of water close by or have had one in the past (Lundelius 1967). Based on its wide climatic distribution, the presence of $O$. zibethicus at Wilson-Leonard tells little about the climate, but it is unlikely that it was warmer or drier than today.

Specimens belonging to the genus Microtus sp., the pine/prairie vole, are identified from 36 isolated teeth and tooth fragments from the upper two-thirds of the column (Units IIIc-Icl). These specimens could not be identified to the species level ( $M$. pinetorum, the pine vole, or $M$. ochrogaster, the prairie vole) due to the high level of fragmentation. M. pinetorum occurs in a wide variety of environments from closed-canopy forests to grassy fields providing some sort of shrubby cover and is widely distributed over most of the southeast from the eastern edge of Texas to coastal Virginia and north to south-central Wisconsin (Smolen 1981) (Figure 35-11). M. ochrogaster has a more central and north-central distribution in North America and prefers open grasslands, meadows, and prairies from the southern edge of the Texas-Oklahoma panhandle region north into southern Canada and from central Mon- tana in the west to eastern Kentucky (Stalling 1990) (Figure 35-11). The ranges of both voles are limited by minimum moisture levels.

The distributional pattern of Microtus sp. specimens in the Square 20 column is somewhat unpronounced because of low sampling levels, but a small peak in abundance does occur between Levels 28-38 (Units II/IIIa through Isi-c/II), spanning the entire stratigraphic interval of Unit II from approximately 8700-9500 B.P. (Figure 35-12). Occurrences, mostly limited to a single specimen, do occur sporadically in increasingly younger levels up to Level 7 (Unit IIIc) and one outlying specimen occurs deeper in the column in Level 51 (Unit Icl). The recovery of Microtus sp. from many archeological and paleontological sites in Texas dating from the Middle and Late Holocene has been interpreted as an indication of levels of moisture greater than at present during that time (Lundelius 1967); however, more recently obtained evidence of significant drying in the Middle Holocene brings this interpretation into question (Collins 1995; Toomey 1993). A careful review of the distributional evidence for Microtus sp. is probably in order, taking into account the possibility of persistence of this taxon in locally favorable microhabitats. The recovery of a specimen from Level 7 indicates that Microtus sp. was present in Central Texas until at least 1000 в.P., but decreasing numbers of specimens recovered from WilsonLeonard, Hall's Cave, Miller's Cave, and the Barton Road site after about 3500 в.P. suggest a gradual extirpation of 


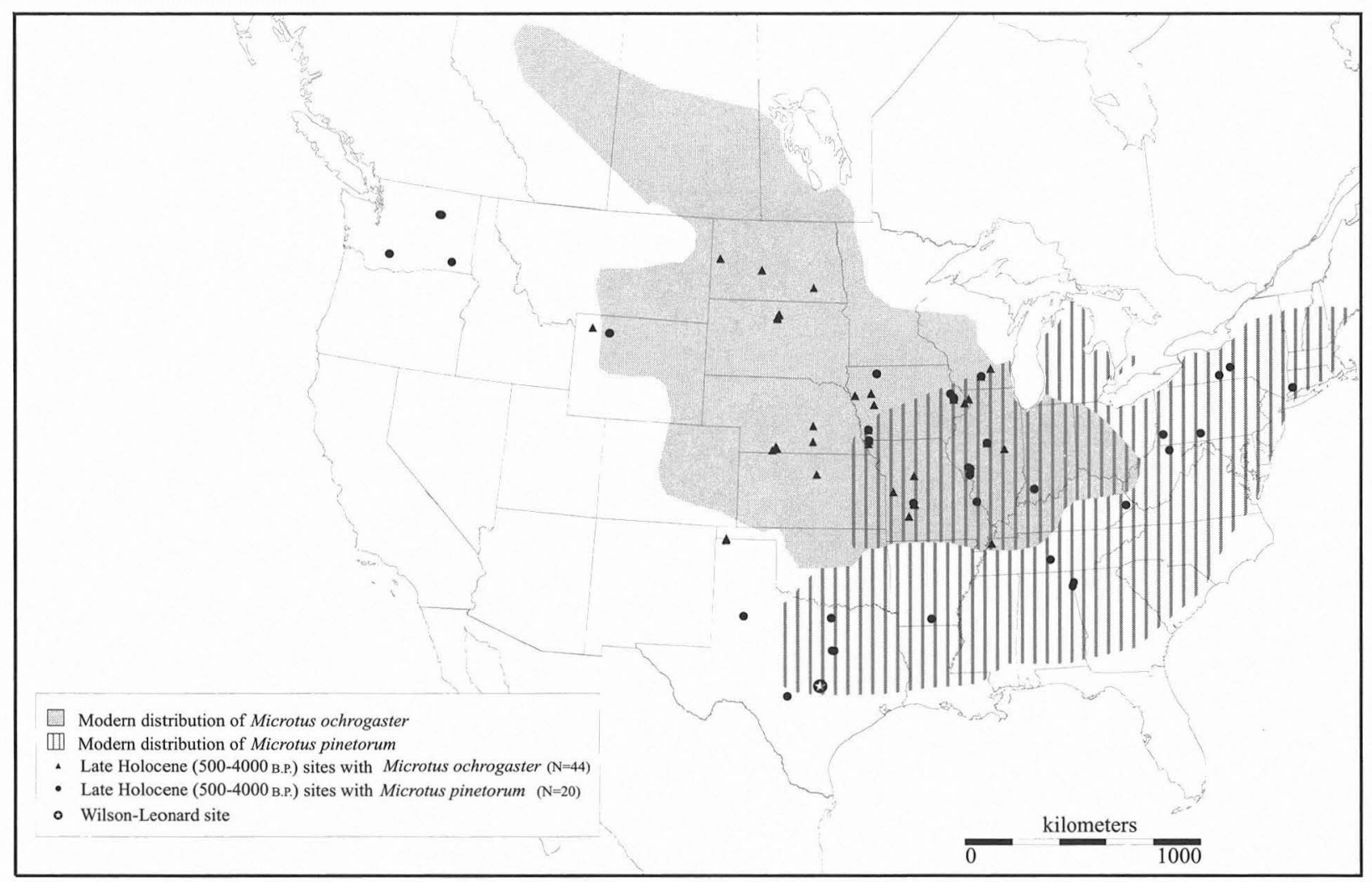

FIGURE 35-11. Range map of Microtus pinetorum/ochrogaster.

Microtus sp. from Central Texas as moisture levels began to approach their modern limits (Toomey 1993).

Specimens referred to as Geomys sp., the eastern pocket gopher, are also consistently present in generally increasing numbers from Level 44 to Level 6 (Unit Icl/Isi-IIIc), with one specimen recovered deeper in the section from Level 55a (Unit Igl//si/Icl) (Figure 35-13). Some controversy surrounds the frequently changing specific names and diagnoses of Geomys in Texas and it is possible the referred material from Square 20 may include any of seven nominal species whose divisions are based on chromosomal and morphometric differences not diagnosable in fragmented fossil forms. These include G. bursarius (north-central and most of the Panhandle), G. attwateri (east-central Texas), G. personatus (southern Texas), G. texensis (Llano uplift region), G. arenius (El Paso County), G. breviceps (northeastern Texas), and $G$. knoxjonesi (southwestern panhandle) (Sulentich et al. 1991). Because three of these species, G. bursarius, G. breviceps, and G. attwateri, occur immediately adjacent to Travis and Williamson counties and only on their eastern edges, it can be assumed that referred fossil material from Square 20 may belong to any of these three and should not be referred to beyond the generic level Geomys sp. (Figure 35-14). Referred material consists of 217 specimens of readily identifiable molars, incisors, and postcranial fragments.

Factors limiting Geomys sp. from inhabiting an area are based primarily on soil type and depth, their preference being sandy soils with a low clay content and a minimal depth of $10 \mathrm{~cm}$ (Schmidly 1983). Although there are no distinct patterns in their distribution in Square 20 (see Figure 35-13), the consistent presence of Geomys at Wilson-Leonard through the uppermost collected level indicates that soil levels around the immediate site area were sufficiently deep for this gopher to live there at least until 1000 в.P. It is probable that the actual record of Geomys sp. at Wilson-Leonard may have ended more recently and is limited by the stratigraphic extent of the column. Specimens recovered from the black fill at Longhorn Cavern in Burnet County, indicate that Geomys sp. was present in historic times at least within the vicinity of the cave. Semken (1961) suggests that the extirpation of Geomys from areas of Central Texas may be related to the stripping of soil caused by erosion resulting from overgrazing by European livestock. This, along with the natural processes of soil stripping occurring in Central Texas during the last 3,000 years, may have led to current conditions of poor, rocky soils in Williamson County. The faunal record of Geomys sp. at Hall's Cave, however, does end at approximately 1000 B.P., suggesting an earlier time of extirpation on the western edge of Central Texas.

The identification of two specimens of Thomomys sp. from Levels 24 and 25B (Units IIIa-II/IIIa) suggests drier or possibly equable conditions may have existed in the early Holocene, or at approximately 8700 B.P. Identification of Thomomys sp. is somewhat tentative due to a considerable amount of variation seen in gopher teeth from WilsonLeonard and the apparent atypical shape of one of the two 


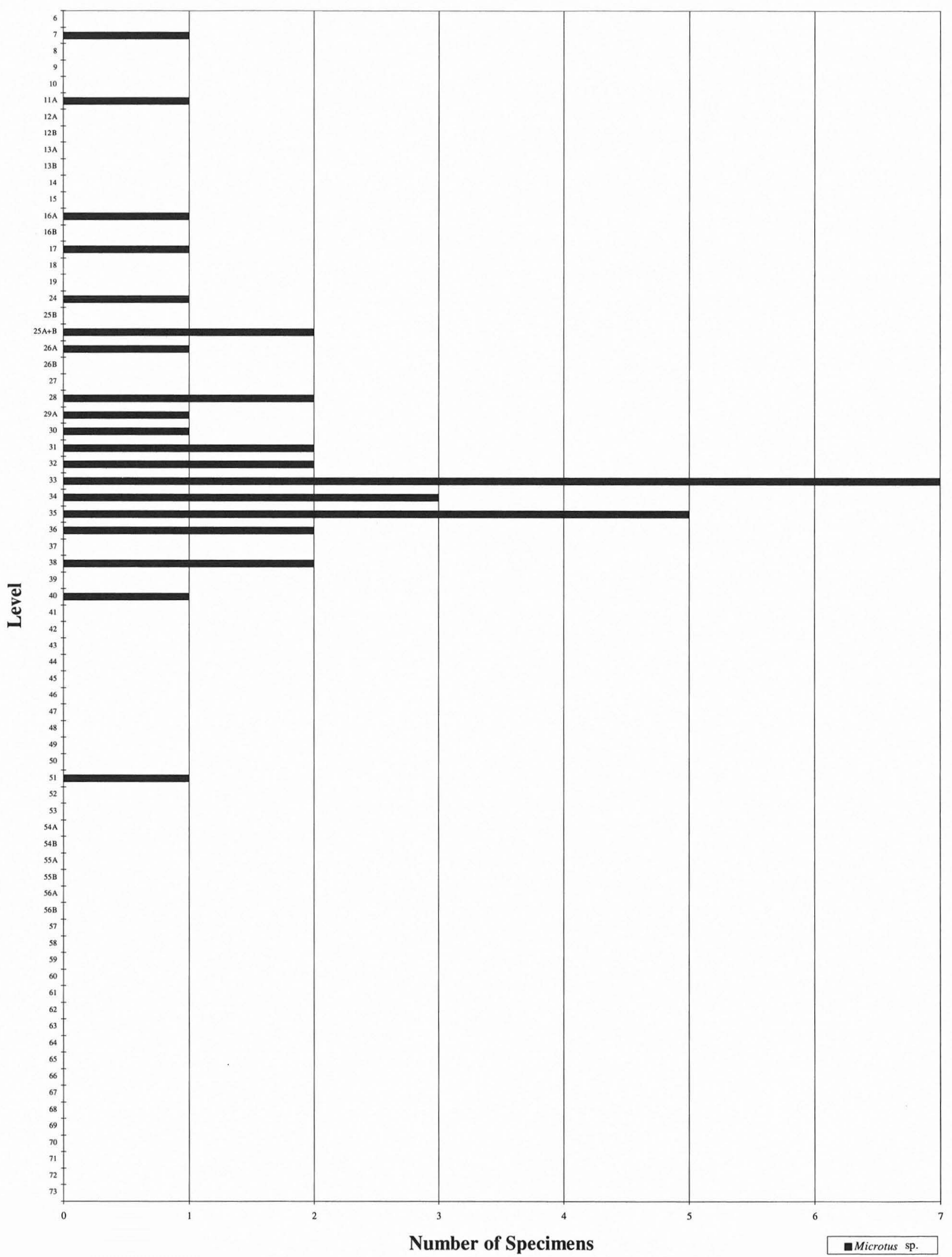

FIGURE 35-12. Distribution of specimens of Microtus sp. 


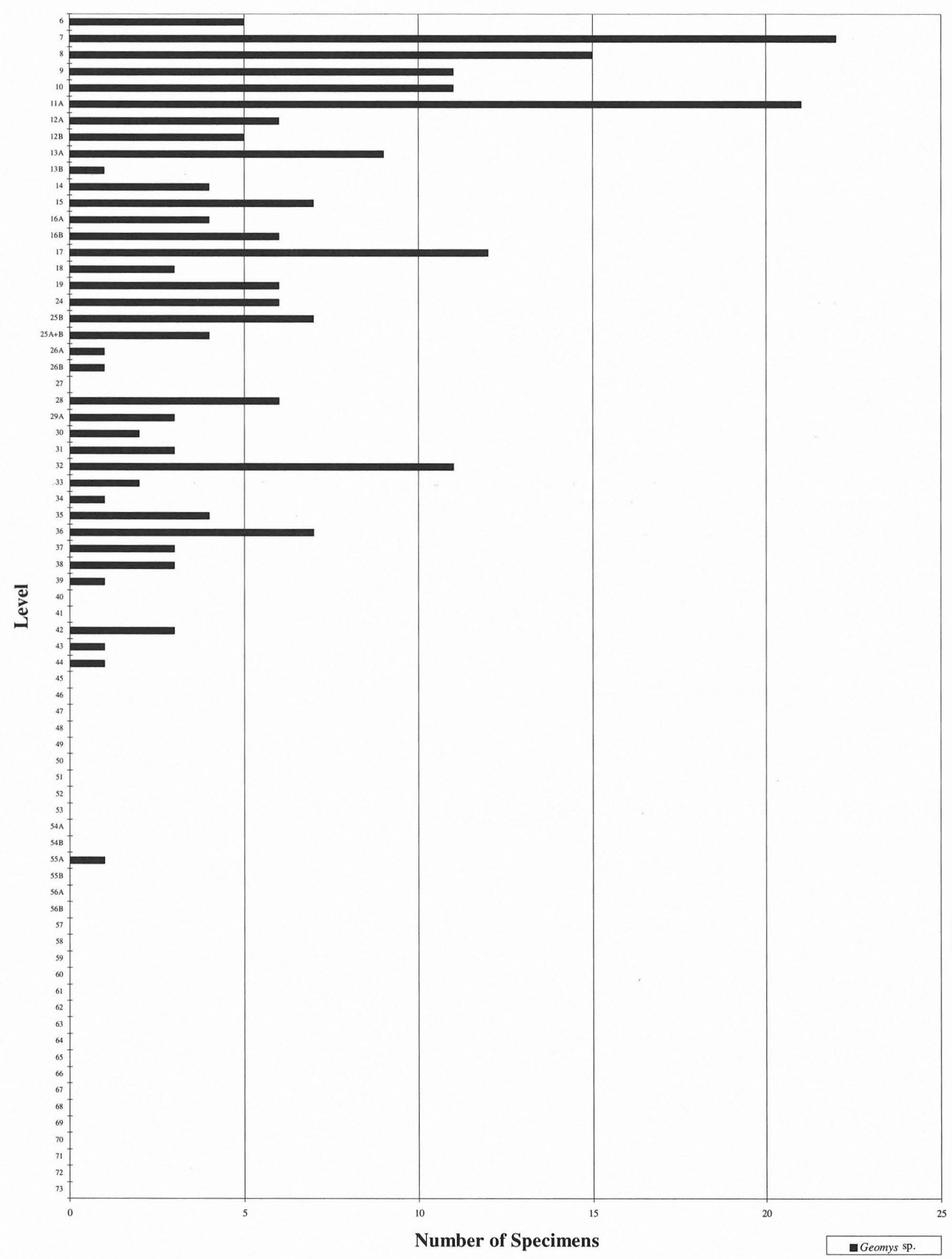

FIGURE 35-13. Distribution of specimens of Geomys sp. 


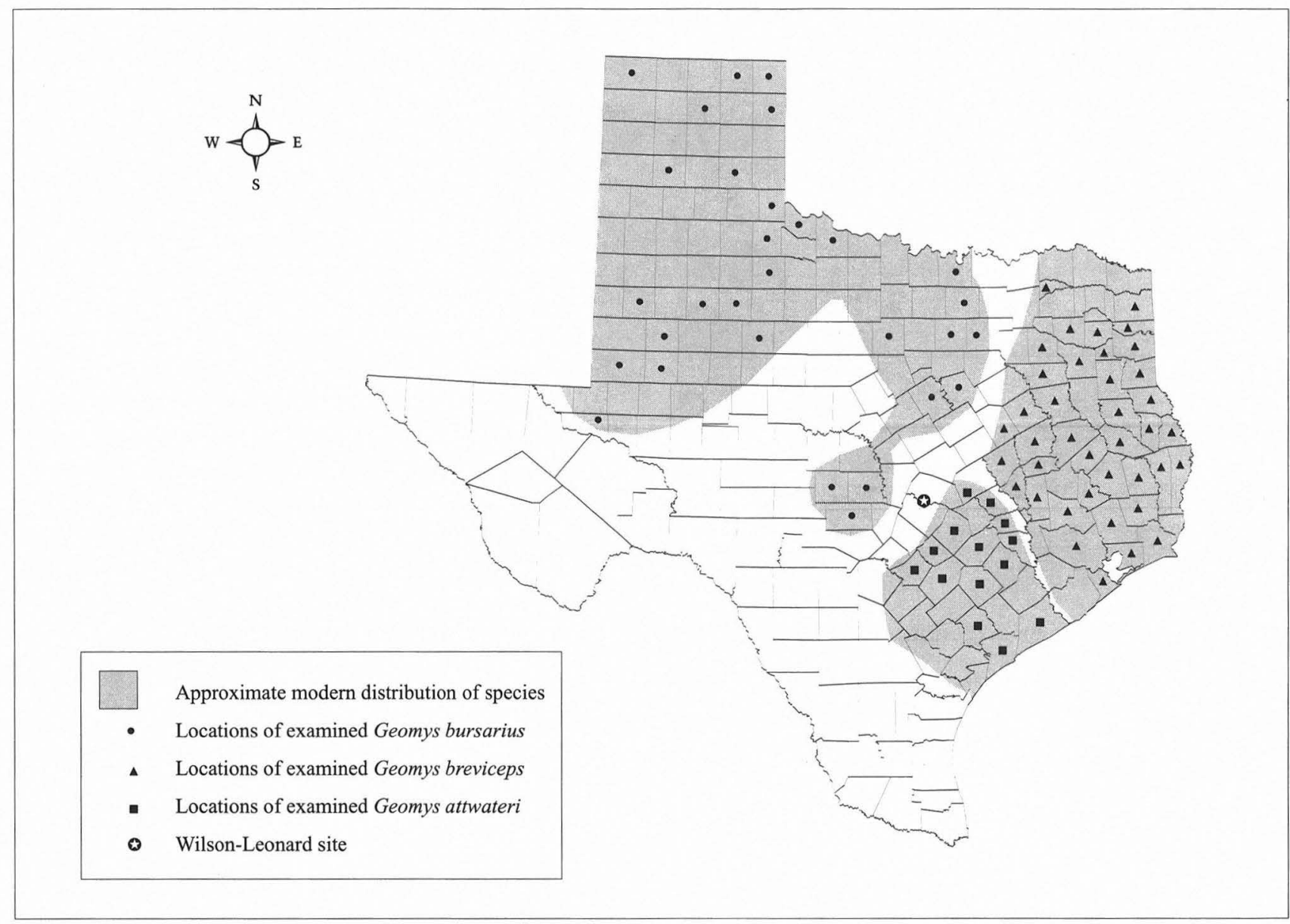

FIGURE 35-14. Range map depicting the distributions of the three species of Geomys in central Texas. (1) Geomys bursarius; (2) Geomys breviceps; (3) Geomys attwateri.

referred specimens. The specimen recovered from Level 24 is an upper left M2 that is buccally pinched with two plates of enamel, comparable to T. bottae (Figure 35-15). The specimen from Level 25 is an upper right $\mathrm{P} 4$ which is also comparable to $T$. bottae in having pinched lingual and buccal sides; however, the reentrant loph from the buccal side extends approximately $70-75 \%$ across the width of the tooth (Figure 35-16). Although the teeth of most gophers are not exactly symmetrical, the notable asymmetry of this particular specimen is anomalous. The approximate size, unrooted condition, and strong reentrant loph initially raised the possibility that this tooth may be a fragment of a Synaptomys cooperi molar, however, there is no apparent breakage on the anterior side of the tooth and the enamel plates are not joined laterally. The age of the specimen is also somewhat younger than the estimated Late Pleistocene records of the extirpation of S. cooperi from Central Texas.

If both of these specimens are referable to Thomomys, their presence at Wilson-Leonard and sympatry with both Geomys sp. and Microtus sp. pose some interesting questions about the climate and soil conditions at that time. Early and middle Holocene records of Thomomys are rare and were

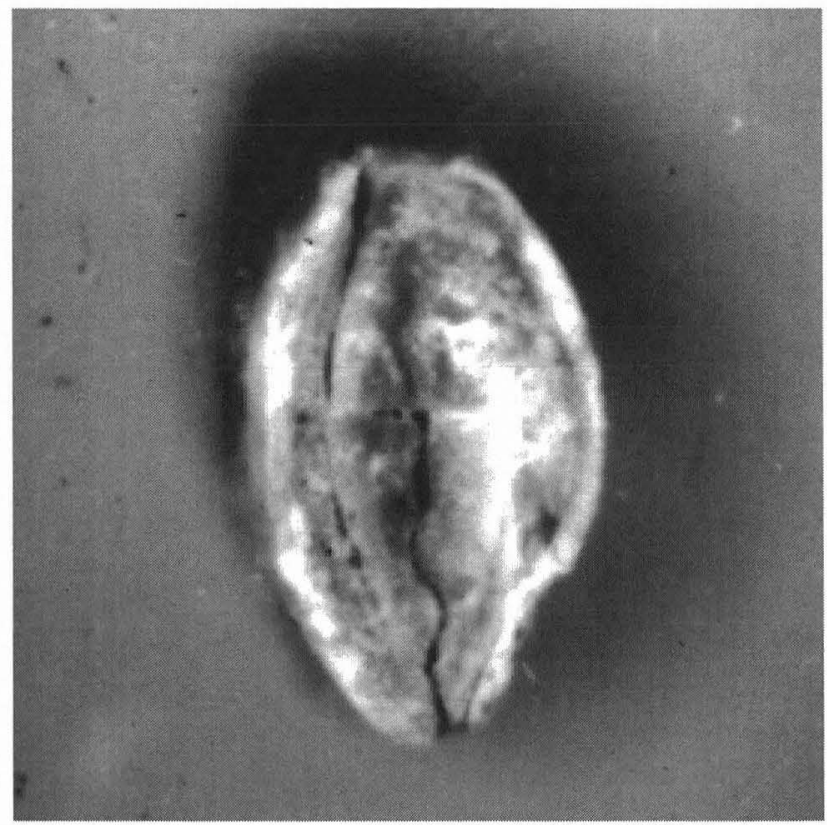

FIGURE 35-15. Upper left M2 of Thomomys sp. (No. 43157-2087) from Level 24 (at 15X). 


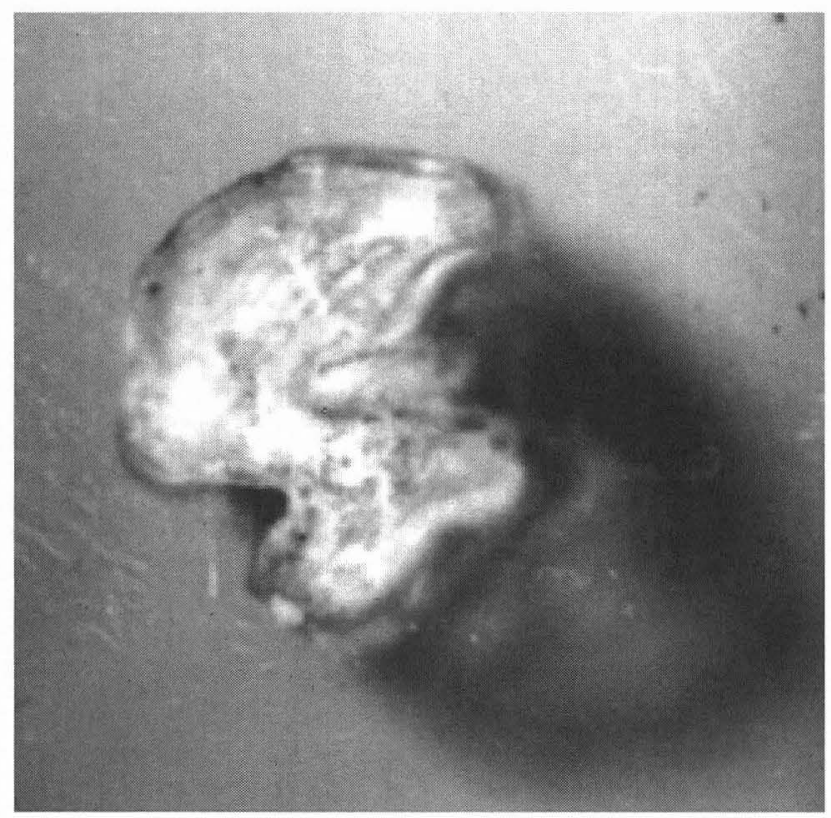

FIGURE 35-16. P4 fragment of Thomomys sp. (No. 43157-2790) from Level 25 (at 15X).

only known from Schultz Cave and Klein Cave until Hall's Cave was thoroughly analyzed by Toomey (1993). Thomomys does occur sporadically at Hall's Cave in the early and middle Holocene, and it was interpreted that Hall's Cave probably represented the easternmost range of Thomomys during that time interval. Dalquest and Kilpatrick (1973) suggest that the range of Thomomys may have been significantly expanded eastward from the latest Pleistocene until approximately 4000 в.P. (Figure 35-17). Based on the Wilson-Leonard specimens, this could indeed be the case and the identification of Thomomys specimens from the Square 20 column further expands the known limit at Hall's Cave an additional $100 \mathrm{~km}$ eastward.

Dalquest and Kilpatrick (1973) also suggest that Geomys and Thomomys were sympatric over a large area of the Edwards Plateau during the late Pleistocene and Holocene. Toomey (1993) interprets this sympatry more as a result of Geomys expanding their range westward rather than an eastward range expansion for Thomomys, but he questions why there was no eastward expansion across the Edwards Plateau when specimens of Thomomys have been recovered from Pleistocene deposits such as Lubbock Lake and Howard Ranch north of the plateau. With the identification of Thomomys from early Holocene deposits at Wilson-Leonard, this gap in the Central Texas record is potentially filled; the expansion of Thomomys did indeed reach the eastern edge of the Edwards Plateau. Its presence during the early Holocene at Wilson-Leonard, therefore, has important implications for future range studies of smooth-toothed pocket gophers.

The sympatric association between Thomomys sp. and Microtus sp. is more complicated since conditions of in- creased moisture indicated by the presence of Microtus appear contrary to the dry soil conditions preferred by Thomomys. It is possible that at the time Thomomys and Microtus were sympatric at Wilson-Leonard, one or both of these taxa might have been marginal in the area. Other sympatric associations of Thomomys and Microtus do exist in low numbers at other sites in Texas including the late Pleistocene deposits of Shultze Cave (Dalquest et al. 1969) and also at Hall's Cave in several mid Holocene levels (Toomey 1993). Based on observations from Shultze Cave, Dalquest et al. (1969) report a decrease in abundance of Microtus specimens after the Pleistocene in western Texas. This decrease in the presence of Microtus sp. corresponds to an increase in the number of Thomomys sp. present in postPleistocene levels.

This pattern generally can be observed during the early Holocene at both Hall's Cave and Wilson-Leonard. Toomey (1993) suggests that Thomomys sp. was present around Hall's Cave in low densities from approximately 10,500 B.P. until 5500 в.P. Between 5500 в.P. and 2500 в.P., Thomomys became more common and was continuously present in relatively high population densities before its decrease in abundance and gradual extirpation after approximately 2500 в.P. Microtus is consistently present at Hall's Cave from the Late Pleistocene to approximately 4500 B.P., after which it was still a common taxon but present in much lower numbers. The levels at Hall's Cave with the greatest abundance of Microtus are Late Pleistocene, suggesting a gradual decline in population from that time. The two Wilson-Leonard specimens of Thomomys from Levels 24 and 25B (approximately 8700 B.P.) also occur later than the peak abundances of Microtus in Levels 28-38 (approximately 8700-9500 B.P.) (see Figure 3512). Although the sample size of both Thomomys and $M i$ crotus at Wilson-Leonard is much smaller and the timing is earlier in the Holocene, the pattern of distribution still holds considerable significance.

It is also possible that the occurrence of Thomomys at Wilson-Leonard was more marginal than that of Microtus. Wilson-Leonard is much farther east from the current extralimital boundary of Thomomys than Shulze Cave or Hall's Cave, and it is likely that Wilson-Leonard may represent the extreme margin of its boundary for the early Holocene. While conditions for Microtus may have been in decline during this time, small populations persisted on the eastern side of the Edwards Plateau with relict populations surviving in isolated microhabitats into historic times (E. L. Lundelius, personal communication 1996)

An alternative explanation for the Thomomys/Microtus sympatry is that more equable conditions during the late Pleistocene, proposed by Hibbard (1960), may have lingered into the early Holocene in the eastern portion of Texas, making the environment around Wilson-Leonard more inviting for disharmonious faunal members at that time. This would be difficult to support, however, since only one taxon is disharmonious and it is represented by only two specimens. 


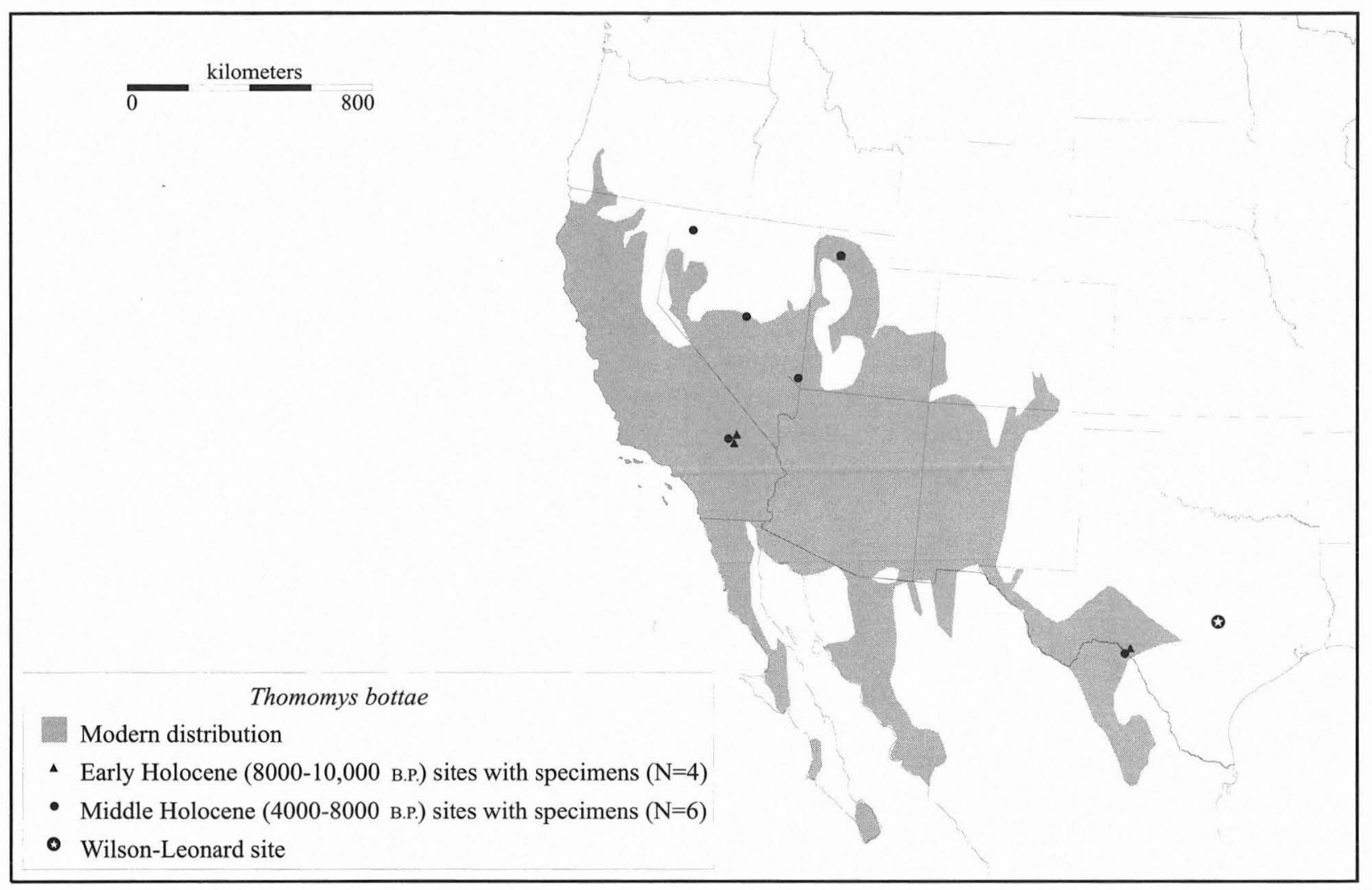

FIGURE 35-17. Range map of Thomomys bottae.

Based on the lack of Thomomys in other sites on the eastern edge of the Edwards Plateau, one can only conclude that the conditions at Wilson-Leonard or the area immediately surrounding the site must have been suitable to meet the minimum tolerances of both animals on at least a marginal level.

\section{SUMMARY}

Despite the fragmentary nature and poor preservation of the Square 20 column faunal sample, a fairly diverse fauna with several species useful as paleoenvironmental indicators was identified. The identifications of seven genera and species of extralimital rodents allowed for an interpretation of complex, fluctuating climates and moisture levels at the Wilson-Leonard site between ca. 12,000 to 1000 B.P. The recovery of Synaptomys cooperi from the gravels of mid Igl suggests a period of cooler, moister conditions prior to 12,000 B.P. and may represent specimens redeposited from older stratigraphic layers. The presence of Cratogeomys castanops slightly higher in the section (near the transition of Units Icl, Isi, and Igl) suggests a climatic change to more-xeric conditions and the presence of relatively deep soils from ca. 11,500 to 11,000 B.P. The identification of the marsh rice rat, Oryzomys palustris from Unit Isi-c and the muskrat, Ondatra zibethicus, from slightly higher in the section in Unit II indicates a return to moister conditions at Wilson-Leonard during approximately 9500 to 8700 B.P. and the presence of a permanent source of water at Brushy Creek.

The recovery of two specimens of Thomomys sp. in lower Unit IIIa suggests drier or possibly more equitable conditions returned to Central Texas ca. 8700 B.P. The sympatric association of Thomomys sp. with Microtus sp. suggests that local conditions surrounding Wilson-Leonard may have supported a disharmonious faunal community and conditions at that time may have been marginal for either Thomomys, which requires drier soils, or for Microtus, which requires minimum levels of moisture. From approximately 8700 B.P. to ca. 4000 B.P., the climate was drier, and soils became shallower on the Lampasas Cut Plain. This is supported by the gradually declining abundance of Microtus sp. from the middle of Unit II to Unit IIIc at the top of the section. Because both Microtus sp. and Geomys sp. are present fairly consistently through the top of the section but neither are present in the area today, it can be inferred that both of these rodents became extirpated from this area within the last 1,000 years due to insufficient moisture and soil levels. It is also possible that the extirpation of Geomys may have occurred within historic times as a consequence of the erosional effects of overgrazing.

In addition to their importance as paleoenvironmental indicators, the recovery of two taxa of extralimital gophers, Cratogeomys castanops and Thomomys sp., are the first to be reported for the eastern edge of the Edwards Plateau, 
and their presence at Wilson-Leonard represents the easternmost known occurrences for these taxa. Undoubtedly, this will have important implications for future paleoenvironmental research in Central Texas as more of the fossil record is uncovered. In this regard, there also remains the unanalyzed material from Square 12 that upon analysis has the potential of increasing the sample, and thereby the resolution, of the microfaunal data from the site.

Some controversy surrounds the usefulness of fine screening a site because of the time-consuming procedures and high level of effort involved in the identification of extremely small fragments. In the light of this, it is important to note that the paleoclimatic information gained from the microfauna recovered at the Wilson-Leonard site would not have been possible without the techniques of fine-screen recovery. With the exception of the Cratogeomys and Ondatra specimens, all of the other extralimital rodents identified from the Square 20 column were recovered from the fine fraction, including $100 \%$ of the Microtus specimens and over $95 \%$ of the Geomys specimens. Furthermore, little diversity would have been reported without all the small rodents, reptiles, amphibians, fish, and birds recovered from the fine fraction. Wilson-Leonard thus demonstrates the benefits of fine-screening in order to retrieve potentially vital paleoecological data, and the implementation of this technique should be encouraged at all archeological sites showing a viable potential. 


\section{Chapter 36}

\section{EGGSHELL ANALYSIS}

by Susan Decker

\section{INTRODUCTION}

Numerous small fragments of bird eggshells were recovered from the 1/8-inch and 1/16-inch mesh of the waterscreened matrix. The fragments were found in matrix from Units I, II, and III, some associated with features and some from nonfeature contexts. For the present analysis, which seeks a viable method for studying archeological eggshells, a sample of 172 fragments, all from feature contexts, were analyzed. These were retrieved from feature sediment samples from both the TxDOT and TARL excavations; the samples were water screened (see Chapter 34) and picked by the present author. Other faunal remains were also recovered in this process (see Chapters 26 and 35), but only the eggshell is reported here.

Wilson-Leonard is one of the few prehistoric sites in Texas that has archeological bird eggshell among its reported faunal remains. This is in part due to the fact that very small fine-screened eggshell fragments are difficult to identify. They can easily be mistaken for small fragments of snail shells unless they are sorted under a microscope. However, a technician with a microscope and a sample of modern eggshell for comparison can be trained to recognize the attributes that distinguish bird eggshells from snail shells: small eggshell fragments have a matte finish and are almost flat, with pores on the exterior surface and a rough interior surface; snail shells are shiny, curved, and smooth with no pores, and they are made of microthin layers. The eggshells of tortoises, turtles, and certain species of snakes are either soft shelled or have a distinctly different morphology from that of bird eggshells and would not normally be confused with them. No reptile eggshells were present in the WilsonLeonard samples.

The focus of this analysis is to determine the minimum number of species represented in each feature and the size range of those species. No attempt is made here to analyze spatial or temporal distributions of the eggshell fragments, because they were recovered from different volumes of matrix and only from the features that had adequate numbers of sediment samples (see Chapter 26). The counts are minimums and are not comparable between features; other features not listed here may also have contained eggshell that was not retrieved. The value of this investigation lies in its contribution of a new line of evidence for human subsistence behaviors. By providing a means for analyzing bird eggshells, this study expands the scope of retrievable data for avian fauna, which are not otherwise well represented in most archeological sites because their thin, hollow bones are easily fragmented and broken down chemically or microbially.

\section{PRESERVATION}

Eggshells of domestic fowl are known to contain calcium carbonate as well as small amounts of magnesium carbonate and tricalcium phosphate, along with other trace elements (Burley and Vadehra 1989:Table 3.2; Tyler 1969:95). The calcium content is fairly constant, mostly deriving from feed, although $30-40 \%$ of it is supplied by the female bird's bones (Burley and Vadehra 1989:60). Calcium carbonate accounts for $97 \%$ or more of the shell, while only $2-3 \%$ is made up of organics, which include proteins, carbohydrates, and nitrogen (Burley and Vadehra 1989:35, 38-39, Tables 3.2,3.6).

The high mineral content, especially of calcium carbonate, means that eggshells are not likely to be broken down by leaching or by chemical taphonomic processes in a matrix that also has a high calcium carbonate content, as is the case at the Wilson-Leonard site. Tyler (1969:82) reported that an egg from a tomb in Cyprus dated to 700 B.c. had not changed in its crystal structure, which suggests that preservation is not necessarily the reason for the lack of archeological eggshell finds. But the shells do break easily into small fragments, and therefore, fine screening is usually 
required for their recovery. Most of the fragments from the Wilson-Leonard features measured between $1 / 8$-inch and 1/16-inch, while a few were larger than $1 / 8$-inch.

\section{STRUCTURE}

Bird eggshells are formed from the inner surface outward as mineral crystals develop at certain cell points on the membrane that surrounds the ovum (Burley and Vadehra 1989:35-44, 58-62; Sidell 1993:6-7). The crystals build up from those points into cones, called mammillae, with the cone tip at the original cell point. The mammillae stop growing when they have fused together, and at this point, a palisade or column layer of elongated crystals forms. A very thin crystalline layer forms at the external surface in some species. Interspersed among the mammillae are pores that allow the exchange of gases, particularly carbon dioxide, and water vapor between the inside of the egg and the outside (Burley and Vadehra 1989:43). A very thin organic cuticle about 5-30 microns thick appears as an external membrane in some species (Burley and Vadehra 1989:27).

The crystalline pattern of the mammillae cones is unique to each species, as is the distribution of the pores. The pigmentation pattern of the shell is also species specific, but the pigment is primarily applied to the organic cuticle on the exterior surface of the egg and is rarely preserved archeologically (Burley and Vadehra 1989:31; McKusick 1986:Chapter 12).

\section{PREVIOUS METHODS}

A recent experimental study by Sidell (1993) demonstrates that scanning electron micrographs (SEM) of the mammillae on the inner egg surface and of the eggshell crosssections allow precise identification to species, because the exact crystalline structure is clearly visible at this level of enlargement. Although she provides SEM photographs of a broad range of bird species, many of these species-such as puffin and ostrich-are not regularly found in archeological contexts, or in Texas. However, she does have data for turkey, rock dove, and quail that can be useful to archeological analyses in Texas. Unfortunately, it is not yet known whether archeological eggshells exposed to depositional and long-term burial processes can be compared in SEMs to modern, fresh eggshells. If the mammillae remain intact in the archeological specimens, this technique should be successful. However, in order to match archeological eggs to modern species, a very large SEM database needs to be compiled of modern eggshells. There are over 400 bird species currently present in a small region of south-central Texas alone (Kutac 1994:47), and at least that many need to be in the comparative database, including species that may have been extant in the past but that are no longer found in the area. In order to speciate archeological eggshells, each of those fragments would need to be photographed using the
SEM technique and matched to the modern specimens. The matching process will be difficult and time-consuming until more systematic methods are developed for categorizing attributes visible in SEMs. Until then, we can extract many useful data from eggshells by other means, even if we cannot identify them to species.

The size and density of the mammillae were identified as characteristic of each species as early as 1871 (Romanoff and Romanoff 1949:164). The area of the mammilla crosssection has been shown to vary by a negligible $1 / 1000 \mathrm{~mm}$ within one egg and one species in modern specimens (Romanoff and Romanoff 1949:164 and Table 13). For archeological specimens, however, which tend to retain dirt between the mammillae, it is difficult to determine the mammilla boundaries. The density of mammillae per unit area is equally difficult to ascertain on archeological specimens, because many are obscured by dirt or are incomplete. In preliminary measurements of the Wilson-Leonard eggshell fragments, the difficulty in determining the mammillae boundaries caused a variability in mammillae width values of up to $50 \%$ in one shell, even at $200 \mathrm{X}$ enlargement. As a result, the effort to measure the mammillae was abandoned.

Pore attributes are related to the bird species but are generally not unique to one species or cannot be determined on the basis of a small fragment of eggshell. The shape of the pores is fairly constant within a species, but the number of shape categories is so small that many species have the same pore shape (Romanoff and Romanoff 1949:168). Pores are distributed unevenly over the surface of a single egg (Romanoff and Romanoff 1949:166-167), although not randomly (Tyler 1969:100), which means that a fragment of eggshell from an unknown part of the egg cannot be classified to a single taxon on the basis of pore density. The number and size of pores per egg varies within each species, which eliminates them as speciating criteria.

\section{ANEW METHOD}

A different approach is needed, one that is less affected by shell fragmentation and adhering dirt. It should be usable on tiny fragments and measurable even if some dirt obscures part of the shell. A comparative collection or data set should be available for all species that are potentially represented in the archeological sample. The measurements should have a direct relationship to the bird species. They should have a low degree of variability within one species and should be measurable to a high degree of accuracy.

Eggshell thickness satisfies all of these criteria. No matter how small the eggshell fragment is in area, its thickness is still measurable. Adhering dirt normally does not obscure all cross-section views on a specimen, and the boundaries of the surfaces are easily determinable. A comprehensive data set for eggshell thickness for most bird species in the world is available for comparing archeological eggshell thicknesses in an exhaustive hand- 
book of measurements, including eggshell thickness, for all bird orders (Schönwetter 1960-1988).

Because eggshell thickness is directly related to the volume, size, and weight of the egg, which are in turn related to the size of the bird, Romanoff and Romanoff (1949:150) determined that shell thickness can be used to identify taxa. However, the eggshell thickness is the same for many species, and therefore thickness can only be used to establish to what size group the bird belongs, not the precise species (Tyler 1969:110).

The relationship between the size of an egg and the size of the female bird is constant within each species. Egg mass (W) is related to bird body mass (B) by the equation $\mathrm{W}=0.277 \mathrm{~B}^{0.770}$ (Ar et al. 1979:335). Very small birds have eggs that are a greater percentage of their body weight than very large birds (Romanoff and Romanoff 1949:61, Figure 40 ). In the smallest bird species, egg mass is about $20 \%$ of body mass, while it is only $2 \%$ in the largest birds (Ar et al. 1979:335).

Romanoff and Romanoff (1949:107) have demonstrated that the weight of the eggshell is directly related to the total weight of the egg. Their formula is based on fresh, whole eggs, and cannot be applied to archeological eggshell fragments, but it shows that the eggshells have a predictable relationship to egg weight, which is related to egg size. They note a difference between altricial birds, which are naked and helpless when hatched, and precocial birds, which are covered in down and able to move when hatched. The shell of altricial bird eggs is only $5 \%$ of the egg weight, while the shell of precocial birds is $10-14 \%$ of the egg weight (Romanoff and Romanoff 1949:108). In general, the smaller the egg, the thinner the shell and the smaller the percentage of shell weight to egg weight (Romanoff and Romanoff 1949:115). Eggshell thickness is not greatly variable in the eggs of a single bird (Romanoff and Romanoff 1949:151; Tyler 1946:111, 113) and is considered to be an inherited characteristic (Tyler 1969:107). Ar et al. (1979:332) found that in any one egg, the shell thickness varies only by $\pm 7 \%$ around the equator and at each pole. Usually the broad pole is thinner than the narrow pole; the equatorial region of an egg shows little variation in thickness (Tyler 1969:109).

Eggshell thickness is affected by factors that change the calcium metabolism of a bird, namely seasonality, nutrition, "physiological efficiency," and "hereditary endowment" (Romanoff and Romanoff 1949:152). The season of the year is a factor because the rise in temperature above about $90^{\circ} \mathrm{F}$ or a rise in humidity creates a decrease in shell thickness, which differs from bird to bird (Romanoff and Romanoff 1949:153; Tyler 1969:108-109). However, Jenkins and Tyler (1960:330) suggest that the effect of temperature may depend on the month in which the bird comes into lay due to metabolic processes early in the laying period that tend to increase shell thickness, counteracting the effects of temperature and humidity.
Thinned eggshells can be caused by a deficiency in calcium sometimes due to a deficiency in Vitamin D which affects the calcium metabolism, but Tyler (1946:112, 1969:108) states that a bird will not lay an egg if its calcium reserves would produce one with less than $60 \%$ of the normal shell thickness. The effects of an excess of calcium in the bird's diet are equivocal: in one study of domesticated chickens, a high calcium diet produced thicker shells although only in the earliest stage of the experiment (Jenkins and Tyler 1960:324, 330), while a later study found that high calcium levels did not increase the thickness of the shell but instead appeared to be the cause of soft-shelled eggs (Tyler 1946:113). Likewise in one study, phosphorus had no effect on shell thickness (Jenkins and Tyler 1960:324), while in another experiment, low phosphorus levels were linked to thicker shells (Tyler 1969:108). In general, any effects due to changes in the diet are immediately reflected in the eggshell thickness, whereas those same changes have a delayed effect on the composition of the more slowly forming yolk (Jenkins and Tyler 1960:330).

For domesticated birds, the greatest variability in shell thickness from one bird to another in one species occurs when the birds first come into lay, whereas they tend to reach a fairly uniform thickness thereafter (Jenkins and Tyler 1960:330). But since domestication and year-round breeding apparently increases variability, the same may not be true for wild species (Romanoff and Romanoff 1949:115, 151). Although the number of eggs in a clutch affects egg size, wild birds have have a fairly constant number of eggs within a species (Romanoff and Romanoff 1949:10), and so the variability should be more predictable for wild species than for domestic birds. It has been noted, however, that wild birds usually have at least one egg in a clutch that is not of the average size, whether too large or too small (Romanoff and Romanoff 1949:65, 151). Dwarf eggs have been observed for wild birds (Romanoff and Romanoff 1949:259), but are not common enough to be statistically probable in any archeological sample.

Eggshell thickness also varies with the length of incubation, with the greatest thickness occurring just after laying and the least just prior to hatching, as the developing embryo reabsorbs some of the calcium in the eggshell for bone growth. In modern chickens, 0.1 to $0.15 \mathrm{~g}$ of calcium is transferred from the shell to the embryo (Tyler 1969:122). This accounts for about $80 \%$ of the calcium needed for the embryo's skeleton, and its dissolution starts after about day 10 of incubation (Burley and Vadehra 1989:284). If eggs are collected before this period, then no alteration in thickness will occur. The eggs of wild birds are usually fertilized, and so any difference between fertilized and unfertilized eggs should not be a factor in variability for archeological eggshell.

Fortunately, the uniformity of eggshell thickness within any one species is fairly high, even given potential variability factors. In an experiment by Ar et al. (1979:Table 1) on 
eggshell strength, multiple thickness measurements were taken for 47 species and reported as the mean, the standard error (assumed to be one standard deviation from the mean, given the way the term is used), and the number of eggs measured. Of the 38 wild species having eggshells not thicker than $0.35 \mathrm{~mm}$, like the Wilson-Leonard sample, all but one had standard errors of $\pm 0.012 \mathrm{~mm}$ or less, and 31 species had errors of $\pm 0.006 \mathrm{~mm}$ or less; although some were based on less than 5 measurements, others had more than 10 measurements. In the case of the Ringed Turtle Dove (Streptopelia risoria) in 75 measurements the deviation from the mean was only $\pm 0.001 \mathrm{~mm}$. Only Anas platyrhynchos had a higher standard error of $\pm 0.019 \mathrm{~mm}$.

As a result, the range of variation in eggshell thickness for a given species, accounting for variations due to clutch position, temperature, diet, and other factors, is usually not very great. Given a range of variation demonstrated to be normally $\pm 0.012 \mathrm{~mm}$ or less at $68 \%$ probability and $\pm 0.024 \mathrm{~mm}$ at a confidence interval of $95 \%$, the variation for the species in the Wilson-Leonard size range should not be expected to be greater than $\pm 0.02 \mathrm{~mm}$ in a conservative estimate. To be even more conservative, we can allow for a variation of $\pm 0.04 \mathrm{~mm}$ for species with eggshells measuring $0.31 \mathrm{~mm}$ or thicker to include the range of variability of Anas platyrhynchos at a 95\% probability level. In this analysis, I have assumed that an archeological eggshell fragment of thickness $\mathrm{T}=0.30 \mathrm{~mm}$ or less should be assigned to a bird size group that has a thickness of $\mathrm{T} \pm 0.02 \mathrm{~mm}$ and fragments of thickness $\mathrm{T}=0.31 \mathrm{~mm}$ or greater to a size group of $\mathrm{T} \pm 0.04 \mathrm{~mm}$. I have also assumed that if two archeological eggshells have a difference in thickness of more than $0.04 \mathrm{~mm}$ (accounting for a deviation of up to $0.02 \mathrm{~mm}$ for each specimen), they can be considered to be different species (or a difference of $0.08 \mathrm{~mm}$ if larger than $0.31 \mathrm{~mm}$ thick). Fortunately, eggshells can be measured with an accuracy of less than a hundredth of a millimeter.

\section{MEASUREMENTTECHNIQUE}

One of the greatest difficulties in working with archeological eggshell is measuring the tiny fragments. Modern shell is sometimes measured with a micrometer screw gauge with anvil jaws (Tyler 1969:105). But the calipers do not account for the slightly curved surface (Tyler 1969:112) unless they have a ball attachment, as used by Ar et al. (1979:332). The problem of holding a fragment smaller than $1 / 16$-inch in width or length between caliper jaws is obvious. Others use digital calipers or an eyepiece graticule in a light microscope, although Sidell (1993:9) warns that calipers are not as accurate as the graticule. I found that I could not get a sufficiently accurate reading with the micrometer lens/graticule in a light microscope, because standard micrometers do not have sufficiently fine divisions. A method of indirectly gauging the shell thickness is to use formulae to calculate the surface area and the weight of shell per unit area (Jenkins and Tyler 1960:323-324). The formula for surface area, however, requires the fresh whole egg weight and therefore cannot be used for archeological eggshell.

The measurement problem was solved in the current analysis by using a digital imaging computer program hooked up to a videocamera attachment on a light microscope. First of all, I used a slide micrometer to set up calibration files in the computer for the magnifications I intended to use. For setting up the eggshell fragments under the microscope, I pressed them into a small piece of wax so that the cross-sectional edges I wanted to measure were immobile in the microscope's field of view. The wax was on a tray that I placed on a movable stage, which allowed me to move the fragments to precisely the desired area on the shell. I measured the thickness at $80 \mathrm{X}$.

I loaded the image into the computer with a database in EnhancedView Version 3.2.1.0. I then imported the image into Image-Pro Plus Version 1.2 and accentuated the outlines using the program's filters. For thickness, I measured three points on the image, all perpendicular to the shell wall, by drawing a line from edge to edge in Image Pro Plus and having the program calculate the distance of the line, based on the calibration I had entered. The measurements were in fractions of a millimeter accurate to eight decimal places, because the program measures the number of pixels in the line, which is much more accurate than I could achieve with a micrometer lens. In many cases, two of the three thickness measurements were the same up to the third or fourth decimal place (i.e., to $1 / 10,000$ of a millimeter), for which reason I am confidant of their accuracy.

Because some of the fragments had experienced abrasion and postdepositional weathering, some surface areas were thinner than others. In all cases, at least one of the three measurements was at the thickest point on the shell. For the final analysis, only the thickest of the three measurements per fragment was used, because it is closest to the original thickness. I expected the shells to be slightly thinner than the original, but never thicker. In Image Pro Plus, the measurements were saved as tool files and then imported into Microsoft Excel.

\section{DETERMINATION OF MINIMUM NUMBER OF SPECIES AND SIZE GROUPS}

For each feature, the minimum number of species represented by the eggshell thicknesses is provided. This was determined by assuming that thickness values within 0.04 $\mathrm{mm}$ of each other could be from the same species (and accounting for a difference of up to $0.08 \mathrm{~mm}$ for the thickest shells), but values with a distance greater than $0.04 \mathrm{~mm}$ must be separate species. For example, in Feature 206, the eggshells with thicknesses of 0.22 and $0.24 \mathrm{~mm}$ could be from the same species, but both must be from a different species than the eggshell that is $0.17 \mathrm{~mm}$ thick. The eggshells could 
actually belong to more species than this minimum, the maximum being the total count of eggshells.

The approximate size range of the species represented by the eggshells is determined by matching the eggshell thicknesses with known thicknesses of eggshells of modern species. In compiling a list of the species that could be represented in the archeological sample, the ideal data set would be a list of bird species known from archeological sites from the same geographical region and time period as WilsonLeonard. Unfortunately, when avian species are found among the faunal remains of archeological sites, they are rarely identified to species. As a result, I had to employ a list of modern species that currently reside in the area. I chose species from Kutac and Caran (1994) that are present in south-central Texas today and that are known to have nested here. Obviously some species of birds are now present in Williamson County that were not present during the occupation of the site, while other species that used to inhabit the area are no longer found in these same ranges. Therefore this list will not be completely accurate for prehistoric Texas, but it at least includes species that have the potential for being found archeologically.

In the 19-county area that includes Williamson County, a total of 445 species of birds currently can be found or have been reported by birdwatchers in the recent past (Kutac 1994:47). I reduced this total to exclude the migratory birds that nest elsewhere, birds whose presence is considered accidental, as when a Gulf coast storm blows seabirds inland, and the species that have been introduced in historic times. I also excluded all birds whose eggshells are significantly thinner or thicker than the archeological eggshells that make up the Wilson-Leonard sample. I further excluded all species for which no eggshell thickness measurements are available.

The resulting list of 60 species was then matched with Schönwetter's (1960-1988) multivolume treatise on eggshells, and I used his thickness measurements for each of the species in the compiled list, so that all of the comparative measurements would derive from a consistent source by a consistent method (Table 36-1). In matching the archeological eggshell thicknesses to the comparative data set, thickness values to two decimal points were used to match Schönwetter's measurements. It should be noted that his thickness measurements were only rarely directly measured on the shell, because he examined whole eggs. Instead, he used a formula (Schönwetter 1985 Lief.42:79 ff) based on the egg weight, which is directly related to shell thickness. His thickness values should be considered average values for the species.

In some cases, Schönwetter gives data for several subspecies of the species listed by Kutac. In these cases, I chose the subspecies that Schönwetter listed as present in or near Texas (see Table 36-1). The comparative species list does not have species with eggshell thickness values of $0.21,0.22$, and $0.28 \mathrm{~mm}$. This is because no species with eggshells of these thickness values met the criteria given above for inclusion on the list. Any archeological eggshells that have these values are assigned to the nearest size group.

It cannot be overemphasized that the comparative data from modern species may not be representative of the species available to the Wilson-Leonard occupants. In the following analysis, when I state that the eggshells from a certain feature are from the size group of the wood duck or in the size range of the pileated woodpecker, I am only using these species as a means of relating the eggs to the size of the bird. I do not mean that these eggshells are definitely from the species wood duck or pileated woodpecker. For each thickness value, dozens of species belong to the same size group, and the \pm 0.02 -mm variability means that any of the species with thicknesses within that standard error could belong in the same group. The exact species cannot be identified without extensive SEM analysis.

\section{RESULTS}

The 172 eggshells range in thickness from $0.12 \mathrm{~mm}$ to $0.35 \mathrm{~mm}$ (Table 36-2). They are all larger than most of the passerines and are all smaller than wild turkey, the vultures, and most of the goose species. At the small-size end of the range are eggshells with thicknesses like those of kingfishers, woodpeckers, grackles, and others, while the largest eggshells in the sample are similar in size to the larger hawks, ducks, and owls, among others (see Table 36-1). Eggshells were found in sediment samples from 18 features distributed throughout the three major stratigraphic units.

\section{Unit IIII}

Sediment samples from six Unit III features yielded 35 eggshell fragments with thickness values ranging from 0.15 to $0.33 \mathrm{~mm}$ (Table $36-3$ ). The minimum number of species ranges from one to three, with the Feature 204, 206, and 213 samples having at least three species each. The Feature 204 and 206 samples each have a well-defined smaller species group and two larger groups that could represent several more species. The Feature 215 sample has two well-separated species size groups, and Burned Rock Midden 1 and Feature 209 sample each have a minimum of one species.

Most of the shell fragments in Unit III are greater than $0.22 \mathrm{~mm}$ in thickness, which puts them in the lower (thicker) half of the comparative species list in Table 36-2. The features have similar patterns of size distribution, and some of the same species may be represented in more than one feature. The Burned Rock Midden 1 sample had two eggshells in the size range of the Black-crowned night-heron. The Feature 206 and 204 samples have a wider spread of thickness values, mostly in the 0.22 to $0.33 \mathrm{~mm}$ range but also smaller. The Feature 206 sample has one tern-sized shell fragment and the Feature 204 sample has two in the killdeer and crow size range. The Feature 209 sample has a single duck-sized 
TABLE 36-1

Comparative Modern Species List by Eggshell Thickness

\begin{tabular}{|c|c|c|}
\hline Eggshell Thickness (mm)* & Common Name & \begin{tabular}{|l} 
Species** (Subspecies*) \\
\end{tabular} \\
\hline 0.12 & Green kingfisher & Chloroceryle americana (septentrionalis) \\
\hline 0.12 & Lesser nighthawk & Chordeiles acutipennis (texensis) \\
\hline 0.12 & Least bittern & Ixobrychus exilis (exilis) \\
\hline 0.12 & Red-bellied woodpecker & Melanerpes carolinus (carolinus) \\
\hline 0.12 & Bronzed cowbird & Molothrus aeneus (loyei) \\
\hline 0.12 & Great-tailed grackle & Quiscalis mexicanus (prosopidicola) \\
\hline 0.12 & Common grackle & Quiscalus quiscula (quiscula) \\
\hline 0.13 & Spotted sandpiper & Actitis macularia \\
\hline 0.13 & Belted kingfisher & Ceryle alcyon (alcyon) \\
\hline 0.13 & Golden-fronted woodpecker & Melanerpes aurifrons (aurifrons) \\
\hline 0.14 & Chuck-will's-widow & Caprimulgus carolinensis \\
\hline 0.14 & Common nighthawk & Chordeiles minor (henryi) \\
\hline 0.14 & Yellow-billed cuckoo & Coccyzus americanus (occidentalis) \\
\hline 0.14 & Ruff/Reeve & Philomachus pugnax \\
\hline 0.15 & Killdeer & Charadrius vociferus (vociferus) \\
\hline 0.15 & Pileated woodpecker & Dryocopus pileatus (pileatus) \\
\hline 0.15 & Burrowing owl & Speotyto cunicularia (hypugaea) \\
\hline 0.16 & Northern flicker & Colaptes auratus (auratus) \\
\hline 0.16 & American crow & Corvus brachyrhynchus (brachyrhynchus) \\
\hline 0.17 & Forster's tern & Sterna forsteri \\
\hline 0.17 & Common tern & Sterna hirundo (hirundo) \\
\hline 0.18 & Ringed kingfisher & Ceryle torquata (torquata) \\
\hline 0.18 & Bobwhite & Colinus virginianus (texanus) \\
\hline 0.18 & Montezuma quail & Cyrtonyx montezumae (mearnsi) \\
\hline 0.18 & American kestrel & Falco sparverius (phalaena) \\
\hline 0.18 & Purple gallinule & Porphyrula martinica \\
\hline 0.19 & Chihuahuan raven & Corvus cryptoleucas \\
\hline 0.19 & Greater Roadrunner & Geococcyx californianus \\
\hline 0.20 & Short-eared owl & Asio flammeus (flammeus) \\
\hline 0.20 & Upland sandpiper & Bartramia longicauda \\
\hline 0.20 & Common raven & Corvus corax (sinuatus) \\
\hline 0.20 & Screech owl & Otus asio (aikeni) \\
\hline 0.20 & Black Skimmer & Rhynchops niger ( $R$. nigra nigra) \\
\hline 0.23 & Black-crowned night-heron & Nycticorax nycticorax (hoactli) \\
\hline 0.24 & Merlin & Falco columbarius (columbarius) \\
\hline 0.25 & Common black-hawk & Buteogallus anthracinus (anthracinus) \\
\hline 0.25 & Common moorhen & Gallinula chloropus (cacchinnans) \\
\hline 0.25 & Barn owl & Tyto alba (pratincola) \\
\hline 0.26 & Green-winged teal & Anas crecca (carolinensis) \\
\hline 0.26 & Great Egret & Casmerodius albus (egretta) \\
\hline 0.26 & Oldsquaw & Clangula hyemalis \\
\hline 0.26 & Ring-billed gull & Larus delawarensis \\
\hline 0.27 & Cinnamon teal & Anas cyanoptera (cyanoptera) \\
\hline 0.27 & Northern harrier & Circus cyaneus (hudsonius) \\
\hline 0.27 & American coot & Fulica americana (americana) \\
\hline 0.29 & Northern pintail & Anas acuta (tzitzihoa) \\
\hline 0.29 & Greater prairie chicken & Tympanuchus cupido (pinnatus) \\
\hline 0.30 & Mottled duck & Anas fulvigula (maculosa) \\
\hline 0.30 & Anhinga & Anhinga anhinga \\
\hline 0.31 & Cooper's hawk & Accipter cooperii \\
\hline 0.31 & Mallard & Anas platyrhynchus (platyrhynchus) \\
\hline 0.32 & Wood duck & Aix sponsa \\
\hline 0.32 & Broad-winged hawk & Buteo platypterus (platypterus) \\
\hline 0.32 & Ross' goose & Chen rossii \\
\hline 0.33 & Barred owl & Strix varia (helveola) \\
\hline 0.34 & Red-shouldered hawk & Buteo lineatus (texanus and alleni) \\
\hline 0.34 & Red-breasted merganser & Mergus serrator \\
\hline 0.35 & Prairie falcon & Falco mexicanus \\
\hline 0.35 & Common merganser & Mergus merganser (americanus) \\
\hline 0.35 & Harris' hawk & Parabuteo unicinctus (harrisi) \\
\hline
\end{tabular}

*From Schönwetter 1960-1988.

**From Kutac 1994. 
TABLE 36-2

Counts of Feature Eggshells by Thickness

\begin{tabular}{cc}
\hline Thickness $(\mathrm{mm})$ & Count \\
\hline 0.12 & 1 \\
0.13 & 5 \\
0.14 & 1 \\
0.15 & 9 \\
0.16 & 13 \\
0.17 & 8 \\
0.18 & 17 \\
0.19 & 11 \\
0.20 & 3 \\
0.21 & 5 \\
0.22 & 5 \\
0.23 & 4 \\
0.24 & 7 \\
0.25 & 18 \\
0.26 & 13 \\
0.27 & 12 \\
0.28 & 14 \\
0.29 & 10 \\
0.30 & 6 \\
0.31 & 5 \\
0.32 & 1 \\
0.33 & 3 \\
0.34 & 0 \\
0.35 & 1 \\
\hline Total: & 172 \\
\hline \hline
\end{tabular}

eggshell fragment in the range of the mottled duck or the anhinga.

The Feature 213 and 215 samples have similar distributions to those of Features 204 and 206 but with slightly narrower ranges. The Feature 213 sample has two shell fragments in the quail- and roadrunner-size group and at least two other species ranging in size from the night-heron to the Greater prairie chicken. The Feature 215 sample has fragments in the killdeer/crow/quail-size range and at least one more species in the merlin- to coot-size range.

In general, the Unit III samples have similar thickness distributions, covering a wide range of sizes that cluster in the $0.15-0.19-\mathrm{mm}$ and $0.22-0.33-\mathrm{mm}$ ranges. No one of the features has a unique or distinctive distribution pattern. The presence of multiple species in some of these samples indicates that the eggshells are not the result of a single intrusive event in which the fragments of one egg became buried in the feature fill.

\section{Unit II/IIIIa}

Samples from three features found in the II/IIIa transition unit (Features 181, 233, and 224) contained a total of 122 eggshell fragments (Table 36-4). The Feature 181 sample contained the highest counts of any of the features, but this

TABLE 36-3

Unit III Feature Eggshell Thicknesses $(\mathrm{N}=35)$

\begin{tabular}{|c|c|c|c|c|c|c|c|}
\hline & \multicolumn{6}{|c|}{ Stratigraphic Unit } & \multirow[b]{2}{*}{ Totals } \\
\hline & $\begin{array}{c}\text { Y/IIIc* } \\
\text { Burned Rock Midden 1 }\end{array}$ & $\begin{array}{c}\text { IIIb/c } \\
\text { Feature 206 }\end{array}$ & $\begin{array}{c}\text { IIIb } \\
\text { Feature 204 } \\
\end{array}$ & \begin{tabular}{|c|} 
IIIb \\
Feature 209 \\
\end{tabular} & \begin{tabular}{|c|}
$\mathrm{IIIa} / \mathrm{b}$ \\
Feature 213 \\
\end{tabular} & \begin{tabular}{|c|} 
IIIa/b \\
Feature 215 \\
\end{tabular} & \\
\hline $\begin{array}{c}\text { Sediment sample volume (liters) } \\
\text { Thickness (mm): } \\
0.12 \\
0.13 \\
0.14 \\
0.15 \\
0.16 \\
0.17 \\
0.18 \\
0.19 \\
0.20 \\
0.21 \\
0.22 \\
0.23 \\
0.24 \\
0.25 \\
0.26 \\
0.27 \\
0.28 \\
0.29 \\
0.30 \\
0.31 \\
0.32 \\
0.33 \\
0.34 \\
0.35 \\
\end{array}$ & . & $\begin{array}{l}1 \\
\\
1 \\
2 \\
1 \\
1 \\
2 \\
1\end{array}$ & $\begin{array}{l}1 \\
1\end{array}$ & . & $\begin{array}{l}2 \\
1 \\
1\end{array}$ & $\begin{array}{l}1 \\
2 \\
1 \\
1\end{array}$ & $\begin{array}{l}3 \\
2 \\
1 \\
2 \\
1 \\
\\
2 \\
2 \\
3 \\
3 \\
4 \\
2 \\
3 \\
3 \\
2 \\
1 \\
1\end{array}$ \\
\hline Totals: & 2 & 9 & 7 & 1 & 7 & 9 & 35 \\
\hline Minimum number of species & 1 & 3 & 3 & 1 & 3 & 2 & \\
\hline
\end{tabular}

* from Valley Margin A. All others are from Valley Floor A. 
TABLE 36-4

Unit II/IIIa Feature Eggshell Thicknesses ( $\mathrm{N}=122)$

\begin{tabular}{|c|c|c|c|c|}
\hline & \multicolumn{4}{|c|}{ Feature } \\
\hline & 181 & 233 & 224 & Totals \\
\hline $\begin{array}{l}\text { Volume of sediment } \\
\text { (liters) } \\
\text { Thickness (mm): } \\
0.12 \\
0.13 \\
0.14 \\
0.15 \\
0.16 \\
0.17 \\
0.18 \\
0.19 \\
0.20 \\
0.21 \\
0.22 \\
0.23 \\
0.24 \\
0.25 \\
0.26 \\
0.27 \\
0.28 \\
0.29 \\
0.30 \\
0.31 \\
0.32 \\
0.33 \\
0.34 \\
0.35 \\
\end{array}$ & $\begin{array}{c} \\
3 \\
1 \\
5 \\
10 \\
5 \\
11 \\
9 \\
1 \\
3 \\
2 \\
\\
2 \\
13 \\
8 \\
8 \\
9 \\
5 \\
3 \\
3 \\
1 \\
2 \\
\\
1 \\
\end{array}$ & $\begin{array}{c}5.0 \\
1 \\
2\end{array}$ & 3.8 & $\begin{array}{c}1 \\
5 \\
1 \\
5 \\
10 \\
7 \\
14 \\
10 \\
2 \\
3 \\
3 \\
0 \\
2 \\
14 \\
8 \\
8 \\
10 \\
7 \\
4 \\
4 \\
1 \\
2 \\
0 \\
1 \\
\end{array}$ \\
\hline Totals: & 105 & 16 & 1 & 122 \\
\hline $\begin{array}{l}\text { Minimum number of } \\
\text { species }\end{array}$ & 5 & 4 & 1 & \\
\hline
\end{tabular}

is in part due to the larger amount of matrix that was screened and sorted from this context (see Chapter 26). Nevertheless, it is clear that Feature 181 had a high concentration of eggshell fragments with many different thicknesses and from at least five species but potentially from many more. The distribution of thickness values in this feature suggests that the greater the count of eggshells that are retrieved, the greater the number of species represented. This is contrary to the common assumption that eggshell fragments in archeological contexts are mostly from the same egg. The Feature 233 sample has far fewer eggshell fragments, but the thickness values, which have almost as broad a range as do those from Feature 181, indicate that at least four species are represented in this feature. The Feature 224 sample contained only one eggshell and therefore at least one species.

In the Feature 181 sample, there are 105 eggshells from almost every thickness value from 0.13 to $0.35 \mathrm{~mm}$, so that no species groups are well defined and separable from the rest. The smallest shells are spotted sandpiper-sized, and the largest is prairie falcon-sized. Certain thickness values have higher counts than others. Ten fragments are $0.16 \mathrm{~mm}$ in thickness, which is within the size range of the northern flicker and American crow. Eleven shell fragments are $0.18 \mathrm{~mm}$ thick, in the range of the ringed kingfisher, bobwhite, Montezuma quail, American kestrel, and purple gallinule. Thirteen fragments are $0.25 \mathrm{~mm}$ thick, which is similar in size to the common black-hawk, common moorhen, and barn owl.

The Feature 233 sample had far fewer eggshells than Feature 181, but the 16 fragments recovered have a similar broad range of sizes, from 0.12 to $0.31 \mathrm{~mm}$ in thickness. Given the similarity, some of the apparently well-defined clusters in the Feature 233 distribution may not have been as clearcut if more eggshells had been retrieved. The smallest shells in the feature are the size of the green kingfisher, grackles, and smaller woodpeckers. A second cluster is in the range of the terns, quails and bobwhites, and roadrunner, among others. The rest are broadly distributed in a size range that includes the night-heron on the small end and the mallard on the large end.

The Feature 224 sample contained a single shell fragment of the size of the common raven or screech owl. In general, the Unit II/III a features have a broad distribution of eggshell sizes, which probably represent numerous species. More were recovered from this unit than from any other, primarily because of the wealth of remains in Feature 181 (and perhaps the relatively large volume of sediment processed from this feature). The number and size distribution of eggshells from this feature alone suggest that they are not accidental intrusions but are more likely to be cultural debris, regardless of how they came to be in the feature.

\section{Unit II}

A much smaller number of shell fragments were retrieved from the Unit II samples (Table 36-5), possibly because all of these sediment samples had relatively small volumes. Only five eggshell fragments make up the recovery from three features $(157,184$, and 185). Though the counts are low, the two shells from Feature 157 are clearly from two different species (see Table 36-5).

The Feature 157 sample has a shell fragment from a small species in the range of the killdeer, and one from a medium-sized species in the range of the black-crowned night-heron. The Feature 184 sample has two shells in the merlin- to coot-size group, and the Feature 185 sample has a single shell of merlin size. All three samples have shells in the $0.23-0.27-\mathrm{mm}$ range and are therefore quite similar, although this could be a function of the small sample sizes.

\section{Unit Id/II}

The Unit Id/II transition is represented by samples from Features 236 and 246, which together contained four eggshells (Table 36-6). Three of these eggshells are from Feature 236 and from three different species, as shown by their widely separated thickness values. The variety of species 
TABLE 36-5

Unit II Feature Eggshell Thicknesses ( $\mathrm{N}=5$ )

\begin{tabular}{|c|c|c|c|c|}
\hline & \multicolumn{4}{|c|}{ Feature } \\
\hline & 157 & 184 & 185 & Totals \\
\hline $\begin{array}{l}\text { Volume of sediment } \\
\text { sample (liters) }\end{array}$ & 0.9 & 1.0 & 1.3 & \\
\hline Thickness (mm): & & & & \\
\hline 0.12 & & & & \\
\hline 0.13 & & & & \\
\hline 0.14 & & & & \\
\hline 0.15 & 1 & & & 1 \\
\hline 0.16 & & & & \\
\hline 0.17 & & & & \\
\hline 0.18 & & & & \\
\hline 0.19 & & & & \\
\hline 0.20 & & & & \\
\hline 0.21 & & & & \\
\hline 0.22 & & & & \\
\hline 0.23 & 1 & & & 1 \\
\hline 0.24 & & 1 & 1 & 2 \\
\hline 0.25 & & & & \\
\hline 0.26 & & & & \\
\hline 0.27 & & 1 & & 1 \\
\hline 0.28 & & & & \\
\hline 0.29 & & & & \\
\hline 0.30 & & & & \\
\hline 0.31 & & & & \\
\hline 0.32 & & & & \\
\hline 0.33 & & & & \\
\hline 0.34 & & & & \\
\hline 0.35 & & & & \\
\hline Totals: & 2 & 2 & 1 & 5 \\
\hline $\begin{array}{l}\text { Minimum number of } \\
\text { species }\end{array}$ & 2 & 1 & 1 & \\
\hline
\end{tabular}

represented by even very low counts of specimens is both striking and significant.

The Feature 236 sample has one eggshell in the size group of the northern flicker and American crow. The shell with a thickness of $0.21 \mathrm{~mm}$ has no exact match on the comparative species list but is close to the range for the screech owl and others. The third species is represented by one shell in the size range of the cinnamon teal, northern harrier, and American coot. The Feature 246 sample has one eggshell similar in size $-0.26 \mathrm{~mm}$ - to the latter species group, or the size of the green-winged teal and others. The distribution of these few eggshells is similar to that of the Unit II features in spite of the small sample size.

\section{Unit I}

Sediment samples collected from four features in Unit I yielded six eggshell fragments (Table 36-7). The Feature 169 and 255 samples have a minimum of one species, while the Feature 257 sample has at least two species. One eggshell was recovered from Burial 2 pit fill.

The eggshell from the burial pit is in the size group of the short-eared owl, upland sandpiper, common raven,
TABLE 36-6

Unit Id/II Feature Eggshell Thicknesses (N=4)

\begin{tabular}{c|c|c|c}
\hline & \multicolumn{2}{|c|}{ Feature } & \multirow{2}{*}{ Totals } \\
\cline { 2 - 3 } & 236 & 246 & \\
Volume of sediment sample & & & \\
(liters) & 27.0 & 19.5 & \\
Thickness (mm): & & & \\
0.12 & & & \\
0.13 & & & \\
0.14 & & & \\
0.15 & 1 & & \\
0.16 & & & \\
0.17 & & & \\
0.18 & & & \\
0.19 & 1 & & \\
0.20 & & & \\
0.21 & & & \\
0.22 & & & \\
0.23 & & 1 & 1 \\
0.24 & & & 1 \\
0.25 & & & \\
0.26 & & & \\
0.27 & & & \\
0.28 & & & \\
0.29 & & & \\
0.30 & & & \\
0.31 & & & \\
0.32 & & & \\
0.33 & & & \\
0.34 & & & \\
0.35 & & & \\
\hline Totals: & & & \\
\hline Minimum number of species & 3 & & \\
\hline \hline
\end{tabular}

screech owl, and black skimmer. The rest of the features have shells within the $0.18-0.28$-mm range but are variously distributed within that range. The shell from Feature 169 is in the size range of the green-winged teal and great egret, while the shell from Feature 255 is slightly larger, closer to a prairie chicken in size. Feature 257 has three shells within a fairly narrow range but belonging to at least two species in the quail to night-heron group.

Unlike the other units, the features in Unit I did not have a strong resemblance to each other in their size distributions, although they did belong to a fairly narrow subset of values. The recovery of only one eggshell from ca. 94 liters of Burial 2 fill suggests this shell is intrusive to the burial rather than a fragment of an intentional offering. Items as small as this shell can work their way down through the soil from above, but there are alternative explanations. The eggshell was most likely in or on the soil that was used for the burial fill, and this soil contained occupation debris.

\section{DISCUSSION}

Whether the eggshells found in these features are remnants of those feature activities or are debris present in the 
TABLE 36-7

Unit I Feature Eggshell Thicknesses ( $\mathrm{N}=7$ )

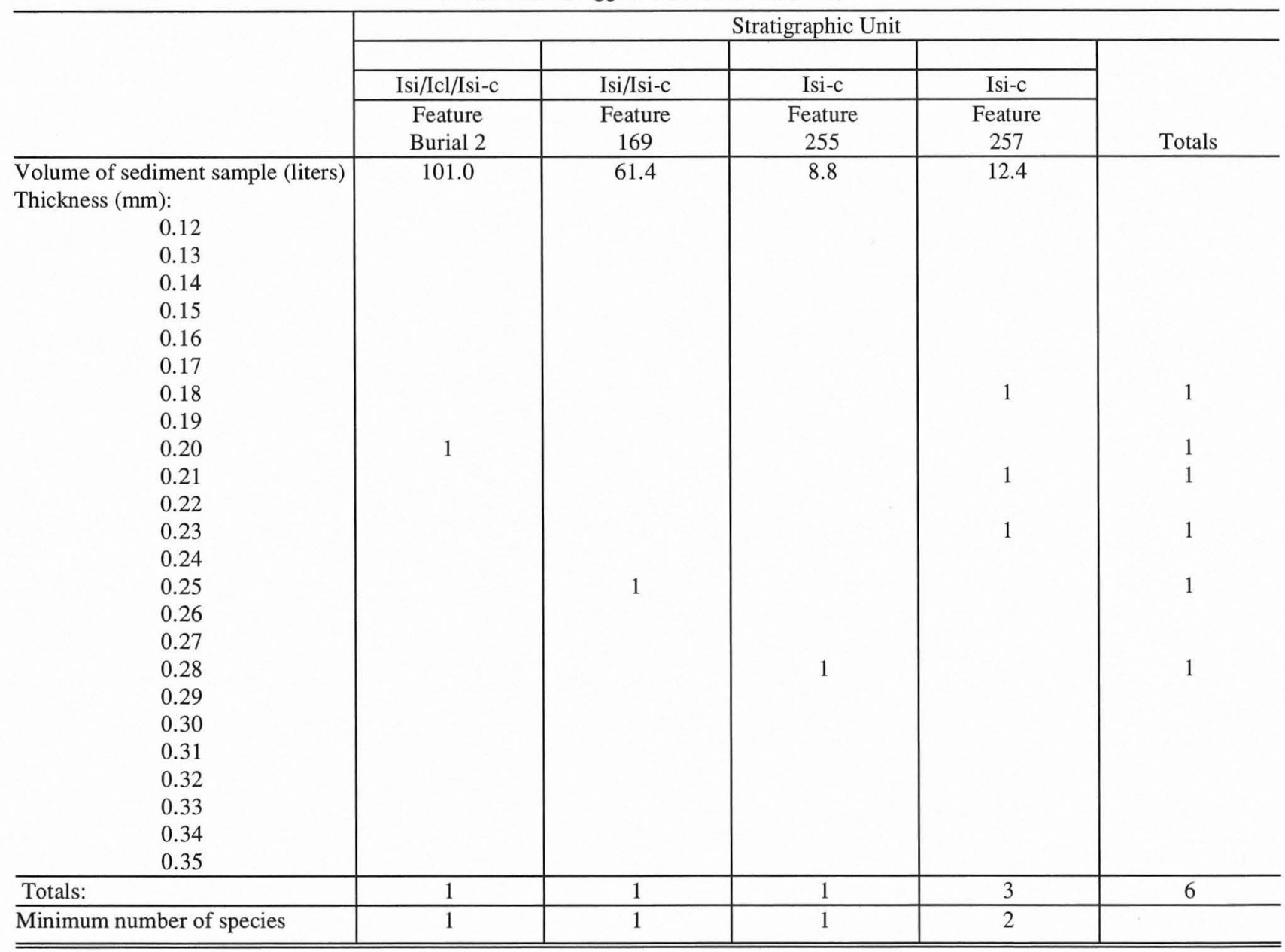

soil that became the feature fill, the sheer number of species present vertically throughout the site is strong evidence that they are not accidental intrusions. The fact that even small samples contained multiple species and that the larger the counts the more species are represented is further evidence that the eggshells primarily represent cultural refuse.

The importance of eggs in prehistoric diets should not be underrated. Eggs supply protein, vitamins, minerals, certain fatty acids, and amino acids (Burley and Vadehra 1989:352). Egg protein has the highest true digestibility of major foods, and the nutritive value of eggs is high because the proteins contain essential amino acids necessary for human nutritive needs (Burley and Vadehra 1989:353). Likewise, the yolk lipids contain essential nutrients, such as linoleic acid (Burley and Vadehra 1989:353). The list of vitamins in eggs is lengthy-Vitamins A, D, E, B12, biotin, choline, folic acid, inositol, niacin, panthothenic acid, pyroxidine, riboflavin and thiamin - as is that of minerals - calcium, chlorine, copper, iodine, iron, magnesium, manganese, phosphorus, potassium, sodium, sulfur, and zinc (Burley and Vadehra 1989:Table A1).
Eggs that are eaten raw have different nutritive values than cooked eggs, and the manner of cooking also affects the dietary value (Burley and Vadehra 1989:351, 354-357). During cooking, proteins undergo denaturation, which facilitates proteolysis and therefore makes more nutrients available. Cooked eggs, especially baked eggs, followed by steamed, then boiled eggs, have a higher availability of iron in the egg yolk, because the heating process prevents the binding of iron to phosphopeptides and therefore makes the iron available to the body. Similarly, heating stops certain proteins from binding to biotin and vitamin B12. On the other hand, raw eggs do not lose amino acids from oxidation, unlike overcooked eggs. Raw eggs maintain all of the nutritive value of the lipids, which can be decreased by heating. Reasons for not eating eggs include their high cholesterol value, which is a modern complaint, and the presence of proteins that are allergens in some people sensitized by eating eggs early in infancy (Burley and Vadehra 1989:357-362). Allergies are not documented in the ethnographic/ethnohistoric record as far as I know, and may also be a modern phenomenon. 
The consumption of bird eggs is documented in the ethnographic/ethnohistoric record. Among the Beothuks in Newfoundland, bird eggs certainly formed part of the diet, as reported by Howley (1915, cited in Reynolds 1978:102). The eggs were gathered from up to 40 miles away from camp and then were hard-boiled to preserve them for later consumption. The same account explains that the eggs were boiled in a birch rind vessel, and then dried in birch rind.

The Chiricahua Apache are reported to have eaten the eggs of several species. Opler's (1941:366) account is as follows:

We always ate eggs. Some women won't eat eggs for fear of getting children, however. But this is according to the shamans's direction. We eat the eggs of the quail and duck. ...Some people eat the eggs of the quail, the duck, and other birds. A good many quail eggs are found together. The eggs are boiled, or a fire is made, the ashes are pushed aside, the eggs are put in there, and the ashes are put back over them.

In this account, the size of the egg is not as important as the availability. Quail eggs are not too small to eat even when larger duck eggs can be found. Quail eggs are desirable because many can be collected from one location. Since most wild bird eggs are fertilized, we must assume that the ethnographic references refer to fertilized egg consumption. In the stages directly following laying, the only difference between the fertilized and unfertilized eggs are "a few nanograms of nucleic acid and protein" (Burley and Vadehra 1989:363). And since calcium absorption does not begin until the tenth day of incubation, up until then the fetus is not well developed. At the same time, it may be that bird fetuses were considered good to eat.

Of the two cooking methods mentioned by Opler, boiling does not burn the eggshell, and therefore unburned shell should not necessarily be discounted as noncultural. The other method, cooking in ashes, could burn the shell if the ashes were hot enough. Even if the cooking method does not burn the shells, after consumption of the egg, the shells can be tossed in a fire and burned as refuse. Thus, it would not be unusual to find both burned and unburned eggshell fragments among the cultural debris of a site.

Burned and unburned eggshells have been reported from a few prehistoric sites in Texas. The Lewisville site, a Clovis campsite in North-Central Texas on the east fork of the Trinity River, contained bird eggshells in 2 of 23 hearths (Crook and Harris 1957:30-32; Story et al. 1990:183). In Hearth 4 , burned eggshell fragments, identified as a large bird, possibly turkey or goose, were found in association with charcoal, burned mouse skeletal elements, the burned leg bone of a large mammal, and charred hackberry seeds. More fragments of turkey or goose eggshells, some burned, some unburned, were found in Hearth 6. The association of the eggshells with what appears to be cultural food debris gives credence to the assumption that eggshells could be the remains of a food resource.

A few eggshell fragments were also reported from Archaic deposits in Horn Shelter No. 2, a stratified rockshelter located on the Brazos River in Bosque County, Texas (Redder 1985:61). At Antelope House in Canyon de Chelly National Monument in Arizona, a concentration of 11 eggshell fragments was found in Room 21 (McKusick 1986:142, 156). The eggshells were found in all but one of the occupation periods, from Pueblo I (beginning in about A.D. 825-850) to Navajo times, although they are represented by only 1 or 2 fragments in each period (McKusick 1986:Table 55). One eggshell fragment was eroded and without pigment, and therefore was not identifiable (McKusick 1986:143). Ten of the remaining 11 were still pigmented and were identified as turkey eggshells on the basis of the coloring. All of the other turkey bones and feathers were identified as Meleagris gallopavo (Indian domestic turkey), not wild turkey, and presumably the eggs were also from domesticated birds. McKusick (1986:148) reports that the thickness of the shells ranged from 0.275 to $0.425 \mathrm{~mm}$, with a mean of $0.375 \mathrm{~mm}$. She does not specify the method of measurement, and I suspect that an unreliable technique may account for the unusually large range. McKusick takes the mean thickness to infer that the turkeys were healthy, with an adequate access to calcium. However, since calcium levels may not be the cause of thicker eggshells, her conclusion may not be valid.

Although the excavators could not be certain whether the debris in Room 21 was from human refuse or from turkeys inhabiting the room after its abandonment, the presence of numerous cultural artifacts made from turkey bones and feathers suggests that the presence of turkeys was contemporaneous with the human habitation. McKusick (1986:151) further speculates that the juvenile bones and eggshells signify that the turkeys were being raised by the human occupants.

Eggs can be used for nonfood purposes as well (Burley and Vadehra 1989:366). In processing leather, the egg albumen is used for preparing the surface of the hide to help dyes stick, to aid in waterproofing, and to improve the feel of the leather. The whole egg can be used in fat liquoring, in which the oils penetrate the dried hides to make them stronger and more elastic. Eggs are also good for preparing paints, although the archeological evidence for it would not be preserved.

Given the value of eggs as a nutritional resource and the ethnographic examples of egg collecting and consumption, the archeological eggshells from the Wilson-Leonard features can reasonably be considered to be part of the cultural debris of the site. The wide variety of size groups represented throughout Units I, II, and III adds credence to this view.

The next step is to be able to speciate the eggshells in order to take a closer look at the selection of eggs of certain 
bird species. Then we need to be able to determine at what stage of incubation the eggs were broken open. At the fifteenth day of incubation, the inner membranes separate from the shell and create a hole at the center of each mammillary knob (Tyler 1969:120). I have not yet determined how to distinguish between center holes due to incubation and center holes due to postdepositional abrasion and breakage of archeological eggshells, but if this distinction is possible, then we can establish at what point in the development of the egg it was collected and consumed. Mammillae without center holes would have been collected soon after laying when the fetus is barely developed. Another technique is suggested by the fact that the protein in the mammillary cores is a vehicle for decalcifying agents during incubation. "Decalcification starts with the mammillary layer, and removal of calcium from it can be used to determine if an old shell is from an egg that had been incubated" (Burley and Vadehra 1989:43). A technique that calculates the loss of calcium from archeological eggshell would be valuable.

Eggshells have great potential as a new analytical tool for interpreting human subsistence behaviors, and combined with other faunal and macrobotanical remains, can fill in gaps in our knowledge of available resources. When speciating eggshells becomes viable, such an analysis can aid in paleoenvironmental reconstructions by contributing supplemental data on avian fauna. Further research in this field is certainly warranted, and more archeological eggshells need to be retrieved and analyzed. As water screening through fine mesh becomes more standard in archeological procedures, the potential for more data increases. 


\section{Chapter 37}

\section{THE MOLLUSCAN PALEOASSEMBLAGE}

by Leslie C. Shaw, Raymond W. Neck, James L. Theler, and Michael B. Collins

\section{INTRODUCTION \\ by Michael B. Collins}

Gastropod and mussel remains were found in large numbers at Wilson-Leonard and their analysis offers both environmental and cultural information of value in the interpretation of the site. This chapter considers mollusk shells lacking apparent cultural modification; the culturally modified shells are reported along with bone artifacts in Chapter 21.

Detailed studies of molluscan assemblages from archeological sites were comparatively uncommon at the time of the initial Wilson-Leonard excavations, and an important part of that effort was a pioneering study of a large sample of snail tests by Raymond W. Neck. Neck produced a manuscript report of that study (Neck 1988) and was among the consultants who conducted specialized studies in conjunction with the second excavations. He again produced a draft report (Neck 1993) but was unable to continue on the project to finalize his efforts. The first part of this chapter is an integration of Neck's two studies by Leslie C. Shaw.

This is followed with a study by James L. Theler of gastropod remains recovered in feature contexts during both seasons of excavation. Although excavated as matrix samples at different times, the snails were all extracted by Theler using identical laboratory techniques. Theler's contribution is directed primarily toward the environmental implications of these samples. An intriguing question in this set of studies is why Theler found Phreatodrobia nugax nugax in matrix samples from features while no examples of this taxon were found in Neck's samples. One explanation could be that among the activities associated with the features was the introduction of water, vegetation, or larger animals from spring-fed pools that inadvertently introduced these very small snails as well. Alternatively, there may be a difference in the procedures employed by the two investigators. Similarly, the two species Hawaiia minuscula identified by Theler and Helicodiscus singleyanus identified by Neck are so simi- lar in morphology that the reported frequencies may represent analyst differences in identification. Possible cultural significance of some of the occurrences of snails in features is discussed further in Chapter 26.

Mussel shell from both seasons of excavation is discussed in the next section by Shaw who identified those from the second season and incorporated Neck's identifications from the earlier season. These were collected using various field and laboratory techniques.

The final section, by Shaw, integrates the findings of all three of these separate studies. Based on the uncertainties regarding any cultural processes that might account for the presence of snails in the site, Shaw primarily discusses how natural processes probably account for the presence as well as the condition and relative abundance of mollusks in the various stratigraphic units of the site. As she makes clear, more needs to be known about the taphonomy of modern gastropods before archeology can enjoy their full interpretive value. In contrast, most of the mussel shell found at the site is more likely the result of cultural introductions. When the environmentally sensitive mollusks are considered for their environmental implications, their distributions in the site agree with other paleoenvironmental evidence in broadly indicating a sequence from an early mesic, through a long xeric, to a final more mesic interval.

Much has changed in the study of gastropods from archeological contexts since Neck initiated his first study of snails from the Wilson-Leonard excavation. The changes and improvements that have been made affect both field collecting and laboratory processing techniques, and as such, different points along that historical continuum are represented by the various phases of mollusk studies reported here. This adversely affects the comparability of results, a problem that can only be acknowledged and then minimized by fully reporting the sampling and processing procedures for each excavation. Also, the species identifications are provided in full so that other investigators can 
fully consider these inherent biases when comparing the Wilson-Leonard data to those from other sites.

\section{ANALYSIS OF A GASTROPODA ASSEMBLAGE}

by Raymond W. Neck and Leslie C. Shaw

Mollusk remains found in archeological sites have come to be recognized as important indicators of past ecological and cultural conditions. Shells often preserve better than most types of other organic remains and can offer some of the best evidence for the reconstruction of paleoenvironments. The habitat requirements of certain terrestrial and freshwater gastropods have been used to identify subtle changes in such conditions as forest cover, water temperature, and amount of habitat disturbance.

Studies of mollusks within archeological contexts have been frustrated in part by issues of sampling and methods of recovery. Improvements in the collection of column samples of uniform size, flotation systems, and species quantification strategies have amplified the research potential of mollusk assemblages. What becomes most apparent when comparing assemblages between sites is that context, sampling strategies, and recovery methods greatly shape the resulting assemblages, and these need to be explicitly stated for comparisons to be made.

A second area inhibiting the potential for interpreting mollusk assemblages is the lagging study of the natural history, habitat tolerances, and ranges of species in a modern context. Few analyses of paleomolluscan assemblages from Central Texas have been published (see Neck 1981a, 1987a, 1992, 1994). As a result, the dynamics of molluscan faunas in the Pleistocene and Holocene in Central Texas are still essentially unknown. Even the vertebrate faunas of the Pleistocene and Holocene of Central Texas are relatively unknown when compared to other parts of Texas and the central United States (see Lundelius 1967). This lack of information is slowly being remedied, and the involvement of archeologists in the collection of these types of data is of particular importance.

\section{Methodology and Contexts}

An overview of the collection strategies, cultural contexts, and analytical procedures used for the study of mollusk remains from the Wilson-Leonard site is warranted because important differences exist between the methods used during the TxDOT and TARL excavations. This overview is presented here to aid in comparisons between the TxDOT and TARL subassemblages and between the identifications provided in this section and those contributed by Theler.

While mollusk remains were recognized early on as an important data set, the systematic recovery of shell during excavation seasons at the Wilson-Leonard site varied. Large subassemblages were retrieved during TxDOT field screening using 1/4-inch-mesh screens, but these samples include only the larger-sized species and/or better preserved indi- viduals. Efforts to collect a more representative sample during the TxDOT excavations included the retrieval of shell from finer screening (1/16-inch mesh) of one square and the collection of sediment samples that could be processed in the laboratory from three other squares. The later TARL excavations used water screening of uniform-volume sediment samples to provide the most comprehensive recovery of gastropods. These samples, collected from columns in two squares, provide good control over temporal contexts and are most useful for identifying ecological changes through time.

The majority of the gastropod remains recovered during the TXDOT and TARL excavations were identified to species by Neck $(1988,1993)$, using his personal familiarity and reference collection along with standard identification guides (Burch 1962, 1982; Cheatum and Fullington 1971, 1973; Clarke 1981; Fullington 1978; Fullington and Pratt 1974). Shells were classified as adult and immature $(0+0)$ except for shells of Rabdotus mooreanus from cultural features, which were identified as adult+adolescent + juvenile+hatchling. The samples from the combined excavations were collected from six excavation squares and from four features.

The recovery methods used and the matrix volume sizes varied for the different sample contexts, and this variation should be considered when comparing results. Gastropods were also collected less systematically from the screen in the field, and these were not used in this analysis because of the lack of control on sediment volume and the large screen size used. The gastropods from field screening are curated for future study.

The first series of gastropod samples collected during the TxDOT excavations was retrieved from sediment columns placed in the walls of three excavation squares. The column samples were collected from two adjacent squares (E20/S78 and E22/S78) located on the valley floor and from one square (E22/S88) located $8 \mathrm{~m}$ upslope on the valley margin. Sample collection procedures were incompletely documented in the TxDOT field notes but secondary evidence suggests that sediment samples were collected in 10-cm levels from excavation square walls. The series of gastropod samples recovered from Square E20/S78 represents a column concentrating on the time span of roughly 8700 to 2000 B.P. (stratigraphic Units IIIa - IIIc) with two samples from Unit Isi-c/Id, which covers the time span between roughly 10,000 and 9,500 years ago. The four samples from E22/S78 focus on the lower stratigraphic units (II - IIIa) of the valley floor and complement the data recovered from the adjacent square. The gastropod column from E22/S88 was collected from Burned Rock Midden 1 in the upper levels of this square. Five sediment samples were collected from the midden deposit in the square wall (Levels 3, 4, 5, 7, and 9), and a sixth sample was collected directly below the base of the midden (Level 12).

The second series of gastropod samples was collected from the "fine-screened unit" (E28/S78). This square had all 
excavated sediment water screened through nested $1 / 4$ - and 1/16-inch-mesh screens. Although gastropod recovery methods were not well documented in the TxDOT field notes, gastropods were apparently picked from the screened matrix. Forty-three levels were evaluated providing a continuum covering the full human occupation of the site. The 1/16inch screen would not recover many of the smaller species, so the assemblage from this square reflects the larger species and larger individuals within a species.

The limited documentation of the methods used to collect the TxDOT snail samples poses problems in identifying analytical biases. Likewise, the processing methods for the column samples from the TxDOT excavations are not clearly recorded (Neck 1988). At least some of the sediment samples were processed at the Dallas Museum of Science, with the resulting matrix samples picked by members of the Dallas Shell Club. The lack of documentation on recovery methods limits how much weight can be placed on the final analysis results. The documentation of the methods used to collect gastropods from the fine-screen unit is also less than complete. The high number counts for this square suggest the sample was retrieved from both the 1/4-inch and 1/16-inch screens, but it is not clear from the field notes if this sample represents the total $2-\mathrm{x}-2-\mathrm{m}$ square or is limited to a $1-\mathrm{m}$ quadrant of this square.

During the TARL excavations, two $1-\mathrm{x}-1-\mathrm{m}$ squares (Squares 12 and 20) were selected for the collection of sediment samples for gastropod analysis. From Square 12, a total of 46 uniform 1.5-liter sediment samples was collected in a stratigraphic column. Square 20, located in the northeast area of the site, had 41 uniform 1.5-liter sediment samples collected during the excavation. These sediment samples were processed by Neck using water screening through a nested set of geological sieves (U.S. Standard Sieve Series) with a maximum screen mesh of $4.76 \mathrm{~mm}$ (sieve \#4) and a minimum screen mesh of $.425 \mathrm{~mm}$ (sieve\#40). All complete gastropod shells were removed from the processed residue for identification.

Five cultural features excavated during the TARL project were also evaluated for gastropods (see also additional feature samples analyzed by Theler, this chapter). The recovery method for the features was the same as for the squares, with 1.5-liter sediment samples water screened through four nested geological sieves. Feature 231, a large, burned rock accumulation associated with the Early Archaic occupation in stratigraphic Unit IIIa, had five uniform 1.5-liter samples processed. Four of these samples were collected from Square 52 (Levels 24 and 25), and one was recovered from adjacent Square 38 (Level 23).

Feature 260, also in Square 52 but located below Feature 231, was also sampled for gastropod recovery. A single 1.5-liter sediment sample was processed from excavation Level 42B. This feature is a Late Paleoindian burned rock cluster found in stratigraphic Unit Isi-c (dating to roughly 10,000 в.P.)
Feature 245 was sampled by three 1.5 -liter sediment samples. Feature 245 is a burned rock basin in Squares 28 and 52. This feature was located in the lower portion of Unit IIIa and is associated with an Early Archaic occupation. Burned Rock Midden 1 (sampled with TARL Square 100) was investigated by six sediment snail samples, each from different levels. The lower two levels are from the base or slightly below the burned rock midden. These samples complement the earlier series of gastropod samples collected from Burned Rock Midden 1 during the TxDOT excavations (see above).

\section{Zoogeographical Setting}

The Wilson-Leonard site is located in an area that contains one major and one minor transition between zoogeographical regions (Blair 1950). The major transition zone is associated with the Balcones Fault zone, which forms the boundary between an upland, bedrock-dominated area (Texas Hill Country and Edwards Plateau) and the soil-dominated Coastal Plain. This upland area is characterized by a number of limestone formations and contains a characteristic molluscan fauna that includes several species that do not range east or north of the Wilson-Leonard site (Cheatum and Fullington 1971, 1973; Fullington and Pratt 1974). The Coastal Plain contains a variety of geological substrates, but most of them are noncalcareous in nature. Molluscan species more typical of slow-moving streams and riparian woodlands occur on the Coastal Plain.

The minor transition in the area of the Wilson-Leonard site involves the subtle but biogeographically significant transition between the Texas Hill Country and the Lampasas Cut Plain. The biotic changeover across this transition is less dramatic than that along the Balcones Fault zone. However, a number of terrestrial gastropods are not found north of this transition zone. The location of this transition zone appears to be along the drainage divide between the Colorado and Brazos river systems. The line between Travis and Williamson counties is defined as that divide and is located only a few kilometers south of the Wilson-Leonard site.

\section{Taxonomic Analysis of Subassemblages}

Examination of the paleomolluscan assemblages from the Wilson-Leonard site revealed the presence of a diverse fauna containing many species of terrestrial and freshwater gastropods as well as a few fragments of freshwater unionids (see below). In total, 23 terrestrial gastropod taxa and 11 freshwater-aquatic gastropod taxa were identified. The TxDOT sediment column samples yielded primarily terrestrial species, with 17 terrestrial and 7 aquatic species represented, but the specimens by count comprise largely terrestrial individuals. The fine-screened unit from the TxDOT excavations included 21 terrestrial and 9 freshwater species, which suggests that biases such as the screen size 
and matrix picking biases may have affected the column and fine screen units samples differently.

Except for the introduced Rumina decollata, all terrestrial gastropod species recovered from Wilson-Leonard are native to Texas (see Table 37-1 for habitat preferences). One of these native species, Gastrocopta armifera, is not known to live in the Central Texas area today. Several of the freshwater gastropods recovered do not live in the area of the Wilson-Leonard site today. Pomatiopsis lapidaria is typical of the southeastern United States but has not been reported from modern gastropod studies in Texas (although suitable habitat would appear to be present in easternmost Texas). Elimia comalensis is today restricted to a few streams below major springs; the only known living population of E. comalensis in the drainage of the Brazos River is in Salado Creek in Bell County. Two small lymnaeid snails (Fossaria parva and Fossaria dalli) are not known to be living in Central Texas waters. $F$. dalli is known to be living in northwestern Texas, but $F$. parva has yet to be reported living anywhere in Texas. A third species of aquatic gastropod that has not been recorded for modern Central Texas was identified in the TARL subassemblage. This is the small Cincinnatia cincinnatiensis, which has only been reported from Pleistocene contexts in eastern Texas.

A total of 52,375 gastropod shells from the TxDOT subassemblages was identified to taxon and the raw frequency data are presented in Tables 37-2 through 37-6. The sediment processing of the two columns and four features from the TARL excavations resulted in the recovery of a total of 3,781 specimens with 23 species of gastropods (16 terrestrial and 7 aquatic) represented. Counts for gastropod shells from the TARL excavations are presented in Tables 37-7 through 37-10.

\section{Annotated List}

\section{Terrestrial Gastropods}

Oligyra orbiculata is the only terrestrial operculate gastropod in Texas. This species also has one of the widest environmental tolerances of any terrestrial gastropod in Texas. Populations have been found in open woodlands as well as grassland areas with some woody plants or rocks available to provide cover. O. orbiculata is found from northeastern Mexico through the eastern two-thirds of Texas into Oklahoma and the southeastern United States (Fullington and Pratt 1974).

Carychium mexicanum is found in very moist microhabitats, being most abundant in mesic floodplains and marsh margins. C. mexicanum ranges from Guatemala northward into the Gulf Coastal Plain and the southern Atlantic Coastal Plain as far north as South Carolina (Fullington and Pratt 1974).

Pupoides albilabris is very tolerant of drought conditions and is found in almost any habitat that contains some rock or downed wood to provide cover. $P$. albilabris ranges throughout eastern North America as far west as Arizona and the Dakotas, southward into Mexico and the Caribbean area (Metcalf 1984; Pilsbry 1948).

TABLE 37-1

Habitat Preferences of the Terrestrial Gastropods from TxDOT Unit E28/S78

\begin{tabular}{l|l}
\hline Terrestrial Taxa & Habitat \\
\hline Oligyra orbiculata & wide tolerance \\
Pupoides albilabris & drier tolerance \\
Gastrocopta armifera & woodland \\
wastrocopta contracta & semiarid grasslands \\
Gastrocopta cristata & wide tolerance \\
Gastrocopta pellucida & wide tolerance \\
Gastrocopta procera & woodland \\
Strobilops texasiana & \\
Succineidae & woodland \\
Anguispira strongylodes & drier tolerance \\
Helicodiscus eigenmanni & woodland \\
Helicodiscus parallelus & wide tolerance \\
Helicodiscus singleyanus & woodland \\
Glyphyalinia roemeri & woodland \\
Glyphylinia umbilicata & woodland \\
Mesomphix friabilis & woodland \\
Zonitoides arboreus & urban areas, open woodland \\
Rumina decollata & drier tolerance \\
Rabdotus mooreanus & drier tolerance \\
Polygyra mooreana & woodland \\
Polygyra texasiana & wide tolerance \\
Praticolella berlandieriana &
\end{tabular}


TABLE 37-2

Terrestrial Gastropod Taxa Frequencies by Level, E28/S78 (Fine-screened unit 1/4-inch and 1/16-inch mesh)

\begin{tabular}{|c|c|c|c|c|c|c|c|c|c|c|c|c|c|c|c|c|c|c|c|c|c|c|c|}
\hline & 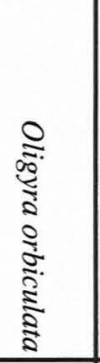 & 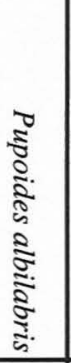 & 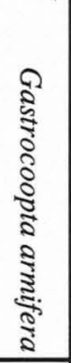 & 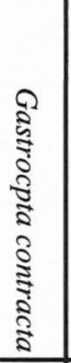 & 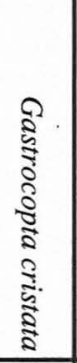 & 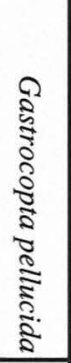 & 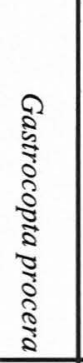 & 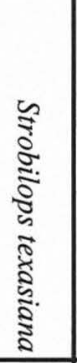 & 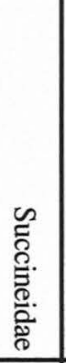 & 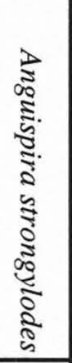 & 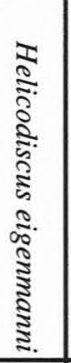 & 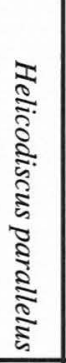 & 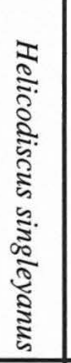 & 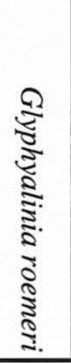 & 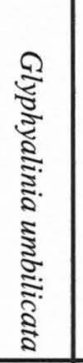 & 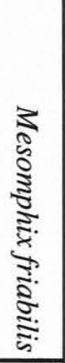 & 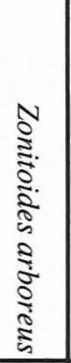 & 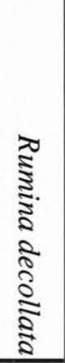 & 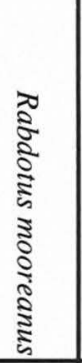 & 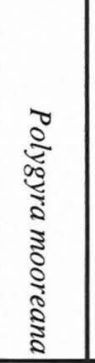 & 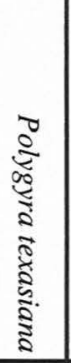 & 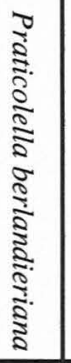 & 官 \\
\hline $\begin{array}{l}\text { Unit IIIc: } \\
\text { Level 1 } \\
\text { Level } 2 \\
\text { Level } 4 \\
\text { Level } 6 \\
\end{array}$ & $\begin{array}{r}594 \\
3,350 \\
1,745 \\
1,469 \\
\end{array}$ & $\begin{array}{r}39 \\
4 \\
7 \\
21 \\
\end{array}$ & & $\begin{array}{r}3 \\
3 \\
8 \\
11 \\
\end{array}$ & 1 & & $\begin{array}{r}97 \\
4 \\
12\end{array}$ & $\begin{array}{l}28 \\
12 \\
18\end{array}$ & & & & & 4 & 2 & $\begin{array}{l}5 \\
8 \\
9 \\
3 \\
\end{array}$ & $\begin{array}{l}5 \\
3\end{array}$ & & 1 & $\begin{array}{r}67 \\
212 \\
140 \\
78 \\
\end{array}$ & $\begin{array}{r}56 \\
643 \\
278 \\
238 \\
\end{array}$ & & $\begin{array}{r}8 \\
44 \\
24 \\
33 \\
\end{array}$ & $\begin{array}{r}903 \\
4,285 \\
2,246 \\
1,853 \\
\end{array}$ \\
\hline $\begin{array}{l}\text { Units IIIc-IIIb: } \\
\text { Level } 7 \\
\text { Level } 8 \\
\text { Level } 9 \\
\text { Level } 10 \\
\text { Level } 11 \\
\end{array}$ & $\begin{array}{l}2,518 \\
1,827 \\
3,088 \\
2,369 \\
1,683 \\
\end{array}$ & $\begin{array}{r}5 \\
14 \\
16 \\
71 \\
59 \\
\end{array}$ & & $\begin{array}{l}1 \\
2 \\
3 \\
1 \\
\end{array}$ & 3 & 5 & $\begin{array}{r}1 \\
31 \\
\end{array}$ & $\begin{array}{l}1 \\
4 \\
\end{array}$ & $\begin{array}{l}1 \\
1 \\
\end{array}$ & & & 1 & $\begin{array}{l}1 \\
1 \\
5\end{array}$ & 1 & $\begin{array}{r}9 \\
8 \\
1 \\
16 \\
3 \\
\end{array}$ & & 2 & & $\begin{array}{l}453 \\
105 \\
184 \\
408 \\
442\end{array}$ & $\begin{array}{r}782 \\
553 \\
665 \\
1,137 \\
548 \\
\end{array}$ & $\begin{array}{l}1 \\
2\end{array}$ & $\begin{array}{r}40 \\
21 \\
34 \\
15 \\
1\end{array}$ & $\begin{array}{l}3,809 \\
2,531 \\
3,996 \\
4,024 \\
2,783 \\
\end{array}$ \\
\hline $\begin{array}{l}\text { Units IIIb: } \\
\text { Level } 12 \\
\text { Level } 13 \\
\end{array}$ & $\begin{array}{l}1,930 \\
2,144 \\
\end{array}$ & $\begin{array}{r}26 \\
9 \\
\end{array}$ & & 1 & & & & 1 & & & & & 1 & & 3 & & & & $\begin{array}{l}203 \\
326 \\
\end{array}$ & $\begin{array}{r}535 \\
1,036 \\
\end{array}$ & 1 & 1 & $\begin{array}{l}2,695 \\
3,522 \\
\end{array}$ \\
\hline $\begin{array}{l}\text { Unit IIIb-IIIa: } \\
\text { Level } 14 \\
\text { Level } 15\end{array}$ & $\begin{array}{l}615 \\
941\end{array}$ & 3 & & & & & & & & & & & & & $\begin{array}{l}1 \\
1\end{array}$ & & & & $\begin{array}{l}196 \\
246\end{array}$ & $\begin{array}{l}152 \\
230\end{array}$ & & & $\begin{array}{r}964 \\
1421 \\
\end{array}$ \\
\hline $\begin{array}{r}\text { Unit IIIa: } \\
\text { Level } 16 \\
\text { Level } 17 \\
\end{array}$ & $\begin{array}{l}283 \\
494 \\
\end{array}$ & 2 & & & & & & & & & & & & & 1 & & & & $\begin{array}{l}138 \\
321 \\
\end{array}$ & $\begin{array}{l}54 \\
97\end{array}$ & 3 & & $\begin{array}{l}476 \\
917 \\
\end{array}$ \\
\hline $\begin{array}{l}\text { Unit II-IIIa: } \\
\text { Level } 18 \\
\text { Level } 19 \\
\text { Level } 20 \\
\end{array}$ & $\begin{array}{r}683 \\
850 \\
1,086 \\
\end{array}$ & 3 & 1 & 1 & & & & & & 5 & 1 & & 16 & & $\begin{array}{r}2 \\
8 \\
\end{array}$ & & & & $\begin{array}{l}181 \\
102 \\
125 \\
\end{array}$ & $\begin{array}{l}165 \\
233 \\
224 \\
\end{array}$ & 6 & & $\begin{array}{r}1031 \\
1186 \\
1,475 \\
\end{array}$ \\
\hline $\begin{array}{l}\text { Unit II: } \\
\text { Level } 21 \\
\text { Level } 22 \\
\text { Level } 23 \\
\text { Level } 24\end{array}$ & $\begin{array}{l}920 \\
701 \\
290 \\
344\end{array}$ & 1 & 2 & $\begin{array}{l}1 \\
1 \\
2\end{array}$ & & & & 1 & 1 & 2 & & & 2 & & $\begin{array}{l}6 \\
7 \\
2 \\
6\end{array}$ & & & & $\begin{array}{l}66 \\
44 \\
39 \\
59\end{array}$ & $\begin{array}{r}141 \\
140 \\
104 \\
60\end{array}$ & $\begin{array}{l}2 \\
2\end{array}$ & & $\begin{array}{r}1140 \\
898 \\
439 \\
475\end{array}$ \\
\hline
\end{tabular}




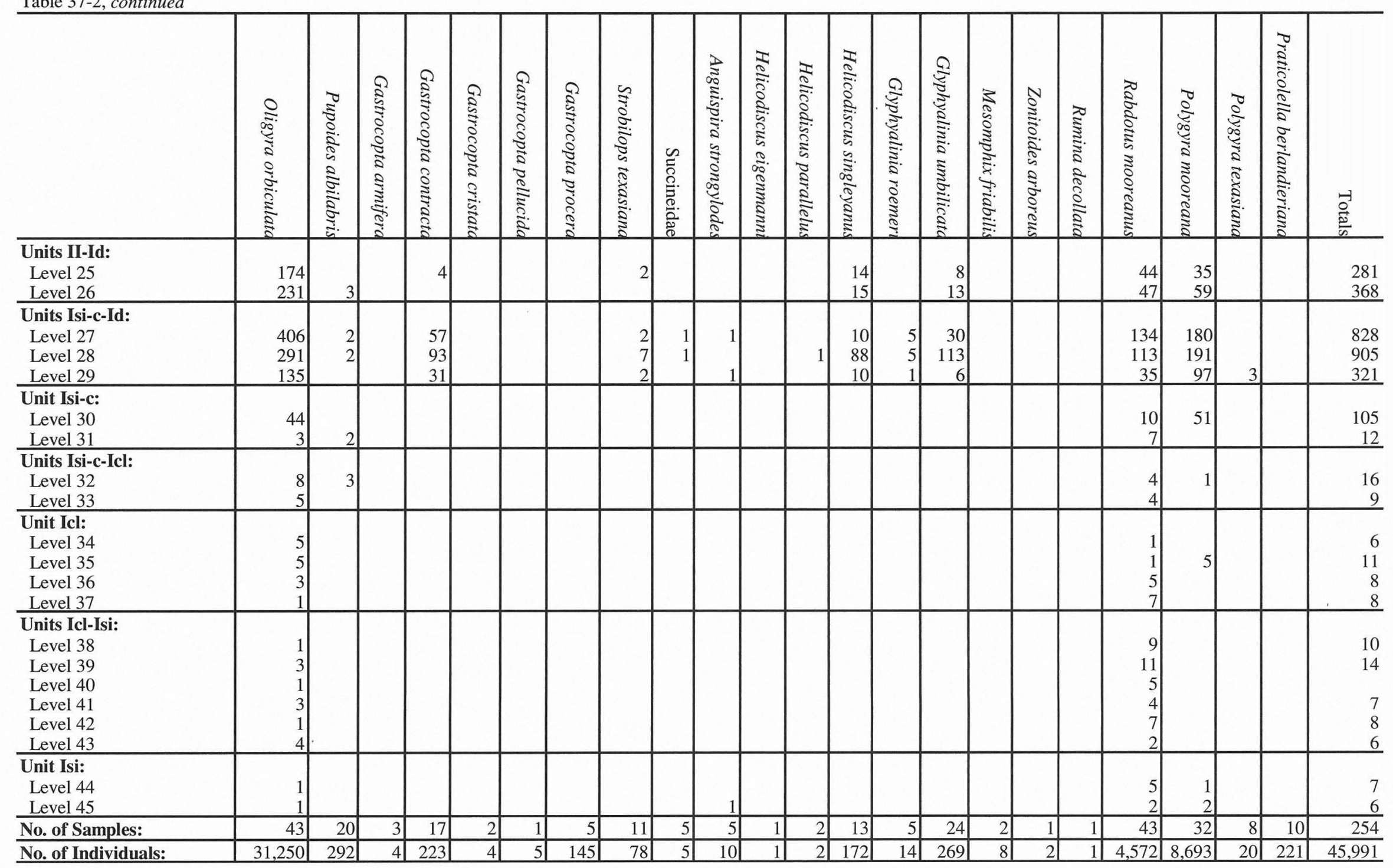


TABLE 37-3

Terrestrial Gastropod Taxa Frequencies by Level, TxDOT Square E20/S78 (mesh size unknown)

\begin{tabular}{|c|c|c|c|c|c|c|c|c|c|c|c|c|c|c|c|c|}
\hline & 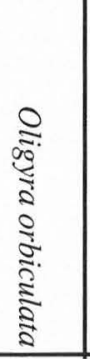 & 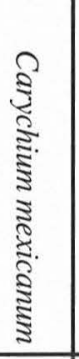 & 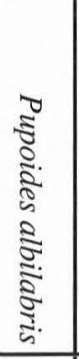 & 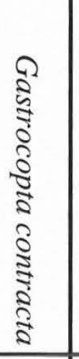 & 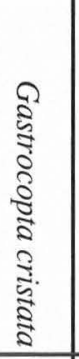 & 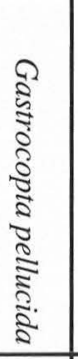 & 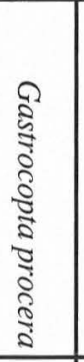 & 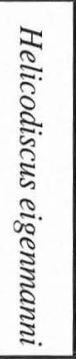 & 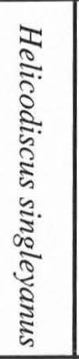 & 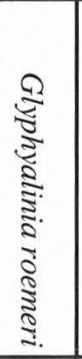 & 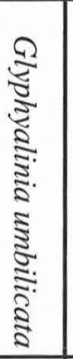 & 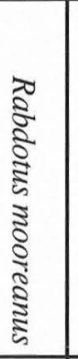 & 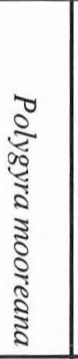 & 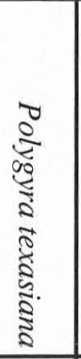 & 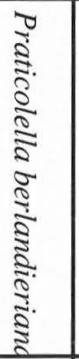 & 年 \\
\hline $\begin{array}{l}\text { Unit IIIc: } \\
\text { Level } 4 \\
\text { Level } 5 \\
\text { Level } 6\end{array}$ & $\begin{array}{l}210 \\
406 \\
302 \\
\end{array}$ & & & $\begin{array}{l}5 \\
2 \\
3 \\
\end{array}$ & & 1 & 2 & 1 & & & 3 & $\begin{array}{l}21 \\
66 \\
24\end{array}$ & $\begin{array}{r}49 \\
112 \\
97 \\
\end{array}$ & & $\begin{array}{r}4 \\
12 \\
21 \\
\end{array}$ & $\begin{array}{l}292 \\
600 \\
449 \\
\end{array}$ \\
\hline $\begin{array}{l}\text { Units IIIb/c: } \\
\text { Level } 7 \\
\text { Level } 8 \\
\end{array}$ & $\begin{array}{l}305 \\
320 \\
\end{array}$ & & 2 & $\begin{array}{l}4 \\
6 \\
\end{array}$ & & & $\begin{array}{l}3 \\
1 \\
\end{array}$ & & & & 2 & $\begin{array}{l}43 \\
37 \\
\end{array}$ & $\begin{array}{l}125 \\
101\end{array}$ & & $\begin{array}{r}22 \\
5\end{array}$ & $\begin{array}{l}504 \\
472 \\
\end{array}$ \\
\hline $\begin{array}{l}\text { Units IIb: } \\
\text { Level } 10 \\
\text { Level } 11 \\
\end{array}$ & $\begin{array}{l}135 \\
174 \\
\end{array}$ & & $\begin{array}{l}4 \\
8 \\
\end{array}$ & $\begin{array}{r}4 \\
12 \\
\end{array}$ & 3 & & 2 & & $\begin{array}{r}6 \\
12 \\
\end{array}$ & & 3 & $\begin{array}{l}18 \\
36 \\
\end{array}$ & $\begin{array}{l}66 \\
73 \\
\end{array}$ & & & 235 \\
\hline $\begin{array}{l}\text { Unit IIa/b-IIa: } \\
\text { Level } 14\end{array}$ & 46 & & 2 & & & 3 & & & 22 & & & 8 & 6 & & & 87 \\
\hline $\begin{array}{l}\text { Units Isi-c/Id: } \\
\text { Level } 24 \\
\text { Level } 28 \\
\end{array}$ & $\begin{array}{l}61 \\
10 \\
\end{array}$ & 3 & & 4 & & & & & $\begin{array}{l}14 \\
14 \\
\end{array}$ & 1 & 3 & $\begin{array}{r}15 \\
5 \\
\end{array}$ & 16 & 5 & 1 & 112 \\
\hline No. of Samples: & 10 & 1 & 4 & 8 & 1 & 2 & 4 & 1 & 5 & 1 & 4 & 10 & 9 & 1 & 6 & 67 \\
\hline No. of Individuals: & 1,969 & 3 & 16 & 40 & 3 & 4 & 8 & 1 & 68 & 1 & 11 & 273 & 645 & 5 & 65 & 3,112 \\
\hline
\end{tabular}

TABLE $37-4$

Terrestrial Gastropod Taxa Frequencies by Level, TxDOT Square E22/S88 (mesh size unknown)

\begin{tabular}{|c|c|c|c|c|c|c|c|c|c|c|c|c|}
\hline & 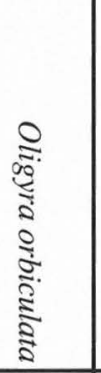 & 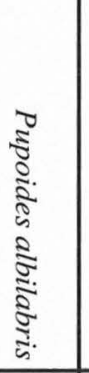 & 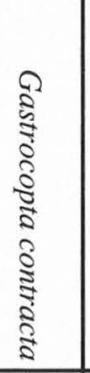 & 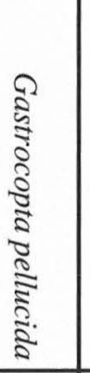 & 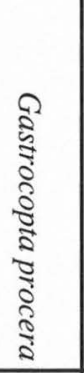 & 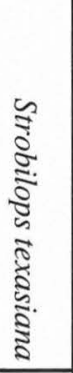 & 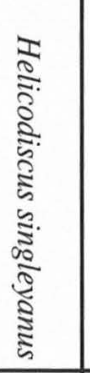 & 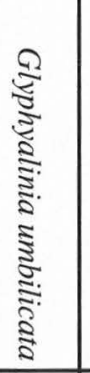 & 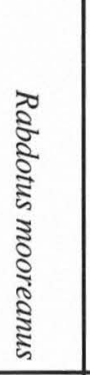 & 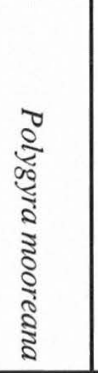 & 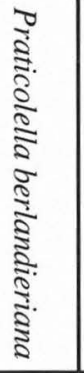 & 蒠 \\
\hline $\begin{array}{l}\text { Burned Rock Midd } \\
\text { Unit IIIc: } \\
\text { Level } 3 \\
\text { Level } 4 \\
\text { Level } 5 \\
\text { Level } 7 \\
\text { Unit Y/IIIc: } \\
\text { Level } 9\end{array}$ & $\begin{array}{l}150 \\
365 \\
400 \\
273 \\
214\end{array}$ & $\begin{array}{l}1 \\
6 \\
5\end{array}$ & $\begin{array}{r}1 \\
3 \\
13\end{array}$ & $\begin{array}{l}5 \\
4 \\
8 \\
8\end{array}$ & $\begin{array}{r}2 \\
3 \\
14 \\
10\end{array}$ & 2 & $\begin{array}{r}3 \\
14 \\
12 \\
12 \\
12\end{array}$ & $\begin{array}{l}4 \\
9 \\
4\end{array}$ & $\begin{array}{l}34 \\
56 \\
45 \\
55 \\
53\end{array}$ & $\begin{array}{r}99 \\
135 \\
184 \\
114 \\
69\end{array}$ & $\begin{array}{r}1 \\
16 \\
9 \\
1\end{array}$ & $\begin{array}{l}295 \\
597 \\
697 \\
487 \\
\\
352 \\
\end{array}$ \\
\hline $\begin{array}{l}\text { Unit X/Y/IIIb: } \\
\text { Level } 12 \\
\end{array}$ & 174 & & 11 & 6 & & & 23 & 3 & 61 & 46 & 1 & 325 \\
\hline No. of Samples: & 6 & 3 & 4 & 5 & 4 & 1 & 6 & 4 & 6 & 6 & 5 & 50 \\
\hline No. of Individuals: & 1,576 & 12 & 28 & 31 & 29 & 2 & 76 & 20 & 304 & 647 & 28 & 2,753 \\
\hline
\end{tabular}


TABLE 37-5

Terrestrial Gastropod Taxa Frequencies by Level, TxDOT Square E22/S78 (mesh size unknown)

\begin{tabular}{|c|c|c|c|c|c|c|c|c|c|c|}
\hline & 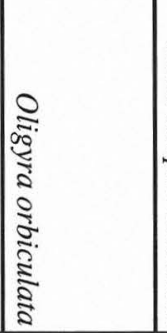 & 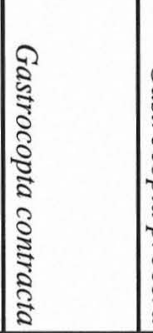 & 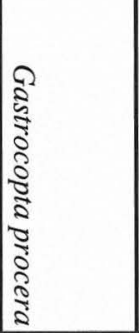 & 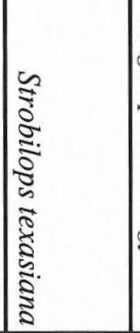 & 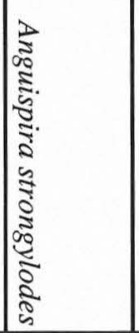 & 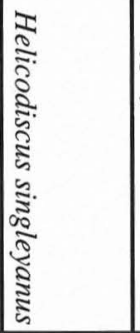 & 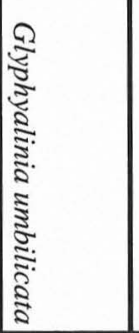 & 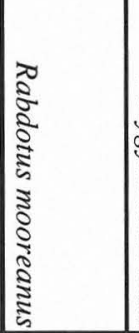 & 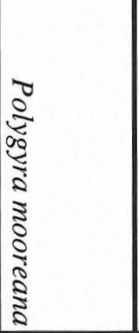 & $\overrightarrow{\frac{0}{0}}$ \\
\hline $\begin{array}{r}\text { Unit IIIa: } \\
\text { Level } 16\end{array}$ & 31 & & 1 & & & 8 & & 24 & 8 & 72 \\
\hline $\begin{array}{c}\text { Units III: } \\
\text { Level } 20 \\
\text { Level } 22\end{array}$ & $\begin{array}{l}72 \\
47\end{array}$ & 3 & & 1 & & $\begin{array}{l}5 \\
7\end{array}$ & $\begin{array}{l}1 \\
1\end{array}$ & $\begin{array}{l}24 \\
14\end{array}$ & $\begin{array}{r}8 \\
10\end{array}$ & $\begin{array}{r}111 \\
82\end{array}$ \\
\hline $\begin{array}{l}\text { Unit Id/II: } \\
\text { Level } 23\end{array}$ & 48 & 4 & & & 1 & 5 & 8 & 33 & 20 & 119 \\
\hline No. of Samples: & 4 & 2 & 1 & 1 & 1 & 4 & 3 & 4 & 4 & 24 \\
\hline No. of Individuals: & 198 & 7 & 1 & 1 & 1 & 25 & 10 & 95 & 46 & 384 \\
\hline
\end{tabular}

Gastrocopta armifera is usually found in wooded areas on calcareous soil with exposed rock or downed wood as well as accumulations of leaf litter to provide cover (Cheatum and Fullington 1973; Leonard 1943; Neck 1984a). The species has also been found in prairie areas (Baker 1939; La Rocque 1966). Habitat studies in Oklahoma have found $G$. armifera mainly in riparian woods along rivers and creeks and in shrub areas in floodplains (Metcalf 1984). G. armifera ranges over much of eastern North America from Alberta to Quebec and southward to Florida and New Mexico (Pilsbry 1948). However, contemporary Texas records are restricted to northern Texas, the Panhandle, and montane areas of western Texas (Cheatum and Fullington 1973; Neck 1984a).

Gastrocopta contracta is typically found in moderately mesic woodlands or savannas with sufficient downed wood or rocks for cover. This species requires more-mesic conditions than the following species of Gastrocopta. G. contracta ranges through eastern North America from Ontario and Maine to Manitoba, south to Florida and eastern Mexico (Pilsbry 1948).

Gastrocopta cristata is most commonly found in deep woodlands or in woodlands along pools or streams (Allen and Cheatum 1961).

Gastrocopta procera is found in a variety of mesic and xeric microhabitats in woodlands, savannas, and grasslands; this species generally requires more-mesic conditions than Gastrocopta pellucida and Pupoides albilabris, but not as much moisture as Gastrocopta contracta. G. procera ranges through most of the southern United States from Maryland to Iowa and Arizona (Hubricht 1985).

Gastrocopta pellucida survives in a variety of habitats, even those that are moderately xeric (Metcalf 1984). Habitats occupied include open woodlands, riparian communities, and prairies. G. pellucida ranges over much of North America from New Jersey to Colorado, southward to
Florida, Baja California, and southern Mexico (Pilsbry 1948).

Strobilops texasiana is generally found in closed to open woodlands or savannas with large amounts of rock or downed wood to conserve moisture. S. texasiana occurs in the south central United States from Central Texas and Oklahoma eastward to Arkansas and Louisiana (Fullington and Pratt 1974).

The family Succineidae includes three genera and several species of land snails, many but not all of which live near water or in marshy situations. Since identification is usually made from soft parts, in most cases archeological examples of succineid snails cannot be identified below the family level, and it is consequently difficult to be specific about habitat preference. Catinella (below) is an example of a succineid snail.

Catinella avara is the currently used name that has been applied to a series of populations that are found in wetland margin habitats or periodically moist slopes over much of the eastern United States (Hubricht 1985:98).

Anguispira strongylodes is found in mesic woodlands, normally associated with flood plains of modern streams. A. strongylodes ranges from the Balcones Escarpment zone eastward through eastern Texas to Florida, North Carolina, and northward into Missouri and Illinois (Hubricht 1985).

Helicodiscus eigenmanni is found in xeric grasslands and savannas with wood or rock as cover. H. eigenmanni ranges from Central Texas westward to Arizona (Hubricht 1985).

Helicodiscus parallelus is found in mesic flood plain woodlands under logs or deep leaf litter, although it is reasonably tolerant of diverse habitats (Metcalf 1984). $\mathrm{H}$. parallelus ranges from the Eastern Caprock Escarpment and the Balcones Escarpment Zone eastward to Alabama and northward to Maine and South Dakota (Neck 1984a; Pilsbry 1948). 
TABLE 37-6

Freshwater Gastropod Taxa Frequencies by Square and Level

\begin{tabular}{|c|c|c|c|c|c|c|c|c|c|c|c|}
\hline & 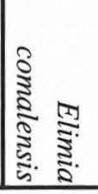 & 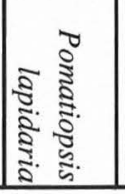 & 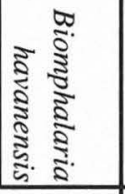 & 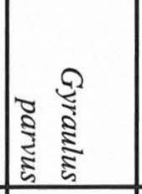 & 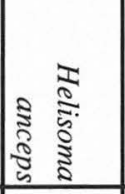 & 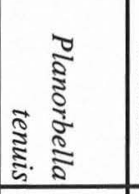 & 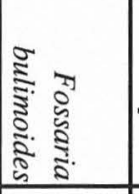 & 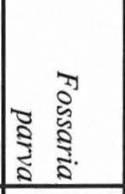 & 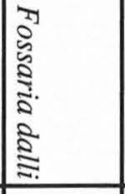 & 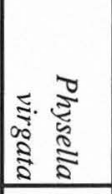 & 节 \\
\hline \multicolumn{12}{|c|}{ TxDOT Square E20/S78 (mesh size unknown): } \\
\hline \multicolumn{12}{|c|}{ Unit Id-Isi-c: $\quad|\quad| \quad \mid$} \\
\hline \multicolumn{12}{|l|}{ Level 28} \\
\hline \multicolumn{12}{|l|}{ No. of Samples: } \\
\hline \multicolumn{12}{|c|}{\begin{tabular}{l|l|l|l} 
No. of Individuals: & & & \\
\end{tabular}} \\
\hline \multicolumn{12}{|c|}{ TxDOT Square E22/S78 (mesh size unknown): } \\
\hline \multicolumn{12}{|c|}{ Unit IIIa: $\quad|\quad|$} \\
\hline \multicolumn{12}{|l|}{ Level 16} \\
\hline \multicolumn{12}{|l|}{ Unit II: } \\
\hline \multicolumn{12}{|l|}{ Level 20} \\
\hline \multicolumn{12}{|l|}{ Unit Id/II: } \\
\hline Level 23 & & & & & & 1 & & & & & 2 \\
\hline No. of Samples: & & & & 1 & & 2 & 1 & & 1 & & 6 \\
\hline No. of Individuals: & & & & 1 & & 2 & 1 & & 1 & & 6 \\
\hline \multicolumn{12}{|c|}{ TxDOT Square E28/S78 (1/4- and 1/16-inch screened): } \\
\hline \multicolumn{12}{|c|}{\begin{tabular}{l|l|l|} 
Unit IIIc: & $\mid$ & $\mid$
\end{tabular}} \\
\hline \multicolumn{12}{|l|}{ Level 1} \\
\hline \multicolumn{12}{|l|}{ Level 2} \\
\hline \multicolumn{12}{|l|}{ Level 4} \\
\hline \multicolumn{12}{|l|}{ Level 6} \\
\hline \multicolumn{12}{|l|}{ Units IIIc-IIIb: } \\
\hline \multicolumn{12}{|l|}{ Level 7} \\
\hline Level 8 & & & & & 1 & & & & 2 & & 3 \\
\hline Level 9 & & & & & & & & & & & 0 \\
\hline Level 10 & & & & & & & & 1 & 1 & & 2 \\
\hline Level 11 & & & 1 & & & 1 & & & 3 & & 5 \\
\hline Unit IIIlb: & & & & & & & & & & & \\
\hline Level 12 & & & & & & & & & & & 0 \\
\hline Level 13 & & & & & & 1 & 1 & & 1 & & 3 \\
\hline Units IIIb-IIIa: & & & & & & & & & & & \\
\hline Level 14 & & & & & & 2 & & & & & 2 \\
\hline Level 15 & & & & 1 & & 1 & & & 1 & & 3 \\
\hline Unit IIIa: & & & & & & & & & & & \\
\hline Level 16 & & & & & & 1 & & & & & 1 \\
\hline Level 17 & & & & 1 & 2 & 5 & & & & & 8 \\
\hline Units IIIa-II: & & & & & & & & & & & \\
\hline Level 18 & & & & & & 2 & & & & 2 & 4 \\
\hline Level 19 & & & & & & 8 & 1 & & & & 9 \\
\hline Level 20 & & & & & & 5 & 1 & & 2 & 1 & 9 \\
\hline Unit II: & & & & & & & & & & & \\
\hline Level 21 & & & & & & & 2 & & & & 2 \\
\hline Level 22 & & 1 & & & & 5 & 3 & & & & 9 \\
\hline Level 23 & & & & & & 1 & 1 & & & & 2 \\
\hline Level 24 & & 1 & & & & 1 & & & & & 2 \\
\hline Units II-Id: & & & & & & & & & & & \\
\hline Level 25 & & & & 1 & & 2 & & & & 1 & 4 \\
\hline Level 26 & & & & 1 & & & 8 & & & & 9 \\
\hline
\end{tabular}




\begin{tabular}{|c|c|c|c|c|c|c|c|c|c|c|c|}
\hline & 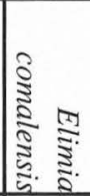 & 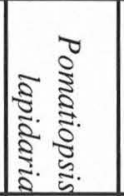 & 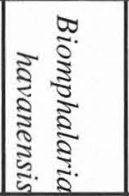 & 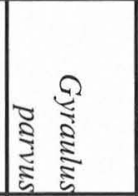 & 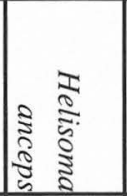 & 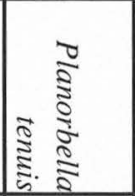 & 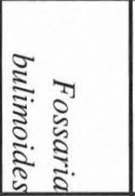 & 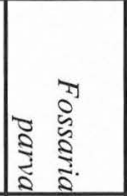 & $\begin{array}{c}7 \\
0 \\
\vdots \\
\vdots \\
\vdots \\
\vdots \\
\vdots \\
\vdots \\
\vdots \\
\vdots \\
2\end{array}$ & 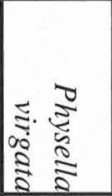 & $\frac{\overrightarrow{0}}{\stackrel{0}{\overrightarrow{0}}}$ \\
\hline $\begin{array}{l}\text { Units Id-Isi-c: } \\
\text { Level } 27 \\
\text { Level } 28 \\
\text { Level } 29\end{array}$ & & 2 & & 1 & & $\begin{array}{l}5 \\
2\end{array}$ & & $\begin{array}{l}6 \\
1 \\
2\end{array}$ & 7 & 1 & $\begin{array}{r}12 \\
13 \\
2\end{array}$ \\
\hline No. of Samples: & & 3 & 1 & 7 & 3 & 17 & 7 & 4 & 8 & 4 & 54 \\
\hline No. of Individuals: & & 4 & 1 & 11 & 7 & 45 & 17 & 10 & 18 & 5 & 118 \\
\hline $\begin{array}{l}\text { TxDOT Square E22 } \\
\text { Burned Rock Midd } \\
\text { Level } 4 \\
\text { Level } 5 \\
\text { Level } 7 \\
\text { No. of Samples: } \\
\text { No. of Individuals: }\end{array}$ & mesh & unknov & wn): & & $\begin{array}{l}1 \\
2\end{array}$ & $\begin{array}{l}2 \\
1 \\
2 \\
3\end{array}$ & & & $\begin{array}{l}1 \\
1 \\
\end{array}$ & & $\begin{array}{l}3 \\
2 \\
2 \\
5 \\
7\end{array}$ \\
\hline
\end{tabular}

Helicodiscus singleyanus is found in xeric to mesic habitats in woodlands, savannas, and grasslands. $H$. singleyanus encompasses a complex of populations over much of the eastern United States (Pilsbry 1948).

Glyphyalinia roemeri is found in very mesic, usually hygric, flood plain habitats or in mesic caves. G. roemeri is found only in Central Texas (Hubricht 1985).

Glyphyalinia umbilicata is found in seasonally mesic woodlands and savannas with moisture-conserving rocks or downed wood. G. umbilicata ranges from the Carolinas and Florida westward to central Texas (Hubricht 1985).

Mesomphix friabilis is found in flood plain woodlands usually with leaf litter accumulations. $M$. friabilis ranges from the Balcones Fault Zone eastward through eastern Texas into Alabama, Ohio, and Missouri (Hubricht 1985).

Zonitoides arboreus is found under downed wood in savannas and woodlands. Z. arboreus is a wide-ranging complex of populations that occur from northern Canada southward to Costa Rica (Hibbard and Taylor 1960).

Rumina decollata is found in heavily disturbed urban habitats, marginally impacted areas peripheral to urban areas, and in flood plain woodlands downstream of urban populations; some downed wood or lumber and trash appear to be the only requirement for this species in Central Texas. $R$. decollata is native to land areas surrounding the Mediterranean Sea but has established populations in many portions of the southern United States (Fullington and Pratt 1974).

Rabdotus mooreanus is found in open woodlands and grassland habitats. R. mooreanus ranges throughout northcentral and Central Texas (Fullington and Pratt 1974).

Polygyra texasiana is generally found in mesic flood plain woodlands under downed wood. P. texasiana ranges from Texas and Oklahoma northward to Arkansas and Ala- bama (Cheatum and Fullington 1971). The modern range and habitat preferences for this species are not well known, but based on its presence at several archeological sites, it seems well suited to semi-arid, wooded grasslands (Murray 1987).

Polygyra mooreana is found in generally xeric woodlands with calcareous soils. P. mooreana ranges throughout east central, central, and southern Texas (Cheatum and Fullington 1971).

Praticolella berlandieriana is found in open, often disturbed habitats that support savannas or woodlands under undisturbed conditions. P. berlandieriana is generally found in central and south central Texas (Hubricht 1985).

\section{Freshwater Gastropods}

Pomatiopsis lapidaria is generally found in marsh habitats with grasses, sedges, and cattail along the margins. $P$. lapidaria ranges throughout much of the eastern United States but has not as yet been reported living in Texas (Fullington 1978).

Elimia comalensis is found in springfed streams with clear water and limestone substrate. E. comalensis is endemic to Texas, being found only in central Texas streams (Fullington 1978).

Cincinnatia cincinnatiensis is found in shallow, springfed streams with a firm substrate and slow current. Widespread in the eastern half of Texas during the Pleistocene, $C$. cincinnatiensis has subsequently been extirpated from Texas (unless the enigmatic "Amnicola" peracuta is conspecific).

Biomphalaria havanensis is found in slow-moving or still waters often of a temporary nature. $B$. havanensis ranges from Mexico northward throughout southern, central, north central, and the middle Coastal Plain of Texas (Fullington 1978). 
TABLE $37-7$

Gastropod Taxa Frequencies by Level, TARL Square 12

\begin{tabular}{|c|c|c|c|c|c|c|c|c|c|c|c|c|c|c|c|c|c|c|c|c|c|c|c|c|c|}
\hline & \multicolumn{15}{|c|}{ Terrestrial } & \multicolumn{10}{|c|}{ Freshwater } \\
\hline & 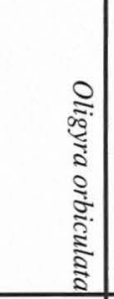 & 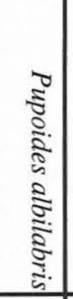 & 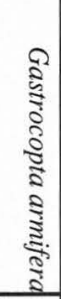 & 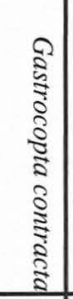 & 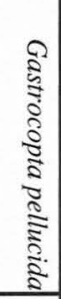 & 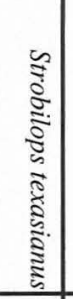 & 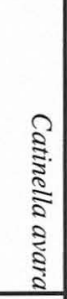 & 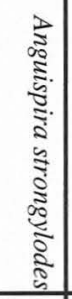 & 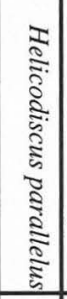 & 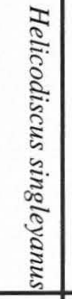 & 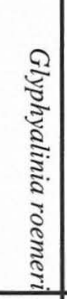 & 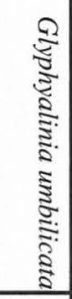 & 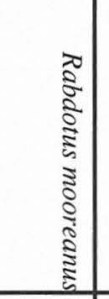 & 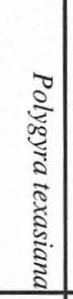 & 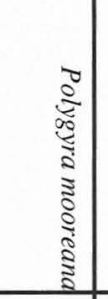 & 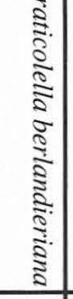 & 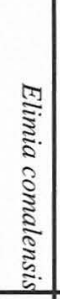 & 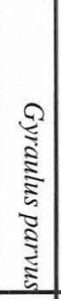 & 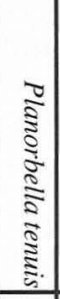 & $\begin{array}{c}1 \\
0 \\
\vdots \\
\vdots \\
\vdots \\
\vdots \\
\vdots \\
\vdots \\
\vdots \\
\end{array}$ & 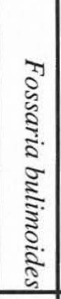 & 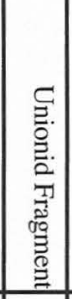 & 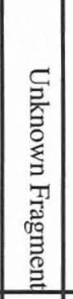 & 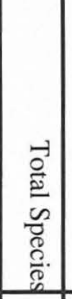 & 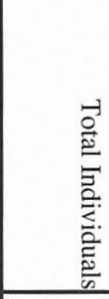 \\
\hline $\begin{array}{l}\text { Fill/Unit IIIc: } \\
\text { Level } 2 / 3 \\
\end{array}$ & $21+5$ & & & & & & & & & & & & $1+4$ & & $7+3$ & & & & & & & & & 3 & $29+12$ \\
\hline $\begin{array}{l}\text { Unit IIIc: } \\
\text { Level } 4 \\
\text { Level } 5 \\
\end{array}$ & $\begin{array}{l}15+4 \\
40+5 \\
\end{array}$ & & & $\begin{array}{r}2 \\
2+1 \\
\end{array}$ & & $\begin{array}{r}2+1 \\
1 \\
\end{array}$ & & & & & & $\begin{array}{l}0+1 \\
2+1 \\
\end{array}$ & $\begin{array}{l}4+7 \\
7+6 \\
\end{array}$ & & $\begin{array}{l}14+8 \\
12+2 \\
\end{array}$ & 2 & & & & & & & & $\begin{array}{l}7 \\
6 \\
\end{array}$ & $\begin{array}{l}39+21 \\
64+15 \\
\end{array}$ \\
\hline $\begin{array}{l}\text { Unit IIIb/c: } \\
\text { Level } 6 \\
\text { Level } 7 \\
\end{array}$ & $\begin{array}{r}66+5 \\
110+13 \\
\end{array}$ & 1 & & 1 & & & & & & & & & $\begin{array}{l}6+2 \\
4+9 \\
\end{array}$ & & $\begin{array}{l}15+4 \\
26+9 \\
\end{array}$ & $\begin{array}{l}0+1 \\
4+2 \\
\end{array}$ & & & & 1 & & 1 & & $\begin{array}{l} \\
8 \\
\end{array}$ & $\begin{array}{r}87+12 \\
148+33 \\
\end{array}$ \\
\hline $\begin{array}{c}\text { Unit IIIb: } \\
\text { Level } 8 \\
\text { Level } 9 \\
\text { Level } 10 \\
\end{array}$ & $\begin{array}{l}128+10 \\
118+12 \\
102+21 \\
\end{array}$ & & & & & & & & & 1 & 1 & 1 & $\begin{array}{r}12+4 \\
10+13 \\
7+5 \\
\end{array}$ & & $\begin{array}{r}34+13 \\
53+8 \\
29+9 \\
\end{array}$ & $\begin{array}{r}5+5 \\
1 \\
3+1 \\
\end{array}$ & & & & & & & & $\begin{array}{l}4 \\
6 \\
5 \\
\end{array}$ & \begin{tabular}{|l}
$179+32$ \\
$184+34$ \\
$142+36$ \\
\end{tabular} \\
\hline $\begin{array}{l}\text { Unit IIIa/b: } \\
\text { Level } 11 \\
\text { Level } 12 \\
\end{array}$ & $\begin{array}{l}51+14 \\
57+12 \\
\end{array}$ & $\begin{array}{l}2 \\
1 \\
\end{array}$ & & 2 & 1 & & $0+1$ & $0+1$ & & 4 & & $1+2$ & $\begin{array}{l}11+8 \\
24+2 \\
\end{array}$ & & $\begin{array}{r}19+13 \\
26+5 \\
\end{array}$ & & & & & & & & & $\begin{array}{r}10 \\
4 \\
\end{array}$ & $\begin{array}{r}91+39 \\
108+19 \\
\end{array}$ \\
\hline $\begin{array}{c}\text { Unit IIIa } \\
\text { Level } 13 \\
\text { Level } 14 \\
\text { Level } 15 \\
\text { Level } 16 \\
\text { Level } 17 \\
\text { Level } 18 \\
\text { Level } 19 \\
\end{array}$ & $\begin{array}{l}26+5 \\
30+8 \\
13+0 \\
15+4 \\
14+6 \\
20+3 \\
20+3 \\
\end{array}$ & $\begin{array}{l}1 \\
1\end{array}$ & & $\begin{array}{l}1 \\
2\end{array}$ & & & & & & $\begin{array}{r}5+1 \\
1 \\
3 \\
2 \\
3 \\
\end{array}$ & & $\begin{array}{r}0+1 \\
0+1 \\
1 \\
1 \\
1 \\
0+1\end{array}$ & $\begin{array}{r}2+7 \\
6+2 \\
6+1 \\
2+4 \\
8+3 \\
12+3 \\
5+6 \\
\end{array}$ & $\begin{array}{r}1 \\
1 \\
1 \\
2+1 \\
1+2 \\
0+1 \\
\end{array}$ & $\begin{array}{r}26+7 \\
4+3 \\
2+1 \\
6+1 \\
1 \\
1+2 \\
0+5 \\
\end{array}$ & & 1 & & & & & & & $\begin{array}{l}4 \\
5 \\
7 \\
7 \\
7 \\
7 \\
5 \\
\end{array}$ & $\begin{array}{r}54+20 \\
41+14 \\
29+3 \\
27+9 \\
30+10 \\
38+11 \\
28+15 \\
\end{array}$ \\
\hline $\begin{array}{c}\text { Unit II/IIIa: } \\
\text { Level } 20 \\
\text { Level } 21 \\
\text { Level } 22 \\
\end{array}$ & $\begin{array}{l}19+9 \\
18+5 \\
12+8 \\
\end{array}$ & $0+1$ & & & & & & & & $\begin{array}{r}2 \\
5+1 \\
4 \\
\end{array}$ & & $1+1$ & \begin{tabular}{r|}
$12+4$ \\
$8+5$ \\
$5+2$ \\
\end{tabular} & $\begin{array}{l}4+8 \\
4+6 \\
1+2 \\
\end{array}$ & $\begin{array}{r}1 \\
1+2 \\
\end{array}$ & & & & 1 & & 1 & 1 & & $\begin{array}{l}6 \\
8 \\
5 \\
\end{array}$ & $\begin{array}{l}39+21 \\
38+19 \\
23+14 \\
\end{array}$ \\
\hline $\begin{array}{l}\text { Unit II: } \\
\text { Level } 23 \\
\text { Level 24 } \\
\end{array}$ & $\begin{array}{l}11+3 \\
17+1 \\
\end{array}$ & & & & & & & & & 3 & & $0+1$ & $\begin{array}{l}1+2 \\
4+3 \\
\end{array}$ & $\begin{array}{r}3+3 \\
4 \\
\end{array}$ & $\begin{array}{r}3+2 \\
1 \\
\end{array}$ & & & & & & & & & $\begin{array}{l}5 \\
6 \\
\end{array}$ & $\begin{array}{l}18+11 \\
30+42 \\
\end{array}$ \\
\hline
\end{tabular}




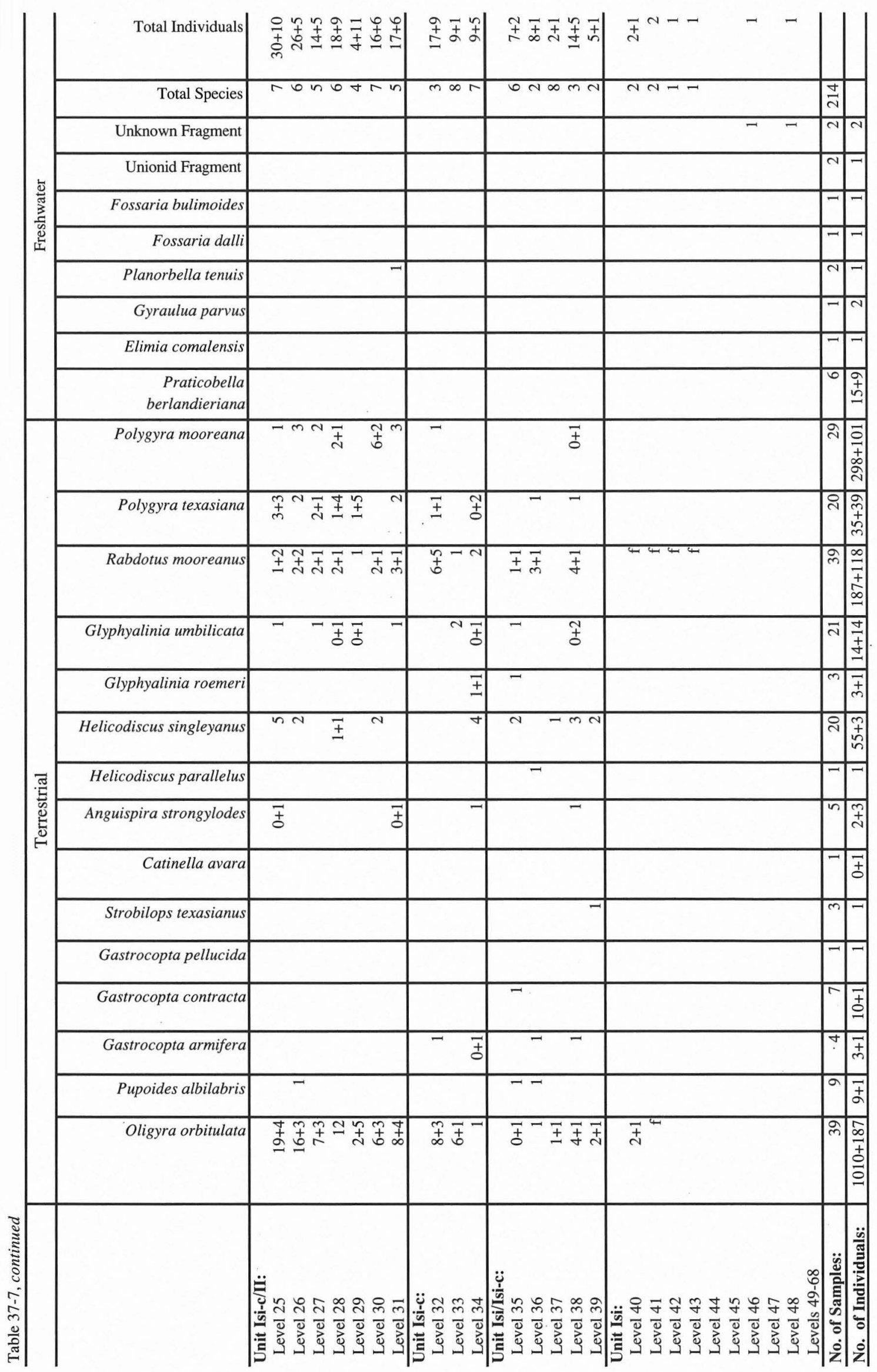


TABLE 37-8

Gastropod Taxa Frequencies by Level, TARL Square 20 (4.76 and $0.425 \mathrm{~mm}$ mesh)

\begin{tabular}{|c|c|c|c|c|c|c|c|c|c|c|c|c|c|c|c|c|c|}
\hline & & & & & & Terre & strial & & & & & & Freshy & Nater & & & \\
\hline & 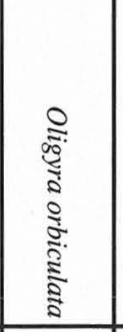 & 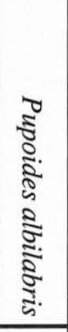 & 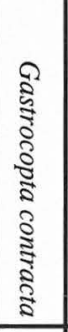 & 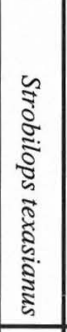 & 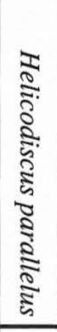 & 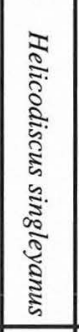 & 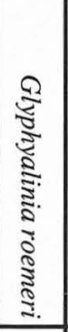 & 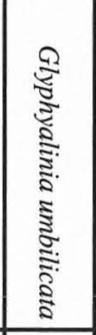 & 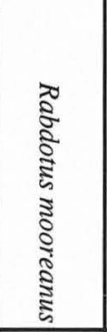 & 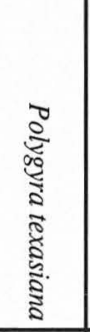 & 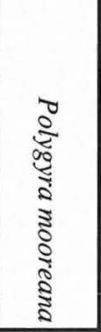 & 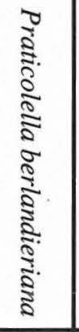 & 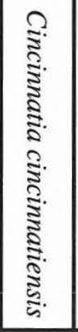 & 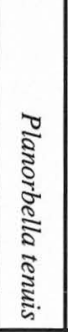 & 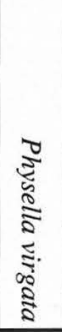 & 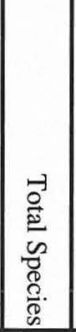 & 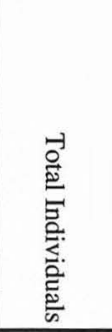 \\
\hline $\begin{array}{l}\text { Fill/Unit IIIc: } \\
\text { Level } 6\end{array}$ & $23+2$ & & & & & & & & $2+3$ & 2 & $2+3$ & & & & & 4 & $29+8$ \\
\hline $\begin{array}{l}\text { Unit IIIc: } \\
\text { Level } 7\end{array}$ & $15+5$ & & & & & & & & $2+2$ & $0+2$ & $0+2$ & & & & & 6 & $19+11$ \\
\hline $\begin{array}{l}\text { Unit IIIIb/c: } \\
\text { Level } 8 \\
\text { Level 9 } \\
\end{array}$ & $\begin{array}{l}44+2 \\
51+8 \\
\end{array}$ & 1 & $\begin{array}{l}1 \\
2 \\
\end{array}$ & 2 & & & 1 & $0+1$ & $\begin{array}{l}5+10 \\
11+4 \\
\end{array}$ & & $\begin{array}{r}12+9 \\
16+11 \\
\end{array}$ & 1 & & & & $\begin{array}{l}6 \\
7 \\
\end{array}$ & $\begin{array}{l}64+22 \\
83+23 \\
\end{array}$ \\
\hline $\begin{array}{c}\text { Unit IIIIb: } \\
\text { Level } 10 \\
\text { Level } 11 \\
\text { Level } 12 \\
\text { Level } 13 \\
\text { Level } 14 \\
\end{array}$ & $\begin{array}{r}36+5 \\
48+7 \\
52+9 \\
39+13 \\
31+2 \\
\end{array}$ & 1 & 1 & & & 1 & $0+1$ & $\begin{array}{l}1 \\
1\end{array}$ & $\begin{array}{r}4+3 \\
3+8 \\
1+8 \\
7 \\
19+3 \\
\end{array}$ & $\begin{array}{l}0+2 \\
1+8 \\
3+1 \\
0+3 \\
\end{array}$ & $\begin{array}{r}10+4 \\
18+2 \\
22+1 \\
16+2 \\
5+1 \\
\end{array}$ & \begin{tabular}{r|}
2 \\
$3+1$ \\
2 \\
$1+1$ \\
$0+1$ \\
\end{tabular} & & & & $\begin{array}{l}8 \\
5 \\
7 \\
6 \\
5 \\
\end{array}$ & $\begin{array}{l}54+15 \\
73+18 \\
80+28 \\
67+17 \\
55+10 \\
\end{array}$ \\
\hline $\begin{array}{l}\text { Unit IIIa/b: } \\
\text { Level } 15 \\
\text { Level } 16 \\
\end{array}$ & $\begin{array}{l}49+2 \\
11+3 \\
\end{array}$ & & 1 & & & & & 1 & $\begin{array}{r}-7+2 \\
1+6 \\
\end{array}$ & $\begin{array}{r}2 \\
0+4 \\
\end{array}$ & $\begin{array}{r}14+6 \\
0+2 \\
\end{array}$ & & & & & $\begin{array}{l}5 \\
5 \\
\end{array}$ & $\begin{array}{l}73+10 \\
13+15 \\
\end{array}$ \\
\hline $\begin{array}{r}\text { Unit IIIIa: } \\
\text { Level } 17 \\
\text { Level } 18 \\
\text { Level } 24 \\
\end{array}$ & $\begin{array}{l}5+0 \\
5+3 \\
4+4\end{array}$ & & & & & & $0+1$ & & $\begin{array}{r}4+3 \\
5 \\
3+4 \\
\end{array}$ & $1+1$ & $1+1$ & & & & & $\begin{array}{l}3 \\
4 \\
3\end{array}$ & $\begin{array}{r}10+4 \\
11+4 \\
8+8 \\
\end{array}$ \\
\hline $\begin{array}{l}\text { Unit II/IIIa: } \\
\text { Level } 25 \\
\text { Level } 26 \\
\text { Level } 27 \\
\text { Level } 28 \\
\end{array}$ & $\begin{array}{r}6+2 \\
7+3 \\
5+2 \\
10+4 \\
\end{array}$ & & & & & & $0+1$ & & $\begin{array}{r}5 \\
4+2 \\
2 \\
3+1 \\
\end{array}$ & $\begin{array}{l}2+2 \\
0+2 \\
\\
0+1\end{array}$ & $\begin{array}{r}0+1 \\
1 \\
0+1 \\
1\end{array}$ & & & & & $\begin{array}{l}4 \\
5 \\
3 \\
4\end{array}$ & $\begin{array}{r}13+5 \\
12+8 \\
7+3 \\
14+6 \\
\end{array}$ \\
\hline $\begin{array}{l}\text { Unit II: } \\
\text { Level } 29 \\
\text { Level } 30 \\
\text { Level } 31 \\
\text { Level } 32 \\
\text { Level } 33 \\
\text { Level } 34 \\
\text { Level } 35 \\
\text { Level } 36 \\
\text { Level } 37 \\
\end{array}$ & $\begin{array}{r}16+5 \\
15+7 \\
8+4 \\
12 \\
10+3 \\
9+3 \\
13+1 \\
2+2\end{array}$ & & & & & & & $\begin{array}{r}1+1 \\
\\
3+1 \\
1 \\
1+1 \\
\end{array}$ & $\begin{array}{r}6+2 \\
3+1 \\
2 \\
3+1 \\
3+2 \\
4 \\
3+1 \\
2 \\
2+3 \\
\end{array}$ & $\begin{array}{l}1+1 \\
1+2 \\
\\
0+1 \\
4+1 \\
0+1\end{array}$ & 1 & & & 2 & & $\begin{array}{l}5 \\
4 \\
2 \\
4 \\
4 \\
4 \\
4 \\
3 \\
2 \\
\end{array}$ & $\begin{array}{r}25+9 \\
21+10 \\
10+4 \\
16+2 \\
18+6 \\
16+5 \\
19+2 \\
5+2 \\
3+4 \\
\end{array}$ \\
\hline $\begin{array}{l}\text { Unit Isi-c/II: } \\
\text { Level } 38\end{array}$ & 3 & & & & & & & 1 & $3+3$ & $1+1$ & & & & & & 4 & $8+4$ \\
\hline $\begin{array}{c}\text { Unit Isi-c: } \\
\text { Level } 39 \\
\text { Level } 40 \\
\text { Level } 41 \\
\text { Level } 42 \\
\text { Level } 43 \\
\end{array}$ & $\begin{array}{r}3 \\
2+1 \\
0+1 \\
2+1 \\
2 \\
\end{array}$ & & $\begin{array}{l}3 \\
2 \\
4\end{array}$ & & & $\begin{array}{r}2 \\
9+3 \\
2 \\
2\end{array}$ & & $\begin{array}{l}0+2 \\
2+1 \\
1+3 \\
0+1\end{array}$ & $\begin{array}{r}4+7 \\
4+3 \\
\mathrm{f} \\
\mathrm{f} \\
\mathrm{f} \\
\end{array}$ & $\begin{array}{r}2+5 \\
2 \\
2+1 \\
3+3 \\
\mathrm{f} \\
\end{array}$ & $\begin{array}{r}2 \\
0+1 \\
2 \\
1\end{array}$ & & 1 & 1 & 1 & $\begin{array}{l}8 \\
8 \\
7 \\
8 \\
3 \\
\end{array}$ & $\begin{array}{r}15+14 \\
23+9 \\
10+5 \\
14+5 \\
4 \\
\end{array}$ \\
\hline $\begin{array}{c}\text { Icl/Isi-c: } \\
\text { Level } 44 \\
\text { Level } 45 \\
\text { Level } 46 \\
\end{array}$ & $\mathrm{f}$ & & & & & & & & f & & & & & & & $\begin{array}{l}1 \\
1 \\
1\end{array}$ & $\begin{array}{l}1 \\
1 \\
1\end{array}$ \\
\hline $\begin{array}{l}\text { Unit Icl: } \\
\text { Level 48 } \\
\text { Level 49 } \\
\text { Level 50 } \\
\text { Level 51 } \\
\text { Levels 52-73 } \\
\end{array}$ & 1 & & & & & & & & f & & & & & & & 1 & 1 \\
\hline No. of Samples: & 33 & 2 & 7 & & & \begin{tabular}{|l|}
5 \\
\end{tabular} & 4 & 15 & 30 & 22 & 24 & 의 & 1 & 4 & 2 & 38 & \\
\hline No. of Individuals: & $540+104$ & 2 & 14 & 2 & & $16+3$ & $1+3$ & $15+11$ & $133+82$ & $28+42$ & $127+47$ & $9+3$ & 1 & 6 & 2 & & $897+295$ \\
\hline
\end{tabular}


TABLE 37-9

Gastropod Taxa Frequencies for Selected Features (from TARL excavation; 1.5 liter sample, 4.76 and 0.424 mm mesh)

\begin{tabular}{|c|c|c|c|c|c|c|c|c|c|c|}
\hline & 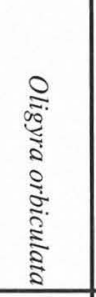 & 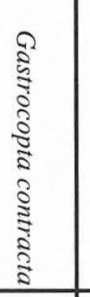 & 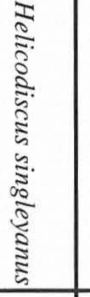 & 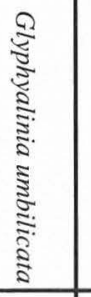 & 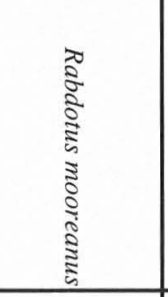 & 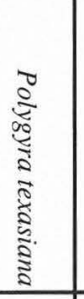 & 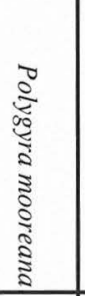 & 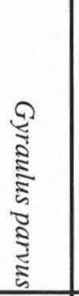 & 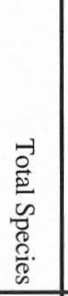 & 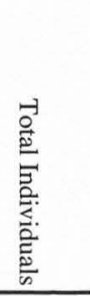 \\
\hline \multicolumn{11}{|l|}{ Unit IIIa/II: } \\
\hline Feature 231, Lot 1648 (Square 52, Level 24) & $9+5 *$ & & $3+0$ & $1+1$ & $5+1+2+10^{* *}$ & & $1+1$ & & 5 & $19+20$ \\
\hline Feature 231, Lot 1744 (Square 52, Level 25) & $4+2$ & & $1+0$ & & $3+0+0+0$ & & $3+2$ & & 4 & $11+4$ \\
\hline Feature 231, Lot 1354 (Square 38, Level 23) & $12+4$ & & & $0+1$ & $1+1+6+5$ & $3+4$ & & $1+0$ & 5 & $17+21$ \\
\hline Feature 245, Lot 1462 (Square 52, Level 24) & $11+6$ & & $1+0$ & & $3+0+3+5$ & & $0+1$ & & 4 & $15+15$ \\
\hline Feature 245, Lot 1488 (Square 28, Level 24) & $5+0$ & & & & $2+0+1+2$ & & $0+1$ & & 3 & $7+4$ \\
\hline Feature 245, Lot 1579 (Square 28, Level 25) & $1+2$ & & $2+0$ & & $1+0+1+3$ & & $1+0$ & & 4 & $5+6$ \\
\hline \multicolumn{11}{|l|}{ Unit Isi-c: } \\
\hline No. of Samples: & 6 & 1 & 4 & 2 & 6 & 1 & 5 & 1 & 7 & \\
\hline No. of Individuals: & $42+19$ & $1+0$ & $7+0$ & $1+2$ & $15+2+13+15$ & $3+4$ & $5+5$ & $1+0$ & & $75+70$ \\
\hline
\end{tabular}

TABLE 37-10

Gastropod Taxa Frequencies in Burned Rock Midden 1 (TARL Square 100; 4.76 and 0.425 mm mesh)

\begin{tabular}{|c|c|c|c|c|c|c|c|c|c|c|c|c|}
\hline & 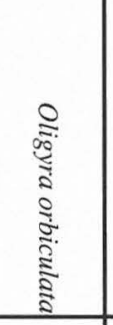 & 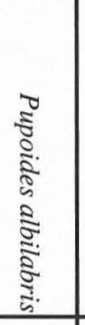 & 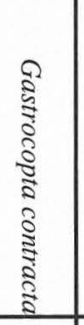 & 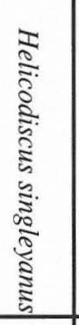 & 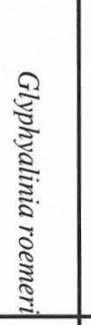 & 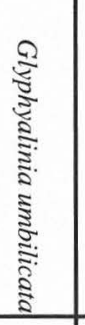 & 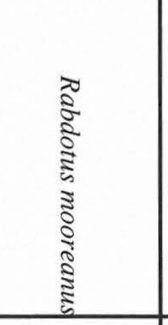 & 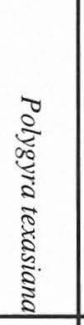 & 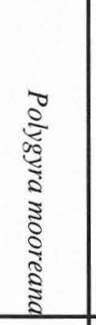 & 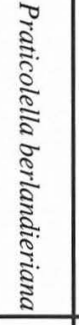 & 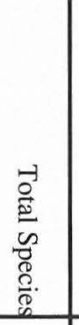 & 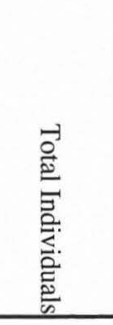 \\
\hline Unit IIIc: & & & & & & & & & & & & \\
\hline Lot 1308, Level 5 & $16+11 *$ & $1+0$ & $1+0$ & $1+0$ & $1+2$ & $1+0$ & $2+2+5+3 * *$ & & $11+5$ & & 8 & $34+28$ \\
\hline Lot 1353, Level 6 & $28+9$ & & $1+0$ & $1+0$ & & & $3+2+0+2$ & & $10+7$ & & 5 & $43+20$ \\
\hline Lot 1384, Level 7 & $15+6$ & & & & $0+1$ & & $3+0+4+4$ & & $2+4$ & $1+0$ & 5 & $21+19$ \\
\hline Lot 1422, Level 8 & $13+8$ & & & & $2+0$ & & $4+1+0+7$ & $1+0$ & $7+4$ & & 5 & $27+20$ \\
\hline Lot 1501, Level 9 & $11+1$ & & & & & & $3+2+8+3$ & $2+3$ & $2+0$ & & 4 & $18+17$ \\
\hline Lot 1563, Level 10 & $11+5$ & $1+0$ & & $2+0$ & $1+1$ & & $5+2+4+7$ & $0+1$ & $4+1$ & & 7 & $24+21$ \\
\hline No. of Samples: & 6 & 2 & 2 & 3 & 4 & 1 & 6 & 3 & 6 & 1 & 6 & \\
\hline No. of Individuals: & $90+40$ & $2+0$ & $2+0$ & $4+0$ & $4+4$ & $1+0$ & $20+9+21+26$ & $3+4$ & $36+21$ & $1+0$ & & $167+125$ \\
\hline
\end{tabular}

Gyraulus parvus is generally found in spring- or seepfed streams or pools with some aquatic vegetation. G. parvus ranges throughout most of North America (Taylor 1960).

Helisoma anceps is most often found in clear, springfed waters on limestone bedrock or gravel substrates. $H$. anceps ranges over North America from Canada southward to Georgia, Texas, and northeastern Mexico (Clarke 1981).

Planorbella tenuis is found in slow-moving or quiet waters, occasionally in temporary waters. $P$. tenuis ranges over the southwestern United States and southward into Mexico (Fullington 1978).
Fossaria bulimoides is generally found in still-water areas, most frequently in temporary ponds. F. bulimoides ranges from Alabama to southern California and southward into Mexico (Baker 1911).

Fossaria parva generally occurs in marshes, mud flats, lake shores, and the terrestrial margins of these plants (Clarke 1981). F. parva is known from Connecticut to Alberta southward to Maryland, Oklahoma, and Arizona (Burch 1982).

Fossaria dalli is found in moist vegetation around or in shallow ponds and streams (Baker 1911). F. dalli ranges 
from Ohio to Montana, southward to Texas and Arizona (Baker 1928; Fullington 1978).

Physella virgata is found in slow-moving margins of streams or in ponded areas. $P$. virgata ranges from southern California and Kansas, southward through Texas and into Mexico (Hibbard and Taylor 1966).

\section{Discussion}

\section{Environmental Indicator Species}

Although any species represented in a fossil assemblage can be used to reconstruct the environmental conditions for a particular strata, many species have such wideranging habitat requirements that no meaningful habitat reconstruction can be accomplished. For this reason, certain species with specific habitat limitations are preferentially used to reconstruct ecological conditions of the past. These indicator species for the Wilson-Leonard site include both terrestrial and freshwater gastropods as well as freshwater mussels.

Two terrestrial gastropods that are rare or no longer present in the vicinity of the Wilson-Leonard site provide significant clues to the paleoenvironments of this area. Gastrocopta armifera is usually found in wooded habitats with significant amounts of leaf litter and downed wood (Neck 1984a). G. armifera is found living no closer to the Wilson-Leonard site today than the Panhandle and north central Texas. Four examples of this species were recovered from excavation Square E28/S78 (the fine-screened unit) from stratigraphic Unit II (see Table 37-2), and four specimens of this species were found in TARL Square 12 in the lower stratigraphic Units Isi-c and Isi /Isi-c (see Table 37-7).

A second species that is particularly rare in the area of Wilson-Leonard is Glyphyalinia roemeri, which is found in spring mounds, caves, and other hygric epigean or hypogean habitats (Reddell 1965, 1970). Glyphyalinia roemeri is rare to absent in the drainage of Brushy Creek today. This species has been reported as rare from surface sites in central Texas (Neck 1994) but abundant in a sinkhole used as a human burial shaft (Bement 1994). In the Wilson-Leonard assemblage, $G$. roemeri was recovered from stratigraphic Unit IIIc down to Isi /Isi-c (see Tables 37-2, 37-7, 37-8), but it is slightly more frequent in the lower strata. This species may have been introduced in the Wilson-Leonard deposits during overbank flooding because of its spring or watersource habitats.

Carychium mexicanum is found in very mesic woodlands and marsh margins. In Bell County, Neck found $C$. mexicanum in rock-bottomed creeks with leaf litter and overhanging trees to provide shade. This latter habitat type does not appear likely to have occurred in the vicinity of the Wilson-Leonard site; thick exposures of a limestone block with deeply dissected creeks would be required. The only specimens of this species recovered were from TxDOT Square
E20/S78 from stratigraphic Unit Isi-c/Id (see Table 37-3) and TARL Features 236 (Unit Id/II) and 255 (Unit Isi-c).

Of the significant freshwater snails, the three species that are most useful for paleoenvironmental reconstruction indicate aquatic environments of somewhat different characteristics from that of modern Brushy Creek. Elimia comalensis indicates a spring-fed stream with water temperatures that remain cool even during the hottest summer weather. E. comalensis is very rare in the Wilson-Leonard assemblage with one specimen from TxDOT Square E22/S78 in stratigraphic Unit Id/II (see Table 37-6) and one specimen from TARL Square 12 in stratigraphic Unit IIIa (see Table 37 7). The occurrence of Cincinnatia cincinnatiensis and Fossaria dalli indicate the perennial occurrence of shallow, nonstagnant water.

Other environmental reconstructions can be made from the terrestrial gastropod species present in these assemblages. Two species (Strobilops texasiana and Praticolella berlandieriana) are present only or are more abundant in the upper layers of these sediments. S. texasiana and $P$. berlandieriana are primarily found in stratigraphic Units IIIc and IIIb although several specimens of $S$. texasiana were also recovered in Units II, Id, and Isi-c, and one specimen of $P$. berlandieriana was recovered in Unit Isi-c (see Tables 37-2 through 37-10). S. texasiana is an indicator of well-developed woodlands, but another floodplain woodland indicator, Anguispira strongylodes, is more abundant in the lower levels (but still lives in the area today). This species was found in stratigraphic Units IIIb/IIIa to Isi (see Tables 37-2, 37-5, 37-7). The differences in relative occurrences of these woodland species indicate that the woodlands at the site have become progressively more xeric through time.

The restriction of Praticolella berlandieriana to the upper layers had not been observed in the analysis of archeological assemblages from other sites in central Texas. $P$. berlandieriana today is rarely found in dense concentrations except in disturbed habitats and especially those that have artificial cover in the form of lumber or trash piles. Analysis of additional sites will be required to determine if $P$. berlandieriana is a late arrival (i.e., mid-Holocene) species in central Texas.

Rumina decollata is present only in the uppermost levels, because it is an introduced species that has been present in the Brushy Creek drainage only in historic times. $R$. decollata could contaminate buried archeological deposits (Neck 1981a), because this species is able to burrow into the soil. However, the occurrence of $R$. decollata in only the top level of the Wilson-Leonard site (Level 1 in Square E28/S78 [see Table 37-2]) and at other archeological sites (Neck, unpublished data) indicates that $R$. decollata is unlikely to contaminate buried archeological deposits.

Whereas the above discussions have indicated significant changes in the environment around the WilsonLeonard site, another analysis indicates that some stability 
has occurred during this period of change. One of the dominant species of terrestrial gastropods in these samples is Polygyra mooreana, which is common or at least present in nearly all levels. Less abundant and generally found more in the lower sediments is the related Polygyra texasiana (found most commonly in stratigraphic Units IIIa, IIIb, II, and Isi-c [see Tables 37-2, 37-3, 37-7, 37-8]). Polygyra mooreana is usually found in upland open woodlands on calcareous substrates, whereas P. texasiana is most often found in moremesic woodlands especially those associated with creeks and rivers. The continued presence of $P$. mooreana even in the lower sediments (where $P$. texasiana is more abundant) indicates that the more developed riparian woodlands present during the early Holocene were restricted to a narrow gallery along the stream and did not extend laterally and upward in elevation into the surrounding uplands.

\section{Habitat Variations Through Time}

The distribution of gastropod shells from the two TARL unit columns (see Tables 37-7 and 37-8) indicates a change in habitat types in the area immediately surrounding the Wilson-Leonard site during the last 10,000 years. The lowermost portion of Square 12 (stratigraphic Unit Isi and below [Levels 49-68 in Table 37-7]) contains no molluscan shell material and is overlain by a series of samples (Unit Isi [Levels 40-48]) that contain very little shell material, much of which is fragmentary in nature. No environmental reconstruction is possible for these strata. The paucity of shell material in the lower deposits of the site may be due to either lack of shells in original deposits (which is probable given the comparatively higher rates of deposition) or diagenetic dissolution of shell material due to significant carbonate mobility (see also Chapter 29). The first levels with significant numbers of shells (Units Isi-c through Isi/Isi-c [Levels 32-39]) indicate the presence of a woodland community with significant downed wood material and relatively high soil moisture levels. Above these deposits (Units II/IIIa through Isi-c/II [Levels 20-31]) are gastropod samples that indicate a period during which an open woodland to savanna occupied the Wilson-Leonard site area. A return of a closed woodland is indicated in stratigraphic Units IIIa/b through IIIa (Levels 11-19). The uppermost samples in Square 12, coming from stratigraphic Units IIIc and IIIb (Levels 0-10), reflect a more open habitat (savanna to prairie) that includes a period of moderate to drastic disturbance of the natural molluscan fauna.

The samples from Square 20 (see Table 37-8) reveal a parallel pattern to Square 12 in degree of available information (amount of shell material present) and indicated degree of woody plant cover at this site. At the bottom of the Square 20 column, no shell is present in stratigraphic Units Icl through Igl (Levels 52-73) and very little shell, usually in fragmentary condition, is present in Units Icl to Icl/Isi-c (Levels 44-51). Above these strata are samples from Unit Isi-c (Levels 39-
43) that indicate a period when a diverse, closed woodland occupied the area. During the periods represented by stratigraphic Units IIIa/b through Isi-c/II (Levels 15-38), a period of open woodland is indicated. Alternatively, the shells present in these levels could be interpreted as a closed woodland that experienced scouring floods that removed much of the understory and downed wood that would normally accumulate through time and provide cover for terrestrial gastropods. This latter hypothesis is supported by the particular indication of environmental disturbance in Levels 26 and 27. Above this in stratigraphic Units IIIIc and IIIb (Levels 714), the molluscan remains indicate the existence of a closed woodland with a diverse community present. The species found in the top of Unit IIIc (Level 6) indicate an open woodland.

The similar pattern of variation of community types indicated in TARL Squares 12 and 20 are most likely due to the continuum nature of the environment between these two columns. Comparison of the radiocarbon dates available for these two columns provides the method of time analysis on environmental variation in the area surrounding the WilsonLeonard site.

\section{Gastropods from Burned Rock Midden 1}

As previously noted, two series of gastropod samples were collected from Burned Rock Midden 1. The first series was collected from TxDOT Square E22 2 S88 (see Tables 37-4 and 37-6) and the second series from TARL Square 100 (see Table 37-10). Although sample size and recovery methods differ considerably for the two series, both are dominated by three terrestrial taxa. Most abundant are Oligyra orbiculata, Polygyra mooreana, and Rabdotus mooreanus (see Tables 37-4 and 37-10). Both O. orbiculata and P. mooreana are typically found in rocky habitats and generally oviposit underneath or at the margins of rocks lying on soil. R. mooreanus oviposits in soil although rocks may be present.

All three of the above species were utilizing the burned rock midden for cover and oviposition. The occurrence of all sizes (age classes) of Oligyra orbiculata and Polygyra mooreana indicates that an abandoned burned rock midden is very suitable as a microhabitat for all life stages of these species. These middens are suitable for adults and for successful oviposition and hatching of Rabdotus mooreanus. However, the number of hatchling $R$. mooreanus (in relation to number of adults) in these samples indicates that these middens eventually become too dry to maintain living hatchlings of this species. Praticolella berlandieriana is represented by all size classes of shells including the "winter resting stage" shells with a partially reflected lip. Apparently, dry winter weather was particularly harsh for survival of $P$. berlandieriana.

Rabdotus mooreanus was much more common in the samples from the burned rock midden than in a paired column in an area without a cultural feature (although the area 
was certainly utilized by the human inhabitants of the site). Thus, the "background level" of $R$. mooreanus was rather low, as it often is in natural habitats today. $R$. mooreanus and the other species in these midden deposits were attracted to remnant organic materials and were able to reproduce during periods when the deposits were not being utilized as a cooking area.

\section{Cultural Utilization}

Utilization of various species of Rabdotus as food has been discussed (Clark 1973, 1976; Hester and Hill 1975) and undoubtedly did occur (Deisler 1986; Neck 1981b, 1994) at times in southern and Central Texas. However, the pattern of occurrence of Rabdotus mooreanus at the Wilson-Leonard site indicates that this snail was not a prime food item of the inhabitants of this site. Some of the R. mooreanus shells in the burned rock midden (see Table 37-10) are rather large for this species, but young shells are common. In addition, shells of R. mooreanus from nonmidden samples (see Tables 37-7, $37-8$, and 37-9) include shells that are just as large. Shells of $R$. mooreanus from the midden samples are encrusted with a soil/ash mixture, but they are not charred. The majority, and possibly all, of the $R$. mooreanus shells at the WilsonLeonard site can be explained most easily as the reaction of living snails to the periodic occurrence of enhanced levels of organic material in these burned rock middens.

\section{Taphonomy of Shells}

Many of the shells recovered from the Wilson-Leonard site are broken or fragmented, although one assumes that all shells originally were complete. Some breakage is due to compaction of rocky strata and probably direct compaction by human feet. If the rocks in these burned rock middens were dug out prior to re-use of the area for plant processing, shells could easily have been broken.

Considering the large number of shells recovered at this site, remarkably few were burned. In samples with burned specimens, only a few out of many were burned. Burning, therefore, appears to have been an "accident." When the burned rock midden area was being used as a plant processing center, heat from above could char shells in lower levels. This effect would also explain the reduced number of shells in the lowermost levels.

Samples from various depths below the surface also allowed observation of another taphonomic process. Shells from upper levels were often empty; whatever soil material was present in the shell when it was in the soil had been removed during the sorting and washing process. Shells from a somewhat lower depth were filled with hard-packed soil particles. Farther down, shells contained calcareous deposits on their inner surfaces or packed soil cemented with carbonate material. The lowermost levels contained fossil remains with some shell material missing, revealing internal molds (steinkerns). As these steinkerns were only partially indurated, further removal of shell material left a weak steinkern which then disintegrated or crumbled to smaller pieces which would not be recognizable as a fossil.

\section{Summary}

Paleomolluscan assemblages recovered from the Wilson-Leonard site contain a diverse fauna of terrestrial and freshwater gastropods. Significant changes in the microhabitats available for mollusks have occurred during the period represented by the investigated samples. Several terrestrial species indicate that soil moisture was much greater during the time of deposition of the lower samples. Freshwater gastropods indicate water resources that were more stable in time and larger in size. Substrates included exposed limestone as well as soft material (i.e., mud) and spring flow was perennial. Marshes and well-developed woodlands were present. However, the woodlands were only gallery forests along Brushy Creek and did not extend into the uplands (which were prairie or savannas). The most important changes revealed in the biotic community through time involve several cycles of variation in the density of individuals and the overall structure of the plant community itself (i.e., alternating open and closed habitats as reflected in the amount and density of woody vegetation). Occurrence of species-presence changes through time are likely to have been of much less significance than the variations in community structure and density.

Terrestrial gastropods are well represented in the burned rock midden samples. The most abundant species are typically associated with rocky soils and/or very open habitats. Whereas some archeological sites contain evidence to indicate that Rabdotus mooreanus was consumed by the aboriginal inhabitants, no such evidence is present at the Wilson-Leonard site.

Most shells were well preserved although a large number were broken. The few shells that were charred were probably heated when the burned rock midden was being utilized. Shells from upper levels are filled with the appropriate soil matrix. Middle samples contain shells with internal calcium carbonate incrustations. Lower samples contain shells with slightly indurated soil matrix. In the lowermost samples, shell material has been partially dissolved and weakly indurated steinkerns are being formed.

\section{PALEOENVIRONMENTALINTERPRETATION FROMGASTROPODS RECOVERED FROMFEATURES}

by James L. Theler

Mollusk shells are abundant in many Quaternary deposits on the Plains, where they have been used by researchers since the early part of the twentieth century as proxy indicators of past environmental conditions. The use 
of subfossil snail assemblages to characterize certain components of paleoenvironments involves the assumption that a species habitat preference has remained constant through time. Researchers working with subfossil gastropods generally agree that the factors exerting the greatest influence on the distribution and abundance of gastropod communities on the Plains during the Quaternary are temperature and moisture. Habitat and range distribution data from living gastropod species are used as a source of proxy information to interpret subfossils of the same species in the reconstruction of paleoenvironments. The available data on living snail taxa are sometimes limited, a factor that can dilute the potential interpretation in environmental reconstructions.

\section{Methods}

Gastropod shells were recovered from 12 sediment samples from separate excavated features in the Paleoindian and Archaic components at the Wilson-Leonard site. Sediment samples were dried, their volume measured and then water screened with material larger than $.425 \mathrm{~mm}$ retained in a Tyler \#40 geologic sieve. One of the samples (from Burned Rock Midden 1) measured 0.8 liter in volume while the remainder measured 1.0 liter. All complete and potentially identifiable shell fragments were isolated from water-screened residue under a low-power (10X) binocular microscope. The gastropod shells were sorted to taxon using standard reference guides. Following identification, shells were counted, catalogued by taxa, and stored in glass vials containing individual labels with pertinent taxonomy and provenience information.

\section{Results}

The 12 matrix samples from the Wilson-Leonard features with a total sediment volume of 11.8 liters, produced 3,311 individual gastropods or an average of approximately 281 individuals/liter (ind/l). The range was 36 ind/l in Feature 255 to $668 \mathrm{ind} / 1$ in Feature 206. A minimum of 20 terrestrial and 5 aquatic taxa are represented, with the terrestrial snails accounting for $99 \%(3,274$ of 3,311$)$ of all individuals.

Eleven of the samples are from burned rock clusters or burned rock basins dating from ca. 10,000 B.P. to 2000 B.P. (see Chapter 26). The twelfth sample, which is from Burned Rock Midden 1, complements the samples analyzed by Neck (see above) from lower levels of this feature. Burned Rock Midden 1 is assignable to the Middle and Late Archaic periods (dating from ca. 4000 to 1000 B.P.).

The majority of the snails from these features are terrestrial taxa, and although at least 20 taxa are represented, 6 taxa comprise $93 \%$ of the identifiable terrestrial snails. The 12 samples contained 2,676 identifiable terrestrial snails, with the 598 specifically unidentified shells of juveniles excluded from the current calculations. The most abundant species in the samples was Hawaiia minuscula with 797 individuals representing $29.8 \%$ of the total (Table $37-11$ ). Next in abundance were 01igyra orbiculata with $742(27.7 \%)$ individuals, Rabdotus with 528 (19.7\%) individuals, Polygyra mooreana and juvenile Polygyra combined to equal 224 (8.4\%) individuals, followed by Gastrocopta pellucida with $128(4.8 \%)$ individuals, and Gastrocopta contracta with 66 individuals or $2.5 \%$ of the total identifiable specimens.

While these six taxa contribute most of the identifiable specimens at Wilson-Leonard, their sheer numbers offer little useful information as proxy indicators of past environmental conditions. It is useful here to evaluate trends in species through time by comparing the raw numbers obtained from the 11 constant volume (1-liter) samples (see Table 37-11).

An initial difference is apparent in the distribution of aquatic and terrestrial snails. It will be recalled that these features span the period ca. 10,000 to 2000 B.P. The 37 aquatic snail shells were recovered in low density from the earliest seven samples. These samples date from ca. 9990 B.P. (Feature 255) to ca. 8000 B.P. (Feature 224). The most interesting species in the aquatic assemblage is Phreatodrobia nugax nugax. P. n. nugax was found in four feature samples with a total of eight individuals represented. P. n. nugax is a minute $(<2 \mathrm{~mm})$, fragile, colorless hydrobiid species that inhabits the deep artesian waters of the Edwards (Balcones Fault Zone) Aquifer. This species is a member of the troglobitic biota that is sometimes expelled from the deep artesian zone with other Balcones ground water fauna. This species was first described from stream drift shells and has only recently been recovered living from artesian wells (Hershler and Longley 1986:127).

Other Wilson-Leonard aquatic gastropods include Fossaria dalli and juveniles of the genera Physella, Gyraulus, and Planorbella. These four taxa are typically found in shallow-water pools having aquatic vegetation rooted in a soft substrate, and it is open to interpretation how they came to be present in these features. The tiny aquatic snail shells recovered at the site are difficult to see with the unaided eye, and it may be assumed that they are present as individuals deposited with sediment/flotsam detritus on the site's surface (although it is possible that at least some relate to human activity).

Phreatodrobia nugax nugax probably entered the Brushy Creek drainage somewhere upstream through a spring "pipe." Springs may have produced marsh conditions that would have supported the other aquatic taxa. Some terrestrial species such as Carychium mexicanum and Punctum vitreum may owe their origins in the early levels of the site to overbank deposition.

A number of significant shifts occur in the land snail component of the assemblage when viewed from our 11 samples. In Texas, Oligyra orbiculata occurs "in localized colonies, usually on limestone, in deciduous or juniper woodlands. ...It is absent from grassland habitats, although it is often found in the woodland corridors along prairie streams" (Fullington and Pratt 1974:8). In the Wilson-Leonard 


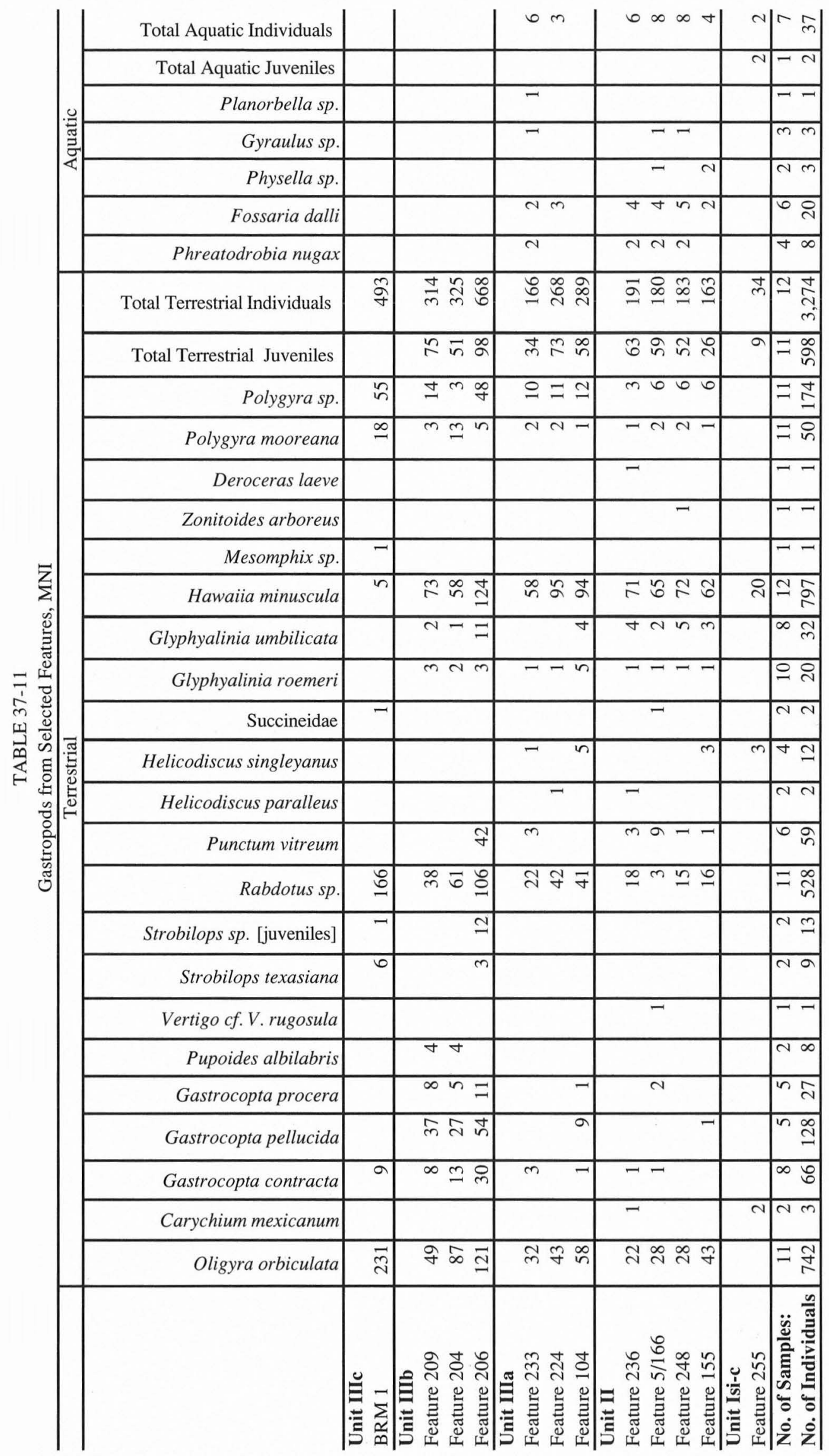


samples, $O$. orbiculata is rare in early levels, with its earliest occurrence in Feature 236 (radiocarbon dated between 10,400 and 9650 B.P.), but it increases in frequency in Units II and III (see Table 37-11). The numbers of this species seem to have increased after 4000 в.P. This parallels a general increase in Hawaiia minuscula through the sequence of sampled features. H. minuscula is a small species that can occur in some numbers in prairie or savanna settings, but it seems to achieve its greatest numbers in woodland habitats. $H$. minuscula, the most common species in the sampled feature sequence, is slightly more abundant in the post- 8000 B.P. samples.

Rabdotus is the third most abundant taxon in the Wilson-Leonard samples. Neck (see above) refers all WilsonLeonard Rabdotus to Rabdotus mooreanus, I am, however, insufficiently familiar with this taxon to separate subfossil adult and juveniles $R$. mooreanus from $R$. dealtutes. These species are considered by some to be "separate, but weakly defined species," having a sympatric range (Fullington and Pratt 1974:18). Rabdotus first appeared at 10,400-9650 в.P. but did not become abundant until ca. 8000 B.P. (Feature 224); like Oligyra orbiculata, Rabdotus became most common after 4000 в.P.

The small land snails, Gastrocopta pellucida and Gastrocopta procera, are rare members of the assemblage until after ca. 7470 в.P. (Feature 19/104), when both species show dramatic increases in abundance. These are species of xeric vegetation communities and along with Pupoides albilabris, mark local stands of prairie/savanna vegetation at the Wilson-Leonard site.

\section{Discussion and Conclusion}

Species such as Carychium mexicanum, Gastrocopta contracta, and Punctum vitreum are all taxa that prefer moist vegetation detritus. The small number of sporadically occurring individuals of these species in the earlier portion of the sequence is perhaps indicative of site alluviation as the principal mechanism of shell arrival rather than accumulations from in situ living populations. The small number of prairie/savanna species (Gastrocopta pellucida and Gastrocopta procera) may also be reasonably explained as arrivals with flotsam, washed into the Brushy Creek drainage from nearby prairie settings.

Oligyra orbiculata maintained what appears to be a stable to growing population at the Wilson-Leonard site and was perhaps associated with a riparian/gallery woodlands. This woodland habitat may have been a local response to artesian waters that were surfacing somewhere upstream of the site. The semi-arboreal habits of $O$. orbiculata perhaps aided in its persistence in this setting, as it appears to have achieved somewhat higher numbers than Rabdotus until the end of persistent overbank alluviation. Between 8000 and 4000 B.P., the Wilson-Leonard terrace became drier and shifted from a gallery woodland to a setting with a mix of woodlands and well-established stands of prairie vegetation which supported species such as Gastrocopta pellucida and Gastrocopta procera. A signaling of moister conditions on the terrace is marked by the appearance of Strobilops texasiana and Punctum vitreum and the sharp increase in a number of moisturedependent species.

\section{AN ANALYSIS OF THE FRESHWATER MOLLUSK (UNIONID) PALEOASSEMIBLAGE}

\author{
by Leslie C. Shaw
}

The excavations at the Wilson-Leonard site recovered a sample of almost 1,300 freshwater bivalve shells or shell fragments. This paleoassemblage is heavily fragmented, but 12 distinct taxa have been identified. These are all freshwater pearly mussels (unionids) that are found in Texas today. The shell remains suggest the use of mollusks as a food resource during all periods of site use. A consideration of the environmental tolerances of the species utilized provides information on the characteristics of the aquatic paleoenvironments associated with these mussels.

The 12 taxa of unionid mussels identified in the WilsonLeonard paleoassemblage are present in the rivers of Central Texas today, although Neck (personal communication to Michael Collins, 1992) reports their absence in modern Brushy Creek, the small drainage adjacent the site. Historic impacts, such as water impoundment, pollution, and increased siltation due to erosion, have adversely affected the mollusk populations in many of North America's rivers and creeks (Warren 1991) and may explain the loss of these species in Brushy Creek today.

The mussel shells from the Wilson-Leonard site were distributed widely although in low frequencies across the site and were recovered from all major strata corresponding to the multiple human occupations dating from the Paleoindian through Late Prehistoric periods. No distinct shell lenses such as have been reported for a number of other sites in Texas, especially those located on floodplains (Anthony 1994) were encountered at Wilson-Leonard.

The Wilson-Leonard mussel remains were collected either directly in situ during excavation, during dry or water screening in the field, or water flotation in the laboratory. The majority recovered during the TxDOT excavations were originally analyzed by Raymond Neck (1988), who provided species identifications. An additional small sample of TxDOT shell that had not been supplied to Neck and all the TARL sample were identified by the author. These samples have been combined for interpretations of environmental data and for discussions of the human use of unionid mollusks as a food resource.

The documentation of the data followed procedures established by Neck. All shell and shell fragments were inspected to determine genus and species whenever possible. Subform (subspecies) designations were used for only two 
genera. There is currently little known about unionids in Texas waterways, which reduces the degree to which subforms reflecting regional and/or environmental variation can be identified. In addition, the fragmentary nature of the Wilson-Leonard sample makes it difficult to go beyond species identifications. Shell fragments that could not be identified to genus, were coded as to shell portion and general shell thickness.

\section{Taxonomic Composition}

The analysis of the TxDOT and TARL mussel shell samples resulted in the identification of 12 taxa from 4 subfamilies of Unionidae (Table 37-12). In total, 183 shell or shell fragments were identified to the species level, and an additional 7 were identified only to the genus level. Provenience and identification information is given in Table 37-13, and stratigraphic associations are summmerized in Table 37-14. The following discussion of each species, which incorporates Raymond Neck's comments on the TxDOT assemblage, provides information on their environmental tolerances and their frequencies at the Wilson-Leonard site.

Anodonta grandis is a wide-ranging species which is found in a variety of aquatic habitats but tends to prefer reasonably shallow water with a sand or mud substrate (Clarke 1981; Murray and Leonard 1962). The thin shell of this genus makes it particularly fragile, which may account for its rare occurrence in Texas sites (Murray 1982, 1986). Murray (1986) has suggested that the occurrence of Anodonta only in later sites may indicate this species arrived late in the region's waterways but Neck (1993) has argued that other factors, such as the fragility of its shell, may account for its absence in earlier cultural deposits.

The three examples of this species from Wilson-Leonard were all recovered from the the upper $20 \mathrm{~cm}$ of Unit IIIc, which parallels the temporal occurrence of this genus at other Texas sites.
Arcidens confragosus is generally found in shallow, moderate to still waters in both rivers and lake environments (Murray and Leonard 1962; Parmalee 1967). A. confragosus can tolerate some variation in substrate composition but is generally found in mud to sand (with some gravel) locations.

Only two examples of $A$. confragosus were identified in the Wilson-Leonard assemblage, and these came from different and temporally separated strata (see Table 37-13). One example was from stratigraphic Unit II and the second was found in Unit IIIc.

Amblema plicata is one of three members of the subfamily Ambleminae found at the Wilson-Leonard site, and is the most common of the three in the assemblage (see Tables 37-12 and 37-13). The thick-shelled A. plicata is generally tolerant of a wide range of environmental conditions, although it tends to be restricted in waters under 5 feet (Clarke 1981; Murray and Leonard 1962; Parmalee et al. 1972). This species is commonly found in larger waterways with a variety of currents, and although it is found in the full range of substrate types, it tends to prefer a coarser substrate. This species can be the dominant species found at prehistoric sites in Texas, especially those adjacent to larger creeks and rivers (e.g., Brown 1987; Neck 1994).

This species is found in relatively moderate numbers at Wilson-Leonard with a total of 14 specimens recovered (see Tables 37-13 and 37-14). These were found in Units II/IIIa, $\mathrm{IIIa} / \mathrm{b}, \mathrm{IIIb} / \mathrm{c}$, IIIc, and Unit X in the Valley Margin.

Megalonaias nervosa is a large, thick-shelled species that inhabits larger waterways, preferring deeper water (roughly 1-5 m) and silty substrates (Murray and Leonard 1962; Parmalee 1967). It tends to be found in slow-moving waters. Although this species is widespread, it is generally rare in prehistoric sites which may reflect its low numbers in the environment (Theler 1991) or difficulty in acquiring them from deeper water parts of their habitats. This species may have increased in density in major rivers in historic times

TABLE $37-12$

Scientific and Common Names for the Freshwater Mussel Shells*, Family Unionidae

\begin{tabular}{l|l|l}
\hline Subfamily & Genus/species & Common Name \\
\hline Anodontinae & Anodonta grandis (Say 1829) & $\begin{array}{l}\text { Giant floater } \\
\text { Rock-pocketbook }\end{array}$ \\
\hline Ambleminae & Amblems confragosus (Say 1829) & Threeridge \\
& Megalonaias nervosa (Rafinesque 1820) & Washboard \\
& Pimpleback \\
& Quadrula pustulosa (I. Lea 1831) & False spike \\
\hline Pleurobemini & Uniomerus tetralasmus (Say 1831) & Pondhorn \\
\hline Lampsilinae & Lampsilis teres (Rafinesque 1820) & Yellow sandshell \\
& Lampsilis radiata (Gmelin 1791) & Eastern lampmussel \\
& Leptodea fragilis (Rafinesque 1820) & Fragile paper shell \\
& Potamilus purpuratus (Lamarck 1819) & Bleufer \\
& Toxolasma texasensis (I. Lea 1857) & Texas lilliput \\
\hline
\end{tabular}

*Following Parmalee et al. 1972; Turgeon et al. 1988; Vaught 1989. 
TABLE 37-13

Identification and Provenience of Freshwater Mollusk Remains by Excavation and Stratigraphic Unit

\begin{tabular}{|c|c|c|c|c|c|c|}
\hline Unit & Square & Level & Feature & Number & Analyzed Part & Identification \\
\hline \multicolumn{4}{|c|}{ TxDOT Excavations, Valley Floor: } & & & \\
\hline Unknown & Trench? & & & 1 & Valve fragment & Megalonaias nervosa \\
\hline IIIIc & E20、S72 & 4 & & 1 & Umbo fragment & Amblema plicata \\
\hline IIIIc & E20\S72 & 6 & & 1 & Valve fragment & Lampsilis teres \\
\hline IIIc & E20\S72 & 6 & & 1 & Valve fragment & Quadrula pustulosa mortoni \\
\hline IIIc & E20\S74 & 3 & & 1 & Valve fragment & Potamilus purpuratus, 2 holes, possibly modified \\
\hline IIIc & E20、S76 & 3 & & 1 & Fragment & Thin shell thickness \\
\hline IIIc & E20、S76 & 4 & & 1 & Hinge fragment & Potamilus purpuratus \\
\hline IIIc & E20\S78 & 3 & & 1 & Pseudocardinal & Medium shell thickness \\
\hline IIIc & E20\S78 & 4 & & 1 & Hinge fragment & Potamilus purpuratus \\
\hline IIIc & E20\S78 & 5 & & 1 & Entire valve & Amblema plicata \\
\hline IIIc & E20、S78 & 6 & & 1 & Fragment & Medium shell thickness \\
\hline IIIc & E20、S 80 & 2 & & 2 & Fragment & Medium shell thickness \\
\hline IIIc & E20NS 80 & 4 & & 2 & Fragment & Medium shell thickness \\
\hline IIIc & E20NS80 & 6 & & 1 & Fragment & Medium shell thickness \\
\hline IIIc & E20、S82 & 1 & & 1 & Hinge fragment & Anodonta grandis \\
\hline IIIc & E20、S82 & 2 & F7 & 2 & Fragment & Medium shell thickness \\
\hline IIIc & E20、S82 & 4 & & 1 & Valve fragment & Potamilus purpuratus \\
\hline IIIc & E28\S78 & 2 & & 1 & Fragment & Thin shell thickness \\
\hline IIIc & E28\S78 & 2 & & 1 & Pseudocardinal & Potamilus purpuratus \\
\hline IIIc & E28\S78 & 2 & & 1 & Hinge fragment & Medium shell thickness, burned \\
\hline IIIc & E28\S78 & 2 & & 1 & Fragment & Thick shell thickness \\
\hline IIIIc & E28\S78 & 3 & & 4 & Fragment & Medium shell thickness \\
\hline IIIc & E28\S78 & 4 & & 1 & Fragment & Medium shell thickness \\
\hline IIIc & E28\S78 & 4 & & 1 & Fragment & Medium shell thickness \\
\hline IIIc & E28\S78 & 4 & & 1 & Valve fragment & Lampsilis teres \\
\hline IIIc & E28\S78 & 5 & F173 & 12 & Fragment & Thick shell thickness \\
\hline IIIc & E28VS78 & 5 & F173 & 1 & Umbo fragment & Amblema plicata \\
\hline IIIIc & E281S78 & 6 & & 4 & Fragment & Medium shell thickness \\
\hline IIIc & E40、S70 & 2 & & 3 & Fragment & Medium shell thickness \\
\hline IIIc & E40、S70 & 3 & & 1 & Fragment & Medium shell thickness \\
\hline IIIc & E40、S70 & 5 & & 1 & Entire valve & Amblema plicata, with posterior margin removed \\
\hline IIIc & E40、S70 & 6 & & 1 & Fragment & Medium shell thickness \\
\hline $\mathrm{IIIb} / \mathrm{c}$ & E20、S72 & 8 & & 1 & Hinge fragment & Thin to medium shell thickness \\
\hline $\mathrm{IIIb} / \mathrm{c}$ & E20、S74 & 8 & & 1 & Fragment & Medium shell thickness \\
\hline $\mathrm{IIIb} / \mathrm{c}$ & E20、S78 & 7 & & 1 & Umbo fragment & Lampsilis teres \\
\hline $\mathrm{IIIb} / \mathrm{c}$ & E20\S78 & 8 & & 1 & Fragment & Medium shell thickness \\
\hline $\mathrm{IIIb} / \mathrm{c}$ & E20、S78 & $9 \mathrm{~A}$ & & 1 & Fragment & Medium shell thickness \\
\hline $\mathrm{IIIb} / \mathrm{c}$ & E20、S82 & 7 & & 1 & Umbo fragment & Megalonaias nervosa, water worn, from very large shell \\
\hline $\mathrm{IIIb} / \mathrm{c}$ & E20、S82 & 8 & & 1 & Fragment & Thin shell thickness \\
\hline $\mathrm{IIIb} / \mathrm{c}$ & $\mathrm{E} 22 \mathrm{~S} 80$ & 8 & & 1 & Fragment & Amblema plicata \\
\hline $\mathrm{IIIb} / \mathrm{c}$ & E28\S78 & 7 & & 1 & Umbo fragment & Potamilus purpuratus \\
\hline $\mathrm{IIIb} / \mathrm{c}$ & E28VS78 & 7 & & 1 & Fragment & Medium shell thickness \\
\hline $\mathrm{IIIb} / \mathrm{c}$ & E40IS70 & 7 & & 1 & Fragment & Medium shell thickness \\
\hline $\mathrm{IIIb} / \mathrm{c}$ & E40SS70 & 7 & & 1 & Umbo fragment & Lampsilis teres \\
\hline $\mathrm{IIIb} / \mathrm{c}$ & E40SS70 & 8 & & 3 & Fragment & Thin shell thickness \\
\hline $\mathrm{IIIb} / \mathrm{c}$ & E40\S70 & 8 & & 4 & Fragment & Medium shell thickness \\
\hline $\mathrm{IIIb} / \mathrm{c}$ & E40、S70 & 9 & & 1 & Hinge fragment & Potamilus purpuratus \\
\hline $\mathrm{IIIb} / \mathrm{c}$ & E40\S70 & 9 & & 2 & Fragment & Medium shell thickness \\
\hline $\mathrm{IIIb} / \mathrm{c}$ & E40SS70 & 9 & & 2 & Fragment & Medium shell thickness \\
\hline IIIb & E20、S72 & $11 \mathrm{~B}$ & & 1 & Fragment & Medium to thick shell thickness \\
\hline IIIb & E20、S72 & 13B & & 1 & Fragment & Medium shell thickness \\
\hline
\end{tabular}


Table 37-13, continued

\begin{tabular}{|c|c|c|c|c|c|c|}
\hline Unit & Square & Level & Feature & Number & Analyzed Part & Identification \\
\hline $\mathrm{IIIb}$ & E20\S76 & $11 \mathrm{~A}$ & & 1 & Fragment & Medium shell thickness \\
\hline IIIb & E20\S76 & $12 \mathrm{~A}$ & & 1 & Valve fragment & Leptodea fragilis \\
\hline $\mathrm{IIIb}$ & E20\S76 & $13 \mathrm{~A}$ & & 1 & Fragment & Thin to medium shell thickness \\
\hline IIIb & E20\S76 & $13 \mathrm{~B}$ & & 1 & Fragment & Medium shell thickness \\
\hline IIIb & E20\S78 & 12 & F50 & 1 & Umbo fragment & Lampsilis teres \\
\hline IIIb & E20\S78 & $12 \mathrm{~A}$ & & 1 & Fragment & Medium shell thickness \\
\hline IIIb & E20\S78 & $12 \mathrm{~B}$ & & 1 & Fragment & Medium shell thickness \\
\hline IIIb & E20\S80 & 10 & & 1 & Valve fragment & Potamilus purpuratus \\
\hline IIIb & E20\S80 & 11 & & 1 & Fragment & Lampsilis teres \\
\hline IIIlb & E20 \S80 & 12 & & 2 & Fragment & Medium shell thickness \\
\hline IIIb & E20\S82 & 12 & & 1 & Fragment & Thin to medium shell thickness \\
\hline IIIb & E20\S82 & 12 & & 1 & Hinge fragment & Medium shell thickness \\
\hline IIIb & E20\S82 & 13 & & 1 & Valve fragment & Thick shell thickness, leached \\
\hline IIIb & E20 \S82 & 13 & & 2 & Fragment & Medium shell thickness \\
\hline IIIb & $\mathrm{E} 22 \backslash \mathrm{S} 80$ & 9 & & 1 & Fragment & Thick shell thickness, leached \\
\hline IIIb & E22\S80 & 11 & & 1 & Fragment & Medium shell thickness \\
\hline IIIb & E28\S78 & 10 & & 1 & Umbo fragment & Thin to medium shell thickness \\
\hline IIIb & E28\S78 & 11 & & 1 & Hinge fragment & Lampsilis teres \\
\hline IIIb & E28\S78 & 12 & & 1 & Fragment & Thick shell thickness \\
\hline IIIb & E28\S78 & 12 & & 3 & Fragment & Medium shell thickness \\
\hline IIIb & E28\S78 & 13 & & 1 & Fragment & Thin shell thickness \\
\hline IIIb & E40\S70 & 10 & & 3 & Fragment & Thin to medium shell thickness \\
\hline IIIb & E40\S70 & 11 & & 2 & Fragment & Medium shell thickness \\
\hline $\mathrm{IIIa} / \mathrm{b}$ & E20\S76 & 14B & & 1 & Valve fragment & Potamilus purpuratus \\
\hline IIIa/b & E20\S82 & 14 & & 1 & Fragment & Medium shell thickness, leached \\
\hline IIIa/b & E20\S82 & 14 & & 1 & Valve fragment & Potamilus purpuratus \\
\hline $\mathrm{IIIa} / \mathrm{b}$ & E22\S72 & 15 & & 1 & Fragment & Thick shell thickness \\
\hline IIIa/b & E22\S72 & $16 \mathrm{~A}$ & & 3 & Fragment & Medium shell thickness \\
\hline $\mathrm{IIIa} / \mathrm{b}$ & E22\S78 & 15 & & 1 & Fragment & Thin to medium shell thickness \\
\hline $\mathrm{IIIa} / \mathrm{b}$ & E24\S72 & 15 & & 2 & Fragment & Medium shell thickness \\
\hline IIIa/b & E24\S74 & 15 & & 1 & Fragment & Thin to medium shell thickness \\
\hline $\mathrm{IIII} / \mathrm{b}$ & E24\S76 & 15 & & 1 & Valve fragment & Lampsilis teres \\
\hline IIIa/b & E24\S78 & 15 & & 1 & Fragment & Medium to thick shell thickness \\
\hline IIIa/b & E26\576 & 15 & & 4 & Fragment & Thin to medium shell thickness \\
\hline IIIa/b & E26S78 & 15 & & 1 & Valve fragment & Amblema plicata, leached \\
\hline $\mathrm{IIIa} / \mathrm{b}$ & E28\S78 & 14 & & 1 & Umbo fragment & Lampsilis teres \\
\hline $\mathrm{III} / \mathrm{b}$ & E28\S78 & $15 \mathrm{~A}$ & & 1 & Fragment & Thin to medium shell thickness \\
\hline IIIa/b & $\mathrm{E} 40 \backslash \mathrm{S} 70$ & 12 & & 2 & Fragment & Thin to medium shell thickness \\
\hline IIIa & E20\S72 & $16 \mathrm{~A}$ & & 1 & Fragment & Thick shell thickness \\
\hline IIIa & E20\S72 & $16 \mathrm{~A}$ & & 3 & Fragment & Medium shell thickness \\
\hline IIIa & E20\S72 & $16 \mathrm{~B}$ & & 2 & Fragment & Medium shell thickness \\
\hline IIIa & E20\S72 & $17 \mathrm{~A}$ & & 1 & Umbo fragment & Lampsilis teres \\
\hline IIIa & E20\S72 & $17 \mathrm{~B}$ & & 1 & Umbo fragment & Toxolasma texasensis \\
\hline IIIa & E20\S72 & 17B & & 1 & Valve fragment & Lampsilis teres \\
\hline IIIa & E20\S72 & $18 \mathrm{~A}$ & & 5 & Valve fragment & Medium to thick shell thickness \\
\hline IIIa & E20\S72 & $18 \mathrm{~A}$ & & 1 & Valve fragment & Lampsilis teres \\
\hline IIIa & E20\S72 & $18 \mathrm{~B}$ & & 3 & Fragment & Medium shell thickness \\
\hline IIIa & E20\S72 & 19B & & 1 & Fragment & Medium shell thickness \\
\hline IIIa & E20\S74 & $15 B$ & & 7 & Fragment & Medium shell thickness \\
\hline IIIa & E20\S74 & $16 \mathrm{~A}$ & & 1 & Hinge fragment & Medium shell thickness \\
\hline IIIa & E20\S74 & $16 \mathrm{~A}$ & & 3 & Fragment & Medium shell thickness \\
\hline IIIa & E20\S74 & $16 \mathrm{~B}$ & & 4 & Fragment & Medium shell thickness \\
\hline IIIa & E20\S74 & 17B & & 1 & Hinge fragment & Medium shell thickness \\
\hline
\end{tabular}


Table 37-13, continued

\begin{tabular}{|c|c|c|c|c|c|c|}
\hline Unit & Square & Level & Feature & Number & Analyzed Part & Identification \\
\hline IIIa & E20\S74 & 17B & & 1 & Fragment & Medium shell thickness \\
\hline IIIa & E20\S74 & $18 \mathrm{~B}$ & & 1 & Fragment & Medium shell thickness \\
\hline IIIa & E20\S74 & 18B & & 1 & Umbo fragment & Lampsilis radiata hydiana \\
\hline IIIa & E20\S76 & $15 \mathrm{~A}$ & & 2 & Fragment & Thin shell thickness \\
\hline IIIIa & E20\S76 & $15 B$ & & 2 & Fragment & Medium shell thickness \\
\hline IIIa & E20\S76 & $16 \mathrm{~A}$ & & 1 & Valve fragment & Lampsilis teres \\
\hline IIIa & E20\S76 & $17 \mathrm{~B}$ & & 1 & Fragment & Medium shell thickness \\
\hline IIIa & E20\S76 & $18 \mathrm{~B}$ & & 2 & Fragment & Thin to medium shell thickness \\
\hline IIIa & E20\S78 & $15 \mathrm{~A}$ & & 3 & Fragment & Medium shell thickness \\
\hline IIIa & E20、S78 & $15 B$ & & 1 & Valve fragment & Lampsilis teres \\
\hline IIIa & E20\S78 & $16 \mathrm{~A}$ & & 2 & Fragment & Thin shell thickness \\
\hline IIIa & E20、S78 & 17B & & 1 & Valve fragment & Lampsilis teres \\
\hline IIIa & E20、S 80 & 16 & & 4 & Fragment & Medium shell thickness, 1 burned \\
\hline IIIa & E20\S82 & 16 & & 5 & Fragment & Thin to medium shell thickness \\
\hline IIIa & E22\S72 & $18 \mathrm{~A}$ & & 2 & Valve fragment & Potamilus purpuratus \\
\hline IIIa & E22\S72 & $18 \mathrm{~B}$ & & 6 & Fragment & Medium shell thickness \\
\hline IIIIa & $\mathrm{E} 22 \backslash \mathrm{S} 72$ & $19 \mathrm{~A}$ & & 4 & Fragment & Medium shell thickness \\
\hline IIIa & E22\S72 & 19B & & 2 & Fragment & Medium shell thickness \\
\hline IIIa & E22\S74 & $16 \mathrm{~B}$ & & 4 & Fragment & Thin shell thickness \\
\hline IIIa & E22\S74 & $17 \mathrm{~A}$ & & 2 & Fragment & Medium shell thickness \\
\hline IIIa & E22\S74 & 17B & & 1 & Fragment & Medium shell thickness \\
\hline IIIa & E22\S74 & $18 \mathrm{~A}$ & & 2 & Fragment & Medium shell thickness \\
\hline IIIa & E22\S74 & $18 \mathrm{~B}$ & & 1 & Valve fragment & Lampsilis teres \\
\hline IIIa & E22\S76 & $16 \mathrm{~A}$ & & 1 & Valve fragment & Medium shell thickness \\
\hline IIIa & E22\S76 & $16 \mathrm{~B}$ & & 4 & Fragment & Medium shell thickness \\
\hline IIIa & E22\S76 & $18 \mathrm{~A}$ & & 1 & Valve fragment & Lampsilis teres \\
\hline IIIa & E22\S76 & 18B & & 3 & Fragment & Thin to medium shell thickness \\
\hline IIIa & E22\S76 & $19 \mathrm{~A}$ & & 1 & Valve fragment & Lampsilis teres \\
\hline IIIa & $\mathrm{E} 22 \backslash \mathrm{S} 78$ & $17 \mathrm{~A}$ & & 4 & Fragment & Medium shell thickness \\
\hline IIIa & E22\S78 & $18 \mathrm{~A}$ & & 3 & Fragment & Medium shell thickness \\
\hline IIIa & E22\S80 & 16 & & 1 & Fragment & Thin to medium shell thickness \\
\hline IIIa & E24\S72 & $16 \mathrm{~A}$ & & 1 & Fragment & Medium shell thickness \\
\hline IIIa & E24S72 & 17B & & 1 & Valve fragment & Lampsilis teres \\
\hline IIIa & E24\S72 & $18 \mathrm{~A}$ & & 1 & Fragment & Medium shell thickness \\
\hline IIIa & E24\S72 & $18 \mathrm{~B}$ & & 1 & Valve fragment & Lampsilis teres \\
\hline IIIa & E24\S72 & $19 \mathrm{~A}$ & & 1 & Hinge fragment & Medium shell thickness \\
\hline IIIa & E24ST2 & $19 \mathrm{~A}$ & & 1 & Entire valve & Lampsilis teres \\
\hline IIIa & E24\S72 & $19 \mathrm{~A}$ & & 1 & Fragment & Medium shell thickness \\
\hline IIIa & E24\S74 & $16 \mathrm{~B}$ & & 1 & Fragment & Thin to medium shell thickness \\
\hline IIIa & E24\S74 & $17 \mathrm{~A}$ & & 3 & Fragment & Medium shell thickness \\
\hline IIIa & E24\S74 & 17B & & 1 & Fragment & Thin shell thickness \\
\hline IIIa & E24\S74 & 17B & & 2 & Fragment & Thick shell thickness \\
\hline IIIa & E24\S74 & $18 \mathrm{~A}$ & & 1 & Umbo fragment & Lampsilis teres \\
\hline IIIa & E24\S74 & $18 \mathrm{~B}$ & & 3 & Fragment & Medium shell thickness \\
\hline IIIa & E24\S74 & $19 \mathrm{~A}$ & & 1 & Fragment & Medium shell thickness \\
\hline IIIa & E24\S74 & 19B & & 1 & Fragment & Medium shell thickness \\
\hline IIIa & E24\S76 & $16 \mathrm{~A}$ & & 1 & Fragment & Thin to medium shell thickness \\
\hline IIIa & E24\S76 & $16 \mathrm{~B}$ & & 1 & Fragment & Medium shell thickness \\
\hline IIIa & E24S76 & $17 \mathrm{~A}$ & & 1 & Fragment & Medium shell thickness \\
\hline IIIa & E24\S76 & $17 \mathrm{~A}$ & & 1 & Valve fragment & Lampsilis teres \\
\hline IIIa & E24S76 & $17 \mathrm{~B}$ & & 1 & Fragment & Medium shell thickness \\
\hline IIIa & E24\S76 & $18 \mathrm{~A}$ & & 3 & Fragment & Medium to thick shell thickness \\
\hline IIIa & E24\S76 & $19 \mathrm{~A}$ & & 2 & Fragment & Medium shell thickness \\
\hline
\end{tabular}


Table 37-13, continued

\begin{tabular}{|c|c|c|c|c|c|c|}
\hline Unit & Square & Level & Feature & Number & Analyzed Part & Identification \\
\hline IIIa & E24\S78 & $16 \mathrm{~A}$ & & 5 & Fragment & Medium shell thickness \\
\hline IIIa & E24\S78 & $17 \mathrm{~A}$ & & 1 & Fragment & Medium shell thickness \\
\hline IIIa & E24\S78 & $18 \mathrm{~B}$ & & 1 & Valve fragment & Lampsilis teres, bleached \\
\hline IIIa & E26S72 & $16 \mathrm{~A}$ & & 1 & Umbo fragment & Medium shell thickness \\
\hline IIIa & E26S72 & $16 \mathrm{~A}$ & & 2 & Fragment & Medium shell thickness \\
\hline IIIa & E26S72 & 17B & & 2 & Fragment & Medium shell thickness \\
\hline IIIa & E26S72 & $18 \mathrm{~A}$ & & 1 & Valve fragment & Lampsilis teres, bleached \\
\hline IIIa & E26S72 & $18 \mathrm{~B}$ & & 1 & Umbo fragment & Lampsilis radiata hydiana \\
\hline IIIa & E26S72 & 18B & & 6 & Fragment & Medium shell thickness \\
\hline IIIa & E26S72 & $19 \mathrm{~A}$ & & 1 & Fragment & Medium shell thickness \\
\hline IIIa & E26S74 & $16 \mathrm{~A}$ & & 1 & Fragment & Thin to medium shell thickness \\
\hline IIIa & E26S74 & $16 \mathrm{~B}$ & & 1 & Fragment & Thin shell thickness \\
\hline IIIa & E26S74 & $17 \mathrm{~A}$ & & 1 & Fragment & Medium shell thickness \\
\hline IIIa & E20S74 & 17B & & 1 & Fragment & Thin to medium shell thickness \\
\hline IIIa & E26S74 & $18 \mathrm{~B}$ & & 1 & Fragment & Medium shell thickness \\
\hline IIIa & E26S74 & $18 \mathrm{~B}$ & & 1 & Valve fragment & Lampsilis teres \\
\hline IIIa & E26S76 & $16 \mathrm{~A}$ & & 2 & Fragment & Medium shell thickness \\
\hline IIIa & E26S76 & $17 \mathrm{~A}$ & & 1 & Fragment & Medium shell thickness \\
\hline IIIa & E26S76 & 17B & & 1 & Entire valve & Potamilus purpuratus \\
\hline IIIa & E26S76 & $18 \mathrm{~A}$ & & 3 & Fragment & Thin to medium shell thickness \\
\hline IIIa & E26S78 & $16 \mathrm{~A}$ & F124 & 3 & Fragment & Medium shell thickness \\
\hline IIIa & E26S78 & $16 \mathrm{~B}$ & F124 & 1 & Fragment & Thick shell thickness \\
\hline IIIa & E26S78 & $16 \mathrm{~B}$ & F124 & 1 & Fragment & Medium shell thickness \\
\hline IIIa & E26S78 & $17 \mathrm{~A}$ & & 4 & Fragment & Medium shell thickness \\
\hline IIIa & E26S78 & $18 \mathrm{~A}$ & & 1 & Entire valve & Lampsilis teres \\
\hline IIIa & E26S78 & $18 \mathrm{~A}$ & & 3 & Fragment & Medium shell thickness \\
\hline IIIa & E26\78 & $18 \mathrm{~B}$ & & 2 & Fragment & Medium shell thickness, bleached \\
\hline IIIa & E28\S78 & $16 \mathrm{~A}$ & F181 & 1 & Fragment & Medium shell thickness \\
\hline IIIa & E28\S78 & $16 \mathrm{~B}$ & F181 & 1 & Valve fragment & Potamilus purpuratus \\
\hline IIIa & E28\S78 & $16 \mathrm{~B}$ & F181 & 1 & Hinge fragment & Toxolasma texasensis, large individual \\
\hline IIIa & E28\S78 & $17 \mathrm{~A}$ & & 1 & Fragment & Medium shell thickness \\
\hline IIIa & E28\S78 & $17 \mathrm{~A}$ & & 3 & Hinge fragment & Medium shell thickness \\
\hline IIIa & E28\S78 & 17B & F181 & 3 & Fragment & Thin to medium shell thickness \\
\hline IIIa & E28\S78 & $18 \mathrm{~A}$ & & 3 & Fragment & Thin to medium shell thickness \\
\hline IIIa & E40 $\ 70$ & 14 & & 1 & Valve fragment & Lampsilis teres \\
\hline IIIa & E40\S70 & 15 & & 1 & Fragment & Medium shell thickness \\
\hline IIIa & E40 $\ 70$ & 15 & & 1 & Valve fragment & Potamilus purpuratus \\
\hline IIIa & E40 570 & 16 & & 1 & Valve fragment & Lampsilis teres \\
\hline IIIa & E40\S70 & 17 & & 1 & Fragment & Thin to medium shell thickness \\
\hline III & E0WN8 & 8 & BRM 2 & 1 & Hinge fragment & Leptodea fragilis \\
\hline III & E0W8 & 10 & BRM 2 & 1 & Fragment & Medium shell thickness \\
\hline III & E0WN8 & 11 & BRM 2 & 1 & Fragment & Thin shell thickness \\
\hline III & E0UN8 & 11 & BRM 2 & 1 & Fragment & Medium shell thickness \\
\hline III & EON8 & 14 & & 1 & Fragment & Medium shell thickness \\
\hline III & E0WN8 & 15 & & 1 & Umbo fragment & Lampsilis teres \\
\hline III & E0WN8 & 17 & & 1 & Fragment & Medium shell thickness \\
\hline III & EON8 & 18 & & 1 & Fragment & Thin shell thickness \\
\hline III & E0WN8 & 20 & & 1 & Fragment & Thin to medium shell thickness \\
\hline III & E0UN8 & 20 & & 1 & Fragment & Medium shell thickness \\
\hline III & E0UN8 & 21 & & 1 & Fragment & Medium shell thickness \\
\hline III & E0WN8 & 21 & & 1 & Pseudocardinal & Medium shell thickness \\
\hline III & E24\S64 & 14 & & 1 & Fragment & Medium shell thickness \\
\hline III & E24\S64 & 15 & & 1 & Fragment & Medium shell thickness \\
\hline
\end{tabular}


Table 37-13, continued

\begin{tabular}{|c|c|c|c|c|c|c|}
\hline Unit & Square & Level & Feature & Number & Analyzed Part & Identification \\
\hline III & E24\S64 & 15 & & 1 & Fragment & Thin to medium shell thickness \\
\hline III & E24\S64 & 15 & & 1 & Fragment & Thin to medium shell thickness \\
\hline III & E24\S64 & 15 & & 1 & Fragment & Medium shell thickness \\
\hline III & E24\S64 & 15 & & 1 & Umbo fragment & Lampsilis teres \\
\hline III & E24\S64 & 16 & & 1 & Umbo fragment & Medium shell thickness \\
\hline III & E24\S64 & 16 & & 2 & Fragment & Medium shell thickness \\
\hline III & E24\S64 & 16 & & 2 & Fragment & Medium shell thickness \\
\hline III & E24\S64 & 16 & & 2 & Fragment & Medium shell thickness \\
\hline III & E2\N8 & 7 & BRM 2 & 1 & Fragment & Medium shell thickness \\
\hline III & E2LN8 & 11 & BRM 2 & 1 & Fragment & Thin to medium shell thickness \\
\hline III & E2WN8 & 11 & BRM 2 & 2 & Fragment & Thin to medium shell thickness \\
\hline III & E2lN8 & 12 & & 1 & Fragment & Thin shell thickness \\
\hline III & E2LN8 & 14 & & 1 & Fragment & Medium shell thickness \\
\hline III & E2WN8 & 15 & & 2 & Hinge fragment & Medium shell thickness \\
\hline III & E2WN8 & 16 & & 2 & Fragment & Thin shell thickness \\
\hline III & E2lN8 & 19 & & 1 & Fragment & Thin to medium shell thickness \\
\hline III & E2WN8 & 20 & & 1 & Umbo fragment & Lampsilis teres \\
\hline II/IIIa & E20\S74 & $20 \mathrm{~A}$ & & 1 & Fragment & Medium shell thickness \\
\hline II/IIIa & E20\S78 & $19 \mathrm{~A}$ & & 1 & Hinge fragment & Medium shell thickness, burned \\
\hline II/IIIa & E20、S80 & 17 & & 1 & Fragment & Medium shell thickness \\
\hline II/IIIa & E20\S82 & 18 & & 1 & Valve fragment & Lampsilis teres \\
\hline II/IIIa & E22\S72 & $20 \mathrm{~A}$ & & 1 & Umbo fragment & Lampsilis teres \\
\hline II/IIIa & E22\S72 & $20 \mathrm{~B}$ & & 1 & Fragment & Medium shell thickness \\
\hline II/IIIa & E22\S72 & $20 \mathrm{~B}$ & & 1 & Fragment & Medium shell thickness \\
\hline II/IIIa & E22\S72 & $20 \mathrm{~B}$ & & 1 & Fragment & Medium shell thickness \\
\hline II/IIIa & E22\S72 & $21 \mathrm{~A}$ & & 1 & Hinge fragment & Medium shell thickness \\
\hline II/IIIa & E22\S72 & $21 \mathrm{~A}$ & & 1 & Fragment & Thick shell thickness \\
\hline II/IIIa & E22\S74 & $19 \mathrm{~B}$ & & 4 & Fragment & Medium shell thickness \\
\hline II/IIIa & E22\S74 & $20 \mathrm{~A}$ & & 1 & Entire valve & Lampsilis teres \\
\hline II/IIIa & E24\S74 & $21 \mathrm{~B}$ & F150 & 1 & Fragment & Medium shell thickness \\
\hline II/IIIa & E22\S76 & $20 \mathrm{~A}$ & & 1 & Fragment & Medium shell thickness, bleached \\
\hline II/IIIa & E22\S78 & $18 \mathrm{~B}$ & & 1 & Fragment & Medium shell thickness \\
\hline II/IIIa & E22\S78 & 19B & & 1 & Fragment & Medium shell thickness \\
\hline II/IIIa & E22\S80 & 17 & & 1 & Fragment & Medium shell thickness \\
\hline II/IIIa & E24\S72 & 19B & & 1 & Fragment & Thin to medium shell thickness \\
\hline II/IIIa & E24S72 & 19B & & 1 & Fragment & Medium shell thickness \\
\hline II/IIIa & E24\S72 & $20 \mathrm{~B}$ & & 1 & Fragment & Medium shell thickness \\
\hline II/IIIa & E24\S72 & $21 \mathrm{~A}$ & & 1 & Hinge fragment & Medium shell thickness \\
\hline II/IIIa & E24\S72 & $21 \mathrm{~A}$ & & 1 & Fragment & Medium shell thickness \\
\hline II/IIIa & E24S74 & $20 \mathrm{~B}$ & & 1 & Fragment & Medium shell thickness \\
\hline II/IIIa & E24S76 & $19 \mathrm{~B}$ & & 1 & Fragment & Medium shell thickness \\
\hline II/IIIa & E24\S76 & $20 \mathrm{~A}$ & & 1 & Fragment & Medium shell thickness \\
\hline II/IIIa & E24S76 & $20 \mathrm{~B}$ & & 1 & Fragment & Thin to medium shell thickness \\
\hline II/IIIa & E24\S78 & $19 \mathrm{~A}$ & & 3 & Fragment & Medium shell thickness \\
\hline II/IIIa & E24S78 & $19 \mathrm{~B}$ & & 1 & Fragment & Medium shell thickness \\
\hline II/IIIa & E26S72 & 19B & & 2 & Fragment & Thin shell thickness \\
\hline II/IIIa & E26\S72 & $20 \mathrm{~A}$ & & 1 & Fragment & Medium shell thickness \\
\hline II/IIIa & E26S72 & $20 \mathrm{~A}$ & & 1 & Entire valve & Lampsilis teres \\
\hline II/IIIa & E2@S72 & $20 \mathrm{~B}$ & & 1 & Fragment & Medium shell thickness \\
\hline II/IIIa & E26S74 & $20 \mathrm{~B}$ & & 1 & Umbo fragment & Lampsilis teres \\
\hline II/IIIa & E2@S74 & $21 \mathrm{~A}$ & & 2 & Fragment & Medium shell thickness \\
\hline II/IIIa & E26S76 & 19B & & 1 & Fragment & Thin to medium shell thickness \\
\hline II/WIa & E26S76 & 19B & & 1 & Entire valve & Lampsilis radiata hydiana \\
\hline
\end{tabular}


Table 37-13, continued

\begin{tabular}{|c|c|c|c|c|c|c|}
\hline Unit & Square & Level & Feature & Number & Analyzed Part & Identification \\
\hline II/IIIa & E26S76 & 19B & & 1 & Fragment & Medium shell thickness \\
\hline II/IIIa & E26S76 & 19B & & 1 & Valve fragment & Toxolasma texasensis \\
\hline II/IIIa & E2@S76 & $20 \mathrm{~A}$ & & 1 & Fragment & Thin to medium shell thickness \\
\hline II/IIIa & E26S76 & $20 \mathrm{~B}$ & & 1 & Fragment & Medium shell thickness \\
\hline II/IIIa & E26S76 & $20 \mathrm{~B}$ & & 1 & Fragment & Medium shell thickness, leached \\
\hline II/IIIa & E26S78 & $19 \mathrm{~B}$ & & 1 & Umbo fragment & Lampsilis teres \\
\hline II/IIIa & E28\S78 & $18 \mathrm{~A}$ & & 1 & Fragment & Thin shell thickness \\
\hline II/IIIa & E28\S78 & 18B & & 1 & Fragment & Medium shell thickness \\
\hline II/IIIa & E28\S78 & $18 \mathrm{~B}$ & F183 & 1 & Fragment & Thin shell thickness \\
\hline II/IIIa & E28\S78 & $18 \mathrm{~B}$ & F183 & 1 & Valve fragment & Lampsilis teres \\
\hline II/III & E2WN8 & 23 & & 1 & Fragment & Medium shell thickness \\
\hline II & E20、S72 & $21 \mathrm{~A}$ & & 1 & Fragment & Thin to medium shell thickness \\
\hline II & E20\S80 & 20 & & 1 & Fragment & Thin to medium shell thickness \\
\hline II & E20\S80 & 21 & & 1 & Valve fragment & Toxolasma texasensis \\
\hline II & E20\S82 & 19 & & 1 & Fragment & Medium shell thickness \\
\hline II & E20\S82 & 21 & & 1 & Fragment & Medium shell thickness \\
\hline II & E22\S72 & $21 B$ & & 1 & Fragment & Medium shell thickness \\
\hline II & E22\S72 & $21 B$ & & 1 & Valve fragment & Toxolasma texasensis \\
\hline II & E22\S72 & $21 B$ & & 1 & Valve fragment & Lampsilis teres \\
\hline II & E22\S72 & $22 \mathrm{~A}$ & & 1 & Fragment & Medium shell thickness \\
\hline II & E22\S72 & $22 \mathrm{~A}$ & & 2 & Fragment & Medium shell thickness \\
\hline II & E22\S72 & $22 B$ & & 1 & Fragment & Medium shell thickness \\
\hline II & E22\S72 & $22 \mathrm{~B}$ & & 1 & Fragment & Medium shell thickness \\
\hline II & E22\S72 & $23 \mathrm{~A}$ & & 2 & Fragment & Thin to medium shell thickness \\
\hline II & E22\S72 & $23 \mathrm{~B}$ & & 1 & Fragment & Lampsilis teres \\
\hline II & E22\S72 & $24 \mathrm{~A}$ & & 1 & Fragment & Medium shell thickness \\
\hline II & E22\S72 & $24 B$ & & 1 & Valve fragment & Lampsilis teres \\
\hline II & E22\S72 & $24 B$ & & 1 & Fragment & Medium to thick shell thickness \\
\hline II & E22\S72 & 24B & & 1 & Valve fragment & Lampsilis teres \\
\hline II & E22\S72 & $25 \mathrm{~A}$ & & 1 & Valve fragment & Lampsilis teres \\
\hline II & E22\S74 & $21 \mathrm{~A}$ & & 2 & Hinge fragment & Medium shell thickness \\
\hline II & E22\S74 & $21 \mathrm{~B}$ & & 1 & Entire valve & Lampsilis teres \\
\hline II & E22\S74 & $23 B$ & & 1 & Fragment & Medium shell thickness \\
\hline II & E22\S74 & $24 \mathrm{~A}$ & & 1 & Entire valve & Lampsilis teres \\
\hline II & E22\S76 & $21 \mathrm{~A}$ & & 1 & Fragment & Medium shell thickness \\
\hline II & E22\S76 & $21 \mathrm{~A}$ & & 1 & Hinge fragment & Medium shell thickness \\
\hline II & E22\S78 & $20 \mathrm{~A}$ & & 1 & Hinge fragment & Medium shell thickness \\
\hline II & E22\S78 & $22 \mathrm{~A}$ & & 1 & Fragment & Medium shell thickness \\
\hline II & E22\S78 & $22 \mathrm{~A}$ & & 1 & Fragment & Medium to thick shell thickness \\
\hline II & E22\S78 & $22 \mathrm{~A}$ & & 1 & Fragment & Medium shell thickness \\
\hline II & E22\S78 & $22 \mathrm{~A}$ & & 1 & Entire valve & Lampsilis teres \\
\hline II & E22\S80 & 18 & & 1 & Fragment & Medium shell thickness \\
\hline II & E22\S80 & 18 & & 1 & Hinge fragment & Medium shell thickness \\
\hline II & E24SS72 & $21 B$ & & 1 & Valve fragment & Medium shell thickness \\
\hline II & E24SS72 & $21 B$ & & 1 & Fragment & Medium shell thickness \\
\hline II & E24ST2 & $21 B$ & & 2 & Fragment & Medium shell thickness \\
\hline II & E24\S72 & $22 \mathrm{~A}$ & & 1 & Umbo fragment & Lampsilis teres \\
\hline II & E24\S72 & $22 B$ & & 1 & Fragment & Medium shell thickness \\
\hline II & E24\S74 & $21 \mathrm{~A}$ & & 2 & Fragment & Medium shell thickness \\
\hline II & E24S74 & $22 \mathrm{~A}$ & & 1 & Fragment & Thin to medium shell thickness \\
\hline II & E24S74 & $22 \mathrm{~A}$ & & 1 & Umbo fragment & Lampsilis teres \\
\hline II & E24\S74 & $22 \mathrm{~A}$ & & 1 & Fragment & Medium shell thickness \\
\hline II & E24\S74 & 22B & & 1 & Fragment & Medium shell thickness \\
\hline
\end{tabular}


Table 37-13, continued

\begin{tabular}{|c|c|c|c|c|c|c|}
\hline Unit & Square & Level & Feature & Number & Analyzed Part & Identification \\
\hline II & E24\S74 & $23 \mathrm{~A}$ & & 1 & Valve fragment & Lampsilis teres \\
\hline II & E24\S74 & $25 \mathrm{~A}$ & & 1 & Fragment & Medium shell thickness \\
\hline II & E24\S74 & $25 \mathrm{~A}$ & & 1 & Fragment & Thin to medium shell thickness \\
\hline II & E24\S74 & $25 \mathrm{~A}$ & & 1 & Entire valve & Lampsilis teres \\
\hline II & E24\S74 & $25 \mathrm{~A}$ & & 1 & Fragment & Medium shell thickness \\
\hline II & E24\S76 & $21 \mathrm{~A}$ & & 1 & Hinge fragment & Medium shell thickness \\
\hline II & E24\S76 & $21 \mathrm{~B}$ & & 1 & Fragment & Medium shell thickness \\
\hline II & E24\S76 & $23 \mathrm{~A}$ & & 1 & Fragment & Medium shell thickness \\
\hline II & E24\S76 & $24 \mathrm{~A}$ & & 1 & Fragment & Medium shell thickness \\
\hline II & E24\S76 & $24 \mathrm{~A}$ & & 1 & Hinge fragment & Lampsilis teres \\
\hline II & E24\S76 & $25 \mathrm{~A}$ & & 1 & Fragment & Medium shell thickness \\
\hline II & E24S76 & $25 \mathrm{~A}$ & & 1 & Valve fragment & Lampsilis teres \\
\hline II & E24\S78 & $21 B$ & & 1 & Fragment & Medium shell thickness \\
\hline II & E24\S78 & $22 \mathrm{~A}$ & & 1 & Fragment & Thin to medium shell thickness \\
\hline II & E26S72 & $21 \mathrm{~B}$ & & 1 & Fragment & Thin to medium shell thickness \\
\hline II & E26S72 & $22 \mathrm{~A}$ & F157 & 1 & Entire valve & Lampsilis teres \\
\hline II & E26S72 & $23 \mathrm{~A}$ & & 1 & Fragment & Medium shell thickness \\
\hline II & E26S72 & 24B & & 1 & Umbo fragment & Uniomerus tetralasmus \\
\hline II & E26S72 & $26 B$ & & 1 & Entire valve & Lampsilis teres \\
\hline II & E26S72 & $26 B$ & & 1 & Fragment & Medium shell thickness \\
\hline II & E26S72 & $27 \mathrm{~A}$ & & 1 & Fragment & Medium shell thickness \\
\hline II & E26S72 & $27 \mathrm{~B}$ & & 2 & Fragment & Medium shell thickness \\
\hline II & E26S74 & $22 \mathrm{~A}$ & & 2 & Fragment & Thin to medium shell thickness \\
\hline II & E26S74 & $23 \mathrm{~A}$ & & 1 & Fragment & Medium to thick shell thickness \\
\hline II & E26S74 & $24 \mathrm{~A}$ & & 1 & Fragment & Medium shell thickness \\
\hline II & E26S74 & 24B & & 1 & Fragment & Thin to medium shell thickness \\
\hline II & E26S74 & $25 \mathrm{~A}$ & & 1 & Fragment & Medium shell thickness \\
\hline II & E26S76 & $21 \mathrm{~B}$ & & 1 & Fragment & Medium shell thickness \\
\hline II & E26S76 & $22 \mathrm{~B}$ & & 1 & Fragment & Lampsilis teres \\
\hline II & E26S76 & $23 \mathrm{~A}$ & & 1 & Fragment & Medium shell thickness \\
\hline II & E26S76 & $23 \mathrm{~A}$ & & 1 & Fragment & Medium shell thickness \\
\hline II & E26S76 & $23 \mathrm{~A}$ & & 1 & Valve fragment & Lampsilis teres \\
\hline II & E26S76 & 24B & & 1 & Umbo fragment & Lampsilis teres \\
\hline II & E26S78 & $21 \mathrm{~A}$ & & 1 & Fragment & Medium shell thickness \\
\hline II & E28\S78 & $18 \mathrm{~B}$ & & 1 & Fragment & Thin to medium shell thickness \\
\hline II & E28\S78 & $20 \mathrm{~B}$ & & 1 & Valve fragment & Lampsilis teres \\
\hline II & E28\S78 & $21 \mathrm{~A}$ & & 1 & Fragment & Medium shell thickness \\
\hline II & E28\S78 & $21 \mathrm{~A}$ & & 1 & Entire valve & Arcidens confragosus \\
\hline II & E28\S78 & $23 \mathrm{~A}$ & & 1 & Fragment & Medium shell thickness \\
\hline II & E40 75 & 21 & & 1 & Valve fragment & Medium to thick shell thickness \\
\hline $\mathrm{Id} / \mathrm{II}$ & E20 $\ 78$ & $22 \mathrm{~A}$ & & 1 & Fragment & Thin to medium shell thickness \\
\hline $\mathrm{Id} / \mathrm{II}$ & E20\S78 & $22 \mathrm{~B}$ & & 1 & Entire valve & Lampsilis teres \\
\hline $\mathrm{Id} / \mathrm{II}$ & E20、S78 & 23B & & 1 & Hinge fragment & Lampsilis teres \\
\hline Id/II & E22\S74 & $25 \mathrm{~B}$ & & 1 & Fragment & Thin to medium shell thickness \\
\hline $\mathrm{Id} / \mathrm{II}$ & E22\S74 & $26 \mathrm{~A}$ & & 1 & Fragment & Medium shell thickness \\
\hline $\mathrm{Id} / \mathrm{II}$ & E22\S76 & $26 \mathrm{~A}$ & & 1 & Fragment & Medium shell thickness \\
\hline Id/II & E22\S78 & $25 \mathrm{~A}$ & & 1 & Fragment & Medium shell thickness \\
\hline $\mathrm{Id} / \mathrm{II}$ & E26S78 & $25 \mathrm{~A}$ & & 1 & Fragment & Medium to thick shell thickness \\
\hline $\mathrm{Id} / \mathrm{II}$ & E26\S78 & $25 \mathrm{~B}$ & & 1 & Fragment & Medium shell thickness \\
\hline $\mathrm{Id} / \mathrm{II}$ & E26S78 & $26 \mathrm{~A}$ & & 1 & Fragment & Thin to medium shell thickness \\
\hline $\mathrm{Id} / \mathrm{II}$ & E28\S78 & $25 \mathrm{~A}$ & & 1 & Fragment & Medium to thick shell thickness \\
\hline Isi-c/II & E24\S72 & $28 \mathrm{~A}$ & & 1 & Fragment & Medium shell thickness \\
\hline Isi-c/II & E24\S74 & $27 \mathrm{~B}$ & & 1 & Fragment & Medium shell thickness \\
\hline
\end{tabular}


Table 37-13, continued

\begin{tabular}{|c|c|c|c|c|c|c|}
\hline Unit & Square & Level & Feature & Number & Analyzed Part & Identification \\
\hline Isi-c/II & E26S72 & $29 \mathrm{~A}$ & & 1 & Valve fragment & Medium shell thickness \\
\hline Isi-c/II & E26S72 & $29 \mathrm{~A}$ & & 1 & Fragment & Medium shell thickness \\
\hline Isi-c/II & E26\S74 & $27 \mathrm{~B}$ & & 1 & Fragment & Medium shell thickness \\
\hline Isi-c/II & E26S74 & $28 \mathrm{~A}$ & & 1 & Fragment & Medium shell thickness \\
\hline I/II & E2WN8 & $25 \mathrm{~A}$ & & 1 & Hinge fragment & Lampsilis teres \\
\hline Isi-c/Id & E22\S78 & $26 \mathrm{~A}$ & F163 & 1 & Umbo fragment & Lampsilis teres \\
\hline Isi-c/Id & E22\S78 & $26 \mathrm{~B}$ & & 1 & Fragment & Medium shell thickness \\
\hline Isi-c/Id & E22\S80 & 24 & & 1 & Fragment & Medium shell thickness \\
\hline Isi-c/Id & E24\S76 & $27 \mathrm{~B}$ & & 1 & Fragment & Medium shell thickness \\
\hline Isi-c/Id & E26S78 & $28 \mathrm{~B}$ & & 1 & Valve fragment & Medium shell thickness \\
\hline Isi-c & E20\S72 & 28B & & 1 & Valve fragment & Lampsilis teres \\
\hline Isi-c & E20\S76 & $27 \mathrm{~A}$ & & 1 & Valve fragment & Lampsilis teres \\
\hline Isi-c & E20\S78 & $27 \mathrm{~A}$ & & 1 & Fragment & Medium shell thickness \\
\hline Isi-c & E20\S80 & 25 & & 1 & Fragment & Medium shell thickness \\
\hline Isi-c & E22\S72 & 28B & & 1 & Fragment & Medium shell thickness \\
\hline Isi-c & $\mathrm{E} 22 \backslash \mathrm{S} 72$ & $28 \mathrm{~B}$ & & 1 & Entire valve & Lampsilis teres \\
\hline Isi-c & E22\S72 & $31 \mathrm{~A}$ & & 3 & Fragment & Thin to medium shell thickness \\
\hline Isi-c & E22\S74 & $28 \mathrm{~B}$ & & 1 & Fragment & Medium shell thickness \\
\hline Isi-c & E22\S74 & 29B & & 1 & Hinge fragment & Medium shell thickness \\
\hline Isi-c & E22\S74 & 29B & & 1 & Umbo fragment & Uniomerus tetralasmus \\
\hline Isi-c & $\mathrm{E} 22 \backslash \mathrm{S} 74$ & $30 \mathrm{~A}$ & & 1 & Fragment & Medium shell thickness \\
\hline Isi-c & E22\S76 & $27 \mathrm{~B}$ & & 1 & Fragment & Medium shell thickness \\
\hline Isi-c & E22\S76 & $27 \mathrm{~B}$ & & 1 & Pseudocardinal & Medium shell thickness \\
\hline Isi-c & $\mathrm{E} 22 \backslash \mathrm{S} 76$ & $28 \mathrm{~A}$ & & 1 & Fragment & Medium shell thickness \\
\hline Isi-c & E22\S76 & $30 \mathrm{~A}$ & & 1 & Fragment & Medium shell thickness \\
\hline Isi-c & E22\S76 & $30 \mathrm{~A}$ & & 1 & Fragment & Medium shell thickness \\
\hline Isi-c & E22\S76 & $30 \mathrm{~A}$ & & 1 & Valve fragment & Potamilus purpuratus \\
\hline Isi-c & E22\S76 & $30 \mathrm{~B}$ & & 1 & Fragment & Medium shell thickness \\
\hline Isi-c & $\mathrm{E} 24 \backslash \mathrm{S} 72$ & 29B & & 1 & Hinge fragment & Medium shell thickness \\
\hline Isi-c & E24\S72 & 29B & & 1 & Hinge fragment & Medium shell thickness \\
\hline Isi-c & E24\S72 & 29B & & 1 & Umbo fragment & Medium shell thickness \\
\hline Isi-c & E24\S72 & $30 \mathrm{~A}$ & & 2 & Fragment & Medium shell thickness \\
\hline Isi-c & E24\S74 & $30 \mathrm{~B}$ & & 1 & Fragment & Medium shell thickness \\
\hline Isi-c & E24\S74 & $30 \mathrm{~A}$ & & 1 & Fragment & Thin to medium shell thickness \\
\hline Isi-c & E24\S78 & $28 \mathrm{~B}$ & & 1 & Hinge fragment & Medium shell thickness \\
\hline Isi-c & E26S72 & $30 \mathrm{~A}$ & & 1 & Fragment & Thin to medium shell thickness \\
\hline Isi-c & E26S72 & $30 \mathrm{~B}$ & & 1 & Fragment & Medium shell thickness \\
\hline Isi-c & E26S72 & $31 \mathrm{~A}$ & & 1 & Fragment & Medium shell thickness \\
\hline Isi-c & E26S72 & $31 \mathrm{~B}$ & & 1 & Fragment & Medium shell thickness \\
\hline Isi-c & E26S74 & $30 \mathrm{~A}$ & & 1 & Fragment & Medium shell thickness \\
\hline Isi-c & E26S76 & $30 \mathrm{~B}$ & & 1 & Fragment & Medium shell thickness \\
\hline Isi-c & E26S78 & $30 \mathrm{~A}$ & & 2 & Fragment & Medium shell thickness \\
\hline Isi-c & E20S78 & $30 \mathrm{~B}$ & & 1 & Valve fragment & Medium shell thickness \\
\hline Isi-c & E26S78 & 30B & & 1 & Fragment & Medium shell thickness, leached \\
\hline Isi-c & E26\S78 & $31 \mathrm{~A}$ & & 1 & Fragment & Medium shell thickness \\
\hline Isi-c & E26S78 & $32 \mathrm{~A}$ & & 1 & Fragment & Medium shell thickness \\
\hline Isi-c & E28\S78 & 28B & & 2 & Valve fragment & Medium shell thickness \\
\hline Isi-c & $\mathrm{E} 28 \backslash \mathrm{S} 78$ & $31 \mathrm{~A}$ & & 1 & Fragment & Thin to medium shell thickness \\
\hline Isi/Isi-c & E20\S76 & 28B & & 1 & Valve fragment & Lampsilis teres \\
\hline Isi/Isi-c & E22\S78 & $28 \mathrm{~B}$ & & 1 & Fragment & Thin shell thickness \\
\hline Isi/Isi-c & E24\S78 & $30 \mathrm{~A}$ & & 1 & Fragment & Thin to medium shell thickness \\
\hline Isi/Isi-c & E24\S78 & $31 \mathrm{~B}$ & & 1 & Entire valve & Quincuncina mitchelli \\
\hline Icl/Isi-c & E22\S72 & $31 \mathrm{~B}$ & & 1 & Umbo fragment & Uniomerus tetralasmus \\
\hline
\end{tabular}


Table 37-13, continued

\begin{tabular}{|c|c|c|c|c|c|c|}
\hline Unit & Square & Level & Feature & Number & Analyzed Part & Identification \\
\hline Icl/Isi-c & E22\S72 & $31 \mathrm{~B}$ & & 1 & Hinge fragment & Thin shell thickness, very small individual \\
\hline Isi/Icl/Isi-c & E22\S76 & $32 \mathrm{~A}$ & & 1 & Fragment & Medium shell thickness \\
\hline I & E2WN8 & $25 \mathrm{~B}$ & & 1 & Fragment & Medium shell thickness \\
\hline I & E2W8 & $26 \mathrm{~A}$ & & 1 & Fragment & Medium shell thickness \\
\hline I & E40\S70 & 23 & & 1 & Fragment & Medium shell thickness \\
\hline Isi/Icl & E26S72 & 39B & & 1 & Fragment & Thin shell thickness, burned \\
\hline Igl/Isi & E24\S72 & $40 \mathrm{~B}$ & & 1 & Fragment & Thin shell thickness \\
\hline \multicolumn{7}{|c|}{ Valley Margin: } \\
\hline Surface & Surface & & & 1 & Entire valve & Quadrula sp. \\
\hline IIIc & E20、S100 & 4 & & 1 & Fragment & Thin to medium shell thickness \\
\hline IIIc & E20\S84 & 3 & & 2 & Valve fragment & Lampsilis teres \\
\hline IIIc & E20\S84 & 4 & & 1 & Valve fragment & Medium shell thickness \\
\hline IIIc & E20\S84 & 5 & & 1 & Fragment & Medium shell thickness \\
\hline IIIc & E20 \S84 & 6 & & 1 & Valve fragment & Potamilus purpuratus \\
\hline IIIc & E20\S84 & 6 & & 2 & Fragment & Medium shell thickness \\
\hline IIIC & E20 \S86 & 2 & & 1 & Hinge fragment & Anodonta grandis \\
\hline IIIc & E20\S86 & 2 & & 1 & Umbo fragment & Lampsilis teres \\
\hline IIIc & E20\S86 & 2 & & 1 & Umbo fragment & Uniomerus tetralasmus \\
\hline IIIc & E20 \S86 & 2 & & 1 & Fragment & Medium shell thickness \\
\hline IIIc & E20\S86 & 6 & & 5 & Fragment & Medium shell thickness \\
\hline IIIc & E20\S88 & 1 & & 1 & Fragment & Thick shell thickness \\
\hline IIIc & E20\S88 & 3 & BRM 1 & 2 & Valve fragment & Amblema plicata \\
\hline IIIc & E20\S88 & 4 & BRM 1 & 12 & Fragment & Medium to thick shell thickness \\
\hline IIIc & E20\S88 & 5 & BRM 1 & 2 & Fragment & Medium shell thickness \\
\hline IIIc & E20\S90 & 1 & & 2 & Fragment & Medium shell thickness \\
\hline IIIc & E20\S90 & 2 & BRM 1 & 10 & Fragment & Medium shell thickness \\
\hline IIIc & E20\S90 & 8 & BRM 1 & 1 & Hinge fragment & Medium shell thickness \\
\hline IIIc & E20\S94 & 5 & BRM 1 & 4 & Fragment & Thin to medium shell thickness \\
\hline IIIc & E20\S94 & 7 & & 1 & Umbo fragment & Lampsilis teres \\
\hline IIIc & E20\S98 & 2 & & 1 & Fragment & Medium shell thickness \\
\hline IIIc & E20\S98 & 2 & & 1 & Hinge fragment & Megalonaias nervosa \\
\hline IIIC & E20 598 & 2 & & 3 & Fragment & Thin to medium shell thickness \\
\hline IIIc & E22\S100 & 1 & & 2 & Valve fragment & Medium shell thickness \\
\hline IIIc & E22\S84 & 6 & & 1 & Fragment & Medium shell thickness \\
\hline IIIC & E22\S86 & 7 & BRM 1 & 1 & Fragment & Thin to medium shell thickness \\
\hline IIIc & E22\S98 & 1 & & 1 & Hinge fragment & Anodonta grandis \\
\hline IIIc & E22\S98 & 1 & & 1 & Umbo fragment & Potamilus purpuratus \\
\hline IIIc & E22\S98 & 1 & & 1 & Hinge fragment & Potamilus purpuratus \\
\hline IIIc & E22\S98 & 5 & BRM 1 & 1 & Hinge fragment & Potamilus purpuratus, probably bleached \\
\hline IIIc & E22\S98 & 5 & BRM 1 & 4 & Fragment & Potamilus purpuratus, probably bleached \\
\hline IIIc/POT & E20\S92 & 1 & & 1 & Hinge fragment & Medium shell thickness \\
\hline IIIc/POT & E20\S92 & 1 & & 2 & Fragment & Medium shell thickness \\
\hline IIIc/POT & E20\S92 & 2 & BRM 1 & 1 & Fragment & Potamilus purpuratus \\
\hline IIIc/POT & E20\S92 & 3 & BRM 1 & 1 & Fragment & Medium shell thickness \\
\hline IIIc/POT & E20\S94 & 1 & & 3 & Fragment & Medium shell thickness \\
\hline IIIc/POT & E20\S94 & 2 & BRM 1 & 1 & Fragment & Medium shell thickness \\
\hline IIIc/POT & E20\S96 & 1 & & 1 & Fragment & Medium shell thickness \\
\hline IIIc/POT & E20\S96 & 2 & BRM 1 & 1 & Fragment & Thin shell thickness \\
\hline IIIc/POT & E20\S96 & 6 & & 11 & Fragment & Medium shell thickness \\
\hline $\mathrm{IIIb} / \mathrm{c}$ & E20 \S84 & 10 & & 2 & Fragment & Medium shell thickness \\
\hline $\mathrm{IIIb} / \mathrm{c}$ & E22\S82 & 6 & & 1 & Fragment & Medium shell thickness \\
\hline $\mathrm{IIIb} / \mathrm{c}$ & E22\S84 & 8 & & 1 & Fragment & Medium shell thickness \\
\hline $\mathrm{IIIb} / \mathrm{c}$ & E22\S84 & 9 & & 2 & Fragment & Medium shell thickness \\
\hline
\end{tabular}


Table 37-13, continued

\begin{tabular}{|c|c|c|c|c|c|c|c|c|}
\hline Unit & Square & Level & Feature & Number & Analyzed Part & Identification & & \\
\hline $\mathrm{IIIb} / \mathrm{c}$ & E22\S86 & 10 & & 1 & Fragment & Medium shell thickness & & \\
\hline Y/IIIc & E20\S88 & 9 & BRM 1 & 1 & Fragment & Medium shell thickness & & \\
\hline Y/IIIc & $\mathrm{E} 20 / \mathrm{S} 90$ & 9 & BRM1 & 1 & Fragment & Thin to medium shell thickness & & \\
\hline Y/IIIc & E20/S94 & 9 & & 1 & Valve fragment & Toxolasma texasensis & & \\
\hline Y/IIIc & E20/S96 & 9 & & 3 & Fragment & Thin to medium shell thickness & & \\
\hline Y/IIIc & $\mathrm{E} 22 / \mathrm{S} 88$ & 9 & BRM1 & 1 & Fragment & Medium shell thickness & & \\
\hline Y/IIIc & $\mathrm{E} 22 / \mathrm{S} 90$ & 8 & BRM1 & 1 & Valve fragment & Uniomerus tetralasmus & & \\
\hline $\mathrm{Y} / \mathrm{IIIb} / \mathrm{c}$ & E20\S88 & 10 & BRM 1 & 1 & Fragment & Medium shell thickness & & \\
\hline $\mathrm{IIIb}$ & E20\S84 & 11 & & 1 & Fragment & Medium shell thickness & & \\
\hline IIIb & E20 284 & 12 & & 1 & Fragment & Medium shell thickness & & \\
\hline IIIb & E20\S84 & 13 & & 2 & Fragment & Thin to medium shell thickness & & \\
\hline IIIb & E20\S86 & 10 & & 1 & Hinge fragment & Thin to medium shell thickness & & \\
\hline IIIb & E20\S86 & 11 & & 1 & Fragment & Medium shell thickness & & \\
\hline IIIb & E20、S86 & 11 & & 1 & Valve fragment & Thin to medium shell thickness & & \\
\hline IIIb & E22\S82 & 10 & & 1 & Fragment & Thin to medium shell thickness & & \\
\hline IIIb & E22\S82 & 12 & & 6 & Fragment & Thin to medium shell thickness & & \\
\hline IIIb & $\mathrm{E} 22 \backslash \mathrm{S} 84$ & 10 & & 1 & Fragment & Thin to medium shell thickness & & \\
\hline IIIb & E22\S84 & 12 & & 3 & Fragment & Medium to thick shell thickness & & \\
\hline IIIb & E22\S84 & 13 & & 3 & Fragment & Medium shell thickness & & \\
\hline IIIb & E22\S86 & 11 & & 2 & Valve fragment & Lampsilis teres & & $=$ \\
\hline IIIb & E22\S86 & 12 & & 2 & Hinge fragment & Medium shell thickness & & \\
\hline IIIb & E22\S86 & 12 & & 1 & Fragment & Medium shell thickness & & \\
\hline Y/IIIb & E22\S88 & 11 & & 1 & Fragment & Medium shell thickness & & \\
\hline Y & E20\S90 & 11 & & 1 & Fragment & Thin shell thickness & " & \\
\hline Y & E20\S94 & 10 & & 1 & Fragment & Medium shell thickness & & \\
\hline $\mathrm{X} / \mathrm{Y} / \mathrm{IIIb}$ & E20 \S88 & 12 & F8 & 1 & Fragment & Medium shell thickness & & \\
\hline $\mathrm{X} / \mathrm{Y} / \mathrm{IIIb}$ & E20 \S88 & 12 & F8 & 1 & Valve fragment & Uniomerus tetralasmus & & \\
\hline $\mathrm{X} / \mathrm{Y} / \mathrm{IIIb}$ & E22\S88 & 12 & & 1 & Valve fragment & Lampsilis teres & & \\
\hline $\mathrm{X} / \mathrm{IIIb}$ & E20\S86 & 13 & & 2 & Fragment & Medium shell thickness & & \\
\hline $\mathrm{X} / \mathrm{IIIb}$ & E20\S88 & 13 & $\mathrm{~F} 8$ & 2 & Hinge fragment & Leptodea fragilis & & \\
\hline $\mathrm{X} / \mathrm{IIIb}$ & $\mathrm{E} 22 \mathrm{~S} 88$ & 13 & & 1 & Fragment & Lampsilis teres & & \\
\hline X/IIIb & E22\S88 & 14 & & 2 & Fragment & Medium shell thickness & & . \\
\hline $\mathrm{X} / \mathrm{Y}$ & E20\S90 & 13 & & 1 & Fragment & Medium shell thickness & & \\
\hline $\mathrm{X} / \mathrm{Y}$ & E20\S98 & 12 & & 1 & Valve fragment & Medium shell thickness, leached & & \\
\hline $\mathrm{X} / \mathrm{Y}$ & E22\S100 & 12 & & 3 & Fragment & Medium shell thickness & & \\
\hline $\mathrm{X} / \mathrm{Y}$ & $\mathrm{E} 22 \backslash \mathrm{S} 90$ & 12 & & 1 & Fragment & Medium shell thickness & & \\
\hline $\mathrm{X} / \mathrm{Y}$ & E22\S90 & 13 & & 1 & Fragment & Medium shell thickness, leached & & \\
\hline IIIa/b & E20\S84 & 15 & & 3 & Fragment & Medium to thick shell thickness & & \\
\hline IIIa/b & E22\S82 & 13 & & 3 & Fragment & Medium shell thickness & & \\
\hline IIIa/b & E22\S84 & 14 & & 1 & Valve fragment & Amblema plicata & & \\
\hline IIIa & E20\S84 & 16 & & 3 & Fragment & Medium shell thickness & & \\
\hline IIIa & E20、S84 & 17 & & 2 & Fragment & Medium to thick shell thickness, burned & & \\
\hline IIIa & E20、S84 & 17 & F28 & 1 & Valve fragment & Lampsilis teres & & \\
\hline IIIa & E22\S82 & 14 & & 1 & Hinge fragment & Medium shell thickness & & \\
\hline IIIa & E22\S84 & 15 & & 1 & Valve fragment & Lampsilis teres & & \\
\hline IIIa & E22\S84 & 15 & & 3 & Fragment & Medium shell thickness & & \\
\hline IIIa & E22\S84 & 16 & & 1 & Umbo fragment & Medium shell thickness & & \\
\hline IIIa & E22\S84 & 16 & & 3 & Fragment & Medium shell thickness & : & \\
\hline X/IIIa & E20\S86 & 15 & F22 & 1 & Entire valve & Lampsilis teres & & \\
\hline X/IIIa & E22\S86 & 15 & & 3 & Fragment & Medium shell thickness & & \\
\hline $\mathrm{X} / \mathrm{III}$ & E22\S86 & 15 & & 2 & Fragment & Thick shell thickness & & \\
\hline II/IIIa & E20\S84 & 18 & & 1 & Entire valve & Lampsilis teres & & \\
\hline II/IIIa & E22\S84 & 17 & & 1 & Fragment & Thin to medium shell thickness & & \\
\hline
\end{tabular}


Table 37-13, continued

\begin{tabular}{|c|c|c|c|c|c|c|}
\hline Unit & Square & Level & Feature & Number & Analyzed Part & Identification \\
\hline X/II/IIIa & E20\S86 & 16 & & 2 & Fragment & Thin to medium shell thickness \\
\hline X/II/IIIa & E22\S86 & 16 & & 1 & Valve fragment & Lampsilis teres \\
\hline $\mathrm{X} / \mathrm{II} / \mathrm{IIIa}$ & E22\S86 & 17 & & 1 & Valve fragment & Lampsilis teres \\
\hline $\mathrm{X} / \mathrm{II} / \mathrm{III}$ & $\mathrm{E} 22 \backslash \mathrm{S} 86$ & 17 & & 1 & Valve fragment & Potamilus purpuratus \\
\hline $\mathrm{X}$ & E20 \S86 & 12 & & 1 & Fragment & Medium shell thickness \\
\hline$X$ & E20 \S88 & 14 & & 4 & Fragment & Medium shell thickness \\
\hline $\mathrm{X}$ & E20 \S88 & 15 & & 3 & Fragment & Medium shell thickness \\
\hline $\mathrm{X}$ & E20 \S88 & 16 & & 1 & Entire valve & Lampsilis teres \\
\hline $\mathrm{X}$ & E20\S88 & 17 & & 1 & Valve fragment & Thick shell thickness \\
\hline $\mathrm{X}$ & E20 \S88 & 18 & & 1 & Fragment & Medium shell thickness \\
\hline $\mathrm{X}$ & E20\S88 & 20 & & 1 & Fragment & Thin to medium shell thickness \\
\hline $\mathrm{X}$ & E20\S90 & 15 & & 2 & Fragment & Medium shell thickness \\
\hline $\mathrm{X}$ & E20\S90 & 16 & F17 & 1 & Fragment & Amblema plicata \\
\hline $\mathrm{X}$ & E20\S94 & 16 & & 1 & Fragment & Thin shell thickness \\
\hline $\mathrm{X}$ & E20\S94 & 17 & & 1 & Fragment & Thick shell thickness \\
\hline $\mathrm{X}$ & E20\S96 & 16 & & 2 & Fragment & Medium shell thickness \\
\hline $\mathrm{X}$ & E20 598 & 13 & & 1 & Fragment & Medium shell thickness \\
\hline $\mathrm{X}$ & E20\S98 & 15 & & 1 & Fragment & Thin shell thickness \\
\hline $\mathrm{X}$ & E22\S88 & 18 & & 1 & Valve fragment & Lampsilis teres \\
\hline $\mathrm{X}$ & E22\S88 & 18 & & 1 & Valve fragment & Amblema plicata \\
\hline $\mathrm{X}$ & E22ไS88 & 19 & & 3 & Fragment & Medium shell thickness \\
\hline $\mathrm{X}$ & E22\S88 & 26 & & 1 & Fragment & Medium shell thickness \\
\hline $\mathrm{X}$ & E22\S90 & 15 & F19/104 & 2 & Fragment & Thin to medium shell thickness \\
\hline $\mathrm{X}$ & E22\S90 & 16 & F19/104 & 1 & Fragment & Medium shell thickness \\
\hline $\mathrm{X}$ & $\mathrm{E} 22 \mathrm{~S} 90$ & 18 & F19/104 & 1 & Fragment & Thin shell thickness \\
\hline $\mathrm{X}$ & E22\S90 & 18 & F19/104 & 1 & Fragment & Thin to medium shell thickness \\
\hline $\mathrm{X}$ & E22\S90 & 18 & F19/104 & 2 & Fragment & Thin to medium shell thickness \\
\hline $\mathrm{X}$ & E22ไS90 & 18 & F19/104 & 2 & Fragment & Thin shell thickness \\
\hline $\mathrm{X}$ & E22\S90 & 19 & & 1 & Fragment & Medium shell thickness \\
\hline $\mathrm{X}$ & E22ไS90 & 21 & & 1 & Fragment & Medium shell thickness \\
\hline $\mathrm{X}$ & E22ไS90 & 23 & & 1 & Fragment & Thin to medium shell thickness \\
\hline $\mathrm{X} / \mathrm{II}$ & E20\S86 & 18 & & 2 & Fragment & Thin to medium shell thickness \\
\hline $\mathrm{X} / \mathrm{II}$ & E20、S86 & 19 & & 2 & Fragment & Medium to thick shell thickness, bleached \\
\hline $\mathrm{X} / \mathrm{II}$ & E22ไS84 & 20 & & 1 & Fragment & Thin to medium shell thickness \\
\hline $\mathrm{X} / \mathrm{II}$ & E22\S86 & 18 & & 1 & Fragment & Medium shell thickness \\
\hline $\mathrm{X} / \mathrm{II}$ & E22\S86 & 20 & & 1 & Fragment & Medium shell thickness \\
\hline II & E20 \S84 & 19 & & 1 & Fragment & Medium shell thickness \\
\hline II & E20 \S84 & 20 & & 1 & Fragment & Medium to thick shell thickness, leached \\
\hline II & E22ไS82 & 20 & & 1 & Fragment & Thin to medium shell thickness \\
\hline II & E22ไS84 & 18 & & 1 & Fragment & Medium shell thickness \\
\hline $\mathrm{Id} / \mathrm{II}$ & E22ไS82 & 23 & & 1 & Fragment & Medium shell thickness \\
\hline Id/II & E22ไS82 & 23 & & 1 & Hinge fragment & Lampsilis teres \\
\hline
\end{tabular}

TARL Excavations, Valley Floor:

\begin{tabular}{l|l} 
IIIc/FILL & 11 \\
IIIc/FILL & 21 \\
IIIc/FILL & 13 \\
IIIc/FILL & 16 \\
IIIc/FILL & 12 \\
IIIc/FILL & 13 \\
IIIb/c/FIL & 19 \\
IIIc & 14 \\
IIIc & 16 \\
IIIc & 16
\end{tabular}

2
5
2
2
$2-3$
2
$8 \mathrm{~A}$
5
$6 \mathrm{~A}$
4

\begin{tabular}{l|l}
5 & Fragment \\
3 & Fragment \\
1 & Fragment \\
1 & Fragment \\
3 & Fragment \\
1 & Fragment \\
1 & Valve \\
1 & Fragment \\
1 & Hinge fragme \\
2 & Fragment
\end{tabular}

Medium shell thickness

Thick shell thickness, possibly fossil or burned Thin shell thickness

Thin to medium shell thickness

Thin to medium shell thickness

Medium shell thickness

Lampsilis teres

Thin shell thickness

\begin{tabular}{l|l}
16 & 4
\end{tabular}


Table 37-13, continued

\begin{tabular}{|c|c|c|c|c|c|c|}
\hline Unit & Square & Level & Feature & Number & Analyzed Part & Identification \\
\hline IIIc & 14 & 5 & & 1 & Fragment & Thin shell thickness \\
\hline IIIc & 15 & $6 \mathrm{~A}$ & & 1 & Fragment & Thin shell thickness \\
\hline IIIc & 15 & 3 & & 1 & Pseudocardinal & Thin shell thickness \\
\hline IIIc & 15 & 3 & & 1 & Fragment & Medium shell thickness \\
\hline IIIc & 100 & 4 & BRM 1 & 4 & Fragment & Thin shell thickness \\
\hline IIIc & 16 & 4 & & 1 & Hinge fragment & $\begin{array}{l}\text { Probably Toxolasma texasensis, burned, large } \\
\text { only partial hinge }\end{array}$ \\
\hline IIIc & 12 & 4 & & 1 & Valve & Medium shell thickness \\
\hline IIIc & 14 & 3 & & 1 & Pseudocardinal & Thin shell thickness \\
\hline IIIc & 17 & 4 & & 1 & Fragment & Thin shell thickness \\
\hline IIIc & 22 & 6 & & 2 & Fragment & Medium shell thickness \\
\hline IIIc & 17 & 4 & & 1 & Hinge fragment & Lampsilis teres \\
\hline IIIc & 11 & 3 & & 1 & FV & Potamilus purpuratus, missing posterior part \\
\hline IIIc & 11 & 4 & & 1 & Fragment & Medium shell thickness \\
\hline IIIc & 17 & 4 & & 1 & Fragment & Medium to thick shell thickness \\
\hline IIIc & 22 & 7 & & 4 & Fragment & Medium to thick shell thickness, probably $\mathrm{MNI}=1$ \\
\hline $\mathrm{IIIb} / \mathrm{c}$ & 16 & 9 & & 1 & Fragment & Medium shell thickness \\
\hline $\mathrm{IIIb} / \mathrm{c}$ & 16 & $7 \mathrm{~A}$ & & 1 & Fragment & Thin to medium shell thickness \\
\hline $\mathrm{IIIb} / \mathrm{c}$ & 11 & 5 & & 1 & Hinge fragment & Amblema plicata \\
\hline $\mathrm{IIIb} / \mathrm{c}$ & 14 & 7 & & 1 & Fragment & Thick shell thickness, burned \\
\hline $\mathrm{IIIb} / \mathrm{c}$ & 37 & 10 & & 2 & Fragment & Thin to medium shell thickness \\
\hline $\mathrm{IIIb} / \mathrm{c}$ & 15 & 8 & & 1 & Hinge fragment & Probably Toxolasma texasensis \\
\hline $\mathrm{IIIb}$ & 21 & 14 & & 7 & Fragment & Medium shell thickness \\
\hline IIIb & 25 & 16 & & 1 & Fragment & Thin to medium shell thickness \\
\hline IIIb & 22 & 14 & & 1 & Fragment & Thin shell thickness \\
\hline IIIb & 25 & 17 & & 2 & Fragment & Thin to medium shell thickness \\
\hline IIIb & 20 & $12 \mathrm{~A}$ & & 1 & Fragment & Thin to medium shell thickness \\
\hline IIIb & 19 & $14 \mathrm{~A}$ & & 1 & Fragment & Thin to medium shell thickness \\
\hline IIIb & 25 & 15 & & 1 & Fragment & Thin shell thickness \\
\hline IIIb & 19 & 11 & & 1 & Fragment & Medium shell thickness, burned \\
\hline IIIb & 19 & 11 & & 1 & Fragment & Thin shell thickness \\
\hline IIIb & 18 & 13 & & 1 & Fragment & Thin to medium shell thickness \\
\hline IIIb & 17 & 10 & & 2 & Fragment & Medium shell thickness \\
\hline IIIb & 17 & 9 & & 1 & Fragment & Medium shell thickness \\
\hline IIIb & 16 & $12 \mathrm{~A}$ & & 1 & Fragment & Thin shell thickness \\
\hline IIIb & 16 & $11 \mathrm{~A}$ & & 1 & Hinge fragment & Probably Toxolasma texasensis \\
\hline IIIb & 15 & 11 & & 4 & Fragment & Thin to medium shell thickness \\
\hline IIIb & 14 & 11 & & 1 & Fragment & Thin shell thickness \\
\hline IIIb & 19 & $14 \mathrm{~A}$ & & 2 & Fragment & Medium shell thickness, 1 probably burned \\
\hline IIIb & 13 & 9 & & 1 & Fragment & Medium shell thickness \\
\hline IIIb & 38 & 10 & & 2 & Pseudocardinal & Medium to thick shell thickness \\
\hline IIIb & 38 & $12 \mathrm{~A}$ & & 10 & Valve & Medium shell thickness \\
\hline IIIb & 27 & 15 & & 1 & Fragment & Medium shell thickness \\
\hline IIIb & 22 & $12 \mathrm{~A}$ & & 1 & Fragment & Thin to medium shell thickness \\
\hline IIIb & 13 & 8 & & 1 & Fragment & Thin shell thickness \\
\hline IIIb & 11 & 10 & & 1 & Hinge fragment & Toxolasma texasensis \\
\hline IIIb & 37 & 13B & 212 & 2 & Fragment & Thin shell thickness \\
\hline IIIb & 13 & $11 \mathrm{~A}$ & & 1 & Fragment & Medium shell thickness \\
\hline $\mathrm{IIIa} / \mathrm{b}$ & 13 & 13 & & 1 & Hinge fragment & Amblema plicata \\
\hline $\mathrm{IIIa} / \mathrm{b}$ & 52 & 17 & & 1 & Fragment & Thin shell thickness \\
\hline $\mathrm{IIIa} / \mathrm{b}$ & 35 & 14 & & 3 & Fragment & Medium shell thickness \\
\hline $\mathrm{IIIa} / \mathrm{b}$ & 37 & 14 & & 2 & Fragment & Thin to medium shell thickness \\
\hline $\mathrm{IIIa} / \mathrm{b}$ & 27 & 17 & & 2 & Fragment & Thin to medium shell thickness \\
\hline
\end{tabular}


Table 37-13, continued

\begin{tabular}{|c|c|c|c|c|c|c|}
\hline Unit & Square & Level & Feature & Number & Analyzed Part & Identification \\
\hline $\mathrm{IIIa} / \mathrm{b}$ & 15 & 13 & & 1 & Fragment & Thin to medium shell thickness \\
\hline $\mathrm{IIIa} / \mathrm{b}$ & 15 & 12 & & 1 & Fragment & Thin shell thickness \\
\hline $\mathrm{IIIa} / \mathrm{b}$ & 38 & 16 & & 1 & Hinge fragment & Medium shell thickness \\
\hline $\mathrm{IIIa} / \mathrm{b}$ & 13 & $12 \mathrm{~A}$ & & 5 & Fragment & Thin to medium shell thickness \\
\hline IIIa & 14 & 14 & & 1 & Fragment & Thin shell thickness \\
\hline IIIa & 14 & 15 & & 4 & Fragment & Thin shell thickness \\
\hline IIIa & 14 & 16 & & 4 & Fragment & Thin to medium shell thickness \\
\hline IIIa & 12 & 19 & & 1 & Fragment & Thin shell thickness \\
\hline IIIa & 25 & 22 & & 1 & Fragment & Thin to medium shell thickness \\
\hline IIIa & 25 & 25 & & 4 & Fragment & Thin shell thickness \\
\hline IIIa & 12 & 19 & & 1 & Fragment & Medium shell thickness \\
\hline IIIa & 32 & 15 & & 1 & Pseudocardinal & Medium shell thickness \\
\hline IIIa & 33 & 19 & 231 & 2 & Fragment & Thin shell thickness \\
\hline IIIa & 30 & 14 & & 1 & Fragment & Medium shell thickness \\
\hline IIIa & 28 & 25 & 245 & 1 & Fragment & Thin shell thickness \\
\hline IIIa & 28 & 24 & 245 & 1 & Fragment & Thin shell thickness \\
\hline IIIa & 28 & 24 & 245 & 1 & Hinge fragment & Thin to medium shell thickness \\
\hline IIIa & 28 & 22 & 231 & 1 & Hinge fragment & Potamilus purpuratus, burned \\
\hline IIIa & 26 & 26 & & 1 & Valve & Probably Leptodea fragilis \\
\hline IIIa & 28 & 20 & 231 & 1 & Hinge fragment & Lampsilis sp., small individual \\
\hline IIIa & 26 & 22 & & 20 & Valve & Probably Lampsilis sp., $\mathrm{MNI}=1$ \\
\hline IIIa & 27 & $24-25$ & 231 & 4 & Fragment & Thin to medium shell thickness \\
\hline IIIa & 27 & 22 & 225 & 1 & Hinge fragment & Lampsilis teres \\
\hline IIIa & 30 & 16 & & 4 & Fragment & Medium shell thickness \\
\hline IIIa & 26 & 26 & & 5 & Fragment & Thin shell thickness \\
\hline IIIa & 28 & 21 & 231 & 1 & Hinge fragment & Thin shell thickness, very small individual \\
\hline IIIa & 26 & 25 & & 1 & Pseudocardinal & Thin to medium shell thickness \\
\hline IIIa & 34 & 18 & & 1 & Fragment & Thin shell thickness \\
\hline IIIa & 44 & 25 & 245 & 1 & Valve & Thin shell thickness \\
\hline IIIa & 39 & 20 & 231 & 1 & Fragment & Thin shell thickness \\
\hline IIIa & 39 & $21 \mathrm{~A}$ & 231 & 2 & Fragment & Thin shell thickness \\
\hline IIIa & 39 & $22 \mathrm{~B}$ & 230 & 4 & Fragment & Thin to medium shell thickness \\
\hline IIIa & 39 & 23 & 231 & 1 & Entire valve & Lampsilis teres \\
\hline IIIa & 39 & 23 & 231 & 4 & Fragment & Thin shell thickness \\
\hline IIIa & 39 & 24 & 231 & 1 & Fragment & Thin shell thickness, breaks like $U$. tetralasmus \\
\hline IIIa & 41 & 22 & & 1 & Fragment & Thin to medium shell thickness \\
\hline IIIa & 42 & 26 & & 1 & Fragment & Medium shell thickness \\
\hline IIIa & 38 & 23 & 231 & 1 & Hinge fragment & Lampsilis teres \\
\hline IIIa & 44 & 20 & 231 & 1 & Hinge fragment & Toxolasma texasensis, very small individual \\
\hline IIIa & 50 & 17 & & 4 & Fragment & Medium shell thickness \\
\hline IIIa & 46 & 18 & & 2 & Fragment & Thin to medium shell thickness \\
\hline IIIa & 47 & 18 & & 1 & Fragment & Thin to medium shell thickness \\
\hline IIIa & 48 & 19 & 231 & 3 & Fragment & Thin to medium shell thickness \\
\hline IIIa & 49 & 17 & & 1 & Hinge fragment & Toxolasma texasensis \\
\hline IIIa & 49 & 18 & & 1 & Fragment & Medium shell thickness \\
\hline IIIa & 49 & 20 & 231 & 1 & Hinge fragment & Lampsilis teres \\
\hline IIIa & 49 & 21 & 231 & 1 & Hinge fragment & Toxolasma texasensis \\
\hline IIIa & 52 & 20 & 231 & 1 & Fragment & Thin shell thickness \\
\hline IIIa & 52 & 22 & 231 & 4 & Fragment & Thin shell thickness \\
\hline IIIa & 52 & 23 & 231 & 1 & Fragment & Thin shell thickness \\
\hline IIIa & 43 & 22 & 231 & 1 & Hinge fragment & Toxolasma texasensis \\
\hline IIIa & 34 & 15 & & 2 & Fragment & Thin to medium shell thickness \\
\hline IIIa & 34 & 21 & 231 & 1 & Hinge fragment & Potamilus purpuratus \\
\hline
\end{tabular}


Table 37-13, continued

\begin{tabular}{|c|c|c|c|c|c|c|}
\hline Unit & Square & Level & Feature & Number & Analyzed Part & Identification \\
\hline IIIa & 38 & 19 & & 3 & Pseudocardinal & Thin to medium shell thickness \\
\hline IIIa & 35 & 21 & 231 & 2 & Fragment & Thin shell thickness \\
\hline IIIa & 37 & 22 & 231 & 3 & Fragment & Thin shell thickness \\
\hline IIIa & 37 & 21 & 231 & 1 & Fragment & Thin shell thickness \\
\hline IIIa & 37 & 18 & & 2 & Fragment & Medium shell thickness \\
\hline II/IIIa & 28 & 28 & & 1 & Fragment & Thin shell thickness, possibly burned \\
\hline II/IIIa & 38 & $25 \mathrm{~B}$ & 231 & 1 & Fragment & Thin shell thickness \\
\hline II/IIIa & 33 & 23 & & 2 & Fragment & Thin shell thickness \\
\hline II/IIIa & 34 & $23 \mathrm{~A}$ & 231 & 6 & Fragment & Thin shell thickness \\
\hline II/IIIa & 34 & 24 & 231 & 2 & Fragment & Thin shell thickness \\
\hline II/IIIa & 38 & 24B- & 231 & 1 & Fragment & Thin shell thickness \\
\hline II/IIIa & 33 & 22 & & 1 & Fragment & Thin shell thickness \\
\hline II/IIIa & 38 & 24 & 231 & 1 & Fragment & Thin shell thickness \\
\hline II/IIIa & 33 & 21 & & 2 & Fragment & Thin shell thickness \\
\hline II/IIIa & 34 & 22 & 231 & 1 & Fragment & Medium shell thickness \\
\hline II/IIIa & 38 & 24 & 231 & 2 & Fragment & Thin shell thickness \\
\hline II/IIIa & 28 & $30 \mathrm{~A}$ & & 1 & Fragment & Thin shell thickness \\
\hline II/IIIa & 30 & 19 & & 1 & Valve & Probably Lampsilis sp. \\
\hline II/IIIa & 35 & 23 & & 1 & Fragment & Thin to medium shell thickness \\
\hline II/IIIa & 35 & 24 & & 1 & Hinge fragment & Uniomerus tetralasmus \\
\hline II/IIIa & 37 & 25 & & 1 & Hinge fragment & Potamilus purpuratus \\
\hline II/IIIa & 37 & $24 \mathrm{~A}$ & & 10 & Fragment & Medium shell thickness, probably $\mathrm{MNI}=1$ \\
\hline II/IIIa & 30 & 18 & & 4 & Fragment & Thin to medium shell thickness \\
\hline II/IIIa & 28 & $27 \mathrm{~B}$ & 245 & 1 & Fragment & Thin shell thickness \\
\hline II/IIIa & 42 & 29 & & 1 & Fragment & Thin shell thickness \\
\hline II/IIIa & 32 & $20 \mathrm{~A}$ & & 7 & Fragment & Thin to medium shell thickness \\
\hline II/IIIa & 32 & 22 & & 10 & Fragment & Thin shell thickness \\
\hline II/IIIa & 35 & 22 & 231 & 1 & Fragment & Thin shell thickness \\
\hline II/IIIa & 25 & 27 & & 1 & Fragment & Medium shell thickness \\
\hline II/IIIa & 49 & 22 & 231 & 1 & Fragment & Thin shell thickness \\
\hline II/IIIa & 51 & 27B & 249 & 1 & Hinge fragment & Amblema plicata \\
\hline II/IIIa & 25 & 28 & & 1 & Fragment & Thin shell thickness \\
\hline II/IIIa & 52 & 24 & 231 & 1 & Fragment & Thin shell thickness \\
\hline II/IIIa & 52 & $25 \mathrm{~B}$ & 231 & 1 & Fragment & Thin shell thickness \\
\hline II/IIIa & 48 & 21 & & 3 & Fragment & Thin to medium shell thickness \\
\hline II/IIIa & 26 & 27 & & 4 & Valve fragment & Medium shell thickness \\
\hline II/IIIa & 26 & 28 & & 1 & Pseudocardinal & Thin to medium shell thickness \\
\hline II/IIIa & 26 & 29 & & 1 & Fragment & Thin shell thickness \\
\hline II/IIIa & 51 & 26 & 231 & 6 & Fragment & Thin shell thickness \\
\hline II/IIIIa & 52 & $26 \mathrm{~B}$ & 231 & 1 & Fragment & Thin to medium shell thickness \\
\hline II/IIIa & 44 & 27 & & 3 & Fragment & Thin shell thickness \\
\hline II/IIIa & 41 & 27 & & 1 & Fragment & Thin shell thickness \\
\hline II/IIIa & 27 & 26 & 231 & 4 & Fragment & Thin shell thickness \\
\hline II/IIIa & 27 & $27 \mathrm{~A}$ & & 1 & Fragment & Thin shell thickness \\
\hline II/IIIa & 43 & 27 & & 1 & Fragment & Thin shell thickness \\
\hline II/IIIa & 39 & 25 & 231 & 4 & Fragment & Thin shell thickness \\
\hline II/IIIa & 25 & 26 & & 11 & Fragment & Thin shell thickness, MNI=1 \\
\hline II/IIIa & 46 & $21 \mathrm{~A}$ & & 2 & Fragment & Thin to medium shell thickness \\
\hline II & 30 & 23 & & 2 & Fragment & Thin shell thickness \\
\hline II & 47 & 25 & & 1 & Hinge fragment & Thin to medium shell thickness \\
\hline II & 26 & 32 & & 4 & Fragment & Thin shell thickness \\
\hline II & 26 & 35 & & 1 & Fragment & Thin to medium shell thickness \\
\hline II & 46 & $28 \mathrm{~A}$ & & 1 & Fragment & Thin shell thickness \\
\hline
\end{tabular}


Table 37-13, continued

\begin{tabular}{|c|c|c|c|c|c|c|}
\hline Unit & Square & Level & Feature & Number & Analyzed Part & Identification \\
\hline II & 46 & $27 \mathrm{~B}$ & 232 & 10 & Fragment & Medium shell thickness \\
\hline II & 46 & $27 \mathrm{~B}$ & 232 & 1 & Entire valve & Toxolasma texasensis \\
\hline II & 37 & 28 & & 1 & Fragment & Thin shell thickness \\
\hline II & $37 / 32$ & $27 \& 37$ & & 1 & Fragment & Thin shell thickness \\
\hline II & 37 & 30 & & 1 & Fragment & Thin shell thickness \\
\hline II & 39 & 32 & & 1 & Entire valve & Potamilus purpuratus \\
\hline II & 39 & 29 & & 1 & Hinge fragment & Probably Toxolasma texasensis \\
\hline II & 39 & 30 & & 1 & Fragment & Thin shell thickness \\
\hline II & 28 & 33 & & 1 & Fragment & Thin shell thickness \\
\hline II & 27 & 32 & & 1 & Fragment & Thin shell thickness \\
\hline II & 28 & 32 & & 1 & Fragment & Thin shell thickness \\
\hline II & 27 & 34 & & 1 & Fragment & Medium shell thickness \\
\hline II & 33 & 29 & & 1 & Pseudocardinal & Thin to medium shell thickness \\
\hline II & 39 & 31 & & 2 & Fragment & Thin to medium shell thickness \\
\hline II & 45 & 21 & & 3 & Fragment & Thin shell thickness \\
\hline II & 35 & $26 \mathrm{~A}$ & & 1 & Fragment & Thin shell thickness \\
\hline II & 34 & $26 \mathrm{~A}$ & & 5 & Fragment & Thin shell thickness, $\mathrm{MNI}=1$ \\
\hline II & 53 & 28 & 248 & 1 & Hinge fragment & Lampsilis sp. \\
\hline II & 52 & 30 & & 1 & Fragment & Thin shell thickness \\
\hline II & 52 & $28 \mathrm{~A}$ & & 1 & Fragment & Thin shell thickness \\
\hline II & 35 & $31 \mathrm{~A}$ & & 5 & Fragment & Thin shell thickness \\
\hline II & 25 & 29 & & 1 & Fragment & Thin shell thickness \\
\hline II & 25 & 30 & & 1 & Entire valve & Lampsilis sp., probably teres \\
\hline II & 25 & 31 & & 1 & Fragment & Thin to medium shell thickness \\
\hline II & 52 & 28 & & 1 & Fragment & Thin shell thickness \\
\hline II & 35 & 29 & & 1 & Fragment & Thin shell thickness \\
\hline II & 25 & 33 & & 1 & Hinge fragment & Toxolasma texasensis \\
\hline II & 50 & $32 \mathrm{~A}$ & & 1 & Fragment & Thin shell thickness \\
\hline II & 35 & $30 \mathrm{~A}$ & & 1 & Fragment & Thin shell thickness \\
\hline II & 50 & 28 & & 1 & Fragment & Thin shell thickness \\
\hline II & 50 & $32 \mathrm{~B}$ & 249 & 1 & Fragment & Thin shell thickness \\
\hline $\mathrm{Id} / \mathrm{II}$ & 34 & $32 \mathrm{~A}$ & & 1 & Fragment & Thin shell thickness \\
\hline $\mathrm{Id} / \mathrm{II}$ & 35 & 34 & & 1 & Fragment & Thin shell thickness \\
\hline $\mathrm{Id} / \mathrm{II}$ & 59 & 36 & & 1 & Hinge fragment & Toxolasma texasensis \\
\hline Isi-c/II & 25 & 36 & & 1 & Entire valve & Lampsilis teres \\
\hline Isi-c/II & 25 & 37 & & 1 & Fragment & Thin shell thickness \\
\hline Id & 57 & 35 & & 1 & Fragment & Thin shell thickness \\
\hline Isi-c/Id & 56 & 36 & & 1 & Fragment & Thin shell thickness \\
\hline Isi-c/Id & 56 & 38 & & 1 & Pseudocardinal & Thin shell thickness \\
\hline Isi-c/Id & 28 & 38 & & 1 & Fragment & Thin shell thickness \\
\hline Isi-c/Id & 33 & 34 & & 1 & Hinge fragment & Potamilus purpuratus \\
\hline Isi-c/Id & 32 & 34 & & 1 & Fragment & Thin to medium shell thickness \\
\hline Isi-c & 46 & 32 & & 2 & Fragment & Thin shell thickness \\
\hline Isi-c & 30 & 32 & & 5 & Fragment & Thin to medium shell thickness, $\mathrm{MNI}=1$ \\
\hline Isi-c & 46 & 33 & & 1 & Fragment & Thin shell thickness \\
\hline Isi-c & 35 & 40 & & 1 & Fragment & Thin shell thickness \\
\hline Isi-c & 30 & $33 \mathrm{~A}$ & & 1 & Fragment & Thin shell thickness \\
\hline Isi-c & 28 & 42 & & 2 & Fragment & Thin shell thickness \\
\hline Isi-c & 28 & 41 & & 2 & Fragment & Thin to medium shell thickness \\
\hline Isi/Isi-c & 32 & 36 & & 1 & Fragment & Thin shell thickness \\
\hline Isi/Isi-c & 32 & 35 & & 3 & Fragment & Medium shell thickness \\
\hline Isi/Isi-c & 57 & 40 & & 2 & Fragment & Thin shell thickness \\
\hline Isi/Isi-c & 46 & 37 & & 1 & Fragment & Thin shell thickness \\
\hline
\end{tabular}


Table 37-13, continued

\begin{tabular}{|c|c|c|c|c|c|c|}
\hline Unit & Square & Level & Feature & Number & Analyzed Part & Identification \\
\hline Isi/Icl/Isi-c & 57 & 41 & & 1 & Fragment & Thin shell thickness \\
\hline Icl & 58 & 47 & & 1 & Fragment & Medium shell thickness, burned \\
\hline Isi & 56 & 46 & & 1 & Fragment & Thin shell thickness \\
\hline Isi & 30 & 43 & & 1 & Fragment & Thin shell thickness \\
\hline Isi & 55 & 49 & & 1 & Fragment & Thin shell thickness \\
\hline Igl & 28 & 59 & & 1 & Fragment & Thin shell thickness, burned, possibly gastropod \\
\hline \multicolumn{7}{|c|}{ Valley Margin: } \\
\hline IIIc & 100 & 3 & BRM 1 & 1 & Valve & Lampsilis sp. \\
\hline IIIc & 100 & 3 & BRM 1 & 4 & Fragment & Thick shell thickness, burned \\
\hline IIIc & 100 & 7 & BRM 1 & 1 & Fragment & Thin shell thickness \\
\hline IIIc & 100 & 7 & BRM 1 & 1 & Fragment & Medium shell thickness, burned or fossil \\
\hline IIIc & 100 & 6 & BRM 1 & 7 & Fragment & Thin shell thickness \\
\hline IIIc & 100 & 2 & BRM 1 & 1 & Pseudocardinal & Probably Potamilus purpuratus, very small \\
\hline Y & 100 & 10 & & 1 & Entire valve & Quadrula sp., probably Q. pustulosa, small individual, 2 \\
\hline $\mathrm{Y}$ & 100 & 11 & & 4 & Fragment & Thin shell thickness \\
\hline $\mathrm{Y}$ & 101 & 12 & & 1 & Fragment & Thin shell thickness \\
\hline $\mathrm{X}$ & 101 & 17 & & 4 & Fragment & Thin to medium shell thickness \\
\hline $\mathrm{X}$ & 101 & 16 & & 1 & Fragment & Thin shell thickness \\
\hline Unknown & Unknown & & & 1 & Pseudocardinal & Medium shell thickness \\
\hline Unknown & Unknown & & & 2 & Hinge fragment & Potamilus purpuratus, $\mathrm{MNI}=2$ \\
\hline
\end{tabular}

due to the damming of waterways and increased siltation, both of which would have expanded the favored habitat of $M$. nervosa. Evidence from a number of sites indicates the large shells of $M$. nervosa were modified for use as tools, particularly as hoes, and it is suspected that its presence at some sites reflects its transport from some distant source (Brown 1987; Murray 1982; Theler 1991).

There are only three examples of $M$. nervosa identified at the Wilson-Leonard site. One is from Unit IIIc, another is from Unit IIIb/c, and the third is from a disturbed/unknown context. The specimen from Unit $\mathrm{IIIb} / \mathrm{c}$ is heavily waterworn, suggesting it was collected postmortem. These shell fragments are from large individuals which suggests they were brought to the site from a larger waterway than that of Brushy Creek.

Quadrula pustulosa is found in larger waterways in a variety of substrates, often in areas of strong currents (Murray and Leonard 1962). Like M. nervosa, it can tolerate a wide range of water depths and is often found in deeper waters. Neck identified one of the Wilson-Leonard examples as Q.p. mortoni (from Unit IIIc) which is found in rivers in the east/central Texas area (Strecker 1931).

The second example from Wilson-Leonard was identified only as Quadrula sp., although it is probably of $Q$. pustulosa (see Tables 37-13 and 37-14). This second individual from Unit $\mathrm{IIb} / \mathrm{c}$ is very small (roughly $2 \mathrm{~cm}$ complete). A third specimen was recovered from the surface.

Uniomerus tetralasmus is a small, thin-shelled species found only in shallow waters with a mud substrate (Burch 1975; Murray and Leonard 1962; Parmalee 1967). This species is generally confined to small creeks with areas of slow- moving waters or in shallow lakes or ponds (Neck, this volume).

The seven examples of this species identified in the Wilson-Leonard assemblage came from upper Unit I (Icl/Isi$\mathrm{c}$ and Isi-c), Unit II, and several mixed stratigraphic units (contexts associated with lower to mid Unit III (II/IIIa, X/Y/ IIIb, Y/IIIc, and IIIc) (see Tables 37-13 and 37-14).

Lampsilis teres is a common species found at prehistoric sites near most types of waterways. Although the environmental tolerances of this species are broad, it tends to prefer the deeper water in creeks, smaller rivers, and lakes with slower currents (Burch 1975; Murray 1986; Murray and Leonard 1962; Parmalee 1967). This species is found in shallow to medium depths, with several subforms adapting best to differing depths. L. teres greatly prefers the soft silt and mud substrates.

Lampsilis teres was the most common species identified in the Wilson-Leonard assemblage with $48 \%$ of the shell identified to genus/species falling in this taxon. It was also found in all stratigraphic units except Unit Icl which overall had a very low number of shell fragments recovered (see Tables 37-13 and 37-14).

A second member of the genus Lampsilis, that of $L$. radiata, was identified by Neck from the TxDOT sample, and he gave it the subform L. r. hydiana. This species ranges from Arkansas and Alabama westward into Texas. The $L$. radiata tends to be found in larger waterways in areas of slow-moving water and a mud substrate. This species of Lampsilis was identified by Neck in only three cases with these examples recovered from stratigraphic Units II/IIIa and IIIa (see Tables 37-13 and 37-14). 
TABLE $37-14$

Distribution of Identified Mollusks by Stratigraphic Unit

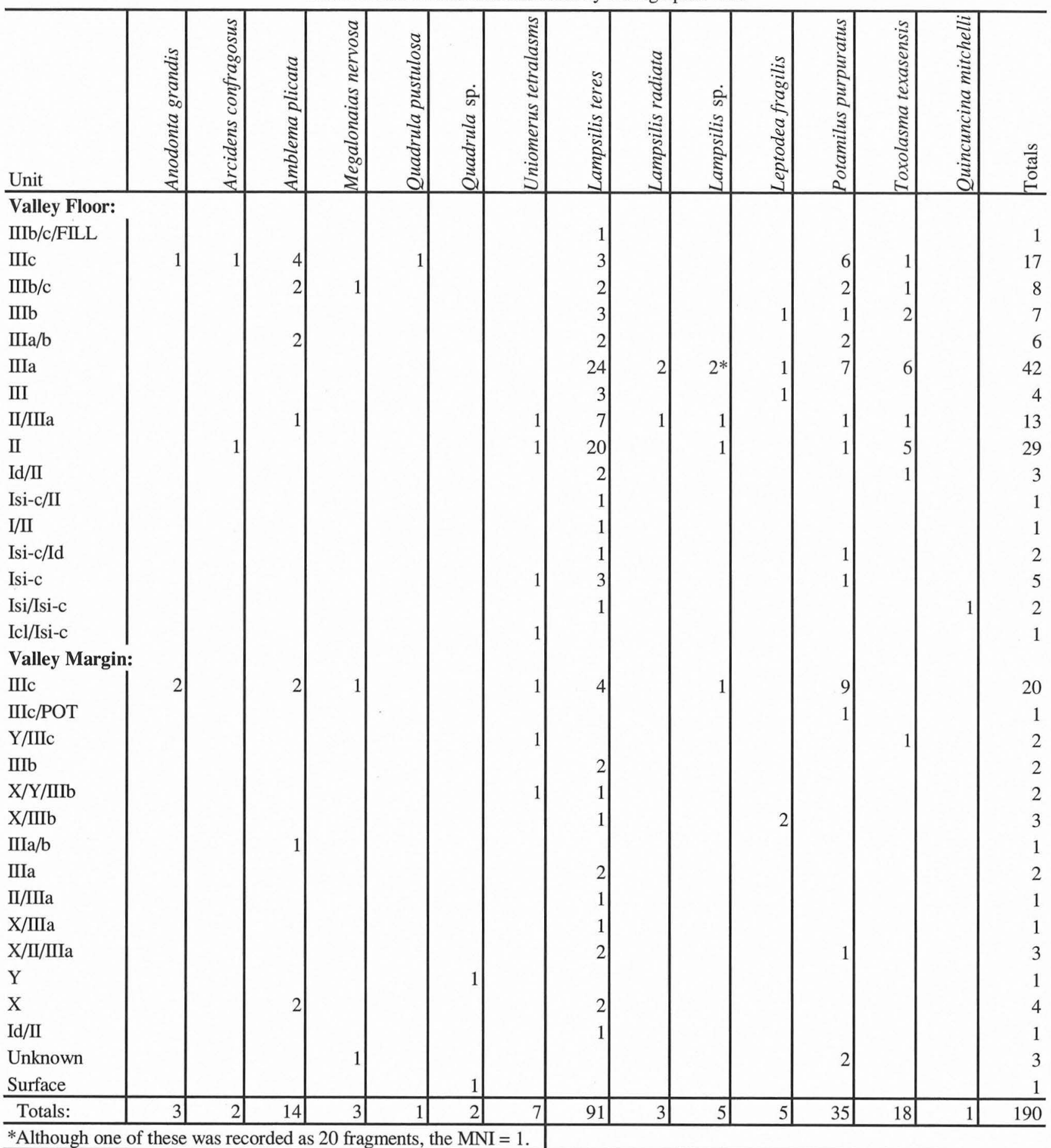

Leptodea fragilis, as the name implies, is a thin-shelled species that has a relatively high range of tolerances for different environmental conditions. It is generally found in larger waterways in areas of slower currents, although it can tolerate faster waters (Murray and Leonard 1962; Parmalee 1967). The substrate preference is generally sand or mud, but it has been known to occur in areas of coarser sub- strates. L. fragilis is also reasonably tolerant in terms of preferred water depth, being found in shallow to moderate (less than about 8 feet) depths.

Five examples of Leptodea fragilis were identified at Wilson-Leonard and these came from stratigraphic Units IIIa, IIIb, and undifferentiated III (see Tables 37-13 and 3714). 
Potamilus purpuratus is found in areas of slow-moving water in rivers and large creeks (Murray and Leonard 1962). It is generally found in moderate (above 2 feet) depths in soft substrates. P. purpuratus was the second most common species within the Wilson-Leonard assemblage making up 18\% of the shell identified at least to genus (see Tables $37-13$ and 37-14). It was found in most strata but was most numerous in stratigraphic Units IIIIa and IIIc. As a general observation, the examples of this species in the WilsonLeonard assemblage tended to be small and/or young individuals, suggesting they were collected in the shallower end of their tolerance range.

Toxolasma texasensis has a particularly restricted environmental tolerence range, being found only in shallow (generally 1 to 2 feet) of water with very slow currents or standing water (Parmalee 1967). This species occurs in smaller rivers, creeks, and lakes and is limited to a mud substrate.

Toxolasma texasensis was found in Units Id/II, II, II/ IIIa, IIIa, IIIIb, IIIb/c, and IIIIc with a slight increase (see Tables $37-13$ and 37-14), in Units II and IIIa. The narrow range of environmental tolerances for this species makes it a good indicator of habitat conditions.

Quincuncina mitchelli is reported by Neck (report on file) to be found today in central Texas in the major waterways. It prefers sand or gravel substrates. Only one example of this species was identified in the Wilson-Leonard sample, and this comes from stratigraphic Unit Isi/Isi-c (see Table 37-13).

A large sample of mussel shell from Wilson-Leonard was unidentifiable to species. These were coded as to the portion and the thickness of the shell. The number of shell fragments was also recorded, although it was counted as one if the fragments were clearly from the same shell. For the purposes of quantifying the unidentifiable shell (see Table 37-13), each bag lot (shell retrieved from the same provenience) was counted as one, unless a clear determination of more than one individual could be made. This errs on the conservative side, possibly underrepresenting the actual number of individuals represented in the assemblage. But this strategy provides a control along which comparisons between stratigraphic units can be made in a consistent manner.

The general frequency of shell represented by the unidentifiable specimens largely follows the distribution of the identifiable individuals (compare Tables 37-13 and 37-14). The frequency of shell in stratigraphic Units I and II (including lenses within these strata) tends to be low, with stratigraphic Units IIIa and IIIc having markedly higher frequencies (see Table 37-14). The thickness of the shell fragments also parallels the size ranges of the known species from the site. Thin- to medium-walled shell far outnumber the thickerwalled types (Table 37-15). This again parallels the higher frequency of thin-shelled species such as $L$. teres, $T$. texasensis, and smaller individuals of $P$. purpuratus, in contrast to a very low frequency of species with thick shells such as A. plicata or M. nervosa.

\section{Reconstruction of Mussel Habitats}

The use of freshwater mussel shells from archeological sites as indicators of associated aquatic habitats has been pursued most vigorously for the Mississippi River drainage system (e.g., Warren 1991). The value of considering archeological mussel data for habitat reconstruction was largely initiated by Matteson (1960) and continued to be of growing interest in the midwest and southeast regions of the U.S. where sites with freshwater shell were numerous (e.g., Parmalee et al. 1972). The use of mussel data in aquatic habitat reconstruction has not been strongly quantitative, making comparisons between sites or regions generally abstract. Warren (1991) has recently proposed a method that formulates the known environmental tolerances for a number of mussel species into both a qualitative and quantitative system for numeric comparison. While Warren's information is based on data from the Mississippi River drainage, the overlap of species in Central Texas with those in his sample allows the method to be applied to the Wilson-Leonard assemblage. The use of this comparative method for the Wilson-Leonard sample is presented only as a general but reconstructable way to compare the aquatic habitats reflected by the site's mussel sample, recognizing that as more species habitat data are collected on Texas populations, this reconstruction can be refined.

The method Warren (1991) developed ranks the known habitat data into three weighted values. He researched the literature on mussel habitats and compiled data for 133 species, 10 of which are found at the Wilson-Leonard site (excluding only Quincuncina mitchelli and Lampsilis radiata hydiana). Warren ranks each species for four habitat categories; (1) water-body type, (2) water depth, (3) current velocity, and (4) substrate composition. Each of the four categories are divided into descriptive types. The raw rankings for the species found at the Wilson-Leonard site are presented in Table 37-16 following Warren (1991:Table 1). A rank of " 1 " means this species is relatively common within a given condition, while a rank of ".5" denotes the species can be present but is relatively uncommon. A rank of " 0 " indicates the species is rare or absent under the given conditions. For example, the species A. grandis is coded for water-body type as being common in lakes and large and small creeks (coded at 1) but is uncommon (coded as .5) in all sizes of rivers (see Table 37-16). For water depth, Warren (1991:29) used 1-foot increments to rank species tolerances, while for current velocity he used four descriptive categories, which include swift, moderate, slow, and standing. Substrate composition is divided into six descriptive types that are widely used by mussel biologists, although he notes overlap may occur in how they are used. These include cobble-gravel, gravel, gravel-sand, sand, sand-mud, and mud. Warren (1991) provides more-specific definitions for each descriptive category in his article, and readers are encouraged to consult this original source for a more-detailed 
TABLE 37-15

Distribution of Thin-, Medium-, and Thick-walled Shells by Stratigraphic Unit

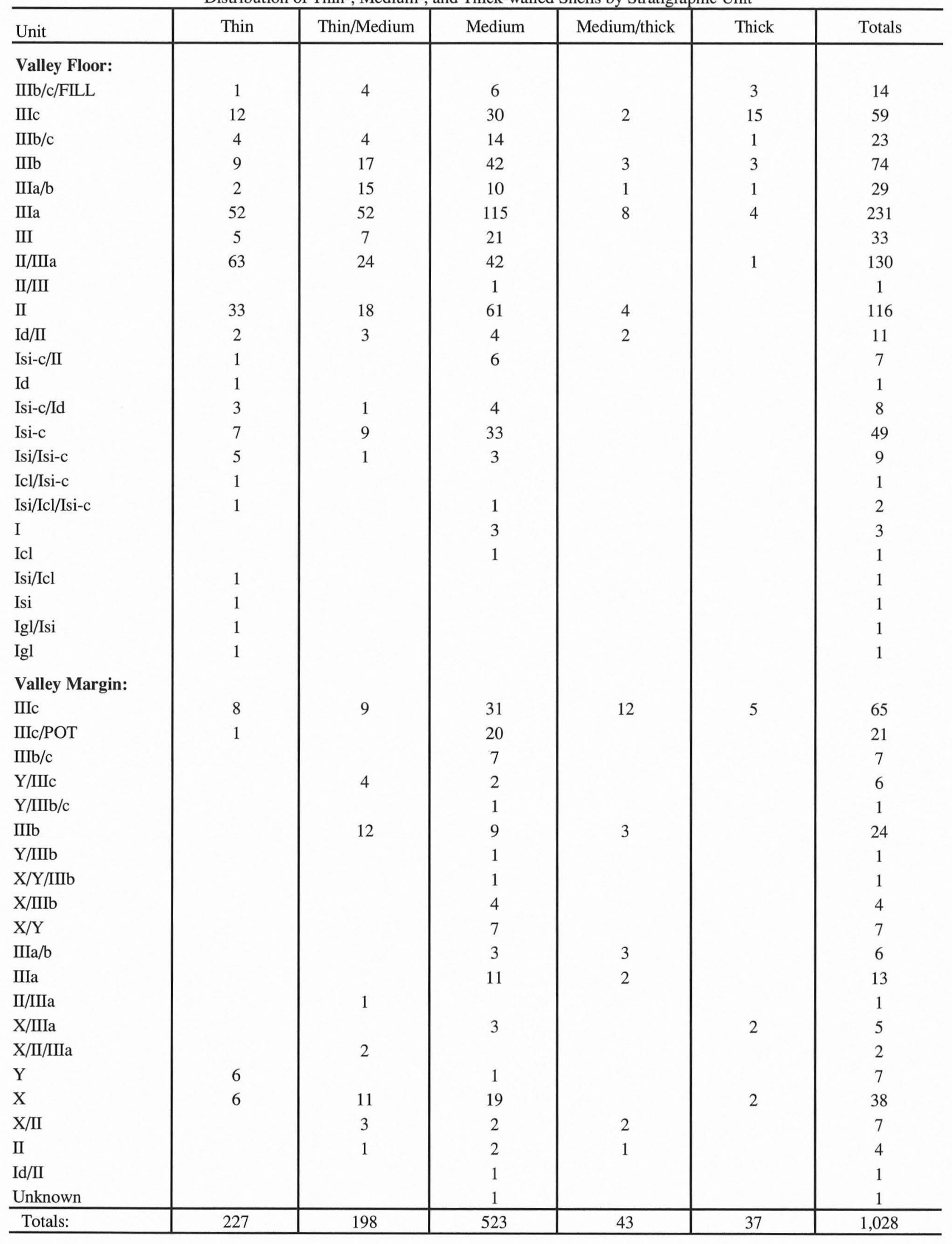


TABLE $37-16$

Rankings of Environmental Characteristics for the Wilson-Leonard Taxa

\begin{tabular}{|c|c|c|c|c|c|c|c|c|c|c|c|c|c|c|c|c|c|c|c|c|c|c|c|c|c|c|c|c|c|c|c|c|}
\hline & \multicolumn{6}{|c|}{ Water Body } & \multicolumn{16}{|c|}{ Water Depth (in feet) } & \multicolumn{4}{|c|}{ Current } & \multicolumn{6}{|c|}{ Substrate } \\
\hline & 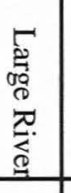 & 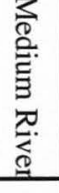 & 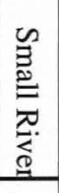 & 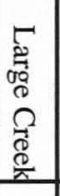 & 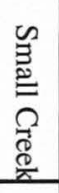 & 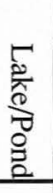 & 0 & 1 & 2 & 3 & 4 & 5 & 6 & 7 & 8 & 9 & 10 & 11 & 12 & 13 & 14 & 15 & 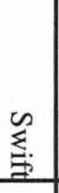 & $\begin{array}{l}3 \\
\frac{1}{0} \\
0 \\
\frac{0}{0} \\
\frac{0}{0} \\
\end{array}$ & $\frac{\Omega}{\vdots}$ & 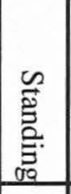 & 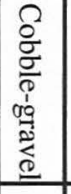 & 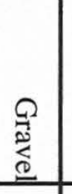 & 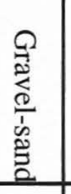 & $\begin{array}{l}\tilde{a} \\
\tilde{\Xi}\end{array}$ & 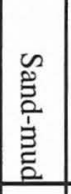 & 3. \\
\hline Anodonta grandis & 0.5 & 0.5 & 0.5 & 1 & 1 & 1 & 0 & 1 & 1 & 1 & 1 & 1 & 1 & 0 & 0 & 0 & 0 & 0 & 0 & 0 & 0 & 0 & 0 & 0 & 0.5 & 1 & 0 & 0 & 0 & 0.5 & 1 & 1 \\
\hline Arcidens confragosus & 1 & 1 & 0 & 0 & 0 & 1 & 1 & 1 & 1 & 1 & 1 & 0 & 0 & 0 & 0 & 0 & 0 & 0 & 0 & 0 & 0 & 0 & 0 & 0.5 & 1 & 1 & 0 & 0 & 0.5 & 1 & 1 & 1 \\
\hline Amblema plicata & 0 & 0.5 & 1 & 1 & 0 & 0 & 1 & 1 & 1 & 1 & 1 & 1 & 0 & 0 & 0 & 0 & 0 & 0 & 0 & 0 & 0 & 0 & 1 & 1 & 1 & 0.5 & 0.5 & 1 & 1 & 1 & 0.5 & 0.5 \\
\hline Megalonaias nervosa & 1 & 0.5 & 0.5 & 0 & 0 & 0 & 1 & 1 & 1 & 1 & 1 & 1 & 1 & 1 & 1 & 1 & 1 & 1 & 1 & 1 & 1 & 1 & 0 & 0 & 1 & 1 & 1 & 1 & 0 & 0 & 0 & 1 \\
\hline Quadrula pustulosa & 1 & 1 & 1 & 1 & 0 & 0 & 1 & 1 & 1 & 1 & 1 & 1 & 1 & 1 & 1 & 1 & 1 & 1 & 1 & 0.5 & 0.5 & 0.5 & 1 & 1 & 1 & 0 & 0.5 & 1 & 1 & 1 & 0.5 & 0.5 \\
\hline Uniomerus tetralasmus & 0 & 0 & 0 & 0 & 1 & 1 & 1 & 1 & 1 & 1 & 0 & 0 & 0 & 0 & 0 & 0 & 0 & 0 & 0 & 0 & 0 & 0 & 0 & 0 & 0 & 1 & 0 & 0 & 0 & 0 & 0 & 1 \\
\hline Lampsilis teres & 0.5 & 0.5 & 1 & 1 & 1 & 1 & 1 & 1 & 1 & 1 & 1 & 0 & 0 & 0 & 0 & 0 & 0 & 0 & 0 & 0 & 0 & 0 & 0 & 0.5 & 1 & 1 & 0 & 0 & 0 & 0 & 0 & 1 \\
\hline Leptodea fragilis & 1 & 0.5 & 0.5 & 0.5 & 0 & 0 & 1 & 1 & 1 & 1 & 1 & 1 & 1 & 1 & 1 & 0 & 0 & 0 & 0 & 0 & 0 & 0 & 0.5 & 0.5 & 1 & 1 & 0 & 0.5 & 0.5 & 1 & 1 & 1 \\
\hline Potamilus purpuratus & 1 & 1 & 1 & 0 & 0 & 0 & 0 & 0 & 0 & 1 & 1 & 1 & 1 & 1 & 1 & 1 & 1 & 1 & 1 & 1 & 1 & 1 & 0 & 0 & 1 & 1 & 0 & 0 & 0.5 & 0.5 & 0.5 & 1 \\
\hline Taxolasma texasensis & 0 & 0 & 1 & 1 & 1 & 1 & 0 & 1 & 1 & 0 & 0 & 0 & 0 & 0 & 0 & 0 & 0 & 0 & 0 & 0 & 0 & 0 & 0 & 0 & 0 & 1 & 0 & 0 & 0 & 0 & 0 & 0 \\
\hline
\end{tabular}


account of how this method was developed and is used.

The ranked habitat data are used for a "computational procedure for determining the habitat profile of a mussel assemblage" (Warren 1991:35). This can be done in a qualitative way in which the data are determined for each species present (as in Table 37-16) but with each species weighted equally. By multiplying each cell by the actual number of individuals of each species represented within a sample, the data can be quantified to reflect the significance of each species within that sample. These data can be turned into percentage values that indicate the numerical weight of each cell in relation to the total number of specimens in a sample. For example, if all the species represented in a sample are coded as " 1 " for a specific value (such as large creek), than that value would be $100 \%$. Each value (or cell) is ranked independently, so the percentage reflects ranking within but not between cells. Once these data have been converted to percentage values, they can be used to compare against other habitat profiles.

Warren's (1991) method is used here to help compare the habitat profiles indicated by three different cultural levels at the Wilson-Leonard site. It is used to sort out the various habitat indicators into a general picture of the aquatic conditions from which the mussels were collected to determine if there is any indication of change through time. As mentioned earlier, this habitat reconstruction is presented here to be used in general terms because of the use of reference data from outside Texas and because the WilsonLeonard samples are relatively small. This reconstruction can be useful for corroboration by other data from the site, such as freshwater gastropods, vertebrates, and soil/hydrological indicators. It is important to note that the following discussion is based on the assumption that the mussels found at Wilson-Leonard came from Brushy Creek near the site.

The three temporally discrete levels selected for comparison are stratigraphic Unit II (dating ca. 9500-8700 в.P.), stratigraphic Unit IIIa (ca. 8700 to $6000-6500$ B.P.), and stratigraphic Unit IIIc (roughly 4000-0 B.P.). Admittedly, these strata represent large blocks of time so habitat reconstructions will project only general conditions. These strata had the largest mussel shell samples, and in an effort to minimize any biases that might be imposed by small sample size, only these larger samples are used to develop habitat profiles. The raw data for each strata were calculated using the frequency data in Table 37-14 multiplied by the rank data presented in Table 37-16. The percentage values are used for comparison and are illustrated in graphic form.

The indications of water body type (Figure 37-1) for each stratigraphic unit show an interesting contrast between the earlier two strata and Unit IIIc. While a small river habitat is most pronounced for each stratum, the more-recent stratigraphic Unit IIIc suggests a shift toward a larger waterway. The occurrence of only one specimen of Toxolasma texasensis in this unit (see Table 37-14), which is generally

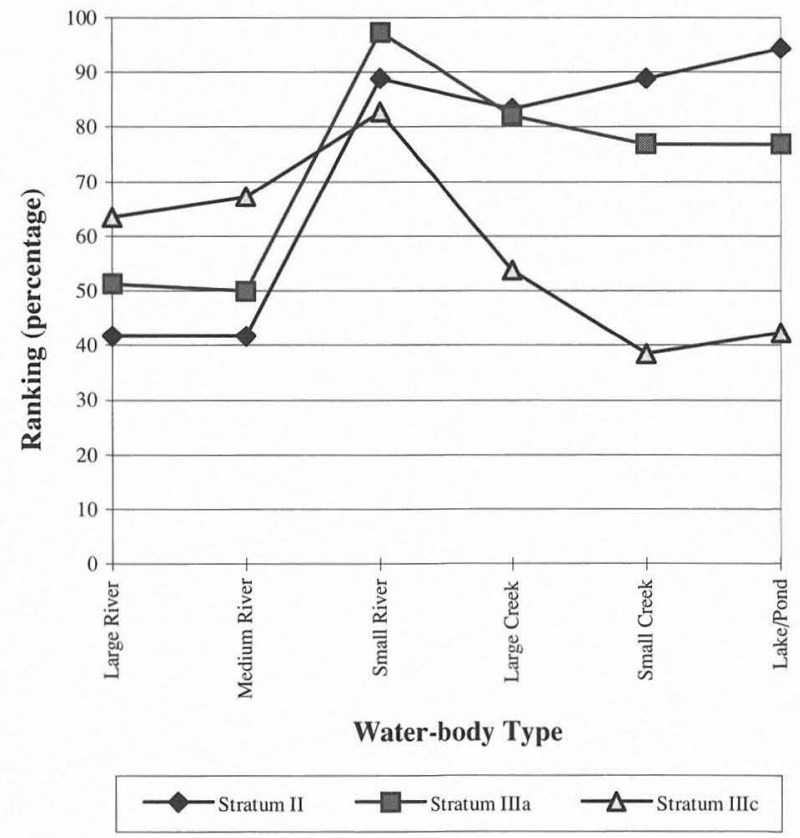

FIGURE 37-1. Comparison of water-body type rankings for Units II, IIIa, and IIIc.

restricted to shallow areas with little to no current, supports the decrease in such habitats that may be associated with a small creek or impounded water.

The evidence for water depth also suggests some differences between strata (Figure 37-2). The habitat profile generated from the Wilson-Leonard data suggests a trend toward deeper water conditions in more-recent times, although the continued presence of shallow water habitats would be expected. This trend, however, may be somewhat overemphasized in the profile data because it is caused by the higher proportional frequency of Potamilus purpuratus and the exclusive presence of Megalonaias nervosa and Quadrula pustulosa, all of which have a wide range of water-depth tolerances and therefore, could also be supported in shallower water (see Table 37-14). But the increase in frequency of deeper-water-tolerant species in stratigraphic Unit IIIc, and the low frequency of Toxolasma texasensis which favors very shallow water, does suggest a possible increase in the maximum water depths in more recent times.

The indicators for current velocity for the three stratigraphic units under comparison show less clear distinctions between each sample (Figure 37-3). The data indicate a slowmoving current (1-24 cm per second), possibly with areas of standing water. The evidence for greater current velocity in the later strata is generally due to the wide tolerances of Amblema plicata, while the relatively high frequency of Potamilus purpuratus in Unit IIIc, which favors slow currents, probably more accurately reflects the conditions in Brushy Creek.

The last category under consideration, that of substrate composition, is strongly weighted toward soft, particularly 

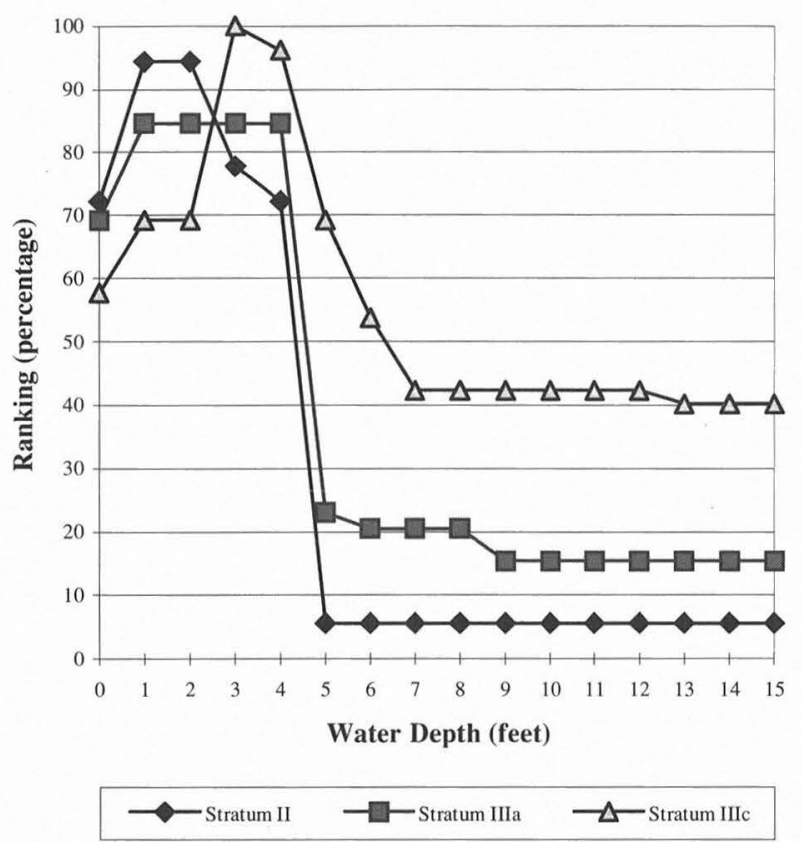

FIGURE 37-2. Comparison of water depth rankings for Units II, IIIa, and IIIc.

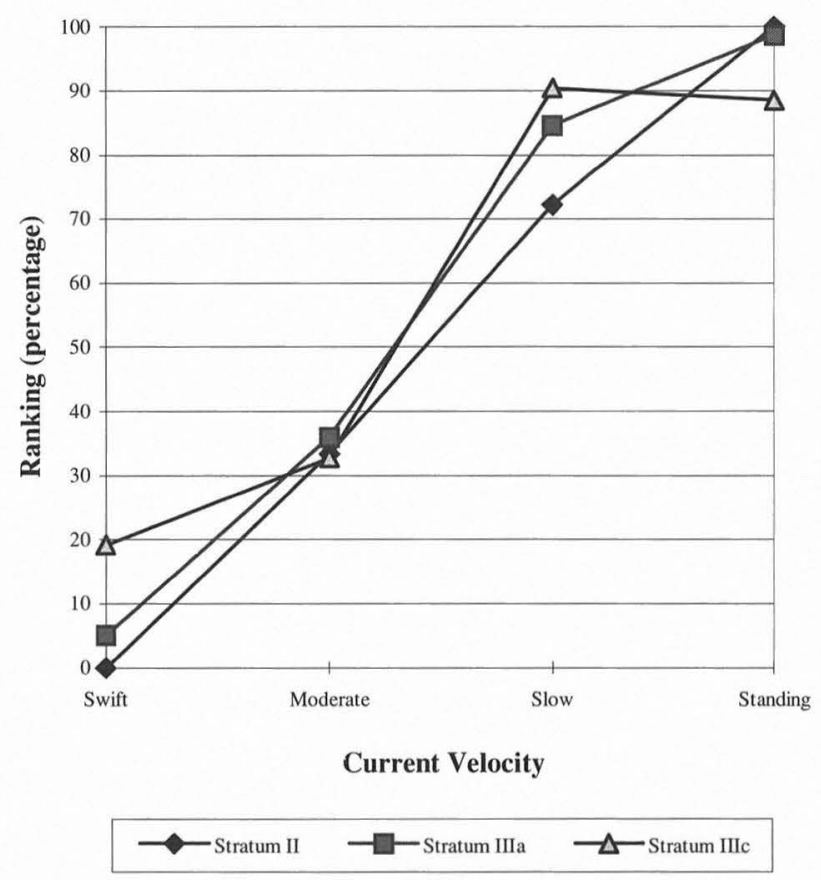

FIGURE 37-3. Comparison of current velocity for Units II, IIIa, and IIIc.

mud, substrates (Figure 37-4). Warren (1991:30) defines mud as consisting of silt and clay. The profile for stratigraphic Unit IIIc suggests the possibility that several substrates can be found in Brushy Creek, but no species intolerant of a mud substrate were found, leaving the possibility that only the mud substrate existed. The generalization that thickwalled species tend to avoid soft substrates coupled with

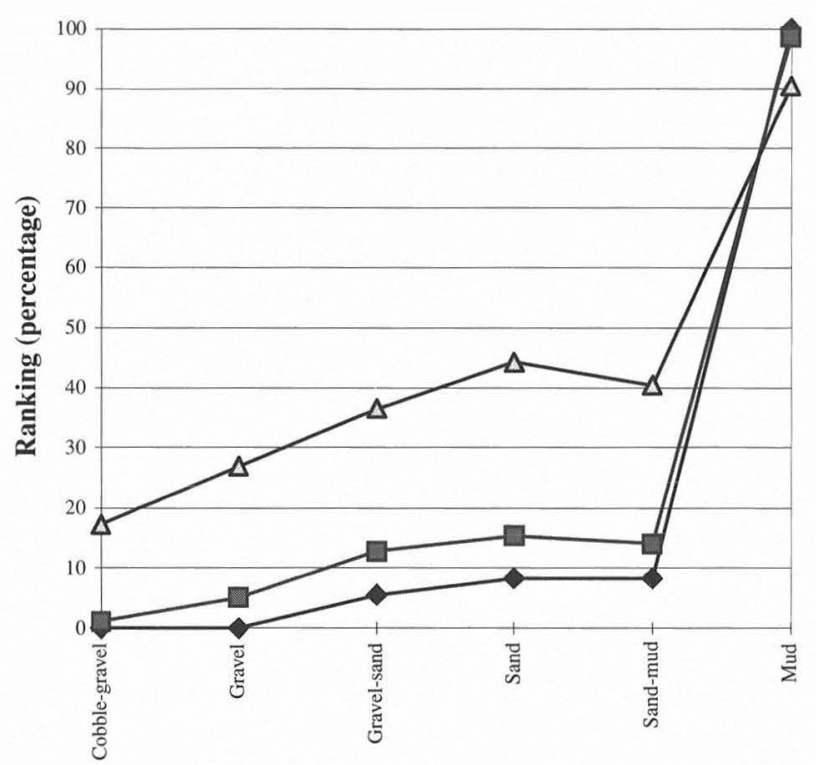

Substrate Composition

$\smile$ Stratum II $\quad-$ Stratum IIIa $\quad-\Delta$ Stratum IIIc

FIGURE 37-4. Comparison of substrate composition rankings for Units II, IIIa, and IIIc.

the low frequency of thick shell fragments (see Table 37-15) further supports a predominantly soft substrate for the aquatic habitat reflected in the Wilson-Leonard assemblage.

By combining the data from the four habitat categories, a general habitat reconstruction can be proposed for the aquatic environment from which the Wilson-Leonard mussel was procured, presumably that of Brushy Creek. The evidence suggests generally consistent conditions existed through time with a creek to small river-sized drainage with continuous flow, which had a slow current and a mud substrate. The comparison between three temporally differentiated strata suggests wetter conditions in more recent times (analogous with stratigraphic Unit IIIc), possibly resulting in a deeper and wider drainage. Neither current velocity nor substrate composition seemed to be altered significantly by these wetter conditions.

As an alternative interpretation given the limited catchment and ground-water source potential of Brushy Creek, the increased stream size indicated by the mussels in Unit IIIc could be the result of inhabitants having collected some of the recovered mussels from other, larger streams or from farther down Brushy Creek.

\section{Mussels as a Food Resource}

The mussel shell recovered from the Wilson-Leonard site is generally assumed to reflect the use of freshwater mussels for food, although mussel shell can be introduced by nonhuman factors such as by animals or birds or mixed with flooding debris. One bivalve fragment from stratigraphic 
Unit IIIc (Lot 16C) was found by Neck to have two holes that may have been made by humans. Other than this example, none of the freshwater bivalve shells exhibits any evidence of modification for any purposes other than meat extraction. Freshwater mussels are generally thought to represent a supplementary protein resource, but the predictable availability may have made them an important expedient food source (Parmalee et al. 1972). In Texas, shellfish were most intensively used during the Late Archaic through Late Prehistoric periods when there may have been increasing dietary stresses imposed by a growing population density and a changing environment (Brown 1989). Freshwater mussels would have been a compatible resource for special task camps, such as plant processing, because they are relatively predictable in terms of location and seasonality, and they require only short periods of time for collection.

The mollusk paleoassemblage from the Wilson-Leonard site suggests that mussels were used as an intermittent resource but never in large quantities. The site has a relatively small sample of bivalve remains compared to many sites in the region (e.g., Anthony 1994; Brown 1987), particularly when considering the long time depth of the site. The aquatic habitat adjacent to the site probably never supported dense populations of the larger mussel species such as Amblema plicata or Lampsilis teres. The mussel populations near Wilson-Leonard may have been limited to moderate densities of a variety of species, with proportionally higher representations of smaller and/or younger individuals of those species able to grow larger in bigger waterways. But the use of this limited resource by the occupants of Wilson-Leonard suggests that it was considered an available resource. The higher frequency of shell remains in more-recent times parallels that noted for other sites, possibly suggesting that growing food stresses encouraged more-intensive utilization of marginal resources (e.g., Brown 1989).

A comparison of the frequency of shell in feature contexts against the frequency in nonfeature deposits reveals a slight clustering of shell in features. Of the total count of 1,294 mussel shells or shell fragments, $34 \%(n=441)$ were found in feature contexts, including the burned rock midden. This is significant if the total volume of deposits excavated is calculated, but the higher frequency in features may be due to the intensive recovery methods (i.e., water screening and flotation) that were used to process feature sediments. Comparison of the frequency of mussel shell between the Burned Rock Midden 1 and squares outside but adjacent to this feature again did not reveal major differences. Within Burned Rock Midden 1 (using Squares E20/S86-94), the range is between 3 and 5 specimens per lot while outside the feature (using Squares E20/S72-84) the range is between 1 and 8 specimens. The slightly higher numbers are from the squares at the margin of the feature, with Square E20/S84 with 8 specimens and Square E20/S82 with 6. While these frequency data do not conclusively support a clustering of shell along the burned rock midden edge, it may suggest that this is a research question for future excavations of this type of feature. It would be important to determine if this clustering of shell along the midden edge is a pattern seen elsewhere and whether the mussel shell reflects a disposal context or a cooking context associated with the primary function of the burned rock feature.

The Wilson-Leonard samples provide little information on the processing and cooking methods used for the mussels. This is due primarily to the very fragmentary nature of this assemblage. Only one specimen, that of Amblema plicata, exhibits a broken posterior margin such as has been interpreted at other sites to indicate the opening of the shell to extract the meat (e.g., Neck 1994). The incidence of burned shell at Wilson-Leonard is very low $(1.2 \%, \mathrm{n}=16)$ which is comparable to other sites and probably reflects unintentional postconsumption burning (Anthony 1994).

\section{Summary}

The analysis of the freshwater mussel paleoassemblage from the Wilson-Leonard site has identified 12 taxa consistent with the aquatic habitat adjacent to the site. The species of unionids identified from the site sample (see Table 37-12) suggest these mussels were collected from a small but continuously flowing waterway with a slow current and a soft substrate. A comparison of habitat indicators between three samples ranging from Late Paleoindian to Late Prehistoric times suggests conditions may have been slightly wetter in the later periods resulting in a wider and deeper waterway.

Freshwater mussels appear to have been only a minor resource throughout the various occupations of the site, although they may have been utilized more intensively during later occupations. If conditions were wetter during later periods, as suggested by the habitat reconstructions, than some of this increased use may simply reflect the greater abundance of mussels in the immediate environment. The very fragmentary nature of the Wilson-Leonard assemblage limits statements concerning how the mussels were processed and cooked but the few indicators suggest it is consistent with practices detected at other Texas sites.

\section{INTEGRATING RESULTS OFTHE MOLLUSK STUDIES \\ by Leslie C. Shaw}

The results of the three studies dealing with mollusk remains from the Wilson-Leonard site all support a similar trend in immediate habitat and climatic conditions. This similarity must remain on a general level because of the many cultural and natural factors that have affected the mollusk samples over the 11,000 years when occupations occurred at this site. Both gastropod and bivalve shells can be introduced into a cultural deposit by many avenues, ranging 
from natural death to human deposition. In addition, the sampling and recovery methodologies used to collect mollusks from archeological contexts can have a significant affect on the composition of the overall assemblage.

Although certain species of gastropods are known to have been eaten by prehistoric inhabitants in Texas, there is no compelling evidence from Wilson-Leonard for their use as food. The gastropod shells recovered from the site were most likely the result of the use of the abandoned site by terrestrial species and the deposition of both terrestrial and aquatic species by water during periods of flooding and downslope wash. Humans could inadvertently introduce gastropods into the site by such means as bringing wetland vegetation or water to the site or through their introduction with other animals, such as in stomach contents of fish. The deep spring-dwelling Phreatodrobia nugax nugax identified by Theler could have been deposited in features as a result of humans collecting water directly from a spring source, but this species could as easily have been introduced during flooding. While it is difficult to distinguish between natural and cultural explanations at the Wilson-Leonard site, this situation raises a contextual problem that may be addressed at other sites through a carefully developed sampling strategy.

The high numbers of snail shells recovered from the site, particularly in association with rock features, suggests that the abandoned site offered particularly favorable conditions for certain species of gastropods. Such attractive conditions probably included vegetation, organic trash, higher moisture, and exposed limestone rocks which offered protected conditions for wintering and reproduction. The density of gastropods varies between strata, and this is well exemplified by the snail frequencies per level in Square E28/S78 (see Table 37-2). Mollusk remains are very low in number in stratigraphic Units Isi-c through Icl and there are indications that this may be due in part to preservation. The fact that the gastropod species represented in these lower levels are the same species that are found in such high numbers in upper levels also leaves open the possibility that at least some of the snails in the lower levels could be intrusive. These possibilities, therefore, limit the environmental statements that can be made using this information.

The numbers of mollusk remains increase in the overlapping stratigraphic Units Id through II (Levels 29 - 21 in Square E28/S78) but increase most dramatically in stratigraphic Unit III (see Table 37-2). The high density of gastropods suggests that the environs of the Wilson-Leonard site provided excellent habitat for a variety of species. Whether this was a normal distribution found all along Brushy Creek or was in response to the human modifications of the environment is not known. The Wilson-Leonard gastropod subassemblages highlight the need for archeologists to explore the taphonomy of snails in an archeological context in comparison to natural settings. Such comparative data will improve the potential to distinguish between the natural occurrence or the cultural introduction of snails into archeological contexts.

The mussel shell remains from Wilson-Leonard probably reflect their use as food, although natural means of introduction cannot be excluded. Heavy flooding and movement of mussels by birds or mammals could introduce shells into a cultural deposit. The mussel shells were widely distributed across the site but were more numerous in the uppermost stratum (Unit IIIc). As with the gastropods, there is evidence that shell preservation varies between strata at the site, with particularly poor preservation in the lowest levels.

The indications of past environmental conditions from gastropod and mussel remains can be useful in identifying significant climatic change. Such data are best used in conjunction with other environmentally sensitive evidence to fully address paleoenvironments and the impacts humans had on these environments. The mollusk data evaluated here support a change in climatic conditions over the 11,000 years of human occupation. This change, in broad overview, includes a gradual shift from wetter conditions with riparian and marsh environments during the early Holocene (ca. 9,000-10,000 years ago) to drier conditions supporting prairie savanna vegetation following about 9,000 years ago. Another period of wetter conditions is evident between roughly 4,000 and 800 years ago (Unit IIIc), but the extensive marshes and woodlands present during the early Holocene are not indicated. This later period may have included periods of increased rainfall with higher flow in the streams in this escarpment area, but xeric vegetation probably continued to dominate the landscape.

The wetter conditions during the early period of occupation (roughly 10,000-9000 B.P.) are indicated by the presence of aquatic gastropods that favor marsh vegetation, such as Gastrocopta armifera. The terrestrial Carychium mexicanum, which favors vegetation along waterways, was found exclusively in these early deposits. By calculating standard deviations to evaluate the expected frequency of species from differing habitats, the aquatic and mesic woodland species were found in greater than expected numbers in the lower stratigraphic Units I and II (C. Britt Bousman, personal communication 1994).

The shift to drier conditions is indicated by the marked rise in frequency in open woodland to grassland species as seen in both Neck's and Theler's studies. There is also a marked drop in aquatic species. Caution is needed, however, in considerating the significance of the decrease in aquatic species. The geomorphological indications of a decrease in overbank flooding following about 9,500 years ago (see Chapter 6) could have reduced the natural introduction of aquatic species into the site. The overall interpretation of drier conditions, however, is supported by the terrestrial species present and the high numbers of several of these species. 
The move toward wetter conditions following about 4,000 years ago is suggested by the mollusk data. The wetter conditions are indicated most strongly by the mussel data. The frequency and diversity of mussel species suggest that higher water volume, seen as wider and deeper waterways, may have been present in Brushy Creek at this time. The gastropod species do not indicate a return to marsh vegetation along the creek like that seen during the early Holocene, but Neck suggests an increase in wooded conditions along the waterway. The increase in such species as Strobilops texasiana and Glyphyalinia umbilicata suggests higher moisture levels in the immediate environment. 


\section{Chapter 38}

\section{DIATOM ANALYSIS}

by Barbara Winsborough

\section{INTRODUCTION}

Diatoms are microscopic, single-celled algae with a silica cell wall. They are often preserved in Holocene marsh, stream, and lake deposits including sediments associated with archeological sites in Texas and adjacent areas (Hohn 1975; Hohn and Hellerman 1961; Lohman 1935; Meltzer 1991; Patrick 1938; Winsborough 1988, 1995). Each diatom species has its own specific preferences and restrictions with regard to habitat, substrate, salinity, nutrient and pollution levels, current, light, depth, temperature, and moisture (Lowe 1974; Round 1981). Because of their individual environmental preferences and requirements, diatoms can provide information about the aquatic environment at the time the sediments were deposited. They are sensitive monitors of water quality, and changes in the composition of the assemblage are related to changes in climate, local hydrological regime, or land use. Sediment samples were collected from cultural features and profiles at the Wilson-Leonard site because of its proximity to stream and wetland habitats and because the possibility that diatoms preserved in the soils may contribute to paleoenvironmental reconstruction.

\section{METHODS}

Twenty-five samples were collected for diatom analysis from exposed profiles and from features during the 1992 TARL excavations (Table 38-1). A starting volume of about $1 \mathrm{cc}$ of material was divided into two subsamples, designated A and B. Sample A was heated in hydrogen peroxide and then nitric acid, followed by washes with distilled water until clean of acid residue. Small, carbonate-rich nodules a few millimeters in diameter were picked out of the remaining subsample (Sample B) with forceps and processed in the same way as Sample A. The insoluble residues containing the diatom remains were mounted on glass slides with Hyrax, a resin with a high refractive index. Slides were scanned at a magnification of $1500 \mathrm{X}$, and every diatom cell was recorded.

\section{RESULTS AND DISCUSSION}

A few diatoms were recovered from some of the bulk samples, but their numbers are insufficient to allow any reliable paleoenvironmental interpretations. Diatoms were present in substantial numbers only in the carbonate-rich nodules extracted from two early Holocene samples, WL-92214B and WL-92-228B. These samples came from the east wall of Square 20. The former was collected at the lower boundary of the Stiba soil, Level 25, stratigraphic Unit II/ IIIa, (8800 в.P.); and sample WL-92-228B was collected in the lower portion of the Leanne soil, Levels 42-43, stratigraphic Unit Isi-c (9500-10,000 B.P.).

The kinds and numbers of diatoms found in these two samples are presented on Table 38-2. Eighteen species were found in a total count of 650 cells. Of these, 10 species were present in both samples with the following 4 being common to abundant in both samples (25-100+ cells): Fragilaria capucina var. rumpens (Kützing) Lange-Bertalot, Gomphonema intricatum var. vibrio (Ehrenberg) Cleve, Cymbella cistula (Ehrenberg) Kirchner, and Gomphonema angustum Agardh. Two species were found in low numbers in WL-92-214B, however they were common to abundant in WL-92-228B: C. gaeumannii Meister, and G. subclavatum var. mexicanum (Grunow) Patrick. These 6 species are especially useful in paleoenvironmental reconstruction because a diatom that is common in a sample is presumed to be living well within its range and can be considered as part of the diatom association that characterizes the habitat.

The two most common species, Gomphonema intricatum var. vibrio and Fragilaria capucina var. rumpens, are alkaliphilous species (occurring at a $\mathrm{pH}$ around 7 with 
TABLE 38-1

Samples Analyzed for Diatom Content

\begin{tabular}{|c|c|c|c|c|}
\hline Square & Level & Stratrigraphic Unit & Micromorphology No. & Sample Description \\
\hline 20 & 11 & IIIIb & WL-92-206 & A, B \\
\hline 51 & 24 & IIIa & & Feature 231 , elevation $95.68 \mathrm{~m}$ \\
\hline$?$ & $?$ & IIIa & & Early Archaic feature, elevation $95.55 \mathrm{~m}$ \\
\hline 20 & 25 & II/IIa & WL-92-214 & A, B; positive \\
\hline 51 & 26 & II/IIIa & & Feature 249, elevation $95.50 \mathrm{~m}$ \\
\hline 20 & 32,33 & II & WL-92-218 & below gravel horizon \\
\hline 20 & 35,36 & II & WL-92-221 & \\
\hline 20 & 39 & Isi-c & WL-92-224 & \\
\hline 20 & 40 & Isi-c & WL-92-225 & $\mathrm{A}, \mathrm{B}$ \\
\hline 20 & 41 & Isi-c & WL-92-226 & $\mathrm{A}, \mathrm{B}$ \\
\hline 20 & 42,43 & Isi-c & WL-92-227 & \\
\hline 20 & 42,43 & Isi-c & WL-92-228 & A, B; positive \\
\hline 20 & 44 & Isi/Isi-c & WL-92-230 & \\
\hline 20 & 46,47 & Isi/Isi-c & WL-92-231 & $\mathrm{A}, \mathrm{B}$ \\
\hline 20 & 47,48 & Icl & WL-92-232 & $\mathrm{A}, \mathrm{B}$ \\
\hline 20 & 48,49 & Icl & WL-92-233 & \\
\hline 20 & 48,49 & Icl & WL-92-233 & $\mathrm{A}, \mathrm{B}$ \\
\hline 20 & 51 & Icl & WL-92-235 & $\mathrm{A}, \mathrm{B}$ \\
\hline 20 & 51 & Icl & WL-92-236 & $\mathrm{A}, \mathrm{B}$ \\
\hline 20 & 51 & Icl & WL-92-236 & top of column, left of column tags \\
\hline 20 & 57 & Igl & & $40 \mathrm{~cm}$ below WL-92-236 \\
\hline 35 & 46 & Isi/lcl & WL-92-410 & \\
\hline 20 & $?$ & Igl & & $35 \mathrm{~cm}$ above bedrock, $680 \mathrm{~cm}$ below surface \\
\hline$?$ & $?$ & $?$ & & lower pit, clayey silt \\
\hline$?$ & $?$ & & & middle lower gravel, abundant pyrite \\
\hline
\end{tabular}

best development over 7). They are tolerant of a range of conductivity from fresh water to slightly saline, such as to be expected from habitats that experience occasional drying conditions. Almost all the species are epiphytic (attached to other plants), a few of the diatoms found in small numbers are also found in mud (Krammer and LangeBertalot 1986, 1991; Lowe 1974; Patrick and Reimer 1966, 1975). This epiphytic life-form strategy is based on attachment to and movement along substrate surfaces where the diatoms can capitalize on nutrients and other resources adsorbed to surfaces or derived from higher aquatic plants (Bradbury 1975). Fragilaria is a littoral zone genus that prefers quiet environments where water currents are slowed by growth of aquatic macrophytes (Bradbury 1975). F. capucina has the added advantage of being tychoplanktonic, meaning able to live suspended in the water column as well as on the bottom among the benthic diatoms (Denys 1990; Lowe 1974).

Except for Cymbella gaeumannii, which was somewhat common in both samples, the assemblage consists of species typically found in circumneutral to alkaline slowflowing streams, shallow lakes, and ponds. These species can be found in spring-fed streams and ponds in Travis County today (Christensen 1978; Winemiller and Winsborough 1990; Winsborough 1995). C. gaeumannii prefers slightly acid, low nutrient, low electrolyte, marshy conditions and is found in Scandinavian alpine locations today (Krammer and Lange-Bertalot 1986). It is also common in lake sediments of some northern Great Lakes states. For example, in Dunnigan Lake, a shallow seepage lake with one of the lowest alkalinity values in Minnesota, $C$. gaeumannii prefers low total alkalinity and reflects a diatom 
TABLE 38-2

Diatom Abundance in Sediments from the Wilson-Leonard Site

\begin{tabular}{|c|c|c|c|}
\hline & WL-92-214B & WL-92-228B & Totals \\
\hline Achnanthes minutissima Kützing & 6 & & 6 \\
\hline Cyclotella meneghiniana Kützing & & 1 & 1 \\
\hline Cymbella cistula (Ehrenberg) Kirchner & 27 & 32 & 59 \\
\hline Cymbella gaeumannii Meister & 8 & 20 & 28 \\
\hline Denticula elegans Kützing & 9 & 2 & 11 \\
\hline Denticula kuetzingii Grunow & 11 & 4 & 15 \\
\hline Epithemia argus (Ehrenberg) Kützing & & 2 & 2 \\
\hline Fragilaria capucina var. rumpens (Kützing) Lange-Bertalot & 99 & 55 & 154 \\
\hline Fragilaria ulna (Nitzsch) Lange-Bertalot & 9 & & 9 \\
\hline Gomphonema affine Kützing & 15 & 4 & 19 \\
\hline Gomphonema angustum Agardh & 33 & 39 & 72 \\
\hline Gomphonema intricatum var. vibrio (Ehrenberg) Cleve & 102 & 82 & 188 \\
\hline Gomphonema subclavatum var. mexicanum (Grunow) Patrick & 9 & 50 & 59 \\
\hline Navicula cryptotenella Lange-Bertalot & & 6 & 6 \\
\hline Navicula radiosa Kützing & & 4 & 4 \\
\hline Navicula viridula var. linearis Hustedt & 4 & & 4 \\
\hline Nitzschia amphibia Grunow & & 6 & 6 \\
\hline Pinnularia viridis (Nitzsch) Ehrenberg & 2 & 5 & 7 \\
\hline Totals: & 334 & 316 & 650 \\
\hline
\end{tabular}

inferred $\mathrm{pH}$ that ranges from 6.4-6.8; and Denton Lake, Wisconsin, has a diatom inferred $\mathrm{pH}$ of 5.5-6.0 (Kingston et al. 1990). Alexander Wolfe (personal communication 1996) reports finding an assemblage similar to the one found at the Wilson Leonard site, including $C$. gaeumannii, in well-buffered alpine lakes in Bolivia. The presence of $C$. gaeumannii in the Wilson-Leonard material suggests that there was some slightly acidic water with a rather dilute solute load, such as found in a boggy, poorly drained area with oak detritus.

Estimates of diatom salinity ranges have been calculated for nine of the diatom species found at the WilsonLeonard site, including four of the common species, using a data set that includes 111 lakes in British Columbia, Canada (Wilson et al. 1994). Optimal salt concentrations are in the range or $240-770 \mathrm{ppm}$, but the diatom species would be tolerant of seasonal salinity fluctuations as might be expected in shallow streams, ponds, and marshes. The water was well-aerated, low to moderate in nutrient concentration, had a neutral to slightly alkaline $\mathrm{pH}$, and was not heavily polluted. With regard to paleotemperature interpretations, a shallow environment such as a marsh or pond is quick to heat up and cool down, and the diatoms are adapted to these temperature fluctuations. A somewhat colder climate than present today is indicated by the modern alpine distribution of $C$. gaeumannii. The absence of planktonic diatoms, which require abundant dissolved nutrients to maintain large populations in open waters (Kuhn et al. 1981), suggests that the water was probably not very high in nutrients and/or too shallow to support such a population.

\section{CONCLUSIONS}

The upland habitats of the Wilson-Leonard site were generally too dry to support the growth of diatoms. Of the 25 samples examined, diatoms were present in substantial numbers in only 2, both early Holocene in age. Diatoms were concentrated within small, carbonate-rich nodules in the sediments. The carbonate nodules may have been part of the stream sediment load that was transported to the site with any associated diatoms during high water, or they may have been associated with colluvial deposits from nearby slopes. A third possibility is that the nodules may be pedogenic in origin and postdate diatom deposition. In any case, the diatoms are local species, and the paleoenvironmental observations relate to the site and its habitats at the time the sediments were deposited. The assemblage contains species characteristic of several habitats. Many of the diatoms are circumneutral to hardwater species found typically in shallow, marshy, vegetated ponds or streams, with slow-flowing and standing water. The diatoms indicate that the water was perennial, but may have fluctuated in depth and solute concentration over the annual cycle. Flood events would have transported these taxa to the site as overbank deposits. A few of the species 
prefer damp, shady substrates such as boggy areas, seeps, and wet ledges. Thus, the diatomaceous material preserved in these deposits consists of species from all of the habi- tats associated with the drainage, and, in this case, anywhere the occupants gathered water or exploited aquatic resources. 


\section{Chapter 39}

\section{ANALYSIS OF OSTRACODE REMAINS}

by Marion J. Henry, Mervin Kontrovitz, and Jerry Marie Slack

\section{INTRODUCTION}

Ostracodes were used to interpret paleoenvironments associated with Late Pleistocene and Early Holocene Paleoindian occupations at the Wilson-Leonard site. Ostracodes are a distinct subclass of crustaceans, usually with two small calcitic valves, each 1-2 mm in length. They have a geologic range from Late Cambrian to modern and are useful for stratigraphic and paleoenvironmental interpretations (Van Morkhoven 1962).

Two distinct assemblages of ostracodes were recovered from the samples. One, not useful in this research, was composed of Cretaceous brackish and marine species reworked from the local Mesozoic sediments. The resulting high calcite content could well have been responsible for the preservation of the second assemblage, the relatively fragile latest Pleistocene and earliest Holocene freshwater forms. The subject of this study is the latter group, that which is contemporaneous with the Paleoindian archeological material (Figure 39-1).

\section{MATERIALS AND METHODS}

All sediment samples, contextual data, and estimates of age were provided by TARL. Roughly equal volumes of at least $25 \mathrm{cc}$ (dry) of sediment from each sample were soaked in distilled water for about 24 hours, then gently washed over a U.S. Standard 200-mesh sieve. Residues were air dried and "picked" for ostracodes. All samples were picked using Olympus stereomicroscopes at 15X. This standard magnification is sufficient for the smallest species and even the earliest (smallest) molt stages. For study of individual shells, magnifications from $100 \mathrm{X}$ to several $1000 \mathrm{X}$ with a scanning electron microscope were used. No detergents or phosphate products were used at any stage of the preparation because they could damage or destroy shells, especially delicate freshwater forms (Kontrovitz et al. 1991).
Environmental interpretations were based on the occurrence of species as reported in the literature on freshwater Ostracoda (Delorme 1970a, 1970b, 1971a, 1971b, 1978; Delorme and Zoltai 1984; Furtos 1933; Hoff 1942; Kitchell and Clark 1979; Staplin 1963a, 1963b; Westgate et al. 1987).

\section{RESULTS}

Twelve species of freshwater ostracodes were recovered from eight sediment samples collected from stratigraphic Unit I (Table 39-1). Most of the species are wellknown freshwater forms (see Figure 39-1). All water depth and temperature interpretations were approximations based upon modern occurrences of the species (see references cited).

The deepest ostracode sample, designated Ostracode Sample 1 ( $<12,000$ B.P.), was collected from Unit Igl (ca. $70 \mathrm{~cm}$ below upper contact at $92.1-92.00 \mathrm{~m}$ ); it had 4 species represented by 24 specimens (Table 39-2). They were Candona elliptica Furtos, 1933, Candona sp. cf. C. marengoensis Klie, 1931, Candona punctata Furtos, 1933, and Candona sp. cf. C. subtriangulata Benson and McDonald, 1963. These forms prefer a habitat of permanent alkaline water and imply a maximum depth of about $3 \mathrm{~m}$. The maximum water temperature was probably about $19^{\circ} \mathrm{C}$ (Table 39-3).

Ostracode Sample 2 (ca. 12,000 to 11,500 B.P.), was collected from the upper portion of $\operatorname{Igl}(\mathrm{ca} .92 .84 \mathrm{~m})$. It also had four species, represented by nine specimens. Candona lactea Baird, 1850, Candona sp. cf. C. marengoensis, Candona punctata, and Cyclocypris sp. were present. These indicate a permanent, alkaline water body with a maximum water depth of approximately $3 \mathrm{~m}$. The maximum water temperature was about $20^{\circ} \mathrm{C}$.

The next higher sample (Ostracode Sample 3; ca. 11,500 to 11,000 B.P.) was collected from the base of Unit Icl in the Icl/Isi transition ( 93.21 to $93.16 \mathrm{~m}$ ). There were 26 specimens representing 6 species, namely, Candona sp. cf. C. caudata 


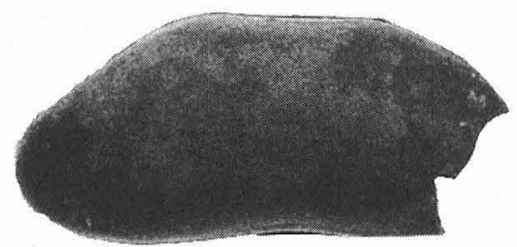

a

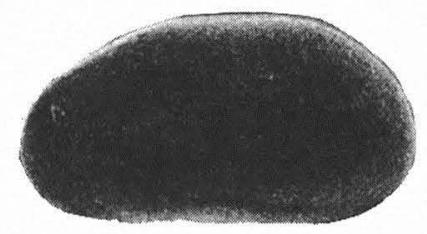

d

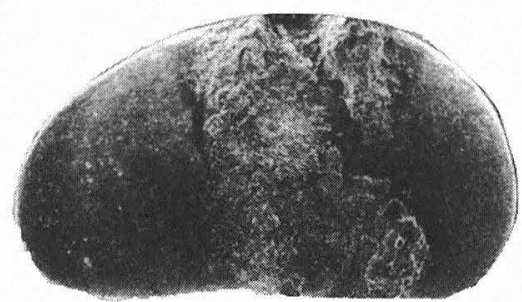

g
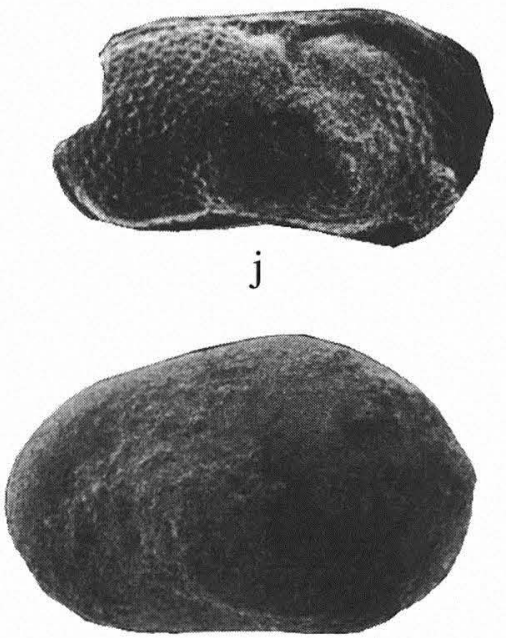

1

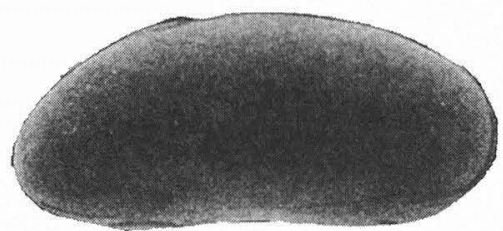

b

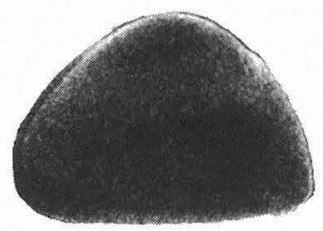

e

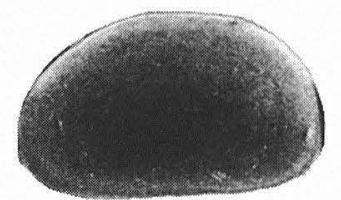

$\mathrm{h}$

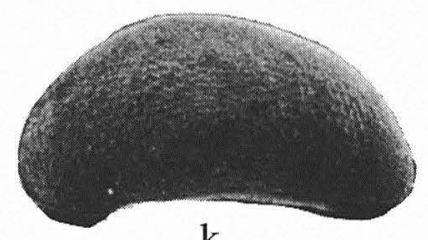

$\mathrm{k}$

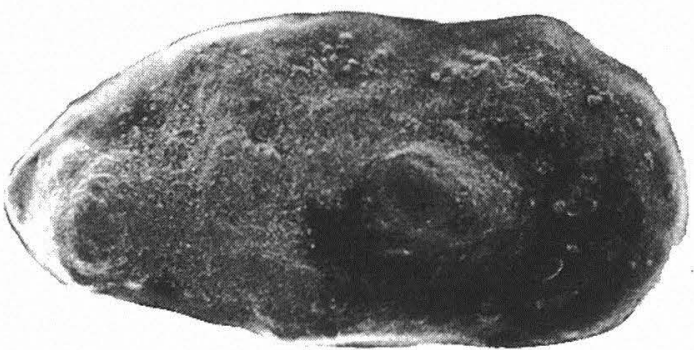

$\mathrm{m}$

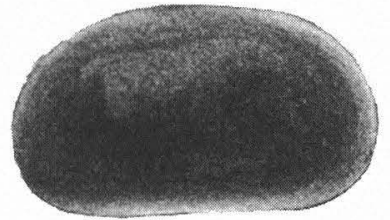

c

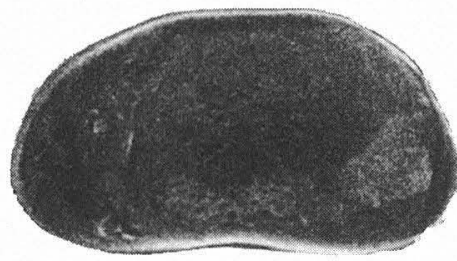

f

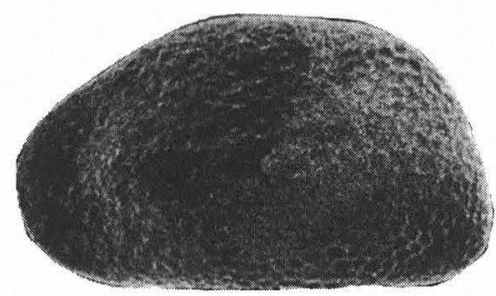

i
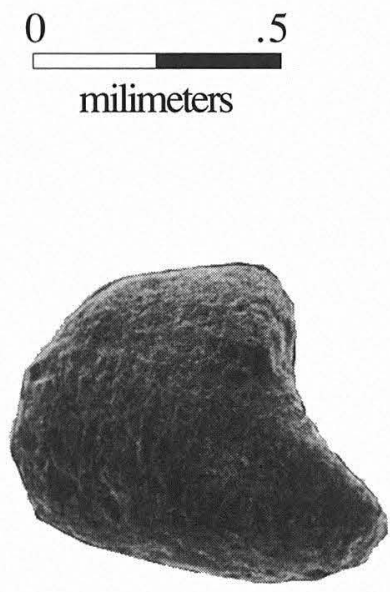

n

FIGURE 39-1. Scanning electron photomicrographs (54X) of ostracodes from the Wilson Leonard site. (a-k) latest Pleistocene ostracodes; (1-n) Cretaceous ostracodes. (a) Candona sp. cf. C. Caudata Kaufmann, 1900, right valve damaged; (b) Candona elliptica Furtos, 1933, right valve; (c) Candona lactea Baird, 1850, right valve; (d) Candona sp. cf. C. marengoensis Klie, 1931, left valve; (e) Candona punctata Furtos, 1933, left valve; (f) Candona sp. cf. C. subtriangulata Benson and McDonald, 1963, left valve; (g) Candona candida (Muller, 1776), left valve, with debris; (h) Cyclocypris ovum (Jurine, 1820), left valve; (I) Cyclocypris sp., left valve; (j) Limnocythere reticulata Sharpe, 1897, right valve, damaged; (k) Potamocypris smaragdina (Varva 1891), left valve; (l) left valve, recrystallized; (m) right valve, recrystallized; (n) fragment, recrystallized. 
TABLE 39-1

Provenience of Ostracode Samples

\begin{tabular}{c|c|c|c|c}
\hline Sample No. & Stratigraphic Unit & Square & Level & Elevation (m) \\
\hline 8 & lower Isi-c & 20 & 42 & 94.22 \\
7 & lower Isi-c & 20 & 43 & 94.10 \\
6 & upper Icl & E28/S78 & $34 \mathrm{~B}$ & $94.01-94.06$ \\
5 & upper Icl & E28/S78 & $36 \mathrm{~A}$ & $93.86-93.91$ \\
4 & lower Icl & E28/S78 & $40 \mathrm{~A}$ & $93.46-93.51$ \\
3 & lower Icl/Isi & E28/S78 & $53 \mathrm{~A}$ & $93.16-93.21$ \\
2 & upper Igl & 43 & 56 & 92.84 \\
1 & Igl & Test Unit B & 12,13 & $92.00-92.10$ \\
\hline \hline
\end{tabular}

TABLE 39-2

Ostracode Valve Count by Species

\begin{tabular}{|c|c|c|c|c|c|c|c|c|c|c|c|c|c|}
\hline \multirow[b]{2}{*}{ Sample No. } & \multicolumn{12}{|c|}{ Ostracode Species } & \multirow[b]{2}{*}{ Totals } \\
\hline & 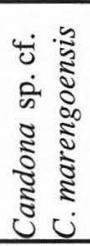 & 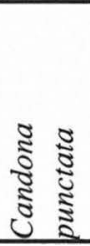 & 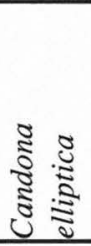 & 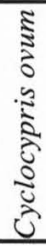 & 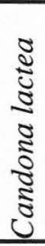 & 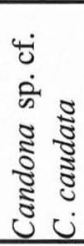 & 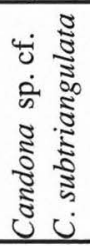 & 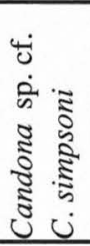 & 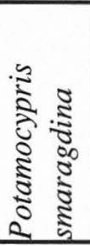 & 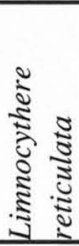 & 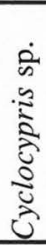 & 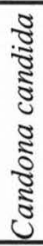 & \\
\hline 8 & & & 3 & & 3 & & & & & & & & 6 \\
\hline 7 & & & & & 1 & 1 & & & & & & & 2 \\
\hline 6 & 27 & 4 & 2 & 5 & 3 & 1 & 2 & 2 & 1 & 1 & & 2 & 50 \\
\hline 5 & 4 & 3 & & & & 1 & & & 2 & & & & 10 \\
\hline 4 & 3 & 9 & 3 & 5 & 5 & & 2 & & & & 2 & & 29 \\
\hline 3 & 7 & 9 & & 3 & 3 & 3 & & & & & 1 & & 26 \\
\hline 2 & 5 & 2 & & & 1 & & & & & & 1 & & 9 \\
\hline 1 & 1 & 14 & 8 & & & & 1 & & & & & & 24 \\
\hline
\end{tabular}

Kaufmann, 1900, Candona lactea, Candona sp. cf. C. marengoensis, Candona punctata, Cyclocypris ovum Jurine, 1820, and Cyclocypris sp. They indicate an alkaline, permanent water body with a maximum water depth of about $2 \mathrm{~m}$ and a maximum water temperature of about $22^{\circ} \mathrm{C}$.

Ostracode Sample 4 (ca. 11,500 to 11,000 B.P.), collected from the lower portion of Unit Icl ( 93.51 to $93.46 \mathrm{~m}$ ), had 29 specimens from the 7 species-Candona elliptica, Candona lactea, Candona sp. cf. C. marengoensis, Candona punctata, Candona sp. cf. C. subtriangulata, Cyclocypris ovum, and Cyclocypris sp. These, too, indicate an alkaline, permanent water body that was shallow (maximum of about $2 \mathrm{~m}$ ). Maximum water temperature probably was about $19^{\circ} \mathrm{C}$.

The next higher sample (Ostracode Sample 5; 93.91 to $93.86 \mathrm{~m}$ ), collected from the upper portion of Icl, has an estimated age of 11,000 to 10,500 в.P. Ten specimens from 4 species are represented-Candona sp. cf. C. caudata, Candona sp. cf. C. marengoensis, Candona punctata, and Potamocypris smaragdina Varva, 1891. These indicate a maximum water temperature of about $21.5^{\circ} \mathrm{C}$ and a maximum depth of approximately $2 \mathrm{~m}$ in an alkaline, permanent water body.

Ostracode Sample 6 was collected from the upper portion of Unit Icl at an elevation of 94.06 to $94.01 \mathrm{~m}$, also with an estimated age of 11,000 to 10,500 B.P. It had 11 species and 50 specimens. They are Candona candida Muller, 1776, Candona sp. cf. C. caudata, Candona elliptica, Candona lactea, Candona sp. cf. C. marengoensis, Candona punctata, Candona sp. cf. C. simpsoni Sharpe, 1897, Candona sp. cf. C. subtriangulata, Cyclocypris ovum, Limnocythere reticulata Sharpe, 1897, and Potamocypris smaragdina. The species indicate a maximum water temperature of about $20.5^{\circ} \mathrm{C}$ and maximum water depth of about $3 \mathrm{~m}$ in an alkaline, permanent, eutrophic water body.

Sample 7 ( $94.16 \mathrm{~m})$ was collected from the lower portion of the Leanne soil (Isi-c). It had two species, Candona lactea and Candona sp. cf. C. caudata, that indicate a maximum water temperature of $20^{\circ} \mathrm{C}$ and a maximum water depth of a few meters in an alkaline permanent water body.

The highest and youngest ostracode sample $(8, \mathrm{ca}$. 10,000 to 9,500 B.P.), at about $94.25 \mathrm{~m}$, was also collected from 
TABLE 39-3

Approximate Maximum Water Depth and Temperature for Ostracodes by Sample

\begin{tabular}{c|c|c}
\hline & $\begin{array}{c}\text { Maximum Water } \\
\text { Depth }(\mathrm{m})\end{array}$ & $\begin{array}{c}\text { Maximum Water } \\
\text { Temperature }\left({ }^{\circ} \mathrm{C}\right)\end{array}$ \\
\hline 8 & $2-3$ & 19.5 \\
7 & few & 20 \\
6 & 3 & 20.5 \\
5 & 2 & 21.5 \\
4 & 2 & 19 \\
3 & 2 & 22 \\
2 & 3 & 20 \\
1 & 3 & 19 \\
\hline \hline
\end{tabular}

lower Unit Isi-c deposits. There were six specimens of two species of ostracodes, Candona elliptica and Candona lactea, indicative of a maximum water temperature of about $19.5^{\circ} \mathrm{C}$ and a maximum water depth of perhaps $2-3 \mathrm{~m}$ in alkaline, permanent water.

\section{CONCLUSIONS}

Freshwater ostracodes of latest Pleistocene/earliest Holocene age may have been preserved in the WilsonLeonard sediments because of the considerable calcium carbonate content derived from Cretaceous material in the area. All ostracode samples indicated an alkaline water body or water bodies at each level where freshwater ostracodes were recovered. It could not be determined if there was one longterm ("permanent") body or if there were several in the area over the time span (ca. 2,000 years) represented by the samples. Whichever the case, the waters were highly productive and shallow, ranging in depth to about only $3 \mathrm{~m}$. There was a "northern" aspect to the assemblages-some of these species currently live in the area of Illinois, Wisconsin, and Minnesota. This suggests that the climate in the site area at 12,000 to 10,000 B.P. was cooler than that of today.

Small samples of ostracodes yielded data relevant to interpreting the past environment of this locality. Pools of alkaline water here or upstream in the Brushy Creek or Spanish Oak Creek valleys are indicated. These appear to have been less than 2 or $3 \mathrm{~m}$ deep with water temperatures of between $19^{\circ}$ and $22^{\circ} \mathrm{C}$. Water temperature seems to have oscillated (Figure 39-2) and may reflect air temperatures, but this is not certain. Water temperatures must be used cautiously to interpret air temperatures since water conditions may be influenced by the influx of spring waters cooler or warmer than ambient air temperature. Ostracodes may be recoverable in deposits lacking other paleoenvironmental indicators, and the analysis of these remains can be used to infer the nature of water bodies and, to some extent, the climatic conditions under which those water bodies existed. Archeologists and others interested in paleoecology need to be alert to this class of evidence and explore its potentials.

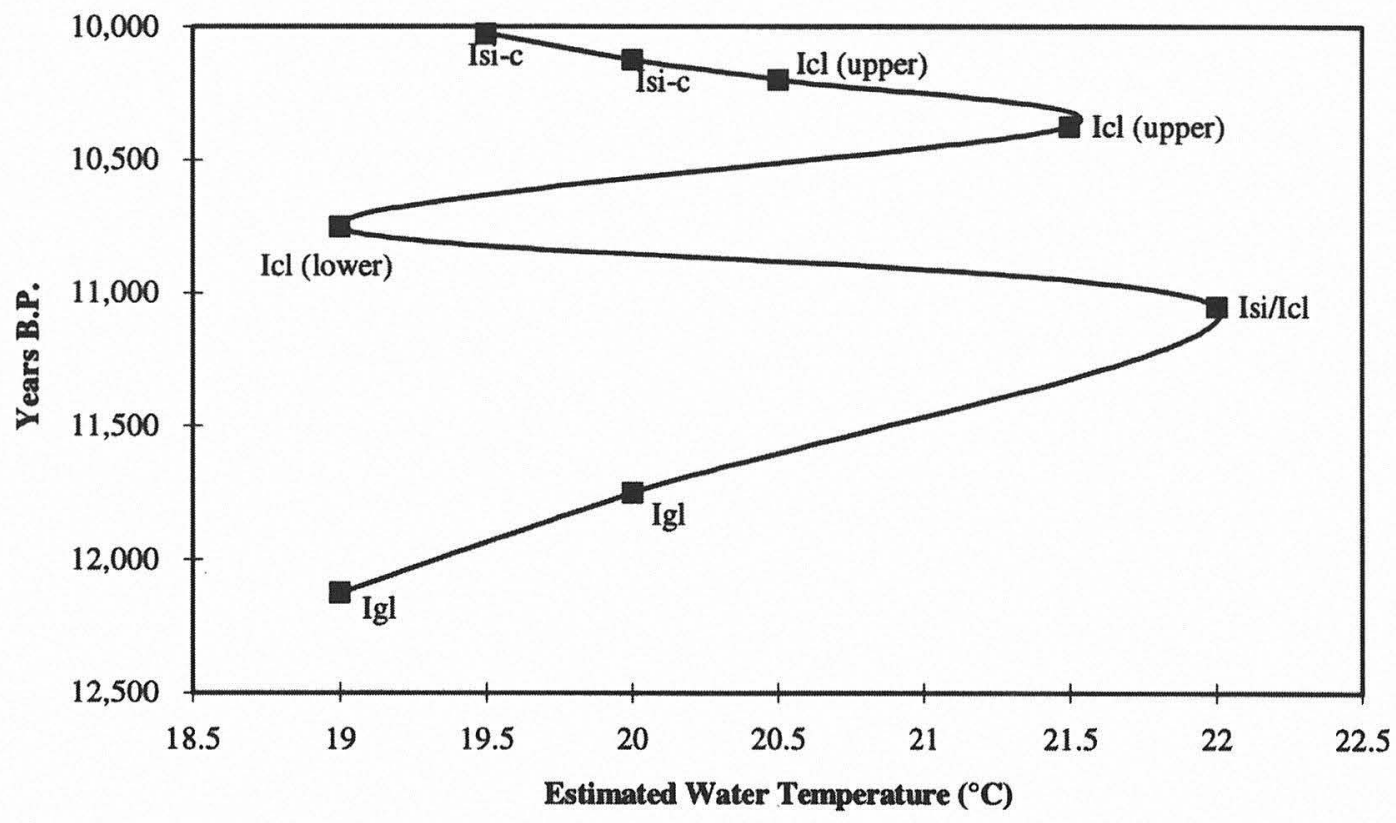

FIGURE 39-2. Estimate of water temperatures based on ostracode remains from early stratigraphic units. 


\title{
Chapter 40
}

\section{CARBONIZED PLANT REMAINS}

\author{
by J. Philip Dering
}

\section{INTRODUCTION}

Flotation samples and macroplant samples were submitted to the Paleoethnobotanical Laboratory at Texas A\&M University for analysis. The "flotation samples" were processed from bulk unscreened sediments of a known volume and collected from specific contexts during excavation. The botanical materials from the flotation samples were separated later in the Paleoethnobotanical Laboratory. "Macroplant samples," on the other hand, were collected by the excavators, either from in situ contexts or during the screening process, and bagged separately. Many of the macroplant samples were labeled "charcoal or "C-14" samples. In order to follow standard archeobotanical terminology, these samples are referred to in this study as macroplant samples.

The goals of the Wilson-Leonard macrobotanical study were as follows:

(1) Inventory the archeological plant remains recovered from the Wilson-Leonard site.

(2) Assess the condition of the archeobotanical record.

(3) Address the following questions using the archeobotanical database:

a. what plant foraging activities are evidenced at the site, and how did these activities change through time?

b. what can be said regarding changes in local vegetation during the Holocene period?

c. how did land use change through time?

(4) Present conclusions and recommendations for future research.

Each goal was entirely dependent on the quality of the data generated by the study, which in turn was dependent on the quality of plant preservation in the archeological sediments.

\section{METHODS}

\section{Terminology}

The plant remains analyzed in this study came from two types of samples. First, a total of 210 sediment samples (595.35 liters) collected during excavations at the Wilson-Leonard site was processed by flotation at the Texas Archeological Research Laboratory, The University of Texas at Austin. These samples are referred to as flotation samples. In addition, 460 individually collected plant samples were submitted for identification. These are referred to as macroplant samples. There were three types of macroplant samples examined in the analysis. The samples with ${ }^{14} \mathrm{C}$ numbers were point collected during the TARL excavations. Samples designated by " $\mathrm{CH}$ " were collected during the TxDOT excavations; some of these were point collected, and some were picked from screens. Finally, screen-collected samples were assigned only lot numbers.

\section{Processing and Sorting}

\section{Macroplant Samples}

Of the 461 macroplant samples examined in this study, 239 were from the TxDOT excavations and 222 were from the TARL excavations. Macroplant samples varied widely in character, from a mixture of charcoal flecks and sediment to single pieces of charred wood or nutshell. This is due to the fact that the carbonized material was collected primarily for the purpose of radiocarbon dating, and not for quantification of plant remains. Macroplant samples were examined for identification of the plant material only. A few of the samples consisted of several charcoal fragments of unsorted site matrix. Five charred fragments were selected and identified from these samples. No attempt was made to quantify the plant material within each sample, because 
the primary constituent in many of the samples was sediment.

\section{Flotation Samples}

Samples were either scanned or fully sorted. Although 210 sediment samples were floated by personnel at TARL, visual examination suggested that only 76 had a potential to yield plant remains (Table 40-1). These 76 (214.1 liters) light fraction samples were submitted to Texas A\&M University for analysis. Forty-six of these samples (120.65 liters) were completely sorted. The remaining 30 samples were scanned for carbonized plant remains.

Scan samples were spread across a large tray and quickly examined under $5 \mathrm{X}$ magnification for carbonized plant remains. In this manner, potentially productive samples could be selected and then subjected to the full-sort process. Fully sorted samples were passed through a series of four brass nested geological screens with mesh sizes ranging from 4 $\mathrm{mm}$ to $0.5 \mathrm{~mm}$. Each size grade was scanned and sorted under a binocular dissecting microscope at $8 \mathrm{X}$. All seed, fruit, and nut fragments from the light fractions were separated and counted.

Because of the poor preservation encountered at open sites, only the carbonized plant remains are considered to be potentially a part of the prehistoric record (Bryant 1989; Miksicek 1987). Most identifications were made using an epi-illuminated light microscope at low magnification $(<75 \mathrm{X})$ by comparing the archeological specimens to reference collections housed at Texas A\&M University.

\section{Identification Methods}

\section{Seeds and Nutshell Fragments}

All seeds and nutshell fragments were identified using modern reference material housed at Texas A\&M University and in the personal collection of the author. Each specimen was examined with a low-power binocular dissecting microscope and then identified when possible. Seed or nutshell fragments that were extensively altered by site formation processes were assigned to the general categories "seed fragment" or "nutshell."

\section{Wood}

Wood identifications were made to the most precise level possible by examining cross sections of the archeological material at 35-75X magnification. Often, however, identifications to the species level were not possible, and therefore, most were made to the genus level. It is also quite common for the wood of several tree species to be quite similar, and thus, certain groups of tree taxa are lumped into artificial categories called "wood types." Two oak wood types are used in this report, the "live oak wood type," which separates live oak from the deciduous oaks, and "oak wood type," which refers to the deciduous oaks. Both of these oak wood types are in the genus Quercus. The wood of shrubs in the bean family is often difficult to separate into different taxa. For this reason, "arboreal legume wood type" (Fabaceae) is used, which includes wood of the genera Acacia, Prosopis (mesquite), and Gleditsia (honey locust). Other tree taxa are lumped into family designations, such as the willow family, which includes cottonwood (Populus deltoides) and willow (Salix sp.). Other family-level identifications include the rose family (Rosaceae) and the elm family (Ulmaceae). The rose family includes the hawthorne, wild plum, and cherry trees. The charred wood of these trees is difficult to distinguish below the family level. Often members of the elm family can be identified to the genus level, such as hackberry (Celtis spp.) and elm (Ulmus spp.). In cases where the sample is small or preservation is poor, these are placed in the more general family-level category.

\section{Bulbs}

The presence of relatively intact carbonized plant bulbs in the sample presented an added challenge to the identification process. Recent investigations have begun to push the methods utilized to identify root plants that have no external diagnostic features visible at low magnification (550X). This work has been pioneered by archeologists and archeobotanists studying plant use in regions where geophytic foods are most important. Seeds, flowers, and fruits, which have very distinctive characteristics, usually are related directly to the taxonomy and hence the classification of the plant. On the other hand, the qualities of geophytic roots or bulbs may in no way be related directly to the classification scheme of the plant. Therefore, the assemblage and replicative charring of all possible edible bulbs in the region was critical to the identification of charred bulb remains (Hather 1991:674).

First, the carbonized plant material was examined carefully in order to confirm that the specimens were indeed bulbs and not a similar-appearing geophytic structure such as a corm. The overall shape of the archeological material, which had been charred in a buried hearth, was variable due to the heat and pressure of the process. The outer layers were present in some of the samples and absent in others.

Once the material was identified as a true bulb, examples of edible species that produce bulbs and grow in the area of the site were collected $3 / 4$ two species of wild onion, (Allium canadense var. canadense, Allium drummondii), false garlic (Nothoscordum bivalve), wild hyacinth (Camassia scilloides), and dog's tooth violet (Erythronium albidum). Each of these plants has an underground storage organ that stores nutrients for these perennials, and as such, they provide an excellent food source.

With Hather's (1991) caveat in mind, reference specimens of each species were obtained and were baked using 
TABLE 40-1

Provenience of Flotation Samples

\begin{tabular}{|c|c|c|c|c|c|}
\hline Sample No. & Feature & Square & Level & Unit & Volume (in liters) \\
\hline 1 & & E28/S78 & $20 \mathrm{~B}$ & II & 2 \\
\hline $2 *$ & & E28/S78 & $23 \mathrm{~A}$ & II & 2 \\
\hline 3 & & E28/S78 & 23 & II & 2 \\
\hline $4 *$ & & E28/S78 & $43 \mathrm{~A}$ & Isi & 2 \\
\hline 5 & & E28/S78 & $32 \mathrm{~A}$ & Icl/Isi-c & 2 \\
\hline 6 & & E28/S78 & $24 \mathrm{~B}$ & Id/II & 2 \\
\hline $7 *$ & & $\mathrm{E} 28 / \mathrm{S} 78$ & $41 \mathrm{~B}$ & Isi & 2 \\
\hline 8 & & E28/S78 & $22 \mathrm{~A}$ & II & 2 \\
\hline 9 & & E28/S78 & $37 \mathrm{~A}$ & Icl & 2 \\
\hline $10^{*}$ & & $\mathrm{E} 28 / \mathrm{S} 78$ & $30 \mathrm{~B}$ & Isi-c & 2 \\
\hline 11 & & E28/S78 & $36 \mathrm{~A}$ & Icl & 2 \\
\hline $12^{*}$ & & $\mathrm{E} 28 / \mathrm{S} 78$ & $29 \mathrm{~B}$ & Isi-c & 2 \\
\hline $13^{*}$ & & $\mathrm{E} 28 / \mathrm{S} 78$ & $35 \mathrm{~B}$ & Ic & 2 \\
\hline 14 & & $\mathrm{E} 28 / \mathrm{S} 78$ & $21 \mathrm{~A}$ & II & 2 \\
\hline 15 & & E28/S78 & $27 \mathrm{~A}$ & Isi-c/Id & 2 \\
\hline 16 & & E28/S78 & 28B & Isi-c/Id & 2 \\
\hline 17 & & $\mathrm{E} 28 / \mathrm{S} 78$ & $26 \mathrm{~A}$ & $\mathrm{Id} / \mathrm{II}$ & 2 \\
\hline $18^{*}$ & & E28/S78 & $27 \mathrm{~B}$ & Id & 2 \\
\hline 19 & & E28/S78 & $34 \mathrm{~B}$ & Icl & 2 \\
\hline $20 *$ & & E28/S78 & $38 \mathrm{~A}$ & Icl & 2 \\
\hline 21 & & E28/S78 & $39 B$ & Isi/Ic & 2 \\
\hline 22 & & E28/S78 & $40 \mathrm{~A}$ & Icl & 2 \\
\hline $23 *$ & & E28/S78 & $16 \mathrm{~A}$ & IIIa & 2 \\
\hline $24 *$ & & E28/S78 & $17 \mathrm{~A}$ & IIIIa & 2 \\
\hline 25 & & E28/S78 & 17B & IIIa & 2 \\
\hline 26 & & E28/S78 & 14 & IIIa/b & 2 \\
\hline 27 & & E28/S78 & $16 B$ & IIIa & 2 \\
\hline 28 & & E28/S78 & $39 \mathrm{~A}$ & Isi/Icl & 2 \\
\hline $29 *$ & & E28/S78 & $15 \mathrm{~A}$ & IIIa/b & 2 \\
\hline $30 *$ & & E28/S78 & 8 & IIIb/c & 2 \\
\hline $31 *$ & & E28/S78 & 11 & IIIb & 2 \\
\hline 32 & & E28/S78 & $25 \mathrm{~A}$ & $\mathrm{Id} / \mathrm{II}$ & 2 \\
\hline 33 & & E28/S78 & $21 B$ & II & 2 \\
\hline 34 & & E28/S78 & $19 \mathrm{~A}$ & II/IIIa & 2 \\
\hline 35 & & E28/S78 & $30 \mathrm{~B}$ & Isi-c & 2 \\
\hline 36 & & E28/S78 & $17 \mathrm{~A}$ & IIIa & 2 \\
\hline $37 *$ & F104 & $\mathrm{E} 22 / \mathrm{S} 90$ & $15-18$ & $\mathrm{X}$ & 2 \\
\hline 38 & F155 & E24/S76 & $22 \mathrm{~A} \& \mathrm{~B}$ & II & 2 \\
\hline $39 *$ & F157 & E26/S72 & $22 \mathrm{~A} \& \mathrm{~B}$ & II & 2 \\
\hline 40 & F168 & E20/S76 & $32 \mathrm{~A} 35 \mathrm{~B}$ & Isi/Icl/Isi-c & 5 \\
\hline 41 & F168 & E20/S76 & $35 \mathrm{~B}$ & Isi/Icl/Isi-c & 2 \\
\hline 42 & F168 & E20/S76 & $35 \mathrm{~B}$ & Isi/Icl/Isi-c & 2 \\
\hline 43 & F169 & E20/S76 & $33 \mathrm{~B}-34 \mathrm{~A}$ & Isi/Isi-c & 5 \\
\hline 44 & F169 & E20/S78 & $30 \mathrm{~A}-34 \mathrm{~A}$ & Isi/Isi-c & 5 \\
\hline $45^{*}$ & F169 & E20/S78 & $30 \mathrm{~A}-34 \mathrm{~A}$ & Isi/Isi-c & 5 \\
\hline $46^{*}$ & F169 & E20/S76 & $33 \mathrm{~B}-34 \mathrm{~A}$ & Isi/Isi-c & 5 \\
\hline 47 & F169 & E20/S78 & $30 \mathrm{~A}-34 \mathrm{~A}$ & Isi/Isi-c & 5 \\
\hline $48^{*}$ & F175 & E26/S78 & $37 \mathrm{~A}-38 \mathrm{~A}$ & Isi/Icl & 4 \\
\hline 49 & F175 & E26/S76 & $37 \mathrm{~A}-38 \mathrm{~A}$ & Isi/Icl & 5 \\
\hline 50 & F176 & E28/S78 & 9-10 & IIIb/c & 4 \\
\hline $51^{*}$ & F181 & E28/S78 & $18 \mathrm{~A}$ & II/IIIa & 2 \\
\hline $52 *$ & F181 & E28/S78 & $20 \mathrm{~A}$ & II/IIIIa & 2 \\
\hline $53 *$ & F181 & E28/S78 & 17B & II/IIIa & 2 \\
\hline $54 *$ & F181 & E28/S78 & $18 \mathrm{~B}$ & II/IIIa & 2 \\
\hline $55^{*}$ & F181 & E28/S78 & 19B & II/IIIa & 2 \\
\hline $56^{*}$ & F181 & E28/S78 & $18 \mathrm{~A}$ & II/IIIa & 2 \\
\hline $57 *$ & F181 & E28/S78 & $19 \mathrm{~A}$ & II/IIIa & 1 \\
\hline $58^{*}$ & F181 & E28/S78 & $18 \mathrm{~A}$ & II/IIIa & 2 \\
\hline $59 *$ & F181 & E28/S78 & $17 \mathrm{~A}$ & II/IIIa & 2 \\
\hline
\end{tabular}

*Submitted to Texas A\&M University for analysis. 
Table 40-1, continued

\begin{tabular}{|c|c|c|c|c|c|}
\hline Sample No. & Feature & Square & Level & Unit & Volume (in liters) \\
\hline $60 *$ & F181 & E28/S78 & $17 \mathrm{~A}$ & II/IIIa & 2 \\
\hline $61 *$ & & $\mathrm{E} 28 / \mathrm{S} 78$ & $20 \mathrm{~A}$ & II & 2 \\
\hline $62 *$ & & $\mathrm{E} 28 / \mathrm{S} 78$ & $25 \mathrm{~B}$ & $\mathrm{Id} / \mathrm{II}$ & 2 \\
\hline $63^{*}$ & & $\mathrm{E} 28 / \mathrm{S} 78$ & $19 \mathrm{~B}$ & II & 2 \\
\hline $64 *$ & & $\mathrm{E} 28 / \mathrm{S} 78$ & $18 \mathrm{~B}$ & II/IIIa & 2 \\
\hline 65 & F184 & E28/S78 & $19 \mathrm{~B}$ & II/IIIa & 2 \\
\hline $66^{*}$ & F185 & E28/S78 & $20 \mathrm{~B}$ & II & 2 \\
\hline 67 & F166 & $\mathrm{E} 2 / \mathrm{N} 8$ & $26 \mathrm{~B}$ & I & 0.15 \\
\hline 68 & F166 & $\mathrm{E} 2 / \mathrm{N} 8$ & $26 \mathrm{~A}$ & I & 0.15 \\
\hline 69 & Burial 2 & E20/S74 & $31 \mathrm{~A}$ & Isi/Icl/Isi-c & 3 \\
\hline 70 & Burial 2 & $\mathrm{E} 20 / \mathrm{S} 74$ & $31 \mathrm{~A}$ & Isi/Icl/Isi-c & 3 \\
\hline 71 & Burial 2 & E20/S74 & $31 \mathrm{~A}$ & Isi/Icl/Isi-c & 3 \\
\hline 72 & Burial 2 & E20/S74 & $31 \mathrm{~A}$ & $\mathrm{Isi} / \mathrm{Icl} / \mathrm{Isi}-\mathrm{c}$ & 1.5 \\
\hline 73 & Burial 2 & $\mathrm{E} 20 / \mathrm{S} 74$ & $31 \mathrm{~A}$ & Isi/Icl/Isi-c & 2 \\
\hline $74 *$ & Burial 2 & $\mathrm{E} 20 / \mathrm{S} 74$ & $31 \mathrm{~A}$ & Isi/Icl/Isi-c & 1.3 \\
\hline 75 & Burial 2 & E20/S74 & $31 \mathrm{~A}$ & Isi/Icl/Isi-c & 2 \\
\hline 76 & Burial 2 & E20/S74 & $31 \mathrm{~A}$ & Isi/Icl/Isi-c & 4.4 \\
\hline 77 & Burial 2 & E20/S74 & $31 \mathrm{~A}$ & Isi/Icl/Isi-c & 5.2 \\
\hline 78 & Burial 2 & E20/S74 & $31 \mathrm{~A}$ & Isi/Icl/Isi-c & 2.8 \\
\hline 79 & Burial 2 & E20/S74 & $31 \mathrm{~A}$ & Isi/Icl/Isi-c & 3 \\
\hline 80 & Burial 2 & E20/S74 & $31 \mathrm{~A}$ & Isi/Icl/Isi-c & 3.2 \\
\hline 81 & Burial 2 & E20/S74 & $31 \mathrm{~A}$ & Isi/Icl/Isi-c & 2.55 \\
\hline 82 & Burial 2 & E20/S74 & $31 \mathrm{~A}$ & Isi/Icl/Isi-c & 1.6 \\
\hline 83 & Burial 2 & E20/S74 & $31 \mathrm{~A}$ & Isi/Icl/Isi-c & 3.7 \\
\hline 84 & Burial 2 & $\mathrm{E} 20 / \mathrm{S} 74$ & $31 \mathrm{~A}$ & Isi/Icl/Isi-c & 2.65 \\
\hline 85 & Burial 2 & E20/S74 & $31 \mathrm{~A}$ & Isi/Icl/Isi-c & 2.75 \\
\hline 86 & Burial 2 & E20/S74 & $31 \mathrm{~A}$ & Isi/Icl/Isi-c & 3.8 \\
\hline 87 & Burial 2 & $\mathrm{E} 20 / \mathrm{S} 74$ & $31 \mathrm{~A}$ & Isi/Icl/Isi-c & 1.7 \\
\hline 88 & Burial 2 & E20/S74 & $31 \mathrm{~A}$ & Isi/Icl/Isi-c & 2.4 \\
\hline 89 & Burial 2 & $\mathrm{E} 20 / \mathrm{S} 74$ & $31 \mathrm{~A}$ & Isi/Icl/Isi-c & 4 \\
\hline 90 & Burial 2 & E20/S74 & $31 \mathrm{~A}$ & Isi/Icl/Isi-c & 4.4 \\
\hline 91 & Burial 2 & E20/S74 & $31 \mathrm{~A}$ & Isi/Icl/Isi-c & 3.2 \\
\hline 92 & Burial 2 & E20/S74 & $31 \mathrm{~A}$ & Isi/Icl/Isi-c & 3 \\
\hline $93 *$ & Burial 2 & E20/S74 & $31 \mathrm{~A}$ & Isi/Icl/Isi-c & 3 \\
\hline $94 *$ & Burial 2 & E20/S74 & $31 \mathrm{~A}$ & Isi/Icl/Isi-c & 2.1 \\
\hline 95 & Burial 2 & E20/S74 & $31 \mathrm{~A}$ & Isi/Icl/Isi-c & 2.4 \\
\hline 96 & Burial 2 & E20/S74 & $31 \mathrm{~A}$ & Isi/Icl/Isi-c & 1.8 \\
\hline 97 & Burial 2 & E20/S74 & $31 \mathrm{~A}$ & Isi/Icl/Isi-c & 1.8 \\
\hline 98 & Burial 2 & E20/S74 & $31 \mathrm{~A}$ & $\mathrm{Isi} / \mathrm{Icl} / \mathrm{Isi}-\mathrm{c}$ & 2.5 \\
\hline 99 & Burial 2 & E20/S74 & $31 \mathrm{~A}$ & Isi/Icl/Isi-c & 3 \\
\hline 100 & Burial 2 & E20/S74 & $31 \mathrm{~A}$ & $\mathrm{Isi} / \mathrm{Icl} / \mathrm{Isi}-\mathrm{c}$ & 3 \\
\hline 101 & Burial 2 & E20/S74 & $31 \mathrm{~A}$ & Isi/Icl/Isi-c & 2.2 \\
\hline $102 *$ & F187 & E28/S78 & $32 \mathrm{~B}$ & Ic/Isi-c & 5 \\
\hline 103 & Burial 2 & E20/S74 & $31 \mathrm{~A}$ & Isi/Icl/Isi-c & 3.1 \\
\hline 104 & & 46 & $28 \mathrm{~A}$ & & 1 \\
\hline 105 & & 39 & $38 \mathrm{~B}$ & Isi-c/Id & 5 \\
\hline $106^{*}$ & BRM 1 & 100 & 4 & IIIc & 1 \\
\hline $107 *$ & BRM 1 & 100 & 6 & IIIc & 1.2 \\
\hline 108 & BRM 1 & 100 & 8 & IIIc & 0.25 \\
\hline $109 *$ & BRM 1 & 100 & 8 & IIIc & 1 \\
\hline $110^{*}$ & BRM 1 & 100 & 10 & Y & 2 \\
\hline 111 & Burrow & 12 & $39 \mathrm{~A}$ & Isi/Isi-c & 0.15 \\
\hline $112 *$ & 203 & 19 & $9 \mathrm{~B}$ & IIIJ/c & 2 \\
\hline 113 & 204 & 20 & $11 \mathrm{~B}$ & IIIb & 2.25 \\
\hline $114 *$ & 204 & 20 & $11 \mathrm{~B}$ & $\mathrm{IIIb}$ & 5 \\
\hline 115 & 204 & 20 & $12 \mathrm{~B}$ & IIIb & 5 \\
\hline $116^{*}$ & 204 & 20 & $12 B$ & $\mathrm{IIIb}$ & 5 \\
\hline $117 *$ & 205 & 22 & 8 & $\mathrm{IIIb} / \mathrm{c}$ & 2 \\
\hline $118 *$ & 206 & 16 & $6 \mathrm{~B}$ & IIIc & 5 \\
\hline $119 *$ & 206 & 16 & $6 \mathrm{~B}$ & IIIc & 5 \\
\hline $120 *$ & 207 & 14 & $6 \mathrm{~B}$ & IIIc & 2 \\
\hline
\end{tabular}


Table 40-1, continued

\begin{tabular}{|c|c|c|c|c|c|}
\hline Sample No. & Feature & Square & Level & Unit & Volume (in liters) \\
\hline 121 & 208 & 17 & $7 \mathrm{~B}$ & $\mathrm{IIIb} / \mathrm{c}$ & 4 \\
\hline 122 & 210 & 22 & $9 \mathrm{~B}$ & $\mathrm{IIIJ} / \mathrm{c}$ & 1 \\
\hline 123 & 211 & 17 & $8 \mathrm{~B}$ & IIIb/c & 3 \\
\hline 124 & 212 & 37 & $13 \mathrm{~B}$ & IIIb & 1.5 \\
\hline $125^{*}$ & 213 & 13 & $10 \mathrm{~B}$ & IIIb & 5 \\
\hline 126 & 213 & 13 & $11 \mathrm{~B}$ & IIIb & 4 \\
\hline $127 *$ & 213 & 12 & $12 \mathrm{~B}$ & $\mathrm{III} a / \mathrm{b}$ & 5 \\
\hline $128^{*}$ & 214 & 16 & $10 \mathrm{~B}$ & IIIb & 1.25 \\
\hline 129 & & 16 & $11 \mathrm{~B}$ & IIIb & 1.25 \\
\hline $130 *$ & & 16 & $12 \mathrm{~B}$ & IIIb & 1 \\
\hline 131 & 215 & 20 & $16 \mathrm{~B}$ & IIIa/b & 5 \\
\hline $132 *$ & 215 & 20 & $16 \mathrm{~B}$ & IIIa/b & 5 \\
\hline 133 & 216 & 22 & $12 \mathrm{~B}$ & IIIb & 1 \\
\hline 134 & 220 & 52 & $15 B$ & IIIIa/b & 1 \\
\hline $135^{*}$ & 222 & 37 & $16 \mathrm{~B}$ & IIIa & 2 \\
\hline 136 & 224 & 12 & $20 \mathrm{~B}$ & II/IIIa & 5 \\
\hline 137 & 226 & 46 & $20 \mathrm{AB}$ & II/IIIa & 1 \\
\hline 138 & 226 & 46 & $21 \mathrm{~B}$ & II/IIIa & 1 \\
\hline 139 & 227 & 30 & $21 \mathrm{~B}$ & II & 1 \\
\hline 140 & 227 & 30 & $22 \mathrm{~B}$ & II & 1 \\
\hline 141 & 228 & 38 & $21 \mathrm{~B}$ & IIIa & 1 \\
\hline 142 & 230 & 39 & $21 \mathrm{~B}$ & IIIa & 1 \\
\hline $143^{*}$ & 231 & 52 & 23 & IIIa & 2 \\
\hline 144 & 231 & 28 & 22 & IIIa & 1 \\
\hline $145^{*}$ & 231 & 38 & 24 & II/IIIa & 4 \\
\hline 146 & 231 & 51 & 24 & IIIa & 1.3 \\
\hline 147 & 231 & 38 & $25 B$ & II/IIIa & 4 \\
\hline 148 & 231 & 51 & 25 & IIIa & 2 \\
\hline 149 & 231 & 38 & $26 B$ & II/IIIa & 5 \\
\hline 150 & 231 & 38 & $26 \mathrm{~B}$ & II/IIIa & 5 \\
\hline $151^{*}$ & 231 & 51 & 26 & II/IIIa & 5 \\
\hline $152^{*}$ & 206 & 15 & $6 \mathrm{~B}$ & IIIc & 5 \\
\hline $153^{*}$ & 208 & 16 & $7 \mathrm{~B}$ & $\mathrm{IIIb} / \mathrm{c}$ & 3.5 \\
\hline $154^{*}$ & 209 & 20 & $13 \mathrm{~B}$ & IIIb & 5 \\
\hline $155^{*}$ & 213 & 12 & $11 \mathrm{~B}$ & IIIa/b & 2.2 \\
\hline 156 & 213 & 12 & $12 \mathrm{~B}$ & IIIa/b & 5 \\
\hline $157^{*}$ & 224 & 12 & $20 \mathrm{~B}$ & II/IIIa & 5 \\
\hline $158^{*}$ & 231 & 38 & $27 \mathrm{~B}$ & II & 5 \\
\hline 159 & 231 & 51 & $27 \mathrm{~B}$ & II/IIIa & 2 \\
\hline 160 & $231 / 245$ & 52 & 24 & II/IIIa & 1.4 \\
\hline 161 & $231 / 245$ & 52 & 24 & II/IIIa & 0.7 \\
\hline $162^{*}$ & 231 & 52 & 24 & II/IIIa & 1.8 \\
\hline 163 & $231 / 245$ & 52 & $25 B$ & II/IIIa & 2.5 \\
\hline $164 *$ & 233 & 20 & $25 B$ & II/IIIa & 5 \\
\hline 165 & 233 & 20 & $26 \mathrm{~B}$ & II/IIIa & 5 \\
\hline 166 & 233 & 20 & $26 \mathrm{~B}$ & II/IIIa & 5 \\
\hline 167 & 234 & 30 & 30 & Isi-c/II & 1 \\
\hline $168^{*}$ & 235 & 32 & 29B & Isi-c/II & 1 \\
\hline 169 & 236 & 33 & $30 \mathrm{~B} / 31 \mathrm{~B}$ & II & 5 \\
\hline $170 *$ & 236 & 33 & $30 \mathrm{~B} / 31 \mathrm{~B}$ & II & 5 \\
\hline 171 & 236 & 33 & 31B & $\mathrm{Id} / \mathrm{II}$ & 5 \\
\hline 172 & 236 & 33 & $31 \mathrm{~B}$ & $\mathrm{Id} / \mathrm{II}$ & 5 \\
\hline 173 & 236 & 33 & $31 \mathrm{~B}$ & $\mathrm{Id} / \mathrm{II}$ & 5 \\
\hline 174 & 236 & 48 & $30 \mathrm{~B}$ & II & 3.6 \\
\hline 175 & 236 & 48 & $31 \mathrm{~B}$ & $\mathrm{Id} / \mathrm{II}$ & 5.4 \\
\hline 176 & 236 & 48 & $31 \mathrm{~B}$ & $\mathrm{Id} / \mathrm{II}$ & 5 \\
\hline 177 & 239 & 34 & $26 \mathrm{~B}$ & II & 1 \\
\hline $178^{*}$ & 239 & 34 & $27 \mathrm{~B}$ & II & 1.5 \\
\hline 179 & 241 & 35 & $26 \mathrm{~B}$ & II & 0.75 \\
\hline 180 & 242 & 20 & $29 \mathrm{~B}$ & II & 5 \\
\hline
\end{tabular}


Table 40-1, continued

\begin{tabular}{|c|c|c|c|c|c|}
\hline Sample No. & Feature & Square & Level & Unit & Volume (in liters) \\
\hline 181 & 242 & 20 & $29 \mathrm{~B}$ & II & 5 \\
\hline $182 *$ & 245 & 28 & 24 & IIIa & 1.5 \\
\hline 183 & 245 & 28 & 25 & IIIa & 1.75 \\
\hline $184 *$ & 245 & 28 & 26 & II/IIIa & 3.25 \\
\hline 185 & 246 & 34 & $32 \mathrm{~B}$ & $\mathrm{Id} / \mathrm{II}$ & 5 \\
\hline 186 & 246 & 34 & $32 B$ & Id/II & 5 \\
\hline $187^{*}$ & 246 & 49 & $31 \mathrm{~B}$ & II & 3.5 \\
\hline 188 & 246 & $34 / 49$ & $32 B$ & $\mathrm{Id} / \mathrm{II}$ & 5 \\
\hline 189 & 246 & $34 / 49$ & $32 \mathrm{~B}$ & $\mathrm{Id} / \mathrm{II}$ & 5 \\
\hline 190 & 246 & $34 / 49$ & $32 \mathrm{~B}$ & $\mathrm{Id} / \mathrm{II}$ & 5 \\
\hline 191 & 248 & 28 & $29 \mathrm{C}$ & II/IIIa & 1.25 \\
\hline 192 & 248 & 44 & $28 \mathrm{~B}$ & II/IIIa & 1 \\
\hline 193 & 249 & 51 & $27 \mathrm{C}$ & II/IIIa & 1 \\
\hline 194 & 249 & 51 & 28B & II/IIIa & 4.25 \\
\hline 195 & 252 & 46 & $42 B \& 43 B$ & Isi/Isi-c & 3 \\
\hline 196 & 252 & 55 & 43B & Isi/Isi-c & 2 \\
\hline $197 *$ & 252 & 55 & $43 B$ & Isi/Isi-c & 3 \\
\hline $198^{*}$ & 255 & 59 & $42 B$ & Isi-c & 5 \\
\hline 199 & 255 & 59 & $42 B$ & Isi-c & 5 \\
\hline 200 & 256 & 28 & $42 B$ & Isi-c & 1 \\
\hline 201 & $256^{*}$ & 28 & $42 \mathrm{~A}$ & Isi-c & 1 \\
\hline 202 & 257 & 53 & $39 B$ & Isi-c/Id & 5 \\
\hline 203 & 258 & 38 & $26 \mathrm{C}$ & II/IIIa & 5 \\
\hline 204 & 260 & 52 & $42 B$ & Isi-c & 5 \\
\hline $205^{*}$ & 260 & 52 & $42 B$ & Isi-c & 5 \\
\hline 206 & 261 & 20 & $54 \mathrm{~B}$ & $\mathrm{Ig} / \mathrm{Isi} / \mathrm{Icl}$ & 5 \\
\hline 207 & 262 & 27 & $51 \mathrm{~B}$ & Isi/Icl & 5 \\
\hline $208 *$ & 262 & 27 & $52 \mathrm{~B}$ & Isi/Icl & 5 \\
\hline $209^{*}$ & BRM 1 & 100 & 2 & IIIc & 2 \\
\hline 210 & 236 & 33 & 30B\&31B & II & 5 \\
\hline
\end{tabular}

an electric kiln in an oxygen-deficient environment for 10-15 minutes at 300/C. Each specimen then was compared to the archeological material, but most gross features were not diagnostic and external observations did not yield a positive identification. Except for Allium canadense, which is covered with a reticulate net of vascular tissue, none of the bulbs had external distinguishing features. The inner bulb scales were just as enigmatic to the unaided eye or the hand lens. Thus, the presence and location of distinctive features were sought at a slightly higher magnification.

A scanning electron microscope was utilized in order to take advantage of its great depth of field and high resolution at relatively low magnification. The idea was to scan one of the broken up specimens in order to identify whether distinctive features in the archeological material had survived charring and 8,000 years of site formation processes. Further, scanning at a sufficiently low magnification would mean that the same feature might be recognizable by an epi-illuminated light microscope.

Fragments of archeological specimens were attached to stubs using AQUADAG colloidal graphite. After drying for 24 hours in a desiccator, the samples were coated by pumping a vacuum chamber down to 60 millitor and coating the target for 8 minutes. A thick coating produced the best results.
Using the SEM, the material was examined at low magnification, which revealed that the inner (or upper) epidermis of the archeological material did indeed exhibit distinctive cell patterns. A survey of the literature indicated that bulbs exhibit distinct differences between upper and lower epidermal patterns and also that the most reliable parts of the bulb to examine for the cell patterns are the outer two or three scales (Hoffman 1933; Mann 1952; Park 1985). Although the only detailed descriptions found were for onions and a very few other commercially important species, the information helped determine what characteristics were necessary to begin assigning bulbs to taxonomic groups.

Having established that the archeological material had retained enough structural integrity to identify the shapes of epidermal cells, the next step was to examine the reference material to see if there was interspecific variation in the shapes of epidermal cells. The cells of the upper epidermis were examined, because these survived in the archeological material. In addition, the inner epidermis appeared to be a somewhat reliable aid in the identification of certain bulbs. In a monograph on the genus Allium, Owenby (1950) used the cell shapes of the inner epidermis as one of the main characteristics in her key to the species.

The results were encouraging. Different epidermal cell shapes were indeed recognized in the five modern species 
that were examined. A key to each species, based on epidermal cell morphology, is presented in Table 40-2. SEM photos of the archeological samples were examined and compared to the modern reference material for identification.

\section{RESULTS}

A total of 19 plant taxa were identified in the macroplant (Table 40-3) and flotation samples (Table 40-4). Represented by at least 16 wood types or taxa, carbonized wood dominated the plant assemblage; a nutlet and nutshells were also identified for 2 of the wood taxa. The samples contained 3 taxa of grass seeds, and 1 bulb-producing geophyte. Wood and seed or nutshell remains of walnut and hackberry were identified in the samples.

\section{Flotation Samples}

Of the 76 flotation samples, 3 of the fully sorted samples produced identifiable fragments of carbonized plant remains. The other 73 samples had no identifiable remains. Six plant taxa, including 3 grasses and 3 wood types, were identified (see Table 40-4).

Juniper wood charcoal was the most common plant material in the flotation samples. Oak wood was recovered from a single sample (flotation sample 155). Flotation sample 154 contained the most material of all the samples, including the seeds of bristlegrass, panic grass, and paspalum grass. The poor recovery of plant remains is addressed below.

\section{Macroplant Samples}

Most of the macroplant samples contained 2-15 fragments of carbonized plant material; some contained hundreds of very tiny fragments or charcoal flecks. Plant parts recovered in these samples included wood, nut fragments, and bulbs and bulb fragments. Positive identifications were obtained in 228 of the samples. All macroplant samples, their proveniences, and identifications are presented in Table 405 and $40-6$.
At least 16 plant taxa or wood types were identified in the macroplant samples analyzed from this site (see Table 40-3). Juniper wood and oak wood dominate the macroplant samples. Of the 207 samples in which a wood identification was determined, 73 contained oak and 83 contained juniper. The remaining 13 taxa or wood types accounted for only 51 of the samples in which a positive identification was obtained.

Plant food resources were not abundant in the site sediments. Carbonized bulbs and bulb fragments, however, were present in 12 samples from 3 different features. The excellent preservation of these whole carbonized bulbs contrasts with the paucity of seeds or fruits in the archeological sediments. Eight macroplant samples contained fragments of walnut shells. These came both from feature fill and general contexts. One charred hackberry nutlet (seed) was identified with the macroplant samples sent for identification. Uncharred hackberry nutlets (seeds) were present in many samples, and, along with the other uncharred botanical remains, were considered to be modern and were not analyzed in this study.

\section{Plant Remains from Features}

Macroplant samples from 63 features were examined, and 62 flotation samples from 31 features were either scanned or fully sorted. Although most of these samples contained very few plant remains, identifiable plant remains were found in samples from 29 features (Table 40-7).

Evidence of at least seven burned trees was recovered at the site. Macroplant samples of this charcoal were submitted for identification, and the results appear in Table 408. All seven trees were radiocarbon dated (see Chapter 25). Five of the burned trees (Features 164, 165, 167, 198, and 253) are from Late Paleoindian contexts, in the lower part of stratigraphic Unit II and the upper part of Unit I. Dates on these trees range from ca. 9240 to 9610 в.Р.

Four of the trees were classed as live oak and the fifth (Feature 164) could not be identified because no anatomical structures could be identified. This material either was

TABLE $40-2$

Key to the Potentially Economic Bulbs of the Study Area

\begin{tabular}{l|l}
\hline Species & Description* \\
\hline $\begin{array}{l}\text { Allium canadense var. canadense } \\
\text { Allium drummondii }\end{array}$ & Inner epidermal cells vertically elongate and sinuously contorted \\
& Inner epidermal cells vertically elongate, 4 to 5-sided, 100-125 micrometers \\
Camassia scilloides & long, not contorted \\
Inner epidermal cells vertically elongate, 5 to 7-sided, mostly 6-sided, 50-60 \\
mothoscordum bivalve & micrometers long, not contorted \\
Erythronium albidum & Inner epidermal cells irregularly shaped, horizontally or vertically elongate \\
\hline
\end{tabular}

*Based on the morphology of the inner epidermis. 
TABLE $40-3$

Plant Taxa Identified in the Macroplant Samples

\begin{tabular}{|c|c|c|c|}
\hline Scientific Name & Common Name & Part & No. of Samples \\
\hline Arboreal Legume & cf. Honey locust, mesquite, or acacia & Wood & 3 \\
\hline Bumelia lanuginosa & Gum bumelia & Wood & 1 \\
\hline Camassia scilloides & Wild hyacinth & Bulb & 12 \\
\hline Carya illinoiensis & Pecan & Wood & 1 \\
\hline Celtis sp. & Hackberry & Wood & 4 \\
\hline Celtis sp. & Hackberry & Nutlet & 1 \\
\hline Cornus drummondii & Dogwood & Wood & 1 \\
\hline Unknown hardwood & Unknown hardwood & Wood & 15 \\
\hline Juglans sp. & Walnut & Wood & 1 \\
\hline Juglans sp. & Walnut & Nutshell & 8 \\
\hline Juniperus sp. & Juniper & Wood & 83 \\
\hline Moraceae & Mulberry family & Wood & 1 \\
\hline Morus rubra & Mulberry & Wood & 1 \\
\hline Quercus sp. & Live Oak Wood Type & Wood & 67 \\
\hline Quercus sp. & Oak Wood Type & Wood & 6 \\
\hline Rosaceae & Rose Family & Wood & 4 \\
\hline Salicaceae & Willow Family (e.g., willow or cottonwood) & Wood & 8 \\
\hline Ulmaceae & Elm Family (Elm, hackberry) & Wood & 10 \\
\hline Ulmus sp. & Elm & Wood & 1 \\
\hline Indeterminable & & Charcoal flecks & 232 \\
\hline \multicolumn{3}{|c|}{ Total macroplant samples examined: } & 460 \\
\hline
\end{tabular}

TABLE $40-4$

Carbonized Remains from Wilson-Leonard Flotation Samples

\begin{tabular}{|c|c|c|c|c|c|c|}
\hline $\begin{array}{l}\text { Feature } \\
\text { Number }\end{array}$ & $\begin{array}{c}\text { Stratigraphic } \\
\text { Unit } \\
\end{array}$ & $\begin{array}{c}\text { Flotation } \\
\text { Sample No. }\end{array}$ & Common Name & Scientific Name & Part Identified & Count \\
\hline \multirow[t]{5}{*}{209} & $\mathrm{IIIb}$ & 154 & Juniper & Juniperus sp. & Wood & 5 \\
\hline & & & Rose Family & Rosaceae & Wood & 4 \\
\hline & & & Bristlegrass & Setaria sp. & Seed & 2 \\
\hline & & & Panic Grass & Panicum sp. & Seed & 4 \\
\hline & & & Paspalum Grass & Paspalum sp. & Seed & 1 \\
\hline 213 & $\mathrm{IIIb} / \mathrm{a}$ & 155 & Oak Wood Type & Quercus sp. & Wood & 5 \\
\hline 233 & IIIa & 164 & Juniper & Juniperus sp. & Wood & 7 \\
\hline
\end{tabular}

wood charcoal that had been reduced to soot or soot-coated sediment. Two of the burned trees (Features 50 and 199) are from Middle Archaic contexts in stratigraphic Unit IIIb, dating to ca. 5500 B.P. These were live oak and red mulberry tree roots or trunks.

These may have burned in a natural fire while the site was not occupied, or they may have been intentionally burned by the people living there. These trees are an important indication of the nature of the overstory growing in the immediate vicinity of the site.

Fragments of at least 10 bulbs were identified in Feature 181. As described below in the section on the identification and use of wild hyacinth (Camassia scilloides), these bulbs were associated with fire-cracked rocks and heat-altered sediments. Five additional charcoal samples were examined from this feature, but none could be identified.

The most productive flotation sample came from Feature 209. Seeds of panic grass, bristlegrass, and paspalum were identified. Rose family wood type and juniper wood also were found in the flotation sample. Elm family wood was identified in a single macroplant sample.

Twenty-one macroplant samples were examined from Feature 231. Juniper (Juniperus) was identified in three samples, live oak (Quercus) wood in two samples, and unknown hardwood wood in one sample.

\section{Burned Rock Midden 1}

This burned rock feature contained wood from several tree taxa and charred walnut shell fragments. The tree taxa included juniper, live oak, elm family, and arboreal legume. The variety of wood taxa indicates that the feature may have been reused many times. The presence of fire-cracked rocks and carbonized wood provides evidence that the feature may have been utilized at least in part to cook plant foods. Any detailed functional interpretation should tie 
TABLE $40-5$

Identification of Macroplant Samples from the TxDOT Excavations

\begin{tabular}{|c|c|c|c|c|c|c|c|c|}
\hline Lot No. & \begin{tabular}{|l|} 
Charcoal \\
Sample No.
\end{tabular} & Unit & Square & Quad & Level & Feature & Taxa & Part \\
\hline $1 \mathrm{H}$ & & Y & E20/S100 & & 8 & & Indeterminate & wood \\
\hline $10 \mathrm{~B}$ & & IIIIc & E20/S86 & & 2 & & Quercus sp.; live oak type & wood \\
\hline 10B & & IIIIc & E20/S86 & & 2 & & Quercus sp.; live oak type & wood \\
\hline $10 \mathrm{G}$ & & IIIIc & E20/S86 & & 7 & BRM 1 & Indeterminate & wood \\
\hline $10 \mathrm{H}$ & & IIIc & E20/S86 & & 8 & & Indeterminate & wood \\
\hline $10 \mathrm{R}$ & & II/ $\mathrm{X}$ & E20/S86 & & 18 & & Indeterminate & wood \\
\hline $11 \mathrm{~B}$ & & IIIIc & E20/S84 & & 2 & & Rosaceae & wood \\
\hline $11 \mathrm{C}$ & & IIIlc & E20/S84 & & 3 & & Indeterminate & wood \\
\hline $11 \mathrm{~F}$ & & IIIIc & E20/S84 & & 6 & & Ulmaceae & wood \\
\hline $12 \mathrm{~A}$ & & IIIc & E20/S82 & & 1 & & Juniperus sp. & wood \\
\hline $12 \mathrm{~B}$ & & IIII & E20/S82 & & 2 & 7 & Ulmaceae & wood \\
\hline $12 \mathrm{C}$ & & IIIIc & E20/S82 & & 3 & & Indeterminate & wood \\
\hline $12 \mathrm{G}$ & & $\mathrm{IIIb} / \mathrm{c}$ & E20/S82 & & 7 & & Ulmus sp. & wood \\
\hline $14 \mathrm{~A}$ & & IIIc & E20/S78 & & 1 & & Juniperus sp. & wood \\
\hline $14 \mathrm{C}$ & & IIIlc & E20/S78 & & 3 & & Juniperus sp. & wood \\
\hline $14 \mathrm{D}$ & & IIIlc & E20/S78 & & 4 & & Indeterminate & \\
\hline $14 \mathrm{E}$ & & IIIIc & E20/S78 & & 5 & & Indeterminate & root \\
\hline $15 \mathrm{FF} 1 \mathrm{C}$ & & $\mathrm{Isi} / \mathrm{Icl}$ & E20/S76 & SE & $32 \mathrm{~A}$ & & Celtis sp. & nutlet \\
\hline $16 \mathrm{E}$ & & IIIc & E20/S74 & & 5 & & Indeterminate & wood \\
\hline $17 \mathrm{~A}$ & & IIIc & E20/S72 & & 1 & & Juniperus sp. & wood \\
\hline $19 \mathrm{H}$ & & IIIIc & E22/S88 & & 8 & BRM 1 & Ulmaceae & wood \\
\hline $20 \mathrm{~F}$ & & IIII & E22/S86 & & 6 & BRM 1 & Indeterminate & wood \\
\hline $20 \mathrm{G}$ & & IIIc & E22/S86 & & 7 & BRM 1 & Indeterminate & wood \\
\hline $20 \mathrm{I}$ & & $\mathrm{IIIb} / \mathrm{c}$ & E22/S86 & & 9 & & Celtis sp. & wood \\
\hline $20 \mathrm{I}$ & & $\mathrm{IIIb} / \mathrm{c}$ & E22/S86 & & 9 & & Juglans sp. & nutshell \\
\hline $21 \mathrm{~F}$ & & IIIc & E22/S84 & & 6 & & Celtis sp. & wood \\
\hline $3 \mathrm{~A}$ & & IIIIc & E20/S98 & & 1 & & Indeterminate & wood \\
\hline $3 \mathrm{~B}$ & & IIIIc & E20/S98 & & 2 & & Indeterminable hardwood & wood \\
\hline $35 \mathrm{AA} 1 \mathrm{~A}$ & & III & E26/S72 & $\mathrm{NE}$ & $27 \mathrm{~A}$ & 165 & Quercus sp.; live oak type & wood \\
\hline $36 \mathrm{E}$ & & IIIIc & $\mathrm{E} 40 / \mathrm{S} 70$ & & 5 & & Indeterminate & wood \\
\hline $36 \mathrm{G}$ & & $\mathrm{mllb} / \mathrm{c}$ & E40/S70 & 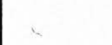 & 7 & & Juniperus sp. & wood \\
\hline $36 \mathrm{~L}$ & & IIIa/b & $\mathrm{E} 40 / \mathrm{S} 70$ & & 12 & & Juniperus sp. & wood \\
\hline $5 \mathrm{~A}$ & & IIIc/POT & E20/S96 & & 1 & & Rosaceae & wood \\
\hline $5 \mathrm{~B}$ & & IIIc/POT & E20/S96 & & 2 & BRM 1 & Arboreal legume & wood \\
\hline $50 \mathrm{H} \mathrm{B}$ & & IIIc & E0/N8 & NW & 8 & BRM 2 & Indeterminate & wood \\
\hline $50 \mathrm{IA}$ & & IIII & E0/N8 & $\mathrm{NE}$ & 9 & BRM 2 & Indeterminate & wood \\
\hline $51 \mathrm{~K} \mathrm{C}$ & & III & E2/N8 & SE & 11 & BRM 2 & Quercus sp.;live oak type & wood \\
\hline $6 \mathrm{~A}$ & & $\mathrm{IIIc} / \mathrm{POT}$ & E20/S94 & & 1 & & Juniperus sp. & wood \\
\hline $8 \mathrm{~A}$ & & IIIIc & E20/S90 & & 1 & & Juniperus sp. & wood \\
\hline $9 \mathrm{~A}$ & & IIIIc & E20/S88 & & 1 & & Juniperus sp. & wood \\
\hline $32 \mathrm{FF} 2 \mathrm{~B}$ & CH-0506 & Isi/Icl/Isi-c & E26/S78 & NW & $32 \mathrm{~B}$ & & Indeterminate & wood \\
\hline 32 FF2 D & CH-0507 & Isi/Icl/Isi-c & E26/S78 & SW & $32 B$ & & Indeterminate & wood \\
\hline 32 KKLL1 B & CH-0510 & Isi/Icl & E26/S78 & NW & $37-38 \mathrm{~A}$ & 175 & Indeterminate & wood \\
\hline 32 Q1 & CH-0514 & IIIa & E26/S78 & & $17 \mathrm{~A}$ & & Indeterminate & wood \\
\hline $32 \mathrm{Q} 2 \mathrm{AB}$ & CH-0515 & IIIIa & E26/S78 & NE, NW & 17B & & Indeterminate & wood \\
\hline 33 KK1LL1 D & $\mathrm{CH}-0578$ & Isi/Icl & E26/S76 & SW & $37 \mathrm{~A}-38 \mathrm{~A}$ & 175 & Indeterminate & wood \\
\hline 33 Q1 & CH-0584 & IIIa & E26/S76 & & $17 \mathrm{~A}$ & & Indeterminate & wood \\
\hline $33 \mathrm{X} 2 \mathrm{~A}$ & CH-0600 & III & E26/S76 & $\mathrm{NE}$ & $24 \mathrm{~B}$ & 162 & Indeterminate & wood \\
\hline $33 \mathrm{X} 2 \mathrm{~A}$ & CH-0601 & II & E26/S76 & NE & $24 \mathrm{~B}$ & 162 & Indeterminate & wood \\
\hline $33 \times 2 \mathrm{~A}$ & CH-0602 & III & E26/S76 & NE & $24 B$ & 162 & Indeterminate & wood \\
\hline $33 \mathrm{Z2}$ & CH-0609 & II & E26/S76 & & $26 \mathrm{~B}$ & 164 & Indeterminate & wood \\
\hline
\end{tabular}


Table 40-5, continued

\begin{tabular}{|c|c|c|c|c|c|c|c|c|}
\hline Lot No. & \begin{tabular}{|l|} 
Charcoal \\
Sample No.
\end{tabular} & Unit & Square & Quad & Level & Feature & Taxa & Part \\
\hline $34 \mathrm{HH} 1 \mathrm{ABCD}$ & $\mathrm{CH}-0636$ & Icl/Isi-c & E26/S74 & All & $34 \mathrm{~A}$ & & Indeterminate & wood \\
\hline $34 \mathrm{JJ} 2 \mathrm{~A}$ & $\mathrm{CH}-0644$ & Icl & E26/S74 & $\mathrm{NE}$ & $36 \mathrm{~B}$ & & Indeterminate & wood \\
\hline 34 U1 D & $\mathrm{CH}-0653$ & III/IIIa & E26/S74 & SW & $21 \mathrm{~A}$ & & Indeterminate & wood \\
\hline 34 U2 B & $\mathrm{CH}-0654$ & II & E26/S74 & NW & $21 B$ & & Indeterminate & wood \\
\hline $31 \mathrm{KK} 2 \mathrm{C}$ & CH-0672 & Isi/Icl & E24/S72 & SE & $37 \mathrm{~B}$ & & Indeterminate & wood \\
\hline $35 \mathrm{AA} 1 \mathrm{~A}$ & $\mathrm{CH}-0704$ & II & E26/S72 & $\mathrm{NE}$ & $27 \mathrm{~A}$ & 165 & Quercus sp.; live oak type & wood \\
\hline $35 \mathrm{AA} 1 \mathrm{~A}$ & CH-0705 & II & E26/S72 & NE & $27 \mathrm{~A}$ & 165 & Quercus sp.; live oak type & wood \\
\hline $35 \mathrm{AA} 1 \mathrm{~A}$ & CH-0706 & III & E26/S72 & NE & $27 \mathrm{~A}$ & 165 & Quercus sp.; live oak type & wood \\
\hline 35 AA1 D & CH-0707 & II & E26/S72 & SW & $27 \mathrm{~A}$ & 165 & Quercus sp.; live oak type & wood \\
\hline 35 AA $1 \& 2$ & CH-0708 & II & E26/S72 & & $27 \mathrm{~A} \& \mathrm{~B}$ & 165 & Quercus sp.; live oak type & wood \\
\hline $35 \mathrm{AA} 2 \mathrm{~A}$ & CH-0709 & II & E26/S72 & NE & $27 \mathrm{~B}$ & 165 & Quercus sp.; live oak type & wood \\
\hline 35 AA2 A & $\mathrm{CH}-0710$ & II & E26/S72 & $\mathrm{NE}$ & $27 \mathrm{~B}$ & 165 & Indeterminate & wood \\
\hline $35 \mathrm{AA} 2 \mathrm{BCD}$ & CH-0711 & II & E26/S72 & NW, SE, SW & $27 \mathrm{~B}$ & & Quercus sp.; live oak type & wood \\
\hline $35 \mathrm{BB} 1 \mathrm{~A}$ & CH-0712 & III & E26/S72 & $\mathrm{NE}$ & $28 \mathrm{~A}$ & 165 & Indeterminate & wood \\
\hline $35 \mathrm{BB} 2 \mathrm{~A}$ & CH-0713 & Isi-c/II & E26/S72 & NE & $28 \mathrm{~B}$ & 165 & Quercus sp.; live oak type & wood \\
\hline $35 \mathrm{CC} 1 \mathrm{~A}$ & CH-0716 & Isi-c/II & E26/S72 & $\mathrm{NE}$ & $29 \mathrm{~A}$ & 165 & Indeterminate & wood \\
\hline $35 \mathrm{CC} 1 \mathrm{~A}$ & CH-0717 & Isi-c/II & E26/S72 & $\mathrm{NE}$ & $29 \mathrm{~A}$ & 165 & Indeterminate & wood \\
\hline $35 \mathrm{CC} 1 \mathrm{~A}$ & CH-0718 & Isi-c/II & E26/S72 & NE & $29 \mathrm{~A}$ & 165 & Indeterminate & wood \\
\hline $35 \mathrm{OO} 1 \mathrm{D}$ & CH-0735 & $\operatorname{Igl} / \operatorname{Isi}$ & E26/S72 & SW & $41 \mathrm{~A}$ & & Indeterminate & wood \\
\hline $35 \mathrm{~S} 2 \mathrm{C}$ & CH-0737 & II/IIIa & E26/S72 & SE & 19B & & Quercus sp.; live oak type & wood \\
\hline 35 U1 & CH-0738 & II/IIIa & E26/S72 & & $21 \mathrm{~A}$ & 146 & Indeterminate & wood \\
\hline $35 \mathrm{~V} 1 \mathrm{~A}$ & CH-0740 & II & E26/S72 & NE & $22 \mathrm{~A}$ & 157 & Indeterminate & wood \\
\hline $35 \mathrm{~V} 1 \mathrm{D}$ & CH-0741 & II & E26/S72 & SW & $22 \mathrm{~A}$ & & Indeterminate & wood \\
\hline $35 \mathrm{~V} 2 \mathrm{~A}$ & CH-0742 & II & E26/S72 & $\mathrm{NE}$ & $22 \mathrm{~B}$ & 157 & Indeterminate & wood \\
\hline $35 \mathrm{~V} 2 \mathrm{C}$ & $\mathrm{CH}-0743$ & II & E26/S72 & SE & $22 \mathrm{~B}$ & 157 & Indeterminate & wood \\
\hline $35 \mathrm{Z} 2 \mathrm{~A}$ & CH-0761 & II & E26/S72 & NE & $26 \mathrm{~B}$ & 165 & Quercus sp.; live oak type & wood \\
\hline $35 \mathrm{Z} 2 \mathrm{~A}$ & CH-0762 & II & E26/S72 & NE & $26 \mathrm{~B}$ & 165 & Quercus sp.; live oak type & wood \\
\hline $36 \mathrm{~B}$ & CH-0764 & IIIlc & $\mathrm{E} 40 / \mathrm{S} 70$ & & 2 & & Indeterminate & \\
\hline $36 \mathrm{~K}$ & CH-0769 & IIIb & E40/S70 & & 11 & & Indeterminate & wood \\
\hline $36 \mathrm{Z}$ & $\mathrm{CH}-0773$ & $\mathrm{I}$ & $\mathrm{E} 40 / \mathrm{S} 70$ & & 26 & & Indeterminate & wood \\
\hline $36 \mathrm{Z}$ & CH-0774 & I & E40/S70 & & 26 & & Juniperus sp. & wood \\
\hline $37 \mathrm{C} \mathrm{C}$ & CH-0790 & IIIIc & E28/S78 & SE & 3 & & Quercus sp.; live oak type & wood \\
\hline $37 \mathrm{DD} 1 \mathrm{D}$ & CH-0801 & Isi-c & E28/S78 & SW & $30 \mathrm{~A}$ & 193 & Indeterminate & \\
\hline 37 FF2GG1 A & CH-0820 & Isi-c & E28/S78 & $\mathrm{NE}$ & $32 \mathrm{~B}-33 \mathrm{~A}$ & 187 & Indeterminate & wood \\
\hline $37 \mathrm{H} \mathrm{C}$ & CH-0826 & $\mathrm{IIIb} / \mathrm{c}$ & E28/S78 & SE & 8 & & Quercus sp.; live oak type & wood \\
\hline 37 I A & CH-0831 & $\mathrm{IIIb} / \mathrm{c}$ & E28/S78 & $\mathrm{NE}$ & 9 & & Indeterminate & wood \\
\hline 37 I B & CH-0832 & $\mathrm{IIlb} / \mathrm{c}$ & E28/S78 & NW & 9 & & Quercus sp.; live oak type & wood \\
\hline 37 I B & CH-0833 & $\mathrm{IIIb} / \mathrm{c}$ & E28/S78 & NW & 9 & & Quercus sp.; live oak type & wood \\
\hline $37 \mathrm{~J} \mathrm{~A}$ & CH-0840 & $\mathrm{IIIb} / \mathrm{c}$ & E28/S78 & $\mathrm{NE}$ & 10 & & Indeterminate & wood \\
\hline $37 \mathrm{~K} \mathrm{C}$ & CH-0843 & IIIb & E28/S78 & SE & 11 & & Indeterminate & wood \\
\hline $37 \mathrm{~K} \mathrm{D}$ & CH-0844 & IIIlb & E28/S78 & SW & 11 & & Indeterminate & wood \\
\hline $37 \mathrm{~L} \mathrm{C}$ & CH-0846 & IIIb & E28/S78 & SE & 12 & & Indeterminate & wood \\
\hline $37 \mathrm{O} 2 \mathrm{~A}$ & CH-0859 & IIIa/b & E28/S78 & NE & $15 \mathrm{~B}$ & & Indeterminate & \\
\hline $37 \mathrm{P} 1 \mathrm{C}$ & CH-0865 & II/IIIa & E28/S78 & SE & $16 \mathrm{~A}$ & 181 & Indeterminate & wood \\
\hline 37 Q1 A & $\mathrm{CH}-0870$ & II/IIIa & E28/S78 & NE & $17 \mathrm{~A}$ & 181 & Indeterminate & wood \\
\hline 37 Q1 B & CH-0872 & IIIIa & E28/S78 & NW & $17 \mathrm{~A}$ & & Indeterminate & \\
\hline $37 \mathrm{R} 1 \mathrm{C}$ & CH-0874 & IIIIa & E28/S78 & SE & $18 \mathrm{~A}$ & & Indeterminate & \\
\hline $37 \mathrm{R} 1 \mathrm{C}$ & $\mathrm{CH}-0875$ & IIIla & E28/S78 & SE & $18 \mathrm{~A}$ & & Indeterminate & \\
\hline 37 R1 D & $\mathrm{CH}-0876$ & IIIIa & E28/S78 & SW & $18 \mathrm{~A}$ & 183 & Indeterminate & wood \\
\hline $37 \mathrm{R} 2 \mathrm{~A}$ & CH-0877 & II/IIIa & E28/S78 & NE & $18 \mathrm{~B}$ & 181 & Indeterminate & wood \\
\hline $37 \mathrm{~S} 1 \mathrm{~A}$ & CH-0878 & II/IIIa & E28/S78 & NE & $19 \mathrm{~A}$ & 181 & Indeterminate & wood \\
\hline 37 S2 A & CH-0880 & II/IIIa & E28/S78 & NE & 19B & 181 & Indeterminate & wood \\
\hline $37 \mathrm{~S} 2 \mathrm{C}$ & CH-0881 & II/IIIa & E28/S78 & SE & 19B & & Indeterminate & \\
\hline
\end{tabular}


Table 40-5, continued

\begin{tabular}{|c|c|c|c|c|c|c|c|c|}
\hline Lot No. & \begin{tabular}{|l|} 
Charcoal \\
Sample No.
\end{tabular} & Unit & Square & Quad & Level & Feature & Taxa & Part \\
\hline $37 \mathrm{~T} 2 \mathrm{ABCD}$ & $\mathrm{CH}-0882$ & II & E28/S78 & All & $20 \mathrm{~B}$ & & Indeterminate & wood \\
\hline $37 \mathrm{~T} 1 \mathrm{D}$ & CH-0883 & II & E28/S78 & SW & $20 \mathrm{~A}$ & & Indeterminate & wood \\
\hline $37 \mathrm{~T} 2 \mathrm{~B}$ & $\mathrm{CH}-0884$ & II & E28/S78 & NW & 20B & & Indeterminate & wood \\
\hline $37 \mathrm{~T} 2 \mathrm{~B}$ & CH-0885 & II & E28/S78 & NW & $20 \mathrm{~B}$ & & Indeterminate & wood \\
\hline $37 \mathrm{~T} 2 \mathrm{C}$ & $\mathrm{CH}-0886$ & II & E28/S78 & SE & $20 \mathrm{~B}$ & & Indeterminate & \\
\hline $37 \mathrm{~T} 2 \mathrm{C}$ & CH-0887 & II & E28/S78 & SE & 20B & & Indeterminate & \\
\hline $50 \mathrm{AA} 1 \mathrm{~B}$ & CH-0914 & $\mathrm{I} / \mathrm{II}$ & E0/N8 & NW & $27 \mathrm{~A}$ & 198 & Quercus sp.; live oak type & wood \\
\hline $50 \mathrm{BB} 2 \mathrm{~B}$ & CH-0919 & $\mathrm{I} / \mathrm{II}$ & $\mathrm{E} 0 / \mathrm{N} 8$ & NW & $28 \mathrm{~B}$ & 198 & Quercus sp.; live oak type & wood \\
\hline $50 \mathrm{CC} 2 \mathrm{~B}$ & CH-0921 & $\mathrm{I} / \mathrm{II}$ & $\mathrm{E} 0 / \mathrm{N} 8$ & NW & $29 B$ & 198 & Quercus sp.; live oak type & wood \\
\hline $50 \mathrm{DD} B$ & $\mathrm{CH}-0922$ & $\mathrm{I} / \mathrm{II}$ & $\mathrm{E} 0 / \mathrm{N} 8$ & NW & 30 & 198 & Quercus sp.; live oak type & wood \\
\hline $50 \mathrm{G} \mathrm{B}$ & CH-0923 & IIIIc & $\mathrm{E} 0 / \mathrm{N} 8$ & NW & 7 & BRM 2 & Indeterminate & wood \\
\hline $50 \mathrm{H} \mathrm{B}$ & CH-0924 & IIIIc & $\mathrm{E} 0 / \mathrm{N} 8$ & NW & 8 & BRM 2 & Indeterminate & wood \\
\hline $50 \mathrm{H} \mathrm{D}$ & CH-0925 & IIII & $\mathrm{E} 0 / \mathrm{N} 8$ & SW & 8 & BRM 2 & Camassia scilloides & bulb \\
\hline $50 \mathrm{~J} \mathrm{~A}$ & CH-0928 & III & $\mathrm{E} 0 / \mathrm{N} 8$ & NE & 10 & 195 & Indeterminate & wood \\
\hline $50 \mathrm{~J} \mathrm{BD}$ & CH-0929 & III & $\mathrm{E} 0 / \mathrm{N} 8$ & NW, SW & 10 & BRM 2 & Indeterminate & wood \\
\hline $50 \mathrm{~J} \mathrm{C}$ & $\mathrm{CH}-0930$ & III/IIIC & $\mathrm{E} 0 / \mathrm{N} 8$ & SE & 10 & 194 & Indeterminate & wood \\
\hline $50 \mathrm{~K} \mathrm{~A}$ & CH-0932 & IIII & $\mathrm{E} 0 / \mathrm{N} 8$ & NE & 11 & 195 & Quercus sp.; live oak type & wood \\
\hline $50 \mathrm{~K} \mathrm{~A}$ & CH-0933 & III & E0/N8 & NE & 11 & 195 & Quercus sp.; live oak type & wood \\
\hline $50 \mathrm{~K} \mathrm{C}$ & CH-0934 & III & $\mathrm{E} 0 / \mathrm{N} 8$ & SE & 11 & 195 & Juglans sp. & wood \\
\hline $50 \mathrm{~K} \mathrm{C}$ & $\mathrm{CH}-0935$ & III & $\mathrm{E} 0 / \mathrm{N} 8$ & SE & 11 & 195 & Indeterminate & wood \\
\hline $50 \mathrm{NA}$ & CH-0944 & III & $\mathrm{E} 0 / \mathrm{N} 8$ & NE & 14 & & Indeterminate & wood \\
\hline $50 \mathrm{NC}$ & $\mathrm{CH}-0945$ & III & $\mathrm{E} 0 / \mathrm{N} 8$ & SE & 14 & & Indeterminate & wood \\
\hline $51 \mathrm{AA} 1 \mathrm{D}$ & CH-0953 & I/II & E2/N8 & SW & $27 \mathrm{~A}$ & 166 & Indeterminate & wood \\
\hline $51 \mathrm{AA} 2 \mathrm{BB} 1 \mathrm{D}$ & $\mathrm{CH}-0954$ & I/II & $\mathrm{E} 2 / \mathrm{N} 8$ & SW & 27B-28A & 166 & Indeterminate & wood \\
\hline $51 \mathrm{JD}$ & $\mathrm{CH}-0957$ & IIII & E2/N8 & SW & 10 & BRM 2 & Indeterminate & wood \\
\hline $51 \mathrm{~K} \mathrm{~A}$ & $\mathrm{CH}-0959$ & IIIIc & $\mathrm{E} 2 / \mathrm{N} 8$ & NE & 11 & BRM 2 & Quercus sp.; live oak type & wood \\
\hline $51 \mathrm{~K} \mathrm{~B}$ & $\mathrm{CH}-0960$ & IIIIc & $\mathrm{E} 2 / \mathrm{N} 8$ & NW & 11 & BRM 2 & Quercus sp.; live oak type & wood \\
\hline $51 \mathrm{~K} \mathrm{~B}$ & $\mathrm{CH}-0961$ & IIIIC & E2/N8 & NW & 11 & BRM 2 & Ulmaceae & wood \\
\hline $51 \mathrm{MD}$ & $\mathrm{CH}-0967$ & III & $\mathrm{E} 2 / \mathrm{N} 8$ & SW & 13 & & Indeterminate & wood \\
\hline $51 \mathrm{MD}$ & CH-0968 & III & $\mathrm{E} 2 / \mathrm{N} 8$ & SW & 13 & & Indeterminate & wood \\
\hline $51 \mathrm{NB}$ & $\mathrm{CH}-0970$ & III & $\mathrm{E} 2 / \mathrm{N} 8$ & NW & 14 & 196 & Indeterminate & wood \\
\hline $51 \mathrm{NB}$ & $\mathrm{CH}-0971$ & III & $\mathrm{E} 2 / \mathrm{N} 8$ & NW & 14 & 196 & Indeterminate & wood \\
\hline $51 \mathrm{ND}$ & $\mathrm{CH}-0972$ & III & E2/N8 & SW & 14 & 196 & Indeterminate & wood \\
\hline $51 \mathrm{ND}$ & $\mathrm{CH}-0973$ & III & E2/N8 & SW & 14 & 196 & Indeterminate & wood \\
\hline $51 \mathrm{YD}$ & $\mathrm{CH}-0977$ & $\mathrm{I} / \mathrm{II}$ & $\mathrm{E} 2 / \mathrm{N} 8$ & SW & 25 & 166 & Indeterminate & wood \\
\hline $51 \mathrm{Z2} \mathrm{B}$ & CH-0987 & I/II & E2/N8 & NW & $26 \mathrm{~B}$ & & Indeterminate & wood \\
\hline $51 \mathrm{Z} 2 \mathrm{D}$ & CH-0989 & I/II & $\mathrm{E} 2 / \mathrm{N} 8$ & SW & $26 \mathrm{~B}$ & 166 & Indeterminate & wood \\
\hline $6 \mathrm{~K}$ & $\mathrm{CH}-0993$ & $\mathrm{X} / \mathrm{Y} / \mathrm{IIIb}$ & E20/S94 & & 11 & 4 & Indeterminate & wood \\
\hline $7 \mathrm{~K}$ & $\mathrm{CH}-0995$ & $\mathrm{Y}$ & E20/S92 & & 11 & & Quercus sp.; live oak type & wood \\
\hline $7 \mathrm{~K}$ & CH-0996 & $\mathrm{Y}$ & E20/S92 & & 11 & & Quercus sp.; live oak type & wood \\
\hline $8 \mathrm{E}$ & CH-0997 & IIIIc & E20/S90 & & 5 & BRM 1 & Indeterminate & \\
\hline $8 \mathrm{~J}$ & CH-0998 & $\mathrm{X} / \mathrm{Y} / \mathrm{IIIb}$ & E20/S90 & & 10 & 8 & Camassia scilloides & bulb \\
\hline $8 \mathrm{~L}$ & CH-0999 & $\mathrm{X} / \mathrm{Y}$ & E20/S90 & & 12 & & Indeterminate & wood \\
\hline $8 \mathrm{M}$ & $\mathrm{CH}-1000$ & $\mathrm{X} / \mathrm{Y}$ & E20/S90 & & 13 & & Indeterminate & wood \\
\hline $8 \mathrm{P}$ & $\mathrm{CH}-1001$ & $\mathrm{x}$ & E20/S90 & & 16 & 17 & Arboreal legume & wood \\
\hline $8 \mathrm{P}$ & $\mathrm{CH}-1002$ & $\mathrm{x}$ & E20/S90 & & 16 & 17 & Arboreal legume & wooc \\
\hline $9 \mathrm{~F}$ & CH-1004 & IIIc & E20/S88 & & 6 & BRM 1 & Ulmaceae & wood \\
\hline $9 \mathrm{I}$ & $\mathrm{CH}-1005$ & Y/IIIc & E20/S88 & & 9 & BRM 1 & Indeterminate & wooc \\
\hline $9 \mathrm{~L}$ & $\mathrm{CH}-1006$ & $\mathrm{X} / \mathrm{Y} / \mathrm{IIb}$ & E20/S88 & & 12 & & Indeterminate & wooc \\
\hline $9 \mathrm{M}$ & CH-1007 & $\mathrm{X} / \mathrm{IIIb}$ & E20/S88 & & 13 & & Indeterminate & wooc \\
\hline $9 \mathrm{~N}$ & $\mathrm{CH}-1008$ & $\mathrm{X} / \mathrm{Y} / \mathrm{IIb}$ & E20/S88 & & 14 & 12 & Indeterminate & wooc \\
\hline $9 \mathrm{~N}$ & CH-1009 & $\mathrm{X} / \mathrm{Y} / \mathrm{IIIb}$ & E20/S88 & & 14 & 12 & Indeterminate & wooc \\
\hline
\end{tabular}


Table 40-5, continued

\begin{tabular}{|c|c|c|c|c|c|c|c|c|}
\hline Lot No. & \begin{tabular}{|l} 
Charcoal \\
Sample No.
\end{tabular} & Unit & Square & Quad & Level & Feature & Taxa & Part \\
\hline Trench 1 & $\mathrm{CH}-1013$ & Unknown & Trench 1 & & & & Quercus sp.; live oak type & wood \\
\hline $10 \mathrm{D}$ & $\mathrm{CH}-1015$ & IIIc & E20/S86 & & 4 & & Cornus drummondii & wood \\
\hline $10 \mathrm{E}$ & $\mathrm{CH}-1016$ & IIIlc & E20/S86 & & 5 & & Moraceae & wood \\
\hline $10 \mathrm{~F}$ & $\mathrm{CH}-1017$ & IIIc & E20/S86 & & 6 & & Quercus sp.; live oak type & wood \\
\hline $10 \mathrm{I}$ & $\mathrm{CH}-1018$ & $\mathrm{IIIb} / \mathrm{c}$ & E20/S86 & & 9 & & Indeterminate & wood \\
\hline $10 \mathrm{I}$ & CH-1019 & $\mathrm{IIIb} / \mathrm{c}$ & E20/S86 & & 9 & & Indeterminate & wood \\
\hline $10 \mathrm{~S}$ & $\mathrm{CH}-1022$ & $\mathrm{X} / \mathrm{II}$ & E20/S86 & & 19 & & Indeterminate & wood \\
\hline $11 \mathrm{E}$ & $\mathrm{CH}-1024$ & IIIc & E20/S84 & & 5 & 10 & Celtis sp. & wood \\
\hline $11 \mathrm{~J}$ & $\mathrm{CH}-1025$ & $\mathrm{IIIb} / \mathrm{c}$ & E20/S84 & & 10 & & Indeterminate & wood \\
\hline $11 \mathrm{M}$ & $\mathrm{CH}-1027$ & IIIlb & E20/S84 & & 13 & & Quercus sp.; live oak type & wood \\
\hline $11 \mathrm{P}$ & $\mathrm{CH}-1028$ & IIIIa & E20/S84 & & 16 & & Indeterminate & wood \\
\hline $12 \mathrm{G}$ & $\mathrm{CH}-1032$ & $\mathrm{mllb} / \mathrm{c}$ & E20/S82 & & 7 & & Salicaceae & wood \\
\hline $12 \mathrm{I}$ & $\mathrm{CH}-1033$ & $\mathrm{IIIb} / \mathrm{c}$ & E20/S82 & & 9 & & Salicaceae & wood \\
\hline $13 \mathrm{E}$ & $\mathrm{CH}-1040$ & IIIc & E20/S80 & & 5 & & Bumelia lanuginosa & wood \\
\hline $14 \mathrm{D}$ & $\mathrm{CH}-1041$ & IIIc & E20/S78 & & 4 & & Quercus sp.; live oak type & wood \\
\hline 14 DDHH1 B & $\mathrm{CH}-1043$ & Isi/Isi-c & E20/S78 & NW & $30-34 \mathrm{~A}$ & 169 & Indeterminate & wood \\
\hline $14 \mathrm{I} 1$ & $\mathrm{CH}-1050$ & $\mathrm{IIIb} / \mathrm{c}$ & E20/S78 & & $9 \mathrm{~A}$ & & Celtis sp. & wood \\
\hline $14 \mathrm{I} 2$ & $\mathrm{CH}-1051$ & $\mathrm{IIb} / \mathrm{c}$ & E20/S78 & & $9 \mathrm{~B}$ & & Ulmaceae & wood \\
\hline $14 \mathrm{~L} 1$ & $\mathrm{CH}-1053$ & ШІІа/Шाँ & E20/S78 & & $12 \mathrm{~A}$ & 50 & Quercus sp.; live oak type & wood \\
\hline $14 \mathrm{~L} 1$ & $\mathrm{CH}-1054$ & $\mathrm{IIIa} / \mathrm{IIIb}$ & E20/S78 & & $12 \mathrm{~A}$ & 50 & Quercus sp.; live oak type & wood \\
\hline $14 \mathrm{~L} 1$ & $\mathrm{CH}-1055$ & IIIa/IIIb & E20/S78 & & $12 \mathrm{~A}$ & 50 & Indeterminate & wood \\
\hline $14 \mathrm{~L} 2$ & $\mathrm{CH}-1056$ & Ша/Шl & E20/S78 & & $12 B$ & 50 & Indeterminate & wood \\
\hline $15 \mathrm{EE} 1 \mathrm{AB}$ & $\mathrm{CH}-1060$ & Isi/Icl/Isi-c & E20/S76 & NE, NW & $31 \mathrm{~A}$ & 168 & Indeterminate & wood \\
\hline $15 \mathrm{~K} 2$ & $\mathrm{CH}-1069$ & IIIIb & E20/S76 & & $11 \mathrm{~B}$ & & Quercus sp.; live oak type & wood \\
\hline $16 \mathrm{AA} 2$ & $\mathrm{CH}-1072$ & Isi-c & E20/S74 & & $27 \mathrm{~B}$ & 72 & Indeterminate & wood \\
\hline $16 \mathrm{BB} 2 \mathrm{~A}$ & $\mathrm{CH}-1073$ & Isi-c & E20/S74 & NE & $28 \mathrm{~B}$ & 73 & Indeterminate & wood \\
\hline $16 \mathrm{BB} 1$ & $\mathrm{CH}-1074$ & Isi-c & E20/S74 & & $28 \mathrm{~A}$ & & Indeterminate & wood \\
\hline $16 \mathrm{C}$ & $\mathrm{CH}-1075$ & IIIc & E20/S74 & & 3 & & Quercus sp.; live oak type & wood \\
\hline $16 \mathrm{CC} 2 \mathrm{~A}$ & $\mathrm{CH}-1076$ & Isi-c & E20/S74 & NE & 29B & 73 & Indeterminate & wood \\
\hline $16 \mathrm{DD} 1$ & $\mathrm{CH}-1077$ & Isi/Icl/Isi-c & E20/S74 & & $30 \mathrm{~A}$ & & Indeterminate & wood \\
\hline $16 \mathrm{EE} 1 \mathrm{~B}$ & CH-1079 & Isi/Icl/Isi-c & E20/S74 & NW & $31 \mathrm{~A}$ & Burial 2 & Indeterminate & wood \\
\hline $16 \mathrm{~N}$ & $\mathrm{CH}-1085$ & IIIb & E20/S74 & & 14 & 199 & Morus rubra & wood \\
\hline $16 \mathrm{~S} 2$ & $\mathrm{CH}-1086$ & ШII & E20/S74 & & 19B & & Indeterminate & wood \\
\hline $16 \mathrm{~S} 2$ & $\mathrm{CH}-1087$ & IIIla & E20/S74 & & 19B & & Indeterminate & wood \\
\hline $16 \mathrm{~S} 2$ & $\mathrm{CH}-1088$ & IIIa & E20/S74 & & 19B & & Indeterminate & wood \\
\hline $18 \mathrm{~J}$ & $\mathrm{CH}-1110$ & $\mathrm{Y} / \mathrm{IIIC}$ & E22/S90 & & 10 & BRM 1 & Indeterminate & wood \\
\hline $18 \mathrm{~N}$ & $\mathrm{CH}-1112$ & $\mathrm{x}$ & $\mathrm{E} 22 / \mathrm{S} 90$ & & 14 & & Quercus sp.; live oak type & wood \\
\hline $18 \mathrm{R}$ & $\mathrm{CH}-1113$ & $\mathrm{x}$ & E22/S90 & & 18 & 19 & Indeterminate & wood \\
\hline $18 \mathrm{R}$ & $\mathrm{CH}-1114$ & $\mathrm{x}$ & $\mathrm{E} 22 / \mathrm{S} 90$ & & 18 & 19 & Indeterminate & wood \\
\hline $2 \mathrm{M}$ & $\mathrm{CH}-1119$ & $\mathrm{x}$ & $\mathrm{E} 22 / \mathrm{S} 100$ & & 13 & & Indeterminate . & wood \\
\hline $20 \mathrm{~K}$ & $\mathrm{CH}-1120$ & IIIb & E22/S86 & & 11 & & Rosaceae & wood \\
\hline $20 \mathrm{~S}$ & $\mathrm{CH}-1124$ & $\mathrm{X} / \mathrm{II}$ & E22/S86 & & 19 & 33 & Indeterminate & wood \\
\hline $22 \mathrm{~F}$ & $\mathrm{CH}-1129$ & $\mathrm{mb} / \mathrm{c}$ & E22/S82 & & 6 & & Indeterminate & wood \\
\hline $23 \mathrm{~F}$ & $\mathrm{CH}-1130$ & IIIc & E22/S80 & & 6 & & Quercus sp.; live oak type & wood \\
\hline $23 \mathrm{~J}$ & $\mathrm{CH}-1131$ & IIIlb & $\mathrm{E} 22 / \mathrm{S} 80$ & & 10 & & Indeterminate & wood \\
\hline 24 FF1 D & $\mathrm{CH}-1149$ & Isi/Icl/Isi-c & E22/S78 & SW & $32 \mathrm{~A}$ & & Indeterminate & \\
\hline $24 \mathrm{Y} 2 \mathrm{~A}$ & $\mathrm{CH}-1162$ & Isi-c/Id & E22/S78 & $\mathrm{NE}$ & $25 \mathrm{~B}$ & & Indeterminate & wood \\
\hline $24 \mathrm{Y} 2 \mathrm{~B}$ & $\mathrm{CH}-1163$ & Isi-c/Id & E22/S78 & NW & $25 \mathrm{~B}$ & & Indeterminate & wood \\
\hline $24 \mathrm{Z} 1 \mathrm{D}$ & $\mathrm{CH}-1164$ & Isi-c/Id & E22/S78 & SW & $26 \mathrm{~A}$ & 163 & Indeterminate & wood \\
\hline $24 \mathrm{Z} 2 \mathrm{ABCD}$ & $\mathrm{CH}-1165$ & Isi-c/Id & E22/S78 & All & $26 \mathrm{~B}$ & & Indeterminate & wood \\
\hline $25 \mathrm{Q} 1 \mathrm{~A}$ & $\mathrm{CH}-1186$ & IIIIa & E22/S76 & NE & $17 \mathrm{~A}$ & & Indeterminable hardwood & wood \\
\hline $25 \mathrm{~S} 1$ & $\mathrm{CH}-1188$ & II/IIIa & E22/S76 & & $19 \mathrm{~A}$ & & Carya illinoiensis & wood \\
\hline
\end{tabular}


Table 40-5, continued

\begin{tabular}{|c|c|c|c|c|c|c|c|c|c|}
\hline$\underline{\text { Lot No. }}$ & \begin{tabular}{|l|} 
Charcoal \\
Sample No.
\end{tabular} & Unit & Square & Quad & Level & Feature & Taxa & Part & \\
\hline & $\mathrm{CH}-1214$ & & & & & 167 & Indeterminate & wood & \\
\hline $26 \mathrm{DD} 1 \mathrm{D}$ & $\mathrm{CH}-1217$ & Isi-c & E22/S74 & SW & $30 \mathrm{~A}$ & 167 & Quercus sp.; live oak type & wood & \\
\hline $28 \mathrm{EE} 2 \mathrm{D}$ & $\mathrm{CH}-1295$ & Isi/Isi-c & E24/S78 & SW & $31 \mathrm{~B}$ & & Indeterminate & wood & \\
\hline $28 \mathrm{Q} 2$ & $\mathrm{CH}-1305$ & IIIa & E24/S78 & & 17B & & Indeterminate & wood & \\
\hline $28 \mathrm{R} 2$ & CH-1306 & IIIIa & E24/S78 & & $18 \mathrm{~B}$ & 131 & Indeterminate & wood & \\
\hline $28 \mathrm{U} 1 \& 2 \mathrm{C}$ & CH-1311 & III & E24/S78 & SE & $21 \mathrm{~A} \& \mathrm{~B}$ & & Indeterminate & wood & \\
\hline 28 W1 D & $\mathrm{CH}-1318$ & III & E24/S78 & SW & $23 \mathrm{~A}$ & & Juniperus sp. & wood & \\
\hline $29 \mathrm{~T} 2 \mathrm{C}$ & $\mathrm{CH}-1370$ & II/ma & $\mathrm{E} 24 / \mathrm{S} 76$ & SE & $20 \mathrm{~B}$ & & Indeterminate & & \\
\hline 29 U1 A & $\mathrm{CH}-1372$ & III & E24/S76 & NE & $21 \mathrm{~A}$ & & Indeterminate & & \\
\hline $34 \& 35 \mathrm{~V} 1$ & $\mathrm{CH}-1376$ & II/IIIa & E26/S74 & & $22 \mathrm{~A}$ & 146 & Indeterminate & wood & \\
\hline $3 \mathrm{~B}$ & $\mathrm{CH}-1400$ & IIIIc & E20/S98 & & 2 & & Indeterminate & wood & \\
\hline $30 \mathrm{Q} 2$ & $\mathrm{CH}-1431$ & IIIIa & E24/S74 & & $17 \mathrm{~B}$ & 130 & Indeterminate & wood & \\
\hline $30 \mathrm{Q} 2$ & CH-1432 & IIIIa & E24/S74 & & $17 \mathrm{~B}$ & 130 & Indeterminate & wood & \\
\hline $30 \mathrm{U} 2 \mathrm{~A}$ & $\mathrm{CH}-1433$ & II/IIIa & E24/S74 & NE & $21 \mathrm{~B}$ & 150 & Indeterminate & wood & \\
\hline $30 \mathrm{U} 2 \mathrm{C}$ & $\mathrm{CH}-1434$ & III & E24/S74 & SE & 21B & & Indeterminate & wood & \\
\hline $30 \mathrm{U} 2 \mathrm{C}$ & $\mathrm{CH}-1435$ & III & E24/S74 & SE & $21 \mathrm{~B}$ & & Indeterminate & wood & \\
\hline $31 \mathrm{HH} 1 \mathrm{~A}$ & CH-1471 & Icl/Isi-c & E24/S72 & NE & $34 \mathrm{~A}$ & & Indeterminate & wood & \\
\hline $31 \mathrm{KK} 2 \mathrm{~A}$ & $\mathrm{CH}-1472$ & Isi/Icl & E24/S72 & NE: & 37B & & Indeterminate & wood & \\
\hline $35 \mathrm{Z} 2 \mathrm{~A}$ & $\mathrm{CH}-1473$ & III & E26/S72 & NE & $26 \mathrm{~B}$ & 165 & Quercus sp.; live oak type & wood & \\
\hline $35 \mathrm{Z} 2 \mathrm{~A}$ & $\mathrm{CH}-1474$ & II & E26/S72 & NE & $26 \mathrm{~B}$ & 165 & Indeterminate & wood & \\
\hline $35 \mathrm{Z} 2 \mathrm{~A}$ & $\mathrm{CH}-1475$ & II & E26/S72 & NE & 26B & 165 & Indeterminate & wood & \\
\hline $35 \mathrm{Z} 2 \mathrm{~A}$ & $\mathrm{CH}-1476$ & III & E26/S72 & NE & 26B & 165 & Indeterminate & wood & \\
\hline $50 \mathrm{~K} \mathrm{C}$ & $\mathrm{CH}-1477$ & III & E0/N8 & SE & 11 & BRM 2 & Quercus sp.; live oak type & wood & \\
\hline $37 \mathrm{R} 2 \mathrm{~A}$ & $\mathrm{CH}-1478$ & IIIIa & E28/S78 & NE & 18B & 181 & Camassia scilloides & bulb & \\
\hline $37 \mathrm{Q} 1 \mathrm{C}$ & CH-1479 & IIIIa & E28/S78 & SE & $17 \mathrm{~A}$ & 181 & Camassia scilloides & bulb & \\
\hline $37 \mathrm{~T} 1 \mathrm{~B}$ & $\mathrm{CH}-1480$ & II/IIIa & E28/S78 & NW & $20 \mathrm{~A}$ & 181 & Camassia scilloides & bulb & \\
\hline $24 \mathrm{CC} 1 \mathrm{~B}$ & $\mathrm{CH}-1481$ & Isi/Isi-c & E22/S78 & NW & $29 \mathrm{~A}$ & & Juglans sp. & nut shell & \\
\hline 37 Q2 A & CH-1482 & IIIa & E28/S78 & $\mathrm{NE}$ & 17B & 181 & Camassia scilloides & bulb & \\
\hline 37 R1 B & CH-1483-1 & IIIIa & E28/S78 & NW & $18 \mathrm{~A}$ & 181 & Camassia scilloides \#1 & bulb \#1 & \\
\hline 37 R1 B & CH-1483-2 & IIIa & E28/S78 & NW & $18 \mathrm{~A}$ & 181 & Camassia scilloides \#2 & bulb \#2 & \\
\hline $37 \mathrm{P} 2 \mathrm{C}$ & $\mathrm{CH}-1484$ & IIIIa & E28/S78 & SE & 16B & 181 & Camassia scilloides & bulb & \\
\hline
\end{tabular}

this information to related archeological evidence before a final conclusion regarding function is reached.

\section{Burned Rock Midden 2}

Live oak wood was identified in six samples from this feature, walnut wood was identified in one sample, and elm family wood was found in another sample. At least one function of the feature, plant processing, may be inferred by the presence of a wild hyacinth (Camassia scilloides) bulb (CH925).

\section{Postdepositional Destructive Processes}

The results presented above suggest that identifiable plant remains are relatively scarce in the Wilson-Leonard site deposits. Only 3 of the 210 flotation samples (totaling 595.35 liters) yielded identifiable remains and only $49 \%$ (228 of 460) of the macroplant samples could be identified. Occu- pation at the Wilson-Leonard site extended over ten millenia, and human activities resulted in the deposition of tons of fire-cracked rocks and chipped stone debris numbering in the thousands. The length of time the site was used and the fact that the area occasionally was used intensely suggests that greater quantities of charred plant remains should have been present in the sediments. Their scarcity in the archeological record merits examination.

Two factors may have been responsible for the low frequency of plant remains. The first possibility is that very little plant material was charred at the site, but the presence of large thermally altered rock concentrations argues against this scenario. The second possibility is that postdepositional processes reduced the archeobotanical record (see Chapters 6 and 26).

Plant remains are transformed and reduced in size and quantity by a variety of postdepositional processes, including those of biological, chemical, and mechanical derivation (Bryant 1989). Archeological sites open to weathering and 
TABLE 40-6

Identification of Macroplant Samples from the TARL Excavations

\begin{tabular}{|c|c|c|c|c|c|c|c|}
\hline Lot & Sample & Unit & Feature & Unit & Level & Plant & Part \\
\hline 107 & & Isi & & A & 4 & Juniperus sp. & wood \\
\hline 1115 & & IIIIa & 231 & 34 & 21 & Juniperus sp. & wood \\
\hline 1159 & & IIIIa & 231 & 37 & 22 & Indeterminate & wood \\
\hline 1199 & & II/IIIa & & 26 & 27 & Juniperus sp. & wood \\
\hline 1206 & & IIIIc & BRM 1 & 100 & 2 & Juglans sp. & nutshell \\
\hline 1206 & & IIIIc & BRM 1 & 100 & 2 & Quercus sp.; live oak type & wood \\
\hline 124 & & Isi & & A & 6 & Indeterminate & wood \\
\hline 129 & & IIIc & 201 & 15 & $6 \mathrm{~A}$ & Juniperus sp. & wood \\
\hline 1419 & & II & & 26 & 30 & Juniperus sp. & wood \\
\hline 1422 & & IIIIc & BRM 1 & 100 & 8 & Juglans nigra & nutshell \\
\hline 1422 & & IIIIc & BRM 1 & 100 & 8 & Juniperus sp. & wood \\
\hline 1426 & & Isi/Isi-c & & 30 & 35 & Juniperus sp. & wood \\
\hline 143 & & Igl/Isi & & B & 3 & Juniperus sp. & wood \\
\hline 1505 & & $\mathrm{Y} / \mathrm{IIIc}$ & BRM 1 & 100 & 9 & Juglans sp. & nutshell \\
\hline 1561 & & II/IIIa & & 37 & 25 & Salicaceae & wood \\
\hline 1648 & & II/IIIa & 231 & 52 & 24 & Indeterminate & wood \\
\hline 1668 & & $\mathrm{Y}$ & BRM 1 & 100 & 11 & Juniperus sp. & wood \\
\hline 168 & & IIIIc & & 16 & 3 & Juniperus sp. & wood \\
\hline 1685 & & II & & 35 & 29 & Juniperus sp. & wood \\
\hline 173 & & IIIIa & 231 & 38 & $21 \mathrm{~A}$ & Unknown hardwood & wood \\
\hline 1805 & & UNKNOWN & & 34 & $*$ & Juniperus sp. & wood \\
\hline 1924 & & $\mathrm{Id} / \mathrm{II}$ & & 35 & 34 & Juniperus sp. & wood \\
\hline 1954 & & Isi-c & & 57 & 37 & Quercus sp.; live oak type & wood \\
\hline 1957 & & II/IIIa & 245 & 28 & 24 & Juniperus sp. & wood \\
\hline 196 & & Igl & & B & 11 & Unknown hardwood & wood \\
\hline 2001 & & Isi-c/Id & & 35 & 37 & Indeterminate & wood \\
\hline 2016 & & Isi-c & & 26 & 41 & Indeterminate & wood \\
\hline 202 & & IIIIc & & 12 & 4 & Salicaceae & wood \\
\hline 2029 & & Isi-c & & 57 & 39 & Indeterminate & wood \\
\hline 2100 & & Isi/Icl/Isi-c & & 57 & 41 & Quercus sp.; live oak type & wood \\
\hline 218 & & $\mathrm{IIIb} / \mathrm{c}$ & 201 & 20 & 8 & Indeterminate & \\
\hline 2182 & & $\mathrm{IIIa} / \mathrm{b}$ & & 14 & 12 & Indeterminate & wood \\
\hline 226 & & IIIIc & 201 & 22 & 6 & Indeterminate & wood \\
\hline 2315 & & II/Шlа & 231 & 38 & 24 & Indeterminate & wood \\
\hline 250 & & $\mathrm{IIIb} / \mathrm{c}$ & 201 & 20 & 8 & Indeterminate & wood \\
\hline 2538 & & $\mathrm{Isi} / \mathrm{Icl}$ & 262 & 27 & $51 \mathrm{~B}$ & Indeterminate & \\
\hline 2541 & & Isi-c & 253 & 57 & $37-39$ & Quercus sp.; live oak type & wood \\
\hline 2620 & & Isi & & 57 & 54 & Quercus sp.; live oak type & wood \\
\hline 2641 & & Isi & & 56 & 50 & Quercus sp.; live oak type & wood \\
\hline 2658 & & $\mathrm{Id} / \mathrm{II}$ & & 27 & 37 & Juniperus sp. & wood \\
\hline 2659 & & Icl/Isi-c & & 35 & 44 & Quercus sp.; live oak type & wood \\
\hline 267 & & IIIIc & 201 & 21 & $7 \mathrm{~A}$ & Quercus sp.; live oak type & wood \\
\hline 274 & & IIIIc & & 12 & 5 & Indeterminate & wood \\
\hline 2758 & & Icl & & 39 & 49 & Juniperus sp. & wood \\
\hline 2788 & & Isi/Icl & & 53 & 51 & Quercus sp.; live oak type & wood \\
\hline 2877 & & IIII & 206 & 16 & $6 \mathrm{~B}$ & Quercus sp.; live oak type & wood \\
\hline 327 & & IIIIc & & 13 & 5 & Juniperus sp. & wood \\
\hline 371 & & IIIb/c/FILL & 201 & 18 & 9 & Juniperus sp. & wood \\
\hline 385 & & IIIc & & 15 & $4 \mathrm{~B}^{*}$ & Juniperus sp. & wood \\
\hline 387 & & IIIIc & 201 & 15 & $5 \mathrm{~A}$ & Juniperus sp. & wood \\
\hline 390 & & IIIIc & 201 & 17 & 6 & Juglans sp. & nutshell \\
\hline 391 & & IIIIc & 201 & 16 & 5 & Juniperus sp. & wood \\
\hline
\end{tabular}


Table 40-6, continued

\begin{tabular}{|c|c|c|c|c|c|c|c|}
\hline Lot & Sample & Unit & Feature & Unit & Level & Plant & Part \\
\hline 396 & & IIIc & 201 & 16 & 5 & Quercus sp.; live oak type & wood \\
\hline 399 & & $\mathrm{IIIb} / \mathrm{c}$ & 205 & 22 & 8 & Juniperus sp. & wood \\
\hline 412 & & $\mathrm{IIb} / \mathrm{c}$ & & 18 & 10 & Juniperus sp. & wood \\
\hline 431 & & $\mathrm{IIb} / \mathrm{c}$ & 201 & 21 & 8 & Juniperus sp. & wood \\
\hline 454 & & $\mathrm{IIIb} / \mathrm{c}$ & 201 & 17 & $7 \mathrm{~A}$ & Quercus sp. & wood \\
\hline 480 & & $\mathrm{IIIb} / \mathrm{c}$ & 201 & 16 & $7 \mathrm{~A}$ & Indeterminate & wood \\
\hline 487 & & $\mathrm{IIIb} / \mathrm{c}$ & & 19 & 10 & Salicaceae & wood \\
\hline 488 & & $\mathrm{IIIb} / \mathrm{c}$ & & 14 & 7 & Rosaceae & wood \\
\hline 489 & & $\mathrm{mll} b$ & & 20 & $13 \mathrm{~A}$ & Indeterminate & wood \\
\hline 490 & & IIIb/c & & 13 & 7 & Unknown hardwood & wood \\
\hline 503 & & $\mathrm{IIIb} / \mathrm{c}$ & & 21 & 9 & Juniperus sp. & wood \\
\hline 506 & & $\mathrm{IIIb} / \mathrm{c}$ & & 14 & 8 & Juniperus sp. & wood \\
\hline 508 & & IIIlb & & 11 & 8 & Juniperus sp. & wood \\
\hline 513 & & IIIlb & & 19 & 11 & Juniperus sp. & wood \\
\hline 515 & & IIIb & & 38 & 10 & Juniperus sp. & wood \\
\hline 520 & & $\mathrm{IIb} / \mathrm{c}$ & & 37 & 10 & Juniperus sp. & wood \\
\hline 521 & & $\mathrm{IIIb} / \mathrm{c}$ & & 22 & $9 \mathrm{~A}$ & Quercus sp.; oak type & wood \\
\hline 527 & & IIIb & & 38 & 11 & Juniperus sp. & wood \\
\hline 532 & & IIIb & & 37 & 11 & Juniperus sp. & wood \\
\hline 534 & & IIIb & & 11 & 9 & Unknown hardwood & wood \\
\hline 535 & & IIIb & & 38 & $12 \mathrm{~A}$ & Juniperus sp. & wood \\
\hline 538 & & IIIb & & 22 & $10 \mathrm{~A}$ & Juniperus sp. & wood \\
\hline 544 & & IIIlb & & 17 & 9 & Quercus sp.; live oak type & wood \\
\hline 549 & & IIIb & & 15 & 11 & Quercus sp.; live oak type & wood \\
\hline 552 & & IIIlb & & 11 & 10 & Juniperus sp. & wood \\
\hline 555 & & IIIlb & & 21 & 11 & Juniperus sp. & wood \\
\hline 557 & & IIIb & & 37 & $12 \mathrm{~A}$ & Juniperus sp. & wood \\
\hline 560 & & IIIb & 213 & 13 & 10B & Juniperus sp. & wood \\
\hline 561 & & IIIa/b & & 14 & 12 & Ulmaceae & wood \\
\hline 563 & & IIIb & & 13 & $11 \mathrm{~A}$ & Juniperus sp. & wood \\
\hline 566 & & $\mathrm{IIIb} / \mathrm{c}$ & 210 & 22 & $10 \mathrm{~B}$ & Juniperus sp. & wood \\
\hline 574 & & $\mathrm{mII} / \mathrm{b}$ & & 14 & 13 & Salicaceae & wood \\
\hline 576 & & $\mathrm{IIIb} / \mathrm{c}$ & 208 & 17 & $7 \mathrm{~B}$ & Juniperus sp. & wood \\
\hline 580 & & IIIlb & & 16 & $11 \mathrm{~A}$ & Juniperus sp. & wood \\
\hline 593 & & $\mathrm{mIla} / \mathrm{b}$ & & 38 & 15 & Juniperus sp. & wood \\
\hline 594 & & IIlb & & 21 & 13 & Juniperus sp. & wood \\
\hline 596 & & IIIa/b & & 15 & 13 & Indeterminate & \\
\hline 596 & & IIIa/b & & 15 & 13 & Salicaceae & wood \\
\hline 600 & & IIIa/b & & 15 & 12 & Juniperus sp. & wood \\
\hline 603 & & IIIa & & 20 & 18 & Unknown hardwood & wood \\
\hline 607 & & IIIb & & 18 & 12 & Juniperus sp. & wood \\
\hline 609 & & IIIlb & 214 & 16 & 10B & Juniperus sp. & wood \\
\hline 610 & & IIIb & & 22 & $12 \mathrm{~A}$ & Indeterminate & wood \\
\hline 611 & & $\mathrm{III} / \mathrm{b}$ & & 11 & 12 & Juniperus sp. & wood \\
\hline 626 & & IIIb & & 19 & 12 & Juglans sp. & nutshell \\
\hline 639 & & IIIa/b & & 38 & 16 & Juniperus sp. & wood \\
\hline 640 & & IIIa/b & & 15 & 14 & Juglans sp. & nut shell \\
\hline 649 & & IIIb & & 21 & 14 & Juniperus sp. & wood \\
\hline 651 & & IIIlb & & 16 & $12 \mathrm{~A}$ & Indeterminate & wood \\
\hline 652 & & IIIb & & 17 & 11 & Indeterminate & wood \\
\hline 660 & & IIIc & 201 & 15 & $5 \mathrm{~A}$ & Indeterminate & wood \\
\hline 662 & & IIIlb & & 18 & 14 & Juniperus sp. & wood \\
\hline 667 & & IIIa & & 38 & $17 \mathrm{~A}$ & Unknown hardwood & wood \\
\hline
\end{tabular}


Table 40-5, continued

\begin{tabular}{|c|c|c|c|c|c|c|c|}
\hline Lot & Sample & Unit & Feature & Unit & Level & Plant & Part \\
\hline 669 & & IIIlb & & 16 & $12 \mathrm{~B}$ & Indeterminate & \\
\hline 673 & & $\mathrm{III} a / \mathrm{b}$ & & 37 & 14 & Indeterminate & wood \\
\hline 675 & & $\mathrm{mllb}$ & & 22 & 14 & Quercus sp.; oak type & wood \\
\hline 676 & & IIIb & & 17 & 12 & Indeterminate & wood \\
\hline 682 & & IIIIa & & 33 & 16 & Juniperus sp. & wood \\
\hline 683 & & IIIIa & & 32 & 14 & Juniperus sp. & wood \\
\hline 692 & & $\mathrm{ma} \mathrm{a} / \mathrm{b}$ & & 37 & 15 & Juniperus sp. & wood \\
\hline 697 & & IIIlb & & 25 & 14 & Juniperus sp. & wood \\
\hline 698 & & IIIb & & 27 & 15 & Juniperus sp. & wood \\
\hline 709 & & IIIa/b & & 35 & 14 & Juniperus sp. & wood \\
\hline 717 & & IIIa & & 32 & 16 & Juniperus sp. & wood \\
\hline 722 & & $\mathrm{ma} / \mathrm{b}$ & & 39 & $15 \mathrm{~A}$ & Juniperus sp. & wood \\
\hline 757 & & IIIa/b & 221 & 39 & $15 \mathrm{C}$ & Indeterminate & wood \\
\hline 765 & & IIIIa & & 30 & 17 & Juniperus sp. & wood \\
\hline 774 & & $\mathrm{mII} / \mathrm{b}$ & 220 & 52 & $15 B$ & Juniperus sp. & wood \\
\hline 778 & & IIIa & & 37 & $16 \mathrm{~A}$ & Quercus sp.; live oak type & wood \\
\hline 825 & & IIIIa & & 37 & $17 \mathrm{~A}$ & Juniperus sp. & wood \\
\hline 848 & & $\mathrm{IIIa} / \mathrm{b}$ & & 25 & 19 & Juniperus sp. & wood \\
\hline 852 & & IIIa & & 37 & 18 & Juniperus sp. & wood \\
\hline 887 & & IIIIa & 231 & 27 & 21 & Juniperus sp. & wood \\
\hline 893 & & IIIIa & 231 & 37 & 19 & Juniperus sp. & wood \\
\hline 910 & & IIIa & 231 & 52 & 21 & Indeterminate & wood \\
\hline 920 & & IIIIa & & 50 & 19 & Indeterminate & wood \\
\hline 962 & & III & & 30 & $22 \mathrm{~A}$ & Juniperus sp. & wood \\
\hline 964 & & III & & 47 & 24 & Juniperus sp. & wood \\
\hline 524 & C14-10 & $\mathrm{mb} / \mathrm{c}$ & & 22 & $9 \mathrm{~A}$ & Quercus sp.; live oak type & wood \\
\hline 528 & C14-11 & IIIb & 209 & 20 & $13 \mathrm{~B}$ & Ulmaceae & wood \\
\hline 1369 & C14-110 & II/IIa & & 27 & $27 \mathrm{~A}$ & Indeterminate & wood \\
\hline 1370 & C14-111 & Isi-c/II & 238 & 30 & $33 \mathrm{~B} / 34 \mathrm{~B}$ & Indeterminate & wood \\
\hline 1517 & C14-117 & III & & 25 & 33 & Indeterminate & wood \\
\hline 1519 & C14-119 & III & & 25 & 33 & Indeterminate & wood \\
\hline 606 & C14-12 & $\mathrm{III} / \mathrm{b}$ & 213 & 12 & $11 \mathrm{~B}$ & Indeterminate & wood \\
\hline 1523 & C14-121 & III & & 25 & 33 & Unknown hardwood & wood \\
\hline 1525 & C14-123 & $\mathrm{Id} / \mathrm{II}$ & 236 & 33 & $31 \mathrm{~B}$ & Indeterminate & wood \\
\hline 1541 & C14-127 & II/IIIa & & 37 & 25 & Indeterminate & wood \\
\hline 1553 & C14-132 & IIIa/II & 245 & 44 & 25 & Unknown hardwood & wood \\
\hline 1559 & C14-133 & $\mathrm{Id} / \mathrm{II}$ & & 48 & 32 & Indeterminate & wood \\
\hline 1564 & C14-134 & III & & 35 & 28 & Indeterminate & wood \\
\hline 1584 & C14-139 & II/IIIa & & 27 & $29 \mathrm{~A}$ & Indeterminate & wood \\
\hline 630 & C14-14 & IIIb & & 18 & 12 & Unknown hardwood & wood \\
\hline 668 & C14-15 & IIIb & 214 & 16 & $12 \mathrm{~B}$ & Juniperus sp. & wood \\
\hline 553 & C14-158 & II/IIIa & 181 & 52 & 24 & Camassia scilloides & bulb \\
\hline 699 & C14-16 & IIIa & 217 & 33 & 17B & Quercus sp.; live oak type & wood \\
\hline 1649 & C14-161 & II & & 35 & 29 & Ulmaceae & wood \\
\hline 1673 & C14-168 & III & 247 & 34 & $31 \mathrm{C}$ & Indeterminate & wood \\
\hline 1674 & C14-169 & III & 246 & 34 & $31 \mathrm{~B}$ & Indeterminate & wood \\
\hline 1680 & C14-172 & II & 247 & 34 & $31 \mathrm{C}$ & Indeterminate & wood \\
\hline 1681 & C14-173 & II & & 34 & $31 \mathrm{~A}$ & Indeterminate & wood \\
\hline 1690 & C14-174 & III & 247 & 35 & $30 \mathrm{~B}$ & Indeterminate & wood \\
\hline 1702 & C14-177 & III & 248 & 52 & $28 \mathrm{~B}$ & Indeterminate & wood \\
\hline 747 & C14-18 & IIIIa & & 30 & 16 & Quercus sp.; live oak type & wood \\
\hline 1718 & C14-182 & III & 246 & 34 & $31 \mathrm{~B}$ & Indeterminate & wood \\
\hline 1722 & C14-184 & III & 246 & 34 & $32 B$ & Indeterminate & wood \\
\hline
\end{tabular}


Table 40-6, continued

\begin{tabular}{|c|c|c|c|c|c|c|c|}
\hline Lot & Sample & Unit & Feature & Unit & Level & Plant & Part \\
\hline 1732 & C14-188 & II & & 35 & $30 \mathrm{~A}$ & Indeterminate & wood \\
\hline 769 & C14-19 & IIIa/b & 221 & 39 & $15 \mathrm{C}$ & Juniperus sp. & wood \\
\hline 1751 & C14-197 & II/IIa & & 28 & $27 \mathrm{~A}$ & Indeterminate & wood \\
\hline 349 & C14-2 & IIIIc & & 13 & 5 & Juniperus sp. & wood \\
\hline 1615 & C14-207 & Isi/Isi-c & & 12 & 36 & Indeterminate & wood \\
\hline 1632 & C14-208 & Isi/Isi-c & & 46 & 37 & Quercus sp.; live oak type & wood \\
\hline 1635 & C14-209 & II/IIIa & & 28 & $27 \mathrm{~B}$ & Indeterminate & wood \\
\hline 1638 & C14-212 & II & 246 & 34 & $32 \mathrm{~B}$ & Indeterminate & wood \\
\hline 1780 & C14-219 & II/IIIa & 181 & 52 & 25 & Camassia scilloides & bulb \\
\hline 792 & C14-22 & IIIIa & & 35 & 15 & Ulmaceae & wood \\
\hline 1808 & C14-227 & $\mathrm{Id} / \mathrm{II}$ & 246 & 34 & $32 \mathrm{~B}$ & Indeterminate & wood \\
\hline 793 & C14-23 & IIIa/b & 220 & 52 & $15 B$ & Salicaceae & wood \\
\hline 1866 & C14-236 & II & 248 & 52 & $29 \mathrm{~B}$ & Indeterminate & wood \\
\hline 1867 & C14-237 & II & 248 & 52 & 29B & Quercus sp.; live oak type & wood \\
\hline 1875 & C14-238 & II & 248 & 52 & 29B & Unknown hardwood & wood \\
\hline 1910 & C14-247 & II & & 39 & 27 & Unknown hardwood & wood \\
\hline 921 & C14-25 & IIIIa & 231 & 52 & 21 & Indeterminate & wood \\
\hline 931 & C14-26 & ШII & 231 & 37 & 20 & Indeterminate & wood \\
\hline 955 & C14-28 & IIIa & 231 & 52 & 22 & Indeterminate & wood \\
\hline 2030 & C14-296 & Isi-c & 253 & 57 & 38 & Indeterminate & wood \\
\hline 432 & C14-3 & $\mathrm{IIb} / \mathrm{c}$ & & 19 & $9 \mathrm{~A}$ & Quercus sp.; live oak type & wood \\
\hline 2068 & C14-309 & Isi-c & 253 & 57 & 39 & Quercus sp.; live oak type & wood \\
\hline 1035 & C14-32 & IIIIa & 231 & 39 & $21 \mathrm{~A}$ & Indeterminate & wood \\
\hline 2107 & C14-320 & II/IIIa & & 28 & $30 \mathrm{~A}$ & Unknown hardwood & wood \\
\hline 1046 & C14-33 & IIIa & 231 & 27 & 24 & Indeterminate & wood \\
\hline 2196 & C14-339 & Isi-c & 255 & 59 & $42 \mathrm{~B}$ & Indeterminate & wood \\
\hline 2197 & C14-340 & Isi-c & 255 & 59 & $42 \mathrm{~B}$ & Indeterminate & wood \\
\hline 2198 & C14-341 & Isi-c & 255 & 59 & $42 B$ & Indeterminate & wood \\
\hline 1048 & C14-35 & III & & 30 & 25 & Quercus sp.; oak type & wood \\
\hline 2210 & C14-354 & IIIa & 181 & 51 & 24 & Camassia scilloides & bulb \\
\hline 2214 & C14-358 & Isi-c/Id & 257 & 53 & $38 \mathrm{~B}$ & Indeterminate & wood \\
\hline 2215 & C14-359 & Isi-c/Id & 257 & 53 & $38 \mathrm{~B}$ & Indeterminate & wood \\
\hline 2219 & C14-363 & Isi-c/Id & 257 & 53 & 39B & Indeterminate & wood \\
\hline 2220 & C14-364 & Isi-c/Id & 257 & 53 & $39 \mathrm{~B}$ & Indeterminate & wood \\
\hline 2221 & C14-365 & Isi-c/Id & 257 & 53 & $39 \mathrm{~B}$ & Indeterminate & wood \\
\hline 2223 & C14-367 & Isi-c/Id & 257 & 53 & $39 \mathrm{~B}$ & Indeterminate & wood \\
\hline 1053 & C14-37 & II/IIIa & 231 & 35 & 22 & Indeterminate & wood \\
\hline 2244 & C14-388 & Isi-c & 260 & 39 & 42 & Indeterminate & wood \\
\hline 2649 & C14-408 & $\operatorname{Igl}$ & & 20 & 68 & Quercus sp.; oak type & wood \\
\hline 1122 & C14-45 & IIIIa & 231 & 52 & 23 & Indeterminate & wood \\
\hline 1138 & C14-48 & IIIIa & 231 & 52 & 23 & Indeterminate & wood \\
\hline 1145 & C14-49 & Ша & 231 & 38 & $21 \mathrm{~A}$ & Indeterminate & wood \\
\hline 1165 & C14-53 & IIIIa & 231 & 53 & 23 & Indeterminate & wood \\
\hline 1174 & C14-59 & IIIa & 231 & 37 & 22 & Quercus sp.; live oak type & wood \\
\hline 1188 & C14-64 & IIIa & 231 & 51 & 22 & Indeterminate & wood \\
\hline 1186 & $\mathrm{C} 14-65$ & II/IIIa & 233 & 20 & $25 \mathrm{~B}$ & Indeterminate & wood \\
\hline 1192 & C14-66 & Шlа & 231 & 38 & 22 & Indeterminate & wood \\
\hline 1193 & C14-67 & Isi-c/II & 234 & 30 & 29 & Indeterminate & wood \\
\hline 1194 & C14-68 & ПI/IIIa & 233 & 20 & $26 \mathrm{~B}$ & Indeterminate & wood \\
\hline 1202 & C14-69 & ПI/ШІа & & 25 & 27 & Quercus sp.; oak type & wood \\
\hline 493 & C14-7 & IIIb/c & & 21 & 9 & Juniperus sp. & wood \\
\hline 1233 & C14-73 & II/IIIa & & 35 & 23 & Unknown hardwood & wood \\
\hline 1239 & C14-74 & Isi-c/II & 235 & 32 & $28 \mathrm{~B}$ & Indeterminate & wood \\
\hline
\end{tabular}


Table 40-6, continued

\begin{tabular}{l|l|l|l|l|l|l|l}
\hline Lot & Sample & Unit & Feature & Unit & Level & Plant & Part \\
\hline 1242 & C14-75 & Isi-c/II & 235 & 32 & $28 \mathrm{~B}$ & Indeterminate & wood \\
1254 & C14-77 & Isi-c/II & & 12 & 29 & Indeterminate & wood \\
1272 & C14-79 & Isi-c/II & 235 & 32 & $29 \mathrm{~B}$ & Indeterminate & wood \\
1302 & C14-83 & Isi-c/II & 238 & 30 & $33 \mathrm{~B}$ & Quercus sp.; live oak type & wood \\
1332 & C14-85 & III & 231 & 39 & 23 & Quercus sp.; live oak type & wood \\
1333 & C14-86 & Isi-c/II & 238 & 30 & $33 \mathrm{~B}$ & Indeterminate & wood \\
1335 & C14-88 & II & & 25 & 30 & Indeterminate & wood \\
1388 & C14-91 & Isi-c & & 12 & 33 & Indeterminate & wood \\
1404 & C14-94 & II & & 33 & $30 \mathrm{~A}$ & Indeterminate & wood \\
1430 & C14-97 & II & 239 & 34 & $26 \mathrm{~B}$ & Indeterminate & wood \\
1435 & C14-98 & II & 25 & 33 & Quercus sp.;live oak type & \\
\hline \hline
\end{tabular}

located in warm temperate climates are poor depositional environments for the preservation of plant remains (Miksicek 1987:215). For this reason, only carbonized plants are considered to be a potential part of the archeological record (Minnis 1981).

The question remains, then, in an occupation that produced so many fire-cracked rocks, what reduced the size of the charred plant record? Carbonized plant remains are usually about $50-60 \%$ elemental carbon and as such are fairly inert to chemical or microbiological degradation. At the Wilson-Leonard site, the dominant processes reducing the size and condition of the macrobotanical record are most likely mechanical, both from physical sources and from biological sources.

Physical-mechanical degradation of plant materials is caused by a variety of factors. Along the eastern edge of the Edwards Plateau, long periods of drought followed by intense rains are common. Wet-dry cycles are a major contributor to the destruction of plant material. This can also take the form of soil or sediment movement, a process by which clays tend to shrink and swell, or sands move as a result of colluvial or aeolian forces (Bryant 1989).

Another major cause of degradation is the movement of organisms through the profile. This includes burrowing vertebrates as well as invertebrates. The activities of rodents tend to displace and damage plant remains. An even more damaging factor is the collective impact of earthworms that can move tons of sediment through their guts over time (see Chapter 29). This may have had a drastic impact on the smaller-sized botanical remains, especially seeds. With the exception of a very few seeds, the surviving carbonized plant material at the site was either wood, nut fragments, roots and tree trunks, or the comparatively large wild hyacinth bulbs. None of this material was recovered in the flotation samples. Rather, the macroplant samples that were collected in situ or off the field screen by the excavators provided the great majority of the data for this report. These relatively large-sized plant remains would be much more resistant to displacement through a soil profile, and they would be much less affected by earthworms.
Seeds, on the other hand, would tend to move through the soil profile, be consumed by arthropods or annelids, and suffer rapid mechanical degradation via both of these processes.

\section{DISCUSSION}

\section{Seeds and Nut Fragments}

\section{Grass Seeds (Panicum, Paspalum, and Setaria)}

Seeds were the rarest of the plant remains identified in the sediments. A total of seven grass seeds from three different species was identified in one flotation sample (Number 154). They represent three warm season grassesCpanic grass (Panicum), paspalum grass (Paspalum), and bristlegrass (Setaria). These grasses set seeds in late summer/early fall. The seeds may have been carbonized by a fire that burned through the area, they may have resulted from food preparation or other activities of the inhabitants, or they may be the result of other uses of grass by the site occupants.

There are no historic or ethnographic references to the consumption of these genera by Native Americans residing in the region of Central Texas or East Texas. In other words, there is no ethnographic corroboration for human utilization of the grasses identified at the Wilson-Leonard site. There are, however, abundant references to the use of grasses as food in the genus Panicum by Native Americans throughout in arid southwestern North America (Yanovsky 1936:89). Setaria leucopila was identified in many contexts from Hinds Cave in Val Verde County (Dering 1979:37-39). These grasses flourish in open, well-drained soils of moderate depth. They would be indicative of an open canopy parkland environment, perhaps at the edge of the Brushy Creek flood plain. Other grasses, most commonly tanglehead (Heteropogon contortus), have been identified as constituents in woven grass mats and grass "sleeping nests" in archeological sites in the lower Pecos River region of Texas (Shafer and Bryant 1977:32, 42, 61). 
TABLE 40-7

Plant Remains from Feature Contexts

\begin{tabular}{|c|c|c|c|c|c|}
\hline $\begin{array}{l}\text { Feature } \\
\text { No. }\end{array}$ & Feature Type & Unit & \begin{tabular}{|l|} 
Archeological \\
Chronology \\
\end{tabular} & Sample (*dated samples) & Identification \\
\hline 4 & large burned rock basin & $\mathrm{X} / \mathrm{Y}$ & Early Archaic & $\mathrm{CH}-993$ & indeterminate wood \\
\hline 7 & burned rock scatter & IIIc & $\begin{array}{l}\text { Late Prehistoric or } \\
\text { Late Archaic }\end{array}$ & lot $12 \mathrm{~B}$ & Ulmaceae wood \\
\hline 8 & burned rock accumulation & $\mathrm{X} / \mathrm{Y} / \mathrm{IIIb}$ & Early Archaic & CH-998* & Camassia scilloides bulb \\
\hline 10 & small burned rock basin? & & Late Archaic & $\mathrm{CH}-1024 *$ & Celtis sp. wood \\
\hline 12 & large burned rock basin & $\mathrm{X} / \mathrm{Y} / \mathrm{IIIb}$ & Early Archaic & CH-1008,1009 & indeterminate wood \\
\hline 17 & burned rock scatter & $\mathrm{X}$ & Early Archaic & $\mathrm{CH}-1001,1002$ & Arboreal Legume wood \\
\hline 19 & large burned rock basin & $\mathrm{X}$ & Early Archaic & $\mathrm{CH}-1113,1114$ & indeterminate wood \\
\hline 33 & burned rock cluster & $\mathrm{X} / \mathrm{II}$ & $\begin{array}{l}\text { Late Paleoindian or } \\
\text { Early Archaic }\end{array}$ & $\mathrm{CH}-1124$ & indeterminate wood \\
\hline 50 & burned tree & $\mathrm{III} / \mathrm{IIIb}$ & Middle Archaic & $\begin{array}{l}\text { CH-1053, 1054* } \\
\text { CH-1055, } 1056\end{array}$ & $\begin{array}{l}\text { Quercus sp. (live oak type) wood } \\
\text { indeterminate wood }\end{array}$ \\
\hline 72 & burned root (part of F167) & Isi-c & Late Paleoindian & $\mathrm{CH}-1072$ & indeterminate wood \\
\hline 73 & burned root (part of F167) & Isi/Icl/Isi-c & Late Paleoindian & $\mathrm{CH}-1073,1076$ & indeterminate wood \\
\hline 130 & large burned rock basin & IIIa & Early Archaic & $\mathrm{CH}-1431,1432$ & indeterminate wood \\
\hline 131 & large burned rock basin & IIIa & Early Archaic & CH-1306 & indeterminate wood \\
\hline 146 & large burned rock basin & II/IIIa & Early Archaic & CH-738,1376 & indeterminate wood \\
\hline 150 & large burned rock basin & II/IIIa & Early Archaic & $\mathrm{CH}-1433$ & indeterminate wood \\
\hline 157 & burned rock cluster & II & Late Paleoindian & $\mathrm{CH}-740 *, 742,743$ & indeterminate wood \\
\hline 162 & $\begin{array}{l}\text { burned sediment with a few } \\
\text { burned rocks }\end{array}$ & II & Late Paleoindian & $\mathrm{CH}-600,601,602$ & indeterminate wood \\
\hline 163 & burned rock cluster & Isi-c/Id & Late Paleoindian & $\mathrm{CH}-1164$ & indeterminate wood \\
\hline 164 & burned tree & Isi-c/Id/II & Late Paleoindian & CH-609 & indeterminate wood \\
\hline 165 & burned tree & Isi-c/II & Late Paleoindian & $\begin{array}{l}\mathrm{CH}-704,705,706,707 \\
708,709,713,761,762, \\
\text { 1473; lot 35AA1A } \\
\text { CH-710, 712, 716, 717, } \\
718,1474,1475,1476\end{array}$ & $\begin{array}{l}\text { Quercus sp. (live oak type) wood } \\
\text { indeterminate wood }\end{array}$ \\
\hline 166 & large burned rock basin & I/II? & Late Paleoindian & CH-953, 954, 977, 989 & indeterminate wood \\
\hline 167 & burned tree & Isi/Icl/Isi-c & Late Paleoindian & $\begin{array}{l}\mathrm{CH}-1214 \\
\mathrm{CH}-1217 *\end{array}$ & $\begin{array}{l}\text { indeterminate } \\
\text { Quercus sp. (live oak type) wood }\end{array}$ \\
\hline 168 & pit & Isi/Icl/Isi-c & Late Paleoindian & $\mathrm{CH}-1060$ & indeterminate wood \\
\hline 169 & & Isi/Isi-c & Late Paleoindian & $\mathrm{CH}-1043$ & indeterminate wood \\
\hline 175 & burrow & Isi/Icl & $\begin{array}{l}\text { Early or Late } \\
\text { Paleoindian }\end{array}$ & CH-510, 578 & indeterminate wood \\
\hline 181 & large burned rock basin & ІІ/ШІа, ПІІа & Early Archaic & $\begin{array}{l}\text { C14-158, 219*, 354*; CH- } \\
1478^{*}, 1479^{*}, 1480^{*}, \\
1482^{*}, 1483-1^{*}, 1483-2^{*}, \\
1484^{*} \\
\text { CH-865, } 870,877,878, \\
880, \text { CH14-64 }\end{array}$ & indeterminate wood \\
\hline 183 & burned rock cluster & II/IIIa & Early Archaic & CH-876 & indeterminate wood \\
\hline 187 & burned rock cluster & Isi-c & Late Paleoindian & $\mathrm{CH}-820$ & indeterminate wood \\
\hline 193 & burned rock cluster & Isi-c & Late Paleoindian & CH-801 & indeterminate \\
\hline 194 & pit? & $\mathrm{IIIb} / \mathrm{c}$ & $\begin{array}{l}\text { Late or Middle } \\
\text { Archaic }\end{array}$ & CH-930 & indeterminate wood \\
\hline 196 & burned plant? & III & $\begin{array}{l}\text { Middle or Early } \\
\text { Archaic }\end{array}$ & CH-970, 971, 972, 973 & indeterminate wood \\
\hline 198 & burned tree & $\mathrm{I} / \mathrm{II}$ & Late Paleoindian & CH-914, 919, 921*, 922 & Quercus sp. (live oak type) wood \\
\hline 199 & burned tree & & Middle Archaic & $\mathrm{CH}-1085^{*}$ & Morus rubra wood \\
\hline 201 & burned rock accumulation & IIIc, IIIb/c & Late Archaic & $\begin{array}{l}\text { Ch14-3; lot 267, 396, } 454 \\
\text { lot } 129,371,387,391,431 \\
\text { lot } 390 \\
\text { lot } 226,250,480,660 \\
\text { lot } 218\end{array}$ & $\begin{array}{l}\text { Quercus } \text { sp. (live oak type) wood } \\
\text { Juniperus } \text { sp. wood } \\
\text { Juglans } \text { sp. nutshell } \\
\text { indeterminate wood } \\
\text { indeterminate }\end{array}$ \\
\hline 205 & burned rock scatter & $\mathrm{IIIb} / \mathrm{c}$ & Late Archaic & lot 399 & Juniperus sp. wood \\
\hline 206 & burned rock cluster & IIIc & $\begin{array}{l}\text { Late or Middle } \\
\text { Archaic }\end{array}$ & lot 2877 & Quercus sp. (live oak type) wood \\
\hline 208 & burned rock cluster & $\mathrm{IIIb} / \mathrm{c}$ & Late Archaic & lot 576 & Juniperus sp. wood \\
\hline 209 & $\begin{array}{l}\text { burned sediment with a few } \\
\text { burned rocks }\end{array}$ & IIIb & Middle Archaic & $\begin{array}{l}\text { C14-11 } \\
\text { flotation sample } 154\end{array}$ & $\begin{array}{l}\text { Ulmaceae wood } \\
\text { Juniperus sp. wood, Rosaceae wood, } \\
\text { grass seeds (bristlegrass, panic grass, } \\
\text { paspalum) }\end{array}$ \\
\hline 210 & burned rock scatter & $\mathrm{IIIb} / \mathrm{c}$ & $\begin{array}{l}\text { Late or Middle } \\
\text { Archaic }\end{array}$ & lot 566 & Juniperus sp. wood \\
\hline
\end{tabular}


Table 40-7, continued

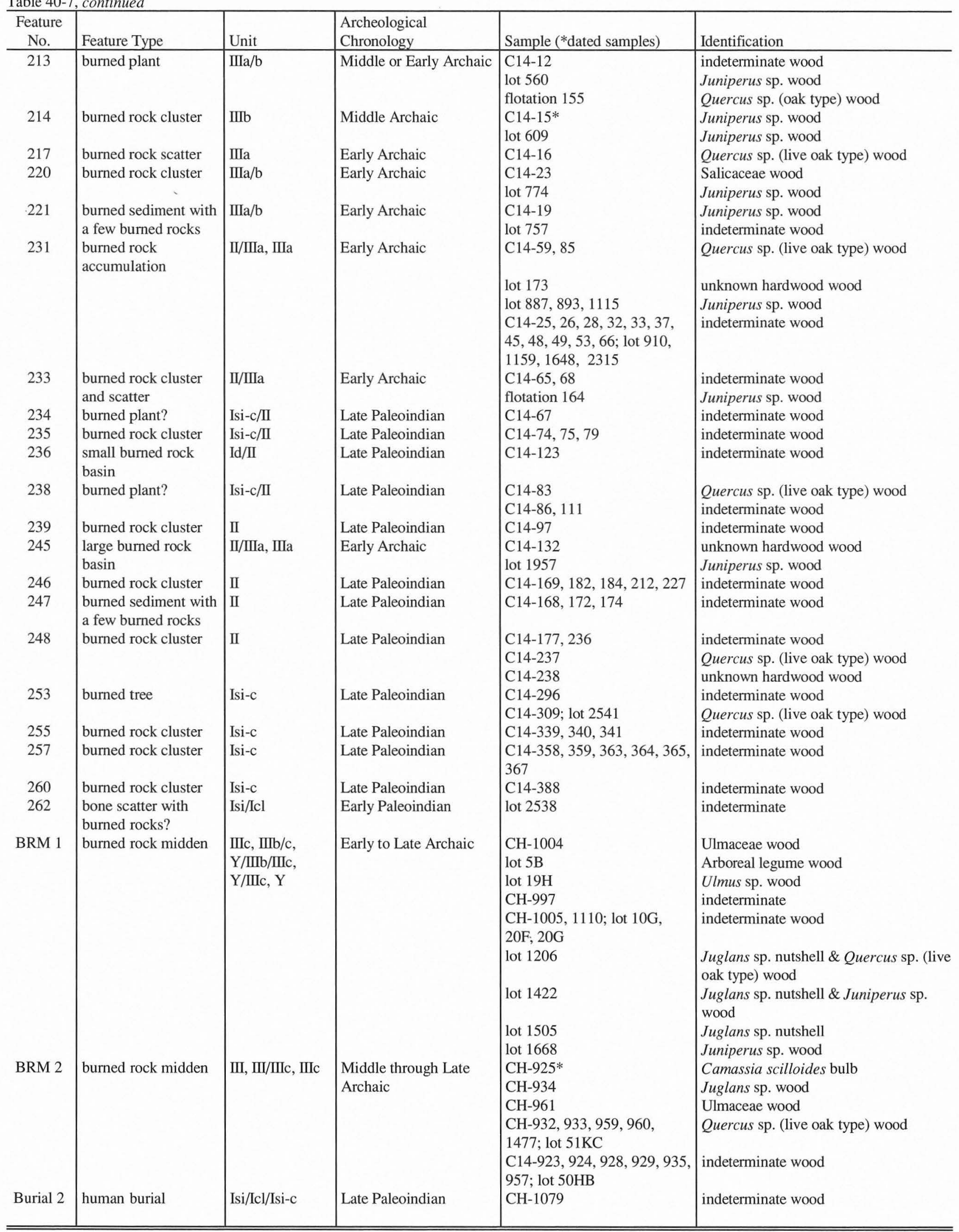


TABLE $40-8$

Features Identified as Carbonized Tree Trunks or Roots

\begin{tabular}{|c|c|c|c|c|}
\hline $\begin{array}{l}\text { Feature } \\
\text { No. }\end{array}$ & ${ }^{14} \mathrm{C}$ or $\mathrm{CH}$ Number & Other Number & Identification & Time Period \\
\hline 50 & $1053-1056$ & & $\begin{array}{l}\text { 1053, 1054: live oak wood type; } \\
\text { 1055, 1056: indeterminable }\end{array}$ & Middle Archaic \\
\hline 164 & 609 & & indeterminable & Late Paleoindian \\
\hline 165 & $\begin{array}{l}704-710,712,713,716- \\
718,761,762,1473-1476\end{array}$ & lot $35 \mathrm{AA} 1 \mathrm{~A}$ & live oak wood type or indeterminable & Late Paleoindian \\
\hline 167 & 1214,1217 & & $\begin{array}{l}\text { 11214: indeterminable } \\
\text { 1217: live oak wood type }\end{array}$ & Late Paleoindian \\
\hline 198 & $914,919,921,922$ & & live oak wood type & Late Paleoindian \\
\hline 199 & 1085 & & red mulberry & Middle Archaic \\
\hline 253 & 296,309 & & 296:indeterminable, 309: live oak wood & Late Paleoindian \\
\hline
\end{tabular}

\section{Walnut (Juglans spp.)}

Nutshell fragments are commonly recovered from archeological sites, mainly because they are inedible, very likely to be carbonized, and highly resistant to deterioration (Munson et al. 1971:427). Walnut trees were widely utilized throughout the range of the genus; three species grow in Texas, and two in the study area, Juglans arizonica and $J$. nigra. Espinosa reported that the Caddo used a thick-shelled nut extensively, and this most likely would have been hickory nuts and walnuts (Swanton 1942:133). Reservation-dwelling Comanche in Oklahoma reported a tradition of eating walnuts (Carlson and Jones 1940:522). Hickory nuts and walnuts were recovered from sediments at the Caddoan site of Spoonbill (Pertulla et al. 1982:92-93), and walnuts from a late Prehistoric site, 41MS32 (Dering 1997).

Carbonized walnut shell fragments were recovered from Burned Rock Midden 1 and from four nonfeature contexts at the Wilson-Leonard site. Nutshell fragments can be carbonized by human activities, especially during processing when the shell fragments are separated from the nut meat. The shells can be recycled as fuel.

\section{Hackberry (Celtis sp.)}

Although one discolored hackberry seed that presumably exhibits burning was identified, hundreds of unmodified hackberry seeds were recovered from the sediments. Because they are an excellent carbohydrate source, hackberry fruits undoubtedly were utilized in most prehistoric economies. Unfortunately, hackberry seeds, which are actually calcareous nutlets, are a common intrusive element at many open archeological sites. Therefore it is very difficult to determine the extent to which this resource was exploited.

There are six species of hackberry in Texas, but only two, sugarberry (Celtis laevigata) and netleaf hackberry $(C$. reticulata), grow in the study area. The best-documented hackberry use is of the large $C$. occidentalis, which is distributed across the midwestern and northeastern sections of North America, and the shrubby desert hackberry $C$. reticulata, which grows in west Texas. Hackberry fruits (drupes) among the species are very similarCa carbohydrate rich exocarp surrounding a calcareous endocarp. The entire fruit of $C$. occidentalis was eaten raw or ground into a meal and mixed with other foods by the Pawnee, the Omaha, and the Dakota (Gilmore 1977:24). Hackberry trees grow in upland, intermittent stream settings and also in better-watered riparian habitats.

\section{Carbonized Wood}

By far the most abundant plant material recovered from the Wilson-Leonard site was carbonized wood. At least 16 wood types were identified, and the great majority of the woody remains came from the macroplant samples or ${ }^{14} \mathrm{C}$ samples that were separated during the excavation. The main problem with this type of sample is that the results cannot be used to compare taxon frequencies or densities among the levels. There is no guarantee that material was not missed during the excavation.

Woody plant remains have been utilized to reconstruct past environments at archeological sites, to document the environmental impact of human populations on the environment, and to analyze land-use patterns (Miksicek 1985; Shackleton and Prins 1992; Weir and Dering 1986). Such analyses must be undertaken with care, because they are based on the "Principle of Least Effort," which states that groups will utilize the nearest, most convenient fuel woods available. Ford (1979) has cautioned against such gross generalizations, citing examples of cultural preference. On the other hand, Shackleton and Prins (1992:635) maintain that highly preferred species may be selectively reduced with increasing harvesting pressure.

At the Wilson-Leonard site, two woods, oak and juniper, dominate the macroplant samples throughout the sequence. Two factors, cultural selection and postdepositional deterioration, have led to this overwhelming dominance. First, both oak and juniper are preferred fuel. Second, and perhaps 
more important, oak and juniper preserve well and are easily identified, even in a very deteriorated state.

The following discussion provides information regarding the ethnobotanical record and the landform preferences of each tree identified in the macrobotanical remains.

\section{Arboreal Legume (cf. honey locust Gleditsia tricanthos)}

Honey locust is not a preferred wood nor is it an often mentioned plant resource. Swanton (1946:285) reports that the Creek and Cherokee utilized honey locust seeds.

Honey locust is a tree that grows best in moist, fertile soils. In the immediate area of the site, it would be part of the Brushy Creek gallery forest.

\section{Gum Bumelia (Bumelia lanuginosa)}

No ethnobotanical references are available.

Gum bumelia is a shrub or small tree that grows in fairly deep soils in open woodlands. Although gum bumelia grows throughout Texas except for the high plains, it is most common as an understory plant in the post oak savanna region east of the current study area. It probably grew on the edge of the narrow Brushy Creek flood plain.

\section{Pecan (Carya illinoiensis)}

Although pecan wood was recovered in one macroplant sample, no carbonized pecan shell was encountered. In terms of heat production, pecan is only a fair quality fuel wood (Self 1982), and no ethnobotanical references to pecan wood are available.

On the other hand, pecan nut was a food resource for the Native Americans who lived within its range. Swanton (1946:133) quotes Fray Isidro Espinosa, a prolific early historical observer of the Caddo, reporting that they were collecting "thin-shelled nuts." These were, most likely, pecan. Espinosa also observed nut collecting and storage near the San Marcos River, where he described how the Indians shelled nuts and removed the kernels whole. He describes these nuts as being "longer and thinner," and they were probably pecans. These nuts were available in such quantities that they were stored and consumed throughout the year. Storage was effected in underground pits, and the pecans were transported unshelled threaded on strings or shelled in leather pouches (Tous 1930:10-11).

Pecan trees grow to heights over 130 feet. They are a major component of the gallery forest of most Central Texas stream valleys and may have grown along the flood plain and lower terraces of Brushy Creek at times when it was stable.

\section{Dogwood (Cornus sp.)}

Although dogwood is not often identified at archeological sites, it is a potentially useful fuel wood. The wood is quite heavy and makes excellent charcoal (Self 1982:131). No ethnographic use was found for the wood of this genus. Dogwood fruit was consumed by the Chippewa and the Potawatomi (Densmore 1928:321; Smith 1933:98).

The species of dogwood that grows in the area today, Cornus drummondii, is primarily an understory shrub or small tree. It would prefer the flood plain soils of Brushy Creek.

\section{Walnut (Juglans spp.)}

Walnut wood is both dense and heavy and is an excellent fuel (Self 1982). It has been reported in the charcoal remains of many Texas and midwestern archeological sites (Dering 1993:343-345; Johannessen 1984:210). Espinosa reported that a "black wood" was used by the Caddo to fashion plates or saucers (Swanton 1942:155). This emphasized the utility of black walnut for fashioning tools or other small utilitarian objects.

Black walnut (Juglans nigra) trees grow to a height of 80 feet and prefer moist deep soils. The tree could grow on the flood plain of Brushy Creek.

\section{Juniper, Cedar (Juniperus spp.)}

Juniper wood was the most abundant taxon in the identified samples at the Wilson-Leonard site. Juniper was the only taxon present in all stratigraphic units. Juniper wood is a preferred fuel throughout its range in the arid southwest of North America and is commonly reported from archeological sites throughout its range. In Texas, this includes southcentral Texas (Black and McGraw 1985) and the northeastern edge of the Edwards Plateau (Dering 1997).

Although three species potentially grow in the region, it is impossible to identify juniper charcoal to the species level. Ashe juniper (Juniperus asheii) is the most likely candidate for the Wilson-Leonard site. The other species, southern red cedar (J. silicola) and eastern red cedar (J. virginiana) grow in deep soils, which in the immediate study area would have been confined to the Brushy Creek flood plain. Southern red cedar, for example, grows near water and is dependent on a very shallow water table. Eastern red cedar reaches prominence just beyond the eastern edge of the Edwards Plateau. The rocky limestone hills overlooking Brushy Creek, on the other hand, are ideal habitat for ashe juniper. Ashe juniper may be a good indicator of either human intervention or climate change, because it is very sensitive to fire. If a landscape is subjected to fairly frequent fire (more than one a decade), ashe juniper will be restricted to erosional breaks and other protected habitats (Smeins and Merrill 1988).

\section{Mulberry Family and Red Mulberry (Moraceae and Morus rubra)}

The mulberry family includes mulberry and bois d'arc. Mulberry wood is not mentioned in Texas ethnohistoric 
reports, however, the strong and elastic wood of bois d'arc was technologically valuable, especially as a material for making bows. The wood was used for many other purposesCto haft tools, to make clubs, and to make lances (Carlson and Jones 1940:534). Although mulberry fruit was not recovered in the samples, its almost universal use by Native Americans raises the possibility that the fruit was consumed. The Caddo consumed mulberries, as did other Indians observed between the San Marcos and Colorado rivers by the eighteenth-century observer Fray Isidro Espinosa (Swanton 1942:143; Tous 1930:12).

Red mulberry (Morus rubra) is a medium-sized tree $(<60$ feet) that prefers moist, deep soils and open spaces. It probably grew in the Brushy Creek flood plain, along the edge, and in open areas of the gallery forest. Bois d'arc (Maclura pomifera) is a small tree that is native to the Blackland Prairie, with its distribution centered in the Red River valley. Its range has been extended by extensive transplanting. Because bois d'arc needs ample moisture and fire control to survive, it would have grown in the Brushy Creek watershed or been brought into the region by the site's inhabitants.

\section{Live Oak and Oak (Quercus spp.)}

Live oak wood is the second most commonly occurring taxon in the samples. In addition, the identification of at least four in situ burned oak trunks and roots provide direct evidence that live oak grew at the site. An ideal fuel (Self 1982), oak (Quercus) wood was preferred by most Native Americans living within the range of abundant oak stands. Although very little has been reported in the local ethnographic literature regarding oak wood, archeological reports of Central Texas Archaic age through Late Prehistoric sites indicate oak is perhaps the most commonly identified of all woods (Dering 1997).

The ethnohistoric literature of Texas has several reports of acorn utilization (Swanton 1942:134; Tous 1930:12-13). Ethnographic reports from surrounding regions indicate that most groups utilized acorns in some manner, although none of them indicates that acorns were a staple (see Castetter 1935:47; Havard 1895:119; Robbins et al. 1916:44).

Several species of oak grow in the region, but live oak was by far the most abundant of the oak wood types identified in the samples. There are two species of live oak growing in the study area, Quercus fusiformis and $Q$. virginiana, both of which intergrade along the eastern edge of the Edwards Plateau. Both very closely related species prefer open, well-drained upland contexts.

\section{Rose Family (Rosaceae)}

The wood of the Rosaceae is not identifiable to the genus level using gross anatomical features at low magnification. The rose family includes several small tree species of relatively minor importance, including hawthorn
(Crataegus), wild plum and wild cherry (Prunus), and crabapple (Pyrus).

The fruit of certain species of all of these genera has been of some economic use, either as a food condiment or as a medicine, by many different groups in the southern plains and regions adjacent to the southern plains (see Carlson and Jones 1940:521-523; Gilmore 1977:34-35; Swanton 1942:133). Unfortunately, no Rosaceae seeds were recovered from the Wilson-Leonard samples, but the presence of wood demonstrates that the resource grew in the area and was available to the people living there.

Hawthorns (Crataegus) adapt to a variety of lowland or upland settings, but they are shade intolerant. They live in open spaces on the outer edges of higher sections of the Brushy Creek flood plain or on deeper soils in the uplands. Prunus (wild plum and cherry) has a similar habit, preferring open spaces but being relatively tolerant to extremes of moisture as long as the soil is well drained.

\section{Willow Family (Salicaceae)}

The trees of the willow family growing in the study area are cottonwood (Populus deltoides) and willow (Salix). Carbonized specimens of these two trees are currently indistinguishable using standard identification methods. Both are very valuable raw materials for many technological applications. Although ethnohistoric reports from Texas do not mention its use, willow (Salix) is perhaps one of the most widely used woods in North America. Applications of willow wood include basketry, arrows, lances, snares, roofing material or other uses in structures, and as a medicine (Carlson and Jones 1940:524; Gilmore 1977:21-22).

Cottonwood (Populus deltoides) is another economically important tree. In Texas, ethnohistoric sources do not mention the uses of cottonwood, but in the southwest its root is useful for carving icons and for building construction (Vestal 1952:22). In the Great Plains, the inner bark was eaten, and the leaf buds produced a yellow dye (Gilmore 1977:20). Both willow and cottonwood are part of the riparian woodlands and are confined to the flood plain of Brushy Creek.

\section{Elm Family (Ulmaceae)}

\section{$\operatorname{ELM}(U L M U S$ SP.)}

The elm family includes several species of elm and hackberry trees. Elm tree trunks were utilized as mortars (Swanton 1942:131).

\section{HACKBERRY (CELTIS SPP.)}

No record of the use of hackberry wood in the ethnohistories of Texas was found. The wood charcoal, however, often is recovered from archeological sites in central Texas (Dering 1997). 
Sugarberry (Celtis reticulata) is a tree that grows to 60 feet in virtually any type of well-drained soil, from calcareous loams to black clay. It would grow best on the edge of the flood plain and on the slopes overlooking the flood plain.

\section{Interpretation of Woody Plant Remains}

The carbonized wood identified in the samples gives a general impression, but not a detailed or quantitative evaluation, of the nature of the vegetation around the site. In addition to the previously discussed sampling problem, cultural selection or preference most likely had a great affect on the nature of the plant remains, including wood, at the site. Second, preservation factors have greatly reduced the macrobotanical record. For these reasons, it is not possible to develop a detailed model of local environmental change from the data (see Shackleton and Prins 1992:632). Third, because of the highly deteriorated nature of the material, it is impossible to determine the source of most of the charcoal identified at the site. The charcoal may have been deposited by alluvial activity, by colluvial activity, or it may have been growing in the immediate area. The exceptions are the identifications of seven tree stumps/roots that were burned in situ.

Both juniper and oak are present today as well as in stratigraphic Units Isi to IIIc (ca. 0-10,000 B.P.). This indicates that for at least 10,000 years, the floristics of the woody vegetation of the region did not change radically. This does not eliminate the possibility that local changes in vegetation occurred throughout the Holocene. Such changes may have been wrought by climatic change or human influences. Although the floristics of major tree/shrub species remained very similar, the species composition and distribution of the plant populations, including what plants dominated which landforms, may well have changed. Unfortunately these changes are beyond the resolution of detail that can be generated by this study.

\section{Geophytes: The Significance of Wild Hyacinth (Camassia scilloides)}

Given the condition of plant remains recovered from archeological sites in Central Texas, the presence of carbonized intact bulbs at the Wilson-Leonard site is a remarkable find. The fact that very little is known of plant foraging strategies along the southern plains increases the importance of these specimens. For this reason, an extra effort has been placed on the identification and interpretation of these bulbs. The inner epidermal cell shapes of the archeological bulbs, as reported in the methods section, match very well with the Camassia scilloides in the collections. Three of the suspected species, Allium canadense var. canadense (Canada garlic), Nothoscordum bivalve (false garlic), and Erythronium albidum (dog's tooth violet), were eliminated as possibilities, while the cells of A. drummondii (Drummond onion) are similar. On the average, they have one less side and are about twice the size of the $C$. scilloides (wild hyacinth) cells (Figure 40-1). Wild hyacinth is by far the best match for the archeological material. Given the nature of the match and the fact that these bulbs most likely came from a food processing context (Table 40-9), the potential of wild hyacinth as an economically important plant should be addressed.

To my knowledge, no one has identified wild hyacinth from archeological sites. Such oversight is probably due to the scarcity of archeological plant material of this nature and to the difficulty encountered in identification. The exterior shape of bulbs become radically altered when they are cooked and accidentally charred in an earth oven by a combination of pressure and heat; bulbs of the genus Camassia shrink radically and change shape as they are dried and/or charred. This means that an examination of gross characteristics such as shape or size have limited value in making an identification (Stenholm 1987). These factors have combined to render many possible plant root resources virtually invisible in the archeological record.

Camassia scilloides is commonly known as wild hyacinth, eastern camas, or blue camas. It is a member of the Lily family, and the genus contains seven species, all from North America. Wild hyacinth is a geophyte, a plant that stores food in the form of carbohydrates in subsurface structures. The underground structure may be a modified stem, as is the case of the potato tuber; a modified root, as a carrot; or a modified leaf, as exemplified by bulb producing plants such as the onion. Wild hyacinth produces a bulb. A scapose perennial, wild hyacinth grows from a subglobose, black, scale-coated bulb that measures between $2-4 \mathrm{~cm}$ across. The flower stalk of light blue flowers can reach $70 \mathrm{~cm}$ in height. The plant is well suited to periodic harvesting for two reasons. First, the flower produces around 15 seeds per fruit (a capsule), but a single plant can produce up to 100 capsules (Gould 1942:720; Great Plains Flora Association 1986:1248). Second, the bulbs generate offsets, that is, the main bulb reproduces vegetatively by producing small bulbs. When the bulb is dug up using a digging stick, the younger bulbs often are left behind (Scooter Cheatham, personal communication 1995).

Wild hyacinth is the only member of the genus that grows east of the Rocky Mountains. It is distributed in a very wide band from the Edwards Plateau and Post Oak Savanna of Texas, along the eastern side of the Great Plains through Oklahoma and Missouri north to Ohio (Gould 1942). It is locally abundant in slightly dry to wet prairies and open woods throughout the southern and central parts of its range (Great Plains Flora Association 1986). In Texas, wild hyacinth grows in locally dense stands in the Blackland Prairie and along the eastern edge of the Edwards Plateau (Scooter Cheatham, personal communication 1995). The Wilson-Leonard site is located in the same environmental setting. 

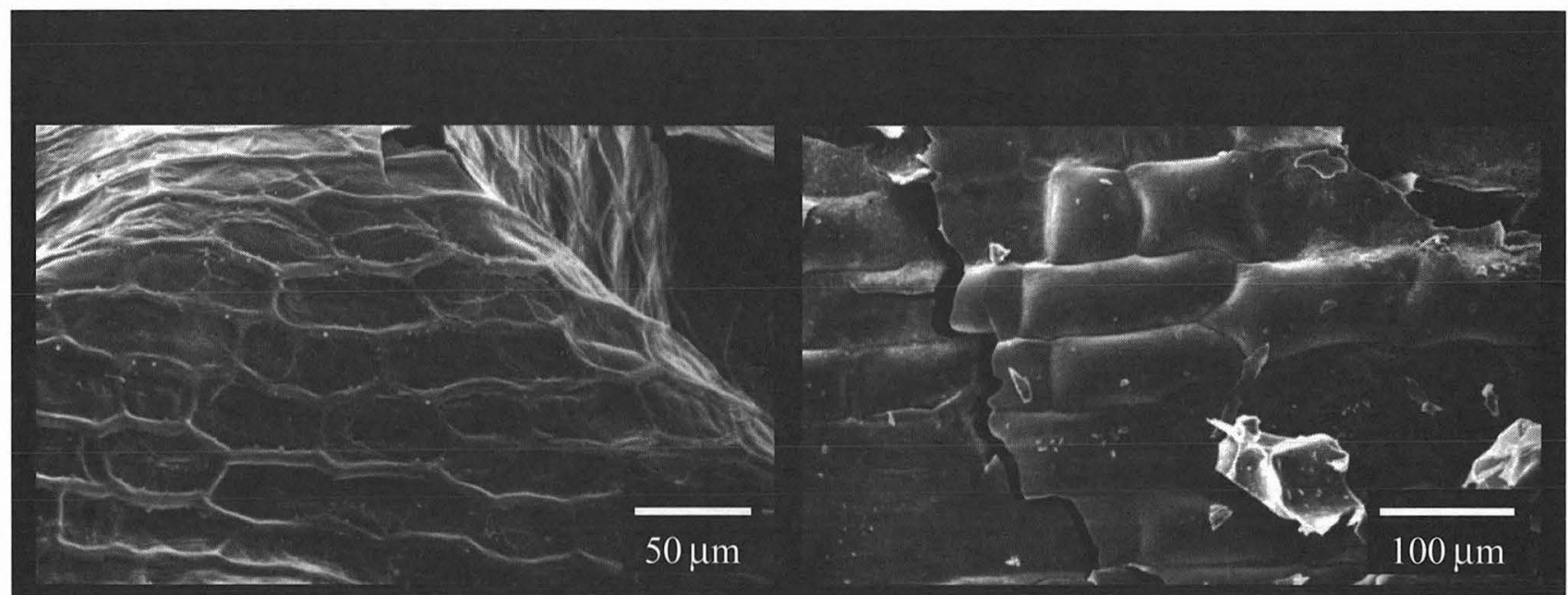

a

b

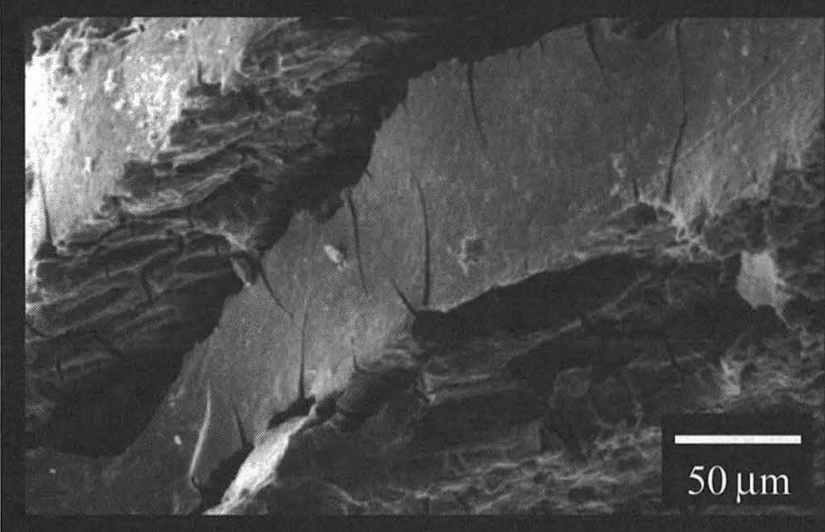

c

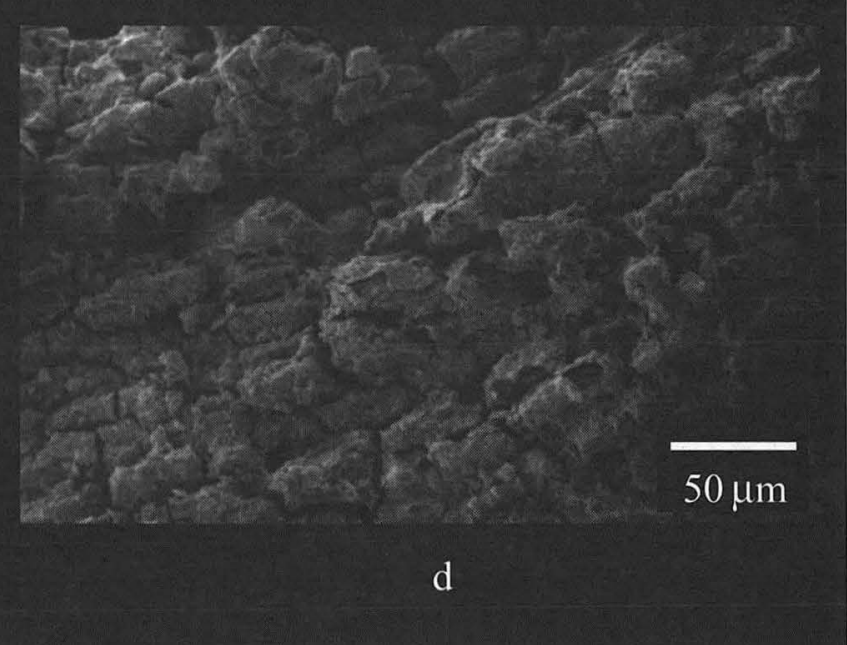

FIGURE 40-1. SEM photographs of archeological and comparative bulbs. (a) carbonized inner epidermis of Camassia scilloides reference material (350X); (b) carbonized inner epidermis of Allium drummondii reference material (200X); (c) Wilson-Leonard sample 1483-1 oblique angle view of carbonized bulb showing layering of bulb scales; (d) Wilson-Leonard sample 1483-1 tangential view of carbonized bulb angle to inner epidermis, showing shape and size of cells (350X).

Carlson and Jones (1940:520) report that the older Comanches they interviewed mentioned that wild hyacinth was eaten raw. Such a practice does not signify that this bulb was an important staple, as the closely related camas was in the Pacific Northwest. Still, the presence of wild hyacinth in association with fire-cracked rocks suggests that it was cooked in an earth oven. This would be necessary for individuals to eat large quantities of any bulbs in the genus Camassia, because they contain the indigestible polysaccharide inulin (Kindscher 1987:74; Thoms 1989:157). Inulin is a complex carbohydrate that must be broken down by hydrolysis into simple sugars before it can be digested. Inulin is broken down by baking the camas bulbs in the presence of steam for an extended time, usually 24-48 hours. Hydrolysis, the splitting of chemical bonds by the addition of water, breaks down long chain carbohydrates into usable short chain sugars (Thoms 1989:157).

Hydrolysis of the chemicals in camas and other plants is accomplished by baking them for extended time periods in an earth oven. Using a pit filled with hot rocks that serve as the heating element, the bulbs are wrapped in moist vegetal packing material and buried for at least 24 hours. The resulting steam and heat provide the environment necessary to break down inulin and other indigestible chemicals within the plant.

Kindscher (1987:74) speculates that the indigenous peoples of the Great Plains did not use wild hyacinth as a major food source, because it contained the indigestible inulin, and because it closely resembles death camas (Zigadenus). Thoms (1989:158) reports that some groups in 
TABLE 40-9

Provenience of Camassia scilloides by Feature

\begin{tabular}{l|l|l|l}
\hline Feature & Unit & Feature Type & Charcoal/ ${ }^{14}$ C Sample Number \\
\hline 8 & Y & Burned rock accumulation & CH-998 \\
Burned Rock Midden 2 & IIIc & Burned rock midden & CH-0925 \\
181 & IIIa & Earth oven & CH-1483-1, CH-1483-2 \\
181 & IIIa & Earth oven & CH-1478 \\
181 & IIII & Earth oven & CH-1479 \\
181 & IIIa & Earth oven & CH-1482 \\
181 & IIIla & Earth oven & CH-1484 \\
181 & IIIa & Earth oven & CH-1480 \\
181 & IIIa & Earth oven & CH-158 \\
181 & IIIa & Earth oven & C14-219 \\
181 & IIIa & Earth oven & C14-354 \\
\hline \hline
\end{tabular}

the northern Rocky Mountains, such as the Thompson, used camas as a staple, and the Cour d'Alene used it as a condiment. These differences were due to a complex set of factors including cultural preferences, availability of suitable camas stands, and availability of other natural resources.

It is doubtful that indigenous groups had difficulty telling the difference between death camas and wild hyacinth. For example, both death camas and edible species of camas grow abundantly in certain areas of the Pacific Northwest, but this did not prevent the collection and mass processing of camas by many indigenous peoples in the $\mathrm{Pa}-$ cific northwest (Stenholm 1987:490). We know that Native Americans possessed the technological skills to properly prepare the camas and other bulbs for mass consumption because the archeological record at the Wilson-Leonard site testifies to the time depth of this knowledge. All of the bulbs come from Archaic contexts. Ten of the bulbs were recovered from the Feature 181 and have been radiocarbon dated to 8000 B.P., and the 1 bulb recovered from Feature 8 has a radiocarbon date of 8250 в.P. A single bulb was identified in a Late Archaic Burned Rock Midden 2 and dates to 3780 в.P.

Recent macrobotanical analyses have produced other identifications of bulb resources across the Edwards Plateau. A cache of 62 bulbs from Horn Shelter (41BQ47), also located in a creek setting within a savanna-prairie ecotone $100 \mathrm{~km}$ north of the Wilson-Leonard site, was recovered from a hearth or oven that dates to the late prehistoric period, around 500 B.P (Watt 1978:119). Examination of the bulbs from Horn Shelter indicated that they were also eastern camas. This provides direct archeological evidence that the practice of collecting and cooking bulbs probably persisted throughout the Holocene period.

\section{SUMMARY AND CONCLUSIONS}

This analysis has generated an archeobotanical record consisting of at least 20 plant taxa, including wood, bulbs, nuts, and seeds. Only 3 of the 76 flotation samples examined contained identifiable carbonized plant remains. Carbonized wood made up the bulk of the material in the macroplant samples. At least 16 wood types were identified, but the overwhelming majority was juniper and oak. The wood assemblage was dominated by the most resistant and easily identified wood types in the region, another indication that the archeobotanical assemblage has been reduced greatly by postdepositional formation processes.

Despite the reduced condition of the assemblage, 12 eastern camas bulbs were recovered from fire-cracked rock contexts. Other plant resources include walnuts, 3 species of grass seed, and hackberry fruit.

Walnut shell fragments were recovered from stratigraphic Units Isi/Isi-c, IIIa, IIIb, and IIIc. No walnut fragments were recovered from stratigraphic Unit II. Walnut fragments were not recovered in flotation samples, and they were not recovered in large numbers from feature contexts. However, a few walnut shell fragments were recovered from Burned Rock Midden 1. For this reason, it is difficult to make an argument regarding the intensity of walnut exploitation at the site. A few shell fragments do not make a good argument for the utilization of the riparian forest, but they do suggest that riparian woodland resources were utilized.

A single carbonized hackberry nutlet was found in Isi/ Icl. Uncarbonized hackberry (Celtis) nutlets were recovered throughout the profile. Although probably a food source, the presence of dozens of possibly intrusive nutlets make assessment of the extent to which is was utilized impossible. 
The grass seeds (Paspalum, Setaria) may have become carbonized in a grass fire or as a result of human activities. Only Panicum has abundant ethnohistoric references to its use a food source, and these references are confined to arid southwestern North America.

The 16 wood types identified in the macroplant samples illustrate only a fraction of the range of woody plants that grew in the area. The deteriorated nature of the archeobotanical assemblage may account for this. The majority of macroplant samples $(232$, or $50 \%)$ could not be identified. Juniper and oak (156, or $68 \%)$ were the most commonly recognized wood types in the macroplant assemblage. All other wood taxa accounted for only $22 \%(n=51)$ of the macroplant samples. The high frequency of occurrence of juniper and oak in the samples may be the result of several factors. First, both wood types are easily identifiable even in a highly degraded state. Second, both trees probably were a dominant part of the woody vegetation in the region throughout the Holocene. Third, both are preferred fuel woods. It is difficult to determine which one or more of these factors is indicated by the prevalence of juniper and oak in the archeological assemblage.

Significantly, 10 carbonized plant bulbs were recovered from an Early Archaic oven in stratigraphic Unit IIIa and 1 from an Early Archaic burned rock accumulation in Unit Y. One bulb was identified from a Late Archaic burned rock midden in stratigraphic Unit IIIc. The bulbs from Units IIIa and $\mathrm{Y}$ have ages ranging from $7870-8420$ B.P. The Late Archaic bulb has been dated to 3780 B.P.

Using scanning electron microscopy, the bulbs have been identified as wild hyacinth (Camassia scilloides), an eastern relative of the camas plant. No detailed ethnographic information is available for the wild hyacinth, but it is very closely related to the camas of the Pacific Northwest. Although the plant flowers from late March to early May, the bulb is best harvested in the fall, after photosynthesis has generated adequate carbohydrate stores (Thoms 1989). Dense stands of wild hyacinth potentially can provide a significant carbohydrate source to human populations.

\section{THE MACROBOTANICAL RECORDAND PLANT AND LAND USE THROUGHOUT THE HOLOCENE}

The reduced nature of the archeobotanical record limits discussions on site seasonality, plant resource exploitation, and fuel wood utilization. This analysis, however, resulted in the development of a new method for identifying geophyte remains recovered from archeological sites. The identification of a new resource, wild hyacinth, should encourage increased effort and focus on the technology of food processing, especially poorly understood carbohydrate resources such as plant roots. Current models of prehistoric plant and land use have not sufficiently explored the potential of geophyte exploitation along the southern plains periphery.
The wild hyacinth (Camassia scilloides) is a carbohydrate-rich resource that was collected at some time before it flowered, perhaps in the fall. If processed correctly, it provides an ideal source of carbohydrates. As a result of habitat destruction, stands of wild hyacinth are difficult to locate. However, the plant is distributed longitudinally along the eastern edge of the Edwards Plateau (Scooter Cheatham, personal communication 1995), and the Wilson-Leonard site is located along this line. It has been observed growing on rocky hillsides overlooking creeks and in deeper soils along creek bottoms. Along the eastern edge of the Balcones escarpment, wild hyacinth has been observed growing in the open canopy flood plains of creeks, for example Shoal Creek and Onion Creek. In the immediate vicinity of the WilsonLeonard site, the most likely area would be on the open areas of the Brushy Creek flood plain.

Most of the wild hyacinth remains were recovered in a context of fire-cracked rocks, in Feature 181 and Burned Rock Midden 2. One of the primary functions of an earth oven is to process plant resources containing carbohydrates. The most parsimonious interpretation for Feature 181 is that it was used in at least one event to prepare a quantity of wild hyacinth bulbs.

Given that aboriginal populations maintained grasslands and productive stands of plant food resources using controlled burning, it is tempting to link burning episodes in the archeological record to maintenance of grasslands. Drawing a connection between wild hyacinth bulb processing and burning episodes at Wilson-Leonard presents problems. First, the fires and the feature in which the bulbs were deposited are not contemporaneous. At least two fires are documented by the presence of burned tree trunks, the earliest around 9500 B.P., and the second around 5500 B.P. The wild hyacinth bulbs are is dated to around 8000 B.P. and 3780 в.P. Second, the burning of oak or mulberry tree trunks and roots indicates an intense crown fire. Normally, Native Americans set small, more-controlled ground fires (Lewis 1973:55).

Recovering this type of direct evidence of burning is rare. Although the two feature types, the ovens and tree trunks, cannot be linked to each other temporally, the fact that wild hyacinth grew in exploitable populations suggests that there were open, well-drained and well-watered grasslands in the immediate vicinity of the site. In this region, and in any climate that approximates what we are experiencing in the Holocene, fire is the only force that would keep the open canopy vegetation cover necessary for the growth of wild hyacinth populations. This area may have been an open live oak savanna at 8000 B.P.

The possibility that fires were utilized as a landscape modification technique should be considered in future research. Wild hyacinth will not grow in dense woodland stands without an open canopy (Gould 1942). Further, growth in the stands is encouraged by winter burning which controls competitors and releases nutrients into the soil, stimulating growth of the bulbs in the following spring. 
Researchers have begun to reconstruct the history of aboriginal maintenance of prairies, grasslands, and oak savannas using scheduled burning for the purpose of both wildlife and vegetation management. This includes purposeful management of vegetation by burning to enhance the growth of bulb resources (Anderson 1993:167; Thoms 1987:169; Timbrook et al. 1993:145), of oak savannas for the exploitation of acorn crops (McCarthy 1993:220), and for the management of wildlife populations (Lewis 1973:33). Granted, some of these techniques are best documented for the California chaparral, but they are also documented for certain areas of the Great Plains (Stewart 1954; Wedel 1957:62).

I recently have identified wild hyacinth at Horn Shelter (41BQ47), which, like the Wilson-Leonard site, is located along the ecotone between the plains and the woodlands. This is a plant resource that has been completely overlooked to date, and has not been considered seriously as a potential staple in the Archaic subsistence patterns of the southern plains periphery.

Geophytic resources, once thought to be invisible in the archeological record, are now becoming known, thanks to increased awareness on the part of archeologists and to improvements in identification techniques. As the integration of disparate data sets, such as modern plant ecology, geomorphology, and ethnohistory proceeds, more sophisticated models of the gathering systems used by hunter/gatherers living at the edge of the southern plains will be elucidated. 


\title{
Chapter 41
}

\section{PHYTOLITH ANALYSIS}

\author{
by Glen Fredlund
}

Opal phytolith analysis provides evidence of both vegetation change and plant use at the Wilson-Leonard site. Local and regional vegetation change is inferred from a stratigraphic column of 78 close-interval samples. Analysis of 13 archeological feature samples and comparisons with the stratigraphic column provide the basis for ethnobotanical inferences. Other nonsilicate phytolith forms (Jones and Bryant 1992) are unlikely to have survived in the soil-forming environment at Wilson-Leonard and were not pursued. The primary emphasis of the investigation of opal phytoliths is on regional paleovegetational records.

The inference of local and regional vegetation change from phytolith assemblages requires a full understanding of phytolith production, dispersal, deposition (assemblage formation), taphonomy, recovery, and identification (Piperno 1988). Our understanding of these topics remains incomplete. As with the more mature study of Quaternary pollen, the key to applying phytolith analytical methods is the study of contemporary environments. Toward that end, this study also includes analysis of 15 modern phytolith assemblages from 6 Central Texas localities. The results of these studies are included and used as a basis for interpretation. While these modern samples are helpful, there remains much to be done before phytolith analysis can be applied with the same level of confidence as Quaternary palynology.

\section{LITERATUREREVIEW}

Previous Texas phytolith studies demonstrate the potential utility of the method in this region of poor pollen preservation (Robinson 1979, 1982; summarized in Piperno 1988:184-187). Robinson used three separate signals to infer regional vegetation and climate change in south-central Texas: (1) the relative abundance of arboreal phytoliths, (2) change in the grass short-cell assemblages (cf. Twiss et al. 1969), and (3) relative abundance of aquatic silicate fossils (diatoms, chrysophytes, and sponges). Arboreal phytolith forms produced by palms, elms, hackberries, and oaks were found to be of particular importance in these studies. Robinson used isolated samples from various archeological sites in south-central Texas to construct a model of regional vegetation change over the last 8,000 years. From these data, he suggested that the arboreal component of vegetation dropped dramatically between 7000 and 8000 B.P. and did not begin re-expansion until about 2000 в.P. His data also suggest that grassland composition fluctuated throughout the Holocene with peaks in xeric short-grasses occurring around 7000 and 4500 в.P. (Piperno 1988:137). In general, Robinson's interpretations are in keeping with other models of Holocene vegetation and climate change in central Texas (Bousman 1994; Collins 1995).

In Robinson's approach, there is an implicit assumption that phytolith assemblages reflect regional, rather than local, vegetation. This assumption is especially critical for interpretations but remains poorly tested. Contrasting with Robinson's work are archeological interpretations of microvariability among phytolith assemblages. These interpretations depend on the alternative assumption of local source area, also called "decay-in-place," which is cited as essential for the ethnobotanical interpretations of intrasite variability (e.g., Pearsall 1989:311-438). Modern soil data gathered from across the Great Plains grasslands suggest that the assumption of "decay-in-place" is not valid for the grass short-cell portion of the phytolith assemblage (Fredlund and Tieszen 1994). These data suggest that grass short-cell phytolith assemblages are often more likely representative of regional vegetation than the result of in situ decay. This does not mean that ethnobotanical interpretations of archeological samples are invalid but rather that they should be strongly based on an understanding of non-anthropogenic variability among local phytolith assemblages (Lawlor 1995). Such an approach will better identify phytolith assemblages resulting from specific human plant use. 
The extension of the extralocal model of assemblage formation may not be valid for the arboreal component of the phytolith assemblage. Both production and dispersal of arboreal phytoliths affect assemblage formation. Annual phytolith production is about an order of magnitude lower for forest than for grassland. Many large arboreal phytoliths are probably less susceptible to extralocal transportation than are smaller grass forms. Unfortunately, little empirical data for forest assemblages exists. Piperno's (1988) study of modern surface samples demonstrates that local decay-inplace formation processes dominate within a tropical rain forest. The applicability of the local decay-in-place model of assemblage formation to the open woodlands of Central Texas is undetermined.

Other researchers have used phytolith analysis to infer change in woodland-grassland boundaries and in community composition. These applications fall into two broad categories: those using total phytolith mass and those using a morphological classification of phytolith forms. A few researchers have combined the two approaches. Underlying the use of phytolith mass is the general difference in grassland and forest phytolith production (Johnston et al. 1967; Wilding and Drees 1968; Wilding et al. 1977). Grasses, sedges, and some forbs produce high levels of phytoliths. Production ranges from 1 to $6 \%$ of the net annual production for grasslands. Annual production by trees and shrubs is typically a fraction of that for grasses. This differential production of phytoliths is ultimately reflected in the soil content. Soils from stable grassland have substantially higher opal phytolith content than do soils from woodlands (Jones and Beavers 1964). This line of reasoning has been successfully used to infer long-term vegetation change from buried soil horizons.

This difference has also been applied to extant soil systems to infer either local vegetation stability or ephemerality (succession). For example, Kalisz and Boettcher (1990) have used differences in phytolith mass estimates to argue for the long-term stability of prairie patches known as Buffalo Beats in southeastern Ohio. Other researchers have used the lack of difference in phytolith mass across ecotone or patch boundaries to argue for forest encroachment or successional processes (cf. Fisher et al. 1986; Fuller and Anderson 1993; Witty and Knox 1964). Implicit in these applications is an assumption of local spatial scale for soil phytolith assemblages.

The second general approach relies on morphological classification of phytolith forms. Grasses produce very distinctive, densely silicifed, short-cell phytoliths that are readily identifiable (Piperno 1988; Rovner 1971, 1983; Twiss et al. 1969). Trees and shrubs produce a wide variety of phytolith forms. Although there is no complete catalog of phytolith forms for North American trees, shrubs, and forbs, the more common forms are fairly well defined (Bozarth 1992, 1993; Geis 1973; Klein and Geis 1978; Piperno 1988; Wilding and Drees 1971,1973). The most common forms encountered in soil samples include silicified epidermal and mesophyll cells, hair bases, and hair structures produced and shed annually with needles or leaves. Classification schemes of arboreal forms have varied with specific paleoecological applications. They range from a very simple gross separation and categorization of the large nongrass forms in southeastern North America (Carbone 1978) to the very detailed study and classification of forms produced within a diverse neo-tropical plant community (Piperno 1988).

One of the variables that affects the application of phytolith analysis to arboreal assemblages is taphonomy. Many arboreal phytolith forms are weakly silicified and more susceptible to dissolution in the soils than other more densely silicified forms. Large arboreal forms, especially weakly silicified epidermal fragments, are also more susceptible to mechanical damage than are grass short-cell phytoliths. Where preservation is variable, a simpler but less taxonomically sensitive classification of nongraminoid phytoliths may provide a more reliable measure of shifts in grassland-woodland composition.

One strategy employed in this study is separate analysis of grass phytolith assemblages. Although grasses produce many forms (short cells, elongate cells, bulliforms, tricomes), the most taxonomically and environmentally significant are the short cells (Fredlund and Tieszen 1994; Twiss et al. 1969). Although the correlation of the short-cell forms with grass taxonomy is imperfect, when analyzed as assemblages, short cells provide a means for documenting change in regional grassland composition. Short-cell assemblages are not only sensitive to shifts between cool-season adapted $\mathrm{C}_{3}$ and warm-season adapted $\mathrm{C}_{4}$ grasses but can also measure relative changes between the xeric-adapted short grasses and the mesic-adapted tall grasses.

\section{METHODS}

\section{Sample Collection}

Modern soil samples were collected from six localities in Central Texas. These localities included a variety of prairie and woodland communities and comprise a short transect (from Bell County to Kerr County) across a steep climatic gradient in Central Texas (Table 41-1). As with any modern study, identifying and sampling appropriate and relatively intact plant communities was a problem. Historic land use of the region has greatly altered vegetation. Some of the localities that appeared to have mature vegetation had little soil development, indicating historic soil loss. Even so, the six localities provide some basis for calibrating fossil phytolith assemblages.

Undisturbed areas were sought within each of the modern localities. Multiple samples were collected to explore the level of local variability. Multiple samples from within a locality include both replicate samples collected within homogeneous areas and transects of samples along local 
TABLE 41-1

Modern Sample Sites in Central Texas

\begin{tabular}{l|l|l|l|l}
\hline Code & Site Name & County & Vegetation & Comment \\
\hline SM & Spohn Meadow & Bell & prairie & nonnative species \\
IP & Irish Prairie & Bell & prairie & unplowed hay field \\
WL & Wilson-Leonard, upland & Willianson & oak-juniper & soil erosion \\
PF & Pedernales Falls & Blanco & oak woodland & soil erosion \\
KS & Kerrville-Schreiner & Kerr & oak woodland & woodland succession \\
HR & Hall's Ranch & Kerr & oak savanna & heavily overgrazed; soil erosion \\
\hline \hline
\end{tabular}

topographic gradients representing maximum local variability. Each sample is a composite of four individual soil samples from within a 4- $\mathrm{m}^{2}$ area. The surface litter layer (or O-horizon), where present, was collected separately. The upper Ahorizon (upper 2 to $3 \mathrm{~cm}$ ) was pooled and analyzed separately from the litter layer samples.

At the Wilson-Leonard site, the stratigraphic column of 78 samples, which forms the basis of this paleoenvironmental interpretation for the site, was collected from the TARL Square 12 profile, with deeper stratigraphic samples taken from the profile of Square 55. The sampling interval was approximately $10 \mathrm{~cm}$ throughout the column. A set of 12 samples taken from another deep excavation unit representative of the deepest strata (Igl) were also analyzed. Additional samples were collected from a variety of archeological features throughout the TARL excavation.

\section{Phytolith Extraction}

Eight grams of air-dried sediment were used for each phytolith extraction, except where limited by sample size. The process of isolating opal phytoliths from soil samples includes: (1) the oxidation of carbonates, (2) removal of clays, (3) oxidation of residual organic matter, and (4) heavy liquid fractionation. Twenty milliliters of $37 \%$ hydrochloric acid were used to oxidize carbonates. After all carbonates were oxidized, the samples were repeatedly washed with distilled water until $\mathrm{pH}$ was neutralized. A 0.1 -molar solution of sodium hexametaphosphate was used to deflocculate clays and oxidize colloidal organics. Dispersed clays and colloids were decanted after silts and sands settled. All clays were removed through repeated stirring, settling, and decanting. The samples were then treated with a $30 \%$ hydrogen peroxide solution in a boiling water bath to oxidize residual organics. Clays and colloids released by this process were then decanted as described above. The biogenic silicates were isolated from the heavier mineral fraction with a 2.35 specific gravity solution of zinc bromide. The heavy liquid flotation was repeated three times. A 5-micron pore membrane was used to recover phytoliths from among the decanted clays and colloids and from dilute heavy liquid. The isolated fraction was washed and stored dry. The dried extracted fractions (material less than specific gravity 2.35 ) were weighed for each sample. Each weight is expressed as a percentage of the air-dried weight of the original sediment sample (Percent Extracted Weight).

Visual assessment of preservation was applied to each fossil assemblage. A five-point scale was used in the evaluation of preservation: (1) barren, (2) poor, (3) adequate, (4) good, and (5) excellent. Samples rated below adequate were judged unsuitable for quantitative analysis. Key visual features used in this somewhat subjective characterization include density of phytoliths (relative to nonbiogenic silicates) and the degree to which larger phytoliths exhibit dissolution pitting.

\section{Phytolith Identification and Counting}

This study began with the morphological classification and quantification of phytolith forms. At least two slides were prepared for each extraction. A glycerin solution was used as the mounting medium. Glycerin allows for rotation of the micro fossils under the cover slip for more accurate classification. Slides were systematically scanned at $630 \mathrm{X}$ magnification with a Leitz Laborlux-S microscope. Rapid, point-count procedure was used to estimate the frequency of nonbiogenic silicates and irregular phytolith fragments. Other forms were counted individually. Identification and classification of arboreal and related angiosperm forms was based on published descriptions (Bozarth 1992; Geis 1973; Klein and Geis 1978; Piperno 1988) and comparative collections. The anatomical classification of arboreal and gymnosperm forms included polyhedral epidermis and mesophyll forms, epidermal hairs and hair bases, silicified trachiary elements, and the palm type. Several very diagnostic but unknown forms were also defined. Classification of grass forms was based on the system proposed by Twiss et al. (1969) and modified by Brown (1984), Mulholland (1986, 1989), Mulholland and Rapp (1992), and Piperno (1988). The grass short-cell classification has been collapsed to 12 morphological types for purposes of analysis and display (Fredlund and Tieszen 1994). Classification of sedge phytolith forms followed the scheme proposed by Ollendorf (1992).

Three principal measures for inferring changes in vegetation and climate were used: (1) estimates of total phytolith mass expressed as percent weight, (2) relative change in woodland-grassland ratio, and (3) percentages of grass short-cell phytolith types. The mass or percent weight of 
phytoliths recovered for each sample is not simply an indicator of production. It is the resulting balance between production, surface stability (affected by both aggradation and degradation), and phytolith dissolution. The dissolution factor was independently evaluated with a visual inspection for pitting and destruction. The woodland-grassland ratio is the ratio of large, blocky, and polylateral arboreal phytolith forms divided by the total grass short-cell count times one hundred.

\section{RESULTS}

\section{Modern Assemblages}

Analysis of modern samples is the basis for interpreting fossil assemblages. It provides a means for calibrating phytolith assemblages with vegetation and an indicator of the stochastical range of variability that can be expected to occur naturally among fossil assemblages. This set of modern soil samples is used to test the validity of the woodland-grassland ratio as a measure of woodland vegetation cover. Percent weight recovery was also calculated for all upper A-horizon (A1) samples (Table 41-2). Phytolith extractions for many modern samples were problematic, and the resulting weights may not be representative of the true phytolith weights of these soils. The problem was caused by the persistence of clays and colloids prior to specific gravity separation. The assemblage composition, however, appeared to be unaffected and should be representative. Weights were not calculated for the litter-layer horizon samples. Localities are discussed along a northeast to southwest transect.
Two true grassland localities were sampled near Temple, Texas-Spohn Meadow and Irish Prairie. Although the contemporary grass composition of the two localities is quite different, both fall within the Blackland Prairie Region (Diamond and Smeins 1985). Spohn Meadow, a small (5-acre) unplowed lowland prairie remnant, is dominated by big bluestem (Andropogon gerardii). This meadow has been used for hay. The prairie does contain some nonnative taxa, most notably Johnson grass (Sorghum halepense). Sample SM-1 is representative of this grassland remnant. SM-2 was taken from within a large successional patch of hackberry (Celtis sp.) which appeared to be about 20 years old. Irish Prairie is a slightly larger (ca. 21-acre) unplowed prairie remnant. This prairie encompasses a local gradient from xeric exposed uplands to mesic settings along an ephemeral stream. Xeric sites are dominated by a patchy mosaic of little bluestem (Schizachyrium scoparium) and hairy grama (Bouteloua hirsuta). Side-slope composition is dominated by little bluestem (Schizachyrium scoparium). The mesic, riparian setting is dominated by a mix of big bluestem (Andropogon gerardii), gamma grass (Tripsacum dactyloides), and King Ranch Bluestem (Bothriochloa ischaemum). An extensive complement of native forbs also persists on this remnant. Four samples (IP-1 through IP-4) represent the vegetation and soils of this local landscape gradient.

The remaining sites are more typical of the open woodlands of Central Texas. A single sample was collected from the open juniper woodlands above the Wilson-Leonard site. The vegetation of this locality, like most of the region, had been significantly altered historically. Erosion was evident and little soil remained. Two samples were analyzed from Pedernales Falls State Park. Both localities were collected

TABLE 41-2

Modern Sample Data: Percent Weight Recovered and Woodland/Grassland Ratio

\begin{tabular}{l|l|l|l|c|c}
\hline Lab No. & Field No. & $\begin{array}{l}\text { Soil } \\
\text { Horizon }\end{array}$ & $\begin{array}{l}\text { Dominate Local } \\
\text { Vegetation }\end{array}$ & $\begin{array}{l}\text { Percent } \\
\text { Weight }\end{array}$ & $\begin{array}{l}\text { Woodland-grassland } \\
\text { Ratio }\end{array}$ \\
\hline 93012605 & SM-1 & A1 & Big Blue Stem & 0.42 & 8.209 \\
93012609 & SM-2 & A1 & Hackberry succession & 0.37 & 16.117 \\
93012608 & IP-1 & A1 & Grama grass & 0.52 & 13.527 \\
93012610 & IP-2 & A1 & Grama/Little Blue & 0.35 & 10.593 \\
93012611 & IP-3 & Aittle Blue Stem & 0.47 & 8.333 \\
93012612 & AP-4 & Big Blue/Gamma grass & 0.67 & 6.818 \\
93012607 & WL & Juniper woodland & 0.72 & 22.093 \\
93080903 & PF-1 & Grama grass/woodland & N/A & 26.102 \\
92121407 & PF-1 & Grama grass/woodland & 2.68 & 9.950 \\
93080904 & PF-2 & Arama grass/woodland & 0.79 & 10.823 \\
93080905 & KS-1 & A1 & Oak woodland & N/A & 23.551 \\
93012604 & KS-1 & Oak woodland & 0.92 & 23.735 \\
93080906 & KS-2 & A1 & Oak woodland & 1.27 & 20.435 \\
93012601 & KS-2 & Aitter & Oak woodland & 0.87 & 28.470 \\
93012603 & HR-1 & A1 & Oak savanna/three awn & & 16.129 \\
\hline \hline
\end{tabular}


from small openings dominated by blue grama (Bouteloua gracilis) and surrounded by oak woodlands typical of the Texas Hill Country. For sample PF-1, both the leaf-litter layer (O-horizon) and upper A-horizon (A1) were analyzed. There was no litter layer remaining on the thin mineral soil at the PF-2 sampling locality. Two additional woodland samples were obtained from upland sites in the western portions of Kerrville-Schreiner State Park. The oak woodlands appeared to be more stable at these localities and both sites have thick leaf litter (O-horizon). The final modern sample analyzed came from Hall's Ranch in western Kerr County. The sample was collected from the open oak savanna above the Hall's Cave site. The range community had been heavily impacted by grazing at this locality. Standing grass composition was dominated by three-awns (Aristida spp.).

The modern data set suggests that soil phytolith assemblages can be used to infer change in the woodlandgrassland composition. Although there is some variability among the sites, grassland assemblages have a lower woodland-grassland ratio than do the woodland samples (see Table 41-2). Average woodland-grassland ratio values for the grassland assemblages (excluding SM-2, the successional hackberry woodland) is less than 10 . The average value for the woodland sites is greater than 20 . If the low values obtained for the Pedernales Falls State Park A1 horizon samples are omitted, the average value is about 23. Except for the abnormally low Pedernales Falls State Park samples, the range of values within the woodlands group also conforms with expectations. More open woodlands such as Hall's Ranch have lower values. The Kerrville-Schreiner
State Park with denser, more-stable woodland had the highest values. It is unclear why the woodland-grassland ratio values for the Pedernales Falls State Park samples were low. It may be a reflection of recent changes in vegetation resulting from land use or of erosion and soil loss. Overall, these data suggest that this measure may be worth further development. The data suggest a local spatial scale for the formation of the woodland assemblages.

Modern grass phytolith assemblages from these localities corroborate observations from elsewhere in the Great Plains (Fredlund and Tieszen 1994). As is the case for specific pollen taxa, individual phytolith types must be individually calibrated to biomass or percent cover of the taxa which produces them. The lobate forms (Simple Bilobates, Panicoid-type, Cross, and Other Lobate forms) could be considered as "underrepresented" while the short-grass saddletype phytoliths appear "overrepresented" (Table 41-3). The percentage of all tall-grass phytolith types typically ranges between 18 to 25 even where tall-grass taxa dominate. Percentages of saddle types characteristic of short grasses are at least twice as high (averaging 53.5\%), even though local short-grass biomass may be relatively low. These differences are probably primarily the result of differential production but may be affected by other factors including transportation and preservation.

\section{Analysis of the Stratigraphic Column}

Description and discussion of the phytolith record follows the stratigraphy defined by changes in the sediments,

TABLE 41-3

Modern Sample Data: Percentage of Grass Short Cells by Phytolith Morphotype

\begin{tabular}{|c|c|c|c|c|c|c|c|c|c|c|c|c|c|}
\hline Field No. & Horizon & Keeled & Rondel & Rectangle & Sinuate & Saddle & $\begin{array}{l}\text { Stipa- } \\
\text { type }\end{array}$ & $\begin{array}{l}\text { Simple } \\
\text { Bilobate }\end{array}$ & $\begin{array}{l}\text { Panicoid- } \\
\text { type }\end{array}$ & Cross & $\begin{array}{l}\text { Other } \\
\text { Lobate } \\
\text { Forms }\end{array}$ & $\begin{array}{l}\text { Irregular } \\
\text { Short } \\
\text { Cells }\end{array}$ & Count \\
\hline SM-1 & A1 & 4.85 & 15.30 & 4.48 & \begin{tabular}{|l|}
0.75 \\
\end{tabular} & 50.00 & 3.73 & 10.45 & 5.60 & 1.87 & 1.49 & 1.49 & 268 \\
\hline SM-2 & A1 & 6.59 & 17.58 & 5.13 & 0.73 & 40.29 & 7.69 & 14.65 & 5.13 & 0.37 & 0.73 & 1.10 & 273 \\
\hline IP-1 & A1 & 6.28 & 14.49 & 4.83 & 0.48 & 54.11 & 3.38 & 7.25 & 7.25 & 1.45 & 0.48 & 0.48 & 207 \\
\hline IP-2 & A1 & 4.24 & 9.75 & 3.81 & 0.85 & 61.44 & 2.97 & 10.59 & 5.93 & 0.00 & 0.85 & 0.42 & 236 \\
\hline IP-3 & A1 & 5.00 & 9.17 & 3.75 & 0.83 & 65.83 & 1.25 & 5.42 & 7.50 & 0.42 & 0.42 & 0.42 & 240 \\
\hline IP-4 & A1 & 5.91 & 19.55 & 5.45 & 1.82 & 41.82 & 2.73 & 10.45 & 8.18 & 2.27 & 0.45 & 1.82 & 220 \\
\hline WL & A1 & 5.81 & 13.37 & 6.40 & 1.16 & 59.88 & 1.16 & 6.98 & 4.07 & 0.00 & 0.58 & 1.16 & 172 \\
\hline PF-1 & $\mathrm{O}$ & 7.21 & 13.68 & 4.98 & 0.25 & 41.04 & 7.46 & 8.96 & 11.44 & 1.49 & 2.24 & 1.24 & 402 \\
\hline PF-1 & A1 & 5.42 & 11.19 & 2.03 & 0.68 & 50.85 & 3.05 & 12.20 & 12.88 & 0.68 & 4.41 & 0.34 & 295 \\
\hline PF-2 & A1 & 6.49 & 11.69 & 1.73 & 0.00 & 61.90 & 3.03 & 6.93 & 6.49 & 1.30 & 0.87 & 0.43 & 231 \\
\hline KS-1 & $\mathrm{O}$ & 7.97 & 13.77 & 2.17 & 0.36 & 59.78 & 1.81 & 4.71 & 7.61 & 1.09 & 0.72 & 0.36 & 276 \\
\hline KS-1 & A1 & 8.56 & 9.73 & 2.33 & 0.78 & 62.26 & 1.95 & 6.61 & 5.45 & 0.39 & 1.17 & 1.17 & 257 \\
\hline KS-2 & $\mathrm{O}$ & 7.39 & 12.17 & 2.17 & 0.43 & 63.91 & 1.30 & 3.91 & 6.96 & 0.43 & 1.30 & 0.43 & 230 \\
\hline KS-2 & A1 & 8.90 & 18.86 & 1.78 & 1.78 & 60.14 & 0.71 & 3.56 & 2.49 & 0.71 & 0.36 & 1.07 & 281 \\
\hline HR-1 & A1 & 4.52 & 14.84 & 1.94 & 1.94 & 50.97 & 7.10 & 9.68 & 6.45 & 0.65 & 1.29 & 1.29 & 155 \\
\hline Average & & 6.65 & 13.64 & 3.58 & 0.82 & 53.50 & 3.26 & 8.57 & 7.19 & 1.35 & 1.15 & 0.87 & 252 \\
\hline
\end{tabular}


soil, and archeology of the site. Generally, change in the phytolith record does reflect the Wilson-Leonard stratigraphy, although the stratigraphic units do not necessarily coincide with the natural zonation of the phytolith record.

\section{Phytolith Recovery and Preservation}

The first step in the analysis of the stratigraphic column is the evaluation of phytolith preservation. Two criteria are used: percent extracted weight and a visual assessment of preservation (Table 41-4). Three variables affect the percent weight of phytoliths from the Wilson-Leonard samples: production and deposition, ground surface stability (or instability), and the rate of phytolith dissolution and destruction. The primary factor shaping the percent weight recovery curve in the lower strata (below Unit III) is hypothesized to be progressive destruction by dissolution through time (Figure 41-1). Although there is some variability in recovery, the trend through this portion of the record is one of progressive destruction. Variability in phytolith content, as measured by percent extracted weight, has no single cause. Preservation probably does impact the lower portion of Unit IIIa.

\section{TABLE $41-4$}

Phytolith Recovery, Preservation, and Woodland-Grassland Ratios for the Excavation Unit 12 Profile and Exploratory Deeper Samples

\begin{tabular}{|c|c|c|c|c|c|c|c|c|c|c|c|c|c|}
\hline Unit & Field No. & Lab No. & Depth & Weight & Preservation & $\begin{array}{l}\text { Woodland- } \\
\text { grassland } \\
\text { Ratio }\end{array}$ & Unit & $\begin{array}{l}\text { Field } \\
\text { No. } \\
\end{array}$ & Lab No. & Depth & Weight & Preservation & \begin{tabular}{|l} 
Woodland- \\
grassland \\
Ratio
\end{tabular} \\
\hline IIIc & WL57 & 93010512 & 97.36 & 0.69 & excellent & 84.42 & II & WL21 & 93020212 & 95.60 & 0.12 & adequate & 125.00 \\
\hline IIIc & WL56 & 93010511 & 97.32 & 0.67 & excellent & 49.48 & Isi-c & WL20 & 93020211 & 95.56 & 0.14 & adequate & 227.27 \\
\hline IIIc & WL55 & 93020412 & 97.28 & 0.45 & excellent & 25.93 & Isi-c & WL19 & 93020210 & 95.49 & 0.12 & adequate & 227.68 \\
\hline IIIc & WL54 & 93010509 & 97.22 & 1.05 & excellent & 25.91 & Isi-c & WL18 & 93020209 & 95.44 & 0.15 & adequate & 263.16 \\
\hline IIIc & WL53 & 93010508 & 97.15 & 0.99 & excellent & 20.94 & Isi-c & WL17 & 93020208 & 95.38 & 0.21 & poor & 54.84 \\
\hline IIIc & WL52 & 93010507 & 97.10 & 1.05 & excellent & 29.76 & Isi-c & WL16 & 93020207 & 95.33 & 0.14 & adequate & 168.75 \\
\hline IIIc & WL51 & 93010506 & 97.05 & 1.25 & excellent & 16.67 & Isi-c & WL15 & 93020206 & 95.28 & 0.29 & poor & 223.21 \\
\hline IIIC & WL50 & 93010505 & 97.03 & 1.22 & excellent & 20.00 & Isi-c & WL14 & 93020205 & 95.23 & 0.07 & poor & 476.19 \\
\hline IIIc & WL49 & 93010504 & 97.00 & 1.30 & excellent & 26.90 & Isi-c & WL13 & 93020204 & 95.16 & 0.12 & poor & 250.00 \\
\hline IIIc & WL48 & 93010503 & 96.94 & 1.46 & excellent & 20.49 & Isi-c & WL11 & 93020202 & 95.15 & 0.15 & poor & 1333.33 \\
\hline IIIc & WL47 & 93010502 & 96.90 & 1.45 & excellent & 22.25 & Isi-c & WL12 & 93020203 & 95.10 & 0.12 & poor & 875.00 \\
\hline IIIc & WL46 & 93010501 & 96.86 & 1.29 & excellent & 24.15 & Isi-c & WL10 & 93020201 & 95.09 & 0.20 & poor & 300.00 \\
\hline IIlb & WL45 & 93010612 & 96.80 & 1.35 & excellent & 22.73 & Isi-c & WL09 & 93020410 & 95.07 & 0.21 & poor & $\mathrm{n} / \mathrm{a}$ \\
\hline $\mathrm{IIlb}$ & WL44 & 93010611 & 96.72 & 1.05 & good & 20.75 & Isi-c & WL08 & 93020409 & 95.03 & 0.29 & poor & $\mathrm{n} / \mathrm{a}$ \\
\hline IIIb & WL43 & 93010610 & 96.68 & 1.02 & excellent & 35.18 & Isi-c & WL07 & 93020408 & 95.00 & 0.15 & poor & 29.41 \\
\hline IIIb & WL42 & 93010609 & 96.64 & 0.97 & good & 33.85 & Isi & WL06 & 93020407 & 94.90 & 0.17 & poor & 81.08 \\
\hline IIIb & WLA1 & 93010608 & 96.60 & 0.85 & good & 42.47 & Isi & WL05 & 93020406 & 94.81 & 0.21 & poor & $\mathrm{n} / \mathrm{a}$ \\
\hline IIIb & WL40 & 93010607 & 96.56 & 0.84 & good & 20.88 & Isi & WL04 & 93020405 & 94.76 & 0.09 & poor & n/a \\
\hline IIIb & WL39 & 93010606 & 96.52 & 0.57 & good & 13.16 & Isi & WL03 & 93020404 & 94.71 & 0.14 & adequate & 24.69 \\
\hline IIIa & WL38 & 93010605 & 96.47 & 0.47 & good & 77.67 & Isi & WL02 & 93020403 & 94.61 & 0.09 & poor & $\mathrm{n} / \mathrm{a}$ \\
\hline IIIa & WL37 & 93010604 & 96.42 & 0.37 & adequate & 44.27 & Isi & WL01 & 93020402 & 94.51 & 0.06 & poor & $\mathrm{n} / \mathrm{a}$ \\
\hline IIIIa & WL36 & 93010603 & 96.38 & 0.41 & adequate & 57.77 & Isi & WLO0 & 93020401 & 94.41 & 0.06 & adequate & 31.25 \\
\hline IIIa & WL35 & 93010602 & 96.33 & 0.54 & adequate & 41.67 & Isi & WL62 & 92101607 & $\mathrm{n} / \mathrm{a}$ & 0.02 & poor & 152.54 \\
\hline IIIa & WL34 & 93010601 & 96.27 & 0.30 & adequate & 78.13 & $\operatorname{Igl}$ & WL73 & 92101608 & $n / a$ & 0.04 & poor & $\mathrm{n} / \mathrm{a}$ \\
\hline IIIa & WL33 & 93011512 & 96.22 & 0.35 & adequate & 68.50 & Igl & WL224 & 93102801 & $n / a$ & 0.02 & barren & $\mathrm{n} / \mathrm{a}$ \\
\hline IIIa & WL32 & 93011511 & 96.17 & 0.35 & adequate & 88.42 & Igl & WL225 & 93102802 & $n / a$ & 0.01 & poor & $\mathrm{n} / \mathrm{a}$ \\
\hline IIIa & WL31 & 93011510 & 96.11 & 0.34 & adequate & 85.57 & Igl & WL226 & 93102803 & $\mathrm{n} / \mathrm{a}$ & 0.01 & poor & n/a \\
\hline IIIa & WL30 & 93011509 & 96.05 & 0.34 & adequate & 120.53 & Igl & WL227 & 93102804 & $n / a$ & 0.02 & poor & $\mathrm{n} / \mathrm{a}$ \\
\hline IIIa & WL29 & 93011508 & 96.00 & 0.36 & adequate & 108.28 & Igl & WL228 & 93102805 & $\mathrm{n} / \mathrm{a}$ & 0.01 & poor & n/a \\
\hline IIIa & WL28 & 93011507 & 95.95 & 0.32 & adequate & 77.27 & $\operatorname{Ig} 1$ & WL229 & 93102806 & $n / a$ & 0.01 & poor & $\mathrm{n} / \mathrm{a}$ \\
\hline IIIa & WL27 & 93011506 & 95.91 & 0.30 & adequate & 104.32 & $\operatorname{Igl}$ & WL230 & 93102807 & $n / a$ & 0.02 & barren & n/a \\
\hline IIIa & WL26 & 93011505 & 95.87 & 0.31 & adequate & 33.33 & Igl & WL231 & 93102808 & $n / a$ & 0.02 & poor & n/a \\
\hline II & WL25 & 93011504 & 95.83 & 0.29 & adequate & 68.94 & Igl & WL232 & 93102809 & $n / a$ & 0.02 & poor & n/a \\
\hline II & WL24 & 93011503 & 95.79 & 0.24 & adequate & 115.04 & $\operatorname{Igl}$ & WL233 & 93102810 & $n / a$ & 0.02 & poor & n/a \\
\hline II & WL23 & 93011502 & 95.72 & 0.29 & adequate & 101.27 & Igl & WL234 & 93102811 & $\mathrm{n} / \mathrm{a}$ & 0.01 & poor & n/a \\
\hline II & WL22 & 93011501 & 95.65 & 0.24 & adequate & 106.80 & Igl & WL234 & 93102812 & $\mathrm{n} / \mathrm{a}$ & 0.01 & barren & $\mathrm{n} / \mathrm{a}$ \\
\hline
\end{tabular}

Note: Depth is in meters relative to datum; weight is expressed in percentage of air dry weight of sediment; woodland ratio equals large arboreal cell count divided by grass short-cell count times 100 . 


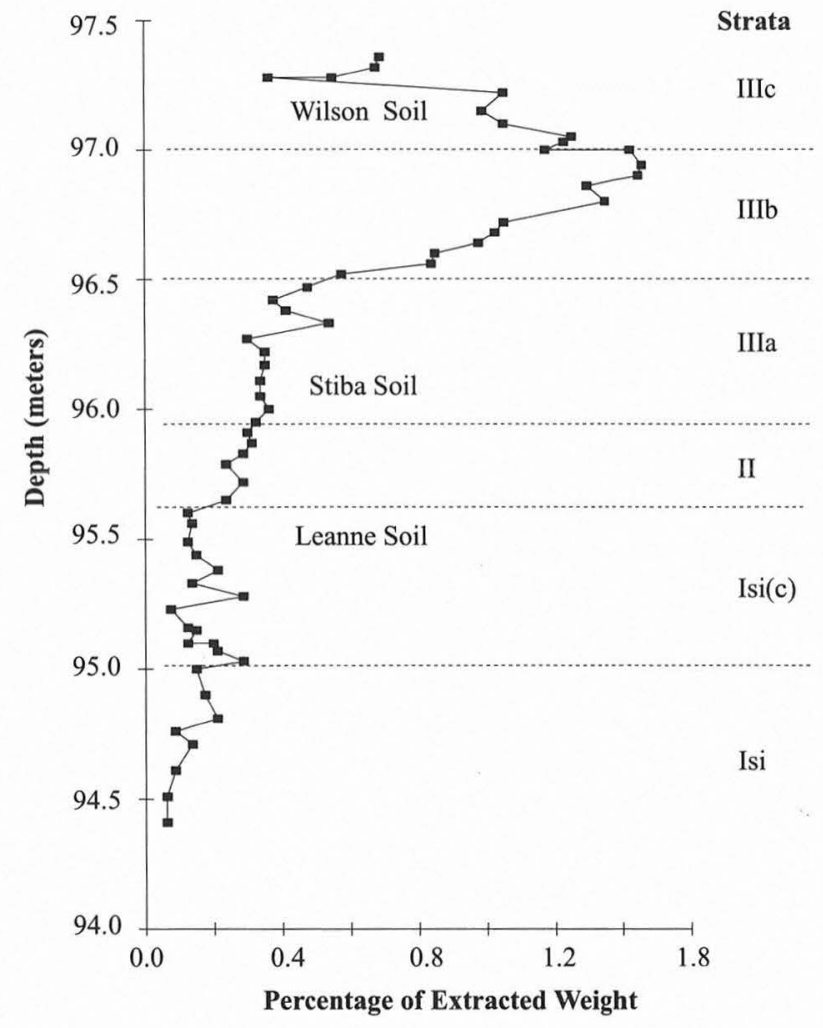

Figure 41-1. Percent weight of extracted phytoliths by depth. Percentages are based on the unadjusted weights of the recovered phytolith fraction (specific gravity less than 2.35) and air-dried weights of sediment subsample processed.

However, the peak in recovery at the IIIb/IIIc boundary and the lower percentages above (Unit IIIc) are probably not related to changes in preservation. These fluctuations in phytolith content are probably a reflection of both changing phytolith production and surface stability. Because of the inequality of phytolith production in grasslands and in woodlands, increases in production should be related to increases in grassland cover. The question of surface stability is addressed by the soils and geomorphic studies. Note that much of the modern surface soil was absent from this profile and therefore the increase in phytolith content typical of surface soils is missing.

Progressive decay with depth (or time) is also apparent in the visual ratings of phytolith preservation (see Table 41-4). Preservation was judged to be "excellent" throughout Unit IIIc, and "good" throughout most of IIIb. Preservation continued to decline throughout Unit IIIa and II but remained "adequate" down to the middle of Unit Isi-c. Phytoliths were present but very poorly preserved below this level, and complete quantitative results are therefore unobtainable. Because of poor preservation, the lower column of samples collected from excavation Square 55 was not analyzed beyond a few exploratory samples
(WL62 and WL73). Poor preservation also characterized the samples from the lowermost unit (Igl).

\section{The Woodland-Grassland Ratio}

The woodland-grassland ratio was constructed to assess relative change in the balance between woodlands and grasslands (see Table 41-4). Although this ratio had high intersample variability, a line chart using a simple, 3 -sample running average reduces the individual sample variation and exhibits significant temoral zonation (Figure 41-2). The data are interpreted as indicating the dominance of local woodland vegetation during the deposition of the lower stratum (Unit Isi). This interpretation of the lower portion of the profile, however, comes with a caveat. Woodland-grassland ratio values in the lower portion of the profile may be affected by differential preservation and observed change in values could be an artifact of changing preservation. This alternative interpretation is based on the assumption that large, block phytolith forms will persist while smaller grass short-cell forms will be more quickly dissolved. (Little is currently known about the taphonomy and dissolution of phytoliths, and it is possible that grass phytoliths are more susceptible to dissolution than are some large arboreal forms.) I assume that the observed change is not caused by differential preservation but reflects a real change in the balance between grassland and woodlands.

The general change in the woodland-grassland ratio shows a general grassland expansion throughout most of

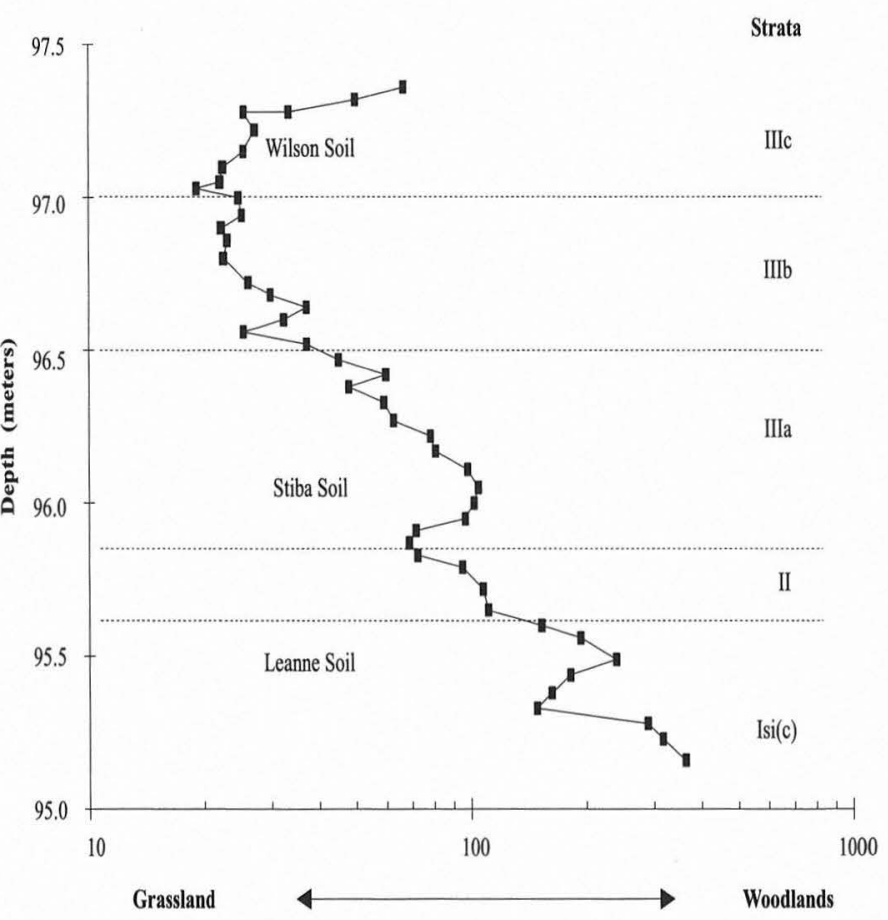

FIGURE 41-2. Woodland-grassland ratio by depth. This ratio is the large arboreal phytolith count divided by the total grass short-cell count times 100 . Note log scale used for ratio. 
the Holocene (Unit Isi-c through Unit IIIb). This expansion began during the early Holocene (ca. 9500 B.P.) and continued into the mid Holocene (ca. 4000 в.P.). The woodlandgrassland ratio signal also suggests that there was a significant increase in the rate of grassland expansion around 8700 B.P. (the upper portion of Unit II). The signal reaches its minimum in the mid to late Holocene (Units IIIb and IIIc, ca. 6000 to 2000 в.P.). Values in this portion of the record fall within the range obtained in the analysis of modern openwoodland samples. There is also a strong suggestion of the re-expansion of woodlands during the late Holocene (upper portion of Unit IIIc, after 2000 B.P.).

\section{Distinctive Nongraminoid Phytolith Forms}

The occurrence of distinctive arboreal and other diagnostic forms provides additional evidence for local woodland vegetation composition (Table 41-5). Forms are grouped into five anatomical categories: polylateral or polyhedral epidermal and mesophyll forms (Figure 41-3a and b), forms associated with epidermal hair forms (Figure 41-3c), silicified trachiary elements (Figure 41-3d), unknown diagnostic forms (Figure 41-3e and f), and Palm-like forms (Piperno 1988). The listed and illustrated morphotypes represent only a fraction of the total number of types potentially distinguishable in the Wilson-Leonard assemblages. Further exploration of the phytoliths produced by the flora of Texas is needed to identify these distinctive types. Because these types occur in such low frequencies, they are presented as counts rather than percentages.

One of the most distinctive polyhedral epidermal types observed is the Celtis (hackberry) type (Bozarth 1992). This thick epidermal plate typically has five sides of differing lengths and a distinctly echinate surface (see Figure 413a1). The finely raised points of the plate surface often translate into ridges along the plate sides. At the lower focal plane under higher magnifications (630X), the fine-grained echinate pattern often appears reticulated (see Figure 413a2). These forms appear somewhat more frequently in Units IIIb and IIIc but are present down into Unit II (see Table 41$5)$.

Other types of epidermal and mesophyll forms include distinctive polyhedrals and "puzzle piece" epidermal cells, frequently occurring in articulated epidermal fragments (Bozarth 1992; Geis 1973). Tentative identification of Wilson-Leonard forms include Quercus (oaks), Ulmus (elms), and Fraxinus (ash). No single form appears more frequently in any portion of the profile. The lower counts of this group in deeper samples may also be an artifact of progressive dissolution and destruction with depth.

Silicified epidermal hairs and hair bases comprise the second anatomical group of phytoliths (see Table 41-5). The following four subgroupings are used: silicified hair bases, five-sided plate, silicified hair fragments, other undifferentiated fragments. Piperno (1988) found this anatomical group of phytoliths to be especially useful in identifying individual plant taxa in the neotropical rain forest assemblages. Probable taxa observed at Wilson-Leonard include Ulmus (elm), Maclura (osage orange or bois d'arc), and Celtis (hackberry). Again, there is no pronounced stratigraphic pattern in the occurrence of this group of phytoliths.

Silicified trachiary elements comprise another common component of the Wilson-Leonard assemblage. These solidly silicified vascular elements from woody tissues are generally cylindrical with spiraled exteriors (see Figure 41-3d). Present throughout the profile is one large (up to $120 \mu \mathrm{m}$ long) distinctive subtype with a large triangular cross section ( 8 to $12 \mu \mathrm{m}$ diameter). The distinctiveness and consistency of this subtype suggests that it is produced by a single plant taxon, the identity of which is unknown. The other groups are less consistent and probably related to a number of different taxa. The small, branching forms observed are consistent with those from Artemisia (sage) but are probably produced by any number of forbs (Bozarth 1992).

Several unclassified forms are of special interest because of their distinctiveness. They may represent the exploitation of specific plant resources at the site or merely components of the local vegetation. One of the most unusual is a small ( 12 to $15 \mu \mathrm{m}$ maximum diameter) conical form (see Table 41-5). This type has a convex base and six to eight faces converging on a small concave platform (see Figure 41-3f). These delicate-looking forms appear spongy rather than solidly silicified. A distinct pore or cavity occurs at the base of each of the scalloped faces. This form is most likely a hair-base or seed-coat structure.

A second distinctive morphotype is also probably associated with hair bases or analogous anatomical structure of some specific taxon (see Table 41-5). This elongated, sixor eight-sided, tear-drop-shaped form is typically 15 to $20 \mu \mathrm{m}$ in length (see Figure 41-3e). The base of the form is semihollow and has a dark, spongy-looking texture. The smaller end, when unbroken, supports a number of fine clavate (club-like) structures. The form is often broken in half, but both portions are distinctive and readily distinguished.

A third distinctive but rare form is a very large $(>100 \mu \mathrm{m})$ cylinder with rounded ends (see Table 41-5). No complete examples were found, and its total dimensions and shape remain undefined. The diameter of fragments are typically 15 to 20 microns. This morphotype is solidly silicified and is without cavities or openings. The sides of the cylinder are irregularly faceted or "scalloped" (but not fluted). Its anatomical origin is as uncertain as its taxonomic identification. The structure is likely part of a silicified hair, thorn, or other armored structure. It may also result from silicification of a large vascular cell. It does not appear to be a sponge spicule. This form is rare throughout the profile but observed most frequently in several consecutive samples from Unit II.

The two remaining unknown forms listed separately may also represent silicified vascular tissues (see Table 41-5). 
TABLE 41-5

Occurrence (Counts) of Distinctive Arboreal and Other Diagnostic Morphotypes

\begin{tabular}{|c|c|c|c|c|c|c|c|c|c|c|c|c|c|c|c|}
\hline No. & $\mathrm{A} 1$ & $\mathrm{~A} 2$ & B1 & B2 & B3 & B4 & $\mathrm{C} 1$ & $\mathrm{C} 2$ & C3 & D1 & D2 & D3 & D4 & D5 & $\mathrm{E}$ \\
\hline 57 & 3 & 1 & 2 & 1 & 0 & 0 & 1 & 0 & 1 & 4 & 0 & 0 & 1 & 0 & 0 \\
\hline 56 & 1 & 1 & 2 & 3 & 1 & 0 & 1 & 0 & 1 & 1 & 0 & 0 & 0 & 0 & 0 \\
\hline 55 & 1 & 1 & 0 & 0 & 0 & 0 & 1 & 0 & 0 & 4 & 1 & 1 & 2 & 0 & 0 \\
\hline 54 & 1 & 1 & 1 & 0 & 0 & 0 & 2 & 0 & 1 & 1 & 0 & 0 & 0 & 0 & 0 \\
\hline 53 & 2 & 0 & 4 & 1 & 0 & 0 & 1 & 0 & 0 & 4 & 0 & 0 & 1 & 0 & 0 \\
\hline 52 & 2 & 0 & 1 & 0 & 0 & 0 & 0 & 1 & 0 & 2 & 0 & 1 & 0 & 1 & 0 \\
\hline 51 & 2 & 2 & 3 & 3 & 4 & 0 & 7 & 0 & 4 & 8 & 2 & 0 & 1 & 0 & 0 \\
\hline 50 & 6 & 3 & 3 & 0 & 2 & 0 & 4 & 0 & 0 & 6 & 2 & 0 & 1 & 2 & 0 \\
\hline 49 & 5 & 0 & 2 & 1 & 2 & 0 & 4 & 2 & 1 & 4 & 0 & 0 & 0 & 1 & 0 \\
\hline 48 & 1 & 0 & 3 & 0 & 0 & 0 & 1 & 0 & 0 & 5 & 0 & 0 & 1 & 1 & 0 \\
\hline 47 & 3 & 3 & 1 & 2 & 0 & 0 & 4 & 0 & 1 & 3 & 1 & 0 & 4 & 1 & 0 \\
\hline 46 & 2 & 0 & 2 & 0 & 6 & 0 & 0 & 0 & 0 & 8 & 2 & 0 & 0 & 4 & 0 \\
\hline 45 & 1 & 2 & 1 & 0 & 3 & 0 & 0 & 0 & 0 & 4 & 9 & 0 & 1 & 0 & 0 \\
\hline 44 & 3 & 0 & 1 & 0 & 1 & 0 & 3 & 0 & 0 & 4 & 5 & 0 & 1 & 2 & 0 \\
\hline 43 & 5 & 2 & 1 & 0 & 0 & 0 & 2 & 0 & 0 & 3 & 0 & 0 & 0 & 0 & 0 \\
\hline 42 & 3 & 4 & 3 & 0 & 1 & 0 & 6 & 2 & 5 & 2 & 0 & 0 & 0 & 0 & 0 \\
\hline 41 & 1 & 0 & 7 & 0 & 4 & 1 & 5 & 0 & 2 & 6 & 4 & 0 & 0 & 1 & 0 \\
\hline 40 & 4 & 2 & 1 & 0 & 3 & 0 & 1 & 0 & 1 & 4 & 2 & 0 & 0 & 0 & 0 \\
\hline 39 & 4 & 2 & 2 & 0 & 1 & 0 & 3 & 0 & 1 & 4 & 2 & 0 & 0 & 0 & 0 \\
\hline 38 & 3 & 6 & 5 & 1 & 2 & 1 & 3 & 0 & 0 & 11 & 7 & 0 & 0 & 2 & 0 \\
\hline 37 & 2 & 3 & 3 & 0 & 0 & 2 & 6 & 0 & 0 & 5 & 3 & 1 & 0 & 1 & 0 \\
\hline 36 & 3 & 2 & 2 & 1 & 1 & 0 & 1 & 0 & 0 & 7 & 2 & 0 & 0 & 1 & 0 \\
\hline 35 & 2 & 1 & 2 & 0 & 2 & 0 & 3 & 0 & 0 & 3 & 0 & 0 & 0 & 0 & 0 \\
\hline 34 & 1 & 2 & 3 & 0 & 3 & 2 & 5 & 0 & 1 & 6 & 0 & 0 & 0 & 0 & 0 \\
\hline 33 & 3 & 1 & 3 & 0 & 3 & 1 & 1 & 0 & 0 & 1 & 2 & 0 & 0 & 3 & 0 \\
\hline 32 & 2 & 0 & 2 & 0 & 2 & 0 & 2 & 0 & 0 & 0 & 1 & 0 & 0 & 1 & 0 \\
\hline 31 & 0 & 2 & 3 & 0 & 1 & 0 & 4 & 0 & 0 & 1 & 3 & 0 & 1 & 1 & 0 \\
\hline 30 & 0 & 1 & 4 & 0 & 1 & 1 & 6 & 0 & 1 & 2 & 1 & 0 & 0 & 0 & 0 \\
\hline 29 & 1 & 4 & 2 & 1 & 1 & 0 & 1 & 0 & 0 & 0 & 1 & 0 & 0 & 0 & 0 \\
\hline 28 & 1 & 1 & 2 & 0 & 1 & 0 & 0 & 1 & 1 & 2 & 4 & 0 & 0 & 0 & 1 \\
\hline 27 & 0 & 1 & 0 & 0 & 3 & 0 & 2 & 0 & 1 & 0 & 0 & 0 & 0 & 1 & 1 \\
\hline 26 & 0 & 2 & 2 & 0 & 2 & 0 & 1 & 0 & 2 & 0 & 3 & 0 & 0 & 0 & 0 \\
\hline 25 & 2 & 2 & 1 & 2 & 1 & 2 & 2 & 0 & 0 & 3 & 0 & 0 & 0 & 1 & 0 \\
\hline 24 & 1 & 3 & 1 & 1 & 2 & 0 & 0 & 0 & 1 & 1 & 2 & 0 & 1 & 0 & 0 \\
\hline 23 & 0 & 6 & 5 & 1 & 3 & 1 & 3 & 0 & 3 & 0 & 1 & 2 & 0 & 0 & 1 \\
\hline 22 & 0 & 3 & 2 & 2 & 3 & 0 & 1 & 0 & 0 & 1 & 0 & 1 & 0 & 0 & 0 \\
\hline 21 & 2 & 3 & 1 & 1 & 3 & 0 & 5 & 1 & 1 & 2 & 1 & 0 & 0 & 0 & 0 \\
\hline 20 & 1 & 2 & 1 & 0 & 1 & 1 & 1 & 0 & 1 & 0 & 1 & 1 & 3 & 1 & 0 \\
\hline 19 & 0 & 1 & 0 & 0 & 4 & 0 & 1 & 0 & 1 & 0 & 0 & 0 & 0 & 1 & 2 \\
\hline 18 & 1 & 5 & 2 & 0 & 5 & 3 & 2 & 0 & 1 & 1 & 0 & 0 & 0 & 2 & 1 \\
\hline 17 & 0 & 3 & 3 & 0 & 1 & 0 & 0 & 0 & 0 & 1 & 0 & 1 & 0 & 0 & 0 \\
\hline 16 & 0 & 4 & 1 & 0 & 1 & 0 & 0 & 0 & 0 & 0 & 0 & 0 & 0 & 0 & 0 \\
\hline 15 & 0 & 1 & 1 & 0 & 3 & 2 & 1 & 0 & 1 & 1 & 0 & 0 & 0 & 0 & 0 \\
\hline 14 & 0 & 6 & 1 & 0 & 2 & 0 & 0 & 0 & 0 & 0 & 2 & 1 & 0 & 0 & 3 \\
\hline 13 & 0 & 2 & 0 & 0 & 1 & 0 & 0 & 0 & 0 & 0 & 0 & 1 & 0 & 0 & 1 \\
\hline 12 & 0 & 0 & 0 & 0 & 0 & 0 & 0 & 0 & 0 & 0 & 0 & 0 & 0 & 0 & 0 \\
\hline 11 & 0 & 0 & 1 & 0 & 2 & 1 & 0 & 0 & 0 & 0 & 1 & 0 & 0 & 1 & 0 \\
\hline 10 & 0 & 0 & 0 & 0 & 0 & 0 & 0 & 0 & 0 & 0 & 0 & 0 & 0 & 0 & 0 \\
\hline 06 & 0 & 0 & 0 & 0 & 1 & 0 & 0 & 0 & 0 & 0 & 0 & 0 & 0 & 0 & 0 \\
\hline 03 & 0 & 0 & 0 & 3 & 1 & 0 & 3 & 0 & 0 & 0 & 0 & 0 & 0 & 1 & 3 \\
\hline 00 & 0 & 2 & 0 & 3 & 0 & 0 & 5 & 0 & 3 & 0 & 0 & 0 & 0 & 0 & 0 \\
\hline
\end{tabular}

Key: $A=$ polyhedral epidermis and mesophyll forms: (A1) Celtis-type; (A2) other undifferentiated. $\mathrm{B}=$ Epidermal hairs and hair bases: (B1) silicified hair bases; (B2) five-sided plate; (B3) silicified hair fragments; (B4) other undifferentiated hairs and hari bases. $\mathrm{C}=$ Silicified trachiary elements: $(\mathrm{C} 1)$ large tracheas with triangular cross section; (C2) small branching forms; (C3) other trachea forms general. $\mathrm{D}=$ Unclassified silicified forms: (D1) conical form with 6 to 8 faces and pores; (D2) tear-drop-shaped hair base(?) structure; (D3) very large cylindrical elongate with facited or scalloped sides; (D4) large elongate triangular; (D5) foursided, spirally arranged clavie, along straight cylinder. E = Palm-type. 


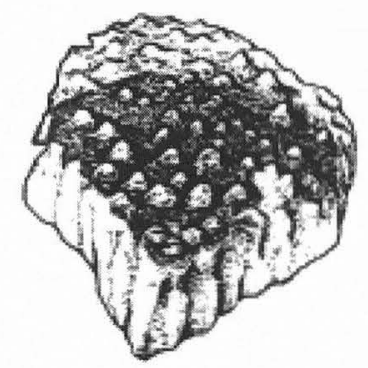

A1

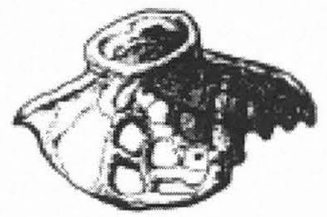

C. -

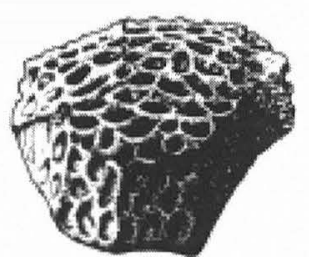

$\mathrm{A}_{2}$

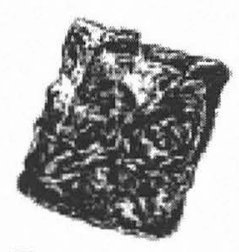

B. -

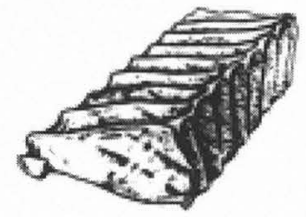

D.

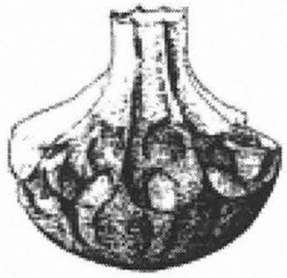

F2.

F1.

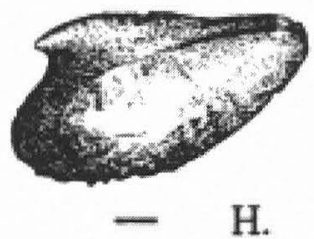

H.

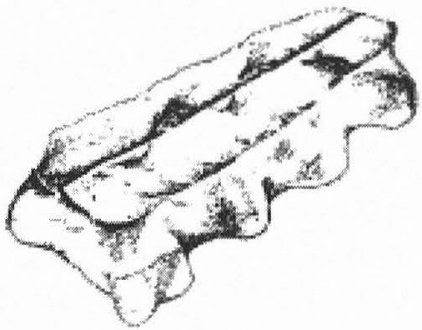

I.
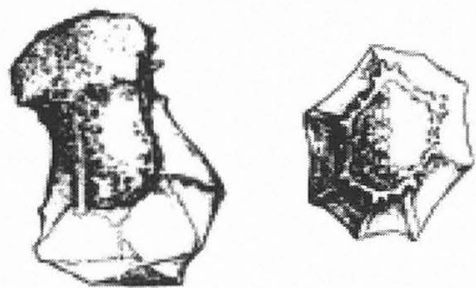

E.

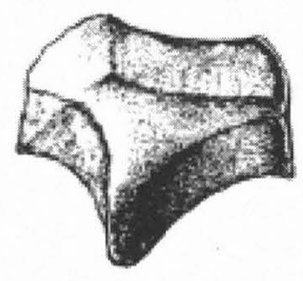

G.

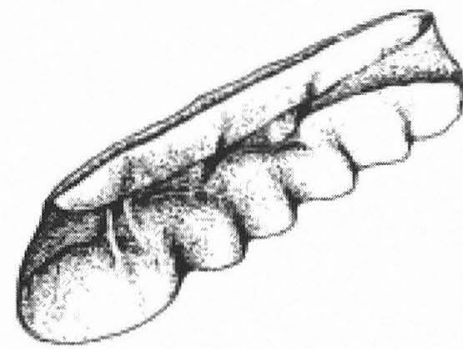

J.

FIGURE 41-3. Diagnostic phytolith forms. (a $)$ Celtis epidermal plate at high focus (WL-50); ( $\mathrm{a}_{2}$ ) Celtis epidermal plate at low focus (WL50); (b) silicified "quadrilateral" epidermal cell (WL-49); (c) unknown silidified hair base (WL-39); (d) large silicified tracheid with triangular cross section (WL-34); (e) unknown tear-drop-shaped form (WL-47); $\left(\mathrm{f}_{1}\right)$ unknown conical forms (WL-50); ( $\mathrm{f}_{2}$ ) unknown conical forms (idealized); (g) bulliform cell (WL-50); (h) common tricome type (WL-49); (i, j) common crenate subtypes (WL-49). 
The first is a smaller ( 18 to $24 \mu \mathrm{m}$ ) elongated form with sharp, triangular cross sections. The other is a four-sided, spirally arranged set of gemi or clave attached to a central straight cylinder. Both forms are solidly silicified. It may not be possible to attribute either of these forms to a single plant taxon.

The final phytolith morphotype listed individually consists of the echinate spheroids typically related to the palms. This heavily silicified, spheroidal, echinate morphotype is readily identifiable (Piperno 1988). This form is also rare throughout the Wilson-Leonard profile but appears to be relatively more common in Units I and II. Again, this appearance of being more common in the lower samples may be an artifact of the differential preservation of this solidly silicified form. As palms are extralocal in the region, its occurrence is problematic at Wilson-Leonard. It is possible, but unlikely, that it represents human import of palm leaves form several hundred miles to the southeast where a single species of palm is native. It is far more likely that this form is either being recycled fossil from older rocks or is a form produced by other, as yet unrecognized plant taxa.

\section{Grass Short-cell Phytolith Assemblages}

Changes in the grass short-cell phytolith assemblages are hypothesized to represent climatically driven changes in the regional grassland composition. Probably due to low (less than 200 count) short-cell sums, the sample-to-sample variability of percentages is higher than typically encountered (Table 41-6). Unusual local vegetation and/or human alteration of local vegetation and plant use may also contribute to the higher than normal variability. A strong regional signal is discernible even through this high variability (Figure 41-4). Although the early Holocene grassland was dominated by cool-weather-adapted $\mathrm{C}_{3}$ grasses (represented by high percentages of conical forms), the grassland composition also included at least some tall and short $\mathrm{C}_{4}$ grasses as represented by the percentages of saddle and lobate types. It is likely that some of these $\mathrm{C}_{4}$ grasses were locally present even during the late Pleistocene. Other $\mathrm{C}_{4}$ grass species may have migrated into the region during the early Holocene.

Changes in grassland composition are evident through Units Isi-c and II. The most important is the rise in relative frequencies of saddle-shaped forms indicative of the short grasses. A complementary decline in percentages of conical, rectangular, and crenate types match this rise. The rate of change is greatest approaching the Unit II/Unit III boundary. Saddle percentages jump from below $30 \%$ to levels over $50 \%$. There is also a smaller, but significant, increase in the lobate forms diagnostic of the $\mathrm{C}_{4}$ tall-grasses at this same boundary. This change represents a major shift in climate toward warmer and drier conditions.

Consistencies among short-cell assemblages suggest that climatic conditions were comparatively stable throughout the deposition of Units IIIIa, IIIJ, and IIIc. Saddle per- centages from this portion of the record fall within the levels obtained in the analysis of the modern Texas soil samples. However, percentages of some other grass short-cell forms are beyond the range documented in the modern soil assemblages from Texas or elsewhere. Specifically, the WilsonLeonard assemblages have significantly higher percentages of crenate forms than observed elsewhere. Crenate percentages decline only slightly through time, and remain greater than 5\% throughout Unit III. This irregularity could be explained either by some local, atypical stream-side or woodland understory grass community or by human behavior. The low variability of the crenate forms present are dominated by two distinctive subtypes (see Figure 41-3). This suggests that only one or two taxa of grass are contributing. The lack of modern analogs for these fossil assemblages makes precise qualitative estimates of climate change problematic.

\section{Other Graminoid Morphotypes}

Graminoid grasses and sedges produce a variety of other distinctive morphotypes in addition to the short-cell forms (Table 41-7). These include elongates, bulliform cells, tricomes, and sedge plates. There are no clear patterns to the occurrence of these grass forms. The frequency of sedge forms is greatest in the upper levels of Unit IIIb. Because sedges are not always wet-site indicators, this zonation does not necessarily indicate increased mesic conditions.

\section{Aquatic Silicate Microfossils}

The occurrence of aquatic, silicate microfossils (diatom, crysophytes, and sponges) was also documented (see Table 41-7). Many of the diatom and crysophyte taxa may be local soil organisms rather than standing-water organisms. Others are probably wind or water deposited along with the freshwater sponge forms. There is no clear pattern to diatom occurrence. Crysophytes show a clear increase in the upper portions of Unit IIIb. The environmental implications of this zonation are unclear at this time. Sponge spicules are relatively more common in the lower samples of Unit II and in Unit I. This may be due either to the increased alluvial deposition and influence in the lower strata, or to the more-mesic regional conditions. It is more likely however, that this increase is a artifact of preservation. Sponge spicules are heavily silicified and therefore more resistant to dissolution.

\section{Analysis of Archeological Feature Samples}

Only 3 of the 13 feature samples analyzed contained significant reasonably well-preserved phytolith assemblages (Table 41-8). As with the primary stratigraphic column, samples from the lower depositional units (Isi) had extremely poor preservation, as did the Paleoindian burial (Burial 2). Most phytolith assemblages from the upper depositional 
TABLE 41-6

Grass Short-cell Phytolith Percentages

\begin{tabular}{|c|c|c|c|c|c|c|c|c|c|c|c|c|c|}
\hline Field No. & Depth & A & B & $\mathrm{C}$ & D & E & $\mathrm{F}$ & G & $\mathrm{H}$ & I & $\mathrm{J}$ & K & Count \\
\hline WL57 & 97.36 & 8.44 & 27.92 & 5.19 & 0.00 & 46.75 & 2.60 & 3.90 & 3.25 & 0.65 & 0.65 & 0.65 & 154 \\
\hline WL56 & 97.32 & 6.25 & 12.50 & 3.65 & 4.69 & 62.50 & 1.04 & 4.17 & 3.65 & 0.52 & 0.52 & 1.04 & 192 \\
\hline WL55 & 97.28 & 11.50 & 23.89 & 3.54 & 4.42 & 48.67 & 1.77 & 1.77 & 2.65 & 0.00 & 0.00 & 1.77 & 113 \\
\hline WL55 & 97.28 & 7.05 & 24.07 & 3.73 & 8.71 & 47.30 & 0.83 & 3.32 & 3.32 & 0.83 & 0.00 & 0.83 & 241 \\
\hline WL54 & 97.22 & 7.77 & 22.80 & 5.70 & 5.18 & 48.19 & 1.04 & 5.18 & 2.07 & 0.00 & 0.00 & 2.07 & 193 \\
\hline WL53 & 97.15 & 6.81 & 21.99 & 5.24 & 5.24 & 52.88 & 1.05 & 2.09 & 3.66 & 0.52 & 0.52 & 0.52 & 191 \\
\hline WL52 & 97.10 & 13.10 & 21.43 & 3.57 & 6.55 & 39.88 & 2.98 & 5.36 & 5.36 & 0.60 & 0.60 & 1.19 & 168 \\
\hline WL51 & 97.05 & 10.48 & 14.76 & 3.33 & 4.76 & 58.57 & 1.90 & 2.86 & 2.86 & 0.00 & 0.95 & 0.48 & 210 \\
\hline WL50 & 97.03 & 7.59 & 18.62 & 3.45 & 10.69 & 45.52 & 1.72 & 3.45 & 5.17 & 2.41 & 1.38 & 1.03 & 290 \\
\hline WL49 & 97.00 & 9.04 & 16.95 & 6.21 & 3.95 & 51.98 & 1.69 & 5.08 & 2.82 & 1.13 & 0.00 & 1.13 & 177 \\
\hline WL49 & 97.00 & 7.02 & 23.25 & 4.82 & 7.02 & 48.68 & 1.75 & 2.19 & 3.95 & 0.88 & 0.00 & 0.44 & 228 \\
\hline WL48 & 96.94 & 8.29 & 17.56 & 2.93 & 5.37 & 56.59 & 1.95 & 3.41 & 1.95 & 0.49 & 0.98 & 1.46 & 205 \\
\hline WL47 & 96.90 & 9.38 & 16.35 & 4.29 & 8.31 & 52.01 & 1.07 & 4.29 & 2.14 & 0.27 & 1.34 & 1.07 & 373 \\
\hline WL46 & 96.86 & 8.30 & 19.62 & 3.02 & 7.55 & 51.70 & 1.51 & 3.77 & 3.40 & 0.38 & 0.75 & 0.38 & 265 \\
\hline WL45 & 96.80 & 13.13 & 21.72 & 2.02 & 9.60 & 43.94 & 2.02 & 3.03 & 3.03 & 0.51 & 1.01 & 0.51 & 198 \\
\hline WL44 & 96.72 & 7.47 & 14.11 & 2.90 & 8.30 & 57.26 & 2.49 & 2.07 & 2.90 & 0.41 & 1.24 & 1.24 & 241 \\
\hline WL43 & 96.68 & 10.05 & 24.12 & 3.52 & 7.04 & 46.23 & 2.01 & 2.51 & 3.52 & 0.00 & 0.50 & 0.50 & 199 \\
\hline WL42 & 96.64 & 14.36 & 22.05 & 4.62 & 8.72 & 35.90 & 4.10 & 4.10 & 5.13 & 0.00 & 0.51 & 1.03 & 195 \\
\hline WL41 & 96.60 & 9.65 & 17.37 & 4.25 & 7.34 & 51.35 & 1.54 & 4.25 & 2.70 & 0.00 & 0.77 & 0.77 & 259 \\
\hline WL40 & 96.56 & 7.14 & 19.23 & 2.75 & 14.84 & 43.41 & 2.75 & 2.20 & 4.40 & 0.55 & 2.20 & 1.10 & 182 \\
\hline WL39 & 96.52 & 14.04 & 19.74 & 2.63 & 7.46 & 46.05 & 1.75 & 3.51 & 3.51 & 0.44 & 1.32 & 0.44 & 228 \\
\hline WL38 & 96.47 & 7.28 & 29.13 & 4.37 & 11.65 & 35.92 & 1.94 & 4.85 & 3.40 & 0.00 & 0.49 & 1.46 & 206 \\
\hline WL37 & 96.42 & 6.77 & 21.35 & 3.13 & 5.73 & 51.04 & 2.08 & 3.65 & 4.17 & 0.52 & 1.04 & 1.04 & 192 \\
\hline WL36 & 96.38 & 6.77 & 19.52 & 4.78 & 6.77 & 51.79 & 1.59 & 2.79 & 3.98 & 0.40 & 0.80 & 1.20 & 251 \\
\hline WL35 & 96.33 & 7.46 & 17.11 & 4.39 & 5.70 & 55.26 & 2.19 & 2.63 & 3.95 & 0.00 & 0.44 & 0.88 & 228 \\
\hline WL34 & 96.27 & 6.25 & 21.48 & 5.86 & 7.81 & 47.27 & 1.17 & 3.13 & 6.25 & 0.00 & 0.39 & 0.78 & 256 \\
\hline WL33 & 96.22 & 9.00 & 26.50 & 4.50 & 10.50 & 39.50 & 2.00 & 3.50 & 3.50 & 0.00 & 0.00 & 1.00 & 200 \\
\hline WL32 & 96.17 & 7.89 & 26.32 & 5.26 & 5.26 & 46.84 & 1.05 & 2.63 & 2.63 & 0.53 & 1.05 & 1.05 & 190 \\
\hline WL31 & 96.11 & 6.47 & 20.90 & 4.98 & 5.97 & 50.75 & 1.49 & 3.98 & 3.98 & 0.50 & 0.00 & 1.00 & 201 \\
\hline WL30 & 96.05 & 7.95 & 29.80 & 7.28 & 7.95 & 39.07 & 1.99 & 1.99 & 2.65 & 0.66 & 0.66 & 0.66 & 151 \\
\hline WL29 & 96.00 & 7.64 & 20.38 & 5.10 & 4.46 & 52.87 & 1.91 & 3.18 & 3.82 & 0.00 & 0.64 & 0.64 & 157 \\
\hline WL28 & 95.95 & 5.3 & 18.94 & 7.58 & 5.30 & 53.79 & 1.52 & 3.79 & 3.0 & 0.00 & 0.76 & 0.76 & 132 \\
\hline WL27 & 95.91 & 10.07 & 33.81 & 5.76 & 7.19 & 32.37 & 2.16 & 2.16 & 3.60 & 0.00 & 1.44 & 2.16 & 139 \\
\hline WL26 & 95.87 & 9.20 & 30.46 & 5.75 & 10.92 & 35.06 & 2.30 & 2.30 & 2.87 & 0.00 & 0.00 & 1.15 & 174 \\
\hline WL25 & 95.83 & 9.85 & 28.03 & 8.33 & 9.09 & 37.88 & 1.52 & 3.03 & 0.7 & 0.00 & 0.00 & 1.52 & 132 \\
\hline WL24 & 95.79 & 7.08 & 45.13 & 10.62 & 7.96 & 23.89 & 1.77 & 0.00 & 0.88 & 0.88 & 0.88 & 1.77 & 113 \\
\hline WL23 & 95.72 & 6.33 & 34.81 & 10.76 & 15.19 & 27.22 & 1.90 & 1.90 & 1.90 & 0.00 & 1.27 & 0.00 & 158 \\
\hline WL22 & 95.65 & 10.68 & 32.04 & 11.65 & 10.68 & 28.16 & 0.97 & 1.94 & 1.9 & 0.00 & 0.97 & 1.94 & 103 \\
\hline WL21 & 95.60 & 12.50 & 31.58 & 7.89 & 5.92 & 33.55 & 2.63 & 4.61 & 0.66 & 0.00 & 0.00 & 0.66 & 152 \\
\hline WL20 & 95.56 & 12.40 & 40.50 & 6.61 & 6.61 & 26.45 & 0.83 & 1.65 & 2.48 & 0.83 & 1.65 & 1.65 & 121 \\
\hline WL19 & 95.49 & & 40.18 & 7.14 & 9.82 & 26.79 & 1.79 & 0.89 & 1.7 & 0.00 & 0.00 & 0.89 & 112 \\
\hline WL18 & 95.44 & 11.40 & 38.60 & 7.89 & 10.53 & 20.18 & 2.63 & 2.63 & 2.63 & 0.88 & 0.88 & 2.63 & 114 \\
\hline WL17 & 95.38 & 9.68 & 29.84 & 5.65 & 9.68 & 36.29 & 3.23 & 2.42 & 3.23 & 0.00 & 0.00 & 0.00 & 124 \\
\hline WL16 & 95.33 & & 36.25 & 11.25 & 7.50 & 30.00 & 0.00 & 2.50 & 1.25 & 0.00 & 0.00 & 1.25 & 80 \\
\hline WL03 & 94.71 & 11.11 & 28.40 & 11.11 & 6.17 & 29.63 & 3.70 & 3.70 & 3.70 & 0.00 & 1.23 & 1.23 & 81 \\
\hline WL00 & 94.41 & 11.25 & 22.50 & 13.75 & 8.75 & 33.75 & 2.50 & 2.50 & 1.25 & 1.25 & 0.00 & 2.50 & 80 \\
\hline WL62 & & 6.78 & 25.42 & 15.25 & 3.39 & 32.20 & 3.39 & 5.08 & 5.08 & 0.00 & 1.69 & 1.69 & 59 \\
\hline
\end{tabular}

Key: $\mathrm{A}=$ keeled; $\mathrm{B}=$ rondel $\mathrm{C}=$ rectangle; $\mathrm{D}=$ crenate; $\mathrm{E}=$ saddles; $\mathrm{F}=$ stipa-type; $\mathrm{G}=$ simple bilobates; $\mathrm{H}=$ panicoid-type; $\underline{\mathrm{I}=\text { cross; } \mathrm{J}=\text { other lobate forms; } \mathrm{K}=\text { irregular short-cell forms. }}$

units (IIIa, b, and c) are interpretable. As expected, the better-preserved samples also tend to be the assemblages with higher percentage of weight extracted (see Table 41-8). The one exception to this is feature sample 181 (Unit IIIa).

Ideally, ethnobotanical inferences based on phytolith assemblage data begin with comparisons to contemporane- ous samples from nonarcheological context (Lawlor 1995). Although we do not have nonarcheological comparitive samples, we can make some comparisons with the statigraphic column that represents the average composition within the site. Thus, any phytolith signal unique to features resulting from specific function or plant use should be revealed. This 


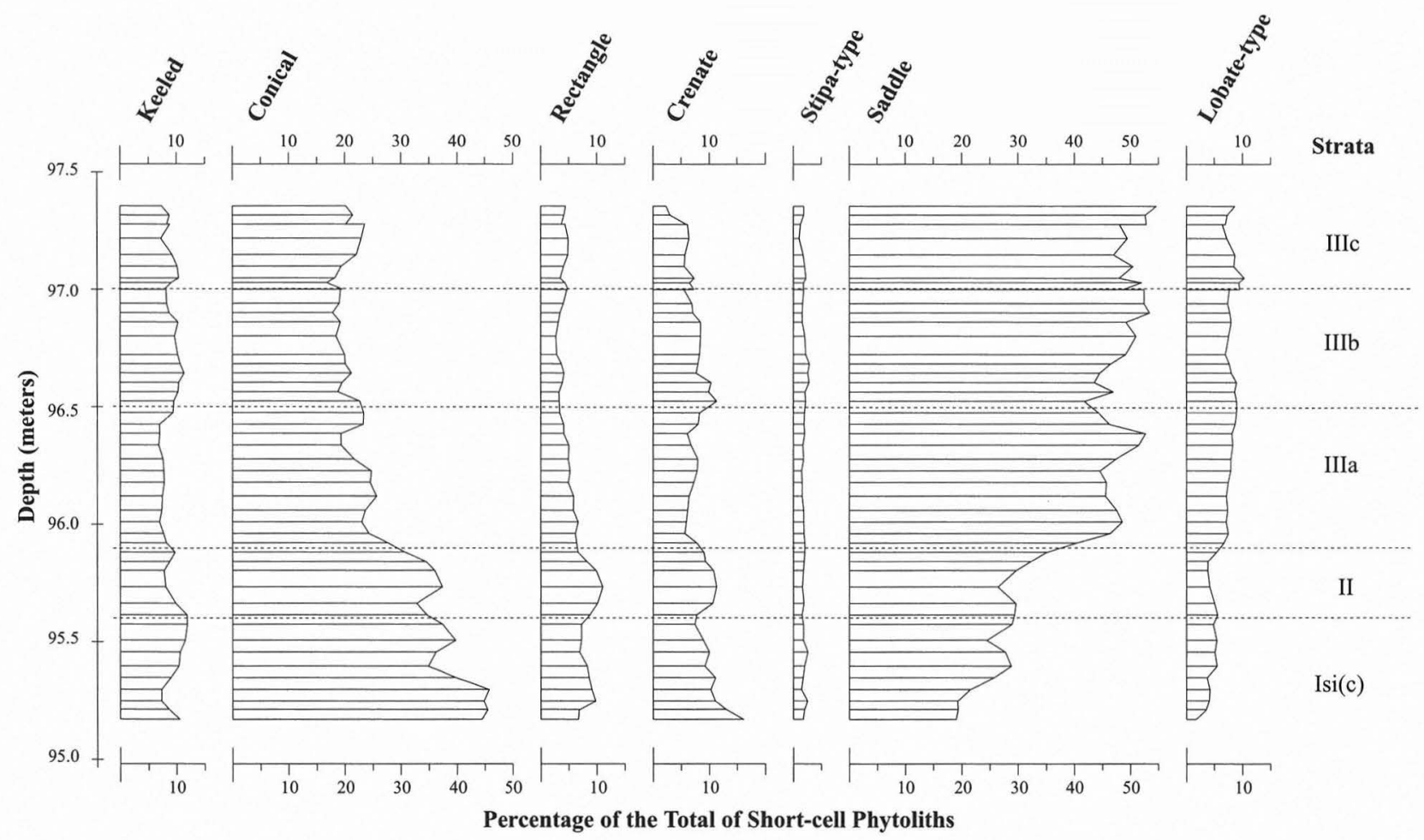

FIGURE 41-4. Grass short-cell phytolith percentages (based on the short-cell sum).

comparison is done subjectively rather than statistically for the current small feature sample.

Grass short-cell assemblages for two of the three feature samples fall within the expected range recognized from the corresponding stratigraphic samples (Table 41-9). Again the exception to this is feature sample 181 (Unit IIIa); the same sample that had relatively low percent extracted weight. This sample has lower than expected percentages of saddle forms and higher than expected conical forms. This short-cell form is not particularly diagnostic, which makes it difficult to infer which grasses are responsible. These differences do suggest that this sample is related to feature function. The next step is the search for consistencies among samples from this and similar features. An examination of nongrass phytolith forms is also important in interpreting feature samples. The nongrass phytolith assemblages did not contain any forms out of the ordinary, nor did the feature samples contain any "ordinary" nongrass forms in unusually high frequencies. Based on these preliminary data, we cannot fully address the problems of feature function or specific plant use associated with archeological features.

\section{CONCLUSIONS}

Phytolith analysis at the Wilson-Leonard site documents regional and local changes in vegetation. In the deepest strata, including the Leanne soil (Unit Isi-c), preservation is at its poorest, and little can be confidently inferred from the surviving assemblages. The earliest assemblages that do survive are primarily from the upper portions of this zone (ca. 10,000 to 9500 B.P.). Composition of these assemblages suggests woodlands were more closed than today. Grass short-cell assemblages recovered from these lower strata indicate that although both tall and short $\mathrm{C}_{4}$ grasses were present, the overall grassland composition was significantly different than any in Texas today. Cooler and more-mesic conditions than present are indicated. Phytolith preservation improves somewhat in the stratum immediately above the Leanne soil (Unit II). The overall assemblage composition is interpreted as woodlands but increasingly more open in structure. The grass phytolith assemblage also shows significant change during this critical period (ca. 9500 to 8700 в.P.). The primary change in grassland composition was the expansion of the xericadapted short grasses, most likely grama grasses (Bouteloua spp.). Within Unit IIIa (ca. 8700 to 6000 B.P.), the grassland composition reached the range observed in modern soil samples from the region. Preservation within this unit and all of those above is good to excellent. The data also suggest that throughout this time, woodlands continued to become more open. The overall vegetation composition reached its modern balance of woodlands and grassland within Unit IIIc (ca. 4000 в.P. to present). The overall composition of these assemblages is very similar to modern leaf-litter assemblages from Central Texas woodlands today. Identifiable arboreal taxa include oaks, elms, and hackberry. This unit also represents the maximum 
TABLE $41-7$

Other Graminoid Phytolith Forms and Aquatic-type Microfossils

\begin{tabular}{|c|c|c|c|c|c|c|c|c|}
\hline \multirow[b]{2}{*}{ No. } & \multicolumn{5}{|c|}{ Other Graminoid Forms } & \multicolumn{3}{|c|}{ Aquatic Silicate Microfossils } \\
\hline & Elongates & $\begin{array}{l}\text { Bulliform } \\
\text { Cells }\end{array}$ & Tricomes & $\begin{array}{c}\text { Other Graminoid } \\
\text { Types }\end{array}$ & $\begin{array}{l}\text { Sedge Plates } \\
\text { and Tricomes }\end{array}$ & Diatom & Crysophyte & Sponge \\
\hline 57 & 9 & 3 & 4 & 0 & 0 & 0 & 1 & 1 \\
\hline 56 & 14 & 2 & 3 & 0 & 1 & 1 & 0 & 3 \\
\hline 55 & 31 & 2 & 8 & 0 & 1 & 0 & 1 & 0 \\
\hline 54 & 19 & 3 & 3 & 0 & 0 & 0 & 1 & 0 \\
\hline 53 & 16 & 2 & 2 & 0 & 0 & 0 & 2 & 0 \\
\hline 52 & 31 & 6 & 5 & 1 & 2 & 1 & 6 & 1 \\
\hline 51 & 26 & 3 & 7 & 0 & 3 & 1 & 18 & 2 \\
\hline 50 & 20 & 4 & 9 & 1 & 1 & 2 & 7 & 0 \\
\hline 49 & 35 & 2 & 8 & 0 & 4 & 4 & 12 & 1 \\
\hline 48 & 19 & 3 & 3 & 0 & 0 & 1 & 28 & 0 \\
\hline 47 & 24 & 3 & 3 & 0 & 4 & 9 & 26 & 1 \\
\hline 46 & 23 & 4 & 5 & 0 & 4 & 2 & 20 & 0 \\
\hline 45 & 18 & 3 & 3 & 0 & 1 & 0 & 8 & 0 \\
\hline 44 & 29 & 2 & 8 & 0 & 1 & 4 & 10 & 0 \\
\hline 43 & 27 & 4 & 2 & 0 & 1 & 0 & 2 & 0 \\
\hline 42 & 42 & 2 & 5 & 0 & 1 & 6 & 2 & 0 \\
\hline 41 & 18 & 2 & 1 & 0 & 1 & 0 & 7 & 0 \\
\hline 40 & 20 & 4 & 5 & 0 & 0 & 3 & 2 & 0 \\
\hline 39 & 13 & 1 & 3 & 0 & 0 & 4 & 3 & 1 \\
\hline 38 & 27 & 4 & 6 & 0 & 1 & 0 & 3 & 0 \\
\hline 37 & 17 & 5 & 6 & 1 & 0 & 0 & 3 & 1 \\
\hline 36 & 25 & 6 & 7 & 0 & 0 & 0 & 5 & 0 \\
\hline 35 & 12 & 3 & 4 & 0 & 0 & 5 & 12 & 1 \\
\hline 34 & 33 & 5 & 5 & 0 & 0 & 0 & 5 & 0 \\
\hline 33 & 36 & 13 & 5 & 1 & 4 & 2 & 9 & 0 \\
\hline 32 & 30 & 4 & 4 & 0 & 4 & 2 & 3 & 1 \\
\hline 31 & 32 & 7 & 7 & 0 & 0 & 0 & 2 & 2 \\
\hline 30 & 23 & 8 & 9 & 0 & 1 & 0 & 0 & 0 \\
\hline 29 & 42 & 6 & 5 & 1 & 1 & 0 & 3 & 2 \\
\hline 28 & 27 & 7 & 4 & 0 & 0 & 0 & 0 & 0 \\
\hline 27 & 15 & 6 & 4 & 1 & 0 & 2 & 1 & 0 \\
\hline 26 & 39 & 4 & 5 & 0 & 0 & 1 & 0 & 4 \\
\hline 25 & 37 & 4 & 6 & 0 & 1 & 0 & 2 & 2 \\
\hline 24 & 30 & 10 & 8 & 1 & 0 & 0 & 2 & 3 \\
\hline 23 & 70 & 4 & 8 & 0 & 3 & 2 & 1 & 1 \\
\hline 22 & 36 & 3 & 3 & 0 & 1 & 2 & 1 & 1 \\
\hline 21 & 29 & 3 & 7 & 0 & 0 & 0 & 5 & 0 \\
\hline 20 & 39 & 9 & 9 & 0 & 0 & 3 & 3 & 7 \\
\hline 19 & 37 & 5 & 7 & 0 & 0 & 1 & 2 & 3 \\
\hline 18 & 58 & 5 & 5 & 0 & 0 & 0 & 2 & 3 \\
\hline 17 & 16 & 4 & 4 & 0 & 1 & 0 & 1 & 1 \\
\hline 16 & 43 & 3 & 4 & 0 & 1 & 1 & 0 & 0 \\
\hline 15 & 32 & 4 & 3 & 0 & 0 & 1 & 1 & 6 \\
\hline 14 & 12 & 8 & 7 & 0 & 0 & 0 & 1 & 2 \\
\hline 13 & 18 & 4 & 5 & 0 & 0 & 1 & 0 & 0 \\
\hline 12 & 8 & 0 & 0 & 0 & 0 & 0 & 0 & 0 \\
\hline 11 & 16 & 2 & 1 & 0 & 0 & 0 & 0 & 1 \\
\hline 10 & 3 & 0 & 0 & 0 & 0 & 0 & 0 & 0 \\
\hline 06 & 30 & 0 & 2 & 0 & 0 & 1 & 3 & 1 \\
\hline 03 & 36 & 2 & 4 & 0 & 0 & 2 & 4 & 0 \\
\hline 00 & 18 & 1 & 3 & 0 & 0 & 0 & 3 & 0 \\
\hline
\end{tabular}


TABLE $41-8$

Phytolith Recovery and Preservation in Feature Samples

\begin{tabular}{|c|c|c|c|c|c|c|}
\hline Lab No. & Field No. & Feature No. & $\begin{array}{c}\text { Stratigraphic } \\
\text { Unit }\end{array}$ & Preservation & $\begin{array}{l}\% \text { Weight } \\
\text { Extracted }\end{array}$ & $\begin{array}{c}\text { Woodland/Grassland } \\
\text { Ratio }\end{array}$ \\
\hline 94090801 & 7 & 168 & Isi & Poor & 0.06 & $\mathrm{n} / \mathrm{a}$ \\
\hline 94090802 & 9 & 169 & Isi & Absent & 0.05 & $\mathrm{n} / \mathrm{a}$ \\
\hline 94090803 & 14 & 181 & IIIa & Useable & 0.11 & 108.19 \\
\hline 94090804 & 22 & Burial 2 & Isi & Poor & 0.06 & $\mathrm{n} / \mathrm{a}$ \\
\hline 94090805 & 23 & Burial 2 & Isi & Absent & 0.10 & $\mathrm{n} / \mathrm{a}$ \\
\hline 94090806 & 28 & Burial 2 & Isi & Absent & 0.05 & $\mathrm{n} / \mathrm{a}$ \\
\hline 94090807 & 29 & Burial 2 & Isi & Absent & 0.04 & $\mathrm{n} / \mathrm{a}$ \\
\hline 94090808 & 31 & Burial 2 & Isi & Absent & 0.05 & $\mathrm{n} / \mathrm{a}$ \\
\hline 94090809 & 33 & 204 & IIIb & Good & 0.93 & 16.24 \\
\hline 94090810 & 47 & 236 & IIIb & Absent & 0.08 & $\mathrm{n} / \mathrm{a}$ \\
\hline 94090811 & 49 & 245 & IIIa & Useable & 0.90 & 173.08 \\
\hline 94090812 & 52 & 252 & Isi & Absent & 0.06 & $\mathrm{n} / \mathrm{a}$ \\
\hline 94090813 & 53 & 255 & Isi & Poor & 0.17 & $\mathrm{n} / \mathrm{a}$ \\
\hline
\end{tabular}

TABLE 4-9

Grass Short-cell Percentages in the Feature Samples

\begin{tabular}{c|c|c|c|c|c|c|c|c|c|c|c}
\hline Lab No. & $\begin{array}{c}\text { Feature } \\
\text { No. }\end{array}$ & Keeled & Conical & Rectangle & Crenate & Saddles & Stipa-type & $\begin{array}{c}\text { Simple } \\
\text { Bilobates }\end{array}$ & $\begin{array}{c}\text { Other } \\
\text { Panicoid-type }\end{array}$ & $\begin{array}{c}\text { Lobates* } \\
\text { Total }\end{array}$ \\
\hline 94090803 & 181 & 11.86 & 32.20 & 5.08 & 8.47 & 36.44 & 1.69 & 2.54 & 1.69 & 0.00 & 171 \\
94090809 & 204 & 6.60 & 14.72 & 2.54 & 4.06 & 58.88 & 3.55 & 7.61 & 1.02 & 0.51 \\
94090811 & 245 & 15.09 & 18.87 & 5.66 & 1.89 & 50.94 & 1.89 & 3.77 & 1.89 & 0.00 & 53 \\
\hline \hline
\end{tabular}

phytolith concentration as measured by percent weight recovered. Curiously, there is no corresponding change in the grass short-cell assemblage. This suggests that the high phytolith content may not be solely attributable to increased production associated with grassland but may to some extent reflect increased surface stability. Although grass composition continued to remain steady in the upper strata (Unit IIIc), the balance between woodland and grassland appears to reverse its former trend. The record suggests local conditions became less open during this late Holocene period (post-2000 в.P.).

This record of vegetation and climatic change, as inferred from the Wilson-Leonard phytolith record, corroborates with other records of Holocene vegetation and climate change in Texas (Bousman 1994; Humphrey and Ferring 1994; Nordt et al. 1994; Robinson 1982 [summarized in Piperno 1988:184-187]). The degree of regional agreement among independent records suggests that climate is the primary factor driving vegetation change. As has been rightly pointed out by Humphrey and Ferring (1994), the observed changes in vegetation may also be affected through changes in the regional fire regime. Both climatic and anthropogenic ignition contribute to the regional fire regime and the relative importance of these factors remains debatable. Changes in the fire regime, whatever its cause, may be especially important in affecting the woodland-grassland balance.

The close correlation of the Wilson-Leonard record with other independent records from the region also validates the use of phytolith methods for paleoenvironmental reconstruction. These other records affirm and provide confidence to this immature method. This is especially important in this instance which is hampered by poor preservation. The results suggest that future investments in phytolith analysis for the Texas region are warranted. This effort should include systematic investigation of phytolith production and identification and an expanded analysis of modern assemblages. With these additional data, it will be possible to infer even more from the Wilson-Leonard record. 
"This page intentionally left blank" 


\section{Chapter 42}

\section{STABLE CARBON ISOTOPE ANALYSIS OF SOIL ORGANIC MATTER}

by Glen Fredlund and Larry L. Tieszen

\section{OBJECTIVES}

Recent applications of stable carbon isotopic methods to Texas paleoenvironments have been encouraging (Humphrey and Ferring 1994; Nordt et al. 1994). Broad changes in Holocene vegetation and climate inferred from these records are supported by independent data sets (Bousman 1994; Bryant and Holloway 1985; Collins 1995:Table 2; Robinson 1982 [summarized in Piperno 1988:184187]). Further corroboration was provided by the results of the phytolith record from the Wilson-Leonard site (see Chapter 41). Although there are some significant differences among these regional paleoenvironmental chronologies, overall there appears to be a movement toward a regional consensus (e.g., Bousman 1994; Nordt et al. 1994).

We hypothesized that stable carbon isotopic analysis of soil organic matter (SOM) from the Wilson-Leonard site should corroborate both the local phytolith record from the site and the emerging regional Holocene sequence. Given the chronology of the sediments, the Wilson-Leonard isotopic record was expected to display at least four distinctive features: (1) late Pleistocene-early Holocene (Units Isi and Isi-c) $\mathrm{C}_{3}$-dominated signal from woodlands; (2) a strong shift from woodlands toward warm-weather $\left(\mathrm{C}_{4}\right)$ grasslands centered around 8000 B.P. (Unit IIIa); (3) a strongly $\mathrm{C}_{4}$ mid-Holocene thermal maximum (ca. 7000 to 3000 B.P., Unit IIIb); and (4) a re-expansion of woodlands, with minor fluctuations after 3000 в.P. (Unit IIIc).

\section{METHODS}

A six-sample stratigraphic column originally collected for phytolith analysis was used for the isotopic analysis. Initial processing of subsamples was performed at the University of Wisconsin Milwaukee, Soils and Physical Geography Laboratory. Isotopic analysis of the materials was done at the mass spectrometry laboratory at the Department of
Biology, Augustana College, Sioux Falls, South Dakota. Samples were sieved to remove gravel and other large materials before being hand ground with mortar and pestle. Protocol included processing of seven replicate subsamples (Table 42-1).

A homogeneous portion of each subsample was decarbonated with $1.0 \mathrm{~N} \mathrm{HCl}$ and continuous stirring (up to 48 hours) until no effervescence under vacuum was detected. The treated sample was centrifuged at $12,000 \mathrm{x}$ gravity, resuspended in distilled water, and centrifuged. The resulting pellet of material was dried, pulverized, and loaded into tin cups for combustion under pure oxygen and at high temperatures in the Carlo Erba CHN analyzer. Samples were of variable sizes to provide adequate carbon for isotopic analysis. The combusted sample was separated into $\mathrm{CO}_{2}$ and $\mathrm{N}_{2}$ gases and quantified with a gas chromatographic column. These provided concentrations of $\mathrm{C}$ and $\mathrm{N}$ for $\mathrm{C}: \mathrm{N}$ calculations and elemental composition.

The combustion products were passed through a drying column, and $\mathrm{CO}_{2}$ was trapped at liquid nitrogen temperature in the triple trap of a VG SIRA-10 Isotope Ratio Mass Spectrometer (IRMS). Remaining gases were removed under high vacuum, and the $\mathrm{CO}_{2}$ was analyzed by the IRMS (Tieszen and Fagre 1993a). The isotope ratio is presented as the $\delta^{13} \mathrm{C}$ values where:

$$
\delta^{13} \mathbf{C}(\%)=\left(\left(\mathbf{R}_{\mathrm{s}}-\mathbf{R}_{\mathrm{p}}\right) / \mathbf{R}_{\mathrm{p}}\right) \times 1000
$$

$$
\begin{aligned}
& \mathrm{R}_{\mathrm{s}}=\text { ratio of }{ }^{13} \mathrm{C} \text { in the sample } \\
& \mathrm{R}_{\mathrm{p}}=\text { ratio of }{ }^{13} \mathrm{C} \text { in the standard }
\end{aligned}
$$

\section{RESULTS AND INTERPRETATION}

This ratio diagnostically distinguishes between $\mathrm{C}_{3}$ and $\mathrm{C}_{4}$ species with mean values in native prairie species in North America of $-26.7 \%$ for $\mathrm{C}_{3}$ species and $-12.6 \%$ for $\mathrm{C}_{4}$ species (Tieszen 1994). This ratio effectively serves as a label for the 
TABLE 42-1

Isotopic Data for the Wilson-Leonard Stratigraphic Column

\begin{tabular}{|c|c|c|c|c|c|c|c|c|c|c|c|c|c|}
\hline Unit & Field No. & Depth & $\% \mathrm{~N}$ & $\% \mathrm{C}$ & C:N & $\delta^{13} \mathrm{C}$ & Unit & Field No. & Depth & $\% \mathrm{~N}$ & $\% \mathrm{C}$ & C:N & $\delta^{13} \mathrm{C}$ \\
\hline IIIC & WL57 & 97.36 & 0.35 & 5.07 & 14.48 & -22.66 & IIIIa & WL27 & 95.91 & 0.06 & 1.00 & 16.34 & -23.41 \\
\hline IIIC & WL56 & 97.32 & 0.37 & 5.38 & 14.62 & -22.75 & IIIa & WL26 & 95.87 & 0.05 & 0.90 & 16.57 & $\begin{array}{l}-23.55 \\
-23.54\end{array}$ \\
\hline IIIC & WL55 & 97.28 & 0.34 & 5.42 & 15.87 & $\begin{array}{l}-23.05 \\
-23.03\end{array}$ & II & WL25 & 95.83 & 0.07 & 1.12 & 15.64 & -23.56 \\
\hline IIIIc & WL54 & 97.22 & 0.27 & 4.38 & 15.97 & -22.86 & II & WL24 & 95.79 & 0.07 & 1.00 & 15.00 & -23.63 \\
\hline IIII & WL53 & 97.15 & 0.25 & 4.05 & 16.34 & -22.69 & II & WL23 & 95.72 & 0.06 & 0.82 & 14.63 & -23.49 \\
\hline IIIc & WL52 & 97.10 & 0.20 & 3.47 & 16.93 & -22.50 & II & WL22 & 95.65 & 0.07 & 0.96 & 13.53 & $\begin{array}{l}-23.45 \\
-23.46\end{array}$ \\
\hline IIIIc & WL51 & 97.05 & 0.19 & 3.23 & 17.13 & -22.53 & II & WL21 & 95.60 & 0.07 & 0.91 & 12.76 & -23.36 \\
\hline IIIc & WL50 & 97.03 & 0.19 & 3.07 & 15.95 & -22.63 & Isi-c & WL20 & 95.56 & 0.07 & 0.85 & 12.22 & -23.43 \\
\hline IIIIc & WL49 & 97.00 & 0.19 & 3.06 & 16.09 & -23.16 & Isi-c & WL19 & 95.49 & 0.07 & 0.80 & 11.84 & -23.47 \\
\hline IIIC & WL48 & 96.94 & 0.14 & 2.33 & 16.36 & -22.84 & Isi-c & WL18 & 95.44 & 0.07 & 0.77 & 11.70 & -23.36 \\
\hline IIIc & WL47 & 96.90 & 0.16 & 2.56 & 15.81 & -22.86 & Isi-c & WL17 & 95.38 & 0.08 & 0.90 & 11.77 & -23.37 \\
\hline IIIc & WL46 & 96.86 & 0.15 & 2.41 & 16.51 & $\begin{array}{l}-22.92 \\
-22.92\end{array}$ & Isi-c & WL16 & 95.33 & 0.08 & 0.91 & 11.45 & -23.42 \\
\hline IIIlb & WL45 & 96.80 & 0.13 & 2.42 & 18.15 & -23.05 & Isi-c & WL15 & 95.28 & 0.08 & 0.85 & 10.94 & -23.35 \\
\hline IIIlb & WL44 & 96.72 & 0.12 & 2.17 & 17.40 & -23.11 & Isi-c & WL14 & 95.23 & 0.06 & 0.81 & 12.60 & -23.35 \\
\hline IIIlb & WL43 & 96.68 & 0.12 & 2.12 & 18.22 & -23.20 & Isi & WL13 & 95.16 & 0.06 & 0.81 & 12.45 & -23.29 \\
\hline IIIlb & WL42 & 96.64 & 0.09 & 1.69 & 18.11 & -23.09 & Isi & WL11 & 95.15 & 0.07 & 0.90 & 12.39 & -23.40 \\
\hline IIIlb & WL41 & 96.60 & 0.08 & 1.62 & 19.08 & -23.08 & Isi & WL12 & 95.10 & 0.06 & 0.74 & 12.17 & -23.11 \\
\hline IIIIb & WL40 & 96.56 & 0.10 & 1.76 & 18.50 & -23.19 & Isi & WL10 & 95.10 & 0.06 & 0.82 & 13.11 & -23.20 \\
\hline IIIb & WL39 & 96.52 & 0.08 & 1.29 & 17.16 & -23.09 & Isi & WL09 & 95.07 & 0.06 & 0.74 & 12.24 & -23.09 \\
\hline IIIc & WL38 & 96.47 & 0.07 & 1.25 & 17.97 & -23.19 & Isi & WL08 & 95.03 & 0.07 & 0.75 & 10.82 & -23.08 \\
\hline IIIc & WL37 & 96.42 & 0.09 & 1.49 & 17.10 & -23.25 & Isi & WL07 & 95.00 & 0.08 & 0.84 & 10.10 & -22.99 \\
\hline IIIIc & WL36 & 96.38 & 0.07 & 1.27 & 17.75 & -23.26 & Isi & WL06 & 94.90 & 0.06 & 0.63 & 10.13 & $\begin{array}{l}-22.98 \\
-22.99\end{array}$ \\
\hline IIIC & WL35 & 96.33 & 0.09 & 1.64 & 17.55 & -23.33 & Isi & WL05 & 94.81 & 0.05 & 0.47 & 10.16 & -22.87 \\
\hline IIII & WL34 & 96.27 & 0.09 & 1.45 & 16.58 & -23.29 & Isi & WL04 & 94.76 & 0.04 & 0.47 & 10.69 & $\begin{array}{l}-23.11 \\
-23.04\end{array}$ \\
\hline IIIc & WL33 & 96.22 & 0.07 & 1.26 & 17.17 & -23.27 & Isi & WL03 & 94.71 & 0.05 & 0.50 & 10.21 & -23.06 \\
\hline IIII & WL32 & 96.17 & 0.07 & 1.14 & 17.25 & $\begin{array}{l}-23.24 \\
-23.21\end{array}$ & Isi & WL02 & 94.61 & 0.03 & 0.35 & 10.14 & -22.89 \\
\hline IIIC & L31 & 96.11 & 0.07 & 1.13 & 16.49 & -23.21 & Isi & WL01 & 94.51 & 0.04 & 0.38 & 9.83 & -22.79 \\
\hline IIIC & WL30 & 96.05 & 0.07 & 1.16 & 16.36 & -23.32 & Isi & WL00 & 94.41 & 0.03 & 0.34 & 10.41 & -22.71 \\
\hline IIIIc & WL29 & 96.00 & 0.07 & 1.21 & 16.77 & -23.33 & Isi & WL62 & & 0.04 & 0.68 & 18.57 & -22.27 \\
\hline IIII & WL28 & 95.95 & 0.06 & 1.00 & 16.59 & -23.32 & Ig1 & WL73 & & 0.03 & 0.42 & 14.48 & -23.26 \\
\hline
\end{tabular}

Note: Primary (first) value used in analysis. Second value is replicate subsample.

SOM (Wedin et al. 1995) which accumulates in soil thereby allowing a reconstruction of past vegetation assemblages (Tieszen and Archer 1990; von Fischer and Tieszen 1995).

All soil samples possessed large amounts of carbonate which was released by treatment with $\mathrm{HCl}$. The $\mathrm{C}$ and $\mathrm{N}$ elemental determinations and the isotopic values showed very consistent patterns with depth (Figure 42-1). The upper samples of Unit IIIc possessed $\mathrm{C}$ and $\mathrm{N}$ values slightly reduced from those a few decimeters below, but the values then decreased progressively with depth to be the lowest in the oldest unit (Unit Isi). There are no corresponding peaks in $\mathrm{C}$ or $\mathrm{N}$ concentration associated with the Stiba or Leanne paleosols. The gradual decay with depth and the lack of expression associated with paleosol horizons suggest that contemporary pedogenic processes have historically and are continuing to strongly affect the profile.

The reduction in $\mathrm{C}$ and $\mathrm{N}$ concentrations, however, are not proportional with depth. The result is a $\mathrm{C}: \mathrm{N}$ ratio that shows substantial dynamics through the profile. The highest values, around 18 in Unit IIIb, are higher than those that typically characterize modern grassland soils. Ecosystems, including woodlands, with higher lignin concentrations or 


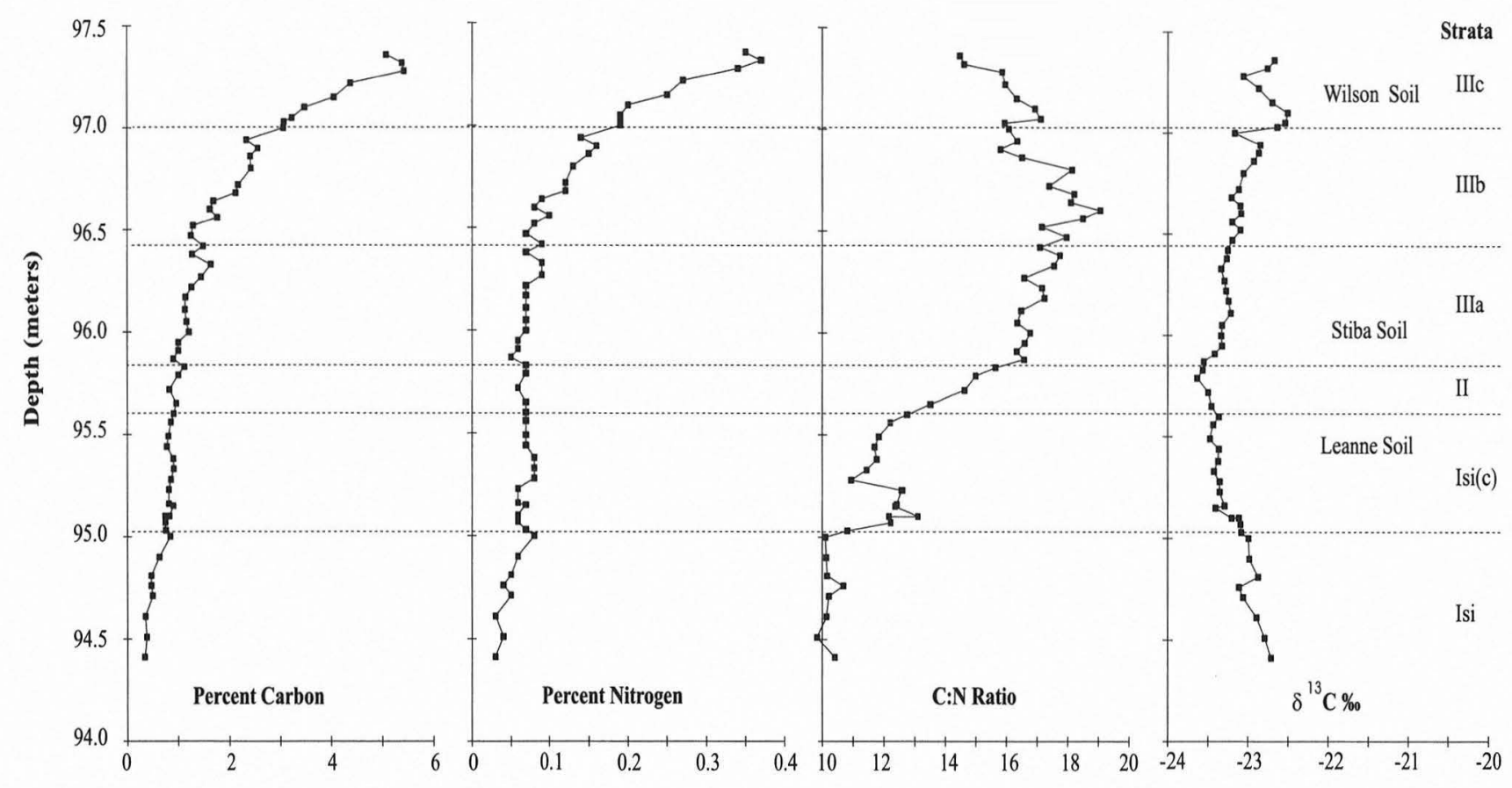

FIGURE 42-1. Stable carbon isotope analysis.

more recalcitrant carbon might possess higher ratios than those found in grassland where the $\mathrm{C}: \mathrm{N}$ equilibrium value in recalcitrant carbon is often between 9 and 12 . There are also some abrupt transitions in the $\mathrm{C}: \mathrm{N}$ ratio associated with the stratigraphic boundaries. The strongest of these is the shift from low values just above 10 to a peak of greater than 13 at the upper boundary of Unit Isi. Although this zonation is probably related to the paleosol, its environmental significance remains unclear.

The carbon isotope ratios are quite interesting but somewhat problematic. Because the modern surface was partially truncated by previous road construction, the record lacks a complete modern baseline for comparisons. The average $\mathrm{d}^{13} \mathrm{C}$ value for Blackland Prairie SOM in Texas is around $-14.4 \%$ (Tieszen, unpublished). Although the range of $\mathrm{d}^{13} \mathrm{C} \mathrm{SOM}$ values for modern Texas oak-juniper woodlands is unknown, it should be substantially more negative (ca. $-18 \%$ to $-22 \%$ ) than found in prairie sites. Modern soil samples are also typically somewhat more positive with a strong decrease in values within the upper several centimeters reflecting the historical incorporation of anthropogenically depleted carbon.

Apart from the unexpectedly negative nature of the isotopic values, the most striking feature of the data is the consistence of the trend through time and the high repeatability (see Table 42-1). Overall, the Wilson-Leonard SOM carbon isotope values are quite negative (strongly $\mathrm{C}_{3}$ ) centering around $-23 \%$. There is little zonation in the signal associated with the stratigraphic boundaries as defined by soil, geomorphology, and archeology. The profile does exhibit a broad drift from greater values at the base $(>-$
$23 \%$ ) toward more negative values $(<-23 \%)$ in mid-profile. Values reach their maximum $\mathrm{C}_{3}$ (most negative) within Unit II. Values at this level are equivalent to only a $15 \%$ contribution by $\mathrm{C}_{4}$ vegetation, based on end members. This shift, albeit a gradual one, is at odds with that hypothesized from Wilson-Leonard phytoliths or other regional data sets. The relatively minor fluctuation in the stable carbon isotopic values toward the top of the profile, however, is in general agreement with the phytolith record. These data suggest a maximum contribution by $\mathrm{C}_{4}$ grasslands at, or just above, the Unit IIIb/IIIc boundary and a shift back toward more pure $\mathrm{C}_{3}$ values above. The phytolith assemblages from these samples suggest local or regional woodland expansion. Relative to the potential range in stable carbon values, these fluctuations are relatively insignificant. Given the generally $\mathrm{C}_{4}$ composition of the grasslands, at least during the late Holocene, this suggests that the site has been largely woodland to open woodland throughout the Holocene.

\section{CONCLUSIONS}

The stable carbon isotopic analysis of the WilsonLeonard profile, while not strongly contradicting the phytolith record, lends little support to evidence of vegetation and climatic change during the Holocene. The lack of sensitivity in this record is somewhat perplexing. Several explanations are possible, including massive translocation of SOM throughout the profile or alteration of the isotopic signature during SOM decay. Neither of these is likely. The documented phytolith zonation argues against the former. 
The latter is contrary to current research on carbon isotopic signal fidelity and organic decay processes (see discussion in Boutton et al. 1994; von Fisher and Tieszen 1995; Wedin et al. 1995).

The only palatable explanation for the difference between the carbon isotopic and the phytolith records is one of spatial scale. The observed changes in the phytolith profile relate to influx of grass short-cell phytoliths. The regional eolian contribution of this group of phytoliths is sub- stantial (Fredlund and Tieszen 1994). The relative contribution of organic matter from regional sources, whether by eolian or fluvial processes, is relatively much smaller. This difference in transportation results in a phytolith record that is more sensitive to regional vegetation change, while the SOM, at least at the Wilson-Leonard site, remains primarily a local signature. This interpretation is supported by the relatively high phytolith indicators of woodlands present throughout the Holocene record. 


\section{REFERENCES CITED IN VOLUME V}

Agricultural Research Service

1981 Nutritive Value of Foods. United States Department of Agriculture, Washington, D.C.

Alexander, H. L., Jr.

1963 The Levi Site: A Paleo-Indian Campsite in Central Texas. American Antiquity 28:510-528.

Allen, D. C., and E. P. Cheatum

1961 Ecological Implications of Fresh-Water and Land Gastropods in Texas Archeology. Bulletin of the Texas Archeological Society 31(for 1960):291-316.

Ambrose, S. H.

1993 Isotopic Analysis of Paleodiets: Methodological and Interpretive Considerations. In Investigations of Ancient Human Tissue, edited by M. K. Sanford, pp. 59-130. Gordon and Breach Science Publishers, Langhorne, Pennsylvania.

Anderson, K.

1993 Native Californians as Ancient and Contemporary Cultivators. In Before the Wilderness: Environmental Management by Native Californians, edited by T. C. Blackburn and K. Anderson, pp. 151-174. Ballena Press, Ramona, California.

Andrews, P.

1990 Owls, Caves and Fossils: Predation, Preservation, and Accumulation of Small Mammal Bones in Caves, with an Analysis of Pleistocene Cave Faunas from Westburysub-Mendip, Somerset, UK. University of Chicago Press, Chicago.

Andrews, P., and E. M. Nesbit Evans

1983 Small Mammal Bone Accumulations Produced by Mammalian Carnivores. Paleobiology 9:289-307.

Anthony, D.

1994 Mussel Shell Procurement in North-Central Texas. In Archaeological Investigations in the Denton Creek Floodplain: Data Recovery Excavations at 41DL270, Denton and Dallas Counties, Texas, edited by D. Anthony and D. O. Brown, pp. 265-275. Archaeological Series 37. Hicks and Co., Austin.

Ar, A., H. Rahn, and C. V. Paganelli

1979 The Avian Egg: Mass and Strength. Condor 81:331337.

Artz, J. A.

1983 Bone Preservation and Soil Phosphorus: Pedologic Mechanisms for Post-Depositional Weathering of Bone in Archaeological Sites. Paper presented at the 41st Plains Anthropological Conference, Rapid City, South Dakota.

Auffenberg, W.

1969 The Fossil Snakes of Florida. Tulane Studies in Zoology 10:131-216.
Baker, B. W.

1992 Early Through Late Archaic Period Faunal Exploitation in a South-Central Texas Riparian Habitat: Vertebrate Remains from the Richard Beene Site (41BX831). Southeastern Archaeological Conference Bulletin 35:8. Abstracts of the Forty-Ninth Annual Meeting of the Southeastern Archaeological Conference, Little Rock.

1993a A Late Pleistocene Record of the Ringtail from SouthCentral Texas. Current Research in the Pleistocene 10:94-96.

1993b A Review of Central Texas Archaic Subsistence Practices. In Archaeological Investigations in Bull Branch: Results of the 1990 Summer Archaeological Field School, edited by D. L. Carlson, pp. 35-45. Research Report No. 19. Archaeological Resource Management Series, United States Army Fort Hood, Texas.

1994 Vertebrate Remains from the Wilson-Leonard Site (41WM235), Williamson County, Texas: Holocene Animal Exploitation in Central Texas Prehistory. Unpublished Master's thesis, Department of Anthropology, Texas A\&M University, College Station.

1996 Zooarchaeology. In Archaeological Investigations Along Owl Creek: Results of the 1992 Summer Archaeological Field School, edited by D. L. Carlson, pp. 27-40. Research Report No. 29. Archaeological Resource Management Series, United States Army Fort Hood, Texas. In press.

1997 Appendix C: Faunal Analysis. In NRHP Testing of 19 Prehistoric Archeological Sites on Fort Hood, Texas: The 1995 Field Season, (draft) by G. Mehalchick, K. Kleinbach, S. A. Tomka, D. K. Boyd, and K. W. Kibler. Research Report No. 37. Archaeological Resource Management Series, United States Army Fort Hood, Texas.

Baker, B. W., and D. G. Steele

1992 A Late Pleistocene Through Late Holocene Faunal Assemblage from the Richard Beene Archaeological Site (41BX831), Bexar County, South-Central Texas: Preliminary Results. In Late Cenozoic Alluvial Stratigraphy and Prehistory of the Inner Gulf Coastal Plain, SouthCentral Texas, (draft) edited by R. D. Mandel, and S. C. Caran. Series No. 4. Lubbock Lake Landmark Quaternary Research Center, Lubbock.

Baker, F. C

1911 The Lymnaeidae of North and Middle America, Recent and Fossil. Special Publication 3. Chicago Academy of Science, Chicago.

1928 The Fresh Water Mollusca of Wisconsin. Part I. Gastropoda. Wisconsin Geological and Natural History Survey Bulletin 70:1-507.

1939 Fieldbook of Illinois Land Snails.Manual 2.Urbana, Illinois. 
Balkwill, D. M., and S. L. Cumbaa

1992 A Guide to the Identification of Postcranial Bones of Bos taurus and Bison bison. Syllogeus No. 71. Canadian Museum of Nature, Ottawa.

Baugh, S. T.

1986 Late Prehistoric Bison Distributions in Oklahoma. In Current Trends in Southern Plains Archaeology, edited by T. G. Baugh, pp. 83-96. Plains Anthropologist, Memoir 21, Vol. 31, No. 114.

Behrensmeyer, A. K.

1978 Taphonomic and Ecologic Information from Bone Weathering. Paleobiology 4:150-162.

Behrensmeyer, A. K., and A. P. Hill (editors)

1980 Fossils in the Making: Vertebrate Taphonomy and Paleoecology. University of Chicago Press, Chicago.

Bement, L. C.

1991 Hunter-Gatherer Mortuary Practices During the Archaic in Central Texas. Ph.D. dissertation, The University of Texas at Austin. University Microfilms, Ann Arbor.

1994 Hunter-Gatherer Mortuary Practices During the Central Texas Archaic. The University of Texas Press, Austin.

1994 Chapter 6: Faunal Analysis. In Hunter-Gatherer Mortuary Practices During the Central Texas Archaic, pp. 43-60. University of Texas Press, Austin.

Berger, R.

1975 Advances and Results in Radiocarbon Dating: Early Man in America. World Archaeology 7:174-184.

Binford, L. R.

1978 Nunamiut Ethnoarchaeology. Academic Press, New York.

1981 Bones: Ancient Men and Modern Myths. Academic Press, New York.

Binford, L. R., and J. B. Bertram

1977 Bone Frequencies and Attritional Process. In For Theory Building in Archaeology, edited by L. R. Binford, pp. 77-153. Academic Press, New York.

Black, S. L.

1989 Central Texas Plateau Prairie. In From the Gulf to the Rio Grande: Human Adaptation in Central, South, and Lower Pecos Texas, by T. R. Hester, S. L. Black, D. G. Steele, B. W. Olive, A. A. Fox, K. J. Reinhard, and L. C. Bement, pp. 17-38. Research Series No. 33. Arkansas Archeological Survey, Fayetteville.

Black, S. L., and A. J. McGraw

1985 The Panther Springs Creek Site: Cultural Change and Continuity Within the Upper Salado Creek Watershed, South-Central Texas. Archaeological Survey Report No. 100. Center for Archaeological Research, The University of Texas at San Antonio.
Blair, F. W.

1950 The Biotic Provinces of Texas. The Texas Journal of Science 2:93-117.

Bond, C. L.

1978 Three Archeological Sites at Hoxie Bridge, Williamson County, Texas. Report No. 43. Anthropology Laboratory, Texas A\&M University, College Station.

Bonnichsen, R., and R. T. Will

1980 Cultural Modification of Bone: The Experimental Approach in Faunal Analysis. In Mammalian Osteology, by B. M. Gilbert, pp. 7-30. Modern Printing, Laramie, Wyoming.

Bousman, C. B.

1994 The Central Texas Pollen Record: A Reinterpretation. Current Research in the Pleistocene 11:79-81.

1998 Paleoenvironmental Change in Central Texas: The Palynological Evidence. Plains Anthropologist 43:40-59.

Boutton, T. W., A. T. Harrison, and B. N. Smith

1994 Distribution of Biomass of Species Differing in Photosynthetic Pathways along an Altitudinal Transect in Southeastern Wyoming Grasslands. Oecologia 45:287298.

Bozarth, S. R.

1992 Classification of Opal Phytoliths Formed in Selected Dicotyledons Native to the Great Plains. In Phytolith Systematics: Emerging Issues, edited by G. RappJr. and S. C. Mulholland, pp. 193-214. Advances in Archaeological and Museum Science 1. Plenum Press, New York.

1993 Biosilicate Assemblages of Boreal Forests and Aspen Parklands. In Plytolith Analysis: Applications in Archaeology and Paleoecology, edited by D. M. Pearsall and D. R. Piperno, pp. 95-105. University of Pennsylvania, Philadelphia.

Brace, C. L., and D. P. Tracer

1992 Craniofacial Continuity and Change: A Comparison of Late Pleistocene and Recent Europe and Asia. In The Evolution and Dispersal of Modern Humans in Asia, edited by T. Akazawa, K. Aoki, and T. Kimura, pp. 439-472. Hokusen-sha Publishing, Tokyo.

Bradbury, J. P.

1975 Diatom Stratigraphy and Human Settlement in Minnesota. Special Paper 171. Geological Society of America.

Brain, C. K.

1981 The Hunters or the Hunted? An Introduction to African Cave Taphonomy. University of Chicago Press, Chicago.

Breternitz, D. A., A. C. Swedlund, and D. C. Anderson

1971 An Early Burial from Gordon Creek, Colorado. American Antiquity 36:170-182. 
Brobowsky, P. T.

1984 The History and Science of Gastropods in Archeology. American Antiquity 49:77-93.

Brown, D. A.

1984 Prospects and Limits of a Phytolith Key for Grasses in the Central United States. Journal of Archaeological Science 11:345-368.

Brown, D. O.

1987 Aquilla Lake Food Resource Exploitation: Catchment Analysis Evaluation. In Archeology at Aquilla Lake: 1978-1982 Investigations, Volume III, by D. O. Brown, R. P. Watson, and J. M. Jackson, pp. 43-1 through 4331. Research Report No. 81. Texas Archeological Survey, The University of Texas at Austin.

1989 Prehistoric Subsistence Strategies in Northeastern Central Texas. Bulletin of the Texas Archeological Society 59:201-244.

Brown, D. O. (editor)

1987 Archaeology at Aquilla Lake: 1978-1982 Investigations, Volume III. Research Report 81. Texas Archaeological Survey, The University of Texas at Austin.

Bryan, K., T. Gallucci, and D. H. Riskind

1984 A Checklist of Texas Birds. Technical Series No. 32. Texas Parks \& Wildlife Department, Austin.

Bryant, V. M.

1989 Botanical Remains in Archeological Sites. In Interdisciplinary Workshop on the Physical-Chemical-Biological Processes Affecting Archeological Sites, edited by C. Mathewson, pp. 85-114. United States Army Corps of Engineers, Washington, D.C.

Bryant, V. M., Jr., and R. G. Holloway

1985 A Late-Quaternary Paleoenvironment Record of Texas: An Overview of the Pollen Evidence. In Pollen Records of Late-Quaternary North-American Sediments, edited by V. M. Bryant, Jr. and R. G. Holloway, pp. 39-70. American Association of Stratigraphic Palynologists Foundation, Dallas.

Buikstra, J. E., and M. Swegle

1989 Bone Modification Due to Burning: Experimental Evidence. In Bone Modification, edited by R. Bonnichsen, and M. H. Sorg, pp. 247-258. Center for the Study of First Americans, Orono, Maine.

Burch, J. B.

1962 How to Know the Eastern Land Snails. Wm. C. Brown Co., Dubuque, Iowa.

1975 Freshwater Unionacean Clams (Mollusca: Pelecypoda) of North America. Revised edition. Malacological Publications, Hamburg, Michigan.

1982 Freshwater Snails (Mollusca: Gastropoda) of North America. United States Protection Agency, Cincinnati.
Burley, R.W., and D. V. Vadehra

1989 The Avian Egg: Chemistry and Biology. John Wiley \& Sons, New York.

Butler, B.

1976 Faunal Analysis. In The Hopewell School Site: A Late Archaic Campsite in the Central Brazos River Valley, by J. G. Gallagher, and S. E. Bearden, pp. 75-78. Contributions in Anthropology No. 19. Southern Methodist University, Dallas.

Carbone, V. A.

1978 Phytoliths as Paleoecological Indicators. Annals of New York Academy of Science 288:194-205.

Carlson, D. L., and B. S. Shaffer

1992 Appendix II. dBASE FACS Support Programs and Procedures. In A Vertebrate Faunal Analysis Coding System: With North American Taxonomy and dBASE Support Programs and Procedures (Version 3.3), by B. S. Shaffer, and B. W. Baker, pp. 77-102. Technical Report No. 23. Museum of Anthropology, University of Michigan, Ann Arbor.

Carlson, D. L., and D. G. Steele

1992 Human-Mammoth Sites: Problems and Prospects. In Proboscidean and Paleoindian Interactions, edited by J. W. Fox, C. B. Smith, and K. T. Wilkins, pp. 149-169. Baylor University Press, Waco.

Carlson, D. L., D. G. Steele, and A. G. Comuzzie

1984 Mammoth Excavations at the Duewall-Newberry Site on the Brazos River in Texas, 1983. Current Research in the Pleistocene 1:63-64.

Carlson, G. G., and V. H. Jones

1940 Some Notes on the Uses of Plants by the Comanche Indians. Papers of the Michigan Academy of Arts, Sciences and Letters 25:517-542.

Casteel, R.

1972 Some Biases in the Recovery of Archaeological Faunal Remains. Proceedings of the Prehistoric Society 38:328388.

Castetter, E. F.

1935 Ethnobiological Studies in the American Southwest I. Uncultivated Native Plants Used as Sources of Food. University of New Mexico Bulletin 372 and Biological Series 4. The University of New Mexico, Albuquerque.

Cheatum, E. P., and R. W. Fullington

1971 The Recent and Pleistocene Members of the Molluscan Family Polygyridae in Texas. Dallas Museum of Natural History Bulletin 1 (1):1-74.

1973 The Recent and Pleistocene Members of the Pupil-lidae and Urocoptidae (Gastropoda) in Texas. Dallas Museum of Natural History Bulletin 1 (2):1-67. 
Chelf, C.

1946 Grooved Clubs from a Peat Bog in Milam County, Texas. Bulletin of the Texas Archeological and Paleontological Society 17:42-47.

Chisholm, B. S.

1989 Variation in Diet Reconstructions Based on Stable Carbon Isotopic Evidence. In The Chemistry of Prehistoric Human Bone, edited by T. D. Price, pp. 10-37. Cambridge University Press, Cambridge.

Christensen, C. L.

1978 Observations on the Diatom Flora from Springs along the Balcones Fault, Texas. Phytologia 40 (2):89-104.

Clark, J. W., Jr.

1973 The Problem of the Land Snail Genus Rabdotus in Texas Archeological Sites. The Nautilus 87:24.

1976 Alvar Nuñez and the Snail Rabdotus in Texas. The Nautilus 90:13-14.

Clarke, A. C.

1981 The Freshwater Molluscs of Canada. National Museums of Canada, Ottawa.

Clausen, C. J., H. K. Brooks, and A. B. Wesolowsky

1975 The Early Man Site at Warm Mineral Springs, Florida. Journal of Field Archaeology 2:191-213.

Coffman, R. J.

1986 Appendix C: Vertebrate Faunal Remains at the Kenyon Rockshelter, 41TV742. In Cultural Ecology of the Kenyon Rockshelter and the Cunningham Site, Canyon Creek Development, Travis County, Texas, by R. J. Coffman, M. C. Trachte, and M. B. Collins, pp. 383402. Reports of Investigations No. 53. Prewitt and Associates, Inc., Austin.

Collins, M. B.

1995 Forty Years of Archeology in Central Texas. Bulletin of the Texas Archeological Society 66:361-400.

1996 Arenosa Shelter. In The New Handbook of Texas, Volume 1, p. 236. The Texas State Historical Association, Austin.

Collins, M. B., and C. B. Bousman

1993 Historic Context: Quaternary Environments and Archeology in Northeastern Texas. In Archeology in the Eastern Planning Region, Texas: A Planning Document, edited by N. A. Kenmotsu and T. K. Perttula, pp. 4967. Cultural Resource Management Report 3. Texas Historical Commission, Austin.

Collins, M. B., G. L. Evans, T. N. Campbell, M. C. Winans, and C. E. Mear

1989 Clovis Occupation at Kincaid Shelter, Texas. Current Research in the Pleistocene 6:3-4.

Collins, M. B., J. Guy, and S. Carpenter

1991 An Evaluation of Documentation from 1981-1984 Inves- tigations at the Wilson-Leonard Site (41WM235), Williamson County, Texas. Technical Series 21. Texas Archeological Research Laboratory, The University of Texas at Austin.

Creel, D.

1991 Bison Hides in Late Prehistoric Exchange in the Southern Plains. American Antiquity 56:40-49.

Creel, D., R. F. Scott IV, and M. B. Collins

1990 A Faunal Record from West Central Texas and Its Bearing on Late Holocene Bison Populations Changes in the Southern Plains. Plains Anthropologist 35:55-69.

Crook, W. W., Jr., and R. K. Harris

1957 Hearths and Artifacts of Early Man Near Lewisville, Texas and Associated Faunal Material. Bulletin of the Texas Archeological Society 28:7-97.

Cushing, J. E., Jr.

1945 Quaternary Rodents and Lagomorphs of San Josecito Cave, Nuevo Leon, Mexico. Journal of Mammalogy 26:182-185.

Dalquest, W. W., and W. Kilpatrick

1973 Dynamics of Pocket Gopher Distribution on the Edwards Plateau of Texas. The Southwestern Naturalist 18:1-9.

Dalquest, W. W., E. Roth, and F. Judd

1969 The Mammal Fauna of Schulze Cave, Edwards County, Texas. Bulletin of the Florida State Museum 13(4):205276.

Davidow-Henry, B. R., J. K. Jones, Jr., and R. R. Hollander 1989 Cratogeomys castanops. Mammalian Species 338:1-6.

Davis, L. B., S. A. Aaberg, W. P. Eckerle, J. W. Fisher, Jr., and S. T. Greiser

1989 Montane Paleoindian Occupation of the Barton Gulch Site, Ruby Valley, Southern Montana. Current Research in the Pleistocene 6:7-9.

Davis, S. J. M.

1987 The Archaeology of Animals. Yale University Press, New Haven.

Davis, W. B.

1974 The Mammals of Texas (revised). Bulletin 41. Texas Parks and Wildlife Department, Austin.

1978 The Mammals of Texas. Bulletin 41. Texas Parks and Wildlife Department, Austin.

Deisler, J. E.

1986 Consumption of Rabdotus alternatus alternatus (Say, 1830) by the Aboriginal Inhabitants of the Tucker Archaeological Site, 41NU46, in South Texas. Malacology Data Net 1:13-20.

Delorme, L. D.

1970a Ostracodes as Quaternary Paleoecological Indicators. Canadian Journal of Earth Sciences 6:1471-1476. 
1970b Freshwater Ostracodes of Canada, Part 3, Family Candonidae. Canadian Journal of Zoology 48:10991127.

1971a Freshwater Ostracodes of Canada, Part 5, Families Limnocytheridae, Loxoconchidae. Canadian Journal of Zoology 49:43-64.

1971b Paleoecology of Holocene Sediments from Manitoba Using Freshwater Ostracodes. Special Paper Number 9, pp. 301-304. Geological Association Canada.

1978 Distribution of Freshwater Ostracodes in Lake Erie. International Association Great Lake Research 4:216-220.

Delorme, L. D., and S. C. Zoltai

1984 Distribution of an Arctic Ostracode Fauna in Space and Time. Quaternary Research 21:65-73.

DeMarcay, G. B.

1986 Vertebrate Fauna from Landergin Mesa: An Antelope Creek Period Village Site. Unpublished Master's thesis, Department of Anthropology, Texas A\&M University.

DeMarcay, G. B., and D. G. Steele

1986 The Value of Fine Screening on Inland Based HunterGatherer Habitation Sites. In Archaeological Investigations at 41LK201, Choke Canyon Reservoir, Southern Texas, by C. L. Highley, pp. 250-264. Choke Canyon Series, Vol. 11. Center for Archaeological Research, The University of Texas at San Antonio.

Densmore, F.

1928 Uses of Plants by the Chippewa Indians. Bureau of American Ethnology Annual Report (1926-1927) 44:275-397.

Dent, R. J.

1985 Amerinds and the Environment: Myth, Reality, and the Upper Delaware Valley. In Shawnee Minisink: A Stratified Paleoindian-Archaic Site in the Upper Delaware Valley of Pennsylvannia, edited by C. W. McNett, pp. 123-163. Academic Press, New York.

Denys, L.

1990 Fragilaria Blooms in the Holocene of the Western Coastal Plain of Belgium. In Proceedings of the 10th Diatom Symposium, 1988, pp. 397-406. Koeltz Scientific Books, Koenigstein.

Dering, J. P.

1979 Pollen and Plant Macrofossil Vegetation Record Recovered from Hinds Cave, Val Verde County, Texas. Unpublished Master's thesis. Department of Botany, Texas A\&M University, College Station.

1993 Macrobotanical Analysis of Samples from Four Woodland and Caddoan Period Sites in the Cooper Lake Area of the Upper Sulphur River. In Excavations at the Tick, Spike, Johns Creek, and Peerless Bottoms Sites, Cooper Lake Project, by R. C. Fields, E. F. Gadus, L. W. Klement, C. B. Bousman, and J. B. McLerran, pp. 335-
355. Reports of Investigations 91. Prewitt and Associates, Inc., Austin.

1997 Macrobotanical Remains. In Hot Rock Cooking on the Greater Edwards Plateau: Four Burned Rock Midden Sites in West Central Texas, Volume 2, by S. L. Black, L. W. Ellis, D. G. Creel, and G. T. Goode, pp. 571-600. Studies in Archeology 22 and Archeology Studies Program, Report 2. Texas Archeological Research Laboratory, The University of Texas at Austin and Environmental Affairs Department, Texas Department of Transportation, Austin.

Diamond, D. D., D. H. Riskind, and S. L. Orzell

1987 A Framework for Plant Community Classification and Conservation in Texas. The Texas Journal of Science 39:203-221.

Diamond, D. D. and F. E. Smeins

1985 Composition, Classification and Species Response Patterns of Remnant Tallgrass Prairies in Texas. American Midland Naturalist 113:294-308.

Dice, L. R.

1943 The Biotic Provinces of North America. University of Michigan Press, Ann Arbor.

Dibble, D. S.

1967 Excavations at Arenosa Shelter, 1965-1967. Unpublished report on file at the Texas Archeological Research Laboratory, The University of Texas at Austin.

Dillehay, T. D.

1974 Late Quaternary Bison Population Changes on the Southern Plains. Plains Anthropologist 19:180-196.

Dincauze, D.

1981 Paleoenvironmental Reconstruction in the Northeast: The Art of Multidisciplinary Science. In Foundations of Northeast Archaeology, edited by D. Snow, pp. 51-96. Academic Press, New York.

Dixon, J. R.

1987 Amphibians and Reptiles of Texas: With Keys, Taxonomic Synopses, Bibliography, and Distribution Maps. Texas A\&M University Press, College Station.

Dixon, R. B.

1923 The Racial History of Man. Charles Scribner's Sons, New York.

Duffield, L. F.

1973 Aging and Sexing the Post-Cranial Skeleton of Bison. Plains Anthropologist 18(60):132-139.

Efremov, J. A.

1940 Taphonomy: A New Branch of Paleontology. PanAmerican Geologist 74:81-93.

Evans, G. L.

1961 Part I: The Friesenhahn Cave. Bulletin of the Texas Memorial Museum 2:1-22. Texas Memorial Museum, The University of Texas at Austin. 
Fenneman, N. M.

1938 Physiography of Eastern United States. McGraw-Hill, New York.

Ferring, C. R.

1989 The Aubrey Clovis Site: A Paleoindian Locality in the Upper Trinity River Basin, Texas. Current Research in the Pleistocene 6:9-11.

Fisher, R. F., M. J. Jenkins, and W. F. Fisher

1986 Fire and the Prairie-Forest Modaic of Devils Tower National Monument. American Midland Naturalist 117:250-257.

Flynn, P.

1982 Distribution of Prehistoric Bison Populations on the Southern Plains: A Test of Dillehay's Model. Papers in Anthropology 23:7-35. Department of Anthropology, University of Oklahoma, Norman.

Ford, P. J.

1990 Antelope, Deer, Bighorn Sheep and Mountain Goats: A Guide to the Carpals. Journal of Ethnobiology 10(2):169181.

Ford, R. I.

1979 Paleoethnobotany in American Archaeology. In Advances in Archaeological Method and Theory, edited by M. Schiffer, pp. 285-326. Academic Press, New York.

Forrester, R. E.

1965 Fish in the Diet of Prehistoric Indians: Observations from Personal Excavations in the Area of Lake Whitney, North Central Texas. Oklahoma Anthropological Society Newsletter 13(7):5-8.

1985 Horn Shelter Number 2: The North End, A Preliminary Report. Central Texas Archeologist 10:21-35.

Fox, J. W., C. B. Smith, and D. O. Lintz

1992 Herd Bunching at the Waco Mammoth Site: Preliminary Investigations, 1978-1987. In Proboscidean and Paleoindian Interactions, edited by J. W. Fox, C. B. Smith, and K. T. Wilkins, pp. 51-73. Baylor University Press, Waco.

Fredlund, G. G., and L. L. Tieszen

1994 Modern Phytolith Assemblages from the North American Great Plains. Journal of Biogeography 21:321335 .

Frison, G. C., and C. A. Reher

1970 Appendix I: Age Determination of Buffalo by Teeth Eruption and Wear. In The Glenrock Buffalo Jump, 48CO304, edited by G. Frison. Plains Anthropologist Memoir 7, 15(50, Part 2):46-50.

Fryxell, R., T. Bielicki, R. D. Daugherty, C. E. Gustafson, H. T. Irwin, and B. C. Keel

1968 A Human Skeleton from Sediments of Mid-Pinedale Age in Southeastern Washington. American Antiquity 33:511514.
Fuller, L. G., and D. W. Anderson

1993 Changes in Soil Properties Following Forest Invasion of Black Soils of the Aspen Parkland. Canadian Journal of Soil Science 73:613-627.

Fullington, R. W.

1978 The Recent and Fossil Freshwater Gastropod Fauna of Texas. Ph.D. dissertation, North Texas State University, Denton.

Fullington, R. W., and W. L. Pratt, Jr.

1974 The Aquatic and Land Mollusca of Texas. Part Three: The Helicinidae, Carychiidae, Achatinidae, Bradybaenidae, Bulimulidae, Cionellidae, Haplotrematidae, Helicidae, Oreohelicidae, Spiraxidae, Streptaxidae, Strobilopsidae, Thysanophoridae, Valloniidae (Gastropoda) in Texas. Bulletin 1. Dallas Museum of Natural History, Dallas.

1994 The Aquatic and Land Mollusca of Texas. Dallas Museum of Natural History Bulletin 3

Funk, R. E.

1978 Post Pleistocene Adaptations. In Northeast, edited by B. G. Trigger, pp. 16-27. Handbook of North American Indians, vol. 15, W. C. Sturtevant, general editor. Smithsonian Institution, Washington, D.C.

Furtos, N. C

1933 The Ostracoda of Ohio. Bulletin 29. Ohio Biological Survey, p. 413-524.

Gautier, A

1993 Trace Fossils in Archaeozoology. Journal of Archaeological Science 20:511-523.

Gehlbach, F. R.

1991 The East-West Transition Zone of Terrestrial Vertebrates in Central Texas: A Biogeographical Analysis. The Texas Journal of Science 43:415-427.

Geis, J. W.

1973 Biogenic Silica in Selected Species of Deciduous Angiosperms. Soil Science 116:113-130.

Genovese, S. C.

1967 Proportionality of Long Bones and Their Relation to Stature among Mesoamericans. American Journal of Physical Anthropology 26:67-78.

Gifford, D. P.

1981 Taphonomy and Paleoecology: A Critical Review of Archaeology's Sister Disciplines. In Advances in Archaeological Method and Theory, Vol. 4, edited by M. B. Schiffer, pp. 365-438. Academic Press, New York.

Gilbert, B. M.

1980 Mammalian Osteology. B. Miles Gilbert, Publisher, Laramie, Wyoming.

Gilbert, B. M., L. D. Martin, and H. G. Savage

1985 Avian Osteology. Modern Printing Company, Laramie, Wyoming. 
Gilchrist, R., and H. C. Mytum

1986 Experimental Archaeology and Burnt Animal Bone from Archaeological Sites. Circaea 4:29-38.

Gilmore, M.

1977[1919] Uses of Plants by the Indians of the Missouri River Region. Reprint of the 33rd annual Report of the Bureau of American Ethnology. University of Nebraska Press, Lincoln.

Gordon, C. C., and J. E. Buikstra

1981 Soil pH, Bone Preservation, and Sampling Bias at Mortuary Sites. American Antiquity 46:566-571.

Gordon, E. A.

1993 Screen Size and Differential Faunal Recovery: A Hawaiian Example. Journal of Field Archaeology 20:453-460.

Gould, F. W.

1942 A Systematic Treatment of the Genus Camassia. The American Midland Naturalist 28 (3):712-742.

Gould, S. J.

1971 The Paleontology and Evolution of Cerion II: Age and Fauna of Indian Shell Middens of Curacao and Aruba. Brevoria 372:1-26.

Graham, R. W.

1976a Pleistocene and Holocene Mammals, Taphonomy, and Paleoecology of the Friesenhahn Cave Local Fauna, Bexar County, Texas. Unpublished Ph.D. dissertation, Department of Geological Sciences, The University of Texas at Austin.

1976b Friesenhahn Cave Revisited (A Glimpse of Central Texas 20,000 Years Ago). The Mustang 18(5):1-7.

1976c Late Wisconsin Mammalian Faunal and Environmental Gradients of the Eastern United States. Paleobiology 2:343-350.

1984 Paleoenvironmental Implications of the Quaternary Distribution of the Eastern Chipmunk (Tamias striatus) in Central Texas. Quaternary Research 21:111-114.

1987 Late Quaternary Mammalian Faunas and Paleoenvironments of the Southwestern Plains of the United States. In Late Quaternary Mammalian Biogeography and Environments of the Great Plains and Prairies, edited by R. W. Graham, H. A. Semken, Jr., and M. A. Graham, pp. 24-86. Illinois State Museum, Springfield.

Graham, R. W., and J. I. Mead

1987 Environmental Fluctuations and Evolution of Mammalian Faunas During the Last Deglaciation in North America. In North America and Adjacent Oceans During the Last Deglaciation, the Geology of North America, Vol. K-3, edited by W. F. Ruddiman, and H. E. Wright, Jr., pp. 371-402. The Geological Society of America, Boulder, Colorado.
Grayson, D. K.

1979 On the Quantification of Vertebrate Archaeofaunas. In Advances in Archaeological Method and Theory, Vol. 2, edited by M. B. Schiffer, pp. 199-237. Academic Press, New York.

1983 The Paleontology of Gatecliff Shelter: Small Mammals. In The Archaeology of Monitor Valley: 2, edited by D. H. Thomas, pp. 98-126. Anthropological Papers of the American Museum of Natural History, Vol. 59, Part 1, New York.

1984 Quantitative Zooarchaeology: Topics in the Analysis of Archaeological Faunas. Academic Press, New York.

1991 The Small Mammals of Gatecliff Shelter: Did People Make a Difference? In Beamers, Bobwhites, and BluePoints: Tributes to the Career of Paul W. Parmalee, edited by J. R. Purdue, W. E. Klippel, and B. W. Styles, pp. 99-109. Illinois State Museum, Springfield.

Great Plains Flora Association

1986 Flora of the Great Plains. University of Kansas, Lawrence.

Griffitts, J.

1992 Modified Bone and Bone Tool Use on the Southern Plains: An Example from West Central Texas. Society for American Archaeology, Abstracts of the 57th Annual Meeting, p. 55. Pittsburgh, Pennsylvania.

Hafner, D. J.

1993 Reinterpretation of the Wisconsinan Mammalian Fauna and Paleoenvironment of the Edwards Plateau, Texas. Journal of Mammalogy 74:162-167.

Hall, G. D.

1989 Long-Bone Implements from Some Prehistoric Sites in Texas: Functional Interpretations Based on Ethnographic Analogy. Bulletin of the Texas Archeological Society 59:157-176.

Hare, P. E.

1980 Organic Chemistry of Bone and Its Relation to the Survival of Bone in the Natural Environment. In Fossils in the Making: Vertebrate Taphonomy and Paleoecology, edited by A. K. Behrensmeyer and A. P. Hill, pp. 208219. The University of Chicago Press, Chicago.

Harmon, A. M., and J. C. Rose

1988 The Role of Dental Microwear Analysis in the Reconstruction of Prehistoric Diet. Diet and Subsistence: Current Archaeological Perspectives, edited by B. V. Kennedy and G. M. LeMoine, pp. 267-272. Proceedings of the 19th Annual Chacmool Conference Archaeological Association of the University of Calgary, Calgary, Alberta.

Harrell, L. L.

1983 A Study of the Bone and Antler Tools from Hog Creek Reservoir, Bosque and Coryell Counties, Texas. Unpublished Master's thesis, Department of Anthropology, The University of Texas at Austin. 
Hartnady, P., and J. C. Rose

1991 Abnormal Tooth-Loss Patterns among Archaic Period Inhabitants of the Lower Pecos Region, Texas. In Advances in Dental Anthropology, edited by M. A. Kelly and C. S. Larson, pp. 267-278. Wiley-Liss, New York.

Hather, G.

1991 The Identification of Charred Archaeological Remains of Vegetative Parenchymous Tissue. Journal of Archaeological Science 18:661-675.

Havard, V.

1895 Food Plants of the North American Indians. Bulletin of the Torrey Botanical Club 22 (3):98-123.

Haynes, C. V., Jr.

1991 Geoarcheological and Paleohydrological Evidence for a Clovis-age Drought in North America and Its Bearing on Extinction. Quaternary Research 35:438-450.

Haynes, G.

1980 Evidence of Carnivore Gnawing on Pleistocene and Recent Mammalian Bones. Paleobiology 6(3):341-351.

1982 Utilization and Skeletal Disturbances of North American Prey Carcasses. Arctic 35(2):266-281.

1983 A Guide for Differentiating Mammalian Carnivore Taxa Responsible for Gnaw Damage to Herbivore Limb Bones. Paleobiology 9:164-172.

1992 The Waco Mammoths: Possible Clues to Herd Size, Demography, and Reproductive Health. In Proboscidean and Paleoindian Interactions, edited by J. W. Fox, C. B. Smith, and K. T. Wilkins, pp. 111-122. Baylor University Press, Waco.

Hayward, B. W., and F. J. Brook

1981 Exploitation and Redistribution of Flax Snail (Placostylus) by the Prehistoric Maori. New Zealand Journal of Ecology 4:33-36.

Hedges, R. E. M., and A. R. Millard

1995 Bones and Groundwater: Towards the Modelling of Diagenetic Processes. Journal of Archaeological Science 22(2):155-164.

Hershler, R., and G. Longley

1986 Phreatic Hydrobiids (Gastropoda: Prosobranchia) from the Edwards (Balcones Fault Zone) Aquifer Region. South-Central Texas. Malacologia 27 (1):127-172.

Hesse, B., and P. Wapnish

1985 Animal Bone Archeology: From Objectives to Analysis. Manuals on Archaeology No. 5. Taraxacum Press, Washington.

Hester, T. R., and T. C. Hill Jr.

1975 Eating Snails in Prehistoric Southern Texas: Ethnohistoric and Experimental Data. The Nautilus 89:37-38.
Hibbard, C. W.

1960 An Interpretation of Pliocene and Pleistocene Climates in North America. Annual Report of the Michigan Academy of Science, Arts and Letters 62:5-30.

Hibbard, C. W., and D. W. Taylor

1960 Two Late Pleistocene Faunas From Southwestern Kansas. University of Michigan, Museum of Paleontology, Contributions 21 (1):1-66.

Highley, L.

1985 Modified Bone and Antler. In The Panther Springs Creek Site: Cultural Change and Continuity Within the Upper Salado Creek Watershed, South-Central Texas, by S. L. Black, and A. J. McGraw, pp. 199-207. Archaeological Survey Report No. 100. Center for Archaeological Research, The University of Texas at San Antonio.

Hill, W. H.

1971 Pleistocene Snakes from a Cave in Kendall County, Texas. The Texas Journal of Science 22(2-3):209-216.

Hillson, S.

1986 Teeth. Cambridge University Press, New York.

Hoff, C. C.

1942 The Ostracods of Illinois. Illinois Biological Monograph 19, p. 1-196.

Hoffman, C. A.

1933 Developmental Morphology of Allium cepa. The Botanical Gazette 95:279-299.

Hohn, M. H.

1975 The Diatoms. In Late Pleistocene Environments of the Southern High Plains, edited by F. Wendorf and J. J. Hester, pp. 197-200. Ranchos de Taos, Fort Burgwin Research Center.

Hohn, M. H., and J. Hellerman

1961 The Diatoms. In Paleoecology of the Llano Estacado, edited by R. Wendorf, pp. 98-104. Ranchos de Taos, Fort Burgwin Research Center.

Holloway, R. G., and V. M. Bryant, Jr.

n.d. Pollen Analysis of Site 41WM235. Manuscript on file at the Texas Archeological Research Laboratory, The University of Texas at Austin.

Holman, J. A.

1966 The Pleistocene Herpetofauna of Miller's Cave, Texas. The Texas Journal of Science 38:372-377.

Holman, J. A., and K. D. Andrews

1994 North American Quaternary Cold-Tolerant Turtles: Distributional Adaptations and Constraints. Boreas 23:44-52.

Holman, J. A., and A. J. Winkler

1987 A Mid-Pleistocene (Irvingtonian) Herpetofauna from a Cave in South-Central Texas. Pearce-Sellards Series 44:1-17. 
Hooten, E. A.

1933 Racial Types in America and Their Relation to Old World Types. In The American Aborigines, edited by D. Jenness, pp. 131-163. Russell and Russell, New York.

House, K. D.

1978 Faunal Analysis in Texas Archeological Sites. In Texas Archeology: Essays Honoring R. King Harris, edited by K. D. House, pp. 93-131. Reports of Investigations No. 3. Institute for the Study of Earth and Man. Southern Methodist University Press, Dallas, Texas.

Howley, J. P.

1915 The Beothucks, or Red Indians: The Aboriginal Inhabitants of Newfoundland. Cambridge University Press, Cambridge.

Hrdlicka, A.

1923 The Origin and Antiquity of the American Indian. Annual Report of the Board of Regents of the Smithsonian Institution, pp. 481-493. U.S. Government Printing Office, Washington, D.C.

Hubbs, C., R. J. Edwards, and G. P. Garrett

1991 An Annotated Checklist of the Freshwater Fishes of Texas, With Keys to Identification of Species. The Texas Journal of Science 43(4), Supplement.

Hubricht, L.

1985 The Distributions of the Native Land Molluscs of the Eastern United States. Fieldiana: Zoology (n.s.) 24:1191.

Huebner, J. A.

1991 Late Prehistoric Bison Populations in Central and Southern Texas. Plains Anthropologist 36:343-358.

Huebner, J. A., and T. W. Boutton

1992 The Isotopic Composition of Human Diets in Prehistoric Southeastern Texas. Texas Journal of Science 44:4351.

Hughes, D. T.

1977 Analysis of Certain Prehistoric Bison Kills in the Texas Panhandle and Adjacent Areas. Unpublished Master's thesis, Department of Anthropology, University of Arkansas, Fayetteville.

Hulbert, R. C., Jr.

1979 Linear Discriminant Analysis and Variability of Pleistocene and Holocene Leporidae of Texas. Unpublished Master's thesis, Department of Geological Sciences, The University of Texas at Austin.

1984 Latest Pleistocene and Holocene Leporid Faunas from Texas: Their Composition, Distribution and Climatic Implications. Southwestern Naturalist 29:197-210.

1985 Vertebrate Faunal Remains. In The Panther Springs Creek Site: Cultural Change and Continuity Within the Upper Salado Creek Watershed, South-Central Texas, by S. L. Black and A. J. McGraw, pp. 209-215. Archaeological Survey Report No. 100. Center for Archaeological Research, The University of Texas at San Antonio.

Humphrey, J. D., and C. R. Ferring

1994 Stable Isotopic Evidence for Latest Pleistocene and Holocene Climate Change in North-Central Texas. Quaternary Research 41:200-213.

Hunter, C. A.

1987 Appendix VIII: Vertebrate and Invertebrate Faunal Remains from 41BU16. In Excavations at 41BU16: State Highway 21 at the Brazos River, Burleson County, Texas, by E. Roemer, Jr., and S. B. Carlson, pp. 213-261. Contract Reports in Archaeology No. 1. Texas State Department of Highways and Public Transportation, Highway Design Division, Austin.

Jarvis, R. W., and D. D. Crawford

1974 Archaeological Excavations on Interstate Highway 10, Sutton County, Texas. Publications in Archaeology Report No. 4. Texas Highway Department, Highway Design Division, Austin.

Jenkins, N. K., and C. Tyler

1960 Changes in Eggshell Thickness and White and Yolk Weight and Composition over a Period of a Year. Journal of Agricultural Science 55:323-331.

Jenks, A. E.

1936 Pleistocene Man in Minnesota: A Fossil Homo sapiens. University of Minnesota Press, Minneapolis.

1937 Minnesota's Browns Valley Man and Associated Burial Artifacts. Memoirs of the American Anthropological Association No. 49. American Anthropological Association, Menasha, Wisconsin.

Jenks, A. E., and L. A. Wilford

1938 Sauk Valley Skeleton. Bulletin of the Texas Archeological and Paleontological Society 10:162-163.

Johannessen, $\mathrm{S}$.

1984 Paleoethnobotany. In American Bottom Archaeology, edited by C. J. Bareis and J. W. Porter, pp. 197-214. University of Illinois Press, Urbana.

Johnson, E

1977 Animal Food Resources of Paleoindians. The Museum Journal 17:65-77.

1985 Current Developments in Bone Technology. In Advances in Archaeological Method and Theory, Vol. 8, edited by Michael B. Schiffer, pp. 157-235. Academic Press, New York.

Johnson, E. (editor)

1987 Lubbock Lake, Late Quaternary Studies on the Southern High Plains. Texas A\&M University Press, College Station. 
Johnson, L., Jr.

1991 Early Archaic Life at the Sleeper Archaeological Site, $41 B C 65$ of the Texas Hill Country, Blanco County, Texas. Publications in Archaeology Report No. 39. Texas State Department of Highways and Public Transportation, Highway Design Division, Austin.

Johnston, A., L. M. Bezeau, and Smoliak

1967 Variation in Silica Content of Range Grasses. Canadian Journal of Plant Science 47:65-71.

Jones, J. G., and V. M. Bryant, Jr.

1992 Phytolith Taxonomy in Selected Species of Texas Cacti. In Phytolith Systematics: Emerging Issues, edited by G. Rapp, Jr., and S. C. Mulholland, pp. 214-238. Plenum Press, New York.

Jones, J. K., Jr.

1993 The Concept of Threatened and Endangered Species as Applied to Texas Mammals. The Texas Journal of Science 45:115-128.

Jones, J. K., Jr., and C. Jones

1992 Revised Checklist of Recent Land Mammals of Texas, with Annotations. The Texas Journal of Science 44:53-74.

Jones, R. L., and A. H. Beavers

1964 Variation of Opal Phytolith Content Among Some Great Soil Groups in Illinois. Soil Science Society of America 28:711-712.

Kalisz, P. J., and S. E. Boettcher

1990 Phytolith Analysis of Soils at Buffalo Beats, a Small Forest Opening in Southeastern Ohio. Bulletin of the Torrey Botanical Club 117:445-449.

Katzenberg, M. A., H. P. Schwartz, and M. Knyf

1995 Stable Isotope Evidence for Maize Horticulture and Paleodiet in Southern Ontario, Canada. American Antiquity 60 (2):335-350.

Kaufman, T. S.

1980 Early Prehistory of the Clear Lake Area, Lake County, California. Unpublished Ph.D. dissertation, University of California, Los Angeles.

Kelly, R., and L. C. Todd

1988 Coming into the Country: Early Paleoindian Hunting and Mobility. American Antiquity 53:231-244.

Kindscher, K.

1987 Edible Wild Plants of the Prairie. University Press of Kansas, Lawrence.

Kingston, J. C., R. B. Cook, R. G. Kreis Jr., and Cambu

1990 Paleoecological Investigation of Recent Lake Acidification in the Northern Great Lake States. Journal of Paleolimnology 4:153-201.

Kitchell, J. A., and D. L. Clark

1979 Distribution, Ecology, and Taxonomy of Recent Freshwater Ostracoda of Lake Mendota, Wisconsin. Uni- versity of Wisconsin Natural History Series 1:1-24.

Klein, R. G., and K. Cruz-Uribe

1984 The Analysis of Animal Bones from Archeological Sites. University of Chicago Press, Chicago.

Klein, R. L., and J. W. Geis

1978 Biogenic Silica in the Pinaceae. Soil Science 126:145-156.

Knight, J. A.

1985 Differential Preservation of Calcined Bone at the Hirundo Site, Alton, Maine. Unpublished Master's thesis, Department of Anthropology, Orono, Maine.

Koch, C. P.

1989 Taphonomy: A Bibliographic Guide to the Literature. Center for the Study of First Americans, Orono, Maine.

Kontrovitz, M., J. M. Slack, and Y. Zhao

1991 On the Use of Some Phosphates in the Preparation of Ostracode Shells. Journal of Micropalaeontology 10(2):121-126.

Kornfeld, M.

1988 The Rocky Folsom Site: A Small Folsom Assemblage from the Northwestern Plains. North American Archaeologist 9:197-222.

Kotter, S. M.

1985 Cherry Tree Shelter: Excavation of a Stratified Late Archaic and Neoarchaic Rockshelter, Travis County, Texas. Research Report No. 92. Texas Archeological Survey, The University of Texas at Austin.

Krammer, K., and H. Lange-Bertalot

1986 Bacillariophyceae I. Teil. Naviculaceae. Susswasserflora von Mitteleuropa Band 2(1):876.

1991 Bacillariophyceae III. Teil. Centrales, Fragilariaceae, Eunotiaceae. Susswasserflora von Mitteleuropa Band 2(3):576.

Kreutzer, L. A.

1992 Bison and Deer Bone Mineral Densities: Comparisons and Implications for the Interpretation of Archaeological Faunas. Journal of Archaeological Science 19:271294.

Kroeber, A. L.

1962 The Ranco La Brea Skull. American Antiquity 27:416-419.

Krueger, H. W., and C. H. Sullivan

1984 Models for Carbon Isotope Fractionation between Diet and Bone. In Stable Isotopes in Nutrition, edited by J. E. Turnlund and P. E. Johnson, pp. 205-222. Symposium Series 258. American Chemical Society, Washington, D.C.

Kuhn, D. L., J. L. Plafkin, and J. Cairns Jr.

1981 Qualitative Characterization of Aquatic Environments Using Diatom Life-Form Strategies. Transactions of the American Microscience Society 100(2):165-182. 
Kutac, E. A.

1994 Birds. In Birds and Other Wildlife of South Central Texas, by E. A. Kutac, and S. C. Caran, pp. 47-102. University of Texas Press, Austin.

Kutac, E. A., and S. C. Caran

1994 Birds and Other Wildlife of South Central Texas. University of Texas Press, Austin.

La Rocque, A.

1966 Pleistocene Mollusca of Ohio. State of Ohio, Department of Natural Resources, Divison of Geological Survey Bulletin $62: 1-800$.

Lawlor, E. J.

1995 Archaeological Site-formation Processes Affecting Plant Remains in the Mojave Desert. Ph.D. dissertation, University of California, Riverside. University Microfilms International, Ann Arbor.

Lawrence, B.

1951 Post-Cranial Skeletal Characters of Deer, Pronghorn, and Sheep-Goat With Notes on Bos and Bison. Papers of the Peabody Museum of American Archaeology and Ethnology Vol. 35, No. 2, Part 2. Harvard University, Cambridge.

Leechman, D.

1951 Bone Grease. American Antiquity 16:355-356.

Leonard, A. B.

1943 The Mollusca of Meade and Clarke Counties, Kansas. Transactions of the Kansas Academy of Science 46:226-240.

Lewall, E. F., and I. M. Cowan

1963 Age Determination in Black-Tailed Deer by Degree of Ossification of the Epiphyseal Plate in the Lone Bones. Canadian Journal of Zoology 41:629-636.

Lewis, H. T.

1973 Patterns of Indian Burning in California: Ecology and Ethnohistory. Ballena Press, Ramona, California.

Lintz, C. R.

1976 The McGrath Site of the Panhandle Aspect. Oklahoma Anthropological Society Bulletin 25:1-110.

Linzey, A. V.

1983 Synaptomys cooperi. Mammalian Species 210:1-5.

Little, E. A., and M. J. Schoeninger

1995 The Late Woodland Diet on Nantucket Island and the Problem of Maize in Coastal New England. American Antiquity 60 (2):351-368.

Lohman, K. E.

1935 Diatoms from Quaternary Lake Beds near Clovis, New Mexico. Journal of Paleontology 9:455-459.

Lowe, R.

1974 Environmental Requirements. EPA-670/4-74-005U.S. Environmental Protection Agency, Cincinnati, Ohio.
Lundelius, E. L., Jr.

1960 Mylohyus nasutus, Long-Nosed Peccary of the Texas Pleistocene. Bulletin of the Texas Memorial Museum No. 1. Texas Memorial Museum, The University of Texas at Austin.

1962 Appendix 2: Nonhuman Skeletal Material from the Kyle Site. In The Kyle Site: A Stratified Central Texas Aspect Site in Hill County, Texas, edited by E. B. Jelks, pp. 111112. Archaeology Series No. 5. Department of Anthropology, The University of Texas at Austin.

1967 Late Pleistocene and Holocene Faunal History of Central Texas. In Pleistocene Extinctions: The Search for a Cause, edited by P. S. Martin, and H. E. Wright, pp. 287-319. Yale University Press, New Haven.

1974 The Last Fifteen Thousand Years of Faunal Change in North America. The Museum Journal XV: History and Prehistory of the Lubbock Lake Site, edited by C. C. Black, pp. 141-160. West Texas Museum Association, Lubbock.

1985 Pleistocene Vertebrates from Laubach Cave. In Edwards Aquifer-Northern Segment, Travis, Williamson, and Bell Counties, Texas, edited by C. M. Woodruff, F. Snyder, L. De La Garza, and R. Slade, pp. 41-45. Guidebook No. 8. Austin Geological Society, Texas.

1986 Vertebrate Paleontology of the Balcones Fault Trend. In The Balcones Escarpment: Geology, Hydrology, Ecology and Social Development in Central Texas, edited by P. L. Abbott, and C. M. Woodruff, pp. 41-50. Geological Society of America Annual Meeting, San Antonio, Texas.

1992a Quaternary Paleofaunas of the Southwest. In Proboscidean and Paleoindian Interactions, edited by J. W. Fox, C. B. Smith, and K. T. Wilkins, pp. 35-49. Baylor University Press, Waco.

1992b Quaternary Faunal Assemblages from Central Texas. In Late Cenozoic Alluvial Stratigraphy and Prehistory of the Inner Gulf Coastal Plain, South-Central Texas, (draft) edited by R. D. Mandel, and S. C. Caran. Lubbock Lake Landmark Quaternary Research Center Series No. 4.

1992c The Avenue Local Fauna, Late Pleistocene Vertebrates from Terrace Deposits at Austin, Texas. Annales Zoologici Fennici 28:329-340.

1993 Quaternary Faunal Assemblages from Central Texas. Unpublished manuscript on file at the Vertebrate Paleontology Laboratory, The University of Texas at Austin.

Lundelius, E. L., Jr., R. W. Graham, E. Anderson, J. Guilday, J. A. Holman, D. W. Steadman, and S. D. Webb

1983 Terrestrial Vertebrate Faunas. In Late Quaternary Environments of the United States, Vol. 1, The Late Pleistocene, edited by S. C. Porter, pp. 311-353. University of Minnesota Press, Minneapolis. 
Lyman, R. L.

1982a Archaeofaunas and Subsistence Studies. In Advances in Archaeological Method and Theory, Vol. 5, edited by M. B. Schiffer, pp. 331-393. Academic Press, New York.

1982b The Taphonomy of Vertebrate Archaeofaunas: Bone Density and Differential Survival of Fossil Classes. Ph.D. dissertation, University of Washington. University Microfilms, Ann Arbor.

1984 Bone Density and Differential Survivorship of Fossil Classes. Journal of Anthropological Archaeology 3:259299.

1985 Bone Frequencies: Differential Transport, In Situ Destruction, and the MGUI. Journal of Archaeological Science 12:221-236.

1987 Archaeofaunas and Butchery Studies: A Taphonomic Perspective. In Advances in Archaeological Method and Theory, Vol. 10, edited by M. B. Schiffer, pp. 249337. Academic Press, New York.

1988 Was There a Last Supper at Last Supper Cave? In Danger Cave, Last Supper Cave, and Hanging Rock Shelter: The Faunas, edited by D. K. Grayson, pp. 81-104. Anthropological Papers Vol. 66, Part 1. American Museum of Natural History, New York.

1993 Density-Mediated Attrition of Bone Assemblages: New Insights. In From Bone to Behavior: Ethnoarchaeological Contributions to the Interpretation of Faunal Remains, edited by J. Hudson, pp. 324-341. Occasional Paper No. 21. Center for Archaeological Investigations, Southern Illinois University at Carbondale.

1994 Quantitative Units and Terminology in Zooarchaeology. American Antiquity 59(1):36-71.

Lyman, R. L., and G. L. Fox

1989 A Critical Evaluation of Bone Weathering as an Indication of Bone Assemblage Formation. Journal of Archaeological Science 16:293-317.

Lynott M. J.

1979 Prehistoric Bison Populations of Northcentral Texas. Bulletin of the Texas Archeological Society 50:89-101.

1980 Hypothesis Testing and Historic Preservation at Bear Creek Shelter, Hill County, Texas. Bulletin of the Texas Archeological Society 51:209-241.

Mann, L. K.

1952 Anatomy of the Garlic Bulb and Factors Affecting Bulb Development. Hilgardia 21(8):195-251.

Marean, C. W., and C. L. Ehrhardt

1995 Paleoanthropological and Paleoecological Implications of the Taphonomy of a Sabertooth's Den. Journal of Human Evolution 29:515-547.
Marks, M. K., J. C. Rose, and E. L. Buie

1988 Bioarchaeology of the Seminole Sink. Seminole Sink: Excavation of a Vertical Shaft Tomb, Val Verde County, Texas, edited by S. A. Turpin, pp. 75-118. Plains Anthropologist Memoir No. 22. Plains Anthropological Society, Lincoln.

Marshall, F., and T. Pilgram

1993 NISP vs. MNI in Quantification of Body-Part Representation. American Antiquity 58:261-269.

Martin, R. A.

1968 Further Study of the Friesenhahn Cave Peromyscus. The Southwestern Naturalist 13:253-266.

Martin, W. A., with contributions by B. C. Yates, and G. J. Fritz 1987 Exploitation of Subsistence Resources Within the Mountain Creek Drainage. In Late Holocene Prehistory of the Mountain Creek Basin, Volume 1b, edited by D. E. Peter, and R. W. Moir, pp. 15-1 through 15-13. Archaeology Research Program, Institute for the Study of Early Man, Southern Methodist University, Dallas.

Masson, M. A., and M. W. Holderby

1994 Subsistence Patterns at 41HY209 and 41HY202: An Analysis of Vertebrate Faunal Remains. In Archaic and Late Prehistoric Human Ecology in the Middle Onion Creek Valley, Hays County, Texas. Volume 2, Topical Studies, edited by R. A. Ricklis and M. B. Collins, pp. 403-489. Studies in Archeology No. 19. Texas Archeological Research Laboratory, The University of Texas at Austin.

Matteson, M. R.

1960 Reconstruction of Prehistoric Environments through the Analysis of Molluscan Collections from Shell Middens. American Antiquity 26:117-120.

McCarthy, $\mathrm{H}$.

1993 Managing Oaks and the Acorn Crop. In Before the Wilderness: Environmental Management by Native Californians, edited by T. C. Blackburn and K. Anderson, pp. 213-228. Ballena Press, Ramona, California.

McDonald, J.

1974 Appendix II: Non-Human Bones from the Loeve-Fox Site: A Preliminary Analysis. In Archeological Investigations at the Loeve-Fox Site, Williamson County, Texas, by E. R. Prewitt, pp. 132-134. Research Report No. 49. Texas Archeological Survey, The University of Texas at Austin.

McGraw, A. J.

1985 The Importance of White-Tailed Deer at 41BX228. In The Panther Springs Creek Site: Cultural Change and Continuity Within the Upper Salado Creek Watershed, South-Central Texas, by S. L. Black, and A. J. McGraw, pp. 288-289. Archaeological Survey Report No. 100. Center for Archaeological Research, The University of Texas at San Antonio. 
McGregor, D. E., and J. E. Bruseth (editors)

1987 Hunter-Gatherer Adaptations Along the Prairie Margin: Site Excavations and Synthesis of Prehistoric Archaeology. Richland Creek Technical Series, Vol. 3. Archaeology Research Program, Institute for the Study of Earth and Man, Southern Methodist University, Dallas.

McGuire, K. R.

1980 Cave Sites, Faunal Analysis, and Big-Game Hunters of the Great Basin: A Caution. Quaternary Research 14:263-268.

McKenna, M. C.

1965 Collecting Microvertebrate Fossils by Washing and Screening. In Handbook of Paleontological Techniques, edited by Bernhard Kummel and David Raup, pp. 193-203. W.H. Freeman and Company, San Fransisco.

McKusick, C.

1986 The Avian Remains. In Archeological Investigations at Antelope House, by D. P. Morris, pp. 142-158. National Park Service, U.S. Department of the Interior, Washington, D.C.

Meade, G. E.

1961 The Saber-Toothed Cat, Dinobastis serus. Bulletin of the Texas Memorial Museum 2:25-60. Texas Memorial Museum, The University of Texas at Austin.

Meltzer, D. J.

1988 Late Pleistocene Human Adaptations in Eastern North America. Journal of World Prehistory 2(1):1-52.

1991 Altithermal Archaeology and Paleooecology at Mustang Springs, on the Southern High Plains. American Antiquity $56: 236-267$

Meltzer, D. J., and B. D. Smith

1986 Paleoindian and Early Archaic Subsistence Strategies in Eastern North America. In Foraging, Collecting, and Harvesting: Archaic Period Subsistence and Settlement in the Eastern Woodlands, edited by S. W. Neusius, pp. 3-31. Occasional Paper 6. Center for Archaeological Investigations, Southern Illinois University, Carbondale.

Metcalf, A. L.

1984 Land Snails (Gastropoda: Pulmonata) from Cimarron County, Oklahoma. The Texas Journal of Science XXXVI(1):53-64.

Metcalfe, D., and K. T. Jones

1988 A Reconstruction of Animal Body-Part Utility Indices. American Antiquity 53:486-504.

Miksicek, C. H.

1987 Formation Processes of the Archaeobotanical Record. In Advances in Archaeological Method and Theory, Volume 10, edited by M. B. Schiffer, pp. 211-247. Academic Press, New York.
1985 Paleoecology: The Charcoal Evidence. In Excavations at the Valencia Site, A Preclassic Hohokam Village in the Southern Tucson Basin, edited by W. H. Doelle, pp. 235-239. Anthropological Papers 3. Institute for American Research, Tucson.

Milstead, W. W.

1956 Fossil Turtles of the Friesenhahn Cave, Texas, with the Description of a New Species of Testudo. Copeia 3:162171.

Minnis, P. E.

1981 Economic and Organizational Responses to Food Stress by Non-Stratified Societies: An Example from Prehistoric New Mexico. Unpublished Ph.D. dissertation. Department of Anthropology, University of Michigan, Ann Arbor.

Morey, D. F., and W. E. Klippel

1991 Canid Scavenging and Deer Bone Survivorship at an Archaic Period Site in Tennessee. ArchaeoZoologia 4(1):11-28.

Mulholland, S. C.

1986 Classification of Grass Silica Phytoliths. In Plant Opal Phytolith Analysis in Archaeology and Paleoecology: Proceedings of the 1984 Phytolith Research Workshop, Raleigh, North Carolina. Occasional Papers of the Phytolitharien Vol. 1.

1989 Phytolith Shape Frequencies in North Dakota Grasses: A Comparison to General Patterns. Journal of Archaeological Science 16:489-511.

Mulholland, S. C., and G. Rapp Jr.

1992 A Morphological Classification of Grass Silica-Bodies. In Phytolith Systematics: Emerging Issues, edited by G. Rapp Jr., and S. C. Mulholland, pp. 65-90. Plenum Press, New York.

Munson, P., P. Parmalee, and R. Yarnell

1971 Subsistence Ecology of Scovill, A Terminal Middle Woodland Village. American Antiquity 35(4):410-431.

Murray, H. D.

1982 An Analysis of Unionids (Freshwater Mussels) Recovered in Phase I Archaeological Investigations at Choke Canyon Reservior. In Archaeological Investigations at Choke Canyon Reservoir, South Texas: The Phase I Findings, edited by G. D. Hall, S. L. Black, and C. Graves, pp. 541-555. Center for Archaeological Research, the University of Texas at San Antonio.

1986 Freshwater Bivalves. The Clemente and Herminia Hinojosa Site, 41JW8: Atoyah Horizon Campsite in Southern Texas, edited by S. L. Black. Special Report 18. Center for Archaeological Research, The University of Texas at San Antonio.

Murray, H. D., and A. B. Leonard

1962 Handbook of Unionid Mussels in Kansas. Misc. Publications 28. Museum of Natural History, University of Kansas, Lawrence. 
Murry, P. R.

1978 Vertebrate Faunal Remains. In An Archaeological Assessment of the Bear Creek Shelter, Lake Whitney, Texas, by M. J. Lynott, pp. 48-70. Research Report No. 115. Archaeology Research Program, Southern Methodist University, Dallas.

1982 Ecology, Seasonality, and Faunal Utilization. In Settlement of the Prairie Margin: Archaeology of the Richland Creek Reservoir, Navarro and Freestone Counties, Texas, 1980-1981. Archaeological Monographs No. 1. Archaeology Research Program, Southern Methodist University, Dallas.

1987a Analysis of Faunal Remains. In The Bird Point Island and Adams Ranch Sites: Methodological and Theoretical Contributions to North Central Texas Archaeology, edited by J. E. Bruseth and W. A. Martin, pp. 136-140. Richland Creek Technical Series, Vol. 2. Archaeology Research Program, Institute for the Study of Earth and Man, Southern Methodist University, Dallas.

1987b Vertebrate Faunal Assemblage. In The Bird Point Island and Adams Ranch Sites: Methodological and Theoretical Contributions to North Central Texas Archaeology, edited by J. E. Bruseth and W. A. Martin, pp. 247-252. Richland Creek Technical Series, Vol. 2. Archaeology Research Program, Institute for the Study of Earth and Man, Southern Methodist University, Dallas.

Neck, R. W.

1981a Analysis of Gastropods Recovered from Archeological Sites in the Palmetto Bend Reservoir. In Phase III: Prehistoric Archeological Research Within Palmetto Bend Reservoir, Jackson County, Texas, edited by Research Staff, pp. 121-127. Research Report 82. Texas Archeological Survey, The University of Texas at Austin.

1981b Gastropods of the McKinney Homestead (41TV289), McKinney Falls State Park, Travis County, Texas. Bulletin of the Texas Archeological Society 51:136-139.

1984a Living Gastropods of the Eastern Caprock Escarpment of Texas. The Nautilus 98:68-74.

1984b Restricted and Declining Nonmarine Molluscs of Texas, edited by R. W. Neck, pp. 1-17. Technical Series 34. Texas Parks and Wildlife Department, Austin.

1986 The Balcones Fault Zone as a Major Zoogeographic Feature. In The Balcones Escarpment: Geology, Hydrology, Ecology and Social Development in Central Texas, edited by P. L. Abbott, and C. M. Woodruff, pp. 35-40. Geological Society of America Annual Meeting, San Antonio.

1987a Changing Holocene Snail Faunas and Environments Along the Eastern Caprock Escarpment of Texas. Quaternary Research 27:312-322.

1987b Terrestrial Gastropod Succession in a Late Holocene Stream Deposit in South Texas. Quaternary Research 27:202-209.
1988 Analysis of the Paleomolluscan Assemblages of the Wilson-Leonard Site (41WM235). Ms. on file at the Texas Archeological Research Laboratory, The University of Texas at Austin.

1992 Late Pleistocene and Holocene Environments in the Medina Valley of Texas as Revealed by Nonmarine Molluscs. In Late Cenozoic Alluvial Stratigraphy and Prehistory of the Inner Gulf Coastal Plain, South-central Texas, edited by R. D. Mandel and S. C. Caran. Guidebook of the $10^{\text {th }}$ Annual Meeting, South-central Friends of the Pleistocene.

1993 Analysis of the Paleomolluscan Assemblages of the Wilson-Leonard Site (41WM235), 1992 Excavation. Ms. On file at the Texas Archeological Research Laboratory, The University of Texas at Austin.

1994 Analysis of Molluscan Remains from 41DL270. Archaeological Investigations in the Denton Creek Floodplain: Data Recovery Excavations at 41DL270, Denton and Dallas Counties, Texas, edited by D. Anthony and D. O. Brown. Archaeological Series 37. Hicks and Co., Austin.

Neves, W. A., and H. M. Pucciarelli

1989 Extra-Continental Biological Relationships of Early South American Human Remains: a Multivariate Analysis. Ciencia e Cultura 41:566-575.

1991 Morphological Affinities of the First Americans: An Exploratory Analysis Based on Early South American Human Remains. Journal of Human Evolution 21:261273.

Nicholson, R. A.

1996 Bone Degradation, Burial Medium and Species Representation: Debunking the Myths, an Experiment-based Approach. Journal of Archaeological Science 23(4):513533.

Noe-Nygaard, N.

1977 Butchering and Marrow Fracturing as a Taphonomic Factor in Archaeological Deposits. Paleobiology 3:218237.

Nordt, L. C., T. W. Boutton, C. T. Hallmark, and M. Waters

1994 Late Quaternary Vegetation and Climatic Change in Central Texas Based on the Isotopic Composition of Organic Carbon. Quaternary Research 41:109-120.

Ollendorf, A. L.

1992 Towards a Classification Scheme of Sedge (Cyperaceae). In Phytolith Systematics: Emerging Issues, edited by G. Rapp Jr., and S. C. Mulholland, pp. 91-106. Plenum Press, New York.

Olsen, S. J.

1968 Fish, Amphibian and Reptile Remains from Archaeological Sites. Papers of the Peabody Museum of American Archaeology and Ethnology, Vol. 56, No. 2. Harvard University, Cambridge. 
1990 Was Early Man in North America a Big Game Hunter? In Hunters of the Recent Past, edited by L. B. Davis and B. O. K. Reeves, pp. 103-110. Unwin Hyman, London.

Olsen, S. L., and J. W. Olsen

1981 A Comment on Nomenclature in Faunal Studies. American Antiquity 46:192-194.

Opler, M. E.

1941 An Apache Life-Way: The Economic, Social, and Religious Institutions of the Chiricahua Indians. University of Chicago Press, Chicago.

Orr, P. C.

1962 The Arlington Springs Site, Santa Rosa Island. American Antiquity 27:417-419.

1956 Pleistocene Man in Fishbone Cave, Pershing County, Nevada. Nevada State Museum Bulletin 2:1-20.

1974 Notes on the Archaeology of the Winnemucca Lake Caves, 1952-1958. Nevada State Museum Anthropological Papers 16:47-59.

Ortner, D. J., and W. G. J. Putschar

1981 Identification of Pathological Conditions in Human Skeletal Remains. Smithsonian Contributions to Anthropology 57. Smithsonian Institution, Washington, D.C.

Owen, J. G., and J. R. Dixon

1989 An Ecogeographic Analysis of the Herpetofauna of Texas. The Southwestern Naturalist 34:165-180.

Owenby, M.

1950 The Genus Allium. Research Studies of the State College of Washington 18:181-222.

Park, I. K.

1985 Stomata in Onion Bulbs. Phytomorphology 35(1,2):8385.

Parmalee, P. W.

1948 Land Mollusca of North America (North of Mexico), edited by H. A. Pisbry. Monograph 2. Academy of Natural Sciences of Philadelphia.

1958 Marine Shells of Illinois Indian Sites. The Nautilus 71:131-139.

1967 The Fresh-Water Mussels of Illinois. Illinois State Museum Popular Science Series 8:1-108.

1972 Animals Utilized by Woodland Peoples Occupying the Apple Creek Site, Illinois, edited by P. W. Parmalee, A. A. Paloumpis, and D. Wilson. Report of Investigations 23. Illinois State Museum, Springfield.

Parmalee, P. W., A. A. Paloumpis, and N. Wilson

1972 Animals Utilized by Woodland Peoples Occupying the Apple Creek Site, Illinois. Report of Investigations 23. Illinois State Museum, Springfield.
Patrick, R.

1938 The Occurrence of Flints and Extinct Animals in Pluvial Deposits near Clovis, New Mexico. Part V. Diatom Evidence from the Mammoth Pit. Proceedings of the Academy of Natural Sciences of Philadelphia 40:1524.

Patrick, R., and C. W. Reimer

1966 The Diatoms of the United States 1. Monograph 13. Academy of Natural Sciences of Philadelphia, Philadelphia.

1975 The Diatoms of the United States 2, Part 1. Monograph 13. Academy of Natural Sciences of Philadelphia, Philadelphia.

Patterson, L. W.

1992 Prehistoric Bison in Southeast Texas. Houston Archeological Society Journal 102:14-19.

Patton, T. H.

1962 Fossil Vertebrates from Miller's Cave, Llano County, Texas. Unpublished Master's thesis, Department of Geological Sciences, The University of Texas at Austin.

1963 Fossil Vertebrates for Miller's Cave, Llano County, Texas. Bulletin of the Texas Memorial Museum 7:1-41. Texas Memorial Museum, The University of Texas at Austin.

Payne, S.

1972 On the Interpretation of Bone Samples from Archaeological Sites. In Papers in Economic Prehistory, edited by E. S. Higgs, pp. 65-82. Cambridge University Press, Cambridge.

1975 Partial Recovery and Sample Bias. In Archaeozoological Studies, edited by A. T. Clason, pp. 7-17. American Elsevier, New York.

Peale, T. R.

1978 Uses of Brains and Marrow of Animals among the Indians of North America. Minnesota Archaeologist 37(2):56-58.

Pearsall, D. M.

1989 Paleoethnobotany: A Handbook of Procedures. Academic Press, San Diego.

Person, D. A., Jr., R. J. Widmer, and W. Taylor

1990 Soil Chemistry and Archaeological Preservation at Copan. Paper presented at the 55th Annual Meeting of the Society for American Archaeology, Pittsburgh, Pennsylvania.

Perttula, T. K.

1989 The Paleoindian Archaeological Record in Northeast Texas: Evidence from Avocational Collecting Activities. Current Research in the Pleistocene 6:19-21.

Perttula, T. K., C. Crane, and J. Bruseth

1982 A Consideration of Caddoan Subsistence. Southeastern Archaeology 1(2):89-102. 
Peterson, R. T.

1960 A Field Guide to the Birds of Texas and Adjacent States. Houghton Mifflin, Boston.

Pettus, D.

1956 Fossil Rabbits (Lagomorpha) of the Friesenhahn Cave Deposit, Texas. The Southwestern Naturalist 1(3):109115.

Phelps, E., J. Few, B. P. Gatliff, D. B., D. G. Steele, and F. A. Weir 1994 Burial to Bronze: Excavation Analysis and Facial Reconstruction of a Burial from the Wilson-Leonard Site, Texas. Bulletin of the Texas Archeological Society 62:7586.

Pisbry, H. A.

1948 Land Mollusca of North America (North of Mexico). Academy of Natural Sciences of Philadelphia Monograph 2(2).

Piperno, D. R.

1988 Phytolith Analysis. Academic Press, New York.

Powell, J. F., and D. G. Steele

1994 Diet and Health of Paleoindians: An Examination of Early Holocene Human Dental Remains. In Paleonutrition: The Diet and Health of Prehistoric Americans, edited by K. D. Sobolik, pp. 178-194. Occasional Paper No. 22. Center for Archaeological Investigations, Southern Illinois University, Carbondale.

Prewitt, E. R.

1974 Archeological Investigations at the Loeve-Fox Site, Williamson County, Texas. Research Report 49. Texas Archeological Survey, The University of Texas at Austin.

Price, T. D.

1989 The Chemistry of Prehistoric Human Bone. Cambridge University Press, Cambridge.

Protsch, R. R.

1978 Catalog of Fossil Hominids of North America. Gustav Fischer, New York.

Purdue, J. R.

1983a Epiphyseal Closure in White-tailed Deer. Journal of Wildlife Management 47:1207-1213.

1983b Methods of Determining Sex and Body Size in Prehistoric Samples of White-tailed Deer (Odocoileus virginianus). Transactions of the Illinois State Academy of Science 76:351-357.

1986 The Size of White-tailed Deer (Odocoileus virginianus) During the Archaic Period in Central Illinois. In Foraging, Collecting, and Harvesting: Archaic Period Subsistence and Settlement in the Eastern Woodlands, edited by S. W. Neusius, pp. 65-95. Occasional Paper No. 6. Center for Archaeological Investigations, Southern Illinois University, Carbondale.
1987 Estimation of Body Weight of White-Tailed Deer (Odocoileus virginianus) from Bone Size. Journal of Ethnobiology 7(1):1-12.

1989 Changes During the Holocene in the Size of White-Tailed Deer (Odocoileus virginianus) from Central Illinois. Quaternary Research 32:307-316.

1991 Dynamism in the Body Size of White-Tailed Deer (Odocoileus virginianus) from Southern Illinois. In Beamers, Bobwhites, and Blue-Points: Tributes to the Career of Paul W. Parmalee, edited by J. R. Purdue, W. E. Klippel, and B. W. Styles, pp. 277-283. Illinois State Museum, Springfield.

Ramsey, C. W., and M. J. Shult

n.d. The Age of a Deer. Texas Agricultural Extension Service, College Station.

Reddell, J. R.

1965 A Checklist of the Cave Fauna of Texas. I. The Invertebrata (Exclusive of Insecta). The Texas Journal of Science 17:143-187.

1970 A Checklist of the Cave Fauna of Texas. IV. Additional Records of Invertebrata (Exclusive Insecta). The Texas Journal of Science 21:389-415.

Redder, A. J.

1985 Horn Shelter Number 2: The South End, a Preliminary Report. Central Texas Archeologist 10:37-65.

Reitz, E. J.

1987 Zooarchaeological Theory and Method. In The Zooarchaeology of Eastern North America: History, Method and Theory, and Bibliography, edited by A. E. Bogan, and N. D. Robison, pp. 27-65. Miscellaneous Paper No. 12. Tennessee Anthropological Association, UT Graphic Arts Service, University of Tennessee, Knoxville.

Reynolds, B.

1978 Beothuk. In Northeast, edited by B. G. Trigger, pp. 101108. Handbook of North American Indians, vol. 15, W. C. Sturtevant, general editor. Smithsonian Institution, Washington, D.C.

Ricklis, R. A.

1992 The Spread of a Late Prehistoric Bison Hunting Complex: Evidence from the South-Central Coastal Prairie of Texas. Plains Anthropologist 37:261-273.

Ringrose, T. J.

1993 Bone Counts and Statistics: A Critique. Journal of Archaeological Science 20:121-157.

Riskind, D. H., and D. D. Diamond

1986 Plant Communities of the Edwards Plateau of Texas: An Overview Emphasizing the Balcones Escarpment Zone Between San Antonio and Austin with Special 
Attention to Landscape Contrasts and Natural Diversity. In The Balcones Escarpment: Geology, Hydrology, Ecology and Social Development in Central Texas, edited by P. L. Abbott, and C. M. Woodruff, pp. 2132. Geological Society of America Annual Meeting, San Antonio.

1988 An Introduction to Environments and Vegetation. In Edwards Plateau Vegetation: Plant Ecological Studies in Central Texas, edited by B. B. Amos, and F. R. Gehlbach, pp. 1-15. Baylor University Press, Waco.

Robbins, W. W., J. P. Harrington, and B. Freire-Marreco

1916 Ethnobotany of the Tewa Indians. Bureau of American Ethnology Bulletin 55. Smithsonian Institution, Washington, D.C.

Robinson, R.

1979 Biosilica Analysis: Paleoenvironmental Reconstruction of 41LL254. In An Intensive Archaeological Survey of Enchanted Rock State Natural Area, edited by C. Assad and D. Potter, pp. 125-140. Archaeological Survey Report 84. Center for Archaeological Research, The University of Texas at San Antonio.

1982 Biosilica Analysis of Three Prehistoric Archaeological Sites in the Choke Canyon Reservoir, Live Oak County Texas: Preliminary Summary of Climatic Implications. In Archaeological Investigations at Choke Canyon Reservoir, South Texas: Phase I Findings, edited by G. Hall, S. Black, and C. Graves, pp. 597-610. Choke Canyon Series, Vol. 5. Center for Archaeological Research, The University of Texas at San Antonio.

Romanoff, A. L., and A. J. Romanoff

1949 The Avian Egg. John Wiley \& Sons, New York.

Roth, E. L.

1972 Late Pleistocene Mammals from Klein Cave, Kerr County, Texas. The Texas Journal of Science 24:75-84.

Round, F. E.

1981 The Ecology of the Algae. Cambridge University Press, Cambridge.

Sanchez, J. L., and B. S. Shaffer

1993a Faunal Analysis. In Archaeological Investigations in Bull Branch: Results of the 1990 Summer Archaeological Field School, edited by D. L. Carlson, pp. 47-61. Research Report No. 19. Archaeological Resource Management Series, United States Army Fort Hood, Texas.

1993b Faunal Analysis. In Archaeological Investigations in Spicewood Creek: Results of the 1991 Summer Archaeological Field School, edited by D. L. Carlson, pp. 53-69. Research Report No. 22. Archaeological Resource Management Series, United States Army Fort Hood, Texas.

Schmid, E.

1972 Atlas of Animal Bones for Prehistorians, Archaeologists and Quaternary Geologists. Elsevier Publishing Company, New York.
Schmidly, D. J.

1977 The Mammals of Trans-Pecos Texas. Texas A\&M University Press, College Station.

1983 Texas Mammals East of the Balcones Fault Zone. Texas A\&M University Press, College Station.

1991 The Bats of Texas. Texas A\&M University Press, College Station.

Schmitt, D. N., and K. E. Juell

1994 Toward the Identification of Coyote Scatological Faunal Accumulations in Archaeological Contexts. Journal of Archaeological Science 21:249-262.

Schoeninger, M. J.

1989 Reconstructing Prehistoric Human Diet. In The Chemistry of Prehistoric Human Bone, edited by T. D. Price, pp. 38-67. Cambridge University Press, Cambridge.

Schönwetter, M.

1960-1988 Handbuch der Oologie, Lieferungen 1-45, edited by W. Meise. Akademie-Verlag, Berlin.

Scott, R. F., IV

1990 Modified Bone and Antler. In Excavations at 41TG91, Tom Green County, Texas, 1978, by D. Creel, pp. 153159. Publications in Archaeology Report No. 38. Texas State Department of Highways and Public Transportation, Highway Design Division, Austin.

Scott, R. F., IV, and D. Creel

1990 Vertebrate Faunal Analysis. In Excavations at 41TG91, Tom Green County, Texas, 1978, by D. Creel, pp. 165208. Publications in Archaeology Report No. 38. Texas State Department of Highways and Public Transportation, Highway Design Division, Austin.

Self, C. R.

1982 Wood Heating Handbook. TAB Books, Blue Ridge Summit, Pennsylvania.

Semken, H. A., Jr.

1961 Fossil Vertebrates from Longhorn Cavern, Burnet County, Texas. The Texas Journal of Science 13:290310.

1970 Paleoecological and Stratigraphic Significance of the Muskrat in Pleistocene Deposits. Geological Society of America Bulletin 81:3733-3738.

Severinghaus, C. W.

1949 Tooth Development and Wear as Criteria of Age in Whitetailed Deer. Journal of Wildlife Management 13(2):195216.

Shackleton, C. M., and R. Prins

1992 Charcoal Analysis and the "Principle of Least Effort"3/4A Conceptual Model. Journal of Archaeological Science 19:631-637. 
Shafer, H. J., and V. M. Bryant, Jr.

1977 Archeological and Botanical Studies at Hinds Cave, Val Verde County, Texas. Annual Report to the National Science Foundation. Anthropology Laboratory Special Series 1. Texas A\&M University, College Station.

Shaffer, B. S.

1992 Quarter-Inch Screening: Understanding Biases in Recovery of Vertebrate Faunal Remains. American Antiquity 57:129-136.

1994 Appendix III: Analysis of the Vertebrate Faunal Remains. In The Life and Times of Toyah-Culture Folk: The Buckhollow Encampment Site 41KM16, Kimble County, Texas, by L. Johnson, pp. 295-307. Office of the State Archeologist Report No. 38. Texas Department of Transportaton and Texas Historical Commission, Austin.

1995 Appendix F: Analysis of Vertebrate Remains. In NRHP Significance Testing of 57 Prehistoric Archeological Sites on Fort Hood, Texas, Volume II, edited by J. T. Abbott and W. N. Trierweiler, pp. F-1 - F-8. Research Report No. 34. Archeological Resource Management Series, United States Army Fort Hood.

Shaffer, B. S., and B. W. Baker

1992 A Vertebrate Faunal Analysis Coding System: With North American Taxonomy and DBASE Support Programs and Procedures (Version 3.3). Technical Report No. 23. Museum of Anthropology, University of Michigan, Ann Arbor.

Shaffer, B. S., and J. A. Neely

1992 Intrusive Anuran Remains in Pit House Features: A Test of Methods. The Kiva 57:343-351.

Shaffer, B. S., and J. L. J. Sanchez

1994 Comparison of 1/8"-and 1/4"-Mesh Recovery of Controlled Samples of Small-to-Medium-Sized Mammals. American Antiquity 59(3):525-530.

Shipman, P.

1981 Life History of a Fossil: An Introduction to Taphonomy and Paleoecology. Harvard University Press, Cambridge.

Shipman, P., G. Foster, and M. Schoeninger

1984 Burnt Bones and Teeth: An Experimental Study of Color, Morphology, Crystal Structure and Shrinkage. Journal of Archaeological Science 11:307-325.

Sidell, E. J.

1993 A Methodology for the Identification of Archaeological Eggshell. MASCA, The University Museum of Archaeology and Anthropology, University of Pennsylvania, Philadelphia.

Smeins, F. E., and L. B. Merrill

1988 Long-term Change in a Semiarid Grassland. In Edwards Plateau Vegetation: Plant Ecological Studies in Central Texas, edited by B. Amos and F. Gelbach, pp. 101-114. Baylor University Press, Waco, Texas.
Smith, B. D.

1986 The Archaeology of the Southwestern United States: From Dalton to de Sota (10,500-500 B.P.). In Advances in World Archaeology, Vol. 5, edited by F. Wendorf and A. E. Close, pp. 1-92. Academic Press, New York.

Smith, H. H.

1933 Ethnobotany of the Forest Potawatomi Indians. Milwaukee Public Museum Bulletin 4:327-525.

Smolen, M. J.

1981 Microtus pinetorum. Mammalian Species 147:1-7.

Snow, C. C.

1948 Indian Knoll Skeletons of Sites Oh2, Ohio County, Kentucky. The University of Kentucky Reports in Anthropology Volume IV, Number 3, Part II. The University of Kentucky, Lexington.

Sobolik, K. D., and D. G. Steele

1996 A Turtle Atlas to Facilitate Archaeological Identifications. Mammoth Site of Hot Springs, South Dakota, Inc. Fenske Companies, Rapid City, South Dakota.

Sorrow, W. M., H. J. Shafer, and R. E. Ross

1967 Excavations at Stillhouse Hollow Reservoir. Papers of the Texas Archeological Salvage Project No. 11. Texas Archeological Salvage Project, The University of Texas at Austin.

Spennemann, D. H. R., and S. M. Colley

1989 Fire in a Pit: The Effects of Burning on Faunal Remains. ArchaeoZoologia 3:51-64.

Spiess, A.

1987 Faunal Remains: Archaeological Guidebooks. The Northern Raven 7(2):14-23.

Stalling, D. T.

1990 Microtus ochrogaster. Mammalian Species 355:1-9.

Staplin, F. L.

1963a Pleistocene Ostracoda of Illinois, Part 1, Subfamilies Candoninae, Cyprinae, General Ecology, Morphology. Journal of Paleontology 37:758-797.

1963b Pleistocene Ostracoda of Illinois, Part 2, Subfamilies Cyclocyprinae, Cypridopinae, Ilyocyprinae, Families Darwinulidae and Cythereidae, Stratigraphic Ranges and Assemblage Patterns. Journal of Paleontology 37:1164-1203.

Steele, D. G.

1989 Zooarchaeology, Taphonomy and Preservation of the Fossil Faunal Assemblage. In Interdisciplinary Workshop on the Physical-Chemical-Biological Processes Affecting Archeological Sites, edited by C. C. Mathewson, pp. 65-84. U.S. Corps of Engineers, Washington, D.C.

1990 Taphonomic Provenience and Mammoth Bone Modification. In Hunters of the Recent Past, edited by L. B. Davis, and B. O. K. Reeves, pp. 87-102. Unwin Hyman, London. 
Steele, D. G., K. E. Byrd, L. McNatt, and G. Veni

1984 Human and Non-Human Skeletal Remains Recovered from Sorcerer's Cave, Terrell County, Texas. The Texas Journal of Science 36(2-3):169-184.

Steele, D. G., and D. L. Carlson

1984 Excavation and Taphonomy of Mammoth Remains from the Duewall-Newberry Site, Brazos County, Texas. In First International Conference on Bone Modification Abstracts, pp. 34-35. Center for the Study of Early Man, University of Maine, Orono.

1989a Excavation and Taphonomy of Mammoth Remains from the Duewall-Newberry Site, Brazos County, Texas. In Bone Modification, edited by R. Bonnichsen and $\mathrm{M}$. H. Sorg, pp. 413-430. Peopling of the Americas Publications. Center for the Study of First Americans, Institute of Quaternary Studies, University of Maine, Orono.

1989b Human Modification of North American Mammoth Remains at the Duewall-Newberry Site, Brazos County, Texas: An Example of an Initial Bone Processing Station. ArchaeoZoologia 3:65-70.

Steele, D. G., and J. F. Powell

1992 Peopling of the Americas: Paleobiological Evidence. Human Biology 64:303-336.

1993 Paleobiology of the First Americans. Evolutionary Anthropology 2:138-146.

1994 Paleobiological Evidence of the Peopling of the Americas. In Method and Theory for Investigating the Peopling of the Americas, edited by R. Bonnichsen, and D. G. Steele, pp. 141-164. Center for the Study of the First Americans, Department of Anthropology, Oregon State University, Corvalis.

n.d. An Osteological Examination of Prehistoric Hunters and Gatherers of the Southern Desert and Semi-Desert Regions of North America. Manuscript on file. Department of Anthropology, Texas A\&M University, College Station.

Stenholm, N.

1987 Plant Remains. In Prehistoric Land Use in the Northern Rocky Mountians: A Perspective from the Middle Kootenai River Valley, edited by A. V. Thoms, pp. 485512. Washington State University, Pullman.

Stephenson, R. L.

1970 Archeological Investigations in the Whitney Reservoir Area, Central Texas. Bulletin of the Texas Archeological Society 41:37-286.

Stewart, O. C.

1954 The Forgotten Side of Ethnogeography. In Method and Perspective in Anthropology: Papers in Honor Wilson D. Wallis, edited by R. F. Spencer, pp. 211-248. University of Minnesota Press, Minneapolis.
Stewart, T. D.

1960 A Physical Anthropologist's View of the Peopling of the New World. Southwest Journal of Anthropology 16:259273.

1973 The People of America. Charles Scribner's Sons, New York.

Stinson, K. J., and H. A. Wright

1969 Temperature of Headfires in the Southern Mixed Prairie of Texas. Journal of Range Management 22:169-174.

Stoltman, J. B.

1978 Temporal Models in Prehistory: An Example from Eastern North America. Current Anthropology 19:703-746.

Storck, P. L., and A. E. Spiess

1994 The Significance of New Faunal Identifications Attributed to an Early Paleoindian (Gainey Complex) Occupation at the Udora Site, Ontario, Canada. American Antiquity 59(1):121-142.

Story, D. A., J. A. Guy, B. A. Burnett, M. D. Freeman, J. C. Rose, D. G. Steele, B. W. Olive, and K. J. Reinhard

1990 The Archeology and Bioarcheology of the Gulf Coastal Plain: Volume 1. Research Series 38. Arkansas Archeological Survey, Fayetteville.

Strecker, J. K.

1931 The Distribution of Naiades or Pearly Fresh-Water Mussels of Texas. Special Bulletin No. 2. Baylor University Museum, Waco.

Stringer, C. B., and P. Andrews

1988 Genetic and Fossil Evidence for the Origin of Modern Humans. Science 239:1263-1268.

Suhm, D. A.

1957 Excavations at the Smith Rockshelter, Travis County, Texas. Texas Journal of Science 9:26-58.

Sulentich, J. M., L. R. Williams, and G. N. Cameron

1991 Geomys breviceps. Mammalian Species 383:1-4.

Swanton, J. R.

1942 Source Material on the History and Ethnology of the Caddo Indians. Bureau of American Ethnology Bulletin 132. Smithsonian Institution, Washington, D.C.

1946 The Indians of the Southeastern United States. Bureau of American Ethnology Bulletin 137. Smithsonian Institution, Washington, D.C.

Taylor, D. C.

1969 The Wilsall Excavations: An Exercise in Frustration. Proceedings of the Montana Academy of Sciences 29:147150.

Taylor, D. W.

1960 Late Cenozoic Molluscan Faunas From the High Plains. United States Geological Survey Professional Paper 337:1-94 
Taylor, R. E., L. A. Payen, C. A. Prior, P. J. Slota Jr., R. Gillespie, J. A. Gowlett, R. M. C. Hedges, A. J. T. Jull, T. H. Zabel, D. J. Donahue, and R. Berger

1985 Major Revisions in the Pleistocene Age Assignments for North American Human Skeletons by C-14 Accelerator Mass Spectrometry: None Older than 11,000 C-14 Years B.P. American Antiquity 50:136-140.

Tennant, A.

1985 A Field Guide to Texas Snakes. Texas Monthly Press, Austin.

Theler, J. L.

1991 Aboriginal Utilization of Freshwater Mussels at the Aztalan Site, Wisconsin. Beamers, Bobwhites, and BluePoints: Tributes to the Career of Paul W. Parmalee, edited by James R. Purdue, Walter E. Klippel, and Bonnie Styles. Scientific Papers 23. Illinois State Museum, Springfield.

Thoms, A. V.

1987 Prehistoric Land Use in the Northern Rocky Mountains: A Perspective from the Middle Kootenai River Valley. Center for Northwest Anthropology Project Report 4. Washington State University, Pullman.

1989 The Northern Roots of Hunter-Gatherer Intensification: Camas and the Pacific Northwest. Unpublished Ph.D. dissertation. Department of Anthropology, Washington State University, Pullman.

Tieszen, L. L.

1994 Stable Isotopes in the Great Plains: Vegetation Analyses and Diet Determinations. In Skeletal Biology in the Great Plains: A Multidisciplinary View, edited by D. W. Owsley and R. L. Jantz, pp. 261-282. Smithsonian Press, Washington, D.C.

Tieszen, L. L., and S. Archer

1990 Isotopic Assessment of Vegetation Change in Grassland and Woodland Systems. In Plant Biology of Basin and Range, edited by C. B. Osmond, pp. 293-321. Ecological Studies 80. Springer-Verlag, New York.

Tieszen, L. L., and T. Fagre

1993a Carbon Isotopic Variability in Modern and Archaeological Maize. Journal of Archaeological Science 20:2540 .

1993b Effect of Diet Quality and Composition on the Isotopic Composition of Respiratory $\mathrm{CO}_{2}$, Bone Collagen, Bioapatite, and Soft Tissues. In Prehsitoric Human Bone-Archaeology at the Molecular Level, edited by $\mathbf{J}$. B. Lambert and G. Grupe, pp. 261-282. Springer-Verlag, Berlin.

Timbrook, J., J. R. Johnson, and D. D. Earle

1993 Vegetation Burning by the Chumash. In Before the Wilderness: Environmental Management by Native Californians, edited by T. C. Blackburn and K. Anderson, pp. 117-150. Ballena Press, Ramona, California.
Toomey, R. S., III

1989 Hall's Cave. In Geomorphology, Quaternary Stratigraphy, and Paleoecology of Central Texas, edited by S. A. Hall, and T. C. Gustavson, pp. 1-20. Guidebook of the South-Central Friends of the Pleistocene 7th Annual Meeting, Austin.

1991 Hall's Cave: A 13,000 Year Record of Climatic Change from Central Texas. Institute of Tertiary Quaternary Studies Symposia Abstracts. University of Kansas, Lawrence.

1993 Late Pleistocene and Holocene Faunal and Environmental Changes at Hall's Cave, Kerr County, Texas. Unpublished Ph.D. dissertation, Department of Geological Sciences, The University of Texas at Austin.

Toomey, R. S., III, M. D. Blum, and S. Valastro, Jr.

1993 Late Quaternary Climates and Environments of the Edwards Plateau, Texas. Global and Planetary Change 7:299-320

Tous, G. (translator)

1930 The Espinosa-Olivares-Aguirre Expedition of 1709: Espinosa's Diary. Preliminary Studies of the Texas Catholic Historical Society I(3):1-14.

Trotter, M., and G. C. Gleser

1952 Estimation of Stature from Long Bones of American Whites and Negroes. American Association of Physical Anthropology 10:463-514.

Turgeon, D. D., A. E. Bogan, E. V. Coan, W. K. Emerson, W. G. Lyons, W. L. Pratt, C. F. E. Roper, A. Scheltema, F. G. Thompson, and J. D. Williams

1988 Common and Scientific Names of Aquatic Invertebrates from the United States and Canada: Mollusks. Special Publication 16. American Fisheries Society, Bethesda, Maryland.

Turner, C. G.

1985a Dental Evidence for the Peopling of the Americas. $\mathrm{Na}$ tional Geographic Society Research Reports 19:573-596.

1985b The Dental Search for Native American Origins. In Out of Asia, edited by R. Kirk and E. Szathmary, pp. 31-78. Journal of Pacific History, Inc., Australian National University, Canberra.

Twiss, P. C., E. Suess, and R. M. Smith

1969 Morphological Classification of Grass Phytoliths. Soil Science Society of America 33:109-115.

Tyler, C.

1946 The Influence of Different Levels of Dietary Calcium upon Egg-shell Thickness, with a Study of the Relationship between Egg-shell Thickness and Porosity. Journal of Agricultural Science 36:111-116.

1969 Avian Eggshells: Their Structure and Characteristics. In International Review of General and Experimental Zo- 
ology, Vol. 4, edited by W. J. L. Felts, and R. J. Harrison, pp. 82-130. Academic Press, New York.

van der Merwe, N. J.

1982 Carbon Isotopes, Photosynthesis, and Archaeology. American Scientist 70:209-215.

van der Merwe, N. J., and J. C. Vogel

1978 13C Content of Human Collagen as a Measure of Prehistoric Diet in Woodland North America. Nature 276:815816.

Van Morkhoven, F. P. C. M.

1962 Post-Palaeozoic Ostracoda. Vol. I. Elsevier Publishing Co., Amsterdam.

Vehik, S. C.

1977 Bone Fragments and Bone Grease Manufacturing: A Review of Their Archaeological Use and Potential. Plains Anthropologist 22:169-182.

Vestal, P. A.

1952 Ethnobotany of the Ramah Navaho. Papers of the Peabody Museum of American Archaeology and Ethnology XL(4). Harvard University, Cambridge.

Voellinger, L. R., and R. L. Gearhart, II

1987 Mitigation of Impacts at Three Burned Rock Midden Sites in the Block House Creek Development, Williamson County, Texas. Espey, Huston \& Associates, Austin, Texas.

Vogel, J. C., and N. J. van der Merwe

1977 Isotopic Evidence for Early Maize Cultivation in New York State. American Antiquity 42 (2):238-242.

von Fischer, J. C., and L. L. Tieszen

1995 Carbon Isotope Characterization of Soil Organic Matter from Four Tropical Forests in Luquillo, Puerto Rico. Biotropica, in press.

Ward, R., E. G. Zimmerman, and T. L. King

1990 Multivariate Analysis of Terrestrial Reptilian Distribution in Texas: An Alternate View. The Southwestern Naturalist 35:441-445.

Warren, R. E.

1991 Freshwater Mussels as Paleoenvironmental Indicators: A Quantitative Approach to Assemblage Analysis. In Beamers, Bobwhites, and Blue-Points: Tributes to the Career of Paul W. Parmalee, edited by James R. Purdue, Walter E. Klippel, and Bonnie Styles, pp. 23-66. Scientific Papers 23. Illinois State Museum, Springfield.

Waters, M. R.

1986 Sulphur Springs Woman: An Early Human Skeleton from South-Eastern Arizona. American Antiquity 51:361-365.

Watt, F. H.

1978 Radiocarbon Chronology of Sites in the Central Brazos Valley. Bulletin of the Texas Archeological Society 49:111138.
Wedel, W.

1957 The Central North American Grassland: Man-Made or Natural? In Studies in Human Ecology, pp. 39-69. Social Science Monographs III. Pan American Union, Washington, D.C.

Wedin, D. A., L. L. Tieszen, B. Dewey, and J. Pastor

1995 Carbon Isotope Dynamics During Grass Decomposition and Soil Organic Matter Formation. Ecology, in press.

Weir, F. A.

1979 Greenhaw: An Archaic Site in Central Texas. Bulletin of the Texas Archeological Society 50:5-67.

Weir, G. H., and J. P. Dering

1986 The Lomas of Paloma: Human-Environmental Relations in a Central Peruvian Fog Oasis: Archaeobotany and Palynology. In Andean Archaeology, Papers in Memory Clifford Evans, edited by R. Matos, S. A. Turpin, and H. H. Eling, Jr.. Monograph XXVII. Institute of Archaeology, University of California, Los Angeles.

Wesolowsky, A. B., T. R. Hester, and D. R. Brown

1976 Archeological Investigations at the Jetta Court Site (41TV151) Travis County, Texas. Bulletin of the Texas Archeological Society 47:25-87.

Westgate, J. A., F. J. Chen, and L. D. Delorme

1987 Lucustrine Ostracodes in Late Pleistocene Sunnybrook Diamicton of Southern Ontario, Canada. Canadian Journal of Earth Sciences 24:2330-2335.

White, E. M., and L. A. Hannus

1983 Chemical Weathering of Bone in Archaeological Soils. American Antiquity 48:316-322.

Whyte, T. R.

1988 An Experimental Study of Small Animal Remains in Archaeological Pit Features. Ph.D. dissertation, Department of Anthropology, The University of Tennessee, Knoxville.

1991 Small-Animal Remains in Archaeological Pit Features. In Beamers, Bobwhites, and Blue-Points: Tributes to the Career of Paul W. Parmalee, edited by J. R. Purdue, W. E. Klippel, and B. W. Styles, pp. 163-176. Scientific Papers, Vol. 23. Illinois State Museum, Springfield.

Wilding, L. P., and L. R. Drees

1968 Biogenic Opal in Soils as an Index of Vegetation History in the Prairie Peninsula. In The Quaternary of Illinois, edited by R. E. Bergstrom, pp. 99-103. College of Agriculture Special Publication 14. University of Illinois.

1971 Biogenic Opal in Ohio Soils. Soil Science Society of America 35:1004-1010.

1973 Scanning Electron Microscopy of Opaline Forms Isolated from Forest Soils in Ohio. Soil Science Society of America 37:647-650. 
Wilding, L. P., N. E. Smech, and L. R. Drees

1977 Silica in Soils: Quartz, Cristobalite, Tridymite, and Opal. In Minerals in Soil Environments, edited by J. B. Dixon and S. B. Weed, pp. 471-552. Soil Science Society of America, Madison, Wisconsin.

Wilkins, K. T.

1992 Mammalian Paleofaunas of Central Texas from the Late Wisconsinan Glacial Period to the Latest Holocene. The Texas Journal of Science 44:263-281.

Willner, G. R., G. A. Feldhamer, E. E. Zucker, and J. A. Chapman 1980 Ondatra zibethicus. Mammalian Species 141:1-8.

Wilson, S. E., B. F. Cumming, and J. P. Smol

1994 Diatom-Salinity Relationships in 111 Lakes from the Interior Plateau of British Columbia, Canada: The Development of Diatom-Based Models for Paleosalinity Reconstructions. Journal of Paleolimnology 12:197221.

Winemiller, K. O. and B. M. Winsborough

1990 Occurrence of Epizoic Communities on the Parasitic Copepod Lernaea carassii (Lernaeidae). Southwestern Naturalist 35:205-210.

Wing, E. S., and I. R. Quitmyer

1985 Screen Size for Optimal Data Recovery: A Case Study. In Aboriginal Subsistence and Settlement Archaeology of the Kings Bay Locality, Volume 2: Zooarchaeology, edited by W. H. Adams, pp. 49-58. Reports of Investigations No. 2. Department of Anthropology, University of Florida, Gainesville.

Winkler, A. J.

n.d. Small Vertebrates from the Wilson-Leonard Archaeological Site (41WM235), Williamson County, Texas. Manuscript on file, Texas Archeological Research Laboratory, The University of Texas at Austin.

1990 Small Mammals from a Holocene Sequence in Central Texas and Their Paleoenvironmental Implications. The Southwestern Naturalist 35(2):199-205.

Winsborough, B. M.

1988 Paleoecological Analysis of Holocene Algal Mat Diatomites Associated with Prehistoric Wells on the Texas High Plains. Paper presented at the 22nd Annual Meeting of the South-Central Section of the Geological Society of America, Lawrence, Kansas.

1995 Diatom-based Paleoecological Analysis of the Late Quaternary Valley Fill. In Stratigraphy and Paleoenvironments of Late Quaternary Valley Fills on the Southern High Plains, edited by V. T. Holiday, pp. 67-82. Memoir of the Geological Society of America 186. Geological Society of America, Boulder.

Witter, D. C.

1969 Appendix B. Identification of Faunal Remains. In Archeological Investigations at the John Ischy Site: A Burnt
Rock Midden in Williamson County, Texas, by W. M. Sorrow, pp. 61-62. Papers of the Texas Archeological Salvage Project 18. Texas Archeological Salvage Project, The University of Texas at Austin.

Witty, J. R., and E. G. Knox

1964 Glass Opal in Some Chesnut and Forest Soils of North Central Oregon. Soil Science Society of America 28:685688.

Wolfe, J. L.

1982 Oryzomys palustris. Mammalian Species 176:1-5.

Wood, W. R., and D. L. Johnson

1978 A Survey of Disturbance Processes in Archaeological Site Formation. In Advances in Archaeological Method and Theory, edited by M. B. Schiffer, pp. 315-381. Academic Press, New York.

Wright, T., and E. Lundelius, Jr.

1963 Post-Pleistocene Raccoons from Central Texas and Their Zoogeographic Significance. The Pearce-Sellards Series No. 2. Texas Memorial Museum, The University of Texas at Austin.

Yanovsky, E.

1936 Food Plants of the North American Indians. Miscellaneous Publications 27. United States Department of Agriculture, Washington D.C.

Yates, B. C.

1982 Vertebrate Faunal Remains. In Archaeological Investigations at the San Gabriel Reservoir Districts, Central Texas, Vol. 2, by T. R. Hays, pp. 15-57 through 15-227. Institute of Applied Sciences, North Texas State University, Denton.

1985 Appendix 4: Faunal Analysis. In Waco Lake, McLennan County, Texas: An Inventory and Assessment of Cultural Resources, by D. J. Prikryl, and J. M. Jackson, pp. 313-323. Reports of Investigations No. 39. Prewitt and Associates, Inc., Austin.

Yesner, D. R., C. E. Holmes, and K. J. Crossen

1992 Archaeology and Paleoecology of the Broken Mammoth Site, Central Tanana Valley, Interior Alaska, USA. Current Research in the Pleistocene 9:53-57.

Young, D. E.

1986 The Paleoindian Skeletal Material from Horn Shelter, Number 2 in Central Texas: An Analysis and Perspective. Unpublished Master's thesis, Department of Anthropology, Texas A\&M University, College Station.

1988 The Double Burial at Horn Shelter: An Osteological Analysis. Central Texas Archaeologist 11:11-115.

Zierhut, N. W.

1967 Bone Breaking Activities of the Calling Lake Cree. Alberta Anthropologist 1:33-36. 
APPENDIX 8: FAUNAL REMAINS RECOVERED FROM SELECT FEATURES

by

Joy Becker 
TABLE A8-1

Number and Percentage of Faunal Remains by Class for Select Features

\begin{tabular}{|c|c|c|c|c|c|}
\hline & No. & $\%$ of Total & No. Burned & $\begin{array}{c}\% \text { Burned of } \\
\text { Total }\end{array}$ & $\begin{array}{c}\% \text { of Class } \\
\text { Burned }\end{array}$ \\
\hline \multicolumn{6}{|c|}{ Feature 155 ( $\mathrm{N}=42 ; 5.5$ liters $)$} \\
\hline Mammalia & 7 & 17 & 5 & 12 & 71 \\
\hline Reptilia & 1 & 2 & 1 & 2 & 100 \\
\hline Rodentia & 8 & 19 & 3 & 7 & 38 \\
\hline Vertebrata & 26 & 62 & 10 & 24 & 38 \\
\hline \multicolumn{6}{|c|}{ Feature $157(\mathrm{~N}=63 ; 0.85$ liters $)$} \\
\hline Lagomorph & 1 & 2 & 0 & 0 & 0 \\
\hline Mammalia & 2 & 3 & 1 & 2 & 50 \\
\hline Rodentia & 7 & 11 & 7 & 11 & 100 \\
\hline Testudines & 1 & 2 & 0 & 0 & 0 \\
\hline Vertebrata & 52 & 83 & 34 & 54 & 65 \\
\hline \multicolumn{6}{|c|}{ Feature $166(\mathrm{~N}=24 ; 1.25$ liters $)$} \\
\hline Mammalia & 9 & 38 & 9 & 38 & 100 \\
\hline Vertebrata & 15 & 63 & 11 & 46 & 73 \\
\hline \multicolumn{6}{|c|}{ Feature 168 ( $\mathrm{N}=356$; unknown volume) } \\
\hline Amphibian & 2 & 1 & 0 & 0 & 0 \\
\hline Mammalia & 51 & 14 & 21 & 6 & 41 \\
\hline Osteichthyes & 3 & 1 & 1 & 0 & 33 \\
\hline Reptilia & 1 & 0 & 0 & 0 & 0 \\
\hline Rodentia & 27 & 8 & 12 & 3 & 44 \\
\hline Serpentes & 1 & 0 & 1 & 0 & 100 \\
\hline Testudines & 3 & 1 & 2 & 1 & 67 \\
\hline Vertebrata & 268 & 75 & 89 & 25 & 33 \\
\hline \multicolumn{6}{|c|}{ Feature $169(\mathrm{~N}=722 ; 61.4$ liters $)$} \\
\hline Aves & 1 & 0 & 0 & 0 & 0 \\
\hline Lagomorph & 2 & 0 & 0 & 0 & 0 \\
\hline Mammalia & 58 & 8 & 38 & 5 & 66 \\
\hline Osteichthyes & 12 & 2 & 3 & 0 & 25 \\
\hline Reptilia & 2 & 0 & 1 & 0 & 50 \\
\hline Rodentia & 48 & 7 & 16 & 2 & 33 \\
\hline Serpentes & 2 & 0 & 2 & 0 & 100 \\
\hline Testudines & 4 & 1 & 3 & 0 & 75 \\
\hline Vertebrata & 593 & 82 & 172 & 24 & 29 \\
\hline \multicolumn{6}{|c|}{ Feature $175(\mathrm{~N}=50 ;$ ca. 1 liter $)$} \\
\hline Mammalia & 11 & 22 & 5 & 10 & 45 \\
\hline Serpentes & 1 & 2 & 1 & 2 & 100 \\
\hline Rodentia & 5 & 10 & 1 & 2 & 20 \\
\hline Testudines & 4 & 8 & 2 & 4 & 50 \\
\hline Vertebrata & 29 & 58 & 12 & 24 & 41 \\
\hline \multicolumn{6}{|c|}{ Feature 181 ( $N=13,377$; unknown volume) } \\
\hline Amphibia & 9 & 0 & 0 & 0 & 0 \\
\hline Lagomorph & 29 & 0 & 8 & 0 & 28 \\
\hline Mammalia & 350 & 3 & 123 & 1 & 35 \\
\hline Osteichthyes & 176 & 1 & 43 & 0 & 24 \\
\hline Reptilia & 4 & 0 & 0 & 0 & 0 \\
\hline Rodentia & 665 & 5 & 169 & 1 & 25 \\
\hline Serpentes & 31 & 0 & 2 & 0 & 6 \\
\hline Testudines & 274 & 2 & 51 & 0 & 19 \\
\hline Vertebrata & 11,839 & 88 & 2,656 & 20 & 22 \\
\hline \multicolumn{6}{|c|}{ Feature 187 (N=84; unknown volume) } \\
\hline Lagomorph & 2 & 2 & 0 & 0 & 0 \\
\hline Mammalia & 6 & 7 & 3 & 4 & 50 \\
\hline Osteichthyes & 1 & 1 & 0 & 0 & 0 \\
\hline Rodentia & 3 & 4 & 0 & 0 & 0 \\
\hline Testudines & 3 & 4 & 0 & 0 & 0 \\
\hline Vertebrata & 69 & 82 & 34 & 40 & 49 \\
\hline
\end{tabular}


Table A8-1, continued

\begin{tabular}{|c|c|c|c|c|c|}
\hline & No. & $\%$ of Total & No. Burned & $\begin{array}{c}\% \text { Burned of } \\
\text { Total }\end{array}$ & $\begin{array}{c}\% \text { of Class } \\
\text { Burned }\end{array}$ \\
\hline \multicolumn{6}{|c|}{ Feature 206 (N=791; ca. 9.75 liters) } \\
\hline Lagomorpha & 2 & 0 & 0 & 0 & 0 \\
\hline Mammalia & 63 & 8 & 21 & 3 & 33 \\
\hline Osteichthyes & 9 & 1 & 2 & 0 & 22 \\
\hline Serpentes & 5 & 1 & 2 & 0 & 40 \\
\hline Rodentia & 31 & 4 & 5 & 1 & 16 \\
\hline Testudines & 1 & 0 & 1 & 0 & 100 \\
\hline Vertebrata & 680 & 86 & 121 & 15 & 18 \\
\hline \multicolumn{6}{|c|}{ Feature $213(\mathrm{~N}=115 ; 4.5$ liters $)$} \\
\hline Amphibian & 1 & 1 & 0 & 0 & 0 \\
\hline Mammalia & 3 & 3 & 0 & 0 & 0 \\
\hline Rodentia & 12 & 10 & 2 & 2 & 17 \\
\hline Vertebrata & 99 & 86 & 17 & 15 & 17 \\
\hline \multicolumn{6}{|c|}{ Feature 224 ( $N=155$; ca. 3.75 liters $)$} \\
\hline Amphibian & 1 & 1 & 0 & 0 & 0 \\
\hline Mammalia & 18 & 12 & 8 & 5 & 44 \\
\hline Osteichthyes & 5 & 3 & 0 & 0 & 0 \\
\hline Rodentia & 1 & 1 & 0 & 0 & 0 \\
\hline Testudines & 16 & 10 & 3 & 2 & 19 \\
\hline Vertebrata & 114 & 74 & 36 & 23 & 32 \\
\hline \multicolumn{6}{|c|}{ Feature 231 ( $\mathrm{N}=101 ; 2.7$ liters $)$} \\
\hline Mammalia & 13 & 13 & 3 & 3 & 23 \\
\hline Osteichthyes & 2 & 2 & 2 & 2 & 100 \\
\hline Reptilia & 1 & 1 & 0 & 0 & 0 \\
\hline Rodentia & 17 & 17 & 6 & 6 & 35 \\
\hline Testudines & 1 & 1 & 0 & 0 & 0 \\
\hline Vertebrata & 67 & 66 & 32 & 32 & 48 \\
\hline \multicolumn{6}{|c|}{ Feature $235(\mathrm{~N}=27 ; 0.5$ liters $)$} \\
\hline Mammalia & 1 & 4 & 1 & 4 & 100 \\
\hline Rodentia & 1 & 4 & 1 & 4 & 100 \\
\hline Vertebrata & 25 & 93 & 7 & 26 & 28 \\
\hline \multicolumn{6}{|c|}{ Feature $236(\mathrm{~N}=542 ; 27$ liters $)$} \\
\hline Amphibian & 1 & 0 & 0 & 0 & 0 \\
\hline Lagomorpha & 5 & 1 & 5 & 1 & 100 \\
\hline Mammalia & 61 & 11 & 40 & 7 & 66 \\
\hline Osteichthyes & 3 & 1 & 1 & 0 & 33 \\
\hline Reptilia & 2 & 0 & 2 & 0 & 100 \\
\hline Rodentia & 46 & 8 & 24 & 4 & 52 \\
\hline Testudines & 1 & 0 & 1 & 0 & 100 \\
\hline Vertebrata & 423 & 78 & 232 & 43 & 55 \\
\hline \multicolumn{6}{|c|}{ Feature $245(\mathrm{~N}=76 ; 2.7$ liters $)$} \\
\hline Mammalia & 2 & 3 & 1 & 1 & 50 \\
\hline Osteichthyes & 5 & 7 & 2 & 3 & 40 \\
\hline Rodentia & 3 & 4 & 2 & 3 & 67 \\
\hline Testudines & 1 & 1 & 0 & 0 & 0 \\
\hline Vertebrata & 65 & 86 & 28 & 37 & 43 \\
\hline \multicolumn{6}{|c|}{ Feature 252 ( $\mathrm{N}=33$; ca. 1 liter $)$} \\
\hline Aves & 11 & 22 & 5 & 10 & 45 \\
\hline Mammalia & 1 & 2 & 1 & 2 & 100 \\
\hline Rodentia & 5 & 10 & 1 & 2 & 20 \\
\hline Testudines & 4 & 8 & 2 & 4 & 50 \\
\hline Vertebrata & 29 & 58 & 12 & 24 & 41 \\
\hline \multicolumn{6}{|c|}{ Feature 255 ( $\mathrm{N}=47 ;$ ca. 8.75 liters $)$} \\
\hline Lagomorph & 1 & 2 & 0 & 0 & 0 \\
\hline Mammalia & 13 & 28 & 7 & 15 & 54 \\
\hline Rodentia & 3 & 6 & 1 & 2 & 33 \\
\hline Testudines & 1 & 2 & 0 & 0 & 0 \\
\hline Vertebrata & 29 & 62 & 13 & 28 & 45 \\
\hline
\end{tabular}


Table A8-1, continued

\begin{tabular}{|c|c|c|c|c|c|}
\hline & No. & $\%$ of Total & No. Burned & $\begin{array}{c}\% \text { Burned of } \\
\text { Total }\end{array}$ & $\begin{array}{c}\% \text { of Class } \\
\text { Burned }\end{array}$ \\
\hline \multicolumn{6}{|c|}{ Feature 257 ( $\mathrm{N}=65 ;$ ca. 12.4 liters $)$} \\
\hline Mammalia & 11 & 17 & 8 & 12 & 73 \\
\hline Osteichthyes & 1 & 2 & 0 & 0 & 0 \\
\hline Reptilia & 1 & 2 & 0 & 0 & 0 \\
\hline Rodentia & 10 & 15 & 3 & 5 & 30 \\
\hline Vertebrata & 42 & 65 & 19 & 29 & 45 \\
\hline \multicolumn{6}{|c|}{ Feature $260(\mathrm{~N}=14 ; 6.5$ liters $)$} \\
\hline Lagomorph & 1 & 7 & 1 & 7 & 100 \\
\hline Mammalia & 3 & 21 & 2 & 14 & 67 \\
\hline Osteichthyes & 1 & 7 & 0 & 0 & 0 \\
\hline Vertebrata & 9 & 64 & 3 & 21 & 33 \\
\hline \multicolumn{6}{|c|}{ Feature $262(\mathrm{~N}=455 ; 98$ liters $)$} \\
\hline Lagomorpha & 1 & 0 & 1 & 0 & 100 \\
\hline Mammalia & 119 & 26 & 17 & 4 & 14 \\
\hline Osteichthyes & 1 & 0 & 0 & 0 & 0 \\
\hline Serpentes & 1 & 0 & 0 & 0 & 0 \\
\hline Rodentia & 15 & 3 & 9 & 2 & 60 \\
\hline Testudines & 4 & 1 & 3 & 1 & 75 \\
\hline Vertebrata & 313 & 69 & 68 & 15 & 22 \\
\hline \multicolumn{6}{|c|}{ Burned Rock Midden 1 ( $N=54 ; 3$ liters) } \\
\hline Amphibia & 1 & 2 & 0 & 0 & 0 \\
\hline Mammalia & 5 & 9 & 2 & 4 & 40 \\
\hline Osteichthyes & 2 & 4 & 1 & 2 & 50 \\
\hline Reptilia & 1 & 2 & 0 & 0 & 0 \\
\hline Rodentia & 6 & 11 & 4 & 7 & 67 \\
\hline Vertebrata & 39 & 72 & 7 & 13 & 18 \\
\hline
\end{tabular}




\section{APPENDIX 9: FAUNAL TAXA DESCRIPTIONS}

by Barry W. Baker 


\section{TAXA DESCRIPTIONS}

Presented below are descriptions of the 1/4-inch and 1/8-inch screened taxa recovered from the Wilson-Leonard site. All material, regardless of whether or not it has been linked to stratum and time period is described. In limited cases, provenience information is also included. Information about the fauna that is important in interpreting human behavior or environmental conditions at the site is discussed. Fish classification follows Romer and Parsons (1977:566567). Classification of the turtles follows Dixon (1987). Classification of birds follows Texas Ornithological Society (1984). Mammal classification follows Jones and Jones (1992).

\section{PHYLUMCHORDATA(CHORDATES) Subphylum Vertebrata (Vertebrates) Class Indeterminate}

Material: The sample consists of fragments from throughout the site that could not be identified to class or animal size category. Seventy percent $(n=15,309)$ of the total $1 / 4$ inch assemblage $(\mathrm{N}=21,867)$ from the site could not be identified more precisely. Of the 38,618 specimens from the $1 / 8$ inch sample, 26,251 (68\%) could not be identified more precisely.

Remarks: Most of the material probably represents mammals, though fragmentation made positive identification to the level of class impossible. Despite the fact that much of the sample could not be identified to class, many specimens could be assigned to general animal size categories. For example, many small, degraded long bone shaft fragments from the site could represent rabbits or birds. Indeterminate vertebrate fragments were grouped by size category where possible as follows: (1) small vertebrate (smaller than a cottontail rabbit); (2) small/medium-sized vertebrate; (3) mediumsized vertebrate (jackrabbit to fox-sized); (4) medium/largesized vertebrate; and (5) large vertebrate (larger than foxsized). Counts for these categories from each assemblage is presented in Appendix 10.

\section{Class Elasmobranchiomorphi (Sharks and Allies)}

\section{SUBCLASS CHONDRICHTHYES (CARTILAGINOUS FISHES) \\ Infraclass Elasmobranchii (Sharks, Skates, and Rays) \\ Order Selachii (Common Sharks)}

Material: One shark tooth fragment (1/4-inch sample; Lot 37CC1D); 1 shark tooth fragment (1/8-inch sample; Lot 1938). Remarks: An additional shark tooth was recovered from the human Paleoindian burial, but was not included in this analysis. The shark teeth are likely Cretaceous fossils from local deposits. For a review of Cretaceous shark teeth from Texas see Welton and Farish (1993).

\section{Class Osteichthyes (Boney fishes)}

\author{
SUBCLASS ACTINOPTERYGII (RAY-FINNED FISHES) \\ Superorder Teleostei \\ Order Indeterminate
}

Material: The 1/4-inch sample includes 1 small-fish vertebra (Lot 37II1D; centrum width $=5 \mathrm{~mm}$ ), 1 small-fish atlas (Lot 37FF2D; centrum width $=2.5 \mathrm{~mm}$ ), 1 vertebra (Lot $10 \mathrm{E}$; centrum width $=7 \mathrm{~mm}$ ), 1 tooth (Lot 37QQ2D). The 1/8-inch sample includes 26 additional small vertebrae and otoliths of small freshwater fish.

Remarks: The atlas from Lot 37FF2D is burned black. The tooth from Lot 37QQ2D resembles a freshwater drum, though no positive identification could be made. The frequency of fish was undoubtedly biased by the use of $1 / 4$-inch screens.

Order Siluriformes (Catfish)

Family Ictaluridae (Freshwater Catfish)

Ictalurus sp.

Material: One pectoral spine fragment (1/8-inch sample; Lot 1199).

Remarks: This specimen is burned.

\section{Class Amphibia (Amphibians)}

\section{ORDER ANURA (FROGS ANDTOADS)}

Family Indeterminate

Material: Fourteen post-cranial elements from the $1 / 8$-inch sample.

Remarks: These specimens could not be identified to family. Amphibians were absent from the 1/4-inch sample.

\section{Class Reptilia (Reptiles)}

\section{ORDER TESTUDINATA (TURTLES ANDTORTOISES)}

Family Indeterminate

Material: The 1/4-inch sample included 98 indeterminate shell fragments, 2 carapace fragments (Lots 10E, 37GD), 1 nuchal (Lot 15F), 3 neurals (Lots 24RL, 36F, 37Z1D), 5 pleurals (Lots 9J, 10B, 10E, 36E, 36G), 15 peripherals (Lots 3B, 5C, 10E [n=2], 14N2, 20H, 20R, 17CC1, 22O, 22P, 27DD2C, 30MM2A, 36D, 36G, 37DD2D), 5 plastron fragments (Lots 10F, 18N, $20 \mathrm{H}[\mathrm{n}=2], 22 \mathrm{~K})$. An additional 313 specimens were recovered from the $1 / 8$-inch sample.

Remarks: Distinct scute lines on turtle shells make these bones easily distinguishable from other vertebrates, even when very small fragments are recovered. The majority of specimens categorized here as unidentified are probably hard-shell turtles, exclusive of the soft-shelled turtle family Trionychidae. Soft-shelled turtles can be recognized easily by their characteristically dimpled shells. These remains were recovered throughout the site. 


\section{CF. TESTUDINATA}

Material: One possible shell fragment (Lot 29Y1B).

Remarks: The apparent scute line on this bone is not distinct enough to definitely classify it as turtle. The bone was recovered from Unit II.

Family Kinosternidae (Mud and Musk Turtles)

Genus Indeterminate

Material: The 1/4-inch sample includes 1 shell fragment (Lot 10D), 9 peripherals (Lots 0 [right], 8B [left], 11C [left], 12F, 24S1, 36B [left], 36E, 37DD1B [left], 50OC [left]), 1 pygal (Lot 50lB), 1 plastron fragment (Lot 0), 1 right hypoplastron (Lot 36F). Seven additional specimens were recovered from the 1/8-inch sample.

Remarks: The family Kinosternidae is represented by two genera in Texas: Kinosternon (mud turtle), and Sternotherus (musk turtle) (Dixon 1987:79-81). Of the five Kinosternidae species occurring in Texas, $K$. flavescens (yellow mud turtle), K. subrubrum (Mississippi mud turtle), S. carinatus (razorback musk turtle), and S. odoratus (stinkpot) are within the range of Williamson County today (Dixon 1987:176-181). The peripherals of the Kinosternidae are very distinct, with marginal scute outlines located distally, in contrast to their medial location in other taxa (Sobolik and Steele 1996:22). The pygal is also distinct in that it has "a slight notch on the posterior end, and the marginal scute outline...is V-shaped or U-shaped" (Sobolik and Steele 1996:22). The hypoplastron is small and rectangular with pointed axial notches (Sobolik and Steele 1996:23).

Mud and musk turtles are highly aquatic and are only occasionally found out of water. They are usually found crawling along water bottoms, and sun themselves in shallow waters or on floating vegetation (Behler and King 1985:438). Their presence at the site suggests nearby aquatic environments.

\section{Kinosternon sp. (Mud Turtles)}

Material: Two peripherals, lateral aspects (Lots 733, 887). Remarks: Mud turtles in Texas include $K$. flavescens (yellow mud turtle), $K$. hirtipes (Mexican mud turtle), and $K$. subrubrum (eastern mud turtle).

Sternotherus sp. (Musk turtles)

Material: One left hyoplastron (Lot 27KK2D), 1 right hyoplastron (Lot 17J2).

Remarks: Both of these musk turtle bones are burned. The hyoplastron from Lot $17 \mathrm{~J} 2$ is from Unit IIIb/IIIc, the mixed Middle Archaic through Late Prehistoric deposits at the site. The bone from Lot 27KK2D is from Early Paleoindian deposits in Unit Igl/Isi.

Two species of musk turtles occur in Texas today. These include S. carinatus (razorback musk turtle) and S. odoratus (stinkpot) (Dixon 1987:80-81). S. ordoratus is more common throughout the central Texas area (Dixon 1987:181). Dixon (1987:180) reports no record of S. carinatus from Williamson County, though it is found in Bell and Milam counties, immediately to the north and east. Musk turtles prefer soft-bottomed waters that are shallow and slow moving (Behler and King 1985:443, 445; Ernst and Barbour 1972:34), though it has been taken from gravel-bottomed streams as well (Ernst and Barbour 1972:34).

The hyoplastron of Sternotherus is characterized by an unmovable suture junction with the epi/entoplastron, distinguishing it from Kinosternon which possesses a flexible hinge at this junction (Sobolik and Steele 1996:24).

Family Emydidae (Water and box turtles)

Genus Indeterminate

Material: The 1/4-inch sample includes 1 shell fragment (Lot 37JA), 2 neurals (Lots 8C, 12F), 1 right peripheral (Lot 27BB2D). Fifteen additional specimens were recovered from the $1 / 8$-inch sample.

Remarks: Emydidae is the largest living family of turtles and is represented in Texas by Terrapene (box turtles), Graptemys (map turtles), Chrysemys sensu stricto (painted turtles), Pseudemys (cooters and redbelly turtles), Trachemys (sliders), and Deirochelys (chicken turtles) (Dixon 1987:8186; Ernst and Barbour 1972:69; Seidel and Smith 1986).

Peripherals of the family Emydidae are characterized by medially positioned scute lines forming a wide margin between the scute line and the lateral edge of the peripheral (Sobolik and Steele 1996:5). Neurals are typically six or eight sided, are longer than they are wide, and are relatively thick (Sobolik and Steele 1996:5-6). A series of sharp, distinct ridges can often be seen on larger Emydidae turtles, referred to by Sobolik and Steele $(1996: 6,90)$ as "a washboard effect." The presence of water turtles provides further evidence of riverine exploitation by prehistoric humans at the site.

Chrysemys sensu lato (Painted Turtles/cooters/sliders)

Material: One suprapygal (Lot 518); 1 peripheral (Lot 572). Remarks: Both of these specimens were recovered from the 1/8-inch sample. The use of the taxon Chrysemys sensu lato here follows the inclusion of painted turtles, cooters, and sliders within a single genus. These species are often difficult to distinguish.

\section{Terrapene sp. (Box turtles)}

Material: One pygal (Lot 7A) from the 1/4-inch sample.

Remarks: Box turtles are terrestrial reptiles. In Texas, this genus includes two species, Terrapene ornata (ornate or western box turtle) and $T$. carolina (eastern or common box turtle). Dixon (1987:191) reported no records of $T$. carolina 
from Williamson County, though the area is within its range. Two subspecies of the ornate box turtle are known from Texas. T. ornata ornata occupies the central Texas region, while T. ornata luteola is restricted to west Texas (Dixon 1987:192). The eastern box turtle is found predominantly in open woodlands, but is also known from pastures, marshy meadows, scrub forests and brushy grasslands (Ernst and Barbour 1989:195). Habitats of the western box turtle include open prairies, grazed pasture lands, open woodlands, and waterways in arid, sandy-soiled terrain (Behler and King 1985:470). The pygal of Terrapene is distinct in remaining unnotched and showing straight scute lines on the bone (Sobolik and Steele 1996:10).

Family Trionychidae (Softshell Turtles)

Trionyx sp. (Softshell Turtle)

Material: The 1/4-inch sample yielded 1 shell fragment (Lot 22F), 2 pygal fragments (Lot 10F). The 1/8-inch sample produced 1 shell fragment (Lot 744).

Remarks: Two extant species of Trionyx occur in Texas. These are T. muticus (smooth softshell turtle) and $T$. spiniferus (spiny softshell turtle) (Dixon 1987:86-87). T. spiniferus is the most common of these species in Texas and occurs throughout the central Texas area (Dixon 1987:195-196). Dixon (1987:195) reported no records of T. muticus from Williamson County, though it is known from adjacent Milam County. Habitats of the softshell turtle include marshy creeks, ponds, lakes, and rivers. T. muticus rarely leaves the water, though $T$. spiniferus often basks along banks and on logs exposed in the water (Ernst and Barbour 1972:258, 262). Softshelled turtles are easily distinguished from other families by their characteristically dimpled shells. Consequently, they are often over represented in taxonomic frequency lists.

\section{ORDER SQUAMATA (LIZARDS AND SNAKES)}

Suborder Indeterminate

Material: Nine vertebrae fragments.

Remarks: These specimens were recovered from the 1/8inch sample. Due to fragmentation and their small size they could not be distinguished between lizards and snakes.

Suborder Serpentes (Snakes)

Family Indeterminate

Material: Sixteen dorsal vertebrae (Lots 5B, 9M, 10E, 11H, $11 \mathrm{~F}, 36 \mathrm{D}, 36 \mathrm{G}[\mathrm{n}=2], 37 \mathrm{CC}, 37 \mathrm{HH} 1 \mathrm{~B}, 37 \mathrm{II} 1 \mathrm{~B}, 37 \mathrm{OO} 1 \mathrm{~B}[\mathrm{n}=2]$, $37 \mathrm{HH} 2 \mathrm{~A}, 37 \mathrm{HH} 2 \mathrm{C}, 37 \mathrm{OO} 2 \mathrm{~B}$ ) from the $1 / 4$-inch sample. An additional 127 specimens were recovered from the $1 / 8$-inch sample.

Remarks: It is interesting that 8 of the 16 vertebrae from the 1/4-inch sample are from different levels of the same excavation unit (Square 37), suggesting they may represent a single snake. All of the burned 1/4-inch recovered snake from the site is from Square 37. Generic and species identification of snakes from skeletal elements is difficult, and commonly requires detailed morphometric assessment (Auffenberg 1969; Holman 1981; Meylan 1982). Identification to the family level (Colubridae vs. Viperidae) has proven simpler based on hemal keel morphology.

Family Colubridae (Colubrid snakes)

Genus Indeterminate

Material: Nine dorsal vertebrae (Lots 8K [n=4], 10B, 11D, 19G, 36F, 37PP2A). Ninety-four additional specimens from the $1 / 8$-inch sample.

Remarks: The four vertebrae from Lot $8 \mathrm{~K}$ are articulated and represent a single snake. The vertebra from Lot 37PP2A is burned. The Colubrid family is the largest of the snake families. In the United States, these species constitute the nonpoisonous snakes (Behler and King 1985:589). Numerous colubrid species currently inhabit Williamson County (Dixon 1987; Tennant 1985). The Colubridae show a reduced or absent hemal keel, while those of the Viperidae (poisonous snakes) are typically long and pronounced. The high degree of sample fragmentation hindered more specific identifications.

Family Viperidae (Pit Viper Snakes)

Genus Indeterminate

Material: Fourteen vertebrae from the 1/8-inch sample.

Remarks: These vertebrae of poisonous snakes were not identified to genus.

\section{Class Aves (Birds)}

\section{ORDER INDETERMINATE}

Indeterminate Bird

Material: One long bone shaft fragment (Lot 16AA2) from the 1/4-inch sample.

Remarks: Most bird bones are relatively thin and fragile and are more susceptible to postdepositional taphonomic forces. Consequently, they are commonly either totally destroyed, or the bones are reduced to fragments small enough to pass through $1 / 4$-inch screens. Differential preservation of burned to unburned bird bone is suggested by the fact that three of the four 1/4-inch bird bones are burned.

Small Bird Indeterminate

Material: 1 distal phalanx (Lot686) from the 1/8-inch sample.

Medium-sized Bird Indeterminate

Material: One right tarsometatarsus, shaft fragment (Lot 486); 1 left carpometacarpus, distal end (Lot 1689); 1 distal phalanx, proximal end (Lot 1856). 
Remarks: All of these specimens were recovered from the 1/8-inch sample.

\section{cf. Medium-sized Bird}

Material: One long bone shaft (Lot 19I) from the 1/4-inch sample. Remarks: This bone shaft is unburned and compares favorably with bird.

\section{Large Bird Indeterminate}

Material: One distal phalanx (Lot 29X1A) from the 1/4-inch sample. Specimens from the $1 / 8$-inch sample include 1 distal phalanx (Lot 455) and 1 vertebra (Lot 1991).

Remarks: The toe bone from the $1 / 4$-inch sample is complete and is from a bird about the size of a hawk.

\section{ORDER GALLIFORMES (TURKEYS, GROUSE, QUAILS, AND CHACHALACAS) \\ Family Phasianidae \\ Subfamily Odontophorinae (New World Quail) \\ Genus Indeterminate}

Material: One right humerus, distal end (Lot 37NN2C) from the 1/4-inch sample.

Remarks: This bone is burned. The specimen represents either the northern bobwhite (Colinus virginianus) or the scaled quail (Callipepla squamata), both of which are known from the area (Texas Ornithological Society 1984:37-38). The scaled quail is common in arid scrublands and grasslands, while the northern bobwhite can be found in open woods, brushy areas, and field edges (Farrand 1988:188, 193).

\section{Class Mammalia (Mammals)}

\section{ORDER INDETERMINATE}

Material: Unidentifiable fragments were recovered from throughout the site.

Remarks: As with the unidentified vertebrate sample, mammals that could not be identified to order were grouped by animal size category. Counts are presented in Appendix 10. Definitions are as follows: (1) small mammal (up to cottontail rabbit sized); (2) small/medium-sized mammal; (3) mediumsized mammal (raccoon, canid-sized); (4) medium/large-sized mammal; (5) large mammal (deer, pronghorn-sized); (6) large/ very large mammal; (7) very large mammal (bison-sized); (8) mammal, size indeterminate.

\section{ORDER INSECTIVORA(INSECTIVORES)}

Family Soricidae

Blarina sp. (Shrew)

Material: One mandible, left ramus with M1 (Lot 2029) from the $1 / 8$-inch sample.
Remarks: Several shrew genera occur in Texas including Blarina, Cryptotis and Notiosorex. Species of Blarina include $B$. carolinensis (southern short-tailed shrew) and $B$. hylophaga (Elliot's short-tailed shrew) (Davis and Schmidly 1994:18-25). Blarina is the largest of the North American shrews.

ORDER LAGOMORPHA (RABBITS, HARES, AND PIKAS) Family Leporidae (Rabbits and Hares)

Genus Indeterminate

Material: Seventy isolated teeth and skeletal elements from throughout the 1/4-inch sample. An additional 291 specimens were recovered from the $1 / 8$-inch sample.

Remarks: Leporids are represented by two genera in Texas. These include Sylvilagus and Lepus (Schmidly 1983:104115). The species that occur today in or near the area of the site in Williamson County include $S$. floridanus (eastern cottontail), S. audubonii (desert cottontail), S. aquaticus (swamp rabbit), and L. californicus (black-tailed jack rabbit) (Davis 1978:236-244). The morphological similarities and the size overlap between $S$. aquaticus and $L$. californicus, along with common degradation of the bone elements, made identification to either of these species difficult. Hulbert $(1979,1984)$ used discriminant analysis on maxillae, mandibles, and lower third premolars to distinguish between these four taxa. Following Findley et al. (1975), Dalquest et al. (1989) used enamel crenelation patterns of the third lower premolar to separate $S$. floridanus from S. audubonii. Neusius and Flint (1985) further showed that metrical separation of cottontail species can be difficult.

cf. Leporidae (Rabbit)

Material: One alveolar ridge fragment (Lot 17T2), 1 left humerus shaft fragment (Lot 11H), 1 left acetabulum fragment (Lot 11P). An additional 11 specimens were recovered from the 1/8-inch sample.

Remarks: These specimens appear to be rabbit, but could not be positively assigned.

\section{cf. Lepus californicus (Jackrabbit)}

Material: Five specimens from the 1/8-inch sample.

Remarks: These specimens compare favorably with jackrabbit, but could not be positively assigned.

\section{Lepus californicus (Black-tail Jackrabbit)}

Material: Nineteen skeletal elements from throughout the 1/ 4-inch sample (Lot 0, 7I, 10F [n=2] 10K, 10P, 18G, 19I, 22L, 22S, 27CC2D, 29GG1D, 29S2A, 33T1B, 37DB, 37ND, 37S2A, $50 \mathrm{NC}, 51 \mathrm{Z} 2 \mathrm{C}]$. An additional 116 specimens were recovered from the 1/8-inch sample. 
Remarks: While there may be overlap in size between Sylvilagus floridanus and Lepus californicus, the very large size of these specimens suggests they are jackrabbit. $L$. californicus is the only species of Lepus occurring in the area today. The jackrabbit is common in dry scrubland habitats and occasionally inhabits coniferous forests (Davis 1978:237).

\section{Sylvilagus sp. (Rabbits)}

Material: Forty-one skeletal elements from the 1/4-inch sample. An additional 347 specimens were recovered from the 1/8-inch sample.

Remarks: Sylvilagus is represented by three species in the Williamson County area. These include $S$. floridanus (eastern cottontail), S. audubonii (desert cottontail), and $S$. aquaticus (swamp rabbit) (Davis 1978:236-244; Schmidly 1983:104-111). Specimens were identified as Sylvilagus based on their small size. This suggests they probably represent S. audubonii or S. floridanus, and not the larger S. aquaticus. Sylvilagus typically inhabits open country, pastures, and grassy areas, but can also be found in swamps and woodlands. Swamp rabbits are associated primarily with creek and riverine floodplains (Schmidly 1983:109).

\section{cf. Sylvilagus (Rabbits)}

Material: The following were recovered from the 1/4-inch sample: 1 humerus, distal end (Lot 37NN2B), 1 right ulna, semi-lunar notch (Lot 30U1C), 1 left calcaneus, proximal aspect (Lot 36G). An additional five specimens were recorded from the $1 / 8$-inch sample.

Remarks: These specimens compare favorably with Sylvilagus, but could not be positively assigned.

\section{ORDER RODENTIA(RODENTS)}

Family Indeterminate

Material: One incisor (Lot 396).

Remarks: The specimen was recovered from the 1/8-inch sample.

\section{Small Rodent Indeterminate (Mouse-sized)}

Material: Two incisors (Lot 36I, 37NN1A) from the 1/4-inch sample. Fifteen additional specimens were recovered from the $1 / 8$-inch sample.

Remarks: These mouse-sized elements could not be assigned to family.

\section{Small/Medium-sized Rodent Indeterminate (Mouse/rat-sized)}

Material: One right femur shaft (Lot 8P) from the 1/4-inch sample. Four additional elements were recovered from the 1/8-inch sample.
Remarks: These mouse to rat-sized rodent elements could not be assigned to family.

Medium-sized Rodent Indeterminate (Rat/gopher-sized)

Material: Two humeri, distal ends (Lot 25BB2C, 25S1) from the 1/4-inch sample. Forty-two additional specimens from the $1 / 8$-inch sample.

Remarks: These medium-sized rodents could not be assigned to family.

Family Sciuridae (Squirrels)

Sciurus sp. (Tree squirrel)

Material: One right humerus, distal end (Lot 36D), 1 right calcaneus (Lot 11E) from the 1/4-inch sample. A right humerus, proximal end (Lot 1978) was recovered from the 1/8inch sample.

Remarks: The humerus from the 1/8-inch sample was recovered from Feature 245 and is burned. Squirrels in Williamson County and surrounding areas can be divided into ground squirrels (Spermophilus mexicanus [Mexican ground squirrel], $S$. variegatus [rock squirrel], $S$. tridecemlineatus [thirteen-lined ground squirrel], and Cynomys ludovicianus [black-tailed prairie dog]), flying squirrels (Glaucomys volans), and tree squirrels (Sciurus carolinensis [eastern gray squirrel] and S. niger [fox squirrel]). S. niger is the most common tree squirrel in the area (Davis 1978:146-164; Schmidly 1983:119-134). The gray squirrel is more common east of Williamson County. Tree squirrels can be found in a variety of settings, and are common in bottomland areas and upland creeks lined with hardwoods (Schmidly 1983:124, 128).

\section{cf. Spermophilus mexicanus (Mexican Ground Squirrel)}

Material: One left humerus, distal end (Lot 1991) from the 1/ 8-inch sample.

Remarks: This specimen from Late Paleoindian deposits has a distal breadth of $7.5 \mathrm{~mm}$ and is much larger than Sciurus. Other ground squirrels that occur in Texas include $S$. variegatus (rock squirrel), S. tridecemlineatus (thirteen-lined ground squirrel) and S. spilosoma (spotted ground squirrel). Only S. mexicanus occurs in the area today (Davis and Schmidly 1994:104-112). The species typically inhabits grassy or brushy areas.

Family Geomyidae (Pocket Gophers)

cf. Geomys sp. (Pocket Gopher)

Material: One maxilla fragment (Lot 649), 1 lower right incisor (Lot 1991).

Remarks: Both of these specimens are from the 1/8-inch sample. While they compare favorably with pocket gopher, they could not be positively assigned. 
Geomys sp. (Pocket gopher)

Material: One maxillary incisor (Lot 30FF2B), 1 right tibia, distal end (Lot 16F) from the 1/4-inch sample. An additional 101 specimens were identified from the 1/8-inch sample.

Remarks: Three gopher genera occur in Texas today: Thomomys, Geomys, and Cratogeomys (formerly Pappogeomys) (Davis 1978:164-171; Jones and Jones 1992:60-62). Without upper incisors, morphological distinction of gopher genera from skeletal material is difficult. Typically, upper incisors of Thomomys are un-grooved, Cratogeomys shows a single grove, and Geomys has two grooves (Akersten 1973; Schmidly 1977:76).

The classification of Texas geomyids in general is complex (Jones and Jones 1992:60-62). Many of the currently recognized species of Geomys, for example, are identified principally from chromosomal and biochemical differences. Of the three Texas geomyid genera, only Geomys is currently known from the eastern Edwards Plateau. Species include G. bursarius (plains pocket gopher), G. attwateri (Attwater's pocket gopher), and G. texensis (Llano pocket gopher) (Davis 1978:164-171; Schmidly 1983:134-143; Smolen et al. 1993). Geomys is presently absent from the Leander area (Winkler 1990:201). Modern land use patterns and soil erosion account for much of its disappearance (Semken 1961). While no specimens exhibited the incisor morphology typical of Thomomys, species were assigned to Geomys based on modern biogeography. Balinsky (see Chapter 35), however, identified several specimens of Thomomys from the fine-screen sample, suggesting a range extension for this species in central Texas.

Despite the fact that gophers spend much of their time underground, there is sufficient evidence to indicate they were exploited by North American Indians, and therefore should not be ignored as a possible food source for the inhabitants of the site (Shaffer 1991:132-136, 1992, and references therein). Winkler (1990:201) notes that gophers prefer sandy soil and generally avoid clayey soils. Since most of the sediments at the site are clayey deposits, she inferred that gophers were not living at the site, but were transported there. Winkler (1990:201) stated that gophers were one of the most common animals from the site.

Family Cricetidae (New World Rats and Mice) Indeterminate Cricetid

Material: One left calcaneus, distal aspect (Lot 518), 1 right tibia, distal end (Lot 527).

Remarks: Both specimens were recovered from the 1/8-inch sample.

\section{Small Indeterminate Cricetid (Mouse-sized)}

Material: Five specimens from the 1/8-inch sample that could not be assigned to genus.
Medium-sized Indeterminate Cricetid (Rat-sized)

Material: Seven specimens from the $1 / 8$-inch sample that could not be assigned to genus.

cf. Sigmodon hispidus (Hispid Cotton Rat)

Material: One left complete femur shaft (Lot 18n) from the 1/ 4-inch sample; 1 right calcaneus (Lot512) from the 1/8-inch sample.

Remarks: These specimens compare favorably with a hispid cotton rat, though a positive identification could not be made. The femur is from a subadult and shows unfused proximal and distal epiphyses.

\section{Sigmodon hispidus (Hispid Cotton Rat)}

Material: The 1/4-inch sample yielded 1 right mandible with I-M3 (Lot 18G), 1 left mandible with M2 (Lot 36I), 1 left mandible with I-M2 (Lot $18 \mathrm{~N}$ ), and 1 right mandible with I and M3 (Lot 37EC). An additional 22 specimens were recovered from the 1/8-inch sample.

Remarks: Of the three extant Texas Sigmodon species (Jones and Jones 1992:66), only S. hispidus (hispid cotton rat) occurs in the region today. Extant records of S. fulviventer (tawny-bellied cotton rat) were recently reported from the Davis Mountains of the Trans-Pecos region of Texas (Stangl 1992). The yellow-nosed cotton rat (S. ochrognathus) is also restricted in Texas to the western portions of the state (Davis 1978:216). Cotton rats prefer well-drained areas and dense ground vegetation, though they can be found in many vegetative regions (Schmidly 1983:191).

\section{Neotoma sp. (Woodrats)}

Material: One mandibular M1 or M2 (Lot 37RR1A) from the 1/4-inch sample. Forty-six specimens were recovered from the $1 / 8$-inch sample.

Remarks: Only the eastern woodrat (Neotoma floridana) presently occurs in Williamson County, although the specimen may also represent the southern plains woodrat $(N$. micropus) or the white-throated wood rat ( $N$. albigula) (Jones and Jones 1992:66; Schmidly 1983:197-205). N. floridana prefers riparian habitats, while $N$. micropus and N. albigula are more common in semiarid or xeric environments (Davis 1978:221; Schmidly 1983:197, 202). Winkler (1990:202-203) reviewed methods of distinguishing these three species based on dental metrics and stylid development.

\section{cf. Microtus sp. (Vole)}

Material: One right mandible, horizontal ramus fragment with M1 (Lot 626) from the 1/8-inch sample.

Remarks: The specimen compares favorably with vole and 
could represent $M$. pinetorum (woodland vole) or $M$. ochrogaster (prairie vole). These species are difficult to distinguish (Winkler 1990:203).

\section{Ondatra zibethicus (Muskrat)}

Material: One right, upper M3 (Lot 2796).

Remarks: The specimen is from Early Paleoindian deposits in the 1/8-inch sample. Muskrats require aquatic environments and are relatively rare in the central Texas fossil record.

\section{ORDER CARNIVORA(CARNIVORES) \\ Family Indeterminate}

Material: Twenty-five dental and skeletal elements from throughout the site (Lots 12C, 12G, 17BB1 [n=4], 17KK2/ LL1, 21I, 22K, 24Y1C, 25BB1A, 25KK2D [n=2], 27V2B, 27W2B, 29BB1C, 29JJ2B [n=2], 35V2D, 36D, 37CB, 37EB, 37JJ1C, 37NN1B, 37O1D). Seventeen additional specimens were recovered from the $1 / 8$-inch sample.

Remarks: These carnivore teeth and bones are not diagnostic enough for family assignment.

Family Procyonidae (Raccoons and Relatives)

cf. Procyon lotor (Raccoon)

Material: One left upper premolar (Lot 532) from the 1/8inch sample.

Remarks: The specimen is a fragment and could not be positively assigned to species.

\section{Procyon lotor (Raccoon)}

Material: The 1/4-inch sample included 1 left maxillary $\mathrm{Pm} 4$ (Lot 36E), and 1 left mandibular M1 (Lot 15C). A lower, left M1 (Lot 532) was recovered from the 1/8-inch sample.

Remarks: Raccoons occur in many vegetational regions in Texas but prefer hard timbered habitats near larger streams. Raccoons are primarily nocturnal and do not hibernate during the winter (Schmidly 1983:255-256).

Family Mustelidae (Weasels, Minks, and Skunks)

Subfamily Mephitinae (Skunks)

Genus Indeterminate

Material: One left mandibular horizontal ramus with Pm3M1 (Lot 8B) from the 1/4-inch sample.

Remarks: Skunk species whose range currently includes Williamson county include the eastern spotted skunk (Spilogale putorius), the striped skunk (Mephitis mephitis), and the hog-nosed skunk (Conepatus mesoleucus). These skunks occur in a variety of habitats including open fields, forest edges, and woodlands (Schmidly 1983:269283).
Family Canidae (Dogs and Relatives)

cf. Canidae

Material: One right maxilla fragment (Lot 37EA).

Remarks: This bone compares favorably with the family Canidae, though a positive identification could not be made. It is not burned, and remains unlinked to its associated stratum.

\section{cf. Canis (Coyote/wolf/dog)}

Material: The 1/4-inch sample yielded 1 right accessory carpal (Lot 16AA1) and 1 left astragalus (Lot 25Z1D). A left parietal (Lot 480) and left petrosal fragment (Lot 480) were recovered from the $1 / 8$-inch sample.

Remarks: These specimens compare favorably with Canis, though a positive identification could not be made.

Canis sp. (Coyote/wolf/dog)

Material: Twenty-three dental and skeletal elements from throughout the 1/4-inch sample. Four additional specimens were recovered from the $1 / 8$-inch sample.

Remarks: Species of Canis whose ranges have included the project area include $C$. latrans (coyote), C. lupus (gray wolf), C. rufus (red wolf), and C. familiaris (domestic dog) (Davis 1978:123-129; Jones and Jones 1992:68; Schmidly 1983:234-245). Characteristics distinguishing these various taxa are reviewed extensively by Nowak (1979) and Olsen (1985).

Family Felidae (Cats)

Felis rufus (Bobcat)

Material: One left ulna, proximal end (Lot 110) from the 1/4inch sample.

Remarks: Bobcats prefer heavily wooded uplands and bottomland forests (Schmidly 1983:288).

\section{ORDER ARTIODACTYLA (ARTIODACTYLS)}

Family Indeterminate

Material: One hundred six dental and skeletal elements from throughout $1 / 4$-inch sample. Fifty additional specimens were recovered from the $1 / 8$-inch sample.

Remarks: These are primarily small tooth fragments that exhibit artiodactyl morphology but could not be identified to family. Holocene artiodactyls native to the area include deer, pronghorn, and bison.

Medium-sized Artiodactyl Indeterminate (Deer-sized)

Material: Six teeth fragments (Lots 32T1D, 37DD, 37ED [n=2]) and 1 left petrosal fragment (Lot 14B) from the 1/4-inch sample. 
Remarks: These probably represent deer or pronghorn, but could not be positively identified.

Large Artiodactyl Indeterminate (Bison-sized)

Material: One tooth fragment (Lot 21F), 2 rib fragments (Lots 15F, 20I), 1 long bone shaft fragment (Lot 15F).

Remarks: These bovid-sized fragments probably represent bison, but could not be positively identified.

Family Cervidae (Deer and relatives)

cf. Odocoileus (Deer)

Material: The 1/4-inch sample yielded 1 right tibia, distal end (Lot 10D), 1 left fused third and fourth metacarpal, proximal anterior aspect (Lot 19F), 1 fused third and fourth metacarpal, distal end (Lot 36G), 1 left intermediate carpal, anterior aspect (Lot 6D). Three additional specimens were recovered from the 1/8-inch sample

Remarks: These bones compare favorably with deer, but could not be positively identified.

\section{Odocoileus sp. (Deer)}

Material: One hundred forty-eight dental and skeletal elements from the 1/4-inch sample; 153 specimens from the 1/8inch sample.

Remarks: Specimens were distinguished from pronghorn based on Ford's (1990) and Lawrence's (1951) criteria used in conjunction with comparative material. Morphological overlap between Odocoileus virginianus (white-tailed deer) and $O$. hemionus (mule deer) makes species identification difficult with post-cranial material. Currently, only $O$. virginianus inhabits the area (Jones and Jones 1992:72). Whitetailed deer are common in all vegetational zones in Texas, with bottomland hardwoods being the preferred habitat. Mule deer are typically found in more arid settings. Deer remains are common throughout archeological sites in the region.

\section{cf. Antilocapra americana/Odocoileus Indeterminate (Pronghorn/deer)}

Material: One left pubis fragment (Lot 9L) and 1 tibia shaft fragment (Lot 9D) from the 1/4-inch sample.

Remarks: These specimens appear to be either pronghorn or deer.

Antilocapra americana/Odocoileus indeterminate (Pronghorn/deer)

Material: Two hundred ninety-nine dental and skeletal elements from the 1/4-inch sample; 72 specimens from the 1/8inch sample.

Remarks: These specimens are too fragmented or undiagnostic to identify to genus.
Family Antilocapridae

Antilocapra americana (Pronghorn)

Material: The 1/4-inch sample yielded 1 left maxillary M3 (Lot 36E), 1 right maxillary M1 or M2 (Lot 16F) and 1 left fused third and fourth metatarsal, proximal end (Lot 8C). Five specimens were recovered from the $1 / 8$-inch sample including 1 right upper M1 (Lot 390), 1 left upper fourth premolar (Lot 399), 2 tooth enamel fragments (Lot 462), and 1 upper right molar (Lot 507).

Remarks: Currently, pronghorn are restricted to the panhandle and western portion of the state (Davis 1978:248). Formerly, pronghorn occupied the western portion of Texas as far east as Robertson and McLennan counties (Jones and Jones 1992:72). Pronghorn are found in open grassland habitats.

Family Bovidae (Bovids)

cf. Bison (Bison)

Material: The 1/4-inch sample included 1 vertebra neural area (Lot 34NN2B), 1 rib shaft fragment (Lot 35NN1/2D) and 1 right metacarpal, proximal lateral end (Lot 32OO2/PP1A).

Remarks: These specimens compare favorably with bison, but could not be positively assigned.

\section{Bison sp. (Bison)}

Material: The 1/4-inch sample included 32 dental and skeletal elements, predominately from Paleoindian components of the site. Two additional specimens were identified in the 1/8-inch sample.

Remarks: Material was assigned to bison based on morphological features and the temporal setting of the site. In addition to comparative specimens, identification guides were also consulted (Balkwill and Cumbaa 1992; Brown and Gustafson 1989; Olsen 1960). Species identification of fossil bison is problematic. Bison latifrons existed from the Illinoian in North America to possibly the late Pleistocene (McDonald 1981:75). Bison antiquus occurred from the late Pleistocene to roughly 5,000-4,000 в.P. The appearance of modern bison (Bison bison) in the mid-Holocene marks the termination of B. antiquus (McDonald 1981:84). The formerly recognized $B$. occidentalis is now subsumed as a subspecies of $B$. antiquus (B. antiquus occidentalis) (McDonald 1981:82).

McDonald (1981:54-55) showed that limb bones and dentition (both gross morphology and metrics) were not useful in distinguishing between these species. Only identifications based on horn core morphology were considered reliable by McDonald. No horn cores were recovered from the Wilson-Leonard site, thus all specimens were assigned to Bison sp. Based on McDonald's temporal assessment, it seems likely that the Paleoindian associated bison from the Wilson-Leonard site may represent Bison antiquus. 
ORDER PERISSODACTYLA (ODD-TOEDUNGULATES) Family Equidae (Horses)

Equus sp. (Horse)

Material: One complete left central tarsal (Lot 37MM1/2C) from the 1/4-inch sample.

Remarks: This central tarsal represents a small to mediumsized horse. Following the measurements of Driesch (1976:91), it has a greatest breadth of $4.56 \mathrm{~cm}$. Late Pleistocene and early Holocene records of horse in Texas are reviewed by Toomey (1993:407-413). Kurtén and Anderson $(1980: 291)$ noted that terminal dates for native Equus in North America may extend to ca. 8,000 B.P. However, Meltzer and Mead (1983) reported the youngest reliable age for North American Equus as 10,370 \pm 350 B.P. from Jaguar Cave in Idaho. More recently, Toomey (1993:409) reported Equus from Hall's Cave on the western Edwards Plateau of central Texas dating to $8,700-9,200$ в.P. He stated, however, that
"Until more radiocarbon dating...can be done, it would be premature to claim late horse survival in central Texas" (Toomey 1993:409). Though presently uncorrelated to stratum, a more detailed chronological assessment of the Wilson-Leonard specimen could provide insight on this issue.

Toomey (1993:409) noted that all late Pleistocene Equids are considered cursorial grazers and that their presence suggests the presence of open grasslands. A taxonomic assessment of the Wilson-Leonard specimen remains difficult. Small late Pleistocene Equids may be of either the $E$. francisci group (stilt-legged), or the E. alaskae group (stout-legged) (Toomey 1993:408; Winans 1985, 1989). The E. alaskae group of Winans $(1985,1989)$ includes what is most commonly identified as E.conversidens. Distinction between the small stilt- and stout-legged forms is based on cranial and metapodial metrics. Since the Wilson-Leonard sample produced only a single Equid tarsal, a more detailed assignment beyond Equus sp. could not be made.

\section{REFERENCES CITED}

Akersten, W. A.

1973 Upper Incisor Grooves in the Geomyinae. Journal of Mammalogy 54(2):349-355.

Auffenberg, W.

1969 The Fossil Snakes of Florida. Tulane Studies in Zoology 10:131-216.

Balkwill, D. M., and S. L. Cumbaa

1992 A Guide to the Identification of Postcranial Bones of Bos taurus and Bison bison. Syllogeus No. 71. Canadian Museum of Nature, Ottawa.

Behler, J. L., and F. W. King

1985 The Audubon Society Field Guide to North American Reptiles and Amphibians. Alfred A. Knopf, New York.

Brown, C. L., and C. E. Gustafson

1989 A Key to Postcranial Skeletal Remains of Cattle/Bison, Elk, and Horse. Reports of Investigations No. 57. Laboratory of Anthropology, Washington State University, Pullman.

Dalquest, W. W., F. B. Stangl, Jr., and J. V. Grimes

1989 The Third Lower Premolar of the Cottontail, Genus Sylvilagus, and its Value in the Discrimination of Three Species. The American Midland Naturalist 121:293-301.

Davis, W. B.

1978 The Mammals of Texas. Bulletin 41. Texas Parks and Wildlife Department, Austin.

Davis W. B., and D. J. Schmidly

1994 The Mammals of Texas. Texas Parks and Wildlife Press, Austin.
Dixon, J. R.

1987 Amphibians and Reptiles of Texas: With Keys, Taxonomic Synopses, Bibliography, and Distribution Maps. Texas A\&M University Press, College Station.

Driesch, A. von den

1976 A Guide to the Measurement of Animal Bones from Archaeological Sites. Bulletin No. 1. Peabody Museum of Archaeology and Ethnology, Harvard University. Cambridge, Massachusetts.

Ernst, C. H., and R. W. Barbour

1972 Turtles of the United States. The University Press of Kentucky Press, Lexington.

1989 Turtles of the World. Smithsonian Institution, Washington, D. C.

Fenneman, N. M.

1938 Physiography of Eastern United States. McGraw-Hill, New York.

Findley, J. S., A. H. Harris, D. E. Wilson, and C. Jones

1975 Mammals of New Mexico. University of New Mexico Press, Albuquerque.

Ford, P. J.

1990 Antelope, Deer, Bighorn Sheep and Mountain Goats: A Guide to the Carpals. Journal of Ethnobiology 10(2):169181.

Holman, J. A.

1981 A Review of North American Tertiary Snakes. Publications of Michigan State University Museum Paleontology Series 1(6):203-260. 
Hulbert, R. C., Jr.

1979 Linear Discriminant Analysis and Variability of Pleistocene and Holocene Leporidae of Texas. Unpublished Master's thesis, Department of Geological Sciences, The University of Texas at Austin.

1984 Latest Pleistocene and Holocene Leporid Faunas from Texas: Their Composition, Distribution and Climatic Implications. Southwestern Naturalist 29:197-210.

Jones, J. K., Jr., and C. Jones

1992 Revised Checklist of Recent Land Mammals of Texas, With Annotations. The Texas Journal of Science 44:53-74.

Kurtén, B., and E. Anderson

1980 Pleistocene Mammals of North America. Columbia University Press, New York.

Lawrence, B.

1951 Post-Cranial Skeletal Characters of Deer, Pronghorn, and Sheep-Goat With Notes on Bos and Bison. Papers of the Peabody Museum of American Archaeology and Ethnology Vol. 35, No. 2, Part 2. Harvard University, Cambridge.

McDonald, J.

1981 North American Bison: Their Classification and Evolution. University of California Press, Los Angeles.

Meylan, P. A.

1982 The Squamate Reptiles of the Inglis Ia Fauna (Irvingtonian: Citrus County, Florida). Bulletin of the Florida State Museum, Biological Sciences 27(3):1-85.

Neusius, S. W., and P. R. Flint

1985 Cottontail Species Identification: Zooarchaeological Use of Mandibular Measurements. Journal of Ethnobiology 5:51-58.

Nowak, R. M.

1979 North American Quaternary Canis. Monograph of the Museum of Natural History, University of Kansas No. 6. University of Kansas, Lawrence.

Olsen, S. J.

1960 Post-Cranial Skeletal Characters of $\underline{\text { Bison }}$ and $\underline{\text { Bos. }}$. Papers of the Peabody Museum of American Archaeology and Ethnology, Vol. 35, No. 4. Harvard University, Cambridge.

1985 Origins of the Domestic Dog: The Fossil Record. University of Arizona Press, Tucson.

Romer, A. S., and T. S. Parsons

1977 The Vertebrate Body, 5th edition. W. B. Saunders Company, Philadelphia.

Schmidly, D. J.

1977 The Mammals of Trans-Pecos Texas. Texas A\&M University Press, College Station.

1983 Texas Mammals East of the Balcones Fault Zone. Texas A\&M University Press, College Station.

Seidel, M. E., and H. M. Smith

1986 Chrysemys, Pseudemys, Trachemys (Testudines: Emydi- dae): Did Agassiz Have it Right? Herpetologica 42:242-248.

Semken, H. A., Jr.

1961 Fossil Vertebrates from Longhorn Cavern, Burnet County, Texas. The Texas Journal of Science 13:290-310.

Shaffer, B. S.

1991 The Economic Importance of Vertebrate Faunal Remains from the NAN Ruin (LA15049), a Classic Mimbres Pueblo Site, Grant County, New Mexico. Unpublished Master's thesis, Department of Anthropology, Texas A\&M University, College Station.

1992 Interpretation of Gopher Remains from Southwestern Archaeological Assemblages. American Antiquity 57:683-691.

Smolen, M. J., R. M. Pitts, and J. W. Bickham

1993 A New Subspecies of Pocket Gopher (Geomys) from Texas (Mammalia: Rodentia: Geomyidae). Proceedings of the Biological Society of Washington 106:5-23.

Sobolik, K. D., and D. G. Steele

1996 A Turtle Atlas to Facilitate Archaeological Identifications. Mammoth Site of Hot Springs, South Dakota, Inc. Fenske Companies, Rapid City, South Dakota.

Stangl, F. B., Jr.

1992 First Record of Sigmodon fulviventer in Texas: Natural History and Cytogenetic Observations. The Southwestern Naturalist 37:213-214.

Tennant, A.

1985 A Field Guide to Texas Snakes. Texas Monthly Press, Austin, Texas.

Texas Ornithological Society

1984 Checklist of the Birds of Texas, 2nd edition. Hart Graphics, Austin, Texas.

Toomey, R. S., III

1993 Late Pleistocene and Holocene Faunal and Environmental Changes at Hall's Cave, Kerr County, Texas. Unpublished Ph.D. dissertation, Department of Geological Sciences, The University of Texas at Austin.

Welton, B. J., and R. F. Farish

1993 The Collector's Guide to Fossil Sharks and Rays from the Cretaceous of Texas. Before Time Publishers, U.S.A.

Winans, M. C.

1985 Revision of North American Fossil Species of the Genus Equus (Mammalia: Perissodactyla: Equidae). Unpublished Ph.D. dissertation, Department of Geological Sciences, The University of Texas at Austin.

1989 A Quantitative Study of North American Fossil Species of the Genus Equus. In The Evolution of Perissodactyls, edited by Donald R. Prothero, and Robert M. Schoch, pp. 262-297. Clarendon Press, New York.

Winkler, A. J.

1990 Small Mammals from a Holocene Sequence in Central Texas and Their Paleoenvironmental Implications. The Southwestern Naturalist 35:199-205. 
APPENDIX 10: PROVENIENCE OF FAUNAL REMAINS

by Barry W. Baker 
TABLE A10-1

Provenience of Faunal Remains Recovered from 1/4-inch Screens, TxDOT Excavations

\begin{tabular}{|c|c|c|c|c|c|c|c|c|}
\hline Square & Level & Lot & Unit & Cultural Affinity & Feature & Taxon & Element & No. \\
\hline Surface & 0 & 0 & Unknown & Unassigned & & Antilocapra/Odocoileus & Distal fibula & 1 \\
\hline Surface & 0 & 0 & Unknown & Unassigned & & Antilocapra/Odocoileus & Femur & 1 \\
\hline Surface & 0 & 0 & Unknown & Unassigned & & Antilocapra/Odocoileus & Metapodial & 1 \\
\hline Surface & 0 & 0 & Unknown & Unassigned & & Antilocapra/Odocoileus & Proximal sesamoid & 1 \\
\hline Surface & 0 & 0 & Unknown & Unassigned & & Antilocapra/Odocoileus & Tibia & 1 \\
\hline Surface & 0 & 0 & Unknown & Unassigned & & Artiodactyla & Calcaneus & 1 \\
\hline Surface & 0 & 0 & Unknown & Unassigned & & Artiodactyla & Tooth, perm./decid. ind. & 3 \\
\hline Surface & 0 & 0 & Unknown & Unassigned & & Kinosternidae & Peripheral & 1 \\
\hline Surface & 0 & 0 & Unknown & Unassigned & & Kinosternidae & Plastron fragment ind. & 1 \\
\hline Surface & 0 & 0 & Unknown & Unassigned & & Leporidae & Humerus & 1 \\
\hline Surface & 0 & 0 & Unknown & Unassigned & & Lepus californicus & Astragalus & 1 \\
\hline Surface & 0 & 0 & Unknown & Unassigned & & Mammalia (Large) & Indeterminate & 1 \\
\hline Surface & 0 & 0 & Unknown & Unassigned & & Mammalia (Large) & Long bone & 3 \\
\hline Surface & 0 & 0 & Unknown & Unassigned & & Mammalia (Large) & Pelvis & 2 \\
\hline Surface & 0 & 0 & Unknown & Unassigned & & Mammalia (Large) & Vertebra & 1 \\
\hline Surface & 0 & 0 & Unknown & Unassigned & & Mammalia (Medium/large) & Caudal vertebra & 1 \\
\hline Surface & 0 & 0 & Unknown & Unassigned & & Mammalia (Medium/large) & Indeterminate & 9 \\
\hline Surface & 0 & 0 & Unknown & Unassigned & & Mammalia (Medium/large) & Long bone & 3 \\
\hline Surface & 0 & 0 & Unknown & Unassigned & & Odocoileus sp. & Calcaneus & 1 \\
\hline Surface & 0 & 0 & Unknown & Unassigned & & Odocoileus sp. & Metapodial & 1 \\
\hline Surface & 0 & 0 & Unknown & Unassigned & & Odocoileus sp. & Permanent tooth & 2 \\
\hline Surface & 0 & 0 & Unknown & Unassigned & & Odocoileus sp. & Prox. phalange of paradigit & 1 \\
\hline Surface & 0 & 0 & Unknown & Unassigned & & Vertebrata & Indeterminate & 132 \\
\hline W0/N8 & 8 & $50 \mathrm{HB}$ & IIIlc & M. Archaic & BRM2 & Vertebrata & Indeterminate & 1 \\
\hline W0/N8 & 8 & $50 \mathrm{HD}$ & IIIIc & M. Archaic & BRM2 & Mammalia (Large) & Indeterminate & 2 \\
\hline W0/N8 & 8 & $50 \mathrm{HD}$ & IIII & M. Archaic & BRM2 & Mammalia (Medium/large) & Indeterminate & 1 \\
\hline W0/N8 & 9 & $50 \mathrm{ID}$ & IIIlc & M. Archaic & BRM2 & Small/Medium Vertebrata & Long bone & 1 \\
\hline W0/N8 & 10 & $50 \mathrm{JA}$ & IIIc & M. Archaic & BRM2 & Mammalia (Medium/large) & Indeterminate & 2 \\
\hline W0/N8 & 10 & $50 \mathrm{JA}$ & IIIc & M. Archaic & BRM2 & Testudinata & Shell fragment & 1 \\
\hline W0/N8 & 10 & $50 \mathrm{JA}$ & IIIIc & M. Archaic & BRM2 & Vertebrata & Indeterminate & 9 \\
\hline W0/N8 & 10 & $50 \mathrm{JB}$ & IIIC & M. Archaic & BRM2 & Mammalia (Medium/large) & Indeterminate & 4 \\
\hline W0/N8 & 10 & $50 \mathrm{JB}$ & IIIc & M. Archaic & BRM2 & Vertebrata & Indeterminate & 17 \\
\hline W0/N8 & 10 & $50 \mathrm{JC}$ & IIIC & M. Archaic & BRM2 & Vertebrata & Indeterminate & 2 \\
\hline W0/N8 & 10 & $50 \mathrm{JD}$ & IIIIc & M. Archaic & BRM2 & Odocoileus sp. & Prox. phalange of paradigit & 1 \\
\hline W0/N8 & 10 & $50 J \mathrm{D}$ & IIIC & M. Archaic & BRM2 & Vertebrata & Indeterminate & 5 \\
\hline W0/N8 & 11 & $50 \mathrm{KA}$ & IIIC & Early/M. Archaic & BRM2 & Mammalia (Medium/large) & Indeterminate & 1 \\
\hline W0/N8 & 11 & $50 \mathrm{KA}$ & IIII & Early/M. Archaic & BRM2 & Vertebrata & Indeterminate & 4 \\
\hline W0/N8 & 11 & $50 \mathrm{~KB}$ & IIIc & Early/M. Archaic & BRM2 & Testudinata & Shell fragment & 3 \\
\hline W0/N8 & 11 & $50 \mathrm{~KB}$ & IIIlc & Early/M. Archaic & BRM2 & Vertebrata & Indeterminate & 12 \\
\hline W0/N8 & 11 & $50 \mathrm{KC}$ & IIIc & Early/M. Archaic & BRM2 & Mammalia (Large) & Long bone & 1 \\
\hline W0/N8 & 11 & $50 \mathrm{KC}$ & IIIc & Early/M. Archaic & BRM2 & Vertebrata & Indeterminate & 2 \\
\hline W0/N8 & 11 & $50 \mathrm{KD}$ & IIIIc & Early/M. Archaic & BRM2 & Mammalia (Medium/large) & Indeterminate & 1 \\
\hline W0/N8 & 11 & $50 \mathrm{KD}$ & IIIC & Early/M. Archaic & BRM2 & Odocoileus sp. & Proximal phalange & 1 \\
\hline W0/N8 & 11 & $50 \mathrm{KD}$ & IIIc & Early/M. Archaic & BRM2 & Vertebrata & Indeterminate & 7 \\
\hline W0/N8 & 12 & $50 \mathrm{LA}$ & III & E. Archaic & & Mammalia (Medium/large) & Indeterminate & 2 \\
\hline W0/N8 & 12 & $50 \mathrm{LA}$ & IIII & E. Archaic & & Mammalia (Medium/large) & Long bone & 3 \\
\hline W0/N8 & 12 & 50LA & IIII & E. Archaic & & Medium/Large Vertebrata & Indeterminate & 1 \\
\hline W0/N8 & 12 & $50 \mathrm{LA}$ & III & E. Archaic & & Small/Medium Vertebrata & Long bone & 1 \\
\hline W0/N8 & 12 & $50 \mathrm{LA}$ & III & E. Archaic & & Vertebrata & Indeterminate & 3 \\
\hline W0/N8 & 12 & $50 \mathrm{LB}$ & IIII & E. Archaic & & Kinosternidae & Pygal & 1 \\
\hline W0/N8 & 12 & $50 \mathrm{LB}$ & III & E. Archaic & & Vertebrata & Indeterminate & 3 \\
\hline W0/N8 & 12 & $50 \mathrm{LC}$ & III & E. Archaic & & Mammalia (Large) & Indeterminate & 1 \\
\hline W0/N8 & 12 & $50 \mathrm{LC}$ & III & E. Archaic & & Vertebrata & Indeterminate & 5 \\
\hline W0/N8 & 13 & $50 \mathrm{MA}$ & III & E. Archaic & & Vertebrata & Indeterminate & 1 \\
\hline W0/N8 & 13 & $50 \mathrm{MC}$ & III & E. Archaic & & Mammalia (Large) & Indeterminate & 2 \\
\hline W0/N8 & 13 & $50 \mathrm{MC}$ & III & E. Archaic & & Mammalia (Medium/large) & Indeterminate & 6 \\
\hline W0/N8 & 13 & 50MD & III & E. Archaic & & Medium/Large Vertebrata & Long bone & 1 \\
\hline W0/N8 & 14 & $50 \mathrm{NA}$ & III & E. Archaic & & Mammalia (Large) & Long bone & 1 \\
\hline W0/N8 & 14 & $50 \mathrm{NA}$ & III & E. Archaic & & Mammalia (Medium/large) & Indeterminate & 2 \\
\hline W0/N8 & 14 & 50NA & III & E. Archaic & & Vertebrata & Indeterminate & 5 \\
\hline W0/N8 & 14 & $50 \mathrm{NB}$ & IIII & E. Archaic & & Vertebrata & Indeterminate & 1 \\
\hline W0/N8 & 14 & $50 \mathrm{NC}$ & III & E. Archaic & & Lepus californicus & Calcaneus & 1 \\
\hline W0/N8 & 14 & $50 \mathrm{NC}$ & III & E. Archaic & & Vertebrata & Indeterminate & 3 \\
\hline W0/N8 & 14 & $50 \mathrm{NC}$ & III & E. Archaic & & Vertebrata & Long bone & 1 \\
\hline W0/N8 & 15 & $50 \mathrm{OC}$ & III & E. Archaic & & Kinosternidae & Peripheral & 1 \\
\hline
\end{tabular}




\begin{tabular}{|c|c|c|c|c|c|c|c|c|}
\hline Square & Level & Lot & Unit & Cultural Affinity & Feature & Taxon & Element & No. \\
\hline$\overline{\mathrm{W} 0 / \mathrm{N} 8}$ & 15 & $500 D$ & IIII & E. Archaic & & Vertebrata & Indeterminate & 2 \\
\hline W0/N8 & 16 & 50PA & III & E. Archaic & & Vertebrata & Indeterminate & 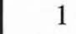 \\
\hline W0/N8 & 17 & $50 \mathrm{QB}$ & IIII & E. Archaic & & Vertebrata & Indeterminate & 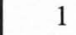 \\
\hline W0/N8 & 18 & 50RBD & III & E. Archaic & & Mammalia (Medium/large) & Long bone & ( \\
\hline W0/N8 & 18 & 50RBD & III & E. Archaic & & Vertebrata & Indeterminate & . \\
\hline W0/N8 & 20 & $50 \mathrm{TD}$ & III & E. Archaic & & Mammalia (Medium/large) & Indeterminate & \\
\hline W0/N8 & 24 & $50 X A$ & II & L. Paleo. & & Vertebrata & Indeterminate & \\
\hline W0/N8 & 24 & $50 \times B$ & III & L. Paleo. & & Small/Medium Vertebrata & Long bone & . \\
\hline W0/N8 & 24 & $50 \times C$ & II & L. Paleo. & & Medium/Large Vertebrata & Indeterminate & \\
\hline W0/N8 & 24 & $50 \times C$ & III & L. Paleo. & & Vertebrata & Indeterminate & \\
\hline W0/N8 & 24 & $50 \times D$ & III & L. Paleo. & & Vertebrata & Indeterminate & \\
\hline W0/N8 & 25 & 50YA & I/II & L. Paleo. & & Medium/Large Vertebrata & Long bone & \\
\hline W0/N8 & 25 & 50YA & I/II & L. Paleo. & & Vertebrata & Indeterminate & \\
\hline W0/N8 & 25 & $50 \mathrm{YB}$ & $\mathrm{I} / \mathrm{II}$ & L. Paleo. & & Medium/Large Vertebrata & Long bone & \\
\hline W0/N8 & 25 & $50 \mathrm{YC}$ & I/II & L. Paleo. & & Vertebrata & Indeterminate & \\
\hline W0/N8 & 26 & $50 \mathrm{ZA}$ & I & Paleoindian & & Mammalia (Large) & Tooth, perm./decid. ind. & \\
\hline W0/N8 & 26 & $50 \mathrm{ZB}$ & |I & Paleoindian & & Mammalia (Medium/large) & Tooth, perm./decid. ind. & \\
\hline W0/N8 & 26 & $50 \mathrm{ZD}$ & I & Paleoindian & & Vertebrata & Indeterminate & \\
\hline W0/N8 & $26 \mathrm{~B}$ & $50 \mathrm{Z} 2 \mathrm{C}$ & II & Paleoindian & & Mammalia (Medium/large) & Tooth, perm./decid. ind. & \\
\hline W0/N8 & $26 \mathrm{~B}$ & $50 \mathrm{Z} 2 \mathrm{C}$ & I & Paleoindian & & Small/Medium Vertebrata & Indeterminate & \\
\hline W0/N8 & $26 \mathrm{~B}$ & $50 \mathrm{Z} 2 \mathrm{C}$ & I & Paleoindian & & Small/Medium Vertebrata & Long bone & \\
\hline W0/N8 & $26 \mathrm{~B}$ & $50 \mathrm{Z} 2 \mathrm{C}$ & |I & Paleoindian & & Vertebrata & Indeterminate & \\
\hline W0/N8 & $27 \mathrm{~A}$ & 50AA1A & I & Paleoindian & & Vertebrata & Indeterminate & \\
\hline W0/N8 & $27 \mathrm{~A}$ & 50AA1A & I & Paleoindian & & Vertebrata & Long bone & \\
\hline W0/N8 & $27 \mathrm{~A}$ & $50 \mathrm{AA} 1 \mathrm{~B}$ & II & Paleoindian & & Mammalia (Medium) & Ulna & \\
\hline W0/N8 & $27 \mathrm{~A}$ & 50AA1D & II & Paleoindian & & Vertebrata & Indeterminate & 10 \\
\hline W0/N8 & 27B & $50 \mathrm{AA} 2 \mathrm{~A}$ & I & Paleoindian & & Mammalia (Medium) & Axis & \\
\hline W0/N8 & $27 \mathrm{~B}$ & $50 \mathrm{AA} 2 \mathrm{~A}$ & II & Paleoindian & & Mammalia (Medium/large) & Indeterminate & . \\
\hline W0/N8 & $27 \mathrm{~B}$ & 50AA2A & I & Paleoindian & & Vertebrata & Indeterminate & 33 \\
\hline W0/N8 & 27B & $50 \mathrm{AA} 2 \mathrm{~B}$ & I & Paleoindian & & Mammalia (Medium) & Cranium & \\
\hline W0/N8 & $27 \mathrm{~B}$ & $50 \mathrm{AA} 2 \mathrm{~B}$ & I & Paleoindian & & Vertebrata & Indeterminate & \\
\hline W0/N8 & $27 \mathrm{~B}$ & $50 \mathrm{AA} 2 \mathrm{C}$ & I & Paleoindian & & Vertebrata & Indeterminate & \\
\hline W0/N8 & 27B & 50AA2D & I & Paleoindian & & Mammalia (Medium/large) & Indeterminate & \\
\hline W0/N8 & $27 \mathrm{~B}$ & 50AA2D & II & Paleoindian & & Vertebrata & Indeterminate & 10 \\
\hline W0/N8 & 28 & $50 \mathrm{BB}$ & II & Paleoindian & & Mammalia (Medium/large) & Indeterminate & \\
\hline W0/N8 & $28 \mathrm{~A}$ & $50 \mathrm{BB} 1 \mathrm{~A}$ & I & Paleoindian & & Vertebrata & Indeterminate & ( \\
\hline W0/N8 & $28 \mathrm{~A}$ & 50BB1B & I & Paleoindian & & Mammalia (Medium/large) & Indeterminate & 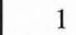 \\
\hline W0/N8 & $28 \mathrm{~A}$ & 50BB1B & I & Paleoindian & & Vertebrata & Indeterminate & \\
\hline W0/N8 & $28 \mathrm{~A}$ & $50 \mathrm{BB} 1 \mathrm{C}$ & I & Paleoindian & & Vertebrata & Indeterminate & . \\
\hline W0/N8 & $28 \mathrm{~A}$ & 50BB1D & I & Paleoindian & & Vertebrata & Indeterminate & 2 \\
\hline W0/N8 & 28B & $50 \mathrm{BB} 2 \mathrm{~A}$ & I & Paleoindian & & Mammalia (Medium/large) & Indeterminate & 1 \\
\hline W0/N8 & 28B & $50 \mathrm{BB} 2 \mathrm{~A}$ & I & Paleoindian & & Vertebrata & Indeterminate & 1 \\
\hline W0/N8 & $28 \mathrm{~B}$ & 50BB2D & I & Paleoindian & & Vertebrata & Indeterminate & 1 \\
\hline W0/N8 & $29 \mathrm{~A}$ & $50 \mathrm{CC} 1 \mathrm{~A}$ & I & Paleoindian & & Vertebrata & Indeterminate & 2 \\
\hline W0/N8 & $29 \mathrm{~A}$ & $50 \mathrm{CC} 1 \mathrm{~A}$ & I & Paleoindian & & Vertebrata & Long bone & \\
\hline W0/N8 & $29 \mathrm{~A}$ & $50 \mathrm{CC} 1 \mathrm{~B}$ & I & Paleoindian & & Vertebrata & Indeterminate & 11 \\
\hline W0/N8 & $29 \mathrm{~A}$ & $50 \mathrm{CC} 1 \mathrm{~B}$ & I & Paleoindian & & Vertebrata & Long bone & 1 \\
\hline W0/N8 & $29 \mathrm{~A}$ & $50 \mathrm{CC} 1 \mathrm{C}$ & I & Paleoindian & & Vertebrata & Indeterminate & 3 \\
\hline W0/N8 & $29 \mathrm{~A}$ & 50CC1D & I & Paleoindian & & Vertebrata & Indeterminate & \\
\hline W0/N8 & 29B & $50 \mathrm{CC} 2 \mathrm{~A}$ & I & Paleoindian & & Vertebrata & Indeterminate & 1 \\
\hline W0/N8 & $29 \mathrm{~B}$ & $50 \mathrm{CC} 2 \mathrm{~B}$ & I & Paleoindian & & Vertebrata & Indeterminate & 1 \\
\hline W0/N8 & $29 \mathrm{~B}$ & $50 \mathrm{CC} 2 \mathrm{C}$ & I & Paleoindian & & Vertebrata & Indeterminate & 2 \\
\hline W0/N8 & 29B & $50 \mathrm{CC} 2 \mathrm{D}$ & I & Paleoindian & & Vertebrata & Indeterminate & 2 \\
\hline W0/N8 & 30 & 50DDA & |I & Paleoindian & & Vertebrata & Indeterminate & 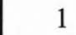 \\
\hline W0/N8 & 30 & $50 \mathrm{DDB}$ & I & Paleoindian & & Mammalia (Medium/large) & Long bone & 1 \\
\hline W0/N8 & 30 & 50DDB & II & Paleoindian & & Vertebrata & Indeterminate & 1 \\
\hline W0/N8 & $33 \mathrm{~A} \& \mathrm{~B}$ & 50GG1\&2 & II & Paleoindian & & Vertebrata & Indeterminate & \\
\hline W0/N8 & $33 \mathrm{~A} \& \mathrm{~B}$ & $50 \mathrm{GG} 1 \& 2$ & II & Paleoindian & & Vertebrata & Indeterminate & 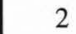 \\
\hline W0/N8 & $34 \mathrm{~A} \& \mathrm{~B}$ & $50 \mathrm{HH} 1 \& 2$ & II & Paleoindian & & Vertebrata & Indeterminate & \\
\hline W0/N8 & $35 \mathrm{~A} \& \mathrm{~B}$ & 50LL1\&2 & II & Paleoindian & & Vertebrata & Indeterminate & ( \\
\hline W0/N8 & $37 \mathrm{~A} \& \mathrm{~B}$ & $50 \mathrm{KK} 1 \& 2$ & II & Paleoindian & & Vertebrata & Indeterminate & ( \\
\hline $\mathrm{E} 2 / \mathrm{N} 8$ & 7 & $51 \mathrm{GA}$ & IIIc & Middle/L. Archaic & BRM2 & Vertebrata & Indeterminate & \\
\hline $\mathrm{E} 2 / \mathrm{N} 8$ & 8 & $51 \mathrm{HD}$ & IIII & Middle/L. Archaic & BRM2 & Mammalia (Medium/large) & Indeterminate & \\
\hline $\mathrm{E} 2 / \mathrm{N} 8$ & 9 & $51 \mathrm{IB}$ & IIII & M. Archaic & BRM2 & Vertebrata & Indeterminate & \\
\hline $\mathrm{E} 2 / \mathrm{N} 8$ & 10 & $51 \mathrm{JB}$ & IIIC & M. Archaic & BRM2 & Leporidae & Mandible & \\
\hline $\mathrm{E} 2 / \mathrm{N} 8$ & 10 & $51 \mathrm{JB}$ & IIII & M. Archaic & BRM2 & Leporidae & Permanent tooth & 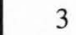 \\
\hline $\mathrm{E} 2 / \mathrm{N} 8$ & 10 & $51 \mathrm{JB}$ & IIII & M. Archaic & BRM2 & Vertebrata & Indeterminate & . \\
\hline
\end{tabular}




\begin{tabular}{|c|c|c|c|c|c|c|c|c|}
\hline Square & Level & Lot & Unit & Cultural Affinity & Feature & Taxon & Element & No. \\
\hline E2/N8 & 11 & $51 \mathrm{KA}$ & IIIc & M. Archaic & BRM2 & Antilocapra/Odocoileus & Fused 3rd \& 4th metacarpal & 1 \\
\hline $\mathrm{E} 2 / \mathrm{N} 8$ & 11 & $51 \mathrm{KA}$ & IIIc & M. Archaic & BRM2 & Antilocapra/Odocoileus & Humerus & 1 \\
\hline $\mathrm{E} 2 / \mathrm{N} 8$ & 11 & $51 \mathrm{KA}$ & IIIc & M. Archaic & BRM2 & Leporidae & Mandible & 1 \\
\hline $\mathrm{E} 2 / \mathrm{N} 8$ & 11 & $51 \mathrm{KA}$ & IIIc & M. Archaic & BRM2 & Leporidae & Permanent tooth & 3 \\
\hline $\mathrm{E} 2 / \mathrm{N} 8$ & 11 & $51 \mathrm{KA}$ & IIIc & M. Archaic & BRM2 & Mammalia (Medium/large) & Indeterminate & 3 \\
\hline E2/N8 & 11 & $51 \mathrm{KA}$ & IIIc & M. Archaic & BRM2 & Odocoileus sp. & Fused 3rd \& 4th metatarsal & 1 \\
\hline $\mathrm{E} 2 / \mathrm{N} 8$ & 11 & $51 \mathrm{KA}$ & IIIIc & M. Archaic & BRM2 & Vertebrata & Indeterminate & 7 \\
\hline $\mathrm{E} 2 / \mathrm{N} 8$ & 11 & $51 \mathrm{~KB}$ & IIIc & M. Archaic & BRM2 & Mammalia (Large) & Long bone & 2 \\
\hline $\mathrm{E} 2 / \mathrm{N} 8$ & 11 & $51 \mathrm{~KB}$ & IIIc & M. Archaic & BRM2 & Vertebrata & Indeterminate & 1 \\
\hline $\mathrm{E} 2 / \mathrm{N} 8$ & 11 & $51 \mathrm{KC}$ & IIIc & M. Archaic & BRM2 & Mammalia (Large) & Indeterminate & 1 \\
\hline $\mathrm{E} 2 / \mathrm{N} 8$ & 11 & $51 \mathrm{KC}$ & IIIc & M. Archaic & BRM2 & Mammalia (Medium) & Ulna & 1 \\
\hline $\mathrm{E} 2 / \mathrm{N} 8$ & 11 & $51 \mathrm{KC}$ & IIIc & M. Archaic & BRM2 & Mammalia (Medium/large) & Indeterminate & 4 \\
\hline $\mathrm{E} 2 / \mathrm{N} 8$ & 11 & $51 \mathrm{KC}$ & IIIc & M. Archaic & BRM2 & Mammalia (Medium/large) & Long bone & 1 \\
\hline $\mathrm{E} 2 / \mathrm{N} 8$ & 11 & $51 \mathrm{KC}$ & IIIc & M. Archaic & BRM2 & Vertebrata & Indeterminate & 5 \\
\hline $\mathrm{E} 2 / \mathrm{N} 8$ & 11 & $51 \mathrm{KD}$ & IIIc & M. Archaic & BRM2 & Vertebrata & Indeterminate & 2 \\
\hline $\mathrm{E} 2 / \mathrm{N} 8$ & 12 & $51 \mathrm{LA}$ & III & M. Archaic & & Mammalia (Medium/large) & Indeterminate & 1 \\
\hline $\mathrm{E} 2 / \mathrm{N} 8$ & 12 & $51 \mathrm{LA}$ & III & M. Archaic & & Mammalia (Medium/large) & Long bone & 1 \\
\hline $\mathrm{E} 2 / \mathrm{N} 8$ & 12 & $51 \mathrm{LA}$ & III & M. Archaic & & Vertebrata & Indeterminate & 1 \\
\hline $\mathrm{E} 2 / \mathrm{N} 8$ & 12 & $51 \mathrm{LC}$ & III & M. Archaic & & Mammalia (Large) & Long bone & 1 \\
\hline $\mathrm{E} 2 / \mathrm{N} 8$ & 12 & $51 \mathrm{LC}$ & III & M. Archaic & & Mammalia (Medium/large) & Indeterminate & 2 \\
\hline $\mathrm{E} 2 / \mathrm{N} 8$ & 12 & $51 \mathrm{LC}$ & III & M. Archaic & & Mammalia (Medium/large) & Long bone & 2 \\
\hline $\mathrm{E} 2 / \mathrm{N} 8$ & 12 & $51 \mathrm{LC}$ & III & M. Archaic & & Vertebrata & Indeterminate & 2 \\
\hline $\mathrm{E} 2 / \mathrm{N} 8$ & 13 & $51 \mathrm{MA}$ & III & M. Archaic & & Mammalia (Large) & Indeterminate & 1 \\
\hline $\mathrm{E} 2 / \mathrm{N} 8$ & 13 & 51MA & III & M. Archaic & & Mammalia (Medium/large) & Indeterminate & 1 \\
\hline $\mathrm{E} 2 / \mathrm{N} 8$ & 13 & $51 \mathrm{MB}$ & III & M. Archaic & & Mammalia (Medium/large) & Indeterminate & 2 \\
\hline $\mathrm{E} 2 / \mathrm{N} 8$ & 13 & $51 \mathrm{MB}$ & III & M. Archaic & & Mammalia (Medium/large) & Long bone & 2 \\
\hline $\mathrm{E} 2 / \mathrm{N} 8$ & 13 & $51 \mathrm{MC}$ & III & M. Archaic & & Mammalia (Medium/large) & Long bone & 1 \\
\hline $\mathrm{E} 2 / \mathrm{N} 8$ & 13 & $51 \mathrm{MC}$ & III & M. Archaic & & Vertebrata & Indeterminate & 8 \\
\hline $\mathrm{E} 2 / \mathrm{N} 8$ & 13 & $51 \mathrm{MD}$ & III & M. Archaic & & Mammalia (Medium/large) & Flat bone & 3 \\
\hline $\mathrm{E} 2 / \mathrm{N} 8$ & 13 & $51 \mathrm{MD}$ & III & M. Archaic & & Mammalia (Medium/large) & Indeterminate & 5 \\
\hline $\mathrm{E} 2 / \mathrm{N} 8$ & 13 & $51 \mathrm{MD}$ & III & M. Archaic & & Mammalia (Medium/large) & Long bone & 2 \\
\hline $\mathrm{E} 2 / \mathrm{N} 8$ & 13 & $51 \mathrm{MD}$ & III & M. Archaic & & Medium/Large Vertebrata & Indeterminate & 4 \\
\hline $\mathrm{E} 2 / \mathrm{N} 8$ & 13 & $51 \mathrm{MD}$ & III & M. Archaic & & Testudinata & Shell fragment & 1 \\
\hline $\mathrm{E} 2 / \mathrm{N} 8$ & 13 & $51 \mathrm{MD}$ & III & M. Archaic & & Vertebrata & Indeterminate & 4 \\
\hline $\mathrm{E} 2 / \mathrm{N} 8$ & 14 & $51 \mathrm{NB}$ & III & Early/M. Archaic & & Mammalia (Large) & Long bone & 1 \\
\hline $\mathrm{E} 2 / \mathrm{N} 8$ & 14 & $51 \mathrm{NB}$ & III & Early/M. Archaic & & Mammalia (Medium/large) & Indeterminate & 2 \\
\hline $\mathrm{E} 2 / \mathrm{N} 8$ & 14 & $51 \mathrm{NC}$ & III & Early/M. Archaic & & Vertebrata & Indeterminate & 3 \\
\hline $\mathrm{E} 2 / \mathrm{N} 8$ & 14 & $51 \mathrm{ND}$ & III & Early/M. Archaic & & Vertebrata & Indeterminate & 7 \\
\hline $\mathrm{E} 2 / \mathrm{N} 8$ & 15 & $510 \mathrm{~A}$ & III & E. Archaic & & Vertebrata & Indeterminate & 1 \\
\hline $\mathrm{E} 2 / \mathrm{N} 8$ & 15 & $510 \mathrm{C}$ & III & E. Archaic & & Mammalia (Large) & Long bone & 1 \\
\hline $\mathrm{E} 2 / \mathrm{N} 8$ & 15 & $510 \mathrm{C}$ & III & E. Archaic & & Mammalia (Medium/large) & Long bone & 1 \\
\hline $\mathrm{E} 2 / \mathrm{N} 8$ & 15 & $510 D$ & III & E. Archaic & & Mammalia (Medium/large) & Long bone & 2 \\
\hline $\mathrm{E} 2 / \mathrm{N} 8$ & 15 & $510 D$ & III & E. Archaic & & Medium/Large Vertebrata & Indeterminate & 1 \\
\hline $\mathrm{E} 2 / \mathrm{N} 8$ & 16 & $51 \mathrm{PA}$ & III & E. Archaic & & Vertebrata & Indeterminate & 3 \\
\hline $\mathrm{E} 2 / \mathrm{N} 8$ & 16 & $51 \mathrm{PC}$ & III & E. Archaic & & Mammalia (Medium/large) & Indeterminate & 2 \\
\hline $\mathrm{E} 2 / \mathrm{N} 8$ & 17 & $51 \mathrm{QC}$ & III & E. Archaic & & Vertebrata & Indeterminate & 5 \\
\hline $\mathrm{E} 2 / \mathrm{N} 8$ & 17 & $51 \mathrm{QD}$ & III & E. Archaic & & Vertebrata & Indeterminate & 2 \\
\hline $\mathrm{E} 2 / \mathrm{N} 8$ & 19 & $51 \mathrm{SB}$ & III & E. Archaic & & Vertebrata & Indeterminate & 1 \\
\hline $\mathrm{E} 2 / \mathrm{N} 8$ & 20 & $51 \mathrm{~TB}$ & III & E. Archaic & & Vertebrata & Indeterminate & 2 \\
\hline $\mathrm{E} 2 / \mathrm{N} 8$ & 21 & 51UA & III & E. Archaic & & Medium/Large Vertebrata & Indeterminate & 1 \\
\hline $\mathrm{E} 2 / \mathrm{N} 8$ & 21 & $51 \mathrm{UB}$ & III & E. Archaic & & Vertebrata & Indeterminate & 1 \\
\hline $\mathrm{E} 2 / \mathrm{N} 8$ & 22 & $51 \mathrm{VB}$ & III & E. Archaic & & Mammalia (Medium/large) & Indeterminate & 1 \\
\hline $\mathrm{E} 2 / \mathrm{N} 8$ & 22 & $51 \mathrm{VC}$ & III & E. Archaic & & Mammalia (Medium/large) & Indeterminate & 1 \\
\hline $\mathrm{E} 2 / \mathrm{N} 8$ & 23 & $51 \mathrm{WB}$ & II/III & L. Paleo./E. Archaic & & Mammalia (Medium/large) & Indeterminate & 1 \\
\hline $\mathrm{E} 2 / \mathrm{N} 8$ & 24 & $51 \mathrm{XA}$ & III & L. Paleo. & & Vertebrata & Indeterminate & 1 \\
\hline $\mathrm{E} 2 / \mathrm{N} 8$ & 24 & $51 \mathrm{XB}$ & III & L. Paleo. & & Vertebrata & Indeterminate & 2 \\
\hline $\mathrm{E} 2 / \mathrm{N} 8$ & 24 & $51 \mathrm{XD}$ & III & L. Paleo. & & Medium/Large Vertebrata & Indeterminate & 1 \\
\hline $\mathrm{E} 2 / \mathrm{N} 8$ & 24 & $51 \mathrm{XD}$ & III & L. Paleo. & & Medium/Large Vertebrata & Long bone & 4 \\
\hline $\mathrm{E} 2 / \mathrm{N} 8$ & $25 \mathrm{~A}$ & $51 \mathrm{Y} 1 \mathrm{~B}$ & I/II & L. Paleo. & & Vertebrata & Indeterminate & 1 \\
\hline $\mathrm{E} 2 / \mathrm{N} 8$ & $25 \mathrm{~A}$ & $51 \mathrm{Y} 1 \mathrm{C}$ & I/II & L. Paleo. & & Mammalia (Medium) & Femur & 1 \\
\hline $\mathrm{E} 2 / \mathrm{N} 8$ & $25 \mathrm{~A}$ & $51 \mathrm{Y} 1 \mathrm{C}$ & I/II & L. Paleo. & & Mammalia (Medium/large) & Tooth, perm./decid. ind. & 1 \\
\hline $\mathrm{E} 2 / \mathrm{N} 8$ & $25 \mathrm{~A}$ & $51 \mathrm{Y} 1 \mathrm{C}$ & I/II & L. Paleo. & & Vertebrata & Indeterminate & 1 \\
\hline $\mathrm{E} 2 / \mathrm{N} 8$ & $25 \mathrm{~A}$ & 51Y1D & I/II & L. Paleo. & & Vertebrata & Indeterminate & 9 \\
\hline $\mathrm{E} 2 / \mathrm{N} 8$ & $25 \mathrm{~B}$ & $51 \mathrm{Y} 2 \mathrm{~B}$ & I & Paleoindian & & Mammalia (Medium/large) & Long bone & 1 \\
\hline $\mathrm{E} 2 / \mathrm{N} 8$ & $25 \mathrm{~B}$ & $51 \mathrm{Y} 2 \mathrm{~B}$ & I & Paleoindian & & Small/Medium Vertebrata & Indeterminate & 2 \\
\hline $\mathrm{E} 2 / \mathrm{N} 8$ & 25B & $51 \mathrm{Y} 2 \mathrm{C}$ & I & Paleoindian & & Vertebrata & Indeterminate & 5 \\
\hline $\mathrm{E} 2 / \mathrm{N} 8$ & $25 \mathrm{~B}$ & 51Y2D & I & Paleoindian & & Leporidae & Cranium & 1 \\
\hline
\end{tabular}




\begin{tabular}{|c|c|c|c|c|c|c|c|c|}
\hline Square & Level & Lot & Unit & Cultural Affinity & Feature & Taxon & Element & No. \\
\hline $\mathrm{E} 2 / \mathrm{N} 8$ & $25 \mathrm{~B}$ & 51Y2D & II & Paleoindian & & Small/Medium Vertebrata & Indeterminate & 1 \\
\hline E2/N8 & $25 \mathrm{~B}$ & $51 Y 2 D$ & I & Paleoindian & & Small/Medium Vertebrata & Long bone & 1 \\
\hline E2/N8 & $25 \mathrm{~B}$ & 51Y2D & |I & Paleoindian & & Vertebrata & Indeterminate & 1 \\
\hline $\mathrm{E} 2 / \mathrm{N} 8$ & $26 \mathrm{~A}$ & $51 \mathrm{Z1A}$ & |I & Paleoindian & & Vertebrata & Indeterminate & 1 \\
\hline $\mathrm{E} 2 / \mathrm{N} 8$ & $26 \mathrm{~A}$ & 51Z1D & I & Paleoindian & f166 & Vertebrata & Indeterminate & 9 \\
\hline $\mathrm{E} 2 / \mathrm{N} 8$ & $26 \mathrm{~B}$ & $51 \mathrm{Z2A}$ & |I & Paleoindian & & Vertebrata & Indeterminate & 1 \\
\hline $\mathrm{E} 2 / \mathrm{N} 8$ & $26 \mathrm{~B}$ & $51 \mathrm{Z2B}$ & I & Paleoindian & & Vertebrata & Indeterminate & 2 \\
\hline $\mathrm{E} 2 / \mathrm{N} 8$ & $26 \mathrm{~B}$ & $51 \mathrm{Z} 2 \mathrm{C}$ & II & Paleoindian & & Lepus californicus & Calcaneus & 1 \\
\hline $\mathrm{E} 2 / \mathrm{N} 8$ & 26B & $51 \mathrm{Z} 2 \mathrm{C}$ & |I & Paleoindian & & Mammalia (Medium) & Metapodial & 1 \\
\hline $\mathrm{E} 2 / \mathrm{N} 8$ & $26 \mathrm{~B}$ & $51 \mathrm{Z} 2 \mathrm{C}$ & II & Paleoindian & & Vertebrata & Indeterminate & 2 \\
\hline $\mathrm{E} 2 / \mathrm{N} 8$ & $26 \mathrm{~B}$ & 51Z2D & I & Paleoindian & f166 & Medium/Large Vertebrata & Long bone & 1 \\
\hline E2/N8 & $26 \mathrm{~B}$ & 51Z2D & I & Paleoindian & f166 & Small/Medium Vertebrata & Long bone & 1 \\
\hline $\mathrm{E} 2 / \mathrm{N} 8$ & $26 \mathrm{~B}$ & $51 Z 2 \mathrm{D}$ & I & Paleoindian & f166 & Vertebrata & Indeterminate & 6 \\
\hline E2/N8 & $27 \mathrm{~A}$ & 51AA1D & II & Paleoindian & f166 & Vertebrata & Indeterminate & 3 \\
\hline E2/N8 & 27B & 51AA2D & |I & Paleoindian & f166 & Vertebrata & Indeterminate & 1 \\
\hline E2/N8 & $28 \mathrm{~A}$ & 51BB1 & I & Paleoindian & & Medium/Large Vertebrata & Indeterminate & 1 \\
\hline $\mathrm{E} 2 / \mathrm{N} 8$ & $28 \mathrm{~A}$ & $51 \mathrm{BB} 1$ & I & Paleoindian & & Vertebrata & Indeterminate & 2 \\
\hline $\mathrm{E} 20 / \mathrm{S} 72$ & 2 & 17B & IIIIc & L. Archaic/L. Prehist. & & Artiodactyla & Tooth, perm./decid. ind. & 1 \\
\hline E20/S72 & 2 & $17 \mathrm{~B}$ & IIIc & L. Archaic/L. Prehist. & & Vertebrata & Indeterminate & 7 \\
\hline E20/S72 & 3 & $17 \mathrm{C}$ & IIIIc & L. Archaic & & Artiodactyla & Phalange & 3 \\
\hline E20/S72 & 3 & $17 \mathrm{C}$ & IIIIc & L. Archaic & & Mammalia (Large) & Femur & 1 \\
\hline E20/S72 & 3 & $17 \mathrm{C}$ & IIIIc & L. Archaic & & Mammalia (Large) & Indeterminate & 1 \\
\hline E20/S72 & 3 & $17 \mathrm{C}$ & IIIIc & L. Archaic & & Mammalia (Large) & Long bone & 1 \\
\hline E20/S72 & 3 & $17 \mathrm{C}$ & IIIIc & L. Archaic & & Mammalia (Medium/large) & Indeterminate & 6 \\
\hline E20/S72 & 3 & $17 \mathrm{C}$ & |IIIc & L. Archaic & & Mammalia (Medium/large) & Long bone & 1 \\
\hline E20/S72 & 3 & $17 \mathrm{C}$ & IIIIc & L. Archaic & & Sylvilagus sp. & Calcaneus & 1 \\
\hline E20/S72 & 3 & $17 \mathrm{C}$ & IIIIC & L. Archaic & & Vertebrata & Indeterminate & 37 \\
\hline E20/S72 & 4 & 17D & IIIIc & L. Archaic & & Antilocapra/Odocoileus & Permanent tooth & 1 \\
\hline E20/S72 & 4 & 17D & IIIC & L. Archaic & & Artiodactyla & Tooth, perm./decid. ind. & 1 \\
\hline E20/S72 & 4 & 17D & IIIIC & L. Archaic & & Bison sp. & Fused second \& third tarsal & 1 \\
\hline E20/S72 & 4 & 17D & IIII & L. Archaic & & Mammalia (Large) & Long bone & 1 \\
\hline E20/S72 & 4 & 17D & IIIIc & L. Archaic & & Odocoileus sp. & Distal phalange & 1 \\
\hline E20/S72 & 4 & 17D & IIIIc & L. Archaic & & Vertebrata & Indeterminate & 30 \\
\hline E20/S72 & 5 & $17 \mathrm{E}$ & IIII & L. Archaic & & Mammalia (Medium/large) & Indeterminate & 4 \\
\hline E20/S72 & 5 & $17 \mathrm{E}$ & IIIC & L. Archaic & & Mammalia (Medium/large) & Tooth, perm./decid. ind. & 2 \\
\hline E20/S72 & 5 & $17 \mathrm{E}$ & IIIIc & L. Archaic & & Odocoileus sp. & Permanent tooth & 2 \\
\hline $\mathrm{E} 20 / \mathrm{S} 72$ & 5 & $17 \mathrm{E}$ & IIII & L. Archaic & & Vertebrata & Indeterminate & 28 \\
\hline E20/S72 & 6 & $17 \mathrm{~F}$ & IIIIc & Middle/L. Archaic & & Mammalia (Large) & Indeterminate & 1 \\
\hline E20/S72 & 6 & $17 \mathrm{~F}$ & |IIIc & Middle/L. Archaic & & Mammalia (Large) & Long bone & 1 \\
\hline E20/S72 & 6 & $17 \mathrm{~F}$ & IIII & Middle/L. Archaic & & Mammalia (Medium/large) & Indeterminate & 5 \\
\hline E20/S72 & 6 & $17 \mathrm{~F}$ & IIIIc & Middle/L. Archaic & & Sylvilagus sp. & Humerus & 1 \\
\hline $\mathrm{E} 20 / \mathrm{S} 72$ & 6 & $17 \mathrm{~F}$ & |IIIC & Middle/L. Archaic & & Vertebrata & Indeterminate & 41 \\
\hline E20/S72 & 7 & $17 \mathrm{G}$ & IIII & Middle/L. Archaic & & Antilocapra/Odocoileus & Fused 3rd \& 4th metatarsal & 1 \\
\hline $\mathrm{E} 20 / \mathrm{S} 72$ & 7 & $17 \mathrm{G}$ & IIIIc & Middle/L. Archaic & & Mammalia (Medium/large) & Indeterminate & 4 \\
\hline E20/S72 & 7 & $17 \mathrm{G}$ & IIIIc & Middle/L. Archaic & & Mammalia (Medium/large) & Long bone & 1 \\
\hline E20/S72 & 7 & $17 \mathrm{G}$ & IIIIc & Middle/L. Archaic & & Mammalia (Medium/large) & Tooth, perm./decid. ind. & 1 \\
\hline E20/S72 & 7 & $17 \mathrm{G}$ & IIIIc & Middle/L. Archaic & & Vertebrata & Indeterminate & 38 \\
\hline E20/S72 & 8 & $17 \mathrm{H}$ & $\mathrm{IIIb} / \mathrm{c}$ & M. Archaic & & Artiodactyla & Tooth, perm./decid. ind. & 1 \\
\hline E20/S72 & 8 & $17 \mathrm{H}$ & $\mathrm{IIIb} / \mathrm{c}$ & M. Archaic & & Vertebrata & Indeterminate & 27 \\
\hline E20/S72 & $9 \mathrm{~A}$ & 17II & IIIlb/c & M. Archaic & & Mammalia (Medium/large) & Indeterminate & 1 \\
\hline E20/S72 & $9 \mathrm{~A}$ & 17I1 & $\mathrm{IIIb} / \mathrm{c}$ & M. Archaic & & Vertebrata & Indeterminate & 3 \\
\hline E20/S72 & $9 \mathrm{~B}$ & $17 \mathrm{I} 2$ & $\mathrm{IIb} / \mathrm{c}$ & M. Archaic & & Mammalia (Medium/large) & Indeterminate & 1 \\
\hline E20/S72 & $9 \mathrm{~B}$ & 1712 & IIIIb/c & M. Archaic & & Vertebrata & Indeterminate & 2 \\
\hline E20/S72 & $10 \mathrm{~A}$ & $17 \mathrm{~J} 1$ & $\mathrm{IIIlb} / \mathrm{c}$ & Early/M. Archaic & & Vertebrata & Indeterminate & 2 \\
\hline E20/S72 & $10 \mathrm{~B}$ & $17 \mathrm{~J} 2$ & $\mathrm{IIIb} / \mathrm{c}$ & Early/M. Archaic & & Sternotherus sp. & Hyoplastron & 1 \\
\hline E20/S72 & $10 \mathrm{~B}$ & $17 \mathrm{~J} 2$ & $\mathrm{IITb} / \mathrm{c}$ & Early/M. Archaic & & Vertebrata & Indeterminate & 3 \\
\hline $\mathrm{E} 20 / \mathrm{S} 72$ & $11 \mathrm{~A}$ & $17 \mathrm{~K} 1$ & IIIIb/c & Early/M. Archaic & & Mammalia (Medium/large) & Indeterminate & 2 \\
\hline E20/S72 & $11 \mathrm{~A}$ & $17 \mathrm{~K} 1$ & IIIb/c & Early/M. Archaic & & Vertebrata & Indeterminate & 3 \\
\hline E20/S72 & $11 \mathrm{~B}$ & $17 \mathrm{~K} 2$ & IIIlb & Early/M. Archaic & & Mammalia (Medium/large) & Indeterminate & 1 \\
\hline E20/S72 & $14 \mathrm{~A}$ & $17 \mathrm{~N} 1$ & IIIlb & E. Archaic & & Vertebrata & Indeterminate & 1 \\
\hline E20/S72 & 14B & $17 \mathrm{~N} 2$ & IIIa/b & E. Archaic & & Mammalia (Large) & Long bone & 1 \\
\hline E20/S72 & 14B & $17 \mathrm{~N} 2$ & IIIIa/b & E. Archaic & & Medium/Large Vertebrata & Long bone & 1 \\
\hline E20/S72 & $15 \mathrm{~A}$ & 1701 & IIIa/b & E. Archaic & & Mammalia (Medium/large) & Long bone & 1 \\
\hline E20/S72 & $16 \mathrm{~B}$ & $17 \mathrm{P} 2$ & ШШа & E. Archaic & & Mammalia (Medium/large) & Indeterminate & 1 \\
\hline E20/S72 & 16B & $17 \mathrm{P} 2$ & IIIIa & E. Archaic & & Vertebrata & Indeterminate & 4 \\
\hline E20/S72 & 17B & $17 \mathrm{Q} 2$ & IIIIa & E. Archaic & & Vertebrata & Indeterminate & 1 \\
\hline $\mathrm{E} 20 / \mathrm{S} 72$ & $18 \mathrm{~B}$ & $17 \mathrm{R} 2$ & IIIa & E. Archaic & & Mammalia (Medium/large) & Indeterminate & 1 \\
\hline
\end{tabular}




\begin{tabular}{|c|c|c|c|c|c|c|c|c|}
\hline Square & Level & Lot & Unit & Cultural Affinity & Feature & Taxon & Element & No. \\
\hline E20/S72 & $19 \mathrm{~A}$ & $17 \mathrm{~S} 1$ & $\overline{\mathrm{IIIa}}$ & E. Archaic & & Vertebrata & Indeterminate & 2 \\
\hline E20/S72 & 19B & $17 \mathrm{~S} 2$ & IIIIa & E. Archaic & & Mammalia (Medium/large) & Indeterminate & 1 \\
\hline E20/S72 & 19B & $17 \mathrm{~S} 2$ & IIIa & E. Archaic & & Vertebrata & Indeterminate & 4 \\
\hline E20/S72 & $20 \mathrm{~B}$ & $17 T 2$ & II/IIIa & L. Paleo./E. Archaic & & cf. Leporidae & Alveolar ridge fragment & 1 \\
\hline E20/S72 & 20B & $17 \mathrm{~T} 2$ & II/IIIa & L. Paleo./E. Archaic & & Mammalia (Medium/large) & Indeterminate & 3 \\
\hline E20/S72 & $20 \mathrm{~B}$ & $17 \mathrm{~T} 2$ & II/IIIa & L. Paleo./E. Archaic & & Medium/Large Vertebrata & Indeterminate & 1 \\
\hline E20/S72 & $20 \mathrm{~B}$ & $17 \mathrm{~T} 2$ & II/IIIa & L. Paleo./E. Archaic & & Small/Medium Vertebrata & Long bone & 1 \\
\hline E20/S72 & $20 \mathrm{~B}$ & $17 \mathrm{~T} 2$ & II/IIIIa & L. Paleo./E. Archaic & & Vertebrata & Indeterminate & 6 \\
\hline E20/S72 & $21 \mathrm{~A}$ & 17U1 & III & L. Paleo. & & Mammalia (Medium/large) & Indeterminate & 1 \\
\hline E20/S72 & $21 \mathrm{~A}$ & 17U1 & III & L. Paleo. & & Mammalia (Medium/large) & Long bone & 1 \\
\hline E20/S72 & $21 \mathrm{~A}$ & 17U1 & II & L. Paleo. & & Vertebrata & Indeterminate & 1 \\
\hline E20/S72 & $21 \mathrm{~B}$ & 17U2 & III & L. Paleo. & & Small/Medium Vertebrata & Long bone & 1 \\
\hline E20/S72 & $22 \mathrm{~A}$ & $17 \mathrm{~V} 1$ & III & L. Paleo. & & Mammalia (Medium/large) & Long bone & 1 \\
\hline E20/S72 & $22 \mathrm{~A}$ & $17 \mathrm{~V} 1$ & III & L. Paleo. & & Medium/Large Vertebrata & Indeterminate & 1 \\
\hline E20/S72 & $22 \mathrm{~A}$ & $17 \mathrm{~V} 1$ & III & L. Paleo. & & Vertebrata & Indeterminate & 3 \\
\hline E20/S72 & $23 \mathrm{~A}$ & $17 \mathrm{~W} 1$ & III & L. Paleo. & & Antilocapra/Odocoileus & Proximal abaxial sesamoid & 1 \\
\hline E20/S72 & $23 \mathrm{~A}$ & $17 \mathrm{~W} 1$ & III & L. Paleo. & & Vertebrata & Indeterminate & 2 \\
\hline E20/S72 & $23 \mathrm{~B}$ & $17 \mathrm{~W} 2$ & III & L. Paleo. & & Medium/Large Vertebrata & Indeterminate & 2 \\
\hline E20/S72 & $23 \mathrm{~B}$ & $17 \mathrm{~W} 2$ & III & L. Paleo. & & Vertebrata & Indeterminate & 7 \\
\hline E20/S72 & $24 B$ & $17 X 2$ & III & L. Paleo. & & Mammalia (Medium/large) & Indeterminate & 2 \\
\hline E20/S72 & $24 \mathrm{~B}$ & $17 \times 2$ & III & L. Paleo. & & Vertebrata & Indeterminate & 1 \\
\hline E20/S72 & $25 \mathrm{~A}$ & $17 \mathrm{Y} 1$ & Id/II & L. Paleo. & & Mammalia (Medium/large) & Long bone & 1 \\
\hline E20/S72 & $25 \mathrm{~A}$ & $17 \mathrm{Y} 1$ & Id/II & L. Paleo. & & Vertebrata & Indeterminate & 1 \\
\hline E20/S72 & $25 \mathrm{~B}$ & $17 \mathrm{Y} 2$ & $\mathrm{Id} / \mathrm{II}$ & L. Paleo. & & Medium/Large Vertebrata & Indeterminate & 5 \\
\hline E20/S72 & $25 \mathrm{~B}$ & $17 \mathrm{Y} 2$ & $\mathrm{Id} / \mathrm{II}$ & L. Paleo. & & Small/Medium Vertebrata & Long bone & 1 \\
\hline E20/S72 & $26 \mathrm{~A}$ & $17 \mathrm{Z1}$ & Isi-c/Id/II & L. Paleo. & & Mammalia (Medium) & Axis & 1 \\
\hline E20/S72 & $26 \mathrm{~A}$ & $17 \mathrm{Z} 1$ & Isi-c/Id/II & L. Paleo. & & Mammalia (Medium/large) & Long bone & 2 \\
\hline E20/S72 & $26 \mathrm{~A}$ & $17 \mathrm{Z} 1$ & Isi-c/Id/II & L. Paleo. & & Medium/Large Vertebrata & Indeterminate & 7 \\
\hline E20/S72 & $26 \mathrm{~A}$ & $17 \mathrm{Z} 1$ & Isi-c/Id/II & L. Paleo. & & Testudinata & Indeterminate & 1 \\
\hline E20/S72 & $26 \mathrm{~A}$ & $17 \mathrm{Z1}$ & Isi-c/Id/II & L. Paleo. & & Vertebrata & Indeterminate & 7 \\
\hline E20/S72 & $26 \mathrm{~B}$ & $17 \mathrm{Z} 2$ & Isi-c/Id/II & L. Paleo. & & Mammalia (Medium) & Proximal phalange & 1 \\
\hline E20/S72 & $26 \mathrm{~B}$ & $17 \mathrm{Z} 2$ & Isi-c/Id/II & L. Paleo. & & Mammalia (Medium/large) & Indeterminate & 3 \\
\hline E20/S72 & $26 \mathrm{~B}$ & $17 \mathrm{Z} 2$ & Isi-c/Id/II & L. Paleo. & & Mammalia (Medium/large) & Long bone & 1 \\
\hline $\mathrm{E} 20 / \mathrm{S} 72$ & $26 \mathrm{~B}$ & $17 \mathrm{Z} 2$ & Isi-c/Id/II & L. Paleo. & & Medium/Large Vertebrata & Indeterminate & 1 \\
\hline $\mathrm{E} 20 / \mathrm{S} 72$ & $26 \mathrm{~B}$ & $17 \mathrm{Z} 2$ & Isi-c/Id/II & L. Paleo. & & Medium/Large Vertebrata & Long bone & 3 \\
\hline E20/S72 & $26 \mathrm{~B}$ & $17 \mathrm{Z} 2$ & Isi-c/Id/II & L. Paleo. & & Vertebrata & Indeterminate & 8 \\
\hline E20/S72 & 27B & 17AA2 & Isi-c/Id/II & L. Paleo. & & Mammalia (Medium/large) & Long bone & 4 \\
\hline $\mathrm{E} 20 / \mathrm{S} 72$ & $27 \mathrm{~B}$ & $17 \mathrm{AA} 2$ & Isi-c/Id/II & L. Paleo. & & Mammalia (Medium/large) & Proximal phalange & 1 \\
\hline $\mathrm{E} 20 / \mathrm{S} 72$ & 27B & 17AA2 & Isi-c/Id/II & L. Paleo. & & Mammalia (Medium/large) & Tooth, perm./decid. ind. & 1 \\
\hline E20/S72 & 27B & 17AA2 & Isi-c/Id/II & L. Paleo. & & Vertebrata & Caudal vertebra & 1 \\
\hline $\mathrm{E} 20 / \mathrm{S} 72$ & $27 \mathrm{~B}$ & $17 \mathrm{AA} 2$ & Isi-c/Id/II & L. Paleo. & & Vertebrata & Indeterminate & 36 \\
\hline $\mathrm{E} 20 / \mathrm{S} 72$ & $27 \mathrm{~B}$ & $17 \mathrm{AA} 2$ & Isi-c/Id/II & L. Paleo. & & Vertebrata & Long bone & 1 \\
\hline E20/S72 & $28 \mathrm{~A}$ & 17BB1 & Isi-c/Id & L. Paleo. & & Carnivora & Permanent tooth & 4 \\
\hline E20/S72 & $28 \mathrm{~A}$ & $17 \mathrm{BB} 1$ & Isi-c/Id & L. Paleo. & & Mammalia (Medium) & Caudal vertebra & 1 \\
\hline $\mathrm{E} 20 / \mathrm{S} 72$ & $28 \mathrm{~A}$ & 17BB1 & Isi-c/Id & L. Paleo. & & Mammalia (Medium) & Metapodial & 1 \\
\hline E20/S72 & $28 \mathrm{~A}$ & 17BB1 & Isi-c/Id & L. Paleo. & & Mammalia (Medium/large) & Indeterminate & 3 \\
\hline $\mathrm{E} 20 / \mathrm{S} 72$ & $28 \mathrm{~A}$ & 17BB1 & Isi-c/Id & L. Paleo. & & Mammalia (Medium/large) & Long bone & 2 \\
\hline E20/S72 & $28 \mathrm{~A}$ & 17BB1 & Isi-c/Id & L. Paleo. & & Medium/Large Vertebrata & Long bone & 17 \\
\hline E20/S72 & $28 \mathrm{~A}$ & 17BB1 & Isi-c/Id & L. Paleo. & & Small/Medium Vertebrata & Indeterminate & 13 \\
\hline E20/S72 & $28 \mathrm{~A}$ & 17BB1 & Isi-c/Id & L. Paleo. & & Vertebrata & Indeterminate & 30 \\
\hline E20/S72 & $28 \mathrm{~B}$ & 17BB2 & Isi-c & L. Paleo. & & Mammalia (Medium) & Middle phalange & 1 \\
\hline E20/S72 & $28 \mathrm{~B}$ & 17BB2 & Isi-c & L. Paleo. & & Mammalia (Medium/large) & Caudal vertebra & 1 \\
\hline E20/S72 & $28 \mathrm{~B}$ & 17BB2 & Isi-c & L. Paleo. & & Mammalia (Medium/large) & Indeterminate & 4 \\
\hline $\mathrm{E} 20 / \mathrm{S} 72$ & $28 \mathrm{~B}$ & 17BB2 & Isi-c & L. Paleo. & & Mammalia (Medium/large) & Long bone & 13 \\
\hline E20/S72 & 28B & 17BB2 & Isi-c & L. Paleo. & & Medium/Large Vertebrata & Indeterminate & 23 \\
\hline E20/S72 & $28 \mathrm{~B}$ & 17BB2 & Isi-c & L. Paleo. & & Small/Medium Vertebrata & Long bone & 1 \\
\hline $\mathrm{E} 20 / \mathrm{S} 72$ & $29 \mathrm{~A}$ & $17 \mathrm{CC} 1$ & Isi-c & L. Paleo. & & Mammalia (Medium) & Middle phalange & 1 \\
\hline E20/S72 & $29 \mathrm{~A}$ & $17 \mathrm{CC} 1$ & Isi-c & L. Paleo. & & Mammalia (Medium/large) & Alveolar ridge fragment & 1 \\
\hline E20/S72 & $29 \mathrm{~A}$ & $17 \mathrm{CC} 1$ & Isi-c & L. Paleo. & & Testudinata & Peripheral & 1 \\
\hline $\mathrm{E} 20 / \mathrm{S} 72$ & $29 \mathrm{~A}$ & $17 \mathrm{CC} 1$ & Isi-c & L. Paleo. & & Vertebrata & Indeterminate & 10 \\
\hline E20/S72 & 29B & $17 \mathrm{CC} 2$ & Isi-c & L. Paleo. & & Mammalia (Medium/large) & Long bone & 1 \\
\hline E20/S72 & $29 \mathrm{~B}$ & $17 \mathrm{CC} 2$ & Isi-c & L. Paleo. & & Vertebrata & Indeterminate & 10 \\
\hline E20/S72 & $30 \mathrm{~A}$ & 17DD1 & $\mathrm{Icl} / \mathrm{Isi}-\mathrm{c}$ & Paleoindian & & Vertebrata & Indeterminate & 1 \\
\hline E20/S72 & 31 & 17EE & Isi/Icl/Isi-c & Paleoindian & & Mammalia (Medium/large) & Long bone & 2 \\
\hline E20/S72 & 31 & $17 \mathrm{EE}$ & Isi/Icl/Isi-c & Paleoindian & & Medium/Large Vertebrata & Indeterminate & 2 \\
\hline E20/S72 & 31 & $17 \mathrm{EE}$ & Isi/Icl/Isi-c & Paleoindian & & Vertebrata & Indeterminate & 25 \\
\hline E20/S72 & $34 \mathrm{~A}$ & $17 \mathrm{HH} 1$ & Isi/Icl/Isi-c & Paleoindian & & Vertebrata & Indeterminate & 4 \\
\hline
\end{tabular}




\begin{tabular}{|c|c|c|c|c|c|c|c|c|}
\hline Square & Level & Lot & Unit & Cultural Affinity & Feature & Taxon & Element & No. \\
\hline$\overline{\mathrm{E} 20 / \mathrm{S} 72}$ & $34 \mathrm{~B}-35 \mathrm{~A}$ & $17 \mathrm{HH} 2 / \mathrm{II}$ & Isi/Icl & E. Paleo. & & Mammalia (Medium/large) & Long bone & 1 \\
\hline E20/S72 & $34 \mathrm{~B}-35 \mathrm{~A}$ & $17 \mathrm{HH} 2 / \mathrm{II}$ & Isi/Icl & E. Paleo. & & Medium/Large Vertebrata & Indeterminate & 2 \\
\hline $\mathrm{E} 20 / \mathrm{S} 72$ & $35 \mathrm{~B}-36 \mathrm{~A}$ & $17 \mathrm{III} / \mathrm{JJ} 1$ & Isi/Icl & E. Paleo. & & Vertebrata & Indeterminate & 3 \\
\hline E20/S72 & $36 \mathrm{~B}-37 \mathrm{~A}$ & $17 \mathrm{JJ} 2 / \mathrm{KK}$ & Isi/Icl & E. Paleo. & & Bison sp. & Astragalus & 1 \\
\hline $\mathrm{E} 20 / \mathrm{S} 72$ & $36 \mathrm{~B}-37 \mathrm{~A}$ & $17 \mathrm{JJ} 2 / \mathrm{KK}$ & Isi/Icl & E. Paleo. & & Mammalia (Medium/large) & Indeterminate & 4 \\
\hline $\mathrm{E} 20 / \mathrm{S} 72$ & $36 \mathrm{~B}-37 \mathrm{~A}$ & $17 \mathrm{JJ} 2 / \mathrm{KK}$ & Isi/Icl & E. Paleo. & & Vertebrata & Indeterminate & 13 \\
\hline E20/S72 & 37B-38A & $17 \mathrm{KK} 2 / \mathrm{LI}$ & Isi & E. Paleo. & & Canis sp. & Permanent tooth & 5 \\
\hline E20/S72 & 37B-38A & $17 \mathrm{KK} 2 / \mathrm{LI}$ & Isi & E. Paleo. & & Carnivora & Permanent tooth & 1 \\
\hline E20/S72 & 37B-38A & $17 \mathrm{KK} 2 / \mathrm{LI}$ & Isi & E. Paleo. & & Mammalia (Large) & Long bone & 11 \\
\hline E20/S72 & 37B-38A & $17 \mathrm{KK} 2 / \mathrm{LI}$ & Isi & E. Paleo. & & Mammalia (Medium/large) & Indeterminate & 3 \\
\hline E20/S72 & 37B-38A & $17 \mathrm{KK} 2 / \mathrm{LI}$ & Isi & E. Paleo. & & Mammalia (Medium/large) & Long bone & 1 \\
\hline E20/S72 & 37B-38A & $17 \mathrm{KK} 2 / \mathrm{LI}$ & Isi & E. Paleo. & & Medium/Large Vertebrata & Indeterminate & 2 \\
\hline E20/S72 & 37B-38A & $17 \mathrm{KK} 2 / \mathrm{LI}$ & Isi & E. Paleo. & & Vertebrata & Indeterminate & 62 \\
\hline E20/S72 & $38 \mathrm{~B}-39 \mathrm{~A}$ & $17 \mathrm{LL} 2 / \mathrm{Ml}$ & Isi & E. Paleo. & & Mammalia (Medium/large) & Indeterminate & 10 \\
\hline E20/S72 & 38B-39A & $17 \mathrm{LL} 2 / \mathrm{Ml}$ & Isi & E. Paleo. & & Vertebrata & Indeterminate & 17 \\
\hline E20/S72 & $39 \mathrm{~B}-40 \mathrm{~A}$ & $17 \mathrm{MM} 2 / \mathrm{N}$ & $\operatorname{Ig} 1 / \mathrm{Isi}$ & E. Paleo. & & Mammalia (Medium/large) & Indeterminate & 1 \\
\hline E20/S72 & $39 \mathrm{~B}-40 \mathrm{~A}$ & $17 \mathrm{MM} 2 / \mathrm{N}$ & $\operatorname{Ig} 1 / \operatorname{Isi}$ & E. Paleo. & & Medium/Large Vertebrata & Indeterminate & 9 \\
\hline E20/S72 & $39 \mathrm{~B}-40 \mathrm{~A}$ & $17 \mathrm{MM} 2 / \mathrm{N}$ & Igl//si & E. Paleo. & & Medium/Large Vertebrata & Long bone & 1 \\
\hline E20/S72 & $39 \mathrm{~B}-40 \mathrm{~A}$ & $17 \mathrm{MM} 2 / \mathrm{N}$ & Igl//si & E. Paleo. & & Small/Medium Vertebrata & Long bone & 1 \\
\hline E20/S72 & $39 \mathrm{~B}-40 \mathrm{~A}$ & $17 \mathrm{MM} 2 / \mathrm{N}$ & $\operatorname{Ig} 1 / \mathrm{Isi}$ & E. Paleo. & & Vertebrata & Indeterminate & 1 \\
\hline E20/S72 & $40 \mathrm{~B}-41 \mathrm{~A}$ & $17 \mathrm{NN} 2 / \mathrm{O}$ & Igl//si & E. Paleo. & & Small/Medium Vertebrata & Long bone & 4 \\
\hline E20/S72 & $41 \mathrm{~B}-42 \mathrm{~A}$ & $170 \mathrm{OO} / \mathrm{PH}$ & Igl & E. Paleo. & & Mammalia & Indeterminate & 1 \\
\hline E20/S72 & $42 \mathrm{~B}-43 \mathrm{~A}$ & $17 \mathrm{PP} 2 / \mathrm{Q}$ & Igl & E. Paleo. & & Vertebrata & Indeterminate & 1 \\
\hline E20/S72 & $43 \mathrm{~B}-44 \mathrm{~A}$ & $17 \mathrm{QQ} 2 / \mathrm{R}$ & Igl & E. Paleo. & & Vertebrata & Indeterminate & 2 \\
\hline E20/S72 & $44 \mathrm{~B}-45 \mathrm{~A}$ & 17RR2/SS & Igl & E. Paleo. & & Vertebrata & Indeterminate & 4 \\
\hline E20/S72 & $45 \mathrm{~B}-46 \mathrm{~A}$ & $17 \mathrm{SS} 2 / \mathrm{TT}$ & Igl & E. Paleo. & & Vertebrata & Indeterminate & 4 \\
\hline E20/S74 & 1 & $16 \mathrm{~A}$ & IIIIc & L. Prehist. & & Vertebrata & Indeterminate & 5 \\
\hline E20/S74 & 2 & 16B & IIIc & L. Archaic/L. Prehist. & & Vertebrata & Indeterminate & 3 \\
\hline E20/S74 & 3 & $16 \mathrm{C}$ & IIIc & L. Archaic & & Mammalia (Large) & Indeterminate & 4 \\
\hline E20/S74 & 3 & $16 \mathrm{C}$ & IIIc & L. Archaic & & Mammalia (Large) & Long bone & 3 \\
\hline E20/S74 & 3 & $16 \mathrm{C}$ & IIIc & L. Archaic & & Mammalia (Medium/large) & Alveolar ridge fragment & 1 \\
\hline E20/S74 & 3 & $16 \mathrm{C}$ & IIIc & L. Archaic & & Mammalia (Medium/large) & Indeterminate & 8 \\
\hline E20/S74 & 3 & $16 \mathrm{C}$ & IIIc & L. Archaic & & Odocoileus sp. & Calcaneus & 1 \\
\hline E20/S74 & 3 & $16 \mathrm{C}$ & IIII & L. Archaic & & Vertebrata & Indeterminate & 39 \\
\hline E20/S74 & 4 & $16 \mathrm{D}$ & IIIc & L. Archaic & & Mammalia (Large) & Long bone & 2 \\
\hline E20/S74 & 4 & 16D & IIIc & L. Archaic & & Mammalia (Medium/large) & Indeterminate & 3 \\
\hline E20/S74 & 4 & 16D & IIIc & L. Archaic & & Mammalia (Medium/large) & Long bone & 2 \\
\hline E20/S74 & 4 & $16 \mathrm{D}$ & IIII & L. Archaic & & Vertebrata & Indeterminate & 58 \\
\hline E20/S74 & 4 & 16D & IIIc & L. Archaic & & Vertebrata & Long bone & 1 \\
\hline E20/S74 & 5 & $16 \mathrm{E}$ & IIII & L. Archaic & & Mammalia (Large) & Long bone & 2 \\
\hline E20/S74 & 5 & $16 \mathrm{E}$ & IIIc & L. Archaic & & Mammalia (Large/very large) & Indeterminate & 1 \\
\hline E20/S74 & 5 & $16 \mathrm{E}$ & IIIc & L. Archaic & & Mammalia (Medium) & Pelvis & 1 \\
\hline E20/S74 & 5 & $16 \mathrm{E}$ & IIIc & L. Archaic & & Mammalia (Medium/large) & Indeterminate & 2 \\
\hline E20/S74 & 5 & $16 \mathrm{E}$ & IIIc & L. Archaic & & Odocoileus sp. & Antler & 1 \\
\hline E20/S74 & 5 & $16 \mathrm{E}$ & IIIc & L. Archaic & & Vertebrata & Indeterminate & 10 \\
\hline E20/S74 & 6 & $16 \mathrm{~F}$ & IIIc & Middle/L. Archaic & & Antilocapra americana & Permanent tooth & 1 \\
\hline E20/S74 & 6 & $16 \mathrm{~F}$ & IIII & Middle/L. Archaic & & Antilocapra/Odocoileus & Femur & 1 \\
\hline E20/S74 & 6 & $16 \mathrm{~F}$ & IIIC & Middle/L. Archaic & & Antilocapra/Odocoileus & Fused 3rd \& 4th metacarpal & 1 \\
\hline E20/S74 & 6 & $16 \mathrm{~F}$ & IIIC & Middle/L. Archaic & & Bison sp. & Permanent tooth & 1 \\
\hline E20/S74 & 6 & $16 \mathrm{~F}$ & IIIc & Middle/L. Archaic & & Geomys sp. & Tibia & 1 \\
\hline E20/S74 & 6 & $16 \mathrm{~F}$ & IIIc & Middle/L. Archaic & & Mammalia (Large) & Indeterminate & 3 \\
\hline E20/S74 & 6 & $16 \mathrm{~F}$ & IIII & Middle/L. Archaic & & Mammalia (Large) & Long bone & 6 \\
\hline E20/S74 & 6 & $16 \mathrm{~F}$ & III & Middle/L. Archaic & & Mammalia (Medium) & Thoracic vertebra & 1 \\
\hline E20/S74 & 6 & $16 \mathrm{~F}$ & IIIc & Middle/L. Archaic & & Mammalia (Medium/large) & Indeterminate & 17 \\
\hline E20/S74 & 6 & $16 \mathrm{~F}$ & IIII & Middle/L. Archaic & & Mammalia (Medium/large) & Long bone & 3 \\
\hline E20/S74 & 6 & $16 \mathrm{~F}$ & IIIc & Middle/L. Archaic & & Odocoileus sp. & Distal phalange & 1 \\
\hline E20/S74 & 6 & $16 \mathrm{~F}$ & IIIC & Middle/L. Archaic & & Vertebrata & Indeterminate & 69 \\
\hline E20/S74 & 7 & $16 \mathrm{G}$ & IIIC & Middle/L. Archaic & & Antilocapra/Odocoileus & Cranium & 1 \\
\hline E20/S74 & 7 & $16 \mathrm{G}$ & IIIc & Middle/L. Archaic & & Antilocapra/Odocoileus & Fibula & 1 \\
\hline E20/S74 & 7 & $16 \mathrm{G}$ & IIIc & Middle/L. Archaic & & Antilocapra/Odocoileus & Fused 3rd \& 4th metacarpal & 1 \\
\hline E20/S74 & 7 & $16 \mathrm{G}$ & IIIc & Middle/L. Archaic & & Antilocapra/Odocoileus & Fused 3rd \& 4th metatarsal & 3 \\
\hline E20/S74 & 7 & $16 \mathrm{G}$ & IIIc & Middle/L. Archaic & & Antilocapra/Odocoileus & Metapodial & 3 \\
\hline E20/S74 & 7 & $16 \mathrm{G}$ & IIIc & Middle/L. Archaic & & Mammalia (Large) & Long bone & 2 \\
\hline E20/S74 & 7 & $16 \mathrm{G}$ & III & Middle/L. Archaic & & Mammalia (Large) & Mandible & 1 \\
\hline E20/S74 & 7 & $16 \mathrm{G}$ & IIIc & Middle/L. Archaic & & Mammalia (Medium/large) & Indeterminate & 8 \\
\hline E20/S74 & 7 & $16 \mathrm{G}$ & IIIc & Middle/L. Archaic & & Mammalia (Medium/large) & Long bone & 2 \\
\hline E20/S74 & 7 & $16 \mathrm{G}$ & IIIIc & Middle/L. Archaic & & Odocoileus sp. & Fused 3rd \& 4th metatarsal & 1 \\
\hline
\end{tabular}




\begin{tabular}{|c|c|c|c|c|c|c|c|c|}
\hline Square & Level & Lot & Unit & Cultural Affinity & Feature & Taxon & Element & No. \\
\hline$\overline{\mathrm{E} 20 / \mathrm{S} 74}$ & 7 & $16 \mathrm{G}$ & IIIc & Middle/L. Archaic & & Vertebrata & Indeterminate & 26 \\
\hline E20/S74 & 8 & $16 \mathrm{H}$ & $\mathrm{IIIb} / \mathrm{c}$ & M. Archaic & & Antilocapra/Odocoileus & Fused 3rd \& 4th metacarpal & 1 \\
\hline E20/S74 & 8 & $16 \mathrm{H}$ & $\mathrm{mIll} \mathrm{b} / \mathrm{c}$ & M. Archaic & & Mammalia (Medium) & Rib & 1 \\
\hline E20/S74 & 8 & $16 \mathrm{H}$ & $\mathrm{IIIb} / \mathrm{c}$ & M. Archaic & & Mammalia (Medium/large) & Long bone & 1 \\
\hline E20/S74 & 8 & $16 \mathrm{H}$ & IIIIb/c & M. Archaic & & Testudinata & Shell fragment & 1 \\
\hline E20/S74 & 8 & $16 \mathrm{H}$ & $\mathrm{IIIb} / \mathrm{c}$ & M. Archaic & & Vertebrata & Indeterminate & 21 \\
\hline E20/S74 & $9 \mathrm{~A}$ & $16 \mathrm{I1}$ & $\mathrm{IIIb} / \mathrm{c}$ & M. Archaic & & Mammalia (Medium/large) & Indeterminate & 1 \\
\hline E20/S74 & $9 \mathrm{~A}$ & $16 \mathrm{II}$ & $\mathrm{IIIb} / \mathrm{c}$ & M. Archaic & & Mammalia (Medium/large) & Tooth, perm./decid. ind. & 2 \\
\hline E20/S74 & $9 \mathrm{~A}$ & $16 \mathrm{I1}$ & $\mathrm{IIIb} / \mathrm{c}$ & M. Archaic & & Vertebrata & Indeterminate & 4 \\
\hline E20/S74 & 9B & $16 \mathrm{I} 2$ & $\mathrm{IIIb} / \mathrm{c}$ & M. Archaic & & Vertebrata & Indeterminate & 3 \\
\hline E20/S74 & $10 \mathrm{~A}$ & $16 \mathrm{~J} 1$ & IIIIb/c & Early/M. Archaic & & Mammalia (Medium/large) & Indeterminate & 1 \\
\hline E20/S74 & $10 \mathrm{~A}$ & $16 \mathrm{~J} 1$ & $\mathrm{IIIb} / \mathrm{c}$ & Early/M. Archaic & & Vertebrata & Indeterminate & 9 \\
\hline E20/S74 & $10 \mathrm{~B}$ & $16 \mathrm{~J} 2$ & $\mathrm{IIIb} / \mathrm{c}$ & Early/M. Archaic & & Antilocapra/Odocoileus & Astragalus & 1 \\
\hline E20/S74 & $10 \mathrm{~B}$ & $16 \mathrm{~J} 2$ & $\mathrm{IIIb} / \mathrm{c}$ & Early/M. Archaic & & Mammalia (Medium/large) & Indeterminate & 1 \\
\hline E20/S74 & $10 \mathrm{~B}$ & $16 \mathrm{~J} 2$ & $\mathrm{mb} / \mathrm{c}$ & Early/M. Archaic & & Vertebrata & Indeterminate & 1 \\
\hline E20/S74 & 12B & $16 \mathrm{~L} 2$ & IIIlb & E. Archaic & & Vertebrata & Indeterminate & 3 \\
\hline E20/S74 & $14 \mathrm{~A}$ & $16 \mathrm{~N} 1$ & IIIlb & E. Archaic & & Vertebrata & Indeterminate & 2 \\
\hline E20/S74 & $16 \mathrm{~A}$ & 16P1 & IIIIa & E. Archaic & & Small/Medium Vertebrata & Long bone & 1 \\
\hline E20/S74 & $16 \mathrm{~A}$ & 16P1 & IIIIa & E. Archaic & & Vertebrata & Indeterminate & 1 \\
\hline E20/S74 & $16 \mathrm{~B}$ & $16 \mathrm{P} 2$ & IIIIa & E. Archaic & & Mammalia (Medium/large) & Indeterminate & 1 \\
\hline E20/S74 & $16 \mathrm{~B}$ & $16 \mathrm{P} 2$ & IIIIa & E. Archaic & & Mammalia (Medium/large) & Long bone & 1 \\
\hline E20/S74 & $17 \mathrm{~A}$ & 16Q1 & IIIIa & E. Archaic & & Vertebrata & Indeterminate & 1 \\
\hline E20/S74 & 17B & 16Q2 & IIIIa & E. Archaic & & Mammalia (Medium/large) & Indeterminate & 1 \\
\hline E20/S74 & 17B & 16Q2 & IIIIa & E. Archaic & & Medium/Large Vertebrata & Indeterminate & 2 \\
\hline E20/S74 & $18 \mathrm{~A}$ & 16R1 & IIIIa & E. Archaic & & Vertebrata & Indeterminate & 1 \\
\hline E20/S74 & $18 \mathrm{~B}$ & $16 \mathrm{R} 2$ & IIIa & E. Archaic & & Vertebrata & Indeterminate & 3 \\
\hline E20/S74 & 19 & $16 \mathrm{ST}$ & II/IIIa & L. Paleo./E. Archaic & & Medium/Large Vertebrata & Long bone & 1 \\
\hline E20/S74 & 19 & $16 \mathrm{ST}$ & II/IIIa & L. Paleo./E. Archaic & & Vertebrata & Indeterminate & 1 \\
\hline E20/S74 & $19 \mathrm{~A}$ & $16 \mathrm{~S} 1$ & IIIa & E. Archaic & & Medium/Large Vertebrata & Indeterminate & 2 \\
\hline E20/S74 & $19 \mathrm{~A}$ & $16 \mathrm{~S} 1$ & IIIa & E. Archaic & & Medium/Large Vertebrata & Long bone & 2 \\
\hline E20/S74 & 19B & $16 \mathrm{~S} 2$ & IIIIa & E. Archaic & & Mammalia (Medium/large) & Indeterminate & 1 \\
\hline E20/S74 & 19B & $16 \mathrm{~S} 2$ & IIIIa & E. Archaic & & Mammalia (Medium/large) & Long bone & 1 \\
\hline E20/S74 & 19B & $16 \mathrm{~S} 2$ & IIIa & E. Archaic & & Vertebrata & Indeterminate & 2 \\
\hline E20/S74 & $20 \mathrm{~A}$ & 16T1 & II/IIIa & L. Paleo./E. Archaic & & Vertebrata & Indeterminate & 11 \\
\hline E20/S74 & $20 \mathrm{~B}$ & $16 \mathrm{~T} 2$ & ПI/IIIa & L. Paleo./E. Archaic & & Mammalia (Medium/large) & Long bone & 3 \\
\hline E20/S74 & $20 \mathrm{~B}$ & $16 \mathrm{~T} 2$ & II/II & L. Paleo./E. Archaic & & Medium/Large Vertebrata & Indeterminate & 4 \\
\hline E20/S74 & $20 \mathrm{~B}$ & $16 \mathrm{~T} 2$ & II/IIIa & L. Paleo./E. Archaic & & Small/Medium Vertebrata & Long bone & 1 \\
\hline E20/S74 & $20 \mathrm{~B}$ & $16 \mathrm{~T} 2$ & II/IIIa & L. Paleo./E. Archaic & & Vertebrata & Indeterminate & 1 \\
\hline E20/S74 & $21 \mathrm{~A}$ & 16U1 & III & L. Paleo. & & Vertebrata & Indeterminate & 1 \\
\hline E20/S74 & 21B & $16 \mathrm{U} 2$ & II & L. Paleo. & & Mammalia (Medium/large) & Indeterminate & 1 \\
\hline E20/S74 & 21B & $16 \mathrm{U} 2$ & III & L. Paleo. & & Medium/Large Vertebrata & Indeterminate & 1 \\
\hline E20/S74 & $22 \mathrm{~A}$ & $16 \mathrm{~V} 1$ & III & L. Paleo. & & Small/Medium Vertebrata & Long bone & 1 \\
\hline E20/S74 & $22 \mathrm{~B}$ & $16 \mathrm{~V} 2$ & III & L. Paleo. & & Mammalia (Large) & Long bone & 1 \\
\hline E20/S74 & $23 \mathrm{~A}$ & 16W1 & II & L. Paleo. & & Mammalia (Large) & Long bone & 1 \\
\hline E20/S74 & $23 \mathrm{~A}$ & $16 \mathrm{~W} 1$ & II & L. Paleo. & & Small/Medium Vertebrata & Long bone & 1 \\
\hline E20/S74 & $23 \mathrm{~B}$ & $16 \mathrm{~W} 2$ & $\mathrm{Id} / \mathrm{II}$ & L. Paleo. & & Mammalia (Medium/large) & Indeterminate & 1 \\
\hline E20/S74 & 24B & $16 \times 2$ & $\mathrm{Id} / \mathrm{II}$ & L. Paleo. & & Mammalia (Medium/large) & Long bone & 2 \\
\hline E20/S74 & 24B & $16 \times 2$ & Id/II & L. Paleo. & & Medium/Large Vertebrata & Indeterminate & 3 \\
\hline E20/S74 & 24B & $16 \times 2$ & Id/II & L. Paleo. & & Vertebrata & Indeterminate & 3 \\
\hline E20/S74 & $25 \mathrm{~A}$ & $16 \mathrm{Y} 1$ & $\mathrm{Id} / \mathrm{II}$ & L. Paleo. & & Medium/Large Vertebrata & Indeterminate & 1 \\
\hline E20/S74 & $25 \mathrm{~B}$ & $16 \mathrm{Y} 2$ & Isi-c/Id/II & L. Paleo. & & Mammalia (Medium/large) & Indeterminate & 2 \\
\hline E20/S74 & $25 \mathrm{~B}$ & $16 Y 2$ & Isi-c/Id/II & L. Paleo. & & Vertebrata & Indeterminate & 11 \\
\hline E20/S74 & $26 \mathrm{~A}$ & $16 \mathrm{Z} 1$ & Isi-c/Id/II & L. Paleo. & & Medium/Large Vertebrata & Indeterminate & 3 \\
\hline E20/S74 & 26B & $16 \mathrm{Z} 2$ & Isi-c/Id & L. Paleo. & & Medium/Large Vertebrata & Indeterminate & 1 \\
\hline E20/S74 & 26B & $16 \mathrm{Z} 2$ & Isi-c/Id & L. Paleo. & & Vertebrata & Indeterminate & 1 \\
\hline E20/S74 & $27 \mathrm{~A}$ & 16AA1 & Isi-c & L. Paleo. & & cf. Canis sp. & Accessory carpal bone & 1 \\
\hline E20/S74 & $27 \mathrm{~A}$ & 16AA1 & Isi-c & L. Paleo. & & Large vertebrate, class ind. & Indeterminate & 1 \\
\hline E20/S74 & $27 \mathrm{~A}$ & 16AA1 & Isi-c & L. Paleo. & & Mammalia (Medium/large) & Indeterminate & 4 \\
\hline E20/S74 & $27 \mathrm{~A}$ & 16AA1 & Isi-c & L. Paleo. & & Mammalia (Medium/large) & Long bone & 1 \\
\hline E20/S74 & $27 \mathrm{~A}$ & 16AA1 & Isi-c & L. Paleo. & & Vertebrata & Indeterminate & 2 \\
\hline E20/S74 & 27B & $16 \mathrm{AA} 2$ & Isi-c & L. Paleo. & & Antilocapra/Odocoileus & Astragalus & 1 \\
\hline E20/S74 & $27 \mathrm{~B}$ & $16 \mathrm{AA} 2$ & Isi-c & L. Paleo. & & Aves & Long bone & 1 \\
\hline E20/S74 & 27B & $16 \mathrm{AA} 2$ & Isi-c & L. Paleo. & & Mammalia (Medium/large) & Indeterminate & 1 \\
\hline E20/S74 & 27B & $16 \mathrm{AA} 2$ & Isi-c & L. Paleo. & & Mammalia (Medium/large) & Long bone & 1 \\
\hline E20/S74 & 27B & $16 \mathrm{AA} 2$ & Isi-c & L. Paleo. & & Medium/Large Vertebrata & Indeterminate & 2 \\
\hline E20/S74 & $27 \mathrm{~B}$ & $16 \mathrm{AA} 2$ & Isi-c & L. Paleo. & & Small/Medium Vertebrata & Long bone & 1 \\
\hline E20/S74 & 27B & $16 \mathrm{AA} 2$ & Isi-c & L. Paleo. & & Vertebrata & Indeterminate & 1 \\
\hline
\end{tabular}




\begin{tabular}{|c|c|c|c|c|c|c|c|c|}
\hline Square & Level & Lot & Unit & Cultural Affinity & Feature & Taxon & Element & No. \\
\hline$\overline{\text { E20/S74 }}$ & $28 \mathrm{~A}$ & $16 \mathrm{BB} 1$ & Isi-c & L. Paleo. & & Mammalia (Medium/large) & Indeterminate & 1 \\
\hline E20/S74 & $28 \mathrm{~A}$ & 16BB1 & Isi-c & L. Paleo. & & Mammalia (Medium/large) & Long bone & 1 \\
\hline E20/S74 & $28 \mathrm{~A}$ & 16BB1 & Isi-c & L. Paleo. & & Medium/Large Vertebrata & Indeterminate & 1 \\
\hline $\mathrm{E} 20 / \mathrm{S} 74$ & $28 \mathrm{~A}$ & 16BB1 & Isi-c & L. Paleo. & & Small/Medium Vertebrata & Long bone & 3 \\
\hline E20/S74 & $28 \mathrm{~A}$ & 16BB1 & Isi-c & L. Paleo. & & Vertebrata & Indeterminate & 4 \\
\hline E20/S74 & $29 \mathrm{~A}$ & $16 \mathrm{CC} 1$ & Isi/Icl/Isi-c & Paleoindian & & Vertebrata & Indeterminate & 3 \\
\hline E20/S74 & $30 \mathrm{~A}$ & 16DD1 & Isi/Icl/Isi-c & Paleoindian & & Mammalia (Medium/large) & Indeterminate & 1 \\
\hline E20/S74 & $30 \mathrm{~A}$ & 16DD1 & |Isi/Icl/Isi-c & Paleoindian & & Vertebrata & Indeterminate & 1 \\
\hline E20/S74 & $32 \mathrm{~A}$ & $16 \mathrm{FF} 1 \mathrm{C}$ & Isi/Icl & E. Paleo. & & Mammalia (Medium/large) & Indeterminate & 1 \\
\hline E20/S74 & $32 \mathrm{~B}$ & $16 \mathrm{FF} 2 \mathrm{~A}$ & Isi/Icl & E. Paleo. & & Vertebrata & Indeterminate & 1 \\
\hline E20/S74 & 33B & $16 \mathrm{GG} 2 \mathrm{C}$ & Isi/Icl & E. Paleo. & & Vertebrata & Indeterminate & 5 \\
\hline E20/S74 & $34 \mathrm{~A}$ & $16 \mathrm{HH} 1 \mathrm{~A}$ & Isi/Icl & E. Paleo. & & Vertebrata & Indeterminate & 1 \\
\hline E20/S74 & $34 \mathrm{~A}$ & $16 \mathrm{HH} 1 \mathrm{~B}$ & Isi/Icl & E. Paleo. & & Vertebrata & Indeterminate & 3 \\
\hline E20/S74 & $34 \mathrm{~B}$ & $16 \mathrm{HH} 2 \mathrm{~A}$ & Isi/Icl & E. Paleo. & & Mammalia (Medium/large) & Long bone & 1 \\
\hline E20/S74 & 34B & $16 \mathrm{HH} 2 \mathrm{~B}$ & Isi/Icl & E. Paleo. & & Mammalia (Medium/large) & Indeterminate & 1 \\
\hline E20/S74 & 34B & $16 \mathrm{HH} 2 \mathrm{~B}$ & Isi/Icl & E. Paleo. & & Vertebrata & Indeterminate & 1 \\
\hline E20/S74 & $35 \mathrm{~A}$ & $16 \Pi 1 \mathrm{~A}$ & Isi & E. Paleo. & & Vertebrata & Indeterminate & 1 \\
\hline E20/S74 & $35 \mathrm{~A}$ & $16 \amalg 1 \mathrm{~B}$ & Isi & E. Paleo. & & Vertebrata & Indeterminate & 1 \\
\hline $\mathrm{E} 20 / \mathrm{S} 74$ & $35 \mathrm{~A}$ & $16 \Pi 1 \mathrm{C}$ & Isi & E. Paleo. & & Vertebrata & Indeterminate & 25 \\
\hline E20/S74 & $35 \mathrm{~B}$ & $16 \mathrm{II} 2 \mathrm{~A}$ & Isi & E. Paleo. & & Mammalia (Medium/large) & Indeterminate & 1 \\
\hline E20/S74 & $35 \mathrm{~B}$ & $16 \mathrm{II} 2 \mathrm{~A}$ & Isi & E. Paleo. & & Mammalia (Medium/large) & Long bone & 1 \\
\hline E20/S74 & $35 \mathrm{~B}$ & $16112 \mathrm{~A}$ & Isi & E. Paleo. & & Vertebrata & Indeterminate & 34 \\
\hline E20/S74 & $35 \mathrm{~B}$ & $16 \mathrm{II} 2 \mathrm{~B}$ & Isi & E. Paleo. & & Vertebrata & Indeterminate & 3 \\
\hline E20/S74 & $36 \mathrm{~A}$ & $16 \mathrm{JJ} 1 \mathrm{~A}$ & Isi & E. Paleo. & & Vertebrata & Indeterminate & 8 \\
\hline E20/S74 & $36 \mathrm{~A}$ & $16 J J 1 D$ & |Isi & E. Paleo. & & Vertebrata & Indeterminate & 1 \\
\hline E20/S74 & 36B & 16JJ2D & Isi & E. Paleo. & & Vertebrata & Indeterminate & 2 \\
\hline E20/S74 & $37 \mathrm{~A}$ & $16 \mathrm{KK} 1 \mathrm{~B}$ & Isi & E. Paleo. & & Vertebrata & Indeterminate & 1 \\
\hline $\mathrm{E} 20 / \mathrm{S} 76$ & 1 & $15 \mathrm{~A}$ & IIIIc & L. Prehist. & & Antilocapra/Odocoileus & Fused 3rd \& 4th metatarsal & 1 \\
\hline E20/S76 & 1 & $15 \mathrm{~A}$ & |IIIc & L. Prehist. & & Vertebrata & Indeterminate & 6 \\
\hline E20/S76 & 2 & 15B & IIIIc & L. Archaic/L. Prehist. & & Antilocapra/Odocoileus & Fused 3rd \& 4th metatarsal & 1 \\
\hline E20/S76 & 2 & 15B & IIIIc & L. Archaic/L. Prehist. & & Mammalia (Medium/large) & Indeterminate & 1 \\
\hline E20/S76 & 2 & 15B & |IIIc & L. Archaic/L. Prehist. & & Vertebrata & Indeterminate & 8 \\
\hline E20/S76 & 3 & $15 \mathrm{C}$ & IIII & L. Archaic & & AntilocapralOdocoileus & Fused central/fourth tarsal & 1 \\
\hline E20/S76 & 3 & $15 \mathrm{C}$ & IIIIc & L. Archaic & & Leporidae & Cranium & 2 \\
\hline E20/S76 & 3 & $15 \mathrm{C}$ & IIIIc & L. Archaic & & Mammalia (Large) & Indeterminate & 3 \\
\hline E20/S76 & 3 & $15 \mathrm{C}$ & IIII & L. Archaic & & Mammalia (Large) & Long bone & 1 \\
\hline E20/S76 & 3 & $15 \mathrm{C}$ & IIIIc & L. Archaic & & Mammalia (Medium/large) & Indeterminate & 10 \\
\hline E20/S76 & 3 & $15 \mathrm{C}$ & IIIIc & L. Archaic & & Odocoileus sp. & Distal phalange & 1 \\
\hline E20/S76 & 3 & $15 \mathrm{C}$ & IIIc & L. Archaic & & Procyon lotor & Permanent tooth & 1 \\
\hline E20/S76 & 3 & $15 \mathrm{C}$ & IIIIc & L. Archaic & & Vertebrata & Indeterminate & 39 \\
\hline E20/S76 & 4 & 15D & IIIIc & L. Archaic & & Antilocapra/Odocoileus & Fused second \& third tarsal & 1 \\
\hline E20/S76 & 4 & 15D & IIIIc & L. Archaic & & Bison sp. & Proximal sesamoid & 1 \\
\hline E20/S76 & 4 & 15D & IIIIc & L. Archaic & & Mammalia (Large) & Indeterminate & 1 \\
\hline E20/S76 & 4 & 15D & IIIIc & L. Archaic & & Mammalia (Large) & Long bone & 1 \\
\hline $\mathrm{E} 20 / \mathrm{S} 76$ & 4 & 15D & IIIIc & L. Archaic & & Mammalia (Medium/large) & Indeterminate & 5 \\
\hline E20/S76 & 4 & 15D & IIIIc & L. Archaic & & Mammalia (Very large) & Long bone & 1 \\
\hline E20/S76 & 4 & 15D & IIII & L. Archaic & & Odocoileus sp. & Permanent tooth & 1 \\
\hline E20/S76 & 4 & 15D & IIIIc & L. Archaic & & Vertebrata & Indeterminate & 52 \\
\hline E20/S76 & 4 & 15D & IIIIc & L. Archaic & & Vertebrata & Long bone & 1 \\
\hline E20/S76 & 5 & $15 \mathrm{E}$ & IIII & L. Archaic & & Mammalia (Large) & Long bone & 6 \\
\hline E20/S76 & 5 & $15 \mathrm{E}$ & IIIc & L. Archaic & & Mammalia (Medium/large) & Long bone & 10 \\
\hline E20/S76 & 5 & $15 \mathrm{E}$ & IIIIc & L. Archaic & & Mammalia (Small) & Sacrum & 1 \\
\hline E20/S76 & 5 & $15 \mathrm{E}$ & IIIIc & L. Archaic & & Medium/Large Vertebrata & Indeterminate & 2 \\
\hline E20/S76 & 5 & $15 \mathrm{E}$ & IIIIc & L. Archaic & & Odocoileus sp. & Permanent tooth & 1 \\
\hline E20/S76 & 5 & $15 \mathrm{E}$ & IIIIc & L. Archaic & & Vertebrata & Indeterminate & 32 \\
\hline E20/S76 & 6 & $15 \mathrm{~F}$ & IIII & Middle/L. Archaic & & Artiodactyla (Large) & Long bone & 1 \\
\hline E20/S76 & 6 & $15 \mathrm{~F}$ & IIIIc & Middle/L. Archaic & & Artiodactyla (Large) & Rib & 1 \\
\hline E20/S76 & 6 & $15 \mathrm{~F}$ & IIIIc & Middle/L. Archaic & & Mammalia (Large) & Indeterminate & 1 \\
\hline E20/S76 & 6 & $15 \mathrm{~F}$ & IIIIc & Middle/L. Archaic & & Mammalia (Large) & Long bone & 5 \\
\hline E20/S76 & 6 & $15 \mathrm{~F}$ & IIII & Middle/L. Archaic & & Mammalia (Medium/large) & Indeterminate & 4 \\
\hline E20/S76 & 6 & $15 \mathrm{~F}$ & IIIIc & Middle/L. Archaic & & Odocoileus sp. & Tooth, perm./decid. ind. & 1 \\
\hline E20/S76 & 6 & $15 \mathrm{~F}$ & IIIIc & Middle/L. Archaic & & Testudinata & Nuchal & 1 \\
\hline E20/S76 & 6 & $15 \mathrm{~F}$ & IIIIc & Middle/L. Archaic & & Vertebrata & Indeterminate & 9 \\
\hline E20/S76 & 7 & $15 \mathrm{G}$ & IIIIc & Middle/L. Archaic & & Antilocapra/Odocoileus & Fused second \& third tarsal & 1 \\
\hline E20/S76 & 7 & $15 \mathrm{G}$ & IIIIc & Middle/L. Archaic & & Mammalia (Large) & Long bone & 1 \\
\hline E20/S76 & 7 & $15 \mathrm{G}$ & IIIIc & Middle/L. Archaic & & Mammalia (Medium/large) & Indeterminate & 4 \\
\hline E20/S76 & 7 & $15 \mathrm{G}$ & IIIIc & Middle/L. Archaic & & Mammalia (Medium/large) & Long bone & 1 \\
\hline
\end{tabular}




\begin{tabular}{|c|c|c|c|c|c|c|c|c|}
\hline Square & Level & Lot & Unit & Cultural Affinity & Feature & Taxon & Element & No. \\
\hline E20/S76 & 7 & $15 \mathrm{G}$ & IIIc & Middle/L. Archaic & & Vertebrata & Indeterminate & 1 \\
\hline E20/S76 & 7 & $15 \mathrm{G}$ & IIII & Middle/L. Archaic & & Vertebrata & Long bone & 4 \\
\hline E20/S76 & 8 & $15 \mathrm{H}$ & $\mathrm{IIIb} / \mathrm{c}$ & M. Archaic & & Testudinata & Shell fragment & \\
\hline E20/S76 & 8 & $15 \mathrm{H}$ & $\mathrm{IIIb} / \mathrm{c}$ & M. Archaic & & Vertebrata & Indeterminate & \\
\hline E20/S76 & $9 \mathrm{~A}$ & $15 \mathrm{Il}$ & $\mathrm{IIIb} / \mathrm{c}$ & Archaic & & Mammalia (Medium/large) & Indeterminate & \\
\hline E20/S76 & $9 \mathrm{~B}$ & $15 \mathrm{I} 2$ & $\mathrm{IIIb} / \mathrm{c}$ & Archaic & & Mammalia (Large) & Indeterminate & \\
\hline E20/S76 & $9 B$ & $15 \mathrm{I} 2$ & $\mathrm{IIIb} / \mathrm{c}$ & Archaic & & Mammalia (Medium/large) & Indeterminate & \\
\hline E20/S76 & $9 \mathrm{~B}$ & $15 \mathrm{I} 2$ & $\mathrm{IIIb} / \mathrm{c}$ & Archaic & & Vertebrata & Indeterminate & \\
\hline E20/S76 & $10 \mathrm{~A}$ & $15 \mathrm{~J} 1$ & $\mathrm{IIIb} / \mathrm{c}$ & Early/M. Archaic & & Mammalia (Large) & Long bone & \\
\hline E20/S76 & $10 \mathrm{~A}$ & $15 \mathrm{~J} 1$ & $\mathrm{IIIb} / \mathrm{c}$ & Early/M. Archaic & & Mammalia (Medium/large) & Indeterminate & \\
\hline E20/S76 & $10 \mathrm{~A}$ & $15 \mathrm{~J} 1$ & $\mathrm{IIIb} / \mathrm{c}$ & Early/M. Archaic & & Vertebrata & Indeterminate & \\
\hline E20/S76 & $10 \mathrm{~B}$ & $15 \mathrm{~J} 2$ & IIIb & Early/M. Archaic & & Vertebrata & Indeterminate & \\
\hline E20/S76 & 10B & $15 \mathrm{~J} 2$ & IIIb & Early/M. Archaic & & Vertebrata & Long bone & \\
\hline E20/S76 & $11 \mathrm{~A}$ & $15 \mathrm{~K} 1$ & IIIb & Early/M. Archaic & & Vertebrata & Indeterminate & \\
\hline E20/S76 & $12 \mathrm{~A}$ & $15 \mathrm{~L} 1$ & IIIb & E. Archaic & & Artiodactyla & Tooth, perm./decid. ind. & \\
\hline E20/S76 & $12 \mathrm{~A}$ & $15 \mathrm{~L} 1$ & IIIb & E. Archaic & & Mammalia (Large) & Long bone & \\
\hline E20/S76 & $12 \mathrm{~A}$ & $15 \mathrm{~L} 1$ & IIIb & E. Archaic & & Mammalia (Medium/large) & Long bone & \\
\hline E20/S76 & $12 \mathrm{~A}$ & $15 \mathrm{~L} 1$ & IIItb & E. Archaic & & Medium/Large Vertebrata & Indeterminate & \\
\hline E20/S76 & $12 \mathrm{~A}$ & $15 \mathrm{~L} 1$ & IIIb & E. Archaic & & Small/Medium Vertebrata & Long bone & \\
\hline E20/S76 & $12 \mathrm{~A}$ & $15 \mathrm{~L} 1$ & IIIb & E. Archaic & & Vertebrata & Indeterminate & \\
\hline E20/S76 & $13 \mathrm{~A}$ & 15M1 & IIIb & E. Archaic & & Mammalia (Medium/large) & Indeterminate & \\
\hline E20/S76 & $13 \mathrm{~A}$ & 15M1 & IIIb & E. Archaic & & Vertebrata & Indeterminate & \\
\hline E20/S76 & $16 \mathrm{~A}$ & 15P1 & IIIa & E. Archaic & & Vertebrata & Indeterminate & \\
\hline E20/S76 & 17B & 15Q2 & IIIIa & E. Archaic & & Mammalia (Medium/large) & Long bone & \\
\hline E20/S76 & $18 \mathrm{~A}$ & 15R1 & IIIIa & E. Archaic & & Vertebrata & Indeterminate & \\
\hline E20/S76 & $18 \mathrm{~B}$ & $15 \mathrm{R} 2$ & IIIIa & E. Archaic & & Vertebrata & Indeterminate & \\
\hline E20/S76 & $19 \mathrm{~A}$ & $15 \mathrm{~S} 1$ & III/IIIa & L. Paleo./E. Archaic & & Vertebrata & Indeterminate & \\
\hline E20/S76 & $19 \mathrm{~A}$ & $15 \mathrm{~S} 1$ & III/IIIa & L. Paleo./E. Archaic & & Vertebrata & Tooth, perm./decid. ind. & \\
\hline E20/S76 & 19B & $15 \mathrm{~S} 2$ & II/IIIa & L. Paleo./E. Archaic & & Mammalia (Medium) & Axis & \\
\hline E20/S76 & 19B & $15 \mathrm{~S} 2$ & III/IIIa & L. Paleo./E. Archaic & & Mammalia (Medium/large) & Indeterminate & \\
\hline E20/S76 & 19B & $15 \mathrm{~S} 2$ & II/Ша & L. Paleo./E. Archaic & & Vertebrata & Indeterminate & \\
\hline E20/S76 & $20 \mathrm{~A}$ & $15 \mathrm{~T} 1$ & II/IIIa & L. Paleo./E. Archaic & & Mammalia (Medium/large) & Mandible & \\
\hline E20/S76 & $20 \mathrm{~A}$ & $15 \mathrm{~T} 1$ & II/IIIa & L. Paleo./E. Archaic & & Medium/Large Vertebrata & Indeterminate & the \\
\hline E20/S76 & $20 \mathrm{~A}$ & $15 \mathrm{~T} 1$ & II/IIIIa & L. Paleo./E. Archaic & & Small/Medium Vertebrata & Long bone & \\
\hline E20/S76 & $20 \mathrm{~A}$ & $15 \mathrm{~T} 1$ & II/IIIa & L. Paleo./E. Archaic & & Vertebrata & Indeterminate & \\
\hline E20/S76 & 20B & $15 \mathrm{~T} 2$ & III & L. Paleo. & & Mammalia (Medium/large) & Indeterminate & \\
\hline E20/S76 & 20B & $15 \mathrm{~T} 2$ & III & L. Paleo. & & Medium/Large Vertebrata & Indeterminate & \\
\hline E20/S76 & $20 \mathrm{~B}$ & $15 \mathrm{~T} 2$ & III & L. Paleo. & & Vertebrata & Indeterminate & \\
\hline E20/S76 & $21 \mathrm{~A}$ & $15 \mathrm{U} 1$ & III & L. Paleo. & & Small/Medium Vertebrata & Long bone & \\
\hline E20/S76 & $21 \mathrm{~A}$ & $15 \mathrm{U} 1$ & III & L. Paleo. & & Vertebrata & Indeterminate & \\
\hline E20/S76 & 21B & $15 \mathrm{U} 2$ & III & L. Paleo. & & Mammalia (Very large) & Tooth, perm./decid. ind. & \\
\hline E20/S76 & 21B & $15 \mathrm{U} 2$ & III & L. Paleo. & & Medium/Large Vertebrata & Indeterminate & \\
\hline E20/S76 & 21B & $15 \mathrm{U} 2$ & III & L. Paleo. & & Vertebrata & Indeterminate & \\
\hline E20/S76 & 23B & $15 \mathrm{~W} 2$ & IId/II & L. Paleo. & & Testudinata & Shell fragment & \\
\hline E20/S76 & 23B & $15 \mathrm{~W} 2$ & $\mathrm{Id} / \mathrm{II}$ & L. Paleo. & & Vertebrata & Indeterminate & \\
\hline E20/S76 & $24 \mathrm{~A}$ & $15 \mathrm{X} 1$ & $\mathrm{Id} / \mathrm{II}$ & L. Paleo. & & Mammalia (Medium/large) & Long bone & \\
\hline E20/S76 & $24 \mathrm{~A}$ & $15 \mathrm{X} 1$ & Id/II & L. Paleo. & & Mammalia (Very large) & Long bone & \\
\hline E20/S76 & $24 \mathrm{~A}$ & $15 \mathrm{X} 1$ & IId/II & L. Paleo. & & Medium/Large Vertebrata & Indeterminate & \\
\hline E20/S76 & $24 \mathrm{~A}$ & $15 X 1$ & IId/II & L. Paleo. & & Small/Medium Vertebrata & Long bone & \\
\hline E20/S76 & $24 \mathrm{~A}$ & $15 \mathrm{X} 1$ & Id/II & L. Paleo. & & Vertebrata & Indeterminate & 10 \\
\hline E20/S76 & 24B & $15 \times 2$ & IId/II & L. Paleo. & & Mammalia (Medium/large) & Indeterminate & \\
\hline E20/S76 & 24B & $15 \times 2$ & IId/II & L. Paleo. & & Mammalia (Medium/large) & Vertebra & \\
\hline E20/S76 & $24 B$ & $15 \mathrm{X} 2$ & IId/II & L. Paleo. & & Medium/Large Vertebrata & Indeterminate & \\
\hline E20/S76 & 24B & $15 \times 2$ & Id/II & L. Paleo. & & Vertebrata & Indeterminate & \\
\hline E20/S76 & $25 \mathrm{~A}$ & $15 \mathrm{Y} 1$ & Isi-c/Id & L. Paleo. & & Mammalia (Medium/large) & Long bone & \\
\hline E20/S76 & $25 \mathrm{~A}$ & $15 \mathrm{Y} 1$ & |Isi-c/Id & L. Paleo. & & Medium/Large Vertebrata & Indeterminate & \\
\hline E20/S76 & $25 \mathrm{~A}$ & $15 \mathrm{Y} 1$ & |Isi-c/Id & L. Paleo. & & Vertebrata & Indeterminate & \\
\hline E20/S76 & $25 \mathrm{~B}$ & $15 \mathrm{Y} 2$ & |Isi-c/Id & L. Paleo. & & Mammalia (Large) & Long bone & \\
\hline E20/S76 & $25 \mathrm{~B}$ & $15 \mathrm{Y} 2$ & Isi-c/Id & L. Paleo. & & Medium/Large Vertebrata & Indeterminate & \\
\hline E20/S76 & $25 \mathrm{~B}$ & $15 \mathrm{Y} 2$ & Isi-c/Id & L. Paleo. & & Testudinata & Shell fragment & \\
\hline E20/S76 & $25 \mathrm{~B}$ & $15 \mathrm{Y} 2$ & Isi-c/Id & L. Paleo. & & Vertebrata & Indeterminate & \\
\hline E20/S76 & $26 \mathrm{~A}$ & $15 \mathrm{Z} 1$ & Isi-c & L. Paleo. & & Mammalia (Large) & Flat bone & \\
\hline E20/S76 & $26 \mathrm{~A}$ & $15 \mathrm{Zl}$ & Isi-c & L. Paleo. & & Mammalia (Large) & Long bone & \\
\hline E20/S76 & $26 \mathrm{~A}$ & $15 \mathrm{Z} 1$ & Isi-c & L. Paleo. & & Medium/Large Vertebrata & Indeterminate & \\
\hline E20/S76 & $26 \mathrm{~A}$ & $15 \mathrm{Z} 1$ & Isi-c & L. Paleo. & & Medium/Large Vertebrata & Long bone & \\
\hline E20/S76 & $26 \mathrm{~A}$ & $15 \mathrm{Z} 1$ & |Isi-c & L. Paleo. & & Odocoileus sp. & Intermediate carpal bone & \\
\hline E20/S76 & $26 \mathrm{~A}$ & $15 \mathrm{Zl}$ & Isi-c & L. Paleo. & & Small/Medium Vertebrata & Long bone & \\
\hline
\end{tabular}




\begin{tabular}{|c|c|c|c|c|c|c|c|c|}
\hline Square & Level & Lot & Unit & Cultural Affinity & Feature & Taxon & Element & No. \\
\hline$\overline{\mathrm{E} 20 / \mathrm{S} 76}$ & $26 \mathrm{~A}$ & $15 \mathrm{Z1}$ & Isi-c & L. Paleo. & & Testudinata & Shell fragment & 1 \\
\hline E20/S76 & 26B & $15 \mathrm{Z} 2$ & Isi-c & L. Paleo. & & Vertebrata & Indeterminate & 2 \\
\hline E20/S76 & 27B & $15 \mathrm{AA} 2$ & Isi-c & L. Paleo. & & Antilocapra/Odocoileus & Metapodial & 1 \\
\hline E20/S76 & 27B & $15 \mathrm{AA} 2$ & Isi-c & L. Paleo. & & Antilocapra/Odocoileus & Ulna & 1 \\
\hline E20/S76 & 27B & $15 \mathrm{AA} 2$ & Isi-c & L. Paleo. & & Artiodactyla & Tooth, perm./decid. ind. & 1 \\
\hline E20/S76 & 27B & $15 \mathrm{AA} 2$ & Isi-c & L. Paleo. & & Bison sp. & Cranium & 1 \\
\hline E20/S76 & 27B & $15 \mathrm{AA} 2$ & Isi-c & L. Paleo. & & Mammalia (Medium/large) & Indeterminate & 2 \\
\hline E20/S76 & 27B & $15 \mathrm{AA} 2$ & Isi-c & L. Paleo. & & Mammalia (Medium/large) & Long bone & 4 \\
\hline E20/S76 & 27B & $15 \mathrm{AA} 2$ & Isi-c & L. Paleo. & & Medium/Large Vertebrata & Indeterminate & 1 \\
\hline E20/S76 & 27B & $15 \mathrm{AA} 2$ & Isi-c & L. Paleo. & & Small/Medium Vertebrata & Long bone & 1 \\
\hline E20/S76 & 27B & $15 \mathrm{AA} 2$ & Isi-c & L. Paleo. & & Vertebrata & Indeterminate & 10 \\
\hline E20/S76 & $28 \mathrm{~A}$ & 15BB1 & Isi-c & L. Paleo. & & Medium/Large Vertebrata & Long bone & 2 \\
\hline E20/S76 & 28B & 15BB2 & Isi/Isi-c & Paleoindian & & Mammalia (Medium/large) & Indeterminate & 1 \\
\hline E20/S76 & 28B & 15BB2 & Isi/Isi-c & Paleoindian & & Vertebrata & Indeterminate & 2 \\
\hline E20/S76 & $29 \mathrm{~A}$ & $15 \mathrm{CC} 1$ & Isi/Icl/Isi-c & Paleoindian & & Mammalia (Medium/large) & Indeterminate & 1 \\
\hline E20/S76 & $29 \mathrm{~A}$ & $15 \mathrm{CC} 1$ & Isi/Icl/Isi-c & Paleoindian & & Mammalia (Medium/large) & Long bone & 3 \\
\hline E20/S76 & 30B & 15DD2 & Isi/Icl & E. Paleo. & & Vertebrata & Indeterminate & 2 \\
\hline E20/S76 & $31 \mathrm{~A}$ & F168 & Isi-c & L. Paleo. & f168 & Vertebrata & Indeterminate & 1 \\
\hline E20/S76 & $32 \mathrm{~A}$ & 15FF1A & Isi//cl & E. Paleo. & & Mammalia (Medium/large) & Tooth, perm./decid. ind. & 1 \\
\hline E20/S76 & $32 \mathrm{~A}$ & 15FF1C & $\mathrm{Isi} / \mathrm{Icl}$ & E. Paleo. & & Mammalia (Medium/large) & Indeterminate & 3 \\
\hline E20/S76 & $32 \mathrm{~A}$ & 15FF1C & Isi//Icl & E. Paleo. & & Medium/Large Vertebrata & Indeterminate & 3 \\
\hline $\mathrm{E} 20 / \mathrm{S} 76$ & $32 \mathrm{~A}$ & 15FF1C & Isi//Icl & E. Paleo. & & Vertebrata & Indeterminate & 2 \\
\hline E20/S76 & $32 \mathrm{~A}$ & 15FF1D & $\mathrm{Isi} / \mathrm{Icl}$ & E. Paleo. & & Vertebrata & Indeterminate & 2 \\
\hline E20/S76 & $32 \mathrm{~B}$ & $15 \mathrm{FF} 2 \mathrm{~A}$ & Isi & E. Paleo. & & Mammalia (Medium/large) & Indeterminate & 1 \\
\hline E20/S76 & $32 \mathrm{~B}$ & $15 \mathrm{FF} 2 \mathrm{~B}$ & Isi & E. Paleo. & & Small/Medium Vertebrata & Long bone & 1 \\
\hline E20/S76 & $32 \mathrm{~B}$ & $15 \mathrm{FF} 2 \mathrm{C}$ & Isi & E. Paleo. & & Mammalia (Medium/large) & Indeterminate & 1 \\
\hline E20/S76 & 32B & $15 \mathrm{FF} 2 \mathrm{C}$ & Isi & E. Paleo. & & Medium/Large Vertebrata & Indeterminate & 2 \\
\hline E20/S76 & $32 \mathrm{~B}$ & 15FF2D & Isi & E. Paleo. & & Small/Medium Vertebrata & Long bone & 1 \\
\hline E20/S76 & 32B & 15FF2D & Isi & E. Paleo. & & Vertebrata & Indeterminate & 1 \\
\hline E20/S76 & $33 \mathrm{~A}$ & 15GG1A & Isi & E. Paleo. & & Mammalia (Medium/large) & Indeterminate & 2 \\
\hline E20/S76 & $33 \mathrm{~A}$ & $15 \mathrm{GG} 1 \mathrm{~A}$ & Isi & E. Paleo. & & Vertebrata & Indeterminate & 1 \\
\hline E20/S76 & 33B & $15 \mathrm{GG} 2 \mathrm{C}$ & Isi & E. Paleo. & & Mammalia (Medium/large) & Permanent tooth & 1 \\
\hline E20/S76 & 33B & $15 \mathrm{GG} 2 \mathrm{C}$ & Isi & E. Paleo. & & Mammalia (Medium/large) & Tooth, perm./decid. ind. & 2 \\
\hline E20/S76 & $34 \mathrm{~A}$ & $15 \mathrm{HH} 1 \mathrm{C}$ & Isi & E. Paleo. & & Vertebrata & Indeterminate & 2 \\
\hline E20/S76 & $34 \mathrm{~A}$ & 15HH1D & Isi & E. Paleo. & & Vertebrata & Indeterminate & 1 \\
\hline E20/S76 & $35 \mathrm{~B}$ & 15II2D & Isi & E. Paleo. & & Vertebrata & Indeterminate & 4 \\
\hline E20/S78 & 1 & $14 \mathrm{~A}$ & IIIc & L. Prehist. & & Mammalia (Medium/large) & Indeterminate & 3 \\
\hline E20/S78 & 1 & $14 \mathrm{~A}$ & IIIc & L. Prehist. & & Vertebrata & Indeterminate & 19 \\
\hline E20/S78 & 2 & 14B & IIIc & L. Archaic/L. Prehist. & & Artiodactyla (Medium) & Cranium & 1 \\
\hline E20/S78 & 2 & $14 \mathrm{~B}$ & IIIc & L. Archaic/L. Prehist. & & Mammalia (Medium/large) & Indeterminate & 3 \\
\hline E20/S78 & 2 & 14B & IIIc & L. Archaic/L. Prehist. & & Sylvilagus sp. & Calcaneus & 1 \\
\hline E20/S78 & 2 & 14B & IIIc & L. Archaic/L. Prehist. & & Vertebrata & Indeterminate & 13 \\
\hline E20/S78 & 3 & $14 \mathrm{C}$ & IIIc & L. Archaic & & Antilocapra/Odocoileus & Proximal sesamoid & 3 \\
\hline E20/S78 & 3 & $14 \mathrm{C}$ & IIIc & L. Archaic & & Mammalia (Medium/large) & Cranium & 1 \\
\hline E20/S78 & 3 & $14 \mathrm{C}$ & IIIc & L. Archaic & & Mammalia (Medium/large) & Indeterminate & 5 \\
\hline E20/S78 & 3 & $14 \mathrm{C}$ & IIIc & L. Archaic & & Odocoileus sp. & Permanent tooth & 2 \\
\hline E20/S78 & 3 & $14 \mathrm{C}$ & IIIc & L. Archaic & & Odocoileus sp. & Proximal phalange & 1 \\
\hline E20/S78 & 3 & $14 \mathrm{C}$ & IIIc & L. Archaic & & Vertebrata & Indeterminate & 18 \\
\hline E20/S78 & 4 & 14D & IIIc & L. Archaic & & AntilocapralOdocoileus & Fused 3rd \& 4th metatarsal & 1 \\
\hline E20/S78 & 4 & 14D & IIIC & L. Archaic & & Antilocapra/Odocoileus & Intermediate carpal bone & 1 \\
\hline E20/S78 & 4 & 14D & IIIc & L. Archaic & & Mammalia (Large) & Long bone & 1 \\
\hline E20/S78 & 4 & 14D & IIIc & L. Archaic & & Mammalia (Large) & Podial & 1 \\
\hline E20/S78 & 4 & 14D & IIII & L. Archaic & & Mammalia (Medium/large) & Indeterminate & 8 \\
\hline E20/S78 & 4 & 14D & IIIc & L. Archaic & & Mammalia (Medium/large) & Long bone & 1 \\
\hline E20/S78 & 4 & 14D & IIIc & L. Archaic & & Mammalia (Medium/large) & Tooth, perm./decid. ind. & 1 \\
\hline E20/S78 & 4 & 14D & IIIc & L. Archaic & & Odocoileus sp. & Permanent tooth & 1 \\
\hline E20/S78 & 4 & 14D & IIIc & L. Archaic & & Vertebrata & Indeterminate & 41 \\
\hline E20/S78 & 5 & $14 \mathrm{E}$ & IIIc & L. Archaic & & Artiodactyla & Tooth, perm./decid. ind. & 4 \\
\hline E20/S78 & 5 & $14 \mathrm{E}$ & IIII & L. Archaic & & Mammalia (Large) & Long bone & 3 \\
\hline E20/S78 & 5 & $14 \mathrm{E}$ & IIIc & L. Archaic & & Mammalia (Medium/large) & Cranium & 1 \\
\hline E20/S78 & 5 & $14 \mathrm{E}$ & IIIc & L. Archaic & & Mammalia (Medium/large) & Indeterminate & 12 \\
\hline E20/S78 & 5 & $14 \mathrm{E}$ & IIIc & L. Archaic & & Odocoileus sp. & Permanent tooth & 1 \\
\hline E20/S78 & 5 & $14 \mathrm{E}$ & IIIc & L. Archaic & & Vertebrata & Indeterminate & 37 \\
\hline E20/S78 & 5 & $14 \mathrm{E}$ & IIIc & L. Archaic & & Vertebrata & Long bone & 1 \\
\hline E20/S78 & 6 & $14 \mathrm{~F}$ & IIIc & Middle/L. Archaic & & AntilocapralOdocoileus & Distal fibula & 1 \\
\hline E20/S78 & 6 & $14 \mathrm{~F}$ & IIIc & Middle/L. Archaic & & Canis sp. & Fourth tarsal & 1 \\
\hline $\mathrm{E} 20 / \mathrm{S} 78$ & 6 & $14 \mathrm{~F}$ & IIIc & Middle/L. Archaic & & Mammalia (Large) & Indeterminate & \\
\hline
\end{tabular}




\begin{tabular}{|c|c|c|c|c|c|c|c|c|}
\hline Square & Level & Lot & Unit & Cultural Affinity & Feature & Taxon & Element & No. \\
\hline E20/S78 & 6 & $14 \mathrm{~F}$ & IIIc & Middle/L. Archaic & & Mammalia (Large) & Long bone & 1 \\
\hline E20/S78 & 6 & $14 \mathrm{~F}$ & IIIc & Middle/L. Archaic & & Mammalia (Medium/large) & Mandible & 1 \\
\hline E20/S78 & 6 & $14 \mathrm{~F}$ & IIIc & Middle/L. Archaic & & Odocoileus sp. & Cranium & 1 \\
\hline $\mathrm{E} 20 / \mathrm{S} 78$ & 6 & $14 \mathrm{~F}$ & IIIc & Middle/L. Archaic & & Odocoileus sp. & Permanent tooth & 2 \\
\hline E20/S78 & 6 & $14 \mathrm{~F}$ & IIIc & Middle/L. Archaic & & Vertebrata & Indeterminate & 48 \\
\hline E20/S78 & 7 & $14 \mathrm{G}$ & $\mathrm{IIlb} / \mathrm{c}$ & Middle/L. Archaic & & Mammalia (Medium/large) & Indeterminate & 1 \\
\hline $\mathrm{E} 20 / \mathrm{S} 78$ & 7 & $14 \mathrm{G}$ & $\mathrm{mllb} / \mathrm{c}$ & Middle/L. Archaic & & Vertebrata & Indeterminate & 8 \\
\hline E20/S78 & 8 & $14 \mathrm{H}$ & $\mathrm{IIlb} / \mathrm{c}$ & M. Archaic & & Canis sp. & Metacarpal 5 & 1 \\
\hline $\mathrm{E} 20 / \mathrm{S} 78$ & 8 & $14 \mathrm{H}$ & $\mathrm{mllb} / \mathrm{c}$ & M. Archaic & & Leporidae & Central tarsal bone & 1 \\
\hline E20/S78 & $9 \mathrm{~A}$ & 14I1 & $\mathrm{IIIb} / \mathrm{c}$ & Early/M. Archaic & & Vertebrata & Indeterminate & 4 \\
\hline E20/S78 & $10 \mathrm{~B}$ & $14 \mathrm{~J} 2$ & IIIb & E. Archaic & & Vertebrata & Indeterminate & 2 \\
\hline E20/S78 & 12 & $14 \mathrm{~L}$ & IIIb & E. Archaic & $\mathrm{f} 50$ & Medium/Large Vertebrata & Long bone & 4 \\
\hline E20/S78 & 12 & $14 \mathrm{~L}$ & IIIlb & E. Archaic & $\mathrm{f} 50$ & Small/Medium Vertebrata & Long bone & 1 \\
\hline E20/S78 & 12 & $14 \mathrm{~L}$ & IIIlb & E. Archaic & $\mathrm{f} 50$ & Vertebrata & Indeterminate & 2 \\
\hline $\mathrm{E} 20 / \mathrm{S} 78$ & $12 \mathrm{~A}$ & $14 \mathrm{~L} 1$ & IIIb & E. Archaic & & Vertebrata & Indeterminate & 11 \\
\hline E20/S78 & $12 \mathrm{~B}$ & 14L2 & IIIlb & E. Archaic & & Medium/Large Vertebrata & Indeterminate & 1 \\
\hline E20/S78 & $12 \mathrm{~B}$ & 14L2 & IIIb & E. Archaic & & Vertebrata & Indeterminate & 1 \\
\hline E20/S78 & $13 \mathrm{~A}$ & 14M1 & IIlb & E. Archaic & & Mammalia (Large) & Long bone & 1 \\
\hline E20/S78 & $13 \mathrm{~A}$ & 14M1 & IIIb & E. Archaic & & Vertebrata & Indeterminate & 1 \\
\hline E20/S78 & $14 \mathrm{~A}$ & $14 \mathrm{~N} 1$ & Ша/ $/ \mathrm{b}$ & E. Archaic & & Vertebrata & Indeterminate & 1 \\
\hline $\mathrm{E} 20 / \mathrm{S} 78$ & 14B & $14 \mathrm{~N} 2$ & IIIa & E. Archaic & & Testudinata & Peripheral & 1 \\
\hline E20/S78 & 14B & $14 \mathrm{~N} 2$ & IIIIa & E. Archaic & & Testudinata & Shell fragment & 3 \\
\hline E20/S78 & $15 \mathrm{~A}$ & 1401 & IIIa & E. Archaic & & Vertebrata & Indeterminate & 1 \\
\hline E20/S78 & $15 B$ & $14 \mathrm{O} 2$ & IIIa & E. Archaic & & Antilocapra/Odocoileus & Astragalus & 1 \\
\hline E20/S78 & 15B & $14 \mathrm{O} 2$ & IIIIa & E. Archaic & & Vertebrata & Indeterminate & 1 \\
\hline E20/S78 & $16 \mathrm{~B}$ & $14 \mathrm{P} 2$ & IIIIa & E. Archaic & & Vertebrata & Indeterminate & 1 \\
\hline E20/S78 & $17 \mathrm{~A}$ & 14Q1 & IIIIa & E. Archaic & & Medium/Large Vertebrata & Indeterminate & 1 \\
\hline E20/S78 & 17B & $14 \mathrm{Q} 2$ & IIIIa & E. Archaic & & Mammalia (Medium/large) & Indeterminate & 1 \\
\hline E20/S78 & 17B & $14 \mathrm{Q} 2$ & IIIa & E. Archaic & & Mammalia (Medium/large) & Long bone & 1 \\
\hline $\mathrm{E} 20 / \mathrm{S} 78$ & 17B & 14Q2 & IIIa & E. Archaic & & Vertebrata & Indeterminate & 3 \\
\hline E20/S78 & $18 \mathrm{~A}$ & $14 \mathrm{R} 1$ & II/IIIa & L. Paleo./E. Archaic & & Mammalia (Medium/large) & Indeterminate & 1 \\
\hline E20/S78 & $18 \mathrm{~B}$ & $14 \mathrm{R} 2$ & II/IIa & L. Paleo./E. Archaic & & Vertebrata & Indeterminate & 2 \\
\hline E20/S78 & $19 \mathrm{~A}$ & 14S1 & II/IIa & L. Paleo./E. Archaic & & Mammalia (Medium/large) & Axis & 1 \\
\hline E20/S78 & 19A & $14 S 1$ & II/IIIa & L. Paleo./E. Archaic & & Mammalia (Medium/large) & Indeterminate & 1 \\
\hline E20/S78 & $19 \mathrm{~A}$ & $14 \mathrm{~S} 1$ & II/IIIa & L. Paleo./E. Archaic & & Vertebrata & Long bone & 1 \\
\hline E20/S78 & $20 \mathrm{~A}$ & $14 \mathrm{~T} 1$ & III & L. Paleo. & & Medium/Large Vertebrata & Indeterminate & 1 \\
\hline $\mathrm{E} 20 / \mathrm{S} 78$ & $20 \mathrm{~A}$ & $14 \mathrm{~T} 1$ & III & L. Paleo. & & Vertebrata & Indeterminate & 1 \\
\hline E20/S78 & $20 \mathrm{~B}$ & $14 \mathrm{~T} 2$ & II & L. Paleo. & & Mammalia (Medium/large) & Indeterminate & 1 \\
\hline E20/S78 & $20 \mathrm{~B}$ & $14 \mathrm{~T} 2$ & II & L. Paleo. & & Mammalia (Medium/large) & Long bone & 3 \\
\hline $\mathrm{E} 20 / \mathrm{S} 78$ & $21 \mathrm{~A}$ & $14 \mathrm{U} 1$ & III & L. Paleo. & & Vertebrata & Indeterminate & 1 \\
\hline E20/S78 & 21B & $14 \mathrm{U} 2$ & Id/II & L. Paleo. & & Mammalia (Medium/large) & Indeterminate & 2 \\
\hline E20/S78 & $21 B$ & $14 \mathrm{U} 2$ & Id/II & L. Paleo. & & Medium/Large Vertebrata & Indeterminate & 2 \\
\hline E20/S78 & 21B & $14 \mathrm{U} 2$ & Id/II & L. Paleo. & & Vertebrata & Indeterminate & 6 \\
\hline E20/S78 & 22B & $14 \mathrm{~V} 2$ & Id/II & L. Paleo. & & Vertebrata & Indeterminate & 2 \\
\hline E20/S78 & $23 \mathrm{~A}$ & $14 \mathrm{~W} 1$ & Id/II & L. Paleo. & & Mammalia (Medium/large) & Long bone & 1 \\
\hline E20/S78 & $23 \mathrm{~A}$ & 14W1 & Id/II & L. Paleo. & & Medium/Large Vertebrata & Indeterminate & 1 \\
\hline E20/S78 & $23 \mathrm{~A}$ & 14W1 & Id/II & L. Paleo. & & Testudinata & Shell fragment & 1 \\
\hline $\mathrm{E} 20 / \mathrm{S} 78$ & $23 \mathrm{~B}$ & $14 \mathrm{~W} 2$ & Id/II & L. Paleo. & & Mammalia (Medium/large) & Long bone & 4 \\
\hline E20/S78 & $23 B$ & $14 \mathrm{~W} 2$ & Id/II & L. Paleo. & & Medium/Large Vertebrata & Indeterminate & 2 \\
\hline E20/S78 & $23 \mathrm{~B}$ & $14 \mathrm{~W} 2$ & Id/II & L. Paleo. & & Odocoileus sp. & Metacarpal & 1 \\
\hline $\mathrm{E} 20 / \mathrm{S} 78$ & $23 \mathrm{~B}$ & $14 \mathrm{~W} 2$ & Id/II & L. Paleo. & & Small/Medium Vertebrata & Long bone & 2 \\
\hline $\mathrm{E} 20 / \mathrm{S} 78$ & $23 \mathrm{~B}$ & $14 \mathrm{~W} 2$ & $\mathrm{Id} / \mathrm{II}$ & L. Paleo. & & Vertebrata & Indeterminate & 9 \\
\hline E20/S78 & $24 \mathrm{~A}$ & $14 \mathrm{X} 1$ & Isi-c/Id & L. Paleo. & & Mammalia (Medium/large) & Long bone & 2 \\
\hline E20/S78 & $24 B$ & $14 \mathrm{X} 2$ & Isi-c/Id & L. Paleo. & & Mammalia (Medium/large) & Indeterminate & 1 \\
\hline $\mathrm{E} 20 / \mathrm{S} 78$ & $24 B$ & $14 \times 2$ & Isi-c/Id & L. Paleo. & & Medium/Large Vertebrata & Indeterminate & 5 \\
\hline $\mathrm{E} 20 / \mathrm{S} 78$ & $24 B$ & $14 \times 2$ & Isi-c/Id & L. Paleo. & & Vertebrata & Indeterminate & 5 \\
\hline E20/S78 & $25 \mathrm{~A}$ & $14 Y 1$ & Isi-c/Id & L. Paleo. & & Medium/Large Vertebrata & Indeterminate & 2 \\
\hline $\mathrm{E} 20 / \mathrm{S} 78$ & $25 B$ & $14 Y 2$ & Isi-c/Id & L. Paleo. & & Medium/Large Vertebrata & Long bone & 2 \\
\hline E20/S78 & $25 B$ & $14 Y 2$ & Isi-c/Id & L. Paleo. & & Vertebrata & Indeterminate & 1 \\
\hline E20/S78 & $26 \mathrm{~A}$ & $14 \mathrm{Z1}$ & Isi-c & L. Paleo. & & Medium/Large Vertebrata & Indeterminate & 3 \\
\hline E20/S78 & $26 B$ & $14 \mathrm{Z} 2$ & Isi-c & L. Paleo. & & Mammalia (Medium/large) & Indeterminate & 1 \\
\hline E20/S78 & $26 B$ & $14 Z 2$ & Isi-c & L. Paleo. & & Mammalia (Medium/large) & Long bone & 1 \\
\hline E20/S78 & $26 B$ & $14 \mathrm{Z} 2$ & Isi-c & L. Paleo. & & Vertebrata & Indeterminate & 1 \\
\hline E20/S78 & $27 \mathrm{~A}$ & 14AA1 & Isi-c & L. Paleo. & & Mammalia (Medium/large) & Long bone & 1 \\
\hline E20/S78 & $27 \mathrm{~A}$ & 14AA1 & Isi-c & L. Paleo. & & Vertebrata & Indeterminate & 1 \\
\hline E20/S78 & 30 & F169 & Isi-c & L. Paleo. & f169 & Vertebrata & Indeterminate & 1 \\
\hline E20/S78 & $30-34 \mathrm{~A}$ & 14DDHH & Isi/Isi-c & Paleoindian & f169 & Mammalia (Medium) & Metapodial & 1 \\
\hline
\end{tabular}




\begin{tabular}{|c|c|c|c|c|c|c|c|c|}
\hline Square & Level & Lot & Unit & Cultural Affinity & Feature & Taxon & Element & No. \\
\hline E20/S78 & $30-34 \mathrm{~A}$ & 14DDHH & Isi/Isi-c & Paleoindian & f169 & Vertebrata & Indeterminate & 1 \\
\hline $\mathrm{E} 20 / \mathrm{S} 78$ & $30 \mathrm{~A}$ & 14DD1A & Isi/Isi-c & Paleoindian & & Vertebrata & Indeterminate & 1 \\
\hline E20/S78 & $30 \mathrm{~B}$ & 14DD2D & Isi/Isi-c & Paleoindian & & Medium/Large Vertebrata & Indeterminate & 1 \\
\hline E20/S78 & $31 \mathrm{~B}$ & 14EE2A & Isi & E. Paleo. & & Vertebrata & Indeterminate & 2 \\
\hline E20/S78 & 31B & 14EE2B & Isi & E. Paleo. & & Mammalia (Medium/large) & Indeterminate & 1 \\
\hline E20/S78 & 37B & $14 \mathrm{KK} 2 \mathrm{C}$ & Isi & E. Paleo. & & Vertebrata & Indeterminate & 1 \\
\hline $\mathrm{E} 20 / \mathrm{S} 80$ & 1 & $13 \mathrm{~A}$ & IIIC & L. Prehist. & & Mammalia (Medium/large) & Indeterminate & 3 \\
\hline $\mathrm{E} 20 / \mathrm{S} 80$ & 1 & $13 \mathrm{~A}$ & IIIc & L. Prehist. & & Vertebrata & Indeterminate & 6 \\
\hline $\mathrm{E} 20 / \mathrm{S} 80$ & 2 & 13B & IIII & L. Archaic/L. Prehist. & & Mammalia (Medium/large) & Indeterminate & 3 \\
\hline $\mathrm{E} 20 / \mathrm{S} 80$ & 2 & $13 B$ & IIIc & L. Archaic/L. Prehist. & & Vertebrata & Indeterminate & 8 \\
\hline $\mathrm{E} 20 / \mathrm{S} 80$ & 3 & $13 \mathrm{C}$ & IIIc & L. Archaic & & Antilocapra/Odocoileus & Astragalus & 1 \\
\hline $\mathrm{E} 20 / \mathrm{S} 80$ & 3 & $13 \mathrm{C}$ & IIIc & L. Archaic & & AntilocapralOdocoileus & Proximal sesamoid & 1 \\
\hline E20/S80 & 3 & $13 \mathrm{C}$ & IIIc & L. Archaic & & Mammalia (Large) & Indeterminate & 2 \\
\hline $\mathrm{E} 20 / \mathrm{S} 80$ & 3 & $13 \mathrm{C}$ & IIIc & L. Archaic & & Mammalia (Medium) & Metapodial & 1 \\
\hline $\mathrm{E} 20 / \mathrm{S} 80$ & 3 & $13 \mathrm{C}$ & IIIc & L. Archaic & & Mammalia (Medium/large) & Indeterminate & 6 \\
\hline E20/S80 & 3 & $13 \mathrm{C}$ & IIIc & L. Archaic & & Vertebrata & Indeterminate & 25 \\
\hline $\mathrm{E} 20 / \mathrm{S} 80$ & 4 & $13 \mathrm{D}$ & IIIC & L. Archaic & & Antilocapra/Odocoileus & Antler & 1 \\
\hline $\mathrm{E} 20 / \mathrm{S} 80$ & 4 & $13 \mathrm{D}$ & IIIc & L. Archaic & & AntilocapralOdocoileus & Femur & 2 \\
\hline E20/S80 & 4 & 13D & IIIc & L. Archaic & & Antilocapra/Odocoileus & Fused 3rd \& 4th metatarsal & 1 \\
\hline $\mathrm{E} 20 / \mathrm{S} 80$ & 4 & $13 \mathrm{D}$ & IIIC & L. Archaic & & Antilocapra/Odocoileus & Pelvis & 1 \\
\hline $\mathrm{E} 20 / \mathrm{S} 80$ & 4 & 13D & IIII & L. Archaic & & Mammalia (Large) & Long bone & 1 \\
\hline E20/S80 & 4 & 13D & IIIc & L. Archaic & & Mammalia (Medium/large) & Indeterminate & 4 \\
\hline $\mathrm{E} 20 / \mathrm{S} 80$ & 4 & $13 \mathrm{D}$ & IIIIc & L. Archaic & & Mammalia (Medium/large) & Long bone & 13 \\
\hline $\mathrm{E} 20 / \mathrm{S} 80$ & 4 & $13 \mathrm{D}$ & IIIc & L. Archaic & & Odocoileus sp. & Fused second \& third carpal & 1 \\
\hline E20/S80 & 4 & 13D & IIIc & L. Archaic & & Sylvilagus sp. & Calcaneus & 1 \\
\hline E20/S80 & 4 & 13D & IIII & L. Archaic & & Vertebrata & Indeterminate & 37 \\
\hline $\mathrm{E} 20 / \mathrm{S} 80$ & 4 & 13D & IIIc & L. Archaic & & Vertebrata & Long bone & 1 \\
\hline $\mathrm{E} 20 / \mathrm{S} 80$ & 5 & $13 \mathrm{E}$ & IIIIc & L. Archaic & & Antilocapra/Odocoileus & Fused 3rd \& 4th metacarpal & 1 \\
\hline E20/S80 & 5 & $13 \mathrm{E}$ & IIII & L. Archaic & & Antilocapra/Odocoileus & Metapodial & 1 \\
\hline $\mathrm{E} 20 / \mathrm{S} 80$ & 5 & $13 \mathrm{E}$ & IIII & L. Archaic & & Mammalia (Medium/large) & Indeterminate & 2 \\
\hline $\mathrm{E} 20 / \mathrm{S} 80$ & 5 & $13 \mathrm{E}$ & IIIc & L. Archaic & & Odocoileus sp. & Fused 3rd \& 4th metatarsal & 1 \\
\hline E20/S80 & 5 & $13 \mathrm{E}$ & IIIIc & L. Archaic & & Vertebrata & Indeterminate & 8 \\
\hline E20/S80 & 6 & $13 \mathrm{~F}$ & IIIc & L. Archaic & & Bison sp. & Proximal axial sesamoid & 1 \\
\hline E20/S80 & 7 & $13 \mathrm{G}$ & $\mathrm{mit} / \mathrm{c}$ & Middle/L. Archaic & & Antilocapra/Odocoileus & Calcaneus & 1 \\
\hline $\mathrm{E} 20 / \mathrm{S} 80$ & 7 & $13 \mathrm{G}$ & $\mathrm{IIIb} / \mathrm{c}$ & Middle/L. Archaic & & Mammalia (Medium/large) & Indeterminate & 5 \\
\hline E20/S80 & 7 & $13 \mathrm{G}$ & $\mathrm{IIb} / \mathrm{c}$ & Middle/L. Archaic & & Vertebrata & Indeterminate & 12 \\
\hline E20/S80 & 8 & $13 \mathrm{H}$ & $\mathrm{mb} / \mathrm{c}$ & Middle/L. Archaic & & Mammalia (Large) & Lumbar vertebra & 1 \\
\hline E20/S80 & 8 & $13 \mathrm{H}$ & $\mathrm{IIIb} / \mathrm{c}$ & Middle/L. Archaic & & Mammalia (Medium/large) & Indeterminate & 4 \\
\hline $\mathrm{E} 20 / \mathrm{S} 80$ & 8 & $13 \mathrm{H}$ & $\mathrm{IIb} / \mathrm{c}$ & Middle/L. Archaic & & Mammalia (Medium/large) & Long bone & 2 \\
\hline E20/S80 & 8 & $13 \mathrm{H}$ & $\mathrm{IIIb} / \mathrm{c}$ & Middle/L. Archaic & & Vertebrata & Indeterminate & 1 \\
\hline $\mathrm{E} 20 / \mathrm{S} 80$ & 9 & $13 I$ & $\mathrm{IIIb} / \mathrm{c}$ & M. Archaic & & Mammalia (Large) & Long bone & 1 \\
\hline E20/S80 & 9 & $13 \mathrm{I}$ & $\mathrm{mb} / \mathrm{c}$ & M. Archaic & & Mammalia (Large) & Patella & 1 \\
\hline E20/S80 & 11 & $13 \mathrm{~K}$ & IIIb & Early/M. Archaic & & Vertebrata & Indeterminate & 2 \\
\hline E20/S80 & 13 & $13 \mathrm{M}$ & IIIb & E. Archaic & & Mammalia (Medium/large) & Long bone & 3 \\
\hline E20/S80 & 14 & $13 \mathrm{~N}$ & IIa/b & E. Archaic & & Mammalia (Medium/large) & Indeterminate & 1 \\
\hline E20/S80 & 16 & $13 \mathrm{P}$ & IIIa & E. Archaic & & Vertebrata & Indeterminate & 3 \\
\hline E20/S80 & 21 & $13 \mathrm{U}$ & II & L. Paleo. & & Mammalia (Medium/large) & Indeterminate & 1 \\
\hline E20/S80 & 22 & $13 \mathrm{~V}$ & $\mathrm{Id} / \mathrm{II}$ & L. Paleo. & & Mammalia (Medium/large) & Indeterminate & 1 \\
\hline E20/S80 & 22 & $13 \mathrm{~V}$ & Id/II & L. Paleo. & & Mammalia (Medium/large) & Long bone & 2 \\
\hline E20/S80 & 23 & $13 \mathrm{~W}$ & Isi-c/Id & L. Paleo. & & Mammalia (Medium/large) & Indeterminate & 1 \\
\hline $\mathrm{E} 20 / \mathrm{S} 80$ & 23 & $13 \mathrm{~W}$ & Isi-c/Id & L. Paleo. & & Mammalia (Medium/large) & Podial & 1 \\
\hline E20/S80 & 25 & $13 \mathrm{Y}$ & Isi-c & L. Paleo. & & Mammalia (Medium) & Long bone & 1 \\
\hline E20/S80 & 25 & $13 Y$ & Isi-c & L. Paleo. & & Mammalia (Medium/large) & Indeterminate & 1 \\
\hline $\mathrm{E} 20 / \mathrm{S} 80$ & 25 & $13 \mathrm{Y}$ & Isi-c & L. Paleo. & & Mammalia (Medium/large) & Long bone & 1 \\
\hline $\mathrm{E} 20 / \mathrm{S} 80$ & 25 & $13 \mathrm{Y}$ & Isi-c & L. Paleo. & & Vertebrata & Indeterminate & 3 \\
\hline $\mathrm{E} 20 / \mathrm{S} 80$ & 26 & $13 \mathrm{AA}$ & Isi/Isi-c & Paleoindian & & Antilocapra/Odocoileus & Fused 3rd \& 4th metatarsal & 1 \\
\hline E20/S80 & 26 & $13 \mathrm{AA}$ & Isi/Isi-c & Paleoindian & & Mammalia (Large) & Indeterminate & 1 \\
\hline E20/S80 & 26 & $13 \mathrm{AA}$ & Isi/Isi-c & Paleoindian & & Vertebrata & Indeterminate & 3 \\
\hline E20/S80 & 27 & $13 \mathrm{BB}$ & Isi & E. Paleo. & & Vertebrata & Indeterminate & 8 \\
\hline E20/S82 & 1 & $12 \mathrm{~A}$ & IIIc & L. Prehist. & & Mammalia (Medium/large) & Indeterminate & 1 \\
\hline $\mathrm{E} 20 / \mathrm{S} 82$ & 1 & $12 \mathrm{~A}$ & IIIc & L. Prehist. & & Vertebrata & Indeterminate & 31 \\
\hline E20/S82 & 2 & $12 \mathrm{~B}$ & IIIC & L. Archaic/L. Prehist. & $\mathrm{f} 7$ & Antilocapra/Odocoileus & Fused second \& third tarsal & 1 \\
\hline E20/S82 & 2 & $12 \mathrm{~B}$ & IIIc & L. Archaic/L. Prehist. & f7 & Artiodactyla & Tooth, perm./decid. ind. & 2 \\
\hline E20/S82 & 2 & $12 \mathrm{~B}$ & IIII & L. Archaic/L. Prehist. & $\mathrm{f} 7$ & Mammalia (Large) & Vertebra & 1 \\
\hline E20/S82 & 2 & $12 \mathrm{~B}$ & IIIC & L. Archaic/L. Prehist. & $\mathrm{f} 7$ & Mammalia (Medium/large) & Indeterminate & 4 \\
\hline E20/S82 & 2 & $12 \mathrm{~B}$ & IIIc & L. Archaic/L. Prehist. & $\mathrm{f} 7$ & Vertebrata & Indeterminate & 57 \\
\hline E20/S82 & 3 & $12 \mathrm{C}$ & IIIIc & L. Archaic & & Carnivora & Tooth, perm./decid. ind. & 1 \\
\hline
\end{tabular}




\begin{tabular}{|c|c|c|c|c|c|c|c|c|}
\hline Square & Level & Lot & Unit & Cultural Affinity & Feature & Taxon & Element & No. \\
\hline E20/S82 & 4 & $12 \mathrm{D}$ & IIIc & L. Archaic & & Antilocapra/Odocoileus & Humerus & 2 \\
\hline E20/S82 & 4 & 12D & IIIc & L. Archaic & & Antilocapra/Odocoileus & Proximal sesamoid & 1 \\
\hline $\mathrm{E} 20 / \mathrm{S} 82$ & 4 & $12 \mathrm{D}$ & IIIc & L. Archaic & & Artiodactyla & Phalange & 2 \\
\hline E20/S82 & 4 & 12D & IIIlc & L. Archaic & & Artiodactyla & Tooth, perm./decid. ind. & 3 \\
\hline $\mathrm{E} 20 / \mathrm{S} 82$ & 4 & $12 \mathrm{D}$ & IIIc & L. Archaic & & Bison sp. & Radial carpal bone & 1 \\
\hline E20/S82 & 4 & $12 \mathrm{D}$ & IIIIc & L. Archaic & & Canis sp. & Permanent tooth & 1 \\
\hline E20/S82 & 4 & $12 \mathrm{D}$ & IIIc & L. Archaic & & Mammalia (Large) & Indeterminate & 1 \\
\hline E20/S82 & 4 & $12 \mathrm{D}$ & IIIc & L. Archaic & & Mammalia (Large) & Long bone & 1 \\
\hline $\mathrm{E} 20 / \mathrm{S} 82$ & 4 & $12 \mathrm{D}$ & IIIc & L. Archaic & & Mammalia (Medium/large) & Indeterminate & 4 \\
\hline $\mathrm{E} 20 / \mathrm{S} 82$ & 4 & $12 \mathrm{D}$ & IIIc & L. Archaic & & Mammalia (Medium/large) & Tooth, perm./decid. ind. & 1 \\
\hline E20/S82 & 4 & $12 \mathrm{D}$ & IIIc & L. Archaic & & Vertebrata & Indeterminate & 61 \\
\hline E20/S82 & 5 & $12 \mathrm{E}$ & IIIc & L. Archaic & & Antilocapra/Odocoileus & Astragalus & 1 \\
\hline $\mathrm{E} 20 / \mathrm{S} 82$ & 5 & $12 \mathrm{E}$ & IIIc & L. Archaic & & Antilocapra/Odocoileus & Fused 3rd \& 4th metatarsal & 2 \\
\hline $\mathrm{E} 20 / \mathrm{S} 82$ & 5 & $12 \mathrm{E}$ & IIIc & L. Archaic & & AntilocapralOdocoileus & Proximal phalange & 1 \\
\hline $\mathrm{E} 20 / \mathrm{S} 82$ & 5 & $12 \mathrm{E}$ & IIIc & L. Archaic & & Artiodactyla & Tooth, perm./decid. ind. & 7 \\
\hline $\mathrm{E} 20 / \mathrm{S} 82$ & 5 & $12 \mathrm{E}$ & IIIc & L. Archaic & & Leporidae & Permanent tooth & 1 \\
\hline $\mathrm{E} 20 / \mathrm{S} 82$ & 5 & $12 \mathrm{E}$ & IIIc & L. Archaic & & Leporidae & Tibia & 1 \\
\hline E20/S82 & 5 & $12 \mathrm{E}$ & IIIc & L. Archaic & & Mammalia (Large) & Long bone & 4 \\
\hline E20/S82 & 5 & $12 \mathrm{E}$ & IIIc & L. Archaic & & Mammalia (Medium/large) & Indeterminate & 25 \\
\hline $\mathrm{E} 20 / \mathrm{S} 82$ & 5 & $12 \mathrm{E}$ & IIIc & L. Archaic & & Mammalia (Medium/large) & Long bone & 2 \\
\hline E20/S82 & 5 & $12 \mathrm{E}$ & IIIc & L. Archaic & & Medium/Large Vertebrata & Long bone & 1 \\
\hline E20/S82 & 5 & $12 \mathrm{E}$ & IIIc & L. Archaic & & Odocoileus sp. & Mandible & 1 \\
\hline $\mathrm{E} 20 / \mathrm{S} 82$ & 5 & $12 \mathrm{E}$ & IIIc & L. Archaic & & Odocoileus sp. & Pelvis & 1 \\
\hline $\mathrm{E} 20 / \mathrm{S} 82$ & 5 & $12 \mathrm{E}$ & IIIc & L. Archaic & & Odocoileus sp. & Permanent tooth & 1 \\
\hline $\mathrm{E} 20 / \mathrm{S} 82$ & 5 & $12 \mathrm{E}$ & IIIc & L. Archaic & & Odocoileus sp. & Prox. phalange of paradigit & 1 \\
\hline E20/S82 & 5 & $12 \mathrm{E}$ & IIIc & L. Archaic & & Sylvilagus sp. & Humerus & 1 \\
\hline E20/S82 & 5 & $12 \mathrm{E}$ & IIIc & L. Archaic & & Vertebrata & Indeterminate & 262 \\
\hline E20/S82 & 5 & $12 \mathrm{E}$ & IIIc & L. Archaic & & Vertebrata & Rib & 1 \\
\hline E20/S82 & 6 & $12 \mathrm{~F}$ & IIIc & M. Archaic & & AntilocapralOdocoileus & Fused 3rd \& 4th metatarsal & 1 \\
\hline E20/S82 & 6 & $12 \mathrm{~F}$ & ШII & M. Archaic & & Antilocapra/Odocoileus & Radius & 1 \\
\hline E20/S82 & 6 & $12 \mathrm{~F}$ & IIIc & M. Archaic & & AntilocapralOdocoileus & Ulna & 1 \\
\hline E20/S82 & 6 & $12 \mathrm{~F}$ & IIIc & M. Archaic & & Emydidae & Neural & 1 \\
\hline E20/S82 & 6 & $12 \mathrm{~F}$ & IIIc & M. Archaic & & Kinosternidae & Peripheral & 1 \\
\hline $\mathrm{E} 20 / \mathrm{S} 82$ & 6 & $12 \mathrm{~F}$ & IIIc & M. Archaic & & Leporidae & Radius & 1 \\
\hline $\mathrm{E} 20 / \mathrm{S} 82$ & 6 & $12 \mathrm{~F}$ & IIIc & M. Archaic & & Mammalia (Large) & Long bone & 1 \\
\hline E20/S82 & 6 & $12 \mathrm{~F}$ & IIIc & M. Archaic & & Mammalia (Medium/large) & Cranium & 1 \\
\hline E20/S82 & 6 & $12 \mathrm{~F}$ & IIIc & M. Archaic & & Mammalia (Medium/large) & Indeterminate & 3 \\
\hline $\mathrm{E} 20 / \mathrm{S} 82$ & 6 & $12 \mathrm{~F}$ & IIIc & M. Archaic & & Mammalia (Medium/large) & Long bone & 2 \\
\hline E20/S82 & 6 & $12 \mathrm{~F}$ & IIIc & M. Archaic & & Mammalia (Small/medium) & Ulna & 1 \\
\hline E20/S82 & 6 & $12 \mathrm{~F}$ & IIIc & M. Archaic & & Odocoileus sp. & Distal phalange & 1 \\
\hline $\mathrm{E} 20 / \mathrm{S} 82$ & 6 & $12 \mathrm{~F}$ & IIIc & M. Archaic & & Testudinata & Shell fragment & 1 \\
\hline E20/S82 & 6 & $12 \mathrm{~F}$ & IIIc & M. Archaic & & Vertebrata & Indeterminate & 52 \\
\hline E20/S82 & 7 & $12 \mathrm{G}$ & $\mathrm{IIIb} / \mathrm{c}$ & Early/M. Archaic & & Carnivora & Tooth, perm./decid. ind. & 1 \\
\hline $\mathrm{E} 20 / \mathrm{S} 82$ & 7 & $12 \mathrm{G}$ & $\mathrm{IIlb} / \mathrm{c}$ & Early/M. Archaic & & Leporidae & Humerus & 1 \\
\hline E20/S82 & 7 & $12 \mathrm{G}$ & $\mathrm{IIIb} / \mathrm{c}$ & Early/M. Archaic & & Leporidae & Permanent tooth & 1 \\
\hline E20/S82 & 7 & $12 \mathrm{G}$ & $\mathrm{IIIb} / \mathrm{c}$ & Early/M. Archaic & & Testudinata & Shell fragment & 1 \\
\hline $\mathrm{E} 20 / \mathrm{S} 82$ & 7 & $12 \mathrm{G}$ & $\mathrm{mllb} / \mathrm{c}$ & Early/M. Archaic & & Vertebrata & Indeterminate & 23 \\
\hline E20/S82 & 8 & $12 \mathrm{H}$ & $\mathrm{IIIb} / \mathrm{c}$ & Early/M. Archaic & & Mammalia (Large) & Indeterminate & 4 \\
\hline E20/S82 & 8 & $12 \mathrm{H}$ & $\mathrm{IIIb} / \mathrm{c}$ & Early/M. Archaic & & Mammalia (Large) & Long bone & 1 \\
\hline E20/S82 & 8 & $12 \mathrm{H}$ & $\mathrm{IIIb} / \mathrm{c}$ & Early/M. Archaic & & Odocoileus sp. & Distal phalange & 1 \\
\hline E20/S82 & 8 & $12 \mathrm{H}$ & $\mathrm{IIIb} / \mathrm{c}$ & Early/M. Archaic & & Vertebrata & Indeterminate & 16 \\
\hline E20/S82 & 9 & $12 \mathrm{I}$ & $\mathrm{IIIb} / \mathrm{c}$ & Early/M. Archaic & & AntilocapralOdocoileus & Fourth carpal bone & 1 \\
\hline E20/S82 & 9 & $12 \mathrm{I}$ & $\mathrm{mb} / \mathrm{c}$ & Early/M. Archaic & & Mammalia (Large) & Indeterminate & 1 \\
\hline $\mathrm{E} 20 / \mathrm{S} 82$ & 9 & $12 \mathrm{I}$ & $\mathrm{mllb} / \mathrm{c}$ & Early/M. Archaic & & Mammalia (Medium/large) & Indeterminate & 2 \\
\hline E20/S82 & 9 & $12 \mathrm{I}$ & $\mathrm{mIllb} / \mathrm{c}$ & Early/M. Archaic & & Vertebrata & Indeterminate & 12 \\
\hline E20/S82 & 10 & $12 \mathrm{~J}$ & IIIlb & Early/M. Archaic & & Vertebrata & Indeterminate & 8 \\
\hline $\mathrm{E} 20 / \mathrm{S} 82$ & 11 & $12 \mathrm{~K}$ & IIIb & E. Archaic & & Mammalia (Medium/large) & Indeterminate & 2 \\
\hline E20/S82 & 11 & $12 \mathrm{~K}$ & IIIlb & E. Archaic & & Vertebrata & Indeterminate & 1 \\
\hline $\mathrm{E} 20 / \mathrm{S} 82$ & 12 & $12 \mathrm{~L}$ & IIIlb & E. Archaic & & Mammalia (Medium/large) & Indeterminate & 4 \\
\hline $\mathrm{E} 20 / \mathrm{S} 82$ & 12 & $12 \mathrm{~L}$ & IIIlb & E. Archaic & & Vertebrata & Indeterminate & 10 \\
\hline E20/S82 & 13 & $12 \mathrm{M}$ & IIIlb & E. Archaic & & Canis sp. & Permanent tooth & 1 \\
\hline E20/S82 & 13 & $12 \mathrm{M}$ & IIIb & E. Archaic & & Mammalia (Large) & Indeterminate & 1 \\
\hline $\mathrm{E} 20 / \mathrm{S} 82$ & 13 & $12 \mathrm{M}$ & IIIb & E. Archaic & & Mammalia (Medium) & Proximal phalange & 1 \\
\hline E20/S82 & 13 & $12 \mathrm{M}$ & IIIlb & E. Archaic & & Mammalia (Medium/large) & Indeterminate & 1 \\
\hline E20/S82 & 13 & $12 \mathrm{M}$ & IIIb & E. Archaic & & Mammalia (Medium/large) & Long bone & 4 \\
\hline E20/S82 & 13 & $12 \mathrm{M}$ & IIIlb & E. Archaic & & Medium/Large Vertebrata & Indeterminate & 1 \\
\hline E20/S82 & 13 & $12 \mathrm{M}$ & IIIlb & E. Archaic & & Small/Medium Vertebrata & Long bone & 1 \\
\hline
\end{tabular}




\begin{tabular}{|c|c|c|c|c|c|c|c|c|}
\hline Square & Level & Lot & Unit & Cultural Affinity & Feature & Taxon & Element & No. \\
\hline E20/S82 & 13 & $12 \mathrm{M}$ & IIIb & E. Archaic & & Vertebrata & Indeterminate & 9 \\
\hline E20/S82 & 14 & $12 \mathrm{~N}$ & Шаa/b & E. Archaic & & Vertebrata & Indeterminate & 3 \\
\hline E20/S82 & 15 & 120 & $\mathrm{IIa} / \mathrm{b}$ & E. Archaic & & Mammalia (Medium/large) & Long bone & 1 \\
\hline E20/S82 & 15 & 120 & $\mathrm{IIIa} / \mathrm{b}$ & E. Archaic & & Medium/Large Vertebrata & Indeterminate & 4 \\
\hline E20/S82 & 15 & 120 & $\mathrm{IIa} / \mathrm{b}$ & E. Archaic & & Vertebrata & Indeterminate & 2 \\
\hline E20/S82 & 16 & $12 \mathrm{P}$ & IIIa & E. Archaic & & Mammalia (Large) & Indeterminate & 1 \\
\hline $\mathrm{E} 20 / \mathrm{S} 82$ & 16 & $12 \mathrm{P}$ & IIIa & E. Archaic & & Mammalia (Large) & Long bone & 2 \\
\hline E20/S82 & 16 & $12 \mathrm{P}$ & IIIa & E. Archaic & & Mammalia (Medium/large) & Indeterminate & 1 \\
\hline E20/S82 & 16 & $12 \mathrm{P}$ & Ша & E. Archaic & & Vertebrata & Indeterminate & 1 \\
\hline $\mathrm{E} 20 / \mathrm{S} 82$ & 17 & $12 \mathrm{Q}$ & IIIIIa & L. Paleo./E. Archaic & & Mammalia (Medium/large) & Indeterminate & 4 \\
\hline E20/S82 & 17 & $12 Q$ & II/IIIa & L. Paleo./E. Archaic & & Mammalia (Medium/large) & Long bone & 2 \\
\hline E20/S82 & 17 & $12 Q$ & I/IIIa & L. Paleo./E. Archaic & & Medium/Large Vertebrata & Indeterminate & 1 \\
\hline E20/S82 & 17 & $12 Q$ & Ш/Ша & L. Paleo./E. Archaic & & Testudinata & Shell fragment & 2 \\
\hline E20/S82 & 17 & $12 Q$ & II/IIIa & L. Paleo./E. Archaic & & Vertebrata & Indeterminate & 6 \\
\hline E20/S82 & 18 & $12 R$ & Ш/Ша & L. Paleo./E. Archaic & & Vertebrata & Indeterminate & 9 \\
\hline E20/S82 & 18 & $12 \mathrm{R}$ & П/Ша & L. Paleo./E. Archaic & & Vertebrata & Phalange & 1 \\
\hline E20/S82 & 19 & $12 \mathrm{~S}$ & II & L. Paleo. & & Vertebrata & Indeterminate & 6 \\
\hline E20/S82 & 20 & $12 \mathrm{~T}$ & II & L. Paleo. & & Mammalia (Medium/large) & Indeterminate & 7 \\
\hline $\mathrm{E} 20 / \mathrm{S} 82$ & 20 & $12 \mathrm{~T}$ & II & L. Paleo. & & Mammalia (Medium/large) & Long bone & 8 \\
\hline $\mathrm{E} 20 / \mathrm{S} 82$ & 20 & $12 \mathrm{~T}$ & II & L. Paleo. & & Medium/Large Vertebrata & Cranium & 1 \\
\hline E20/S82 & 20 & $12 \mathrm{~T}$ & II & L. Paleo. & & Small/Medium Vertebrata & Indeterminate & 5 \\
\hline $\mathrm{E} 20 / \mathrm{S} 82$ & 20 & $12 \mathrm{~T}$ & II & L. Paleo. & & Small/Medium Vertebrata & Long bone & 1 \\
\hline E20/S82 & 20 & $12 \mathrm{~T}$ & II & L. Paleo. & & Vertebrata & Indeterminate & 4 \\
\hline E20/S82 & 21 & $12 \mathrm{U}$ & II & L. Paleo. & & Antilocapra/Odocoileus & Humerus & 1 \\
\hline $\mathrm{E} 20 / \mathrm{S} 82$ & 21 & $12 \mathrm{U}$ & II & L. Paleo. & & Mammalia (Medium) & Pelvis & 1 \\
\hline $\mathrm{E} 20 / \mathrm{S} 82$ & 21 & $12 U$ & II & L. Paleo. & & Mammalia (Medium/large) & Indeterminate & 1 \\
\hline E20/S82 & 21 & $12 \mathrm{U}$ & II & L. Paleo. & & Vertebrata & Indeterminate & 1 \\
\hline E20/S82 & 22 & $12 \mathrm{~V}$ & III & L. Paleo. & & Mammalia (Medium/large) & Long bone & 9 \\
\hline E20/S82 & 22 & $12 \mathrm{~V}$ & II & L. Paleo. & & Medium/Large Vertebrata & Indeterminate & 3 \\
\hline E20/S82 & 22 & $12 \mathrm{~V}$ & II & L. Paleo. & & Vertebrata & Indeterminate & 6 \\
\hline E20/S82 & 23 & $12 \mathrm{~W}$ & Id/II & L. Paleo. & & Vertebrata & Indeterminate & 2 \\
\hline E20/S84 & 1 & $11 \mathrm{~A}$ & IIIc & L. Prehist. & & Mammalia (Large) & Long bone & 1 \\
\hline E20/S84 & 1 & $11 \mathrm{~A}$ & IIIc & L. Prehist. & & Mammalia (Medium/large) & Alveolar ridge fragment & 1 \\
\hline E20/S84 & 1 & $11 \mathrm{~A}$ & IIIc & L. Prehist. & & Mammalia (Medium/large) & Indeterminate & 5 \\
\hline E20/S84 & 1 & $11 \mathrm{~A}$ & IIIc & L. Prehist. & & Vertebrata & Indeterminate & 17 \\
\hline E20/S84 & 2 & 11B & IIIc & L. Archaic/L. Prehist. & & Antilocapra/Odocoileus & Third carpal bone & 1 \\
\hline E20/S84 & 2 & 11B & IIIc & L. Archaic/L. Prehist. & & Antilocapra/Odocoileus & Ulnar carpal bone & 1 \\
\hline E20/S84 & 2 & 11B & IIIc & L. Archaic/L. Prehist. & & Mammalia (Large) & Long bone & 1 \\
\hline E20/S84 & 2 & 11B & Шाс & L. Archaic/L. Prehist. & & Mammalia (Medium/large) & Indeterminate & 2 \\
\hline E20/S84 & 2 & 11B & IIIc & L. Archaic/L. Prehist. & & Mammalia (Medium/large) & Long bone & 2 \\
\hline E20/S84 & 2 & 11B & IIIc & L. Archaic/L. Prehist. & & Odocoileus sp. & Humerus & 4 \\
\hline E20/S84 & 2 & 11B & ШІ丨 & L. Archaic/L. Prehist. & & Odocoileus sp. & Permanent tooth & 1 \\
\hline E20/S84 & 2 & $11 \mathrm{~B}$ & IIIc & L. Archaic/L. Prehist. & & Vertebrata & Indeterminate & 48 \\
\hline E20/S84 & 3 & $11 \mathrm{C}$ & IIIc & L. Archaic & & Antilocapra/Odocoileus & Astragalus & 1 \\
\hline E20/S84 & 3 & $11 \mathrm{C}$ & IIIc & L. Archaic & & AntilocapralOdocoileus & Pelvis & 1 \\
\hline E20/S84 & 3 & $11 \mathrm{C}$ & IIIc & L. Archaic & & Kinosternidae & Peripheral & 1 \\
\hline E20/S84 & 3 & $11 \mathrm{C}$ & IIIc & L. Archaic & & Mammalia (Large) & Indeterminate & 4 \\
\hline E20/S84 & 3 & $11 \mathrm{C}$ & Ш一с & L. Archaic & & Mammalia (Large) & Long bone & 2 \\
\hline E20/S84 & 3 & $11 \mathrm{C}$ & IIIc & L. Archaic & & Mammalia (Medium/large) & Indeterminate & 9 \\
\hline E20/S84 & 3 & $11 \mathrm{C}$ & IIIc & L. Archaic & & Odocoileus sp. & Antler & 1 \\
\hline E20/S84 & 3 & $11 \mathrm{C}$ & IIIc & L. Archaic & & Odocoileus sp. & Permanent tooth & 1 \\
\hline E20/S84 & 3 & $11 \mathrm{C}$ & IIIc & L. Archaic & & Odocoileus sp. & Tooth, perm./decid. ind. & 1 \\
\hline E20/S84 & 3 & $11 \mathrm{C}$ & IIIc & L. Archaic & & Testudinata & Shell fragment & 1 \\
\hline E20/S84 & 3 & $11 \mathrm{C}$ & IIIc & L. Archaic & & Vertebrata & Indeterminate & 71 \\
\hline E20/S84 & 4 & 11D & IIIc & L. Archaic & & Antilocapra/Odocoileus & Fused central/fourth tarsal & 1 \\
\hline E20/S84 & 4 & 11D & IIIc & L. Archaic & & AntilocapralOdocoileus & Metapodial & 1 \\
\hline E20/S84 & 4 & 11D & IIIc & L. Archaic & & Colubridae & Dorsal vertebra & 1 \\
\hline E20/S84 & 4 & 11D & IIIc & L. Archaic & & Mammalia (Large) & Vertebra & 1 \\
\hline E20/S84 & 4 & 11D & IIIc & L. Archaic & & Mammalia (Medium/large) & Indeterminate & 9 \\
\hline E20/S84 & 4 & 11D & IIIc & L. Archaic & & Mammalia (Small/medium) & Alveolar ridge fragment & 1 \\
\hline E20/S84 & 4 & 11D & IIIc & L. Archaic & & Vertebrata & Indeterminate & 46 \\
\hline E20/S84 & 4 & 11D & IIIc & L. Archaic & & Vertebrata & Long bone & 2 \\
\hline E20/S84 & 5 & $11 \mathrm{E}$ & IIIc & L. Archaic & & Antilocapra/Odocoileus & Proximal sesamoid & 2 \\
\hline E20/S84 & 5 & $11 \mathrm{E}$ & IIIc & L. Archaic & & Antilocapra/Odocoileus & Radius & 1 \\
\hline E20/S84 & 5 & $11 \mathrm{E}$ & IIIc & L. Archaic & & Artiodactyla & Tooth, perm./decid. ind. & 9 \\
\hline E20/S84 & 5 & $11 \mathrm{E}$ & IIIc & L. Archaic & & Mammalia (Large) & Long bone & 2 \\
\hline E20/S84 & 5 & $11 \mathrm{E}$ & IIIc & L. Archaic & & Mammalia (Medium) & Middle phalange & 1 \\
\hline
\end{tabular}




\begin{tabular}{|c|c|c|c|c|c|c|c|c|}
\hline Square & Level & Lot & Unit & Cultural Affinity & Feature & Taxon & Element & No. \\
\hline$\overline{E 20 / S 84}$ & 5 & $11 \mathrm{E}$ & $\overline{\mathrm{IIIc}}$ & L. Archaic & & Mammalia (Medium) & Ulna & 1 \\
\hline E20/S84 & 5 & $11 \mathrm{E}$ & IIIc & L. Archaic & & Mammalia (Medium/large) & Alveolar ridge fragment & 1 \\
\hline E20/S84 & 5 & $11 \mathrm{E}$ & IIIc & L. Archaic & & Mammalia (Medium/large) & Indeterminate & 8 \\
\hline E20/S84 & 5 & $11 \mathrm{E}$ & IIIc & L. Archaic & & Odocoileus sp. & Permanent tooth & 1 \\
\hline E20/S84 & 5 & $11 \mathrm{E}$ & IIIc & L. Archaic & & Odocoileus sp. & Tooth, perm./decid. ind. & 1 \\
\hline E20/S84 & 5 & $11 \mathrm{E}$ & IIIc & L. Archaic & & Sciurus sp. & Calcaneus & 1 \\
\hline E20/S84 & 5 & $11 \mathrm{E}$ & III & L. Archaic & & Testudinata & Shell fragment & 1 \\
\hline E20/S84 & 5 & $11 \mathrm{E}$ & IIIc & L. Archaic & & Vertebrata & Indeterminate & 98 \\
\hline E20/S84 & 6 & $11 \mathrm{~F}$ & IIIc & Middle/L. Archaic & & Artiodactyla & Tooth, perm./decid. ind. & 6 \\
\hline E20/S84 & 6 & $11 \mathrm{~F}$ & III & Middle/L. Archaic & & Leporidae & Permanent tooth & 1 \\
\hline E20/S84 & 6 & $11 \mathrm{~F}$ & IIIc & Middle/L. Archaic & & Mammalia (Medium) & Tooth, perm./decid. ind. & 1 \\
\hline E20/S84 & 6 & $11 \mathrm{~F}$ & IIIc & Middle/L. Archaic & & Mammalia (Medium/large) & Indeterminate & 3 \\
\hline E20/S84 & 6 & $11 \mathrm{~F}$ & IIIc & Middle/L. Archaic & & Odocoileus sp. & Fused 3rd \& 4th metatarsal & 1 \\
\hline E20/S84 & 6 & $11 \mathrm{~F}$ & IIIc & Middle/L. Archaic & & Odocoileus sp. & Permanent tooth & 1 \\
\hline E20/S84 & 6 & $11 \mathrm{~F}$ & IIIC & Middle/L. Archaic & & Serpentes & Dorsal vertebra & 1 \\
\hline E20/S84 & 6 & $11 \mathrm{~F}$ & IIc & Middle/L. Archaic & & Vertebrata & Indeterminate & 75 \\
\hline E20/S84 & 7 & $11 \mathrm{G}$ & IIIc & Middle/L. Archaic & & AntilocapralOdocoileus & Metapodial & 1 \\
\hline E20/S84 & 7 & $11 \mathrm{G}$ & IIII & Middle/L. Archaic & & AntilocapralOdocoileus & Tibia & 2 \\
\hline E20/S84 & 7 & $11 \mathrm{G}$ & IIII & Middle/L. Archaic & & Mammalia (Medium/large) & Indeterminate & 1 \\
\hline E20/S84 & 7 & $11 \mathrm{G}$ & IIIc & Middle/L. Archaic & & Mammalia (Medium/large) & Long bone & 3 \\
\hline E20/S84 & 7 & $11 \mathrm{G}$ & IIIc & Middle/L. Archaic & & Medium/Large Vertebrata & Phalange & 1 \\
\hline E20/S84 & 7 & $11 \mathrm{G}$ & IIIc & Middle/L. Archaic & & Small/Medium Vertebrata & Long bone & 2 \\
\hline E20/S84 & 7 & $11 \mathrm{G}$ & IIIc & Middle/L. Archaic & & Vertebrata & Indeterminate & 9 \\
\hline E20/S84 & 8 & $11 \mathrm{H}$ & $\mathrm{IIIb} / \mathrm{c}$ & Middle/L. Archaic & & AntilocapralOdocoileus & Fused 3rd \& 4th metatarsal & 1 \\
\hline E20/S84 & 8 & $11 \mathrm{H}$ & $\mathrm{IIb} / \mathrm{c}$ & Middle/L. Archaic & & AntilocapralOdocoileus & Proximal abaxial sesamoid & 1 \\
\hline E20/S84 & 8 & $11 \mathrm{H}$ & $\mathrm{IIIb} / \mathrm{c}$ & Middle/L. Archaic & & cf. Leporidae & Humerus & 1 \\
\hline E20/S84 & 8 & $11 \mathrm{H}$ & $\mathrm{IITb} / \mathrm{c}$ & Middle/L. Archaic & & Leporidae & Cranium & 1 \\
\hline E20/S84 & 8 & $11 \mathrm{H}$ & $\mathrm{IIb} / \mathrm{c}$ & Middle/L. Archaic & & Mammalia (Medium) & Middle phalange & 1 \\
\hline E20/S84 & 8 & $11 \mathrm{H}$ & $\mathrm{IITb} / \mathrm{c}$ & Middle/L. Archaic & & Mammalia (Medium/large) & Long bone & 1 \\
\hline E20/S84 & 8 & $11 \mathrm{H}$ & $\mathrm{IITb} / \mathrm{c}$ & Middle/L. Archaic & & Medium/Large Vertebrata & Indeterminate & 5 \\
\hline E20/S84 & 8 & $11 \mathrm{H}$ & $\mathrm{IIb} / \mathrm{c}$ & Middle/L. Archaic & & Serpentes & Dorsal vertebra & 1 \\
\hline E20/S84 & 8 & $11 \mathrm{H}$ & $\mathrm{IIb} / \mathrm{c}$ & Middle/L. Archaic & & Small/Medium Vertebrata & Long bone & 2 \\
\hline E20/S84 & 8 & $11 \mathrm{H}$ & $\mathrm{IITb} / \mathrm{c}$ & Middle/L. Archaic & & Vertebrata & Indeterminate & 6 \\
\hline E20/S84 & 9 & $11 \mathrm{I}$ & $\mathrm{IIb} / \mathrm{c}$ & M. Archaic & & AntilocapralOdocoileus & Radius & 1 \\
\hline E20/S84 & 9 & $11 \mathrm{I}$ & $\mathrm{IIm} / \mathrm{c}$ & M. Archaic & & Mammalia (Medium/large) & Indeterminate & 2 \\
\hline E20/S84 & 9 & $11 \mathrm{I}$ & $\mathrm{IIIb} / \mathrm{c}$ & M. Archaic & & Medium/Large Vertebrata & Indeterminate & 1 \\
\hline E20/S84 & 9 & $11 \mathrm{I}$ & IIIb/c & M. Archaic & & Vertebrata & Indeterminate & 3 \\
\hline E20/S84 & 10 & $11 \mathrm{~J}$ & $\mathrm{IIb} / \mathrm{c}$ & Early/M. Archaic & & AntilocapralOdocoileus & Proximal phalange & 1 \\
\hline E20/S84 & 10 & $11 \mathrm{~J}$ & $\mathrm{IITb} / \mathrm{c}$ & Early/M. Archaic & & AntilocapralOdocoileus & Radial carpal bone & 1 \\
\hline E20/S84 & 10 & $11 \mathrm{~J}$ & IIIb/c & Early/M. Archaic & & AntilocapralOdocoileus & Radius & 1 \\
\hline E20/S84 & 10 & $11 \mathrm{~J}$ & IIIb/c & Early/M. Archaic & & Mammalia (Large) & Long bone & 1 \\
\hline E20/S84 & 10 & $11 \mathrm{~J}$ & $\mathrm{IIIb} / \mathrm{c}$ & Early/M. Archaic & & Mammalia (Medium/large) & Indeterminate & 3 \\
\hline E20/S84 & 10 & $11 \mathrm{~J}$ & IIIIb/c & Early/M. Archaic & & Vertebrata & Indeterminate & 71 \\
\hline E20/S84 & 11 & $11 \mathrm{~K}$ & IIIb & Early/M. Archaic & & Mammalia (Medium) & Metapodial & 1 \\
\hline E20/S84 & 11 & $11 \mathrm{~K}$ & IIItb & Early/M. Archaic & & Mammalia (Medium/large) & Indeterminate & 1 \\
\hline E20/S84 & 11 & $11 \mathrm{~K}$ & IIIlb & Early/M. Archaic & & Odocoileus sp. & Distal phalange & 1 \\
\hline E20/S84 & 11 & $11 \mathrm{~K}$ & ШІІь & Early/M. Archaic & & Vertebrata & Indeterminate & 4 \\
\hline E20/S84 & 12 & $11 \mathrm{~L}$ & IIItb & E. Archaic & & Mammalia (Medium/large) & Indeterminate & 1 \\
\hline E20/S84 & 12 & $11 \mathrm{~L}$ & IIIIb & E. Archaic & & Mammalia (Medium/large) & Long bone & 1 \\
\hline E20/S84 & 12 & $11 \mathrm{~L}$ & IIIlb & E. Archaic & & Medium/Large Vertebrata & Indeterminate & 6 \\
\hline E20/S84 & 12 & $11 \mathrm{~L}$ & IIIb & E. Archaic & & Small/Medium Vertebrata & Long bone & 2 \\
\hline E20/S84 & 12 & $11 \mathrm{~L}$ & IIIlb & E. Archaic & & Vertebrata & Indeterminate & 6 \\
\hline E20/S84 & 13 & $11 \mathrm{M}$ & IIIb & E. Archaic & & Leporidae & Tibia & 1 \\
\hline E20/S84 & 13 & $11 \mathrm{M}$ & IIIb & E. Archaic & & Vertebrata & Indeterminate & 14 \\
\hline E20/S84 & 14 & $11 \mathrm{~N}$ & $\mathrm{ma} / \mathrm{b}$ & E. Archaic & & Mammalia (Medium/large) & Indeterminate & 1 \\
\hline E20/S84 & 14 & $11 \mathrm{~N}$ & $\mathrm{III} / \mathrm{b}$ & E. Archaic & & Vertebrata & Indeterminate & 25 \\
\hline E20/S84 & 15 & 110 & $\mathrm{IIa} / \mathrm{b}$ & E. Archaic & & AntilocapralOdocoileus & Fused central/fourth tarsal & 1 \\
\hline E20/S84 & 15 & 110 & $\mathrm{mlla} / \mathrm{b}$ & E. Archaic & & Canis sp. & Permanent tooth & 4 \\
\hline E20/S84 & 15 & 110 & IIIa/b & E. Archaic & & Felis rufus & Ulna & 1 \\
\hline $\mathrm{E} 20 / \mathrm{S} 84$ & 15 & 110 & $\mathrm{ma} / \mathrm{b}$ & E. Archaic & & Mammalia (Medium/large) & Indeterminate & 7 \\
\hline E20/S84 & 15 & 110 & $\mathrm{III} / \mathrm{b}$ & E. Archaic & & Medium vertebrate, class ind. & Proximal phalange & 1 \\
\hline E20/S84 & 15 & 110 & IIIa/b & E. Archaic & & Medium/Large Vertebrata & Indeterminate & 2 \\
\hline E20/S84 & 15 & 110 & $\mathrm{IIa} / \mathrm{b}$ & E. Archaic & & Vertebrata & Indeterminate & 15 \\
\hline E20/S84 & 16 & $11 \mathrm{P}$ & IIIa & E. Archaic & & Antilocapra/Odocoileus & Calcaneus & 1 \\
\hline E20/S84 & 16 & $11 \mathrm{P}$ & IIIIa & E. Archaic & & Antilocapra/Odocoileus & Radius & 1 \\
\hline E20/S84 & 16 & $11 \mathrm{P}$ & III & E. Archaic & & Antilocapra/Odocoileus & Tibia & 1 \\
\hline E20/S 84 & 16 & $11 \mathrm{P}$ & Ша & E. Archaic & & cf. Leporidae & Pelvis & 1 \\
\hline
\end{tabular}




\begin{tabular}{|c|c|c|c|c|c|c|c|c|}
\hline Square & Level & Lot & Unit & Cultural Affinity & Feature & Taxon & Element & No. \\
\hline$\overline{E 20 / S 84}$ & 16 & $11 \mathrm{P}$ & IIIa & E. Archaic & & Mammalia (Medium/large) & Indeterminate & 4 \\
\hline $\mathrm{E} 20 / \mathrm{S} 84$ & 16 & $11 \mathrm{P}$ & IIIa & E. Archaic & & Mammalia (Medium/large) & Long bone & 5 \\
\hline $\mathrm{E} 20 / \mathrm{S} 84$ & 16 & $11 \mathrm{P}$ & IIIa & E. Archaic & & Medium/Large Vertebrata & Indeterminate & 8 \\
\hline $\mathrm{E} 20 / \mathrm{S} 84$ & 16 & $11 \mathrm{P}$ & IIIa & E. Archaic & & Medium/Large Vertebrata & Long bone & 3 \\
\hline $\mathrm{E} 20 / \mathrm{S} 84$ & 16 & $11 \mathrm{P}$ & IIIa & E. Archaic & & Vertebrata & Indeterminate & 3 \\
\hline E20/S84 & 17 & $11 Q$ & IIIa & E. Archaic & & Mammalia (Large) & Long bone & 1 \\
\hline $\mathrm{E} 20 / \mathrm{S} 84$ & 17 & $11 \mathrm{Q}$ & IIIa & E. Archaic & & Mammalia (Medium/large) & Indeterminate & 1 \\
\hline $\mathrm{E} 20 / \mathrm{S} 84$ & 17 & 11Q & IIIa & E. Archaic & & Vertebrata & Indeterminate & 14 \\
\hline E20/S84 & 18 & $11 \mathrm{R}$ & II/IIIa & L. Paleo./E. Archaic & & Artiodactyla & Phalange & 1 \\
\hline E20/S84 & 18 & $11 \mathrm{R}$ & II/IIIa & L. Paleo./E. Archaic & & Mammalia (Medium/large) & Indeterminate & 1 \\
\hline E20/S84 & 18 & $11 R$ & IIIIIIa & L. Paleo./E. Archaic & & Sylvilagus sp. & Ulna & 1 \\
\hline E20/S84 & 18 & $11 R$ & II/IIIa & L. Paleo./E. Archaic & & Vertebrata & Indeterminate & 11 \\
\hline E20/S84 & 19 & $11 \mathrm{~s}$ & II & L. Paleo. & & Mammalia (Medium/large) & Indeterminate & 1 \\
\hline E20/S84 & 19 & $11 \mathrm{~S}$ & II & L. Paleo. & & Mammalia (Medium/large) & Long bone & 1 \\
\hline E20/S84 & 19 & $11 \mathrm{~S}$ & II & L. Paleo. & & Medium/Large Vertebrata & Long bone & 1 \\
\hline E20/S84 & 19 & $11 \mathrm{~S}$ & II & L. Paleo. & & Small/Medium Vertebrata & Long bone & 1 \\
\hline E20/S84 & 19 & $11 \mathrm{~S}$ & III & L. Paleo. & & Vertebrata & Indeterminate & 3 \\
\hline E20/S84 & 20 & $11 \mathrm{~T}$ & III & L. Paleo. & & Mammalia (Medium/large) & Long bone & 4 \\
\hline E20/S84 & 20 & $11 \mathrm{~T}$ & II & L. Paleo. & & Medium/Large Vertebrata & Long bone & 1 \\
\hline E20/S84 & 20 & $11 \mathrm{~T}$ & III & L. Paleo. & & Vertebrata & Indeterminate & 6 \\
\hline E20/S84 & 21 & $11 \mathrm{U}$ & $\mathrm{X} / \mathrm{II}$ & L. Paleo. & & Mammalia (Medium/large) & Indeterminate & 8 \\
\hline E20/S84 & 21 & $11 \mathrm{U}$ & $\mathrm{X} / \mathrm{II}$ & L. Paleo. & & Mammalia (Medium/large) & Long bone & 1 \\
\hline E20/S84 & 21 & $11 \mathrm{U}$ & $\mathrm{X} / \mathrm{II}$ & L. Paleo. & & Medium/Large Vertebrata & Indeterminate & 2 \\
\hline E20/S84 & 21 & $11 \mathrm{U}$ & $\mathrm{X} / \mathrm{II}$ & L. Paleo. & & Testudinata & Shell fragment & 1 \\
\hline E20/S84 & 21 & $11 \mathrm{U}$ & $\mathrm{X} / \mathrm{II}$ & L. Paleo. & & Vertebrata & Indeterminate & 2 \\
\hline E20/S84 & 22 & $11 \mathrm{~V}$ & $\mathrm{X} / \mathrm{II}$ & L. Paleo. & & Mammalia (Medium/large) & Indeterminate & 5 \\
\hline E20/S84 & 22 & $11 \mathrm{~V}$ & $\mathrm{X} / \mathrm{II}$ & L. Paleo. & & Medium/Large Vertebrata & Indeterminate & 1 \\
\hline E20/S84 & 22 & $11 \mathrm{~V}$ & $\mathrm{X} / \mathrm{II}$ & L. Paleo. & & Small/Medium Vertebrata & Long bone & 2 \\
\hline E20/S84 & 23 & $11 \mathrm{~W}$ & $\mathrm{X} / \mathrm{Id} / \mathrm{II}$ & L. Paleo. & & Vertebrata & Indeterminate & 3 \\
\hline E20/S86 & 1 & $10 \mathrm{~A}$ & IIIc & L. Prehist. & & Mammalia (Medium/large) & Indeterminate & 1 \\
\hline E20/S86 & 1 & $10 \mathrm{~A}$ & IIIc & L. Prehist. & & Vertebrata & Indeterminate & 56 \\
\hline E20/S86 & 2 & 10B & IIIIc & L. Archaic/L. Prehist. & & AntilocapralOdocoileus & Astragalus & 1 \\
\hline E20/S86 & 2 & $10 \mathrm{~B}$ & IIII & L. Archaic/L. Prehist. & & Antilocapra/Odocoileus & Fused 3rd \& 4th metatarsal & 2 \\
\hline E20/S86 & 2 & $10 \mathrm{~B}$ & IIII & L. Archaic/L. Prehist. & & AntilocapralOdocoileus & Fused second \& third tarsal & 1 \\
\hline E20/S86 & 2 & 10B & IIIIC & L. Archaic/L. Prehist. & & AntilocapralOdocoileus & Metapodial & 2 \\
\hline E20/S86 & 2 & $10 \mathrm{~B}$ & IIII & L. Archaic/L. Prehist. & & AntilocapralOdocoileus & Middle phalange & 1 \\
\hline E20/S86 & 2 & $10 \mathrm{~B}$ & IIII & L. Archaic/L. Prehist. & & Antilocapra/Odocoileus & Proximal sesamoid & 1 \\
\hline E20/S86 & 2 & 10B & IIII & L. Archaic/L. Prehist. & & AntilocapralOdocoileus & Radial carpal bone & 1 \\
\hline E20/S86 & 2 & 10B & IIIC & L. Archaic/L. Prehist. & & Antilocapra/Odocoileus & Tibia & 1 \\
\hline E20/S86 & 2 & $10 \mathrm{~B}$ & IIIIc & L. Archaic/L. Prehist. & & Artiodactyla & Phalange & 1 \\
\hline E20/S86 & 2 & 10B & IIIIc & L. Archaic/L. Prehist. & & Artiodactyla & Prox. phalange of paradigit & 1 \\
\hline E20/S86 & 2 & 10B & IIIC & L. Archaic/L. Prehist. & & Artiodactyla & Tooth, perm./decid. ind. & 3 \\
\hline E20/S86 & 2 & 10B & IIIIc & L. Archaic/L. Prehist. & & Colubridae & Dorsal vertebra & 1 \\
\hline E20/S86 & 2 & 10B & IIIc & L. Archaic/L. Prehist. & & Mammalia (Large) & Cranium & 1 \\
\hline E20/S86 & 2 & 10B & IIII & L. Archaic/L. Prehist. & & Mammalia (Large) & Indeterminate & 5 \\
\hline E20/S86 & 2 & 10B & IIIIc & L. Archaic/L. Prehist. & & Mammalia (Medium/large) & Indeterminate & 19 \\
\hline E20/S86 & 2 & 10B & IIII & L. Archaic/L. Prehist. & & Mammalia (Medium/large) & Long bone & 2 \\
\hline E20/S86 & 2 & 10B & IIII & L. Archaic/L. Prehist. & & Odocoileus sp. & Calcaneus & 1 \\
\hline E20/S86 & 2 & 10B & IIIc & L. Archaic/L. Prehist. & & Odocoileus sp. & Humerus & 1 \\
\hline E20/S86 & 2 & 10B & IIIIc & L. Archaic/L. Prehist. & & Odocoileus sp. & Permanent tooth & 2 \\
\hline E20/S86 & 2 & $10 \mathrm{~B}$ & IIII & L. Archaic/L. Prehist. & & Odocoileus sp. & Tooth, perm./decid. ind. & 1 \\
\hline E20/S86 & 2 & $10 \mathrm{~B}$ & IIIc & L. Archaic/L. Prehist. & & Testudinata & Pleural & 1 \\
\hline E20/S86 & 2 & $10 \mathrm{~B}$ & IIIIc & L. Archaic/L. Prehist. & & Testudinata & Shell fragment & 1 \\
\hline E20/S86 & 2 & $10 \mathrm{~B}$ & IIIc & L. Archaic/L. Prehist. & & Vertebrata & Indeterminate & 385 \\
\hline E20/S86 & 3 & $10 \mathrm{C}$ & IIIc & L. Archaic & & AntilocapralOdocoileus & Intermediate carpal bone & 1 \\
\hline E20/S86 & 3 & $10 \mathrm{C}$ & IIIC & L. Archaic & & AntilocapralOdocoileus & Scapula & 1 \\
\hline E20/S86 & 3 & $10 \mathrm{C}$ & IIIc & L. Archaic & & Artiodactyla & Tooth, perm./decid. ind. & 1 \\
\hline E20/S86 & 3 & $10 \mathrm{C}$ & IIIc & L. Archaic & & Mammalia (Large) & Long bone & 4 \\
\hline E20/S86 & 3 & $10 \mathrm{C}$ & IIIIc & L. Archaic & & Mammalia (Medium/large) & Indeterminate & 13 \\
\hline E20/S86 & 3 & $10 \mathrm{C}$ & IIII & L. Archaic & & Odocoileus sp. & Dist. phalange of paradigit & 1 \\
\hline E20/S86 & 3 & $10 \mathrm{C}$ & IIIc & L. Archaic & & Odocoileus sp. & Middle phalange & 1 \\
\hline E20/S86 & 3 & $10 \mathrm{C}$ & IIII & L. Archaic & & Testudinata & Shell fragment & 1 \\
\hline E20/S86 & 3 & $10 \mathrm{C}$ & IIIc & L. Archaic & & Vertebrata & Indeterminate & 124 \\
\hline E20/S86 & 4 & $10 \mathrm{D}$ & IIIc & L. Archaic & & Antilocapra/Odocoileus & Humerus & 1 \\
\hline E20/S86 & 4 & $10 \mathrm{D}$ & IIIC & L. Archaic & & cf. Odocoileus sp. & Tibia & 1 \\
\hline E20/S86 & 4 & 10D & IIIc & L. Archaic & & Kinosternidae & Shell fragment & 1 \\
\hline E20/S86 & 4 & 10D & IIIc & L. Archaic & & Mammalia (Medium/large) & Indeterminate & 1 \\
\hline
\end{tabular}




\begin{tabular}{|c|c|c|c|c|c|c|c|c|}
\hline Square & Level & Lot & Unit & Cultural Affinity & Feature & Taxon & Element & No. \\
\hline$\overline{\mathrm{E} 20 / \mathrm{S} 86}$ & 4 & 10D & IIIc & L. Archaic & & Mammalia (Medium/large) & Tooth, perm./decid. ind. & 1 \\
\hline E20/S86 & 4 & 10D & IIIc & L. Archaic & & Vertebrata & Indeterminate & 17 \\
\hline E20/S86 & 5 & $10 \mathrm{E}$ & IIIc & L. Archaic & & Antilocapra/Odocoileus & Cervical vertebra & 1 \\
\hline E20/S86 & 5 & $10 \mathrm{E}$ & IIIc & L. Archaic & & Antilocapra/Odocoileus & Distal fibula & 1 \\
\hline E20/S86 & 5 & $10 \mathrm{E}$ & IIIc & L. Archaic & & Bison sp. & Fused 3rd \& 4th metacarpal & 1 \\
\hline E20/S86 & 5 & $10 \mathrm{E}$ & IIIc & L. Archaic & & Leporidae & Scapula & 1 \\
\hline E20/S86 & 5 & $10 \mathrm{E}$ & IIIc & L. Archaic & & Mammalia (Large) & Indeterminate & 3 \\
\hline E20/S86 & 5 & $10 \mathrm{E}$ & IIIc & L. Archaic & & Mammalia (Large) & Long bone & 2 \\
\hline E20/S86 & 5 & $10 \mathrm{E}$ & IIIc & L. Archaic & & Mammalia (Medium/large) & Alveolar ridge fragment & 1 \\
\hline E20/S86 & 5 & $10 \mathrm{E}$ & IIIc & L. Archaic & & Mammalia (Medium/large) & Cranium & 1 \\
\hline E20/S86 & 5 & $10 \mathrm{E}$ & IIIc & L. Archaic & & Mammalia (Medium/large) & Indeterminate & 1 \\
\hline E20/S86 & 5 & $10 \mathrm{E}$ & IIIc & L. Archaic & & Mammalia (Medium/large) & Long bone & 2 \\
\hline E20/S86 & 5 & $10 \mathrm{E}$ & IIIc & L. Archaic & & Mammalia (Very large) & Rib & 2 \\
\hline E20/S86 & 5 & $10 \mathrm{E}$ & IIIc & L. Archaic & & Medium/Large Vertebrata & Compact bone & 1 \\
\hline E20/S86 & 5 & $10 \mathrm{E}$ & IIIIc & L. Archaic & & Medium/Large Vertebrata & Indeterminate & 18 \\
\hline E20/S86 & 5 & $10 \mathrm{E}$ & IIIc & L. Archaic & & Odocoileus sp. & Middle phalange & 1 \\
\hline E20/S86 & 5 & $10 \mathrm{E}$ & III & L. Archaic & & Osteichthyes & Vertebra & 1 \\
\hline E20/S86 & 5 & $10 \mathrm{E}$ & IIIc & L. Archaic & & Serpentes & Dorsal vertebra & 1 \\
\hline E20/S86 & 5 & $10 \mathrm{E}$ & IIIc & L. Archaic & & Sylvilagus sp. & Humerus & 1 \\
\hline E20/S86 & 5 & $10 \mathrm{E}$ & IIIc & L. Archaic & & Testudinata & Carapace fragment ind. & 1 \\
\hline E20/S86 & 5 & $10 \mathrm{E}$ & IIIc & L. Archaic & & Testudinata & Peripheral & 2 \\
\hline E20/S86 & 5 & $10 \mathrm{E}$ & IIIc & L. Archaic & & Testudinata & Pleural & 1 \\
\hline E20/S86 & 5 & $10 \mathrm{E}$ & IIII & L. Archaic & & Testudinata & Shell fragment & 2 \\
\hline E20/S86 & 5 & $10 \mathrm{E}$ & IIIc & L. Archaic & & Vertebrata & Indeterminate & 69 \\
\hline E20/S86 & 6 & $10 \mathrm{~F}$ & IIIc & Middle/L. Archaic & & Antilocapra/Odocoileus & Mid. phalange of paradigit & 1 \\
\hline E20/S86 & 6 & $10 \mathrm{~F}$ & IIIc & Middle/L. Archaic & & Antilocapra/Odocoileus & Thoracic vertebra & 1 \\
\hline E20/S86 & 6 & $10 \mathrm{~F}$ & IIIc & Middle/L. Archaic & & Artiodactyla & Tooth, perm./decid. ind. & 3 \\
\hline E20/S86 & 6 & $10 \mathrm{~F}$ & ШІ & Middle/L. Archaic & & Lepus californicus & Cranium & 2 \\
\hline E20/S86 & 6 & $10 \mathrm{~F}$ & IIIc & Middle/L. Archaic & & Mammalia (Medium/large) & Indeterminate & 5 \\
\hline E20/S86 & 6 & $10 \mathrm{~F}$ & IIIc & Middle/L. Archaic & & Mammalia (Medium/large) & Tooth, perm./decid. ind. & 1 \\
\hline E20/S86 & 6 & $10 \mathrm{~F}$ & III & Middle/L. Archaic & & Testudinata & Plastron fragment ind. & 1 \\
\hline E20/S86 & 6 & $10 \mathrm{~F}$ & IIIc & Middle/L. Archaic & & Testudinata & Shell fragment & 1 \\
\hline E20/S86 & 6 & $10 \mathrm{~F}$ & IIIc & Middle/L. Archaic & & Trionyx sp. & Neural & 2 \\
\hline E20/S86 & 6 & $10 \mathrm{~F}$ & IIIc & Middle/L. Archaic & & Vertebrata & Indeterminate & 47 \\
\hline E20/S86 & 7 & $10 \mathrm{G}$ & IIIc & Middle/L. Archaic & BRM1 & Antilocapra/Odocoileus & Fused 3rd \& 4th metacarpal & 1 \\
\hline E20/S86 & 7 & $10 \mathrm{G}$ & IIIc & Middle/L. Archaic & BRM1 & Mammalia (Medium/large) & Indeterminate & 4 \\
\hline E20/S86 & 7 & $10 \mathrm{G}$ & IIII & Middle/L. Archaic & BRM1 & Vertebrata & Indeterminate & 16 \\
\hline E20/S86 & 8 & $10 \mathrm{H}$ & IIII & M. Archaic & & Testudinata & Shell fragment & 1 \\
\hline E20/S86 & 8 & $10 \mathrm{H}$ & IIIIc & M. Archaic & & Vertebrata & Indeterminate & 12 \\
\hline E20/S86 & 9 & $10 \mathrm{I}$ & $\mathrm{IIIb} / \mathrm{c}$ & Early/M. Archaic & & Antilocapra/Odocoileus & Fused 3rd \& 4th metatarsal & 1 \\
\hline E20/S86 & 9 & 10I & IIIb/c & Early/M. Archaic & & Mammalia (Large) & Indeterminate & 1 \\
\hline E20/S86 & 9 & 10I & $\mathrm{milb} / \mathrm{c}$ & Early/M. Archaic & & Mammalia (Large) & Long bone & 1 \\
\hline E20/S86 & 9 & $10 \mathrm{I}$ & $\mathrm{IIIb} / \mathrm{c}$ & Early/M. Archaic & & Mammalia (Medium/large) & Indeterminate & 3 \\
\hline E20/S86 & 9 & 10I & IIIb/c & Early/M. Archaic & & Vertebrata & Indeterminate & 9 \\
\hline E20/S86 & 10 & $10 \mathrm{~J}$ & IIIb & Early/M. Archaic & & AntilocapralOdocoileus & Radius & 1 \\
\hline E20/S86 & 10 & $10 \mathrm{~J}$ & IIIlb & Early/M. Archaic & & Mammalia (Large) & Long bone & 1 \\
\hline E20/S86 & 10 & $10 \mathrm{~J}$ & IIIlb & Early/M. Archaic & & Mammalia (Medium/large) & Indeterminate & 2 \\
\hline E20/S86 & 10 & $10 \mathrm{~J}$ & IIIb & Early/M. Archaic & & Vertebrata & Indeterminate & 3 \\
\hline E20/S86 & 11 & $10 \mathrm{~K}$ & IIIlb & E. Archaic & & Lepus californicus & Tibia & 1 \\
\hline E20/S86 & 11 & $10 \mathrm{~K}$ & IIIb & E. Archaic & & Mammalia (Large) & Humerus & 1 \\
\hline E20/S86 & 11 & $10 \mathrm{~K}$ & IIIb & E. Archaic & & Mammalia (Large) & Indeterminate & 5 \\
\hline $\mathrm{E} 20 / \mathrm{S} 86$ & 11 & $10 \mathrm{~K}$ & IIIlb & E. Archaic & & Mammalia (Medium/large) & Indeterminate & 2 \\
\hline E20/S86 & 11 & $10 \mathrm{~K}$ & IIIlb & E. Archaic & & Vertebrata & Indeterminate & 17 \\
\hline $\mathrm{E} 20 / \mathrm{S} 86$ & 12 & $10 \mathrm{~L}$ & $\mathrm{X} / \mathrm{IIIb}$ & E. Archaic & & Vertebrata & Indeterminate & 2 \\
\hline $\mathrm{E} 20 / \mathrm{S} 86$ & 13 & $10 \mathrm{M}$ & $\mathrm{X} / \mathrm{IIIb}$ & E. Archaic & & Mammalia (Medium/large) & Indeterminate & 1 \\
\hline E20/S86 & 13 & $10 \mathrm{M}$ & $\mathrm{X} / \mathrm{IIIb}$ & E. Archaic & & Vertebrata & Indeterminate & 6 \\
\hline E20/S86 & 14 & $10 \mathrm{~N}$ & $\mathrm{X} / \mathrm{III} \mathrm{a} / \mathrm{b}$ & E. Archaic & & Mammalia (Medium/large) & Indeterminate & 3 \\
\hline $\mathrm{E} 20 / \mathrm{S} 86$ & 14 & $10 \mathrm{~N}$ & $\mathrm{X} / \mathrm{III} \mathrm{a} / \mathrm{b}$ & E. Archaic & & Mammalia (Medium/large) & Long bone & 1 \\
\hline $\mathrm{E} 20 / \mathrm{S} 86$ & 14 & $10 \mathrm{~N}$ & $\mathrm{X} / \mathrm{III} \mathrm{a} / \mathrm{b}$ & E. Archaic & & Vertebrata & Indeterminate & 1 \\
\hline E20/S86 & 15 & 100 & X/Wa & E. Archaic & & Mammalia (Large) & Indeterminate & 1 \\
\hline $\mathrm{E} 20 / \mathrm{S} 86$ & 15 & 100 & $\mathrm{X} / \mathrm{III}$ & E. Archaic & & Mammalia (Medium/large) & Indeterminate & 1 \\
\hline $\mathrm{E} 20 / \mathrm{S} 86$ & 15 & 100 & $\mathrm{X} / \mathrm{III}$ & E. Archaic & & Vertebrata & Indeterminate & 13 \\
\hline $\mathrm{E} 20 / \mathrm{S} 86$ & 16 & $10 \mathrm{P}$ & $\mathrm{X} / \mathrm{IL} / \mathrm{III}$ & E. Archaic & & Lepus californicus & Calcaneus & 1 \\
\hline $\mathrm{E} 20 / \mathrm{S} 86$ & 16 & $10 \mathrm{P}$ & $\mathrm{X} / \mathrm{IL} / \mathrm{II}$ & E. Archaic & & Mammalia (Medium/large) & Indeterminate & 5 \\
\hline $\mathrm{E} 20 / \mathrm{S} 86$ & 16 & $10 \mathrm{P}$ & $\mathrm{X} / \mathrm{II} / \mathrm{III}$ & E. Archaic & & Mammalia (Medium/large) & Long bone & 4 \\
\hline E20/S86 & 16 & $10 \mathrm{P}$ & $\mathrm{X} / \mathrm{II} / \mathrm{III}$ & E. Archaic & & Medium/Large Vertebrata & Indeterminate & 2 \\
\hline $\mathrm{E} 20 / \mathrm{S} 86$ & 16 & $10 \mathrm{P}$ & $\mathrm{X} / \mathrm{II} / \mathrm{Wa}$ & E. Archaic & & Small/Medium Vertebrata & Long bone & 1 \\
\hline
\end{tabular}




\begin{tabular}{|c|c|c|c|c|c|c|c|c|}
\hline Square & Level & Lot & Unit & Cultural Affinity & Feature & Taxon & Element & No. \\
\hline E20/S86 & 16 & $10 \mathrm{P}$ & $\mathrm{X} / \mathrm{II} / \mathrm{IIIa}$ & E. Archaic & & Vertebrata & Indeterminate & 1 \\
\hline E20/S86 & 17 & $10 Q$ & $\mathrm{X} / \mathrm{II} / \mathrm{II}$ & E. Archaic & & Mammalia (Medium/large) & Indeterminate & 3 \\
\hline E20/S86 & 17 & $10 Q$ & $\mathrm{X} / \mathrm{II} / \mathrm{III}$ & E. Archaic & & Odocoileus sp. & Tibia & 1 \\
\hline E20/S86 & 17 & $10 Q$ & $\mathrm{X} / \mathrm{II} / \mathrm{II} \mathrm{a}$ & E. Archaic & & Vertebrata & Indeterminate & 13 \\
\hline E20/S86 & 18 & $10 \mathrm{R}$ & $\mathrm{X} / \mathrm{II}$ & L. Paleo./E. Archaic & & Mammalia (Large) & Indeterminate & 1 \\
\hline E20/S86 & 18 & $10 \mathrm{R}$ & $\mathrm{X} / \mathrm{II}$ & L. Paleo./E. Archaic & & Mammalia (Medium) & Proximal phalange & 1 \\
\hline E20/S86 & 18 & $10 \mathrm{R}$ & $\mathrm{X} / \mathrm{II}$ & L. Paleo./E. Archaic & & Mammalia (Medium/large) & Indeterminate & 1 \\
\hline E20/S86 & 18 & $10 \mathrm{R}$ & $\mathrm{X} / \mathrm{II}$ & L. Paleo./E. Archaic & & Vertebrata & Indeterminate & 6 \\
\hline E20/S86 & 19 & $10 \mathrm{~S}$ & $\mathrm{X} / \mathrm{II}$ & L. Paleo. & & Mammalia (Medium/large) & Indeterminate & 1 \\
\hline E20/S86 & 19 & $10 \mathrm{~S}$ & $\mathrm{X} / \mathrm{II}$ & L. Paleo. & & Vertebrata & Indeterminate & 16 \\
\hline E20/S86 & 20 & $10 \mathrm{~T}$ & $\mathrm{X} / \mathrm{II}$ & L. Paleo. & & Mammalia (Medium/large) & Indeterminate & 3 \\
\hline E20/S86 & 20 & $10 \mathrm{~T}$ & $\mathrm{X} / \mathrm{II}$ & L. Paleo. & & Vertebrata & Indeterminate & 3 \\
\hline E20/S86 & 21 & $10 \mathrm{U}$ & $\mathrm{X}$ & L. Paleo. & & Mammalia (Medium/large) & Long bone & 3 \\
\hline E20/S86 & 22 & $10 \mathrm{~V}$ & $\mathrm{X}$ & L. Paleo. & & Medium/Large Vertebrata & Long bone & 1 \\
\hline E20/S88 & 1 & $9 \mathrm{~A}$ & IIIc & L. Prehist. & & Artiodactyla & Astragalus & 2 \\
\hline E20/S88 & 1 & $9 \mathrm{~A}$ & IIIc & L. Prehist. & & Mammalia (Medium/large) & Indeterminate & 9 \\
\hline E20/S88 & 1 & $9 \mathrm{~A}$ & IIIc & L. Prehist. & & Mammalia (Medium/large) & Tooth, perm./decid. ind. & 1 \\
\hline E20/S88 & 1 & $9 \mathrm{~A}$ & IIIc & L. Prehist. & & Vertebrata & Indeterminate & 19 \\
\hline E20/S88 & 3 & $9 \mathrm{C}$ & IIIc & L. Archaic & BRM1 & Antilocapra/Odocoileus & First tarsal & 1 \\
\hline E20/S88 & 3 & $9 \mathrm{C}$ & IIIc & L. Archaic & BRM1 & AntilocapralOdocoileus & Fourth carpal bone & 1 \\
\hline E20/S88 & 3 & $9 \mathrm{C}$ & IIIC & L. Archaic & BRM1 & Antilocapra/Odocoileus & Fused 3rd \& 4th metatarsal & 1 \\
\hline E20/S88 & 3 & $9 \mathrm{C}$ & IIIC & L. Archaic & BRM1 & AntilocapralOdocoileus & Metapodial & 1 \\
\hline E20/S88 & 3 & $9 \mathrm{C}$ & IIIc & L. Archaic & BRM1 & AntilocapralOdocoileus & Proximal phalange & 1 \\
\hline E20/S88 & 3 & $9 \mathrm{C}$ & IIIc & L. Archaic & BRM1 & AntilocapralOdocoileus & Proximal sesamoid & 1 \\
\hline E20/S88 & 3 & $9 \mathrm{C}$ & IIIc & L. Archaic & BRM1 & AntilocapralOdocoileus & Radial carpal bone & 1 \\
\hline E20/S88 & 3 & $9 \mathrm{C}$ & IIIc & L. Archaic & BRM1 & AntilocapralOdocoileus & Tibia & 1 \\
\hline E20/S88 & 3 & $9 \mathrm{C}$ & IIII & L. Archaic & BRM1 & Artiodactyla & Tooth, perm./decid. ind. & 2 \\
\hline E20/S88 & 3 & $9 \mathrm{C}$ & IIIc & L. Archaic & BRM1 & Leporidae & Tibia & 1 \\
\hline E20/S88 & 3 & $9 \mathrm{C}$ & IIIc & L. Archaic & BRM1 & Mammalia (Large) & Cranium & 2 \\
\hline E20/S88 & 3 & $9 \mathrm{C}$ & IIIc & L. Archaic & BRM1 & Mammalia (Large) & Femur & 1 \\
\hline E20/S88 & 3 & $9 \mathrm{C}$ & IIIc & L. Archaic & BRM1 & Mammalia (Large) & Indeterminate & 4 \\
\hline E20/S88 & 3 & $9 \mathrm{C}$ & IIIc & L. Archaic & BRM1 & Mammalia (Large) & Long bone & 1 \\
\hline E20/S88 & 3 & $9 \mathrm{C}$ & IIIc & L. Archaic & BRM1 & Mammalia (Medium) & Thoracic vertebra & 1 \\
\hline E20/S88 & 3 & $9 \mathrm{C}$ & IIIc & L. Archaic & BRM1 & Mammalia (Medium/large) & Indeterminate & 28 \\
\hline E20/S88 & 3 & $9 \mathrm{C}$ & IIIc & L. Archaic & BRM1 & Mammalia (Medium/large) & Vertebra & 1 \\
\hline E20/S88 & 3 & $9 \mathrm{C}$ & IIIC & L. Archaic & BRM1 & Odocoileus sp. & Permanent tooth & 1 \\
\hline E20/S88 & 3 & $9 \mathrm{C}$ & IIIC & L. Archaic & BRM1 & Testudinata & Shell fragment & 1 \\
\hline E20/S88 & 3 & $9 \mathrm{C}$ & IIIc & L. Archaic & BRM1 & Vertebrata & Indeterminate & 204 \\
\hline E20/S88 & 4 & 9D & IIIc & L. Archaic & BRM1 & cf. Antilocapra/Odocoileus & Tibia & 1 \\
\hline E20/S88 & 4 & 9D & IIIc & L. Archaic & BRM1 & Mammalia (Large) & Indeterminate & 1 \\
\hline E20/S88 & 4 & 9D & IIIc & L. Archaic & BRM1 & Mammalia (Large) & Long bone & 1 \\
\hline E20/S88 & 4 & 9D & IIII & L. Archaic & BRM1 & Mammalia (Medium/large) & Cranium & 1 \\
\hline E20/S88 & 4 & 9D & IIIc & L. Archaic & BRM1 & Mammalia (Medium/large) & Indeterminate & 1 \\
\hline E20/S88 & 4 & 9D & IIII & L. Archaic & BRM1 & Mammalia (Medium/large) & Long bone & 3 \\
\hline E20/S88 & 4 & 9D & IIIc & L. Archaic & BRM1 & Medium/Large Vertebrata & Indeterminate & 8 \\
\hline E20/S88 & 4 & 9D & IIIc & L. Archaic & BRM1 & Odocoileus sp. & Fourth carpal bone & 1 \\
\hline E20/S88 & 4 & 9D & IIII & L. Archaic & BRM1 & Vertebrata & Indeterminate & 15 \\
\hline E20/S88 & 5 & $9 \mathrm{E}$ & IIIc & L. Archaic & BRM1 & AntilocapralOdocoileus & Fused 3rd \& 4th metatarsal & 1 \\
\hline E20/S88 & 5 & $9 \mathrm{E}$ & IIIc & L. Archaic & BRM1 & Vertebrata & Indeterminate & 14 \\
\hline E20/S88 & 6 & $9 \mathrm{~F}$ & IIIc & Middle/L. Archaic & BRM1 & Vertebrata & Indeterminate & 6 \\
\hline E20/S88 & 7 & $9 \mathrm{G}$ & IIII & Middle/L. Archaic & BRM1 & Mammalia (Large) & Indeterminate & 1 \\
\hline E20/S88 & 7 & $9 \mathrm{G}$ & IIIc & Middle/L. Archaic & BRM1 & Mammalia (Medium/large) & Indeterminate & 1 \\
\hline E20/S88 & 7 & $9 \mathrm{G}$ & IIIc & Middle/L. Archaic & BRM1 & Mammalia (Medium/large) & Mandible & 1 \\
\hline E20/S88 & 7 & $9 \mathrm{G}$ & IIII & Middle/L. Archaic & BRM1 & Vertebrata & Indeterminate & 5 \\
\hline E20/S88 & 7 & $9 \mathrm{G}$ & WI & Middle/L. Archaic & BRM1 & Vertebrata & Long bone & 1 \\
\hline E20/S88 & 8 & $9 \mathrm{H}$ & IIIc & Archaic & BRM1 & Mammalia (Medium/large) & Indeterminate & 2 \\
\hline E20/S88 & 8 & $9 \mathrm{H}$ & IIIc & Archaic & BRM1 & Vertebrata & Indeterminate & 1 \\
\hline E20/S88 & 9 & 9I & Y/IIIc & Archaic & BRM1 & Odocoileus sp. & Cranium & 2 \\
\hline E20/S88 & 10 & $9 \mathrm{~J}$ & $\mathrm{Y} / \mathrm{IIIb} / \mathrm{c}$ & Archaic & BRM1 & Artiodactyla & Tooth, perm./decid. ind. & 2 \\
\hline E20/S88 & 10 & $9 \mathrm{~J}$ & $\mathrm{Y} / \mathrm{IIIb} / \mathrm{c}$ & Archaic & BRM1 & Mammalia (Medium) & Metapodial & 1 \\
\hline E20/S88 & 10 & $9 \mathrm{~J}$ & $\mathrm{Y} / \mathrm{IIIb} / \mathrm{c}$ & Archaic & BRM1 & Mammalia (Medium/large) & Indeterminate & 2 \\
\hline E20/S88 & 10 & $9 \mathrm{~J}$ & $\mathrm{Y} / \mathrm{IIIb} / \mathrm{c}$ & Archaic & BRM1 & Mammalia (Medium/large) & Mandible & 1 \\
\hline E20/S88 & 10 & $9 \mathrm{~J}$ & $\mathrm{Y} / \mathrm{IIIb} / \mathrm{c}$ & Archaic & BRM1 & Odocoileus sp. & Cranium & 1 \\
\hline E20/S88 & 10 & $9 \mathrm{~J}$ & $\mathrm{Y} / \mathrm{IIIb} / \mathrm{c}$ & Archaic & BRM1 & Odocoileus sp. & Mandible & 1 \\
\hline E20/S88 & 10 & $9 \mathrm{~J}$ & $\mathrm{Y} / \mathrm{IIIb} / \mathrm{c}$ & Archaic & BRM1 & Odocoileus sp. & Permanent tooth & 3 \\
\hline E20/S88 & 10 & $9 \mathrm{~J}$ & $\mathrm{Y} / \mathrm{IIIb} / \mathrm{c}$ & Archaic & BRM1 & Testudinata & Pleural & 1 \\
\hline E20/S88 & 10 & $9 \mathrm{~J}$ & $\mathrm{Y} / \mathrm{III} / \mathrm{c}$ & Archaic & BRM1 & Testudinata & Shell fragment & 1 \\
\hline
\end{tabular}




\begin{tabular}{|c|c|c|c|c|c|c|c|c|}
\hline Square & Level & Lot & Unit & Cultural Affinity & Feature & Taxon & Element & No. \\
\hline E20/S88 & 10 & $9 \mathrm{~J}$ & $\mathrm{Y} / \mathrm{IIIb} / \mathrm{c}$ & Archaic & BRM1 & Vertebrata & Indeterminate & 12 \\
\hline E20/S88 & 12 & $9 \mathrm{~L}$ & $\mathrm{X} / \mathrm{Y} / \mathrm{IIIb}$ & E. Archaic & f8 & AntilocapralOdocoileus & Pelvis & 1 \\
\hline E20/S88 & 12 & $9 \mathrm{~L}$ & $\mathrm{X} / \mathrm{Y} / \mathrm{IIIb}$ & E. Archaic & f8 & cf. AntilocapralOdocoileus & Pelvis & 1 \\
\hline E20/S88 & 12 & $9 \mathrm{~L}$ & $\mathrm{X} / \mathrm{Y} / \mathrm{IIIb}$ & E. Archaic & f8 & Leporidae & Alveolar ridge fragment & 1 \\
\hline E20/S88 & 12 & $9 \mathrm{~L}$ & $\mathrm{X} / \mathrm{Y} / \mathrm{IIIb}$ & E. Archaic & f8 & Mammalia (Large) & Long bone & 1 \\
\hline E20/S88 & 12 & $9 \mathrm{~L}$ & $\mathrm{X} / \mathrm{Y} / \mathrm{IIIb}$ & E. Archaic & f8 & Mammalia (Medium/large) & Indeterminate & 4 \\
\hline E20/S88 & 12 & $9 \mathrm{~L}$ & $\mathrm{X} / \mathrm{Y} / \mathrm{IIIb}$ & E. Archaic & f8 & Medium/Large Vertebrata & Indeterminate & 7 \\
\hline E20/S88 & 12 & $9 \mathrm{~L}$ & $\mathrm{X} / \mathrm{Y} / \mathrm{IIIb}$ & E. Archaic & f8 & Vertebrata & Indeterminate & 27 \\
\hline E20/S88 & 13 & $9 \mathrm{M}$ & |X/IIIb & E. Archaic & f8 & Leporidae & Calcaneus & 1 \\
\hline E20/S88 & 13 & $9 \mathrm{M}$ & $\mathrm{X} / \mathrm{IIIb}$ & E. Archaic & f8 & Mammalia (Large) & Long bone & 1 \\
\hline E20/S88 & 13 & $9 \mathrm{M}$ & $\mathrm{X} / \mathrm{IIIb}$ & E. Archaic & f8 & Mammalia (Medium/large) & Long bone & 1 \\
\hline E20/S88 & 13 & $9 \mathrm{M}$ & $\mathrm{X} / \mathrm{IIIb}$ & E. Archaic & f8 & Medium/Large Vertebrata & Indeterminate & 1 \\
\hline E20/S88 & 13 & $9 \mathrm{M}$ & $\mathrm{X} / \mathrm{IIIb}$ & E. Archaic & f8 & Serpentes & Dorsal vertebra & 1 \\
\hline E20/S88 & 13 & $9 \mathrm{M}$ & $\mathrm{X} / \mathrm{IIIb}$ & E. Archaic & f8 & Small/Medium Vertebrata & Long bone & 2 \\
\hline E20/S88 & 13 & $9 \mathrm{M}$ & $\mathrm{X} / \mathrm{IIIb}$ & E. Archaic & f8 & Testudinata & Shell fragment & 3 \\
\hline E20/S88 & 13 & $9 \mathrm{M}$ & $\mathrm{X} / \mathrm{IIIb}$ & E. Archaic & f8 & Vertebrata & Indeterminate & 12 \\
\hline E20/S88 & 15 & 90 & $\mathrm{X}$ & E. Archaic & & Medium/Large Vertebrata & Indeterminate & 2 \\
\hline E20/S88 & 15 & 90 & $\mathrm{x}$ & E. Archaic & & Vertebrata & Indeterminate & 6 \\
\hline E20/S88 & 16 & $9 \mathrm{P}$ & $\mathrm{x}$ & E. Archaic & & Medium/Large Vertebrata & Indeterminate & 1 \\
\hline E20/S88 & 18 & $9 \mathrm{R}$ & $\mathrm{X}$ & L. Paleo./E. Archaic & & Mammalia (Medium/large) & Indeterminate & 1 \\
\hline E20/S88 & 18 & $9 \mathrm{R}$ & $\mathrm{X}$ & L. Paleo./E. Archaic & & Vertebrata & Indeterminate & 2 \\
\hline E20/S88 & 19 & $9 \mathrm{~S}$ & $\mathrm{X}$ & L. Paleo./E. Archaic & & Mammalia (Large) & Indeterminate & 4 \\
\hline E20/S88 & 19 & $9 \mathrm{~S}$ & $\mathrm{X}$ & L. Paleo./E. Archaic & & Mammalia (Medium/large) & Indeterminate & 4 \\
\hline $\mathrm{E} 20 / \mathrm{S} 88$ & 19 & $9 \mathrm{~S}$ & $\mathrm{X}$ & L. Paleo./E. Archaic & & Vertebrata & Indeterminate & 3 \\
\hline E20/S88 & 20 & $9 \mathrm{~T}$ & $\mathrm{X}$ & L. Paleo./E. Archaic & & Mammalia (Medium/large) & Indeterminate & 4 \\
\hline E20/S88 & 21 & $9 \mathrm{U}$ & $\mathrm{x}$ & L. Paleo./E. Archaic & & Mammalia (Medium/large) & Indeterminate & 1 \\
\hline E20/S88 & 22 & $9 \mathrm{~V}$ & $\mathrm{X}$ & L. Paleo. & & Mammalia (Medium/large) & Indeterminate & 3 \\
\hline E20/S88 & 22 & $9 \mathrm{~V}$ & $\mathrm{X}$ & L. Paleo. & & Vertebrata & Indeterminate & 9 \\
\hline E20/S90 & 1 & $8 \mathrm{~A}$ & IIIIc & L. Prehist. & & Antilocapra/Odocoileus & Proximal sesamoid & 1 \\
\hline $\mathrm{E} 20 / \mathrm{S} 90$ & 1 & $8 \mathrm{~A}$ & IIII & L. Prehist. & & Artiodactyla & Proximal phalange & 1 \\
\hline E20/S90 & 1 & $8 \mathrm{~A}$ & IIII & L. Prehist. & & Mammalia (Large) & Indeterminate & 4 \\
\hline $\mathrm{E} 20 / \mathrm{S} 90$ & 1 & $8 \mathrm{~A}$ & IIII & L. Prehist. & & Mammalia (Medium/large) & Indeterminate & 10 \\
\hline E20/S90 & 1 & $8 \mathrm{~A}$ & IIIIc & L. Prehist. & & Odocoileus sp. & Fused 3rd \& 4th metatarsal & 1 \\
\hline E20/S90 & 1 & $8 \mathrm{~A}$ & IIII & L. Prehist. & & Odocoileus sp. & Permanent tooth & 2 \\
\hline E20/S90 & 1 & $8 \mathrm{~A}$ & IIII & L. Prehist. & & Vertebrata & Indeterminate & 171 \\
\hline E20/S90 & 2 & $8 \mathrm{~B}$ & IIIc & L. Archaic/L. Prehist. & BRM1 & AntilocapralOdocoileus & Astragalus & 1 \\
\hline E20/S90 & 2 & $8 \mathrm{~B}$ & IIIIc & L. Archaic/L. Prehist. & BRM1 & Antilocapra/Odocoileus & Distal phalange & 1 \\
\hline E20/S90 & 2 & 8B & IIII & L. Archaic/L. Prehist. & BRM1 & Antilocapra/Odocoileus & Fused central/fourth tarsal & 1 \\
\hline E20/S90 & 2 & $8 \mathrm{~B}$ & IIII & L. Archaic/L. Prehist. & BRM1 & AntilocapralOdocoileus & Metapodial & 2 \\
\hline E20/S90 & 2 & $8 \mathrm{~B}$ & IIII & L. Archaic/L. Prehist. & BRM1 & AntilocapralOdocoileus & Middle phalange & 1 \\
\hline E20/S90 & 2 & $8 \mathrm{~B}$ & IIII & L. Archaic/L. Prehist. & BRM1 & AntilocapralOdocoileus & Proximal phalange & 1 \\
\hline E20/S90 & 2 & $8 \mathrm{~B}$ & IIII & L. Archaic/L. Prehist. & BRM1 & AntilocapralOdocoileus & Proximal sesamoid & 1 \\
\hline $\mathrm{E} 20 / \mathrm{S} 90$ & 2 & 8B & IIIIc & L. Archaic/L. Prehist. & BRM1 & Antilocapra/Odocoileus & Tibia & 1 \\
\hline E20/S90 & 2 & 8B & IIIIc & L. Archaic/L. Prehist. & BRM1 & Antilocapra/Odocoileus & Ulnar carpal bone & 1 \\
\hline E20/S90 & 2 & 8B & IIIc & L. Archaic/L. Prehist. & BRM1 & Artiodactyla & Tooth, perm./decid. ind. & 3 \\
\hline $\mathrm{E} 20 / \mathrm{S} 90$ & 2 & 8B & IIIC & L. Archaic/L. Prehist. & BRM1 & Kinosternidae & Peripheral & 1 \\
\hline E20/S90 & 2 & 8B & IIIIc & L. Archaic/L. Prehist. & BRM1 & Mammalia (Large) & Alveolar ridge fragment & 1 \\
\hline E20/S90 & 2 & 8B & IIIc & L. Archaic/L. Prehist. & BRM1 & Mammalia (Large) & Cranium & 1 \\
\hline E20/S90 & 2 & 8B & IIIC & L. Archaic/L. Prehist. & BRM1 & Mammalia (Large) & Femur & 1 \\
\hline $\mathrm{E} 20 / \mathrm{S} 90$ & 2 & 8B & IIIC & L. Archaic/L. Prehist. & BRM1 & Mammalia (Large) & Humerus & 1 \\
\hline E20/S90 & 2 & 8B & IIIIc & L. Archaic/L. Prehist. & BRM1 & Mammalia (Large) & Indeterminate & 19 \\
\hline E20/S90 & 2 & 8B & IIIl & L. Archaic/L. Prehist. & BRM1 & Mammalia (Large) & Long bone & 22 \\
\hline $\mathrm{E} 20 / \mathrm{S} 90$ & 2 & 8B & IIIC & L. Archaic/L. Prehist. & BRM1 & Mammalia (Large) & Pelvis & 1 \\
\hline $\mathrm{E} 20 / \mathrm{S} 90$ & 2 & $8 \mathrm{~B}$ & IIIIc & L. Archaic/L. Prehist. & BRM1 & Mammalia (Large) & Vertebra & 1 \\
\hline $\mathrm{E} 20 / \mathrm{S} 90$ & 2 & $8 \mathrm{~B}$ & IIIc & L. Archaic/L. Prehist. & BRM1 & Mammalia (Medium) & Permanent tooth & 1 \\
\hline $\mathrm{E} 20 / \mathrm{S} 90$ & 2 & $8 \mathrm{~B}$ & IIIlc & L. Archaic/L. Prehist. & BRM1 & Mammalia (Medium) & Tooth, perm./decid. ind. & 2 \\
\hline E20/S90 & 2 & 8B & IIIIc & L. Archaic/L. Prehist. & BRM1 & Mammalia (Medium/large) & Alveolar ridge fragment & 1 \\
\hline $\mathrm{E} 20 / \mathrm{S} 90$ & 2 & 8B & IIIc & L. Archaic/L. Prehist. & BRM1 & Mammalia (Medium/large) & Indeterminate & 65 \\
\hline E20/S90 & 2 & 8B & IIIIc & L. Archaic/L. Prehist. & BRM1 & Mammalia (Medium/large) & Rib & 2 \\
\hline $\mathrm{E} 20 / \mathrm{S} 90$ & 2 & 8B & IIII & L. Archaic/L. Prehist. & BRM1 & Mammalia (Medium/large) & Tooth, perm./decid. ind. & 1 \\
\hline E20/S90 & 2 & 8B & IIIc & L. Archaic/L. Prehist. & BRM1 & Mustelidae & Mandible & 1 \\
\hline $\mathrm{E} 20 / \mathrm{S} 90$ & 2 & $8 \mathrm{~B}$ & IIIIc & L. Archaic/L. Prehist. & BRM1 & Mustelidae & Permanent tooth & 3 \\
\hline $\mathrm{E} 20 / \mathrm{S} 90$ & 2 & 8B & IIIIc & L. Archaic/L. Prehist. & BRM1 & Odocoileus sp. & Calcaneus & 1 \\
\hline $\mathrm{E} 20 / \mathrm{S} 90$ & 2 & 8B & IIIIc & L. Archaic/L. Prehist. & BRM1 & Odocoileus sp. & Distal phalange & 1 \\
\hline E20/S90 & 2 & $8 \mathrm{~B}$ & IIIc & L. Archaic/L. Prehist. & BRM1 & Odocoileus sp. & Middle phalange & 1 \\
\hline $\mathrm{E} 20 / \mathrm{S} 90$ & 2 & $8 \mathrm{~B}$ & IIIIc & L. Archaic/L. Prehist. & BRM1 & Odocoileus sp. & Permanent tooth & 6 \\
\hline $\mathrm{E} 20 / \mathrm{S} 90$ & 2 & $8 \mathrm{~B}$ & IIIc & L. Archaic/L. Prehist. & BRM1 & Odocoileus sp. & Proximal phalange & 1 \\
\hline
\end{tabular}




\begin{tabular}{|c|c|c|c|c|c|c|c|c|}
\hline Square & Level & Lot & Unit & Cultural Affinity & Feature & Taxon & Element & No. \\
\hline E20/S90 & 2 & $8 \mathrm{~B}$ & IIII & L. Archaic/L. Prehist. & BRM1 & Odocoileus sp. & Tooth, perm./decid. ind. & \\
\hline $\mathrm{E} 20 / \mathrm{S} 90$ & 2 & $8 \mathrm{~B}$ & IIIc & L. Archaic/L. Prehist. & BRM1 & Testudinata & Shell fragment & 4 \\
\hline $\mathrm{E} 20 / \mathrm{S} 90$ & 2 & $8 \mathrm{~B}$ & IIIIc & L. Archaic/L. Prehist. & BRM1 & Vertebrata & Indeterminate & 490 \\
\hline $\mathrm{E} 20 / \mathrm{S} 90$ & 2 & $8 \mathrm{~B}$ & IIIIc & L. Archaic/L. Prehist. & BRM1 & Vertebrata & Long bone & \\
\hline $\mathrm{E} 20 / \mathrm{S} 90$ & 3 & $8 \mathrm{C}$ & IIIC & L. Archaic & BRM1 & Antilocapra americana & Fused 3rd \& 4th metatarsal & \\
\hline $\mathrm{E} 20 / \mathrm{S} 90$ & 3 & $8 \mathrm{C}$ & IIIC & L. Archaic & BRM1 & AntilocapralOdocoileus & Astragalus & \\
\hline $\mathrm{E} 20 / \mathrm{S} 90$ & 3 & $8 \mathrm{C}$ & IIIIc & L. Archaic & BRM1 & Antilocapra/Odocoileus & Proximal sesamoid & \\
\hline $\mathrm{E} 20 / \mathrm{S} 90$ & 3 & $8 \mathrm{C}$ & IIIC & L. Archaic & BRM1 & Emydidae & Neural & \\
\hline $\mathrm{E} 20 / \mathrm{S} 90$ & 3 & $8 \mathrm{C}$ & IIIC & L. Archaic & BRM1 & Mammalia (Large) & Femur & \\
\hline $\mathrm{E} 20 / \mathrm{S} 90$ & 3 & $8 \mathrm{C}$ & IIII & L. Archaic & BRM1 & Mammalia (Large) & Indeterminate & \\
\hline $\mathrm{E} 20 / \mathrm{S} 90$ & 3 & $8 \mathrm{C}$ & IIIc & L. Archaic & BRM1 & Mammalia (Large) & Long bone & \\
\hline $\mathrm{E} 20 / \mathrm{S} 90$ & 3 & $8 \mathrm{C}$ & IIIC & L. Archaic & BRM1 & Mammalia (Large) & Rib & \\
\hline $\mathrm{E} 20 / \mathrm{S} 90$ & 3 & $8 \mathrm{C}$ & IIII & L. Archaic & BRM1 & Mammalia (Medium/large) & Indeterminate & 11 \\
\hline $\mathrm{E} 20 / \mathrm{S} 90$ & 3 & $8 \mathrm{C}$ & IIIIC & L. Archaic & BRM1 & Odocoileus sp. & Antler & 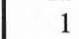 \\
\hline $\mathrm{E} 20 / \mathrm{S} 90$ & 3 & $8 \mathrm{C}$ & IIII & L. Archaic & BRM1 & Vertebrata & Indeterminate & 65 \\
\hline $\mathrm{E} 20 / \mathrm{S} 90$ & 3 & $8 \mathrm{C}$ & IIII & L. Archaic & BRM1 & Vertebrata & Long bone & \\
\hline $\mathrm{E} 20 / \mathrm{S} 90$ & 4 & $8 \mathrm{D}$ & IIIC & L. Archaic & BRM1 & Artiodactyla & Tooth, perm./decid. ind. & \\
\hline $\mathrm{E} 20 / \mathrm{S} 90$ & 4 & $8 \mathrm{D}$ & IIIC & L. Archaic & BRM1 & Mammalia (Large) & Cranium & 1 \\
\hline $\mathrm{E} 20 / \mathrm{S} 90$ & 4 & $8 \mathrm{D}$ & IIII & L. Archaic & BRM1 & Vertebrata & Indeterminate & 12 \\
\hline $\mathrm{E} 20 / \mathrm{S} 90$ & 5 & $8 \mathrm{E}$ & IIIC & L. Archaic & BRM1 & AntilocapralOdocoileus & Fused 3rd \& 4th metatarsal & \\
\hline $\mathrm{E} 20 / \mathrm{S} 90$ & 5 & $8 \mathrm{E}$ & IIIIc & L. Archaic & BRM1 & Vertebrata & Indeterminate & \\
\hline $\mathrm{E} 20 / \mathrm{S} 90$ & 8 & $8 \mathrm{H}$ & IIIc & Archaic & BRM1 & Vertebrata & Indeterminate & \\
\hline $\mathrm{E} 20 / \mathrm{S} 90$ & 9 & $8 \mathrm{I}$ & Y/Wc & Archaic & BRM1 & Mammalia (Medium/large) & Indeterminate & \\
\hline $\mathrm{E} 20 / \mathrm{S} 90$ & 9 & $8 \mathrm{I}$ & $\mathrm{Y} / \mathrm{IIIC}$ & Archaic & BRM1 & Vertebrata & Indeterminate & \\
\hline $\mathrm{E} 20 / \mathrm{S} 90$ & 9 & $8 \mathrm{I}$ & $\mathrm{Y} / \mathrm{IIIC}$ & Archaic & BRM1 & Vertebrata & Phalange & \\
\hline $\mathrm{E} 20 / \mathrm{S} 90$ & 10 & $8 \mathrm{~J}$ & Y/IIIc & Archaic & BRM1 & Mammalia (Medium/large) & Indeterminate & \\
\hline $\mathrm{E} 20 / \mathrm{S} 90$ & 10 & $8 \mathbf{J}$ & $\mathrm{Y} / \mathrm{IIIC}$ & Archaic & BRM1 & Vertebrata & Indeterminate & \\
\hline $\mathrm{E} 20 / \mathrm{S} 90$ & 11 & $8 \mathrm{~K}$ & $\mathrm{Y}$ & E. Archaic & & Colubridae & Dorsal vertebra & \\
\hline $\mathrm{E} 20 / \mathrm{S} 90$ & 11 & $8 \mathrm{~K}$ & $\mathrm{Y}$ & E. Archaic & & Mammalia (Medium/large) & Indeterminate & \\
\hline $\mathrm{E} 20 / \mathrm{S} 90$ & 11 & $8 \mathrm{~K}$ & $\mathrm{Y}$ & E. Archaic & & Vertebrata & Indeterminate & \\
\hline $\mathrm{E} 20 / \mathrm{S} 90$ & 12 & $8 \mathrm{~L}$ & $\mathrm{X} / \mathrm{Y}$ & E. Archaic & f8 & Mammalia (Medium/large) & Long bone & \\
\hline $\mathrm{E} 20 / \mathrm{S} 90$ & 12 & $8 \mathrm{~L}$ & $\mathrm{X} / \mathrm{Y}$ & E. Archaic & f8 & Vertebrata & Indeterminate & \\
\hline $\mathrm{E} 20 / \mathrm{S} 90$ & 13 & $8 \mathrm{M}$ & $\mathrm{X} / \mathrm{Y}$ & E. Archaic & & Mammalia (Medium/large) & Indeterminate & \\
\hline $\mathrm{E} 20 / \mathrm{S} 90$ & 13 & $8 \mathrm{M}$ & $\mathrm{X} / \mathrm{Y}$ & E. Archaic & & Mammalia (Medium/large) & Rib & \\
\hline $\mathrm{E} 20 / \mathrm{S} 90$ & 13 & $8 \mathrm{M}$ & $\mathrm{X} / \mathrm{Y}$ & E. Archaic & & Small/Medium Vertebrata & Long bone & \\
\hline $\mathrm{E} 20 / \mathrm{S} 90$ & 13 & $8 \mathrm{M}$ & $\mathrm{X} / \mathrm{Y}$ & E. Archaic & & Vertebrata & Indeterminate & \\
\hline E20/S90 & 14 & $8 \mathrm{~N}$ & $\mathrm{X}$ & E. Archaic & & Mammalia (Medium/large) & Middle phalange & \\
\hline $\mathrm{E} 20 / \mathrm{S} 90$ & 15 & 80 & $\mathrm{X}$ & E. Archaic & & Mammalia (Medium/large) & Indeterminate & \\
\hline $\mathrm{E} 20 / \mathrm{S} 90$ & 15 & 80 & $\mathrm{X}$ & E. Archaic & & Vertebrata & Indeterminate & \\
\hline $\mathrm{E} 20 / \mathrm{S} 90$ & 16 & $8 \mathrm{P}$ & $\mathrm{X}$ & E. Archaic & $\mathrm{f} 17$ & Mammalia (Medium) & Femur & \\
\hline $\mathrm{E} 20 / \mathrm{S} 90$ & 16 & $8 \mathrm{P}$ & $\mathrm{X}$ & E. Archaic & $\mathrm{f} 17$ & Mammalia (Medium/large) & Indeterminate & \\
\hline $\mathrm{E} 20 / \mathrm{S} 90$ & 16 & $8 \mathrm{P}$ & $\mathrm{X}$ & E. Archaic & f17 & Mammalia (Medium/large) & Rib & \\
\hline $\mathrm{E} 20 / \mathrm{S} 90$ & 16 & $8 \mathrm{P}$ & $\mathrm{X}$ & E. Archaic & f17 & Rodentia (Small/Medium) & Femur & \\
\hline $\mathrm{E} 20 / \mathrm{S} 90$ & 16 & $8 \mathrm{P}$ & $\mathrm{X}$ & E. Archaic & f17 & Vertebrata & Indeterminate & \\
\hline $\mathrm{E} 20 / \mathrm{S} 90$ & 17 & $8 Q$ & $\mathrm{X}$ & L. Paleo./E. Archaic & & Antilocapra/Odocoileus & Phalange & \\
\hline $\mathrm{E} 20 / \mathrm{S} 90$ & 17 & $8 Q$ & $\mathrm{X}$ & L. Paleo./E. Archaic & & Vertebrata & Indeterminate & \\
\hline $\mathrm{E} 20 / \mathrm{S} 90$ & 18 & $8 \mathrm{R}$ & $\mathrm{X}$ & L. Paleo./E. Archaic & & Mammalia (Medium/large) & Indeterminate & \\
\hline E20/S90 & 18 & $8 \mathrm{R}$ & $\mathrm{X}$ & L. Paleo./E. Archaic & & Vertebrata & Indeterminate & \\
\hline $\mathrm{E} 20 / \mathrm{S} 90$ & 19 & $8 \mathrm{~S}$ & $\mathrm{X}$ & L. Paleo./E. Archaic & & Mammalia (Medium/large) & Long bone & \\
\hline $\mathrm{E} 20 / \mathrm{S} 90$ & 19 & $8 \mathrm{~S}$ & $\mathrm{X}$ & L. Paleo./E. Archaic & & Vertebrata & Indeterminate & \\
\hline E20/S92 & 1 & $7 \mathrm{~A}$ & IIIc/POT & Archaic/L. Prehist. & & Antilocapra/Odocoileus & Astragalus & \\
\hline $\mathrm{E} 20 / \mathrm{S} 92$ & 1 & $7 \mathrm{~A}$ & IIIc/POT & Archaic/L. Prehist. & & Antilocapra/Odocoileus & Fused central/fourth tarsal & \\
\hline $\mathrm{E} 20 / \mathrm{S} 92$ & 1 & $7 \mathrm{~A}$ & IIIc/POT & Archaic/L. Prehist. & & Antilocapra/Odocoileus & Middle phalange & \\
\hline E20/S92 & 1 & $7 \mathrm{~A}$ & IIIc/POT & Archaic/L. Prehist. & & Antilocapra/Odocoileus & Phalange & \\
\hline E20/S92 & 1 & $7 \mathrm{~A}$ & IIIc/POT & Archaic/L. Prehist. & & Antilocapra/Odocoileus & Tibia & \\
\hline $\mathrm{E} 20 / \mathrm{S} 92$ & 1 & $7 \mathrm{~A}$ & IIIc/POT & Archaic/L. Prehist. & & Antilocapra/Odocoileus & Ulna & \\
\hline E20/S92 & 1 & $7 \mathrm{~A}$ & IIIc/POT & Archaic/L. Prehist. & & Mammalia (Large) & Indeterminate & \\
\hline E20/S92 & 1 & $7 \mathrm{~A}$ & IIIc/POT & Archaic/L. Prehist. & & Mammalia (Large) & Long bone & \\
\hline E20/S92 & 1 & $7 \mathrm{~A}$ & IIIc/POT & Archaic/L. Prehist. & & Mammalia (Large) & Vertebra & \\
\hline E20/S92 & 1 & $7 \mathrm{~A}$ & IIII/POT & Archaic/L. Prehist. & & Mammalia (Medium) & Proximal phalange & 1 \\
\hline E20/S92 & 1 & $7 \mathrm{~A}$ & IIIc/POT & Archaic/L. Prehist. & & Mammalia (Medium/large) & Indeterminate & 23 \\
\hline E20/S92 & 1 & $7 \mathrm{~A}$ & IIIc/POT & Archaic/L. Prehist. & & Odocoileus sp. & Antler & \\
\hline E20/S92 & 1 & $7 \mathrm{~A}$ & IIII/POT & Archaic/L. Prehist. & & Terrapene sp. & Pygal & \\
\hline E20/S92 & 1 & $7 \mathrm{~A}$ & IIIc/POT & Archaic/L. Prehist. & & Testudinata & Shell fragment & \\
\hline $\mathrm{E} 20 / \mathrm{S} 92$ & 1 & $7 \mathrm{~A}$ & IIIc/POT & Archaic/L. Prehist. & & Vertebrata & Indeterminate & 117 \\
\hline E20/S92 & 2 & $7 \mathrm{~B}$ & IIIc/POT & Archaic/L. Prehist. & BRM1 & Mammalia (Large) & Indeterminate & \\
\hline E20/S92 & 2 & $7 \mathrm{~B}$ & IIIc/POT & Archaic/L. Prehist. & BRM1 & Mammalia (Large) & Tooth, perm./decid. ind. & \\
\hline
\end{tabular}




\begin{tabular}{|c|c|c|c|c|c|c|c|c|}
\hline Square & Level & Lot & Unit & Cultural Affinity & Feature & Taxon & Element & No. \\
\hline E20/S92 & 2 & $7 \mathrm{~B}$ & $\overline{\mathrm{III} / \mathrm{POT}}$ & Archaic/L. Prehist. & BRM1 & Mammalia (Medium/large) & Indeterminate & 3 \\
\hline E20/S92 & 2 & $7 \mathrm{~B}$ & IIIc/POT & Archaic/L. Prehist. & BRM1 & Vertebrata & Indeterminate & 13 \\
\hline E20/S92 & 3 & $7 \mathrm{C}$ & IIIc/POT & Archaic & BRM1 & Testudinata & Shell fragment & 1 \\
\hline E20/S92 & 3 & $7 \mathrm{C}$ & IIIc/POT & Archaic & BRM1 & Vertebrata & Indeterminate & 3 \\
\hline $\mathrm{E} 20 / \mathrm{S} 92$ & 6 & $7 \mathrm{~F}$ & IIIc/POT & Archaic & BRM1 & Mammalia (Medium/large) & Indeterminate & 2 \\
\hline E20/S92 & 8 & $7 \mathrm{H}$ & IIIC & Archaic & BRM1 & Mammalia (Large) & Long bone & 1 \\
\hline E20/S92 & 9 & 71 & $\mathrm{Y} / \mathrm{III} \mathrm{c}$ & Archaic & & Lepus californicus & Calcaneus & 1 \\
\hline $\mathrm{E} 20 / \mathrm{S} 92$ & 11 & $7 \mathrm{~K}$ & $\mathrm{Y}$ & E. Archaic & & Mammalia (Large) & Long bone & 1 \\
\hline E20/S92 & 11 & $7 \mathrm{~K}$ & $\mathrm{Y}$ & E. Archaic & & Mammalia (Small) & Rib & 1 \\
\hline E20/S92 & 11 & $7 \mathrm{~K}$ & Y & E. Archaic & & Vertebrata & Indeterminate & 10 \\
\hline E20/S92 & 13 & $7 \mathrm{M}$ & Y & E. Archaic & & Vertebrata & Indeterminate & 1 \\
\hline E20/S92 & 14 & $7 \mathrm{~N}$ & $\mathrm{X} / \mathrm{Y}$ & E. Archaic & & Medium/Large Vertebrata & Long bone & 1 \\
\hline E20/S94 & 1 & $6 \mathrm{~A}$ & IIIc/POT & Archaic/L. Prehist. & & Antilocapra/Odocoileus & Astragalus & 1 \\
\hline E20/S94 & 1 & $6 \mathrm{~A}$ & IIIc/POT & Archaic/L. Prehist. & & Antilocapra/Odocoileus & Ulnar carpal bone & 1 \\
\hline E20/S94 & 1 & $6 \mathrm{~A}$ & IIIc/POT & Archaic/L. Prehist. & & Mammalia (Large) & Vertebra & 1 \\
\hline E20/S94 & 1 & $6 \mathrm{~A}$ & IIIc/POT & Archaic/L. Prehist. & & Mammalia (Medium/large) & Indeterminate & 20 \\
\hline E20/S94 & 1 & $6 \mathrm{~A}$ & IIIc/POT & Archaic/L. Prehist. & & Vertebrata & Indeterminate & 124 \\
\hline E20/S94 & 2 & $6 \mathrm{~B}$ & IIIc/POT & Archaic/L. Prehist. & BRM1 & Antilocapra/Odocoileus & Fused 3rd \& 4th metatarsal & 4 \\
\hline E20/S94 & 2 & $6 \mathrm{~B}$ & IIIc/POT & Archaic/L. Prehist. & BRM1 & Antilocapra/Odocoileus & Metapodial & 1 \\
\hline E20/S94 & 2 & $6 \mathrm{~B}$ & IIIc/POT & Archaic/L. Prehist. & BRM1 & AntilocapralOdocoileus & Middle phalange & 1 \\
\hline E20/S94 & 2 & $6 \mathrm{~B}$ & IIIc/POT & Archaic/L. Prehist. & BRM1 & Antilocapra/Odocoileus & Proximal phalange & 1 \\
\hline E20/S94 & 2 & $6 \mathrm{~B}$ & IIIc/POT & Archaic/L. Prehist. & BRM1 & Antilocapra/Odocoileus & Proximal sesamoid & 1 \\
\hline E20/S94 & 2 & $6 \mathrm{~B}$ & IIIc/POT & Archaic/L. Prehist. & BRM1 & Antilocapra/Odocoileus & Ulnar carpal bone & 1 \\
\hline E20/S94 & 2 & $6 \mathrm{~B}$ & IIIc/POT & Archaic/L. Prehist. & BRM1 & Mammalia (Large) & Long bone & 1 \\
\hline E20/S94 & 2 & $6 \mathrm{~B}$ & IIIc/POT & Archaic/L. Prehist. & BRM1 & Mammalia (Medium/large) & Indeterminate & 6 \\
\hline E20/S94 & 2 & $6 \mathrm{~B}$ & IIIc/POT & Archaic/L. Prehist. & BRM1 & Mammalia (Medium/large) & Long bone & 1 \\
\hline E20/S94 & 2 & $6 \mathrm{~B}$ & IIIc/POT & Archaic/L. Prehist. & BRM1 & Odocoileus sp. & Middle phalange & 1 \\
\hline E20/S94 & 2 & $6 \mathrm{~B}$ & IIIc/POT & Archaic/L. Prehist. & BRM1 & Testudinata & Shell fragment & 1 \\
\hline E20/S94 & 2 & $6 \mathrm{~B}$ & IIIc/POT & Archaic/L. Prehist. & BRM1 & Vertebrata & Indeterminate & 41 \\
\hline $\mathrm{E} 20 / \mathrm{S} 94$ & 3 & $6 \mathrm{C}$ & IIIc/POT & Archaic/L. Prehist. & BRM1 & Mammalia (Medium/large) & Indeterminate & 1 \\
\hline E20/S94 & 3 & $6 \mathrm{C}$ & IIIc/POT & Archaic/L. Prehist. & BRM1 & Vertebrata & Indeterminate & 7 \\
\hline E20/S94 & 4 & $6 \mathrm{D}$ & IIIc/POT & Archaic & BRM1 & cf. Odocoileus sp. & Intermediate carpal bone & 1 \\
\hline E20/S94 & 4 & $6 \mathrm{D}$ & IIIc/POT & Archaic & BRM1 & Mammalia (Medium/large) & Indeterminate & 2 \\
\hline E20/S94 & 4 & $6 \mathrm{D}$ & IIIc/POT & Archaic & BRM1 & Vertebrata & Indeterminate & 5 \\
\hline E20/S94 & 5 & $6 \mathrm{E}$ & IIIc & Archaic & BRM1 & Vertebrata & Indeterminate & 2 \\
\hline E20/S94 & 6 & $6 \mathrm{~F}$ & IIIc & Archaic & BRM1 & Antilocapra/Odocoileus & Proximal phalange & 1 \\
\hline E20/S94 & 6 & $6 \mathrm{~F}$ & IIIc & Archaic & BRM1 & Mammalia (Large) & Indeterminate & 1 \\
\hline E20/S94 & 6 & $6 \mathrm{~F}$ & IIIc & Archaic & BRM1 & Mammalia (Medium/large) & Indeterminate & 2 \\
\hline E20/S94 & 6 & $6 \mathrm{~F}$ & IIIc & Archaic & BRM1 & Vertebrata & Indeterminate & 3 \\
\hline E20/S94 & 7 & $6 \mathrm{G}$ & IIIIc & Archaic & & Vertebrata & Indeterminate & 2 \\
\hline E20/S94 & 8 & $6 \mathrm{H}$ & $\mathrm{Y} / \mathrm{IIIc}$ & Archaic & & Vertebrata & Indeterminate & 1 \\
\hline E20/S94 & 9 & $6 \mathrm{I}$ & Y/IIIc & Archaic & & Mammalia (Medium/large) & Indeterminate & 1 \\
\hline E20/S94 & 9 & $6 I$ & Y/IIIc & Archaic & & Vertebrata & Indeterminate & 19 \\
\hline E20/S94 & 10 & $6 \mathrm{~J}$ & $\mathrm{Y}$ & E. Archaic & & Mammalia (Large) & Cranium & 1 \\
\hline E20/S94 & 10 & $6 \mathrm{~J}$ & Y & E. Archaic & & Vertebrata & Indeterminate & 1 \\
\hline E20/S94 & 11 & $6 \mathrm{~K}$ & Y & E. Archaic & f4 & Vertebrata & Indeterminate & 5 \\
\hline $\mathrm{E} 20 / \mathrm{S} 94$ & 12 & $6 \mathrm{~L}$ & $\mathrm{X} / \mathrm{Y}$ & E. Archaic & $\mathrm{f} 4$ & Vertebrata & Indeterminate & 4 \\
\hline E20/S94 & 13 & $6 \mathrm{M}$ & $\mathrm{X} / \mathrm{Y}$ & E. Archaic & & Mammalia (Medium/large) & Indeterminate & 2 \\
\hline E20/S94 & 13 & $6 \mathrm{M}$ & $\mathrm{X} / \mathrm{Y}$ & E. Archaic & & Mammalia (Medium/large) & Long bone & 1 \\
\hline E20/S94 & 13 & $6 \mathrm{M}$ & $\mathrm{X} / \mathrm{Y}$ & E. Archaic & & Vertebrata & Indeterminate & 5 \\
\hline $\mathrm{E} 20 / \mathrm{S} 94$ & 14 & $6 \mathrm{~N}$ & $\mathrm{X} / \mathrm{Y}$ & E. Archaic & & Mammalia (Medium/large) & Indeterminate & 4 \\
\hline E20/S94 & 14 & $6 \mathrm{~N}$ & $\mathrm{X} / \mathrm{Y}$ & E. Archaic & & Mammalia (Medium/large) & Long bone & 3 \\
\hline E20/S94 & 14 & $6 \mathrm{~N}$ & $\mathrm{X} / \mathrm{Y}$ & E. Archaic & & Medium/Large Vertebrata & Indeterminate & 5 \\
\hline $\mathrm{E} 20 / \mathrm{S} 94$ & 14 & $6 \mathrm{~N}$ & $\mathrm{X} / \mathrm{Y}$ & E. Archaic & & Vertebrata & Indeterminate & 6 \\
\hline $\mathrm{E} 20 / \mathrm{S} 94$ & 15 & 60 & $\mathrm{x}$ & E. Archaic & & Vertebrata & Indeterminate & 6 \\
\hline $\mathrm{E} 20 / \mathrm{S} 94$ & 16 & $6 \mathrm{P}$ & $\mathrm{X}$ & E. Archaic & & Mammalia (Medium/large) & Indeterminate & 2 \\
\hline $\mathrm{E} 20 / \mathrm{S} 94$ & 16 & $6 \mathrm{P}$ & $\mathrm{X}$ & E. Archaic & & Mammalia (Medium/large) & Long bone & 6 \\
\hline $\mathrm{E} 20 / \mathrm{S} 94$ & 16 & $6 \mathrm{P}$ & $\mathrm{X}$ & E. Archaic & & Medium/Large Vertebrata & Indeterminate & 4 \\
\hline E20/S94 & 16 & $6 \mathrm{P}$ & $\mathrm{X}$ & E. Archaic & & Medium/Large Vertebrata & Long bone & 1 \\
\hline $\mathrm{E} 20 / \mathrm{S} 94$ & 16 & $6 \mathrm{P}$ & $\mathrm{X}$ & E. Archaic & & Vertebrata & Indeterminate & 11 \\
\hline E20/S94 & 18 & $6 \mathrm{R}$ & $\mathrm{X}$ & L. Paleo./E. Archaic & & Vertebrata & Indeterminate & 1 \\
\hline $\mathrm{E} 20 / \mathrm{S} 96$ & 1 & $5 \mathrm{~A}$ & IIIc/POT & Archaic/L. Prehist. & & Antilocapra/Odocoileus & First tarsal & 1 \\
\hline $\mathrm{E} 20 / \mathrm{S} 96$ & 1 & $5 \mathrm{~A}$ & IIIc/POT & Archaic/L. Prehist. & & AntilocapralOdocoileus & Fused 3rd \& 4th metacarpal & 1 \\
\hline E20/S96 & 1 & $5 \mathrm{~A}$ & IIIc/POT & Archaic/L. Prehist. & & Antilocapra/Odocoileus & Fused 3rd \& 4th metatarsal & 1 \\
\hline $\mathrm{E} 20 / \mathrm{S} 96$ & 1 & $5 \mathrm{~A}$ & II $/$ POT & Archaic/L. Prehist. & & AntilocapralOdocoileus & Intermediate carpal bone & 1 \\
\hline $\mathrm{E} 20 / \mathrm{S} 96$ & 1 & $5 \mathrm{~A}$ & IIIc/POT & Archaic/L. Prehist. & & Antilocapra/Odocoileus & Tibia & 1 \\
\hline E20/S96 & 1 & $5 \mathrm{~A}$ & IIIc/POT & Archaic/L. Prehist. & & Artiodactyla & Tooth, perm./decid. ind. & 1 \\
\hline
\end{tabular}




\begin{tabular}{|c|c|c|c|c|c|c|c|c|}
\hline Square & Level & Lot & Unit & Cultural Affinity & Feature & Taxon & Element & No. \\
\hline E20/S96 & 1 & $5 \mathrm{~A}$ & IIIc/POT & Archaic/L. Prehist. & & Mammalia (Large) & Indeterminate & 4 \\
\hline E20/S96 & 1 & $5 \mathrm{~A}$ & III/POT & Archaic/L. Prehist. & & Mammalia (Large) & Vertebra & 1 \\
\hline E20/S96 & 1 & $5 \mathrm{~A}$ & III/POT & Archaic/L. Prehist. & & Mammalia (Medium/large) & Indeterminate & 34 \\
\hline E20/S96 & 1 & $5 \mathrm{~A}$ & IIIc/POT & Archaic/L. Prehist. & & Odocoileus sp. & Permanent tooth & 1 \\
\hline E20/S96 & 1 & $5 \mathrm{~A}$ & IIIc/POT & Archaic/L. Prehist. & & Odocoileus sp. & Proximal phalange & 1 \\
\hline E20/S96 & 1 & $5 \mathrm{~A}$ & III/POT & Archaic/L. Prehist. & & Vertebrata & Indeterminate & 160 \\
\hline E20/S96 & 2 & $5 \mathrm{~B}$ & IIIc/POT & Archaic/L. Prehist. & BRM1 & AntilocapralOdocoileus & Fused 3rd \& 4th metatarsal & 1 \\
\hline E20/S96 & 2 & $5 \mathrm{~B}$ & IIIc/POT & Archaic/L. Prehist. & BRM1 & AntilocapralOdocoileus & Phalange & 1 \\
\hline E20/S96 & 2 & $5 \mathrm{~B}$ & $\mathrm{IIc} / \mathrm{POT}$ & Archaic/L. Prehist. & BRM1 & Antilocapra/Odocoileus & Ulna & 1 \\
\hline E20/S96 & 2 & $5 \mathrm{~B}$ & IIIc/POT & Archaic/L. Prehist. & BRM1 & Artiodactyla & Tooth, perm./decid. ind. & 7 \\
\hline E20/S96 & 2 & $5 \mathrm{~B}$ & IIIc/POT & Archaic/L. Prehist. & BRM1 & Mammalia (Large) & Indeterminate & 5 \\
\hline E20/S96 & 2 & $5 \mathrm{~B}$ & IIIc/POT & Archaic/L. Prehist. & BRM1 & Mammalia (Large) & Long bone & 1 \\
\hline E20/S96 & 2 & $5 \mathrm{~B}$ & $\mathrm{III} / \mathrm{POT}$ & Archaic/L. Prehist. & BRM1 & Mammalia (Large) & Rib & 1 \\
\hline E20/S96 & 2 & $5 \mathrm{~B}$ & IIIc/POT & Archaic/L. Prehist. & BRM1 & Mammalia (Medium) & Middle phalange & 1 \\
\hline E20/S96 & 2 & $5 \mathrm{~B}$ & III/POT & Archaic/L. Prehist. & BRM1 & Mammalia (Medium/large) & Cranium & 1 \\
\hline E20/S96 & 2 & $5 \mathrm{~B}$ & IIIc/POT & Archaic/L. Prehist. & BRM1 & Mammalia (Medium/large) & Indeterminate & 17 \\
\hline E20/S96 & 2 & $5 \mathrm{~B}$ & IIIc/POT & Archaic/L. Prehist. & BRM1 & Mammalia (Medium/large) & Thoracic vertebra & 2 \\
\hline E20/S96 & 2 & $5 \mathrm{~B}$ & IIIc/POT & Archaic/L. Prehist. & BRM1 & Odocoileus sp. & Metapodial of paradigit & 1 \\
\hline E20/S96 & 2 & $5 \mathrm{~B}$ & IIIc/POT & Archaic/L. Prehist. & BRM1 & Serpentes & Dorsal vertebra & 1 \\
\hline E20/S96 & 2 & $5 \mathrm{~B}$ & IIIc/POT & Archaic/L. Prehist. & BRM1 & Testudinata & Shell fragment & 1 \\
\hline E20/S96 & 2 & $5 \mathrm{~B}$ & IIIc/POT & Archaic/L. Prehist. & BRM1 & Vertebrata & Indeterminate & 111 \\
\hline $\mathrm{E} 20 / \mathrm{S} 96$ & 3 & $5 \mathrm{C}$ & III/POT & Archaic & BRM1 & Antilocapra/Odocoileus & Metapodial & 1 \\
\hline E20/S96 & 3 & $5 \mathrm{C}$ & IIIc/POT & Archaic & BRM1 & Mammalia (Large) & Long bone & 1 \\
\hline E20/S96 & 3 & $5 \mathrm{C}$ & Шा/POT & Archaic & BRM1 & Medium/Large Vertebrata & Indeterminate & 1 \\
\hline E20/S96 & 3 & $5 \mathrm{C}$ & IIIc/POT & Archaic & BRM1 & Testudinata & Peripheral & 1 \\
\hline E20/S96 & 4 & 5D & IIIc/POT & Archaic & BRM1 & Vertebrata & Indeterminate & 2 \\
\hline E20/S96 & 5 & $5 \mathrm{E}$ & IIIc/POT & Archaic & BRM1 & Vertebrata & Indeterminate & 4 \\
\hline E20/S96 & 6 & $5 \mathrm{~F}$ & IIIc/POT & Archaic & & Vertebrata & Indeterminate & 1 \\
\hline E20/S96 & 7 & $5 \mathrm{G}$ & IIIc & Archaic & & Mammalia (Large) & Long bone & 1 \\
\hline E20/S96 & 7 & $5 \mathrm{G}$ & ШІ丨 & Archaic & & Mammalia (Medium/large) & Indeterminate & 1 \\
\hline E20/S96 & 7 & $5 G$ & Wic & Archaic & & Vertebrata & Indeterminate & 10 \\
\hline E20/S96 & 10 & $5 \mathrm{~J}$ & $\mathrm{Y}$ & E. Archaic & & Mammalia (Medium/large) & Indeterminate & 2 \\
\hline E20/S96 & 10 & $5 \mathrm{~J}$ & $\mathrm{Y}$ & E. Archaic & & Vertebrata & Indeterminate & 5 \\
\hline E20/S96 & 11 & $5 \mathrm{~K}$ & Y & E. Archaic & & Mammalia (Large) & Indeterminate & 1 \\
\hline E20/S96 & 12 & $5 \mathrm{~L}$ & $\mathrm{X} / \mathrm{Y}$ & E. Archaic & & Mammalia (Medium/large) & Indeterminate & 1 \\
\hline E20/S96 & 12 & $5 \mathrm{~L}$ & $\mathrm{X} / \mathrm{Y}$ & E. Archaic & & Mammalia (Medium/large) & Long bone & 1 \\
\hline E20/S96 & 12 & $5 \mathrm{~L}$ & $\mathrm{X} / \mathrm{Y}$ & E. Archaic & & Vertebrata & Indeterminate & 4 \\
\hline E20/S96 & 13 & $5 \mathrm{M}$ & $\mathrm{X} / \mathrm{Y}$ & E. Archaic & & Mammalia (Large) & Long bone & 1 \\
\hline E20/S96 & 13 & $5 \mathrm{M}$ & $\mathrm{X} / \mathrm{Y}$ & E. Archaic & & Vertebrata & Indeterminate & 3 \\
\hline E20/S96 & 14 & $5 \mathrm{~N}$ & $\mathrm{X}$ & E. Archaic & & Mammalia (Small) & Femur & 1 \\
\hline E20/S96 & 14 & $5 \mathrm{~N}$ & $\mathrm{X}$ & E. Archaic & & Vertebrata & Indeterminate & 1 \\
\hline E20/S96 & 15 & 50 & $\mathrm{X}$ & E. Archaic & & Antilocapra/Odocoileus & Astragalus & 1 \\
\hline E20/S96 & 15 & 50 & $\mathrm{X}$ & E. Archaic & & Mammalia (Medium/large) & Indeterminate & 2 \\
\hline E20/S96 & 15 & 50 & $\mathrm{X}$ & E. Archaic & & Small/Medium Vertebrata & Long bone & 3 \\
\hline E20/S96 & 15 & 50 & $\mathrm{X}$ & E. Archaic & & Vertebrata & Indeterminate & 15 \\
\hline E20/S96 & 16 & $5 \mathrm{P}$ & $\mathrm{X}$ & L. Paleo./E. Archaic & & Vertebrata & Indeterminate & 3 \\
\hline E20/S98 & 1 & $3 \mathrm{~A}$ & IIIc & L. Prehist. & & Antilocapra/Odocoileus & Intermediate carpal bone & 1 \\
\hline E20/S98 & 1 & $3 \mathrm{~A}$ & III & L. Prehist. & & Mammalia (Large) & Indeterminate & 1 \\
\hline E20/S98 & 1 & $3 \mathrm{~A}$ & IIIc & L. Prehist. & & Mammalia (Large) & Long bone & 1 \\
\hline E20/S98 & 1 & $3 \mathrm{~A}$ & IIIIc & L. Prehist. & & Mammalia (Medium/large) & Indeterminate & 37 \\
\hline E20/S98 & 1 & $3 \mathrm{~A}$ & IIIC & L. Prehist. & & Mammalia (Medium/large) & Long bone & 8 \\
\hline E20/S98 & 1 & $3 \mathrm{~A}$ & IIIc & L. Prehist. & & Mammalia (Medium/large) & Rib & 1 \\
\hline E20/S98 & 1 & $3 \mathrm{~A}$ & IIIIc & L. Prehist. & & Odocoileus sp. & Antler & 2 \\
\hline E20/S98 & 1 & $3 \mathrm{~A}$ & IIIIc & L. Prehist. & & Odocoileus sp. & Proximal phalange & 1 \\
\hline E20/S98 & 1 & $3 \mathrm{~A}$ & IIII & L. Prehist. & & Vertebrata & Indeterminate & 71 \\
\hline E20/S98 & 2 & $3 \mathrm{~B}$ & IIIIc & L. Archaic/L. Prehist. & & Antilocapra/Odocoileus & Astragalus & 1 \\
\hline E20/S98 & 2 & 3B & IIIIc & L. Archaic/L. Prehist. & & Antilocapra/Odocoileus & Fused 3rd \& 4th metacarpal & 1 \\
\hline E20/S98 & 2 & 3B & IIIC & L. Archaic/L. Prehist. & & AntilocapralOdocoileus & Fused 3rd \& 4th metatarsal & 3 \\
\hline E20/S98 & 2 & $3 \mathrm{~B}$ & IIIIc & L. Archaic/L. Prehist. & & AntilocapralOdocoileus & Fused second \& third tarsal & 1 \\
\hline E20/S98 & 2 & 3B & IIII & L. Archaic/L. Prehist. & & Antilocapra/Odocoileus & Metapodial & 2 \\
\hline E20/S98 & 2 & $3 \mathrm{~B}$ & IIIIc & L. Archaic/L. Prehist. & & AntilocapralOdocoileus & Proximal phalange & 1 \\
\hline E20/S98 & 2 & 3B & IIIc & L. Archaic/L. Prehist. & & AntilocapralOdocoileus & Radius & 1 \\
\hline E20/S98 & 2 & 3B & IIIIc & L. Archaic/L. Prehist. & & Artiodactyla & Phalange & 4 \\
\hline E20/S98 & 2 & $3 \mathrm{~B}$ & IIIC & L. Archaic/L. Prehist. & & Artiodactyla & Tooth, perm./decid. ind. & 1 \\
\hline E20/S98 & 2 & $3 \mathrm{~B}$ & IIIIc & L. Archaic/L. Prehist. & & Canis sp. & Cranium & 1 \\
\hline E20/S98 & 2 & $3 \mathrm{~B}$ & IIIIc & L. Archaic/L. Prehist. & & Canis sp. & Permanent tooth & 3 \\
\hline $\mathrm{E} 20 / \mathrm{S} 98$ & 2 & 3B & IIIc & L. Archaic/L. Prehist. & & Mammalia (Large) & |Humerus & 1 \\
\hline
\end{tabular}




\begin{tabular}{|c|c|c|c|c|c|c|c|c|}
\hline Square & Level & Lot & Unit & Cultural Affinity & Feature & Taxon & Element & No. \\
\hline E20/S98 & 2 & $3 \mathrm{~B}$ & IIIc & L. Archaic/L. Prehist. & & Mammalia (Large) & Indeterminate & 2 \\
\hline E20/S98 & 2 & $3 \mathrm{~B}$ & IIIc & L. Archaic/L. Prehist. & & Mammalia (Large) & Long bone & 9 \\
\hline E20/S98 & 2 & $3 \mathrm{~B}$ & IIIc & L. Archaic/L. Prehist. & & Mammalia (Large) & Mandible & 2 \\
\hline E20/S98 & 2 & $3 \mathrm{~B}$ & IIIc & L. Archaic/L. Prehist. & & Mammalia (Medium/large) & Indeterminate & 44 \\
\hline E20/S98 & 2 & $3 \mathrm{~B}$ & IIIc & L. Archaic/L. Prehist. & & Odocoileus sp. & Distal phalange & 1 \\
\hline E20/S98 & 2 & 3B & IIIc & L. Archaic/L. Prehist. & & Odocoileus sp. & Middle phalange & 1 \\
\hline E20/S98 & 2 & $3 \mathrm{~B}$ & IIIc & L. Archaic/L. Prehist. & & Odocoileus sp. & Permanent tooth & 1 \\
\hline E20/S98 & 2 & $3 \mathrm{~B}$ & IIIc & L. Archaic/L. Prehist. & & Testudinata & Peripheral & 1 \\
\hline E20/S98 & 2 & $3 \mathrm{~B}$ & IIIc & L. Archaic/L. Prehist. & & Testudinata & Shell fragment & 1 \\
\hline E20/S98 & 2 & $3 \mathrm{~B}$ & IIIc & L. Archaic/L. Prehist. & & Vertebrata & Indeterminate & 193 \\
\hline E20/S98 & 2 & $3 \mathrm{~B}$ & IIIc & L. Archaic/L. Prehist. & & Vertebrata & Long bone & 3 \\
\hline E20/S98 & 3 & $3 \mathrm{C}$ & IIIc & L. Archaic & BRM1 & AntilocapralOdocoileus & Metapodial & 1 \\
\hline E20/S98 & 3 & $3 \mathrm{C}$ & IIIc & L. Archaic & BRM1 & Mammalia (Medium/large) & Indeterminate & 3 \\
\hline E20/S98 & 3 & $3 \mathrm{C}$ & IIIc & L. Archaic & BRM1 & Vertebrata & Indeterminate & 4 \\
\hline E20/S98 & 5 & $3 \mathrm{E}$ & IIIc & Middle/L. Archaic & BRM1 & Mammalia (Medium/large) & Indeterminate & 1 \\
\hline $\mathrm{E} 20 / \mathrm{S} 98$ & 5 & $3 \mathrm{E}$ & IIIc & Middle/L. Archaic & BRM1 & Vertebrata & Indeterminate & 2 \\
\hline $\mathrm{E} 20 / \mathrm{S} 98$ & 6 & $3 \mathrm{~F}$ & Y/IIIc & Archaic & & Odocoileus sp. & Permanent tooth & 1 \\
\hline E20/S98 & 7 & $3 \mathrm{G}$ & $\mathrm{Y} / \mathrm{IIIC}$ & Archaic & & Vertebrata & Indeterminate & 1 \\
\hline E20/S98 & 8 & $3 \mathrm{H}$ & $\mathrm{Y} / \mathrm{IIIC}$ & E. Archaic & & Mammalia (Large) & Indeterminate & 1 \\
\hline E20/S98 & 10 & $3 \mathrm{~J}$ & Y & E. Archaic & & Antilocapra/Odocoileus & Proximal phalange & 1 \\
\hline $\mathrm{E} 20 / \mathrm{S} 98$ & 10 & $3 \mathrm{~J}$ & Y & E. Archaic & & Mammalia (Medium/large) & Indeterminate & 1 \\
\hline E20/S98 & 10 & $3 \mathrm{~J}$ & Y & E. Archaic & & Vertebrata & Indeterminate & 1 \\
\hline E20/S98 & 11 & $3 \mathrm{~K}$ & $\mathrm{X} / \mathrm{Y}$ & E. Archaic & & Mammalia (Medium/large) & Indeterminate & 4 \\
\hline $\mathrm{E} 20 / \mathrm{S} 98$ & 11 & $3 \mathrm{~K}$ & $\mathrm{X} / \mathrm{Y}$ & E. Archaic & & Vertebrata & Indeterminate & 1 \\
\hline E20/S98 & 13 & $3 \mathrm{M}$ & $\mathrm{x}$ & E. Archaic & & Mammalia (Medium/large) & Indeterminate & 3 \\
\hline E20/S98 & 13 & $3 \mathrm{M}$ & $\mathrm{X}$ & E. Archaic & & Vertebrata & Indeterminate & 1 \\
\hline $\mathrm{E} 20 / \mathrm{S} 98$ & 15 & 30 & $\mathrm{X}$ & L. Paleo./E. Archaic & & Mammalia (Medium/large) & Indeterminate & 1 \\
\hline E20/S98 & 15 & 30 & $\mathrm{X}$ & L. Paleo./E. Archaic & & Medium/Large Vertebrata & Long bone & 1 \\
\hline E20/S98 & 15 & 30 & $\mathrm{X}$ & L. Paleo./E. Archaic & & Vertebrata & Indeterminate & 8 \\
\hline E20/S100 & 1 & $1 \mathrm{~A}$ & IIIc & L. Prehist. & & AntilocapralOdocoileus & Proximal phalange & 1 \\
\hline $\mathrm{E} 20 / \mathrm{S} 100$ & 1 & $1 \mathrm{~A}$ & IIIC & L. Prehist. & & Mammalia (Large) & Indeterminate & 1 \\
\hline $\mathrm{E} 20 / \mathrm{S} 100$ & 1 & $1 \mathrm{~A}$ & IIIc & L. Prehist. & & Mammalia (Large) & Long bone & 3 \\
\hline $\mathrm{E} 20 / \mathrm{S} 100$ & 1 & $1 \mathrm{~A}$ & IIIc & L. Prehist. & & Mammalia (Medium/large) & Indeterminate & 1 \\
\hline $\mathrm{E} 20 / \mathrm{S} 100$ & 1 & $1 \mathrm{~A}$ & IIIC & L. Prehist. & & Vertebrata & Indeterminate & 35 \\
\hline E20/S100 & 2 & $1 \mathrm{~B}$ & IIIc & L. Archaic/L. Prehist. & & Mammalia (Medium/large) & Indeterminate & 7 \\
\hline E20/S 100 & 2 & $1 \mathrm{~B}$ & IIIc & L. Archaic/L. Prehist. & & Vertebrata & Indeterminate & 10 \\
\hline E20/S100 & 3 & $1 \mathrm{C}$ & IIIc & L. Archaic & & AntilocapralOdocoileus & Calcaneus & 1 \\
\hline E20/S100 & 3 & $1 \mathrm{C}$ & IIIc & L. Archaic & & Mammalia (Large) & Femur & 2 \\
\hline $\mathrm{E} 20 / \mathrm{S} 100$ & 3 & $1 \mathrm{C}$ & IIIc & L. Archaic & & Mammalia (Large) & Indeterminate & 1 \\
\hline E20/S100 & 3 & $1 \mathrm{C}$ & IIIc & L. Archaic & & Mammalia (Large) & Long bone & 3 \\
\hline E20/S100 & 3 & $1 \mathrm{C}$ & IIIc & L. Archaic & & Mammalia (Medium/large) & Indeterminate & 5 \\
\hline E20/S100 & 3 & $1 \mathrm{C}$ & IIIc & L. Archaic & & Odocoileus sp. & Fused 3rd \& 4th metacarpal & 1 \\
\hline $\mathrm{E} 20 / \mathrm{S} 100$ & 3 & $1 \mathrm{C}$ & IIIC & L. Archaic & & Vertebrata & Indeterminate & 3 \\
\hline E20/S100 & 7 & $1 \mathrm{G}$ & Y & E. Archaic & & AntilocapralOdocoileus & Proximal phalange & 1 \\
\hline $\mathrm{E} 20 / \mathrm{S} 100$ & 7 & $1 \mathrm{G}$ & Y & E. Archaic & & Vertebrata & Indeterminate & 6 \\
\hline E20/S100 & 10 & $1 \mathrm{~J}$ & $\mathrm{Y}$ & E. Archaic & & Mammalia (Medium/large) & Indeterminate & 1 \\
\hline E20/S100 & 12 & $1 \mathrm{~L}$ & $\mathrm{X} / \mathrm{Y}$ & E. Archaic & & Mammalia (Medium/large) & Indeterminate & 3 \\
\hline $\mathrm{E} 20 / \mathrm{S} 100$ & 12 & $1 \mathrm{~L}$ & $\mathrm{X} / \mathrm{Y}$ & E. Archaic & & Vertebrata & Indeterminate & 8 \\
\hline $\mathrm{E} 22 / \mathrm{S} 72$ & 15 & 270 & IIIa/b & E. Archaic & & Antilocapra/Odocoileus & Astragalus & 1 \\
\hline $\mathrm{E} 22 / \mathrm{S} 72$ & 15 & 270 & IIIa/b & E. Archaic & & Mammalia (Medium/large) & Indeterminate & 3 \\
\hline $\mathrm{E} 22 / \mathrm{S} 72$ & 15 & 270 & IIIa/b & E. Archaic & & Medium/Large Vertebrata & Long bone & 1 \\
\hline $\mathrm{E} 22 / \mathrm{S} 72$ & 15 & 270 & $\mathrm{IIT} / \mathrm{b}$ & E. Archaic & & Vertebrata & Indeterminate & 1 \\
\hline $\mathrm{E} 22 / \mathrm{S} 72$ & 15 & 270 & IIIa/b & E. Archaic & & Vertebrata & Long bone & 1 \\
\hline $\mathrm{E} 22 / \mathrm{S} 72$ & $16 \mathrm{~B}$ & $27 \mathrm{P} 2$ & IIIa & E. Archaic & & Mammalia (Medium/large) & Long bone & 1 \\
\hline $\mathrm{E} 22 / \mathrm{S} 72$ & $17 \mathrm{~A}$ & 27Q1 & IIIa & E. Archaic & & Mammalia (Medium/large) & Indeterminate & 1 \\
\hline E22/S72 & $17 \mathrm{~A}$ & $27 Q 1$ & IIIIa & E. Archaic & & Vertebrata & Indeterminate & 1 \\
\hline $\mathrm{E} 22 / \mathrm{S} 72$ & $17 \mathrm{~B}$ & $27 Q 2$ & IIIa & E. Archaic & & Vertebrata & Indeterminate & 1 \\
\hline $\mathrm{E} 22 / \mathrm{S} 72$ & $18 \mathrm{~A}$ & $27 R 1$ & ШIa & E. Archaic & & Mammalia (Medium/large) & Indeterminate & 1 \\
\hline $\mathrm{E} 22 / \mathrm{S} 72$ & $18 \mathrm{~A}$ & 27R1 & ПIIа & E. Archaic & & Vertebrata & Indeterminate & 1 \\
\hline $\mathrm{E} 22 / \mathrm{S} 72$ & $18 \mathrm{~B}$ & $27 \mathrm{R} 2$ & IIIa & E. Archaic & & Sylvilagus sp. & Humerus & 1 \\
\hline $\mathrm{E} 22 / \mathrm{S} 72$ & $18 \mathrm{~B}$ & $27 R 2$ & Ша & E. Archaic & & Vertebrata & Indeterminate & 6 \\
\hline $\mathrm{E} 22 / \mathrm{S} 72$ & $18 \mathrm{~B}$ & $27 \mathrm{R} 2$ & IIIa & E. Archaic & & Vertebrata & Long bone & 1 \\
\hline $\mathrm{E} 22 / \mathrm{S} 72$ & $19 \mathrm{~A}$ & $27 \mathrm{~S} 1$ & IIIa & E. Archaic & & Vertebrata & Indeterminate & 3 \\
\hline $\mathrm{E} 22 / \mathrm{S} 72$ & 19B & $27 \mathrm{~S} 2 \mathrm{~B}$ & IIIa & E. Archaic & & AntilocapralOdocoileus & Tooth, perm./decid. ind. & 3 \\
\hline $\mathrm{E} 22 / \mathrm{S} 72$ & 19B & 27S2D & IIIa & E. Archaic & & Artiodactyla & Tooth, perm./decid. ind. & 1 \\
\hline $\mathrm{E} 22 / \mathrm{S} 72$ & 19B & 27S2D & ШІа & E. Archaic & & Vertebrata & Indeterminate & 1 \\
\hline $\mathrm{E} 22 / \mathrm{S} 72$ & $20 \mathrm{~A}$ & $27 \mathrm{~T} 1$ & II/Wa & L. Paleo./E. Archaic & & Testudinata & Shell fragment & 1 \\
\hline
\end{tabular}




\begin{tabular}{|c|c|c|c|c|c|c|c|c|}
\hline Square & Level & Lot & Unit & Cultural Affinity & Feature & Taxon & Element & No. \\
\hline E22/S72 & $20 \mathrm{~A}$ & 27T1 & $\overline{\mathrm{II} / \mathrm{III}}$ & L. Paleo./E. Archaic & & Vertebrata & Indeterminate & 2 \\
\hline $\mathrm{E} 22 / \mathrm{S} 72$ & $20 \mathrm{~A}$ & 27T1A & II/IIIa & L. Paleo./E. Archaic & & Vertebrata & Indeterminate & \\
\hline E22/S72 & $20 \mathrm{~A}$ & 27T1B & II/WIIa & L. Paleo./E. Archaic & & Leporidae & Tibia & \\
\hline $\mathrm{E} 22 / \mathrm{S} 72$ & $20 \mathrm{~A}$ & 27T1B & II/IIIIa & L. Paleo./E. Archaic & & Mammalia (Medium/large) & Long bone & \\
\hline E22/S72 & $20 \mathrm{~A}$ & 27T1B & II/Wa & L. Paleo./E. Archaic & & Small/Medium Vertebrata & Long bone & \\
\hline E22/S72 & $20 \mathrm{~A}$ & 27T1B & II/IIIa & L. Paleo./E. Archaic & & Vertebrata & Indeterminate & \\
\hline E22/S72 & $20 \mathrm{~A}$ & 27T1D & II/IIIa & L. Paleo./E. Archaic & & Mammalia (Medium/large) & Indeterminate & \\
\hline E22/S72 & $20 \mathrm{~A}$ & 27T1D & II/IIIa & L. Paleo./E. Archaic & & Vertebrata & Indeterminate & \\
\hline E22/S72 & $20 \mathrm{~B}$ & $27 \mathrm{~T} 2 \mathrm{~A}$ & II/Wa & L. Paleo./E. Archaic & & Medium/Large Vertebrata & Indeterminate & \\
\hline E22/S72 & 20B & $27 \mathrm{~T} 2 \mathrm{~B}$ & II/IIIa & L. Paleo./E. Archaic & & Mammalia (Medium/large) & Indeterminate & \\
\hline $\mathrm{E} 22 / \mathrm{S} 72$ & $20 \mathrm{~B}$ & $27 \mathrm{~T} 2 \mathrm{~B}$ & II/IIIa & L. Paleo./E. Archaic & & Small/Medium Vertebrata & Long bone & \\
\hline E22/S72 & $20 \mathrm{~B}$ & $27 \mathrm{~T} 2 \mathrm{~B}$ & II/IIIa & L. Paleo./E. Archaic & & Testudinata & Shell fragment & \\
\hline E22/S72 & 20B & $27 \mathrm{~T} 2 \mathrm{~B}$ & II/WIIa & L. Paleo./E. Archaic & & Vertebrata & Indeterminate & \\
\hline E22/S72 & $21 \mathrm{~A}$ & 27U1B & II/IIIa & L. Paleo./E. Archaic & & Vertebrata & Indeterminate & \\
\hline E22/S72 & $21 \mathrm{~B}$ & $27 \mathrm{U} 2 \mathrm{C}$ & III & L. Paleo. & & Mammalia (Medium/large) & Indeterminate & \\
\hline E22/S72 & 21B & $27 \mathrm{U} 2 \mathrm{C}$ & III & L. Paleo. & & Medium/Large Vertebrata & Long bone & \\
\hline E22/S72 & $21 \mathrm{~B}$ & $27 \mathrm{U} 2 \mathrm{C}$ & III & L. Paleo. & & Vertebrata & Indeterminate & \\
\hline E22/S72 & $21 \mathrm{~B}$ & 27U2D & III & L. Paleo. & & Vertebrata & Indeterminate & \\
\hline E22/S72 & $22 \mathrm{~A}$ & 27V1A & III & L. Paleo. & & Mammalia (Large) & Indeterminate & \\
\hline E22/S72 & $22 \mathrm{~A}$ & 27V1A & II & L. Paleo. & & Vertebrata & Indeterminate & \\
\hline E22/S72 & $22 \mathrm{~A}$ & 27V1D & II & L. Paleo. & & Mammalia (Medium/large) & Indeterminate & \\
\hline E22/S72 & $22 \mathrm{~A}$ & 27V1D & III & L. Paleo. & & Vertebrata & Indeterminate & 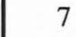 \\
\hline E22/S72 & $22 \mathrm{~B}$ & $27 \mathrm{~V} 2 \mathrm{~A}$ & III & L. Paleo. & & Mammalia (Medium/large) & Indeterminate & \\
\hline E22/S72 & $22 \mathrm{~B}$ & $27 \mathrm{~V} 2 \mathrm{~A}$ & III & L. Paleo. & & Vertebrata & Indeterminate & \\
\hline E22/S72 & $22 \mathrm{~B}$ & $27 \mathrm{~V} 2 \mathrm{~B}$ & III & L. Paleo. & & Carnivora & Permanent tooth & 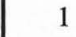 \\
\hline E22/S72 & $22 \mathrm{~B}$ & $27 \mathrm{~V} 2 \mathrm{~B}$ & II & L. Paleo. & & Medium/Large Vertebrata & Indeterminate & \\
\hline E22/S72 & $22 \mathrm{~B}$ & $27 \mathrm{~V} 2 \mathrm{~B}$ & III & L. Paleo. & & Vertebrata & Indeterminate & \\
\hline E22/S72 & 22B & $27 \mathrm{~V} 2 \mathrm{C}$ & III & L. Paleo. & & Mammalia (Medium/large) & Indeterminate & 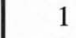 \\
\hline E22/S72 & $23 \mathrm{~A}$ & 27W1A & III & L. Paleo. & & Vertebrata & Indeterminate & 1 \\
\hline E22/S72 & $23 \mathrm{~B}$ & $27 \mathrm{~W} 2 \mathrm{~A}$ & II & L. Paleo. & & Vertebrata & Indeterminate & 7 \\
\hline E22/S72 & 23B & $27 \mathrm{~W} 2 \mathrm{~B}$ & III & L. Paleo. & & Carnivora & Tooth, perm./decid. ind. & 1 \\
\hline E22/S72 & 23B & $27 \mathrm{~W} 2 \mathrm{~B}$ & III & L. Paleo. & & Mammalia (Medium/large) & Indeterminate & 1 \\
\hline E22/S72 & $23 \mathrm{~B}$ & $27 \mathrm{~W} 2 \mathrm{C}$ & II & L. Paleo. & & Vertebrata & Indeterminate & 1 \\
\hline E22/S72 & $24 \mathrm{~A}$ & $27 \mathrm{X} 1 \mathrm{~A}$ & II & L. Paleo. & & Small/Medium Vertebrata & Long bone & 1 \\
\hline $\mathrm{E} 22 / \mathrm{S} 72$ & $24 \mathrm{~A}$ & 27X1A & II & L. Paleo. & & Sylvilagus sp. & Astragalus & 1 \\
\hline $\mathrm{E} 22 / \mathrm{S} 72$ & $24 \mathrm{~A}$ & $27 \mathrm{X} 1 \mathrm{~A}$ & II & L. Paleo. & & Vertebrata & Indeterminate & 1 \\
\hline E22/S72 & $24 \mathrm{~A}$ & $27 X 1 B$ & III & L. Paleo. & & Mammalia (Medium/large) & Indeterminate & 1 \\
\hline $\mathrm{E} 22 / \mathrm{S} 72$ & $24 \mathrm{~A}$ & 27X1B & II & L. Paleo. & & Medium/Large Vertebrata & Indeterminate & 1 \\
\hline $\mathrm{E} 22 / \mathrm{S} 72$ & $24 \mathrm{~A}$ & $27 \mathrm{X} 1 \mathrm{~B}$ & II & L. Paleo. & & Vertebrata & Indeterminate & \\
\hline $\mathrm{E} 22 / \mathrm{S} 72$ & $24 \mathrm{~A}$ & $27 \mathrm{X} 1 \mathrm{C}$ & II & L. Paleo. & & Mammalia (Medium/large) & Tooth, perm./decid. ind. & 1 \\
\hline $\mathrm{E} 22 / \mathrm{S} 72$ & $24 \mathrm{~A}$ & 27X1D & II & L. Paleo. & & Vertebrata & Indeterminate & \\
\hline $\mathrm{E} 22 / \mathrm{S} 72$ & $24 \mathrm{~B}$ & $27 \mathrm{X} 2 \mathrm{~B}$ & II & L. Paleo. & & Small/Medium Vertebrata & Indeterminate & 1 \\
\hline $\mathrm{E} 22 / \mathrm{S} 72$ & 24B & $27 X 2 B$ & III & L. Paleo. & & Vertebrata & Indeterminate & \\
\hline E22/S72 & 24B & 27X2D & III & L. Paleo. & & Vertebrata & Indeterminate & \\
\hline E22/S72 & $25 \mathrm{~A}$ & 27Y1B & III & L. Paleo. & & Vertebrata & Indeterminate & 2 \\
\hline E22/S72 & $25 \mathrm{~B}$ & $27 \mathrm{Y} 2 \mathrm{~B}$ & III & L. Paleo. & & Vertebrata & Indeterminate & 2 \\
\hline E22/S72 & $26 \mathrm{~A}$ & 27Z1A & III & L. Paleo. & & Mammalia (Medium/large) & Indeterminate & \\
\hline $\mathrm{E} 22 / \mathrm{S} 72$ & $26 \mathrm{~A}$ & 27Z1B & III & L. Paleo. & & Small/Medium Vertebrata & Long bone & 1 \\
\hline E22/S72 & $26 \mathrm{~A}$ & 27Z1D & III & L. Paleo. & & Vertebrata & Indeterminate & 3 \\
\hline E22/S72 & $26 \mathrm{~B}$ & $27 \mathrm{Z} 2 \mathrm{~A}$ & III & L. Paleo. & & Medium/Large Vertebrata & Long bone & 1 \\
\hline E22/S72 & $26 \mathrm{~B}$ & $27 \mathrm{Z} 2 \mathrm{~A}$ & III & L. Paleo. & & Small/Medium Vertebrata & Long bone & . \\
\hline E22/S72 & $26 \mathrm{~B}$ & $27 \mathrm{Z} 2 \mathrm{~A}$ & III & L. Paleo. & & Vertebrata & Indeterminate & 3 \\
\hline E22/S72 & $26 \mathrm{~B}$ & 27Z2D & II & L. Paleo. & & Vertebrata & Indeterminate & 2 \\
\hline E22/S72 & $27 \mathrm{~A}$ & 27AA1A & III & L. Paleo. & & Vertebrata & Indeterminate & 3 \\
\hline E22/S72 & $27 \mathrm{~A}$ & 27AA1B & III & L. Paleo. & & Vertebrata & Indeterminate & \\
\hline E22/S72 & $27 \mathrm{~A}$ & 27AA1C & II & L. Paleo. & & Mammalia (Medium/large) & Indeterminate & . \\
\hline E22/S72 & $27 \mathrm{~A}$ & 27AA1C & II & L. Paleo. & & Vertebrata & Indeterminate & 5 \\
\hline E22/S72 & $27 \mathrm{~A}$ & 27AA1C & III & L. Paleo. & & Vertebrata & Long bone & 1 \\
\hline E22/S72 & $27 \mathrm{~A}$ & 27AA1D & II & L. Paleo. & & Vertebrata & Indeterminate & 2 \\
\hline E22/S72 & $27 \mathrm{~A}$ & 27AA1D & III & L. Paleo. & & Vertebrata & Long bone & 1 \\
\hline E22/S72 & $27 \mathrm{~B}$ & 27AA2A & III & L. Paleo. & & Mammalia (Medium/large) & Indeterminate & . \\
\hline E22/S72 & 27B & 27AA2B & III & L. Paleo. & & Vertebrata & Indeterminate & 3 \\
\hline E22/S72 & $27 \mathrm{~B}$ & 27AA2C & II & L. Paleo. & & Vertebrata & Indeterminate & \\
\hline E22/S72 & 27B & 27AA2D & III & L. Paleo. & & Mammalia (Medium) & Metapodial & \\
\hline E22/S72 & 27B & 27AA2D & III & L. Paleo. & & Mammalia (Medium/large) & Indeterminate & 3 \\
\hline E22/S72 & 27B & 27AA2D & II & L. Paleo. & & Vertebrata & Indeterminate & 2 \\
\hline E22/S72 & $28 \mathrm{~A}$ & 27BB1A & Isi-c/II & L. Paleo. & & Mammalia (Medium/large) & Long bone & 3 \\
\hline
\end{tabular}




\begin{tabular}{|c|c|c|c|c|c|c|c|c|}
\hline Square & Level & Lot & Unit & Cultural Affinity & Feature & Taxon & Element & No. \\
\hline$\overline{\mathrm{E} 22 / \mathrm{S} 72}$ & $28 \mathrm{~A}$ & 27BB1A & Isi-c/II & L. Paleo. & & Medium vertebrate, class ind. & Proximal phalange & 1 \\
\hline $\mathrm{E} 22 / \mathrm{S} 72$ & $28 \mathrm{~A}$ & 27BB1A & Isi-c/II & L. Paleo. & & Medium/Large Vertebrata & Indeterminate & 3 \\
\hline $\mathrm{E} 22 / \mathrm{S} 72$ & $28 \mathrm{~A}$ & $27 \mathrm{BB} 1 \mathrm{~A}$ & Isi-c/II & L. Paleo. & & Small/Medium Vertebrata & Long bone & 1 \\
\hline $\mathrm{E} 22 / \mathrm{S} 72$ & $28 \mathrm{~A}$ & 27BB1A & Isi-c/II & L. Paleo. & & Vertebrata & Indeterminate & 23 \\
\hline E22/S72 & $28 \mathrm{~A}$ & 27BB1B & Isi-c/II & L. Paleo. & & Medium/Large Vertebrata & Indeterminate & 1 \\
\hline E22/S72 & $28 \mathrm{~A}$ & 27BB1D & Isi-c/II & L. Paleo. & & Mammalia (Medium/large) & Long bone & 1 \\
\hline $\mathrm{E} 22 / \mathrm{S} 72$ & $28 \mathrm{~B}$ & 27BB2A & Isi-c & L. Paleo. & & Vertebrata & Indeterminate & 2 \\
\hline $\mathrm{E} 22 / \mathrm{S} 72$ & 28B & 27BB2B & Isi-c & L. Paleo. & & Antilocapra/Odocoileus & Middle phalange & 1 \\
\hline $\mathrm{E} 22 / \mathrm{S} 72$ & $28 \mathrm{~B}$ & 27BB2B & Isi-c & L. Paleo. & & Antilocapra/Odocoileus & Phalange & 1 \\
\hline $\mathrm{E} 22 / \mathrm{S} 72$ & 28B & 27BB2B & Isi-c & L. Paleo. & & Mammalia (Medium) & Astragalus & 1 \\
\hline $\mathrm{E} 22 / \mathrm{S} 72$ & 28B & 27BB2B & Isi-c & L. Paleo. & & Mammalia (Medium/large) & Indeterminate & 3 \\
\hline $\mathrm{E} 22 / \mathrm{S} 72$ & $28 \mathrm{~B}$ & 27BB2B & Isi-c & L. Paleo. & & Mammalia (Medium/large) & Long bone & 2 \\
\hline $\mathrm{E} 22 / \mathrm{S} 72$ & 28B & 27BB2B & Isi-c & L. Paleo. & & Vertebrata & Indeterminate & 50 \\
\hline E22/S72 & 28B & $27 \mathrm{BB} 2 \mathrm{C}$ & Isi-c & L. Paleo. & & Vertebrata & Indeterminate & 2 \\
\hline $\mathrm{E} 22 / \mathrm{S} 72$ & $28 \mathrm{~B}$ & 27BB2D & Isi-c & L. Paleo. & & Emydidae & Peripheral & 1 \\
\hline $\mathrm{E} 22 / \mathrm{S} 72$ & $28 \mathrm{~B}$ & 27BB2D & Isi-c & L. Paleo. & & Mammalia (Medium/large) & Indeterminate & 1 \\
\hline $\mathrm{E} 22 / \mathrm{S} 72$ & 28B & 27BB2D & Isi-c & L. Paleo. & & Medium/Large Vertebrata & Indeterminate & 1 \\
\hline $\mathrm{E} 22 / \mathrm{S} 72$ & $28 \mathrm{~B}$ & 27BB2D & Isi-c & L. Paleo. & & Vertebrata & Indeterminate & 8 \\
\hline E22/S72 & $29 \mathrm{~A}$ & 27CC1A & Isi-c & L. Paleo. & & Mammalia (Large) & Long bone & 1 \\
\hline $\mathrm{E} 22 / \mathrm{S} 72$ & $29 \mathrm{~A}$ & $27 \mathrm{CC} 1 \mathrm{~A}$ & Isi-c & L. Paleo. & & Mammalia (Medium/large) & Indeterminate & 1 \\
\hline $\mathrm{E} 22 / \mathrm{S} 72$ & $29 \mathrm{~A}$ & $27 \mathrm{CC} 1 \mathrm{~A}$ & Isi-c & L. Paleo. & & Mammalia (Medium/large) & Long bone & 1 \\
\hline $\mathrm{E} 22 / \mathrm{S} 72$ & $29 \mathrm{~A}$ & $27 \mathrm{CC} 1 \mathrm{~A}$ & Isi-c & L. Paleo. & & Vertebrata & Indeterminate & 3 \\
\hline $\mathrm{E} 22 / \mathrm{S} 72$ & $29 \mathrm{~A}$ & $27 \mathrm{CC} 1 \mathrm{~B}$ & Isi-c & L. Paleo. & & Mammalia (Medium/large) & Caudal vertebra & 1 \\
\hline $\mathrm{E} 22 / \mathrm{S} 72$ & $29 \mathrm{~A}$ & $27 \mathrm{CC} 1 \mathrm{~B}$ & Isi-c & L. Paleo. & & Mammalia (Medium/large) & Indeterminate & 1 \\
\hline $\mathrm{E} 22 / \mathrm{S} 72$ & $29 \mathrm{~A}$ & $27 \mathrm{CC} 1 \mathrm{~B}$ & Isi-c & L. Paleo. & & Mammalia (Medium/large) & Long bone & 1 \\
\hline $\mathrm{E} 22 / \mathrm{S} 72$ & $29 \mathrm{~A}$ & $27 \mathrm{CC} 1 \mathrm{~B}$ & Isi-c & L. Paleo. & & Vertebrata & Indeterminate & 22 \\
\hline $\mathrm{E} 22 / \mathrm{S} 72$ & $29 \mathrm{~A}$ & $27 \mathrm{CC} 1 \mathrm{C}$ & Isi-c & L. Paleo. & & Antilocapra/Odocoileus & Fused 3rd \& 4th metatarsal & 1 \\
\hline $\mathrm{E} 22 / \mathrm{S} 72$ & $29 \mathrm{~A}$ & $27 \mathrm{CC} 1 \mathrm{C}$ & Isi-c & L. Paleo. & & Mammalia (Medium/large) & Long bone & 1 \\
\hline $\mathrm{E} 22 / \mathrm{S} 72$ & $29 \mathrm{~A}$ & $27 \mathrm{CC} 1 \mathrm{C}$ & Isi-c & L. Paleo. & & Vertebrata & Indeterminate & 4 \\
\hline $\mathrm{E} 22 / \mathrm{S} 72$ & $29 \mathrm{~A}$ & 27CC1D & Isi-c & L. Paleo. & & Mammalia (Medium) & Proximal phalange & 1 \\
\hline $\mathrm{E} 22 / \mathrm{S} 72$ & $29 \mathrm{~A}$ & 27CC1D & Isi-c & L. Paleo. & & Mammalia (Medium/large) & Rib & 1 \\
\hline $\mathrm{E} 22 / \mathrm{S} 72$ & $29 \mathrm{~A}$ & 27CC1D & Isi-c & L. Paleo. & & Mammalia (Medium/large) & Tooth, perm./decid. ind. & 1 \\
\hline $\mathrm{E} 22 / \mathrm{S} 72$ & $29 \mathrm{~A}$ & 27CC1D & Isi-c & L. Paleo. & & Vertebrata & Indeterminate & 24 \\
\hline $\mathrm{E} 22 / \mathrm{S} 72$ & $29 \mathrm{~B}$ & $27 \mathrm{CC} 2 \mathrm{~A}$ & Isi-c & L. Paleo. & & Vertebrata & Indeterminate & 2 \\
\hline $\mathrm{E} 22 / \mathrm{S} 72$ & 29B & $27 \mathrm{CC} 2 \mathrm{~B}$ & Isi-c & L. Paleo. & & Artiodactyla & Tooth, perm./decid. ind. & 3 \\
\hline $\mathrm{E} 22 / \mathrm{S} 72$ & $29 \mathrm{~B}$ & $27 \mathrm{CC} 2 \mathrm{~B}$ & Isi-c & L. Paleo. & & Mammalia (Large) & Long bone & 1 \\
\hline $\mathrm{E} 22 / \mathrm{S} 72$ & 29B & $27 \mathrm{CC} 2 \mathrm{~B}$ & Isi-c & L. Paleo. & & Mammalia (Medium) & Metapodial & 1 \\
\hline $\mathrm{E} 22 / \mathrm{S} 72$ & 29B & $27 \mathrm{CC} 2 \mathrm{~B}$ & Isi-c & L. Paleo. & & Mammalia (Medium) & Middle phalange & 1 \\
\hline $\mathrm{E} 22 / \mathrm{S} 72$ & $29 \mathrm{~B}$ & $27 \mathrm{CC} 2 \mathrm{~B}$ & Isi-c & L. Paleo. & & Mammalia (Medium) & Rib & 1 \\
\hline $\mathrm{E} 22 / \mathrm{S} 72$ & 29B & $27 \mathrm{CC} 2 \mathrm{~B}$ & Isi-c & L. Paleo. & & Mammalia (Medium/large) & Long bone & 3 \\
\hline $\mathrm{E} 22 / \mathrm{S} 72$ & 29B & $27 \mathrm{CC} 2 \mathrm{~B}$ & Isi-c & L. Paleo. & & Mammalia (Medium/large) & Tooth, perm./decid. ind. & 1 \\
\hline $\mathrm{E} 22 / \mathrm{S} 72$ & 29B & $27 \mathrm{CC} 2 \mathrm{~B}$ & Isi-c & L. Paleo. & & Odocoileus sp. & Permanent tooth & 1 \\
\hline $\mathrm{E} 22 / \mathrm{S} 72$ & 29B & $27 \mathrm{CC} 2 \mathrm{~B}$ & Isi-c & L. Paleo. & & Vertebrata & Indeterminate & 45 \\
\hline $\mathrm{E} 22 / \mathrm{S} 72$ & $29 \mathrm{~B}$ & $27 \mathrm{CC} 2 \mathrm{C}$ & Isi-c & L. Paleo. & & Vertebrata & Indeterminate & 8 \\
\hline $\mathrm{E} 22 / \mathrm{S} 72$ & $29 \mathrm{~B}$ & $27 \mathrm{CC} 2 \mathrm{D}$ & Isi-c & L. Paleo. & & Lepus californicus & Calcaneus & 1 \\
\hline $\mathrm{E} 22 / \mathrm{S} 72$ & 29B & $27 \mathrm{CC} 2 \mathrm{D}$ & Isi-c & L. Paleo. & & Mammalia (Medium/large) & Indeterminate & 1 \\
\hline $\mathrm{E} 22 / \mathrm{S} 72$ & $29 \mathrm{~B}$ & $27 \mathrm{CC} 2 \mathrm{D}$ & Isi-c & L. Paleo. & & Mammalia (Medium/large) & Long bone & 2 \\
\hline E22/S72 & 29B & $27 \mathrm{CC} 2 \mathrm{D}$ & Isi-c & L. Paleo. & & Vertebrata & Indeterminate & 60 \\
\hline E22/S72 & $30 \mathrm{~A}$ & 27DD1A & Isi-c & L. Paleo. & & Mammalia (Large) & Long bone & 1 \\
\hline $\mathrm{E} 22 / \mathrm{S} 72$ & $30 \mathrm{~A}$ & 27DD1A & Isi-c & L. Paleo. & & Vertebrata & Indeterminate & 9 \\
\hline E22/S72 & $30 \mathrm{~A}$ & 27DD1B & Isi-c & L. Paleo. & & Vertebrata & Indeterminate & 3 \\
\hline $\mathrm{E} 22 / \mathrm{S} 72$ & $30 \mathrm{~A}$ & 27DD1C & Isi-c & L. Paleo. & & Mammalia (Medium/large) & Indeterminate & 1 \\
\hline $\mathrm{E} 22 / \mathrm{S} 72$ & $30 \mathrm{~A}$ & 27DD1C & Isi-c & L. Paleo. & & Vertebrata & Indeterminate & 12 \\
\hline $\mathrm{E} 22 / \mathrm{S} 72$ & $30 \mathrm{~A}$ & 27DD1D & Isi-c & L. Paleo. & & Mammalia (Medium/large) & Indeterminate & 2 \\
\hline $\mathrm{E} 22 / \mathrm{S} 72$ & $30 \mathrm{~A}$ & 27DD1D & Isi-c & L. Paleo. & & Medium/Large Vertebrata & Long bone & 2 \\
\hline $\mathrm{E} 22 / \mathrm{S} 72$ & $30 \mathrm{~A}$ & 27DD1D & Isi-c & L. Paleo. & & Small/Medium Vertebrata & Long bone & 3 \\
\hline $\mathrm{E} 22 / \mathrm{S} 72$ & $30 \mathrm{~A}$ & 27DD1D & Isi-c & L. Paleo. & & Vertebrata & Indeterminate & 5 \\
\hline $\mathrm{E} 22 / \mathrm{S} 72$ & $30 \mathrm{~B}$ & 27DD2A & Isi-c & L. Paleo. & & Mammalia (Medium/large) & Indeterminate & 1 \\
\hline $\mathrm{E} 22 / \mathrm{S} 72$ & $30 \mathrm{~B}$ & 27DD2B & Isi-c & L. Paleo. & & Vertebrata & Indeterminate & 3 \\
\hline $\mathrm{E} 22 / \mathrm{S} 72$ & $30 \mathrm{~B}$ & 27DD2C & Isi-c & L. Paleo. & & Mammalia & Indeterminate & 1 \\
\hline $\mathrm{E} 22 / \mathrm{S} 72$ & $30 \mathrm{~B}$ & 27DD2C & Isi-c & L. Paleo. & & Testudinata & |Peripheral & 1 \\
\hline $\mathrm{E} 22 / \mathrm{S} 72$ & 30B & 27DD2C & Isi-c & L. Paleo. & & Vertebrata & Indeterminate & 3 \\
\hline $\mathrm{E} 22 / \mathrm{S} 72$ & $31 \mathrm{~A}$ & 27EE1A & Isi-c & L. Paleo. & & Mammalia (Medium/large) & Indeterminate & 1 \\
\hline $\mathrm{E} 22 / \mathrm{S} 72$ & $31 \mathrm{~A}$ & 27EE1A & Isi-c & L. Paleo. & & Vertebrata & Indeterminate & 1 \\
\hline $\mathrm{E} 22 / \mathrm{S} 72$ & $31 \mathrm{~A}$ & 27EE1B & Isi-c & L. Paleo. & & Small/Medium Vertebrata & Long bone & 1 \\
\hline $\mathrm{E} 22 / \mathrm{S} 72$ & $31 \mathrm{~A}$ & 27EE1B & Isi-c & L. Paleo. & & Vertebrata & Indeterminate & 1 \\
\hline $\mathrm{E} 22 / \mathrm{S} 72$ & $31 \mathrm{~A}$ & 27EE1D & Isi-c & L. Paleo. & & Medium/Large Vertebrata & Long bone & 1 \\
\hline
\end{tabular}




\begin{tabular}{|c|c|c|c|c|c|c|c|c|}
\hline Square & Level & Lot & Unit & Cultural Affinity & Feature & Taxon & Element & No. \\
\hline E22/S72 & $31 \mathrm{~A}$ & 27EE1D & $\overline{\text { Isi-c }}$ & L. Paleo. & & Small/Medium Vertebrata & Long bone & \\
\hline $\mathrm{E} 22 / \mathrm{S} 72$ & $31 \mathrm{~A}$ & 27EE1D & Isi-c & L. Paleo. & & Vertebrata & Indeterminate & \\
\hline E22/S72 & $31 \mathrm{~B}$ & 27EE2A & $\mathrm{Icl} / \mathrm{Isi}-\mathrm{c}$ & Paleoindian & & Mammalia (Medium/large) & Indeterminate & \\
\hline $\mathrm{E} 22 / \mathrm{S} 72$ & $31 \mathrm{~B}$ & 27EE2A & $\mathrm{Icl} / \mathrm{Isi}-\mathrm{c}$ & Paleoindian & & Small/Medium Vertebrata & Long bone & \\
\hline E22/S72 & 31B & 27EE2A & $\mathrm{Icl} / \mathrm{Isi}-\mathrm{c}$ & Paleoindian & & Vertebrata & Indeterminate & \\
\hline E22/S72 & $31 \mathrm{~B}$ & 27EE2C & $\mathrm{Icl} / \mathrm{Isi}-\mathrm{c}$ & Paleoindian & & Small/Medium Vertebrata & Long bone & \\
\hline $\mathrm{E} 22 / \mathrm{S} 72$ & $31 \mathrm{~B}$ & 27EE2D & $\mathrm{Icl} / \mathrm{Isi}-\mathrm{c}$ & Paleoindian & & Vertebrata & Indeterminate & \\
\hline E22/S72 & $32 \mathrm{~A}$ & 27FF1A & $\mathrm{Icl} / \mathrm{Isi}-\mathrm{c}$ & Paleoindian & & Mammalia (Medium/large) & Indeterminate & \\
\hline E22/S72 & $32 \mathrm{~A}$ & 27FF1A & $\mathrm{Icl} / \mathrm{Isi}-\mathrm{c}$ & Paleoindian & & Mammalia (Medium/large) & Long bone & \\
\hline $\mathrm{E} 22 / \mathrm{S} 72$ & $32 \mathrm{~A}$ & 27FF1A & $\mathrm{Icl} / \mathrm{Isi}-\mathrm{c}$ & Paleoindian & & Vertebrata & Indeterminate & \\
\hline E22/S72 & $32 \mathrm{~B}$ & 27FF2A & $\mathrm{Icl} / \mathrm{Isi}-\mathrm{c}$ & Paleoindian & & Vertebrata & Indeterminate & \\
\hline E22/S72 & $32 \mathrm{~B}$ & $27 \mathrm{FF} 2 \mathrm{~B}$ & $\mathrm{Icl} / \mathrm{Isi}-\mathrm{c}$ & Paleoindian & & Mammalia (Medium/large) & Indeterminate & \\
\hline $\mathrm{E} 22 / \mathrm{S} 72$ & $32 \mathrm{~B}$ & 27FF2C & $\mathrm{Icl} / \mathrm{Isi}-\mathrm{c}$ & Paleoindian & & Mammalia (Medium/large) & Indeterminate & \\
\hline $\mathrm{E} 22 / \mathrm{S} 72$ & $32 \mathrm{~B}$ & $27 \mathrm{FF} 2 \mathrm{C}$ & $\mathrm{Icl} / \mathrm{Isi}-\mathrm{c}$ & Paleoindian & & Mammalia (Medium/large) & Long bone & \\
\hline E22/S72 & $33 \mathrm{~A}$ & 27GG1B & $\mathrm{Icl} / \mathrm{Isi}-\mathrm{c}$ & Paleoindian & & Sylvilagus sp. & Ulna & \\
\hline E22/S72 & $33 \mathrm{~A}$ & 27GG1B & $\mathrm{Icl} / \mathrm{Isi}-\mathrm{c}$ & Paleoindian & & Vertebrata & Indeterminate & \\
\hline $\mathrm{E} 22 / \mathrm{S} 72$ & $33 \mathrm{~A}$ & $27 \mathrm{GG1C}$ & $\mathrm{Icl} / \mathrm{Isi}-\mathrm{c}$ & Paleoindian & & Vertebrata & Indeterminate & \\
\hline E22/S72 & $33 \mathrm{~A}$ & 27GG1D & $\mathrm{Icl} / \mathrm{Isi}-\mathrm{c}$ & Paleoindian & & Small/Medium Vertebrata & Long bone & \\
\hline $\mathrm{E} 22 / \mathrm{S} 72$ & $34 \mathrm{~A}$ & 27HH1A & Icl & E. Paleo. & & Vertebrata & Indeterminate & \\
\hline $\mathrm{E} 22 / \mathrm{S} 72$ & $34 \mathrm{~B}$ & $27 \mathrm{HH} 2 \mathrm{C}$ & Icl & E. Paleo. & & Mammalia (Medium/large) & Long bone & \\
\hline $\mathrm{E} 22 / \mathrm{S} 72$ & $35 \mathrm{~A}$ & 27IIIA & Isi/Icl & E. Paleo. & & Odocoileus sp. & Middle phalange & \\
\hline $\mathrm{E} 22 / \mathrm{S} 72$ & $35 \mathrm{~A}$ & $27 I I 1 \mathrm{~A}$ & Isi//lcl & E. Paleo. & & Vertebrata & Indeterminate & \\
\hline E22/S72 & $35 \mathrm{~A}$ & $27 \mathrm{IIIC}$ & Isi//Icl & E. Paleo. & & Mammalia (Medium/large) & Long bone & 1 \\
\hline $\mathrm{E} 22 / \mathrm{S} 72$ & $35 \mathrm{~A}$ & $27 I I 1 \mathrm{C}$ & Isi//Icl & E. Paleo. & & Vertebrata & Indeterminate & 13 \\
\hline $\mathrm{E} 22 / \mathrm{S} 72$ & $35 \mathrm{~B}$ & 27 III $2 \mathrm{~A}$ & Isi//cl & E. Paleo. & & Vertebrata & Indeterminate & 3 \\
\hline $\mathrm{E} 22 / \mathrm{S} 72$ & $36 \mathrm{~B}$ & 27JJ2D & Isi/Icl & E. Paleo. & & Medium/Large Vertebrata & Indeterminate & \\
\hline $\mathrm{E} 22 / \mathrm{S} 72$ & $36 \mathrm{~B}$ & 27JJ2D & Isi/Icl & E. Paleo. & & Vertebrata & Indeterminate & 10 \\
\hline $\mathrm{E} 22 / \mathrm{S} 72$ & $37 \mathrm{~A}$ & $27 \mathrm{KK} 1 \mathrm{~A}$ & Isi & E. Paleo. & & Vertebrata & Indeterminate & 14 \\
\hline $\mathrm{E} 22 / \mathrm{S} 72$ & $37 \mathrm{~A}$ & $27 \mathrm{KK} 1 \mathrm{C}$ & Isi & E. Paleo. & & Mammalia (Small) & Tooth, perm./decid. ind. & 1 \\
\hline $\mathrm{E} 22 / \mathrm{S} 72$ & $37 \mathrm{~A}$ & 27KK1D & Isi & E. Paleo. & & Mammalia (Medium/large) & Indeterminate & 1 \\
\hline E22/S72 & $37 \mathrm{~A}$ & 27KK1D & Isi & E. Paleo. & & Vertebrata & Indeterminate & 7 \\
\hline E22/S72 & 37B & $27 \mathrm{KK} 2 \mathrm{~A}$ & $\mathrm{Igl} / \mathrm{Isi}$ & E. Paleo. & & Vertebrata & Indeterminate & 10 \\
\hline E22/S72 & 37B & 27KK2B & Igl/Isi & E. Paleo. & & Vertebrata & Indeterminate & 1 \\
\hline E22/S72 & $37 \mathrm{~B}$ & 27KK2D & $\mathrm{Igl} / \mathrm{Isi}$ & E. Paleo. & & Sternotherus sp. & Hyoplastron & 1 \\
\hline E22/S72 & $38 \mathrm{~A}$ & 27LL1A & $\mathrm{Igl} / \mathrm{Isi}$ & E. Paleo. & & Mammalia (Medium/large) & Indeterminate & \\
\hline E22/S72 & $38 \mathrm{~A}$ & 27LL1A & Igl/Isi & E. Paleo. & & Vertebrata & Indeterminate & 3 \\
\hline $\mathrm{E} 22 / \mathrm{S} 72$ & $38 \mathrm{~A}$ & 27LL1C & $\mathrm{Igl} / \mathrm{Isi}$ & E. Paleo. & & Vertebrata & Indeterminate & 12 \\
\hline E22/S72 & $38 \mathrm{~A}$ & 27LL1D & $\mathrm{Igl} / \mathrm{Isi}$ & E. Paleo. & & Medium/Large Vertebrata & Indeterminate & 1 \\
\hline E22/S72 & 38B & 27LL2A & Igl/Isi & E. Paleo. & & Vertebrata & Indeterminate & 16 \\
\hline $\mathrm{E} 22 / \mathrm{S} 72$ & 38B & 27LL2B & $\mathrm{Igl} / \mathrm{Isi}$ & E. Paleo. & & Medium/Large Vertebrata & Indeterminate & \\
\hline E22/S72 & $38 \mathrm{~B}$ & 27LL2C & $\mathrm{Igl} / \mathrm{Isi}$ & E. Paleo. & & Vertebrata & Indeterminate & \\
\hline E22/S74 & 15 & 260 & IIIa/b & E. Archaic & & Vertebrata & Indeterminate & \\
\hline E22/S74 & $16 \mathrm{~B}$ & $26 \mathrm{P} 2$ & IIIa & E. Archaic & & Mammalia (Medium/large) & Indeterminate & \\
\hline E22/S74 & $16 \mathrm{~B}$ & $26 \mathrm{P} 2$ & IIIIa & E. Archaic & & Mammalia (Medium/large) & Long bone & \\
\hline E22/S74 & $17 \mathrm{~A}$ & 26Q1 & IIIIa & E. Archaic & & Vertebrata & Indeterminate & 1 \\
\hline E22/S74 & 17B & 26Q2 & IIIa & E. Archaic & & Vertebrata & Indeterminate & 13 \\
\hline E22/S74 & $18 \mathrm{~A}$ & 26R1 & IIIIa & E. Archaic & & Mammalia (Medium/large) & Indeterminate & 1 \\
\hline E22/S74 & $18 \mathrm{~A}$ & 26R1 & IIIIa & E. Archaic & & Small/Medium Vertebrata & Long bone & \\
\hline E22/S74 & $18 \mathrm{~A}$ & 26R1 & IIIa & E. Archaic & & Vertebrata & Indeterminate & 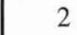 \\
\hline E22/S74 & $18 \mathrm{~B}$ & $26 \mathrm{R} 2$ & IIIIa & E. Archaic & & Vertebrata & Indeterminate & \\
\hline E22/S74 & 19A & $26 \mathrm{~S} 1$ & II/IIIa & L. Paleo./E. Archaic & & Vertebrata & Indeterminate & \\
\hline E22/S74 & 19B & $26 \mathrm{~S} 2 \mathrm{~A}$ & I/ШIIa & L. Paleo./E. Archaic & & Vertebrata & Indeterminate & ( \\
\hline E22/S74 & 19B & 26S2D & II/IIIa & L. Paleo./E. Archaic & & Medium/Large Vertebrata & Long bone & \\
\hline E22/S74 & 19B & 26S2D & II/WII & L. Paleo./E. Archaic & & Vertebrata & Indeterminate & \\
\hline E22/S74 & $20 \mathrm{~A}$ & 26T1A & II/Wa & L. Paleo./E. Archaic & & Vertebrata & Indeterminate & \\
\hline E22/S74 & $20 \mathrm{~A}$ & 26T1B & II/IIIa & L. Paleo./E. Archaic & & Vertebrata & Indeterminate & \\
\hline E22/S74 & $20 \mathrm{~A}$ & $26 \mathrm{~T} 1 \mathrm{C}$ & II/IIIa & L. Paleo./E. Archaic & & Small/Medium Vertebrata & Long bone & \\
\hline E22/S74 & $20 \mathrm{~A}$ & 26T1C & II/Wa & L. Paleo./E. Archaic & & Vertebrata & Indeterminate & \\
\hline E22/S74 & $20 \mathrm{~A}$ & 26T1D & IIIIIIa & L. Paleo./E. Archaic & & Vertebrata & Indeterminate & \\
\hline E22/S74 & $20 \mathrm{~B}$ & $26 \mathrm{~T} 2 \mathrm{~A}$ & III & L. Paleo. & & Vertebrata & Indeterminate & \\
\hline E22/S74 & $20 \mathrm{~B}$ & $26 \mathrm{~T} 2 \mathrm{~B}$ & III & L. Paleo. & & Vertebrata & Indeterminate & \\
\hline E22/S74 & $20 \mathrm{~B}$ & $26 \mathrm{~T} 2 \mathrm{C}$ & III & L. Paleo. & & Medium/Large Vertebrata & Indeterminate & \\
\hline E22/S74 & $20 \mathrm{~B}$ & $26 \mathrm{~T} 2 \mathrm{C}$ & II & L. Paleo. & & Vertebrata & Indeterminate & \\
\hline E22/S74 & $20 \mathrm{~B}$ & 26T2D & III & L. Paleo. & & Mammalia (Medium/large) & Long bone & \\
\hline E22/S74 & $20 \mathrm{~B}$ & 26T2D & III & L. Paleo. & & Medium/Large Vertebrata & Indeterminate & \\
\hline E22/S74 & $20 \mathrm{~B}$ & 26T2D & III & L. Paleo. & & Vertebrata & Indeterminate & \\
\hline E22/S74 & $21 \mathrm{~A}$ & 26U1A & II & L. Paleo. & & Mammalia (Medium/large) & Indeterminate & \\
\hline
\end{tabular}




\begin{tabular}{|c|c|c|c|c|c|c|c|c|}
\hline Square & Level & Lot & Unit & Cultural Affinity & Feature & Taxon & Element & No. \\
\hline E22/S74 & $21 \mathrm{~A}$ & 26U1B & III & L. Paleo. & & Vertebrata & Indeterminate & 1 \\
\hline E22/S74 & $21 \mathrm{~A}$ & $26 \mathrm{U} 1 \mathrm{C}$ & II & L. Paleo. & & Vertebrata & Indeterminate & 1 \\
\hline E22/S74 & 21B & $26 U 2 B$ & II & L. Paleo. & & Mammalia (Large) & Long bone & 1 \\
\hline E22/S74 & 21B & 26U2B & II & L. Paleo. & & Vertebrata & Indeterminate & 3 \\
\hline E22/S74 & 21B & $26 \mathrm{U} 2 \mathrm{C}$ & II & L. Paleo. & & Medium/Large Vertebrata & Indeterminate & 1 \\
\hline E22/S74 & 21B & $26 \mathrm{U} 2 \mathrm{C}$ & II & L. Paleo. & & Vertebrata & Indeterminate & 2 \\
\hline E22/S74 & 21B & 26U2D & II & L. Paleo. & & Vertebrata & Indeterminate & 1 \\
\hline E22/S74 & $22 \mathrm{~A}$ & $26 \mathrm{~V} 1 \mathrm{~A}$ & II & L. Paleo. & & Medium/Large Vertebrata & Indeterminate & 3 \\
\hline E22/S74 & $22 \mathrm{~A}$ & $26 \mathrm{~V} 1 \mathrm{C}$ & II & L. Paleo. & & Vertebrata & Indeterminate & 1 \\
\hline E22/S74 & $22 \mathrm{~A}$ & 26V1D & II & L. Paleo. & & Mammalia (Medium/large) & Indeterminate & 1 \\
\hline E22/S74 & $22 \mathrm{~A}$ & 26V1D & II & L. Paleo. & & Small/Medium Vertebrata & Long bone & 1 \\
\hline $\mathrm{E} 22 / \mathrm{S} 74$ & $22 \mathrm{~B}$ & $26 \mathrm{~V} 2 \mathrm{C}$ & II & L. Paleo. & & Mammalia (Medium/large) & Long bone & 1 \\
\hline $\mathrm{E} 22 / \mathrm{S} 74$ & $22 \mathrm{~B}$ & $26 \mathrm{~V} 2 \mathrm{C}$ & II & L. Paleo. & & Vertebrata & Indeterminate & 2 \\
\hline E22/S74 & $22 \mathrm{~B}$ & $26 \mathrm{~V} 2 \mathrm{D}$ & II & L. Paleo. & & Vertebrata & Indeterminate & 2 \\
\hline $\mathrm{E} 22 / \mathrm{S} 74$ & $23 \mathrm{~A}$ & 26W1A & II & L. Paleo. & & Vertebrata & Indeterminate & 4 \\
\hline $\mathrm{E} 22 / \mathrm{S} 74$ & $23 \mathrm{~A}$ & 26W1C & II & L. Paleo. & & Medium/Large Vertebrata & Indeterminate & 1 \\
\hline E22/S74 & $23 \mathrm{~A}$ & 26W1D & II & L. Paleo. & & Vertebrata & Indeterminate & 1 \\
\hline E22/S74 & $23 \mathrm{~B}$ & $26 \mathrm{~W} 2 \mathrm{~A}$ & II & L. Paleo. & & Small/Medium Vertebrata & Long bone & 2 \\
\hline E22/S74 & $23 \mathrm{~B}$ & $26 \mathrm{~W} 2 \mathrm{~A}$ & II & L. Paleo. & & Vertebrata & Indeterminate & 2 \\
\hline $\mathrm{E} 22 / \mathrm{S} 74$ & $23 \mathrm{~B}$ & 26W2B & II & L. Paleo. & & Mammalia (Medium/large) & Indeterminate & 1 \\
\hline $\mathrm{E} 22 / \mathrm{S} 74$ & $23 \mathrm{~B}$ & $26 \mathrm{~W} 2 \mathrm{~B}$ & II & L. Paleo. & & Mammalia (Small/medium) & Alveolar ridge fragment & 1 \\
\hline $\mathrm{E} 22 / \mathrm{S} 74$ & $23 \mathrm{~B}$ & $26 \mathrm{~W} 2 \mathrm{C}$ & II & L. Paleo. & & Vertebrata & Indeterminate & 2 \\
\hline E22/S74 & $24 \mathrm{~A}$ & $26 \mathrm{X} 1 \mathrm{~A}$ & II & L. Paleo. & & Vertebrata & Indeterminate & 1 \\
\hline $\mathrm{E} 22 / \mathrm{S} 74$ & $24 \mathrm{~A}$ & $26 \times 1 B$ & II & L. Paleo. & & Vertebrata & Indeterminate & 2 \\
\hline $\mathrm{E} 22 / \mathrm{S} 74$ & $24 \mathrm{~A}$ & 26X1D & II & L. Paleo. & & Mammalia (Large) & Long bone & 1 \\
\hline E22/S74 & $24 B$ & 26X2B & II & L. Paleo. & & Mammalia (Large) & Long bone & 1 \\
\hline E22/S74 & $24 \mathrm{~B}$ & $26 \mathrm{X} 2 \mathrm{C}$ & II & L. Paleo. & & Small/Medium Vertebrata & Indeterminate & 1 \\
\hline $\mathrm{E} 22 / \mathrm{S} 74$ & $24 \mathrm{~B}$ & 26X2D & II & L. Paleo. & & Medium/Large Vertebrata & Indeterminate & 1 \\
\hline E22/S74 & $25 \mathrm{~A}$ & 26Y1A & II & L. Paleo. & & Vertebrata & Indeterminate & 1 \\
\hline E22/S74 & $25 \mathrm{~A}$ & $26 \mathrm{Y} 1 \mathrm{C}$ & II & L. Paleo. & & Mammalia (Medium) & Middle phalange & 1 \\
\hline $\mathrm{E} 22 / \mathrm{S} 74$ & $25 \mathrm{~A}$ & $26 \mathrm{Y} 1 \mathrm{C}$ & II & L. Paleo. & & Medium/Large Vertebrata & Indeterminate & 1 \\
\hline E22/S74 & $25 \mathrm{~A}$ & 26Y1D & II & L. Paleo. & & Medium/Large Vertebrata & Indeterminate & 1 \\
\hline $\mathrm{E} 22 / \mathrm{S} 74$ & $25 \mathrm{~A}$ & 26Y1D & II & L. Paleo. & & Vertebrata & Indeterminate & 2 \\
\hline $\mathrm{E} 22 / \mathrm{S} 74$ & $25 \mathrm{~B}$ & $26 \mathrm{Y} 2 \mathrm{~A}$ & $\mathrm{Id} / \mathrm{II}$ & L. Paleo. & & Mammalia (Medium/large) & Indeterminate & 1 \\
\hline $\mathrm{E} 22 / \mathrm{S} 74$ & $25 B$ & $26 \mathrm{Y} 2 \mathrm{~A}$ & $\mathrm{Id} / \mathrm{II}$ & L. Paleo. & & Vertebrata & Indeterminate & 3 \\
\hline E22/S74 & $25 \mathrm{~B}$ & $26 \mathrm{Y} 2 \mathrm{C}$ & $\mathrm{Id} / \mathrm{II}$ & L. Paleo. & & Vertebrata & Indeterminate & 2 \\
\hline $\mathrm{E} 22 / \mathrm{S} 74$ & $25 \mathrm{~B}$ & 26Y2D & $\mathrm{Id} / \mathrm{II}$ & L. Paleo. & & Mammalia (Medium/large) & Indeterminate & 1 \\
\hline $\mathrm{E} 22 / \mathrm{S} 74$ & $26 \mathrm{~A}$ & $26 \mathrm{Z} 1 \mathrm{~A}$ & Id/II & L. Paleo. & & Mammalia (Large) & Long bone & 1 \\
\hline $\mathrm{E} 22 / \mathrm{S} 74$ & $26 \mathrm{~A}$ & 26Z1B & Id/II & L. Paleo. & & Vertebrata & Indeterminate & 4 \\
\hline $\mathrm{E} 22 / \mathrm{S} 74$ & $26 \mathrm{~A}$ & $26 \mathrm{Z1C}$ & Id/II & L. Paleo. & & Vertebrata & Indeterminate & 5 \\
\hline $\mathrm{E} 22 / \mathrm{S} 74$ & $26 \mathrm{~A}$ & 26Z1D & Id/II & L. Paleo. & & Mammalia (Medium/large) & Indeterminate & 1 \\
\hline $\mathrm{E} 22 / \mathrm{S} 74$ & $26 \mathrm{~A}$ & 26Z1D & Id/II & L. Paleo. & & Mammalia (Medium/large) & Long bone & 1 \\
\hline $\mathrm{E} 22 / \mathrm{S} 74$ & $26 \mathrm{~A}$ & 26Z1D & $\mathrm{Id} / \mathrm{II}$ & L. Paleo. & & Vertebrata & Indeterminate & 9 \\
\hline $\mathrm{E} 22 / \mathrm{S} 74$ & $26 \mathrm{~B}$ & $26 \mathrm{Z} 2 \mathrm{C}$ & Isi-c/Id/II & L. Paleo. & & Mammalia (Medium/large) & Vertebra & 1 \\
\hline $\mathrm{E} 22 / \mathrm{S} 74$ & $26 \mathrm{~B}$ & $26 \mathrm{Z} 2 \mathrm{C}$ & Isi-c/Id/II & L. Paleo. & & Small/Medium Vertebrata & Indeterminate & 1 \\
\hline $\mathrm{E} 22 / \mathrm{S} 74$ & $26 \mathrm{~B}$ & $26 \mathrm{Z} 2 \mathrm{C}$ & Isi-c/Id/II & L. Paleo. & & Vertebrata & Indeterminate & 5 \\
\hline $\mathrm{E} 22 / \mathrm{S} 74$ & $26 \mathrm{~B}$ & 26Z2D & Isi-c/Id/II & L. Paleo. & & Vertebrata & Indeterminate & 3 \\
\hline E22/S74 & $27 \mathrm{~A}$ & 26AA1C & Isi-c/II & L. Paleo. & & Mammalia (Medium/large) & Indeterminate & 1 \\
\hline E22/S74 & $27 \mathrm{~A}$ & 26AA1C & Isi-c/II & L. Paleo. & & Vertebrata & Indeterminate & 13 \\
\hline $\mathrm{E} 22 / \mathrm{S} 74$ & $27 \mathrm{~A}$ & 26AA1D & Isi-c/II & L. Paleo. & & Mammalia (Medium) & Phalange & 1 \\
\hline E22/S74 & $27 \mathrm{~A}$ & 26AA1D & Isi-c/II & L. Paleo. & & Mammalia (Medium/large) & Indeterminate & 1 \\
\hline E22/S74 & $27 \mathrm{~A}$ & 26AA1D & Isi-c/II & L. Paleo. & & Vertebrata & Indeterminate & 21 \\
\hline $\mathrm{E} 22 / \mathrm{S} 74$ & $27 \mathrm{~B}$ & 26AA2 & Isi-c/II & L. Paleo. & & Mammalia (Medium/large) & Indeterminate & 1 \\
\hline $\mathrm{E} 22 / \mathrm{S} 74$ & $27 \mathrm{~B}$ & 26AA2 & Isi-c/II & L. Paleo. & & Mammalia (Medium/large) & Long bone & 1 \\
\hline E22/S74 & $27 \mathrm{~B}$ & 26AA2 & Isi-c/II & L. Paleo. & & Vertebrata & Indeterminate & 15 \\
\hline $\mathrm{E} 22 / \mathrm{S} 74$ & $27 \mathrm{~B}$ & 26AA2A & Isi-c/II & L. Paleo. & & Mammalia (Medium/large) & Long bone & 1 \\
\hline $\mathrm{E} 22 / \mathrm{S} 74$ & $27 \mathrm{~B}$ & 26AA2A & Isi-c/II & L. Paleo. & & Vertebrata & Indeterminate & 10 \\
\hline E22/S74 & 27B & 26AA2B & Isi-c/II & L. Paleo. & & Mammalia (Medium/large) & Indeterminate & 1 \\
\hline $\mathrm{E} 22 / \mathrm{S} 74$ & $27 \mathrm{~B}$ & 26AA2B & Isi-c/II & L. Paleo. & & Vertebrata & Indeterminate & 2 \\
\hline E22/S74 & 27B & 26AA2C & Isi-c/II & L. Paleo. & & Mammalia (Medium/large) & Indeterminate & 1 \\
\hline $\mathrm{E} 22 / \mathrm{S} 74$ & 27B & 26AA2C & Isi-c/II & L. Paleo. & & Mammalia (Medium/large) & Long bone & 1 \\
\hline E22/S74 & $27 \mathrm{~B}$ & 26AA2C & Isi-c/II & L. Paleo. & & Vertebrata & Indeterminate & 4 \\
\hline E22/S74 & $28 \mathrm{~A}$ & 26BB1A & Isi-c & L. Paleo. & & Vertebrata & Indeterminate & 6 \\
\hline $\mathrm{E} 22 / \mathrm{S} 74$ & $28 \mathrm{~A}$ & 26BB1B & Isi-c & L. Paleo. & & Vertebrata & Indeterminate & 6 \\
\hline E22/S74 & $28 \mathrm{~A}$ & 26BB1B & Isi-c & L. Paleo. & & Vertebrata & Metapodial & 1 \\
\hline $\mathrm{E} 22 / \mathrm{S} 74$ & $28 \mathrm{~A}$ & 26BB1C & Isi-c & L. Paleo. & & Mammalia (Medium/large) & Long bone & 2 \\
\hline E22/S74 & $28 \mathrm{~A}$ & $26 \mathrm{BB} 1 \mathrm{C}$ & Isi-c & L. Paleo. & & Vertebrata & Indeterminate & 6 \\
\hline
\end{tabular}




\begin{tabular}{|c|c|c|c|c|c|c|c|c|}
\hline Square & Level & Lot & Unit & Cultural Affinity & Feature & Taxon & Element & No. \\
\hline E22/S74 & $28 \mathrm{~A}$ & 26BB1D & Isi-c & L. Paleo. & & Mammalia (Medium) & Distal phalange & 1 \\
\hline $\mathrm{E} 22 / \mathrm{S} 74$ & $28 \mathrm{~B}$ & $26 \mathrm{BB} 2 \mathrm{~A}$ & Isi-c & L. Paleo. & & Vertebrata & Indeterminate & 19 \\
\hline $\mathrm{E} 22 / \mathrm{S} 74$ & $28 \mathrm{~B}$ & 26BB2B & Isi-c & L. Paleo. & & Vertebrata & Indeterminate & 4 \\
\hline $\mathrm{E} 22 / \mathrm{S} 74$ & $28 \mathrm{~B}$ & 26BB2D & Isi-c & L. Paleo. & & Vertebrata & Indeterminate & 4 \\
\hline $\mathrm{E} 22 / \mathrm{S} 74$ & $29 \mathrm{~A}$ & $26 \mathrm{CC} 1 \mathrm{~A}$ & Isi-c & L. Paleo. & & Mammalia (Medium/large) & Long bone & 1 \\
\hline $\mathrm{E} 22 / \mathrm{S} 74$ & $29 \mathrm{~A}$ & $26 \mathrm{CC} 1 \mathrm{~A}$ & Isi-c & L. Paleo. & & Vertebrata & Indeterminate & 31 \\
\hline $\mathrm{E} 22 / \mathrm{S} 74$ & $29 \mathrm{~A}$ & $26 \mathrm{CC} 1 \mathrm{~A}$ & Isi-c & L. Paleo. & & Vertebrata & Vertebra & 2 \\
\hline $\mathrm{E} 22 / \mathrm{S} 74$ & $29 \mathrm{~A}$ & $26 \mathrm{CC} 1 \mathrm{~B}$ & Isi-c & L. Paleo. & & Mammalia (Medium) & Middle phalange & 1 \\
\hline $\mathrm{E} 22 / \mathrm{S} 74$ & $29 \mathrm{~A}$ & $26 \mathrm{CC} 1 \mathrm{~B}$ & Isi-c & L. Paleo. & & Vertebrata & Indeterminate & 11 \\
\hline $\mathrm{E} 22 / \mathrm{S} 74$ & $29 \mathrm{~A}$ & $26 \mathrm{CC} 1 \mathrm{C}$ & Isi-c & L. Paleo. & & Vertebrata & Indeterminate & 7 \\
\hline $\mathrm{E} 22 / \mathrm{S} 74$ & $29 B$ & $26 \mathrm{CC} 2 \mathrm{~A}$ & Isi-c & L. Paleo. & & Vertebrata & Indeterminate & 4 \\
\hline $\mathrm{E} 22 / \mathrm{S} 74$ & $29 B$ & $26 \mathrm{CC} 2 \mathrm{~B}$ & Isi-c & L. Paleo. & & Vertebrata & Indeterminate & 2 \\
\hline $\mathrm{E} 22 / \mathrm{S} 74$ & $29 \mathrm{~B}$ & $26 \mathrm{CC} 2 \mathrm{C}$ & Isi-c & L. Paleo. & & Mammalia (Medium/large) & Indeterminate & 1 \\
\hline $\mathrm{E} 22 / \mathrm{S} 74$ & $29 \mathrm{~B}$ & $26 \mathrm{CC} 2 \mathrm{C}$ & Isi-c & L. Paleo. & & Mammalia (Medium/large) & Long bone & 1 \\
\hline $\mathrm{E} 22 / \mathrm{S} 74$ & $29 \mathrm{~B}$ & $26 \mathrm{CC} 2 \mathrm{C}$ & Isi-c & L. Paleo. & & Vertebrata & Indeterminate & 10 \\
\hline $\mathrm{E} 22 / \mathrm{S} 74$ & $29 B$ & $26 \mathrm{CC} 2 \mathrm{D}$ & Isi-c & L. Paleo. & & Vertebrata & Indeterminate & 2 \\
\hline $\mathrm{E} 22 / \mathrm{S} 74$ & $30 \mathrm{~A}$ & 26DD1A & Isi-c & L. Paleo. & & Vertebrata & Indeterminate & 5 \\
\hline $\mathrm{E} 22 / \mathrm{S} 74$ & $30 \mathrm{~A}$ & 26DD1B & Isi-c & L. Paleo. & & Vertebrata & Indeterminate & 1 \\
\hline $\mathrm{E} 22 / \mathrm{S} 74$ & $30 \mathrm{~A}$ & 26DD1C & Isi-c & L. Paleo. & & Leporidae & Permanent tooth & 1 \\
\hline $\mathrm{E} 22 / \mathrm{S} 74$ & $30 \mathrm{~A}$ & 26DD1C & Isi-c & L. Paleo. & & Mammalia (Medium/large) & Caudal vertebra & 1 \\
\hline $\mathrm{E} 22 / \mathrm{S} 74$ & $30 \mathrm{~A}$ & 26DD1C & Isi-c & L. Paleo. & & Vertebrata & Indeterminate & 22 \\
\hline $\mathrm{E} 22 / \mathrm{S} 74$ & $30 \mathrm{~A}$ & 26DD1C & Isi-c & L. Paleo. & & Vertebrata & Phalange & 1 \\
\hline $\mathrm{E} 22 / \mathrm{S} 74$ & $30 \mathrm{~A}$ & 26DD1D & Isi-c & L. Paleo. & & Medium/Large Vertebrata & Indeterminate & 1 \\
\hline $\mathrm{E} 22 / \mathrm{S} 74$ & $30 \mathrm{~A}$ & 26DD1D & Isi-c & L. Paleo. & & Vertebrata & Indeterminate & 3 \\
\hline $\mathrm{E} 22 / \mathrm{S} 74$ & $30 \mathrm{~B}$ & 26DD2A & Isi-c & L. Paleo. & & Vertebrata & Indeterminate & 12 \\
\hline $\mathrm{E} 22 / \mathrm{S} 74$ & $30 \mathrm{~B}$ & 26DD2B & Isi-c & L. Paleo. & & Small/Medium Vertebrata & Long bone & 1 \\
\hline $\mathrm{E} 22 / \mathrm{S} 74$ & $30 \mathrm{~B}$ & 26DD2C & Isi-c & L. Paleo. & & Vertebrata & Indeterminate & 2 \\
\hline $\mathrm{E} 22 / \mathrm{S} 74$ & $30 \mathrm{~B}$ & 26DD2D & Isi-c & L. Paleo. & & Odocoileus sp. & Proximal phalange & 1 \\
\hline $\mathrm{E} 22 / \mathrm{S} 74$ & $30 \mathrm{~B}$ & 26DD2D & Isi-c & L. Paleo. & & Vertebrata & Indeterminate & 21 \\
\hline $\mathrm{E} 22 / \mathrm{S} 74$ & $31 \mathrm{~A}$ & 26EE1B & Icl/Isi-c & Paleoindian & & Mammalia (Medium/large) & Indeterminate & 1 \\
\hline $\mathrm{E} 22 / \mathrm{S} 74$ & $31 \mathrm{~B}$ & 26EE2A & Icl/Isi-c & Paleoindian & & Mammalia (Medium/large) & Long bone & 1 \\
\hline $\mathrm{E} 22 / \mathrm{S} 74$ & $31 \mathrm{~B}$ & 26EE2A & Icl/Isi-c & Paleoindian & & Medium/Large Vertebrata & Indeterminate & 5 \\
\hline $\mathrm{E} 22 / \mathrm{S} 74$ & $31 \mathrm{~B}$ & 26EE2B & Icl/Isi-c & Paleoindian & & Medium/Large Vertebrata & Indeterminate & 1 \\
\hline $\mathrm{E} 22 / \mathrm{S} 74$ & $31 \mathrm{~B}$ & 26EE2C & Icl/Isi-c & Paleoindian & & Medium/Large Vertebrata & Indeterminate & 1 \\
\hline $\mathrm{E} 22 / \mathrm{S} 74$ & $31 \mathrm{~B}$ & 26EE2C & Icl/Isi-c & Paleoindian & & Vertebrata & Indeterminate & 10 \\
\hline $\mathrm{E} 22 / \mathrm{S} 74$ & $32 \mathrm{~A}$ & 26FF1A & Icl/Isi-c & Paleoindian & & Vertebrata & Indeterminate & 1 \\
\hline $\mathrm{E} 22 / \mathrm{S} 74$ & $32 \mathrm{~A}$ & 26FF1B & Icl/Isi-c & Paleoindian & & Medium/Large Vertebrata & Indeterminate & 2 \\
\hline $\mathrm{E} 22 / \mathrm{S} 74$ & $32 \mathrm{~A}$ & 26FF1B & Icl/Isi-c & Paleoindian & & Testudinata & Shell fragment & 1 \\
\hline $\mathrm{E} 22 / \mathrm{S} 74$ & $32 \mathrm{~A}$ & 26FF1B & Icl/Isi-c & Paleoindian & & Vertebrata & Indeterminate & 1 \\
\hline $\mathrm{E} 22 / \mathrm{S} 74$ & $32 \mathrm{~A}$ & $26 \mathrm{FF} 1 \mathrm{C}$ & Icl/Isi-c & Paleoindian & & Mammalia (Medium/large) & Long bone & 1 \\
\hline $\mathrm{E} 22 / \mathrm{S} 74$ & $32 \mathrm{~A}$ & $26 \mathrm{FF} 1 \mathrm{C}$ & Icl/Isi-c & Paleoindian & & Medium/Large Vertebrata & Indeterminate & 1 \\
\hline $\mathrm{E} 22 / \mathrm{S} 74$ & $32 \mathrm{~A}$ & $26 \mathrm{FF} 1 \mathrm{C}$ & Icl/Isi-c & Paleoindian & & Vertebrata & Indeterminate & 1 \\
\hline $\mathrm{E} 22 / \mathrm{S} 74$ & $32 \mathrm{~B}$ & $26 \mathrm{FF} 2 \mathrm{C}$ & Icl/Isi-c & Paleoindian & & Vertebrata & Indeterminate & 2 \\
\hline $\mathrm{E} 22 / \mathrm{S} 74$ & $33 \mathrm{~A}$ & 26GG1A & Isi/Icl & E. Paleo. & & Mammalia (Medium/large) & Long bone & 1 \\
\hline E22/S74 & $33 \mathrm{~A}$ & 26GG1A & Isi/Icl & E. Paleo. & & Vertebrata & Indeterminate & 6 \\
\hline $\mathrm{E} 22 / \mathrm{S} 74$ & $33 \mathrm{~A}$ & 26GG1B & Isi/Icl & E. Paleo. & & Mammalia (Medium/large) & Indeterminate & 1 \\
\hline $\mathrm{E} 22 / \mathrm{S} 74$ & $33 \mathrm{~A}$ & 26GG1B & Isi/Icl & E. Paleo. & & Vertebrata & Indeterminate & 2 \\
\hline $\mathrm{E} 22 / \mathrm{S} 74$ & $33 \mathrm{~A}$ & 26GG1C & Isi/Icl & E. Paleo. & & Medium/Large Vertebrata & Long bone & 1 \\
\hline $\mathrm{E} 22 / \mathrm{S} 74$ & $33 \mathrm{~A}$ & 26GG1D & Isi/Icl & E. Paleo. & & Small/Medium Vertebrata & Long bone & 1 \\
\hline E22/S74 & $33 \mathrm{~B}$ & 26GG2C & Isi/Icl & E. Paleo. & & Medium/Large Vertebrata & Indeterminate & 2 \\
\hline E22/S74 & $33 \mathrm{~B}$ & 26GG2C & Isi/Icl & E. Paleo. & & Vertebrata & Indeterminate & 9 \\
\hline $\mathrm{E} 22 / \mathrm{S} 74$ & $34 \mathrm{~A}$ & $26 \mathrm{HH} 1 \mathrm{~B}$ & Isi/Icl & E. Paleo. & & Vertebrata & Indeterminate & 1 \\
\hline E22/S74 & $34 \mathrm{~A}$ & 26HH1D & Isi/Icl & E. Paleo. & & Vertebrata & Indeterminate & 1 \\
\hline $\mathrm{E} 22 / \mathrm{S} 74$ & $34 \mathrm{~B}$ & $26 \mathrm{HH} 2 \mathrm{~A}$ & Isi/Icl & E. Paleo. & & Vertebrata & Indeterminate & 2 \\
\hline $\mathrm{E} 22 / \mathrm{S} 74$ & $34 \mathrm{~B}$ & $26 \mathrm{HH} 2 \mathrm{C}$ & Isi/Icl & E. Paleo. & & Medium/Large Vertebrata & Indeterminate & 1 \\
\hline $\mathrm{E} 22 / \mathrm{S} 74$ & $34 \mathrm{~B}$ & $26 \mathrm{HH} 2 \mathrm{D}$ & Isi/Icl & E. Paleo. & & Vertebrata & Indeterminate & 1 \\
\hline $\mathrm{E} 22 / \mathrm{S} 74$ & $35 \mathrm{~A}$ & 26II1B & Isi/Icl & E. Paleo. & & Vertebrata & Indeterminate & 2 \\
\hline $\mathrm{E} 22 / \mathrm{S} 74$ & $35 \mathrm{~A}$ & 26IIID & Isi/Icl & E. Paleo. & & Vertebrata & Indeterminate & 3 \\
\hline $\mathrm{E} 22 / \mathrm{S} 74$ & $35 \mathrm{~B}$ & $26 \Pi 2 \mathrm{~A}$ & Isi/Icl & E. Paleo. & & Vertebrata & Indeterminate & 6 \\
\hline E22/S74 & $36 \mathrm{~A}$ & $26 \mathrm{JJ} 1 \mathrm{~A}$ & Isi/Icl & E. Paleo. & & Vertebrata & Indeterminate & 1 \\
\hline $\mathrm{E} 22 / \mathrm{S} 74$ & $36 \mathrm{~A}$ & $26 \mathrm{JJ} 1 \mathrm{~B}$ & Isi/Icl & E. Paleo. & & Vertebrata & Indeterminate & 1 \\
\hline E22/S74 & $36 \mathrm{~A}$ & $26 \mathrm{JJ} 1 \mathrm{C}$ & Isi/Icl & E. Paleo. & & Vertebrata & Indeterminate & 4 \\
\hline E22/S74 & $36 \mathrm{~B}$ & $26 \mathrm{JJ} 2 \mathrm{~B}$ & Igl/Isi & E. Paleo. & & Vertebrata & Indeterminate & 1 \\
\hline E22/S74 & $36 \mathrm{~B}$ & 26JJ2D & $\mathrm{Igl} / \mathrm{Isi}$ & E. Paleo. & & Vertebrata & Indeterminate & 25 \\
\hline E22/S74 & $37 \mathrm{~A}$ & $26 \mathrm{KK} 1 \mathrm{~A}$ & $\mathrm{Igl} / \mathrm{Isi}$ & E. Paleo. & & Vertebrata & Indeterminate & 1 \\
\hline E22/S74 & $37 \mathrm{~A}$ & $26 \mathrm{KK} 1 \mathrm{~B}$ & $\mathrm{Igl} / \mathrm{Isi}$ & E. Paleo. & & Vertebrata & Indeterminate & 3 \\
\hline E22/S74 & $37 \mathrm{~A}$ & 26KK1D & $\mathrm{Igl} / \mathrm{Isi}$ & E. Paleo. & & Vertebrata & Indeterminate & 13 \\
\hline
\end{tabular}




\begin{tabular}{|c|c|c|c|c|c|c|c|c|}
\hline Square & Level & Lot & Unit & Cultural Affinity & Feature & Taxon & Element & No. \\
\hline E22/S74 & 37B & $26 \mathrm{KK} 2 \mathrm{~A}$ & $\operatorname{Igl} / / \mathrm{Isi}$ & E. Paleo. & & Vertebrata & Indeterminate & 5 \\
\hline E22/S74 & 37B & $26 \mathrm{KK} 2 \mathrm{~B}$ & $\mathrm{Igl} / / \mathrm{si}$ & E. Paleo. & & Vertebrata & Indeterminate & 20 \\
\hline E22/S74 & 37B & $26 \mathrm{KK} 2 \mathrm{C}$ & $\mathrm{Igl} / \mathrm{Isi}$ & E. Paleo. & & Vertebrata & Indeterminate & 1 \\
\hline E22/S74 & 37B & $26 \mathrm{KK} 2 \mathrm{D}$ & Igl/Isi & E. Paleo. & & Mammalia (Medium/large) & Indeterminate & 1 \\
\hline E22/S74 & 37B & $26 \mathrm{KK} 2 \mathrm{D}$ & $\mathrm{Igl} / / \mathrm{si}$ & E. Paleo. & & Vertebrata & Indeterminate & 10 \\
\hline E22/S74 & $38 \mathrm{~A}$ & 26LL1A & Igl/Isi & E. Paleo. & & Medium/Large Vertebrata & Indeterminate & 1 \\
\hline E22/S74 & $38 \mathrm{~A}$ & 26LL1B & $\mathrm{Igl} / \mathrm{Isi}$ & E. Paleo. & & Medium/Large Vertebrata & Indeterminate & 1 \\
\hline E22/S74 & $38 \mathrm{~A}$ & 26LL1B & $\mathrm{Igl} / / \mathrm{si}$ & E. Paleo. & & Vertebrata & Indeterminate & 15 \\
\hline E22/S74 & $38 \mathrm{~A}$ & 26LL1C & Igl/Isi & E. Paleo. & & Mammalia (Medium/large) & Indeterminate & 1 \\
\hline E22/S74 & $38 \mathrm{~A}$ & 26LL1C & Igl/Isi & E. Paleo. & & Vertebrata & Indeterminate & 4 \\
\hline E22/S74 & $38 \mathrm{~B}$ & 26LL2A & $\mathrm{Igl} / / \mathrm{si}$ & E. Paleo. & & Mammalia (Medium/large) & Indeterminate & 1 \\
\hline E22/S76 & $16 \mathrm{~A}$ & 25P1 & IIIa & E. Archaic & & Vertebrata & Indeterminate & 1 \\
\hline E22/S76 & $16 \mathrm{~B}$ & $25 \mathrm{P} 2$ & IIIa & E. Archaic & & Mammalia (Medium/large) & Indeterminate & 2 \\
\hline E22/S76 & $16 \mathrm{~B}$ & $25 \mathrm{P} 2$ & IIIa & E. Archaic & & Vertebrata & Indeterminate & 1 \\
\hline E22/S76 & $17 \mathrm{~A}$ & 25Q1 & IIIa & E. Archaic & & Vertebrata & Indeterminate & 1 \\
\hline E22/S76 & 17B & $25 \mathrm{Q} 2$ & IIIa & E. Archaic & & Testudinata & Shell fragment & 1 \\
\hline E22/S76 & 17B & 25Q2 & IIIa & E. Archaic & & Vertebrata & Indeterminate & 4 \\
\hline E22/S76 & 17B & 25Q2 & IIIa & E. Archaic & & Vertebrata & Long bone & 1 \\
\hline E22/S76 & $18 \mathrm{~A}$ & $25 \mathrm{R} 1$ & IIIa & E. Archaic & & Vertebrata & Indeterminate & 1 \\
\hline E22/S76 & $18 \mathrm{~B}$ & $25 \mathrm{R} 2$ & IIIa & E. Archaic & & Mammalia (Medium/large) & Indeterminate & 1 \\
\hline E22/S76 & 18B & $25 \mathrm{R} 2$ & IIIa & E. Archaic & & Vertebrata & Indeterminate & 11 \\
\hline E22/S76 & $18 \mathrm{~B}$ & $25 \mathrm{R} 2$ & IIIa & E. Archaic & & Vertebrata & Long bone & 1 \\
\hline E22/S76 & $19 \mathrm{~A}$ & $25 \mathrm{~S} 1$ & II/IIIa & L. Paleo./E. Archaic & & Mammalia (Large) & Indeterminate & 1 \\
\hline E22/S76 & $19 \mathrm{~A}$ & $25 \mathrm{~S} 1$ & II/IIIa & L. Paleo./E. Archaic & & Mammalia (Large) & Long bone & 1 \\
\hline E22/S76 & $19 \mathrm{~A}$ & $25 \mathrm{~S} 1$ & II/IIIa & L. Paleo./E. Archaic & & Mammalia (Medium) & Mandible & 1 \\
\hline E22/S76 & $19 \mathrm{~A}$ & $25 \mathrm{~S} 1$ & IIIIIa & L. Paleo./E. Archaic & & Mammalia (Medium/large) & Alveolar ridge fragment & 2 \\
\hline E22/S76 & $19 \mathrm{~A}$ & $25 \mathrm{~S} 1$ & II/IIIa & L. Paleo./E. Archaic & & Mammalia (Medium/large) & Tooth, perm./decid. ind. & 2 \\
\hline E22/S76 & $19 \mathrm{~A}$ & $25 \mathrm{~S} 1$ & II/IIIa & L. Paleo./E. Archaic & & Mammalia (Medium/large) & Vertebra & 1 \\
\hline $\mathrm{E} 22 / \mathrm{S} 76$ & $19 \mathrm{~A}$ & $25 \mathrm{~S} 1$ & II/IIIa & L. Paleo./E. Archaic & & Medium/Large Vertebrata & Indeterminate & 4 \\
\hline E22/S76 & $19 \mathrm{~A}$ & $25 \mathrm{~S} 1$ & П/ШІІа & L. Paleo./E. Archaic & & Rodentia (Medium) & Humerus & 1 \\
\hline E22/S76 & $19 \mathrm{~A}$ & $25 \mathrm{~S} 1$ & IIШІа & L. Paleo./E. Archaic & & Testudinata & Shell fragment & 1 \\
\hline $\mathrm{E} 22 / \mathrm{S} 76$ & $19 \mathrm{~A}$ & $25 S 1$ & II/IIIa & L. Paleo./E. Archaic & & Vertebrata & Indeterminate & 5 \\
\hline E22/S76 & 19B & 25S2B & II/IIIIa & L. Paleo./E. Archaic & & Medium/Large Vertebrata & Indeterminate & 1 \\
\hline E22/S76 & 19B & 25S2B & II/II & L. Paleo./E. Archaic & & Small/Medium Vertebrata & Long bone & 4 \\
\hline E22/S76 & 19B & $25 S 2 B$ & II/IIIa & L. Paleo./E. Archaic & & Vertebrata & Indeterminate & 2 \\
\hline E22/S76 & $20 \mathrm{~A}$ & 25T1B & II/IIIIa & L. Paleo./E. Archaic & & Mammalia (Medium/large) & Indeterminate & 6 \\
\hline $\mathrm{E} 22 / \mathrm{S} 76$ & $20 \mathrm{~A}$ & 25T1B & II/IIIIa & L. Paleo./E. Archaic & & Medium/Large Vertebrata & Indeterminate & 1 \\
\hline E22/S76 & $20 \mathrm{~A}$ & $25 \mathrm{~T} 1 \mathrm{C}$ & II/IIIa & L. Paleo./E. Archaic & & Medium/Large Vertebrata & Indeterminate & 1 \\
\hline E22/S76 & $20 \mathrm{~A}$ & 25T1D & II/IIIla & L. Paleo./E. Archaic & & Mammalia (Medium/large) & Indeterminate & 4 \\
\hline E22/S76 & $20 \mathrm{~A}$ & 25T1D & II/IIIa & L. Paleo./E. Archaic & & Vertebrata & Indeterminate & 3 \\
\hline $\mathrm{E} 22 / \mathrm{S} 76$ & $20 \mathrm{~B}$ & $25 \mathrm{~T} 2 \mathrm{~A}$ & II & L. Paleo. & & Medium/Large Vertebrata & Indeterminate & 1 \\
\hline $\mathrm{E} 22 / \mathrm{S} 76$ & 20B & $25 \mathrm{~T} 2 \mathrm{~A}$ & II & L. Paleo. & & Small/Medium Vertebrata & Long bone & 1 \\
\hline E22/S76 & $20 \mathrm{~B}$ & $25 \mathrm{~T} 2 \mathrm{~B}$ & II & L. Paleo. & & Vertebrata & Indeterminate & 5 \\
\hline $\mathrm{E} 22 / \mathrm{S} 76$ & $20 \mathrm{~B}$ & $25 \mathrm{~T} 2 \mathrm{C}$ & II & L. Paleo. & & Vertebrata & Indeterminate & 3 \\
\hline E22/S76 & $21 \mathrm{~A}$ & $25 \mathrm{U} 1 \mathrm{~A}$ & II & L. Paleo. & & Vertebrata & Indeterminate & 1 \\
\hline $\mathrm{E} 22 / \mathrm{S} 76$ & $21 \mathrm{~A}$ & 25U1B & II & L. Paleo. & & Medium/Large Vertebrata & Indeterminate & 3 \\
\hline E22/S76 & $21 \mathrm{~A}$ & 25U1B & II & L. Paleo. & & Small/Medium Vertebrata & Long bone & 2 \\
\hline $\mathrm{E} 22 / \mathrm{S} 76$ & $21 \mathrm{~A}$ & 25U1B & II & L. Paleo. & & Vertebrata & Indeterminate & 10 \\
\hline E22/S76 & $21 \mathrm{~A}$ & $25 \mathrm{U} 1 \mathrm{C}$ & II & L. Paleo. & & Mammalia (Medium/large) & Indeterminate & 3 \\
\hline $\mathrm{E} 22 / \mathrm{S} 76$ & $21 \mathrm{~A}$ & $25 \mathrm{U} 1 \mathrm{C}$ & II & L. Paleo. & & Small/Medium Vertebrata & Long bone & 1 \\
\hline $\mathrm{E} 22 / \mathrm{S} 76$ & $21 \mathrm{~A}$ & $25 \mathrm{U} 1 \mathrm{C}$ & II & L. Paleo. & & Vertebrata & Indeterminate & 5 \\
\hline E22/S76 & $21 \mathrm{~B}$ & $25 \mathrm{U} 2 \mathrm{~A}$ & II & L. Paleo. & & Vertebrata & Indeterminate & 1 \\
\hline $\mathrm{E} 22 / \mathrm{S} 76$ & $21 \mathrm{~B}$ & 25U2B & II & L. Paleo. & & Vertebrata & Indeterminate & 2 \\
\hline $\mathrm{E} 22 / \mathrm{S} 76$ & $21 \mathrm{~B}$ & $25 \mathrm{U} 2 \mathrm{C}$ & II & L. Paleo. & & Vertebrata & Indeterminate & 2 \\
\hline $\mathrm{E} 22 / \mathrm{S} 76$ & $21 \mathrm{~B}$ & 25U2D & II & L. Paleo. & & Mammalia (Medium/large) & Indeterminate & 1 \\
\hline $\mathrm{E} 22 / \mathrm{S} 76$ & $21 \mathrm{~B}$ & $25 U 2 D$ & II & L. Paleo. & & Vertebrata & Indeterminate & 1 \\
\hline $\mathrm{E} 22 / \mathrm{S} 76$ & $22 \mathrm{~A}$ & $25 \mathrm{~V} 1 \mathrm{C}$ & II & L. Paleo. & & Vertebrata & Indeterminate & 1 \\
\hline E22/S76 & $22 \mathrm{~A}$ & 25V1D & II & L. Paleo. & & Vertebrata & Indeterminate & 1 \\
\hline E22/S76 & $22 \mathrm{~B}$ & $25 \mathrm{~V} 2 \mathrm{~A}$ & II & L. Paleo. & & Mammalia (Medium) & Radius & 1 \\
\hline $\mathrm{E} 22 / \mathrm{S} 76$ & $22 \mathrm{~B}$ & $25 \mathrm{~V} 2 \mathrm{~A}$ & II & L. Paleo. & & Vertebrata & Indeterminate & 1 \\
\hline E22/S76 & $22 \mathrm{~B}$ & $25 \mathrm{~V} 2 \mathrm{~B}$ & II & L. Paleo. & & Vertebrata & Indeterminate & 2 \\
\hline E22/S76 & $22 \mathrm{~B}$ & $25 \mathrm{~V} 2 \mathrm{C}$ & II & L. Paleo. & & Vertebrata & Indeterminate & 3 \\
\hline $\mathrm{E} 22 / \mathrm{S} 76$ & $23 \mathrm{~A}$ & $25 \mathrm{~W} 1 \mathrm{~A}$ & II & L. Paleo. & & Medium/Large Vertebrata & Long bone & 1 \\
\hline $\mathrm{E} 22 / \mathrm{S} 76$ & $23 \mathrm{~A}$ & $25 \mathrm{~W} 1 \mathrm{~B}$ & II & L. Paleo. & & Mammalia (Medium/large) & Indeterminate & 1 \\
\hline E22/S76 & $23 \mathrm{~A}$ & 25W1B & II & L. Paleo. & & Sylvilagus sp. & Calcaneus & 1 \\
\hline E22/S76 & $23 \mathrm{~A}$ & 25W1B & II & L. Paleo. & & Vertebrata & Indeterminate & 3 \\
\hline $\mathrm{E} 22 / \mathrm{S} 76$ & $23 \mathrm{~A}$ & 25W1C & II & L. Paleo. & & Mammalia (Medium/large) & Long bone & 1 \\
\hline
\end{tabular}




\begin{tabular}{|c|c|c|c|c|c|c|c|c|}
\hline Square & Level & Lot & Unit & \begin{tabular}{|l} 
Cultural Affinity \\
\end{tabular} & Feature & Taxon & Element & No. \\
\hline E22/S76 & $23 \mathrm{~A}$ & $25 \mathrm{~W} 1 \mathrm{C}$ & II & L. Paleo. & & Medium/Large Vertebrata & Indeterminate & 1 \\
\hline E22/S76 & $23 \mathrm{~A}$ & 25W1D & II & L. Paleo. & & Antilocapra/Odocoileus & Phalange & 1 \\
\hline $\mathrm{E} 22 / \mathrm{S} 76$ & $23 \mathrm{~A}$ & 25W1D & II & L. Paleo. & & Mammalia (Medium/large) & Long bone & 1 \\
\hline E22/S76 & $23 \mathrm{~A}$ & 25W1D & II & L. Paleo. & & Vertebrata & Indeterminate & 3 \\
\hline E22/S76 & $23 \mathrm{~B}$ & $25 \mathrm{~W} 2 \mathrm{~A}$ & II & L. Paleo. & & Vertebrata & Indeterminate & 1 \\
\hline E22/S76 & $23 \mathrm{~B}$ & $25 \mathrm{~W} 2 \mathrm{D}$ & III & L. Paleo. & & Medium/Large Vertebrata & Indeterminate & 2 \\
\hline E22/S76 & $23 \mathrm{~B}$ & $25 \mathrm{~W} 2 \mathrm{D}$ & II & L. Paleo. & & Vertebrata & Indeterminate & 3 \\
\hline E22/S76 & $24 \mathrm{~A}$ & $25 \mathrm{X} 1 \mathrm{~A}$ & III & L. Paleo. & & Mammalia (Medium/large) & Long bone & 1 \\
\hline E22/S76 & $24 \mathrm{~A}$ & $25 \mathrm{X} 1 \mathrm{C}$ & II & L. Paleo. & & Vertebrata & Indeterminate & 1 \\
\hline E22/S76 & $24 \mathrm{~A}$ & 25X1D & II & L. Paleo. & & Mammalia (Medium/large) & Long bone & 1 \\
\hline E22/S76 & $24 \mathrm{~B}$ & $25 \mathrm{X} 2 \mathrm{~A}$ & $\mathrm{Id} / \mathrm{II}$ & L. Paleo. & & Vertebrata & Indeterminate & 1 \\
\hline E22/S76 & $24 \mathrm{~B}$ & $25 \mathrm{X} 2 \mathrm{~B}$ & $\mathrm{Id} / \mathrm{II}$ & L. Paleo. & & Mammalia (Medium/large) & Indeterminate & 1 \\
\hline E22/S76 & $24 \mathrm{~B}$ & $25 \mathrm{X} 2 \mathrm{~B}$ & Id/II & L. Paleo. & & Vertebrata & Indeterminate & 7 \\
\hline E22/S76 & $24 \mathrm{~B}$ & $25 \times 2 C$ & $\mathrm{Id} / \mathrm{II}$ & L. Paleo. & & Small/Medium Vertebrata & Indeterminate & 1 \\
\hline E22/S76 & $24 \mathrm{~B}$ & $25 \times 2 D$ & $\mathrm{Id} / \mathrm{II}$ & L. Paleo. & & Medium/Large Vertebrata & Indeterminate & 1 \\
\hline E22/S76 & $24 \mathrm{~B}$ & $25 \mathrm{X} 2 \mathrm{D}$ & $\mathrm{Id} / \mathrm{II}$ & L. Paleo. & & Small/Medium Vertebrata & Indeterminate & 4 \\
\hline E22/S76 & $25 \mathrm{~A}$ & $25 \mathrm{Y} 1 \mathrm{~A}$ & Id/II & L. Paleo. & & Vertebrata & Indeterminate & 1 \\
\hline E22/S76 & $25 \mathrm{~A}$ & $25 \mathrm{Y} 1 \mathrm{~B}$ & $\mathrm{Id} / \mathrm{II}$ & L. Paleo. & & Vertebrata & Indeterminate & 6 \\
\hline E22/S76 & $25 \mathrm{~A}$ & $25 \mathrm{Y} 1 \mathrm{C}$ & $\mathrm{Id} / \mathrm{II}$ & L. Paleo. & & Mammalia (Medium/large) & Long bone & 1 \\
\hline E22/S76 & $25 \mathrm{~A}$ & 25Y1D & Id/II & L. Paleo. & & Small/Medium Vertebrata & Long bone & 1 \\
\hline E22/S76 & $25 \mathrm{~A}$ & 25Y1D & $\mathrm{Id} / \mathrm{II}$ & L. Paleo. & & Vertebrata & Indeterminate & 1 \\
\hline E22/S76 & $25 \mathrm{~B}$ & $25 \mathrm{Y} 2 \mathrm{~A}$ & $\mathrm{Id} / \mathrm{II}$ & L. Paleo. & & Mammalia (Medium/large) & Indeterminate & 1 \\
\hline E22/S76 & $25 \mathrm{~B}$ & $25 \mathrm{Y} 2 \mathrm{~A}$ & $\mathrm{Id} / \mathrm{II}$ & L. Paleo. & & Vertebrata & Indeterminate & 9 \\
\hline E22/S76 & $25 \mathrm{~B}$ & $25 \mathrm{Y} 2 \mathrm{~B}$ & $\mathrm{Id} / \mathrm{II}$ & L. Paleo. & & Small/Medium Vertebrata & Indeterminate & 1 \\
\hline E22/S76 & $25 \mathrm{~B}$ & $25 \mathrm{Y} 2 \mathrm{~B}$ & $\mathrm{Id} / \mathrm{II}$ & L. Paleo. & & Vertebrata & Indeterminate & 3 \\
\hline E22/S76 & $25 \mathrm{~B}$ & $25 \mathrm{Y} 2 \mathrm{C}$ & $\mathrm{Id} / \mathrm{II}$ & L. Paleo. & & Vertebrata & Indeterminate & 1 \\
\hline E22/S76 & $25 \mathrm{~B}$ & $25 \mathrm{Y} 2 \mathrm{D}$ & $\mathrm{Id} / \mathrm{II}$ & L. Paleo. & & Medium/Large Vertebrata & Indeterminate & 2 \\
\hline E22/S76 & $25 \mathrm{~B}$ & $25 \mathrm{Y} 2 \mathrm{D}$ & Id/II & L. Paleo. & & Vertebrata & Indeterminate & 1 \\
\hline E22/S76 & $26 \mathrm{~A}$ & $25 \mathrm{Z} 1 \mathrm{~A}$ & Id/II & L. Paleo. & & Mammalia (Medium/large) & Indeterminate & 2 \\
\hline E22/S76 & $26 \mathrm{~A}$ & 25Z1A & $\mathrm{Id} / \mathrm{II}$ & L. Paleo. & & Vertebrata & Indeterminate & 7 \\
\hline E22/S76 & $26 \mathrm{~A}$ & 25Z1B & $\mathrm{Id} / \mathrm{II}$ & L. Paleo. & & Mammalia (Large) & Long bone & 2 \\
\hline E22/S76 & $26 \mathrm{~A}$ & 25Z1B & Id/II & L. Paleo. & & Mammalia (Medium) & Proximal phalange & 1 \\
\hline E22/S76 & $26 \mathrm{~A}$ & 25Z1B & $\mathrm{Id} / \mathrm{II}$ & L. Paleo. & & Mammalia (Medium/large) & Indeterminate & 1 \\
\hline E22/S76 & $26 \mathrm{~A}$ & 25Z1B & Id/II & L. Paleo. & & Mammalia (Medium/large) & Long bone & 1 \\
\hline E22/S76 & $26 \mathrm{~A}$ & 25Z1B & Id/II & L. Paleo. & & Medium/Large Vertebrata & Indeterminate & 1 \\
\hline E22/S76 & $26 \mathrm{~A}$ & 25Z1B & $\mathrm{Id} / \mathrm{II}$ & L. Paleo. & & Vertebrata & Indeterminate & 10 \\
\hline E22/S76 & $26 \mathrm{~A}$ & $25 \mathrm{Z} 1 \mathrm{C}$ & $\mathrm{Id} / \mathrm{II}$ & L. Paleo. & & Medium/Large Vertebrata & Indeterminate & 1 \\
\hline E22/S76 & $26 \mathrm{~A}$ & $25 \mathrm{ZlC}$ & $\mathrm{Id} / \mathrm{II}$ & L. Paleo. & & Vertebrata & Indeterminate & 5 \\
\hline E22/S76 & $26 \mathrm{~A}$ & 25Z1D & $\mathrm{Id} / \mathrm{II}$ & L. Paleo. & & cf. Canis sp. & Astragalus & 1 \\
\hline E22/S76 & $26 \mathrm{~A}$ & 25Z1D & Id/II & L. Paleo. & & Mammalia (Medium/large) & Long bone & 1 \\
\hline E22/S76 & $26 \mathrm{~A}$ & 25Z1D & $\mathrm{Id} / \mathrm{II}$ & L. Paleo. & & Small/Medium Vertebrata & Long bone & 1 \\
\hline E22/S76 & $26 \mathrm{~A}$ & 25Z1D & $\mathrm{Id} / \mathrm{II}$ & L. Paleo. & & Vertebrata & Indeterminate & 8 \\
\hline E22/S76 & $26 \mathrm{~B}$ & $25 Z 2$ & Isi-c/Id/II & L. Paleo. & & Mammalia (Large) & Indeterminate & 1 \\
\hline E22/S76 & $26 \mathrm{~B}$ & $25 Z 2$ & Isi-c/Id/II & L. Paleo. & & Mammalia (Large) & Long bone & 1 \\
\hline E22/S76 & $26 \mathrm{~B}$ & $25 Z 2$ & Isi-c/Id/II & L. Paleo. & & Mammalia (Medium) & Caudal vertebra & 1 \\
\hline E22/S76 & $26 \mathrm{~B}$ & $25 Z 2$ & Isi-c/Id/II & L. Paleo. & & Mammalia (Medium/large) & Indeterminate & 4 \\
\hline E22/S76 & $26 \mathrm{~B}$ & $25 Z 2$ & Isi-c/Id/II & L. Paleo. & & Mammalia (Medium/large) & Long bone & 1 \\
\hline E22/S76 & $26 \mathrm{~B}$ & $25 Z 2$ & Isi-c/Id/II & L. Paleo. & & Medium/Large Vertebrata & Indeterminate & 3 \\
\hline E22/S76 & $26 \mathrm{~B}$ & $25 Z 2$ & Isi-c/Id/II & L. Paleo. & & Small/Medium Vertebrata & Indeterminate & 1 \\
\hline E22/S76 & $26 \mathrm{~B}$ & $25 Z 2$ & Isi-c/Id/II & L. Paleo. & & Vertebrata & Indeterminate & 44 \\
\hline E22/S76 & $26 \mathrm{~B}$ & $25 Z 2 A$ & Isi-c/Id/II & L. Paleo. & & Vertebrata & Indeterminate & 3 \\
\hline E22/S76 & $26 \mathrm{~B}$ & 25Z2B & Isi-c/Id/II & L. Paleo. & & Medium/Large Vertebrata & Indeterminate & 2 \\
\hline E22/S76 & $26 \mathrm{~B}$ & 25Z2B & Isi-c/Id/II & L. Paleo. & & Vertebrata & Indeterminate & 1 \\
\hline E22/S76 & $26 \mathrm{~B}$ & $25 \mathrm{Z} 2 \mathrm{C}$ & Isi-c/Id/II & L. Paleo. & & Mammalia (Large) & Long bone & 1 \\
\hline E22/S76 & $26 \mathrm{~B}$ & $25 \mathrm{Z} 2 \mathrm{C}$ & Isi-c/Id/II & L. Paleo. & & Medium/Large Vertebrata & Indeterminate & 1 \\
\hline E22/S76 & $26 \mathrm{~B}$ & $25 \mathrm{Z} 2 \mathrm{C}$ & Isi-c/Id/II & L. Paleo. & & Medium/Large Vertebrata & Long bone & 1 \\
\hline E22/S76 & $26 \mathrm{~B}$ & $25 \mathrm{Z} 2 \mathrm{C}$ & Isi-c/Id/II & L. Paleo. & & Vertebrata & Indeterminate & 1 \\
\hline E22/S76 & $26 \mathrm{~B}$ & 25Z2D & Isi-c/Id/II & L. Paleo. & & Vertebrata & Indeterminate & 1 \\
\hline E22/S76 & $27 \mathrm{~A}$ & 25AA1A & Isi-c & L. Paleo. & & Mammalia (Medium/large) & Indeterminate & 2 \\
\hline E22/S76 & $27 \mathrm{~A}$ & 25AA1A & Isi-c & L. Paleo. & & Vertebrata & Indeterminate & 6 \\
\hline E22/S76 & $27 \mathrm{~A}$ & 25AA1B & Isi-c & L. Paleo. & & AntilocapralOdocoileus & Metapodial & 1 \\
\hline E22/S76 & $27 \mathrm{~A}$ & 25AA1B & Isi-c & L. Paleo. & & Mammalia (Medium/large) & Indeterminate & 1 \\
\hline E22/S76 & $27 \mathrm{~A}$ & 25AA1B & Isi-c & L. Paleo. & & Vertebrata & Indeterminate & 11 \\
\hline E22/S76 & $27 \mathrm{~A}$ & 25AA1C & Isi-c & L. Paleo. & & Vertebrata & Indeterminate & 2 \\
\hline E22/S76 & $27 \mathrm{~A}$ & 25AA1D & Isi-c & L. Paleo. & & Mammalia (Medium/large) & Indeterminate & 4 \\
\hline E22/S76 & $27 \mathrm{~A}$ & 25AA1D & Isi-c & L. Paleo. & & Vertebrata & Indeterminate & 7 \\
\hline E22/S76 & $27 \mathrm{~B}$ & 25AA2A & Isi-c & L. Paleo. & & Mammalia (Medium/large) & Indeterminate & 3 \\
\hline
\end{tabular}




\begin{tabular}{|c|c|c|c|c|c|c|c|c|}
\hline Square & Level & Lot & Unit & Cultural Affinity & Feature & Taxon & Element & No. \\
\hline E22/S76 & $27 \mathrm{~B}$ & $25 \mathrm{AA} 2 \mathrm{~A}$ & Isi-c & L. Paleo. & & Vertebrata & Indeterminate & 5 \\
\hline $\mathrm{E} 22 / \mathrm{S} 76$ & $27 \mathrm{~B}$ & 25AA2B & Isi-c & L. Paleo. & & Mammalia (Medium/large) & Long bone & 1 \\
\hline $\mathrm{E} 22 / \mathrm{S} 76$ & $27 \mathrm{~B}$ & 25AA2B & Isi-c & L. Paleo. & & Vertebrata & Indeterminate & 29 \\
\hline $\mathrm{E} 22 / \mathrm{S} 76$ & $27 \mathrm{~B}$ & $25 \mathrm{AA} 2 \mathrm{C}$ & Isi-c & L. Paleo. & & Mammalia (Medium/large) & Indeterminate & 1 \\
\hline $\mathrm{E} 22 / \mathrm{S} 76$ & $27 \mathrm{~B}$ & 25AA2C & Isi-c & L. Paleo. & & Mammalia (Medium/large) & Long bone & 1 \\
\hline $\mathrm{E} 22 / \mathrm{S} 76$ & $27 \mathrm{~B}$ & $25 \mathrm{AA} 2 \mathrm{C}$ & Isi-c & L. Paleo. & & Vertebrata & Indeterminate & 1 \\
\hline $\mathrm{E} 22 / \mathrm{S} 76$ & $27 \mathrm{~B}$ & $25 \mathrm{AA} 2 \mathrm{C}$ & Isi-c & L. Paleo. & & Vertebrata & Long bone & 1 \\
\hline $\mathrm{E} 22 / \mathrm{S} 76$ & $28 \mathrm{~A}$ & $25 B B 1 A$ & Isi-c & L. Paleo. & & Carnivora & Permanent tooth & 1 \\
\hline $\mathrm{E} 22 / \mathrm{S} 76$ & $28 \mathrm{~A}$ & 25BB1A & Isi-c & L. Paleo. & & Medium/Large Vertebrata & Indeterminate & 4 \\
\hline $\mathrm{E} 22 / \mathrm{S} 76$ & $28 \mathrm{~A}$ & 25BB1A & Isi-c & L. Paleo. & & Medium/Large Vertebrata & Long bone & 3 \\
\hline $\mathrm{E} 22 / \mathrm{S} 76$ & $28 \mathrm{~A}$ & 25BB1A & Isi-c & L. Paleo. & & Small/Medium Vertebrata & Long bone & 1 \\
\hline $\mathrm{E} 22 / \mathrm{S} 76$ & $28 \mathrm{~A}$ & 25BB1A & Isi-c & L. Paleo. & & Vertebrata & Indeterminate & 5 \\
\hline $\mathrm{E} 22 / \mathrm{S} 76$ & $28 \mathrm{~A}$ & 25BB1B & Isi-c & L. Paleo. & & Mammalia (Medium/large) & Indeterminate & 1 \\
\hline $\mathrm{E} 22 / \mathrm{S} 76$ & $28 \mathrm{~A}$ & 25BB $1 B$ & Isi-c & L. Paleo. & & Mammalia (Medium/large) & Tooth, perm./decid. ind. & 1 \\
\hline $\mathrm{E} 22 / \mathrm{S} 76$ & $28 \mathrm{~A}$ & 25BB1B & Isi-c & L. Paleo. & & Medium/Large Vertebrata & Indeterminate & 2 \\
\hline $\mathrm{E} 22 / \mathrm{S} 76$ & $28 \mathrm{~A}$ & 25BB1B & Isi-c & L. Paleo. & & Medium/Large Vertebrata & Long bone & 1 \\
\hline $\mathrm{E} 22 / \mathrm{S} 76$ & $28 \mathrm{~A}$ & 25BB1B & Isi-c & L. Paleo. & & Vertebrata & Indeterminate & 12 \\
\hline $\mathrm{E} 22 / \mathrm{S} 76$ & $28 \mathrm{~A}$ & 25BB1C & Isi-c & L. Paleo. & & Medium/Large Vertebrata & Indeterminate & 1 \\
\hline $\mathrm{E} 22 / \mathrm{S} 76$ & $28 \mathrm{~A}$ & 25BB1C & Isi-c & L. Paleo. & & Vertebrata & Indeterminate & 4 \\
\hline $\mathrm{E} 22 / \mathrm{S} 76$ & $28 \mathrm{~B}$ & 25BB2A & Isi-c & L. Paleo. & & Medium/Large Vertebrata & Indeterminate & 1 \\
\hline $\mathrm{E} 22 / \mathrm{S} 76$ & $28 \mathrm{~B}$ & $25 \mathrm{BB} 2 \mathrm{~A}$ & Isi-c & L. Paleo. & & Vertebrata & Indeterminate & 1 \\
\hline $\mathrm{E} 22 / \mathrm{S} 76$ & $28 \mathrm{~B}$ & 25BB2B & Isi-c & L. Paleo. & & Medium/Large Vertebrata & Indeterminate & 1 \\
\hline $\mathrm{E} 22 / \mathrm{S} 76$ & $28 \mathrm{~B}$ & 25BB2B & Isi-c & L. Paleo. & & Testudinata & Shell fragment & 1 \\
\hline $\mathrm{E} 22 / \mathrm{S} 76$ & $28 \mathrm{~B}$ & 25BB2B & Isi-c & L. Paleo. & & Vertebrata & Indeterminate & 5 \\
\hline $\mathrm{E} 22 / \mathrm{S} 76$ & $28 \mathrm{~B}$ & 25BB2C & Isi-c & L. Paleo. & & Odocoileus sp. & Mandible & 1 \\
\hline $\mathrm{E} 22 / \mathrm{S} 76$ & $28 \mathrm{~B}$ & 25BB2C & Isi-c & L. Paleo. & & Odocoileus sp. & Permanent tooth & 2 \\
\hline $\mathrm{E} 22 / \mathrm{S} 76$ & $28 \mathrm{~B}$ & 25BB2C & Isi-c & L. Paleo. & & Rodentia (Medium) & Humerus & 1 \\
\hline $\mathrm{E} 22 / \mathrm{S} 76$ & $28 \mathrm{~B}$ & 25BB2C & Isi-c & L. Paleo. & & Vertebrata & Indeterminate & 8 \\
\hline $\mathrm{E} 22 / \mathrm{S} 76$ & $28 \mathrm{~B}$ & 25BB2D & Isi-c & L. Paleo. & & Mammalia (Medium/large) & Indeterminate & 1 \\
\hline $\mathrm{E} 22 / \mathrm{S} 76$ & $28 \mathrm{~B}$ & 25BB2D & Isi-c & L. Paleo. & & Medium/Large Vertebrata & Indeterminate & 2 \\
\hline $\mathrm{E} 22 / \mathrm{S} 76$ & $29 \mathrm{~A}$ & $25 \mathrm{CC} 1 \mathrm{~A}$ & Isi-c & L. Paleo. & & Vertebrata & Indeterminate & 4 \\
\hline $\mathrm{E} 22 / \mathrm{S} 76$ & $29 \mathrm{~A}$ & $25 \mathrm{CC} 1 \mathrm{C}$ & Isi-c & L. Paleo. & & Vertebrata & Long bone & 1 \\
\hline $\mathrm{E} 22 / \mathrm{S} 76$ & $29 \mathrm{~A}$ & 25CC1D & Isi-c & L. Paleo. & & Vertebrata & Indeterminate & 3 \\
\hline $\mathrm{E} 22 / \mathrm{S} 76$ & $29 \mathrm{~B}$ & $25 \mathrm{CC} 2 \mathrm{~A}$ & Isi-c & L. Paleo. & & Vertebrata & Indeterminate & 3 \\
\hline $\mathrm{E} 22 / \mathrm{S} 76$ & $29 \mathrm{~B}$ & $25 \mathrm{CC} 2 \mathrm{~A}$ & Isi-c & L. Paleo. & & Vertebrata & Long bone & 1 \\
\hline $\mathrm{E} 22 / \mathrm{S} 76$ & 29B & $25 \mathrm{CC} 2 \mathrm{~B}$ & Isi-c & L. Paleo. & & Mammalia (Medium/large) & Long bone & 1 \\
\hline $\mathrm{E} 22 / \mathrm{S} 76$ & $29 \mathrm{~B}$ & $25 \mathrm{CC} 2 \mathrm{~B}$ & Isi-c & L. Paleo. & & Medium/Large Vertebrata & Indeterminate & 5 \\
\hline $\mathrm{E} 22 / \mathrm{S} 76$ & $29 \mathrm{~B}$ & $25 \mathrm{CC} 2 \mathrm{~B}$ & Isi-c & L. Paleo. & & Vertebrata & Indeterminate & 6 \\
\hline $\mathrm{E} 22 / \mathrm{S} 76$ & $30 \mathrm{~A}$ & 25DD1A & Isi-c & L. Paleo. & & Small/Medium Vertebrata & Long bone & 1 \\
\hline $\mathrm{E} 22 / \mathrm{S} 76$ & $30 \mathrm{~A}$ & 25DD1A & Isi-c & L. Paleo. & & Vertebrata & Indeterminate & 2 \\
\hline $\mathrm{E} 22 / \mathrm{S} 76$ & $30 \mathrm{~A}$ & 25DD1B & Isi-c & L. Paleo. & & Medium/Large Vertebrata & Indeterminate & 1 \\
\hline $\mathrm{E} 22 / \mathrm{S} 76$ & $30 \mathrm{~A}$ & 25DD1B & Isi-c & L. Paleo. & & Vertebrata & Indeterminate & 3 \\
\hline $\mathrm{E} 22 / \mathrm{S} 76$ & $30 \mathrm{~A}$ & 25DD1C & Isi-c & L. Paleo. & & Small/Medium Vertebrata & Long bone & 3 \\
\hline $\mathrm{E} 22 / \mathrm{S} 76$ & $30 \mathrm{~A}$ & 25DD1D & Isi-c & L. Paleo. & & Vertebrata & Indeterminate & 4 \\
\hline $\mathrm{E} 22 / \mathrm{S} 76$ & $30 \mathrm{~B}$ & 25DD2A & Isi-c & L. Paleo. & & Vertebrata & Indeterminate & 2 \\
\hline $\mathrm{E} 22 / \mathrm{S} 76$ & $30 \mathrm{~B}$ & 25DD2B & Isi-c & L. Paleo. & & Sylvilagus sp. & Tibia & 1 \\
\hline $\mathrm{E} 22 / \mathrm{S} 76$ & $30 \mathrm{~B}$ & 25DD2B & Isi-c & L. Paleo. & & Vertebrata & Indeterminate & 4 \\
\hline $\mathrm{E} 22 / \mathrm{S} 76$ & $30 \mathrm{~B}$ & 25DD2C & Isi-c & L. Paleo. & & Vertebrata & Indeterminate & 4 \\
\hline $\mathrm{E} 22 / \mathrm{S} 76$ & $31 \mathrm{~A}$ & 25EE1A & Isi/Icl/Isi-c & Paleoindian & & Vertebrata & Indeterminate & 1 \\
\hline $\mathrm{E} 22 / \mathrm{S} 76$ & $31 \mathrm{~A}$ & 25EE1B & Isi/Icl/Isi-c & Paleoindian & & Canis sp. & Metatarsal 2 & 1 \\
\hline $\mathrm{E} 22 / \mathrm{S} 76$ & $31 \mathrm{~A}$ & 25EE1B & Isi/Icl/Isi-c & Paleoindian & & Vertebrata & Indeterminate & 5 \\
\hline $\mathrm{E} 22 / \mathrm{S} 76$ & $31 \mathrm{~A}$ & 25EE1C & Isi/Icl/Isi-c & Paleoindian & & Small/Medium Vertebrata & Long bone & 3 \\
\hline $\mathrm{E} 22 / \mathrm{S} 76$ & $31 \mathrm{~B}$ & 25EE2A & Isi/Icl/Isi-c & Paleoindian & & Vertebrata & Indeterminate & 2 \\
\hline $\mathrm{E} 22 / \mathrm{S} 76$ & $31 \mathrm{~B}$ & 25EE2B & Isi/Icl/Isi-c & Paleoindian & & Vertebrata & Indeterminate & 2 \\
\hline E22/S76 & $31 \mathrm{~B}$ & 25EE2D & Isi/Icl/Isi-c & Paleoindian & & Vertebrata & Indeterminate & 1 \\
\hline $\mathrm{E} 22 / \mathrm{S} 76$ & $32 \mathrm{~A}$ & 25FF1B & Isi/Icl/Isi-c & Paleoindian & & Mammalia (Medium/large) & Indeterminate & 1 \\
\hline E22/S76 & $32 \mathrm{~A}$ & 25FF1B & $\mathrm{Isi} / \mathrm{Icl} / / \mathrm{si}-\mathrm{c}$ & Paleoindian & & Mammalia (Medium/large) & Long bone & 1 \\
\hline $\mathrm{E} 22 / \mathrm{S} 76$ & $32 \mathrm{~A}$ & 25FF1B & $\mathrm{Isi} / \mathrm{Icl} / \mathrm{Isi}-\mathrm{c}$ & Paleoindian & & Vertebrata & Indeterminate & 1 \\
\hline E22/S76 & $32 \mathrm{~B}$ & $25 \mathrm{FF} 2 \mathrm{C}$ & Isi/Icl/Isi-c & Paleoindian & & Medium/Large Vertebrata & Long bone & 1 \\
\hline $\mathrm{E} 22 / \mathrm{S} 76$ & $32 \mathrm{~B}$ & $25 \mathrm{FF} 2 \mathrm{C}$ & Isi/Icl/Isi-c & Paleoindian & & Small/Medium Vertebrata & Long bone & 1 \\
\hline $\mathrm{E} 22 / \mathrm{S} 76$ & $32 \mathrm{~B}$ & $25 \mathrm{FF} 2 \mathrm{C}$ & Isi/Icl/Isi-c & Paleoindian & & Vertebrata & Indeterminate & 2 \\
\hline E22/S76 & $32 \mathrm{~B}$ & 25FF2D & Isi/Icl/Isi-c & Paleoindian & & Mammalia (Medium/large) & Indeterminate & 1 \\
\hline $\mathrm{E} 22 / \mathrm{S} 76$ & $32 \mathrm{~B}$ & 25FF2D & Isi/Icl/Isi-c & Paleoindian & & Medium/Large Vertebrata & Indeterminate & 2 \\
\hline $\mathrm{E} 22 / \mathrm{S} 76$ & $33 \mathrm{~A}$ & 25GG1A & Isi/Icl/Isi-c & Paleoindian & & Vertebrata & Indeterminate & 2 \\
\hline $\mathrm{E} 22 / \mathrm{S} 76$ & $33 \mathrm{~A}$ & $25 \mathrm{GG} 1 \mathrm{C}$ & Isi/Icl/Isi-c & Paleoindian & & Mammalia (Medium/large) & Indeterminate & 1 \\
\hline $\mathrm{E} 22 / \mathrm{S} 76$ & $33 \mathrm{~A}$ & $25 \mathrm{GG} 1 \mathrm{C}$ & Isi/Icl/Isi-c & Paleoindian & & Vertebrata & Indeterminate & 10 \\
\hline E22/S76 & $33 \mathrm{~A}$ & 25GG1D & Isi/Icl/Isi-c & Paleoindian & & Vertebrata & Indeterminate & 3 \\
\hline
\end{tabular}




\begin{tabular}{|c|c|c|c|c|c|c|c|c|}
\hline Square & Level & Lot & Unit & Cultural Affinity & Feature & Taxon & Element & No. \\
\hline E22/S76 & $33 \mathrm{~B}$ & 25GG2D & Isi/Icl & E. Paleo. & & Leporidae & Mandible & $\overline{1}$ \\
\hline E22/S76 & $33 \mathrm{~B}$ & 25GG2D & |Isi/Icl & E. Paleo. & & Leporidae & Permanent tooth & 2 \\
\hline $\mathrm{E} 22 / \mathrm{S} 76$ & $33 \mathrm{~B}$ & 25GG2D & Isi/Icl & E. Paleo. & & Small/Medium Vertebrata & Long bone & 2 \\
\hline $\mathrm{E} 22 / \mathrm{S} 76$ & $33 \mathrm{~B}$ & 25GG2D & Isi/Icl & E. Paleo. & & Vertebrata & Indeterminate & 1 \\
\hline $\mathrm{E} 22 / \mathrm{S} 76$ & $34 \mathrm{~B}$ & $25 \mathrm{HH} 2 \mathrm{~A}$ & Isi/Icl & E. Paleo. & & Medium/Large Vertebrata & Indeterminate & 1 \\
\hline $\mathrm{E} 22 / \mathrm{S} 76$ & $34 \mathrm{~B}$ & $25 \mathrm{HH} 2 \mathrm{~A}$ & Isi/Icl & E. Paleo. & & Vertebrata & Indeterminate & 3 \\
\hline E22/S76 & $34 \mathrm{~B}$ & $25 \mathrm{HH} 2 \mathrm{~B}$ & Isi/Icl & E. Paleo. & & Vertebrata & Indeterminate & 4 \\
\hline E22/S76 & $34 \mathrm{~B}$ & $25 \mathrm{HH} 2 \mathrm{C}$ & Isi/Icl & E. Paleo. & & Mammalia (Medium/large) & Indeterminate & 1 \\
\hline E22/S76 & $35 \mathrm{~A}$ & 25II1B & Isi/Icl & E. Paleo. & & Vertebrata & Indeterminate & 6 \\
\hline $\mathrm{E} 22 / \mathrm{S} 76$ & $35 \mathrm{~A}$ & $25 \mathrm{IIIC}$ & Isi/Icl & E. Paleo. & & Mammalia (Medium/large) & Indeterminate & 1 \\
\hline $\mathrm{E} 22 / \mathrm{S} 76$ & $35 \mathrm{~A}$ & $25 \mathrm{IIIC}$ & Isi/Icl & E. Paleo. & & Vertebrata & Indeterminate & 55 \\
\hline E22/S76 & $35 \mathrm{~A}$ & 25IIID & Isi/Icl & E. Paleo. & & Vertebrata & Long bone & 1 \\
\hline $\mathrm{E} 22 / \mathrm{S} 76$ & $35 \mathrm{~B}$ & 25III B & Isi & E. Paleo. & & Mammalia (Medium/large) & Indeterminate & 1 \\
\hline E22/S76 & $35 \mathrm{~B}$ & 25II2B & Isi & E. Paleo. & & Vertebrata & Indeterminate & 15 \\
\hline $\mathrm{E} 22 / \mathrm{S} 76$ & $35 \mathrm{~B}$ & $25 \mathrm{II} 2 \mathrm{C}$ & Isi & E. Paleo. & & Mammalia (Very large) & Indeterminate & 1 \\
\hline $\mathrm{E} 22 / \mathrm{S} 76$ & $35 \mathrm{~B}$ & $25 \mathrm{II} 2 \mathrm{C}$ & Isi & E. Paleo. & & Vertebrata & Indeterminate & 24 \\
\hline E22/S76 & $36 \mathrm{~A}$ & 25JJ1B & Isi/D? & E. Paleo. & & Vertebrata & Indeterminate & 2 \\
\hline E22/S76 & $36 \mathrm{~B}$ & 25JJ2B & Isi/D? & E. Paleo. & & Mammalia (Medium/large) & Indeterminate & 5 \\
\hline $\mathrm{E} 22 / \mathrm{S} 76$ & $36 \mathrm{~B}$ & $25 \mathrm{JJ} 2 \mathrm{~B}$ & Isi/D? & E. Paleo. & & Vertebrata & Indeterminate & 27 \\
\hline E22/S76 & $36 \mathrm{~B}$ & $25 \mathrm{JJ} 2 \mathrm{C}$ & Isi/D? & E. Paleo. & & Vertebrata & Indeterminate & 3 \\
\hline E22/S76 & 37B & 25KK2D & Isi & E. Paleo. & & Carnivora & Permanent tooth & 2 \\
\hline $\mathrm{E} 22 / \mathrm{S} 76$ & 37B & $25 \mathrm{KK} 2 \mathrm{D}$ & Isi & E. Paleo. & & Mammalia (Medium/large) & Indeterminate & 1 \\
\hline $\mathrm{E} 22 / \mathrm{S} 78$ & 15 & 240 & IIIIa/b & E. Archaic & & Mammalia (Medium/large) & Indeterminate & 2 \\
\hline $\mathrm{E} 22 / \mathrm{S} 78$ & 15 & 240 & $\mathrm{IIa} / \mathrm{b}$ & E. Archaic & & Odocoileus sp. & Dist. phalange of paradigit & 1 \\
\hline $\mathrm{E} 22 / \mathrm{S} 78$ & $16 \mathrm{~A}$ & 24P1 & IIIa & E. Archaic & f123 & Mammalia (Medium/large) & Long bone & 1 \\
\hline E22/S78 & $16 \mathrm{~B}$ & 24P2 & IIIIa & E. Archaic & & Mammalia (Medium/large) & Indeterminate & 1 \\
\hline $\mathrm{E} 22 / \mathrm{S} 78$ & $16 \mathrm{~B}$ & 24P2 & IIIIa & E. Archaic & & Vertebrata & Indeterminate & 2 \\
\hline E22/S78 & $17 \mathrm{~A}$ & 24Q1 & IIIIa & E. Archaic & & Mammalia (Medium/large) & Indeterminate & 3 \\
\hline $\mathrm{E} 22 / \mathrm{S} 78$ & $17 \mathrm{~A}$ & 24Q1 & IIIIa & E. Archaic & & Vertebrata & Indeterminate & 10 \\
\hline E22/S78 & $18 \mathrm{~A}$ & 24R1 & IIIa & L. Paleo./E. Archaic & & Mammalia (Medium/large) & Indeterminate & 4 \\
\hline E22/S78 & $18 \mathrm{~A}$ & 24R1 & IIIIa & L. Paleo./E. Archaic & & Mammalia (Medium/large) & Long bone & 2 \\
\hline E22/S78 & $18 \mathrm{~A}$ & 24R1 & IIIa & L. Paleo./E. Archaic & & Medium/Large Vertebrata & Indeterminate & 4 \\
\hline E22/S78 & $18 \mathrm{~A}$ & 24R1 & IIIa & L. Paleo./E. Archaic & & Small/Medium Vertebrata & Long bone & 1 \\
\hline E22/S78 & $18 \mathrm{~A}$ & 24R1 & IIIIa & L. Paleo./E. Archaic & & Testudinata & Neural & 1 \\
\hline $\mathrm{E} 22 / \mathrm{S} 78$ & $18 \mathrm{~A}$ & 24R1 & IIIIa & L. Paleo./E. Archaic & & Testudinata & Shell fragment & 1 \\
\hline E22/S78 & $18 \mathrm{~A}$ & 24R1 & IIIa & L. Paleo./E. Archaic & & Vertebrata & Indeterminate & 4 \\
\hline E22/S78 & $18 \mathrm{~B}$ & $24 \mathrm{R} 2$ & II/IIIa & L. Paleo./E. Archaic & & Mammalia (Medium/large) & Long bone & 2 \\
\hline $\mathrm{E} 22 / \mathrm{S} 78$ & 18B & $24 \mathrm{R} 2$ & II/IIIa & L. Paleo./E. Archaic & & Vertebrata & Indeterminate & 8 \\
\hline E22/S78 & 19A & $24 \mathrm{~S} 1$ & II/Wa & L. Paleo./E. Archaic & & Kinosternidae & Peripheral & 1 \\
\hline E22/S78 & 19A & $24 \mathrm{~S} 1$ & II/IIIa & L. Paleo./E. Archaic & & Mammalia (Medium/large) & Indeterminate & 1 \\
\hline E22/S78 & $19 \mathrm{~A}$ & $24 \mathrm{~S} 1$ & II/IIa & L. Paleo./E. Archaic & & Medium/Large Vertebrata & Indeterminate & 2 \\
\hline E22/S78 & 19A & $24 \mathrm{~S} 1$ & II/IIIa & L. Paleo./E. Archaic & & Small/Medium Vertebrata & Long bone & 7 \\
\hline E22/S78 & $19 \mathrm{~A}$ & $24 \mathrm{~S} 1$ & II/Wa & L. Paleo./E. Archaic & & Testudinata & Shell fragment & 1 \\
\hline E22/S78 & $19 \mathrm{~A}$ & $24 \mathrm{~S} 1$ & П/Ша & L. Paleo./E. Archaic & & Vertebrata & Indeterminate & 11 \\
\hline E22/S78 & 19B & $24 \mathrm{~S} 2 \mathrm{~A}$ & II/IIa & L. Paleo./E. Archaic & & Vertebrata & Indeterminate & 11 \\
\hline E22/S78 & 19B & 24S2B & II/IIIa & L. Paleo./E. Archaic & & Vertebrata & Indeterminate & 1 \\
\hline E22/S78 & 19B & $24 \mathrm{~S} 2 \mathrm{C}$ & ІІ/Ша & L. Paleo./E. Archaic & & Vertebrata & Indeterminate & 2 \\
\hline E22/S78 & 19B & 24S2D & II/IIIa & L. Paleo./E. Archaic & & Vertebrata & Indeterminate & 2 \\
\hline E22/S78 & $20 \mathrm{~A}$ & 24T1A & III & L. Paleo. & & Vertebrata & Indeterminate & 1 \\
\hline E22/S78 & $20 \mathrm{~A}$ & 24T1B & II & L. Paleo. & & Medium/Large Vertebrata & Indeterminate & 2 \\
\hline E22/S78 & $20 \mathrm{~A}$ & 24T1B & III & L. Paleo. & & Medium/Large Vertebrata & Long bone & 2 \\
\hline E22/S78 & $20 \mathrm{~A}$ & $24 \mathrm{~T} 1 \mathrm{C}$ & III & L. Paleo. & & Medium/Large Vertebrata & Long bone & 1 \\
\hline E22/S78 & $20 \mathrm{~A}$ & $24 \mathrm{~T} 1 \mathrm{C}$ & III & L. Paleo. & & Vertebrata & Indeterminate & 1 \\
\hline $\mathrm{E} 22 / \mathrm{S} 78$ & $20 \mathrm{~A}$ & 24T1D & II & L. Paleo. & & Mammalia (Medium/large) & Indeterminate & 2 \\
\hline $\mathrm{E} 22 / \mathrm{S} 78$ & $20 \mathrm{~A}$ & 24T1D & III & L. Paleo. & & Small/Medium Vertebrata & Long bone & 1 \\
\hline E22/S78 & $20 \mathrm{~B}$ & $24 \mathrm{~T} 2 \mathrm{~A}$ & II & L. Paleo. & & Medium/Large Vertebrata & Indeterminate & 1 \\
\hline E22/S78 & $21 \mathrm{~A}$ & 24U1B & III & L. Paleo. & & Vertebrata & Indeterminate & 3 \\
\hline $\mathrm{E} 22 / \mathrm{S} 78$ & $21 B$ & $24 \mathrm{U} 2 \mathrm{~A}$ & II & L. Paleo. & & Mammalia (Medium/large) & Indeterminate & 1 \\
\hline $\mathrm{E} 22 / \mathrm{S} 78$ & $21 \mathrm{~B}$ & 24U2B & II & L. Paleo. & & Vertebrata & Indeterminate & 2 \\
\hline E22/S78 & $21 \mathrm{~B}$ & $24 \mathrm{U} 2 \mathrm{C}$ & III & L. Paleo. & & Vertebrata & Indeterminate & 1 \\
\hline $\mathrm{E} 22 / \mathrm{S} 78$ & $22 \mathrm{~A}$ & $24 \mathrm{~V} 1 \mathrm{~A}$ & III & L. Paleo. & & Vertebrata & Indeterminate & 2 \\
\hline E22/S78 & $22 \mathrm{~A}$ & $24 \mathrm{~V} 1 \mathrm{C}$ & II & L. Paleo. & & AntilocapralOdocoileus & Metatarsal & 1 \\
\hline $\mathrm{E} 22 / \mathrm{S} 78$ & $22 \mathrm{~B}$ & $24 \mathrm{~V} 2 \mathrm{~A}$ & III & L. Paleo. & & Vertebrata & Indeterminate & 4 \\
\hline E22/S78 & $22 B$ & $24 \mathrm{~V} 2 \mathrm{~B}$ & II & L. Paleo. & & Mammalia (Medium/large) & Long bone & 1 \\
\hline E22/S78 & $22 \mathrm{~B}$ & $24 \mathrm{~V} 2 \mathrm{C}$ & II & L. Paleo. & & Medium/Large Vertebrata & Indeterminate & 1 \\
\hline $\mathrm{E} 22 / \mathrm{S} 78$ & $22 \mathrm{~B}$ & $24 \mathrm{~V} 2 \mathrm{C}$ & III & L. Paleo. & & Vertebrata & Indeterminate & 1 \\
\hline E22/S78 & 22B & 24V2D & III & L. Paleo. & & Mammalia (Medium/large) & Long bone & 1 \\
\hline
\end{tabular}




\begin{tabular}{|c|c|c|c|c|c|c|c|c|}
\hline Square & Level & Lot & Unit & Cultural Affinity & Feature & Taxon & Element & No. \\
\hline E22/S78 & $22 \mathrm{~B}$ & 24V2D & III & L. Paleo. & & Vertebrata & Indeterminate & 1 \\
\hline $\mathrm{E} 22 / \mathrm{S} 78$ & $23 \mathrm{~A}$ & 24W1B & II & L. Paleo. & & Vertebrata & Long bone & 1 \\
\hline E22/S78 & $23 \mathrm{~A}$ & $24 \mathrm{~W} 1 \mathrm{C}$ & III & L. Paleo. & & Small/Medium Vertebrata & Long bone & 1 \\
\hline $\mathrm{E} 22 / \mathrm{S} 78$ & $23 \mathrm{~A}$ & 24W1D & II & L. Paleo. & & Mammalia (Medium/large) & Long bone & 1 \\
\hline $\mathrm{E} 22 / \mathrm{S} 78$ & 23B & $24 \mathrm{~W} 2 \mathrm{~A}$ & Id/II & L. Paleo. & & Vertebrata & Indeterminate & 1 \\
\hline $\mathrm{E} 22 / \mathrm{S} 78$ & 23B & $24 \mathrm{~W} 2 \mathrm{C}$ & Id/II & L. Paleo. & & Medium/Large Vertebrata & Indeterminate & 1 \\
\hline E22/S78 & 23B & 24W2D & Id/II & L. Paleo. & & Testudinata & Shell fragment & 2 \\
\hline E22/S78 & $24 \mathrm{~A}$ & 24X1A & $\mathrm{Id} / \mathrm{II}$ & L. Paleo. & & Vertebrata & Indeterminate & 6 \\
\hline $\mathrm{E} 22 / \mathrm{S} 78$ & $24 \mathrm{~A}$ & 24X1B & Id/II & L. Paleo. & & Medium/Large Vertebrata & Indeterminate & 1 \\
\hline E22/S78 & $24 \mathrm{~A}$ & $24 \mathrm{X} 1 \mathrm{C}$ & Id/II & L. Paleo. & & Vertebrata & Indeterminate & 1 \\
\hline $\mathrm{E} 22 / \mathrm{S} 78$ & $24 \mathrm{~A}$ & 24X1D & $\mathrm{Id} / \mathrm{II}$ & L. Paleo. & & Vertebrata & Indeterminate & 3 \\
\hline $\mathrm{E} 22 / \mathrm{S} 78$ & 24B & $24 \mathrm{X} 2 \mathrm{~A}$ & Id/II & L. Paleo. & & Mammalia (Medium/large) & Indeterminate & 2 \\
\hline $\mathrm{E} 22 / \mathrm{S} 78$ & 24B & $24 \mathrm{X} 2 \mathrm{~A}$ & Id/II & L. Paleo. & & Mammalia (Medium/large) & Long bone & 1 \\
\hline $\mathrm{E} 22 / \mathrm{S} 78$ & 24B & $24 \mathrm{X} 2 \mathrm{~A}$ & Id/II & L. Paleo. & & Medium/Large Vertebrata & Indeterminate & 1 \\
\hline $\mathrm{E} 22 / \mathrm{S} 78$ & 24B & $24 X 2 B$ & $\mathrm{Id} / \mathrm{II}$ & L. Paleo. & & Vertebrata & Compact bone & 1 \\
\hline $\mathrm{E} 22 / \mathrm{S} 78$ & 24B & $24 X 2 B$ & Id/II & L. Paleo. & & Vertebrata & Indeterminate & 9 \\
\hline $\mathrm{E} 22 / \mathrm{S} 78$ & 24B & $24 \mathrm{X} 2 \mathrm{C}$ & Id/II & L. Paleo. & & Mammalia (Medium) & Proximal phalange & 1 \\
\hline E22/S78 & 24B & $24 \mathrm{X} 2 \mathrm{C}$ & $\mathrm{Id} / \mathrm{II}$ & L. Paleo. & & Medium/Large Vertebrata & Long bone & 1 \\
\hline E22/S78 & 24B & $24 \mathrm{X} 2 \mathrm{C}$ & Id/II & L. Paleo. & & Vertebrata & Indeterminate & 1 \\
\hline E22/S78 & 24B & $24 \mathrm{X} 2 \mathrm{D}$ & Id/II & L. Paleo. & & Mammalia (Medium) & Long bone & 1 \\
\hline E22/S78 & 24B & $24 X 2 D$ & $\mathrm{Id} / \mathrm{II}$ & L. Paleo. & & Vertebrata & Indeterminate & 2 \\
\hline E22/S78 & $25 \mathrm{~A}$ & 24Y1A & Id/II & L. Paleo. & & Medium/Large Vertebrata & Long bone & 1 \\
\hline E22/S78 & $25 \mathrm{~A}$ & 24Y1A & $\mathrm{Id} / \mathrm{II}$ & L. Paleo. & & Vertebrata & Indeterminate & 2 \\
\hline E22/S78 & $25 \mathrm{~A}$ & $24 \mathrm{Y} 1 \mathrm{C}$ & $\mathrm{Id} / \mathrm{II}$ & L. Paleo. & & Carnivora & Tooth, perm./decid. ind. & 1 \\
\hline E22/S78 & $25 \mathrm{~A}$ & 24Y1D & Id/II & L. Paleo. & & Vertebrata & Indeterminate & 1 \\
\hline E22/S78 & $25 \mathrm{~B}$ & $24 \mathrm{Y} 2 \mathrm{~A}$ & Isi-c/Id & L. Paleo. & & Medium/Large Vertebrata & Indeterminate & 4 \\
\hline E22/S78 & $25 \mathrm{~B}$ & $24 \mathrm{Y} 2 \mathrm{~A}$ & Isi-c/Id & L. Paleo. & & Vertebrata & Indeterminate & 2 \\
\hline E22/S78 & $25 \mathrm{~B}$ & 24Y2B & Isi-c/Id & L. Paleo. & & Mammalia (Large) & Indeterminate & 1 \\
\hline E22/S78 & $25 \mathrm{~B}$ & $24 \mathrm{Y} 2 \mathrm{~B}$ & Isi-c/Id & L. Paleo. & & Medium/Large Vertebrata & Indeterminate & 2 \\
\hline E22/S78 & $25 \mathrm{~B}$ & $24 \mathrm{Y} 2 \mathrm{~B}$ & Isi-c/Id & L. Paleo. & & Vertebrata & Indeterminate & 1 \\
\hline E22/S78 & $25 \mathrm{~B}$ & $24 \mathrm{Y} 2 \mathrm{C}$ & Isi-c/Id & L. Paleo. & & Medium/Large Vertebrata & Long bone & 2 \\
\hline E22/S78 & $25 \mathrm{~B}$ & $24 \mathrm{Y} 2 \mathrm{C}$ & Isi-c/Id & L. Paleo. & & Vertebrata & Indeterminate & 7 \\
\hline E22/S78 & $25 \mathrm{~B}$ & 24Y2D & Isi-c/Id & L. Paleo. & & Medium/Large Vertebrata & Indeterminate & 1 \\
\hline E22/S78 & $25 \mathrm{~B}$ & 24Y2D & Isi-c/Id & L. Paleo. & & Vertebrata & Indeterminate & 1 \\
\hline E22/S78 & $26 \mathrm{~A}$ & $24 \mathrm{Z} 1 \mathrm{~A}$ & Isi-c/Id & L. Paleo. & f163 & Mammalia (Medium) & Humerus & 1 \\
\hline E22/S78 & $26 \mathrm{~A}$ & $24 \mathrm{Z} 1 \mathrm{~A}$ & Isi-c/Id & L. Paleo. & f163 & Medium/Large Vertebrata & Long bone & 4 \\
\hline E22/S78 & $26 \mathrm{~A}$ & $24 \mathrm{Z} 1 \mathrm{~A}$ & Isi-c/Id & L. Paleo. & f163 & Testudinata & Shell fragment & 1 \\
\hline E22/S78 & $26 \mathrm{~A}$ & $24 \mathrm{Z} 1 \mathrm{~A}$ & Isi-c/Id & L. Paleo. & f163 & Vertebrata & Indeterminate & 4 \\
\hline E22/S78 & $26 \mathrm{~A}$ & 24Z1B & Isi-c/Id & L. Paleo. & f163 & Vertebrata & Indeterminate & 1 \\
\hline E22/S78 & $26 \mathrm{~A}$ & $24 \mathrm{Z} 1 \mathrm{C}$ & Isi-c/Id & L. Paleo. & f163 & Mammalia (Medium/large) & Indeterminate & 1 \\
\hline E22/S78 & $26 \mathrm{~A}$ & $24 \mathrm{Z} 1 \mathrm{C}$ & Isi-c/Id & L. Paleo. & f163 & Mammalia (Medium/large) & Long bone & 1 \\
\hline E22/S78 & $26 \mathrm{~A}$ & $24 \mathrm{Z} 1 \mathrm{C}$ & Isi-c/Id & L. Paleo. & f163 & Small/Medium Vertebrata & Long bone & 4 \\
\hline E22/S78 & $26 \mathrm{~A}$ & $24 \mathrm{Z} 1 \mathrm{C}$ & Isi-c/Id & L. Paleo. & f163 & Vertebrata & Indeterminate & 7 \\
\hline E22/S78 & $26 \mathrm{~A}$ & 24Z1D & Isi-c/Id & L. Paleo. & f163 & AntilocapralOdocoileus & Proximal phalange & 1 \\
\hline E22/S78 & $26 \mathrm{~A}$ & 24Z1D & Isi-c/Id & L. Paleo. & f163 & Medium/Large Vertebrata & Indeterminate & 4 \\
\hline E22/S78 & $26 \mathrm{~A}$ & 24Z1D & Isi-c/Id & L. Paleo. & f163 & Sylvilagus sp. & Calcaneus & 1 \\
\hline E22/S78 & $26 \mathrm{~A}$ & 24Z1D & Isi-c/Id & L. Paleo. & f163 & Testudinata & Shell fragment & 1 \\
\hline E22/S78 & $26 \mathrm{~A}$ & 24Z1D & Isi-c/Id & L. Paleo. & f163 & Vertebrata & Indeterminate & 22 \\
\hline E22/S78 & $26 \mathrm{~B}$ & $24 Z 2$ & Isi-c/Id & L. Paleo. & & AntilocapralOdocoileus & Metapodial & 1 \\
\hline E22/S78 & $26 \mathrm{~B}$ & $24 \mathrm{Z} 2$ & Isi-c/Id & L. Paleo. & & Mammalia (Medium) & Proximal phalange & 1 \\
\hline E22/S78 & $26 \mathrm{~B}$ & $24 Z 2$ & Isi-c/Id & L. Paleo. & & Mammalia (Medium/large) & Indeterminate & 1 \\
\hline E22/S78 & $26 \mathrm{~B}$ & $24 Z 2$ & Isi-c/Id & L. Paleo. & & Medium/Large Vertebrata & Long bone & 2 \\
\hline E22/S78 & $26 \mathrm{~B}$ & $24 Z 2$ & Isi-c/Id & L. Paleo. & & Small/Medium Vertebrata & Long bone & 3 \\
\hline E22/S78 & $26 \mathrm{~B}$ & $24 \mathrm{Z} 2$ & Isi-c/Id & L. Paleo. & & Small/Medium Vertebrata & Proximal phalange & 1 \\
\hline E22/S78 & $26 \mathrm{~B}$ & $24 Z 2$ & Isi-c/Id & L. Paleo. & & Vertebrata & Indeterminate & 48 \\
\hline $\mathrm{E} 22 / \mathrm{S} 78$ & 26B & $24 \mathrm{Z} 2 \mathrm{~A}$ & Isi-c/Id & L. Paleo. & & Mammalia (Medium/large) & Tooth, perm./decid. ind. & 1 \\
\hline E22/S78 & $26 \mathrm{~B}$ & $24 \mathrm{Z} 2 \mathrm{~A}$ & Isi-c/Id & L. Paleo. & & Testudinata & Shell fragment & 1 \\
\hline E22/S78 & $26 \mathrm{~B}$ & 24Z2B & Isi-c/Id & L. Paleo. & & Vertebrata & Indeterminate & 1 \\
\hline $\mathrm{E} 22 / \mathrm{S} 78$ & $26 \mathrm{~B}$ & $24 \mathrm{Z} 2 \mathrm{C}$ & Isi-c/Id & L. Paleo. & & Antilocapra/Odocoileus & Tibia & 1 \\
\hline $\mathrm{E} 22 / \mathrm{S} 78$ & $26 \mathrm{~B}$ & 24Z2D & Isi-c/Id & L. Paleo. & & Mammalia (Medium) & Long bone & 1 \\
\hline E22/S78 & $26 \mathrm{~B}$ & 24Z2D & Isi-c/Id & L. Paleo. & & Vertebrata & Indeterminate & 2 \\
\hline E22/S78 & $27 \mathrm{~A}$ & 24AA1A & Isi-c & L. Paleo. & & Vertebrata & Indeterminate & 2 \\
\hline E22/S78 & $27 \mathrm{~A}$ & 24AA1B & Isi-c & L. Paleo. & & Mammalia (Medium/large) & Indeterminate & 2 \\
\hline E22/S78 & $27 \mathrm{~A}$ & 24AA1B & Isi-c & L. Paleo. & & Vertebrata & Indeterminate & 6 \\
\hline E22/S78 & $27 \mathrm{~A}$ & 24AA1B & Isi-c & L. Paleo. & & Vertebrata & Long bone & 1 \\
\hline E22/S78 & $27 \mathrm{~A}$ & 24AA1B & Isi-c & L. Paleo. & & Vertebrata & Metapodial & 1 \\
\hline E22/S78 & $27 \mathrm{~A}$ & 24AA1C & Isi-c & L. Paleo. & & Mammalia (Medium/large) & Indeterminate & 1 \\
\hline
\end{tabular}




\begin{tabular}{|c|c|c|c|c|c|c|c|c|}
\hline Square & Level & Lot & Unit & Cultural Affinity & Feature & Taxon & Element & No. \\
\hline$\overline{E 22 / S 78}$ & $27 \mathrm{~A}$ & $24 \mathrm{AA} 1 \mathrm{C}$ & Isi-c & L. Paleo. & & Vertebrata & Indeterminate & 2 \\
\hline E22/S78 & $27 \mathrm{~A}$ & 24AA1D & Isi-c & L. Paleo. & & Vertebrata & Indeterminate & 3 \\
\hline E22/S78 & 27B & 24AA2A & Isi-c & L. Paleo. & & Mammalia (Medium) & Phalange & 1 \\
\hline E22/S78 & 27B & 24AA2A & Isi-c & L. Paleo. & & Mammalia (Small/medium) & Tooth, perm./decid. ind. & 1 \\
\hline E22/S78 & 27B & 24AA2A & Isi-c & L. Paleo. & & Vertebrata & Indeterminate & 10 \\
\hline E22/S78 & 27B & 24AA2C & Isi-c & L. Paleo. & & Vertebrata & Indeterminate & 4 \\
\hline E22/S78 & 27B & 24AA2D & Isi-c & L. Paleo. & & Vertebrata & Indeterminate & 1 \\
\hline E22/S78 & $28 \mathrm{~A}$ & 24BB1A & Isi-c & L. Paleo. & & Vertebrata & Indeterminate & 3 \\
\hline E22/S78 & $28 \mathrm{~A}$ & 24BB1B & Isi-c & L. Paleo. & & Mammalia (Medium) & Humerus & 1 \\
\hline E22/S78 & $28 \mathrm{~A}$ & 24BB1B & Isi-c & L. Paleo. & & Vertebrata & Indeterminate & 8 \\
\hline E22/S78 & $28 \mathrm{~A}$ & 24BB1C & Isi-c & L. Paleo. & & Mammalia (Medium/large) & Indeterminate & 1 \\
\hline E22/S78 & $28 \mathrm{~A}$ & 24BB1C & Isi-c & L. Paleo. & & Vertebrata & Indeterminate & 3 \\
\hline E22/S78 & $28 \mathrm{~A}$ & 24BB1D & Isi-c & L. Paleo. & & Mammalia (Medium/large) & Long bone & 1 \\
\hline E22/S78 & $28 \mathrm{~B}$ & 24BB2A & Isi/Isi-c & Paleoindian & & Medium/Large Vertebrata & Indeterminate & 3 \\
\hline E22/S78 & $28 \mathrm{~B}$ & 24BB2A & Isi/Isi-c & Paleoindian & & Vertebrata & Indeterminate & 4 \\
\hline E22/S78 & $28 \mathrm{~B}$ & 24BB2B & Isi/Isi-c & Paleoindian & & Vertebrata & Indeterminate & 1 \\
\hline E22/S78 & $28 \mathrm{~B}$ & $24 B$ B2C & Isi/Isi-c & Paleoindian & & Small/Medium Vertebrata & Long bone & 1 \\
\hline E22/S78 & 28B & 24BB2C & Isi/Isi-c & Paleoindian & & Vertebrata & Indeterminate & 1 \\
\hline E22/S78 & $28 \mathrm{~B}$ & 24BB2D & Isi/Isi-c & Paleoindian & & Vertebrata & Indeterminate & 1 \\
\hline E22/S78 & $29 \mathrm{~A}$ & $24 \mathrm{CC} 1 \mathrm{~A}$ & Isi/Isi-c & Paleoindian & & Mammalia (Medium/large) & Indeterminate & 3 \\
\hline E22/S78 & $29 \mathrm{~A}$ & 24CC1A & Isi/Isi-c & Paleoindian & & Sylvilagus sp. & Calcaneus & 1 \\
\hline E22/S78 & $29 \mathrm{~A}$ & $24 \mathrm{CC} 1 \mathrm{~A}$ & Isi/Isi-c & Paleoindian & & Vertebrata & Indeterminate & 14 \\
\hline E22/S78 & $29 \mathrm{~A}$ & $24 \mathrm{CC} 1 \mathrm{~B}$ & Isi/Isi-c & Paleoindian & & Vertebrata & Indeterminate & 1 \\
\hline E22/S78 & 29B & $24 \mathrm{CC} 2 \mathrm{~A}$ & Isi/Isi-c & Paleoindian & & Vertebrata & Indeterminate & 6 \\
\hline E22/S78 & $29 \mathrm{~B}$ & $24 \mathrm{CC} 2 \mathrm{~B}$ & Isi/Isi-c & Paleoindian & & Vertebrata & Long bone & 1 \\
\hline E22/S78 & $29 \mathrm{~B}$ & $24 \mathrm{CC} 2 \mathrm{C}$ & Isi/Isi-c & Paleoindian & & Vertebrata & Indeterminate & 1 \\
\hline E22/S78 & $30 \mathrm{~A}$ & 24DD1A & Isi/Isi-c & Paleoindian & & Vertebrata & Indeterminate & 3 \\
\hline E22/S78 & $30 \mathrm{~A}$ & 24DD1C & Isi/Isi-c & Paleoindian & & Mammalia (Medium/large) & Long bone & 1 \\
\hline E22/S78 & $30 \mathrm{~A}$ & 24DD1C & Isi/Isi-c & Paleoindian & & Small/Medium Vertebrata & Long bone & 1 \\
\hline E22/S78 & $30 \mathrm{~A}$ & 24DD1C & Isi/Isi-c & Paleoindian & & Vertebrata & Indeterminate & 3 \\
\hline E22/S78 & $30 \mathrm{~A}$ & 24DD1D & Isi/Isi-c & Paleoindian & & Bison sp. & Astragalus & 1 \\
\hline E22/S78 & $30 \mathrm{~A}$ & 24DD1D & Isi/Isi-c & Paleoindian & & Vertebrata & Indeterminate & 16 \\
\hline E22/S78 & $30 \mathrm{~B}$ & 24DD2B & Isi/Isi-c & Paleoindian & & Vertebrata & Indeterminate & 2 \\
\hline E22/S78 & $30 \mathrm{~B}$ & 24DD2C & Isi/Isi-c & Paleoindian & & Mammalia (Large) & Tooth, perm./decid. ind. & 1 \\
\hline E22/S78 & 30B & 24DD2C & Isi/Isi-c & Paleoindian & & Mammalia (Medium/large) & Indeterminate & 1 \\
\hline E22/S78 & 30B & 24DD2D & Isi/Isi-c & Paleoindian & & Mammalia (Very large) & Indeterminate & 1 \\
\hline E22/S78 & $31 \mathrm{~A}$ & 24EE1B & Isi/Isi-c & Paleoindian & & Medium/Large Vertebrata & Indeterminate & 1 \\
\hline E22/S78 & $31 \mathrm{~A}$ & 24EE1B & Isi/Isi-c & Paleoindian & & Vertebrata & Indeterminate & 1 \\
\hline E22/S78 & $31 \mathrm{~A}$ & 24EE1C & Isi/Isi-c & Paleoindian & & Mammalia (Large) & Long bone & 1 \\
\hline E22/S78 & $31 \mathrm{~A}$ & 24EE1C & Isi/Isi-c & Paleoindian & & Mammalia (Medium/large) & Indeterminate & 6 \\
\hline E22/S78 & $31 \mathrm{~A}$ & 24EE1C & Isi/Isi-c & Paleoindian & & Vertebrata & Indeterminate & 9 \\
\hline E22/S78 & $31 \mathrm{~B}$ & 24EE2C & Isi/Icl/Isi-c & Paleoindian & & Medium/Large Vertebrata & Indeterminate & 1 \\
\hline E22/S78 & 31B & 24EE2C & Isi/Icl/Isi-c & Paleoindian & & Vertebrata & Indeterminate & 7 \\
\hline E22/S78 & $32 \mathrm{~A}$ & 24FF1D & Isi/Icl/Isi-c & Paleoindian & & Vertebrata & Indeterminate & 1 \\
\hline E22/S80 & 6 & $23 \mathrm{~F}$ & IIIc & L. Archaic & & Antilocapra/Odocoileus & Astragalus & 1 \\
\hline $\mathrm{E} 22 / \mathrm{S} 80$ & 6 & $23 \mathrm{~F}$ & IIIIc & L. Archaic & & Mammalia (Medium/large) & Indeterminate & 3 \\
\hline $\mathrm{E} 22 / \mathrm{S} 80$ & 6 & $23 \mathrm{~F}$ & IIII & L. Archaic & & Vertebrata & Indeterminate & 9 \\
\hline $\mathrm{E} 22 / \mathrm{S} 80$ & 6 & $23 \mathrm{~F}$ & IIIc & L. Archaic & & Vertebrata & Long bone & 1 \\
\hline E22/S80 & 7 & $23 \mathrm{G}$ & $\mathrm{IIIb} / \mathrm{c}$ & Middle/L. Archaic & & Antilocapra/Odocoileus & Radius & 1 \\
\hline E22/S80 & 7 & $23 \mathrm{G}$ & $\mathrm{IIIb} / \mathrm{c}$ & Middle/L. Archaic & & Mammalia (Medium/large) & Indeterminate & 1 \\
\hline $\mathrm{E} 22 / \mathrm{S} 80$ & 7 & $23 \mathrm{G}$ & $\mathrm{IIIb} / \mathrm{c}$ & Middle/L. Archaic & & Mammalia (Medium/large) & Long bone & 2 \\
\hline $\mathrm{E} 22 / \mathrm{S} 80$ & 7 & $23 \mathrm{G}$ & $\mathrm{IITb} / \mathrm{c}$ & Middle/L. Archaic & & Odocoileus sp. & Proximal phalange & 1 \\
\hline E22/S80 & 7 & $23 \mathrm{G}$ & $\mathrm{IIIb} / \mathrm{c}$ & Middle/L. Archaic & & Vertebrata & Indeterminate & 10 \\
\hline E22/S80 & 8 & $23 \mathrm{H}$ & $\mathrm{IIb} / \mathrm{c}$ & M. Archaic & & Canis sp. & Permanent tooth & 1 \\
\hline $\mathrm{E} 22 / \mathrm{S} 80$ & 8 & $23 \mathrm{H}$ & $\mathrm{IIb} / \mathrm{c}$ & M. Archaic & & Mammalia (Medium/large) & Cranium & 1 \\
\hline E22/S80 & 8 & $23 \mathrm{H}$ & $\mathrm{IIlb} / \mathrm{c}$ & M. Archaic & & Mammalia (Medium/large) & Mandible & 1 \\
\hline E22/S80 & 8 & $23 \mathrm{H}$ & $\mathrm{IIIb} / \mathrm{c}$ & M. Archaic & & Vertebrata & Indeterminate & 21 \\
\hline $\mathrm{E} 22 / \mathrm{S} 80$ & 9 & $23 \mathrm{I}$ & IIIb & M. Archaic & & Vertebrata & Indeterminate & 8 \\
\hline E22/S80 & 10 & $23 \mathrm{~J}$ & IIIlb & Early/M. Archaic & & Mammalia (Medium/large) & Indeterminate & 4 \\
\hline $\mathrm{E} 22 / \mathrm{S} 80$ & 10 & $23 \mathrm{~J}$ & IIIlb & Early/M. Archaic & & Vertebrata & Indeterminate & 4 \\
\hline $\mathrm{E} 22 / \mathrm{S} 80$ & 11 & $23 \mathrm{~K}$ & IIIb & Early/M. Archaic & & Leporidae & Astragalus & 1 \\
\hline E22/S80 & 11 & $23 \mathrm{~K}$ & IIIlb & Early/M. Archaic & & Mammalia (Medium/large) & Long bone & 6 \\
\hline $\mathrm{E} 22 / \mathrm{S} 80$ & 11 & $23 \mathrm{~K}$ & IIIb & Early/M. Archaic & & Odocoileus sp. & Intermediate carpal bone & 2 \\
\hline E22/S80 & 11 & $23 \mathrm{~K}$ & IIIb & Early/M. Archaic & & Vertebrata & Indeterminate & 4 \\
\hline E22/S80 & 12 & $23 \mathrm{~L}$ & IIIlb & E. Archaic & & Mammalia (Medium/large) & Indeterminate & 1 \\
\hline E22/S80 & 12 & $23 \mathrm{~L}$ & IIIb & E. Archaic & & Vertebrata & Indeterminate & 1 \\
\hline $\mathrm{E} 22 / \mathrm{S} 80$ & 13 & $23 \mathrm{M}$ & IIIa/b & E. Archaic & & Mammalia (Medium/large) & Indeterminate & 2 \\
\hline
\end{tabular}




\begin{tabular}{|c|c|c|c|c|c|c|c|c|}
\hline Square & Level & Lot & Unit & Cultural Affinity & Feature & Taxon & Element & No. \\
\hline E22/S80 & 13 & $23 \mathrm{M}$ & $\mathrm{IIa} / \mathrm{b}$ & E. Archaic & & Vertebrata & Indeterminate & 4 \\
\hline $\mathrm{E} 22 / \mathrm{S} 80$ & 15 & 230 & IIIa & E. Archaic & & Mammalia (Medium) & Proximal phalange & 1 \\
\hline $\mathrm{E} 22 / \mathrm{S} 80$ & 15 & 230 & ШІа & E. Archaic & & Mammalia (Medium/large) & Indeterminate & 1 \\
\hline $\mathrm{E} 22 / \mathrm{S} 80$ & 16 & $23 \mathrm{P}$ & IIIa & E. Archaic & & Mammalia (Medium/large) & Indeterminate & 2 \\
\hline $\mathrm{E} 22 / \mathrm{S} 80$ & 16 & $23 \mathrm{P}$ & Ша & E. Archaic & & Vertebrata & Indeterminate & 3 \\
\hline $\mathrm{E} 22 / \mathrm{S} 80$ & 17 & $23 \mathrm{Q}$ & П/Ша & L. Paleo./E. Archaic & & Mammalia (Medium/large) & Indeterminate & 1 \\
\hline $\mathrm{E} 22 / \mathrm{S} 80$ & 17 & $23 \mathrm{Q}$ & II/IIIa & L. Paleo./E. Archaic & & Vertebrata & Indeterminate & 6 \\
\hline $\mathrm{E} 22 / \mathrm{S} 80$ & 18 & $23 \mathrm{R}$ & II & L. Paleo. & & Vertebrata & Indeterminate & 11 \\
\hline $\mathrm{E} 22 / \mathrm{S} 80$ & 18 & $23 \mathrm{R}$ & II & L. Paleo. & & Vertebrata & Long bone & 1 \\
\hline $\mathrm{E} 22 / \mathrm{S} 80$ & 19 & $23 \mathrm{~S}$ & II & L. Paleo. & & Mammalia (Medium/large) & Indeterminate & 3 \\
\hline $\mathrm{E} 22 / \mathrm{S} 80$ & 19 & $23 \mathrm{~S}$ & II & L. Paleo. & & Medium/Large Vertebrata & Indeterminate & 3 \\
\hline $\mathrm{E} 22 / \mathrm{S} 80$ & 19 & $23 \mathrm{~S}$ & II & L. Paleo. & & Vertebrata & Indeterminate & 12 \\
\hline $\mathrm{E} 22 / \mathrm{S} 80$ & 21 & $23 \mathrm{U}$ & II & L. Paleo. & & Small/Medium Vertebrata & Long bone & 1 \\
\hline $\mathrm{E} 22 / \mathrm{S} 80$ & 23 & $23 \mathrm{~W}$ & $\mathrm{Id} / \mathrm{II}$ & L. Paleo. & & Mammalia (Medium/large) & Long bone & 1 \\
\hline $\mathrm{E} 22 / \mathrm{S} 80$ & 23 & $23 \mathrm{~W}$ & $\mathrm{Id} / \mathrm{II}$ & L. Paleo. & & Medium/Large Vertebrata & Indeterminate & 1 \\
\hline E22/S80 & 23 & $23 \mathrm{~W}$ & $\mathrm{Id} / \mathrm{II}$ & L. Paleo. & & Small/Medium Vertebrata & Long bone & 2 \\
\hline $\mathrm{E} 22 / \mathrm{S} 80$ & 23 & $23 \mathrm{~W}$ & $\mathrm{Id} / \mathrm{II}$ & L. Paleo. & & Vertebrata & Indeterminate & 4 \\
\hline $\mathrm{E} 22 / \mathrm{S} 80$ & 24 & $23 \mathrm{X}$ & Isi-c/Id & L. Paleo. & & Mammalia (Large) & Indeterminate & 2 \\
\hline $\mathrm{E} 22 / \mathrm{S} 80$ & 24 & $23 \mathrm{X}$ & Isi-c/Id & L. Paleo. & & Mammalia (Large) & Vertebra & 1 \\
\hline $\mathrm{E} 22 / \mathrm{S} 80$ & 24 & $23 \mathrm{X}$ & Isi-c/Id & L. Paleo. & & Mammalia (Medium/large) & Long bone & 1 \\
\hline $\mathrm{E} 22 / \mathrm{S} 80$ & 24 & $23 X$ & Isi-c/Id & L. Paleo. & & Small/Medium Vertebrata & Long bone & 2 \\
\hline $\mathrm{E} 22 / \mathrm{S} 80$ & 24 & $23 \mathrm{X}$ & Isi-c/Id & L. Paleo. & & Vertebrata & Indeterminate & 10 \\
\hline $\mathrm{E} 22 / \mathrm{S} 80$ & 25 & $23 \mathrm{Y}$ & Isi-c & L. Paleo. & & Vertebrata & Indeterminate & 6 \\
\hline $\mathrm{E} 22 / \mathrm{S} 80$ & 26 & $23 Z$ & Isi-c & L. Paleo. & & Medium/Large Vertebrata & Indeterminate & 3 \\
\hline $\mathrm{E} 22 / \mathrm{S} 80$ & 26 & $23 Z$ & Isi-c & L. Paleo. & & Vertebrata & Indeterminate & 4 \\
\hline $\mathrm{E} 22 / \mathrm{S} 80$ & 27 & $23 \mathrm{AA}$ & Isi/Isi-c & L. Paleo. & & Vertebrata & Indeterminate & 5 \\
\hline E22/S82 & 6 & $22 \mathrm{~F}$ & $\mathrm{IIIb} / \mathrm{c}$ & Middle/L. Archaic & & Mammalia (Medium/large) & Indeterminate & 6 \\
\hline E22/S82 & 6 & $22 \mathrm{~F}$ & $\mathrm{IIIb} / \mathrm{c}$ & Middle/L. Archaic & & Odocoileus sp. & Distal phalange & 1 \\
\hline $\mathrm{E} 22 / \mathrm{S} 82$ & 6 & $22 \mathrm{~F}$ & $\mathrm{IIb} / \mathrm{c}$ & Middle/L. Archaic & & Trionyx sp. & Shell fragment & 1 \\
\hline $\mathrm{E} 22 / \mathrm{S} 82$ & 6 & $22 \mathrm{~F}$ & $\mathrm{IIIb} / \mathrm{c}$ & Middle/L. Archaic & & Vertebrata & Indeterminate & 29 \\
\hline E22/S82 & 7 & $22 \mathrm{G}$ & $\mathrm{IIIb} / \mathrm{c}$ & Middle/L. Archaic & & Antilocapra/Odocoileus & Ulnar carpal bone & 1 \\
\hline $\mathrm{E} 22 / \mathrm{S} 82$ & 7 & $22 \mathrm{G}$ & $\mathrm{IIb} / \mathrm{c}$ & Middle/L. Archaic & & Mammalia (Large) & Rib & 1 \\
\hline $\mathrm{E} 22 / \mathrm{S} 82$ & 7 & $22 \mathrm{G}$ & $\mathrm{mb} / \mathrm{c}$ & Middle/L. Archaic & & Mammalia (Large) & Sacrum & 1 \\
\hline $\mathrm{E} 22 / \mathrm{S} 82$ & 7 & $22 \mathrm{G}$ & $\mathrm{IIIb} / \mathrm{c}$ & Middle/L. Archaic & & Mammalia (Medium/large) & Indeterminate & 5 \\
\hline $\mathrm{E} 22 / \mathrm{S} 82$ & 7 & $22 \mathrm{G}$ & $\mathrm{IIb} / \mathrm{c}$ & Middle/L. Archaic & & Odocoileus sp. & Fused 3rd \& 4th metatarsal & 1 \\
\hline $\mathrm{E} 22 / \mathrm{S} 82$ & 7 & $22 \mathrm{G}$ & $\mathrm{IIb} / \mathrm{c}$ & Middle/L. Archaic & & Odocoileus sp. & Mandible & 1 \\
\hline $\mathrm{E} 22 / \mathrm{S} 82$ & 7 & $22 \mathrm{G}$ & $\mathrm{IIIb} / \mathrm{c}$ & Middle/L. Archaic & & Vertebrata & Indeterminate & 23 \\
\hline $\mathrm{E} 22 / \mathrm{S} 82$ & 8 & $22 \mathrm{H}$ & $\mathrm{IIlb} / \mathrm{c}$ & M. Archaic & & Mammalia (Medium/large) & Long bone & 2 \\
\hline $\mathrm{E} 22 / \mathrm{S} 82$ & 8 & $22 \mathrm{H}$ & $\mathrm{IIlb} / \mathrm{c}$ & M. Archaic & & Odocoileus sp. & Fused 3rd \& 4th metatarsal & 1 \\
\hline $\mathrm{E} 22 / \mathrm{S} 82$ & 8 & $22 \mathrm{H}$ & $\mathrm{IIIb} / \mathrm{c}$ & M. Archaic & & Odocoileus sp. & Permanent tooth & 1 \\
\hline $\mathrm{E} 22 / \mathrm{S} 82$ & 8 & $22 \mathrm{H}$ & $\mathrm{IIb} / \mathrm{c}$ & M. Archaic & & Sylvilagus sp. & Calcaneus & 1 \\
\hline $\mathrm{E} 22 / \mathrm{S} 82$ & 8 & $22 \mathrm{H}$ & $\mathrm{mb} / \mathrm{c}$ & M. Archaic & & Vertebrata & Indeterminate & 9 \\
\hline $\mathrm{E} 22 / \mathrm{S} 82$ & 9 & $22 I$ & IIIb & Early/M. Archaic & & Mammalia (Large) & Indeterminate & 1 \\
\hline $\mathrm{E} 22 / \mathrm{S} 82$ & 9 & $22 I$ & IIIb & Early/M. Archaic & & Mammalia (Large) & Long bone & 1 \\
\hline $\mathrm{E} 22 / \mathrm{S} 82$ & 9 & $22 I$ & IIIb & Early/M. Archaic & & Mammalia (Medium/large) & Indeterminate & 1 \\
\hline $\mathrm{E} 22 / \mathrm{S} 82$ & 9 & $22 \mathrm{I}$ & IIIb & Early/M. Archaic & & Odocoileus sp. & Fused 3rd \& 4th metatarsal & 1 \\
\hline $\mathrm{E} 22 / \mathrm{S} 82$ & 9 & $22 I$ & IIIb & Early/M. Archaic & & Odocoileus sp. & Proximal phalange & 1 \\
\hline $\mathrm{E} 22 / \mathrm{S} 82$ & 9 & $22 I$ & IIIb & Early/M. Archaic & & Vertebrata & Indeterminate & 4 \\
\hline $\mathrm{E} 22 / \mathrm{S} 82$ & 10 & $22 \mathrm{~J}$ & IIIb & Early/M. Archaic & & Antilocapra/Odocoileus & Calcaneus & 1 \\
\hline $\mathrm{E} 22 / \mathrm{S} 82$ & 10 & $22 \mathrm{~J}$ & IIIlb & Early/M. Archaic & & Antilocapra/Odocoileus & Fused 3rd \& 4th metatarsal & 1 \\
\hline $\mathrm{E} 22 / \mathrm{S} 82$ & 10 & $22 \mathrm{~J}$ & IIIb & Early/M. Archaic & & Antilocapra/Odocoileus & Metapodial & 1 \\
\hline $\mathrm{E} 22 / \mathrm{S} 82$ & 10 & $22 \mathrm{~J}$ & IIIb & Early/M. Archaic & & Antilocapra/Odocoileus & Ulna & 1 \\
\hline $\mathrm{E} 22 / \mathrm{S} 82$ & 10 & $22 \mathrm{~J}$ & IIIb & Early/M. Archaic & & Mammalia (Large) & Indeterminate & 2 \\
\hline $\mathrm{E} 22 / \mathrm{S} 82$ & 10 & $22 \mathrm{~J}$ & IIIb & Early/M. Archaic & & Vertebrata & Indeterminate & 12 \\
\hline $\mathrm{E} 22 / \mathrm{S} 82$ & 10 & $22 \mathrm{~J}$ & IIIb & Early/M. Archaic & & Vertebrata & Long bone & 1 \\
\hline $\mathrm{E} 22 / \mathrm{S} 82$ & 11 & $22 \mathrm{~K}$ & IIIb & Early/M. Archaic & & Carnivora & Permanent tooth & 1 \\
\hline $\mathrm{E} 22 / \mathrm{S} 82$ & 11 & $22 \mathrm{~K}$ & IIIb & Early/M. Archaic & & Mammalia (Medium) & Ulna & 1 \\
\hline $\mathrm{E} 22 / \mathrm{S} 82$ & 11 & $22 \mathrm{~K}$ & $\mathrm{IIb}$ & Early/M. Archaic & & Mammalia (Medium/large) & Indeterminate & 1 \\
\hline $\mathrm{E} 22 / \mathrm{S} 82$ & 11 & $22 \mathrm{~K}$ & IIIb & Early/M. Archaic & & Testudinata & Plastron fragment ind. & 1 \\
\hline $\mathrm{E} 22 / \mathrm{S} 82$ & 11 & $22 \mathrm{~K}$ & IIIb & Early/M. Archaic & & Testudinata & Shell fragment & 1 \\
\hline $\mathrm{E} 22 / \mathrm{S} 82$ & 11 & $22 \mathrm{~K}$ & IIIb & Early/M. Archaic & & Vertebrata & Indeterminate & 8 \\
\hline $\mathrm{E} 22 / \mathrm{S} 82$ & 12 & $22 \mathrm{~L}$ & IIIb & E. Archaic & & Lepus californicus & Tibia & 1 \\
\hline $\mathrm{E} 22 / \mathrm{S} 82$ & 12 & $22 \mathrm{~L}$ & IIIlb & E. Archaic & & Mammalia (Large) & Long bone & 1 \\
\hline $\mathrm{E} 22 / \mathrm{S} 82$ & 12 & $22 \mathrm{~L}$ & IIIb & E. Archaic & & Mammalia (Medium/large) & Indeterminate & 6 \\
\hline $\mathrm{E} 22 / \mathrm{S} 82$ & 12 & $22 \mathrm{~L}$ & IIIb & E. Archaic & & Mammalia (Medium/large) & Long bone & 7 \\
\hline $\mathrm{E} 22 / \mathrm{S} 82$ & 12 & $22 \mathrm{~L}$ & IIIb & E. Archaic & & Vertebrata & Indeterminate & 11 \\
\hline $\mathrm{E} 22 / \mathrm{S} 82$ & 13 & $22 \mathrm{M}$ & IIIa/b & E. Archaic & & Mammalia (Medium/large) & Long bone & 1 \\
\hline
\end{tabular}




\begin{tabular}{|c|c|c|c|c|c|c|c|c|}
\hline Square & Level & Lot & Unit & Cultural Affinity & Feature & Taxon & Element & No. \\
\hline$\overline{\mathrm{E} 22 / \mathrm{S} 82}$ & 13 & $22 \mathrm{M}$ & $\overline{\mathrm{IIa} / \mathrm{b}}$ & E. Archaic & & Testudinata & Shell fragment & 1 \\
\hline E22/S82 & 13 & $22 \mathrm{M}$ & IIIa/b & E. Archaic & & Vertebrata & Indeterminate & 4 \\
\hline E22/S82 & 14 & $22 \mathrm{~N}$ & Ша & E. Archaic & & Mammalia (Medium/large) & Indeterminate & 3 \\
\hline E22/S82 & 14 & $22 \mathrm{~N}$ & Ша & E. Archaic & & Medium/Large Vertebrata & Indeterminate & 3 \\
\hline E22/S82 & 14 & $22 \mathrm{~N}$ & IIIa & E. Archaic & & Small/Medium Vertebrata & Long bone & 1 \\
\hline E22/S82 & 14 & $22 \mathrm{~N}$ & IIIa & E. Archaic & & Vertebrata & Indeterminate & 10 \\
\hline E22/S82 & 15 & 220 & IIIa & E. Archaic & & Mammalia (Medium/large) & Indeterminate & 2 \\
\hline E22/S82 & 15 & 220 & IIIIa & E. Archaic & & Mammalia (Medium/large) & Long bone & 1 \\
\hline E22/S82 & 15 & $22 \mathrm{O}$ & ШІІа & E. Archaic & & Testudinata & Peripheral & 1 \\
\hline E22/S82 & 15 & 220 & III & E. Archaic & & Vertebrata & Indeterminate & 15 \\
\hline E22/S82 & 16 & $22 \mathrm{P}$ & II/IIIa & E. Archaic & & Mammalia (Medium/large) & Indeterminate & 3 \\
\hline E22/S82 & 16 & $22 \mathrm{P}$ & II/ШII & E. Archaic & & Testudinata & Peripheral & 1 \\
\hline E22/S82 & 16 & $22 \mathrm{P}$ & II/IIIa & E. Archaic & & Vertebrata & Indeterminate & 9 \\
\hline E22/S82 & 17 & $22 \mathrm{Q}$ & III & L. Paleo. & & Mammalia (Medium/large) & Indeterminate & 2 \\
\hline E22/S82 & 17 & $22 \mathrm{Q}$ & III & L. Paleo. & & Mammalia (Medium/large) & Long bone & 3 \\
\hline E22/S82 & 17 & $22 \mathrm{Q}$ & III & L. Paleo. & & Medium/Large Vertebrata & Indeterminate & 3 \\
\hline E22/S82 & 18 & $22 \mathrm{R}$ & III & L. Paleo. & & Mammalia (Medium/large) & Indeterminate & 1 \\
\hline E22/S82 & 18 & $22 \mathrm{R}$ & III & L. Paleo. & & Vertebrata & Indeterminate & 4 \\
\hline E22/S82 & 19 & $22 \mathrm{~S}$ & III & L. Paleo. & & Lepus californicus & Calcaneus & 1 \\
\hline E22/S82 & 19 & $22 \mathrm{~S}$ & III & L. Paleo. & & Mammalia (Medium/large) & Indeterminate & 3 \\
\hline E22/S82 & 19 & $22 \mathrm{~S}$ & III & L. Paleo. & & Medium/Large Vertebrata & Indeterminate & 6 \\
\hline E22/S82 & 19 & $22 \mathrm{~S}$ & III & L. Paleo. & & Vertebrata & Indeterminate & 8 \\
\hline E22/S82 & 20 & $22 \mathrm{~T}$ & III & L. Paleo. & & Mammalia (Medium/large) & Indeterminate & 4 \\
\hline E22/S82 & 20 & $22 \mathrm{~T}$ & III & L. Paleo. & & Medium/Large Vertebrata & Indeterminate & 3 \\
\hline E22/S82 & 20 & $22 \mathrm{~T}$ & III & L. Paleo. & & Medium/Large Vertebrata & Long bone & 1 \\
\hline E22/S82 & 20 & $22 \mathrm{~T}$ & III & L. Paleo. & & Small/Medium Vertebrata & Long bone & 2 \\
\hline $\mathrm{E} 22 / \mathrm{S} 82$ & 20 & $22 \mathrm{~T}$ & II & L. Paleo. & & Vertebrata & Indeterminate & 2 \\
\hline E22/S82 & 22 & $22 \mathrm{~V}$ & III & L. Paleo. & & Mammalia (Medium/large) & Tooth, perm./decid. ind. & 1 \\
\hline E22/S82 & 22 & $22 \mathrm{~V}$ & III & L. Paleo. & & Medium/Large Vertebrata & Indeterminate & 4 \\
\hline E22/S82 & 22 & $22 \mathrm{~V}$ & III & L. Paleo. & & Vertebrata & Indeterminate & 1 \\
\hline E22/S82 & 23 & $22 \mathrm{~W}$ & Id/II & L. Paleo. & & Mammalia (Large) & Long bone & 1 \\
\hline E22/S82 & 23 & $22 \mathrm{~W}$ & Id/II & L. Paleo. & & Mammalia (Medium/large) & Long bone & 5 \\
\hline E22/S82 & 23 & $22 \mathrm{~W}$ & Id/II & L. Paleo. & & Medium/Large Vertebrata & Indeterminate & 4 \\
\hline E22/S82 & 23 & $22 \mathrm{~W}$ & $\mathrm{Id} / \mathrm{II}$ & L. Paleo. & & Vertebrata & Indeterminate & 1 \\
\hline E22/S82 & 24 & $22 \mathrm{X}$ & Isi-c/Id & L. Paleo. & & Mammalia (Medium/large) & Indeterminate & 2 \\
\hline E22/S82 & 24 & $22 \mathrm{X}$ & Isi-c/Id & L. Paleo. & & Small/Medium Vertebrata & Indeterminate & 5 \\
\hline E22/S82 & 24 & $22 \mathrm{X}$ & Isi-c/Id & L. Paleo. & & Vertebrata & Indeterminate & 6 \\
\hline E22/S82 & 25 & $22 \mathrm{Y}$ & $\mathrm{X} / \mathrm{Isi}$ & Paleoindian & & Mammalia (Large) & Long bone & 1 \\
\hline E22/S82 & 25 & $22 \mathrm{Y}$ & $\mathrm{X} / \mathrm{Isi}$ & Paleoindian & & Medium/Large Vertebrata & Indeterminate & 2 \\
\hline E22/S82 & 25 & $22 \mathrm{Y}$ & $\mathrm{X} / \mathrm{Isi}$ & Paleoindian & & Vertebrata & Indeterminate & 1 \\
\hline E22/S82 & 27 & $22 \mathrm{AA}$ & $\mathrm{X} / \mathrm{Isi}$ & Paleoindian & & Mammalia (Medium/large) & Indeterminate & 1 \\
\hline E22/S82 & 27 & $22 \mathrm{AA}$ & $\mathrm{X} / \mathrm{Isi}$ & Paleoindian & & Vertebrata & Indeterminate & 5 \\
\hline E22/S84 & 6 & $21 \mathrm{~F}$ & IIIIc & Middle/L. Archaic & & Artiodactyla & Tooth, perm./decid. ind. & 1 \\
\hline E22/S84 & 6 & $21 \mathrm{~F}$ & IIII & Middle/L. Archaic & & Artiodactyla (Large) & Tooth, perm./decid. ind. & 2 \\
\hline E22/S84 & 6 & $21 \mathrm{~F}$ & IIIc & Middle/L. Archaic & & Mammalia (Medium/large) & Indeterminate & 3 \\
\hline E22/S84 & 6 & $21 \mathrm{~F}$ & IIIIc & Middle/L. Archaic & & Vertebrata & Indeterminate & 36 \\
\hline E22/S84 & 7 & $21 \mathrm{G}$ & $\mathrm{IITb} / \mathrm{c}$ & M. Archaic & & Antilocapra/Odocoileus & Radius & 1 \\
\hline E22/S84 & 7 & $21 \mathrm{G}$ & $\mathrm{IIlb} / \mathrm{c}$ & M. Archaic & & Mammalia (Large) & Indeterminate & 3 \\
\hline E22/S84 & 7 & $21 \mathrm{G}$ & $\mathrm{IIIb} / \mathrm{c}$ & M. Archaic & & Mammalia (Large) & Long bone & 2 \\
\hline E22/S84 & 7 & $21 \mathrm{G}$ & $\mathrm{IITb} / \mathrm{c}$ & M. Archaic & & Mammalia (Medium/large) & Alveolar ridge fragment & 1 \\
\hline E22/S84 & 7 & $21 \mathrm{G}$ & $\mathrm{IIIb} / \mathrm{c}$ & M. Archaic & & Mammalia (Medium/large) & Indeterminate & 4 \\
\hline E22/S84 & 7 & $21 \mathrm{G}$ & $\mathrm{IIb} / \mathrm{c}$ & M. Archaic & & Mammalia (Small) & Humerus & 1 \\
\hline E22/S84 & 7 & $21 \mathrm{G}$ & $\mathrm{IIIb} / \mathrm{c}$ & M. Archaic & & Vertebrata & Indeterminate & 16 \\
\hline E22/S84 & 8 & $21 \mathrm{H}$ & $\mathrm{IIIb} / \mathrm{c}$ & Early/M. Archaic & & Antilocapra/Odocoileus & Lumbar vertebra & 1 \\
\hline E22/S84 & 8 & $21 \mathrm{H}$ & $\mathrm{IIb} / \mathrm{c}$ & Early/M. Archaic & & Mammalia (Large) & Long bone & 1 \\
\hline E22/S84 & 8 & $21 \mathrm{H}$ & $\mathrm{IIIb} / \mathrm{c}$ & Early/M. Archaic & & Mammalia (Medium/large) & Indeterminate & 5 \\
\hline E22/S84 & 8 & $21 \mathrm{H}$ & $\mathrm{IIIb} / \mathrm{c}$ & Early/M. Archaic & & Vertebrata & Indeterminate & 17 \\
\hline E22/S84 & 9 & $21 \mathrm{I}$ & $\mathrm{IIJb} / \mathrm{c}$ & Early/M. Archaic & & Antilocapra/Odocoileus & Radius & 1 \\
\hline E22/S84 & 9 & $21 \mathrm{I}$ & $\mathrm{IIIb} / \mathrm{c}$ & Early/M. Archaic & & Carnivora & Permanent tooth & 1 \\
\hline E22/S84 & 9 & $21 \mathrm{I}$ & $\mathrm{IIIb} / \mathrm{c}$ & Early/M. Archaic & & Mammalia (Large) & Long bone & 2 \\
\hline E22/S84 & 9 & $21 \mathrm{I}$ & $\mathrm{IIIb} / \mathrm{c}$ & Early/M. Archaic & & Mammalia (Medium/large) & Indeterminate & 1 \\
\hline E22/S84 & 9 & $21 \mathrm{I}$ & $\mathrm{IIb} / \mathrm{c}$ & Early/M. Archaic & & Small/Medium Vertebrata & Long bone & 1 \\
\hline E22/S84 & 9 & $21 \mathrm{I}$ & $\mathrm{IIIb} / \mathrm{c}$ & Early/M. Archaic & & Vertebrata & Indeterminate & 20 \\
\hline E22/S84 & 10 & $21 \mathrm{~J}$ & IIIlb & E. Archaic & & Mammalia (Large) & Long bone & 1 \\
\hline E22/S84 & 10 & $21 \mathrm{~J}$ & IIIb & E. Archaic & & Mammalia (Medium/large) & Indeterminate & 5 \\
\hline E22/S84 & 10 & $21 \mathrm{~J}$ & IIIlb & E. Archaic & & Vertebrata & Indeterminate & 7 \\
\hline E22/S84 & 11 & $21 \mathrm{~K}$ & IIIlb & E. Archaic & & Mammalia (Medium/large) & Indeterminate & 2 \\
\hline
\end{tabular}




\begin{tabular}{|c|c|c|c|c|c|c|c|c|}
\hline Square & Level & Lot & Unit & Cultural Affinity & Feature & Taxon & Element & No. \\
\hline$\overline{\mathrm{E} 22 / \mathrm{S} 84}$ & 11 & $21 \mathrm{~K}$ & $\overline{\mathrm{IIb}}$ & E. Archaic & & Odocoileus sp. & Calcaneus & 1 \\
\hline $\mathrm{E} 22 / \mathrm{S} 84$ & 11 & $21 \mathrm{~K}$ & IIIb & E. Archaic & & Vertebrata & Indeterminate & 1 \\
\hline $\mathrm{E} 22 / \mathrm{S} 84$ & 12 & $21 \mathrm{~L}$ & IIIb & E. Archaic & & Mammalia (Medium/large) & Indeterminate & 1 \\
\hline $\mathrm{E} 22 / \mathrm{S} 84$ & 12 & $21 \mathrm{~L}$ & IIIlb & E. Archaic & & Vertebrata & Indeterminate & 14 \\
\hline $\mathrm{E} 22 / \mathrm{S} 84$ & 13 & $21 \mathrm{M}$ & IIIb & E. Archaic & & Antilocapra/Odocoileus & Calcaneus & 1 \\
\hline $\mathrm{E} 22 / \mathrm{S} 84$ & 13 & $21 \mathrm{M}$ & IIIb & E. Archaic & & Mammalia (Medium/large) & Indeterminate & 2 \\
\hline $\mathrm{E} 22 / \mathrm{S} 84$ & 13 & $21 \mathrm{M}$ & IIIlb & E. Archaic & & Mammalia (Medium/large) & Long bone & 1 \\
\hline E22/S84 & 13 & $21 \mathrm{M}$ & IIIb & E. Archaic & & Medium/Large Vertebrata & Indeterminate & 3 \\
\hline E22/S84 & 13 & $21 \mathrm{M}$ & IIIb & E. Archaic & & Vertebrata & Indeterminate & 2 \\
\hline $\mathrm{E} 22 / \mathrm{S} 84$ & 14 & $21 \mathrm{~N}$ & IIIa/b & E. Archaic & & Antilocapra/Odocoileus & Calcaneus & 1 \\
\hline E22/S84 & 14 & $21 \mathrm{~N}$ & IIIa/b & E. Archaic & & Mammalia (Large) & Indeterminate & 1 \\
\hline E22/S84 & 14 & $21 \mathrm{~N}$ & IIIa/b & E. Archaic & & Mammalia (Medium/large) & Indeterminate & 7 \\
\hline E22/S84 & 14 & $21 \mathrm{~N}$ & IIIa/b & E. Archaic & & Medium/Large Vertebrata & Indeterminate & 2 \\
\hline E22/S84 & 14 & $21 \mathrm{~N}$ & IIIa/b & E. Archaic & & Medium/Large Vertebrata & Long bone & 1 \\
\hline $\mathrm{E} 22 / \mathrm{S} 84$ & 14 & $21 \mathrm{~N}$ & IIIa/b & E. Archaic & & Vertebrata & Indeterminate & 20 \\
\hline $\mathrm{E} 22 / \mathrm{S} 84$ & 15 & 210 & IIIa & E. Archaic & & Mammalia (Large) & Long bone & 1 \\
\hline E22/S84 & 15 & 210 & ШІа & E. Archaic & & Mammalia (Large) & Vertebra & 2 \\
\hline E22/S84 & 15 & 210 & IIIIa & E. Archaic & & Mammalia (Medium/large) & Indeterminate & 3 \\
\hline E22/S84 & 15 & 210 & ШІа & E. Archaic & & Mammalia (Medium/large) & Long bone & 6 \\
\hline E22/S84 & 15 & 210 & IIIa & E. Archaic & & Mammalia (Medium/large) & Rib & 2 \\
\hline E22/S84 & 15 & 210 & IIIa & E. Archaic & & Medium/Large Vertebrata & Indeterminate & 9 \\
\hline E22/S84 & 15 & 210 & ШІа & E. Archaic & & Small/Medium Vertebrata & Long bone & 1 \\
\hline E22/S84 & 15 & 210 & ШІа & E. Archaic & & Testudinata & Shell fragment & 1 \\
\hline E22/S84 & 15 & 210 & ПІІа & E. Archaic & & Vertebrata & Indeterminate & 22 \\
\hline E22/S84 & 16 & $21 \mathrm{P}$ & ШІа & E. Archaic & & Leporidae & Mandible & 1 \\
\hline E22/S84 & 16 & $21 \mathrm{P}$ & III & E. Archaic & & Vertebrata & Indeterminate & 11 \\
\hline $\mathrm{E} 22 / \mathrm{S} 84$ & 17 & $21 \mathrm{Q}$ & II/IIIa & L. Paleo./E. Archaic & & Mammalia (Medium/large) & Indeterminate & 4 \\
\hline $\mathrm{E} 22 / \mathrm{S} 84$ & 17 & $21 \mathrm{Q}$ & Ш/Ша & L. Paleo./E. Archaic & & Vertebrata & Indeterminate & 9 \\
\hline E22/S84 & 18 & $21 \mathrm{R}$ & II & L. Paleo. & & Mammalia (Medium/large) & Indeterminate & 1 \\
\hline $\mathrm{E} 22 / \mathrm{S} 84$ & 18 & $21 \mathrm{R}$ & II & L. Paleo. & & Vertebrata & Indeterminate & 7 \\
\hline E22/S84 & 20 & $21 \mathrm{~T}$ & $\mathrm{X} / \mathrm{II}$ & L. Paleo. & & Mammalia (Medium/large) & Long bone & 1 \\
\hline $\mathrm{E} 22 / \mathrm{S} 84$ & 20 & $21 \mathrm{~T}$ & $\mathrm{X} / \mathrm{II}$ & L. Paleo. & & Small/Medium Vertebrata & Long bone & 1 \\
\hline $\mathrm{E} 22 / \mathrm{S} 84$ & 20 & $21 \mathrm{~T}$ & $\mathrm{X} / \mathrm{II}$ & L. Paleo. & & Vertebrata & Indeterminate & 2 \\
\hline $\mathrm{E} 22 / \mathrm{S} 84$ & 22 & $21 \mathrm{~V}$ & $\mathrm{X} / \mathrm{II}$ & L. Paleo. & & Mammalia (Medium/large) & Indeterminate & 6 \\
\hline $\mathrm{E} 22 / \mathrm{S} 84$ & 22 & $21 \mathrm{~V}$ & $\mathrm{X} / \mathrm{II}$ & L. Paleo. & & Mammalia (Medium/large) & Long bone & 2 \\
\hline $\mathrm{E} 22 / \mathrm{S} 84$ & 22 & $21 \mathrm{~V}$ & $\mathrm{X} / \mathrm{II}$ & L. Paleo. & & Medium/Large Vertebrata & Indeterminate & 6 \\
\hline $\mathrm{E} 22 / \mathrm{S} 84$ & 22 & $21 \mathrm{~V}$ & $\mathrm{X} / \mathrm{II}$ & L. Paleo. & & Vertebrata & Indeterminate & 2 \\
\hline $\mathrm{E} 22 / \mathrm{S} 84$ & 24 & $21 X$ & $\mathrm{X} / \mathrm{Isi}-\mathrm{c} / \mathrm{Id} / \mathrm{II}$ & L. Paleo. & & Mammalia (Large) & Indeterminate & 2 \\
\hline $\mathrm{E} 22 / \mathrm{S} 84$ & 24 & $21 X$ & $\mathrm{X} / \mathrm{Isi}-\mathrm{c} / \mathrm{Id} / \mathrm{II}$ & L. Paleo. & & Mammalia (Medium) & Long bone & 1 \\
\hline $\mathrm{E} 22 / \mathrm{S} 84$ & 24 & $21 X$ & $\mathrm{X} / \mathrm{Isi}-\mathrm{c} / \mathrm{Id} / \mathrm{II}$ & L. Paleo. & & Mammalia (Medium/large) & Indeterminate & 2 \\
\hline $\mathrm{E} 22 / \mathrm{S} 84$ & 24 & $21 X$ & $\mathrm{X} / \mathrm{Isi}-\mathrm{c} / \mathrm{Id} / \mathrm{II}$ & L. Paleo. & & Vertebrata & Indeterminate & 9 \\
\hline $\mathrm{E} 22 / \mathrm{S} 84$ & 25 & $21 Y$ & $\mathrm{X} / \mathrm{Isi}-\mathrm{c} / \mathrm{Id}$ & L. Paleo. & & Mammalia (Medium) & Metapodial & 1 \\
\hline $\mathrm{E} 22 / \mathrm{S} 84$ & 25 & $21 Y$ & $\mathrm{X} / \mathrm{Isi}-\mathrm{c} / \mathrm{Id}$ & L. Paleo. & & Small/Medium Vertebrata & Indeterminate & 1 \\
\hline $\mathrm{E} 22 / \mathrm{S} 84$ & 25 & $21 Y$ & $\mathrm{X} / \mathrm{Isi}-\mathrm{c} / \mathrm{Id}$ & L. Paleo. & & Vertebrata & Indeterminate & 1 \\
\hline $\mathrm{E} 22 / \mathrm{S} 86$ & 6 & $20 \mathrm{~F}$ & IIIc & Middle/L. Archaic & BRM1 & Mammalia (Medium/large) & Indeterminate & 4 \\
\hline $\mathrm{E} 22 / \mathrm{S} 86$ & 6 & $20 \mathrm{~F}$ & IIIc & Middle/L. Archaic & BRM1 & Vertebrata & Indeterminate & 14 \\
\hline $\mathrm{E} 22 / \mathrm{S} 86$ & 7 & $20 \mathrm{G}$ & IIIc & Early/M. Archaic & BRM1 & Antilocapra/Odocoileus & Fused 3rd \& 4th metacarpal & 1 \\
\hline $\mathrm{E} 22 / \mathrm{S} 86$ & 7 & $20 \mathrm{G}$ & IIIc & Early/M. Archaic & BRM1 & Mammalia (Large) & Indeterminate & 1 \\
\hline $\mathrm{E} 22 / \mathrm{S} 86$ & 7 & $20 \mathrm{G}$ & IIIc & Early/M. Archaic & BRM1 & Mammalia (Medium/large) & Indeterminate & 2 \\
\hline $\mathrm{E} 22 / \mathrm{S} 86$ & 7 & $20 \mathrm{G}$ & IIIc & Early/M. Archaic & BRM1 & Odocoileus sp. & Proximal phalange & 1 \\
\hline $\mathrm{E} 22 / \mathrm{S} 86$ & 7 & $20 \mathrm{G}$ & IIIc & Early/M. Archaic & BRM1 & Vertebrata & Indeterminate & 6 \\
\hline E22/S86 & 8 & $20 \mathrm{H}$ & $\mathrm{IIIb} / \mathrm{c}$ & Early/M. Archaic & BRM1 & Antilocapra/Odocoileus & Fused 3rd \& 4th metatarsal & 1 \\
\hline $\mathrm{E} 22 / \mathrm{S} 86$ & 8 & $20 \mathrm{H}$ & $\mathrm{IIIb} / \mathrm{c}$ & Early/M. Archaic & BRM1 & AntilocapralOdocoileus & Lumbar vertebra & 1 \\
\hline $\mathrm{E} 22 / \mathrm{S} 86$ & 8 & $20 \mathrm{H}$ & $\mathrm{IIIb} / \mathrm{c}$ & Early/M. Archaic & BRM1 & Artiodactyla & Tooth, perm./decid. ind. & 1 \\
\hline $\mathrm{E} 22 / \mathrm{S} 86$ & 8 & $20 \mathrm{H}$ & $\mathrm{IIIb} / \mathrm{c}$ & Early/M. Archaic & BRM1 & Mammalia (Large) & Long bone & 5 \\
\hline $\mathrm{E} 22 / \mathrm{S} 86$ & 8 & $20 \mathrm{H}$ & $\mathrm{IIIb} / \mathrm{c}$ & Early/M. Archaic & BRM1 & Mammalia (Large) & Pelvis & 1 \\
\hline $\mathrm{E} 22 / \mathrm{S} 86$ & 8 & $20 \mathrm{H}$ & $\mathrm{IIb} / \mathrm{c}$ & Early/M. Archaic & BRM1 & Mammalia (Large) & $\mathrm{Rib}$ & 1 \\
\hline $\mathrm{E} 22 / \mathrm{S} 86$ & 8 & $20 \mathrm{H}$ & $\mathrm{IIb} / \mathrm{c}$ & Early/M. Archaic & BRM1 & Mammalia (Medium/large) & Indeterminate & 6 \\
\hline $\mathrm{E} 22 / \mathrm{S} 86$ & 8 & $20 \mathrm{H}$ & $\mathrm{IIIb} / \mathrm{c}$ & Early/M. Archaic & BRM1 & Mammalia (Medium/large) & Long bone & 6 \\
\hline $\mathrm{E} 22 / \mathrm{S} 86$ & 8 & $20 \mathrm{H}$ & $\mathrm{IIb} / \mathrm{c}$ & Early/M. Archaic & BRM1 & Odocoileus sp. & Tibia & 1 \\
\hline $\mathrm{E} 22 / \mathrm{S} 86$ & 8 & $20 \mathrm{H}$ & $\mathrm{IIb} / \mathrm{c}$ & Early/M. Archaic & BRM1 & Small/Medium Vertebrata & Long bone & 3 \\
\hline $\mathrm{E} 22 / \mathrm{S} 86$ & 8 & $20 \mathrm{H}$ & $\mathrm{IIIb} / \mathrm{c}$ & Early/M. Archaic & BRM1 & Testudinata & Peripheral & 1 \\
\hline $\mathrm{E} 22 / \mathrm{S} 86$ & 8 & $20 \mathrm{H}$ & $\mathrm{IIb} / \mathrm{c}$ & Early/M. Archaic & BRM1 & Testudinata & Plastron fragment ind. & 2 \\
\hline $\mathrm{E} 22 / \mathrm{S} 86$ & 8 & $20 \mathrm{H}$ & $\mathrm{m} \mathrm{mb} / \mathrm{c}$ & Early/M. Archaic & BRM1 & Testudinata & Shell fragment & 2 \\
\hline $\mathrm{E} 22 / \mathrm{S} 86$ & 8 & $20 \mathrm{H}$ & $\mathrm{IIIb} / \mathrm{c}$ & Early/M. Archaic & BRM1 & Vertebrata & Indeterminate & 20 \\
\hline $\mathrm{E} 22 / \mathrm{S} 86$ & 9 & $20 I$ & $\mathrm{~m} \mathrm{mb} / \mathrm{c}$ & Early/M. Archaic & BRM1 & Antilocapra/Odocoileus & Astragalus & 1 \\
\hline $\mathrm{E} 22 / \mathrm{S} 86$ & 9 & $20 \mathrm{I}$ & $\mathrm{m} \mathrm{mb} / \mathrm{c}$ & Early/M. Archaic & BRM1 & Antilocapra/Odocoileus & Fused 3rd \& 4th metatarsal & 1 \\
\hline
\end{tabular}




\begin{tabular}{|c|c|c|c|c|c|c|c|c|}
\hline Square & Level & Lot & Unit & Cultural Affinity & Feature & Taxon & Element & No. \\
\hline E22/S86 & 9 & $20 I$ & IIlb/c & Early/M. Archaic & BRM1 & Artiodactyla (Large) & Rib & 1 \\
\hline E22/S86 & 9 & $20 I$ & $\mathrm{milb} / \mathrm{c}$ & Early/M. Archaic & BRM1 & Leporidae & Pelvis & 1 \\
\hline E22/S86 & 9 & $20 I$ & $\mathrm{mllb} / \mathrm{c}$ & Early/M. Archaic & BRM1 & Mammalia (Medium) & Pelvis & 1 \\
\hline E22/S86 & 9 & $20 I$ & $\mathrm{IIb} / \mathrm{c}$ & Early/M. Archaic & BRM1 & Mammalia (Medium/large) & Indeterminate & 3 \\
\hline E22/S86 & 9 & $20 I$ & $\mathrm{IIb} / \mathrm{c}$ & Early/M. Archaic & BRM1 & Mammalia (Medium/large) & Long bone & 1 \\
\hline E22/S86 & 9 & $20 I$ & $\mathrm{IIT} / \mathrm{c}$ & Early/M. Archaic & BRM1 & Vertebrata & Indeterminate & 13 \\
\hline E22/S86 & 10 & $20 \mathrm{~J}$ & $\mathrm{IIIb} / \mathrm{c}$ & Early/M. Archaic & BRM1 & Mammalia (Large) & Indeterminate & 1 \\
\hline E22/S86 & 10 & $20 \mathrm{~J}$ & $\mathrm{IIIb} / \mathrm{c}$ & Early/M. Archaic & BRM1 & Mammalia (Large) & Long bone & 3 \\
\hline E22/S86 & 10 & $20 \mathrm{~J}$ & $\mathrm{IIb} / \mathrm{c}$ & Early/M. Archaic & BRM1 & Mammalia (Medium/large) & Indeterminate & 4 \\
\hline E22/S86 & 10 & $20 \mathrm{~J}$ & $\mathrm{IIIb} / \mathrm{c}$ & Early/M. Archaic & BRM1 & Vertebrata & Indeterminate & 3 \\
\hline E22/S86 & 11 & $20 \mathrm{~K}$ & IIIb & E. Archaic & & Vertebrata & Indeterminate & 5 \\
\hline E22/S86 & 12 & $20 \mathrm{~L}$ & IIIb & E. Archaic & & Mammalia (Large) & Long bone & 1 \\
\hline E22/S86 & 12 & $20 \mathrm{~L}$ & IIIlb & E. Archaic & & Medium/Large Vertebrata & Indeterminate & 1 \\
\hline E22/S86 & 12 & $20 \mathrm{~L}$ & IIIb & E. Archaic & & Vertebrata & Indeterminate & 2 \\
\hline E22/S86 & 14 & $20 \mathrm{~N}$ & $\mathrm{X} / \mathrm{III} / \mathrm{b}$ & E. Archaic & & Mammalia (Medium/large) & Indeterminate & 1 \\
\hline E22/S86 & 14 & $20 \mathrm{~N}$ & $\mathrm{X} / \mathrm{III} \mathrm{a} / \mathrm{b}$ & E. Archaic & & Mammalia (Medium/large) & Long bone & 3 \\
\hline E22/S86 & 14 & $20 \mathrm{~N}$ & $\mathrm{X} / \mathrm{III} / \mathrm{b}$ & E. Archaic & & Vertebrata & |Indeterminate & 1 \\
\hline E22/S86 & 15 & 200 & X/IIIa & E. Archaic & & Antilocapra/Odocoileus & Fused 3rd \& 4th metatarsal & 1 \\
\hline E22/S86 & 15 & 200 & $\mathrm{X} / \mathrm{IIIa}$ & E. Archaic & & Mammalia (Medium/large) & Indeterminate & 6 \\
\hline E22/S86 & 15 & 200 & $\mathrm{X} / \mathrm{III}$ & E. Archaic & & Mammalia (Medium/large) & Long bone & 1 \\
\hline E22/S86 & 15 & 200 & $\mathrm{X} / \mathrm{III}$ & E. Archaic & & Medium/Large Vertebrata & Indeterminate & 1 \\
\hline E22/S86 & 15 & 200 & $\mathrm{X} / \mathrm{III}$ & E. Archaic & & Sylvilagus sp. & Tibia & 1 \\
\hline E22/S86 & 15 & 200 & $\mathrm{X} / \mathrm{III}$ & E. Archaic & & Vertebrata & Indeterminate & 4 \\
\hline E22/S86 & 16 & $20 \mathrm{P}$ & X/II/IIIa & E. Archaic & & Mammalia (Large) & Indeterminate & 1 \\
\hline E22/S86 & 16 & $20 \mathrm{P}$ & X/II/IIIa & E. Archaic & & Mammalia (Medium/large) & |Indeterminate & 3 \\
\hline E22/S86 & 16 & $20 \mathrm{P}$ & X/II/IIIa & E. Archaic & & Testudinata & Shell fragment & 1 \\
\hline E22/S86 & 16 & $20 \mathrm{P}$ & X/I/IIIa & E. Archaic & & Vertebrata & |Indeterminate & 8 \\
\hline E22/S86 & 17 & $20 \mathrm{Q}$ & X/II/IIIa & E. Archaic & & Mammalia (Large) & Long bone & 1 \\
\hline E22/S86 & 17 & $20 \mathrm{Q}$ & $\mathrm{X} / \mathrm{II} / \mathrm{III}$ & E. Archaic & & Mammalia (Medium/large) & Indeterminate & 2 \\
\hline E22/S86 & 17 & $20 \mathrm{Q}$ & X/II/IIa & E. Archaic & & Vertebrata & Indeterminate & 8 \\
\hline E22/S86 & 18 & $20 \mathrm{R}$ & $\mathrm{X} / \mathrm{II}$ & E. Archaic & & Antilocapra/Odocoileus & Astragalus & 1 \\
\hline E22/S86 & 18 & $20 \mathrm{R}$ & $\mathrm{X} / \mathrm{II}$ & E. Archaic & & Artiodactyla & Tooth, perm./decid. ind. & 1 \\
\hline E22/S86 & 18 & $20 \mathrm{R}$ & $\mathrm{X} / \mathrm{II}$ & E. Archaic & & Mammalia (Medium/large) & Indeterminate & 6 \\
\hline E22/S86 & 18 & $20 \mathrm{R}$ & $\mathrm{X} / \mathrm{II}$ & E. Archaic & & Small/Medium Vertebrata & Long bone & 1 \\
\hline E22/S86 & 18 & $20 \mathrm{R}$ & $\mathrm{X} / \mathrm{II}$ & E. Archaic & & Testudinata & Peripheral & 1 \\
\hline E22/S86 & 18 & $20 \mathrm{R}$ & $\mathrm{X} / \mathrm{II}$ & E. Archaic & & Testudinata & Shell fragment & 1 \\
\hline E22/S86 & 18 & $20 \mathrm{R}$ & $\mathrm{X} / \mathrm{II}$ & E. Archaic & & Vertebrata & |Indeterminate & 8 \\
\hline E22/S86 & 19 & $20 \mathrm{~S}$ & $\mathrm{X} / \mathrm{II}$ & L. Paleo./E. Archaic & & Vertebrata & Indeterminate & 8 \\
\hline E22/S86 & 20 & $20 \mathrm{~T}$ & $\mathrm{X} / \mathrm{II}$ & L. Paleo./E. Archaic & & Mammalia (Medium/large) & Long bone & 7 \\
\hline E22/S86 & 20 & $20 \mathrm{~T}$ & $\mathrm{X} / \mathrm{II}$ & L. Paleo./E. Archaic & & Small/Medium Vertebrata & Long bone & 1 \\
\hline E22/S86 & 20 & $20 \mathrm{~T}$ & $\mathrm{X} / \mathrm{II}$ & L. Paleo./E. Archaic & & Vertebrata & Indeterminate & 1 \\
\hline E22/S86 & 22 & $20 \mathrm{~V}$ & $\mathrm{X}$ & L. Paleo./E. Archaic & & Medium/Large Vertebrata & Indeterminate & 3 \\
\hline E22/S86 & 22 & $20 \mathrm{~V}$ & $\mathrm{X}$ & L. Paleo./E. Archaic & & Small/Medium Vertebrata & Long bone & 1 \\
\hline E22/S86 & 22 & $20 \mathrm{~V}$ & $\mathrm{X}$ & L. Paleo./E. Archaic & & Vertebrata & Indeterminate & 5 \\
\hline E22/S86 & 23 & $20 \mathrm{~W}$ & $\mathrm{X}$ & L. Paleo. & & Mammalia (Medium) & Ulna & 1 \\
\hline $\mathrm{E} 22 / \mathrm{S} 86$ & 23 & $20 \mathrm{~W}$ & $\mathrm{X}$ & L. Paleo. & & Mammalia (Medium/large) & Rib & 1 \\
\hline $\mathrm{E} 22 / \mathrm{S} 86$ & 23 & $20 \mathrm{~W}$ & $\mathrm{X}$ & L. Paleo. & & Medium/Large Vertebrata & Indeterminate & 1 \\
\hline $\mathrm{E} 22 / \mathrm{S} 86$ & 23 & $20 \mathrm{~W}$ & $\mathrm{X}$ & L. Paleo. & & Vertebrata & Indeterminate & 4 \\
\hline E22/S86 & 24 & $20 \mathrm{X}$ & $\mathrm{X}$ & L. Paleo. & & Mammalia (Medium/large) & Long bone & 2 \\
\hline $\mathrm{E} 22 / \mathrm{S} 86$ & 24 & $20 \mathrm{X}$ & $\mathrm{X}$ & L. Paleo. & & Medium/Large Vertebrata & Indeterminate & 4 \\
\hline E22/S86 & 24 & $20 \mathrm{X}$ & $\mathrm{X}$ & L. Paleo. & & Small/Medium Vertebrata & Long bone & 1 \\
\hline E22/S86 & 24 & $20 x$ & $\mathrm{X}$ & L. Paleo. & & Vertebrata & Indeterminate & 1 \\
\hline $\mathrm{E} 22 / \mathrm{S} 88$ & 6 & $19 \mathrm{~F}$ & IIIc & Middle/L. Archaic & BRM1 & cf. Odocoileus sp. & Fused 3rd \& 4th metacarpal & 1 \\
\hline E22/S88 & 6 & $19 \mathrm{~F}$ & IIIIc & Middle/L. Archaic & BRM1 & Leporidae & Humerus & 1 \\
\hline E22/S88 & 6 & $19 \mathrm{~F}$ & IIIIc & Middle/L. Archaic & BRM1 & Mammalia (Medium/large) & Indeterminate & 2 \\
\hline E22/S88 & 6 & $19 \mathrm{~F}$ & IIIc & Middle/L. Archaic & BRM1 & Mammalia (Medium/large) & Long bone & 1 \\
\hline $\mathrm{E} 22 / \mathrm{S} 88$ & 6 & $19 \mathrm{~F}$ & IIIc & Middle/L. Archaic & BRM1 & Medium/Large Vertebrata & Indeterminate & 7 \\
\hline E22/S88 & 6 & $19 \mathrm{~F}$ & IIIIc & Middle/L. Archaic & BRM1 & Vertebrata & Indeterminate & 3 \\
\hline E22/S88 & 7 & $19 \mathrm{G}$ & IIIIc & Archaic & BRM1 & Antilocapra/Odocoileus & Radius & 1 \\
\hline E22/S88 & 7 & $19 \mathrm{G}$ & IIIc & Archaic & BRM1 & Colubridae & Dorsal vertebra & 1 \\
\hline E22/S88 & 7 & $19 \mathrm{G}$ & IIIIc & Archaic & BRM1 & Mammalia (Medium/large) & |Indeterminate & 1 \\
\hline E22/S88 & 7 & $19 \mathrm{G}$ & IIII & Archaic & BRM1 & Vertebrata & Indeterminate & 6 \\
\hline E22/S88 & 8 & $19 \mathrm{H}$ & IIIc & Archaic & BRM1 & Antilocapra/Odocoileus & Fused central/fourth tarsal & 1 \\
\hline E22/S88 & 8 & $19 \mathrm{H}$ & IIIIc & Archaic & BRM1 & Mammalia (Medium/large) & Indeterminate & 1 \\
\hline E22/S88 & 8 & $19 \mathrm{H}$ & IIIIc & Archaic & BRM1 & Vertebrata & Indeterminate & 2 \\
\hline $\mathrm{E} 22 / \mathrm{S} 88$ & 9 & $19 I$ & $\mathrm{Y} / \mathrm{IIIc}$ & Early/M. Archaic & BRM1 & Antilocapra/Odocoileus & Tooth, perm./decid. ind. & 1 \\
\hline E22/S88 & 9 & 19I & $\mathrm{Y} / \mathrm{III}$ & Early/M. Archaic & BRM1 & Artiodactyla & Tooth, perm./decid. ind. & 1 \\
\hline
\end{tabular}




\begin{tabular}{|c|c|c|c|c|c|c|c|c|}
\hline Square & Level & Lot & Unit & Cultural Affinity & Feature & Taxon & Element & No. \\
\hline E22/S88 & 9 & $19 I$ & $\mathrm{Y} / \mathrm{IIIc}$ & Early/M. Archaic & BRM1 & Canis sp. & Permanent tooth & 1 \\
\hline E22/S88 & 9 & $19 \mathrm{I}$ & $\mathrm{Y} / \mathrm{IIIC}$ & Early/M. Archaic & BRM1 & cf. Aves (Medium) & Long bone & 1 \\
\hline E22/S88 & 9 & 19I & $\mathrm{Y} / \mathrm{III} \mathrm{c}$ & Early/M. Archaic & BRM1 & Lepus californicus & Ulna & 1 \\
\hline E22/S88 & 9 & 19I & $\mathrm{Y} / \mathrm{III} \mathrm{c}$ & Early/M. Archaic & BRM1 & Mammalia (Large) & Indeterminate & 2 \\
\hline E22/S88 & 9 & $19 I$ & $\mathrm{Y} / \mathrm{IIIC}$ & Early/M. Archaic & BRM1 & Mammalia (Large) & Long bone & 2 \\
\hline E22/S88 & 9 & 19I & $\mathrm{Y} / \mathrm{IIIC}$ & Early/M. Archaic & BRM1 & Mammalia (Medium/large) & Long bone & 6 \\
\hline E22/S88 & 9 & 19I & $\mathrm{Y} / \mathrm{III} \mathrm{c}$ & Early/M. Archaic & BRM1 & Mammalia (Medium/large) & Tooth, perm./decid. ind. & 2 \\
\hline E22/S88 & 9 & 19I & $\mathrm{Y} / \mathrm{IIIC}$ & Early/M. Archaic & BRM1 & Medium/Large Vertebrata & Indeterminate & 13 \\
\hline E22/S88 & 9 & 19I & $\mathrm{Y} / \mathrm{III} \mathrm{c}$ & Early/M. Archaic & BRM1 & Small/Medium Vertebrata & Long bone & 1 \\
\hline E22/S88 & 9 & 19I & $\mathrm{Y} / \mathrm{IIIC}$ & Early/M. Archaic & BRM1 & Vertebrata & Indeterminate & 4 \\
\hline E22/S88 & 10 & $19 \mathrm{~J}$ & $\mathrm{Y} / \mathrm{IIIb} / \mathrm{c}$ & Early/M. Archaic & BRM1 & Sylvilagus sp. & Calcaneus & 1 \\
\hline E22/S88 & 10 & $19 \mathrm{~J}$ & $\mathrm{Y} / \mathrm{IIIb} / \mathrm{c}$ & Early/M. Archaic & BRM1 & Vertebrata & Indeterminate & 2 \\
\hline E22/S88 & 11 & $19 \mathrm{~K}$ & $\mathrm{Y} / \mathrm{IImb}$ & E. Archaic & & Antilocapra/Odocoileus & Fused 3rd \& 4th metatarsal & 1 \\
\hline E22/S88 & 11 & $19 \mathrm{~K}$ & Y/IIIb & E. Archaic & & Mammalia (Medium/large) & Indeterminate & 5 \\
\hline E22/S88 & 11 & $19 \mathrm{~K}$ & $\mathrm{Y} / \mathrm{IIIb}$ & E. Archaic & & Vertebrata & Indeterminate & 27 \\
\hline E22/S88 & 12 & 19L & $\mathrm{X} / \mathrm{Y} / \mathrm{IIb}$ & E. Archaic & & Antilocapra/Odocoileus & Fused 3rd \& 4th metacarpal & 1 \\
\hline E22/S88 & 12 & 19L & $\mathrm{X} / \mathrm{Y} / \mathrm{IIIb}$ & E. Archaic & & Odocoileus sp. & Proximal phalange & 1 \\
\hline E22/S88 & 12 & 19L & $\mathrm{X} / \mathrm{Y} / \mathrm{IIIb}$ & E. Archaic & & Small/Medium Vertebrata & Long bone & 3 \\
\hline E22/S88 & 12 & 19L & $\mathrm{X} / \mathrm{Y} / \mathrm{IIb}$ & E. Archaic & & Testudinata & Shell fragment & 1 \\
\hline E22/S88 & 12 & 19L & $\mathrm{X} / \mathrm{Y} / \mathrm{IIIb}$ & E. Archaic & & Vertebrata & Indeterminate & 1 \\
\hline E22/S88 & 13 & $19 \mathrm{M}$ & $\mathrm{X} / \mathrm{IIIb}$ & E. Archaic & & Mammalia (Medium/large) & Indeterminate & 2 \\
\hline E22/S88 & 13 & $19 \mathrm{M}$ & $\mathrm{X} / \mathrm{IIIb}$ & E. Archaic & & Mammalia (Medium/large) & Tooth, perm./decid. ind. & 1 \\
\hline $\mathrm{E} 22 / \mathrm{S} 88$ & 13 & $19 \mathrm{M}$ & $\mathrm{X} / \mathrm{IIIb}$ & E. Archaic & & Vertebrata & Indeterminate & 4 \\
\hline E22/S88 & 14 & $19 \mathrm{~N}$ & $\mathrm{X} / \mathrm{IIlb}$ & E. Archaic & & Mammalia (Medium/large) & Indeterminate & 1 \\
\hline E22/S88 & 14 & $19 \mathrm{~N}$ & $\mathrm{X} / \mathrm{IIIb}$ & E. Archaic & & Mammalia (Medium/large) & Long bone & 1 \\
\hline E22/S88 & 14 & $19 \mathrm{~N}$ & $\mathrm{X} / \mathrm{IIIb}$ & E. Archaic & & Mammalia (Small/medium) & Long bone & 1 \\
\hline E22/S88 & 14 & $19 \mathrm{~N}$ & $\mathrm{X} / \mathrm{IIIb}$ & E. Archaic & & Vertebrata & Indeterminate & 1 \\
\hline E22/S88 & 15 & 190 & $\mathrm{X}$ & E. Archaic & & Mammalia (Medium/large) & Indeterminate & 2 \\
\hline E22/S88 & 15 & 190 & $\mathrm{X}$ & E. Archaic & & Vertebrata & Indeterminate & 4 \\
\hline E22/S88 & 16 & 19P & $\mathrm{X}$ & L. Paleo./E. Archaic & & Mammalia (Medium/large) & Indeterminate & 1 \\
\hline E22/S88 & 16 & 19P & $\mathrm{X}$ & L. Paleo./E. Archaic & & Vertebrata & Indeterminate & 10 \\
\hline E22/S88 & 16 & 19P & $\mathrm{X}$ & L. Paleo./E. Archaic & & Vertebrata & Long bone & 1 \\
\hline $\mathrm{E} 22 / \mathrm{S} 88$ & 17 & $19 Q$ & $\mathrm{X}$ & L. Paleo./E. Archaic & & Mammalia (Medium/large) & Indeterminate & 1 \\
\hline $\mathrm{E} 22 / \mathrm{S} 88$ & 17 & $19 Q$ & $\mathrm{x}$ & L. Paleo./E. Archaic & & Mammalia (Medium/large) & Metapodial & 1 \\
\hline $\mathrm{E} 22 / \mathrm{S} 88$ & 17 & $19 Q$ & $\mathrm{x}$ & L. Paleo./E. Archaic & & Vertebrata & Indeterminate & 2 \\
\hline $\mathrm{E} 22 / \mathrm{S} 88$ & 18 & $19 R$ & $\mathrm{x}$ & L. Paleo./E. Archaic & & Vertebrata & Indeterminate & 1 \\
\hline E22/S88 & 19 & $19 S$ & $\mathrm{x}$ & L. Paleo./E. Archaic & & Mammalia (Medium/large) & Alveolar ridge fragment & 1 \\
\hline $\mathrm{E} 22 / \mathrm{S} 88$ & 19 & $19 \mathrm{~S}$ & $\mathrm{x}$ & L. Paleo./E. Archaic & & Mammalia (Medium/large) & Indeterminate & 2 \\
\hline $\mathrm{E} 22 / \mathrm{S} 88$ & 19 & $19 \mathrm{~S}$ & $\mathrm{x}$ & L. Paleo./E. Archaic & & Mammalia (Medium/large) & Metapodial & 1 \\
\hline E22/S88 & 19 & $19 S$ & $\mathrm{x}$ & L. Paleo./E. Archaic & & Vertebrata & Indeterminate & 5 \\
\hline $\mathrm{E} 22 / \mathrm{S} 88$ & 19 & $19 S$ & $\mathrm{x}$ & L. Paleo./E. Archaic & & Vertebrata & Long bone & 1 \\
\hline $\mathrm{E} 22 / \mathrm{S} 88$ & 20 & $19 \mathrm{~T}$ & $\mathrm{x}$ & L. Paleo./E. Archaic & & Leporidae & Mandible & 1 \\
\hline $\mathrm{E} 22 / \mathrm{S} 88$ & 20 & $19 \mathrm{~T}$ & $\mathrm{x}$ & L. Paleo./E. Archaic & & Mammalia (Large) & Long bone & 2 \\
\hline $\mathrm{E} 22 / \mathrm{S} 88$ & 20 & $19 \mathrm{~T}$ & $\mathrm{X}$ & L. Paleo./E. Archaic & & Mammalia (Medium/large) & Indeterminate & 11 \\
\hline $\mathrm{E} 22 / \mathrm{S} 88$ & 20 & $19 \mathrm{~T}$ & $\mathrm{X}$ & L. Paleo./E. Archaic & & Vertebrata & Indeterminate & 1 \\
\hline $\mathrm{E} 22 / \mathrm{S} 88$ & 22 & $19 \mathrm{~V}$ & $\mathrm{X}$ & L. Paleo./E. Archaic & & Mammalia (Medium/large) & Indeterminate & 1 \\
\hline E22/S88 & 22 & $19 \mathrm{~V}$ & $\mathrm{X}$ & L. Paleo./E. Archaic & & Mammalia (Medium/large) & Long bone & 2 \\
\hline $\mathrm{E} 22 / \mathrm{S} 88$ & 22 & $19 \mathrm{~V}$ & $\mathrm{x}$ & L. Paleo./E. Archaic & & Medium/Large Vertebrata & Indeterminate & 2 \\
\hline $\mathrm{E} 22 / \mathrm{S} 88$ & 22 & $19 \mathrm{~V}$ & $\mathrm{X}$ & L. Paleo./E. Archaic & & Medium/Large Vertebrata & Long bone & 2 \\
\hline $\mathrm{E} 22 / \mathrm{S} 88$ & 22 & $19 \mathrm{~V}$ & $\mathrm{X}$ & L. Paleo./E. Archaic & & Vertebrata & Indeterminate & 3 \\
\hline $\mathrm{E} 22 / \mathrm{S} 88$ & 23 & $19 \mathrm{~W}$ & $\mathrm{X}$ & L. Paleo./E. Archaic & & Artiodactyla & Tooth, perm./decid. ind. & 1 \\
\hline $\mathrm{E} 22 / \mathrm{S} 88$ & 23 & $19 \mathrm{~W}$ & $\mathrm{X}$ & L. Paleo./E. Archaic & & Mammalia (Large) & Indeterminate & 1 \\
\hline $\mathrm{E} 22 / \mathrm{S} 88$ & 23 & $19 \mathrm{~W}$ & $\mathrm{x}$ & L. Paleo./E. Archaic & & Mammalia (Medium/large) & Indeterminate & 4 \\
\hline $\mathrm{E} 22 / \mathrm{S} 88$ & 23 & $19 \mathrm{~W}$ & $\mathrm{X}$ & L. Paleo./E. Archaic & & Small/Medium Vertebrata & Long bone & 2 \\
\hline E22/S88 & 23 & $19 \mathrm{~W}$ & $\mathrm{X}$ & L. Paleo./E. Archaic & & Vertebrata & Indeterminate & 3 \\
\hline E22/S88 & 25 & $19 \mathrm{Y}$ & $\mathrm{X}$ & L. Paleo./E. Archaic & & Mammalia (Medium/large) & Long bone & 1 \\
\hline E22/S88 & 26 & $19 \mathrm{Z}$ & $\mathrm{X}$ & L. Paleo./E. Archaic & & Mammalia (Large) & Long bone & 1 \\
\hline $\mathrm{E} 22 / \mathrm{S} 88$ & 26 & $19 \mathrm{Z}$ & $\mathrm{X}$ & L. Paleo./E. Archaic & & Mammalia (Medium/large) & Long bone & 1 \\
\hline $\mathrm{E} 22 / \mathrm{S} 90$ & 0 & F104 & $X$ & E. Archaic & f104 & Vertebrata & Indeterminate & 1 \\
\hline $\mathrm{E} 22 / \mathrm{S} 90$ & 6 & $18 \mathrm{~F}$ & IIIIc & Middle/L. Archaic & BRM1 & Mammalia (Medium/large) & Indeterminate & 4 \\
\hline $\mathrm{E} 22 / \mathrm{S} 90$ & 6 & $18 \mathrm{~F}$ & IIIc & Middle/L. Archaic & BRM1 & Testudinata & Shell fragment & 1 \\
\hline $\mathrm{E} 22 / \mathrm{S} 90$ & 6 & $18 \mathrm{~F}$ & IIIIc & Middle/L. Archaic & BRM1 & Vertebrata & Indeterminate & 16 \\
\hline $\mathrm{E} 22 / \mathrm{S} 90$ & 6 & $18 \mathrm{~F}$ & IIIlc & Middle/L. Archaic & BRM1 & Vertebrata & Long bone & 1 \\
\hline $\mathrm{E} 22 / \mathrm{S} 90$ & 7 & $18 \mathrm{G}$ & IIIc & Middle/L. Archaic & BRM1 & Lepus californicus & Calcaneus & 1 \\
\hline $\mathrm{E} 22 / \mathrm{S} 90$ & 7 & $18 \mathrm{G}$ & IIIc & Middle/L. Archaic & BRM1 & Mammalia (Medium/large) & Indeterminate & 3 \\
\hline $\mathrm{E} 22 / \mathrm{S} 90$ & 7 & $18 \mathrm{G}$ & IIIc & Middle/L. Archaic & BRM1 & Sigmodon hispidus & Mandible & 1 \\
\hline E22/S90 & 7 & $18 \mathrm{G}$ & IIIc & Middle/L. Archaic & BRM1 & Sigmodon hispidus & Permanent tooth & 4 \\
\hline
\end{tabular}




\begin{tabular}{|c|c|c|c|c|c|c|c|c|}
\hline Square & Level & Lot & Unit & Cultural Affinity & Feature & Taxon & Element & No. \\
\hline$\overline{\mathrm{E} 22 / \mathrm{S} 90}$ & 7 & $18 \mathrm{G}$ & IIIc & Middle/L. Archaic & BRM1 & Vertebrata & Indeterminate & 9 \\
\hline $\mathrm{E} 22 / \mathrm{S} 90$ & 8 & $18 \mathrm{H}$ & Y/IIIc & Middle/L. Archaic & BRM1 & Mammalia (Medium/large) & Long bone & 1 \\
\hline $\mathrm{E} 22 / \mathrm{S} 90$ & 8 & $18 \mathrm{H}$ & $\mathrm{Y} / \mathrm{IIIc}$ & Middle/L. Archaic & BRM1 & Vertebrata & Indeterminate & 4 \\
\hline $\mathrm{E} 22 / \mathrm{S} 90$ & 9 & $18 \mathrm{I}$ & Y/IIIc & Early/M. Archaic & BRM1 & Vertebrata & Indeterminate & 4 \\
\hline $\mathrm{E} 22 / \mathrm{S} 90$ & 10 & $18 \mathrm{~J}$ & $\mathrm{Y} / \mathrm{III} \mathrm{c}$ & Early/M. Archaic & BRM1 & Mammalia (Medium/large) & Indeterminate & 3 \\
\hline $\mathrm{E} 22 / \mathrm{S} 90$ & 10 & $18 \mathrm{~J}$ & $\mathrm{Y} / \mathrm{IIIc}$ & Early/M. Archaic & BRM1 & Mammalia (Medium/large) & Long bone & 2 \\
\hline $\mathrm{E} 22 / \mathrm{S} 90$ & 10 & $18 \mathrm{~J}$ & Y/IIIc & Early/M. Archaic & BRM1 & Vertebrata & Indeterminate & 23 \\
\hline $\mathrm{E} 22 / \mathrm{S} 90$ & 10 & $18 \mathrm{~J}$ & $\mathrm{Y} / \mathrm{IIIc}$ & Early/M. Archaic & BRM1 & Vertebrata & Long bone & 2 \\
\hline $\mathrm{E} 22 / \mathrm{S} 90$ & 12 & $18 \mathrm{~L}$ & $\mathrm{X} / \mathrm{Y}$ & E. Archaic & & Mammalia (Medium/large) & Indeterminate & 1 \\
\hline $\mathrm{E} 22 / \mathrm{S} 90$ & 12 & $18 \mathrm{~L}$ & $\mathrm{X} / \mathrm{Y}$ & E. Archaic & & Medium/Large Vertebrata & Indeterminate & 1 \\
\hline $\mathrm{E} 22 / \mathrm{S} 90$ & 12 & $18 \mathrm{~L}$ & $\mathrm{X} / \mathrm{Y}$ & E. Archaic & & Sylvilagus sp. & Calcaneus & 1 \\
\hline $\mathrm{E} 22 / \mathrm{S} 90$ & 12 & $18 \mathrm{~L}$ & $\mathrm{X} / \mathrm{Y}$ & E. Archaic & & Vertebrata & Indeterminate & 5 \\
\hline $\mathrm{E} 22 / \mathrm{S} 90$ & 13 & $18 \mathrm{M}$ & $\mathrm{X} / \mathrm{Y}$ & E. Archaic & & Mammalia (Large) & Long bone & 1 \\
\hline $\mathrm{E} 22 / \mathrm{S} 90$ & 13 & $18 \mathrm{M}$ & $\mathrm{X} / \mathrm{Y}$ & E. Archaic & & Mammalia (Medium/large) & Indeterminate & 1 \\
\hline $\mathrm{E} 22 / \mathrm{S} 90$ & 13 & $18 \mathrm{M}$ & $\mathrm{X} / \mathrm{Y}$ & E. Archaic & & Mammalia (Medium/large) & Long bone & 1 \\
\hline $\mathrm{E} 22 / \mathrm{S} 90$ & 13 & $18 \mathrm{M}$ & $\mathrm{X} / \mathrm{Y}$ & E. Archaic & & Mammalia (Medium/large) & Tooth, perm./decid. ind. & 1 \\
\hline $\mathrm{E} 22 / \mathrm{S} 90$ & 13 & $18 \mathrm{M}$ & $\mathrm{X} / \mathrm{Y}$ & E. Archaic & & Vertebrata & Indeterminate & 1 \\
\hline $\mathrm{E} 22 / \mathrm{S} 90$ & 14 & $18 \mathrm{~N}$ & $\mathrm{x}$ & E. Archaic & & cf. Sigmodon hispidus & Femur & 1 \\
\hline $\mathrm{E} 22 / \mathrm{S} 90$ & 14 & $18 \mathrm{~N}$ & $\mathrm{x}$ & E. Archaic & & Mammalia (Medium/large) & Long bone & 2 \\
\hline $\mathrm{E} 22 / \mathrm{S} 90$ & 14 & $18 \mathrm{~N}$ & $\mathrm{x}$ & E. Archaic & & Sigmodon hispidus & Mandible & 1 \\
\hline $\mathrm{E} 22 / \mathrm{S} 90$ & 14 & $18 \mathrm{~N}$ & $\mathrm{x}$ & E. Archaic & & Sigmodon hispidus & Permanent tooth & 3 \\
\hline $\mathrm{E} 22 / \mathrm{S} 90$ & 14 & $18 \mathrm{~N}$ & $\mathrm{x}$ & E. Archaic & & Testudinata & Plastron fragment ind. & 1 \\
\hline $\mathrm{E} 22 / \mathrm{S} 90$ & 14 & $18 \mathrm{~N}$ & $\mathrm{x}$ & E. Archaic & & Vertebrata & Indeterminate & 1 \\
\hline $\mathrm{E} 22 / \mathrm{S} 90$ & 15 & 180 & $\mathrm{x}$ & E. Archaic & f104 & Medium/Large Vertebrata & Long bone & 1 \\
\hline $\mathrm{E} 22 / \mathrm{S} 90$ & 15 & 180 & $\mathrm{x}$ & E. Archaic & f104 & Vertebrata & Indeterminate & 1 \\
\hline $\mathrm{E} 22 / \mathrm{S} 90$ & 15 & F104 & $\mathrm{x}$ & E. Archaic & f104 & Mammalia (Medium/large) & Long bone & 1 \\
\hline $\mathrm{E} 22 / \mathrm{S} 90$ & 16 & $18 \mathrm{P}$ & $\mathrm{x}$ & L. Paleo./E. Archaic & f104 & Mammalia (Medium/large) & Indeterminate & 1 \\
\hline $\mathrm{E} 22 / \mathrm{S} 90$ & 17 & $18 Q$ & $\mathrm{x}$ & L. Paleo./E. Archaic & f104 & Vertebrata & Indeterminate & 3 \\
\hline $\mathrm{E} 22 / \mathrm{S} 90$ & 18 & 18RA & $\mathrm{x}$ & L. Paleo./E. Archaic & f104 & Antilocapra/Odocoileus & Proximal phalange & 1 \\
\hline $\mathrm{E} 22 / \mathrm{S} 90$ & 18 & $18 \mathrm{RB}$ & $\mathrm{x}$ & L. Paleo./E. Archaic & f104 & Vertebrata & Indeterminate & 1 \\
\hline $\mathrm{E} 22 / \mathrm{S} 90$ & 18 & $18 \mathrm{RC}$ & $\mathrm{x}$ & L. Paleo./E. Archaic & f104 & Vertebrata & Long bone & 1 \\
\hline $\mathrm{E} 22 / \mathrm{S} 90$ & 18 & 18RD & $\mathrm{x}$ & L. Paleo./E. Archaic & f104 & Mammalia (Medium/large) & Indeterminate & 1 \\
\hline $\mathrm{E} 22 / \mathrm{S} 90$ & 18 & 18RD & $\mathrm{x}$ & L. Paleo./E. Archaic & f104 & Medium/Large Vertebrata & Indeterminate & 2 \\
\hline $\mathrm{E} 22 / \mathrm{S} 90$ & 18 & 18RD & $\mathrm{x}$ & L. Paleo./E. Archaic & f104 & Small/Medium Vertebrata & Long bone & 1 \\
\hline $\mathrm{E} 22 / \mathrm{S} 90$ & 18 & $18 \mathrm{RD}$ & $\mathrm{x}$ & L. Paleo./E. Archaic & f104 & Testudinata & Shell fragment & 1 \\
\hline $\mathrm{E} 22 / \mathrm{S} 90$ & 20 & $18 \mathrm{~TB}$ & $\mathrm{x}$ & L. Paleo./E. Archaic & & Vertebrata & Indeterminate & 1 \\
\hline $\mathrm{E} 22 / \mathrm{S} 90$ & 21 & $18 \mathrm{UA}$ & $\mathrm{x}$ & L. Paleo. & & Small/Medium Vertebrata & Long bone & 1 \\
\hline $\mathrm{E} 22 / \mathrm{S} 90$ & 21 & $18 \mathrm{UC}$ & $\mathrm{X}$ & L. Paleo. & & Mammalia (Medium/large) & Long bone & 1 \\
\hline $\mathrm{E} 22 / \mathrm{S} 98$ & 1 & $4 \mathrm{~A}$ & IIIIc & L. Prehist. & & AntilocapralOdocoileus & Astragalus & 1 \\
\hline $\mathrm{E} 22 / \mathrm{S} 98$ & 1 & $4 \mathrm{~A}$ & IIIIc & L. Prehist. & & Antilocapra/Odocoileus & Calcaneus & 1 \\
\hline $\mathrm{E} 22 / \mathrm{S} 98$ & 1 & $4 \mathrm{~A}$ & IIIIc & L. Prehist. & & Antilocapra/Odocoileus & Femur & 2 \\
\hline $\mathrm{E} 22 / \mathrm{S} 98$ & 1 & $4 \mathrm{~A}$ & IIIIc & L. Prehist. & & Antilocapra/Odocoileus & Humerus & 1 \\
\hline $\mathrm{E} 22 / \mathrm{S} 98$ & 1 & $4 \mathrm{~A}$ & IIIc & L. Prehist. & & Antilocapra/Odocoileus & Metapodial & 2 \\
\hline $\mathrm{E} 22 / \mathrm{S} 98$ & 1 & $4 \mathrm{~A}$ & IIIIc & L. Prehist. & & Antilocapra/Odocoileus & Middle phalange & 1 \\
\hline $\mathrm{E} 22 / \mathrm{S} 98$ & 1 & $4 \mathrm{~A}$ & IIII & L. Prehist. & & Antilocapra/Odocoileus & Radius & 1 \\
\hline $\mathrm{E} 22 / \mathrm{S} 98$ & 1 & $4 \mathrm{~A}$ & IIIc & L. Prehist. & & Antilocapra/Odocoileus & Tibia & 1 \\
\hline $\mathrm{E} 22 / \mathrm{S} 98$ & 1 & $4 \mathrm{~A}$ & IIIIc & L. Prehist. & & Mammalia (Large) & Indeterminate & 3 \\
\hline $\mathrm{E} 22 / \mathrm{S} 98$ & 1 & $4 \mathrm{~A}$ & IIIIc & L. Prehist. & & Mammalia (Large) & Long bone & 2 \\
\hline $\mathrm{E} 22 / \mathrm{S} 98$ & 1 & $4 \mathrm{~A}$ & IIIc & L. Prehist. & & Mammalia (Medium/large) & Indeterminate & 42 \\
\hline $\mathrm{E} 22 / \mathrm{S} 98$ & 1 & $4 \mathrm{~A}$ & IIIIc & L. Prehist. & & Odocoileus sp. & Humerus & 1 \\
\hline $\mathrm{E} 22 / \mathrm{S} 98$ & 1 & $4 \mathrm{~A}$ & IIII & L. Prehist. & & Vertebrata & Indeterminate & 61 \\
\hline $\mathrm{E} 22 / \mathrm{S} 98$ & 2 & $4 \mathrm{~B}$ & IIIIc & L. Archaic/L. Prehist. & & Antilocapra/Odocoileus & Distal fibula & 1 \\
\hline $\mathrm{E} 22 / \mathrm{S} 98$ & 2 & 4B & IIIIc & L. Archaic/L. Prehist. & & Antilocapra/Odocoileus & Metapodial & 1 \\
\hline E22/S98 & 2 & 4B & IIIIc & L. Archaic/L. Prehist. & & Mammalia (Medium/large) & Indeterminate & 5 \\
\hline $\mathrm{E} 22 / \mathrm{S} 98$ & 2 & $4 \mathrm{~B}$ & IIIc & L. Archaic/L. Prehist. & & Odocoileus sp. & Proximal phalange & 1 \\
\hline E22/S98 & 2 & 4B & IIIIc & L. Archaic/L. Prehist. & & Vertebrata & Indeterminate & 15 \\
\hline $\mathrm{E} 22 / \mathrm{S} 98$ & 8 & $4 \mathrm{H}$ & Y/IIIc & Archaic & & Vertebrata & Indeterminate & 3 \\
\hline $\mathrm{E} 22 / \mathrm{S} 98$ & 10 & $4 \mathrm{~J}$ & Y & E. Archaic & & Mammalia (Medium/large) & Indeterminate & 1 \\
\hline E22/S98 & 10 & $4 \mathrm{~J}$ & $\mathrm{Y}$ & E. Archaic & & Vertebrata & Indeterminate & 1 \\
\hline E22/S98 & 11 & $4 \mathrm{~K}$ & $\mathrm{X} / \mathrm{Y}$ & E. Archaic & & Vertebrata & Indeterminate & 1 \\
\hline $\mathrm{E} 22 / \mathrm{S} 98$ & 14 & $4 \mathrm{~N}$ & $\mathrm{x}$ & E. Archaic & & Antilocapra/Odocoileus & Proximal phalange & 1 \\
\hline $\mathrm{E} 22 / \mathrm{S} 98$ & 14 & $4 \mathrm{~N}$ & $\mathrm{X}$ & E. Archaic & & Vertebrata & Indeterminate & 1 \\
\hline $\mathrm{E} 22 / \mathrm{S} 98$ & 15 & 40 & $\mathrm{X}$ & L. Paleo./E. Archaic & & Mammalia (Medium/large) & Indeterminate & 2 \\
\hline $\mathrm{E} 22 / \mathrm{S} 98$ & 15 & 40 & $\mathrm{x}$ & L. Paleo./E. Archaic & & Mammalia (Medium/large) & Metapodial & 1 \\
\hline $\mathrm{E} 22 / \mathrm{S} 100$ & 1 & $2 \mathrm{~A}$ & IIIIc & L. Prehist. & & AntilocapralOdocoileus & Fourth carpal bone & 1 \\
\hline $\mathrm{E} 22 / \mathrm{S} 100$ & 1 & $2 \mathrm{~A}$ & IIIIc & L. Prehist. & & Mammalia (Large) & Indeterminate & 8 \\
\hline $\mathrm{E} 22 / \mathrm{S} 100$ & 1 & $2 \mathrm{~A}$ & IIIIc & L. Prehist. & & Mammalia (Medium/large) & Indeterminate & 15 \\
\hline
\end{tabular}




\begin{tabular}{|c|c|c|c|c|c|c|c|c|}
\hline Square & Level & Lot & Unit & Cultural Affinity & Feature & Taxon & Element & No. \\
\hline E22/S100 & 1 & $2 \mathrm{~A}$ & IIIc & L. Prehist. & & Mammalia (Medium/large) & Rib & 1 \\
\hline E22/S100 & 1 & $2 \mathrm{~A}$ & IIII & L. Prehist. & & Vertebrata & Indeterminate & 45 \\
\hline $\mathrm{E} 22 / \mathrm{S} 100$ & 2 & $2 \mathrm{~B}$ & IIIc & L. Archaic/L. Prehist. & & Mammalia (Medium/large) & Alveolar ridge fragment & 3 \\
\hline E22/S100 & 2 & 2B & IIIc & L. Archaic/L. Prehist. & & Mammalia (Medium/large) & Indeterminate & 4 \\
\hline $\mathrm{E} 22 / \mathrm{S} 100$ & 2 & $2 \mathrm{~B}$ & IIIc & L. Archaic/L. Prehist. & & Vertebrata & Indeterminate & 14 \\
\hline $\mathrm{E} 22 / \mathrm{S} 100$ & 3 & $2 \mathrm{C}$ & IIIIc & L. Archaic & & Mammalia (Medium/large) & Indeterminate & 1 \\
\hline $\mathrm{E} 22 / \mathrm{S} 100$ & 3 & $2 \mathrm{C}$ & IIIc & L. Archaic & & Vertebrata & Indeterminate & 2 \\
\hline $\mathrm{E} 22 / \mathrm{S} 100$ & 4 & 2D & IIIc & L. Archaic & & Mammalia (Large) & Long bone & 3 \\
\hline $\mathrm{E} 22 / \mathrm{S} 100$ & 5 & $2 \mathrm{E}$ & IIIc & L. Archaic & & Mammalia (Medium/large) & Indeterminate & 1 \\
\hline $\mathrm{E} 22 / \mathrm{S} 100$ & 5 & $2 \mathrm{E}$ & IIII & L. Archaic & & Vertebrata & Indeterminate & 4 \\
\hline $\mathrm{E} 22 / \mathrm{S} 100$ & 8 & $2 \mathrm{H}$ & $\mathrm{Y}$ & Archaic & & Mammalia (Medium/large) & Indeterminate & 2 \\
\hline $\mathrm{E} 22 / \mathrm{S} 100$ & 8 & $2 \mathrm{H}$ & $\mathrm{Y}$ & Archaic & & Vertebrata & Indeterminate & 1 \\
\hline $\mathrm{E} 22 / \mathrm{S} 100$ & 9 & $2 \mathrm{I}$ & $\mathrm{Y}$ & E. Archaic & & Mammalia (Medium/large) & Indeterminate & 1 \\
\hline E22/S100 & 9 & $2 I$ & $\mathrm{Y}$ & E. Archaic & & Vertebrata & Indeterminate & 1 \\
\hline $\mathrm{E} 22 / \mathrm{S} 100$ & 13 & $2 \mathrm{M}$ & $\mathrm{X}$ & E. Archaic & & Medium vertebrate, class ind. & Podial & 1 \\
\hline $\mathrm{E} 22 / \mathrm{S} 100$ & 13 & $2 \mathrm{M}$ & $\mathrm{X}$ & E. Archaic & & Vertebrata & Indeterminate & 3 \\
\hline E24/S64 & 15 & $52 \mathrm{OC}$ & III & Archaic & & Mammalia (Medium/large) & Indeterminate & 1 \\
\hline E24/S64 & 16 & $52 \mathrm{PA}$ & III & Archaic & & Vertebrata & Indeterminate & 2 \\
\hline E24/S64 & 16 & $52 \mathrm{PC}$ & III & Archaic & & Mammalia (Medium/large) & Indeterminate & 5 \\
\hline E24/S64 & 16 & $52 \mathrm{PC}$ & III & Archaic & & Vertebrata & Indeterminate & 1 \\
\hline E24/S72 & 15 & 310 & IIIa/b & E. Archaic & & Vertebrata & Indeterminate & 2 \\
\hline E24/S72 & $16 \mathrm{~B}$ & 31P2 & IIIa & E. Archaic & & Vertebrata & Indeterminate & 2 \\
\hline E24/S72 & $17 \mathrm{~A}$ & 31Q1 & IIIIa & E. Archaic & & Vertebrata & Indeterminate & 2 \\
\hline E24/S72 & 17B & 31Q2 & IIIa & E. Archaic & & Vertebrata & Indeterminate & 4 \\
\hline E24/S72 & $18 \mathrm{~A}$ & 31R1 & ШІІа & E. Archaic & & Antilocapra/Odocoileus & & 1 \\
\hline E24/S72 & $18 \mathrm{~A}$ & 31R1 & ШІа & E. Archaic & & Mammalia (Medium/large) & Indeterminate & 1 \\
\hline E24/S72 & $18 \mathrm{~A}$ & 31R1 & IIIa & E. Archaic & & Vertebrata & Indeterminate & 3 \\
\hline E24/S72 & $18 \mathrm{~B}$ & 31R2 & IIIIa & E. Archaic & & Testudinata & Shell fragment & 1 \\
\hline E24/S72 & $18 \mathrm{~B}$ & $31 \mathrm{R} 2$ & IIIIa & E. Archaic & & Vertebrata & Indeterminate & 3 \\
\hline E24/S72 & $19 \mathrm{~A}$ & $31 \mathrm{~S} 1$ & IIIIa & E. Archaic & & Mammalia (Large) & Indeterminate & 1 \\
\hline E24/S72 & $19 \mathrm{~A}$ & $31 \mathrm{~S} 1$ & IIIa & E. Archaic & & Mammalia (Medium/large) & Indeterminate & 1 \\
\hline E24/S72 & $19 \mathrm{~A}$ & $31 S 1$ & IIIa & E. Archaic & & Mammalia (Small/medium) & Femur & 1 \\
\hline E24/S72 & $19 \mathrm{~A}$ & $31 \mathrm{~S} 1$ & IIIIa & E. Archaic & & Vertebrata & Indeterminate & 4 \\
\hline E24/S72 & 19B & $31 \mathrm{~S} 2 \mathrm{~A}$ & Ш/ШІІа & L. Paleo./E. Archaic & & Vertebrata & Indeterminate & 1 \\
\hline E24/S72 & 19B & 31S2D & П/IIIa & L. Paleo./E. Archaic & & Vertebrata & Indeterminate & 2 \\
\hline E24/S72 & $20 \mathrm{~A}$ & $31 \mathrm{~T} 1 \mathrm{C}$ & I/ШIIa & L. Paleo./E. Archaic & & Vertebrata & Indeterminate & 1 \\
\hline E24/S72 & $20 \mathrm{~B}$ & 31T2B & II/IIIa & L. Paleo./E. Archaic & & Mammalia (Medium/large) & Indeterminate & 1 \\
\hline E24/S72 & $20 \mathrm{~B}$ & $31 \mathrm{~T} 2 \mathrm{C}$ & П/Ша & L. Paleo./E. Archaic & & Vertebrata & Long bone & 1 \\
\hline E24/S72 & $20 \mathrm{~B}$ & 31T2D & П/ШIIa & L. Paleo./E. Archaic & & Medium/Large Vertebrata & Indeterminate & 1 \\
\hline E24/S72 & $20 \mathrm{~B}$ & 31T2D & II/IIIa & L. Paleo./E. Archaic & & Vertebrata & Indeterminate & 1 \\
\hline E24/S72 & $21 \mathrm{~A}$ & 31U1A & П/ШІІа & L. Paleo./E. Archaic & & Vertebrata & Indeterminate & 3 \\
\hline E24/S72 & $21 \mathrm{~A}$ & 31U1B & II/IIIa & L. Paleo./E. Archaic & & Vertebrata & Indeterminate & 1 \\
\hline E24/S72 & $21 \mathrm{~A}$ & $31 \mathrm{U1C}$ & II/IIIa & L. Paleo./E. Archaic & & Mammalia (Medium/large) & Long bone & 1 \\
\hline E24/S72 & $21 \mathrm{~A}$ & $31 \mathrm{U1C}$ & П/ШІІа & L. Paleo./E. Archaic & & Medium/Large Vertebrata & Indeterminate & 1 \\
\hline E24/S72 & $21 \mathrm{~A}$ & $31 \mathrm{U1C}$ & II/IIIa & L. Paleo./E. Archaic & & Vertebrata & Indeterminate & 2 \\
\hline E24/S72 & $21 \mathrm{~A}$ & 31U1D & II/IIIa & L. Paleo./E. Archaic & & Vertebrata & Indeterminate & 1 \\
\hline E24/S72 & $21 \mathrm{~B}$ & $31 \mathrm{U} 2 \mathrm{~A}$ & III & L. Paleo. & & Mammalia (Medium/large) & Indeterminate & 1 \\
\hline E24/S72 & 21B & $31 \mathrm{U} 2 \mathrm{~B}$ & III & L. Paleo. & & Mammalia (Medium/large) & Long bone & 1 \\
\hline E24/S72 & 21B & 31U2B & II & L. Paleo. & & Vertebrata & Indeterminate & 1 \\
\hline E24/S72 & $21 \mathrm{~B}$ & $31 \mathrm{U} 2 \mathrm{D}$ & III & L. Paleo. & & Sylvilagus sp. & Scapula & 1 \\
\hline E24/S72 & $22 \mathrm{~A}$ & 31V1B & III & L. Paleo. & & Mammalia (Medium/large) & Indeterminate & 6 \\
\hline E24/S72 & $22 \mathrm{~A}$ & $31 \mathrm{~V} 1 \mathrm{~B}$ & III & L. Paleo. & & Vertebrata & Indeterminate & 4 \\
\hline E24/S72 & $22 \mathrm{~A}$ & $31 \mathrm{~V} 1 \mathrm{C}$ & II & L. Paleo. & & Small/Medium Vertebrata & Long bone & 2 \\
\hline E24/S72 & $22 \mathrm{~A}$ & $31 \mathrm{~V} 1 \mathrm{C}$ & II & L. Paleo. & & Vertebrata & Indeterminate & 3 \\
\hline $\mathrm{E} 24 / \mathrm{S} 72$ & $22 \mathrm{~A}$ & 31V1D & III & L. Paleo. & & Mammalia (Medium/large) & Indeterminate & 6 \\
\hline E24/S72 & $22 \mathrm{~A}$ & 31V1D & III & L. Paleo. & & Medium/Large Vertebrata & Long bone & 1 \\
\hline E24/S72 & $22 \mathrm{~B}$ & $31 \mathrm{~V} 2 \mathrm{~A}$ & II & L. Paleo. & & Mammalia (Medium/large) & Long bone & 2 \\
\hline E24/S72 & $22 \mathrm{~B}$ & $31 \mathrm{~V} 2 \mathrm{C}$ & III & L. Paleo. & & Mammalia (Medium/large) & Indeterminate & 1 \\
\hline E24/S72 & 222B & $31 \mathrm{~V} 2 \mathrm{C}$ & III & L. Paleo. & & Small/Medium Vertebrata & Long bone & 1 \\
\hline $\mathrm{E} 24 / \mathrm{S} 72$ & $22 \mathrm{~B}$ & $31 \mathrm{~V} 2 \mathrm{D}$ & III & L. Paleo. & & Vertebrata & Indeterminate & 1 \\
\hline E24/S72 & $23 \mathrm{~B}$ & $31 \mathrm{~W} 2 \mathrm{~B}$ & III & L. Paleo. & & Vertebrata & Indeterminate & 4 \\
\hline E24/S72 & 23B & $31 \mathrm{~W} 2 \mathrm{C}$ & II & L. Paleo. & & Mammalia (Medium/large) & Indeterminate & 1 \\
\hline E24/S72 & $23 \mathrm{~B}$ & $31 \mathrm{~W} 2 \mathrm{C}$ & III & L. Paleo. & & Small/Medium Vertebrata & Long bone & 1 \\
\hline E24/S72 & $23 \mathrm{~B}$ & $31 \mathrm{~W} 2 \mathrm{C}$ & III & L. Paleo. & & Vertebrata & Indeterminate & 1 \\
\hline $\mathrm{E} 24 / \mathrm{S} 72$ & 23B & $31 \mathrm{~W} 2 \mathrm{D}$ & III & L. Paleo. & & Vertebrata & Indeterminate & 2 \\
\hline E24/S72 & $24 \mathrm{~A}$ & $31 \mathrm{X} 1 \mathrm{~A}$ & II & L. Paleo. & & Vertebrata & Indeterminate & 4 \\
\hline E24/S72 & $24 \mathrm{~A}$ & $31 \mathrm{X} 1 \mathrm{~B}$ & III & L. Paleo. & & Mammalia (Medium/large) & Indeterminate & 3 \\
\hline
\end{tabular}




\begin{tabular}{|c|c|c|c|c|c|c|c|c|}
\hline Square & Level & Lot & Unit & Cultural Affinity & Feature & Taxon & Element & No. \\
\hline E24/S72 & $24 \mathrm{~A}$ & $31 \mathrm{X} 1 \mathrm{~B}$ & $\overline{I I}$ & L. Paleo. & & Vertebrata & Indeterminate & 8 \\
\hline $\mathrm{E} 24 / \mathrm{S} 72$ & $24 \mathrm{~A}$ & $31 X 1 D$ & III & L. Paleo. & & Vertebrata & Indeterminate & 5 \\
\hline $\mathrm{E} 24 / \mathrm{S} 72$ & $24 B$ & $31 \mathrm{X} 2 \mathrm{~A}$ & III & L. Paleo. & & Mammalia (Medium/large) & Long bone & 1 \\
\hline E24/S72 & 24B & $31 \mathrm{X} 2 \mathrm{~A}$ & III & L. Paleo. & & Vertebrata & Indeterminate & 3 \\
\hline $\mathrm{E} 24 / \mathrm{S} 72$ & $24 \mathrm{~B}$ & $31 X 2 B$ & III & L. Paleo. & & Mammalia (Medium/large) & Indeterminate & 1 \\
\hline $\mathrm{E} 24 / \mathrm{S} 72$ & $24 \mathrm{~B}$ & $31 \times 2 C$ & III & L. Paleo. & & Mammalia (Large) & Indeterminate & 1 \\
\hline $\mathrm{E} 24 / \mathrm{S} 72$ & $24 \mathrm{~B}$ & $31 \mathrm{X} 2 \mathrm{C}$ & III & L. Paleo. & & Medium/Large Vertebrata & Indeterminate & 1 \\
\hline $\mathrm{E} 24 / \mathrm{S} 72$ & $25 \mathrm{~A}$ & 31Y1A & III & L. Paleo. & & Medium/Large Vertebrata & Indeterminate & 1 \\
\hline $\mathrm{E} 24 / \mathrm{S} 72$ & $25 \mathrm{~A}$ & $31 \mathrm{Y} 1 \mathrm{C}$ & III & L. Paleo. & & Medium/Large Vertebrata & Long bone & 1 \\
\hline $\mathrm{E} 24 / \mathrm{S} 72$ & $25 \mathrm{~A}$ & $31 \mathrm{Y} 1 \mathrm{C}$ & III & L. Paleo. & & Vertebrata & Indeterminate & 5 \\
\hline $\mathrm{E} 24 / \mathrm{S} 72$ & $25 \mathrm{~A}$ & 31Y1D & III & L. Paleo. & & Mammalia (Medium/large) & Indeterminate & 2 \\
\hline $\mathrm{E} 24 / \mathrm{S} 72$ & $25 \mathrm{~A}$ & 31Y1D & III & L. Paleo. & & Medium/Large Vertebrata & Indeterminate & 1 \\
\hline E24/S72 & $25 \mathrm{~A}$ & 31Y1D & III & L. Paleo. & & Vertebrata & Indeterminate & 3 \\
\hline $\mathrm{E} 24 / \mathrm{S} 72$ & $25 \mathrm{~B}$ & $31 \mathrm{Y} 2 \mathrm{~A}$ & III & L. Paleo. & & Vertebrata & Indeterminate & 1 \\
\hline $\mathrm{E} 24 / \mathrm{S} 72$ & $25 \mathrm{~B}$ & $31 Y 2 B$ & III & L. Paleo. & & Mammalia (Medium/large) & Indeterminate & 1 \\
\hline $\mathrm{E} 24 / \mathrm{S} 72$ & $25 \mathrm{~B}$ & $31 \mathrm{Y} 2 \mathrm{C}$ & III & L. Paleo. & & Small/Medium Vertebrata & Long bone & 1 \\
\hline $\mathrm{E} 24 / \mathrm{S} 72$ & $25 \mathrm{~B}$ & $31 \mathrm{Y} 2 \mathrm{C}$ & II & L. Paleo. & & Vertebrata & Indeterminate & 1 \\
\hline $\mathrm{E} 24 / \mathrm{S} 72$ & $25 \mathrm{~B}$ & $31 Y 2 D$ & III & L. Paleo. & & Vertebrata & Indeterminate & 1 \\
\hline $\mathrm{E} 24 / \mathrm{S} 72$ & $26 \mathrm{~A}$ & 31Z1B & III & L. Paleo. & & Vertebrata & Indeterminate & 5 \\
\hline $\mathrm{E} 24 / \mathrm{S} 72$ & $26 \mathrm{~A}$ & $31 Z 1 D$ & III & L. Paleo. & & Medium/Large Vertebrata & Long bone & 1 \\
\hline $\mathrm{E} 24 / \mathrm{S} 72$ & $26 \mathrm{~A}$ & $31 Z 1 D$ & III & L. Paleo. & & Vertebrata & Indeterminate & 1 \\
\hline $\mathrm{E} 24 / \mathrm{S} 72$ & $26 B$ & $31 \mathrm{Z2A}$ & III & L. Paleo. & & Medium/Large Vertebrata & Indeterminate & 1 \\
\hline $\mathrm{E} 24 / \mathrm{S} 72$ & $26 B$ & $31 \mathrm{Z2C}$ & III & L. Paleo. & & Mammalia (Medium/large) & Indeterminate & 1 \\
\hline $\mathrm{E} 24 / \mathrm{S} 72$ & $26 B$ & $31 Z 2 D$ & III & L. Paleo. & & Mammalia (Medium/large) & Pelvis & 1 \\
\hline E24/S72 & 26B & $31 Z 2 D$ & III & L. Paleo. & & Medium/Large Vertebrata & Indeterminate & 5 \\
\hline $\mathrm{E} 24 / \mathrm{S} 72$ & $26 \mathrm{~B}$ & $31 \mathrm{Z2D}$ & III & L. Paleo. & & Medium/Large Vertebrata & Long bone & 1 \\
\hline E24/S72 & $26 \mathrm{~B}$ & 31Z2D & III & L. Paleo. & & Vertebrata & Indeterminate & 4 \\
\hline E24/S72 & $27 \mathrm{~A}$ & 31AA1A & III & L. Paleo. & & Vertebrata & Indeterminate & 1 \\
\hline $\mathrm{E} 24 / \mathrm{S} 72$ & $27 \mathrm{~A}$ & 31AA1B & III & L. Paleo. & & Canis sp. & Metacarpal 5 & 1 \\
\hline $\mathrm{E} 24 / \mathrm{S} 72$ & $27 \mathrm{~A}$ & 31AA1B & III & L. Paleo. & & Vertebrata & Indeterminate & 4 \\
\hline E24/S72 & $27 \mathrm{~A}$ & $31 \mathrm{AA} 1 \mathrm{C}$ & III & L. Paleo. & & Vertebrata & Indeterminate & 1 \\
\hline E24/S72 & $27 \mathrm{~A}$ & 31AA1D & III & L. Paleo. & & Mammalia (Medium/large) & Long bone & 1 \\
\hline $\mathrm{E} 24 / \mathrm{S} 72$ & $27 \mathrm{~A}$ & 31AA1D & III & L. Paleo. & & Vertebrata & Indeterminate & 3 \\
\hline $\mathrm{E} 24 / \mathrm{S} 72$ & 27B & 31AA2B & III & L. Paleo. & & Vertebrata & Indeterminate & 1 \\
\hline E24/S72 & $27 \mathrm{~B}$ & $31 \mathrm{AA} 2 \mathrm{C}$ & III & L. Paleo. & & Vertebrata & Indeterminate & 4 \\
\hline $\mathrm{E} 24 / \mathrm{S} 72$ & $27 \mathrm{~B}$ & 31AA2D & III & L. Paleo. & & Mammalia (Medium/large) & Mandible & 1 \\
\hline $\mathrm{E} 24 / \mathrm{S} 72$ & 27B & 31AA2D & III & L. Paleo. & & Vertebrata & Indeterminate & 7 \\
\hline $\mathrm{E} 24 / \mathrm{S} 72$ & $28 \mathrm{~A}$ & 31BB1A & Isi-c/II & L. Paleo. & & Medium/Large Vertebrata & Indeterminate & 2 \\
\hline $\mathrm{E} 24 / \mathrm{S} 72$ & $28 \mathrm{~A}$ & 31BB1A & Isi-c/II & L. Paleo. & & Small/Medium Vertebrata & Long bone & 1 \\
\hline $\mathrm{E} 24 / \mathrm{S} 72$ & $28 \mathrm{~A}$ & 31BB1A & Isi-c/II & L. Paleo. & & Vertebrata & Indeterminate & 3 \\
\hline $\mathrm{E} 24 / \mathrm{S} 72$ & $28 \mathrm{~A}$ & 31BB1B & Isi-c/II & L. Paleo. & & Mammalia (Medium/large) & Indeterminate & 1 \\
\hline $\mathrm{E} 24 / \mathrm{S} 72$ & $28 \mathrm{~A}$ & 31BB1B & Isi-c/II & L. Paleo. & & Medium/Large Vertebrata & Indeterminate & 3 \\
\hline E24/S72 & $28 \mathrm{~A}$ & 31BB1B & Isi-c/II & L. Paleo. & & Medium/Large Vertebrata & Long bone & 1 \\
\hline $\mathrm{E} 24 / \mathrm{S} 72$ & $28 \mathrm{~A}$ & 31BB1B & Isi-c/II & L. Paleo. & & Vertebrata & Indeterminate & 4 \\
\hline $\mathrm{E} 24 / \mathrm{S} 72$ & $28 \mathrm{~A}$ & $31 \mathrm{BB} 1 \mathrm{C}$ & Isi-c/II & L. Paleo. & & Mammalia (Medium) & Metapodial & 1 \\
\hline E24/S72 & $28 \mathrm{~A}$ & 31BB1C & Isi-c/II & L. Paleo. & & Mammalia (Medium) & Pelvis & 1 \\
\hline $\mathrm{E} 24 / \mathrm{S} 72$ & $28 \mathrm{~A}$ & $31 \mathrm{BB} 1 \mathrm{C}$ & Isi-c/II & L. Paleo. & & Medium/Large Vertebrata & Indeterminate & 3 \\
\hline $\mathrm{E} 24 / \mathrm{S} 72$ & $28 \mathrm{~A}$ & 31BB1D & Isi-c/II & L. Paleo. & & Mammalia (Medium/large) & Indeterminate & 1 \\
\hline E24/S72 & $28 \mathrm{~A}$ & 31BB1D & Isi-c/II & L. Paleo. & & Mammalia (Medium/large) & Podial & 1 \\
\hline $\mathrm{E} 24 / \mathrm{S} 72$ & $28 \mathrm{~A}$ & 31BB1D & Isi-c/II & L. Paleo. & & Mammalia (Medium/large) & Tooth, perm./decid. ind. & 1 \\
\hline $\mathrm{E} 24 / \mathrm{S} 72$ & $28 \mathrm{~A}$ & 31BB1D & Isi-c/II & L. Paleo. & & Vertebrata & Indeterminate & 3 \\
\hline $\mathrm{E} 24 / \mathrm{S} 72$ & 28B & 31BB2B & Isi-c/II & L. Paleo. & & Vertebrata & Indeterminate & 12 \\
\hline E24/S72 & 28B & $31 \mathrm{BB} 2 \mathrm{C}$ & Isi-c/II & L. Paleo. & & Mammalia (Medium/large) & Long bone & 1 \\
\hline E24/S72 & 28B & $31 \mathrm{BB} 2 \mathrm{C}$ & Isi-c/II & L. Paleo. & & Vertebrata & Indeterminate & 4 \\
\hline E24/S72 & $28 \mathrm{~B}$ & $31 \mathrm{BB} 2 \mathrm{C}$ & Isi-c/II & L. Paleo. & & Vertebrata & Long bone & 1 \\
\hline E24/S72 & $29 \mathrm{~A}$ & $31 \mathrm{CC} 1 \mathrm{~A}$ & Isi-c & L. Paleo. & & Vertebrata & Indeterminate & 10 \\
\hline E24/S72 & $29 \mathrm{~A}$ & $31 \mathrm{CC} 1 \mathrm{C}$ & Isi-c & L. Paleo. & & Mammalia (Medium/large) & Indeterminate & 1 \\
\hline $\mathrm{E} 24 / \mathrm{S} 72$ & $29 \mathrm{~A}$ & $31 \mathrm{CC} 1 \mathrm{C}$ & Isi-c & L. Paleo. & & Vertebrata & Indeterminate & 5 \\
\hline E24/S72 & $29 \mathrm{~B}$ & $31 \mathrm{CC} 2 \mathrm{~A}$ & Isi-c & L. Paleo. & & Vertebrata & Indeterminate & 1 \\
\hline E24/S72 & $29 B$ & $31 \mathrm{CC} 2 \mathrm{~B}$ & Isi-c & L. Paleo. & & Vertebrata & Indeterminate & 3 \\
\hline $\mathrm{E} 24 / \mathrm{S} 72$ & $29 B$ & $31 \mathrm{CC} 2 \mathrm{C}$ & Isi-c & L. Paleo. & & Mammalia (Medium) & Tooth, perm./decid. ind. & 1 \\
\hline E24/S72 & $29 B$ & $31 \mathrm{CC} 2 \mathrm{C}$ & Isi-c & L. Paleo. & & Vertebrata & Indeterminate & 6 \\
\hline E24/S72 & $29 B$ & $31 \mathrm{CC} 2 \mathrm{D}$ & Isi-c & L. Paleo. & & Vertebrata & Indeterminate & 5 \\
\hline $\mathrm{E} 24 / \mathrm{S} 72$ & $30 \mathrm{~A}$ & 31DD1A & Isi-c & L. Paleo. & & Medium/Large Vertebrata & Indeterminate & 1 \\
\hline E24/S72 & $30 \mathrm{~A}$ & 31DD1A & Isi-c & L. Paleo. & & Vertebrata & Indeterminate & 1 \\
\hline E24/S72 & $30 \mathrm{~A}$ & 31DD1B & Isi-c & L. Paleo. & & Medium/Large Vertebrata & Indeterminate & 4 \\
\hline E24/S72 & $30 \mathrm{~A}$ & 31DD1D & Isi-c & L. Paleo. & & Vertebrata & Indeterminate & 18 \\
\hline
\end{tabular}




\begin{tabular}{|c|c|c|c|c|c|c|c|c|}
\hline Square & Level & Lot & Unit & Cultural Affinity & Feature & Taxon & Element & No. \\
\hline E24/S72 & $30 \mathrm{~A}$ & 31DD1D & Isi-c & L. Paleo. & & Vertebrata & Long bone & 1 \\
\hline E24/S72 & $30 \mathrm{~B}$ & 31DD2A & Isi-c & L. Paleo. & & Vertebrata & Indeterminate & 1 \\
\hline $\mathrm{E} 24 / \mathrm{S} 72$ & $30 \mathrm{~B}$ & 31DD2B & Isi-c & L. Paleo. & & Vertebrata & Indeterminate & 1 \\
\hline E24/S72 & $30 \mathrm{~B}$ & 31DD2C & Isi-c & L. Paleo. & & Vertebrata & Indeterminate & 2 \\
\hline E24/S72 & $30 \mathrm{~B}$ & 31DD2D & Isi-c & L. Paleo. & & Vertebrata & Indeterminate & 4 \\
\hline E24/S72 & $31 \mathrm{~A}$ & 31EE1A & Isi-c & L. Paleo. & & Mammalia (Small) & Permanent tooth & 1 \\
\hline E24/S72 & $31 \mathrm{~A}$ & 31EE1A & Isi-c & L. Paleo. & & Medium/Large Vertebrata & Indeterminate & 1 \\
\hline $\mathrm{E} 24 / \mathrm{S} 72$ & $31 \mathrm{~A}$ & 31EE1A & Isi-c & L. Paleo. & & Vertebrata & Indeterminate & 8 \\
\hline $\mathrm{E} 24 / \mathrm{S} 72$ & $31 \mathrm{~A}$ & 31EE1C & Isi-c & L. Paleo. & & Mammalia (Medium/large) & Indeterminate & 2 \\
\hline $\mathrm{E} 24 / \mathrm{S} 72$ & $31 \mathrm{~A}$ & 31EE1C & Isi-c & L. Paleo. & & Vertebrata & Indeterminate & 2 \\
\hline $\mathrm{E} 24 / \mathrm{S} 72$ & $31 \mathrm{~A}$ & 31EE1D & Isi-c & L. Paleo. & & Vertebrata & Indeterminate & 4 \\
\hline $\mathrm{E} 24 / \mathrm{S} 72$ & $31 \mathrm{~B}$ & 31EE2A & Isi-c & L. Paleo. & & Vertebrata & Indeterminate & 1 \\
\hline $\mathrm{E} 24 / \mathrm{S} 72$ & $31 \mathrm{~B}$ & 31EE2C & Isi-c & L. Paleo. & & Mammalia (Medium/large) & Long bone & 1 \\
\hline $\mathrm{E} 24 / \mathrm{S} 72$ & $31 \mathrm{~B}$ & 31EE2C & Isi-c & L. Paleo. & & Vertebrata & Indeterminate & 4 \\
\hline E24/S72 & $31 \mathrm{~B}$ & 31EE2D & Isi-c & L. Paleo. & & Medium/Large Vertebrata & Indeterminate & 1 \\
\hline E24/S72 & 31B & 31EE2D & Isi-c & L. Paleo. & & Vertebrata & Indeterminate & 6 \\
\hline $\mathrm{E} 24 / \mathrm{S} 72$ & $32 \mathrm{~A}$ & 31FF1B & Icl/Isi-c & Paleoindian & & Mammalia (Medium/large) & Indeterminate & 1 \\
\hline E24/S72 & $32 \mathrm{~A}$ & $31 \mathrm{FF} 1 \mathrm{C}$ & Icl/Isi-c & Paleoindian & & Mammalia (Medium/large) & Indeterminate & 2 \\
\hline E24/S72 & $32 \mathrm{~A}$ & 31FF1C & Icl/Isi-c & Paleoindian & & Medium/Large Vertebrata & Indeterminate & 1 \\
\hline E24/S72 & $32 \mathrm{~A}$ & 31FF1C & Icl/Isi-c & Paleoindian & & Vertebrata & Indeterminate & 1 \\
\hline E24/S72 & $32 \mathrm{~A}$ & 31FF1D & Icl/Isi-c & Paleoindian & & Mammalia (Medium/large) & Indeterminate & 1 \\
\hline E24/S72 & $32 \mathrm{~A}$ & 31FF1D & Icl/Isi-c & Paleoindian & & Vertebrata & Indeterminate & 1 \\
\hline $\mathrm{E} 24 / \mathrm{S} 72$ & $32 \mathrm{~B}$ & $31 \mathrm{FF} 2 \mathrm{C}$ & Icl/Isi-c & Paleoindian & & Vertebrata & Indeterminate & 2 \\
\hline E24/S72 & $32 \mathrm{~B}$ & 31FF2D & Icl/Isi-c & Paleoindian & & Medium/Large Vertebrata & Indeterminate & 1 \\
\hline $\mathrm{E} 24 / \mathrm{S} 72$ & $33 \mathrm{~A}$ & 31GG1A & Icl/Isi-c & Paleoindian & & Mammalia (Medium/large) & Vertebra & 1 \\
\hline $\mathrm{E} 24 / \mathrm{S} 72$ & $33 \mathrm{~A}$ & 31GG1D & $\mathrm{Icl} / \mathrm{Isi}-\mathrm{c}$ & Paleoindian & & Vertebrata & Indeterminate & 2 \\
\hline E24/S72 & $33 \mathrm{~B}$ & $31 \mathrm{GG} 2 \mathrm{C}$ & $\mathrm{Icl} / \mathrm{Isi}-\mathrm{c}$ & Paleoindian & & Medium/Large Vertebrata & Indeterminate & 2 \\
\hline $\mathrm{E} 24 / \mathrm{S} 72$ & $33 \mathrm{~B}$ & $31 \mathrm{GG} 2 \mathrm{C}$ & $\mathrm{Icl} / \mathrm{Isi}-\mathrm{c}$ & Paleoindian & & Vertebrata & Indeterminate & 8 \\
\hline E24/S72 & $33 \mathrm{~B}$ & 31GG2D & Icl/Isi-c & Paleoindian & & Mammalia (Medium/large) & Long bone & 1 \\
\hline $\mathrm{E} 24 / \mathrm{S} 72$ & $33 \mathrm{~B}$ & $31 G G 2 D$ & $\mathrm{Icl} / \mathrm{Isi}-\mathrm{c}$ & Paleoindian & & Vertebrata & Indeterminate & 1 \\
\hline E24/S72 & $34 \mathrm{~A}$ & 31HH1A & $\mathrm{Icl} / \mathrm{Isi}-\mathrm{c}$ & Paleoindian & & Mammalia (Medium/large) & Indeterminate & 1 \\
\hline $\mathrm{E} 24 / \mathrm{S} 72$ & $34 \mathrm{~A}$ & 31HH1B & $\mathrm{Icl} / \mathrm{Isi}-\mathrm{c}$ & Paleoindian & & Vertebrata & Indeterminate & 4 \\
\hline $\mathrm{E} 24 / \mathrm{S} 72$ & $34 \mathrm{~B}$ & $31 \mathrm{HH} 2 \mathrm{C}$ & Icl & E. Paleo. & & Medium/Large Vertebrata & Indeterminate & 1 \\
\hline E24/S72 & $34 \mathrm{~B}$ & $31 \mathrm{HH} 2 \mathrm{C}$ & Icl & E. Paleo. & & Small/Medium Vertebrata & Long bone & 1 \\
\hline E24/S72 & $34 \mathrm{~B}$ & $31 \mathrm{HH} 2 \mathrm{D}$ & Icl & E. Paleo. & & Vertebrata & Indeterminate & 3 \\
\hline $\mathrm{E} 24 / \mathrm{S} 72$ & $35 \mathrm{~A}$ & 31II1B & Icl & E. Paleo. & & Vertebrata & Indeterminate & 3 \\
\hline E24/S72 & $35 \mathrm{~A}$ & 31IIIC & Icl & E. Paleo. & & Vertebrata & Indeterminate & 1 \\
\hline E24/S72 & $35 \mathrm{~B}$ & $31 \mathrm{II} 2 \mathrm{C}$ & Icl & E. Paleo. & & Odocoileus sp. & Dist. phalange of paradigit & 1 \\
\hline $\mathrm{E} 24 / \mathrm{S} 72$ & $35 \mathrm{~B}$ & 31IIID & Icl & E. Paleo. & & Mammalia (Medium/large) & Phalange & 1 \\
\hline E24/S72 & $35 \mathrm{~B}$ & 31II2D & Icl & E. Paleo. & & Vertebrata & Indeterminate & 1 \\
\hline $\mathrm{E} 24 / \mathrm{S} 72$ & $36 \mathrm{~A}$ & 31JJ1C & Isi/Icl & E. Paleo. & & Antilocapra/Odocoileus & Proximal phalange & 1 \\
\hline $\mathrm{E} 24 / \mathrm{S} 72$ & $36 \mathrm{~A}$ & 31JJ1D & Isi/Icl & E. Paleo. & & Medium/Large Vertebrata & Indeterminate & 1 \\
\hline $\mathrm{E} 24 / \mathrm{S} 72$ & $36 \mathrm{~B}$ & $31 \mathrm{JJ} 2 \mathrm{~A}$ & Isi/Icl & E. Paleo. & & Vertebrata & Indeterminate & 3 \\
\hline $\mathrm{E} 24 / \mathrm{S} 72$ & $36 \mathrm{~B}$ & 31JJ2B & Isi/Icl & E. Paleo. & & Vertebrata & Indeterminate & 3 \\
\hline E24/S72 & $36 \mathrm{~B}$ & 31JJ2C & Isi/Icl & E. Paleo. & & Mammalia (Medium/large) & Indeterminate & 1 \\
\hline $\mathrm{E} 24 / \mathrm{S} 72$ & $36 \mathrm{~B}$ & $31 \mathrm{JJ} 2 \mathrm{C}$ & Isi/Icl & E. Paleo. & & Vertebrata & Indeterminate & 16 \\
\hline E24/S72 & $36 \mathrm{~B}$ & 31JJ2D & Isi/Icl & E. Paleo. & & Vertebrata & Indeterminate & 3 \\
\hline $\mathrm{E} 24 / \mathrm{S} 72$ & $37 \mathrm{~A}$ & $31 \mathrm{KK} 1 \mathrm{~A}$ & Isi/Icl & E. Paleo. & & Testudinata & Shell fragment & 1 \\
\hline $\mathrm{E} 24 / \mathrm{S} 72$ & $37 \mathrm{~A}$ & 31KK1B & Isi/Icl & E. Paleo. & & Vertebrata & Indeterminate & 5 \\
\hline $\mathrm{E} 24 / \mathrm{S} 72$ & 37B & $31 \mathrm{KK} 2 \mathrm{D}$ & Isi/Icl & E. Paleo. & & Vertebrata & Indeterminate & 2 \\
\hline $\mathrm{E} 24 / \mathrm{S} 72$ & $38 \mathrm{~A}$ & 31LL1D & Isi/Icl & E. Paleo. & & Bison sp. & Permanent tooth & 1 \\
\hline E24/S72 & $38 \mathrm{~A}$ & 31LL1D & Isi/Icl & E. Paleo. & & Vertebrata & Indeterminate & 3 \\
\hline E24/S72 & $38 \mathrm{~B}$ & 31LL2A & Igl/Isi & E. Paleo. & & Mammalia (Medium/large) & Indeterminate & 1 \\
\hline E24/S72 & $38 \mathrm{~B}$ & 31LL2A & Igl/Isi & E. Paleo. & & Vertebrata & Indeterminate & 1 \\
\hline $\mathrm{E} 24 / \mathrm{S} 72$ & $38 \mathrm{~B}$ & 31LL2B & Igl/Isi & E. Paleo. & & Vertebrata & Indeterminate & 3 \\
\hline E24/S72 & $38 \mathrm{~B}-39 \mathrm{~A}$ & 31LL2/MI & $\mathrm{Igl} / \mathrm{Isi}$ & E. Paleo. & & Bison sp. & Proximal phalange & 1 \\
\hline E24/S72 & $38 \mathrm{~B}-39 \mathrm{~A}$ & 31LL2/MI & Igl/Isi & E. Paleo. & & Medium/Large Vertebrata & Indeterminate & 1 \\
\hline $\mathrm{E} 24 / \mathrm{S} 72$ & $39 \mathrm{~A}$ & 31MM1B & $\mathrm{Igl} / \mathrm{Isi}$ & E. Paleo. & & Bison sp. & Permanent tooth & 1 \\
\hline $\mathrm{E} 24 / \mathrm{S} 72$ & $39 \mathrm{~A}$ & 31MM1B & Igl/Isi & E. Paleo. & & Medium/Large Vertebrata & Indeterminate & 2 \\
\hline $\mathrm{E} 24 / \mathrm{S} 72$ & $39 \mathrm{~B}$ & 31MM2A & Igl/Isi & E. Paleo. & & Bison sp. & Calcaneus & 1 \\
\hline $\mathrm{E} 24 / \mathrm{S} 72$ & 39B & $31 \mathrm{MM} 2 \mathrm{~A}$ & Igl/Isi & E. Paleo. & & Medium/Large Vertebrata & Indeterminate & 2 \\
\hline $\mathrm{E} 24 / \mathrm{S} 72$ & 39B & 31MM2A & Igl/Isi & E. Paleo. & & Vertebrata & Indeterminate & 25 \\
\hline $\mathrm{E} 24 / \mathrm{S} 72$ & $39 \mathrm{~B}$ & 31MM2B & Igl/Isi & E. Paleo. & & Bison sp. & Rib & 1 \\
\hline $\mathrm{E} 24 / \mathrm{S} 72$ & 39B & 31MM2B & Igl/Isi & E. Paleo. & & Mammalia (Large) & Indeterminate & 2 \\
\hline $\mathrm{E} 24 / \mathrm{S} 72$ & $39 \mathrm{~B}$ & 31MM2B & Igl/Isi & E. Paleo. & & Mammalia (Medium/large) & Indeterminate & 32 \\
\hline $\mathrm{E} 24 / \mathrm{S} 72$ & 39B & 31MM2B & $\mathrm{Igl} / \mathrm{Isi}$ & E. Paleo. & & Medium/Large Vertebrata & Indeterminate & 1 \\
\hline $\mathrm{E} 24 / \mathrm{S} 72$ & $39 \mathrm{~B}$ & 31MM2B & Igl/Isi & E. Paleo. & & Vertebrata & Indeterminate & 58 \\
\hline
\end{tabular}




\begin{tabular}{|c|c|c|c|c|c|c|c|c|}
\hline Square & Level & Lot & Unit & Cultural Affinity & Feature & Taxon & Element & No. \\
\hline E24/S72 & $39 \mathrm{~B}$ & $31 \mathrm{MM} 2 \mathrm{C}$ & $\overline{I g l} / / \mathrm{Isi}$ & E. Paleo. & & Medium/Large Vertebrata & Indeterminate & 2 \\
\hline $\mathrm{E} 24 / \mathrm{S} 72$ & 39B & $31 \mathrm{MM} 2 \mathrm{C}$ & Igl/Isi & E. Paleo. & & Vertebrata & Indeterminate & 17 \\
\hline E24/S72 & 39B & 31MM2D & Igl/Isi & E. Paleo. & & Mammalia (Small) & Permanent tooth & 1 \\
\hline E24/S72 & 39B & 31MM2D & Igl//si & E. Paleo. & & Testudinata & Shell fragment & 1 \\
\hline E24/S72 & 39B & $31 \mathrm{MM} 2 \mathrm{D}$ & Igl/Isi & E. Paleo. & & Vertebrata & Indeterminate & 6 \\
\hline E24/S72 & $40 \mathrm{~A}$ & $31 \mathrm{NN} 1 \mathrm{~A}$ & Igl/Isi & E. Paleo. & & Leporidae & Permanent tooth & 7 \\
\hline $\mathrm{E} 24 / \mathrm{S} 72$ & $40 \mathrm{~A}$ & $31 \mathrm{NN} 1 \mathrm{~A}$ & $\mathrm{Igl} / \mathrm{Isi}$ & E. Paleo. & & Medium/Large Vertebrata & Indeterminate & 2 \\
\hline E24/S72 & $40 \mathrm{~A}$ & $31 \mathrm{NN} 1 \mathrm{~A}$ & Igl/Isi & E. Paleo. & & Vertebrata & Indeterminate & 10 \\
\hline $\mathrm{E} 24 / \mathrm{S} 72$ & $40 \mathrm{~A}$ & $31 \mathrm{NN} 1 \mathrm{C}$ & Igl/Isi & E. Paleo. & & Medium/Large Vertebrata & Indeterminate & 4 \\
\hline $\mathrm{E} 24 / \mathrm{S} 72$ & $40 \mathrm{~A}$ & $31 \mathrm{NN} 1 \mathrm{C}$ & Igl/Isi & E. Paleo. & & Vertebrata & Indeterminate & 11 \\
\hline E24/S74 & 15 & 300 & IIIa/b & E. Archaic & & Vertebrata & Indeterminate & 5 \\
\hline E24/S74 & $17 \mathrm{~A}$ & 30Q1 & IIIa & E. Archaic & & Vertebrata & Indeterminate & 1 \\
\hline E24/S74 & 17B & $30 \mathrm{Q} 2$ & Ша & E. Archaic & & Leporidae & Astragalus & 1 \\
\hline E24/S74 & 17B & $30 \mathrm{Q} 2$ & IIIa & E. Archaic & & Mammalia (Medium/large) & Indeterminate & 1 \\
\hline E24/S74 & 17B & 30Q2 & IIIIa & E. Archaic & & Testudinata & Shell fragment & 2 \\
\hline E24/S74 & 17B & 30Q2 & Ша & E. Archaic & & Vertebrata & Indeterminate & 4 \\
\hline E24/S74 & $18 \mathrm{~A}$ & 30R1 & ШІа & E. Archaic & & Canis sp. & Permanent tooth & 1 \\
\hline E24/S74 & $18 \mathrm{~A}$ & 30R1 & IIIa & E. Archaic & & Vertebrata & Indeterminate & 10 \\
\hline E24/S74 & $18 \mathrm{~B}$ & 30R2 & III & E. Archaic & & Antilocapra/Odocoileus & Calcaneus & 1 \\
\hline E24/S74 & $19 \mathrm{~A}$ & $30 \mathrm{~S} 1$ & IIIa & E. Archaic & & Mammalia (Medium/large) & Long bone & 1 \\
\hline E24/S74 & $19 \mathrm{~A}$ & $30 \mathrm{~S} 1$ & IIIa & E. Archaic & & Vertebrata & Indeterminate & 1 \\
\hline E24/S74 & 19B & $30 \mathrm{~S} 2 \mathrm{~A}$ & IIIa & E. Archaic & & Vertebrata & Indeterminate & 1 \\
\hline E24/S74 & 19B & $30 \mathrm{~S} 2 \mathrm{~B}$ & IIIa & E. Archaic & & Small/Medium Vertebrata & Long bone & 1 \\
\hline E24/S74 & 19B & 30S2D & IIIа & E. Archaic & & Vertebrata & Indeterminate & 1 \\
\hline E24/S74 & $20 \mathrm{~A}$ & 30T1A & П/Ша & L. Paleo./E. Archaic & & Mammalia (Medium/large) & Long bone & 1 \\
\hline E24/S74 & $20 \mathrm{~A}$ & $30 \mathrm{~T} 1 \mathrm{C}$ & П/Ша & L. Paleo./E. Archaic & & Medium/Large Vertebrata & Long bone & 1 \\
\hline E24/S74 & $20 \mathrm{~A}$ & $30 \mathrm{~T} 1 \mathrm{C}$ & Ш/Ша & L. Paleo./E. Archaic & & Vertebrata & Indeterminate & 2 \\
\hline E24/S74 & $20 \mathrm{~B}$ & $30 \mathrm{~T} 2 \mathrm{~A}$ & П/Ша & L. Paleo./E. Archaic & & Mammalia (Medium/large) & Indeterminate & 1 \\
\hline E24/S74 & $20 \mathrm{~B}$ & 30T2B & I/IIIa & L. Paleo./E. Archaic & & Medium/Large Vertebrata & Indeterminate & 1 \\
\hline E24/S74 & 20B & 30T2B & Ш/Ша & L. Paleo./E. Archaic & & Vertebrata & Indeterminate & 1 \\
\hline E24/S74 & $20 \mathrm{~B}$ & 30T2D & П/IIIa & L. Paleo./E. Archaic & & Vertebrata & Indeterminate & 2 \\
\hline E24/S74 & $20 \mathrm{~B}$ & F150 & II/ШIIa & E. Archaic & f150 & Vertebrata & Indeterminate & 1 \\
\hline $\mathrm{E} 24 / \mathrm{S} 74$ & $21 \mathrm{~A}$ & 30U1A & III & L. Paleo. & & Mammalia (Medium/large) & Long bone & 2 \\
\hline E24/S74 & $21 \mathrm{~A}$ & 30U1A & III & L. Paleo. & & Medium/Large Vertebrata & Indeterminate & 1 \\
\hline E24/S74 & $21 \mathrm{~A}$ & 30U1A & III & L. Paleo. & & Vertebrata & Indeterminate & 2 \\
\hline E24/S74 & $21 \mathrm{~A}$ & 30U1C & III & L. Paleo. & & cf. Sylvilagus sp. & Ulna & 1 \\
\hline E24/S74 & $21 \mathrm{~A}$ & $30 \mathrm{U} 1 \mathrm{C}$ & III & L. Paleo. & & Small/Medium Vertebrata & Long bone & 1 \\
\hline E24/S74 & $21 \mathrm{~A}$ & 30U1C & III & L. Paleo. & & Vertebrata & Indeterminate & 1 \\
\hline E24/S74 & $21 \mathrm{~A}$ & 30U1D & III & L. Paleo. & & Medium/Large Vertebrata & Long bone & 1 \\
\hline E24/S74 & $21 \mathrm{~A}$ & 30U1D & III & L. Paleo. & & Vertebrata & Indeterminate & 3 \\
\hline E24/S74 & 21B & $30 \mathrm{U} 2 \mathrm{~A}$ & III & L. Paleo. & & Mammalia (Medium/large) & Long bone & 1 \\
\hline E24/S74 & 21B & $30 \mathrm{U} 2 \mathrm{~B}$ & II & L. Paleo. & & Mammalia (Medium/large) & Indeterminate & 1 \\
\hline E24/S74 & 21B & $30 \mathrm{U} 2 \mathrm{C}$ & III & L. Paleo. & & Mammalia (Medium/large) & Long bone & 1 \\
\hline E24/S74 & $21 B$ & $30 \mathrm{U} 2 \mathrm{D}$ & II & L. Paleo. & & Mammalia (Medium/large) & Indeterminate & 1 \\
\hline E24/S74 & $21 \mathrm{~B}$ & $30 \mathrm{U} 2 \mathrm{D}$ & III & L. Paleo. & & Vertebrata & Indeterminate & 5 \\
\hline E24/S74 & $22 \mathrm{~A}$ & $30 \mathrm{~V} 1 \mathrm{~A}$ & II & L. Paleo. & & Small/Medium Vertebrata & Long bone & 1 \\
\hline E24/S74 & $22 \mathrm{~A}$ & $30 \mathrm{~V} 1 \mathrm{~A}$ & II & L. Paleo. & & Vertebrata & Indeterminate & 3 \\
\hline E24/S74 & $22 \mathrm{~A}$ & $30 \mathrm{~V} 1 \mathrm{~B}$ & III & L. Paleo. & & Mammalia (Medium/large) & Long bone & 1 \\
\hline E24/S74 & $22 \mathrm{~A}$ & $30 \mathrm{~V} 1 \mathrm{~B}$ & II & L. Paleo. & & Medium/Large Vertebrata & Indeterminate & 1 \\
\hline $\mathrm{E} 24 / \mathrm{S} 74$ & $22 \mathrm{~A}$ & $30 \mathrm{~V} 1 \mathrm{~B}$ & II & L. Paleo. & & Small/Medium Vertebrata & Long bone & 1 \\
\hline E24/S74 & $22 \mathrm{~A}$ & $30 \mathrm{~V} 1 \mathrm{C}$ & II & L. Paleo. & & Small/Medium Vertebrata & Proximal phalange & 1 \\
\hline E24/S74 & $22 \mathrm{~A}$ & $30 \mathrm{~V} 1 \mathrm{C}$ & II & L. Paleo. & & Vertebrata & Indeterminate & 1 \\
\hline E24/S74 & $22 \mathrm{~A}$ & 30V1D & II & L. Paleo. & & Small/Medium Vertebrata & Long bone & 1 \\
\hline E24/S74 & $22 \mathrm{~B}$ & $30 \mathrm{~V} 2 \mathrm{~A}$ & II & L. Paleo. & & Antilocapra/Odocoileus & Fused 3rd \& 4th metatarsal & 1 \\
\hline E24/S74 & $23 \mathrm{~A}$ & 30W1A & III & L. Paleo. & & Small/Medium Vertebrata & Long bone & 1 \\
\hline E24/S74 & $23 \mathrm{~A}$ & 30W1B & III & L. Paleo. & & Vertebrata & Indeterminate & 1 \\
\hline E24/S74 & $23 \mathrm{~A}$ & $30 \mathrm{~W} 1 \mathrm{C}$ & III & L. Paleo. & & Small/Medium Vertebrata & Long bone & 1 \\
\hline E24/S74 & $23 \mathrm{~A}$ & 30W1C & III & L. Paleo. & & Vertebrata & Indeterminate & 1 \\
\hline E24/S74 & 23B & $30 \mathrm{~W} 2 \mathrm{~A}$ & III & L. Paleo. & & Vertebrata & Indeterminate & 4 \\
\hline E24/S74 & 23B & $30 \mathrm{~W} 2 \mathrm{C}$ & III & L. Paleo. & & Small/Medium Vertebrata & Rib & 1 \\
\hline E24/S74 & $23 \mathrm{~B}$ & $30 \mathrm{~W} 2 \mathrm{C}$ & III & L. Paleo. & & Vertebrata & Indeterminate & 1 \\
\hline E24/S74 & 23B & $30 \mathrm{~W} 2 \mathrm{D}$ & III & L. Paleo. & & Vertebrata & Indeterminate & 1 \\
\hline E24/S74 & $24 \mathrm{~A}$ & $30 X 1 \mathrm{~A}$ & III & L. Paleo. & & Vertebrata & Indeterminate & 1 \\
\hline E24/S74 & $24 \mathrm{~A}$ & $30 \times 1 B$ & II & L. Paleo. & & Sylvilagus sp. & Calcaneus & 1 \\
\hline E24/S74 & $24 \mathrm{~A}$ & $30 \times 1 B$ & III & L. Paleo. & & Vertebrata & Indeterminate & 18 \\
\hline E24/S74 & $24 \mathrm{~A}$ & $30 \times 1 C$ & II & L. Paleo. & & Mammalia (Medium) & Cranium & 1 \\
\hline E24/S74 & $24 \mathrm{~A}$ & $30 \times 1 C$ & II & L. Paleo. & & Mammalia (Medium/large) & Long bone & 1 \\
\hline
\end{tabular}




\begin{tabular}{|c|c|c|c|c|c|c|c|c|}
\hline Square & Level & Lot & Unit & Cultural Affinity & Feature & Taxon & Element & No. \\
\hline E24/S74 & $24 \mathrm{~A}$ & $30 \mathrm{X} 1 \mathrm{C}$ & $\overline{I I}$ & L. Paleo. & & Mammalia (Very large) & Long bone & 2 \\
\hline E24/S74 & $24 \mathrm{~A}$ & $30 \mathrm{X} 1 \mathrm{C}$ & II & L. Paleo. & & Vertebrata & Indeterminate & 3 \\
\hline E24/S74 & $24 \mathrm{~A}$ & 30X1D & II & L. Paleo. & & Vertebrata & Indeterminate & 1 \\
\hline E24/S74 & $25 \mathrm{~A}$ & $30 \mathrm{Y} 1 \mathrm{~A}$ & II & L. Paleo. & & Small/Medium Vertebrata & Proximal phalange & 1 \\
\hline E24/S74 & $25 \mathrm{~A}$ & 30Y1A & II & L. Paleo. & & Vertebrata & Indeterminate & 5 \\
\hline E24/S74 & $25 \mathrm{~A}$ & 30Y1B & II & L. Paleo. & & Medium/Large Vertebrata & Indeterminate & 1 \\
\hline E24/S74 & $25 \mathrm{~A}$ & $30 \mathrm{Y} 1 \mathrm{C}$ & II & L. Paleo. & & Leporidae & Tibia & 1 \\
\hline E24/S74 & $25 \mathrm{~A}$ & $30 \mathrm{Y} 1 \mathrm{C}$ & II & L. Paleo. & & Small/Medium Vertebrata & Long bone & 1 \\
\hline E24/S74 & $25 \mathrm{~A}$ & 30Y1D & II & L. Paleo. & & Medium/Large Vertebrata & Long bone & 1 \\
\hline E24/S74 & $25 \mathrm{~B}$ & $30 \mathrm{Y} 2 \mathrm{C}$ & II & L. Paleo. & & Vertebrata & Indeterminate & 1 \\
\hline E24/S74 & $25 \mathrm{~B}$ & $30 \mathrm{Y} 2 \mathrm{D}$ & II & L. Paleo. & & Mammalia (Medium/large) & Long bone & 1 \\
\hline E24/S74 & $25 \mathrm{~B}$ & $30 \mathrm{Y} 2 \mathrm{D}$ & II & L. Paleo. & & Medium/Large Vertebrata & Indeterminate & 1 \\
\hline E24/S74 & $25 B$ & $30 Y 2 D$ & II & L. Paleo. & & Vertebrata & Indeterminate & 2 \\
\hline E24/S74 & $26 \mathrm{~A}$ & $30 \mathrm{Z} 1 \mathrm{~A}$ & II & L. Paleo. & & Vertebrata & Indeterminate & 1 \\
\hline E24/S74 & $26 \mathrm{~A}$ & $30 \mathrm{Z} 1 \mathrm{~B}$ & II & L. Paleo. & & Vertebrata & Indeterminate & 2 \\
\hline E24/S74 & $26 \mathrm{~A}$ & $30 \mathrm{Z} 1 \mathrm{C}$ & II & L. Paleo. & & Small/Medium Vertebrata & Long bone & 2 \\
\hline E24/S74 & $26 \mathrm{~B}$ & 30Z2B & II & L. Paleo. & & Medium/Large Vertebrata & Long bone & 2 \\
\hline E24/S74 & $26 \mathrm{~B}$ & 30Z2B & II & L. Paleo. & & Vertebrata & Indeterminate & 5 \\
\hline E24/S74 & $26 \mathrm{~B}$ & $30 \mathrm{Z} 2 \mathrm{C}$ & II & L. Paleo. & & Vertebrata & Indeterminate & 1 \\
\hline E24/S74 & $27 \mathrm{~A}$ & 30AA1D & III & L. Paleo. & & Vertebrata & Indeterminate & 1 \\
\hline E24/S74 & 27B & 30AA2 & Isi-c/II & L. Paleo. & & Vertebrata & Indeterminate & 1 \\
\hline E24/S74 & $27 \mathrm{~B}$ & $30 \mathrm{AA} 2 \mathrm{~A}$ & Isi-c/II & L. Paleo. & & Mammalia (Medium/large) & Indeterminate & 1 \\
\hline E24/S74 & $27 \mathrm{~B}$ & $30 \mathrm{AA} 2 \mathrm{~A}$ & Isi-c/II & L. Paleo. & & Mammalia (Medium/large) & Long bone & 1 \\
\hline E24/S74 & $27 \mathrm{~B}$ & $30 \mathrm{AA} 2 \mathrm{~A}$ & Isi-c/II & L. Paleo. & & Vertebrata & Indeterminate & 4 \\
\hline E24/S74 & $27 \mathrm{~B}$ & $30 \mathrm{AA} 2 \mathrm{C}$ & Isi-c/II & L. Paleo. & & Mammalia (Medium/large) & Indeterminate & 5 \\
\hline E24/S74 & $27 \mathrm{~B}$ & 30AA2C & Isi-c/II & L. Paleo. & & Vertebrata & Indeterminate & 19 \\
\hline E24/S74 & $27 \mathrm{~B}$ & 30AA2D & Isi-c/II & L. Paleo. & & Antilocapra/Odocoileus & Fused 3rd \& 4th metatarsal & 4 \\
\hline E24/S74 & $28 \mathrm{~A}$ & 30BB1A & Isi-c/II & L. Paleo. & & Mammalia (Large) & Long bone & 1 \\
\hline E24/S74 & $28 \mathrm{~A}$ & 30BB1A & Isi-c/II & L. Paleo. & & Mammalia (Medium/large) & Indeterminate & 1 \\
\hline E24/S74 & $28 \mathrm{~A}$ & 30BB1A & Isi-c/II & L. Paleo. & & Mammalia (Medium/large) & Long bone & 1 \\
\hline E24/S74 & $28 \mathrm{~A}$ & 30BB1A & Isi-c/II & L. Paleo. & & Vertebrata & Indeterminate & 4 \\
\hline E24/S74 & $28 \mathrm{~A}$ & 30BB1B & Isi-c/II & L. Paleo. & & Vertebrata & Indeterminate & 1 \\
\hline E24/S74 & $28 \mathrm{~A}$ & 30BB1C & Isi-c/II & L. Paleo. & & Antilocapra/Odocoileus & Astragalus & 1 \\
\hline E24/S74 & $28 \mathrm{~A}$ & 30BB1C & Isi-c/II & L. Paleo. & & Mammalia (Large) & Long bone & 1 \\
\hline E24/S74 & $28 \mathrm{~A}$ & 30BB1C & Isi-c/II & L. Paleo. & & Mammalia (Medium/large) & Long bone & 5 \\
\hline E24/S74 & $28 \mathrm{~A}$ & $30 \mathrm{BB} 1 \mathrm{C}$ & Isi-c/II & L. Paleo. & & Vertebrata & Indeterminate & 2 \\
\hline E24/S74 & $28 \mathrm{~A}$ & 30BB1D & Isi-c/II & L. Paleo. & & Mammalia (Large) & Long bone & 1 \\
\hline E24/S74 & $28 \mathrm{~A}$ & 30BB1D & Isi-c/II & L. Paleo. & & Mammalia (Medium/large) & Indeterminate & 5 \\
\hline E24/S74 & $28 \mathrm{~A}$ & 30BB1D & Isi-c/II & L. Paleo. & & Medium/Large Vertebrata & Indeterminate & 2 \\
\hline E24/S74 & $28 \mathrm{~A}$ & 30BB1D & Isi-c/II & L. Paleo. & & Vertebrata & Indeterminate & 24 \\
\hline E24/S74 & $28 \mathrm{~B}$ & $30 \mathrm{BB} 2 \mathrm{~A}$ & Isi-c & L. Paleo. & & Vertebrata & Indeterminate & 8 \\
\hline E24/S74 & $28 \mathrm{~B}$ & $30 \mathrm{BB} 2 \mathrm{~B}$ & Isi-c & L. Paleo. & & Mammalia (Medium/large) & Indeterminate & 1 \\
\hline E24/S74 & $28 \mathrm{~B}$ & 30BB2B & Isi-c & L. Paleo. & & Vertebrata & Indeterminate & 2 \\
\hline E24/S74 & $28 \mathrm{~B}$ & $30 \mathrm{BB} 2 \mathrm{C}$ & Isi-c & L. Paleo. & & Mammalia (Medium/large) & Long bone & 1 \\
\hline E24/S74 & $28 \mathrm{~B}$ & $30 \mathrm{BB} 2 \mathrm{C}$ & Isi-c & L. Paleo. & & Vertebrata & Indeterminate & 4 \\
\hline E24/S74 & $28 \mathrm{~B}$ & 30BB2D & Isi-c & L. Paleo. & & Vertebrata & Indeterminate & 1 \\
\hline E24/S74 & $29 \mathrm{~A}$ & $30 \mathrm{CC} 1 \mathrm{~B}$ & Isi-c & L. Paleo. & & Mammalia (Medium/large) & Long bone & 1 \\
\hline E24/S74 & $29 \mathrm{~A}$ & $30 \mathrm{CC} 1 \mathrm{~B}$ & Isi-c & L. Paleo. & & Vertebrata & Indeterminate & 1 \\
\hline E24/S74 & $29 \mathrm{~A}$ & $30 \mathrm{CC} 1 \mathrm{C}$ & Isi-c & L. Paleo. & & Mammalia (Medium/large) & Long bone & 1 \\
\hline E24/S74 & $29 \mathrm{~A}$ & $30 \mathrm{CClC}$ & Isi-c & L. Paleo. & & Vertebrata & Indeterminate & 3 \\
\hline E24/S74 & $29 \mathrm{~A}$ & $30 \mathrm{CC} 1 \mathrm{D}$ & Isi-c & L. Paleo. & & Mammalia (Medium/large) & Long bone & 1 \\
\hline E24/S74 & $29 \mathrm{~A}$ & $30 \mathrm{CC} 1 \mathrm{D}$ & Isi-c & L. Paleo. & & Vertebrata & Indeterminate & 3 \\
\hline E24/S74 & 29B & $30 \mathrm{CC} 2 \mathrm{~A}$ & Isi-c & L. Paleo. & & Vertebrata & Indeterminate & 2 \\
\hline E24/S74 & $29 B$ & $30 \mathrm{CC} 2 \mathrm{~B}$ & Isi-c & L. Paleo. & & Vertebrata & Indeterminate & 5 \\
\hline E24/S74 & $29 B$ & $30 \mathrm{CC} 2 \mathrm{C}$ & Isi-c & L. Paleo. & & Vertebrata & Indeterminate & 5 \\
\hline E24/S74 & 29B & $30 \mathrm{CC} 2 \mathrm{D}$ & Isi-c & L. Paleo. & & Vertebrata & Indeterminate & 4 \\
\hline E24/S74 & $30 \mathrm{~A}$ & 30DD1B & Isi-c & L. Paleo. & & Mammalia (Medium/large) & Indeterminate & 1 \\
\hline E24/S74 & $30 \mathrm{~A}$ & 30DD1B & Isi-c & L. Paleo. & & Vertebrata & Indeterminate & 7 \\
\hline E24/S74 & $30 \mathrm{~A}$ & 30DD1C & Isi-c & L. Paleo. & & Vertebrata & Indeterminate & 3 \\
\hline E24/S74 & $30 \mathrm{~A}$ & 30DD1D & Isi-c & L. Paleo. & & Mammalia (Medium/large) & Indeterminate & 1 \\
\hline $\mathrm{E} 24 / \mathrm{S} 74$ & $30 \mathrm{~A}$ & 30DD1D & Isi-c & L. Paleo. & & Vertebrata & Indeterminate & 4 \\
\hline E24/S74 & $30 \mathrm{~B}$ & 30DD2A & Isi-c & L. Paleo. & & Small/Medium Vertebrata & Long bone & 3 \\
\hline E24/S74 & $30 \mathrm{~B}$ & $30 \mathrm{DD} 2 \mathrm{~B}$ & Isi-c & L. Paleo. & & Medium/Large Vertebrata & Indeterminate & 3 \\
\hline E24/S74 & $30 \mathrm{~B}$ & 30DD2B & Isi-c & L. Paleo. & & Vertebrata & Indeterminate & 5 \\
\hline E24/S74 & $30 \mathrm{~B}$ & $30 \mathrm{DD} 2 \mathrm{C}$ & Isi-c & L. Paleo. & & Mammalia (Medium/large) & Indeterminate & 1 \\
\hline E24/S74 & $30 \mathrm{~B}$ & $30 \mathrm{DD} 2 \mathrm{C}$ & Isi-c & L. Paleo. & & Mammalia (Medium/large) & Long bone & 1 \\
\hline $\mathrm{E} 24 / \mathrm{S} 74$ & $30 \mathrm{~B}$ & $30 \mathrm{DD} 2 \mathrm{C}$ & Isi-c & L. Paleo. & & Testudinata & Shell fragment & 2 \\
\hline
\end{tabular}




\begin{tabular}{|c|c|c|c|c|c|c|c|c|}
\hline Square & Level & Lot & Unit & Cultural Affinity & Feature & Taxon & Element & No. \\
\hline$\overline{E 24 / S 74}$ & $30 \mathrm{~B}$ & 30DD2C & Isi-c & L. Paleo. & & Vertebrata & Indeterminate & \\
\hline E24/S74 & 30B & 30DD2D & Isi-c & L. Paleo. & & Medium/Large Vertebrata & Indeterminate & 2 \\
\hline E24/S74 & $31 \mathrm{~A}$ & 30EE1 & Isi-c & L. Paleo. & & Vertebrata & Indeterminate & 1 \\
\hline E24/S74 & $31 \mathrm{~A}$ & 30EE1B & Isi-c & L. Paleo. & & Vertebrata & Indeterminate & \\
\hline E24/S74 & $31 \mathrm{~A}$ & 30EE1C & Isi-c & L. Paleo. & & Mammalia (Medium/large) & Indeterminate & \\
\hline E24/S74 & $31 \mathrm{~A}$ & $30 \mathrm{EE} 1 \mathrm{C}$ & Isi-c & L. Paleo. & & Vertebrata & Indeterminate & \\
\hline E24/S74 & $31 \mathrm{~A}$ & 30EE1D & Isi-c & L. Paleo. & & Vertebrata & Indeterminate & \\
\hline E24/S74 & $31 \mathrm{~B}$ & $30 \mathrm{EE} 2 \mathrm{~A}$ & Icl/Isi-c & Paleoindian & & Medium/Large Vertebrata & Long bone & \\
\hline E24/S74 & $31 \mathrm{~B}$ & 30EE2D & Icl/Isi-c & Paleoindian & & Mammalia (Medium/large) & Long bone & \\
\hline E24/S74 & $31 \mathrm{~B}$ & 30EE2D & Icl/Isi-c & Paleoindian & & Mammalia (Small) & Femur & \\
\hline E24/S74 & $31 \mathrm{~B}$ & 30EE2D & Icl/Isi-c & Paleoindian & & Vertebrata & Indeterminate & \\
\hline E24/S74 & $32 \mathrm{~A}$ & 30FF1B & Icl/Isi-c & Paleoindian & & Vertebrata & Indeterminate & \\
\hline E24/S74 & $32 \mathrm{~B}$ & 30FF2A & Icl/Isi-c & Paleoindian & & Mammalia (Medium/large) & Indeterminate & \\
\hline E24/S74 & $32 \mathrm{~B}$ & $30 \mathrm{FF} 2 \mathrm{~A}$ & Icl/Isi-c & Paleoindian & & Small/Medium Vertebrata & Long bone & ( \\
\hline E24/S74 & $32 \mathrm{~B}$ & $30 \mathrm{FF} 2 \mathrm{~A}$ & Icl/Isi-c & Paleoindian & & Vertebrata & Indeterminate & 2 \\
\hline E24/S74 & $32 \mathrm{~B}$ & $30 \mathrm{FF} 2 \mathrm{~B}$ & Icl/Isi-c & Paleoindian & & Geomys sp. & Permanent tooth & 1 \\
\hline E24/S74 & $32 \mathrm{~B}$ & $30 \mathrm{FF} 2 \mathrm{~B}$ & Icl/Isi-c & Paleoindian & & Medium/Large Vertebrata & Indeterminate & 1 \\
\hline E24/S74 & $32 \mathrm{~B}$ & $30 \mathrm{FF} 2 \mathrm{~B}$ & Icl/Isi-c & Paleoindian & & Vertebrata & Indeterminate & 3 \\
\hline E24/S74 & $32 \mathrm{~B}$ & $30 \mathrm{FF} 2 \mathrm{C}$ & Icl/Isi-c & Paleoindian & & Vertebrata & Indeterminate & \\
\hline E24/S74 & $33 \mathrm{~A}$ & $30 \mathrm{GG} 1 \mathrm{~A}$ & Icl/Isi-c & Paleoindian & & Mammalia (Small) & Permanent tooth & \\
\hline E24/S74 & $33 \mathrm{~A}$ & 30GG1B & $\mathrm{Icl} / \mathrm{Isi}-\mathrm{c}$ & Paleoindian & & Small/Medium Vertebrata & Long bone & \\
\hline E24/S74 & $33 \mathrm{~A}$ & $30 \mathrm{GG} 1 \mathrm{~B}$ & Icl/Isi-c & Paleoindian & & Vertebrata & Indeterminate & 2 \\
\hline E24/S74 & $33 \mathrm{~A}$ & $30 \mathrm{GG} 1 \mathrm{C}$ & Icl/Isi-c & Paleoindian & & Mammalia (Medium/large) & Podial & \\
\hline E24/S74 & $33 \mathrm{~A}$ & 30GG1C & $\mathrm{Icl} / \mathrm{Isi}-\mathrm{c}$ & Paleoindian & & Medium/Large Vertebrata & Indeterminate & 1 \\
\hline E24/S74 & $33 \mathrm{~A}$ & 30GG1C & Icl/Isi-c & Paleoindian & & Vertebrata & Indeterminate & 3 \\
\hline E24/S74 & $33 \mathrm{~B}$ & 30GG2A & Icl/Isi-c & Paleoindian & & Vertebrata & Indeterminate & 1 \\
\hline E24/S74 & $33 \mathrm{~B}$ & $30 \mathrm{GG} 2 \mathrm{~B}$ & Icl/Isi-c & Paleoindian & & Mammalia (Medium/large) & Long bone & 2 \\
\hline E24/S74 & $33 \mathrm{~B}$ & $30 \mathrm{GG} 2 \mathrm{~B}$ & Icl/Isi-c & Paleoindian & & Small/Medium Vertebrata & Long bone & 1 \\
\hline E24/S74 & $34 \mathrm{~A}$ & 30HH1A & Icl & E. Paleo. & & Vertebrata & Indeterminate & 4 \\
\hline E24/S74 & 34B & $30 \mathrm{HH} 2 \mathrm{~B}$ & Icl & E. Paleo. & & Small/Medium Vertebrata & Phalange & 1 \\
\hline E24/S74 & $34 \mathrm{~B}$ & $30 \mathrm{HH} 2 \mathrm{~B}$ & Icl & E. Paleo. & & Vertebrata & Indeterminate & 2 \\
\hline E24/S74 & 34B & $30 \mathrm{HH} 2 \mathrm{C}$ & Icl & E. Paleo. & & Small/Medium Vertebrata & Long bone & 2 \\
\hline E24/S74 & $35 \mathrm{~A}$ & 30П1B & Isi/Icl & E. Paleo. & & Vertebrata & Indeterminate & 14 \\
\hline E24/S74 & $35 \mathrm{~A}$ & 30П1C & Isi/Icl & E. Paleo. & & Vertebrata & Indeterminate & 1 \\
\hline E24/S74 & $35 \mathrm{~B}$ & $30 \Pi 12 \mathrm{C}$ & Isi/Icl & E. Paleo. & & Vertebrata & Indeterminate & 1 \\
\hline E24/S74 & $36 \mathrm{~B}$ & $30 \mathrm{JJ} 2 \mathrm{C}$ & Isi/Icl & E. Paleo. & & Mammalia (Medium/large) & Long bone & 1 \\
\hline E24/S74 & $36 \mathrm{~B}$ & 30JJ2D & Isi/Icl & E. Paleo. & & Vertebrata & Indeterminate & 8 \\
\hline E24/S74 & $37 \mathrm{~A}$ & $30 \mathrm{KK} 1 \mathrm{~A}$ & Isi/Icl & E. Paleo. & & Mammalia (Medium/large) & Indeterminate & 1 \\
\hline E24/S74 & $37 \mathrm{~A}$ & 30KK1A & Isi/Icl & E. Paleo. & & Vertebrata & Indeterminate & 1 \\
\hline E24/S74 & $37 \mathrm{~A}$ & $30 \mathrm{KK} 1 \mathrm{~B}$ & Isi/Icl & E. Paleo. & & Vertebrata & Indeterminate & 3 \\
\hline E24/S74 & $37 \mathrm{~A}$ & $30 \mathrm{KK} 1 \mathrm{D}$ & Isi/Icl & E. Paleo. & & Vertebrata & Indeterminate & 28 \\
\hline E24/S74 & $37 \mathrm{~A} \& \mathrm{~B}$ & $30 \mathrm{KK} 1 \& 2$ & Isi/Icl & E. Paleo. & & Bison sp. & Humerus & 1 \\
\hline E24/S74 & $37 \mathrm{~A} \& \mathrm{~B}$ & $30 \mathrm{KK} 1 \& 2$ & Isi//Icl & E. Paleo. & & Mammalia (Medium/large) & Indeterminate & 1 \\
\hline E24/S74 & $37 \mathrm{~A} \& \mathrm{~B}$ & $30 \mathrm{KK} 1 \& 2$ & Isi//lcl & E. Paleo. & & Medium/Large Vertebrata & Indeterminate & 11 \\
\hline E24/S74 & $37 \mathrm{~A} \& \mathrm{~B}$ & $30 \mathrm{KK} 1 \& 2$ & Isi/Icl & E. Paleo. & & Vertebrata & Indeterminate & 157 \\
\hline E24/S74 & 37B & $30 \mathrm{KK} 2 \mathrm{~B}$ & Isi/Icl & E. Paleo. & & Vertebrata & Indeterminate & \\
\hline E24/S74 & $38 \mathrm{~A}$ & 30LL1A & Isi/Icl & E. Paleo. & & Mammalia (Medium/large) & Indeterminate & 3 \\
\hline E24/S74 & $38 \mathrm{~A}$ & 30LL1A & Isi/Icl & E. Paleo. & & Medium/Large Vertebrata & Indeterminate & 4 \\
\hline E24/S74 & $38 \mathrm{~A}$ & 30LL1A & Isi//lcl & E. Paleo. & & Medium/Large Vertebrata & Long bone & 1 \\
\hline E24/S74 & $38 \mathrm{~A}$ & 30LL1A & Isi/Icl & E. Paleo. & & Vertebrata & Indeterminate & 38 \\
\hline E24/S74 & $38 \mathrm{~A}$ & 30LL1C & Isi/Icl & E. Paleo. & & Medium/Large Vertebrata & Indeterminate & 1 \\
\hline E24/S74 & $38 \mathrm{~B}$ & 30LL2A & $\mathrm{Igl} / \mathrm{Isi}$ & E. Paleo. & & Bison sp. & Tibia & 1 \\
\hline E24/S74 & $38 \mathrm{~B}$ & 30LL2A & Igl//si & E. Paleo. & & Mammalia (Large) & Indeterminate & 4 \\
\hline E24/S74 & $38 \mathrm{~B}$ & 30LL2A & $\mathrm{Igl} / \mathrm{Isi}$ & E. Paleo. & & Mammalia (Medium/large) & Indeterminate & 1 \\
\hline E24/S74 & $38 \mathrm{~B}$ & 30LL2A & Igl/Isi & E. Paleo. & & Medium/Large Vertebrata & Indeterminate & \\
\hline E24/S74 & $38 \mathrm{~B}$ & 30LL2A & Igl//si & E. Paleo. & & Vertebrata & Indeterminate & 17 \\
\hline E24/S74 & $38 \mathrm{~B}$ & 30LL2C & Igl//si & E. Paleo. & & Mammalia (Medium/large) & Indeterminate & 3 \\
\hline E24/S74 & $38 \mathrm{~B}$ & 30LL2C & Igl//si & E. Paleo. & & Vertebrata & Indeterminate & 3 \\
\hline E24/S74 & $39 \mathrm{~A}$ & $30 \mathrm{MM} 1 \mathrm{~A}$ & Igl//si & E. Paleo. & & Medium/Large Vertebrata & Indeterminate & \\
\hline E24/S74 & $39 \mathrm{~A}$ & $30 \mathrm{MM} 1 \mathrm{C}$ & $\mathrm{Igl} / \mathrm{Isi}$ & E. Paleo. & & Vertebrata & Indeterminate & \\
\hline E24/S74 & 39B & $30 \mathrm{MM} 2 \mathrm{~A}$ & Igl/Isi & E. Paleo. & & Testudinata & Peripheral & \\
\hline E24/S74 & $39 \mathrm{~B}$ & $30 \mathrm{MM} 2 \mathrm{~A}$ & Igl/Isi & E. Paleo. & & Vertebrata & Indeterminate & 1 \\
\hline E24/S76 & 15 & 290 & Шаa/b & E. Archaic & & Mammalia (Medium/large) & Long bone & 4 \\
\hline E24/S76 & 15 & 290 & IIIa/b & E. Archaic & & Medium/Large Vertebrata & Indeterminate & \\
\hline E24/S76 & 15 & 290 & IIIa/b & E. Archaic & & Vertebrata & Indeterminate & 7 \\
\hline E24/S76 & $17 \mathrm{~A}$ & 29Q1 & IIIa & E. Archaic & & Vertebrata & Indeterminate & \\
\hline E24/S76 & $18 \mathrm{~A}$ & 29R1 & IIIa & E. Archaic & & Testudinata & Shell fragment & 1 \\
\hline
\end{tabular}




\begin{tabular}{|c|c|c|c|c|c|c|c|c|}
\hline Square & Level & Lot & Unit & Cultural Affinity & Feature & Taxon & Element & No. \\
\hline E24/S76 & $18 \mathrm{~A}$ & $29 \mathrm{R} 1$ & IIIa & E. Archaic & & Vertebrata & Indeterminate & 5 \\
\hline E24/S76 & $18 \mathrm{~B}$ & $29 \mathrm{R} 2$ & Ша & E. Archaic & & Antilocapra/Odocoileus & Calcaneus & 1 \\
\hline E24/S76 & $18 \mathrm{~B}$ & 29R2 & IIII & E. Archaic & & Mammalia (Large) & Indeterminate & 1 \\
\hline E24/S76 & $18 \mathrm{~B}$ & 29R2 & IIIIa & E. Archaic & & Mammalia (Medium) & Middle phalange & 1 \\
\hline E24/S76 & $18 \mathrm{~B}$ & 29R2 & Ша & E. Archaic & & Mammalia (Medium/large) & Long bone & 2 \\
\hline E24/S76 & $18 \mathrm{~B}$ & 29R2 & IIIa & E. Archaic & & Vertebrata & Indeterminate & 10 \\
\hline E24/S76 & 19B & $29 \mathrm{~S} 2$ & I/IIIa & L. Paleo./E. Archaic & & Mammalia (Medium/large) & Indeterminate & 1 \\
\hline E24/S76 & 19B & $29 \mathrm{~S} 2$ & Ш/Ша & L. Paleo./E. Archaic & & Small/Medium Vertebrata & Long bone & 4 \\
\hline E24/S76 & 19B & $29 \mathrm{~S} 2$ & П/ШाIа & L. Paleo./E. Archaic & & Vertebrata & Indeterminate & 16 \\
\hline E24/S76 & 19B & $29 \mathrm{~S} 2 \mathrm{~A}$ & П/ШІІа & L. Paleo./E. Archaic & & Lepus californicus & Calcaneus & 1 \\
\hline E24/S76 & 19B & 29S2B & Ш/Ша & L. Paleo./E. Archaic & & Vertebrata & Indeterminate & 1 \\
\hline E24/S76 & $20 \mathrm{~A}$ & 29T1A & II/IIIa & L. Paleo./E. Archaic & & Mammalia (Medium/large) & Indeterminate & 1 \\
\hline E24/S76 & $20 \mathrm{~A}$ & 29T1B & ПI/IIIa & L. Paleo./E. Archaic & & Mammalia (Medium/large) & Indeterminate & 1 \\
\hline E24/S76 & $20 \mathrm{~A}$ & 29T1C & Ш/Ша & L. Paleo./E. Archaic & & Vertebrata & Indeterminate & 9 \\
\hline E24/S76 & $20 \mathrm{~B}$ & $29 \mathrm{~T} 2 \mathrm{~A}$ & II/IIIa & L. Paleo./E. Archaic & & Vertebrata & Indeterminate & 1 \\
\hline E24/S76 & 20B & 29T2B & II/IIIa & L. Paleo./E. Archaic & & Mammalia (Medium/large) & Long bone & 1 \\
\hline E24/S76 & 20B & 29T2B & П/Ша & L. Paleo./E. Archaic & & Vertebrata & Indeterminate & 2 \\
\hline E24/S76 & 20B & $29 \mathrm{~T} 2 \mathrm{C}$ & П/IIIa & L. Paleo./E. Archaic & & Mammalia (Medium/large) & Indeterminate & 1 \\
\hline E24/S76 & 20B & 29T2D & ПI/IIIa & L. Paleo./E. Archaic & & Mammalia (Medium/large) & Long bone & 1 \\
\hline E24/S76 & 20B & 29T2D & II/IIa & L. Paleo./E. Archaic & & Small/Medium Vertebrata & Long bone & 1 \\
\hline E24/S76 & $21 \mathrm{~A}$ & 29U1A & II & L. Paleo. & & Vertebrata & Indeterminate & 3 \\
\hline E24/S76 & $21 \mathrm{~A}$ & 29U1B & III & L. Paleo. & & Medium/Large Vertebrata & Indeterminate & 1 \\
\hline E24/S76 & $21 \mathrm{~A}$ & 29U1B & III & L. Paleo. & & Small/Medium Vertebrata & Long bone & 2 \\
\hline E24/S76 & $21 \mathrm{~A}$ & 29U1B & III & L. Paleo. & & Vertebrata & Indeterminate & 6 \\
\hline E24/S76 & $21 \mathrm{~A}$ & 29U1C & II & L. Paleo. & & Mammalia (Medium/large) & Indeterminate & 1 \\
\hline E24/S76 & $21 \mathrm{~A}$ & $29 \mathrm{U} 1 \mathrm{C}$ & III & L. Paleo. & & Vertebrata & Indeterminate & 3 \\
\hline E24/S76 & $21 \mathrm{~A}$ & 29U1D & III & L. Paleo. & & Vertebrata & Indeterminate & 5 \\
\hline E24/S76 & 21B & $29 \mathrm{U} 2 \mathrm{~A}$ & II & L. Paleo. & & Vertebrata & Indeterminate & 1 \\
\hline E24/S76 & $21 \mathrm{~B}$ & 29U2B & II & L. Paleo. & & Vertebrata & Indeterminate & 1 \\
\hline E24/S76 & $21 \mathrm{~B}$ & $29 \mathrm{U} 2 \mathrm{C}$ & II & L. Paleo. & & Mammalia (Medium/large) & Indeterminate & 2 \\
\hline E24/S76 & 21B & $29 \mathrm{U} 2 \mathrm{C}$ & II & L. Paleo. & & Mammalia (Medium/large) & Long bone & 1 \\
\hline E24/S76 & 21B & $29 \mathrm{U} 2 \mathrm{C}$ & II & L. Paleo. & & Small/Medium Vertebrata & Long bone & 2 \\
\hline E24/S76 & $21 \mathrm{~B}$ & $29 \mathrm{U} 2 \mathrm{C}$ & III & L. Paleo. & & Vertebrata & Indeterminate & 2 \\
\hline E24/S76 & 21B & 29U2D & II & L. Paleo. & & Antilocapra/Odocoileus & Metapodial & 1 \\
\hline E24/S76 & 21B & 29U2D & II & L. Paleo. & & Medium/Large Vertebrata & Indeterminate & 1 \\
\hline E24/S76 & 21B & 29U2D & II & L. Paleo. & & Vertebrata & Indeterminate & 1 \\
\hline E24/S76 & $22 \mathrm{~A}$ & 29V1A & III & L. Paleo. & & Mammalia (Medium/large) & Indeterminate & 3 \\
\hline E24/S76 & $22 \mathrm{~A}$ & 29V1A & II & L. Paleo. & & Mammalia (Medium/large) & Long bone & 1 \\
\hline E24/S76 & $22 \mathrm{~A}$ & $29 \mathrm{~V} 1 \mathrm{~A}$ & II & L. Paleo. & & Medium/Large Vertebrata & Indeterminate & 9 \\
\hline E24/S76 & $22 \mathrm{~A}$ & 29V1A & II & L. Paleo. & & Vertebrata & Indeterminate & 5 \\
\hline E24/S76 & $22 \mathrm{~A}$ & 29V1A & II & L. Paleo. & f155 & Mammalia (Large) & Tooth, perm./decid. ind. & 8 \\
\hline E24/S76 & $22 \mathrm{~B}$ & $29 \mathrm{~V} 2 \mathrm{~A}$ & III & L. Paleo. & & Mammalia (Large) & Cranium & 1 \\
\hline E24/S76 & $22 \mathrm{~B}$ & 29V2B & III & L. Paleo. & & Medium/Large Vertebrata & Indeterminate & 1 \\
\hline E24/S76 & 22B & $29 \mathrm{~V} 2 \mathrm{~B}$ & II & L. Paleo. & & Vertebrata & Indeterminate & 1 \\
\hline E24/S76 & 22B & $29 \mathrm{~V} 2 \mathrm{C}$ & II & L. Paleo. & & Mammalia (Medium) & Proximal phalange & 1 \\
\hline E24/S76 & 22B & $29 \mathrm{~V} 2 \mathrm{C}$ & III & L. Paleo. & & Mammalia (Medium/large) & Indeterminate & 1 \\
\hline E24/S76 & $23 \mathrm{~A}$ & 29W1A & III & L. Paleo. & & Vertebrata & Indeterminate & 2 \\
\hline E24/S76 & $23 \mathrm{~A}$ & 29W1B & III & L. Paleo. & & Vertebrata & Long bone & 1 \\
\hline E24/S76 & $23 \mathrm{~A}$ & $29 \mathrm{~W} 1 \mathrm{C}$ & III & L. Paleo. & & Mammalia (Large) & Long bone & 1 \\
\hline E24/S76 & $23 \mathrm{~A}$ & $29 \mathrm{~W} 1 \mathrm{C}$ & III & L. Paleo. & & Mammalia (Medium/large) & Indeterminate & 1 \\
\hline E24/S76 & $23 \mathrm{~A}$ & $29 \mathrm{~W} 1 \mathrm{C}$ & III & L. Paleo. & & Medium/Large Vertebrata & Indeterminate & 7 \\
\hline E24/S76 & $23 \mathrm{~A}$ & $29 \mathrm{~W} 1 \mathrm{C}$ & III & L. Paleo. & & Vertebrata & Indeterminate & 7 \\
\hline E24/S76 & $23 \mathrm{~A}$ & 29W1D & III & L. Paleo. & & Vertebrata & Indeterminate & 3 \\
\hline E24/S76 & 23B & 29W2A & III & L. Paleo. & & Mammalia (Medium/large) & Indeterminate & 1 \\
\hline E24/S76 & $23 \mathrm{~B}$ & $29 \mathrm{~W} 2 \mathrm{C}$ & III & L. Paleo. & & Vertebrata & Indeterminate & 4 \\
\hline E24/S76 & $24 \mathrm{~A}$ & 29X1A & III & L. Paleo. & & Aves (Large) & Distal phalange & 1 \\
\hline E24/S76 & $24 \mathrm{~A}$ & 29X1A & III & L. Paleo. & & Small/Medium Vertebrata & Long bone & 3 \\
\hline E24/S76 & $24 \mathrm{~A}$ & 29X1A & III & L. Paleo. & & Vertebrata & Indeterminate & 3 \\
\hline E24/S76 & $24 \mathrm{~A}$ & $29 \mathrm{X} 1 \mathrm{~B}$ & III & L. Paleo. & & Medium/Large Vertebrata & Indeterminate & 1 \\
\hline E24/S76 & $24 \mathrm{~A}$ & 29X1B & III & L. Paleo. & & Vertebrata & Indeterminate & 7 \\
\hline E24/S76 & $24 \mathrm{~A}$ & 29X1D & III & L. Paleo. & & Medium/Large Vertebrata & Indeterminate & 1 \\
\hline E24/S76 & 24B & $29 \mathrm{X} 2 \mathrm{~A}$ & III & L. Paleo. & & Mammalia (Medium/large) & Long bone & 1 \\
\hline E24/S76 & 24B & $29 \mathrm{X} 2 \mathrm{C}$ & III & L. Paleo. & & Medium/Large Vertebrata & Indeterminate & 1 \\
\hline E24/S76 & 24B & $29 \mathrm{X} 2 \mathrm{C}$ & III & L. Paleo. & & Vertebrata & Indeterminate & 3 \\
\hline E24/S76 & 24B & $29 \mathrm{X} 2 \mathrm{D}$ & III & L. Paleo. & & Vertebrata & Indeterminate & 1 \\
\hline E24/S76 & $25 \mathrm{~A}$ & 29Y1A & III & L. Paleo. & & Medium/Large Vertebrata & Indeterminate & 2 \\
\hline E24/S76 & $25 \mathrm{~A}$ & 29Y1A & III & L. Paleo. & & Vertebrata & Indeterminate & 2 \\
\hline
\end{tabular}




\begin{tabular}{|c|c|c|c|c|c|c|c|c|}
\hline Square & Level & Lot & Unit & Cultural Affinity & Feature & Taxon & Element & No. \\
\hline E24/S76 & $25 \mathrm{~A}$ & 29Y1B & II & L. Paleo. & & cf. Testudinata & Shell fragment & 1 \\
\hline $\mathrm{E} 24 / \mathrm{S} 76$ & $25 \mathrm{~A}$ & 29Y1B & III & L. Paleo. & & Vertebrata & Indeterminate & 1 \\
\hline E24/S76 & $25 \mathrm{~A}$ & 29Y1C & III & L. Paleo. & & Small/Medium Vertebrata & Indeterminate & 1 \\
\hline E24/S76 & $25 \mathrm{~A}$ & $29 \mathrm{Y} 1 \mathrm{C}$ & II & L. Paleo. & & Vertebrata & Indeterminate & 1 \\
\hline E24/S76 & $25 \mathrm{~B}$ & $29 \mathrm{Y} 2 \mathrm{~A}$ & $\mathrm{Id} / \mathrm{II}$ & L. Paleo. & & Mammalia (Medium/large) & Long bone & 1 \\
\hline E24/S76 & $25 \mathrm{~B}$ & 29Y2D & $\mathrm{Id} / \mathrm{II}$ & L. Paleo. & & Medium/Large Vertebrata & Indeterminate & 1 \\
\hline E24/S76 & $25 \mathrm{~B}$ & 29Y2D & $\mathrm{Id} / \mathrm{II}$ & L. Paleo. & & Vertebrata & Indeterminate & 1 \\
\hline E24/S76 & $26 \mathrm{~A}$ & $29 \mathrm{Z} 1 \mathrm{~A}$ & $\mathrm{Id} / \mathrm{II}$ & L. Paleo. & & Vertebrata & Indeterminate & 1 \\
\hline E24/S76 & $26 \mathrm{~A}$ & 29Z1C & $\mathrm{Id} / \mathrm{II}$ & L. Paleo. & & Vertebrata & Indeterminate & 2 \\
\hline E24/S76 & $26 \mathrm{~A}$ & 29Z1D & Id/II & L. Paleo. & & Medium/Large Vertebrata & Indeterminate & 1 \\
\hline E24/S76 & $26 \mathrm{~A}$ & 29Z1D & $\mathrm{Id} / \mathrm{II}$ & L. Paleo. & & Vertebrata & Indeterminate & 1 \\
\hline E24/S76 & $26 \mathrm{~B}$ & $29 \mathrm{Z} 2 \mathrm{~A}$ & Isi-c/Id/II & L. Paleo. & & Vertebrata & Indeterminate & 1 \\
\hline E24/S76 & $26 \mathrm{~B}$ & $29 \mathrm{Z} 2 \mathrm{C}$ & Isi-c/Id/II & L. Paleo. & & Vertebrata & Indeterminate & 2 \\
\hline E24/S76 & $26 \mathrm{~B}$ & 29Z2D & Isi-c/Id/II & L. Paleo. & & Small/Medium Vertebrata & Indeterminate & 3 \\
\hline E24/S76 & $26 \mathrm{~B}$ & 29Z2D & Isi-c/Id/II & L. Paleo. & & Vertebrata & Indeterminate & 6 \\
\hline E24/S76 & $27 \mathrm{~A}$ & 29AA1 & Isi-c/Id/II & L. Paleo. & & Bison sp. & Lumbar vertebra & 1 \\
\hline E24/S76 & $27 \mathrm{~A}$ & 29AA1A & Isi-c/Id/II & L. Paleo. & & Mammalia (Medium/large) & Long bone & 1 \\
\hline E24/S76 & $27 \mathrm{~A}$ & 29AA1A & Isi-c/Id/II & L. Paleo. & & Vertebrata & Indeterminate & 6 \\
\hline $\mathrm{E} 24 / \mathrm{S} 76$ & $27 \mathrm{~A}$ & 29AA1B & Isi-c/Id/II & L. Paleo. & & Vertebrata & Indeterminate & 7 \\
\hline E24/S76 & $27 \mathrm{~A}$ & 29AA1C & Isi-c/Id/II & L. Paleo. & & Mammalia (Medium/large) & Indeterminate & 2 \\
\hline E24/S76 & $27 \mathrm{~A}$ & 29AA1C & Isi-c/Id/II & L. Paleo. & & Vertebrata & Indeterminate & 8 \\
\hline E24/S76 & $27 \mathrm{~A}$ & 29AA1D & Isi-c/Id/II & L. Paleo. & & Mammalia (Medium/large) & Long bone & 1 \\
\hline E24/S76 & $27 \mathrm{~A}$ & 29AA1D & Isi-c/Id/II & L. Paleo. & & Vertebrata & Indeterminate & 8 \\
\hline E24/S76 & 27B & 29AA2A & Isi-c/Id & L. Paleo. & & Mammalia (Medium/large) & Long bone & 2 \\
\hline E24/S76 & 27B & 29AA2A & Isi-c/Id & L. Paleo. & & Vertebrata & Indeterminate & 6 \\
\hline E24/S76 & $27 \mathrm{~B}$ & 29AA2B & Isi-c/Id & L. Paleo. & & Vertebrata & Indeterminate & 8 \\
\hline E24/S76 & 27B & 29AA2D & Isi-c/Id & L. Paleo. & & Vertebrata & Indeterminate & 7 \\
\hline E24/S76 & $28 \mathrm{~A}$ & 29BB1A & Isi-c & L. Paleo. & & Mammalia (Medium/large) & Indeterminate & 1 \\
\hline E24/S76 & $28 \mathrm{~A}$ & 29BB1A & Isi-c & L. Paleo. & & Vertebrata & Indeterminate & 4 \\
\hline E24/S76 & $28 \mathrm{~A}$ & 29BB1B & Isi-c & L. Paleo. & & Vertebrata & Indeterminate & 4 \\
\hline E24/S76 & $28 \mathrm{~A}$ & 29BB1C & Isi-c & L. Paleo. & & Carnivora & Tooth, perm./decid. ind. & 1 \\
\hline E24/S76 & $28 \mathrm{~A}$ & 29BB1C & Isi-c & L. Paleo. & & Mammalia (Medium/large) & Indeterminate & 1 \\
\hline E24/S76 & $28 \mathrm{~A}$ & 29BB1C & Isi-c & L. Paleo. & & Mammalia (Medium/large) & Long bone & 1 \\
\hline E24/S76 & $28 \mathrm{~A}$ & 29BB1C & Isi-c & L. Paleo. & & Vertebrata & Indeterminate & 14 \\
\hline E24/S76 & $28 \mathrm{~A}$ & 29BB1D & Isi-c & L. Paleo. & & Artiodactyla & Tooth, perm./decid. ind. & 1 \\
\hline E24/S76 & $28 \mathrm{~A}$ & 29BB1D & Isi-c & L. Paleo. & & Mammalia (Medium/large) & Indeterminate & 1 \\
\hline E24/S76 & $28 \mathrm{~A}$ & 29BB1D & Isi-c & L. Paleo. & & Vertebrata & Indeterminate & 9 \\
\hline E24/S76 & $28 \mathrm{~B}$ & 29BB2A & Isi-c & L. Paleo. & & Mammalia (Medium/large) & Indeterminate & 2 \\
\hline E24/S76 & 28B & 29BB2A & Isi-c & L. Paleo. & & Medium/Large Vertebrata & Indeterminate & 5 \\
\hline E24/S76 & 28B & 29BB2A & Isi-c & L. Paleo. & & Medium/Large Vertebrata & Long bone & 1 \\
\hline E24/S76 & 28B & 29BB2A & Isi-c & L. Paleo. & & Vertebrata & Indeterminate & 1 \\
\hline E24/S76 & 28B & 29BB2B & Isi-c & L. Paleo. & & Mammalia (Medium) & Astragalus & 1 \\
\hline E24/S76 & $28 \mathrm{~B}$ & 29BB2B & Isi-c & L. Paleo. & & Vertebrata & Indeterminate & 5 \\
\hline E24/S76 & $28 \mathrm{~B}$ & 29BB2C & Isi-c & L. Paleo. & & Medium/Large Vertebrata & Indeterminate & 3 \\
\hline E24/S76 & $28 \mathrm{~B}$ & 29BB2C & Isi-c & L. Paleo. & & Medium/Large Vertebrata & Long bone & 1 \\
\hline E24/S76 & $28 \mathrm{~B}$ & 29BB2C & Isi-c & L. Paleo. & & Vertebrata & Indeterminate & 11 \\
\hline E24/S76 & $28 \mathrm{~B}$ & 29BB2D & Isi-c & L. Paleo. & & Mammalia (Medium/large) & Indeterminate & 1 \\
\hline E24/S76 & 28B & 29BB2D & Isi-c & L. Paleo. & & Medium/Large Vertebrata & Indeterminate & 1 \\
\hline E24/S76 & $28 \mathrm{~B}$ & 29BB2D & Isi-c & L. Paleo. & & Sylvilagus sp. & Calcaneus & 1 \\
\hline E24/S76 & 28B & 29BB2D & Isi-c & L. Paleo. & & Vertebrata & Indeterminate & 18 \\
\hline E24/S76 & $29 \mathrm{~A}$ & 29CC1A & Isi-c & L. Paleo. & & Vertebrata & Indeterminate & 1 \\
\hline E24/S76 & $29 \mathrm{~A}$ & $29 \mathrm{CC} 1 \mathrm{~B}$ & Isi-c & L. Paleo. & & Mammalia (Medium/large) & Indeterminate & 1 \\
\hline E24/S76 & $29 \mathrm{~A}$ & $29 \mathrm{CC} 1 \mathrm{~B}$ & Isi-c & L. Paleo. & & Mammalia (Medium/large) & Long bone & 1 \\
\hline E24/S76 & $29 \mathrm{~A}$ & $29 \mathrm{CC} 1 \mathrm{~B}$ & Isi-c & L. Paleo. & & Vertebrata & Indeterminate & 10 \\
\hline E24/S76 & $29 \mathrm{~A}$ & $29 \mathrm{CC} 1 \mathrm{C}$ & Isi-c & L. Paleo. & & Vertebrata & Indeterminate & 4 \\
\hline E24/S76 & $29 \mathrm{~A}$ & 29CC1D & Isi-c & L. Paleo. & & Vertebrata & Indeterminate & 1 \\
\hline E24/S76 & $29 \mathrm{~A}$ & 29CC1D & Isi-c & L. Paleo. & & Vertebrata & Long bone & 3 \\
\hline E24/S76 & 29B & $29 \mathrm{CC} 2 \mathrm{~A}$ & Isi-c & L. Paleo. & & Vertebrata & Indeterminate & 6 \\
\hline E24/S76 & 29B & 29 CС2B & Isi-c & L. Paleo. & & Mammalia (Medium/large) & Indeterminate & 1 \\
\hline E24/S76 & 29B & $29 \mathrm{CC} 2 \mathrm{~B}$ & Isi-c & L. Paleo. & & Mammalia (Medium/large) & Long bone & 1 \\
\hline E24/S76 & 29B & $29 \mathrm{CC} 2 \mathrm{~B}$ & Isi-c & L. Paleo. & & Testudinata & Shell fragment & 1 \\
\hline E24/S76 & $29 \mathrm{~B}$ & $29 \mathrm{CC} 2 \mathrm{~B}$ & Isi-c & L. Paleo. & & Vertebrata & Indeterminate & 13 \\
\hline E24/S76 & 29B & $29 \mathrm{CC} 2 \mathrm{C}$ & Isi-c & L. Paleo. & & Vertebrata & Indeterminate & 21 \\
\hline E24/S76 & 29B & $29 \mathrm{CC} 2 \mathrm{C}$ & Isi-c & L. Paleo. & & Vertebrata & Long bone & 1 \\
\hline E24/S76 & 29B & 29CC2D & Isi-c & L. Paleo. & & Leporidae & Scapula & 1 \\
\hline E24/S76 & 29B & $29 \mathrm{CC} 2 \mathrm{D}$ & Isi-c & L. Paleo. & & Mammalia (Medium) & Metapodial & 1 \\
\hline E24/S76 & $29 \mathrm{~B}$ & 29CC2D & Isi-c & L. Paleo. & & Mammalia (Medium) & Middle phalange & 1 \\
\hline
\end{tabular}




\begin{tabular}{|c|c|c|c|c|c|c|c|c|}
\hline Square & Level & Lot & Unit & Cultural Affinity & Feature & Taxon & Element & No. \\
\hline E24/S76 & $29 \mathrm{~B}$ & 29CC2D & Isi-c & L. Paleo. & & Mammalia (Medium) & Proximal phalange & 1 \\
\hline E24/S76 & $29 \mathrm{~B}$ & $29 \mathrm{CC} 2 \mathrm{D}$ & Isi-c & L. Paleo. & & Vertebrata & Indeterminate & 6 \\
\hline E24/S76 & 29B & 29CC2D & Isi-c & L. Paleo. & & Vertebrata & Long bone & 1 \\
\hline E24/S76 & $30 \mathrm{~A}$ & 29DD1A & Isi-c & L. Paleo. & & Vertebrata & Indeterminate & 9 \\
\hline E24/S76 & $30 \mathrm{~A}$ & 29DD1B & Isi-c & L. Paleo. & & Vertebrata & Indeterminate & 11 \\
\hline E24/S76 & $30 \mathrm{~A}$ & 29DD1B & Isi-c & L. Paleo. & & Vertebrata & Long bone & 1 \\
\hline E24/S76 & $30 \mathrm{~A}$ & 29DD1C & Isi-c & L. Paleo. & & Vertebrata & Indeterminate & 10 \\
\hline E24/S76 & $30 \mathrm{~A}$ & 29DD1D & Isi-c & L. Paleo. & & Vertebrata & Indeterminate & 1 \\
\hline E24/S76 & 30B & 29DD2A & Isi-c & L. Paleo. & & Vertebrata & Indeterminate & 2 \\
\hline E24/S76 & 30B & 29DD2B & Isi-c & L. Paleo. & & Small/Medium Vertebrata & Long bone & 1 \\
\hline E24/S76 & 30B & 29DD2B & Isi-c & L. Paleo. & & Vertebrata & Indeterminate & 7 \\
\hline E24/S76 & 30B & 29DD2C & Isi-c & L. Paleo. & & Vertebrata & Indeterminate & 2 \\
\hline E24/S76 & 30B & 29DD2D & Isi-c & L. Paleo. & & Vertebrata & Indeterminate & 12 \\
\hline E24/S76 & $31 \mathrm{~A}$ & 29EE1A & Isi-c & L. Paleo. & & Mammalia (Medium) & Humerus & 1 \\
\hline E24/S76 & $31 \mathrm{~A}$ & 29EE1A & Isi-c & L. Paleo. & & Mammalia (Medium) & Metapodial & 1 \\
\hline E24/S76 & $31 \mathrm{~A}$ & 29EE1A & Isi-c & L. Paleo. & & Mammalia (Medium/large) & Tooth, perm./decid. ind. & 1 \\
\hline E24/S76 & $31 \mathrm{~A}$ & 29EE1A & Isi-c & L. Paleo. & & Medium/Large Vertebrata & Long bone & 2 \\
\hline E24/S76 & $31 \mathrm{~A}$ & 29EE1A & Isi-c & L. Paleo. & & Small/Medium Vertebrata & Long bone & 1 \\
\hline E24/S76 & $31 \mathrm{~A}$ & 29EE1A & Isi-c & L. Paleo. & & Vertebrata & Indeterminate & 11 \\
\hline E24/S76 & $31 \mathrm{~A}$ & 29EE1B & Isi-c & L. Paleo. & & Small/Medium Vertebrata & Long bone & 1 \\
\hline E24/S76 & $31 \mathrm{~A}$ & 29EE1B & Isi-c & L. Paleo. & & Vertebrata & Indeterminate & 2 \\
\hline E24/S76 & $31 \mathrm{~A}$ & 29EE1C & Isi-c & L. Paleo. & & Testudinata & Shell fragment & 1 \\
\hline E24/S76 & $31 \mathrm{~A}$ & 29EE1C & Isi-c & L. Paleo. & & Vertebrata & Indeterminate & 3 \\
\hline E24/S76 & $31 \mathrm{~A}$ & 29EE1D & Isi-c & L. Paleo. & & Mammalia (Medium/large) & Long bone & 1 \\
\hline E24/S76 & $31 \mathrm{~A}$ & 29EE1D & Isi-c & L. Paleo. & & Medium/Large Vertebrata & Indeterminate & 3 \\
\hline E24/S76 & $31 \mathrm{~B}$ & 29EE2A & Isi-c & L. Paleo. & & Vertebrata & Indeterminate & 2 \\
\hline E24/S76 & 31B & 29EE2B & Isi-c & L. Paleo. & & Medium/Large Vertebrata & Indeterminate & 3 \\
\hline E24/S76 & 31B & 29EE2B & Isi-c & L. Paleo. & & Vertebrata & Indeterminate & 8 \\
\hline E24/S76 & 31B & 29EE2C & Isi-c & L. Paleo. & & Medium/Large Vertebrata & Indeterminate & 2 \\
\hline E24/S76 & 31B & 29EE2C & Isi-c & L. Paleo. & & Medium/Large Vertebrata & Long bone & 1 \\
\hline E24/S76 & 31B & 29EE2D & Isi-c & L. Paleo. & & Medium/Large Vertebrata & Long bone & 1 \\
\hline E24/S76 & $31 \mathrm{~B}$ & 29EE2D & Isi-c & L. Paleo. & & Small/Medium Vertebrata & Long bone & 4 \\
\hline E24/S76 & 31B & 29EE2D & Isi-c & L. Paleo. & & Vertebrata & Indeterminate & 4 \\
\hline E24/S76 & $32 \mathrm{~A}$ & 29FF1A & Icl/Isi-c & Paleoindian & & Mammalia (Medium/large) & Long bone & 1 \\
\hline E24/S76 & $32 \mathrm{~A}$ & 29FF1A & Icl/Isi-c & Paleoindian & & Small/Medium Vertebrata & Long bone & 3 \\
\hline E24/S76 & $32 \mathrm{~A}$ & 29FF1A & Icl/Isi-c & Paleoindian & & Vertebrata & Indeterminate & 5 \\
\hline E24/S76 & $32 \mathrm{~A}$ & 29FF1B & Icl/Isi-c & Paleoindian & & Mammalia (Medium) & Phalange & 1 \\
\hline E24/S76 & $32 \mathrm{~A}$ & 29FF1B & Icl/Isi-c & Paleoindian & & Mammalia (Medium/large) & Long bone & 4 \\
\hline E24/S76 & $32 \mathrm{~A}$ & 29FF1B & $\mathrm{Icl} / \mathrm{Isi}-\mathrm{c}$ & Paleoindian & & Vertebrata & Indeterminate & 11 \\
\hline E24/S76 & $32 \mathrm{~A}$ & 29FF1C & Icl/Isi-c & Paleoindian & & Small/Medium Vertebrata & Long bone & 2 \\
\hline E24/S76 & $32 \mathrm{~A}$ & 29FF1C & Icl/Isi-c & Paleoindian & & Vertebrata & Indeterminate & 31 \\
\hline E24/S76 & $32 \mathrm{~A}$ & 29FF1D & $\mathrm{Icl} / \mathrm{Isi}-\mathrm{c}$ & Paleoindian & & Mammalia (Medium/large) & Indeterminate & 2 \\
\hline E24/S76 & $32 \mathrm{~A}$ & 29FF1D & $\mathrm{Icl} / \mathrm{Isi}-\mathrm{c}$ & Paleoindian & & Medium/Large Vertebrata & Indeterminate & 5 \\
\hline E24/S76 & $32 \mathrm{~A}$ & 29FF1D & $\mathrm{Icl} / \mathrm{Isi}-\mathrm{c}$ & Paleoindian & & Medium/Large Vertebrata & Tooth, perm./decid. ind. & 1 \\
\hline E24/S76 & $32 \mathrm{~A}$ & 29FF1D & Icl/Isi-c & Paleoindian & & Small/Medium Vertebrata & Long bone & 4 \\
\hline E24/S76 & $32 \mathrm{~A}$ & 29FF1D & $\mathrm{Icl} / \mathrm{Isi}-\mathrm{c}$ & Paleoindian & & Vertebrata & Indeterminate & 38 \\
\hline E24/S76 & 32B & 29FF2A & Icl/Isi-c & Paleoindian & & Mammalia (Medium/large) & Indeterminate & 2 \\
\hline E24/S76 & 32B & $29 \mathrm{FF} 2 \mathrm{~A}$ & Icl/Isi-c & Paleoindian & & Small/Medium Vertebrata & Long bone & 2 \\
\hline E24/S76 & 32B & 29FF2A & Icl/Isi-c & Paleoindian & & Vertebrata & Indeterminate & 2 \\
\hline E24/S76 & 32B & 29FF2B & Icl/Isi-c & Paleoindian & & Mammalia (Medium) & Distal phalange & 1 \\
\hline E24/S76 & 32B & 29FF2B & Icl/Isi-c & Paleoindian & & Mammalia (Medium) & Podial & 1 \\
\hline E24/S76 & 32B & 29FF2B & Icl/Isi-c & Paleoindian & & Medium/Large Vertebrata & Indeterminate & 4 \\
\hline E24/S76 & 32B & 29FF2B & Icl/Isi-c & Paleoindian & & Medium/Large Vertebrata & Long bone & 1 \\
\hline E24/S76 & 32B & 29FF2B & Icl/Isi-c & Paleoindian & & Small/Medium Vertebrata & Long bone & 3 \\
\hline E24/S76 & 32B & 29FF2B & Icl/Isi-c & Paleoindian & & Vertebrata & Indeterminate & 4 \\
\hline E24/S76 & 32B & 29FF2C & Icl/Isi-c & Paleoindian & & Mammalia (Medium/large) & Long bone & 1 \\
\hline E24/S76 & 32B & $29 \mathrm{FF} 2 \mathrm{C}$ & Icl/Isi-c & Paleoindian & & Medium/Large Vertebrata & Indeterminate & 1 \\
\hline E24/S76 & 32B & $29 \mathrm{FF} 2 \mathrm{C}$ & Icl/Isi-c & Paleoindian & & Small/Medium Vertebrata & Long bone & 1 \\
\hline E24/S76 & 32B & $29 \mathrm{FF} 2 \mathrm{C}$ & Icl/Isi-c & Paleoindian & & Vertebrata & Indeterminate & 3 \\
\hline E24/S76 & $32 \mathrm{~B}$ & 29FF2D & Icl/Isi-c & Paleoindian & & Mammalia (Medium/large) & Long bone & 3 \\
\hline E24/S76 & $32 \mathrm{~B}$ & 29FF2D & Icl/Isi-c & Paleoindian & & Small/Medium Vertebrata & Long bone & 3 \\
\hline E24/S76 & 32B & 29FF2D & Icl/Isi-c & Paleoindian & & Vertebrata & Indeterminate & 10 \\
\hline E24/S76 & $33 \mathrm{~A}$ & 29GG1A & Icl/Isi-c & Paleoindian & & Small/Medium Vertebrata & Long bone & 4 \\
\hline E24/S76 & $33 \mathrm{~A}$ & 29GG1A & Icl/Isi-c & Paleoindian & & Vertebrata & Indeterminate & 19 \\
\hline E24/S76 & $33 \mathrm{~A}$ & 29GG1B & Icl/Isi-c & Paleoindian & & Medium/Large Vertebrata & Indeterminate & 1 \\
\hline E24/S76 & $33 \mathrm{~A}$ & 29GG1B & Icl/Isi-c & Paleoindian & & Small/Medium Vertebrata & Long bone & 1 \\
\hline E24/S76 & $33 \mathrm{~A}$ & 29GG1C & Icl/Isi-c & Paleoindian & & Mammalia (Medium) & Middle phalange & 1 \\
\hline
\end{tabular}




\begin{tabular}{|c|c|c|c|c|c|c|c|c|}
\hline Square & Level & Lot & Unit & Cultural Affinity & Feature & Taxon & Element & No. \\
\hline E24/S76 & $33 \mathrm{~A}$ & $29 \mathrm{GG1C}$ & $\mathrm{Icl} / \mathrm{Isi}-\mathrm{c}$ & Paleoindian & & Mammalia (Medium/large) & Long bone & 1 \\
\hline $\mathrm{E} 24 / \mathrm{S} 76$ & $33 \mathrm{~A}$ & 29GG1C & Icl/Isi-c & Paleoindian & & Small/Medium Vertebrata & Long bone & 1 \\
\hline E24/S76 & $33 \mathrm{~A}$ & 29GG1C & Icl/Isi-c & Paleoindian & & Vertebrata & Indeterminate & 7 \\
\hline E24/S76 & $33 \mathrm{~A}$ & 29GG1D & Icl/Isi-c & Paleoindian & & Lepus californicus & Astragalus & 1 \\
\hline E24/S76 & $33 \mathrm{~A}$ & 29GG1D & Icl/Isi-c & Paleoindian & & Mammalia (Medium/large) & Indeterminate & 1 \\
\hline E24/S76 & $33 \mathrm{~A}$ & 29GG1D & Icl/Isi-c & Paleoindian & & Medium/Large Vertebrata & Indeterminate & 2 \\
\hline E24/S76 & $33 \mathrm{~A}$ & 29GG1D & Icl/Isi-c & Paleoindian & & Vertebrata & Indeterminate & 3 \\
\hline E24/S76 & 33B & $29 \mathrm{GG} 2 \mathrm{~A}$ & Isi/Icl/Isi-c & Paleoindian & & Medium/Large Vertebrata & Indeterminate & 1 \\
\hline E24/S76 & 33B & $29 \mathrm{GG} 2 \mathrm{~A}$ & Isi/Icl/Isi-c & Paleoindian & & Small/Medium Vertebrata & Long bone & 1 \\
\hline E24/S76 & 33B & 29GG2A & Isi/Icl/Isi-c & Paleoindian & & Vertebrata & Indeterminate & 2 \\
\hline E24/S76 & 33B & 29GG2B & Isi/Icl/Isi-c & Paleoindian & & Mammalia (Medium/large) & Long bone & 3 \\
\hline E24/S76 & 33B & $29 \mathrm{GG} 2 \mathrm{~B}$ & Isi/Icl/Isi-c & Paleoindian & & Medium/Large Vertebrata & Long bone & 1 \\
\hline E24/S76 & 33B & 29GG2B & Isi/Icl/Isi-c & Paleoindian & & Vertebrata & Indeterminate & \\
\hline E24/S76 & 33B & $29 \mathrm{GG} 2 \mathrm{C}$ & Isi/Icl/Isi-c & Paleoindian & & Vertebrata & Indeterminate & \\
\hline E24/S76 & 33B & 29GG2D & Isi/Icl/Isi-c & Paleoindian & & Mammalia (Medium/large) & Calcaneus & 1 \\
\hline E24/S76 & 33B & 29GG2D & Isi/Icl/Isi-c & Paleoindian & & Small/Medium Vertebrata & Indeterminate & \\
\hline E24/S76 & 33B & 29GG2D & Isi/Icl/Isi-c & Paleoindian & & Small/Medium Vertebrata & Long bone & 1 \\
\hline E24/S76 & 33B & 29GG2D & Isi/Icl/Isi-c & Paleoindian & & Vertebrata & Indeterminate & 11 \\
\hline E24/S76 & $34 \mathrm{~A}$ & 29HH1A & Isi/Icl & E. Paleo. & & Mammalia (Medium/large) & Indeterminate & 2 \\
\hline E24/S76 & $34 \mathrm{~A}$ & 29HH1A & Isi/Icl & E. Paleo. & & Mammalia (Medium/large) & Long bone & 1 \\
\hline E24/S76 & $34 \mathrm{~A}$ & 29HH1A & Isi/Icl & E. Paleo. & & Mammalia (Medium/large) & Tooth, perm./decid. ind. & 1 \\
\hline E24/S76 & $34 \mathrm{~A}$ & 29HH1A & Isi/Icl & E. Paleo. & & Vertebrata & Indeterminate & \\
\hline E24/S76 & $34 \mathrm{~A}$ & 29HH1B & Isi/Icl & E. Paleo. & & Mammalia (Medium/large) & Tooth, perm./decid. ind. & 1 \\
\hline E24/S76 & $34 \mathrm{~A}$ & 29HH1B & Isi/Icl & E. Paleo. & & Vertebrata & Indeterminate & \\
\hline E24/S76 & $34 \mathrm{~A}$ & 29HH1D & Isi/Icl & E. Paleo. & & Vertebrata & Indeterminate & 1 \\
\hline E24/S76 & $34 \mathrm{~B}$ & 29HH2D & Isi/Icl & E. Paleo. & & Vertebrata & Indeterminate & 2 \\
\hline E24/S76 & $35 \mathrm{~A}$ & $29 \amalg 1 \mathrm{C}$ & Isi/Icl & E. Paleo. & & Vertebrata & Indeterminate & \\
\hline E24/S76 & $35 \mathrm{~B}$ & 29II2A & Isi/Icl & E. Paleo. & & Vertebrata & Indeterminate & \\
\hline E24/S76 & $35 \mathrm{~B}$ & $29 \amalg 1 \mathrm{C}$ & Isi/Icl & E. Paleo. & & Vertebrata & Indeterminate & 8 \\
\hline E24/S76 & $35 \mathrm{~B}$ & 29II2D & Isi/Icl & E. Paleo. & & Mammalia (Large) & Indeterminate & 1 \\
\hline E24/S76 & $35 \mathrm{~B}$ & 29II2D & Isi/Icl & E. Paleo. & & Vertebrata & Indeterminate & 9 \\
\hline E24/S76 & $36 \mathrm{~A}$ & 29JJ1A & Isi/Icl & E. Paleo. & & Vertebrata & Indeterminate & 3 \\
\hline E24/S76 & $36 \mathrm{~A}$ & 29JJ1C & Isi/Icl/D & E. Paleo. & & Mammalia (Medium/large) & Long bone & 1 \\
\hline E24/S76 & $36 \mathrm{~A}$ & 29JJ1C & Isi/Icl/D & E. Paleo. & & Vertebrata & Indeterminate & 9 \\
\hline E24/S76 & $36 \mathrm{~A}$ & 29JJ1D & Isi/Icl/D & E. Paleo. & & Mammalia (Medium/large) & Long bone & 1 \\
\hline E24/S76 & $36 \mathrm{~A}$ & 29JJ1D & Isi/Icl/D & E. Paleo. & & Vertebrata & Indeterminate & 1 \\
\hline E24/S76 & $36 \mathrm{~A}$ & 29JJ1D & Isi//Icl/D & E. Paleo. & & Vertebrata & Long bone & 3 \\
\hline E24/S76 & $36 \mathrm{~B}$ & $29 \mathrm{JJ} 2 \mathrm{~B}$ & Isi/Icl & E. Paleo. & & Carnivora & Mandible & 1 \\
\hline E24/S76 & $36 \mathrm{~B}$ & 29JJ2B & Isi/Icl & E. Paleo. & & Carnivora & Permanent tooth & 1 \\
\hline E24/S76 & $36 \mathrm{~B}$ & 29JJ2B & Isi/Icl & E. Paleo. & & Mammalia (Medium) & Long bone & 1 \\
\hline E24/S76 & $36 \mathrm{~B}$ & $29 \mathrm{JJ} 2 \mathrm{~B}$ & Isi/Icl & E. Paleo. & & Mammalia (Medium/large) & Indeterminate & 1 \\
\hline E24/S76 & $36 \mathrm{~B}$ & $29 \mathrm{JJ} 2 \mathrm{~B}$ & Isi//Icl & E. Paleo. & & Vertebrata & Indeterminate & 7 \\
\hline E24/S76 & $36 \mathrm{~B}$ & $29 \mathrm{JJ} 2 \mathrm{C}$ & Isi/Icl/D & E. Paleo. & & Mammalia (Medium/large) & Long bone & 1 \\
\hline E24/S76 & $36 \mathrm{~B}$ & $29 \mathrm{JJ} 2 \mathrm{C}$ & Isi/Icl/D & E. Paleo. & & Vertebrata & Indeterminate & 1 \\
\hline E24/S76 & $36 \mathrm{~B}$ & 29JJ2D & Isi/Icl/D & E. Paleo. & & Mammalia (Medium/large) & Indeterminate & 1 \\
\hline E24/S76 & $37 \mathrm{~A}$ & 29KK1C & Isi/Icl/D & E. Paleo. & & Vertebrata & Indeterminate & 10 \\
\hline E24/S76 & $37 \mathrm{~A}$ & 29KK1D & Isi/Icl/D & E. Paleo. & & Mammalia (Large) & Indeterminate & 1 \\
\hline E24/S76 & $37 \mathrm{~A}$ & 29KK1D & Isi/Icl/D & E. Paleo. & & Vertebrata & Indeterminate & 4 \\
\hline E24/S76 & 37B & 29KK2C & Isi/Icl & E. Paleo. & & Mammalia (Medium/large) & Indeterminate & 5 \\
\hline E24/S76 & 37B & $29 \mathrm{KK} 2 \mathrm{C}$ & Isi/Icl & E. Paleo. & & Medium/Large Vertebrata & Indeterminate & 1 \\
\hline E24/S76 & $37 \mathrm{~B}$ & $29 \mathrm{KK} 2 \mathrm{C}$ & Isi/Icl & E. Paleo. & & Vertebrata & Indeterminate & 17 \\
\hline E24/S76 & $38 \mathrm{~A}$ & 29LL1A & Isi//Icl & E. Paleo. & & Vertebrata & Indeterminate & 2 \\
\hline E24/S76 & $38 \mathrm{~A}$ & 29LL1B & Isi/Icl & E. Paleo. & & Mammalia (Very large) & Indeterminate & 1 \\
\hline E24/S76 & $38 \mathrm{~A}$ & 29LL1B & Isi//Icl & E. Paleo. & & Medium/Large Vertebrata & Indeterminate & 7 \\
\hline E24/S76 & $38 \mathrm{~A}$ & 29LL1B & Isi//Icl & E. Paleo. & & Vertebrata & Indeterminate & 60 \\
\hline E24/S76 & $38 \mathrm{~A}$ & 29LL1D & Isi//Icl & E. Paleo. & & Artiodactyla & Tooth, perm./decid. ind. & 1 \\
\hline E24/S76 & $38 \mathrm{~B}$ & 29LL2A & $\mathrm{Ig} 1 / \mathrm{Isi}$ & E. Paleo. & & Bison sp. & Scapula & 1 \\
\hline E24/S76 & 38B & 29LL2A & Igl/Isi & E. Paleo. & & Mammalia (Large) & Indeterminate & 1 \\
\hline E24/S76 & 38B & 29LL2A & Igl/Isi & E. Paleo. & & Medium/Large Vertebrata & Indeterminate & 6 \\
\hline E24/S76 & 38B & 29LL2A & Igl/Isi & E. Paleo. & & Vertebrata & Indeterminate & 32 \\
\hline E24/S76 & 38B & 29LL2B & Ig1/Isi & E. Paleo. & & Medium/Large Vertebrata & Indeterminate & 2 \\
\hline E24/S76 & 38B & 29LL2B & Igl/Isi & E. Paleo. & & Vertebrata & Indeterminate & 17 \\
\hline E24/S76 & 38B & 29LL2D & |Ig1/Isi & E. Paleo. & & Vertebrata & Indeterminate & 2 \\
\hline E24/S76 & $39 \mathrm{~A}$ & 29MM1A & Isi & E. Paleo. & & Mammalia (Medium/large) & Indeterminate & 1 \\
\hline E24/S76 & $39 \mathrm{~A}$ & 29MM1C & Isi & E. Paleo. & & Mammalia (Medium/large) & Indeterminate & 2 \\
\hline E24/S76 & $39 \mathrm{~A}$ & 29MM1C & Isi & E. Paleo. & & Vertebrata & Indeterminate & 10 \\
\hline E24/S76 & 39B & 29MM2A & Igl/Isi & E. Paleo. & & Medium/Large Vertebrata & Indeterminate & 9 \\
\hline
\end{tabular}




\begin{tabular}{|c|c|c|c|c|c|c|c|c|}
\hline Square & Level & Lot & Unit & Cultural Affinity & Feature & Taxon & Element & No. \\
\hline E24/S76 & 39B & 29MM2A & Igl//si & E. Paleo. & & Vertebrata & Indeterminate & 19 \\
\hline $\mathrm{E} 24 / \mathrm{S} 76$ & 39B & 29MM2C & Igl/Isi & E. Paleo. & & Mammalia (Medium/large) & Indeterminate & 1 \\
\hline E24/S76 & 39B & 29MM2C & Igl/Isi & E. Paleo. & & Mammalia (Medium/large) & Long bone & 1 \\
\hline E24/S76 & $40 \mathrm{~A}$ & 29NN1A & Igl/Isi & E. Paleo. & & Mammalia (Medium/large) & Indeterminate & 4 \\
\hline E24/S76 & $40 \mathrm{~A}$ & 29NN1A & Igl/Isi & E. Paleo. & & Vertebrata & Indeterminate & 17 \\
\hline E24/S78 & 15 & 280 & IIIa/b & E. Archaic & & Mammalia (Medium/large) & Long bone & 9 \\
\hline E24/S78 & 15 & 280 & IIIa/b & E. Archaic & & Medium/Large Vertebrata & Indeterminate & 1 \\
\hline E24/S78 & 15 & 280 & ШШа/b & E. Archaic & & Medium/Large Vertebrata & Long bone & 1 \\
\hline E24/S78 & 15 & 280 & IIIa/b & E. Archaic & & Vertebrata & Indeterminate & 2 \\
\hline E24/S78 & $16 \mathrm{~A}$ & 28P1 & IIIIa & E. Archaic & & Vertebrata & Indeterminate & 5 \\
\hline E24/S78 & $16 \mathrm{~B}$ & $28 \mathrm{P} 2$ & ШІІа & E. Archaic & & Mammalia (Medium/large) & Indeterminate & 4 \\
\hline E24/S78 & $16 \mathrm{~B}$ & 28P2 & IIIa & E. Archaic & & Vertebrata & Indeterminate & 6 \\
\hline E24/S78 & $17 \mathrm{~A}$ & 28Q1 & IIIa & E. Archaic & & Vertebrata & Indeterminate & 3 \\
\hline E24/S78 & $18 \mathrm{~A}$ & 28R1 & IIIIa & E. Archaic & & Vertebrata & Indeterminate & 7 \\
\hline E24/S78 & $18 \mathrm{~B}$ & $28 \mathrm{R} 2$ & IIIIa & E. Archaic & & Vertebrata & Indeterminate & 3 \\
\hline E24/S78 & 19A & $28 \mathrm{~S} 1$ & III/IIIa & L. Paleo./E. Archaic & & Mammalia (Medium) & Middle phalange & 1 \\
\hline E24/S78 & 19A & 28S1 & II/IIIa & L. Paleo./E. Archaic & & Mammalia (Medium) & Proximal phalange & 1 \\
\hline E24/S78 & $19 \mathrm{~A}$ & $28 \mathrm{~S} 1$ & II/IIIa & L. Paleo./E. Archaic & & Small/Medium Vertebrata & Long bone & 1 \\
\hline E24/S78 & $19 \mathrm{~A}$ & $28 \mathrm{~S} 1$ & II/IIIa & L. Paleo./E. Archaic & & Vertebrata & Indeterminate & 2 \\
\hline E24/S78 & 19B & $28 \mathrm{~S} 2 \mathrm{~A}$ & ШІІІШа & L. Paleo./E. Archaic & & Vertebrata & Indeterminate & 1 \\
\hline E24/S78 & 19B & $28 \mathrm{~S} 2 \mathrm{~B}$ & ПI/ШІа & L. Paleo./E. Archaic & & Vertebrata & Indeterminate & 1 \\
\hline $\mathrm{E} 24 / \mathrm{S} 78$ & 19B & $28 \mathrm{~S} 2 \mathrm{C}$ & II/IIIIa & L. Paleo./E. Archaic & & Medium/Large Vertebrata & Long bone & 1 \\
\hline $\mathrm{E} 24 / \mathrm{S} 78$ & 19B & 28S2D & II/IIIa & L. Paleo./E. Archaic & & Vertebrata & Indeterminate & 1 \\
\hline $\mathrm{E} 24 / \mathrm{S} 78$ & $20 \mathrm{~A}$ & 28T1A & III & L. Paleo. & & Vertebrata & Indeterminate & 1 \\
\hline $\mathrm{E} 24 / \mathrm{S} 78$ & $20 \mathrm{~A}$ & 28T1B & III & L. Paleo. & & Medium/Large Vertebrata & Long bone & 1 \\
\hline $\mathrm{E} 24 / \mathrm{S} 78$ & $20 \mathrm{~A}$ & $28 \mathrm{~T} 1 \mathrm{C}$ & II & L. Paleo. & & Medium/Large Vertebrata & Indeterminate & 1 \\
\hline $\mathrm{E} 24 / \mathrm{S} 78$ & $20 \mathrm{~A}$ & $28 \mathrm{~T} 1 \mathrm{C}$ & II & L. Paleo. & & Vertebrata & Indeterminate & 1 \\
\hline $\mathrm{E} 24 / \mathrm{S} 78$ & $20 \mathrm{~A}$ & 28T1D & II & L. Paleo. & & Mammalia (Medium/large) & Indeterminate & 1 \\
\hline $\mathrm{E} 24 / \mathrm{S} 78$ & $20 \mathrm{~B}$ & $28 \mathrm{~T} 2 \mathrm{~A}$ & III & L. Paleo. & & Vertebrata & Indeterminate & 1 \\
\hline $\mathrm{E} 24 / \mathrm{S} 78$ & $20 \mathrm{~B}$ & $28 \mathrm{~T} 2 \mathrm{~B}$ & II & L. Paleo. & & Mammalia (Medium/large) & Indeterminate & 1 \\
\hline $\mathrm{E} 24 / \mathrm{S} 78$ & $20 \mathrm{~B}$ & $28 \mathrm{~T} 2 \mathrm{C}$ & II & L. Paleo. & & Mammalia (Medium/large) & Indeterminate & 2 \\
\hline $\mathrm{E} 24 / \mathrm{S} 78$ & $20 \mathrm{~B}$ & 28T2D & II & L. Paleo. & & Mammalia (Medium/large) & Caudal vertebra & 1 \\
\hline $\mathrm{E} 24 / \mathrm{S} 78$ & $21 \mathrm{~A}$ & $28 \mathrm{U} 1 \mathrm{~A}$ & III & L. Paleo. & & Mammalia (Medium/large) & Indeterminate & 2 \\
\hline $\mathrm{E} 24 / \mathrm{S} 78$ & $21 \mathrm{~A}$ & 28U1A & II & L. Paleo. & & Vertebrata & Indeterminate & 8 \\
\hline $\mathrm{E} 24 / \mathrm{S} 78$ & $21 \mathrm{~A}$ & 28U1B & III & L. Paleo. & & Vertebrata & Indeterminate & 7 \\
\hline $\mathrm{E} 24 / \mathrm{S} 78$ & $21 \mathrm{~A}$ & $28 \mathrm{U} 1 \mathrm{C}$ & III & L. Paleo. & & Vertebrata & Indeterminate & 2 \\
\hline $\mathrm{E} 24 / \mathrm{S} 78$ & $21 \mathrm{~B}$ & $28 \mathrm{U} 2 \mathrm{~A}$ & II & L. Paleo. & & Mammalia (Medium/large) & Indeterminate & 1 \\
\hline $\mathrm{E} 24 / \mathrm{S} 78$ & 21B & 28U2B & III & L. Paleo. & & Vertebrata & Long bone & 1 \\
\hline $\mathrm{E} 24 / \mathrm{S} 78$ & $21 \mathrm{~B}$ & $28 \mathrm{U} 2 \mathrm{D}$ & II & L. Paleo. & & Medium/Large Vertebrata & Indeterminate & 2 \\
\hline $\mathrm{E} 24 / \mathrm{S} 78$ & $21 \mathrm{~B}$ & $28 \mathrm{U} 2 \mathrm{D}$ & III & L. Paleo. & & Vertebrata & Indeterminate & 4 \\
\hline $\mathrm{E} 24 / \mathrm{S} 78$ & $22 \mathrm{~A}$ & $28 \mathrm{~V} 1 \mathrm{~A}$ & III & L. Paleo. & & Medium/Large Vertebrata & Long bone & 1 \\
\hline $\mathrm{E} 24 / \mathrm{S} 78$ & $22 \mathrm{~A}$ & $28 \mathrm{~V} 1 \mathrm{~B}$ & III & L. Paleo. & & Medium/Large Vertebrata & Indeterminate & 2 \\
\hline $\mathrm{E} 24 / \mathrm{S} 78$ & $22 \mathrm{~A}$ & $28 \mathrm{~V} 1 \mathrm{~B}$ & II & L. Paleo. & & Small/Medium Vertebrata & Long bone & 2 \\
\hline $\mathrm{E} 24 / \mathrm{S} 78$ & $22 \mathrm{~A}$ & $28 \mathrm{~V} 1 \mathrm{C}$ & II & L. Paleo. & & Medium/Large Vertebrata & Indeterminate & 1 \\
\hline $\mathrm{E} 24 / \mathrm{S} 78$ & $22 \mathrm{~A}$ & $28 \mathrm{~V} 1 \mathrm{C}$ & II & L. Paleo. & & Vertebrata & Indeterminate & 2 \\
\hline $\mathrm{E} 24 / \mathrm{S} 78$ & $22 \mathrm{~A}$ & $28 \mathrm{~V} 1 \mathrm{D}$ & III & L. Paleo. & & Vertebrata & Indeterminate & 1 \\
\hline $\mathrm{E} 24 / \mathrm{S} 78$ & $22 \mathrm{~B}$ & $28 \mathrm{~V} 2 \mathrm{~A}$ & II & L. Paleo. & & Medium/Large Vertebrata & Indeterminate & 2 \\
\hline $\mathrm{E} 24 / \mathrm{S} 78$ & $22 \mathrm{~B}$ & $28 \mathrm{~V} 2 \mathrm{C}$ & II & L. Paleo. & & Mammalia (Medium/large) & Indeterminate & 2 \\
\hline $\mathrm{E} 24 / \mathrm{S} 78$ & $22 \mathrm{~B}$ & $28 \mathrm{~V} 2 \mathrm{D}$ & III & L. Paleo. & & Medium/Large Vertebrata & Long bone & 1 \\
\hline $\mathrm{E} 24 / \mathrm{S} 78$ & $22 \mathrm{~B}$ & $28 \mathrm{~V} 2 \mathrm{D}$ & II & L. Paleo. & & Vertebrata & Indeterminate & 2 \\
\hline $\mathrm{E} 24 / \mathrm{S} 78$ & $23 \mathrm{~A}$ & 28W1A & II & L. Paleo. & & Mammalia (Large) & Indeterminate & 1 \\
\hline $\mathrm{E} 24 / \mathrm{S} 78$ & $23 \mathrm{~A}$ & 28W1A & III & L. Paleo. & & Vertebrata & Indeterminate & 3 \\
\hline $\mathrm{E} 24 / \mathrm{S} 78$ & $23 \mathrm{~A}$ & 28W1B & II & L. Paleo. & & Medium/Large Vertebrata & Indeterminate & 2 \\
\hline $\mathrm{E} 24 / \mathrm{S} 78$ & $23 \mathrm{~A}$ & 28W1B & II & L. Paleo. & & Vertebrata & Indeterminate & 2 \\
\hline E24/S78 & $23 \mathrm{~A}$ & 28W1C & III & L. Paleo. & & Medium/Large Vertebrata & Indeterminate & 2 \\
\hline $\mathrm{E} 24 / \mathrm{S} 78$ & $23 \mathrm{~A}$ & $28 \mathrm{~W} 1 \mathrm{C}$ & III & L. Paleo. & & Vertebrata & Indeterminate & 4 \\
\hline $\mathrm{E} 24 / \mathrm{S} 78$ & 23B & $28 \mathrm{~W} 2 \mathrm{~A}$ & II & L. Paleo. & & Mammalia (Medium/large) & Indeterminate & 3 \\
\hline $\mathrm{E} 24 / \mathrm{S} 78$ & $23 \mathrm{~B}$ & $28 \mathrm{~W} 2 \mathrm{~A}$ & II & L. Paleo. & & Mammalia (Medium/large) & Long bone & 1 \\
\hline $\mathrm{E} 24 / \mathrm{S} 78$ & $23 \mathrm{~B}$ & 28W2B & III & L. Paleo. & & Mammalia (Medium/large) & Long bone & 1 \\
\hline E24/S78 & 23B & 28W2B & III & L. Paleo. & & Vertebrata & Indeterminate & 4 \\
\hline $\mathrm{E} 24 / \mathrm{S} 78$ & $23 \mathrm{~B}$ & 28W2D & III & L. Paleo. & & Medium/Large Vertebrata & Indeterminate & 1 \\
\hline $\mathrm{E} 24 / \mathrm{S} 78$ & $23 \mathrm{~B}$ & 28W2D & III & L. Paleo. & & Vertebrata & Indeterminate & 4 \\
\hline $\mathrm{E} 24 / \mathrm{S} 78$ & $24 \mathrm{~A}$ & $28 X 1 \mathrm{~A}$ & $\mathrm{Id} / \mathrm{II}$ & L. Paleo. & & Vertebrata & Indeterminate & 1 \\
\hline $\mathrm{E} 24 / \mathrm{S} 78$ & $24 \mathrm{~A}$ & 28X1B & Id/II & L. Paleo. & & Mammalia (Medium) & Middle phalange & 1 \\
\hline $\mathrm{E} 24 / \mathrm{S} 78$ & $24 \mathrm{~A}$ & $28 \times 1 B$ & $\mathrm{Id} / \mathrm{II}$ & L. Paleo. & & Vertebrata & Indeterminate & 1 \\
\hline $\mathrm{E} 24 / \mathrm{S} 78$ & $24 \mathrm{~A}$ & $28 \times 1 C$ & $\mathrm{Id} / \mathrm{II}$ & L. Paleo. & f161 & Medium/Large Vertebrata & Indeterminate & 1 \\
\hline $\mathrm{E} 24 / \mathrm{S} 78$ & 24B & $28 \mathrm{X} 2 \mathrm{~B}$ & $\mathrm{Id} / \mathrm{II}$ & L. Paleo. & & Medium/Large Vertebrata & Indeterminate & 1 \\
\hline
\end{tabular}




\begin{tabular}{|c|c|c|c|c|c|c|c|c|}
\hline Square & Level & Lot & Unit & Cultural Affinity & Feature & Taxon & Element & No. \\
\hline$\overline{\mathrm{E} 24 / \mathrm{S} 78}$ & $24 \mathrm{~B}$ & $28 \times 2 B$ & $\mathrm{Id} / \mathrm{II}$ & L. Paleo. & & Small/Medium Vertebrata & Long bone & 1 \\
\hline E24/S78 & 24B & $28 \mathrm{X} 2 \mathrm{C}$ & $\mathrm{Id} / \mathrm{II}$ & L. Paleo. & & Mammalia (Large) & Long bone & 2 \\
\hline E24/S78 & $24 B$ & $28 \mathrm{X} 2 \mathrm{C}$ & $\mathrm{Id} / \mathrm{II}$ & L. Paleo. & & Mammalia (Medium/large) & Long bone & 1 \\
\hline E24/S78 & $24 B$ & $28 \mathrm{X} 2 \mathrm{C}$ & Id/II & L. Paleo. & & Vertebrata & Indeterminate & 20 \\
\hline E24/S78 & 24B & 28X2D & Id/II & L. Paleo. & & Medium/Large Vertebrata & Indeterminate & 1 \\
\hline E24/S78 & $25 \mathrm{~A}$ & $28 \mathrm{Y} 1 \mathrm{~A}$ & $\mathrm{Id} / \mathrm{II}$ & L. Paleo. & & Medium/Large Vertebrata & Indeterminate & 1 \\
\hline $\mathrm{E} 24 / \mathrm{S} 78$ & $25 \mathrm{~A}$ & 28Y1B & Id/II & L. Paleo. & & Mammalia (Medium/large) & Long bone & 2 \\
\hline E24/S78 & $25 \mathrm{~A}$ & 28Y1B & Id/II & L. Paleo. & & Small/Medium Vertebrata & Long bone & 1 \\
\hline E24/S78 & $25 \mathrm{~A}$ & 28Y1B & Id/II & L. Paleo. & & Vertebrata & Indeterminate & 1 \\
\hline E24/S78 & $25 \mathrm{~A}$ & 28Y1C & Id/II & L. Paleo. & & Mammalia (Medium/large) & Long bone & 5 \\
\hline E24/S78 & $25 \mathrm{~A}$ & 28Y1C & Id/II & L. Paleo. & & Vertebrata & Indeterminate & 1 \\
\hline $\mathrm{E} 24 / \mathrm{S} 78$ & $25 \mathrm{~A}$ & 28Y1D & Id/II & L. Paleo. & & Mammalia (Medium/large) & Long bone & 1 \\
\hline E24/S78 & $25 \mathrm{~B}$ & 28Y2B & Id/II & L. Paleo. & & Mammalia (Medium/large) & Long bone & 2 \\
\hline E24/S78 & $25 \mathrm{~B}$ & 28Y2B & Id/II & L. Paleo. & & Medium/Large Vertebrata & Indeterminate & 3 \\
\hline E24/S78 & $25 \mathrm{~B}$ & 28Y2B & Id/II & L. Paleo. & & Sylvilagus sp. & Calcaneus & 1 \\
\hline E24/S78 & $25 \mathrm{~B}$ & $28 Y 2 B$ & $\mathrm{Id} / \mathrm{II}$ & L. Paleo. & & Vertebrata & Indeterminate & 7 \\
\hline E24/S78 & $25 \mathrm{~B}$ & 28Y2D & Id/II & L. Paleo. & & Medium/Large Vertebrata & Long bone & 2 \\
\hline E24/S78 & $25 \mathrm{~B}$ & 28Y2D & Id/II & L. Paleo. & & Small/Medium Vertebrata & Long bone & 1 \\
\hline E24/S78 & $26 \mathrm{~A}$ & 28Z1A & Isi-c/Id/II & L. Paleo. & & Vertebrata & Indeterminate & 4 \\
\hline E24/S78 & $26 \mathrm{~A}$ & 28Z1B & Isi-c/Id/II & L. Paleo. & & Medium/Large Vertebrata & Indeterminate & 1 \\
\hline E24/S78 & $26 \mathrm{~A}$ & $28 \mathrm{Z} 1 \mathrm{C}$ & Isi-c/Id/II & L. Paleo. & & Vertebrata & Indeterminate & 1 \\
\hline E24/S78 & $26 \mathrm{~A}$ & 28Z1D & Isi-c/Id/II & L. Paleo. & & Mammalia (Large) & Scapula & 2 \\
\hline E24/S78 & $26 \mathrm{~A}$ & 28Z1D & Isi-c/Id/II & L. Paleo. & & Mammalia (Medium/large) & Indeterminate & 3 \\
\hline E24/S78 & $26 \mathrm{~A}$ & 28Z1D & Isi-c/Id/II & L. Paleo. & & Medium/Large Vertebrata & Indeterminate & 9 \\
\hline E24/S78 & $26 \mathrm{~A}$ & 28Z1D & Isi-c/Id/II & L. Paleo. & & Small/Medium Vertebrata & Long bone & 2 \\
\hline E24/S78 & $26 \mathrm{~A}$ & 28Z1D & Isi-c/Id/II & L. Paleo. & & Vertebrata & Indeterminate & 22 \\
\hline $\mathrm{E} 24 / \mathrm{S} 78$ & $26 \mathrm{~B}$ & $28 \mathrm{Z} 2 \mathrm{~A}$ & Isi-c/Id & L. Paleo. & & Medium/Large Vertebrata & Indeterminate & 1 \\
\hline E24/S78 & $26 \mathrm{~B}$ & $28 \mathrm{Z} 2 \mathrm{~A}$ & Isi-c/Id & L. Paleo. & & Vertebrata & Indeterminate & 1 \\
\hline E24/S78 & 26B & 28Z2B & Isi-c/Id & L. Paleo. & & Vertebrata & Indeterminate & 5 \\
\hline $\mathrm{E} 24 / \mathrm{S} 78$ & $26 \mathrm{~B}$ & $28 \mathrm{Z} 2 \mathrm{C}$ & Isi-c/Id & L. Paleo. & & Vertebrata & Indeterminate & 2 \\
\hline E24/S78 & $26 \mathrm{~B}$ & 28Z2D & Isi-c/Id & L. Paleo. & & Mammalia (Medium/large) & Indeterminate & 1 \\
\hline E24/S78 & $26 \mathrm{~B}$ & 28Z2D & Isi-c/Id & L. Paleo. & & Mammalia (Medium/large) & Ulna & 1 \\
\hline E24/S78 & $26 \mathrm{~B}$ & $28 \mathrm{Z} 2 \mathrm{D}$ & Isi-c/Id & L. Paleo. & & Vertebrata & Indeterminate & 13 \\
\hline E24/S78 & $27 \mathrm{~A}$ & 28AA1A & Isi-c/Id & L. Paleo. & & Vertebrata & Indeterminate & 5 \\
\hline E24/S78 & $27 \mathrm{~A}$ & 28AA1B & Isi-c/Id & L. Paleo. & & Vertebrata & Indeterminate & 2 \\
\hline E24/S78 & $27 \mathrm{~A}$ & 28AA1D & Isi-c/Id & L. Paleo. & & Mammalia (Medium/large) & Long bone & 1 \\
\hline E24/S78 & $27 \mathrm{~A}$ & 28AA1D & Isi-c/Id & L. Paleo. & & Vertebrata & Indeterminate & 6 \\
\hline E24/S78 & 27B & 28AA2 & Isi-c/Id & L. Paleo. & & Vertebrata & Indeterminate & 1 \\
\hline E24/S78 & $27 \mathrm{~B}$ & 28AA2A & Isi-c/Id & L. Paleo. & & Vertebrata & Indeterminate & 9 \\
\hline E24/S78 & $27 \mathrm{~B}$ & 28AA2B & Isi-c/Id & L. Paleo. & & Vertebrata & Indeterminate & 4 \\
\hline E24/S78 & 27B & 28AA2B & Isi-c/Id & L. Paleo. & & Vertebrata & Long bone & 2 \\
\hline $\mathrm{E} 24 / \mathrm{S} 78$ & $27 \mathrm{~B}$ & 28AA2D & Isi-c/Id & L. Paleo. & & Vertebrata & Indeterminate & 1 \\
\hline E24/S78 & $28 \mathrm{~A}$ & 28BB1A & Isi-c/Id & L. Paleo. & & Antilocapra/Odocoileus & Third carpal bone & 1 \\
\hline E24/S78 & $28 \mathrm{~A}$ & 28BB1A & Isi-c/Id & L. Paleo. & & Mammalia (Medium/large) & Long bone & 1 \\
\hline E24/S78 & $28 \mathrm{~A}$ & $28 \mathrm{BB} 1 \mathrm{~A}$ & Isi-c/Id & L. Paleo. & & Vertebrata & Indeterminate & 10 \\
\hline E24/S78 & $28 \mathrm{~A}$ & 28BB1B & Isi-c/Id & L. Paleo. & & Mammalia (Medium/large) & Indeterminate & 1 \\
\hline E24/S78 & $28 \mathrm{~A}$ & 28BB1B & Isi-c/Id & L. Paleo. & & Mammalia (Medium/large) & Long bone & 1 \\
\hline E24/S78 & $28 \mathrm{~A}$ & 28BB1B & Isi-c/Id & L. Paleo. & & Vertebrata & Indeterminate & 8 \\
\hline E24/S78 & $28 \mathrm{~A}$ & 28BB1C & Isi-c/Id & L. Paleo. & & Vertebrata & Indeterminate & 1 \\
\hline E24/S78 & $28 \mathrm{~A}$ & 28BB1D & Isi-c/Id & L. Paleo. & & Mammalia (Medium/large) & Indeterminate & 1 \\
\hline E24/S78 & $28 \mathrm{~A}$ & 28BB1D & Isi-c/Id & L. Paleo. & & Vertebrata & Indeterminate & 1 \\
\hline E24/S78 & $28 \mathrm{~A}$ & 28BB1D & Isi-c/Id & L. Paleo. & & Vertebrata & Long bone & 1 \\
\hline E24/S78 & $28 \mathrm{~B}$ & 28BB2A & Isi-c & L. Paleo. & & Medium/Large Vertebrata & Indeterminate & 1 \\
\hline E24/S78 & 28B & 28BB2A & Isi-c & L. Paleo. & & Vertebrata & Indeterminate & 2 \\
\hline E24/S78 & $28 \mathrm{~B}$ & 28BB2B & Isi-c & L. Paleo. & & Medium/Large Vertebrata & Indeterminate & 2 \\
\hline E24/S78 & $28 \mathrm{~B}$ & 28BB2B & Isi-c & L. Paleo. & & Small/Medium Vertebrata & Long bone & 1 \\
\hline E24/S78 & $28 \mathrm{~B}$ & 28BB2B & Isi-c & L. Paleo. & & Testudinata & Shell fragment & 1 \\
\hline E24/S78 & $28 \mathrm{~B}$ & 28BB2B & Isi-c & L. Paleo. & & Vertebrata & Indeterminate & 1 \\
\hline E24/S78 & 28B & $28 \mathrm{BB} 2 \mathrm{C}$ & Isi-c & L. Paleo. & & Mammalia (Medium/large) & Long bone & 3 \\
\hline E24/S78 & $28 \mathrm{~B}$ & $28 \mathrm{BB} 2 \mathrm{C}$ & Isi-c & L. Paleo. & & Small/Medium Vertebrata & Long bone & 3 \\
\hline E24/S78 & $28 \mathrm{~B}$ & $28 \mathrm{BB} 2 \mathrm{C}$ & Isi-c & L. Paleo. & & Vertebrata & Indeterminate & 1 \\
\hline E24/S78 & 28B & 28BB2D & Isi-c & L. Paleo. & & Vertebrata & Indeterminate & 1 \\
\hline E24/S78 & $29 \mathrm{~A}$ & 28CC1A & Isi-c & L. Paleo. & & Vertebrata & Indeterminate & 7 \\
\hline E24/S78 & $29 \mathrm{~A}$ & $28 \mathrm{CC} 1 \mathrm{~B}$ & Isi-c & L. Paleo. & & Vertebrata & Indeterminate & 1 \\
\hline E24/S78 & $29 \mathrm{~A}$ & $28 \mathrm{CC} 1 \mathrm{C}$ & Isi-c & L. Paleo. & & Vertebrata & Indeterminate & 4 \\
\hline E24/S78 & $29 \mathrm{~A}$ & 28CC1D & Isi-c & L. Paleo. & & Mammalia (Medium/large) & Long bone & 1 \\
\hline E24/S78 & 29B & $28 \mathrm{CC} 2 \mathrm{~A}$ & Isi-c & L. Paleo. & & Mammalia (Medium/large) & Long bone & 1 \\
\hline
\end{tabular}




\begin{tabular}{|c|c|c|c|c|c|c|c|c|}
\hline Square & Level & Lot & Unit & Cultural Affinity & Feature & Taxon & Element & No. \\
\hline E24/S78 & $29 \mathrm{~B}$ & $28 \mathrm{CC} 2 \mathrm{~A}$ & Isi-c & L. Paleo. & & Vertebrata & Indeterminate & 2 \\
\hline E24/S78 & 29B & $28 \mathrm{CC} 2 \mathrm{~B}$ & Isi-c & L. Paleo. & & Vertebrata & Indeterminate & 7 \\
\hline E24/S78 & 29B & $28 \mathrm{CC} 2 \mathrm{C}$ & Isi-c & L. Paleo. & & Mammalia (Medium/large) & Indeterminate & 2 \\
\hline E24/S78 & 29B & $28 \mathrm{CC} 2 \mathrm{C}$ & |Isi-c & L. Paleo. & & Vertebrata & Indeterminate & 3 \\
\hline E24/S78 & $30 \mathrm{~A}$ & 28DD1B & Isi/Isi-c & Paleoindian & & Vertebrata & Indeterminate & 1 \\
\hline E24/S78 & $30 \mathrm{~A}$ & 28DD1C & Isi/Isi-c & Paleoindian & & Vertebrata & Indeterminate & 12 \\
\hline E24/S78 & 30B & 28DD2A & Isi/Isi-c & Paleoindian & & Vertebrata & Indeterminate & 11 \\
\hline E24/S78 & 30B & 28DD2A & Isi/Isi-c & Paleoindian & & Vertebrata & Long bone & 1 \\
\hline E24/S78 & 30B & 28DD2B & Isi/Isi-c & Paleoindian & & Vertebrata & Indeterminate & 4 \\
\hline E24/S78 & $31 \mathrm{~A}$ & 28EE1B & Isi/Isi-c & Paleoindian & & Leporidae & Ulna & 1 \\
\hline E24/S78 & $31 \mathrm{~A}$ & 28EE1C & Isi/Isi-c & Paleoindian & & Medium/Large Vertebrata & Indeterminate & 1 \\
\hline E24/S78 & $31 \mathrm{~B}$ & 28EE2A & Isi/Isi-c & Paleoindian & & Mammalia (Medium/large) & Indeterminate & 1 \\
\hline E24/S78 & $31 \mathrm{~B}$ & 28EE2A & Isi/Isi-c & Paleoindian & & Medium/Large Vertebrata & Indeterminate & 1 \\
\hline E24/S78 & $31 \mathrm{~B}$ & 28EE2A & Isi/Isi-c & Paleoindian & & Small/Medium Vertebrata & Long bone & 1 \\
\hline E24/S78 & 31B & 28EE2C & Isi/Isi-c & Paleoindian & & Medium/Large Vertebrata & Indeterminate & 1 \\
\hline E24/S78 & 31B & 28EE2D & Isi/Isi-c & Paleoindian & & Bison sp. & Tibia & 1 \\
\hline E24/S78 & $31 \mathrm{~B}$ & 28EE2D & Isi/Isi-c & Paleoindian & & Mammalia (Medium/large) & Indeterminate & 5 \\
\hline E24/S78 & 31B & 28EE2D & Isi/Isi-c & Paleoindian & & Medium/Large Vertebrata & Long bone & 1 \\
\hline E24/S78 & 31B & 28EE2D & Isi/Isi-c & Paleoindian & & Vertebrata & Indeterminate & 8 \\
\hline E24/S78 & 31B & |F170 & Isi & E. Paleo. & f170 & Large vertebrate, class ind. & Indeterminate & 2 \\
\hline E24/S78 & 31B & F170 & Isi & E. Paleo. & $\mathrm{f} 170$ & Mammalia (Medium/large) & Indeterminate & 25 \\
\hline E24/S78 & $31 \mathrm{~B}$ & F170 & Isi & E. Paleo. & $\mathrm{f} 170$ & Mammalia (Medium/large) & Long bone & 5 \\
\hline E24/S78 & $31 \mathrm{~B}$ & F170 & Isi & E. Paleo. & f170 & Mammalia (Very large) & Long bone & 2 \\
\hline E24/S78 & 31B & F170 & Isi & E. Paleo. & f170 & Vertebrata & Indeterminate & 29 \\
\hline E24/S78 & $32 \mathrm{~A}$ & 28FF1A & |Isi/Icl/Isi-c & Paleoindian & & Medium/Large Vertebrata & Indeterminate & 5 \\
\hline E24/S78 & $32 \mathrm{~A}$ & 28FF1A & |Isi/Icl/Isi-c & Paleoindian & & Vertebrata & Indeterminate & 6 \\
\hline E24/S78 & $32 \mathrm{~A}$ & 28FF1B & |Isi/Icl/Isi-c & Paleoindian & & Small/Medium Vertebrata & Long bone & 1 \\
\hline E24/S78 & $32 \mathrm{~B}$ & $28 \mathrm{FF} 2 \mathrm{~B}$ & Isi/Icl/Isi-c & Paleoindian & & Mammalia (Medium/large) & Long bone & 5 \\
\hline E24/S78 & $32 \mathrm{~B}$ & $28 \mathrm{FF} 2 \mathrm{~B}$ & |Isi/Icl/Isi-c & Paleoindian & & Vertebrata & Indeterminate & 1 \\
\hline E24/S78 & $32 \mathrm{~B}$ & $28 \mathrm{FF} 2 \mathrm{C}$ & Isi/Icl/Isi-c & Paleoindian & & Mammalia (Medium/large) & Indeterminate & 1 \\
\hline E24/S78 & $33 \mathrm{~A}$ & 28GG1A & Isi/Icl/Isi-c & Paleoindian & & Medium/Large Vertebrata & Indeterminate & 1 \\
\hline E24/S78 & $33 \mathrm{~A}$ & 28GG1A & Isi/Icl/Isi-c & Paleoindian & & Small/Medium Vertebrata & Long bone & 1 \\
\hline E24/S78 & $33 \mathrm{~A}$ & 28GG1A & Isi/Icl/Isi-c & Paleoindian & & Vertebrata & Indeterminate & 11 \\
\hline E24/S78 & $33 \mathrm{~A}$ & 28GG1B & Isi/Icl/Isi-c & Paleoindian & & Vertebrata & Indeterminate & 7 \\
\hline E24/S78 & $33 \mathrm{~A}$ & 28GG1C & Isi/Icl/Isi-c & Paleoindian & & Vertebrata & Indeterminate & 1 \\
\hline E24/S78 & $33 \mathrm{~A}$ & 28GG1D & Isi/Icl/Isi-c & Paleoindian & & Mammalia (Medium/large) & Long bone & 1 \\
\hline E24/S78 & $33 \mathrm{~A}$ & 28GG1D & Isi/Icl/Isi-c & Paleoindian & & Mammalia (Medium/large) & Tooth, perm./decid. ind. & 1 \\
\hline E24/S78 & 33B & $28 \mathrm{GG} 2 \mathrm{~A}$ & Isi/Icl & E. Paleo. & & Vertebrata & Indeterminate & 8 \\
\hline $\mathrm{E} 24 / \mathrm{S} 78$ & $33 \mathrm{~B}$ & 28GG2B & Isi/Icl & E. Paleo. & & Vertebrata & Indeterminate & 1 \\
\hline E24/S78 & 33B & 28GG2C & Isi/Icl & E. Paleo. & & Vertebrata & Indeterminate & 2 \\
\hline E24/S78 & $34 \mathrm{~A}$ & $28 \mathrm{HH} 1 \mathrm{~A}$ & Isi/Icl & E. Paleo. & & Mammalia (Medium/large) & Indeterminate & 2 \\
\hline E24/S78 & $34 \mathrm{~A}$ & $28 \mathrm{HH} 1 \mathrm{~A}$ & Isi/Icl & E. Paleo. & & Small/Medium Vertebrata & Long bone & 1 \\
\hline E24/S78 & $34 \mathrm{~A}$ & $28 \mathrm{HH} 1 \mathrm{~B}$ & Isi/Icl & E. Paleo. & & Small/Medium Vertebrata & Long bone & 1 \\
\hline E24/S78 & $34 \mathrm{~A}$ & $28 \mathrm{HH} 1 \mathrm{~B}$ & Isi/Icl & E. Paleo. & & Vertebrata & Indeterminate & 1 \\
\hline E24/S78 & $34 \mathrm{~B}$ & $28 \mathrm{HH} 2 \mathrm{~A}$ & Isi/Icl & E. Paleo. & & Mammalia (Medium/large) & Tooth, perm./decid. ind. & 1 \\
\hline E24/S78 & $34 \mathrm{~B}$ & $28 \mathrm{HH} 2 \mathrm{~A}$ & Isi/Icl & E. Paleo. & & Vertebrata & Indeterminate & 7 \\
\hline E24/S78 & $34 \mathrm{~B}$ & $28 \mathrm{HH} 2 \mathrm{~B}$ & Isi/Icl & E. Paleo. & & Vertebrata & Indeterminate & 3 \\
\hline $\mathrm{E} 24 / \mathrm{S} 78$ & $35 \mathrm{~A}$ & 28II1A & Isi/Icl & E. Paleo. & & Mammalia (Medium/large) & Indeterminate & 1 \\
\hline E24/S78 & $35 \mathrm{~A}$ & 28II1A & Isi/Icl & E. Paleo. & & Vertebrata & Indeterminate & 5 \\
\hline E24/S78 & $35 \mathrm{~A}$ & 28II1B & Isi/Icl & E. Paleo. & & Mammalia (Medium/large) & Indeterminate & 1 \\
\hline E24/S78 & $35 \mathrm{~A}$ & 28II1B & Isi/Icl & E. Paleo. & & Vertebrata & Indeterminate & 4 \\
\hline E24/S78 & 35B & $28 \mathrm{II} 2 \mathrm{~A}$ & Isi/Icl & E. Paleo. & & Mammalia (Medium/large) & Indeterminate & 1 \\
\hline E24/S78 & $36 \mathrm{~A}$ & 28JJ1B & Isi/D & E. Paleo. & & Mammalia (Medium/large) & Indeterminate & 1 \\
\hline E24/S78 & $36 \mathrm{~A}$ & 28JJ1B & Isi/D & E. Paleo. & & Vertebrata & Indeterminate & 6 \\
\hline E24/S78 & $36 \mathrm{~A}$ & $28 \mathrm{JJ} 1 \mathrm{C}$ & Isi & E. Paleo. & & Vertebrata & Indeterminate & 3 \\
\hline E24/S78 & $36 \mathrm{~B}$ & $28 \mathrm{JJ} 2 \mathrm{~A}$ & Isi/D & E. Paleo. & & Vertebrata & Indeterminate & 1 \\
\hline E24/S78 & $36 \mathrm{~B}$ & 28JJ2B & Isi/D & E. Paleo. & & Vertebrata & Indeterminate & 5 \\
\hline $\mathrm{E} 24 / \mathrm{S} 78$ & $37 \mathrm{~A}$ & 28KK1A & Isi/D & E. Paleo. & & Vertebrata & Indeterminate & 4 \\
\hline E24/S78 & 37B & $28 \mathrm{KK} 2 \mathrm{~A}$ & Isi & E. Paleo. & & Vertebrata & Indeterminate & 1 \\
\hline $\mathrm{E} 24 / \mathrm{S} 78$ & $38 \mathrm{~A}$ & 28LL1A & Isi & E. Paleo. & & Medium/Large Vertebrata & Indeterminate & 1 \\
\hline $\mathrm{E} 26 / \mathrm{S} 72$ & $16 \mathrm{~A}$ & $35 \mathrm{P} 1$ & IIIa & E. Archaic & & Mammalia (Large) & Indeterminate & 1 \\
\hline $\mathrm{E} 26 / \mathrm{S} 72$ & $16 \mathrm{~A}$ & $35 \mathrm{P} 1$ & IIIla & E. Archaic & & Vertebrata & Indeterminate & 3 \\
\hline $\mathrm{E} 26 / \mathrm{S} 72$ & $17 \mathrm{~A}$ & $35 \mathrm{Q} 1$ & IIIIa & E. Archaic & & Vertebrata & Indeterminate & 3 \\
\hline E26/S72 & 17B & $35 \mathrm{Q} 2$ & IIIIa & E. Archaic & & Vertebrata & Indeterminate & 3 \\
\hline $\mathrm{E} 26 / \mathrm{S} 72$ & $18 \mathrm{~B}$ & $35 \mathrm{R} 2$ & IIIIa & E. Archaic & & Mammalia (Medium/large) & Indeterminate & 3 \\
\hline E26/S72 & $18 \mathrm{~B}$ & $35 \mathrm{R} 2$ & IIIIa & E. Archaic & & Medium/Large Vertebrata & Indeterminate & 1 \\
\hline E26/S72 & $18 \mathrm{~B}$ & $35 \mathrm{R} 2$ & ШІа & E. Archaic & & Vertebrata & Indeterminate & 1 \\
\hline
\end{tabular}




\begin{tabular}{|c|c|c|c|c|c|c|c|c|}
\hline Square & Level & Lot & Unit & Cultural Affinity & Feature & Taxon & Element & No. \\
\hline$\overline{\mathrm{E} 26 / \mathrm{S} 72}$ & $19 \mathrm{~A}$ & $35 \mathrm{~S} 1$ & $\overline{\mathrm{IIa}}$ & E. Archaic & & Mammalia (Medium/large) & Indeterminate & 1 \\
\hline $\mathrm{E} 26 / \mathrm{S} 72$ & $19 \mathrm{~A}$ & $35 \mathrm{~S} 1$ & IIIa & E. Archaic & & Vertebrata & Indeterminate & 1 \\
\hline E26/S72 & 19B & $35 \mathrm{~S} 2 \mathrm{~B}$ & II/IIIa & L. Paleo./E. Archaic & & Mammalia (Medium/large) & Indeterminate & 1 \\
\hline E26/S72 & 19B & $35 \mathrm{~S} 2 \mathrm{D}$ & II/IIIa & L. Paleo./E. Archaic & & Odocoileus sp. & Permanent tooth & 1 \\
\hline E26/S72 & $20 \mathrm{~A}$ & $35 \mathrm{~T} 1 \mathrm{~B}$ & II/IIIa & L. Paleo./E. Archaic & & Mammalia (Medium/large) & Indeterminate & 2 \\
\hline E26/S72 & $20 \mathrm{~A}$ & 35T1B & II/IIIa & L. Paleo./E. Archaic & & Vertebrata & Indeterminate & 15 \\
\hline E26/S72 & $20 \mathrm{~B}$ & $35 \mathrm{~T} 2 \mathrm{~B}$ & II/Wa & L. Paleo./E. Archaic & & Vertebrata & Indeterminate & 1 \\
\hline E26/S72 & $20 \mathrm{~B}$ & $35 \mathrm{~T} 2 \mathrm{C}$ & II/IIIa & L. Paleo./E. Archaic & & Mammalia (Medium/large) & Long bone & 1 \\
\hline E26/S72 & 20B & $35 \mathrm{~T} 2 \mathrm{C}$ & II/IIIa & L. Paleo./E. Archaic & & Small/Medium Vertebrata & Long bone & 1 \\
\hline E26/S72 & $20 \mathrm{~B}$ & $35 \mathrm{~T} 2 \mathrm{D}$ & Ш/Шаa & L. Paleo./E. Archaic & & Medium/Large Vertebrata & Indeterminate & 2 \\
\hline $\mathrm{E} 26 / \mathrm{S} 72$ & $20 \mathrm{~B}$ & $35 \mathrm{~T} 2 \mathrm{D}$ & II/Wa & L. Paleo./E. Archaic & & Vertebrata & Indeterminate & 1 \\
\hline E26/S72 & $21 \mathrm{~A}$ & $35 \mathrm{U} 1 \mathrm{~A}$ & II & L. Paleo. & & Medium/Large Vertebrata & Indeterminate & 1 \\
\hline E26/S72 & $21 \mathrm{~A}$ & $35 \mathrm{U} 1 \mathrm{~B}$ & III & L. Paleo. & & Mammalia (Medium/large) & Indeterminate & 1 \\
\hline E26/S72 & $21 \mathrm{~A}$ & $35 \mathrm{U} 1 \mathrm{C}$ & III & L. Paleo. & & Mammalia (Medium/large) & Indeterminate & 1 \\
\hline E26/S72 & $21 \mathrm{~A}$ & $35 \mathrm{U} 1 \mathrm{C}$ & III & L. Paleo. & & Medium/Large Vertebrata & Indeterminate & 2 \\
\hline E26/S72 & $21 \mathrm{~A}$ & $35 \mathrm{U} 1 \mathrm{C}$ & III & L. Paleo. & & Testudinata & Shell fragment & 1 \\
\hline E26/S72 & $21 \mathrm{~A}$ & 35U1D & III & L. Paleo. & & Vertebrata & Indeterminate & 1 \\
\hline E26/S72 & 21B & $35 \mathrm{U} 2 \mathrm{~A}$ & III & L. Paleo. & & Mammalia (Medium/large) & Indeterminate & 1 \\
\hline E26/S72 & 21B & $35 \mathrm{U} 2 \mathrm{~A}$ & III & L. Paleo. & & Vertebrata & Indeterminate & 2 \\
\hline E26/S72 & $21 \mathrm{~B}$ & $35 \mathrm{U} 2 \mathrm{~B}$ & III & L. Paleo. & & Small/Medium Vertebrata & Long bone & 1 \\
\hline E26/S72 & 21B & $35 \mathrm{U} 2 \mathrm{C}$ & III & L. Paleo. & & Vertebrata & Indeterminate & 1 \\
\hline $\mathrm{E} 26 / \mathrm{S} 72$ & $22 \mathrm{~A}$ & $35 \mathrm{~V} 1 \mathrm{~A}$ & III & L. Paleo. & f157 & Mammalia (Medium/large) & Indeterminate & 1 \\
\hline E26/S72 & $22 \mathrm{~A}$ & $35 \mathrm{~V} 1 \mathrm{~A}$ & III & L. Paleo. & f157 & Mammalia (Medium/large) & Long bone & 1 \\
\hline E26/S72 & $22 \mathrm{~A}$ & $35 \mathrm{~V} 1 \mathrm{~A}$ & III & L. Paleo. & f157 & Small/Medium Vertebrata & Long bone & 1 \\
\hline E26/S72 & $22 \mathrm{~A}$ & $35 \mathrm{~V} 1 \mathrm{~A}$ & III & L. Paleo. & f157 & Vertebrata & Indeterminate & 2 \\
\hline E26/S72 & $22 \mathrm{~A}$ & $35 \mathrm{~V} 1 \mathrm{C}$ & III & L. Paleo. & f157 & Mammalia (Medium/large) & Long bone & 1 \\
\hline E26/S72 & $22 \mathrm{~A}$ & $35 \mathrm{~V} 1 \mathrm{D}$ & III & L. Paleo. & & Small/Medium Vertebrata & Long bone & 1 \\
\hline E26/S72 & $22 \mathrm{~B}$ & $35 \mathrm{~V} 2 \mathrm{~A}$ & III & L. Paleo. & f157 & Mammalia (Medium/large) & Indeterminate & 1 \\
\hline E26/S72 & $22 \mathrm{~B}$ & $35 \mathrm{~V} 2 \mathrm{~B}$ & III & L. Paleo. & f157 & Vertebrata & Indeterminate & 1 \\
\hline E26/S72 & $22 \mathrm{~B}$ & $35 \mathrm{~V} 2 \mathrm{D}$ & III & L. Paleo. & f157 & Carnivora & Proximal phalange & 1 \\
\hline E26/S72 & 22B & $35 \mathrm{~V} 2 \mathrm{D}$ & II & L. Paleo. & f157 & Vertebrata & Indeterminate & 2 \\
\hline E26/S72 & $23 \mathrm{~A}$ & $35 \mathrm{~W} 1 \mathrm{~A}$ & III & L. Paleo. & & Vertebrata & Indeterminate & 4 \\
\hline E26/S72 & $23 \mathrm{~A}$ & $35 \mathrm{~W} 1 \mathrm{C}$ & III & L. Paleo. & & Vertebrata & Indeterminate & 3 \\
\hline E26/S72 & $23 \mathrm{~B}$ & $35 \mathrm{~W} 2 \mathrm{~A}$ & III & L. Paleo. & & Mammalia (Medium/large) & Indeterminate & 1 \\
\hline E26/S72 & $23 \mathrm{~B}$ & $35 \mathrm{~W} 2 \mathrm{~A}$ & III & L. Paleo. & & Small/Medium Vertebrata & Indeterminate & 1 \\
\hline E26/S72 & $23 \mathrm{~B}$ & $35 \mathrm{~W} 2 \mathrm{~A}$ & III & L. Paleo. & & Small/Medium Vertebrata & Long bone & 1 \\
\hline $\mathrm{E} 26 / \mathrm{S} 72$ & 23B & $35 \mathrm{~W} 2 \mathrm{~A}$ & III & L. Paleo. & & Vertebrata & Indeterminate & 4 \\
\hline $\mathrm{E} 26 / \mathrm{S} 72$ & $23 \mathrm{~B}$ & $35 \mathrm{~W} 2 \mathrm{~B}$ & III & L. Paleo. & & Vertebrata & Indeterminate & 1 \\
\hline E26/S72 & $23 \mathrm{~B}$ & $35 \mathrm{~W} 2 \mathrm{C}$ & III & L. Paleo. & & Mammalia (Medium/large) & Indeterminate & 1 \\
\hline $\mathrm{E} 26 / \mathrm{S} 72$ & $23 \mathrm{~B}$ & $35 \mathrm{~W} 2 \mathrm{C}$ & II & L. Paleo. & & Mammalia (Medium/large) & Long bone & 1 \\
\hline $\mathrm{E} 26 / \mathrm{S} 72$ & $23 \mathrm{~B}$ & $35 \mathrm{~W} 2 \mathrm{C}$ & III & L. Paleo. & & Vertebrata & Indeterminate & 1 \\
\hline E26/S72 & $23 \mathrm{~B}$ & $35 \mathrm{~W} 2 \mathrm{D}$ & III & L. Paleo. & & Vertebrata & Indeterminate & 2 \\
\hline $\mathrm{E} 26 / \mathrm{S} 72$ & $24 \mathrm{~A}$ & $35 \mathrm{X} 1 \mathrm{~A}$ & II & L. Paleo. & & Medium/Large Vertebrata & Indeterminate & 1 \\
\hline E26/S72 & $24 \mathrm{~A}$ & $35 \times 1 B$ & III & L. Paleo. & & Mammalia (Medium) & |Radius & 1 \\
\hline E26/S72 & $24 \mathrm{~A}$ & $35 \times 1 D$ & III & L. Paleo. & & Vertebrata & Indeterminate & 1 \\
\hline E26/S72 & 24B & $35 \mathrm{X} 2 \mathrm{~A}$ & II & L. Paleo. & & Medium/Large Vertebrata & Long bone & 1 \\
\hline E26/S72 & 24B & $35 \times 2 A$ & III & L. Paleo. & & Vertebrata & Indeterminate & 7 \\
\hline E26/S72 & 24B & $35 \mathrm{X} 2 \mathrm{~B}$ & III & L. Paleo. & & Vertebrata & Indeterminate & 1 \\
\hline E26/S72 & 24B & $35 \mathrm{X} 2 \mathrm{C}$ & III & L. Paleo. & & Medium/Large Vertebrata & Long bone & 1 \\
\hline E26/S72 & 24B & $35 \times 2 C$ & III & L. Paleo. & & Vertebrata & Indeterminate & 1 \\
\hline E26/S72 & 24B & $35 \mathrm{X} 2 \mathrm{D}$ & III & L. Paleo. & & Mammalia (Medium/large) & |Vertebra & 1 \\
\hline E26/S72 & 24B & $35 \mathrm{X} 2 \mathrm{D}$ & III & L. Paleo. & & Vertebrata & Indeterminate & 1 \\
\hline $\mathrm{E} 26 / \mathrm{S} 72$ & $25 \mathrm{~A}$ & $35 \mathrm{Y} 1 \mathrm{~A}$ & III & L. Paleo. & & Small/Medium Vertebrata & Long bone & 1 \\
\hline $\mathrm{E} 26 / \mathrm{S} 72$ & $25 \mathrm{~A}$ & 35Y1B & III & L. Paleo. & & Mammalia (Medium/large) & Indeterminate & 1 \\
\hline E26/S72 & $25 \mathrm{~A}$ & 35Y1B & III & L. Paleo. & & Sylvilagus sp. & Calcaneus & 1 \\
\hline E26/S72 & $25 \mathrm{~A}$ & $35 \mathrm{Y} 1 \mathrm{~B}$ & III & L. Paleo. & & Vertebrata & Indeterminate & 4 \\
\hline $\mathrm{E} 26 / \mathrm{S} 72$ & $25 \mathrm{~A}$ & 35Y1D & III & L. Paleo. & & Medium/Large Vertebrata & Indeterminate & 1 \\
\hline E26/S72 & $25 \mathrm{~B}$ & $35 \mathrm{Y} 2 \mathrm{~A}$ & III & L. Paleo. & & Mammalia (Medium/large) & Indeterminate & 1 \\
\hline E26/S72 & $25 \mathrm{~B}$ & $35 \mathrm{Y} 2 \mathrm{~A}$ & III & L. Paleo. & & Vertebrata & Indeterminate & 2 \\
\hline E26/S72 & $25 \mathrm{~B}$ & $35 \mathrm{Y} 2 \mathrm{~B}$ & III & L. Paleo. & & Vertebrata & Indeterminate & 1 \\
\hline E26/S72 & $25 \mathrm{~B}$ & $35 \mathrm{Y} 2 \mathrm{C}$ & III & L. Paleo. & & Small/Medium Vertebrata & Indeterminate & 1 \\
\hline E26/S72 & $25 \mathrm{~B}$ & $35 \mathrm{Y} 2 \mathrm{C}$ & III & L. Paleo. & & Vertebrata & Indeterminate & 8 \\
\hline E26/S72 & $25 \mathrm{~B}$ & $35 Y 2 D$ & III & L. Paleo. & & Mammalia (Medium/large) & Indeterminate & 1 \\
\hline E26/S72 & $25 \mathrm{~B}$ & $35 Y 2 D$ & III & L. Paleo. & & Medium/Large Vertebrata & Indeterminate & 2 \\
\hline E26/S72 & $25 \mathrm{~B}$ & $35 \mathrm{Y} 2 \mathrm{D}$ & II & L. Paleo. & & Vertebrata & Indeterminate & 1 \\
\hline E26/S72 & $26 \mathrm{~A}$ & 35Z1B & II & L. Paleo. & & Small/Medium Vertebrata & Long bone & 1 \\
\hline E26/S72 & $26 \mathrm{~A}$ & $35 \mathrm{Z} 1 \mathrm{C}$ & III & L. Paleo. & & Medium/Large Vertebrata & Indeterminate & 2 \\
\hline
\end{tabular}




\begin{tabular}{|c|c|c|c|c|c|c|c|c|}
\hline Square & Level & Lot & Unit & Cultural Affinity & Feature & Taxon & Element & No. \\
\hline$\overline{\mathrm{E} 26 / \mathrm{S} 72}$ & $26 \mathrm{~B}$ & $35 \mathrm{Z} 2 \mathrm{~A}$ & II & L. Paleo. & & Leporidae & Permanent tooth & 1 \\
\hline E26/S72 & $26 \mathrm{~B}$ & $35 \mathrm{Z} 2 \mathrm{~A}$ & II & L. Paleo. & & Vertebrata & Indeterminate & 3 \\
\hline $\mathrm{E} 26 / \mathrm{S} 72$ & $26 \mathrm{~B}$ & 35Z2B & II & L. Paleo. & & Vertebrata & Indeterminate & 2 \\
\hline $\mathrm{E} 26 / \mathrm{S} 72$ & $26 \mathrm{~B}$ & $35 \mathrm{Z} 2 \mathrm{C}$ & II & L. Paleo. & & Mammalia (Medium/large) & Indeterminate & 1 \\
\hline E26/S72 & $26 \mathrm{~B}$ & $35 \mathrm{Z} 2 \mathrm{D}$ & II & L. Paleo. & & Mammalia (Medium/large) & Indeterminate & 1 \\
\hline E26/S72 & $26 \mathrm{~B}$ & $35 Z 2 D$ & II & L. Paleo. & & Medium/Large Vertebrata & Indeterminate & 1 \\
\hline $\mathrm{E} 26 / \mathrm{S} 72$ & $26 \mathrm{~B}$ & 35Z2D & III & L. Paleo. & & Vertebrata & Indeterminate & 5 \\
\hline $\mathrm{E} 26 / \mathrm{S} 72$ & $27 \mathrm{~A}$ & $35 \mathrm{AA} 1 \mathrm{C}$ & II & L. Paleo. & & Vertebrata & Indeterminate & 8 \\
\hline E26/S72 & $27 \mathrm{~B}$ & $35 \mathrm{AA} 2$ & II & L. Paleo. & & Vertebrata & Indeterminate & 1 \\
\hline E26/S72 & $27 \mathrm{~B}$ & $35 \mathrm{AA} 2 \mathrm{~A}$ & II & L. Paleo. & & Mammalia (Medium/large) & Long bone & 2 \\
\hline E26/S72 & $27 \mathrm{~B}$ & $35 \mathrm{AA} 2 \mathrm{~B}$ & II & L. Paleo. & & Mammalia (Medium/large) & Long bone & 2 \\
\hline E26/S72 & $27 \mathrm{~B}$ & $35 \mathrm{AA} 2 \mathrm{~B}$ & II & L. Paleo. & & Vertebrata & Indeterminate & 8 \\
\hline $\mathrm{E} 26 / \mathrm{S} 72$ & $27 \mathrm{~B}$ & 35AA2D & II & L. Paleo. & & Vertebrata & Indeterminate & 7 \\
\hline E26/S72 & $28 \mathrm{~A}$ & $35 \mathrm{BB} 1 \mathrm{~B}$ & II & L. Paleo. & & Vertebrata & Indeterminate & 2 \\
\hline E26/S72 & $28 \mathrm{~A}$ & $35 \mathrm{BB} 1 \mathrm{C}$ & II & L. Paleo. & & Mammalia (Medium) & Middle phalange & 1 \\
\hline E26/S72 & $28 \mathrm{~A}$ & $35 \mathrm{BB} 1 \mathrm{C}$ & II & L. Paleo. & & Vertebrata & Indeterminate & 1 \\
\hline E26/S72 & $28 \mathrm{~A}$ & 35BB1D & II & L. Paleo. & & Vertebrata & Indeterminate & 3 \\
\hline E26/S72 & $28 \mathrm{~A}$ & 35BB1D & II & L. Paleo. & & Vertebrata & Long bone & 1 \\
\hline E26/S72 & $28 \mathrm{~B}$ & $35 \mathrm{BB} 2 \mathrm{~A}$ & Isi-c/II & L. Paleo. & & Vertebrata & Indeterminate & 1 \\
\hline $\mathrm{E} 26 / \mathrm{S} 72$ & $28 \mathrm{~B}$ & 35BB2B & Isi-c/II & L. Paleo. & & Mammalia (Medium/large) & Tooth, perm./decid. ind. & 1 \\
\hline E26/S72 & $28 \mathrm{~B}$ & $35 \mathrm{BB} 2 \mathrm{C}$ & Isi-c/II & L. Paleo. & & Medium/Large Vertebrata & Indeterminate & 1 \\
\hline E26/S72 & $28 \mathrm{~B}$ & $35 \mathrm{BB} 2 \mathrm{C}$ & Isi-c/II & L. Paleo. & & Vertebrata & Indeterminate & 9 \\
\hline $\mathrm{E} 26 / \mathrm{S} 72$ & $28 \mathrm{~B}$ & 35BB2D & Isi-c/II & L. Paleo. & & Mammalia (Medium/large) & Indeterminate & 1 \\
\hline E26/S72 & $28 \mathrm{~B}$ & 35BB2D & Isi-c/II & L. Paleo. & & Mammalia (Medium/large) & Long bone & 1 \\
\hline E26/S72 & $28 \mathrm{~B}$ & 35BB2D & Isi-c/II & L. Paleo. & & Medium/Large Vertebrata & Indeterminate & 1 \\
\hline $\mathrm{E} 26 / \mathrm{S} 72$ & $28 \mathrm{~B}$ & 35BB2D & Isi-c/II & L. Paleo. & & Vertebrata & Indeterminate & 2 \\
\hline E26/S72 & $29 \mathrm{~A}$ & $35 \mathrm{CC} 1 \mathrm{~A}$ & Isi-c/II & L. Paleo. & & Vertebrata & Indeterminate & 5 \\
\hline E26/S72 & $29 \mathrm{~A}$ & $35 \mathrm{CC} 1 \mathrm{C}$ & Isi-c/II & L. Paleo. & & Vertebrata & Indeterminate & 6 \\
\hline $\mathrm{E} 26 / \mathrm{S} 72$ & $29 \mathrm{~A}$ & $35 \mathrm{CC} 1 \mathrm{D}$ & Isi-c/II & L. Paleo. & & Vertebrata & Indeterminate & 1 \\
\hline $\mathrm{E} 26 / \mathrm{S} 72$ & $30 \mathrm{~A}$ & 35DD1A & Isi-c & L. Paleo. & & Vertebrata & Indeterminate & 1 \\
\hline E26/S72 & $30 \mathrm{~A}$ & $35 \mathrm{DD} 1 \mathrm{~B}$ & Isi-c & L. Paleo. & & Vertebrata & Indeterminate & 1 \\
\hline $\mathrm{E} 26 / \mathrm{S} 72$ & $30 \mathrm{~A}$ & 35DD1C & Isi-c & L. Paleo. & & Vertebrata & Indeterminate & 3 \\
\hline E26/S72 & 30B & 35DD2 & Isi-c & L. Paleo. & & Vertebrata & Indeterminate & 1 \\
\hline E26/S72 & $30 \mathrm{~B}$ & $35 \mathrm{DD} 2 \mathrm{~B}$ & Isi-c & L. Paleo. & & Vertebrata & Indeterminate & 1 \\
\hline E26/S72 & $30 \mathrm{~B}$ & $35 \mathrm{DD} 2 \mathrm{C}$ & Isi-c & L. Paleo. & & Vertebrata & Indeterminate & 1 \\
\hline $\mathrm{E} 26 / \mathrm{S} 72$ & $30 \mathrm{~B}$ & 35DD2D & Isi-c & L. Paleo. & & Vertebrata & Indeterminate & 5 \\
\hline E26/S72 & $31 \mathrm{~A}$ & 35EE1D & Isi-c & L. Paleo. & & Vertebrata & Indeterminate & 2 \\
\hline $\mathrm{E} 26 / \mathrm{S} 72$ & $31 \mathrm{~B}$ & 35EE2C & Isi-c & L. Paleo. & & Medium/Large Vertebrata & Long bone & 1 \\
\hline E26/S72 & $31 \mathrm{~B}$ & $35 \mathrm{EE} 2 \mathrm{C}$ & Isi-c & L. Paleo. & & Small/Medium Vertebrata & Long bone & 2 \\
\hline $\mathrm{E} 26 / \mathrm{S} 72$ & $31 \mathrm{~B}$ & $35 \mathrm{EE} 2 \mathrm{C}$ & Isi-c & L. Paleo. & & Vertebrata & Indeterminate & 4 \\
\hline $\mathrm{E} 26 / \mathrm{S} 72$ & $31 \mathrm{~B}$ & 35EE2D & Isi-c & L. Paleo. & & Medium/Large Vertebrata & Indeterminate & 1 \\
\hline E26/S72 & $31 \mathrm{~B}$ & 35EE2D & Isi-c & L. Paleo. & & Vertebrata & Indeterminate & 1 \\
\hline E26/S72 & $32 \mathrm{~A}$ & $35 \mathrm{FF} 1 \mathrm{~A}$ & Isi-c & L. Paleo. & & Leporidae & Calcaneus & 1 \\
\hline E26/S72 & $32 \mathrm{~A}$ & $35 \mathrm{FF} 1 \mathrm{~A}$ & Isi-c & L. Paleo. & & Mammalia (Medium/large) & Indeterminate & 1 \\
\hline E26/S72 & $32 \mathrm{~A}$ & $35 \mathrm{FF} 1 \mathrm{~A}$ & Isi-c & L. Paleo. & & Vertebrata & Indeterminate & 2 \\
\hline E26/S72 & $32 \mathrm{~A}$ & 35FF1B & Isi-c & L. Paleo. & & Vertebrata & Indeterminate & 1 \\
\hline E26/S72 & $32 \mathrm{~A}$ & 35FF1C & Isi-c & L. Paleo. & & Medium/Large Vertebrata & Indeterminate & 1 \\
\hline $\mathrm{E} 26 / \mathrm{S} 72$ & $32 \mathrm{~A}$ & $35 \mathrm{FF} 1 \mathrm{C}$ & Isi-c & L. Paleo. & & Small/Medium Vertebrata & Long bone & 1 \\
\hline $\mathrm{E} 26 / \mathrm{S} 72$ & $32 \mathrm{~A}$ & $35 \mathrm{FF} 1 \mathrm{C}$ & Isi-c & L. Paleo. & & Vertebrata & Indeterminate & 6 \\
\hline $\mathrm{E} 26 / \mathrm{S} 72$ & $33 \mathrm{~A}$ & 35 GG1B & Icl/Isi-c & Paleoindian & & Vertebrata & Indeterminate & 4 \\
\hline $\mathrm{E} 26 / \mathrm{S} 72$ & $34 \mathrm{~B}$ & $35 \mathrm{HH} 2 \mathrm{~A}$ & $\mathrm{Icl} / \mathrm{Isi}-\mathrm{c}$ & Paleoindian & & Vertebrata & Indeterminate & 1 \\
\hline $\mathrm{E} 26 / \mathrm{S} 72$ & $35 \mathrm{~A}$ & $35 I I 1 \mathrm{~A}$ & Icl & E. Paleo. & & Vertebrata & Indeterminate & 1 \\
\hline $\mathrm{E} 26 / \mathrm{S} 72$ & $35 \mathrm{~A}$ & $35 \mathrm{IIID}$ & Icl & E. Paleo. & & Vertebrata & Indeterminate & 2 \\
\hline $\mathrm{E} 26 / \mathrm{S} 72$ & $35 \mathrm{~B}$ & $35 \mathrm{II} 2 \mathrm{C}$ & Icl & E. Paleo. & & Vertebrata & Indeterminate & 1 \\
\hline $\mathrm{E} 26 / \mathrm{S} 72$ & $36 \mathrm{~A}$ & $35 J J 1 \mathrm{~A}$ & Icl & E. Paleo. & & Vertebrata & Indeterminate & 1 \\
\hline E26/S72 & $36 \mathrm{~A}$ & 35JJ1B & Icl & E. Paleo. & & Vertebrata & Indeterminate & 2 \\
\hline E26/S72 & 36B & 35JJ2D & Icl & E. Paleo. & & Vertebrata & Indeterminate & 1 \\
\hline $\mathrm{E} 26 / \mathrm{S} 72$ & $37 \mathrm{~A}$ & $35 \mathrm{KK} 1 \mathrm{~A}$ & Icl & E. Paleo. & & Vertebrata & Indeterminate & 1 \\
\hline E26/S72 & $37 \mathrm{~A}$ & $35 \mathrm{KK} 1 \mathrm{~B}$ & Icl & E. Paleo. & & Mammalia (Medium/large) & Indeterminate & 1 \\
\hline $\mathrm{E} 26 / \mathrm{S} 72$ & $37 \mathrm{~A}$ & $35 \mathrm{KK} 1 \mathrm{D}$ & Icl & E. Paleo. & & Vertebrata & Indeterminate & 2 \\
\hline E26/S72 & 37B & $35 \mathrm{KK} 2 \mathrm{~A}$ & Isi/Icl & E. Paleo. & & Vertebrata & Indeterminate & 5 \\
\hline E26/S72 & 37B & $35 \mathrm{KK} 2 \mathrm{C}$ & Isi/Icl & E. Paleo. & & Vertebrata & Indeterminate & 1 \\
\hline $\mathrm{E} 26 / \mathrm{S} 72$ & 37B & $35 \mathrm{KK} 2 \mathrm{D}$ & Isi/Icl & E. Paleo. & & Vertebrata & Indeterminate & 48 \\
\hline $\mathrm{E} 26 / \mathrm{S} 72$ & $38 \mathrm{~A}$ & 35LL1A & Isi/Icl & E. Paleo. & & Medium/Large Vertebrata & Indeterminate & 1 \\
\hline $\mathrm{E} 26 / \mathrm{S} 72$ & $38 \mathrm{~A}$ & 35LL1B & Isi/Icl & E. Paleo. & & Medium/Large Vertebrata & Indeterminate & 1 \\
\hline $\mathrm{E} 26 / \mathrm{S} 72$ & $38 \mathrm{~A}$ & 35LL1C & Isi/Icl & E. Paleo. & & Vertebrata & Indeterminate & 1 \\
\hline $\mathrm{E} 26 / \mathrm{S} 72$ & $38 \mathrm{~A}$ & 35LL1D & Isi/Icl & E. Paleo. & & Vertebrata & Indeterminate & 1 \\
\hline
\end{tabular}




\begin{tabular}{|c|c|c|c|c|c|c|c|c|}
\hline Square & Level & Lot & Unit & Cultural Affinity & Feature & Taxon & Element & No. \\
\hline E26/S72 & $38 \mathrm{~B}-39 \mathrm{~A}$ & $35 \mathrm{LL} 2 / \mathrm{MI}$ & $\overline{I s i / I c l}$ & E. Paleo. & & Mammalia (Medium/large) & Cranium & 1 \\
\hline $\mathrm{E} 26 / \mathrm{S} 72$ & $38 \mathrm{~B}-39 \mathrm{~A}$ & $35 \mathrm{LL} 2 / \mathrm{M}$ & Isi/Icl & E. Paleo. & & Mammalia (Medium/large) & Indeterminate & 6 \\
\hline $\mathrm{E} 26 / \mathrm{S} 72$ & $38 \mathrm{~B}-39 \mathrm{~A}$ & $35 \mathrm{LL} 2 / \mathrm{M}$ & Isi/Icl & E. Paleo. & & Mammalia (Medium/large) & Long bone & 1 \\
\hline $\mathrm{E} 26 / \mathrm{S} 72$ & 38B-39A & $35 \mathrm{LL} 2 / \mathrm{M}$ & Isi/Icl & E. Paleo. & & Vertebrata & Indeterminate & 3 \\
\hline $\mathrm{E} 26 / \mathrm{S} 72$ & $38 \mathrm{~B}-39 \mathrm{~A}$ & $35 \mathrm{LL} 2 / \mathrm{M}$ & Isi/Icl & E. Paleo. & & Mammalia (Large) & Long bone & 1 \\
\hline E26/S72 & $38 \mathrm{~B}-39 \mathrm{~A}$ & $35 \mathrm{LL} 2 / \mathrm{M}$ & Isi/Icl & E. Paleo. & & Mammalia (Large/very large) & Indeterminate & 1 \\
\hline E26/S72 & $38 \mathrm{~B}-39 \mathrm{~A}$ & $35 \mathrm{LL} 2 / \mathrm{M}$ & Isi/Icl & E. Paleo. & & Medium/Large Vertebrata & Indeterminate & 4 \\
\hline $\mathrm{E} 26 / \mathrm{S} 72$ & $38 \mathrm{~B}-39 \mathrm{~A}$ & $35 \mathrm{LL} 2 / \mathrm{M}$ & Isi/Icl & E. Paleo. & & Vertebrata & Indeterminate & 25 \\
\hline E26/S72 & $38 \mathrm{~B}-39 \mathrm{~A}$ & $35 \mathrm{LL} 2 / \mathrm{M}$ & Isi/Icl & E. Paleo. & & Mammalia (Medium/large) & Indeterminate & 3 \\
\hline E26/S72 & $38 \mathrm{~B}-39 \mathrm{~A}$ & $35 \mathrm{LL} 2 / \mathrm{M}$ & Isi/Icl & E. Paleo. & & Medium/Large Vertebrata & Indeterminate & 1 \\
\hline $\mathrm{E} 26 / \mathrm{S} 72$ & $38 \mathrm{~B}-39 \mathrm{~A}$ & $35 \mathrm{LL} 2 / \mathrm{Ml}$ & Isi/Icl & E. Paleo. & & Vertebrata & Indeterminate & 4 \\
\hline $\mathrm{E} 26 / \mathrm{S} 72$ & 39B & $35 \mathrm{MM} 2 \mathrm{~A}$ & Isi/Icl & E. Paleo. & & Vertebrata & Indeterminate & 4 \\
\hline $\mathrm{E} 26 / \mathrm{S} 72$ & 39B & $35 \mathrm{MM} 2 \mathrm{~B}$ & Isi/Icl & E. Paleo. & & Vertebrata & Indeterminate & 5 \\
\hline $\mathrm{E} 26 / \mathrm{S} 72$ & 39B & $35 \mathrm{MM} 2 \mathrm{C}$ & Isi/Icl & E. Paleo. & & Mammalia (Small/medium) & Tooth, perm./decid. ind. & 1 \\
\hline $\mathrm{E} 26 / \mathrm{S} 72$ & 39B & $35 \mathrm{MM} 2 \mathrm{D}$ & Isi/Icl & E. Paleo. & & Vertebrata & Indeterminate & 1 \\
\hline $\mathrm{E} 26 / \mathrm{S} 72$ & $40 A \& B$ & $35 N N 1 \& 2$ & Isi/Icl & E. Paleo. & & Vertebrata & Indeterminate & 21 \\
\hline $\mathrm{E} 26 / \mathrm{S} 72$ & 40A\&B & $35 N N 1 \& 2$ & Isi/Icl & E. Paleo. & & Vertebrata & Indeterminate & 18 \\
\hline $\mathrm{E} 26 / \mathrm{S} 72$ & 40A\&B & $35 N N 1 \& 2$ & Isi/Icl & E. Paleo. & & Mammalia (Very large) & Long bone & 1 \\
\hline $\mathrm{E} 26 / \mathrm{S} 72$ & 40A\&B & $35 N N 1 \& 2$ & Isi/Icl & E. Paleo. & & Mammalia (Large/very large) & Flat bone & 1 \\
\hline E26/S72 & 40A\&B & $35 N N 1 \& 2$ & Isi/Icl & E. Paleo. & & Bison sp. & Fused central/fourth tarsal & 1 \\
\hline $\mathrm{E} 26 / \mathrm{S} 72$ & 40A\&B & $35 N N 1 \& 2$ & Isi/Icl & E. Paleo. & & cf. Bison & Rib & 1 \\
\hline E26/S72 & $40 A \& B$ & $35 N N 1 \& 2$ & Isi/Icl & E. Paleo. & & Mammalia (Large) & Indeterminate & 1 \\
\hline $\mathrm{E} 26 / \mathrm{S} 72$ & $40 A \& B$ & $35 N N 1 \& 2$ & Isi/Icl & E. Paleo. & & Mammalia (Medium/large) & Indeterminate & 4 \\
\hline E26/S72 & $40 A \& B$ & $35 N N 1 \& 2$ & Isi/Icl & E. Paleo. & & Vertebrata & Indeterminate & 45 \\
\hline E26/S72 & $41 \mathrm{~A}$ & $35001-2$ & Igl/Isi & E. Paleo. & & Mammalia (Medium/large) & Long bone & 2 \\
\hline $\mathrm{E} 26 / \mathrm{S} 72$ & $41 \mathrm{~A}$ & $35001-20$ & Igl//si & E. Paleo. & & Vertebrata & Indeterminate & 34 \\
\hline $\mathrm{E} 26 / \mathrm{S} 72$ & $41 \mathrm{~A}$ & $35001-21$ & Igl//si & E. Paleo. & & Vertebrata & Indeterminate & 52 \\
\hline $\mathrm{E} 26 / \mathrm{S} 72$ & $41 \mathrm{~A}$ & $35001 \mathrm{~A}$ & Igl//si & E. Paleo. & & Mammalia (Large) & Rib & 1 \\
\hline $\mathrm{E} 26 / \mathrm{S} 72$ & $41 \mathrm{~A}$ & $35001 \mathrm{~A}$ & Igl//si & E. Paleo. & & Mammalia (Medium/large) & Indeterminate & 6 \\
\hline E26/S72 & $41 \mathrm{~A}$ & $35001 \mathrm{~A}$ & Igl//si & E. Paleo. & & Vertebrata & Indeterminate & 45 \\
\hline E26/S72 & $41 \mathrm{~A}$ & $35001 \mathrm{~B}$ & Igl/Isi & E. Paleo. & & Artiodactyla & Tooth, perm./decid. ind. & 1 \\
\hline E26/S72 & $41 \mathrm{~A}$ & $35001 B$ & Ig1/Isi & E. Paleo. & & Leporidae & Permanent tooth & 8 \\
\hline E26/S72 & $41 \mathrm{~A}$ & $35001 \mathrm{~B}$ & Igl/Isi & E. Paleo. & & Mammalia (Large) & Long bone & 1 \\
\hline $\mathrm{E} 26 / \mathrm{S} 72$ & $41 \mathrm{~A}$ & $35001 B$ & Igl/Isi & E. Paleo. & & Mammalia (Medium/large) & Indeterminate & 4 \\
\hline E26/S72 & $41 \mathrm{~A}$ & $35001 \mathrm{~B}$ & Ig1//si & E. Paleo. & & Vertebrata & Indeterminate & 25 \\
\hline E26/S72 & $41 \mathrm{~A}$ & $35001 \mathrm{C}$ & Igl/Isi & E. Paleo. & & Vertebrata & Indeterminate & 47 \\
\hline E26/S72 & $41 \mathrm{~A}$ & $35001 \mathrm{D}$ & Igl//si & E. Paleo. & & Leporidae & Permanent tooth & 1 \\
\hline E26/S72 & $41 \mathrm{~A}$ & $35001 \mathrm{D}$ & Igl//si & E. Paleo. & & Mammalia (Large) & Indeterminate & 1 \\
\hline E26/S72 & $41 \mathrm{~A}$ & $35001 \mathrm{D}$ & Igl/Isi & E. Paleo. & & Mammalia (Large) & Long bone & 1 \\
\hline E26/S72 & $41 \mathrm{~A}$ & $35001 D$ & Igl/Isi & E. Paleo. & & Mammalia (Medium/large) & Indeterminate & 9 \\
\hline E26/S72 & $41 \mathrm{~A}$ & 35OO1D & Ig1/Isi & E. Paleo. & & Mammalia (Small) & Tooth, perm./decid. ind. & 7 \\
\hline E26/S72 & $41 \mathrm{~A}$ & 35001D & Igl/Isi & E. Paleo. & & Vertebrata & Indeterminate & 67 \\
\hline E26/S72 & 41A\&B & $35001 \& 2$ & Igl//si & E. Paleo. & & Mammalia (Medium/large) & Long bone & 1 \\
\hline E26/S72 & 41A\&B & $35001 \& 2$ & Igl/Isi & E. Paleo. & & Vertebrata & Indeterminate & 12 \\
\hline E26/S72 & $41 \mathrm{~B}$ & $35002 \mathrm{~A}$ & Igl/Isi & E. Paleo. & & Large vertebrate, class ind. & Indeterminate & 5 \\
\hline E26/S72 & 41B & $35002 \mathrm{~A}$ & Igl//si & E. Paleo. & & Mammalia (Medium/large) & Indeterminate & 1 \\
\hline E26/S72 & 41B & $35002 \mathrm{~A}$ & Igl/Isi & E. Paleo. & & Mammalia (Medium/large) & Long bone & 1 \\
\hline E26/S72 & $41 \mathrm{~B}$ & $35 \mathrm{OO} 2 \mathrm{~A}$ & |gl//si & E. Paleo. & & Mammalia (Very large) & Indeterminate & 5 \\
\hline E26/S72 & 41B & $35 \mathrm{OO} 2 \mathrm{~A}$ & Ig1//si & E. Paleo. & & Medium/Large Vertebrata & Indeterminate & 8 \\
\hline E26/S72 & 41B & $35 \mathrm{OO} 2 \mathrm{~A}$ & Igl/Isi & E. Paleo. & & Vertebrata & Indeterminate & 30 \\
\hline E26/S72 & $41 \mathrm{~B}$ & $35002 \mathrm{~B}$ & Igl//si & E. Paleo. & & Bison sp. & Cervical vertebra & 1 \\
\hline E26/S72 & 41B & $35 \mathrm{OO} 2 \mathrm{~B}$ & Igl//si & E. Paleo. & & Mammalia (Medium/large) & Indeterminate & 3 \\
\hline E26/S72 & 41B & $35002 \mathrm{~B}$ & | Igl//si & E. Paleo. & & Medium/Large Vertebrata & Indeterminate & 2 \\
\hline E26/S72 & 41B & $35 \mathrm{OO} 2 \mathrm{~B}$ & Igl/Isi & E. Paleo. & & Vertebrata & Indeterminate & 24 \\
\hline E26/S72 & $41 \mathrm{~B}$ & $35 \mathrm{OO} 2 \mathrm{C}$ & |gg1//si & E. Paleo. & & Mammalia (Medium/large) & Indeterminate & 2 \\
\hline E26/S72 & 41B & $35 \mathrm{OO} 2 \mathrm{C}$ & Igl/Isi & E. Paleo. & & Vertebrata & Indeterminate & 59 \\
\hline E26/S72 & $42 \mathrm{~A}$ & 35PP1A & |Igl//si & E. Paleo. & & Mammalia (Medium/large) & Indeterminate & 7 \\
\hline E26/S72 & $42 \mathrm{~A}$ & 35PP1A & Igl//si & E. Paleo. & & Mammalia (Medium/large) & Long bone & 1 \\
\hline E26/S72 & $42 \mathrm{~A}$ & 35PP1A & |Ig1//si & E. Paleo. & & Vertebrata & Indeterminate & 19 \\
\hline E26/S74 & 15 & 340 & IIIa/b & E. Archaic & & Antilocapra/Odocoileus & Fused 3rd \& 4th metacarpal & 1 \\
\hline E26/S74 & 15 & 340 & IIIa/b & E. Archaic & & Mammalia (Medium/large) & Indeterminate & 3 \\
\hline E26/S74 & 15 & 340 & IIIa/b & E. Archaic & & Mammalia (Medium/large) & Long bone & 5 \\
\hline E26/S74 & 15 & 340 & IIIa/b & E. Archaic & & Vertebrata & Indeterminate & 3 \\
\hline E26/S74 & $16 \mathrm{~A}$ & $34 \mathrm{P} 1$ & Шlа & E. Archaic & & Vertebrata & Indeterminate & 1 \\
\hline E26/S74 & $17 \mathrm{~A}$ & 34Q1 & ШШа & E. Archaic & & Mammalia (Medium/large) & Indeterminate & 2 \\
\hline E26/S74 & $17 \mathrm{~A}$ & 34Q1 & IIIIa & E. Archaic & & Vertebrata & Indeterminate & 4 \\
\hline E26/S74 & $17 \mathrm{~B}$ & $34 \mathrm{Q} 2$ & ШШа & E. Archaic & & Antilocapra/Odocoileus & Metapodial & 1 \\
\hline
\end{tabular}




\begin{tabular}{|c|c|c|c|c|c|c|c|c|}
\hline Square & Level & Lot & Unit & Cultural Affinity & Feature & Taxon & Element & No. \\
\hline E26/S74 & $17 \mathrm{~B}$ & $\overline{34 Q 2}$ & IIIa & E. Archaic & & Mammalia (Medium/large) & Indeterminate & 1 \\
\hline E26/S74 & 17B & 34Q2 & IIIa & E. Archaic & & Vertebrata & Indeterminate & 2 \\
\hline E26/S74 & $18 \mathrm{~A}$ & 34R1 & IIIa & E. Archaic & & Testudinata & Shell fragment & 1 \\
\hline E26/S74 & $18 \mathrm{~A}$ & 34R1 & IIIIa & E. Archaic & & Vertebrata & Indeterminate & 7 \\
\hline E26/S74 & $18 \mathrm{~B}$ & 34R2 & ПІІа & E. Archaic & & Vertebrata & Indeterminate & 15 \\
\hline E26/S74 & $19 \mathrm{~A}$ & $34 \mathrm{~S} 1$ & IIIIa & E. Archaic & & Mammalia (Medium/large) & Indeterminate & 1 \\
\hline E26/S74 & $19 \mathrm{~A}$ & $34 \mathrm{~S} 1$ & IIIIa & E. Archaic & & Vertebrata & Indeterminate & 7 \\
\hline E26/S74 & $19 \mathrm{~A}$ & F140 & IIIa & E. Archaic & f140 & Vertebrata & Indeterminate & 1 \\
\hline E26/S74 & $20 \mathrm{~A}$ & 34T1A & I/IIIa & L. Paleo./E. Archaic & f146 & Mammalia (Medium/large) & Indeterminate & 1 \\
\hline E26/S74 & $20 \mathrm{~A}$ & 34T1A & П/ШІа & L. Paleo./E. Archaic & f146 & Mammalia (Medium/large) & Long bone & 1 \\
\hline E26/S74 & $20 \mathrm{~A}$ & 34T1A & П/ШाIа & L. Paleo./E. Archaic & f146 & Medium/Large Vertebrata & Indeterminate & 1 \\
\hline E26/S74 & $20 \mathrm{~A}$ & 34T1B & II/IIIa & L. Paleo./E. Archaic & & Mammalia (Medium/large) & Long bone & 1 \\
\hline E26/S74 & $20 \mathrm{~A}$ & $34 \mathrm{~T} 1 \mathrm{C}$ & I/ШІа & L. Paleo./E. Archaic & & Mammalia (Medium/large) & Long bone & 2 \\
\hline E26/S74 & $20 \mathrm{~A}$ & $34 \mathrm{~T} 1 \mathrm{C}$ & П/ШІа & L. Paleo./E. Archaic & & Sylvilagus sp. & Astragalus & 1 \\
\hline E26/S74 & $20 \mathrm{~A}$ & $34 \mathrm{~T} 1 \mathrm{C}$ & II/IIIa & L. Paleo./E. Archaic & & Vertebrata & Indeterminate & 4 \\
\hline E26/S74 & $20 \mathrm{~A}$ & 34T1D & П/Ша & L. Paleo./E. Archaic & & Vertebrata & Indeterminate & 1 \\
\hline E26/S74 & 20B & $34 \mathrm{~T} 2 \mathrm{~B}$ & П/ШІа & L. Paleo./E. Archaic & & Vertebrata & Indeterminate & 1 \\
\hline E26/S74 & 20B & $34 \mathrm{~T} 2 \mathrm{C}$ & П/ШІІа & L. Paleo./E. Archaic & & AntilocapralOdocoileus & Metapodial & 1 \\
\hline E26/S74 & $20 \mathrm{~B}$ & $34 \mathrm{~T} 2 \mathrm{C}$ & Ш/Ша & L. Paleo./E. Archaic & & Mammalia (Medium/large) & Indeterminate & 2 \\
\hline E26/S74 & $20 \mathrm{~B}$ & $34 \mathrm{~T} 2 \mathrm{C}$ & П/Ша & L. Paleo./E. Archaic & & Small/Medium Vertebrata & Long bone & 1 \\
\hline E26/S74 & $20 \mathrm{~B}$ & $34 \mathrm{~T} 2 \mathrm{C}$ & II/IIIa & L. Paleo./E. Archaic & & Vertebrata & Indeterminate & 4 \\
\hline E26/S74 & 20B & $34 \mathrm{~T} 2 \mathrm{D}$ & П/Ша & L. Paleo./E. Archaic & & Mammalia (Medium/large) & Long bone & 1 \\
\hline E26/S74 & $21 \mathrm{~A}$ & $34 \mathrm{U} 1 \mathrm{C}$ & II/IIIa & L. Paleo./E. Archaic & & Mammalia (Medium/large) & Indeterminate & 1 \\
\hline E26/S74 & $21 \mathrm{~A}$ & $34 \mathrm{U} 1 \mathrm{C}$ & II/IIIa & L. Paleo./E. Archaic & & Vertebrata & Indeterminate & 1 \\
\hline E26/S74 & $21 \mathrm{~A}$ & 34U1D & I/IIIa & L. Paleo./E. Archaic & & Mammalia (Medium/large) & Long bone & 1 \\
\hline E26/S74 & 21B & $34 \mathrm{U} 2 \mathrm{~B}$ & III & L. Paleo. & & Mammalia (Medium/large) & Indeterminate & 2 \\
\hline E26/S74 & 21B & $34 \mathrm{U} 2 \mathrm{~B}$ & III & L. Paleo. & & Medium/Large Vertebrata & Indeterminate & 1 \\
\hline E26/S74 & 21B & $34 \mathrm{U} 2 \mathrm{~B}$ & III & L. Paleo. & & Small/Medium Vertebrata & Long bone & 1 \\
\hline E26/S74 & $21 \mathrm{~B}$ & $34 \mathrm{U} 2 \mathrm{~B}$ & III & L. Paleo. & & Vertebrata & Indeterminate & 2 \\
\hline E26/S74 & 21B & $34 \mathrm{U} 2 \mathrm{C}$ & III & L. Paleo. & & Mammalia (Medium/large) & Indeterminate & 1 \\
\hline E26/S74 & 21B & $34 \mathrm{U} 2 \mathrm{C}$ & III & L. Paleo. & & Vertebrata & Indeterminate & 1 \\
\hline E26/S74 & $22 \mathrm{~A}$ & $34 \& 35 \mathrm{~V} 1$ & III & L. Paleo. & f146 & Vertebrata & Indeterminate & 2 \\
\hline E26/S74 & $22 \mathrm{~A}$ & 34V1B & III & L. Paleo. & & Medium/Large Vertebrata & Indeterminate & 1 \\
\hline E26/S74 & $22 \mathrm{~A}$ & $34 \mathrm{~V} 1 \mathrm{C}$ & III & L. Paleo. & & Medium/Large Vertebrata & Indeterminate & 1 \\
\hline E26/S74 & $22 \mathrm{~A}$ & $34 \mathrm{~V} 1 \mathrm{D}$ & III & L. Paleo. & & Mammalia (Medium/large) & Indeterminate & 1 \\
\hline E26/S74 & $22 \mathrm{~A}$ & 34V1D & III & L. Paleo. & & Small/Medium Vertebrata & Long bone & 2 \\
\hline E26/S74 & $22 \mathrm{~A}$ & 34V1D & III & L. Paleo. & & Vertebrata & Indeterminate & 2 \\
\hline E26/S74 & $22 \mathrm{~B}$ & $34 \mathrm{~V} 2 \mathrm{~A}$ & III & L. Paleo. & & Vertebrata & Indeterminate & 1 \\
\hline E26/S74 & $22 \mathrm{~B}$ & $34 \mathrm{~V} 2 \mathrm{~B}$ & III & L. Paleo. & & Mammalia (Medium/large) & Indeterminate & 1 \\
\hline E26/S74 & $22 \mathrm{~B}$ & $34 \mathrm{~V} 2 \mathrm{D}$ & III & L. Paleo. & & Mammalia (Medium/large) & Indeterminate & 1 \\
\hline E26/S74 & $23 \mathrm{~A}$ & $34 \mathrm{~W} 1 \mathrm{~B}$ & II & L. Paleo. & & Vertebrata & Indeterminate & 4 \\
\hline E26/S74 & $23 \mathrm{~A}$ & $34 \mathrm{~W} 1 \mathrm{C}$ & III & L. Paleo. & & Vertebrata & Indeterminate & 3 \\
\hline E26/S74 & $23 \mathrm{~A}$ & 34W1D & III & L. Paleo. & & Vertebrata & Indeterminate & 4 \\
\hline E26/S74 & 23B & $34 \mathrm{~W} 2 \mathrm{~B}$ & II & L. Paleo. & & Small/Medium Vertebrata & Long bone & 1 \\
\hline E26/S74 & $23 \mathrm{~B}$ & $34 \mathrm{~W} 2 \mathrm{C}$ & III & L. Paleo. & & Medium/Large Vertebrata & Indeterminate & 1 \\
\hline E26/S74 & $24 \mathrm{~A}$ & $34 \mathrm{X} 1 \mathrm{C}$ & III & L. Paleo. & & Small/Medium Vertebrata & Long bone & 1 \\
\hline E26/S74 & $24 \mathrm{~A}$ & $34 X 1 D$ & III & L. Paleo. & & Mammalia (Medium/large) & Indeterminate & 1 \\
\hline E26/S74 & $24 \mathrm{~A}$ & $34 X 1 D$ & III & L. Paleo. & & Medium/Large Vertebrata & Indeterminate & 1 \\
\hline E26/S74 & $24 \mathrm{~A}$ & $34 X 1 D$ & III & L. Paleo. & & Small/Medium Vertebrata & Long bone & 2 \\
\hline E26/S74 & $24 \mathrm{~A}$ & $34 X 1 D$ & III & L. Paleo. & & Vertebrata & Indeterminate & 2 \\
\hline E26/S74 & $24 \mathrm{~B}$ & $34 \mathrm{X} 2 \mathrm{~A}$ & III & L. Paleo. & & Mammalia (Medium/large) & Indeterminate & 1 \\
\hline E26/S74 & 24B & $34 \mathrm{X} 2 \mathrm{~A}$ & III & L. Paleo. & & Mammalia (Medium/large) & Long bone & 1 \\
\hline E26/S74 & $24 \mathrm{~B}$ & $34 \mathrm{X} 2 \mathrm{~A}$ & III & L. Paleo. & & Vertebrata & Indeterminate & 3 \\
\hline E26/S74 & 24B & $34 X 2 B$ & III & L. Paleo. & & Mammalia (Medium) & Pelvis & 1 \\
\hline E26/S74 & 24B & $34 X 2 B$ & III & L. Paleo. & & Vertebrata & Indeterminate & 1 \\
\hline E26/S74 & 24B & $34 \mathrm{X} 2 \mathrm{C}$ & III & L. Paleo. & & Antilocapra/Odocoileus & Astragalus & 1 \\
\hline E26/S74 & 24B & $34 \times 2 C$ & III & L. Paleo. & & Mammalia (Large) & Indeterminate & 2 \\
\hline $\mathrm{E} 26 / \mathrm{S} 74$ & $24 \mathrm{~B}$ & $34 \mathrm{X} 2 \mathrm{C}$ & III & L. Paleo. & & Mammalia (Medium/large) & Indeterminate & 1 \\
\hline E26/S74 & $24 B$ & $34 \mathrm{X} 2 \mathrm{C}$ & III & L. Paleo. & & Mammalia (Medium/large) & Long bone & 1 \\
\hline E26/S74 & $24 \mathrm{~B}$ & $34 \mathrm{X} 2 \mathrm{C}$ & III & L. Paleo. & & Medium/Large Vertebrata & Indeterminate & 1 \\
\hline E26/S74 & $24 \mathrm{~B}$ & $34 \mathrm{X} 2 \mathrm{C}$ & III & L. Paleo. & & Medium/Large Vertebrata & Long bone & 1 \\
\hline E26/S74 & $24 \mathrm{~B}$ & $34 \mathrm{X} 2 \mathrm{C}$ & III & L. Paleo. & & Vertebrata & Indeterminate & 3 \\
\hline E26/S74 & $24 \mathrm{~B}$ & $34 \mathrm{X} 2 \mathrm{D}$ & III & L. Paleo. & & Small/Medium Vertebrata & Long bone & 1 \\
\hline E26/S74 & $24 B$ & $34 X 2 D$ & III & L. Paleo. & & Vertebrata & Indeterminate & 3 \\
\hline E26/S74 & $25 \mathrm{~A}$ & $34 \mathrm{Y} 1 \mathrm{~A}$ & III & L. Paleo. & & Mammalia (Small) & Permanent tooth & 1 \\
\hline E26/S74 & $25 \mathrm{~A}$ & $34 \mathrm{Y} 1 \mathrm{C}$ & III & L. Paleo. & & Medium/Large Vertebrata & Indeterminate & 1 \\
\hline E26/S74 & $25 \mathrm{~A}$ & $34 \mathrm{Y} 1 \mathrm{C}$ & III & L. Paleo. & & Vertebrata & Indeterminate & 2 \\
\hline
\end{tabular}




\begin{tabular}{|c|c|c|c|c|c|c|c|c|}
\hline Square & Level & Lot & Unit & Cultural Affinity & Feature & Taxon & Element & No. \\
\hline E26/S74 & $25 \mathrm{~A}$ & 34Y1D & $\bar{\Pi}$ & L. Paleo. & & Vertebrata & Indeterminate & 2 \\
\hline E26/S74 & $25 \mathrm{~B}$ & $34 \mathrm{Y} 2 \mathrm{~A}$ & II & L. Paleo. & & Mammalia (Medium/large) & Long bone & 1 \\
\hline E26/S74 & $25 \mathrm{~B}$ & $34 \mathrm{Y} 2 \mathrm{~A}$ & II & L. Paleo. & & Vertebrata & Indeterminate & 5 \\
\hline E26/S74 & $25 \mathrm{~B}$ & $34 \mathrm{Y} 2 \mathrm{C}$ & II & L. Paleo. & & Small/Medium Vertebrata & Long bone & 1 \\
\hline E26/S74 & $25 \mathrm{~B}$ & $34 \mathrm{Y} 2 \mathrm{D}$ & II & L. Paleo. & & Vertebrata & Indeterminate & 4 \\
\hline E26/S74 & $26 \mathrm{~A}$ & $34 \mathrm{Z} 1 \mathrm{C}$ & II & L. Paleo. & & Vertebrata & Indeterminate & 1 \\
\hline E26/S74 & $26 \mathrm{~B}$ & $34 \mathrm{Z} 2 \mathrm{~A}$ & II & L. Paleo. & & Medium/Large Vertebrata & Long bone & 1 \\
\hline E26/S74 & $26 \mathrm{~B}$ & $34 \mathrm{Z} 2 \mathrm{~A}$ & II & L. Paleo. & & Vertebrata & Indeterminate & 1 \\
\hline E26/S74 & $26 \mathrm{~B}$ & $34 \mathrm{Z} 2 \mathrm{C}$ & II & L. Paleo. & & Medium/Large Vertebrata & Indeterminate & 3 \\
\hline E26/S74 & $26 \mathrm{~B}$ & $34 \mathrm{Z} 2 \mathrm{D}$ & II & L. Paleo. & & Small/Medium Vertebrata & Long bone & 1 \\
\hline E26/S74 & $26 \mathrm{~B}$ & 34Z2D & II & L. Paleo. & & Vertebrata & Indeterminate & 5 \\
\hline E26/S74 & $27 \mathrm{~A}$ & 34AA1B & II & L. Paleo. & & Vertebrata & Indeterminate & 12 \\
\hline E26/S74 & $27 \mathrm{~A}$ & 34AA1D & II & L. Paleo. & & Vertebrata & Indeterminate & 2 \\
\hline E26/S74 & 27B & 34AA2B & Isi-c/II & L. Paleo. & & Mammalia (Medium/large) & Indeterminate & 1 \\
\hline E26/S74 & $27 \mathrm{~B}$ & $34 \mathrm{AA} 2 \mathrm{~B}$ & Isi-c/II & L. Paleo. & & Vertebrata & Indeterminate & 3 \\
\hline E26/S74 & 27B & $34 \mathrm{AA} 2 \mathrm{C}$ & Isi-c/II & L. Paleo. & & Vertebrata & Indeterminate & 1 \\
\hline E26/S74 & $28 \mathrm{~A}$ & 34BB1A & Isi-c/II & L. Paleo. & & Mammalia (Medium/large) & Long bone & 2 \\
\hline E26/S74 & $28 \mathrm{~A}$ & 34BB1A & Isi-c/II & L. Paleo. & & Small/Medium Vertebrata & Long bone & 1 \\
\hline E26/S74 & $28 \mathrm{~A}$ & 34BB1A & Isi-c/II & L. Paleo. & & Vertebrata & Indeterminate & 4 \\
\hline E26/S74 & $28 \mathrm{~A}$ & 34BB1B & Isi-c/II & L. Paleo. & & Vertebrata & Indeterminate & 5 \\
\hline E26/S74 & $28 \mathrm{~A}$ & $34 \mathrm{BB} 1 \mathrm{C}$ & Isi-c/II & L. Paleo. & & Mammalia (Medium/large) & Long bone & 2 \\
\hline E26/S74 & $28 \mathrm{~A}$ & 34BB1C & Isi-c/II & L. Paleo. & & Mammalia (Medium/large) & Rib & 1 \\
\hline $\mathrm{E} 26 / \mathrm{S} 74$ & $28 \mathrm{~A}$ & 34BB1C & Isi-c/II & L. Paleo. & & Mammalia (Medium/large) & Vertebra & 1 \\
\hline E26/S74 & $28 \mathrm{~A}$ & 34BB1C & Isi-c/II & L. Paleo. & & Medium/Large Vertebrata & Indeterminate & 1 \\
\hline E26/S74 & $28 \mathrm{~A}$ & 34BB1D & Isi-c/II & L. Paleo. & & Mammalia (Medium/large) & Long bone & 1 \\
\hline E26/S74 & $28 \mathrm{~A}$ & 34BB1D & Isi-c/II & L. Paleo. & & Small/Medium Vertebrata & Indeterminate & 1 \\
\hline E26/S74 & $28 \mathrm{~B}$ & $34 \mathrm{BB} 2 \mathrm{~A}$ & Isi-c/II & L. Paleo. & & Vertebrata & Indeterminate & 2 \\
\hline E26/S74 & $28 \mathrm{~B}$ & 34BB2B & Isi-c/II & L. Paleo. & & Vertebrata & Indeterminate & 1 \\
\hline E26/S74 & $28 \mathrm{~B}$ & 34BB2D & Isi-c/II & L. Paleo. & & Vertebrata & Long bone & 2 \\
\hline E26/S74 & $29 \mathrm{~A}$ & $34 \mathrm{CC} 1 \mathrm{~A}$ & Isi-c & L. Paleo. & & Leporidae & Permanent tooth & 1 \\
\hline E26/S74 & $29 \mathrm{~A}$ & $34 \mathrm{CC} 1 \mathrm{~A}$ & Isi-c & L. Paleo. & & Vertebrata & Indeterminate & 4 \\
\hline E26/S74 & $29 \mathrm{~A}$ & $34 \mathrm{CC} 1 \mathrm{~B}$ & Isi-c & L. Paleo. & & Vertebrata & Indeterminate & 6 \\
\hline E26/S74 & $29 \mathrm{~A}$ & $34 \mathrm{CC} 1 \mathrm{D}$ & Isi-c & L. Paleo. & & Vertebrata & Indeterminate & 2 \\
\hline E26/S74 & 29B & $34 \mathrm{CC} 2 \mathrm{~A}$ & Isi-c & L. Paleo. & & Vertebrata & Indeterminate & 8 \\
\hline E26/S74 & 29B & $34 \mathrm{CC} 2 \mathrm{~A}$ & Isi-c & L. Paleo. & & Vertebrata & Tooth, perm./decid. ind. & 1 \\
\hline E26/S74 & 29B & $34 \mathrm{CC} 2 \mathrm{~B}$ & Isi-c & L. Paleo. & & Mammalia (Medium/large) & Long bone & 2 \\
\hline $\mathrm{E} 26 / \mathrm{S} 74$ & 29B & $34 \mathrm{CC} 2 \mathrm{~B}$ & Isi-c & L. Paleo. & & Vertebrata & Indeterminate & 12 \\
\hline E26/S74 & $29 B$ & $34 \mathrm{CC} 2 \mathrm{D}$ & Isi-c & L. Paleo. & & Vertebrata & Indeterminate & 6 \\
\hline E26/S74 & $30 \mathrm{~A}$ & 34DD1B & Isi-c & L. Paleo. & & Vertebrata & Indeterminate & 2 \\
\hline E26/S74 & $30 \mathrm{~A}$ & 34DD1C & Isi-c & L. Paleo. & & Mammalia (Medium/large) & Indeterminate & 1 \\
\hline E26/S74 & $30 \mathrm{~A}$ & 34DD1C & Isi-c & L. Paleo. & & Vertebrata & Indeterminate & 4 \\
\hline E26/S74 & $30 \mathrm{~A}$ & 34DD1D & Isi-c & L. Paleo. & & Vertebrata & Indeterminate & 4 \\
\hline E26/S74 & $30 \mathrm{~A}$ & 34DD1D & Isi-c & L. Paleo. & & Vertebrata & Long bone & 1 \\
\hline E26/S74 & $30 \mathrm{~B}$ & 34DD2B & Isi-c & L. Paleo. & & Vertebrata & Indeterminate & 1 \\
\hline E26/S74 & $30 \mathrm{~B}$ & 34DD2C & Isi-c & L. Paleo. & & Vertebrata & Indeterminate & 3 \\
\hline E26/S74 & $30 \mathrm{~B}$ & 34DD2D & Isi-c & L. Paleo. & & AntilocapralOdocoileus & Proximal abaxial sesamoid & 1 \\
\hline E26/S74 & $30 \mathrm{~B}$ & 34DD2D & Isi-c & L. Paleo. & & Vertebrata & Indeterminate & 6 \\
\hline E26/S74 & $31 \mathrm{~A}$ & 34EE1A & Isi-c & L. Paleo. & & Mammalia (Small) & Metapodial & 1 \\
\hline E26/S74 & $31 \mathrm{~A}$ & 34EE1A & Isi-c & L. Paleo. & & Medium/Large Vertebrata & Long bone & 1 \\
\hline E26/S74 & $31 \mathrm{~A}$ & 34EE1A & Isi-c & L. Paleo. & & Vertebrata & Indeterminate & 12 \\
\hline E26/S74 & $31 \mathrm{~A}$ & 34EE1B & Isi-c & L. Paleo. & & Small/Medium Vertebrata & Long bone & 1 \\
\hline E26/S74 & $31 \mathrm{~B}$ & 34EE2A & Isi-c & L. Paleo. & & Vertebrata & Indeterminate & 2 \\
\hline E26/S74 & $31 \mathrm{~B}$ & 34EE2C & Isi-c & L. Paleo. & & Vertebrata & Indeterminate & 2 \\
\hline E26/S74 & $31 \mathrm{~B}$ & 34EE2D & Isi-c & L. Paleo. & & Mammalia (Medium/large) & Indeterminate & 4 \\
\hline E26/S74 & $31 \mathrm{~B}$ & 34EE2D & Isi-c & L. Paleo. & & Vertebrata & Indeterminate & 2 \\
\hline E26/S74 & $32 \mathrm{~A}$ & 34FF1A & Isi-c & L. Paleo. & & Medium/Large Vertebrata & Indeterminate & 1 \\
\hline E26/S74 & $32 \mathrm{~A}$ & 34FF1A & Isi-c & L. Paleo. & & Vertebrata & Indeterminate & 2 \\
\hline E26/S74 & $32 \mathrm{~A}$ & 34FF1D & Isi-c & L. Paleo. & & Small/Medium Vertebrata & Long bone & 3 \\
\hline E26/S74 & $32 \mathrm{~A}$ & 34FF1D & Isi-c & L. Paleo. & & Vertebrata & Indeterminate & 1 \\
\hline E26/S74 & $32 \mathrm{~B}$ & 34FF2D & Isi-c & L. Paleo. & & Vertebrata & Indeterminate & 1 \\
\hline E26/S74 & $33 \mathrm{~A}$ & 34GG1D & Icl/Isi-c & Paleoindian & & Vertebrata & Indeterminate & 1 \\
\hline E26/S74 & $33 \mathrm{~B}$ & $34 \mathrm{GG} 2 \mathrm{~A}$ & Icl/Isi-c & Paleoindian & & Vertebrata & Indeterminate & 2 \\
\hline E26/S74 & $33 \mathrm{~B}$ & 34GG2B & Icl/Isi-c & Paleoindian & & Mammalia (Medium/large) & Indeterminate & 1 \\
\hline E26/S74 & $33 \mathrm{~B}$ & $34 \mathrm{GG} 2 \mathrm{~B}$ & $\mathrm{Icl} / \mathrm{Isi}-\mathrm{c}$ & Paleoindian & & Small/Medium Vertebrata & Long bone & 1 \\
\hline E26/S74 & $33 \mathrm{~B}$ & 34GG2B & $\mathrm{Icl} / \mathrm{Isi}-\mathrm{c}$ & Paleoindian & & Vertebrata & Indeterminate & 2 \\
\hline E26/S74 & $33 \mathrm{~B}$ & 34GG2C & Icl/Isi-c & Paleoindian & & Small/Medium Vertebrata & Long bone & 1 \\
\hline E26/S74 & $34 \mathrm{~A}$ & $34 \mathrm{HH} 1 \mathrm{~A}$ & Icl/Isi-c & Paleoindian & & Vertebrata & Indeterminate & 1 \\
\hline
\end{tabular}




\begin{tabular}{|c|c|c|c|c|c|c|c|c|}
\hline Square & Level & Lot & Unit & Cultural Affinity & Feature & Taxon & Element & No. \\
\hline E26/S74 & $34 \mathrm{~A}$ & $34 \mathrm{HH} 1 \mathrm{C}$ & $\mathrm{Icl} / \mathrm{Isi}-\mathrm{c}$ & Paleoindian & & Vertebrata & Indeterminate & 1 \\
\hline E26/S74 & 34B & $34 \mathrm{HH} 2 \mathrm{~A}$ & Icl & E. Paleo. & & Vertebrata & Indeterminate & 1 \\
\hline E26/S74 & 34B & $34 \mathrm{HH} 2 \mathrm{~B}$ & Icl & E. Paleo. & & Vertebrata & Indeterminate & 3 \\
\hline E26/S74 & $34 \mathrm{~B}$ & $34 \mathrm{HH} 2 \mathrm{C}$ & Icl & E. Paleo. & & Mammalia (Medium/large) & Indeterminate & 1 \\
\hline E26/S74 & 34B & $34 \mathrm{HH} 2 \mathrm{C}$ & Icl & E. Paleo. & & Medium/Large Vertebrata & Indeterminate & 1 \\
\hline E26/S74 & $35 \mathrm{~A}$ & 34II1A & Icl & E. Paleo. & & Vertebrata & Indeterminate & 1 \\
\hline E26/S74 & $35 \mathrm{~B}$ & 34III2B & Icl & E. Paleo. & & Vertebrata & Indeterminate & 2 \\
\hline E26/S74 & $35 \mathrm{~B}$ & 34II2D & Icl & E. Paleo. & & Vertebrata & Indeterminate & 2 \\
\hline E26/S74 & $36 \mathrm{~A}$ & 34JJ1C & Icl & E. Paleo. & & Vertebrata & Indeterminate & 1 \\
\hline E26/S74 & $36 \mathrm{~A}$ & 34JJ1D & Icl & E. Paleo. & & Medium/Large Vertebrata & Indeterminate & 1 \\
\hline $\mathrm{E} 26 / \mathrm{S} 74$ & $36 \mathrm{~A}$ & 34JJ1D & Icl & E. Paleo. & & Small/Medium Vertebrata & Long bone & 1 \\
\hline E26/S74 & $37 \mathrm{~A}$ & $34 \mathrm{KK} 1 \mathrm{~A}$ & Icl & E. Paleo. & & Vertebrata & Indeterminate & 3 \\
\hline E26/S74 & $37 \mathrm{~A}$ & $34 \mathrm{KK} 1 \mathrm{C}$ & Icl & E. Paleo. & & Vertebrata & Indeterminate & 3 \\
\hline E26/S74 & $37 \mathrm{~B}$ & $34 \mathrm{KK} 2 \mathrm{~B}$ & Icl & E. Paleo. & & Artiodactyla & Tooth, perm./decid. ind. & 1 \\
\hline E26/S74 & $37 \mathrm{~B}$ & $34 \mathrm{KK} 2 \mathrm{C}$ & Icl & E. Paleo. & & Mammalia (Medium/large) & Indeterminate & 2 \\
\hline $\mathrm{E} 26 / \mathrm{S} 74$ & $37 \mathrm{~B}$ & $34 \mathrm{KK} 2 \mathrm{C}$ & Icl & E. Paleo. & & Vertebrata & Indeterminate & 2 \\
\hline E26/S74 & $38 \mathrm{~A}$ & 34LL1D & Isi//lcl & E. Paleo. & & Vertebrata & Indeterminate & 1 \\
\hline E26/S74 & $38 \mathrm{~B}-39 \mathrm{~A}$ & $34 \mathrm{LL} 2 / \mathrm{MI}$ & Isi/Icl & E. Paleo. & & Mammalia (Medium/large) & Indeterminate & 1 \\
\hline E26/S74 & $38 \mathrm{~B}-39 \mathrm{~A}$ & $34 \mathrm{LL} 2 / \mathrm{M}$ & Isi/Icl & E. Paleo. & & Medium/Large Vertebrata & Indeterminate & 1 \\
\hline E26/S74 & $38 \mathrm{~B}-39 \mathrm{~A}$ & $34 \mathrm{LL} 2 / \mathrm{M}$ & Isi/Icl & E. Paleo. & & Vertebrata & Indeterminate & 9 \\
\hline E26/S74 & $38 \mathrm{~B}-39 \mathrm{~A}$ & $34 \mathrm{LL} 2 / \mathrm{M}$ & Isi/Icl & E. Paleo. & & Mammalia (Medium/large) & Indeterminate & 1 \\
\hline E26/S74 & $38 \mathrm{~B}-39 \mathrm{~A}$ & $34 \mathrm{LL} 2 / \mathrm{M}$ & Isi/Icl & E. Paleo. & & Medium/Large Vertebrata & Indeterminate & 2 \\
\hline E26/S74 & $38 \mathrm{~B}-39 \mathrm{~A}$ & $34 \mathrm{LL} 2 / \mathrm{MI}$ & Isi/Icl & E. Paleo. & & Vertebrata & Indeterminate & 9 \\
\hline E26/S74 & $40 \mathrm{~A}$ & 34NN1A & Isi/Icl & E. Paleo. & & Mammalia (Medium/large) & Indeterminate & 1 \\
\hline E26/S74 & $40 \mathrm{~A}$ & 34NN1A & Isi//Icl & E. Paleo. & & Medium/Large Vertebrata & Indeterminate & 2 \\
\hline E26/S74 & $40 \mathrm{~A}$ & 34NN1A & Isi//cl & E. Paleo. & & Vertebrata & Indeterminate & 11 \\
\hline E26/S74 & $40 \mathrm{~A}$ & 34NN1B & Isi/Icl & E. Paleo. & & Mammalia (Medium/large) & Indeterminate & 3 \\
\hline E26/S74 & $40 \mathrm{~A}$ & 34NN1B & Isi//Icl & E. Paleo. & & Medium/Large Vertebrata & Indeterminate & 1 \\
\hline E26/S74 & $40 \mathrm{~A}$ & 34NN1B & Isi//lcl & E. Paleo. & & Vertebrata & Indeterminate & 5 \\
\hline E26/S74 & $40 \mathrm{~A}$ & $34 N N 1 C$ & Isi//lcl & E. Paleo. & & Mammalia (Medium/large) & Indeterminate & 6 \\
\hline E26/S74 & $40 \mathrm{~A}$ & $34 \mathrm{NN} 1 \mathrm{C}$ & Isi/Icl & E. Paleo. & & Vertebrata & Indeterminate & 16 \\
\hline E26/S74 & $40 \mathrm{~A}$ & 34NN1D & Isi/Icl & E. Paleo. & & Mammalia (Large) & Long bone & 1 \\
\hline E26/S74 & $40 \mathrm{~A}$ & 34NN1D & Isi/Icl & E. Paleo. & & Mammalia (Medium/large) & Indeterminate & 5 \\
\hline E26/S74 & $40 \mathrm{~A}$ & 34NN1D & Isi//Icl & E. Paleo. & & Vertebrata & Indeterminate & 9 \\
\hline E26/S74 & 40B & $34 \mathrm{NN} 2 \mathrm{~A}$ & Isi & E. Paleo. & & Mammalia (Medium/large) & Indeterminate & 2 \\
\hline E26/S74 & 40B & $34 \mathrm{NN} 2 \mathrm{~A}$ & Isi & E. Paleo. & & Medium/Large Vertebrata & Indeterminate & 4 \\
\hline E26/S74 & 40B & $34 \mathrm{NN} 2 \mathrm{~A}$ & Isi & E. Paleo. & & Small/Medium Vertebrata & Long bone & 1 \\
\hline E26/S74 & $40 \mathrm{~B}$ & 34NN2B & Isi & E. Paleo. & & cf. Bison & Vertebra & 1 \\
\hline E26/S74 & 40B & 34NN2B & Isi & E. Paleo. & & Medium/Large Vertebrata & Indeterminate & 9 \\
\hline E26/S74 & 40B & 34NN2B & Isi & E. Paleo. & & Vertebrata & Indeterminate & 18 \\
\hline E26/S74 & 40B & $34 \mathrm{NN} 2 \mathrm{C}$ & Isi & E. Paleo. & & Mammalia (Large) & Indeterminate & 2 \\
\hline E26/S74 & $40 \mathrm{~B}$ & $34 \mathrm{NN} 2 \mathrm{C}$ & Isi & E. Paleo. & & Mammalia (Medium/large) & Indeterminate & 4 \\
\hline E26/S74 & $40 \mathrm{~B}$ & $34 \mathrm{NN} 2 \mathrm{C}$ & Isi & E. Paleo. & & Medium/Large Vertebrata & Indeterminate & 5 \\
\hline E26/S74 & $40 \mathrm{~B}$ & $34 \mathrm{NN} 2 \mathrm{C}$ & Isi & E. Paleo. & & Vertebrata & Indeterminate & 17 \\
\hline E26/S74 & $40 \mathrm{~B}$ & 34NN2D & Isi & E. Paleo. & & Medium/Large Vertebrata & Indeterminate & 1 \\
\hline E26/S74 & $40 \mathrm{~B}$ & 34NN2D & Isi & E. Paleo. & & Vertebrata & Indeterminate & 6 \\
\hline E26/S74 & $41 \mathrm{~A} \& \mathrm{~B}$ & $34001 \& 2$ & $\mathrm{Igl} / \mathrm{Isi}$ & E. Paleo. & & Bison sp. & Astragalus & 1 \\
\hline E26/S74 & $41 \mathrm{~B}$ & $34 \mathrm{OO} 2 \mathrm{~A}$ & Igl/Isi & E. Paleo. & & Vertebrata & Indeterminate & 38 \\
\hline E26/S74 & 41B & $34002 B$ & $\mathrm{Igl} / \mathrm{Isi}$ & E. Paleo. & & Mammalia (Medium/large) & Indeterminate & 9 \\
\hline E26/S74 & 41B & $34 \mathrm{OO} 2 \mathrm{~B}$ & $\mathrm{Igl} / / \mathrm{Isi}$ & E. Paleo. & & Mammalia (Medium/large) & Long bone & 5 \\
\hline E26/S74 & 41B & $34 \mathrm{OO} 2 \mathrm{~B}$ & $\mathrm{Igl} / \mathrm{Isi}$ & E. Paleo. & & Vertebrata & Indeterminate & 43 \\
\hline E26/S74 & 41B & $34 \mathrm{OO} 2 \mathrm{C}$ & $\mathrm{Igl} / \mathrm{Isi}$ & E. Paleo. & & Vertebrata & Indeterminate & 4 \\
\hline E26/S76 & 15 & 330 & IIIa/b & E. Archaic & & Sylvilagus sp. & Calcaneus & 1 \\
\hline E26/S76 & 15 & 330 & Wa/b & E. Archaic & & Vertebrata & Indeterminate & 5 \\
\hline E26/S76 & $17 \mathrm{~A}$ & 33Q1 & IIIa & E. Archaic & & Vertebrata & Indeterminate & 1 \\
\hline E26/S76 & $18 \mathrm{~A}$ & 33R1 & Ша & E. Archaic & & Mammalia (Medium/large) & Indeterminate & 3 \\
\hline E26/S76 & $18 \mathrm{~A}$ & 33R1 & IIIa & E. Archaic & & Vertebrata & Indeterminate & 12 \\
\hline E26/S76 & $18 \mathrm{~B}$ & 33R2 & IIIIa & E. Archaic & & Mammalia (Medium/large) & Indeterminate & 3 \\
\hline E26/S76 & $18 \mathrm{~B}$ & 33R2 & IIIIa & E. Archaic & & Mammalia (Small/medium) & Proximal phalange & 1 \\
\hline E26/S76 & $18 \mathrm{~B}$ & 33R2 & Ша & E. Archaic & & Testudinata & Shell fragment & 1 \\
\hline E26/S76 & $18 \mathrm{~B}$ & $33 \mathrm{R} 2$ & IIIa & E. Archaic & & Vertebrata & Indeterminate & 6 \\
\hline E26/S76 & 19A & $33 \mathrm{~S} 1$ & Ш//IIa & L. Paleo./E. Archaic & & Vertebrata & Indeterminate & 2 \\
\hline E26/S76 & 19B & $33 \mathrm{~S} 2 \mathrm{~A}$ & I/Шаa & L. Paleo./E. Archaic & & Small/Medium Vertebrata & Long bone & 2 \\
\hline E26/S76 & 19B & $33 \mathrm{~S} 2 \mathrm{~A}$ & П/Ша & L. Paleo./E. Archaic & & Testudinata & Shell fragment & 2 \\
\hline E26/S76 & 19B & $33 \mathrm{~S} 2 \mathrm{~A}$ & ІІШ/Ша & L. Paleo./E. Archaic & & Vertebrata & Indeterminate & 4 \\
\hline E26/S76 & 19B & $33 \mathrm{~S} 2 \mathrm{~B}$ & II/IIIa & L. Paleo./E. Archaic & & Vertebrata & Indeterminate & 1 \\
\hline E26/S76 & 19B & $33 \mathrm{~S} 2 \mathrm{D}$ & Ш/Ша & L. Paleo./E. Archaic & & Mammalia (Large) & Indeterminate & 1 \\
\hline
\end{tabular}




\begin{tabular}{|c|c|c|c|c|c|c|c|c|}
\hline Square & Level & Lot & Unit & Cultural Affinity & Feature & Taxon & Element & No. \\
\hline E26/S76 & $19 \mathrm{~B}$ & $33 \mathrm{~S} 2 \mathrm{D}$ & IIIIIIa & L. Paleo./E. Archaic & & Vertebrata & Indeterminate & 1 \\
\hline $\mathrm{E} 26 / \mathrm{S} 76$ & $20 \mathrm{~A}$ & 33T1B & II/IIIa & L. Paleo./E. Archaic & & Lepus californicus & Astragalus & 1 \\
\hline E26/S76 & $20 \mathrm{~A}$ & 33T1B & III/IIIa & L. Paleo./E. Archaic & & Mammalia (Medium/large) & Indeterminate & 4 \\
\hline E26/S76 & $20 \mathrm{~A}$ & 33T1B & III/IIIa & L. Paleo./E. Archaic & & Medium/Large Vertebrata & Indeterminate & 2 \\
\hline E26/S76 & $20 \mathrm{~A}$ & $33 \mathrm{~T} 1 \mathrm{~B}$ & II/IIIa & L. Paleo./E. Archaic & & Small/Medium Vertebrata & Long bone & 1 \\
\hline E26/S76 & $20 \mathrm{~A}$ & 33T1B & II/IIIIa & L. Paleo./E. Archaic & & Vertebrata & Indeterminate & 1 \\
\hline E26/S76 & $20 \mathrm{~A}$ & $33 \mathrm{~T} 1 \mathrm{C}$ & II/IIIa & L. Paleo./E. Archaic & & Mammalia (Medium/large) & Indeterminate & 1 \\
\hline E26/S76 & $20 \mathrm{~A}$ & $33 \mathrm{~T} 1 \mathrm{C}$ & II/IIIa & L. Paleo./E. Archaic & & Vertebrata & Indeterminate & 6 \\
\hline E26/S76 & $20 \mathrm{~B}$ & $33 \mathrm{~T} 2 \mathrm{C}$ & III/IIIa & L. Paleo./E. Archaic & & Vertebrata & Indeterminate & 1 \\
\hline E26/S76 & $20 \mathrm{~B}$ & $33 \mathrm{~T} 2 \mathrm{D}$ & III/IIIa & L. Paleo./E. Archaic & & Mammalia (Medium/large) & Indeterminate & 3 \\
\hline $\mathrm{E} 26 / \mathrm{S} 76$ & $20 \mathrm{~B}$ & $33 \mathrm{~T} 2 \mathrm{D}$ & IIIIIIa & L. Paleo./E. Archaic & & Sylvilagus sp. & Astragalus & 1 \\
\hline E26/S76 & $20 \mathrm{~B}$ & $33 \mathrm{~T} 2 \mathrm{D}$ & II/IIIa & L. Paleo./E. Archaic & & Vertebrata & Indeterminate & 3 \\
\hline E26/S76 & $21 \mathrm{~A}$ & 33U1A & III/IIIa & L. Paleo./E. Archaic & & Mammalia (Medium/large) & Long bone & 1 \\
\hline $\mathrm{E} 26 / \mathrm{S} 76$ & $21 \mathrm{~A}$ & $33 \mathrm{U} 1 \mathrm{~B}$ & II/IIIa & L. Paleo./E. Archaic & & Leporidae & Ulna & 1 \\
\hline E26/S76 & $21 \mathrm{~A}$ & $33 \mathrm{U} 1 \mathrm{~B}$ & IIIIIIa & L. Paleo./E. Archaic & & Vertebrata & Indeterminate & 2 \\
\hline E26/S76 & $21 \mathrm{~A}$ & 33U1D & II/IIIa & L. Paleo./E. Archaic & & Odocoileus sp. & Tooth, perm./decid. ind. & 1 \\
\hline E26/S76 & $21 \mathrm{~A}$ & 33U1D & IIIIIIa & L. Paleo./E. Archaic & & Vertebrata & Indeterminate & 1 \\
\hline E26/S76 & $21 \mathrm{~B}$ & $33 \mathrm{U} 2 \mathrm{C}$ & III & L. Paleo. & & Antilocapra/Odocoileus & Carpal & 1 \\
\hline E26/S76 & $21 \mathrm{~B}$ & $33 \mathrm{U} 2 \mathrm{C}$ & III & L. Paleo. & & Small/Medium Vertebrata & Long bone & 2 \\
\hline E26/S76 & $21 \mathrm{~B}$ & $33 \mathrm{U} 2 \mathrm{C}$ & III & L. Paleo. & & Vertebrata & Indeterminate & 1 \\
\hline $\mathrm{E} 26 / \mathrm{S} 76$ & $21 \mathrm{~B}$ & $33 \mathrm{U} 2 \mathrm{D}$ & III & L. Paleo. & & Mammalia (Large) & Indeterminate & 1 \\
\hline E26/S76 & $21 \mathrm{~B}$ & $33 \mathrm{U} 2 \mathrm{D}$ & II & L. Paleo. & & Mammalia (Medium/large) & Long bone & 1 \\
\hline E26/S76 & $21 \mathrm{~B}$ & $33 \mathrm{U} 2 \mathrm{D}$ & II & L. Paleo. & & Vertebrata & Indeterminate & 1 \\
\hline E26/S76 & $22 \mathrm{~A}$ & $33 \mathrm{~V} 1 \mathrm{~A}$ & III & L. Paleo. & & Vertebrata & Indeterminate & 1 \\
\hline E26/S76 & $22 \mathrm{~A}$ & $33 \mathrm{~V} 1 \mathrm{~B}$ & II & L. Paleo. & & Mammalia (Medium/large) & Cranium & 1 \\
\hline E26/S76 & $22 \mathrm{~A}$ & $33 \mathrm{~V} 1 \mathrm{~B}$ & II & L. Paleo. & & Mammalia (Medium/large) & Indeterminate & 1 \\
\hline E26/S76 & $22 \mathrm{~A}$ & $33 \mathrm{~V} 1 \mathrm{~B}$ & II & L. Paleo. & & Vertebrata & Indeterminate & 3 \\
\hline E26/S76 & $22 \mathrm{~A}$ & 33V1D & III & L. Paleo. & & Mammalia (Medium/large) & Indeterminate & 1 \\
\hline E26/S76 & $22 \mathrm{~B}$ & $33 \mathrm{~V} 2 \mathrm{~A}$ & III & L. Paleo. & & Mammalia (Medium/large) & Indeterminate & 2 \\
\hline E26/S76 & $22 \mathrm{~B}$ & $33 \mathrm{~V} 2 \mathrm{~B}$ & III & L. Paleo. & & Mammalia (Medium/large) & Indeterminate & \\
\hline E26/S76 & 22B & $33 \mathrm{~V} 2 \mathrm{~B}$ & II & L. Paleo. & & Small/Medium Vertebrata & Long bone & \\
\hline E26/S76 & $22 \mathrm{~B}$ & $33 \mathrm{~V} 2 \mathrm{D}$ & II & L. Paleo. & & Medium/Large Vertebrata & Indeterminate & 3 \\
\hline E26/S76 & $22 B$ & $33 \mathrm{~V} 2 \mathrm{D}$ & III & L. Paleo. & & Vertebrata & Indeterminate & 2 \\
\hline E26/S76 & $23 \mathrm{~A}$ & $33 \mathrm{~W} 1 \mathrm{~A}$ & II & L. Paleo. & & Mammalia (Medium) & Proximal phalange & 1 \\
\hline E26/S76 & $23 \mathrm{~A}$ & $33 \mathrm{~W} 1 \mathrm{~A}$ & III & L. Paleo. & & Vertebrata & Indeterminate & 4 \\
\hline $\mathrm{E} 26 / \mathrm{S} 76$ & $23 \mathrm{~A}$ & $33 \mathrm{~W} 1 \mathrm{~B}$ & III & L. Paleo. & & Mammalia (Medium/large) & Caudal vertebra & 2 \\
\hline E26/S76 & $23 \mathrm{~A}$ & 33W1B & II & L. Paleo. & & Mammalia (Medium/large) & Indeterminate & 1 \\
\hline $\mathrm{E} 26 / \mathrm{S} 76$ & $23 \mathrm{~A}$ & $33 \mathrm{~W} 1 \mathrm{~B}$ & II & L. Paleo. & & Vertebrata & Indeterminate & 1 \\
\hline $\mathrm{E} 26 / \mathrm{S} 76$ & $23 \mathrm{~A}$ & $33 \mathrm{~W} 1 \mathrm{C}$ & III & L. Paleo. & & Antilocapra/Odocoileus & Metatarsal & 1 \\
\hline E26/S76 & $23 \mathrm{~A}$ & $33 \mathrm{~W} 1 \mathrm{C}$ & III & L. Paleo. & & Medium/Large Vertebrata & Indeterminate & 2 \\
\hline E26/S76 & $23 \mathrm{~A}$ & $33 \mathrm{~W} 1 \mathrm{C}$ & III & L. Paleo. & & Vertebrata & Indeterminate & 3 \\
\hline E26/S76 & $23 \mathrm{~A}$ & 33W1D & III & L. Paleo. & & Mammalia (Large) & Indeterminate & 1 \\
\hline E26/S76 & 23B & $33 \mathrm{~W} 2$ & III & L. Paleo. & & Small/Medium Vertebrata & Indeterminate & 6 \\
\hline E26/S76 & 23B & $33 \mathrm{~W} 2$ & III & L. Paleo. & & Vertebrata & Indeterminate & 14 \\
\hline E26/S76 & $23 \mathrm{~B}$ & $33 \mathrm{~W} 2 \mathrm{~A}$ & III & L. Paleo. & & Mammalia (Large) & Indeterminate & 1 \\
\hline E26/S76 & 23B & $33 \mathrm{~W} 2 \mathrm{~A}$ & III & L. Paleo. & & Medium/Large Vertebrata & Indeterminate & 1 \\
\hline E26/S76 & $23 \mathrm{~B}$ & $33 \mathrm{~W} 2 \mathrm{C}$ & II & L. Paleo. & & Mammalia (Medium/large) & Indeterminate & 1 \\
\hline $\mathrm{E} 26 / \mathrm{S} 76$ & $23 \mathrm{~B}$ & $33 \mathrm{~W} 2 \mathrm{D}$ & II & L. Paleo. & & Medium/Large Vertebrata & Indeterminate & 2 \\
\hline $\mathrm{E} 26 / \mathrm{S} 76$ & $23 \mathrm{~B}$ & $33 \mathrm{~W} 2 \mathrm{D}$ & II & L. Paleo. & & Vertebrata & Indeterminate & 7 \\
\hline E26/S76 & $24 \mathrm{~A}$ & $33 \mathrm{X} 1 \mathrm{~A}$ & III & L. Paleo. & & Mammalia (Medium/large) & Indeterminate & 1 \\
\hline E26/S76 & $24 \mathrm{~A}$ & $33 \mathrm{X} 1 \mathrm{~A}$ & III & L. Paleo. & & Mammalia (Medium/large) & Long bone & 1 \\
\hline E26/S76 & $24 \mathrm{~A}$ & $33 \mathrm{X} 1 \mathrm{C}$ & II & L. Paleo. & & Medium/Large Vertebrata & Indeterminate & 1 \\
\hline $\mathrm{E} 26 / \mathrm{S} 76$ & $24 \mathrm{~A}$ & $33 \times 1 D$ & II & L. Paleo. & & Sylvilagus sp. & Calcaneus & 1 \\
\hline $\mathrm{E} 26 / \mathrm{S} 76$ & $24 \mathrm{~B}$ & $33 \mathrm{X} 2 \mathrm{~A}$ & II & L. Paleo. & & Antilocapra/Odocoileus & Phalange & 1 \\
\hline E26/S76 & $24 \mathrm{~B}$ & $33 \mathrm{X} 2 \mathrm{~A}$ & III & L. Paleo. & & Vertebrata & Indeterminate & 3 \\
\hline $\mathrm{E} 26 / \mathrm{S} 76$ & $24 B$ & $33 \mathrm{X} 2 \mathrm{~B}$ & III & L. Paleo. & & Medium/Large Vertebrata & Indeterminate & 2 \\
\hline E26/S76 & 24B & $33 \mathrm{X} 2 \mathrm{~B}$ & III & L. Paleo. & & Small/Medium Vertebrata & Long bone & 1 \\
\hline $\mathrm{E} 26 / \mathrm{S} 76$ & $24 \mathrm{~B}$ & $33 \mathrm{X} 2 \mathrm{~B}$ & III & L. Paleo. & & Vertebrata & Indeterminate & 3 \\
\hline E26/S76 & 24B & $33 \mathrm{X} 2 \mathrm{D}$ & III & L. Paleo. & & Mammalia (Medium/large) & Indeterminate & 1 \\
\hline E26/S76 & $24 \mathrm{~B}$ & $33 \mathrm{X} 2 \mathrm{D}$ & III & L. Paleo. & & Vertebrata & Indeterminate & 1 \\
\hline $\mathrm{E} 26 / \mathrm{S} 76$ & $25 \mathrm{~A}$ & $33 \mathrm{Y} 1 \mathrm{~A}$ & II & L. Paleo. & & Mammalia (Medium) & Middle phalange & 1 \\
\hline $\mathrm{E} 26 / \mathrm{S} 76$ & $25 \mathrm{~A}$ & 33Y1A & III & L. Paleo. & & Mammalia (Medium/large) & Long bone & 1 \\
\hline $\mathrm{E} 26 / \mathrm{S} 76$ & $25 \mathrm{~A}$ & $33 \mathrm{Y} 1 \mathrm{C}$ & II & L. Paleo. & & Mammalia (Medium/large) & Indeterminate & 3 \\
\hline $\mathrm{E} 26 / \mathrm{S} 76$ & $25 \mathrm{~A}$ & $33 \mathrm{Y} 1 \mathrm{C}$ & III & L. Paleo. & & Small/Medium Vertebrata & Phalange & 1 \\
\hline E26/S76 & $25 \mathrm{~A}$ & $33 \mathrm{Y} 1 \mathrm{C}$ & III & L. Paleo. & & Small/Medium Vertebrata & Proximal phalange & 1 \\
\hline E26/S76 & $25 \mathrm{~A}$ & $33 \mathrm{Y} 1 \mathrm{C}$ & III & L. Paleo. & & Vertebrata & Indeterminate & 5 \\
\hline E26/S76 & $25 \mathrm{~A}$ & 33Y1D & III & L. Paleo. & & Medium/Large Vertebrata & Indeterminate & 6 \\
\hline
\end{tabular}




\begin{tabular}{|c|c|c|c|c|c|c|c|c|}
\hline Square & Level & Lot & Unit & Cultural Affinity & Feature & Taxon & Element & No. \\
\hline E26/S76 & $25 \mathrm{~A}$ & 33Y1D & II & L. Paleo. & & Vertebrata & Indeterminate & 2 \\
\hline $\mathrm{E} 26 / \mathrm{S} 76$ & $25 \mathrm{~B}$ & $33 \mathrm{Y} 2 \mathrm{~A}$ & II & L. Paleo. & & Mammalia (Medium/large) & Long bone & 1 \\
\hline E26/S76 & $25 \mathrm{~B}$ & $33 \mathrm{Y} 2 \mathrm{~A}$ & II & L. Paleo. & & Vertebrata & Indeterminate & 1 \\
\hline E26/S76 & $25 \mathrm{~B}$ & $33 \mathrm{Y} 2 \mathrm{~B}$ & II & L. Paleo. & & Mammalia (Medium/large) & Indeterminate & 1 \\
\hline E26/S76 & $25 \mathrm{~B}$ & $33 \mathrm{Y} 2 \mathrm{~B}$ & II & L. Paleo. & & Small/Medium Vertebrata & Long bone & 3 \\
\hline E26/S76 & $25 \mathrm{~B}$ & $33 Y 2 D$ & II & L. Paleo. & & Mammalia (Medium/large) & Long bone & 1 \\
\hline $\mathrm{E} 26 / \mathrm{S} 76$ & $25 \mathrm{~B}$ & $33 Y 2 D$ & II & L. Paleo. & & Vertebrata & Indeterminate & 1 \\
\hline $\mathrm{E} 26 / \mathrm{S} 76$ & $26 \mathrm{~A}$ & $33 \mathrm{Z} 1 \mathrm{~A}$ & II & L. Paleo. & & Mammalia (Medium/large) & Indeterminate & 1 \\
\hline E26/S76 & $26 \mathrm{~A}$ & 33Z1A & II & L. Paleo. & & Medium/Large Vertebrata & Indeterminate & 2 \\
\hline $\mathrm{E} 26 / \mathrm{S} 76$ & $26 \mathrm{~A}$ & $33 \mathrm{Z} 1 \mathrm{~A}$ & II & L. Paleo. & & Vertebrata & Indeterminate & 1 \\
\hline E26/S76 & $26 \mathrm{~A}$ & $33 \mathrm{Z} 1 \mathrm{C}$ & II & L. Paleo. & & Vertebrata & Indeterminate & 1 \\
\hline E26/S76 & $26 \mathrm{~A}$ & 33Z1D & II & L. Paleo. & & Mammalia (Medium/large) & Indeterminate & 1 \\
\hline $\mathrm{E} 26 / \mathrm{S} 76$ & $26 \mathrm{~A}$ & $33 Z 1 D$ & II & L. Paleo. & & Mammalia (Medium/large) & Long bone & 1 \\
\hline E26/S76 & 26B & $33 \mathrm{Z} 2 \mathrm{~A}$ & II & L. Paleo. & & Vertebrata & Indeterminate & 1 \\
\hline $\mathrm{E} 26 / \mathrm{S} 76$ & $26 \mathrm{~B}$ & $33 \mathrm{Z} 2 \mathrm{~B} / \mathrm{D}$ & II & L. Paleo. & & Mammalia (Medium/large) & Indeterminate & 2 \\
\hline $\mathrm{E} 26 / \mathrm{S} 76$ & 26B & $33 \mathrm{Z} 2 \mathrm{C}$ & II & L. Paleo. & & Mammalia (Medium/large) & Indeterminate & 1 \\
\hline $\mathrm{E} 26 / \mathrm{S} 76$ & 26B & $33 \mathrm{Z} 2 \mathrm{C}$ & II & L. Paleo. & & Vertebrata & Indeterminate & 5 \\
\hline E26/S76 & $26 \mathrm{~B}$ & F164 & II & L. Paleo. & f164 & Vertebrata & Indeterminate & 1 \\
\hline $\mathrm{E} 26 / \mathrm{S} 76$ & $27 \mathrm{~A}$ & 33AA1A & $\mathrm{Id} / \mathrm{II}$ & L. Paleo. & & Vertebrata & Indeterminate & 2 \\
\hline $\mathrm{E} 26 / \mathrm{S} 76$ & $27 \mathrm{~A}$ & 33AA1B & $\mathrm{Id} / \mathrm{II}$ & L. Paleo. & & Vertebrata & Indeterminate & 4 \\
\hline E26/S76 & $27 \mathrm{~A}$ & 33AA1C & Id/II & L. Paleo. & & Mammalia (Medium/large) & Indeterminate & 1 \\
\hline $\mathrm{E} 26 / \mathrm{S} 76$ & $27 \mathrm{~A}$ & $33 \mathrm{AA} 1 \mathrm{C}$ & Id/II & L. Paleo. & & Vertebrata & Indeterminate & 6 \\
\hline $\mathrm{E} 26 / \mathrm{S} 76$ & $27 \mathrm{~A}$ & 33AA1D & Id/II & L. Paleo. & & Vertebrata & Long bone & 1 \\
\hline E26/S76 & 27B & $33 \mathrm{AA} 2 \mathrm{~A}$ & Isi-c/Id/II & L. Paleo. & & Vertebrata & Indeterminate & 1 \\
\hline $\mathrm{E} 26 / \mathrm{S} 76$ & $27 \mathrm{~B}$ & $33 \mathrm{AA} 2 \mathrm{~B}$ & Isi-c/Id/II & L. Paleo. & & Vertebrata & Indeterminate & 1 \\
\hline $\mathrm{E} 26 / \mathrm{S} 76$ & 27B & $33 \mathrm{AA} 2 \mathrm{C}$ & Isi-c/Id/II & L. Paleo. & & Vertebrata & Indeterminate & 4 \\
\hline $\mathrm{E} 26 / \mathrm{S} 76$ & $27 \mathrm{~B}$ & 33AA2D & Isi-c/Id/II & L. Paleo. & & Mammalia (Medium/large) & Indeterminate & 1 \\
\hline $\mathrm{E} 26 / \mathrm{S} 76$ & 27B & 33AA2D & Isi-c/Id/II & L. Paleo. & & Vertebrata & Indeterminate & 2 \\
\hline $\mathrm{E} 26 / \mathrm{S} 76$ & $28 \mathrm{~A}$ & 33BB1C & Isi-c/Id/II & L. Paleo. & & Mammalia (Medium/large) & Indeterminate & 1 \\
\hline $\mathrm{E} 26 / \mathrm{S} 76$ & $28 \mathrm{~A}$ & $33 \mathrm{BB} 1 \mathrm{C}$ & Isi-c/Id/II & L. Paleo. & & Vertebrata & Indeterminate & 1 \\
\hline $\mathrm{E} 26 / \mathrm{S} 76$ & $28 \mathrm{~A}$ & 33BB1D & Isi-c/Id/II & L. Paleo. & & Mammalia (Medium/large) & Long bone & 3 \\
\hline $\mathrm{E} 26 / \mathrm{S} 76$ & $28 \mathrm{~A}$ & 33BB1D & Isi-c/Id/II & L. Paleo. & & Vertebrata & Indeterminate & 1 \\
\hline $\mathrm{E} 26 / \mathrm{S} 76$ & $28 \mathrm{~B}$ & $33 \mathrm{BB} 2 \mathrm{~B}$ & Isi-c/Id & L. Paleo. & & Vertebrata & Indeterminate & 4 \\
\hline $\mathrm{E} 26 / \mathrm{S} 76$ & $28 \mathrm{~B}$ & $33 \mathrm{BB} 2 \mathrm{C}$ & Isi-c/Id & L. Paleo. & & Vertebrata & Indeterminate & 5 \\
\hline $\mathrm{E} 26 / \mathrm{S} 76$ & $28 \mathrm{~B}$ & 33BB2D & Isi-c/Id & L. Paleo. & & Vertebrata & Indeterminate & 9 \\
\hline E26/S76 & $28 \mathrm{~B}$ & $33 \mathrm{BB} 2 \mathrm{D}$ & Isi-c/Id & L. Paleo. & & Vertebrata & Long bone & 1 \\
\hline $\mathrm{E} 26 / \mathrm{S} 76$ & $29 \mathrm{~A}$ & $33 \mathrm{CC} 1 \mathrm{~A}$ & Isi-c/Id & L. Paleo. & & Mammalia (Medium) & Vertebra & 1 \\
\hline $\mathrm{E} 26 / \mathrm{S} 76$ & $29 \mathrm{~A}$ & $33 \mathrm{CC} 1 \mathrm{~A}$ & Isi-c/Id & L. Paleo. & & Mammalia (Medium/large) & Long bone & 1 \\
\hline E26/S76 & $29 \mathrm{~A}$ & $33 \mathrm{CC} 1 \mathrm{~A}$ & Isi-c/Id & L. Paleo. & & Vertebrata & Indeterminate & 7 \\
\hline $\mathrm{E} 26 / \mathrm{S} 76$ & $29 \mathrm{~A}$ & $33 \mathrm{CC} 1 \mathrm{~B}$ & Isi-c/Id & L. Paleo. & & Vertebrata & Indeterminate & 4 \\
\hline $\mathrm{E} 26 / \mathrm{S} 76$ & $29 \mathrm{~A}$ & $33 \mathrm{CC} 1 \mathrm{C}$ & Isi-c/Id & L. Paleo. & & Mammalia (Medium/large) & Indeterminate & 2 \\
\hline E26/S76 & $29 \mathrm{~A}$ & $33 \mathrm{CC} 1 \mathrm{C}$ & Isi-c/Id & L. Paleo. & & Small/Medium Vertebrata & Long bone & 1 \\
\hline E26/S76 & $29 \mathrm{~A}$ & $33 \mathrm{CC} 1 \mathrm{C}$ & Isi-c/Id & L. Paleo. & & Vertebrata & Indeterminate & 13 \\
\hline $\mathrm{E} 26 / \mathrm{S} 76$ & $29 \mathrm{~A}$ & 33CC1D & Isi-c/Id & L. Paleo. & & Vertebrata & Indeterminate & 3 \\
\hline E26/S76 & $29 \mathrm{~B}$ & $33 \mathrm{CC} 2 \mathrm{~A}$ & Isi-c & L. Paleo. & & Mammalia (Large) & Long bone & 1 \\
\hline E26/S76 & $29 \mathrm{~B}$ & $33 \mathrm{CC} 2 \mathrm{~A}$ & Isi-c & L. Paleo. & & Mammalia (Medium/large) & Indeterminate & 1 \\
\hline $\mathrm{E} 26 / \mathrm{S} 76$ & $29 \mathrm{~B}$ & $33 \mathrm{CC} 2 \mathrm{~A}$ & Isi-c & L. Paleo. & & Vertebrata & Indeterminate & 13 \\
\hline E26/S76 & $29 \mathrm{~B}$ & $33 \mathrm{CC} 2 \mathrm{~B}$ & Isi-c & L. Paleo. & & Vertebrata & Indeterminate & 9 \\
\hline E26/S76 & $29 \mathrm{~B}$ & $33 \mathrm{CC} 2 \mathrm{C}$ & Isi-c & L. Paleo. & & Vertebrata & Indeterminate & 4 \\
\hline E26/S76 & $29 \mathrm{~B}$ & $33 \mathrm{CC} 2 \mathrm{D}$ & Isi-c & L. Paleo. & & Vertebrata & Indeterminate & 6 \\
\hline E26/S76 & $30 \mathrm{~A}$ & 33DD1A & Isi-c & L. Paleo. & & Mammalia (Medium/large) & Long bone & 1 \\
\hline E26/S76 & $30 \mathrm{~A}$ & 33DD1A & Isi-c & L. Paleo. & & Vertebrata & Indeterminate & 1 \\
\hline $\mathrm{E} 26 / \mathrm{S} 76$ & $30 \mathrm{~A}$ & 33DD1B & Isi-c & L. Paleo. & & Medium/Large Vertebrata & Indeterminate & 1 \\
\hline E26/S76 & $30 \mathrm{~A}$ & 33DD1B & Isi-c & L. Paleo. & & Small/Medium Vertebrata & Long bone & 2 \\
\hline E26/S76 & $30 \mathrm{~A}$ & 33DD1C & Isi-c & L. Paleo. & & Mammalia (Medium) & Vertebra & 1 \\
\hline E26/S76 & $30 \mathrm{~A}$ & 33DD1C & Isi-c & L. Paleo. & & Vertebrata & Indeterminate & 2 \\
\hline $\mathrm{E} 26 / \mathrm{S} 76$ & $30 \mathrm{~A}$ & 33DD1C & Isi-c & L. Paleo. & & Vertebrata & Long bone & 1 \\
\hline $\mathrm{E} 26 / \mathrm{S} 76$ & $30 \mathrm{~A}$ & 33DD1D & Isi-c & L. Paleo. & & Vertebrata & Indeterminate & 1 \\
\hline $\mathrm{E} 26 / \mathrm{S} 76$ & $30 \mathrm{~B}$ & 33DD2A & Isi-c & L. Paleo. & & Vertebrata & Indeterminate & 3 \\
\hline $\mathrm{E} 26 / \mathrm{S} 76$ & $30 \mathrm{~B}$ & 33DD2B & Isi-c & L. Paleo. & & Vertebrata & Indeterminate & 2 \\
\hline $\mathrm{E} 26 / \mathrm{S} 76$ & $30 \mathrm{~B}$ & $33 \mathrm{DD} 2 \mathrm{C}$ & Isi-c & L. Paleo. & & Mammalia (Medium/large) & Indeterminate & 2 \\
\hline $\mathrm{E} 26 / \mathrm{S} 76$ & $30 \mathrm{~B}$ & 33DD2D & Isi-c & L. Paleo. & & Vertebrata & Indeterminate & 4 \\
\hline $\mathrm{E} 26 / \mathrm{S} 76$ & $31 \mathrm{~A}$ & 33EE1A & Isi-c & L. Paleo. & & Medium/Large Vertebrata & Long bone & 1 \\
\hline $\mathrm{E} 26 / \mathrm{S} 76$ & $31 \mathrm{~A}$ & 33EE1B & Isi-c & L. Paleo. & & Mammalia (Medium/large) & Indeterminate & 4 \\
\hline E26/S76 & $31 \mathrm{~A}$ & 33EE1B & Isi-c & L. Paleo. & & Medium/Large Vertebrata & Indeterminate & 1 \\
\hline $\mathrm{E} 26 / \mathrm{S} 76$ & $31 \mathrm{~A}$ & 33EE1B & Isi-c & L. Paleo. & & Testudinata & Shell fragment & 1 \\
\hline $\mathrm{E} 26 / \mathrm{S} 76$ & $31 \mathrm{~A}$ & 33EE1B & Isi-c & L. Paleo. & & Vertebrata & Indeterminate & 7 \\
\hline
\end{tabular}




\begin{tabular}{|c|c|c|c|c|c|c|c|c|}
\hline Square & Level & Lot & Unit & Cultural Affinity & Feature & Taxon & Element & No. \\
\hline E26/S76 & $31 \mathrm{~A}$ & 33EE1C & Isi-c & L. Paleo. & & Antilocapra/Odocoileus & Metapodial & 1 \\
\hline E26/S76 & $31 \mathrm{~A}$ & 33EE1C & Isi-c & L. Paleo. & & Mammalia (Medium/large) & Indeterminate & 1 \\
\hline E26/S76 & $31 \mathrm{~A}$ & 33EE1C & Isi-c & L. Paleo. & & Mammalia (Medium/large) & Long bone & 4 \\
\hline E26/S76 & $31 \mathrm{~A}$ & 33EE1C & Isi-c & L. Paleo. & & Medium/Large Vertebrata & Indeterminate & 3 \\
\hline E26/S76 & $31 \mathrm{~A}$ & 33EE1C & Isi-c & L. Paleo. & & Small/Medium Vertebrata & Long bone & 2 \\
\hline E26/S76 & $31 \mathrm{~A}$ & 33EE1C & Isi-c & L. Paleo. & & Vertebrata & Indeterminate & 12 \\
\hline E26/S76 & 31B & 33EE2A & Isi-c & L. Paleo. & & Medium/Large Vertebrata & Indeterminate & 1 \\
\hline E26/S76 & $31 \mathrm{~B}$ & 33EE2A & Isi-c & L. Paleo. & & Medium/Large Vertebrata & Long bone & 1 \\
\hline E26/S76 & $31 \mathrm{~B}$ & 33EE2A & Isi-c & L. Paleo. & & Small/Medium Vertebrata & Long bone & 14 \\
\hline $\mathrm{E} 26 / \mathrm{S} 76$ & $31 \mathrm{~B}$ & 33EE2A & Isi-c & L. Paleo. & & Sylvilagus sp. & Calcaneus & 1 \\
\hline E26/S76 & $31 \mathrm{~B}$ & 33EE2A & Isi-c & L. Paleo. & & Vertebrata & Indeterminate & 3 \\
\hline E26/S76 & $31 \mathrm{~B}$ & 33EE2C & Isi-c & L. Paleo. & & Mammalia (Medium/large) & Indeterminate & 1 \\
\hline E26/S76 & $31 \mathrm{~B}$ & 33EE2C & Isi-c & L. Paleo. & & Small/Medium Vertebrata & Long bone & 2 \\
\hline E26/S76 & $31 \mathrm{~B}$ & 33EE2C & Isi-c & L. Paleo. & & Vertebrata & Indeterminate & 6 \\
\hline E26/S76 & $31 \mathrm{~B}$ & 33EE2D & Isi-c & L. Paleo. & & Medium/Large Vertebrata & Long bone & 1 \\
\hline E26/S76 & $31 \mathrm{~B}$ & 33EE2D & Isi-c & L. Paleo. & & Vertebrata & Indeterminate & 1 \\
\hline E26/S76 & $32 \mathrm{~A}$ & 33FF1A & Isi-c & L. Paleo. & & Mammalia (Medium/large) & Long bone & 2 \\
\hline E26/S76 & $32 \mathrm{~A}$ & $33 \mathrm{FF} 1 \mathrm{~A}$ & Isi-c & L. Paleo. & & Medium/Large Vertebrata & Indeterminate & 1 \\
\hline E26/S76 & $32 \mathrm{~A}$ & 33FF1B & Isi-c & L. Paleo. & & Vertebrata & Indeterminate & 6 \\
\hline E26/S76 & $32 \mathrm{~A}$ & $33 \mathrm{FF} 1 \mathrm{C}$ & Isi-c & L. Paleo. & & Medium/Large Vertebrata & Indeterminate & 1 \\
\hline E26/S76 & $32 \mathrm{~A}$ & $33 \mathrm{FF} 1 \mathrm{C}$ & Isi-c & L. Paleo. & & Small/Medium Vertebrata & Long bone & 4 \\
\hline E26/S76 & $32 \mathrm{~A}$ & $33 \mathrm{FF} 1 \mathrm{C}$ & Isi-c & L. Paleo. & & Vertebrata & Indeterminate & 3 \\
\hline E26/S76 & $32 \mathrm{~A}$ & 33FF1D & Isi-c & L. Paleo. & & Mammalia (Medium/large) & Tooth, perm./decid. ind. & 1 \\
\hline E26/S76 & $32 \mathrm{~A}$ & 33FF1D & Isi-c & L. Paleo. & & Medium/Large Vertebrata & Indeterminate & 2 \\
\hline E26/S76 & $32 \mathrm{~A}$ & $33 \mathrm{FF} 1 \mathrm{D}$ & Isi-c & L. Paleo. & & Small/Medium Vertebrata & Long bone & 4 \\
\hline E26/S76 & $32 \mathrm{~A}$ & 33FF1D & Isi-c & L. Paleo. & & Vertebrata & Indeterminate & 7 \\
\hline E26/S76 & $33 \mathrm{~A}$ & 33GG1A & Icl/Isi-c & Paleoindian & & Mammalia (Medium/large) & Indeterminate & 1 \\
\hline E26/S76 & $33 \mathrm{~A}$ & 33GG1A & Icl/Isi-c & Paleoindian & & Small/Medium Vertebrata & Long bone & 1 \\
\hline E26/S76 & $33 \mathrm{~A}$ & 33GG1B & Icl/Isi-c & Paleoindian & & Vertebrata & Indeterminate & 6 \\
\hline E26/S76 & $33 \mathrm{~A}$ & $33 \mathrm{GG} 1 \mathrm{C}$ & Icl/Isi-c & Paleoindian & & Medium/Large Vertebrata & Indeterminate & 1 \\
\hline E26/S76 & $33 \mathrm{~A}$ & 33GG1D & Icl/Isi-c & Paleoindian & & Mammalia (Medium/large) & Indeterminate & 2 \\
\hline $\mathrm{E} 26 / \mathrm{S} 76$ & $33 \mathrm{~B}$ & $33 \mathrm{GG} 2 \mathrm{~A}$ & Icl/Isi-c & Paleoindian & & Small/Medium Vertebrata & Long bone & 1 \\
\hline $\mathrm{E} 26 / \mathrm{S} 76$ & $33 \mathrm{~B}$ & 33GG2B & Icl/Isi-c & Paleoindian & & Vertebrata & Indeterminate & 2 \\
\hline E26/S76 & $33 \mathrm{~B}$ & $33 \mathrm{GG} 2 \mathrm{C}$ & Icl/Isi-c & Paleoindian & & Mammalia (Medium/large) & Indeterminate & 1 \\
\hline E26/S76 & $34 \mathrm{~A}$ & 33HН1B & Icl/Isi-c & Paleoindian & & Mammalia (Medium/large) & Indeterminate & 3 \\
\hline $\mathrm{E} 26 / \mathrm{S} 76$ & $34 \mathrm{~A}$ & 33НН1В & Icl/Isi-c & Paleoindian & & Mammalia (Medium/large) & Long bone & 1 \\
\hline E26/S76 & $34 \mathrm{~A}$ & $33 \mathrm{HH} 1 \mathrm{~B}$ & Icl/Isi-c & Paleoindian & & Vertebrata & Indeterminate & 6 \\
\hline $\mathrm{E} 26 / \mathrm{S} 76$ & $34 \mathrm{~A}$ & $33 \mathrm{HH} 1 \mathrm{C}$ & Icl/Isi-c & Paleoindian & & Small/Medium Vertebrata & Long bone & 5 \\
\hline E26/S76 & $34 \mathrm{~A}$ & $33 \mathrm{HH} 1 \mathrm{C}$ & Icl/Isi-c & Paleoindian & & Vertebrata & Indeterminate & 1 \\
\hline $\mathrm{E} 26 / \mathrm{S} 76$ & $34 \mathrm{~A}$ & 33HH1D & Icl/Isi-c & Paleoindian & & Mammalia (Medium/large) & Long bone & 1 \\
\hline $\mathrm{E} 26 / \mathrm{S} 76$ & $34 \mathrm{~A}$ & 33HH1D & Icl/Isi-c & Paleoindian & & Vertebrata & Indeterminate & 2 \\
\hline $\mathrm{E} 26 / \mathrm{S} 76$ & $34 \mathrm{~B}$ & $33 \mathrm{HH} 2 \mathrm{~A}$ & Icl & E. Paleo. & & Small/Medium Vertebrata & Long bone & 3 \\
\hline $\mathrm{E} 26 / \mathrm{S} 76$ & $35 \mathrm{~A}$ & 33II1A & Icl & E. Paleo. & & Vertebrata & Indeterminate & 1 \\
\hline E26/S76 & $35 \mathrm{~A}$ & 33IIID & Icl & E. Paleo. & & Vertebrata & Indeterminate & 19 \\
\hline E26/S76 & $35 \mathrm{~B}$ & $33 \Pi 12 \mathrm{C}$ & Icl & E. Paleo. & & Mammalia (Medium/large) & Indeterminate & 1 \\
\hline E26/S76 & $35 \mathrm{~B}$ & 33II $2 \mathrm{D}$ & Icl & E. Paleo. & & Vertebrata & Indeterminate & 2 \\
\hline E26/S76 & $36 \mathrm{~A}$ & 33JJ1A & Icl & E. Paleo. & & Mammalia (Medium/large) & Long bone & 1 \\
\hline E26/S76 & $36 \mathrm{~A}$ & 33JJ1A & Icl & E. Paleo. & & Vertebrata & Indeterminate & 2 \\
\hline $\mathrm{E} 26 / \mathrm{S} 76$ & $36 \mathrm{~A}$ & 33JJ1C & Icl & E. Paleo. & & Vertebrata & Indeterminate & 1 \\
\hline E26/S76 & $36 \mathrm{~A}$ & 33JJ1C & Icl & E. Paleo. & & Vertebrata & Long bone & 1 \\
\hline E26/S76 & $36 \mathrm{~A}$ & 33JJ1D & Icl/D & E. Paleo. & & Mammalia (Medium/large) & Indeterminate & 1 \\
\hline E26/S76 & $36 \mathrm{~A}$ & 33JJ1D & Icl/D & E. Paleo. & & Vertebrata & Indeterminate & 1 \\
\hline E26/S76 & $36 \mathrm{~B}$ & $33 \mathrm{JJ} 2 \mathrm{~A}$ & Icl & E. Paleo. & & Vertebrata & Indeterminate & 6 \\
\hline E26/S76 & $36 \mathrm{~B}$ & $33 \mathrm{JJ} 2 \mathrm{C}$ & Icl & E. Paleo. & & Vertebrata & Indeterminate & 1 \\
\hline E26/S76 & $36 \mathrm{~B}$ & 33JJ2D & $\mathrm{Icl} / \mathrm{D}$ & E. Paleo. & & Vertebrata & Indeterminate & 3 \\
\hline E26/S76 & $37 \mathrm{~A}$ & $33 \mathrm{KK} 1 \mathrm{~B}$ & Icl & E. Paleo. & & Vertebrata & Indeterminate & 4 \\
\hline E26/S76 & $37 \mathrm{~A}$ & 33KK1D & $\mathrm{Icl} / \mathrm{D}$ & E. Paleo. & & Vertebrata & Indeterminate & 8 \\
\hline E26/S76 & $37 \mathrm{~A}-38 \mathrm{~A}$ & $33 \mathrm{KK} 1 \mathrm{LL}$ & $\mathrm{Icl} / \mathrm{D}$ & E. Paleo. & f175 & Vertebrata & Indeterminate & 6 \\
\hline E26/S76 & $37 \mathrm{~B}$ & $33 \mathrm{KK} 2 \mathrm{~A}$ & Icl & E. Paleo. & & Vertebrata & Indeterminate & 1 \\
\hline $\mathrm{E} 26 / \mathrm{S} 76$ & $37 \mathrm{~B}$ & $33 \mathrm{KK} 2 \mathrm{~B}$ & Icl & E. Paleo. & & Vertebrata & Indeterminate & 1 \\
\hline E26/S76 & $37 \mathrm{~B}$ & $33 \mathrm{KK} 2 \mathrm{C}$ & Icl & E. Paleo. & & Vertebrata & Indeterminate & 3 \\
\hline E26/S76 & $37 \mathrm{~B}$ & 33KK2D & Icl/D & E. Paleo. & & Vertebrata & Indeterminate & 2 \\
\hline E26/S76 & $38 \mathrm{~A}$ & 33LL1A & Isi/Icl & E. Paleo. & & Medium/Large Vertebrata & Indeterminate & 1 \\
\hline E26/S76 & $38 \mathrm{~A}$ & 33LL1B & Isi/Icl & E. Paleo. & & Medium/Large Vertebrata & Indeterminate & 4 \\
\hline E26/S76 & $38 \mathrm{~A}$ & 33LL1B & Isi/Icl & E. Paleo. & & Odocoileus sp. & Phalange & 1 \\
\hline E26/S76 & $38 \mathrm{~A}$ & 33LL1B & Isi/Icl & E. Paleo. & & Vertebrata & Indeterminate & 1 \\
\hline E26/S76 & $38 \mathrm{~A}$ & $33 \mathrm{LL1C}$ & Isi/Icl & E. Paleo. & & Medium/Large Vertebrata & Indeterminate & 1 \\
\hline
\end{tabular}




\begin{tabular}{|c|c|c|c|c|c|c|c|c|c|}
\hline Square & Level & Lot & Unit & Cultural Affinity & Feature & Taxon & Element & & No. \\
\hline E26/S76 & $38 \mathrm{~A}$ & $33 \mathrm{LL1C}$ & Isi/Icl & E. Paleo. & & Vertebrata & Indeterminate & & 1 \\
\hline E26/S76 & $38 \mathrm{~A}$ & 33LL1D & Isi/Icl & E. Paleo. & & Vertebrata & Indeterminate & & 19 \\
\hline E26/S76 & $38 \mathrm{~B}$ & 33LL2A & Isi/Icl & E. Paleo. & & Medium/Large Vertebrata & Indeterminate & & 1 \\
\hline E26/S76 & $38 \mathrm{~B}$ & 33LL2A & Isi/Icl & E. Paleo. & & Vertebrata & Indeterminate & & 3 \\
\hline E26/S76 & $38 \mathrm{~B}$ & 33LL2B & Isi/Icl & E. Paleo. & & Medium/Large Vertebrata & Indeterminate & & 1 \\
\hline E26/S76 & $38 \mathrm{~B}$ & 33LL2B & Isi/Icl & E. Paleo. & & Vertebrata & Indeterminate & & 3 \\
\hline E26/S76 & $38 \mathrm{~B}$ & 33LL2D & Isi/Icl & E. Paleo. & & Vertebrata & Indeterminate & & 5 \\
\hline E26/S76 & $39 \mathrm{~A}$ & 33MM1B & Isi/Icl & E. Paleo. & & Vertebrata & Indeterminate & & 7 \\
\hline E26/S76 & $39 \mathrm{~A}$ & $33 \mathrm{MM} 1 \mathrm{C}$ & Isi/Icl & E. Paleo. & & Vertebrata & Indeterminate & & 1 \\
\hline E26/S76 & $39 \mathrm{~A}$ & 33MM1D & Isi/Icl & E. Paleo. & & Medium/Large Vertebrata & Indeterminate & : & 3 \\
\hline E26/S76 & $39 \mathrm{~A}$ & 33MM1D & Isi/Icl & E. Paleo. & & Vertebrata & Indeterminate & & 12 \\
\hline E26/S76 & $39 \mathrm{~A}$ & $\mathrm{~F} 175$ & $\mathrm{IcI} / \mathrm{Isi}$ & Paleoindian & f175 & Vertebrata & Indeterminate & & 14 \\
\hline E26/S76 & 39B & $33 \mathrm{MM} 2 \mathrm{~A}$ & Isi/Icl & E. Paleo. & & Large vertebrate, class ind. & Indeterminate & & 3 \\
\hline E26/S76 & 39B & $33 \mathrm{MM} 2 \mathrm{~A}$ & Isi/Icl & E. Paleo. & & Vertebrata & Indeterminate & & 10 \\
\hline E26/S76 & 39B & 33MM2B & Isi/Icl & E. Paleo. & & Medium/Large Vertebrata & Indeterminate & & 4 \\
\hline E26/S76 & 39B & 33MM2B & Isi/Icl & E. Paleo. & & Vertebrata & Indeterminate & & 4 \\
\hline E26/S76 & 39B & $33 \mathrm{MM} 2 \mathrm{C}$ & Isi/Icl & E. Paleo. & & Mammalia (Medium/large) & Indeterminate & & 1 \\
\hline $\mathrm{E} 26 / \mathrm{S} 76$ & 39B & 33MM2C & Isi/Icl & E. Paleo. & & Vertebrata & Indeterminate & & 20 \\
\hline E26/S76 & 39B & 33MM2D & Isi/Icl & E. Paleo. & & Large vertebrate, class ind. & Indeterminate & & 1 \\
\hline E26/S76 & 39B & 33MM2D & Isi/Icl & E. Paleo. & & Mammalia (Medium/large) & Indeterminate & & 1 \\
\hline E26/S76 & 39B & 33MM2D & Isi/Icl & E. Paleo. & & Vertebrata & Indeterminate & & 3 \\
\hline $\mathrm{E} 26 / \mathrm{S} 76$ & $40 \mathrm{~A}$ & $33 \mathrm{NN} 1 \mathrm{~A}$ & Isi/Icl & E. Paleo. & & Vertebrata & Indeterminate & & 13 \\
\hline E26/S76 & $40 \mathrm{~A}$ & $33 N N 1 B$ & Isi/Icl & E. Paleo. & & Mammalia (Medium/large) & Indeterminate & & 12 \\
\hline $\mathrm{E} 26 / \mathrm{S} 76$ & $40 \mathrm{~A}$ & 33NN1B & Isi/Icl & E. Paleo. & & Medium/Large Vertebrata & Indeterminate & & 3 \\
\hline E26/S76 & $40 \mathrm{~A}$ & 33NN1B & Isi/Icl & E. Paleo. & & Vertebrata & Indeterminate & & 7 \\
\hline E26/S76 & $40 \mathrm{~A}$ & $33 \mathrm{NN} 1 \mathrm{C}$ & Isi/Icl & E. Paleo. & & Medium/Large Vertebrata & Indeterminate & & 1 \\
\hline $\mathrm{E} 26 / \mathrm{S} 76$ & $40 \mathrm{~A}$ & 33NN1D & Isi/Icl & E. Paleo. & & Mammalia (Large) & Indeterminate & & 8 \\
\hline E26/S76 & $40 \mathrm{~A}$ & 33NN1D & Isi/Icl & E. Paleo. & & Mammalia (Medium/large) & Indeterminate & & 2 \\
\hline E26/S76 & $40 \mathrm{~A}$ & 33NN1D & Isi//Icl & E. Paleo. & & Medium/Large Vertebrata & Indeterminate & & 10 \\
\hline $\mathrm{E} 26 / \mathrm{S} 76$ & $40 \mathrm{~A}$ & 33NN1D & Isi/Icl & E. Paleo. & & Vertebrata & Indeterminate & & 44 \\
\hline E26/S76 & $40 \mathrm{~B}$ & $33 \mathrm{NN} 2 \mathrm{~A}$ & Isi/Icl & E. Paleo. & & Leporidae & Calcaneus & & 1 \\
\hline $\mathrm{E} 26 / \mathrm{S} 76$ & $40 \mathrm{~B}$ & $33 \mathrm{NN} 2 \mathrm{~A}$ & Isi/Icl & E. Paleo. & & Medium/Large Vertebrata & Indeterminate & & 3 \\
\hline E26/S76 & $40 \mathrm{~B}$ & $33 \mathrm{NN} 2 \mathrm{~A}$ & Isi/Icl & E. Paleo. & & Vertebrata & Indeterminate & & 8 \\
\hline $\mathrm{E} 26 / \mathrm{S} 76$ & $40 \mathrm{~B}$ & $33 \mathrm{NN} 2 \mathrm{~B}$ & Isi/Icl & E. Paleo. & & Mammalia (Medium/large) & Indeterminate & & 2 \\
\hline E26/S76 & 40B & $33 \mathrm{NN} 2 \mathrm{~B}$ & Isi/Icl & E. Paleo. & & Medium/Large Vertebrata & Indeterminate & & 4 \\
\hline E26/S76 & $40 \mathrm{~B}$ & $33 \mathrm{NN} 2 \mathrm{~B}$ & Isi/Icl & E. Paleo. & & Vertebrata & Indeterminate & & 8 \\
\hline E26/S76 & $40 \mathrm{~B}$ & $33 \mathrm{NN} 2 \mathrm{C}$ & Isi/Icl & E. Paleo. & & Large vertebrate, class ind. & Indeterminate & & 1 \\
\hline $\mathrm{E} 26 / \mathrm{S} 76$ & $40 \mathrm{~B}$ & $33 \mathrm{NN} 2 \mathrm{C}$ & Isi/Icl & E. Paleo. & & Medium/Large Vertebrata & Indeterminate & & 1 \\
\hline E26/S76 & $40 \mathrm{~B}$ & $33 \mathrm{NN} 2 \mathrm{D}$ & Isi/Icl & E. Paleo. & & Mammalia (Medium/large) & Indeterminate & & 1 \\
\hline $\mathrm{E} 26 / \mathrm{S} 76$ & $40 \mathrm{~B}$ & 33NN2D & Isi/Icl & E. Paleo. & & Vertebrata & Indeterminate & & 1 \\
\hline E26/S76 & 41 & 3300 & Isi/Icl & E. Paleo. & & Mammalia (Very large) & Indeterminate & & 2 \\
\hline $\mathrm{E} 26 / \mathrm{S} 76$ & $41 \mathrm{~A}$ & $33001 \mathrm{~A}$ & Isi/Icl & E. Paleo. & & Vertebrata & Indeterminate & & 15 \\
\hline $\mathrm{E} 26 / \mathrm{S} 76$ & $41 \mathrm{~A}$ & $33001 B$ & Isi/Icl & E. Paleo. & & Vertebrata & Indeterminate & & 14 \\
\hline E26/S76 & $41 \mathrm{~A}$ & $33 \mathrm{OO} 1 \mathrm{C}$ & Isi/Icl & E. Paleo. & & Vertebrata & Indeterminate & & 10 \\
\hline $\mathrm{E} 26 / \mathrm{S} 76$ & $41 B$ & $33 \mathrm{OO} 2 \mathrm{~A}$ & Isi/Icl & E. Paleo. & & Vertebrata & Indeterminate & & 2 \\
\hline $\mathrm{E} 26 / \mathrm{S} 76$ & $41 B$ & $33 \mathrm{OO} 2 \mathrm{C}$ & Isi/Icl & E. Paleo. & & Mammalia (Medium/large) & Indeterminate & & 1 \\
\hline E26/S76 & $41 B$ & $33 \mathrm{OO} 2 \mathrm{C}$ & Isi/Icl & E. Paleo. & & Vertebrata & Indeterminate & & 6 \\
\hline E26/S76 & $42 \mathrm{~A}$ & 33PP1A & $\operatorname{Igl} / \mathrm{Isi} / \mathrm{Icl}$ & E. Paleo. & & Mammalia (Medium/large) & Indeterminate & & 1 \\
\hline E26/S76 & $42 \mathrm{~A}$ & 33PP1A & $\mathrm{Igl} / \mathrm{Isi} / \mathrm{Icl}$ & E. Paleo. & & Vertebrata & Indeterminate & & 8 \\
\hline $\mathrm{E} 26 / \mathrm{S} 78$ & 15 & 320 & IIIa/b & E. Archaic & & Mammalia (Large) & Long bone & & 1 \\
\hline $\mathrm{E} 26 / \mathrm{S} 78$ & 15 & 320 & $\mathrm{III} / \mathrm{b}$ & E. Archaic & & Mammalia (Medium/large) & Indeterminate & & 1 \\
\hline E26/S78 & 15 & 320 & IIIa/b & E. Archaic & & Mammalia (Medium/large) & Long bone & & 2 \\
\hline $\mathrm{E} 26 / \mathrm{S} 78$ & 15 & 320 & $\mathrm{IIa} / \mathrm{b}$ & E. Archaic & & Medium/Large Vertebrata & Indeterminate & & 2 \\
\hline $\mathrm{E} 26 / \mathrm{S} 78$ & 15 & 320 & $\mathrm{mia} / \mathrm{b}$ & E. Archaic & & Vertebrata & Indeterminate & & 3 \\
\hline E26/S78 & $16 \mathrm{~A}$ & 32P1 & IIIa & E. Archaic & F124 & Mammalia (Medium/large) & Long bone & & 1 \\
\hline $\mathrm{E} 26 / \mathrm{S} 78$ & $16 \mathrm{~A}$ & 32P1 & IIIa & E. Archaic & F124 & Vertebrata & Indeterminate & & 3 \\
\hline $\mathrm{E} 26 / \mathrm{S} 78$ & 16B & $32 \mathrm{P} 2$ & IIIa & E. Archaic & $\mathrm{F} 124$ & Mammalia (Medium/large) & Indeterminate & & 5 \\
\hline $\mathrm{E} 26 / \mathrm{S} 78$ & 16B & $32 \mathrm{P} 2$ & IIIa & E. Archaic & $\mathrm{F} 124$ & Mammalia (Medium/large) & Long bone & & 1 \\
\hline $\mathrm{E} 26 / \mathrm{S} 78$ & 16B & $32 \mathrm{P} 2$ & IIIa & E. Archaic & $\mathrm{F} 124$ & Medium/Large Vertebrata & Indeterminate & & 2 \\
\hline $\mathrm{E} 26 / \mathrm{S} 78$ & $16 \mathrm{~B}$ & $32 \mathrm{P} 2$ & IIIa & E. Archaic & $\mathrm{F} 124$ & Small/Medium Vertebrata & Long bone & & 1 \\
\hline $\mathrm{E} 26 / \mathrm{S} 78$ & $16 \mathrm{~B}$ & $32 \mathrm{P} 2$ & IIIa & E. Archaic & F124 & Testudinata & Shell fragment & & 1 \\
\hline $\mathrm{E} 26 / \mathrm{S} 78$ & $16 \mathrm{~B}$ & $32 \mathrm{P} 2$ & IIIa & E. Archaic & F124 & Vertebrata & Indeterminate & & 11 \\
\hline $\mathrm{E} 26 / \mathrm{S} 78$ & $17 \mathrm{~A}$ & $32 \mathrm{Q} 1$ & IIIa & E. Archaic & & Mammalia (Medium/large) & Indeterminate & & 1 \\
\hline $\mathrm{E} 26 / \mathrm{S} 78$ & $17 \mathrm{~A}$ & $32 \mathrm{Q} 1$ & IIIa & E. Archaic & & Sylvilagus sp. & Humerus & & 1 \\
\hline $\mathrm{E} 26 / \mathrm{S} 78$ & $17 \mathrm{~A}$ & $32 \mathrm{Q} 1$ & IIIa & E. Archaic & & Vertebrata & Indeterminate & & 3 \\
\hline $\mathrm{E} 26 / \mathrm{S} 78$ & 17B & $32 \mathrm{Q} 2$ & IIIa & E. Archaic & & Vertebrata & Indeterminate & & 6 \\
\hline $\mathrm{E} 26 / \mathrm{S} 78$ & $18 \mathrm{~A}$ & $32 \mathrm{R} 1$ & IIIa & E. Archaic & & Mammalia (Medium/large) & Indeterminate & & 1 \\
\hline
\end{tabular}




\begin{tabular}{|c|c|c|c|c|c|c|c|c|}
\hline Square & Level & Lot & Unit & Cultural Affinity & Feature & Taxon & Element & No. \\
\hline E26/S78 & $18 \mathrm{~A}$ & $32 \mathrm{R} 1$ & $\overline{\mathrm{IIIa}}$ & E. Archaic & & Vertebrata & Indeterminate & 7 \\
\hline $\mathrm{E} 26 / \mathrm{S} 78$ & 18B & $32 \mathrm{R} 2$ & IIIIa & E. Archaic & & Mammalia (Medium) & Proximal phalange & 1 \\
\hline $\mathrm{E} 26 / \mathrm{S} 78$ & $18 \mathrm{~B}$ & $32 \mathrm{R} 2$ & IIIIa & E. Archaic & & Testudinata & Shell fragment & 1 \\
\hline $\mathrm{E} 26 / \mathrm{S} 78$ & 18B & $32 \mathrm{R} 2$ & IIIIa & E. Archaic & & Vertebrata & Indeterminate & 3 \\
\hline $\mathrm{E} 26 / \mathrm{S} 78$ & 18B & $32 \mathrm{R} 2$ & IIIa & E. Archaic & & Vertebrata & Long bone & 1 \\
\hline $\mathrm{E} 26 / \mathrm{S} 78$ & $19 \mathrm{~A}$ & $32 \mathrm{~S} 1$ & II/IIIa & L. Paleo./E. Archaic & & Antilocapra/Odocoileus & Tibia & 1 \\
\hline $\mathrm{E} 26 / \mathrm{S} 78$ & $19 \mathrm{~A}$ & $32 \mathrm{~S} 1$ & II/IIIa & L. Paleo./E. Archaic & & Mammalia (Large) & Long bone & 1 \\
\hline $\mathrm{E} 26 / \mathrm{S} 78$ & $19 \mathrm{~A}$ & $32 \mathrm{~S} 1$ & II/IIIa & L. Paleo./E. Archaic & & Mammalia (Medium/large) & Indeterminate & 4 \\
\hline $\mathrm{E} 26 / \mathrm{S} 78$ & $19 \mathrm{~A}$ & $32 \mathrm{~S} 1$ & II/IIIa & L. Paleo./E. Archaic & & Mammalia (Medium/large) & Long bone & 2 \\
\hline $\mathrm{E} 26 / \mathrm{S} 78$ & $19 \mathrm{~A}$ & $32 \mathrm{~S} 1$ & II/IIIa & L. Paleo./E. Archaic & & Small/Medium Vertebrata & Long bone & 1 \\
\hline $\mathrm{E} 26 / \mathrm{S} 78$ & $19 \mathrm{~A}$ & $32 \mathrm{~S} 1$ & II/IIIa & L. Paleo./E. Archaic & & Vertebrata & Indeterminate & 26 \\
\hline $\mathrm{E} 26 / \mathrm{S} 78$ & 19B & $32 \mathrm{~S} 2 \mathrm{~A}$ & II/IIIa & L. Paleo./E. Archaic & & Vertebrata & Indeterminate & 1 \\
\hline $\mathrm{E} 26 / \mathrm{S} 78$ & 19B & $32 \mathrm{~S} 2 \mathrm{~B}$ & II/IIIa & L. Paleo./E. Archaic & & Vertebrata & Indeterminate & 4 \\
\hline $\mathrm{E} 26 / \mathrm{S} 78$ & 19B & $32 \mathrm{~S} 2 \mathrm{C}$ & II/IIIa & L. Paleo./E. Archaic & & Vertebrata & Indeterminate & 2 \\
\hline $\mathrm{E} 26 / \mathrm{S} 78$ & $20 \mathrm{~A}$ & $32 \mathrm{~T} 1 \mathrm{~A}$ & III & L. Paleo. & & Mammalia (Medium/large) & Indeterminate & 2 \\
\hline $\mathrm{E} 26 / \mathrm{S} 78$ & $20 \mathrm{~A}$ & $32 \mathrm{~T} 1 \mathrm{~B}$ & III & L. Paleo. & & Small/Medium Vertebrata & Long bone & 1 \\
\hline $\mathrm{E} 26 / \mathrm{S} 78$ & $20 \mathrm{~A}$ & $32 \mathrm{~T} 1 \mathrm{D}$ & III & L. Paleo. & & Artiodactyla (Medium) & Tooth, perm./decid. ind. & 1 \\
\hline $\mathrm{E} 26 / \mathrm{S} 78$ & $20 \mathrm{~A}$ & $32 \mathrm{~T} 1 \mathrm{D}$ & III & L. Paleo. & & Small/Medium Vertebrata & Long bone & 2 \\
\hline $\mathrm{E} 26 / \mathrm{S} 78$ & $20 \mathrm{~A}$ & 32T1D & III & L. Paleo. & & Vertebrata & Indeterminate & 2 \\
\hline E26/S78 & $20 \mathrm{~B}$ & $32 \mathrm{~T} 2 \mathrm{~A}$ & III & L. Paleo. & & Mammalia (Medium/large) & Indeterminate & 2 \\
\hline E26/S78 & 20B & $32 \mathrm{~T} 2 \mathrm{~A}$ & III & L. Paleo. & & Vertebrata & Indeterminate & 1 \\
\hline E26/S78 & $20 \mathrm{~B}$ & $32 \mathrm{~T} 2 \mathrm{~B}$ & III & L. Paleo. & & Mammalia (Medium/large) & Indeterminate & 1 \\
\hline E26/S78 & $20 \mathrm{~B}$ & $32 \mathrm{~T} 2 \mathrm{~B}$ & III & L. Paleo. & & Mammalia (Medium/large) & Long bone & 2 \\
\hline E26/S78 & 20B & $32 \mathrm{~T} 2 \mathrm{~B}$ & III & L. Paleo. & & Medium/Large Vertebrata & Indeterminate & 2 \\
\hline E26/S78 & $20 \mathrm{~B}$ & $32 \mathrm{~T} 2 \mathrm{C}$ & III & L. Paleo. & & Sylvilagus sp. & Astragalus & 1 \\
\hline E26/S78 & $20 \mathrm{~B}$ & $32 \mathrm{~T} 2 \mathrm{C}$ & III & L. Paleo. & & Vertebrata & Indeterminate & 2 \\
\hline E26/S78 & 20B & $32 \mathrm{~T} 2 \mathrm{D}$ & III & L. Paleo. & & Medium/Large Vertebrata & Indeterminate & 4 \\
\hline E26/S78 & $20 \mathrm{~B}$ & $32 \mathrm{~T} 2 \mathrm{D}$ & III & L. Paleo. & & Vertebrata & Indeterminate & 6 \\
\hline E26/S78 & $21 \mathrm{~A}$ & $32 \mathrm{U} 1 \mathrm{~B}$ & III & L. Paleo. & & Vertebrata & Indeterminate & 1 \\
\hline E26/S78 & $21 \mathrm{~A}$ & $32 \mathrm{U} 1 \mathrm{C}$ & II & L. Paleo. & & Mammalia (Medium/large) & Indeterminate & 1 \\
\hline E26/S78 & $21 \mathrm{~A}$ & $32 \mathrm{U} 1 \mathrm{C}$ & III & L. Paleo. & & Mammalia (Medium/large) & Tooth, perm./decid. ind. & 1 \\
\hline E26/S78 & $21 \mathrm{~A}$ & $32 \mathrm{U} 1 \mathrm{C}$ & III & L. Paleo. & & Vertebrata & Indeterminate & 3 \\
\hline E26/S78 & $21 \mathrm{~A}$ & $32 \mathrm{U} 1 \mathrm{D}$ & III & L. Paleo. & & Small/Medium Vertebrata & |Long bone & 3 \\
\hline E26/S78 & $21 \mathrm{~B}$ & $32 \mathrm{U} 2 \mathrm{~A}$ & III & L. Paleo. & & Mammalia (Medium/large) & Indeterminate & 3 \\
\hline E26/S78 & $21 \mathrm{~B}$ & $32 \mathrm{U} 2 \mathrm{~A}$ & III & L. Paleo. & & Small/Medium Vertebrata & Long bone & 1 \\
\hline E26/S78 & 21B & $32 \mathrm{U} 2 \mathrm{~A}$ & III & L. Paleo. & & Vertebrata & Indeterminate & 9 \\
\hline E26/S78 & $21 \mathrm{~B}$ & $32 \mathrm{U} 2 \mathrm{~B}$ & III & L. Paleo. & & Mammalia (Medium/large) & Long bone & 1 \\
\hline E26/S78 & 21B & $32 \mathrm{U} 2 \mathrm{~B}$ & III & L. Paleo. & & Vertebrata & Indeterminate & 1 \\
\hline E26/S78 & $21 \mathrm{~B}$ & $32 \mathrm{U} 2 \mathrm{C}$ & III & L. Paleo. & & Mammalia (Medium/large) & Indeterminate & 1 \\
\hline E26/S78 & $21 \mathrm{~B}$ & $32 \mathrm{U} 2 \mathrm{C}$ & III & L. Paleo. & & Medium/Large Vertebrata & Long bone & 1 \\
\hline E26/S78 & $21 \mathrm{~B}$ & $32 \mathrm{U} 2 \mathrm{D}$ & III & L. Paleo. & & Medium/Large Vertebrata & Indeterminate & 2 \\
\hline E26/S78 & $21 \mathrm{~B}$ & $32 \mathrm{U} 2 \mathrm{D}$ & III & L. Paleo. & & Vertebrata & Indeterminate & 2 \\
\hline E26/S78 & $22 \mathrm{~A}$ & $32 \mathrm{~V} 1 \mathrm{~A}$ & III & L. Paleo. & & Mammalia (Small) & Tooth, perm./decid. ind. & 1 \\
\hline E26/S78 & $22 \mathrm{~A}$ & $32 \mathrm{~V} 1 \mathrm{~A}$ & III & L. Paleo. & & Medium/Large Vertebrata & Indeterminate & 2 \\
\hline E26/S78 & $22 \mathrm{~A}$ & $32 \mathrm{~V} 1 \mathrm{~A}$ & III & L. Paleo. & & Small/Medium Vertebrata & Long bone & 3 \\
\hline E26/S78 & $22 \mathrm{~A}$ & $32 \mathrm{~V} 1 \mathrm{~A}$ & III & L. Paleo. & & Vertebrata & Indeterminate & 1 \\
\hline E26/S78 & $22 \mathrm{~A}$ & $32 \mathrm{~V} 1 \mathrm{~B}$ & III & L. Paleo. & & Mammalia (Medium) & Middle phalange & 1 \\
\hline E26/S78 & $22 \mathrm{~A}$ & $32 \mathrm{~V} 1 \mathrm{~B}$ & III & L. Paleo. & & Mammalia (Medium/large) & Indeterminate & 1 \\
\hline E26/S78 & $22 \mathrm{~A}$ & $32 \mathrm{~V} 1 \mathrm{~B}$ & III & L. Paleo. & & Mammalia (Medium/large) & Long bone & 2 \\
\hline E26/S78 & $22 \mathrm{~A}$ & $32 \mathrm{~V} 1 \mathrm{~B}$ & III & L. Paleo. & & Small/Medium Vertebrata & Long bone & 1 \\
\hline $\mathrm{E} 26 / \mathrm{S} 78$ & $22 \mathrm{~A}$ & $32 \mathrm{~V} 1 \mathrm{~B}$ & III & L. Paleo. & & Vertebrata & Indeterminate & 8 \\
\hline $\mathrm{E} 26 / \mathrm{S} 78$ & $22 \mathrm{~A}$ & $32 \mathrm{~V} 1 \mathrm{C}$ & III & L. Paleo. & & Small/Medium Vertebrata & Long bone & 1 \\
\hline E26/S78 & 22B & $32 \mathrm{~V} 2 \mathrm{~B}$ & III & L. Paleo. & & Vertebrata & Indeterminate & 1 \\
\hline E26/S78 & $22 \mathrm{~B}$ & $32 \mathrm{~V} 2 \mathrm{C}$ & III & L. Paleo. & & Mammalia (Medium/large) & Indeterminate & 4 \\
\hline E26/S78 & $22 \mathrm{~B}$ & $32 \mathrm{~V} 2 \mathrm{C}$ & III & L. Paleo. & & Vertebrata & Indeterminate & 1 \\
\hline E26/S78 & 22B & $32 \mathrm{~V} 2 \mathrm{D}$ & III & L. Paleo. & & Vertebrata & Indeterminate & 5 \\
\hline E26/S78 & $23 \mathrm{~A}$ & $32 \mathrm{~W} 1 \mathrm{~A}$ & III & L. Paleo. & & Mammalia (Medium/large) & Indeterminate & 1 \\
\hline E26/S78 & $23 \mathrm{~A}$ & $32 \mathrm{~W} 1 \mathrm{~A}$ & III & L. Paleo. & & Medium/Large Vertebrata & Indeterminate & 1 \\
\hline E26/S78 & $23 \mathrm{~A}$ & $32 \mathrm{~W} 1 \mathrm{~A}$ & III & L. Paleo. & & Vertebrata & Indeterminate & 16 \\
\hline $\mathrm{E} 26 / \mathrm{S} 78$ & $23 \mathrm{~A}$ & $32 \mathrm{~W} 1 \mathrm{~B}$ & III & L. Paleo. & & Medium/Large Vertebrata & Indeterminate & 2 \\
\hline E26/S78 & $23 \mathrm{~A}$ & $32 \mathrm{~W} 1 \mathrm{~B}$ & III & L. Paleo. & & Medium/Large Vertebrata & Long bone & 1 \\
\hline E26/S78 & $23 \mathrm{~A}$ & $32 \mathrm{~W} 1 \mathrm{~B}$ & III & L. Paleo. & & Vertebrata & Indeterminate & 5 \\
\hline E26/S78 & $23 \mathrm{~A}$ & $32 \mathrm{~W} 1 \mathrm{C}$ & III & L. Paleo. & & Medium/Large Vertebrata & Indeterminate & 1 \\
\hline E26/S78 & $23 \mathrm{~A}$ & $32 \mathrm{~W} 1 \mathrm{D}$ & III & L. Paleo. & & Mammalia (Medium/large) & Indeterminate & 1 \\
\hline E26/S78 & $23 \mathrm{~A}$ & $32 \mathrm{~W} 1 \mathrm{D}$ & III & L. Paleo. & & Vertebrata & Indeterminate & 6 \\
\hline E26/S78 & 23B & $32 \mathrm{~W} 2$ & III & L. Paleo. & & Mammalia (Medium/large) & Indeterminate & 12 \\
\hline E26/S78 & 23B & $32 \mathrm{~W} 2$ & III & L. Paleo. & & Mammalia (Very large) & Long bone & 1 \\
\hline
\end{tabular}




\begin{tabular}{|c|c|c|c|c|c|c|c|c|}
\hline Square & Level & Lot & Unit & Cultural Affinity & Feature & Taxon & Element & No. \\
\hline E26/S78 & $23 \mathrm{~B}$ & $32 \mathrm{~W} 2 \mathrm{~A}$ & III & L. Paleo. & & Leporidae & Radius & 1 \\
\hline $\mathrm{E} 26 / \mathrm{S} 78$ & 23B & $32 \mathrm{~W} 2 \mathrm{~B}$ & III & L. Paleo. & & Mammalia (Medium/large) & Indeterminate & 1 \\
\hline E26/S78 & 23B & $32 \mathrm{~W} 2 \mathrm{C}$ & III & L. Paleo. & & Mammalia (Medium/large) & Long bone & 1 \\
\hline E26/S78 & 23B & $32 \mathrm{~W} 2 \mathrm{C}$ & III & L. Paleo. & & Vertebrata & Indeterminate & 1 \\
\hline E26/S78 & 23B & $32 \mathrm{~W} 2 \mathrm{D}$ & II & L. Paleo. & & Mammalia (Medium/large) & Long bone & 1 \\
\hline E26/S78 & $24 \mathrm{~A}$ & $32 \mathrm{X} 1 \mathrm{C}$ & II & L. Paleo. & & Mammalia (Medium/large) & Long bone & 1 \\
\hline E26/S78 & $24 \mathrm{~A}$ & $32 \mathrm{X} 1 \mathrm{D}$ & II & L. Paleo. & & Medium/Large Vertebrata & Indeterminate & 1 \\
\hline E26/S78 & 24B & $32 \mathrm{X} 2 \mathrm{~A}$ & II & L. Paleo. & & Small/Medium Vertebrata & Long bone & 2 \\
\hline E26/S78 & 24B & $32 \mathrm{X} 2 \mathrm{~B}$ & II & L. Paleo. & & Mammalia (Medium/large) & Indeterminate & 2 \\
\hline E26/S78 & 24B & $32 \mathrm{X} 2 \mathrm{C}$ & III & L. Paleo. & & Vertebrata & Indeterminate & 1 \\
\hline E26/S78 & 24B & $32 X 2 D$ & III & L. Paleo. & & Medium/Large Vertebrata & Indeterminate & 2 \\
\hline E26/S78 & 24B & $32 \mathrm{X} 2 \mathrm{D}$ & II & L. Paleo. & & Vertebrata & Indeterminate & 1 \\
\hline E26/S78 & $25 \mathrm{~A}$ & $32 \mathrm{Y} 1 \mathrm{~A}$ & Id/II & L. Paleo. & & Mammalia (Medium/large) & Long bone & 1 \\
\hline E26/S78 & $25 \mathrm{~A}$ & 32Y1B & Id/II & L. Paleo. & & Vertebrata & Indeterminate & 1 \\
\hline E26/S78 & $25 \mathrm{~A}$ & $32 \mathrm{Y} 1 \mathrm{C}$ & Id/II & L. Paleo. & & Mammalia (Medium) & Proximal phalange & 1 \\
\hline E26/S78 & $25 \mathrm{~A}$ & $32 \mathrm{Y} 1 \mathrm{C}$ & Id/II & L. Paleo. & & Mammalia (Medium/large) & Long bone & 1 \\
\hline E26/S78 & $25 \mathrm{~B}$ & $32 \mathrm{Y} 2 \mathrm{~A}$ & Id/II & L. Paleo. & & Medium/Large Vertebrata & Indeterminate & 3 \\
\hline E26/S78 & $25 \mathrm{~B}$ & $32 \mathrm{Y} 2 \mathrm{~A}$ & Id/II & L. Paleo. & & Vertebrata & Indeterminate & 2 \\
\hline E26/S78 & $25 \mathrm{~B}$ & $32 \mathrm{Y} 2 \mathrm{~B}$ & Id/II & L. Paleo. & & Vertebrata & Indeterminate & 2 \\
\hline E26/S78 & $25 \mathrm{~B}$ & $32 \mathrm{Y} 2 \mathrm{C}$ & Id/II & L. Paleo. & & Medium/Large Vertebrata & Indeterminate & 1 \\
\hline E26/S78 & 25B & $32 \mathrm{Y} 2 \mathrm{C}$ & Id/II & L. Paleo. & & Vertebrata & Indeterminate & 3 \\
\hline E26/S78 & $25 \mathrm{~B}$ & $32 \mathrm{Y} 2 \mathrm{D}$ & Id/II & L. Paleo. & & Mammalia (Medium/large) & Indeterminate & 3 \\
\hline E26/S78 & $25 \mathrm{~B}$ & $32 \mathrm{Y} 2 \mathrm{D}$ & Id/II & L. Paleo. & & Vertebrata & Indeterminate & 7 \\
\hline E26/S78 & $26 \mathrm{~A}$ & 32Z1A & Id/II & L. Paleo. & & Vertebrata & Indeterminate & 4 \\
\hline E26/S78 & $26 \mathrm{~A}$ & 32Z1B & Id/II & L. Paleo. & & Vertebrata & Indeterminate & 1 \\
\hline E26/S78 & $26 \mathrm{~A}$ & $32 \mathrm{Z1C}$ & Id/II & L. Paleo. & & Mammalia (Medium/large) & Long bone & 1 \\
\hline E26/S78 & $26 \mathrm{~A}$ & $32 \mathrm{Z1C}$ & Id/II & L. Paleo. & & Vertebrata & Indeterminate & 6 \\
\hline E26/S78 & 26B & $32 \mathrm{Z} 2 \mathrm{~A}$ & Id/II & L. Paleo. & & Mammalia (Medium/large) & Long bone & 1 \\
\hline E26/S78 & 26B & $32 \mathrm{Z} 2 \mathrm{~A}$ & $\mathrm{Id} / \mathrm{II}$ & L. Paleo. & & Vertebrata & Indeterminate & 3 \\
\hline E26/S78 & $26 \mathrm{~B}$ & $32 \mathrm{Z} 2 \mathrm{C}$ & $\mathrm{Id} / \mathrm{II}$ & L. Paleo. & & Mammalia (Medium/large) & Long bone & 1 \\
\hline E26/S78 & $26 \mathrm{~B}$ & 32Z2D & Id/II & L. Paleo. & & Medium/Large Vertebrata & Indeterminate & 1 \\
\hline E26/S78 & $26 \mathrm{~B}$ & 32Z2D & Id/II & L. Paleo. & & Medium/Large Vertebrata & Long bone & 2 \\
\hline E26/S78 & $26 \mathrm{~B}$ & 32Z2D & Id/II & L. Paleo. & & Small/Medium Vertebrata & Long bone & 1 \\
\hline E26/S78 & $27 \mathrm{~A}$ & $32 \mathrm{AA} 1 \mathrm{~A}$ & Isi-c/Id/II & L. Paleo. & & Vertebrata & Indeterminate & 3 \\
\hline E26/S78 & $27 \mathrm{~A}$ & $32 \mathrm{AA} 1 \mathrm{~B}$ & Isi-c/Id/II & L. Paleo. & & Vertebrata & Indeterminate & 1 \\
\hline E26/S78 & $27 \mathrm{~A}$ & 32AA1D & Isi-c/Id/II & L. Paleo. & & Vertebrata & Indeterminate & 1 \\
\hline E26/S78 & 27B & $32 \mathrm{AA} 2 \mathrm{~A}$ & Isi-c/Id & L. Paleo. & & Vertebrata & Indeterminate & 4 \\
\hline E26/S78 & 27B & 32AA2B & Isi-c/Id & L. Paleo. & & Vertebrata & Indeterminate & 5 \\
\hline E26/S78 & $27 \mathrm{~B}$ & 32AA2D & Isi-c/Id & L. Paleo. & & Mammalia (Medium/large) & Long bone & 1 \\
\hline E26/S78 & 27B & $32 \mathrm{AA} 2 \mathrm{D}$ & Isi-c/Id & L. Paleo. & & Vertebrata & Indeterminate & 2 \\
\hline E26/S78 & $28 \mathrm{~A}$ & 32BB1A & Isi-c/Id & L. Paleo. & & Vertebrata & Indeterminate & 2 \\
\hline E26/S78 & $28 \mathrm{~A}$ & 32BB1B & Isi-c/Id & L. Paleo. & & Vertebrata & Indeterminate & 4 \\
\hline $\mathrm{E} 26 / \mathrm{S} 78$ & $28 \mathrm{~A}$ & 32BB1C & Isi-c/Id & L. Paleo. & & Medium/Large Vertebrata & Indeterminate & 1 \\
\hline E26/S78 & $28 \mathrm{~A}$ & 32BB1C & Isi-c/Id & L. Paleo. & & Small/Medium Vertebrata & Long bone & 2 \\
\hline E26/S78 & $28 \mathrm{~A}$ & 32BB1C & Isi-c/Id & L. Paleo. & & Vertebrata & Indeterminate & 4 \\
\hline E26/S78 & $28 \mathrm{~A}$ & 32BB1D & Isi-c/Id & L. Paleo. & & Vertebrata & Indeterminate & 1 \\
\hline E26/S78 & 28B & $32 \mathrm{BB} 2 \mathrm{~A}$ & Isi-c/Id & L. Paleo. & & Vertebrata & Indeterminate & 1 \\
\hline E26/S78 & 28B & 32BB2B & Isi-c/Id & L. Paleo. & & Mammalia (Large) & Indeterminate & 1 \\
\hline E26/S78 & 28B & 32BB2B & Isi-c/Id & L. Paleo. & & Small/Medium Vertebrata & Long bone & 3 \\
\hline E26/S78 & 28B & 32BB2B & Isi-c/Id & L. Paleo. & & Vertebrata & Indeterminate & 4 \\
\hline E26/S78 & 28B & 32BB2C & Isi-c/Id & L. Paleo. & & Medium/Large Vertebrata & Indeterminate & 1 \\
\hline E26/S78 & $28 \mathrm{~B}$ & 32BB2C & Isi-c/Id & L. Paleo. & & Vertebrata & Indeterminate & 2 \\
\hline E26/S78 & $28 \mathrm{~B}$ & 32BB2C & Isi-c/Id & L. Paleo. & & Vertebrata & Vertebra & 1 \\
\hline E26/S78 & 28B & 32BB2D & Isi-c/Id & L. Paleo. & & Vertebrata & Indeterminate & 1 \\
\hline E26/S78 & $29 \mathrm{~A}$ & $32 \mathrm{CC} 1 \mathrm{~A}$ & Isi-c/Id & L. Paleo. & & Mammalia (Large) & Indeterminate & 3 \\
\hline E26/S78 & $29 \mathrm{~A}$ & $32 \mathrm{CC} 1 \mathrm{~A}$ & Isi-c/Id & L. Paleo. & & Mammalia (Medium/large) & Indeterminate & 1 \\
\hline E26/S78 & $29 \mathrm{~A}$ & $32 \mathrm{CC} 1 \mathrm{~A}$ & Isi-c/Id & L. Paleo. & & Vertebrata & Indeterminate & 18 \\
\hline E26/S78 & $29 \mathrm{~A}$ & $32 \mathrm{CC} 1 \mathrm{~B}$ & Isi-c/Id & L. Paleo. & & Vertebrata & Indeterminate & 5 \\
\hline E26/S78 & $29 \mathrm{~A}$ & $32 \mathrm{CC} 1 \mathrm{C}$ & Isi-c/Id & L. Paleo. & & Mammalia (Medium/large) & Indeterminate & 3 \\
\hline E26/S78 & $29 \mathrm{~A}$ & $32 \mathrm{CClC}$ & Isi-c/Id & L. Paleo. & & Vertebrata & Indeterminate & 7 \\
\hline E26/S78 & 29B & $32 \mathrm{CC} 2 \mathrm{C}$ & Isi-c & L. Paleo. & & Mammalia (Medium) & Calcaneus & 1 \\
\hline E26/S78 & 29B & $32 \mathrm{CC} 2 \mathrm{C}$ & Isi-c & L. Paleo. & & Mammalia (Medium/large) & Long bone & 2 \\
\hline E26/S78 & 29B & $32 \mathrm{CC} 2 \mathrm{C}$ & Isi-c & L. Paleo. & & Sylvilagus sp. & Tibia & 1 \\
\hline E26/S78 & 29B & $32 \mathrm{CC} 2 \mathrm{C}$ & Isi-c & L. Paleo. & & Vertebrata & Indeterminate & 10 \\
\hline E26/S78 & $29 \mathrm{~B}$ & $32 \mathrm{CC} 2 \mathrm{D}$ & Isi-c & L. Paleo. & & Sylvilagus sp. & Calcaneus & 1 \\
\hline E26/S78 & $30 \mathrm{~A}$ & 32DD1A & Isi-c & L. Paleo. & & Vertebrata & Indeterminate & 3 \\
\hline E26/S78 & $30 \mathrm{~A}$ & 32DD1B & Isi-c & L. Paleo. & & Vertebrata & Indeterminate & 6 \\
\hline
\end{tabular}




\begin{tabular}{|c|c|c|c|c|c|c|c|c|}
\hline Square & Level & Lot & Unit & Cultural Affinity & Feature & Taxon & Element & No. \\
\hline E26/S78 & $30 \mathrm{~A}$ & $32 \mathrm{DD} 1 \mathrm{C}$ & Isi-c & L. Paleo. & & Mammalia (Medium/large) & Indeterminate & 2 \\
\hline E26/S78 & $30 \mathrm{~A}$ & 32DD1C & Isi-c & L. Paleo. & & Medium/Large Vertebrata & Indeterminate & 1 \\
\hline E26/S78 & $30 \mathrm{~A}$ & 32DD1C & Isi-c & L. Paleo. & & Sylvilagus sp. & Calcaneus & 1 \\
\hline E26/S78 & $30 \mathrm{~A}$ & 32DD1C & Isi-c & L. Paleo. & & Vertebrata & Indeterminate & 2 \\
\hline E26/S78 & $30 \mathrm{~A}$ & 32DD1D & Isi-c & L. Paleo. & & Medium/Large Vertebrata & Indeterminate & 2 \\
\hline E26/S78 & $30 \mathrm{~A}$ & 32DD1D & Isi-c & L. Paleo. & & Vertebrata & Indeterminate & 6 \\
\hline E26/S78 & 30B & 32DD2A & Isi-c & L. Paleo. & & Mammalia (Medium/large) & Indeterminate & 3 \\
\hline E26/S78 & $30 \mathrm{~B}$ & 32DD2A & Isi-c & L. Paleo. & & Vertebrata & Indeterminate & 19 \\
\hline E26/S78 & $30 \mathrm{~B}$ & $32 \mathrm{DD} 2 \mathrm{~A}$ & Isi-c & L. Paleo. & & Vertebrata & Long bone & 2 \\
\hline E26/S78 & 30B & 32DD2B & Isi-c & L. Paleo. & & Mammalia (Medium/large) & Mandible & 1 \\
\hline E26/S78 & 30B & 32DD2B & Isi-c & L. Paleo. & & Vertebrata & Indeterminate & 1 \\
\hline E26/S78 & $31 \mathrm{~A}$ & 32EE1A & Isi-c & L. Paleo. & & Mammalia (Medium/large) & Indeterminate & 4 \\
\hline E26/S78 & $31 \mathrm{~A}$ & 32EE1A & Isi-c & L. Paleo. & & Mammalia (Medium/large) & Long bone & 3 \\
\hline E26/S78 & $31 \mathrm{~A}$ & 32EE1A & Isi-c & L. Paleo. & & Vertebrata & Indeterminate & 4 \\
\hline E26/S78 & $31 \mathrm{~A}$ & 32EE1B & Isi-c & L. Paleo. & & Small/Medium Vertebrata & Long bone & 1 \\
\hline $\mathrm{E} 26 / \mathrm{S} 78$ & $31 \mathrm{~A}$ & 32EE1B & Isi-c & L. Paleo. & & Vertebrata & Indeterminate & 1 \\
\hline E26/S78 & $31 \mathrm{~B}$ & 32EE2A & Isi-c & L. Paleo. & & Small/Medium Vertebrata & Long bone & 1 \\
\hline E26/S78 & $31 \mathrm{~B}$ & 32EE2C & Isi-c & L. Paleo. & & Mammalia (Medium/large) & Long bone & 2 \\
\hline E26/S78 & $31 \mathrm{~B}$ & 32EE2C & Isi-c & L. Paleo. & & Medium/Large Vertebrata & Indeterminate & 1 \\
\hline E26/S78 & $31 \mathrm{~B}$ & 32EE2C & Isi-c & L. Paleo. & & Small/Medium Vertebrata & Long bone & 1 \\
\hline $\mathrm{E} 26 / \mathrm{S} 78$ & $31 \mathrm{~B}$ & 32EE2C & Isi-c & L. Paleo. & & Vertebrata & Indeterminate & 1 \\
\hline E26/S78 & $31 \mathrm{~B}$ & 32EE2D & Isi-c & L. Paleo. & & Small/Medium Vertebrata & Long bone & 1 \\
\hline E26/S78 & $32 \mathrm{~A}$ & $32 \mathrm{FF} 1 \mathrm{C}$ & Isi-c & L. Paleo. & & Mammalia (Medium/large) & Indeterminate & 3 \\
\hline E26/S78 & $32 \mathrm{~A}$ & $32 \mathrm{FF} 1 \mathrm{C}$ & Isi-c & L. Paleo. & & Vertebrata & Indeterminate & 5 \\
\hline E26/S78 & $32 \mathrm{~B}$ & $32 \mathrm{FF} 2 \mathrm{~A}$ & Isi/Icl/Isi-c & Paleoindian & & Mammalia (Medium/large) & Indeterminate & 1 \\
\hline $\mathrm{E} 26 / \mathrm{S} 78$ & $32 \mathrm{~B}$ & $32 \mathrm{FF} 2 \mathrm{~A}$ & Isi/Icl/Isi-c & Paleoindian & & Vertebrata & Indeterminate & 14 \\
\hline E26/S78 & $33 \mathrm{~A}$ & 32GG1B & Isi/Icl/Isi-c & Paleoindian & & Vertebrata & Indeterminate & 1 \\
\hline $\mathrm{E} 26 / \mathrm{S} 78$ & $33 \mathrm{~A}$ & $32 \mathrm{GG1C}$ & Isi/Icl//si-c & Paleoindian & & Medium/Large Vertebrata & Indeterminate & 1 \\
\hline E26/S78 & $33 \mathrm{~A}$ & 32GG1D & Isi/Icl/Isi-c & Paleoindian & & Mammalia (Small) & Permanent tooth & 1 \\
\hline E26/S78 & $33 \mathrm{~A}$ & 32 GG1D & Isi/Icl/Isi-c & Paleoindian & & Medium/Large Vertebrata & Indeterminate & 4 \\
\hline E26/S78 & $33 \mathrm{~A}$ & 32GG1D & Isi/Icl/Isi-c & Paleoindian & & Vertebrata & Indeterminate & 3 \\
\hline E26/S78 & 33B & $32 \mathrm{GG} 2 \mathrm{~A}$ & Isi/Icl/Isi-c & Paleoindian & & Vertebrata & Indeterminate & 1 \\
\hline E26/S78 & $33 \mathrm{~B}$ & $32 \mathrm{GG} 2 \mathrm{C}$ & Isi/Icl/Isi-c & Paleoindian & & Mammalia (Medium/large) & Indeterminate & 2 \\
\hline E26/S78 & $33 \mathrm{~B}$ & $32 \mathrm{GG} 2 \mathrm{C}$ & Isi/Icl/Isi-c & Paleoindian & & Vertebrata & Indeterminate & 2 \\
\hline E26/S78 & $33 \mathrm{~B}$ & $32 \mathrm{GG} 2 \mathrm{D}$ & Isi/Icl/Isi-c & Paleoindian & & Medium/Large Vertebrata & Indeterminate & 2 \\
\hline E26/S78 & $34 \mathrm{~A}$ & 32HH1A & Isi/Icl/Isi-c & Paleoindian & & Small/Medium Vertebrata & Long bone & 1 \\
\hline E26/S78 & $34 \mathrm{~A}$ & $32 \mathrm{HH} 1 \mathrm{~B}$ & Isi/Icl/Isi-c & Paleoindian & & Mammalia (Medium/large) & Long bone & 1 \\
\hline E26/S78 & $34 \mathrm{~A}$ & 32НH1В & Isi/Icl/Isi-c & Paleoindian & & Vertebrata & Indeterminate & 1 \\
\hline E26/S78 & $34 \mathrm{~A}$ & $32 \mathrm{HH} 1 \mathrm{C}$ & |Isi/Icl/Isi-c & Paleoindian & & Small/Medium Vertebrata & |Long bone & 1 \\
\hline E26/S78 & $34 \mathrm{~A}$ & 32HH1D & |Isi/Icl/Isi-c & Paleoindian & & Vertebrata & Indeterminate & 2 \\
\hline $\mathrm{E} 26 / \mathrm{S} 78$ & $35 \mathrm{~A}$ & 32II1A & Isi/Icl & E. Paleo. & & Artiodactyla & Tooth, perm./decid. ind. & 2 \\
\hline $\mathrm{E} 26 / \mathrm{S} 78$ & $35 \mathrm{~A}$ & 32I1A & Isi/Icl & E. Paleo. & & Mammalia (Medium/large) & Indeterminate & 2 \\
\hline E26/S78 & $35 \mathrm{~A}$ & $32 \Pi 1 \mathrm{~A}$ & Isi/Icl & E. Paleo. & & Vertebrata & Indeterminate & 1 \\
\hline E26/S78 & $35 \mathrm{~B}$ & $32 \mathrm{III} 2 \mathrm{~A}$ & Isi/Icl & E. Paleo. & & Mammalia (Large) & Indeterminate & 1 \\
\hline E26/S78 & $35 \mathrm{~B}$ & $32 \amalg 2 \mathrm{~B}$ & Isi/Icl & E. Paleo. & & Vertebrata & Indeterminate & 1 \\
\hline $\mathrm{E} 26 / \mathrm{S} 78$ & $35 \mathrm{~B}$ & $32 \mathrm{II} 2 \mathrm{C}$ & Isi/Icl & E. Paleo. & & Vertebrata & Indeterminate & 3 \\
\hline $\mathrm{E} 26 / \mathrm{S} 78$ & $35 \mathrm{~B}$ & $32 \mathrm{III} 2 \mathrm{D}$ & Isi/Icl & E. Paleo. & & Vertebrata & Indeterminate & 2 \\
\hline $\mathrm{E} 26 / \mathrm{S} 78$ & $36 \mathrm{~A}$ & 32JJ1A & Isi/Icl & E. Paleo. & & Vertebrata & Indeterminate & 2 \\
\hline $\mathrm{E} 26 / \mathrm{S} 78$ & $36 \mathrm{~B}$ & $32 \mathrm{JJ} 2 \mathrm{~A}$ & Isi/Icl & E. Paleo. & & Medium/Large Vertebrata & Indeterminate & 1 \\
\hline $\mathrm{E} 26 / \mathrm{S} 78$ & 36B & $32 \mathrm{JJ} 2 \mathrm{~A}$ & Isi/Icl & E. Paleo. & & Vertebrata & Indeterminate & 4 \\
\hline E26/S78 & $36 \mathrm{~B}$ & $32 \mathrm{JJ} 2 \mathrm{~B}$ & Isi/Icl/D & E. Paleo. & & Mammalia (Small) & Tooth, perm./decid. ind. & 6 \\
\hline $\mathrm{E} 26 / \mathrm{S} 78$ & $36 \mathrm{~B}$ & $32 \mathrm{JJ} 2 \mathrm{~B}$ & Isi/Icl/D & E. Paleo. & & Vertebrata & Indeterminate & 5 \\
\hline E26/S78 & $36 \mathrm{~B}$ & $32 \mathrm{JJ} 2 \mathrm{C}$ & Isi//Icl & E. Paleo. & & Mammalia (Large) & Long bone & 1 \\
\hline E26/S78 & $36 \mathrm{~B}$ & $32 \mathrm{JJ} 2 \mathrm{C}$ & Isi/Icl & E. Paleo. & & Vertebrata & Indeterminate & 2 \\
\hline E26/S78 & $37 \mathrm{~A}$ & $32 \mathrm{KK} 1 \mathrm{~A}$ & Isi/Icl & E. Paleo. & & Vertebrata & Indeterminate & 2 \\
\hline E26/S78 & $37 \mathrm{~A}$ & $32 \mathrm{KK} 1 \mathrm{~B}$ & Isi/Icl/D & E. Paleo. & & Mammalia (Large) & Indeterminate & 3 \\
\hline E26/S78 & $37 \mathrm{~A}$ & $32 \mathrm{KK} 1 \mathrm{~B}$ & Isi/Icl/D & E. Paleo. & & Vertebrata & Indeterminate & 4 \\
\hline E26/S78 & $37 \mathrm{~A}$ & $32 \mathrm{KK} 1 \mathrm{C}$ & Isi/Icl & E. Paleo. & & Mammalia (Medium/large) & Long bone & 1 \\
\hline $\mathrm{E} 26 / \mathrm{S} 78$ & $37 \mathrm{~A}$ & $32 \mathrm{KK} 1 \mathrm{C}$ & Isi/Icl & E. Paleo. & & Vertebrata & Indeterminate & 4 \\
\hline E26/S78 & $37 \mathrm{~A}$ & $32 \mathrm{KK} 1 \mathrm{D}$ & Isi/Icl & E. Paleo. & & Mammalia (Medium/large) & Indeterminate & 1 \\
\hline E26/S78 & $37 \mathrm{~B}$ & $32 \mathrm{KK} 2 \mathrm{~A}$ & Isi/Icl & E. Paleo. & & Vertebrata & Indeterminate & 9 \\
\hline E26/S78 & $37 \mathrm{~B}$ & $32 \mathrm{KK} 2 \mathrm{~B}$ & Isi/Icl/D & E. Paleo. & & Mammalia (Medium/large) & Indeterminate & 1 \\
\hline E26/S78 & 37B & $32 \mathrm{KK} 2 \mathrm{~B}$ & Isi/Icl/D & E. Paleo. & & Vertebrata & Indeterminate & 12 \\
\hline E26/S78 & $37 \mathrm{~B}$ & $32 \mathrm{KK} 2 \mathrm{C}$ & Isi/Icl & E. Paleo. & & Mammalia (Medium/large) & Long bone & 2 \\
\hline E26/S78 & $37 \mathrm{~B}$ & $32 \mathrm{KK} 2 \mathrm{C}$ & Isi/Icl & E. Paleo. & & Mammalia (Medium/large) & Tooth, perm./decid. ind. & 1 \\
\hline E26/S78 & $37 \mathrm{~B}$ & $32 \mathrm{KK} 2 \mathrm{C}$ & Isi/Icl & E. Paleo. & & Vertebrata & Indeterminate & 9 \\
\hline E26/S78 & $38 \mathrm{~A}$ & 32LL1A & Isi/Icl & E. Paleo. & & Medium/Large Vertebrata & Indeterminate & 1 \\
\hline
\end{tabular}




\begin{tabular}{|c|c|c|c|c|c|c|c|c|}
\hline Square & Level & Lot & Unit & Cultural Affinity & Feature & Taxon & Element & No. \\
\hline E26/S78 & $38 \mathrm{~A}$ & 32 LL1B & Isi/Icl & E. Paleo. & & Mammalia (Medium/large) & Indeterminate & 3 \\
\hline E26/S78 & $38 \mathrm{~A}$ & 32LL1B & Isi//cl & E. Paleo. & & Medium/Large Vertebrata & Indeterminate & 5 \\
\hline E26/S78 & $38 \mathrm{~A}$ & 32LL1B & Isi//lcl & E. Paleo. & & Vertebrata & Indeterminate & 3 \\
\hline E26/S78 & $38 \mathrm{~A}$ & $32 \mathrm{LL1C}$ & Isi//Icl & E. Paleo. & & Mammalia (Medium/large) & Indeterminate & 1 \\
\hline E26/S78 & $38 \mathrm{~A}$ & $32 \mathrm{LL1C}$ & Isi//cl & E. Paleo. & & Medium/Large Vertebrata & Indeterminate & 8 \\
\hline E26/S78 & $38 \mathrm{~A}$ & $32 \mathrm{LL1C}$ & Isi//lcl & E. Paleo. & & Vertebrata & Indeterminate & 6 \\
\hline E26/S78 & $38 \mathrm{~A}$ & 32LL1D & Isi//lcl & E. Paleo. & & Vertebrata & Indeterminate & 16 \\
\hline E26/S78 & 38B & 32LL2A & Isi//cl & E. Paleo. & & Vertebrata & Indeterminate & 1 \\
\hline $\mathrm{E} 26 / \mathrm{S} 78$ & $38 \mathrm{~B}$ & 32LL2B & $\mathrm{Isi} / \mathrm{Icl}$ & E. Paleo. & & Mammalia (Large) & Tooth, perm./decid. ind. & 1 \\
\hline E26/S78 & $38 \mathrm{~B}$ & 32LL2B & Isi/Icl & E. Paleo. & & Medium/Large Vertebrata & Indeterminate & 2 \\
\hline E26/S78 & $38 \mathrm{~B}$ & 32LL2B & Isi/Icl & E. Paleo. & & Vertebrata & Indeterminate & 12 \\
\hline $\mathrm{E} 26 / \mathrm{S} 78$ & $38 \mathrm{~B}$ & 32LL2C & Isi/Icl & E. Paleo. & & Vertebrata & Indeterminate & 3 \\
\hline E26/S78 & $39 \mathrm{~A}$ & $32 \mathrm{MM} 1 \mathrm{~A}$ & Isi/Icl & E. Paleo. & & Medium/Large Vertebrata & Indeterminate & 6 \\
\hline $\mathrm{E} 26 / \mathrm{S} 78$ & $39 \mathrm{~A}$ & $32 \mathrm{MM} 1 \mathrm{~A}$ & Isi/Icl & E. Paleo. & & Vertebrata & Indeterminate & 11 \\
\hline $\mathrm{E} 26 / \mathrm{S} 78$ & $39 \mathrm{~A}$ & $32 \mathrm{MM} 1 \mathrm{~B}$ & Isi/Icl & E. Paleo. & & Bison sp. & Tooth, perm./decid. ind. & 1 \\
\hline E26/S78 & $39 \mathrm{~A}$ & $32 \mathrm{MM} 1 \mathrm{~B}$ & Isi/Icl & E. Paleo. & & Mammalia (Large) & Tooth, perm./decid. ind. & 1 \\
\hline $\mathrm{E} 26 / \mathrm{S} 78$ & $39 \mathrm{~A}$ & $32 \mathrm{MM} 1 \mathrm{C}$ & Isi/Icl & E. Paleo. & & Medium/Large Vertebrata & Indeterminate & 1 \\
\hline $\mathrm{E} 26 / \mathrm{S} 78$ & $39 \mathrm{~A}$ & $32 \mathrm{MM} 1 \mathrm{C}$ & Isi/Icl & E. Paleo. & & Vertebrata & Indeterminate & 1 \\
\hline $\mathrm{E} 26 / \mathrm{S} 78$ & $39 \mathrm{~B}$ & $32 \mathrm{MM} 2 \mathrm{~A}$ & Isi/Icl & E. Paleo. & & Mammalia (Medium/large) & Indeterminate & 4 \\
\hline $\mathrm{E} 26 / \mathrm{S} 78$ & 39B & $32 \mathrm{MM} 2 \mathrm{~A}$ & Isi/Icl & E. Paleo. & & Vertebrata & Indeterminate & 10 \\
\hline $\mathrm{E} 26 / \mathrm{S} 78$ & 39B & $32 \mathrm{MM} 2 \mathrm{~B}$ & Isi/Icl & E. Paleo. & & Bison sp. & Astragalus & 2 \\
\hline E26/S78 & 39B & $32 \mathrm{MM} 2 \mathrm{~B}$ & Isi/Icl & E. Paleo. & & Mammalia (Large) & Tooth, perm./decid. ind. & 1 \\
\hline $\mathrm{E} 26 / \mathrm{S} 78$ & $39 \mathrm{~B}$ & $32 \mathrm{MM} 2 \mathrm{~B}$ & Isi/Icl & E. Paleo. & & Medium/Large Vertebrata & Indeterminate & 6 \\
\hline E26/S78 & 39B & $32 \mathrm{MM} 2 \mathrm{~B}$ & Isi/Icl & E. Paleo. & & Vertebrata & Indeterminate & 19 \\
\hline E26/S78 & 39B & $32 \mathrm{MM} 2 \mathrm{C}$ & Isi/Icl & E. Paleo. & & Mammalia (Medium/large) & Indeterminate & 7 \\
\hline E26/S78 & 39B & $32 \mathrm{MM} 2 \mathrm{C}$ & Isi/Icl & E. Paleo. & & Mammalia (Medium/large) & Long bone & 2 \\
\hline E26/S78 & 39B & $32 \mathrm{MM} 2 \mathrm{C}$ & Isi/Icl & E. Paleo. & & Mammalia (Very large) & Indeterminate & 1 \\
\hline $\mathrm{E} 26 / \mathrm{S} 78$ & 39B & $32 \mathrm{MM} 2 \mathrm{C}$ & Isi/Icl & E. Paleo. & & Vertebrata & Indeterminate & 13 \\
\hline $\mathrm{E} 26 / \mathrm{S} 78$ & $40 \mathrm{~B}$ & $32 \mathrm{NN} 2 \mathrm{~A}$ & Isi/Icl & E. Paleo. & & Mammalia (Large) & Indeterminate & 1 \\
\hline $\mathrm{E} 26 / \mathrm{S} 78$ & $40 \mathrm{~B}$ & $32 \mathrm{NN} 2 \mathrm{~A}$ & Isi/Icl & E. Paleo. & & Mammalia (Medium) & Pelvis & 1 \\
\hline E26/S78 & $40 \mathrm{~B}$ & $32 \mathrm{NN} 2 \mathrm{~A}$ & Isi/Icl & E. Paleo. & & Mammalia (Medium/large) & Indeterminate & 7 \\
\hline $\mathrm{E} 26 / \mathrm{S} 78$ & $40 \mathrm{~B}$ & $32 \mathrm{NN} 2 \mathrm{~A}$ & Isi/Icl & E. Paleo. & & Medium/Large Vertebrata & Indeterminate & 11 \\
\hline $\mathrm{E} 26 / \mathrm{S} 78$ & $40 \mathrm{~B}$ & $32 \mathrm{NN} 2 \mathrm{~A}$ & Isi/Icl & E. Paleo. & & Vertebrata & Indeterminate & 7 \\
\hline $\mathrm{E} 26 / \mathrm{S} 78$ & $40 \mathrm{~B}$ & $32 \mathrm{NN} 2 \mathrm{~B}$ & Isi/Icl & E. Paleo. & & Mammalia (Large) & Tooth, perm./decid. ind. & 1 \\
\hline $\mathrm{E} 26 / \mathrm{S} 78$ & 41 & $32001 \& 2$ & Isi/Icl & E. Paleo. & & Bison sp. & Mandible & 1 \\
\hline $\mathrm{E} 26 / \mathrm{S} 78$ & 41 & $32001 \& 2$ & Isi/Icl & E. Paleo. & & Bison sp. & Permanent tooth & 1 \\
\hline $\mathrm{E} 26 / \mathrm{S} 78$ & 41 & $32001 \& 2$ & Isi/Icl & E. Paleo. & & Medium/Large Vertebrata & Indeterminate & 2 \\
\hline $\mathrm{E} 26 / \mathrm{S} 78$ & 41 & $32001 \& 2$ & Isi/Icl & E. Paleo. & & Vertebrata & Indeterminate & 8 \\
\hline $\mathrm{E} 26 / \mathrm{S} 78$ & $41 \mathrm{~B}$ & $32 \mathrm{OO} 2 \mathrm{~A}$ & Isi/Icl & E. Paleo. & & Mammalia (Large) & Indeterminate & 1 \\
\hline E26/S78 & $41 \mathrm{~B}$ & $32 \mathrm{OO} 2 \mathrm{~A}$ & Isi/Icl & E. Paleo. & & Mammalia (Medium/large) & Indeterminate & 2 \\
\hline $\mathrm{E} 26 / \mathrm{S} 78$ & $41 \mathrm{~B}$ & $32 \mathrm{OO} 2 \mathrm{~A}$ & Isi/Icl & E. Paleo. & & Vertebrata & Indeterminate & 2 \\
\hline E26/S78 & $41 \mathrm{~B}-42 \mathrm{~A}$ & $32 \mathrm{OO} 2 / \mathrm{PH}$ & Isi/Icl & E. Paleo. & & cf. Bison & Metacarpal & 1 \\
\hline E26/S78 & $41 \mathrm{~B}-42 \mathrm{~A}$ & $32 \mathrm{OO} 2 / \mathrm{PA}$ & Isi/Icl & E. Paleo. & & Vertebrata & Indeterminate & 2 \\
\hline $\mathrm{E} 28 / \mathrm{S} 78$ & 1 & $37 \mathrm{AA}$ & IIIC & L. Prehist. & & Mammalia (Medium/large) & Alveolar ridge fragment & 1 \\
\hline $\mathrm{E} 28 / \mathrm{S} 78$ & 1 & $37 \mathrm{AA}$ & IIIc & L. Prehist. & & Mammalia (Medium/large) & Indeterminate & 13 \\
\hline E28/S78 & 1 & $37 \mathrm{AA}$ & IIIc & L. Prehist. & & Mammalia (Medium/large) & Long bone & 2 \\
\hline $\mathrm{E} 28 / \mathrm{S} 78$ & 1 & $37 \mathrm{AA}$ & IIIc & L. Prehist. & & Vertebrata & Indeterminate & 2 \\
\hline $\mathrm{E} 28 / \mathrm{S} 78$ & 1 & $37 \mathrm{AB}$ & IIIIc & L. Prehist. & & Mammalia (Medium/large) & Indeterminate & 3 \\
\hline E28/S78 & 1 & $37 \mathrm{AB}$ & IIIc & L. Prehist. & & Vertebrata & Indeterminate & 10 \\
\hline E28/S78 & 1 & $37 \mathrm{AC}$ & IIIc & L. Prehist. & & Mammalia (Medium/large) & Alveolar ridge fragment & 1 \\
\hline $\mathrm{E} 28 / \mathrm{S} 78$ & 1 & $37 \mathrm{AC}$ & IIIc & L. Prehist. & & Mammalia (Medium/large) & Indeterminate & 1 \\
\hline $\mathrm{E} 28 / \mathrm{S} 78$ & 1 & $37 \mathrm{AC}$ & IIIIc & L. Prehist. & & Mammalia (Medium/large) & Long bone & 2 \\
\hline $\mathrm{E} 28 / \mathrm{S} 78$ & 1 & $37 \mathrm{AC}$ & IIIC & L. Prehist. & & Medium/Large Vertebrata & Indeterminate & 1 \\
\hline $\mathrm{E} 28 / \mathrm{S} 78$ & 1 & $37 \mathrm{AC}$ & IIIIc & L. Prehist. & & Vertebrata & Indeterminate & 1 \\
\hline E28/S78 & 1 & $37 \mathrm{AD}$ & IIIc & L. Prehist. & & Mammalia (Medium/large) & Indeterminate & 12 \\
\hline $\mathrm{E} 28 / \mathrm{S} 78$ & 1 & $37 \mathrm{AD}$ & IIIc & L. Prehist. & & Mammalia (Medium/large) & Long bone & 1 \\
\hline $\mathrm{E} 28 / \mathrm{S} 78$ & 1 & $37 \mathrm{AD}$ & IIIc & L. Prehist. & & Vertebrata & Indeterminate & 3 \\
\hline $\mathrm{E} 28 / \mathrm{S} 78$ & 2 & $37 \mathrm{BA}$ & IIIIc & L. Archaic/L. Prehist. & & Antilocapra/Odocoileus & Mandible & 2 \\
\hline E28/S78 & 2 & $37 \mathrm{BA}$ & IIIIc & L. Archaic/L. Prehist. & & AntilocapralOdocoileus & Proximal phalange & 1 \\
\hline $\mathrm{E} 28 / \mathrm{S} 78$ & 2 & $37 \mathrm{BA}$ & IIIc & L. Archaic/L. Prehist. & & Mammalia (Large) & Alveolar ridge fragment & 2 \\
\hline E28/S78 & 2 & $37 \mathrm{BA}$ & IIIIc & L. Archaic/L. Prehist. & & Mammalia (Large) & Indeterminate & 7 \\
\hline E28/S78 & 2 & $37 \mathrm{BA}$ & IIIIc & L. Archaic/L. Prehist. & & Mammalia (Large) & Long bone & 1 \\
\hline E28/S78 & 2 & $37 \mathrm{BA}$ & IIIIc & L. Archaic/L. Prehist. & & Mammalia (Medium/large) & Indeterminate & 8 \\
\hline E28/S78 & 2 & $37 \mathrm{BA}$ & IIIIc & L. Archaic/L. Prehist. & & Mammalia (Medium/large) & Long bone & 1 \\
\hline E28/S78 & 2 & $37 \mathrm{BA}$ & IIIIc & L. Archaic/L. Prehist. & & Odocoileus sp. & Mandible & 1 \\
\hline $\mathrm{E} 28 / \mathrm{S} 78$ & 2 & $37 \mathrm{BA}$ & IIIc & L. Archaic/L. Prehist. & & Odocoileus sp. & Permanent tooth & 2 \\
\hline E28/S78 & 2 & $37 \mathrm{BA}$ & IIIIc & L. Archaic/L. Prehist. & & Odocoileus sp. & Proximal phalange & 1 \\
\hline
\end{tabular}




\begin{tabular}{|c|c|c|c|c|c|c|c|c|}
\hline Square & Level & Lot & Unit & Cultural Affinity & Feature & Taxon & Element & No. \\
\hline E28/S78 & 2 & $37 \mathrm{BA}$ & IIIc & L. Archaic/L. Prehist. & & Vertebrata & Indeterminate & 55 \\
\hline E28/S78 & 2 & 37BB & IIIc & L. Archaic/L. Prehist. & & Antilocapra/Odocoileus & Axis & 1 \\
\hline $\mathrm{E} 28 / \mathrm{S} 78$ & 2 & 37BB & IIIc & L. Archaic/L. Prehist. & & Antilocapra/Odocoileus & Fused central/fourth tarsal & 1 \\
\hline E28/S78 & 2 & $37 \mathrm{BB}$ & IIIc & L. Archaic/L. Prehist. & & Mammalia (Medium/large) & Indeterminate & 9 \\
\hline $\mathrm{E} 28 / \mathrm{S} 78$ & 2 & $37 \mathrm{BB}$ & IIIc & L. Archaic/L. Prehist. & & Mammalia (Medium/large) & Long bone & 3 \\
\hline E28/S78 & 2 & $37 \mathrm{BB}$ & IIIIc & L. Archaic/L. Prehist. & & Medium/Large Vertebrata & Indeterminate & 7 \\
\hline $\mathrm{E} 28 / \mathrm{S} 78$ & 2 & $37 \mathrm{BB}$ & IIIc & L. Archaic/L. Prehist. & & Odocoileus sp. & Middle phalange & 1 \\
\hline $\mathrm{E} 28 / \mathrm{S} 78$ & 2 & $37 \mathrm{BB}$ & IIIc & L. Archaic/L. Prehist. & & Odocoileus sp. & Proximal phalange & 1 \\
\hline E28/S78 & 2 & $37 \mathrm{BB}$ & IIIc & L. Archaic/L. Prehist. & & Vertebrata & Indeterminate & 8 \\
\hline $\mathrm{E} 28 / \mathrm{S} 78$ & 2 & $37 \mathrm{BC}$ & IIIc & L. Archaic/L. Prehist. & & Antilocapra/Odocoileus & Metatarsal & 1 \\
\hline E28/S78 & 2 & $37 \mathrm{BC}$ & IIIc & L. Archaic/L. Prehist. & & Mammalia (Medium/large) & Cranium & 1 \\
\hline E28/S78 & 2 & $37 \mathrm{BC}$ & IIIc & L. Archaic/L. Prehist. & & Mammalia (Medium/large) & Indeterminate & 27 \\
\hline $\mathrm{E} 28 / \mathrm{S} 78$ & 2 & $37 \mathrm{BC}$ & IIIIc & L. Archaic/L. Prehist. & & Mammalia (Medium/large) & Long bone & 19 \\
\hline $\mathrm{E} 28 / \mathrm{S} 78$ & 2 & $37 \mathrm{BC}$ & IIIIc & L. Archaic/L. Prehist. & & Medium/Large Vertebrata & Indeterminate & 1 \\
\hline E28/S78 & 2 & $37 \mathrm{BC}$ & IIIc & L. Archaic/L. Prehist. & & Small/Medium Vertebrata & Long bone & 1 \\
\hline $\mathrm{E} 28 / \mathrm{S} 78$ & 2 & $37 \mathrm{BC}$ & IIIc & L. Archaic/L. Prehist. & & Vertebrata & Indeterminate & 13 \\
\hline $\mathrm{E} 28 / \mathrm{S} 78$ & 2 & $37 \mathrm{BD}$ & IIIc & L. Archaic/L. Prehist. & & Mammalia (Medium/large) & Indeterminate & 15 \\
\hline E28/S78 & 2 & 37BD & IIIc & L. Archaic/L. Prehist. & & Mammalia (Medium/large) & Long bone & 16 \\
\hline E28/S78 & 2 & $37 \mathrm{BD}$ & IIIc & L. Archaic/L. Prehist. & & Odocoileus sp. & Tibia & 1 \\
\hline E28/S78 & 2 & 37BD & IIIc & L. Archaic/L. Prehist. & & Vertebrata & Indeterminate & 9 \\
\hline E28/S78 & 3 & $37 \mathrm{CA}$ & IIIc & L. Archaic & & Antilocapra/Odocoileus & Metapodial & 1 \\
\hline E28/S78 & 3 & $37 \mathrm{CA}$ & IIIc & L. Archaic & & Antilocapra/Odocoileus & Proximal sesamoid & 1 \\
\hline E28/S78 & 3 & $37 \mathrm{CA}$ & IIIc & L. Archaic & & Mammalia (Large) & Long bone & 1 \\
\hline E28/S78 & 3 & $37 \mathrm{CA}$ & IIIc & L. Archaic & & Mammalia (Medium/large) & Indeterminate & 2 \\
\hline E28/S78 & 3 & $37 \mathrm{CA}$ & IIIc & L. Archaic & & Mammalia (Medium/large) & Long bone & 1 \\
\hline E28/S78 & 3 & $37 \mathrm{CA}$ & IIIc & L. Archaic & & Odocoileus sp. & Tooth, perm./decid. ind. & 1 \\
\hline E28/S78 & 3 & $37 \mathrm{CA}$ & IIIc & L. Archaic & & Vertebrata & Indeterminate & 35 \\
\hline E28/S78 & 3 & $37 \mathrm{CB}$ & IIIc & L. Archaic & & AntilocapralOdocoileus & Proximal phalange & 1 \\
\hline $\mathrm{E} 28 / \mathrm{S} 78$ & 3 & $37 \mathrm{CB}$ & IIIc & L. Archaic & & Artiodactyla & Tooth, perm./decid. ind. & 1 \\
\hline E28/S78 & 3 & $37 \mathrm{CB}$ & IIIc & L. Archaic & & Carnivora & Metapodial & 1 \\
\hline E28/S78 & 3 & $37 \mathrm{CB}$ & IIIc & L. Archaic & & Mammalia (Large) & Indeterminate & 2 \\
\hline E28/S78 & 3 & $37 \mathrm{CB}$ & IIIc & L. Archaic & & Mammalia (Large) & Long bone & 1 \\
\hline E28/S78 & 3 & $37 \mathrm{CB}$ & IIIc & L. Archaic & & Mammalia (Medium/large) & Indeterminate & 14 \\
\hline E28/S78 & 3 & $37 \mathrm{CB}$ & IIIc & L. Archaic & & Vertebrata & Indeterminate & 27 \\
\hline E28/S78 & 3 & $37 \mathrm{CB}$ & IIIc & L. Archaic & & Vertebrata & Long bone & 1 \\
\hline E28/S78 & 3 & $37 \mathrm{CC}$ & IIIc & L. Archaic & & Mammalia (Large) & Long bone & 2 \\
\hline $\mathrm{E} 28 / \mathrm{S} 78$ & 3 & $37 \mathrm{CC}$ & IIIc & L. Archaic & & Mammalia (Large) & Podial & 1 \\
\hline E28/S78 & 3 & $37 \mathrm{CC}$ & IIIc & L. Archaic & & Mammalia (Medium/large) & Indeterminate & 6 \\
\hline $\mathrm{E} 28 / \mathrm{S} 78$ & 3 & $37 \mathrm{CC}$ & IIIc & L. Archaic & & Serpentes & Vertebra & 1 \\
\hline $\mathrm{E} 28 / \mathrm{S} 78$ & 3 & $37 \mathrm{CC}$ & IIIc & L. Archaic & & Vertebrata & Indeterminate & 24 \\
\hline E28/S78 & 3 & $37 \mathrm{CD}$ & IIIc & L. Archaic & & Mammalia (Large) & Indeterminate & 1 \\
\hline $\mathrm{E} 28 / \mathrm{S} 78$ & 3 & $37 \mathrm{CD}$ & IIIc & L. Archaic & & Mammalia (Medium/large) & Indeterminate & 4 \\
\hline E28/S78 & 3 & $37 \mathrm{CD}$ & IIIc & L. Archaic & & Vertebrata & Indeterminate & 11 \\
\hline E28/S78 & 4 & 37DA & IIIc & L. Archaic & & Artiodactyla & Tooth, perm./decid. ind. & 1 \\
\hline E28/S78 & 4 & 37DA & IIIc & L. Archaic & & Mammalia (Medium/large) & Indeterminate & 1 \\
\hline E28/S78 & 4 & 37DA & IIIc & L. Archaic & & Odocoileus sp. & Distal phalange & 1 \\
\hline E28/S78 & 4 & 37DA & IIIc & L. Archaic & & Vertebrata & Indeterminate & 35 \\
\hline E28/S78 & 4 & $37 \mathrm{DB}$ & IIIc & L. Archaic & & Lepus californicus & Calcaneus & 1 \\
\hline $\mathrm{E} 28 / \mathrm{S} 78$ & 4 & $37 \mathrm{DB}$ & IIIc & L. Archaic & & Mammalia (Medium/large) & Alveolar ridge fragment & 1 \\
\hline E28/S78 & 4 & $37 \mathrm{DB}$ & IIIIc & L. Archaic & & Mammalia (Medium/large) & Indeterminate & 2 \\
\hline E28/S78 & 4 & $37 \mathrm{DB}$ & IIIIc & L. Archaic & & Medium/Large Vertebrata & Long bone & 2 \\
\hline E28/S78 & 4 & $37 \mathrm{DB}$ & IIIc & L. Archaic & & Odocoileus sp. & Permanent tooth & 1 \\
\hline E28/S78 & 4 & $37 \mathrm{DB}$ & IIIIc & L. Archaic & & Testudinata & Shell fragment & 1 \\
\hline E28/S78 & 4 & $37 \mathrm{DB}$ & IIIIc & L. Archaic & & Vertebrata & Indeterminate & 4 \\
\hline E28/S78 & 4 & $37 \mathrm{DB}$ & IIIc & L. Archaic & & Vertebrata & Long bone & 1 \\
\hline E28/S78 & 4 & $37 \mathrm{DC}$ & IIIc & L. Archaic & & Antilocapra/Odocoileus & Ulna & 1 \\
\hline E28/S78 & 4 & 37DC & IIII & L. Archaic & & Bison sp. & Mandible & 1 \\
\hline E28/S78 & 4 & $37 \mathrm{DC}$ & IIIc & L. Archaic & & Bison sp. & Permanent tooth & 1 \\
\hline E28/S78 & 4 & $37 \mathrm{DC}$ & IIII & L. Archaic & & Mammalia (Medium/large) & Indeterminate & 4 \\
\hline E28/S78 & 4 & $37 \mathrm{DC}$ & IIIIc & L. Archaic & & Mammalia (Medium/large) & Long bone & 2 \\
\hline $\mathrm{E} 28 / \mathrm{S} 78$ & 4 & $37 \mathrm{DC}$ & IIIc & L. Archaic & & Vertebrata & Indeterminate & 17 \\
\hline E28/S78 & 4 & $37 \mathrm{DC}$ & IIIIc & L. Archaic & & Vertebrata & Long bone & 1 \\
\hline $\mathrm{E} 28 / \mathrm{S} 78$ & 4 & $37 \mathrm{DD}$ & IIIIc & L. Archaic & & Artiodactyla (Medium) & Tooth, perm./decid. ind. & 1 \\
\hline E28/S78 & 4 & 37DD & IIII & L. Archaic & & Mammalia (Large) & Indeterminate & 1 \\
\hline E28/S78 & 4 & $37 \mathrm{DD}$ & IIIIc & L. Archaic & & Mammalia (Medium/large) & Indeterminate & 9 \\
\hline E28/S78 & 4 & 37DD & IIIc & L. Archaic & & Mammalia (Medium/large) & Long bone & 1 \\
\hline E28/S78 & 4 & 37DD & IIIC & L. Archaic & & Medium/Large Vertebrata & Indeterminate & 5 \\
\hline
\end{tabular}




\begin{tabular}{|c|c|c|c|c|c|c|c|c|}
\hline Square & Level & Lot & Unit & Cultural Affinity & Feature & Taxon & Element & No. \\
\hline E28/S78 & 4 & $37 \mathrm{DD}$ & IIIc & L. Archaic & & Vertebrata & Indeterminate & 3 \\
\hline E28/S78 & 5 & $37 \mathrm{EA}$ & IIIIc & L. Archaic & f173 & Antilocapra/Odocoileus & Proximal sesamoid & 1 \\
\hline E28/S78 & 5 & $37 \mathrm{EA}$ & IIIIc & L. Archaic & f173 & Antilocapra/Odocoileus & Third carpal bone & 1 \\
\hline E28/S78 & 5 & $37 \mathrm{EA}$ & IIIIc & L. Archaic & f173 & Artiodactyla & Tooth, perm./decid. ind. & 1 \\
\hline E28/S78 & 5 & $37 \mathrm{EA}$ & IIIIc & L. Archaic & f173 & cf. Canidae & Metatarsal 4 & 1 \\
\hline E28/S78 & 5 & $37 \mathrm{EA}$ & IIIc & L. Archaic & f173 & Mammalia (Large) & Alveolar ridge fragment & 1 \\
\hline E28/S78 & 5 & $37 \mathrm{EA}$ & IIIc & L. Archaic & f173 & Mammalia (Large) & Cranium & 1 \\
\hline E28/S78 & 5 & 37EA & IIIIc & L. Archaic & f173 & Mammalia (Large) & Indeterminate & 1 \\
\hline E28/S78 & 5 & 37EA & IIII & L. Archaic & f173 & Mammalia (Large) & Long bone & 3 \\
\hline E28/S78 & 5 & $37 \mathrm{EA}$ & IIIc & L. Archaic & $\mathrm{f} 173$ & Mammalia (Large) & Tooth, perm./decid. ind. & 1 \\
\hline E28/S78 & 5 & 37EA & IIII & L. Archaic & f173 & Mammalia (Medium/large) & Cranium & 1 \\
\hline E28/S78 & 5 & 37EA & IIII & L. Archaic & f173 & Mammalia (Medium/large) & Indeterminate & 7 \\
\hline E28/S78 & 5 & 37EA & IIIIc & L. Archaic & f173 & Mammalia (Medium/large) & |Tooth, perm./decid. ind. & 4 \\
\hline E28/S78 & 5 & 37EA & IIIc & L. Archaic & f173 & Odocoileus sp. & Permanent tooth & 1 \\
\hline E28/S78 & 5 & 37EA & IIII & L. Archaic & f173 & Vertebrata & Indeterminate & 81 \\
\hline E28/S78 & 5 & $37 \mathrm{~EB}$ & IIIc & L. Archaic & f173 & Antilocapra/Odocoileus & Phalange & 1 \\
\hline E28/S78 & 5 & 37EB & IIIIc & L. Archaic & f173 & Antilocapra/Odocoileus & Proximal phalange & 1 \\
\hline E28/S78 & 5 & $37 \mathrm{~EB}$ & IIIc & L. Archaic & f173 & Carnivora & Metapodial & 1 \\
\hline E28/S78 & 5 & 37EB & IIIc & L. Archaic & f173 & Mammalia (Medium/large) & Indeterminate & 8 \\
\hline E28/S78 & 5 & 37EB & IIIIc & L. Archaic & f173 & Mammalia (Medium/large) & Long bone & 7 \\
\hline E28/S78 & 5 & $37 \mathrm{~EB}$ & IIIIc & L. Archaic & f173 & Medium/Large Vertebrata & Indeterminate & 2 \\
\hline E28/S78 & 5 & 37EB & IIII & L. Archaic & f173 & Vertebrata & Indeterminate & 5 \\
\hline E28/S78 & 5 & $37 \mathrm{EC}$ & IIII & L. Archaic & f173 & Leporidae & Humerus & 1 \\
\hline E28/S78 & 5 & $37 \mathrm{EC}$ & IIII & L. Archaic & f173 & Mammalia (Large) & Indeterminate & 3 \\
\hline E28/S78 & 5 & $37 \mathrm{EC}$ & IIIIc & L. Archaic & f173 & Mammalia (Large) & Long bone & 1 \\
\hline E28/S78 & 5 & $37 \mathrm{EC}$ & IIII & L. Archaic & f173 & Mammalia (Large) & Tooth, perm./decid. ind. & 1 \\
\hline E28/S78 & 5 & $37 \mathrm{EC}$ & IIII & L. Archaic & f173 & Mammalia (Medium/large) & Alveolar ridge fragment & 2 \\
\hline E28/S78 & 5 & $37 \mathrm{EC}$ & IIIC & L. Archaic & f173 & Mammalia (Medium/large) & Compact bone & 1 \\
\hline E28/S78 & 5 & $37 \mathrm{EC}$ & IIIIc & L. Archaic & f173 & Mammalia (Medium/large) & |Indeterminate & 14 \\
\hline E28/S78 & 5 & $37 \mathrm{EC}$ & IIII & L. Archaic & f173 & Mammalia (Medium/large) & Long bone & 8 \\
\hline E28/S78 & 5 & $37 \mathrm{EC}$ & IIIIc & L. Archaic & f173 & Medium/Large Vertebrata & Indeterminate & 10 \\
\hline E28/S78 & 5 & $37 \mathrm{EC}$ & IIIIC & L. Archaic & f173 & Odocoileus sp. & Permanent tooth & 1 \\
\hline E28/S78 & 5 & $37 \mathrm{EC}$ & IIII & L. Archaic & f173 & Sigmodon hispidus & Mandible & 1 \\
\hline E28/S78 & 5 & $37 \mathrm{EC}$ & IIII & L. Archaic & f173 & Sigmodon hispidus & Permanent tooth & 2 \\
\hline E28/S78 & 5 & $37 \mathrm{EC}$ & IIIIc & L. Archaic & f173 & Small/Medium Vertebrata & Long bone & 1 \\
\hline E28/S78 & 5 & $37 \mathrm{EC}$ & IIIIc & L. Archaic & f173 & Vertebrata & Indeterminate & 41 \\
\hline E28/S78 & 5 & $37 \mathrm{ED}$ & IIIIc & L. Archaic & f173 & Antilocapra/Odocoileus & Scapula & 1 \\
\hline E28/S78 & 5 & 37ED & IIIIc & L. Archaic & f173 & Antilocapra/Odocoileus & Sesamoid & 1 \\
\hline E28/S78 & 5 & 37ED & IIIIc & L. Archaic & f173 & Artiodactyla (Medium) & Tooth, perm./decid. ind. & 4 \\
\hline E28/S78 & 5 & $37 \mathrm{ED}$ & IIIc & L. Archaic & f173 & Leporidae & Tibia & 1 \\
\hline E28/S78 & 5 & 37ED & IIIIc & L. Archaic & f173 & Mammalia (Large) & Indeterminate & 1 \\
\hline E28/S78 & 5 & 37ED & IIII & L. Archaic & f173 & Mammalia (Large) & Long bone & 1 \\
\hline E28/S78 & 5 & $37 \mathrm{ED}$ & IIIc & L. Archaic & f173 & Mammalia (Medium/large) & Indeterminate & 12 \\
\hline E28/S78 & 5 & 37ED & IIIlc & L. Archaic & f173 & Mammalia (Medium/large) & Long bone & 5 \\
\hline E28/S78 & 5 & 37ED & IIIIc & L. Archaic & f173 & Mammalia (Medium/large) & Tooth, perm./decid. ind. & 1 \\
\hline E28/S78 & 5 & 37ED & IIIc & L. Archaic & f173 & Mammalia (Medium/large) & Ulna & 1 \\
\hline E28/S78 & 5 & $37 \mathrm{ED}$ & IIIlc & L. Archaic & f173 & Medium/Large Vertebrata & Long bone & 4 \\
\hline E28/S78 & 5 & $37 \mathrm{ED}$ & IIIIc & L. Archaic & f173 & Odocoileus sp. & Permanent tooth & 1 \\
\hline E28/S78 & 5 & $37 \mathrm{ED}$ & IIII & L. Archaic & f173 & Vertebrata & Indeterminate & 13 \\
\hline E28/S78 & 6 & $37 \mathrm{FA}$ & IIIc & L. Archaic & & Vertebrata & Indeterminate & 22 \\
\hline E28/S78 & 6 & $37 \mathrm{FB}$ & IIIIc & L. Archaic & & Mammalia (Large) & Long bone & 1 \\
\hline E28/S78 & 6 & $37 \mathrm{FB}$ & IIIlc & L. Archaic & & Mammalia (Medium/large) & Indeterminate & 7 \\
\hline E28/S78 & 6 & $37 \mathrm{FB}$ & IIIc & L. Archaic & & Mammalia (Very large) & Long bone & 1 \\
\hline $\mathrm{E} 28 / \mathrm{S} 78$ & 6 & $37 \mathrm{FB}$ & IIIc & L. Archaic & & Medium/Large Vertebrata & Long bone & 2 \\
\hline E28/S78 & 6 & $37 \mathrm{FB}$ & IIIlc & L. Archaic & & Vertebrata & Indeterminate & 2 \\
\hline E28/S78 & 6 & $37 \mathrm{FC}$ & IIIc & L. Archaic & & Mammalia (Medium/large) & Indeterminate & 5 \\
\hline E28/S78 & 6 & $37 \mathrm{FC}$ & IIIlc & L. Archaic & & Mammalia (Medium/large) & Long bone & 2 \\
\hline E28/S78 & 6 & $37 \mathrm{FC}$ & IIIc & L. Archaic & & Medium/Large Vertebrata & Indeterminate & 3 \\
\hline $\mathrm{E} 28 / \mathrm{S} 78$ & 6 & $37 \mathrm{FC}$ & IIIc & L. Archaic & & Vertebrata & Indeterminate & 12 \\
\hline E28/S78 & 6 & $37 \mathrm{FD}$ & IIIl & L. Archaic & & Mammalia (Medium/large) & Indeterminate & 1 \\
\hline E28/S78 & 6 & $37 \mathrm{FD}$ & IIIIc & L. Archaic & & Mammalia (Medium/large) & Long bone & 3 \\
\hline $\mathrm{E} 28 / \mathrm{S} 78$ & 6 & $37 \mathrm{FD}$ & IIIc & L. Archaic & & Odocoileus sp. & Permanent tooth & 1 \\
\hline E28/S78 & 6 & $37 \mathrm{FD}$ & IIIIc & L. Archaic & & Vertebrata & Indeterminate & 1 \\
\hline E28/S78 & 7 & $37 \mathrm{GA}$ & IIIIc & Middle/L. Archaic & & Antilocapra/Odocoileus & Ulna & 1 \\
\hline E28/S78 & 7 & $37 \mathrm{GA}$ & IIII & Middle/L. Archaic & & Mammalia (Medium/large) & Indeterminate & 2 \\
\hline E28/S78 & 7 & $37 \mathrm{GA}$ & IIIc & Middle/L. Archaic & & Mammalia (Medium/large) & Long bone & 2 \\
\hline E28/S78 & 7 & $37 \mathrm{GA}$ & IIIc & Middle/L. Archaic & & Medium/Large Vertebrata & Long bone & 1 \\
\hline
\end{tabular}




\begin{tabular}{|c|c|c|c|c|c|c|c|c|}
\hline Square & Level & Lot & Unit & Cultural Affinity & Feature & Taxon & Element & No. \\
\hline E28/S78 & 7 & $37 \mathrm{GA}$ & IIIc & Middle/L. Archaic & & Vertebrata & Indeterminate & 38 \\
\hline E28/S78 & 7 & $37 \mathrm{~GB}$ & IIIc & Middle/L. Archaic & & Mammalia (Medium/large) & Long bone & 1 \\
\hline E28/S78 & 7 & $37 \mathrm{~GB}$ & IIIc & Middle/L. Archaic & & Vertebrata & Indeterminate & 4 \\
\hline E28/S78 & 7 & $37 \mathrm{GC}$ & $\mathrm{IIlb} / \mathrm{c}$ & Middle/L. Archaic & & Mammalia (Medium/large) & Indeterminate & 2 \\
\hline $\mathrm{E} 28 / \mathrm{S} 78$ & 7 & $37 \mathrm{GC}$ & $\mathrm{mb} / \mathrm{c}$ & Middle/L. Archaic & & Vertebrata & Indeterminate & 7 \\
\hline E28/S78 & 7 & $37 \mathrm{GD}$ & $\mathrm{mb} / \mathrm{c}$ & Middle/L. Archaic & & Mammalia (Medium/large) & Cranium & 1 \\
\hline E28/S78 & 7 & $37 \mathrm{GD}$ & $\mathrm{IIlb} / \mathrm{c}$ & Middle/L. Archaic & & Testudinata & Carapace fragment ind. & 1 \\
\hline E28/S78 & 7 & $37 \mathrm{GD}$ & $\mathrm{mb} / \mathrm{c}$ & Middle/L. Archaic & & Vertebrata & Indeterminate & 3 \\
\hline $\mathrm{E} 28 / \mathrm{S} 78$ & 7 & $37 \mathrm{GD}$ & $\mathrm{mb} / \mathrm{c}$ & Middle/L. Archaic & & Vertebrata & Long bone & 1 \\
\hline E28/S78 & 8 & $37 \mathrm{HA}$ & $\mathrm{IIIb} / \mathrm{c}$ & Middle/L. Archaic & & Mammalia (Large) & Indeterminate & 1 \\
\hline E28/S78 & 8 & $37 \mathrm{HB}$ & $\mathrm{IIIb} / \mathrm{c}$ & Middle/L. Archaic & & Mammalia (Large) & Long bone & 1 \\
\hline E28/S78 & 8 & $37 \mathrm{HB}$ & $\mathrm{mb} / \mathrm{c}$ & Middle/L. Archaic & & Medium/Large Vertebrata & Indeterminate & 1 \\
\hline E28/S78 & 8 & $37 \mathrm{HB}$ & $\mathrm{mim} / \mathrm{c}$ & Middle/L. Archaic & & Vertebrata & Indeterminate & 5 \\
\hline E28/S78 & 8 & $37 \mathrm{HC}$ & IIIb/c & Middle/L. Archaic & & Mammalia (Medium/large) & Tooth, perm./decid. ind. & 1 \\
\hline $\mathrm{E} 28 / \mathrm{S} 78$ & 8 & $37 \mathrm{HC}$ & $\mathrm{mllb} / \mathrm{c}$ & Middle/L. Archaic & & Vertebrata & Indeterminate & 4 \\
\hline $\mathrm{E} 28 / \mathrm{S} 78$ & 8 & $37 \mathrm{HD}$ & $\mathrm{mllb} / \mathrm{c}$ & Middle/L. Archaic & & Mammalia (Large) & Cranium & 1 \\
\hline E28/S78 & 8 & $37 \mathrm{HD}$ & $\mathrm{IIIb} / \mathrm{c}$ & Middle/L. Archaic & & Vertebrata & Indeterminate & 3 \\
\hline E28/S78 & 9 & $37 \mathrm{IB}$ & $\mathrm{mb} / \mathrm{c}$ & Middle/L. Archaic & & Mammalia (Medium/large) & Indeterminate & 2 \\
\hline E28/S78 & 9 & 37IB & $\mathrm{milb} / \mathrm{c}$ & Middle/L. Archaic & & Vertebrata & Indeterminate & 1 \\
\hline $\mathrm{E} 28 / \mathrm{S} 78$ & 9 & 37IC & $\mathrm{IIb} / \mathrm{c}$ & Middle/L. Archaic & & Antilocapra/Odocoileus & Patella & 1 \\
\hline $\mathrm{E} 28 / \mathrm{S} 78$ & 9 & 37IC & $\mathrm{mb} / \mathrm{c}$ & Middle/L. Archaic & & Mammalia (Medium/large) & Indeterminate & 2 \\
\hline E28/S78 & 9 & 37IC & $\mathrm{mllb} / \mathrm{c}$ & Middle/L. Archaic & & Medium/Large Vertebrata & Long bone & 1 \\
\hline $\mathrm{E} 28 / \mathrm{S} 78$ & 9 & 37IC & $\mathrm{IIlb} / \mathrm{c}$ & Middle/L. Archaic & & Vertebrata & Indeterminate & 1 \\
\hline $\mathrm{E} 28 / \mathrm{S} 78$ & 9 & $37 \mathrm{ID}$ & $\mathrm{mb} / \mathrm{c}$ & Middle/L. Archaic & & Vertebrata & Indeterminate & 1 \\
\hline $\mathrm{E} 28 / \mathrm{S} 78$ & 10 & $37 \mathrm{~J}$ & $\mathrm{milb} / \mathrm{c}$ & M. Archaic & f177 & Mammalia (Medium/large) & Indeterminate & 2 \\
\hline $\mathrm{E} 28 / \mathrm{S} 78$ & 10 & 37JA & $\mathrm{IIIb} / \mathrm{c}$ & M. Archaic & & Emydidae & Shell fragment & 1 \\
\hline $\mathrm{E} 28 / \mathrm{S} 78$ & 10 & 37JA & $\mathrm{mb} / \mathrm{c}$ & M. Archaic & & Mammalia (Large) & Long bone & 1 \\
\hline $\mathrm{E} 28 / \mathrm{S} 78$ & 10 & 37JA & $\mathrm{IIIb} / \mathrm{c}$ & M. Archaic & & Mammalia (Medium/large) & Indeterminate & 1 \\
\hline $\mathrm{E} 28 / \mathrm{S} 78$ & 10 & 37JA & $\mathrm{IIlb} / \mathrm{c}$ & M. Archaic & & Vertebrata & Indeterminate & 3 \\
\hline $\mathrm{E} 28 / \mathrm{S} 78$ & 10 & $37 \mathrm{JB}$ & IIIb & M. Archaic & & Mammalia (Large) & Long bone & 1 \\
\hline $\mathrm{E} 28 / \mathrm{S} 78$ & 10 & $37 \mathrm{JB}$ & IIIb & M. Archaic & & Mammalia (Medium/large) & Indeterminate & 3 \\
\hline $\mathrm{E} 28 / \mathrm{S} 78$ & 10 & $37 \mathrm{JB}$ & $\mathrm{IIb}$ & M. Archaic & & Vertebrata & Indeterminate & 3 \\
\hline $\mathrm{E} 28 / \mathrm{S} 78$ & 10 & $37 \mathrm{JC}$ & $\mathrm{mb} / \mathrm{c}$ & M. Archaic & & Vertebrata & Indeterminate & 14 \\
\hline $\mathrm{E} 28 / \mathrm{S} 78$ & 10 & 37JD & IIIb & M. Archaic & & Mammalia (Medium/large) & Indeterminate & 2 \\
\hline $\mathrm{E} 28 / \mathrm{S} 78$ & 11 & $37 \mathrm{KA}$ & $\mathrm{IIIb} / \mathrm{c}$ & M. Archaic & & Mammalia (Medium/large) & Indeterminate & 2 \\
\hline $\mathrm{E} 28 / \mathrm{S} 78$ & 11 & $37 \mathrm{KA}$ & $\mathrm{mllb} / \mathrm{c}$ & M. Archaic & & Vertebrata & Indeterminate & 4 \\
\hline $\mathrm{E} 28 / \mathrm{S} 78$ & 11 & $37 \mathrm{~KB}$ & IIIb & M. Archaic & & Vertebrata & Indeterminate & 4 \\
\hline $\mathrm{E} 28 / \mathrm{S} 78$ & 11 & $37 \mathrm{KC}$ & IIIb & M. Archaic & & Vertebrata & Indeterminate & 8 \\
\hline E28/S78 & 11 & $37 \mathrm{KD}$ & IIIb & M. Archaic & & Mammalia (Medium/large) & Indeterminate & 2 \\
\hline E28/S78 & 11 & $37 \mathrm{KD}$ & IIIlb & M. Archaic & & Mammalia (Medium/large) & Long bone & 1 \\
\hline $\mathrm{E} 28 / \mathrm{S} 78$ & 12 & $37 \mathrm{LA}$ & IIIb & Early/M. Archaic & & Vertebrata & Indeterminate & 2 \\
\hline $\mathrm{E} 28 / \mathrm{S} 78$ & 12 & $37 \mathrm{LB}$ & IIIb & Early/M. Archaic & & Mammalia (Medium/large) & Indeterminate & \\
\hline E28/S78 & 12 & $37 \mathrm{LB}$ & IIIb & Early/M. Archaic & & Vertebrata & Indeterminate & 2 \\
\hline E28/S78 & 12 & $37 \mathrm{LC}$ & IIIb & Early/M. Archaic & & Mammalia (Medium/large) & Indeterminate & 1 \\
\hline E28/S78 & 12 & $37 \mathrm{LD}$ & $\mathrm{IIlb}$ & Early/M. Archaic & & Mammalia (Medium/large) & Indeterminate & 3 \\
\hline E28/S78 & 12 & $37 \mathrm{LD}$ & IIIlb & Early/M. Archaic & & Mammalia (Medium/large) & Long bone & 6 \\
\hline E28/S78 & 12 & $37 \mathrm{LD}$ & IIIb & Early/M. Archaic & & Vertebrata & Indeterminate & 2 \\
\hline E28/S78 & 13 & $37 \mathrm{MA}$ & IIb & E. Archaic & & Vertebrata & Indeterminate & 5 \\
\hline E28/S78 & 13 & $37 \mathrm{MC}$ & IIIlb & E. Archaic & & Vertebrata & Indeterminate & 2 \\
\hline E28/S78 & 13 & $37 \mathrm{MD}$ & IIIb & E. Archaic & & Mammalia (Medium/large) & Indeterminate & 1 \\
\hline E28/S78 & 13 & $37 \mathrm{MD}$ & IIIb & E. Archaic & & Medium/Large Vertebrata & Indeterminate & 1 \\
\hline E28/S78 & 14 & 37NA & IIIIb & E. Archaic & & Vertebrata & Indeterminate & 2 \\
\hline E28/S78 & 14 & $37 \mathrm{NB}$ & IIlb & E. Archaic & & Mammalia (Medium/large) & Indeterminate & 1 \\
\hline E28/S78 & 14 & $37 \mathrm{NB}$ & IIIb & E. Archaic & & Vertebrata & Indeterminate & 1 \\
\hline E28/S78 & 14 & $37 \mathrm{NC}$ & IIIa/b & E. Archaic & & Vertebrata & Indeterminate & 3 \\
\hline E28/S78 & 14 & $37 \mathrm{ND}$ & IIIa/b & E. Archaic & & Lepus californicus & Tibia & 1 \\
\hline E28/S78 & 14 & $37 \mathrm{ND}$ & IIIa/b & E. Archaic & & Odocoileus sp. & Dist. phalange of paradigit & 1 \\
\hline E28/S78 & 14 & $37 \mathrm{ND}$ & IIIa/b & E. Archaic & & Small/Medium Vertebrata & Long bone & 1 \\
\hline E28/S78 & $15 \mathrm{~A}$ & $3701 B$ & IIIb & E. Archaic & & Mammalia (Medium/large) & Indeterminate & 1 \\
\hline E28/S78 & $15 \mathrm{~A}$ & $37 \mathrm{O} 1 \mathrm{C}$ & ШШа/b & E. Archaic & & Mammalia (Medium/large) & Indeterminate & 1 \\
\hline E28/S78 & $15 \mathrm{~A}$ & $3701 \mathrm{C}$ & $\mathrm{ma} / \mathrm{b}$ & E. Archaic & & Vertebrata & Indeterminate & 2 \\
\hline E28/S78 & $15 \mathrm{~A}$ & 37O1D & IIIa & E. Archaic & & Carnivora & Metapodial & 1 \\
\hline E28/S78 & $15 \mathrm{~B}$ & 3702 & III & E. Archaic & f181? & Medium/Large Vertebrata & Indeterminate & 1 \\
\hline E28/S78 & $16 \mathrm{~A}$ & 37P1A & IIIIa & E. Archaic & f181 & Vertebrata & Indeterminate & 3 \\
\hline E28/S78 & $16 \mathrm{~A}$ & 37P1B & IIIIa & E. Archaic & f181 & Mammalia (Medium/large) & Indeterminate & 1 \\
\hline E28/S78 & $16 \mathrm{~A}$ & $37 \mathrm{P} 1 \mathrm{C}$ & Ша & E. Archaic & f181 & Vertebrata & Indeterminate & 1 \\
\hline E28/S78 & $16 \mathrm{~A}$ & 37P1D & IIIa & E. Archaic & f181 & Mammalia (Medium/large) & Indeterminate & 1 \\
\hline
\end{tabular}




\begin{tabular}{|c|c|c|c|c|c|c|c|c|}
\hline Square & Level & Lot & Unit & Cultural Affinity & Feature & Taxon & Element & No. \\
\hline$\overline{E 28 / S 78}$ & $16 \mathrm{~A}$ & 37P1D & IIIa & E. Archaic & f181 & Small/Medium Vertebrata & Long bone & 1 \\
\hline E28/S78 & $16 \mathrm{~B}$ & 37P2A & IIIa & E. Archaic & f181 & Vertebrata & Indeterminate & 1 \\
\hline E28/S78 & $16 \mathrm{~B}$ & $37 \mathrm{P} 2 \mathrm{C}$ & ШІа & E. Archaic & f181 & Mammalia (Medium/large) & Indeterminate & 2 \\
\hline E28/S78 & $16 \mathrm{~B}$ & $37 \mathrm{P} 2 \mathrm{C}$ & ШШа & E. Archaic & f181 & Vertebrata & Indeterminate & 1 \\
\hline E28/S78 & $16 \mathrm{~B}$ & 37P2D & IIIa & E. Archaic & & Mammalia (Medium/large) & Long bone & 1 \\
\hline E28/S78 & $16 \mathrm{~B}$ & 37P2D & Ша & E. Archaic & & Medium/Large Vertebrata & Indeterminate & 1 \\
\hline $\mathrm{E} 28 / \mathrm{S} 78$ & $17 \mathrm{~A}$ & 37Q1A & ШІа & E. Archaic & f181 & Mammalia (Medium/large) & Indeterminate & 1 \\
\hline E28/S78 & $17 \mathrm{~A}$ & 37Q1A & IIIIa & E. Archaic & f181 & Small/Medium Vertebrata & Long bone & 1 \\
\hline E28/S78 & $17 \mathrm{~A}$ & $37 \mathrm{Q} 1 \mathrm{~B}$ & Ша & E. Archaic & & Vertebrata & Indeterminate & 1 \\
\hline E28/S78 & $17 \mathrm{~A}$ & $37 \mathrm{Q} 1 \mathrm{C}$ & ШІа & E. Archaic & & Mammalia (Medium/large) & Indeterminate & 1 \\
\hline E28/S78 & $17 \mathrm{~A}$ & $37 \mathrm{Q} 1 \mathrm{C}$ & IIIa & E. Archaic & & Medium/Large Vertebrata & Indeterminate & 1 \\
\hline E28/S78 & $17 \mathrm{~A}$ & 37Q1D & Ша & E. Archaic & f181 & Vertebrata & Indeterminate & 1 \\
\hline E28/S78 & 17B & $37 \mathrm{Q} 2 \mathrm{~A}$ & III & E. Archaic & f181 & Vertebrata & Indeterminate & 4 \\
\hline E28/S78 & 17B & 37Q2B & IIIa & E. Archaic & & Mammalia (Medium/large) & Indeterminate & 10 \\
\hline E28/S78 & 17B & 37Q2B & IIIIa & E. Archaic & & Mammalia (Medium/large) & Long bone & 5 \\
\hline E28/S78 & 17B & $37 \mathrm{Q} 2 \mathrm{~B}$ & ШІа & E. Archaic & & Vertebrata & Indeterminate & 3 \\
\hline E28/S78 & 17B & 37Q2D & IIIIa & E. Archaic & f181 & Small/Medium Vertebrata & Long bone & 1 \\
\hline E28/S78 & $18 \mathrm{~A}$ & 37R1A & IIIa & E. Archaic & f181 & Vertebrata & Indeterminate & 2 \\
\hline E28/S78 & $18 \mathrm{~A}$ & $37 \mathrm{R} 1 \mathrm{~B}$ & IIIa & E. Archaic & & Small/Medium Vertebrata & Long bone & 1 \\
\hline E28/S78 & $18 \mathrm{~A}$ & $37 \mathrm{R} 1 \mathrm{C}$ & IIIIa & E. Archaic & & Medium/Large Vertebrata & Long bone & 1 \\
\hline E28/S78 & $18 \mathrm{~A}$ & 37R1C & ШІа & E. Archaic & & Testudinata & Shell fragment & 2 \\
\hline E28/S78 & $18 \mathrm{~A}$ & 37R1C & ШІа & E. Archaic & & Vertebrata & Indeterminate & 1 \\
\hline E28/S78 & $18 \mathrm{~B}$ & 37R2B & III/IIIa & L. Paleo./E. Archaic & & Mammalia (Medium/large) & Indeterminate & 2 \\
\hline E28/S78 & $18 \mathrm{~B}$ & $37 R 2 B$ & ШІШІШа & L. Paleo./E. Archaic & & Vertebrata & Indeterminate & 1 \\
\hline E28/S78 & $18 \mathrm{~B}$ & $37 \mathrm{R} 2 \mathrm{C}$ & II/IIIa & L. Paleo./E. Archaic & & Sylvilagus sp. & Calcaneus & 1 \\
\hline E28/S78 & $18 \mathrm{~B}$ & 37R2D & III & L. Paleo. & & Mammalia (Medium/large) & Long bone & 1 \\
\hline E28/S78 & $19 \mathrm{~A}$ & $37 \mathrm{~S} 1 \mathrm{~B}$ & II/IIIa & L. Paleo./E. Archaic & & Medium/Large Vertebrata & Indeterminate & 1 \\
\hline E28/S78 & $19 \mathrm{~A}$ & $37 \mathrm{~S} 1 \mathrm{~B}$ & II/IIIa & L. Paleo./E. Archaic & & Small/Medium Vertebrata & Proximal phalange & 1 \\
\hline E28/S78 & $19 \mathrm{~A}$ & $37 \mathrm{~S} 1 \mathrm{C}$ & II/IIIa & L. Paleo./E. Archaic & & Small/Medium Vertebrata & Long bone & 1 \\
\hline E28/S78 & $19 \mathrm{~A}$ & 37 S1D & III & L. Paleo. & & Mammalia (Medium/large) & Indeterminate & 3 \\
\hline E28/S78 & $19 \mathrm{~A}$ & 37 S1D & III & L. Paleo. & & Medium/Large Vertebrata & Long bone & 1 \\
\hline E28/S78 & $19 \mathrm{~A}$ & 37 S1D & III & L. Paleo. & & Vertebrata & Indeterminate & 1 \\
\hline E28/S78 & 19B & $37 \mathrm{~S} 2 \mathrm{~A}$ & II/IIIa & L. Paleo./E. Archaic & f181 & Lepus californicus & Calcaneus & 1 \\
\hline $\mathrm{E} 28 / \mathrm{S} 78$ & 19B & 37 S2B & III & L. Paleo. & & Medium/Large Vertebrata & Long bone & 1 \\
\hline E28/S78 & 19B & $37 \mathrm{~S} 2 \mathrm{~B}$ & III & L. Paleo. & & Small/Medium Vertebrata & Long bone & 1 \\
\hline E28/S78 & 19B & $37 \mathrm{~S} 2 \mathrm{C}$ & II/IIIa & L. Paleo./E. Archaic & & Sylvilagus sp. & Calcaneus & 1 \\
\hline E28/S78 & 19B & $37 S 2 D$ & II & L. Paleo. & & Vertebrata & Indeterminate & 1 \\
\hline E28/S78 & $20 \mathrm{~A}$ & $37 \mathrm{~T} 1 \mathrm{~A}$ & II/IIIa & L. Paleo./E. Archaic & f181?18 & Mammalia (Medium/large) & Long bone & 1 \\
\hline E28/S78 & $20 \mathrm{~A}$ & 37T1B & III & L. Paleo. & & Mammalia (Medium/large) & Indeterminate & 1 \\
\hline E28/S78 & $20 \mathrm{~A}$ & 37T1B & III & L. Paleo. & & Mammalia (Medium/large) & Long bone & 2 \\
\hline E28/S78 & $20 \mathrm{~A}$ & 37T1B & III & L. Paleo. & & Medium/Large Vertebrata & Indeterminate & 1 \\
\hline E28/S78 & $20 \mathrm{~A}$ & 37T1B & III & L. Paleo. & & Small/Medium Vertebrata & Long bone & 1 \\
\hline E28/S78 & $20 \mathrm{~A}$ & $37 \mathrm{~T} 1 \mathrm{~B}$ & III & L. Paleo. & & Vertebrata & Indeterminate & 2 \\
\hline E28/S78 & $20 \mathrm{~A}$ & $37 \mathrm{~T} 1 \mathrm{C}$ & II/IIIa & L. Paleo./E. Archaic & & Medium/Large Vertebrata & Long bone & 1 \\
\hline E28/S78 & $20 \mathrm{~A}$ & 37T1D & II & L. Paleo. & & Testudinata & Shell fragment & 1 \\
\hline E28/S78 & $20 \mathrm{~A}$ & 37T1D & II & L. Paleo. & & Vertebrata & Indeterminate & 1 \\
\hline $\mathrm{E} 28 / \mathrm{S} 78$ & 20B & $37 \mathrm{~T} 2 \mathrm{~B}$ & II & L. Paleo. & & Vertebrata & Indeterminate & 1 \\
\hline E28/S78 & 20B & $37 \mathrm{~T} 2 \mathrm{C}$ & II & L. Paleo. & & Mammalia (Medium/large) & Indeterminate & 1 \\
\hline $\mathrm{E} 28 / \mathrm{S} 78$ & $20 \mathrm{~B}$ & $37 \mathrm{~T} 2 \mathrm{C}$ & II & L. Paleo. & & Mammalia (Medium/large) & Long bone & 1 \\
\hline $\mathrm{E} 28 / \mathrm{S} 78$ & $20 \mathrm{~B}$ & $37 \mathrm{~T} 2 \mathrm{C}$ & II & L. Paleo. & & Medium/Large Vertebrata & Indeterminate & 1 \\
\hline E28/S78 & 20B & $37 \mathrm{~T} 2 \mathrm{C}$ & II & L. Paleo. & & Vertebrata & Indeterminate & 1 \\
\hline E28/S78 & 20B & $37 \mathrm{~T} 2 \mathrm{D}$ & II & L. Paleo. & & Small/Medium Vertebrata & Long bone & 2 \\
\hline E28/S78 & $21 \mathrm{~A}$ & 37U1A & III & L. Paleo. & & Mammalia (Medium/large) & Indeterminate & 2 \\
\hline $\mathrm{E} 28 / \mathrm{S} 78$ & $21 \mathrm{~A}$ & 37U1A & II & L. Paleo. & & Medium/Large Vertebrata & Indeterminate & 1 \\
\hline E28/S78 & $21 \mathrm{~A}$ & 37U1A & III & L. Paleo. & f186 & Mammalia (Medium) & Proximal phalange & 1 \\
\hline E28/S78 & $21 \mathrm{~A}$ & 37U1B & II & L. Paleo. & & Medium/Large Vertebrata & Long bone & 1 \\
\hline E28/S78 & $21 \mathrm{~A}$ & 37U1D & III & L. Paleo. & & Mammalia (Medium/large) & Long bone & 1 \\
\hline E28/S78 & 21B & $37 \mathrm{U} 2$ & II & L. Paleo. & & Medium/Large Vertebrata & Indeterminate & 1 \\
\hline E28/S78 & 21B & $37 \mathrm{U} 2 \mathrm{C}$ & II & L. Paleo. & & Mammalia (Medium/large) & Tooth, perm./decid. ind. & 1 \\
\hline E28/S78 & $22 \mathrm{~A}$ & $37 \mathrm{~V} 1 \mathrm{~A}$ & III & L. Paleo. & & Mammalia (Medium/large) & Long bone & 1 \\
\hline E28/S78 & $22 \mathrm{~A}$ & $37 \mathrm{~V} 1 \mathrm{~A}$ & II & L. Paleo. & & Vertebrata & Indeterminate & 1 \\
\hline $\mathrm{E} 28 / \mathrm{S} 78$ & $22 \mathrm{~A}$ & 37V1B & II & L. Paleo. & & Mammalia (Medium) & Proximal phalange & 1 \\
\hline E28/S78 & $22 \mathrm{~A}$ & $37 \mathrm{~V} 1 \mathrm{~B}$ & III & L. Paleo. & & Medium/Large Vertebrata & Indeterminate & 1 \\
\hline E28/S78 & $22 \mathrm{~A}$ & 37V1B & II & L. Paleo. & & Medium/Large Vertebrata & Long bone & 1 \\
\hline E28/S78 & 22B & $37 \mathrm{~V} 2 \mathrm{~A}$ & II & L. Paleo. & & Medium/Large Vertebrata & Long bone & 1 \\
\hline E28/S78 & $22 \mathrm{~B}$ & $37 \mathrm{~V} 2 \mathrm{~A}$ & III & L. Paleo. & & Small/Medium Vertebrata & Long bone & 1 \\
\hline E28/S78 & $23 \mathrm{~A}$ & $37 \mathrm{~W} 1 \mathrm{~A}$ & II & L. Paleo. & & Mammalia (Large) & Long bone & 1 \\
\hline
\end{tabular}




\begin{tabular}{|c|c|c|c|c|c|c|c|c|}
\hline Square & Level & Lot & Unit & Cultural Affinity & Feature & Taxon & Element & No. \\
\hline E28/S78 & $23 \mathrm{~A}$ & $37 \mathrm{~W} 1 \mathrm{~A}$ & III & L. Paleo. & & Mammalia (Medium/large) & Indeterminate & 1 \\
\hline E28/S78 & $23 \mathrm{~A}$ & $37 \mathrm{~W} 1 \mathrm{~A}$ & II & L. Paleo. & & Medium/Large Vertebrata & Indeterminate & 1 \\
\hline E28/S78 & $23 \mathrm{~A}$ & $37 \mathrm{~W} 1 \mathrm{~A}$ & III & L. Paleo. & & Vertebrata & Indeterminate & 1 \\
\hline E28/S78 & $23 \mathrm{~A}$ & 37W1B & II & L. Paleo. & & Vertebrata & Indeterminate & 1 \\
\hline E28/S78 & 23B & $37 \mathrm{~W} 2 \mathrm{~A}$ & III & L. Paleo. & & Vertebrata & Indeterminate & 1 \\
\hline E28/S78 & 23B & $37 \mathrm{~W} 2 \mathrm{~B}$ & III & L. Paleo. & & Vertebrata & Indeterminate & 1 \\
\hline E28/S78 & 23B & $37 \mathrm{~W} 2 \mathrm{C}$ & II & L. Paleo. & & Small/Medium Vertebrata & Long bone & 1 \\
\hline E28/S78 & 23B & $37 \mathrm{~W} 2 \mathrm{C}$ & III & L. Paleo. & & Vertebrata & Indeterminate & 1 \\
\hline E28/S78 & 23B & $37 \mathrm{~W} 2 \mathrm{D}$ & III & L. Paleo. & & Mammalia (Medium/large) & Indeterminate & 1 \\
\hline E28/S78 & $24 \mathrm{~A}$ & $37 X 1 \mathrm{~A}$ & III & L. Paleo. & & Mammalia (Medium/large) & Caudal vertebra & 1 \\
\hline E28/S78 & $24 \mathrm{~A}$ & $37 X 1 B$ & III & L. Paleo. & & Mammalia (Medium/large) & Indeterminate & 1 \\
\hline E28/S78 & $24 \mathrm{~A}$ & $37 \mathrm{X} 1 \mathrm{C}$ & III & L. Paleo. & & Mammalia (Medium/large) & Tooth, perm./decid. ind. & 1 \\
\hline E28/S78 & $24 \mathrm{~A}$ & 37X1D & III & L. Paleo. & & Medium/Large Vertebrata & Indeterminate & 1 \\
\hline E28/S78 & 24B & $37 \mathrm{X} 2 \mathrm{C}$ & II & L. Paleo. & & Medium/Large Vertebrata & Indeterminate & 1 \\
\hline E28/S78 & $25 \mathrm{~A}$ & 37Y1A & III & L. Paleo. & & Vertebrata & Indeterminate & 1 \\
\hline E28/S78 & $25 \mathrm{~A}$ & 37Y1B & III & L. Paleo. & & Vertebrata & Indeterminate & 1 \\
\hline E28/S78 & $25 \mathrm{~A}$ & 37Y1D & $\mathrm{Id} / \mathrm{II}$ & L. Paleo. & & Mammalia (Medium/large) & Long bone & 1 \\
\hline E28/S78 & $25 \mathrm{~A}$ & 37Y1D & $\mathrm{Id} / \mathrm{II}$ & L. Paleo. & & Vertebrata & Indeterminate & 1 \\
\hline E28/S78 & 25B & $37 \mathrm{Y} 2 \mathrm{~B}$ & $\mathrm{Id} / \mathrm{II}$ & L. Paleo. & & Medium/Large Vertebrata & Indeterminate & 2 \\
\hline E28/S78 & $25 \mathrm{~B}$ & $37 \mathrm{Y} 2 \mathrm{C}$ & $\mathrm{Id} / \mathrm{II}$ & L. Paleo. & & Vertebrata & Indeterminate & 1 \\
\hline E28/S78 & $26 \mathrm{~A}$ & 37Z1B & $\mathrm{Id} / \mathrm{II}$ & L. Paleo. & & Mammalia (Medium/large) & Indeterminate & 1 \\
\hline E28/S78 & $26 \mathrm{~A}$ & 37Z1D & Id & L. Paleo. & & Testudinata & Neural & 1 \\
\hline E28/S78 & $26 \mathrm{~A}$ & 37Z1D & Id & L. Paleo. & & Vertebrata & Indeterminate & 1 \\
\hline E28/S78 & $26 \mathrm{~B}$ & $37 \mathrm{Z} 2 \mathrm{~A}$ & $\mathrm{Id} / \mathrm{II}$ & L. Paleo. & & Vertebrata & Indeterminate & 1 \\
\hline E28/S78 & $26 \mathrm{~B}$ & $37 \mathrm{Z} 2 \mathrm{C}$ & Id & L. Paleo. & & Odocoileus sp. & Permanent tooth & 1 \\
\hline E28/S78 & $26 \mathrm{~B}$ & 37Z2D & Isi-c/Id & L. Paleo. & & Mammalia (Medium/large) & Indeterminate & 1 \\
\hline E28/S78 & $27 \mathrm{~A}$ & 37AA1D & Isi-c/Id & L. Paleo. & & Vertebrata & Indeterminate & 1 \\
\hline E28/S78 & 27B & $37 \mathrm{AA} 2 \mathrm{~A}$ & Id & L. Paleo. & & Vertebrata & Indeterminate & 1 \\
\hline E28/S78 & $27 \mathrm{~B}$ & 37AA2B & Id & L. Paleo. & & Leporidae & Permanent tooth & 1 \\
\hline E28/S78 & $27 \mathrm{~B}$ & 37AA2B & Id & L. Paleo. & & Mammalia (Medium) & Proximal phalange & 1 \\
\hline E28/S78 & 27B & 37AA2B & Id & L. Paleo. & & Mammalia (Medium/large) & Indeterminate & 1 \\
\hline E28/S78 & $27 \mathrm{~B}$ & 37AA2B & Id & L. Paleo. & & Medium/Large Vertebrata & Indeterminate & 1 \\
\hline E28/S78 & $27 \mathrm{~B}$ & 37AA2B & Id & L. Paleo. & & Vertebrata & Indeterminate & 1 \\
\hline E28/S78 & $27 \mathrm{~B}$ & 37AA2C & Isi-c/Id & L. Paleo. & & Vertebrata & Indeterminate & 1 \\
\hline E28/S78 & $28 \mathrm{~A}$ & 37BB1B & Isi-c/Id & L. Paleo. & & Odocoileus sp. & Middle phalange & 1 \\
\hline E28/S78 & $28 \mathrm{~A}$ & 37BB1B & Isi-c/Id & L. Paleo. & & Vertebrata & Indeterminate & 1 \\
\hline E28/S78 & $28 \mathrm{~A}$ & $37 \mathrm{BB} 1 \mathrm{C}$ & Isi-c/Id & L. Paleo. & & Odocoileus sp. & Permanent tooth & 1 \\
\hline E28/S78 & $28 \mathrm{~B}$ & 37BB2A & Isi-c/Id & L. Paleo. & & Vertebrata & Indeterminate & 3 \\
\hline E28/S78 & $28 \mathrm{~B}$ & 37BB2B & Isi-c/Id & L. Paleo. & & Vertebrata & Indeterminate & 1 \\
\hline E28/S78 & 28B & $37 \mathrm{BB} 2 \mathrm{C}$ & Isi-c & L. Paleo. & & Mammalia (Medium/large) & Indeterminate & 1 \\
\hline E28/S78 & 28B & $37 \mathrm{BB} 2 \mathrm{C}$ & Isi-c & L. Paleo. & & Mammalia (Medium/large) & Tooth, perm./decid. ind. & 1 \\
\hline E28/S78 & 28B & 37BB2D & Isi-c & L. Paleo. & & Mammalia (Medium/large) & Indeterminate & 2 \\
\hline E28/S78 & 28B & 37BB2D & Isi-c & L. Paleo. & & Medium/Large Vertebrata & Indeterminate & 1 \\
\hline E28/S78 & $29 \mathrm{~A}$ & $37 \mathrm{CC} 1 \mathrm{~A}$ & Isi-c/Id & L. Paleo. & & Vertebrata & Indeterminate & 3 \\
\hline E28/S78 & $29 \mathrm{~A}$ & $37 \mathrm{CC} 1 \mathrm{~B}$ & Isi-c/Id & L. Paleo. & & Vertebrata & Indeterminate & 1 \\
\hline E28/S78 & $29 \mathrm{~A}$ & $37 \mathrm{CC} 1 \mathrm{C}$ & Isi-c & L. Paleo. & & Vertebrata & Indeterminate & 1 \\
\hline E28/S78 & $29 \mathrm{~A}$ & $37 \mathrm{CC} 1 \mathrm{D}$ & Isi-c & L. Paleo. & & Chondrichthyes & |Tooth & 1 \\
\hline E28/S78 & $29 \mathrm{~A}$ & 37CC1D & Isi-c & L. Paleo. & & Mammalia (Medium/large) & Indeterminate & 1 \\
\hline E28/S78 & $29 \mathrm{~A}$ & 37CC1D & Isi-c & L. Paleo. & & Mammalia (Medium/large) & Long bone & 1 \\
\hline E28/S78 & $29 \mathrm{~A}$ & 37CC1D & Isi-c & L. Paleo. & & Medium/Large Vertebrata & Indeterminate & 1 \\
\hline E28/S78 & $29 \mathrm{~A}$ & $37 \mathrm{CC} 1 \mathrm{D}$ & Isi-c & L. Paleo. & & Sylvilagus sp. & Astragalus & 1 \\
\hline E28/S78 & $29 \mathrm{~A}$ & 37CC1D & Isi-c & L. Paleo. & & Vertebrata & Indeterminate & 3 \\
\hline E28/S78 & 29B & $37 \mathrm{CC} 2 \mathrm{~A}$ & Isi-c & L. Paleo. & & Vertebrata & Indeterminate & 1 \\
\hline E28/S78 & 29B & $37 \mathrm{CC} 2 \mathrm{~B}$ & Isi-c & L. Paleo. & & Mammalia (Medium/large) & Long bone & 5 \\
\hline E28/S78 & 29B & $37 \mathrm{CC} 2 \mathrm{~B}$ & Isi-c & L. Paleo. & & Vertebrata & Long bone & 1 \\
\hline E28/S78 & 29B & $37 \mathrm{CC} 2 \mathrm{C}$ & Isi-c & L. Paleo. & & Mammalia (Medium/large) & Indeterminate & 1 \\
\hline E28/S78 & 29B & $37 \mathrm{CC} 2 \mathrm{D}$ & Isi-c & L. Paleo. & & Mammalia (Medium/large) & Long bone & 1 \\
\hline E28/S78 & 29B & $37 \mathrm{CC} 2 \mathrm{D}$ & Isi-c & L. Paleo. & & Vertebrata & Indeterminate & 1 \\
\hline E28/S78 & $30 \mathrm{~A}$ & 37DD1A & Isi-c & L. Paleo. & & Artiodactyla & Tooth, perm./decid. ind. & 1 \\
\hline E28/S78 & $30 \mathrm{~A}$ & 37DD1A & Isi-c & L. Paleo. & & Mammalia (Large) & Long bone & 1 \\
\hline E28/S78 & $30 \mathrm{~A}$ & 37DD1A & Isi-c & L. Paleo. & & Vertebrata & Indeterminate & 2 \\
\hline E28/S78 & $30 \mathrm{~A}$ & 37DD1B & Isi-c & L. Paleo. & & Kinosternidae & Peripheral & 1 \\
\hline E28/S78 & $30 \mathrm{~A}$ & 37DD1B & Isi-c & L. Paleo. & & Vertebrata & Indeterminate & 1 \\
\hline E28/S78 & 30B & 37DD2A & Isi-c & L. Paleo. & & Vertebrata & Indeterminate & 2 \\
\hline E28/S78 & $30 \mathrm{~B}$ & 37DD2D & Isi-c & L. Paleo. & & Mammalia (Medium/large) & Indeterminate & 2 \\
\hline E28/S78 & 30B & 37DD2D & Isi-c & L. Paleo. & & Mammalia (Medium/large) & Long bone & 1 \\
\hline E28/S78 & 30B & 37DD2D & Isi-c & L. Paleo. & & Testudinata & Peripheral & 1 \\
\hline
\end{tabular}




\begin{tabular}{|c|c|c|c|c|c|c|c|c|}
\hline Square & Level & Lot & Unit & Cultural Affinity & Feature & Taxon & Element & No. \\
\hline E28/S78 & $30 \mathrm{~B}$ & 37DD2D & Isi-c & L. Paleo. & & Vertebrata & Indeterminate & 1 \\
\hline E28/S78 & 31 & $37 \mathrm{EE}$ & Isi-c & L. Paleo. & & Vertebrata & Indeterminate & 7 \\
\hline $\mathrm{E} 28 / \mathrm{S} 78$ & $31 \mathrm{~A}$ & 37EE1D & Isi-c & L. Paleo. & & Mammalia (Medium/large) & Long bone & 1 \\
\hline E28/S78 & $31 \mathrm{~A}$ & 37EE1D & Isi-c & L. Paleo. & & Medium/Large Vertebrata & Indeterminate & 2 \\
\hline E28/S78 & $31 \mathrm{~A}$ & 37EE1D & Isi-c & L. Paleo. & & Sylvilagus sp. & Tibia & 1 \\
\hline E28/S78 & $31 \mathrm{~A}$ & 37EE1D & Isi-c & L. Paleo. & & Testudinata & Shell fragment & 1 \\
\hline $\mathrm{E} 28 / \mathrm{S} 78$ & $31 \mathrm{~B}$ & 37EE2B & Isi-c & L. Paleo. & & Leporidae & Permanent tooth & 1 \\
\hline E28/S78 & 31B & 37EE2C & Isi-c & L. Paleo. & & Mammalia (Medium/large) & Indeterminate & 1 \\
\hline E28/S78 & 31B & 37EE2C & Isi-c & L. Paleo. & & Medium/Large Vertebrata & Indeterminate & 1 \\
\hline E28/S78 & $32 \mathrm{~A}$ & 37FF1A & Isi-c & L. Paleo. & & Mammalia (Medium/large) & Indeterminate & 1 \\
\hline E28/S78 & $32 \mathrm{~A}$ & 37FF1A & Isi-c & L. Paleo. & & Mammalia (Medium/large) & Long bone & 1 \\
\hline E28/S78 & $32 \mathrm{~A}$ & 37FF1B & Icl/Isi-c & Paleoindian & & Mammalia (Medium/large) & Indeterminate & 3 \\
\hline $\mathrm{E} 28 / \mathrm{S} 78$ & $32 \mathrm{~A}$ & 37FF1B & Icl/Isi-c & Paleoindian & & Testudinata & Shell fragment & 1 \\
\hline $\mathrm{E} 28 / \mathrm{S} 78$ & $32 \mathrm{~A}$ & 37FF1D & Isi-c & L. Paleo. & & Mammalia (Medium/large) & Long bone & 1 \\
\hline E28/S78 & $32 \mathrm{~A}$ & 37FF1D & Isi-c & L. Paleo. & & Medium/Large Vertebrata & Indeterminate & 2 \\
\hline E28/S78 & $32 \mathrm{~B}$ & $37 \mathrm{FF} 2 \mathrm{~B}$ & Icl/Isi-c & Paleoindian & & Mammalia (Medium/large) & Indeterminate & 1 \\
\hline E28/S78 & 32B & 37FF2B & Icl/Isi-c & Paleoindian & & Testudinata & Shell fragment & 1 \\
\hline E28/S78 & 32B & $37 \mathrm{FF} 2 \mathrm{~B}$ & Icl/Isi-c & Paleoindian & & Vertebrata & Indeterminate & 1 \\
\hline E28/S78 & 32B & $37 \mathrm{FF} 2 \mathrm{D}$ & Icl/Isi-c & Paleoindian & & Mammalia (Medium/large) & Tooth, perm./decid. ind. & 1 \\
\hline E28/S78 & 32B & $37 \mathrm{FF} 2 \mathrm{D}$ & Icl/Isi-c & Paleoindian & & Mammalia (Small) & Permanent tooth & 1 \\
\hline E28/S78 & $32 \mathrm{~B}$ & 37FF2D & Icl/Isi-c & Paleoindian & & Osteichthyes (Small) & Atlas & 1 \\
\hline $\mathrm{E} 28 / \mathrm{S} 78$ & $32 \mathrm{~B}-33 \mathrm{~A}$ & 37FF2GG & Icl/Isi-c & Paleoindian & f187 & Vertebrata & Indeterminate & 1 \\
\hline $\mathrm{E} 28 / \mathrm{S} 78$ & $33 \mathrm{~A}$ & 37GG1A & Icl/Isi-c & Paleoindian & & Mammalia (Medium/large) & Podial & 1 \\
\hline E28/S78 & $33 \mathrm{~A}$ & 37GG1B & Icl & E. Paleo. & & Vertebrata & Indeterminate & 1 \\
\hline $\mathrm{E} 28 / \mathrm{S} 78$ & $33 \mathrm{~B}$ & 37GG2B & Icl & E. Paleo. & & Mammalia (Small) & Humerus & 1 \\
\hline E28/S78 & $33 \mathrm{~B}$ & $37 \mathrm{GG} 2 \mathrm{C}$ & Icl & E. Paleo. & & Mammalia (Medium/large) & Caudal vertebra & 1 \\
\hline E28/S78 & $33 \mathrm{~B}$ & $37 \mathrm{GG} 2 \mathrm{C}$ & Icl & E. Paleo. & & Medium/Large Vertebrata & Indeterminate & 1 \\
\hline E28/S78 & $33 \mathrm{~B}$ & $37 \mathrm{GG} 2 \mathrm{C}$ & Icl & E. Paleo. & & Small/Medium Vertebrata & Long bone & 3 \\
\hline E28/S78 & $34 \mathrm{~A}$ & 37HH1A & Icl & E. Paleo. & & Medium/Large Vertebrata & Indeterminate & 1 \\
\hline E28/S78 & $34 \mathrm{~A}$ & 37HH1B & Icl & E. Paleo. & & Mammalia (Large) & Indeterminate & 2 \\
\hline E28/S78 & $34 \mathrm{~A}$ & 37НH1В & Icl & E. Paleo. & & Medium/Large Vertebrata & Indeterminate & 2 \\
\hline E28/S78 & $34 \mathrm{~A}$ & $37 \mathrm{HH} 1 \mathrm{~B}$ & Icl & E. Paleo. & & Serpentes & Dorsal vertebra & 1 \\
\hline E28/S78 & $34 \mathrm{~A}$ & $37 \mathrm{HH} 1 \mathrm{~B}$ & Icl & E. Paleo. & & Vertebrata & Indeterminate & 5 \\
\hline E28/S78 & $34 \mathrm{~A}$ & $37 \mathrm{HH} 1 \mathrm{C}$ & Icl & E. Paleo. & & Vertebrata & Indeterminate & 1 \\
\hline $\mathrm{E} 28 / \mathrm{S} 78$ & $34 \mathrm{~B}$ & $37 \mathrm{HH} 2 \mathrm{~A}$ & Icl & E. Paleo. & & Serpentes & Dorsal vertebra & 1 \\
\hline E28/S78 & 34B & $37 \mathrm{HH} 2 \mathrm{C}$ & Icl & E. Paleo. & & Serpentes & Dorsal vertebra & 1 \\
\hline $\mathrm{E} 28 / \mathrm{S} 78$ & $34 \mathrm{~B}$ & $37 \mathrm{HH} 2 \mathrm{C}$ & Icl & E. Paleo. & & Vertebrata & Indeterminate & 2 \\
\hline $\mathrm{E} 28 / \mathrm{S} 78$ & 34B & $37 \mathrm{HH} 2 \mathrm{D}$ & Icl & E. Paleo. & & Small/Medium Vertebrata & Long bone & 1 \\
\hline E28/S78 & $35 \mathrm{~A}$ & 37II1A & Icl & E. Paleo. & & Mammalia (Medium/large) & Indeterminate & 1 \\
\hline E28/S78 & $35 \mathrm{~A}$ & 37II1A & Icl & E. Paleo. & & Vertebrata & Indeterminate & 1 \\
\hline $\mathrm{E} 28 / \mathrm{S} 78$ & $35 \mathrm{~A}$ & 37II1B & Icl & E. Paleo. & & Serpentes & Dorsal vertebra & 1 \\
\hline E28/S78 & $35 \mathrm{~A}$ & 37II1B & Icl & E. Paleo. & & Vertebrata & Indeterminate & 1 \\
\hline E28/S78 & $35 \mathrm{~A}$ & 37II1D & Icl & E. Paleo. & & Mammalia (Medium/large) & Indeterminate & 1 \\
\hline $\mathrm{E} 28 / \mathrm{S} 78$ & $35 \mathrm{~A}$ & 37II1D & Icl & E. Paleo. & & Mammalia (Small) & Caudal vertebra & 1 \\
\hline E28/S78 & $35 \mathrm{~A}$ & 37II1D & Icl & E. Paleo. & & Osteichthyes (Small) & Amphicelous vertebra & 1 \\
\hline $\mathrm{E} 28 / \mathrm{S} 78$ & $35 \mathrm{~A}$ & 37II1D & Icl & E. Paleo. & & Small vertebrate, class ind. & Caudal vertebra & 1 \\
\hline $\mathrm{E} 28 / \mathrm{S} 78$ & $35 \mathrm{~A}$ & 37II1D & Icl & E. Paleo. & & Vertebrata & Indeterminate & 1 \\
\hline E28/S78 & $35 \mathrm{~B}$ & $37 I I 2 \mathrm{~A}$ & Icl & E. Paleo. & & Vertebrata & Indeterminate & 1 \\
\hline E28/S78 & $36 \mathrm{~A}$ & 37JJ1A & Icl & E. Paleo. & & Vertebrata & Indeterminate & 1 \\
\hline $\mathrm{E} 28 / \mathrm{S} 78$ & $36 \mathrm{~A}$ & 37JJ1C & Icl & E. Paleo. & & Carnivora & Tooth, perm./decid. ind. & 1 \\
\hline E28/S78 & $36 \mathrm{~A}$ & 37JJ1D & Icl & E. Paleo. & & Mammalia (Medium/large) & Indeterminate & 1 \\
\hline E28/S78 & $36 \mathrm{~A}$ & 37JJ1D & Icl & E. Paleo. & & Vertebrata & Indeterminate & 1 \\
\hline $\mathrm{E} 28 / \mathrm{S} 78$ & $36 \mathrm{~B}$ & $37 \mathrm{JJ} 2 \mathrm{~A}$ & Icl & E. Paleo. & & Mammalia (Medium/large) & Long bone & 1 \\
\hline $\mathrm{E} 28 / \mathrm{S} 78$ & $36 \mathrm{~B}$ & $37 \mathrm{JJ} 2 \mathrm{~A}$ & Icl & E. Paleo. & & Vertebrata & Indeterminate & 1 \\
\hline E28/S78 & $36 \mathrm{~B}$ & 37JJ2B & Icl & E. Paleo. & & Mammalia (Medium/large) & Indeterminate & 1 \\
\hline E28/S78 & $36 \mathrm{~B}$ & $37 \mathrm{JJ} 2 \mathrm{C}$ & Icl & E. Paleo. & & Vertebrata & Indeterminate & 5 \\
\hline $\mathrm{E} 28 / \mathrm{S} 78$ & $36 \mathrm{~B}$ & 37JJ2D & Icl & E. Paleo. & & Vertebrata & Indeterminate & 1 \\
\hline E28/S78 & $37 \mathrm{~A}$ & $37 \mathrm{KK} 1 \mathrm{C}$ & Icl & E. Paleo. & & Mammalia (Medium/large) & Indeterminate & 1 \\
\hline E28/S78 & $37 \mathrm{~A}$ & $37 \mathrm{KK} 1 \mathrm{D}$ & Icl & E. Paleo. & & Mammalia (Medium/large) & Indeterminate & 2 \\
\hline E28/S78 & $37 \mathrm{~A}$ & $37 \mathrm{KK} 1 \mathrm{D}$ & Icl & E. Paleo. & & Small/Medium Vertebrata & Middle phalange & 1 \\
\hline E28/S78 & $37 \mathrm{~A}$ & $37 \mathrm{KK} 1 \mathrm{D}$ & Icl & E. Paleo. & & Vertebrata & Indeterminate & 15 \\
\hline $\mathrm{E} 28 / \mathrm{S} 78$ & $37 \mathrm{~B}$ & $37 \mathrm{KK} 2 \mathrm{~A}$ & Icl & E. Paleo. & & Vertebrata & Indeterminate & 1 \\
\hline E28/S78 & 37B & $37 \mathrm{KK} 2 \mathrm{~B}$ & Icl & E. Paleo. & & Mammalia (Medium/large) & Indeterminate & 1 \\
\hline E28/S78 & 37B & $37 \mathrm{KK} 2 \mathrm{~B}$ & Icl & E. Paleo. & & Vertebrata & Indeterminate & 3 \\
\hline E28/S78 & 37B & $37 \mathrm{KK} 2 \mathrm{D}$ & Isi//Icl & E. Paleo. & & Mammalia (Medium/large) & Indeterminate & 1 \\
\hline $\mathrm{E} 28 / \mathrm{S} 78$ & $37 \mathrm{~B}$ & $37 \mathrm{KK} 2 \mathrm{D}$ & Isi/Icl & E. Paleo. & & Vertebrata & Indeterminate & 10 \\
\hline E28/S78 & $38 \mathrm{~A}$ & 37LL1B & Icl & E. Paleo. & & Mammalia (Medium) & Pelvis & 1 \\
\hline
\end{tabular}




\begin{tabular}{|c|c|c|c|c|c|c|c|c|}
\hline Square & Level & Lot & Unit & Cultural Affinity & Feature & Taxon & Element & No. \\
\hline E28/S78 & $38 \mathrm{~A}$ & 37 LL1B & Icl & E. Paleo. & & Medium/Large Vertebrata & Indeterminate & 2 \\
\hline $\mathrm{E} 28 / \mathrm{S} 78$ & $38 \mathrm{~A}$ & 37 LL1B & Icl & E. Paleo. & & Vertebrata & Indeterminate & 8 \\
\hline E28/S78 & $38 \mathrm{~A}$ & 37LL1C & Icl & E. Paleo. & & Medium/Large Vertebrata & Indeterminate & 2 \\
\hline E28/S78 & $38 \mathrm{~A}$ & 37LL1D & Isi/Icl & E. Paleo. & & Medium/Large Vertebrata & Indeterminate & 1 \\
\hline E28/S78 & 38B & 37LL2A & Icl & E. Paleo. & & Vertebrata & Indeterminate & 1 \\
\hline E28/S78 & 38B & 37LL2B & Icl & E. Paleo. & & Mammalia (Medium/large) & Indeterminate & 3 \\
\hline E28/S78 & 38B & 37LL2B & Icl & E. Paleo. & & Vertebrata & Indeterminate & 4 \\
\hline E28/S78 & 38B & 37LL2C & Isi/Icl & E. Paleo. & & Medium/Large Vertebrata & Indeterminate & 5 \\
\hline $\mathrm{E} 28 / \mathrm{S} 78$ & 38B & 37LL2C & Isi/Icl & E. Paleo. & & Vertebrata & Indeterminate & 7 \\
\hline $\mathrm{E} 28 / \mathrm{S} 78$ & $39 \mathrm{~A}$ & $37 \mathrm{MM} 1 \mathrm{~A}$ & Icl & E. Paleo. & & Medium/Large Vertebrata & Indeterminate & 1 \\
\hline E28/S78 & $39 \mathrm{~A}$ & $37 \mathrm{MM} 1 \mathrm{~A}$ & Icl & E. Paleo. & & Vertebrata & Indeterminate & 9 \\
\hline $\mathrm{E} 28 / \mathrm{S} 78$ & $39 \mathrm{~A}$ & 37MM1B & Icl & E. Paleo. & & Medium/Large Vertebrata & Indeterminate & 2 \\
\hline E28/S78 & $39 \mathrm{~A}$ & $37 \mathrm{MM} 1 \mathrm{C}$ & Isi/Icl & E. Paleo. & & Bison sp. & Permanent tooth & 1 \\
\hline $\mathrm{E} 28 / \mathrm{S} 78$ & $39 \mathrm{~A}$ & $37 \mathrm{MM} 1 \mathrm{C}$ & Isi/Icl & E. Paleo. & & Mammalia (Medium/large) & Indeterminate & 1 \\
\hline $\mathrm{E} 28 / \mathrm{S} 78$ & $39 \mathrm{~A}$ & 37MM1D & Isi & E. Paleo. & & Mammalia (Medium/large) & Indeterminate & 1 \\
\hline $\mathrm{E} 28 / \mathrm{S} 78$ & $39 \mathrm{~A}$ & 37MM1D & Isi & E. Paleo. & & Medium/Large Vertebrata & Indeterminate & 1 \\
\hline $\mathrm{E} 28 / \mathrm{S} 78$ & $39 \mathrm{~A}$ & 37MM1D & Isi & E. Paleo. & & Vertebrata & Indeterminate & \\
\hline $\mathrm{E} 28 / \mathrm{S} 78$ & $39 A \& B$ & 37MM1\& & Isi/Icl & E. Paleo. & & Equus sp. & Central tarsal bone & 1 \\
\hline $\mathrm{E} 28 / \mathrm{S} 78$ & $39 \mathrm{~B}$ & $37 \mathrm{MM} 2 \mathrm{~A}$ & Isi/Icl & E. Paleo. & & Small/Medium Vertebrata & Long bone & \\
\hline $\mathrm{E} 28 / \mathrm{S} 78$ & $39 \mathrm{~B}$ & $37 \mathrm{MM} 2 \mathrm{~A}$ & Isi/Icl & E. Paleo. & & Testudinata & Shell fragment & \\
\hline $\mathrm{E} 28 / \mathrm{S} 78$ & 39B & $37 \mathrm{MM} 2 \mathrm{~A}$ & Isi/Icl & E. Paleo. & & Vertebrata & Indeterminate & \\
\hline $\mathrm{E} 28 / \mathrm{S} 78$ & 39B & 37MM2B & Icl & E. Paleo. & & Vertebrata & Indeterminate & \\
\hline $\mathrm{E} 28 / \mathrm{S} 78$ & $39 \mathrm{~B}$ & $37 \mathrm{MM} 2 \mathrm{C}$ & Isi/Icl & E. Paleo. & & Mammalia (Medium/large) & Indeterminate & \\
\hline $\mathrm{E} 28 / \mathrm{S} 78$ & $39 \mathrm{~B}$ & 37MM2D & Isi & E. Paleo. & & Medium/Large Vertebrata & Indeterminate & \\
\hline $\mathrm{E} 28 / \mathrm{S} 78$ & $39 \mathrm{~B}$ & 37MM2D & Isi & E. Paleo. & & Vertebrata & Indeterminate & \\
\hline $\mathrm{E} 28 / \mathrm{S} 78$ & $40 \mathrm{~A}$ & 37NN1A & Isi/Icl & E. Paleo. & & Rodentia (Small) & Permanent tooth & \\
\hline E28/S78 & $40 \mathrm{~A}$ & $37 N N 1 A$ & |Isi/Icl & E. Paleo. & & Vertebrata & Indeterminate & \\
\hline E28/S78 & $40 \mathrm{~A}$ & $37 \mathrm{NN} 1 \mathrm{~B}$ & Icl & E. Paleo. & & Carnivora & Middle phalange & \\
\hline E28/S78 & $40 \mathrm{~A}$ & $37 \mathrm{NN} 1 \mathrm{~B}$ & Icl & E. Paleo. & & Medium/Large Vertebrata & Indeterminate & \\
\hline $\mathrm{E} 28 / \mathrm{S} 78$ & $40 \mathrm{~A}$ & $37 N N 1 B$ & Icl & E. Paleo. & & Vertebrata & Indeterminate & 15 \\
\hline $\mathrm{E} 28 / \mathrm{S} 78$ & $40 \mathrm{~A}$ & $37 \mathrm{NN} 1 \mathrm{C}$ & Isi/Icl & E. Paleo. & & Mammalia (Medium/large) & Indeterminate & \\
\hline $\mathrm{E} 28 / \mathrm{S} 78$ & $40 \mathrm{~A}$ & $37 \mathrm{NN} 1 \mathrm{C}$ & Isi/Icl & E. Paleo. & & Medium/Large Vertebrata & Indeterminate & \\
\hline $\mathrm{E} 28 / \mathrm{S} 78$ & $40 \mathrm{~A}$ & $37 \mathrm{NN} 1 \mathrm{C}$ & Isi/Icl & E. Paleo. & & Vertebrata & Indeterminate & \\
\hline E28/S78 & $40 \mathrm{~B}$ & $37 \mathrm{NN} 2 \mathrm{~A}$ & Isi/Icl & E. Paleo. & & Medium/Large Vertebrata & Indeterminate & \\
\hline E28/S78 & $40 \mathrm{~B}$ & $37 \mathrm{NN} 2 \mathrm{~A}$ & Isi/Icl & E. Paleo. & & Small/Medium Vertebrata & Phalange & \\
\hline E28/S78 & $40 \mathrm{~B}$ & $37 \mathrm{NN} 2 \mathrm{~A}$ & Isi/Icl & E. Paleo. & & Vertebrata & Indeterminate & \\
\hline E28/S78 & $40 \mathrm{~B}$ & 37NN2B & Icl & E. Paleo. & & cf. Sylvilagus sp. & Humerus & \\
\hline E28/S78 & $40 \mathrm{~B}$ & $37 \mathrm{NN} 2 \mathrm{~B}$ & Icl & E. Paleo. & & Mammalia (Medium/large) & Indeterminate & 1 \\
\hline E28/S78 & $40 \mathrm{~B}$ & $37 \mathrm{NN} 2 \mathrm{~B}$ & Icl & E. Paleo. & & Vertebrata & Indeterminate & \\
\hline E28/S78 & $40 \mathrm{~B}$ & $37 \mathrm{NN} 2 \mathrm{C}$ & Isi/Icl & E. Paleo. & & Phasianidae & Humerus & 1 \\
\hline E28/S78 & $40 \mathrm{~B}$ & $37 \mathrm{NN} 2 \mathrm{C}$ & Isi/Icl & E. Paleo. & & Vertebrata & Indeterminate & 1 \\
\hline E28/S78 & $40 \mathrm{~B}$ & $37 N N 2 D$ & Isi & E. Paleo. & & Medium/Large Vertebrata & Indeterminate & 6 \\
\hline E28/S78 & $40 \mathrm{~B}$ & $37 N N 2 D$ & Isi & E. Paleo. & & Vertebrata & Indeterminate & 3 \\
\hline E28/S78 & $41 \mathrm{~A}$ & $37001 \mathrm{~A}$ & Isi/Icl & E. Paleo. & & Vertebrata & Indeterminate & 4 \\
\hline E28/S78 & $41 \mathrm{~A}$ & $37001 \mathrm{~B}$ & |Isi/Icl & E. Paleo. & & Mammalia (Medium/large) & Indeterminate & 1 \\
\hline E28/S78 & $41 \mathrm{~A}$ & $37001 \mathrm{~B}$ & Isi/Icl & E. Paleo. & & Mammalia (Medium/large) & Long bone & 1 \\
\hline $\mathrm{E} 28 / \mathrm{S} 78$ & $41 \mathrm{~A}$ & $37001 \mathrm{~B}$ & Isi/Icl & E. Paleo. & & Mammalia (Small) & Metapodial & 1 \\
\hline E28/S78 & $41 \mathrm{~A}$ & $37001 \mathrm{~B}$ & Isi/Icl & E. Paleo. & & Medium/Large Vertebrata & Indeterminate & 2 \\
\hline E28/S78 & $41 \mathrm{~A}$ & $37001 \mathrm{~B}$ & Isi/Icl & E. Paleo. & & Serpentes & Dorsal vertebra & 2 \\
\hline E28/S78 & $41 \mathrm{~A}$ & $37001 \mathrm{~B}$ & Isi/Icl & E. Paleo. & & Vertebrata & Indeterminate & 15 \\
\hline E28/S78 & $41 \mathrm{~A}$ & $37 \mathrm{OO} 1 \mathrm{C}$ & Isi & E. Paleo. & & Vertebrata & Indeterminate & 6 \\
\hline E28/S78 & $41 \mathrm{~A} \& \mathrm{~B}$ & $37001 / 2 A$ & Isi/Icl & E. Paleo. & & Mammalia (Very large) & Vertebra & 3 \\
\hline E28/S78 & $41 \mathrm{~B}$ & $37002 \mathrm{~A}$ & Isi/Icl & E. Paleo. & & Bison sp. & Fused 3rd \& 4th metacarpal & 1 \\
\hline E28/S78 & 41B & $37002 \mathrm{~A}$ & Isi/Icl & E. Paleo. & & Vertebrata & Indeterminate & 5 \\
\hline E28/S78 & $41 \mathrm{~B}$ & $37002 \mathrm{~B}$ & Isi/Icl & E. Paleo. & & Medium/Large Vertebrata & Indeterminate & 1 \\
\hline E28/S78 & $41 \mathrm{~B}$ & $37002 B$ & Isi/Icl & E. Páleo. & & Serpentes & Dorsal vertebra & 1 \\
\hline E28/S78 & $41 \mathrm{~B}$ & $37002 \mathrm{~B}$ & Isi/Icl & E. Paleo. ' & & Vertebrata & Indeterminate & 4 \\
\hline E28/S78 & 41B & $37 \mathrm{OO} 2 \mathrm{C}$ & Isi & E. Paleo. & & Vertebrata & Indeterminate & 5 \\
\hline E28/S78 & $42 \mathrm{~A}$ & 37PP1A & Isi/Icl & E. Paleo. & & Mammalia (Medium/large) & Tooth, perm./decid. ind. & 1 \\
\hline E28/S78 & $42 \mathrm{~A}$ & 37PP1A & Isi/Icl & E. Paleo. & & Vertebrata & Indeterminate & 11 \\
\hline E28/S78 & $42 \mathrm{~A}$ & 37PP1B & Isi/Icl & E. Paleo. & & Mammalia (Medium/large) & Indeterminate & 6 \\
\hline E28/S78 & $42 \mathrm{~A}$ & 37PP1B & Isi/Icl & E. Paleo. & & Mammalia (Medium/large) & Tooth, perm./decid. ind. & 3 \\
\hline $\mathrm{E} 28 / \mathrm{S} 78$ & $42 \mathrm{~A}$ & 37PP1B & Isi/Icl & E. Paleo. & & Medium/Large Vertebrata & Indeterminate & 1 \\
\hline E28/S78 & $42 \mathrm{~A}$ & 37PP1B & Isi/Icl & E. Paleo. & & Vertebrata & Indeterminate & 11 \\
\hline E28/S78 & $42 \mathrm{~A}$ & 37PP1C & Isi & E. Paleo. & & Mammalia (Medium/large) & Indeterminate & 1 \\
\hline E28/S78 & $42 \mathrm{~A}$ & 37PP1C & Isi & E. Paleo. & & Vertebrata & Distal phalange & \\
\hline E28/S78 & $42 \mathrm{~A}$ & 37PP1C & Isi & E. Paleo. & & Vertebrata & Indeterminate & \\
\hline
\end{tabular}




\begin{tabular}{|c|c|c|c|c|c|c|c|c|}
\hline Square & Level & Lot & Unit & Cultural Affinity & Feature & Taxon & Element & No. \\
\hline $\mathrm{E} 28 / \mathrm{S} 78$ & $42 \mathrm{~A}$ & 37PP1D & Isi & E. Paleo. & & Vertebrata & Indeterminate & 1 \\
\hline $\mathrm{E} 28 / \mathrm{S} 78$ & $42 B$ & $37 \mathrm{PP} 2 \mathrm{~A}$ & $\mathrm{Isi} / \mathrm{Icl}$ & E. Paleo. & & Colubridae & Dorsal vertebra & 1 \\
\hline $\mathrm{E} 28 / \mathrm{S} 78$ & $42 \mathrm{~B}$ & 37PP2A & $\mathrm{Isi} / \mathrm{Icl}$ & E. Paleo. & & Mammalia (Large) & Long bone & 1 \\
\hline E28/S78 & $42 \mathrm{~B}$ & 37PP2A & $\mathrm{Isi} / \mathrm{Icl}$ & E. Paleo. & & Mammalia (Medium/large) & Indeterminate & 11 \\
\hline $\mathrm{E} 28 / \mathrm{S} 78$ & $42 \mathrm{~B}$ & 37PP2A & $\mathrm{Isi} / \mathrm{Icl}$ & E. Paleo. & & Mammalia (Very large) & Indeterminate & 2 \\
\hline $\mathrm{E} 28 / \mathrm{S} 78$ & $42 \mathrm{~B}$ & 37PP2A & Isi//Icl & E. Paleo. & & Mammalia (Very large) & Vertebra & 1 \\
\hline $\mathrm{E} 28 / \mathrm{S} 78$ & $42 \mathrm{~B}$ & 37PP2A & $\mathrm{Isi} / \mathrm{Icl}$ & E. Paleo. & & Medium/Large Vertebrata & Indeterminate & 3 \\
\hline $\mathrm{E} 28 / \mathrm{S} 78$ & $42 \mathrm{~B}$ & 37PP2A & Isi/Icl & E. Paleo. & & Vertebrata & Indeterminate & 50 \\
\hline $\mathrm{E} 28 / \mathrm{S} 78$ & $42 \mathrm{~B}$ & 37PP2B & Isi//Icl & E. Paleo. & & Leporidae & Permanent tooth & 2 \\
\hline $\mathrm{E} 28 / \mathrm{S} 78$ & $42 \mathrm{~B}$ & 37PP2B & $\mathrm{Isi} / \mathrm{Icl}$ & E. Paleo. & & Mammalia (Medium/large) & Indeterminate & 1 \\
\hline $\mathrm{E} 28 / \mathrm{S} 78$ & $42 \mathrm{~B}$ & 37PР2B & $\mathrm{Isi} / \mathrm{Icl}$ & E. Paleo. & & Medium/Large Vertebrata & Indeterminate & 7 \\
\hline $\mathrm{E} 28 / \mathrm{S} 78$ & $42 \mathrm{~B}$ & 37PР2B & Isi//cl & E. Paleo. & & Vertebrata & Indeterminate & 11 \\
\hline $\mathrm{E} 28 / \mathrm{S} 78$ & $42 \mathrm{~B}$ & 37PP2C & Isi & E. Paleo. & & Vertebrata & Indeterminate & 1 \\
\hline $\mathrm{E} 28 / \mathrm{S} 78$ & $42 \mathrm{~B}$ & 37PP2D & Isi & E. Paleo. & & Vertebrata & Indeterminate & 1 \\
\hline $\mathrm{E} 28 / \mathrm{S} 78$ & $43 \mathrm{~A}$ & 37QQ1A & Isi/Icl & E. Paleo. & & Mammalia (Large) & Indeterminate & 1 \\
\hline $\mathrm{E} 28 / \mathrm{S} 78$ & $43 \mathrm{~A}$ & 37QQ1A & Isi/Icl & E. Paleo. & & Mammalia (Medium/large) & Indeterminate & 2 \\
\hline $\mathrm{E} 28 / \mathrm{S} 78$ & $43 \mathrm{~A}$ & 37QQ1A & Isi/Icl & E. Paleo. & & Sylvilagus sp. & Permanent tooth & 1 \\
\hline $\mathrm{E} 28 / \mathrm{S} 78$ & $43 \mathrm{~A}$ & 37QQ1A & Isi/Icl & E. Paleo. & & Vertebrata & Indeterminate & 3 \\
\hline $\mathrm{E} 28 / \mathrm{S} 78$ & $43 \mathrm{~A}$ & 37QQ1B & Isi & E. Paleo. & & Leporidae & Permanent tooth & 1 \\
\hline $\mathrm{E} 28 / \mathrm{S} 78$ & $43 \mathrm{~A}$ & 37QQ1B & Isi & E. Paleo. & & Medium/Large Vertebrata & Indeterminate & 5 \\
\hline $\mathrm{E} 28 / \mathrm{S} 78$ & $43 \mathrm{~A}$ & 37QQ1B & Isi & E. Paleo. & & Small/Medium Vertebrata & Long bone & 1 \\
\hline $\mathrm{E} 28 / \mathrm{S} 78$ & $43 \mathrm{~A}$ & 37QQ1B & Isi & E. Paleo. & & Vertebrata & Indeterminate & 3 \\
\hline $\mathrm{E} 28 / \mathrm{S} 78$ & $43 \mathrm{~A}$ & 37QQ1C & Isi & E. Paleo. & & Mammalia (Medium/large) & Indeterminate & 1 \\
\hline E28/S78 & $43 \mathrm{~A}$ & 37QQ1C & Isi & E. Paleo. & & Vertebrata & Distal phalange & 1 \\
\hline $\mathrm{E} 28 / \mathrm{S} 78$ & $43 \mathrm{~A}$ & 37QQ1C & Isi & E. Paleo. & & Vertebrata & Indeterminate & 4 \\
\hline E28/S78 & $43 \mathrm{~A}$ & 37QQ1D & Isi & E. Paleo. & & Vertebrata & Indeterminate & 3 \\
\hline E28/S78 & $43 \mathrm{~B}$ & 37QQ2A & Isi & E. Paleo. & f1 $188 ?$ & Mammalia (Large) & Indeterminate & 1 \\
\hline E28/S78 & $43 \mathrm{~B}$ & 37QQ2C & Isi & E. Paleo. & & Vertebrata & Indeterminate & 1 \\
\hline E28/S78 & $43 \mathrm{~B}$ & 37QQ2D & Isi & E. Paleo. & & Osteichthyes & Tooth & 1 \\
\hline $\mathrm{E} 28 / \mathrm{S} 78$ & $44 \mathrm{~A}$ & 37RR1A & Isi & E. Paleo. & & Neotoma sp. & Permanent tooth & 1 \\
\hline $\mathrm{E} 28 / \mathrm{S} 78$ & $44 \mathrm{~A}$ & 37RR1A & Isi & E. Paleo. & & Vertebrata & Indeterminate & 2 \\
\hline $\mathrm{E} 28 / \mathrm{S} 78$ & $44 \mathrm{~A}$ & 37RR1B & Isi & E. Paleo. & & Vertebrata & Indeterminate & 1 \\
\hline E28/S78 & $45 \mathrm{~A}$ & $37 \mathrm{SS} 1 \mathrm{~A}$ & Isi & E. Paleo. & & Vertebrata & Indeterminate & 1 \\
\hline E28/S78 & $45 \mathrm{~B}$ & $37 \mathrm{SS} 2 \mathrm{~B}$ & Isi & E. Paleo. & & Mammalia (Medium/large) & Tooth, perm./decid. ind. & 1 \\
\hline E28/S78 & $45 \mathrm{~B}$ & $37 \mathrm{SS} 2 \mathrm{~B}$ & Isi & E. Paleo. & & Vertebrata & Indeterminate & 2 \\
\hline $\mathrm{E} 40 / \mathrm{S} 70$ & 0 & $36 ?$ & Unknown & Unassigned & & Mammalia (Medium/large) & Long bone & 1 \\
\hline $\mathrm{E} 40 / \mathrm{S} 70$ & 1 & $36 \mathrm{~A}$ & IIIc & L. Prehist. & & Vertebrata & Indeterminate & 22 \\
\hline $\mathrm{E} 40 / \mathrm{S} 70$ & 2 & $36 \mathrm{~B}$ & IIIc & L. Archaic/L. Prehist. & & AntilocapralOdocoileus & Third carpal bone & 1 \\
\hline $\mathrm{E} 40 / \mathrm{S} 70$ & 2 & $36 \mathrm{~B}$ & IIIc & L. Archaic/L. Prehist. & & Kinosternidae & Peripheral & 1 \\
\hline $\mathrm{E} 40 / \mathrm{S} 70$ & 2 & $36 \mathrm{~B}$ & IIIc & L. Archaic/L. Prehist. & & Mammalia (Medium/large) & Indeterminate & 2 \\
\hline $\mathrm{E} 40 / \mathrm{S} 70$ & 2 & $36 \mathrm{~B}$ & IIIIc & L. Archaic/L. Prehist. & & Vertebrata & Indeterminate & 42 \\
\hline $\mathrm{E} 40 / \mathrm{S} 70$ & 3 & $36 \mathrm{C}$ & IIIc & L. Archaic & & Artiodactyla & Tooth, perm./decid. ind. & 1 \\
\hline $\mathrm{E} 40 / \mathrm{S} 70$ & 3 & $36 \mathrm{C}$ & IIIc & L. Archaic & & Mammalia (Large) & Long bone & 1 \\
\hline $\mathrm{E} 40 / \mathrm{S} 70$ & 3 & $36 \mathrm{C}$ & IIIc & L. Archaic & & Mammalia (Medium/large) & Indeterminate & 2 \\
\hline $\mathrm{E} 40 / \mathrm{S} 70$ & 3 & $36 \mathrm{C}$ & IIII & L. Archaic & & Vertebrata & Indeterminate & 61 \\
\hline $\mathrm{E} 40 / \mathrm{S} 70$ & 4 & $36 \mathrm{D}$ & IIIc & L. Archaic & & Antilocapra/Odocoileus & Astragalus & 2 \\
\hline $\mathrm{E} 40 / \mathrm{S} 70$ & 4 & $36 \mathrm{D}$ & IIIc & L. Archaic & & AntilocapralOdocoileus & Fused 3rd \& 4th metatarsal & 1 \\
\hline $\mathrm{E} 40 / \mathrm{S} 70$ & 4 & $36 \mathrm{D}$ & IIIc & L. Archaic & & Antilocapra/Odocoileus & Metapodial & 2 \\
\hline $\mathrm{E} 40 / \mathrm{S} 70$ & 4 & $36 \mathrm{D}$ & IIIIc & L. Archaic & & Antilocapra/Odocoileus & Radius & 1 \\
\hline $\mathrm{E} 40 / \mathrm{S} 70$ & 4 & $36 \mathrm{D}$ & IIIC & L. Archaic & & Antilocapra/Odocoileus & Third carpal bone & 1 \\
\hline $\mathrm{E} 40 / \mathrm{S} 70$ & 4 & $36 \mathrm{D}$ & IIIIc & L. Archaic & & Bison sp. & Humerus & 1 \\
\hline $\mathrm{E} 40 / \mathrm{S} 70$ & 4 & $36 \mathrm{D}$ & IIIC & L. Archaic & & Carnivora & Metapodial & 1 \\
\hline $\mathrm{E} 40 / \mathrm{S} 70$ & 4 & $36 \mathrm{D}$ & IIIc & L. Archaic & & Mammalia (Large) & Indeterminate & 5 \\
\hline $\mathrm{E} 40 / \mathrm{S} 70$ & 4 & $36 \mathrm{D}$ & IIIc & L. Archaic & & Mammalia (Large) & Long bone & 3 \\
\hline $\mathrm{E} 40 / \mathrm{S} 70$ & 4 & $36 \mathrm{D}$ & IIII & L. Archaic & & Mammalia (Large) & Lumbar vertebra & 1 \\
\hline $\mathrm{E} 40 / \mathrm{S} 70$ & 4 & $36 \mathrm{D}$ & IIIc & L. Archaic & & Mammalia (Medium/large) & Indeterminate & 28 \\
\hline $\mathrm{E} 40 / \mathrm{S} 70$ & 4 & $36 \mathrm{D}$ & IIIc & L. Archaic & & Mammalia (Medium/large) & Vertebra & 1 \\
\hline $\mathrm{E} 40 / \mathrm{S} 70$ & 4 & $36 \mathrm{D}$ & IIIc & L. Archaic & & Sciurus sp. & Humerus & -1 \\
\hline $\mathrm{E} 40 / \mathrm{S} 70$ & 4 & $36 \mathrm{D}$ & IIIc & L. Archaic & & Serpentes & Dorsal vertebra & 1 \\
\hline $\mathrm{E} 40 / \mathrm{S} 70$ & 4 & $36 \mathrm{D}$ & IIIc & L. Archaic & & Testudinata & Peripheral & 1 \\
\hline $\mathrm{E} 40 / \mathrm{S} 70$ & 4 & $36 \mathrm{D}$ & IIIc & L. Archaic & & Vertebrata & Indeterminate & 121 \\
\hline $\mathrm{E} 40 / \mathrm{S} 70$ & 4 & $36 \mathrm{D}$ & IIIc & L. Archaic & & Vertebrata & Long bone & 1 \\
\hline $\mathrm{E} 40 / \mathrm{S} 70$ & 5 & $36 \mathrm{E}$ & IIIc & L. Archaic & & Antilocapra americana & Permanent tooth & 1 \\
\hline $\mathrm{E} 40 / \mathrm{S} 70$ & 5 & $36 \mathrm{E}$ & IIIc & L. Archaic & & Antilocapra/Odocoileus & Astragalus & 2 \\
\hline $\mathrm{E} 40 / \mathrm{S} 70$ & 5 & $36 \mathrm{E}$ & IIIc & L. Archaic & & Antilocapra/Odocoileus & Fused 3rd \& 4th metatarsal & 5 \\
\hline $\mathrm{E} 40 / \mathrm{S} 70$ & 5 & $36 \mathrm{E}$ & IIII & L. Archaic & & Antilocapra/Odocoileus & Proximal sesamoid & 1 \\
\hline $\mathrm{E} 40 / \mathrm{S} 70$ & 5 & $36 \mathrm{E}$ & IIIc & L. Archaic & & Antilocapra/Odocoileus & Tibia & 1 \\
\hline
\end{tabular}




\begin{tabular}{|c|c|c|c|c|c|c|c|c|}
\hline Square & Level & Lot & Unit & Cultural Affinity & Feature & Taxon & Element & No. \\
\hline $\mathrm{E} 40 / \mathrm{S} 70$ & 5 & $36 \mathrm{E}$ & IIIc & L. Archaic & & Antilocapra/Odocoileus & Tooth, perm./decid. ind. & 1 \\
\hline $\mathrm{E} 40 / \mathrm{S} 70$ & 5 & $36 \mathrm{E}$ & IIIc & L. Archaic & & Artiodactyla & Tooth, perm./decid. ind. & 1 \\
\hline $\mathrm{E} 40 / \mathrm{S} 70$ & 5 & $36 \mathrm{E}$ & IIIc & L. Archaic & & Kinosternidae & Peripheral & 1 \\
\hline $\mathrm{E} 40 / \mathrm{S} 70$ & 5 & $36 \mathrm{E}$ & IIIIc & L. Archaic & & Mammalia (Large) & Indeterminate & 3 \\
\hline $\mathrm{E} 40 / \mathrm{S} 70$ & 5 & $36 \mathrm{E}$ & IIIIc & L. Archaic & & Mammalia (Large) & Long bone & 3 \\
\hline $\mathrm{E} 40 / \mathrm{S} 70$ & 5 & $36 \mathrm{E}$ & IIIc & L. Archaic & & Mammalia (Large) & Pelvis & 1 \\
\hline $\mathrm{E} 40 / \mathrm{S} 70$ & 5 & $36 \mathrm{E}$ & IIIc & L. Archaic & & Mammalia (Medium) & Middle phalange & 1 \\
\hline $\mathrm{E} 40 / \mathrm{S} 70$ & 5 & $36 \mathrm{E}$ & IIIc & L. Archaic & & Mammalia (Medium/large) & Indeterminate & 32 \\
\hline $\mathrm{E} 40 / \mathrm{S} 70$ & 5 & $36 \mathrm{E}$ & IIIc & L. Archaic & & Mammalia (Medium/large) & Long bone & 11 \\
\hline $\mathrm{E} 40 / \mathrm{S} 70$ & 5 & $36 \mathrm{E}$ & IIIc & L. Archaic & & Mammalia (Medium/large) & Tooth, perm./decid. ind. & 1 \\
\hline $\mathrm{E} 40 / \mathrm{S} 70$ & 5 & $36 \mathrm{E}$ & IIII & L. Archaic & & Medium/Large Vertebrata & Indeterminate & 12 \\
\hline $\mathrm{E} 40 / \mathrm{S} 70$ & 5 & $36 \mathrm{E}$ & IIIIc & L. Archaic & & Medium/Large Vertebrata & Long bone & 1 \\
\hline $\mathrm{E} 40 / \mathrm{S} 70$ & 5 & $36 \mathrm{E}$ & IIII & L. Archaic & & Odocoileus sp. & Calcaneus & 1 \\
\hline $\mathrm{E} 40 / \mathrm{S} 70$ & 5 & $36 \mathrm{E}$ & IIII & L. Archaic & & Odocoileus sp. & Femur & 1 \\
\hline $\mathrm{E} 40 / \mathrm{S} 70$ & 5 & $36 \mathrm{E}$ & IIIc & L. Archaic & & Procyon lotor & Permanent tooth & 1 \\
\hline $\mathrm{E} 40 / \mathrm{S} 70$ & 5 & $36 \mathrm{E}$ & IIIc & L. Archaic & & Small/Medium Vertebrata & Long bone & 1 \\
\hline $\mathrm{E} 40 / \mathrm{S} 70$ & 5 & $36 \mathrm{E}$ & IIIIc & L. Archaic & & Testudinata & Pleural & 1 \\
\hline $\mathrm{E} 40 / \mathrm{S} 70$ & 5 & $36 \mathrm{E}$ & IIIc & L. Archaic & & Testudinata & Shell fragment & 2 \\
\hline $\mathrm{E} 40 / \mathrm{S} 70$ & 5 & $36 \mathrm{E}$ & IIIc & L. Archaic & & Vertebrata & Indeterminate & 160 \\
\hline $\mathrm{E} 40 / \mathrm{S} 70$ & 5 & $36 \mathrm{E}$ & IIIc & L. Archaic & & Vertebrata & Long bone & 1 \\
\hline $\mathrm{E} 40 / \mathrm{S} 70$ & 6 & $36 \mathrm{~F}$ & IIIc & L. Archaic & & Antilocapra/Odocoileus & Astragalus & 1 \\
\hline $\mathrm{E} 40 / \mathrm{S} 70$ & 6 & $36 \mathrm{~F}$ & IIIc & L. Archaic & & Antilocapra/Odocoileus & Calcaneus & 1 \\
\hline $\mathrm{E} 40 / \mathrm{S} 70$ & 6 & $36 \mathrm{~F}$ & IIIc & L. Archaic & & Antilocapra/Odocoileus & Fused 3rd \& 4th metatarsal & 1 \\
\hline $\mathrm{E} 40 / \mathrm{S} 70$ & 6 & $36 \mathrm{~F}$ & IIIc & L. Archaic & & Antilocapra/Odocoileus & Metapodial & 1 \\
\hline $\mathrm{E} 40 / \mathrm{S} 70$ & 6 & $36 \mathrm{~F}$ & IIIc & L. Archaic & & Antilocapra/Odocoileus & Middle phalange & 1 \\
\hline $\mathrm{E} 40 / \mathrm{S} 70$ & 6 & $36 \mathrm{~F}$ & IIIc & L. Archaic & & Artiodactyla & Tooth, perm./decid. ind. & 1 \\
\hline $\mathrm{E} 40 / \mathrm{S} 70$ & 6 & $36 \mathrm{~F}$ & IIIc & L. Archaic & & Colubridae & Dorsal vertebra & 1 \\
\hline $\mathrm{E} 40 / \mathrm{S} 70$ & 6 & $36 \mathrm{~F}$ & IIIc & L. Archaic & & Kinosternidae & Hypoplastron & 1 \\
\hline $\mathrm{E} 40 / \mathrm{S} 70$ & 6 & $36 \mathrm{~F}$ & IIIc & L. Archaic & & Leporidae & Humerus & 1 \\
\hline $\mathrm{E} 40 / \mathrm{S} 70$ & 6 & $36 \mathrm{~F}$ & IIIc & L. Archaic & & Mammalia (Large) & Cranium & 1 \\
\hline $\mathrm{E} 40 / \mathrm{S} 70$ & 6 & $36 \mathrm{~F}$ & IIIc & L. Archaic & & Mammalia (Large) & Indeterminate & 2 \\
\hline $\mathrm{E} 40 / \mathrm{S} 70$ & 6 & $36 \mathrm{~F}$ & IIIc & L. Archaic & & Mammalia (Large) & Long bone & 6 \\
\hline $\mathrm{E} 40 / \mathrm{S} 70$ & 6 & $36 \mathrm{~F}$ & IIIc & L. Archaic & & Mammalia (Large) & Mandible & 1 \\
\hline $\mathrm{E} 40 / \mathrm{S} 70$ & 6 & $36 \mathrm{~F}$ & IIIc & L. Archaic & & Mammalia (Medium/large) & Indeterminate & 17 \\
\hline E40/S70 & 6 & $36 \mathrm{~F}$ & IIII & L. Archaic & & Mammalia (Medium/large) & Long bone & 2 \\
\hline E40/S70 & 6 & $36 \mathrm{~F}$ & IIII & L. Archaic & & Mammalia (Medium/large) & Podial & 1 \\
\hline $\mathrm{E} 40 / \mathrm{S} 70$ & 6 & $36 \mathrm{~F}$ & IIIc & L. Archaic & & Mammalia (Medium/large) & Tooth, perm./decid. ind. & 1 \\
\hline $\mathrm{E} 40 / \mathrm{S} 70$ & 6 & $36 \mathrm{~F}$ & IIII & L. Archaic & & Mammalia (Small/medium) & Rib & 1 \\
\hline $\mathrm{E} 40 / \mathrm{S} 70$ & 6 & $36 \mathrm{~F}$ & IIIc & L. Archaic & & Testudinata & Neural & 1 \\
\hline $\mathrm{E} 40 / \mathrm{S} 70$ & 6 & $36 \mathrm{~F}$ & IIIc & L. Archaic & & Vertebrata & Indeterminate & 142 \\
\hline $\mathrm{E} 40 / \mathrm{S} 70$ & 7 & $36 \mathrm{G}$ & $\mathrm{IIIb} / \mathrm{c}$ & M. Archaic & & Antilocapra/Odocoileus & Fused second \& third tarsal & 2 \\
\hline $\mathrm{E} 40 / \mathrm{S} 70$ & 7 & $36 \mathrm{G}$ & $\mathrm{IIlb} / \mathrm{c}$ & M. Archaic & & Antilocapra/Odocoileus & Third carpal bone & 1 \\
\hline $\mathrm{E} 40 / \mathrm{S} 70$ & 7 & $36 \mathrm{G}$ & $\mathrm{IIIb} / \mathrm{c}$ & M. Archaic & & Antilocapra/Odocoileus & Tibia & 1 \\
\hline $\mathrm{E} 40 / \mathrm{S} 70$ & 7 & $36 \mathrm{G}$ & $\mathrm{IIIb} / \mathrm{c}$ & M. Archaic & & Antilocapra/Odocoileus & Ulna & 1 \\
\hline $\mathrm{E} 40 / \mathrm{S} 70$ & 7 & $36 \mathrm{G}$ & $\mathrm{IIb} / \mathrm{c}$ & M. Archaic & & Artiodactyla & Tooth, perm./decid. ind. & 2 \\
\hline $\mathrm{E} 40 / \mathrm{S} 70$ & 7 & $36 \mathrm{G}$ & $\mathrm{IIIb} / \mathrm{c}$ & M. Archaic & & cf. Odocoileus sp. & Fused 3rd \& 4th metacarpal & 1 \\
\hline $\mathrm{E} 40 / \mathrm{S} 70$ & 7 & $36 \mathrm{G}$ & $\mathrm{IIIb} / \mathrm{c}$ & M. Archaic & & cf. Sylvilagus sp. & Calcaneus & 1 \\
\hline $\mathrm{E} 40 / \mathrm{S} 70$ & 7 & $36 \mathrm{G}$ & $\mathrm{IIb} / \mathrm{c}$ & M. Archaic & & Leporidae & Metacarpal 4 & 1 \\
\hline $\mathrm{E} 40 / \mathrm{S} 70$ & 7 & 36G & $\mathrm{IIIb} / \mathrm{c}$ & M. Archaic & & Mammalia (Large) & Indeterminate & 2 \\
\hline $\mathrm{E} 40 / \mathrm{S} 70$ & 7 & $36 \mathrm{G}$ & IIIlb/c & M. Archaic & & Mammalia (Large) & Long bone & 3 \\
\hline $\mathrm{E} 40 / \mathrm{S} 70$ & 7 & $36 \mathrm{G}$ & $\mathrm{IIIb} / \mathrm{c}$ & M. Archaic & & Mammalia (Large) & Thoracic vertebra & 1 \\
\hline $\mathrm{E} 40 / \mathrm{S} 70$ & 7 & 36G & $\mathrm{IIIb} / \mathrm{c}$ & M. Archaic & & Mammalia (Large) & Ulna & 1 \\
\hline E40/S70 & 7 & $36 \mathrm{G}$ & IIIb/c & M. Archaic & & Mammalia (Medium) & Proximal phalange & 1 \\
\hline $\mathrm{E} 40 / \mathrm{S} 70$ & 7 & $36 \mathrm{G}$ & $\mathrm{IIIb} / \mathrm{c}$ & M. Archaic & & Mammalia (Medium/large) & Indeterminate & 18 \\
\hline $\mathrm{E} 40 / \mathrm{S} 70$ & 7 & $36 \mathrm{G}$ & $\mathrm{IIb} / \mathrm{c}$ & M. Archaic & & Mammalia (Medium/large) & Long bone & 13 \\
\hline $\mathrm{E} 40 / \mathrm{S} 70$ & 7 & $36 \mathrm{G}$ & $\mathrm{IIIb} / \mathrm{c}$ & M. Archaic & & Odocoileus sp. & Middle phalange & 1 \\
\hline $\mathrm{E} 40 / \mathrm{S} 70$ & 7 & $36 \mathrm{G}$ & $\mathrm{IIIb} / \mathrm{c}$ & M. Archaic & & Odocoileus sp. & Phalange & 1 \\
\hline $\mathrm{E} 40 / \mathrm{S} 70$ & 7 & $36 \mathrm{G}$ & $\mathrm{IIIb} / \mathrm{c}$ & M. Archaic & & Serpentes & Dorsal vertebra & 2 \\
\hline $\mathrm{E} 40 / \mathrm{S} 70$ & 7 & $36 \mathrm{G}$ & $\mathrm{IIIb} / \mathrm{c}$ & M. Archaic & & Small/Medium Vertebrata & Long bone & 2 \\
\hline $\mathrm{E} 40 / \mathrm{S} 70$ & 7 & $36 \mathrm{G}$ & $\mathrm{IIIb} / \mathrm{c}$ & M. Archaic & & Testudinata & Peripheral & 1 \\
\hline $\mathrm{E} 40 / \mathrm{S} 70$ & 7 & $36 \mathrm{G}$ & $\mathrm{IIIb} / \mathrm{c}$ & M. Archaic & & Testudinata & Pleural & 1 \\
\hline $\mathrm{E} 40 / \mathrm{S} 70$ & 7 & $36 \mathrm{G}$ & $\mathrm{IIIb} / \mathrm{c}$ & M. Archaic & & Testudinata & Shell fragment & 3 \\
\hline $\mathrm{E} 40 / \mathrm{S} 70$ & 7 & $36 \mathrm{G}$ & IIIb/c & M. Archaic & & Vertebrata & Indeterminate & 161 \\
\hline $\mathrm{E} 40 / \mathrm{S} 70$ & 8 & $36 \mathrm{H}$ & $\mathrm{IIIb} / \mathrm{c}$ & Early/M. Archaic & & Mammalia (Medium/large) & Long bone & 2 \\
\hline $\mathrm{E} 40 / \mathrm{S} 70$ & 8 & $36 \mathrm{H}$ & $\mathrm{IIIb} / \mathrm{c}$ & Early/M. Archaic & & Sylvilagus sp. & Calcaneus & 1 \\
\hline $\mathrm{E} 40 / \mathrm{S} 70$ & 8 & $36 \mathrm{H}$ & $\mathrm{IIIb} / \mathrm{c}$ & Early/M. Archaic & & Vertebrata & Indeterminate & 19 \\
\hline $\mathrm{E} 40 / \mathrm{S} 70$ & 9 & $36 \mathrm{I}$ & IIIb/c & Early/M. Archaic & & Antilocapra/Odocoileus & Fused 3rd \& 4th metatarsal & 1 \\
\hline
\end{tabular}




\begin{tabular}{|c|c|c|c|c|c|c|c|c|}
\hline Square & Level & Lot & Unit & Cultural Affinity & Feature & Taxon & Element & No. \\
\hline $\mathrm{E} 40 / \mathrm{S} 70$ & 9 & $36 I$ & $\mathrm{IIIb} / \mathrm{c}$ & Early/M. Archaic & & Canis sp. & Permanent tooth & 1 \\
\hline $\mathrm{E} 40 / \mathrm{S} 70$ & 9 & $36 I$ & $\mathrm{IIb} / \mathrm{c}$ & Early/M. Archaic & & Mammalia (Medium/large) & Indeterminate & 8 \\
\hline $\mathrm{E} 40 / \mathrm{S} 70$ & 9 & $36 I$ & $\mathrm{mIlb} / \mathrm{c}$ & Early/M. Archaic & & Odocoileus sp. & Antler & 2 \\
\hline $\mathrm{E} 40 / \mathrm{S} 70$ & 9 & $36 I$ & $\mathrm{IIb} / \mathrm{c}$ & Early/M. Archaic & & Rodentia (Small) & Permanent tooth & 1 \\
\hline $\mathrm{E} 40 / \mathrm{S} 70$ & 9 & $36 I$ & $\mathrm{IIIb} / \mathrm{c}$ & Early/M. Archaic & & Sigmodon hispidus & Mandible & 1 \\
\hline $\mathrm{E} 40 / \mathrm{S} 70$ & 9 & $36 I$ & $\mathrm{IIIb} / \mathrm{c}$ & Early/M. Archaic & & Sigmodon hispidus & Permanent tooth & 1 \\
\hline $\mathrm{E} 40 / \mathrm{S} 70$ & 9 & $36 I$ & $\mathrm{IIb} / \mathrm{c}$ & Early/M. Archaic & & Sylvilagus sp. & Metatarsal 2 & 1 \\
\hline $\mathrm{E} 40 / \mathrm{S} 70$ & 9 & $36 I$ & $\mathrm{IIIb} / \mathrm{c}$ & Early/M. Archaic & & Testudinata & Shell fragment & 1 \\
\hline $\mathrm{E} 40 / \mathrm{S} 70$ & 9 & $36 \mathrm{I}$ & $\mathrm{IIIb} / \mathrm{c}$ & Early/M. Archaic & & Vertebrata & Indeterminate & 68 \\
\hline $\mathrm{E} 40 / \mathrm{S} 70$ & 10 & $36 \mathrm{~J}$ & IIIb & Early/M. Archaic & & Artiodactyla & Tooth, perm./decid. ind. & 1 \\
\hline $\mathrm{E} 40 / \mathrm{S} 70$ & 10 & $36 \mathrm{~J}$ & IIIlb & Early/M. Archaic & & Mammalia (Medium/large) & Indeterminate & 2 \\
\hline $\mathrm{E} 40 / \mathrm{S} 70$ & 10 & $36 \mathrm{~J}$ & IIIlb & Early/M. Archaic & & Mammalia (Medium/large) & Tooth, perm./decid. ind. & 1 \\
\hline $\mathrm{E} 40 / \mathrm{S} 70$ & 10 & $36 \mathrm{~J}$ & IIIlb & Early/M. Archaic & & Vertebrata & Indeterminate & 36 \\
\hline $\mathrm{E} 40 / \mathrm{S} 70$ & 10 & $36 \mathrm{~J}$ & IIIb & Early/M. Archaic & & Vertebrata & Long bone & 1 \\
\hline $\mathrm{E} 40 / \mathrm{S} 70$ & 11 & $36 \mathrm{~K}$ & IIIlb & Early/M. Archaic & & Mammalia (Large) & Long bone & 1 \\
\hline $\mathrm{E} 40 / \mathrm{S} 70$ & 11 & $36 \mathrm{~K}$ & IIIlb & Early/M. Archaic & & Mammalia (Medium/large) & Indeterminate & 5 \\
\hline $\mathrm{E} 40 / \mathrm{S} 70$ & 11 & $36 \mathrm{~K}$ & IIIb & Early/M. Archaic & & Vertebrata & Indeterminate & 65 \\
\hline $\mathrm{E} 40 / \mathrm{S} 70$ & 11 & $36 \mathrm{~K}$ & IIIb & Early/M. Archaic & & Vertebrata & Middle phalange & 1 \\
\hline $\mathrm{E} 40 / \mathrm{S} 70$ & 12 & $36 \mathrm{~L}$ & ШІа/ $/ \mathrm{b}$ & Early/M. Archaic & & Mammalia (Medium/large) & Indeterminate & 1 \\
\hline $\mathrm{E} 40 / \mathrm{S} 70$ & 12 & $36 \mathrm{~L}$ & $\mathrm{ma} / \mathrm{b}$ & Early/M. Archaic & & Vertebrata & Indeterminate & 8 \\
\hline $\mathrm{E} 40 / \mathrm{S} 70$ & 13 & $36 \mathrm{M}$ & IIIa & E. Archaic & & Mammalia (Medium/large) & Indeterminate & 1 \\
\hline $\mathrm{E} 40 / \mathrm{S} 70$ & 13 & $36 \mathrm{M}$ & IIIa & E. Archaic & & Medium/Large Vertebrata & Indeterminate & 8 \\
\hline $\mathrm{E} 40 / \mathrm{S} 70$ & 13 & $36 \mathrm{M}$ & IIIIa & E. Archaic & & Vertebrata & Indeterminate & 17 \\
\hline $\mathrm{E} 40 / \mathrm{S} 70$ & 14 & $36 \mathrm{~N}$ & IIIa & E. Archaic & & Medium/Large Vertebrata & Indeterminate & 3 \\
\hline $\mathrm{E} 40 / \mathrm{S} 70$ & 14 & $36 \mathrm{~N}$ & IIIa & E. Archaic & & Medium/Large Vertebrata & Long bone & 1 \\
\hline $\mathrm{E} 40 / \mathrm{S} 70$ & 14 & $36 \mathrm{~N}$ & IIIla & E. Archaic & & Small/Medium Vertebrata & Long bone & 4 \\
\hline $\mathrm{E} 40 / \mathrm{S} 70$ & 14 & $36 \mathrm{~N}$ & IIIa & E. Archaic & & Vertebrata & Indeterminate & 30 \\
\hline $\mathrm{E} 40 / \mathrm{S} 70$ & 15 & 360 & IIIa & E. Archaic & & Artiodactyla & Tooth, perm./decid. ind. & 2 \\
\hline $\mathrm{E} 40 / \mathrm{S} 70$ & 15 & 360 & IIIla & E. Archaic & & Vertebrata & Indeterminate & 38 \\
\hline $\mathrm{E} 40 / \mathrm{S} 70$ & 16 & $36 \mathrm{P}$ & IIIa & E. Archaic & & Mammalia (Large) & Indeterminate & 1 \\
\hline $\mathrm{E} 40 / \mathrm{S} 70$ & 16 & $36 \mathrm{P}$ & IIIa & E. Archaic & & Mammalia (Medium/large) & Indeterminate & 6 \\
\hline $\mathrm{E} 40 / \mathrm{S} 70$ & 16 & $36 \mathrm{P}$ & IIIa & E. Archaic & & Mammalia (Medium/large) & Long bone & 4 \\
\hline $\mathrm{E} 40 / \mathrm{S} 70$ & 16 & $36 \mathrm{P}$ & IIIla & E. Archaic & & Small/Medium Vertebrata & Indeterminate & 1 \\
\hline $\mathrm{E} 40 / \mathrm{S} 70$ & 16 & $36 \mathrm{P}$ & IIIIa & E. Archaic & & Small/Medium Vertebrata & Long bone & 2 \\
\hline $\mathrm{E} 40 / \mathrm{S} 70$ & 16 & $36 \mathrm{P}$ & IIIa & E. Archaic & & Vertebrata & Indeterminate & 9 \\
\hline $\mathrm{E} 40 / \mathrm{S} 70$ & 17 & $36 Q$ & IIIa & E. Archaic & & Vertebrata & Indeterminate & 37 \\
\hline $\mathrm{E} 40 / \mathrm{S} 70$ & 18 & $36 \mathrm{R}$ & ПI/Шаa & L. Paleo./E. Archaic & & Antilocapra/Odocoileus & Phalange & 1 \\
\hline $\mathrm{E} 40 / \mathrm{S} 70$ & 18 & $36 \mathrm{R}$ & II/ШII & L. Paleo./E. Archaic & & Mammalia (Medium/large) & Indeterminate & 10 \\
\hline $\mathrm{E} 40 / \mathrm{S} 70$ & 18 & $36 \mathrm{R}$ & II/IIIa & L. Paleo./E. Archaic & & Mammalia (Medium/large) & Long bone & 1 \\
\hline $\mathrm{E} 40 / \mathrm{S} 70$ & 18 & $36 \mathrm{R}$ & II/IIIa & L. Paleo./E. Archaic & & Medium/Large Vertebrata & Long bone & 5 \\
\hline $\mathrm{E} 40 / \mathrm{S} 70$ & 18 & $36 \mathrm{R}$ & Ш/Ша & L. Paleo./E. Archaic & & Small/Medium Vertebrata & Long bone & 3 \\
\hline $\mathrm{E} 40 / \mathrm{S} 70$ & 18 & $36 \mathrm{R}$ & II/IIIa & L. Paleo./E. Archaic & & Vertebrata & Indeterminate & 37 \\
\hline $\mathrm{E} 40 / \mathrm{S} 70$ & 19 & $36 \mathrm{~S}$ & II/IIIa & L. Paleo./E. Archaic & & Mammalia (Medium/large) & Indeterminate & 3 \\
\hline $\mathrm{E} 40 / \mathrm{S} 70$ & 19 & $36 \mathrm{~S}$ & II/IIIa & L. Paleo./E. Archaic & & Mammalia (Medium/large) & Tooth, perm./decid. ind. & 1 \\
\hline $\mathrm{E} 40 / \mathrm{S} 70$ & 19 & $36 S$ & II/IIIa & L. Paleo./E. Archaic & & Vertebrata & Indeterminate & 24 \\
\hline $\mathrm{E} 40 / \mathrm{S} 70$ & 20 & $36 \mathrm{~T}$ & II/IIIa & L. Paleo./E. Archaic & & Mammalia (Large) & Proximal phalange & 1 \\
\hline $\mathrm{E} 40 / \mathrm{S} 70$ & 20 & $36 \mathrm{~T}$ & II/IIIa & L. Paleo./E. Archaic & & Mammalia (Medium/large) & Long bone & 1 \\
\hline $\mathrm{E} 40 / \mathrm{S} 70$ & 20 & $36 \mathrm{~T}$ & II/IIa & L. Paleo./E. Archaic & & Vertebrata & Indeterminate & 13 \\
\hline $\mathrm{E} 40 / \mathrm{S} 70$ & 21 & $36 \mathrm{U}$ & II & L. Paleo. & & Medium/Large Vertebrata & Indeterminate & 10 \\
\hline $\mathrm{E} 40 / \mathrm{S} 70$ & 21 & $36 U$ & II & L. Paleo. & & Vertebrata & Indeterminate & 5 \\
\hline $\mathrm{E} 40 / \mathrm{S} 70$ & 22 & $36 \mathrm{~V}$ & $\mathrm{I} / \mathrm{II}$ & L. Paleo. & & Mammalia (Medium/large) & Indeterminate & 7 \\
\hline $\mathrm{E} 40 / \mathrm{S} 70$ & 22 & $36 \mathrm{~V}$ & $\mathrm{I} / \mathrm{II}$ & L. Paleo. & & Mammalia (Medium/large) & Long bone & 4 \\
\hline $\mathrm{E} 40 / \mathrm{S} 70$ & 22 & $36 \mathrm{~V}$ & I/II & L. Paleo. & & Mammalia (Medium/large) & Vertebra & 1 \\
\hline $\mathrm{E} 40 / \mathrm{S} 70$ & 22 & $36 \mathrm{~V}$ & I/II & L. Paleo. & & Small/Medium Vertebrata & Long bone & 4 \\
\hline $\mathrm{E} 40 / \mathrm{S} 70$ & 22 & $36 \mathrm{~V}$ & I/II & L. Paleo. & & Sylvilagus sp. & Calcaneus & 1 \\
\hline $\mathrm{E} 40 / \mathrm{S} 70$ & 22 & $36 \mathrm{~V}$ & I/II & L. Paleo. & & Vertebrata & Indeterminate & 7 \\
\hline $\mathrm{E} 40 / \mathrm{S} 70$ & 23 & $36 \mathrm{~W}$ & I & Paleoindian & & Vertebrata & Indeterminate & 1 \\
\hline $\mathrm{E} 40 / \mathrm{S} 70$ & 24 & $36 \mathrm{X}$ & I & Paleoindian & f154 & Vertebrata & Indeterminate & 2 \\
\hline $\mathrm{E} 40 / \mathrm{S} 70$ & 25 & $36 \mathrm{Y}$ & I & Paleoindian & & Mammalia (Medium/large) & Indeterminate & 1 \\
\hline $\mathrm{E} 40 / \mathrm{S} 70$ & 25 & $36 \mathrm{Y}$ & I & Paleoindian & & Mammalia (Medium/large) & Long bone & 1 \\
\hline $\mathrm{E} 40 / \mathrm{S} 70$ & 26 & $36 Z$ & I & Paleoindian & & Medium/Large Vertebrata & Indeterminate & 1 \\
\hline $\mathrm{E} 40 / \mathrm{S} 70$ & 28 & $36 \mathrm{BBD}$ & I & Paleoindian & & Mammalia (Medium/large) & Long bone & 1 \\
\hline $\mathrm{E} 40 / \mathrm{S} 70$ & 28 & $36 \mathrm{BBD}$ & $\mathrm{I}$ & Paleoindian & & Vertebrata & Indeterminate & 2 \\
\hline T-Pit1 & 1 & TP1A & Unknown & L. Prehist. & & Mammalia (Medium/large) & Indeterminate & 8 \\
\hline T-Pit1 & 1 & TP1A & Unknown & L. Prehist. & & Mammalia (Medium/large) & Long bone & 5 \\
\hline T-Pit1 & 1 & TP1A & Unknown & L. Prehist. & & Mammalia (Medium/large) & Tooth, perm./decid. ind. & 1 \\
\hline T-Pit1 & 1 & TP1A & Unknown & L. Prehist. & & Medium/Large Vertebrata & Indeterminate & 1 \\
\hline
\end{tabular}




\begin{tabular}{|c|c|c|c|c|c|c|c|c|}
\hline Square & Level & Lot & Unit & Cultural Affinity & Feature & Taxon & Element & No. \\
\hline T-Pit1 & 1 & TP1A & Unknown & L. Prehist. & & Vertebrata & Indeterminate & \\
\hline T-Pit1 & 2 & TP1B & Unknown & L. Archaic/L. Prehist. & & Mammalia (Medium/large) & Indeterminate & 1 \\
\hline T-Pit 1 & 2 & TP1B & Unknown & L. Archaic/L. Prehist. & & Mammalia (Medium/large) & Long bone & 7 \\
\hline T-Pit1 & 2 & TP1B & Unknown & L. Archaic/L. Prehist. & & Medium/Large Vertebrata & Indeterminate & 1 \\
\hline T-Pit1 & 2 & TP1B & Unknown & L. Archaic/L. Prehist. & & Vertebrata & Indeterminate & 1 \\
\hline T-Pit1 & 3 & TP1C & Unknown & L. Archaic & & Antilocapra/Odocoileus & Mandible & 1 \\
\hline T-Pit1 & 3 & TP1C & Unknown & L. Archaic & & Mammalia (Medium/large) & Indeterminate & 1 \\
\hline T-Pit1 & 3 & TP1C & Unknown & L. Archaic & & Mammalia (Medium/large) & Long bone & 1 \\
\hline T-Pit1 & 5 & TP1E & Unknown & Unassigned & & Medium/Large Vertebrata & Indeterminate & 1 \\
\hline T-Pit1 & 6 & TP1F & Unknown & Unassigned & & Vertebrata & Indeterminate & 2 \\
\hline T-Pit1 & 9 & TP1I & Unknown & Unassigned & & Antilocapra/Odocoileus & Tooth, perm./decid. ind. & 1 \\
\hline T-Pit2 & 1 & TP2A & Unknown & Unassigned & & Mammalia (Large) & Tooth, perm./decid. ind. & 2 \\
\hline T-Pit2 & 3 & TP2C & Unknown & Unassigned & & Mammalia (Medium/large) & Long bone & 1 \\
\hline T-Pit2 & 4 & TP2D & Unknown & Unassigned & & Mammalia (Large) & Long bone & 1 \\
\hline T-Pit2 & 4 & TP2D & Unknown & Unassigned & & Mammalia (Medium/large) & Indeterminate & 1 \\
\hline T-Pit2 & 4 & TP2D & Unknown & Unassigned & & Mammalia (Medium/large) & Long bone & 1 \\
\hline T-Pit2 & 4 & TP2D & Unknown & Unassigned & & Mammalia (Medium/large) & Tooth, perm./decid. ind. & 1 \\
\hline T-Pit3 & 2 & TP3B & Unknown & L. Archaic/L. Prehist. & & Mammalia (Large) & Indeterminate & 2 \\
\hline T-Pit3 & 2 & TP3B & Unknown & L. Archaic/L. Prehist. & & Mammalia (Medium/large) & Indeterminate & 4 \\
\hline T-Pit3 & 3 & TP3C & Unknown & L. Archaic & & Mammalia (Medium/large) & Indeterminate & 2 \\
\hline T-Pit3 & 4 & TP3D & Unknown & L. Archaic & & Mammalia (Medium/large) & Indeterminate & 4 \\
\hline T-Pit3 & 4 & TP3D & Unknown & L. Archaic & & Medium/Large Vertebrata & Indeterminate & 1 \\
\hline T-Pit3 & 4 & TP3D & Unknown & L. Archaic & & Vertebrata & Indeterminate & 2 \\
\hline T-Pit3 & 5 & TP3E & Unknown & L. Archaic & & Mammalia (Medium/large) & Indeterminate & 6 \\
\hline T-Pit3 & 5 & TP3E & Unknown & L. Archaic & & Vertebrata & Indeterminate & 2 \\
\hline T-Pit3 & 6 & TP3F & Unknown & Unassigned & & AntilocapralOdocoileus & Humerus & 1 \\
\hline T-Pit3 & 6 & TP3F & Unknown & Unassigned & & Mammalia (Medium/large) & Alveolar ridge fragment & 1 \\
\hline T-Pit3 & 6 & TP3F & Unknown & Unassigned & & Mammalia (Medium/large) & Indeterminate & 4 \\
\hline T-Pit3 & 6 & TP3F & Unknown & Unassigned & & Mammalia (Medium/large) & Long bone & 3 \\
\hline T-Pit3 & 6 & TP3F & Unknown & Unassigned & & Odocoileus sp. & Permanent tooth & 1 \\
\hline T-Pit3 & 6 & TP3F & Unknown & Unassigned & & Small/Medium Vertebrata & Indeterminate & 1 \\
\hline T-Pit3 & 6 & TP3F & Unknown & Unassigned & & Vertebrata & Indeterminate & 4 \\
\hline T-Pit3 & 7 & TP3G & Unknown & Unassigned & & Mammalia (Medium/large) & Indeterminate & 5 \\
\hline T-Pit3 & 7 & TP3G & Unknown & Unassigned & & Medium/Large Vertebrata & Indeterminate & 1 \\
\hline T-Pit3 & 7 & TP3G & Unknown & Unassigned & & Vertebrata & Indeterminate & 5 \\
\hline T-Pit3 & 8 & TP3H & Unknown & Unassigned & & Mammalia (Medium/large) & Indeterminate & 1 \\
\hline T-Pit3 & 8 & TP3H & Unknown & Unassigned & & Mammalia (Medium/large) & Long bone & 1 \\
\hline T-Pit3 & 9 & TP3I & Unknown & Unassigned & & AntilocapralOdocoileus & Metapodial & 1 \\
\hline T-Pit3 & 9 & TP3I & Unknown & Unassigned & & Mammalia (Medium/large) & Indeterminate & 3 \\
\hline
\end{tabular}


TABLE A10-2

Provenience of Faunal Materials Recovered from 1/8-inch Screens, TARL Excavations

\begin{tabular}{|c|c|c|c|c|c|c|c|c|}
\hline Square & Level & Lot & Unit & Cultural Affinity & Feature & Taxon & Element & No. \\
\hline Surface & 0 & 707 & $?$ & Unassigned & & Mammalia (Large) & Long bone & 1 \\
\hline 11 & 5 & 323 & IIIIb/c & L. Archaic & & Antilocapra/Odocoileus & Proximal phalange & 1 \\
\hline 11 & 5 & 323 & $\mathrm{IIIb} / \mathrm{c}$ & L. Archaic & & AntilocapralOdocoileus & Ulnar carpal bone & 1 \\
\hline 11 & 5 & 323 & $\mathrm{IIIb} / \mathrm{c}$ & L. Archaic & & Artiodactyla & Tooth, perm./decid. ind. & 1 \\
\hline 11 & 5 & 323 & $\mathrm{IIIb} / \mathrm{c}$ & L. Archaic & & Mammalia (Large) & Indeterminate & 1 \\
\hline 11 & 5 & 323 & $\mathrm{IIIb} / \mathrm{c}$ & L. Archaic & & Mammalia (Medium/large) & Cranium & 1 \\
\hline 11 & 5 & 323 & $\mathrm{IIIb} / \mathrm{c}$ & L. Archaic & & Mammalia (Medium/large) & Indeterminate & 23 \\
\hline 11 & 5 & 323 & $\mathrm{IIIl} / \mathrm{c}$ & L. Archaic & & Medium/Large Vertebrata & Indeterminate & 1 \\
\hline 11 & 5 & 323 & IIIb/c & L. Archaic & & Medium/Large Vertebrata & Long bone & 1 \\
\hline 11 & 5 & 323 & $\mathrm{IIIb} / \mathrm{c}$ & L. Archaic & & Small/Medium Vertebrata & Long bone & 4 \\
\hline 11 & 5 & 323 & IIIlb/c & L. Archaic & & Sylvilagus sp. & Permanent tooth & 1 \\
\hline 11 & 5 & 323 & $\mathrm{IIIb} / \mathrm{c}$ & L. Archaic & & Vertebrata & Indeterminate & 40 \\
\hline 11 & 5 & 575 & $\mathrm{IIIlb} / \mathrm{c}$ & L. Archaic & & Mammalia (Large) & Long bone & 1 \\
\hline 11 & 6 & 405 & $\mathrm{IIIb} / \mathrm{c}$ & Middle/L. Archaic & & Antilocapra/Odocoileus & Phalange & 1 \\
\hline 11 & 6 & 405 & $\mathrm{IIIb} / \mathrm{c}$ & Middle/L. Archaic & & Geomys sp. & Permanent tooth & 1 \\
\hline 11 & 6 & 405 & IIIb/c & Middle/L. Archaic & & Mammalia (Large) & Indeterminate & 1 \\
\hline 11 & 6 & 405 & $\mathrm{IIIlb} / \mathrm{c}$ & Middle/L. Archaic & & Mammalia (Medium) & Femur & 1 \\
\hline 11 & 6 & 405 & $\mathrm{IIIb} / \mathrm{c}$ & Middle/L. Archaic & & Mammalia (Medium) & Middle phalange & 1 \\
\hline 11 & 6 & 405 & $\mathrm{IIIb} / \mathrm{c}$ & Middle/L. Archaic & & Mammalia (Medium) & Rib & 1 \\
\hline 11 & 6 & 405 & $\mathrm{IIIb} / \mathrm{c}$ & Middle/L. Archaic & & Mammalia (Medium/large) & Indeterminate & 13 \\
\hline 11 & 6 & 405 & $\mathrm{IIIb} / \mathrm{c}$ & Middle/L. Archaic & & Serpentes & Dorsal vertebra & 1 \\
\hline 11 & 6 & 405 & $\mathrm{IIIb} / \mathrm{c}$ & Middle/L. Archaic & & Small/Medium Vertebrata & Long bone & 11 \\
\hline 11 & 6 & 405 & IIIlb/c & Middle/L. Archaic & & Sylvilagus sp. & Central tarsal bone & 1 \\
\hline 11 & 6 & 405 & $\mathrm{IIlb} / \mathrm{c}$ & Middle/L. Archaic & & Sylvilagus sp. & Permanent tooth & 1 \\
\hline 11 & 6 & 405 & $\mathrm{IIIb} / \mathrm{c}$ & Middle/L. Archaic & & Vertebrata & Indeterminate & 101 \\
\hline 11 & 7 & 474 & IIIlb & Middle/L. Archaic & & Colubridae & Dorsal vertebra & 1 \\
\hline 11 & 7 & 474 & IIIb & Middle/L. Archaic & & Lepus californicus & Permanent tooth & 1 \\
\hline 11 & 7 & 474 & $\mathrm{IIlb}$ & Middle/L. Archaic & & Lepus californicus & Radius & 1 \\
\hline 11 & 7 & 474 & IIIb & Middle/L. Archaic & & Mammalia (Medium/large) & Indeterminate & 1 \\
\hline 11 & 7 & 474 & IIIb & Middle/L. Archaic & & Mammalia (Small) & Calcaneus & 1 \\
\hline 11 & 7 & 474 & IIIb & Middle/L. Archaic & & Mammalia (Small) & Humerus & 1 \\
\hline 11 & 7 & 474 & IIIlb & Middle/L. Archaic & & Mammalia (Small) & Metapodial & 1 \\
\hline 11 & 7 & 474 & $\mathrm{IIl}$ & Middle/L. Archaic & & Mammalia (Small) & Permanent tooth & 1 \\
\hline 11 & 7 & 474 & $\mathrm{IIIb}$ & Middle/L. Archaic & & Mammalia (Small) & Radius & 1 \\
\hline 11 & 7 & 474 & IIIlb & Middle/L. Archaic & & Mammalia (Small/medium) & Alveolar ridge fragment & 1 \\
\hline 11 & 7 & 474 & IIIb & Middle/L. Archaic & & Neotoma sp. & Permanent tooth & 1 \\
\hline 11 & 7 & 474 & IIIb & Middle/L. Archaic & & Serpentes & Dorsal vertebra & 4 \\
\hline 11 & 7 & 474 & IIIlb & Middle/L. Archaic & & Small/Medium Vertebrata & Distal phalange & 1 \\
\hline 11 & 7 & 474 & IIIlb & Middle/L. Archaic & & Small/Medium Vertebrata & Long bone & 10 \\
\hline 11 & 7 & 474 & $\mathrm{IIlb}$ & Middle/L. Archaic & & Small/Medium Vertebrata & Proximal phalange & 1 \\
\hline 11 & 7 & 474 & IIIlb & Middle/L. Archaic & & Sylvilagus sp. & Astragalus & 1 \\
\hline 11 & 7 & 474 & IIIlb & Middle/L. Archaic & & Sylvilagus sp. & Metatarsal 3 & 1 \\
\hline 11 & 7 & 474 & $\mathrm{IIIb}$ & Middle/L. Archaic & & Testudinata & Shell fragment & 1 \\
\hline 11 & 7 & 474 & IIIlb & Middle/L. Archaic & & Vertebrata & Indeterminate & 88 \\
\hline 11 & 8 & 508 & IIIlb & M. Archaic & & Anura & Humerus & 1 \\
\hline 11 & 8 & 508 & $\mathrm{IIIb}$ & M. Archaic & & Artiodactyla & Tooth, perm./decid. ind. & 1 \\
\hline 11 & 8 & 508 & IIIlb & M. Archaic & & Colubridae & Dorsal vertebra & 4 \\
\hline 11 & 8 & 508 & IIIb & M. Archaic & & Cricetidae (Small) & Femur & 1 \\
\hline 11 & 8 & 508 & IIIb & M. Archaic & & Leporidae & Cranium & 1 \\
\hline 11 & 8 & 508 & IIIb & M. Archaic & & Leporidae & Distal phalange & 1 \\
\hline 11 & 8 & 508 & IIIlb & M. Archaic & & Leporidae & Metapodial & 1 \\
\hline 11 & 8 & 508 & IIIb & M. Archaic & & Lepus californicus & Central tarsal bone & 1 \\
\hline 11 & 8 & 508 & IIIlb & M. Archaic & & Lepus californicus & Humerus & 1 \\
\hline 11 & 8 & 508 & IIIlb & M. Archaic & & Lepus californicus & Permanent tooth & 3 \\
\hline 11 & 8 & 508 & IIIlb & M. Archaic & & Mammalia (Large) & Indeterminate & 1 \\
\hline 11 & 8 & 508 & IIIb & M. Archaic & & Mammalia (Medium/large) & Indeterminate & 4 \\
\hline 11 & 8 & 508 & IIIlb & M. Archaic & & Mammalia (Small) & Alveolar ridge fragment & 1 \\
\hline 11 & 8 & 508 & IIIb & M. Archaic & & Mammalia (Small) & Femur & 1 \\
\hline 11 & 8 & 508 & IIIlb & M. Archaic & & Mammalia (Small) & Metapodial & 1 \\
\hline 11 & 8 & 508 & IIIlb & M. Archaic & & Mammalia (Small) & Permanent tooth & 1 \\
\hline 11 & 8 & 508 & IIIlb & M. Archaic & & Neotoma sp. & Astragalus & 1 \\
\hline 11 & 8 & 508 & IIIlb & M. Archaic & & Neotoma sp. & Calcaneus & 2 \\
\hline 11 & 8 & 508 & IIIlb & M. Archaic & & Small/Medium Vertebrata & Long bone & 13 \\
\hline 11 & 8 & 508 & IIIlb & M. Archaic & & Sylvilagus sp. & Humerus & 1 \\
\hline 11 & 8 & 508 & IIIb & M. Archaic & & Sylvilagus sp. & Permanent tooth & 1 \\
\hline
\end{tabular}




\begin{tabular}{|c|c|c|c|c|c|c|c|c|}
\hline Square & Level & Lot & Unit & Cultural Affinity & Feature & Taxon & Element & No. \\
\hline 11 & 8 & 508 & IIIb & M. Archaic & & Testudinata & Carapace fragment ind. & 1 \\
\hline 11 & 8 & 508 & IIIb & M. Archaic & & Vertebrata & Indeterminate & 133 \\
\hline 11 & 10 & 552 & IIIIb & M. Archaic & & Colubridae & Dorsal vertebra & 3 \\
\hline 11 & 10 & 552 & IIIlb & M. Archaic & & Cricetidae (Medium) & Femur & 1 \\
\hline 11 & 10 & 552 & IIIlb & M. Archaic & & Mammalia (Small) & Caudal vertebra & 2 \\
\hline 11 & 10 & 552 & IIIIb & M. Archaic & & Mammalia (Small) & Cranium & 1 \\
\hline 11 & 10 & 552 & IIIb & M. Archaic & & Mammalia (Small) & Metapodial & 1 \\
\hline 11 & 10 & 552 & IIIb & M. Archaic & & Rodentia (Small) & Permanent tooth & 1 \\
\hline 11 & 10 & 552 & IIIlb & M. Archaic & & Small/Medium Vertebrata & Long bone & 19 \\
\hline 11 & 10 & 552 & IIIlb & M. Archaic & & Sylvilagus sp. & Calcaneus & 1 \\
\hline 11 & 10 & 552 & IIIb & M. Archaic & & Sylvilagus sp. & Humerus & 1 \\
\hline 11 & 10 & 552 & IIItb & M. Archaic & & Sylvilagus sp. & Permanent tooth & 6 \\
\hline 11 & 10 & 552 & IIIIb & M. Archaic & & Sylvilagus sp. & Ulna & 1 \\
\hline 11 & 10 & 552 & IIIb & M. Archaic & & Testudinata & Shell fragment & 2 \\
\hline 11 & 10 & 552 & IIIb & M. Archaic & & Vertebrata & Indeterminate & 71 \\
\hline 11 & 11 & 570 & IIIa/b & Early/M. Archaic & & Lepus californicus & Permanent tooth & 1 \\
\hline 11 & 11 & 570 & IIIa/b & Early/M. Archaic & & Mammalia (Medium/large) & Indeterminate & 3 \\
\hline 11 & 11 & 570 & IIIa/b & Early/M. Archaic & & Mammalia (Medium/large) & Tooth, perm./decid. ind. & 1 \\
\hline 11 & 11 & 570 & IIIa/b & Early/M. Archaic & & Mammalia (Small) & Proximal phalange & 1 \\
\hline 11 & 11 & 570 & IIIa/b & Early/M. Archaic & & Serpentes & Dorsal vertebra & 1 \\
\hline 11 & 11 & 570 & IIIa/b & Early/M. Archaic & & Small/Medium Vertebrata & Long bone & 13 \\
\hline 11 & 11 & 570 & IIIa/b & Early/M. Archaic & & Sylvilagus sp. & Metatarsal 3 & 1 \\
\hline 11 & 11 & 570 & $\mathrm{IIa} / \mathrm{b}$ & Early/M. Archaic & & Vertebrata & Indeterminate & 57 \\
\hline 11 & 12 & 611 & IIIa/b & E. Archaic & & Mammalia (Large) & Long bone & 1 \\
\hline 11 & 12 & 611 & IIIa/b & E. Archaic & & Mammalia (Medium) & Patella & 1 \\
\hline 11 & 12 & 611 & ШІа/b & E. Archaic & & Mammalia (Medium/large) & Indeterminate & 7 \\
\hline 11 & 12 & 611 & IIIa/b & E. Archaic & & Mammalia (Micro) & Permanent tooth & 1 \\
\hline 11 & 12 & 611 & IIIa/b & E. Archaic & & Mammalia (Small) & Metapodial & 1 \\
\hline 11 & 12 & 611 & IIIa/b & E. Archaic & & Neotoma sp. & Permanent tooth & 1 \\
\hline 11 & 12 & 611 & IIIIa/b & E. Archaic & & Small vertebrate, class ind. & Middle phalange & 2 \\
\hline 11 & 12 & 611 & ШШа/b & E. Archaic & & Small/Medium Vertebrata & Long bone & 10 \\
\hline 11 & 12 & 611 & IIIa/b & E. Archaic & & Vertebrata & Indeterminate & 40 \\
\hline 11 & 13 & 658 & IIIIa & E. Archaic & & Kinosternidae & Peripheral & 1 \\
\hline 11 & 13 & 658 & III & E. Archaic & & Mammalia (Medium/large) & Indeterminate & 6 \\
\hline 11 & 13 & 658 & IIII & E. Archaic & & Odocoileus sp. & Permanent tooth & 1 \\
\hline 11 & 13 & 658 & IIIIa & E. Archaic & & Rodentia (Medium) & Caudal vertebra & 1 \\
\hline 11 & 13 & 658 & IIII & E. Archaic & & Small/Medium Vertebrata & Long bone & 1 \\
\hline 11 & 13 & 658 & IIIa & E. Archaic & & Testudinata & Carapace fragment ind. & 1 \\
\hline 11 & 13 & 658 & IIIIa & E. Archaic & & Vertebrata & Indeterminate & 13 \\
\hline 12 & 0 & 681 & ? & Unassigned & & Mammalia (Medium/large) & Indeterminate & 5 \\
\hline 12 & 0 & 681 & ? & Unassigned & & Mammalia (Medium/large) & Long bone & 3 \\
\hline 12 & 0 & 681 & ? & Unassigned & & Vertebrata & Indeterminate & 14 \\
\hline 12 & 4 & 202 & IIIc & L. Archaic & & Mammalia (Medium/large) & Indeterminate & 1 \\
\hline 12 & $12 \mathrm{~B}$ & 613 & $\mathrm{II} \mathrm{a} / \mathrm{b}$ & E. Archaic & 213 & Lepus californicus & Humerus & 1 \\
\hline 12 & 69 & 2501 & Igl & E. Paleoindian & & Vertebrata & Indeterminate & 1 \\
\hline 13 & 3 & 176 & IIII & L. Archaic/L. Prehist. & & Antilocapra/Odocoileus & Metapodial & 1 \\
\hline 13 & 3 & 176 & IIIc & L. Archaic/L. Prehist. & & Antilocapra/Odocoileus & Phalange & 1 \\
\hline 13 & 3 & 176 & IIIc & L. Archaic/L. Prehist. & & Mammalia (Large) & Indeterminate & 1 \\
\hline 13 & 3 & 176 & IIIc & L. Archaic/L. Prehist. & & Mammalia (Large) & Long bone & 1 \\
\hline 13 & 3 & 176 & IIIc & L. Archaic/L. Prehist. & & Mammalia (Medium/large) & Indeterminate & 31 \\
\hline 13 & 3 & 176 & IIIIc & L. Archaic/L. Prehist. & & Mammalia (Medium/large) & Long bone & 8 \\
\hline 13 & 3 & 176 & IIIIc & L. Archaic/L. Prehist. & & Mammalia (Medium/large) & Tooth, perm./decid. ind. & 1 \\
\hline 13 & 3 & 176 & IIIIc & L. Archaic/L. Prehist. & & Mammalia (Small) & Metapodial & 1 \\
\hline 13 & 3 & 176 & IIIIc & L. Archaic/L. Prehist. & & Small/Medium Vertebrata & Long bone & 7 \\
\hline 13 & 3 & 176 & IIIIc & L. Archaic/L. Prehist. & & Vertebrata & Indeterminate & 5 \\
\hline 13 & 5 & 327 & III & L. Archaic & & Antilocapra/Odocoileus & Metapodial & 1 \\
\hline 13 & 5 & 327 & IIII & L. Archaic & & AntilocapralOdocoileus & Proximal abaxial sesamoid & 1 \\
\hline 13 & 5 & 327 & IIIIC & L. Archaic & & Anura & Humerus & 1 \\
\hline 13 & 5 & 327 & IIIC & L. Archaic & & cf. Leporidae & Tibia & 1 \\
\hline 13 & 5 & 327 & IIII & L. Archaic & & Geomys sp. & Permanent tooth & 1 \\
\hline 13 & 5 & 327 & IIIIc & L. Archaic & & Leporidae & Metacarpal 3 & 1 \\
\hline 13 & 5 & 327 & |Шि & L. Archaic & & Mammalia (Medium/large) & Cranium & 1 \\
\hline 13 & 5 & 327 & IIII & L. Archaic & & Mammalia (Medium/large) & Indeterminate & 11 \\
\hline 13 & 5 & 327 & IIIIc & L. Archaic & & Mammalia (Medium/large) & Long bone & 14 \\
\hline 13 & 5 & 327 & IIII & L. Archaic & & Mammalia (Medium/large) & Scapula & 1 \\
\hline 13 & 5 & 327 & ШШ丷 & L. Archaic & & Mammalia (Medium/large) & Tooth, perm./decid. ind. & 3 \\
\hline 13 & 5 & 327 & IIIc & L. Archaic & & Mammalia (Small) & Femur & 1 \\
\hline
\end{tabular}




\begin{tabular}{|c|c|c|c|c|c|c|c|c|}
\hline Square & Level & Lot & Unit & Cultural Affinity & Feature & Taxon & Element & No. \\
\hline 13 & 5 & 327 & $\overline{1 I I c}$ & L. Archaic & & Mammalia (Small/medium) & Alveolar ridge fragment & 1 \\
\hline 13 & 5 & 327 & IIIc & L. Archaic & & Mammalia (Small/medium) & Metapodial & 1 \\
\hline 13 & 5 & 327 & IIIIc & L. Archaic & & Neotoma sp. & Permanent tooth & 2 \\
\hline 13 & 5 & 327 & Шाс & L. Archaic & & Rodentia (Medium) & Permanent tooth & 2 \\
\hline 13 & 5 & 327 & IIIC & L. Archaic & & Serpentes & Dorsal vertebra & 1 \\
\hline 13 & 5 & 327 & |IIIc & L. Archaic & & Small/Medium Vertebrata & Long bone & 17 \\
\hline 13 & 5 & 327 & IIIIc & L. Archaic & & Sylvilagus sp. & Humerus & 1 \\
\hline 13 & 5 & 327 & |IIIc & L. Archaic & & Sylvilagus sp. & Metatarsal 3 & 1 \\
\hline 13 & 5 & 327 & |IIIC & L. Archaic & & Sylvilagus sp. & Permanent tooth & 3 \\
\hline 13 & 5 & 327 & IIIc & L. Archaic & & Testudinata & Neural & 1 \\
\hline 13 & 5 & 327 & IIIc & L. Archaic & & Testudinata & Pleural & 1 \\
\hline 13 & 5 & 327 & IIIIC & L. Archaic & & Vertebrata & Indeterminate & 290 \\
\hline 13 & 5 & 376 & IIIc & L. Archaic & & Mammalia (Large) & Long bone & 15 \\
\hline 13 & 5 & 376 & IIIc & L. Archaic & & Mammalia (Medium/large) & Indeterminate & 2 \\
\hline 13 & 5 & 386 & IIII & L. Archaic & & Mammalia (Very large) & Long bone & 1 \\
\hline 13 & 6 & 447 & |Шा & L. Archaic & & AntilocapralOdocoileus & Femur & 1 \\
\hline 13 & 6 & 447 & IIIc & L. Archaic & & AntilocapralOdocoileus & Metapodial & 1 \\
\hline 13 & 6 & 447 & |IIIC & L. Archaic & & AntilocapralOdocoileus & Middle phalange & 1 \\
\hline 13 & 6 & 447 & IIIc & L. Archaic & & AntilocapralOdocoileus & Proximal abaxial sesamoid & 1 \\
\hline 13 & 6 & 447 & IIIc & L. Archaic & & AntilocapralOdocoileus & Proximal axial sesamoid & 1 \\
\hline 13 & 6 & 447 & IIIIc & L. Archaic & & Colubridae & Dorsal vertebra & 1 \\
\hline 13 & 6 & 447 & |IIIc & L. Archaic & & Leporidae & Permanent tooth & 1 \\
\hline 13 & 6 & 447 & |Шाс & L. Archaic & & Lepus californicus & Humerus & 1 \\
\hline 13 & 6 & 447 & IIIIc & L. Archaic & & Mammalia (Large) & Long bone & 2 \\
\hline 13 & 6 & 447 & |Шा & L. Archaic & & Mammalia (Medium/large) & Indeterminate & 24 \\
\hline 13 & 6 & 447 & IIIc & L. Archaic & & Mammalia (Medium/large) & Long bone & 7 \\
\hline 13 & 6 & 447 & IIIIc & L. Archaic & & Mammalia (Medium/large) & Tooth, perm./decid. ind. & 3 \\
\hline 13 & 6 & 447 & |IIIc & L. Archaic & & Mammalia (Small/medium) & Patella & 1 \\
\hline 13 & 6 & 447 & IIIc & L. Archaic & & Medium vertebrate, class ind. & Phalange & 1 \\
\hline 13 & 6 & 447 & IIIc & L. Archaic & & Neotoma sp. & Permanent tooth & 1 \\
\hline 13 & 6 & 447 & |IIC & L. Archaic & & Odocoileus sp. & Dist. phalange of paradigit & 1 \\
\hline 13 & 6 & 447 & IIIc & L. Archaic & & Sigmodon hispidus & Mandible & 1 \\
\hline 13 & 6 & 447 & IIIIc & L. Archaic & & Sigmodon hispidus & Permanent tooth & 1 \\
\hline 13 & 6 & 447 & IIIIc & L. Archaic & & Small/Medium Vertebrata & Long bone & 3 \\
\hline 13 & 6 & 447 & |IIIc & L. Archaic & & Small/Medium Vertebrata & Proximal phalange & 1 \\
\hline 13 & 6 & 447 & IIIc & L. Archaic & & Testudinata & Peripheral & 1 \\
\hline 13 & 6 & 447 & IIIIc & L. Archaic & & Testudinata & Plastron fragment ind. & 1 \\
\hline 13 & 6 & 447 & IIII & L. Archaic & & Testudinata & Shell fragment & 5 \\
\hline 13 & 6 & 447 & IIIc & L. Archaic & & Vertebrata & Indeterminate & 230 \\
\hline 13 & 7 & 490 & $\mathrm{mllb} / \mathrm{c}$ & Middle/L. Archaic & & Lepus californicus & Permanent tooth & 1 \\
\hline 13 & 7 & 490 & $\mathrm{IIlb} / \mathrm{c}$ & Middle/L. Archaic & & Mammalia (Medium/large) & Indeterminate & 2 \\
\hline 13 & 7 & 490 & $\mathrm{IIlb} / \mathrm{c}$ & Middle/L. Archaic & & Mammalia (Small/medium) & Alveolar ridge fragment & 1 \\
\hline 13 & 7 & 490 & IIIIb/c & Middle/L. Archaic & & Mammalia (Small/medium) & Middle phalange & 1 \\
\hline 13 & 7 & 490 & IIIlb/c & Middle/L. Archaic & & Vertebrata & Indeterminate & 3 \\
\hline 13 & 8 & 494 & IIIb & M. Archaic & & Geomys sp. & Cranium & 1 \\
\hline 13 & 8 & 494 & IIIIb & M. Archaic & & Mammalia (Medium/large) & Indeterminate & 2 \\
\hline 13 & 8 & 494 & IIIlb & M. Archaic & & Small/Medium Vertebrata & Long bone & 5 \\
\hline 13 & 8 & 494 & IIlb & M. Archaic & & Vertebrata & Indeterminate & 8 \\
\hline 13 & 9 & 518 & IIIb & M. Archaic & & Chrysemys sensu lato & Suprapygal & 1 \\
\hline 13 & 9 & 518 & IIIl b & M. Archaic & & Colubridae & Dorsal vertebra & 2 \\
\hline 13 & 9 & 518 & IIIb & M. Archaic & & Cricetidae & Calcaneus & 1 \\
\hline 13 & 9 & 518 & IIIb & M. Archaic & & Geomys sp. & Humerus & 1 \\
\hline 13 & 9 & 518 & $\mathrm{IIlb}$ & M. Archaic & & Lepus californicus & Permanent tooth & 1 \\
\hline 13 & 9 & 518 & IIIlb & M. Archaic & & Mammalia (Large) & Long bone & 3 \\
\hline 13 & 9 & 518 & IIIb & M. Archaic & & Mammalia (Medium/large) & Indeterminate & 7 \\
\hline 13 & 9 & 518 & IIIb & M. Archaic & & Mammalia (Medium/large) & Long bone & 1 \\
\hline 13 & 9 & 518 & IIIl & M. Archaic & & Mammalia (Medium/large) & Tooth, perm./decid. ind. & 1 \\
\hline 13 & 9 & 518 & IIlb & M. Archaic & & Mammalia (Small) & Long bone & 1 \\
\hline 13 & 9 & 518 & IIIl & M. Archaic & & Mammalia (Small) & Metapodial & 1 \\
\hline 13 & 9 & 518 & IIIIb & M. Archaic & & Mammalia (Small) & Permanent tooth & 1 \\
\hline 13 & 9 & 518 & IIIb & M. Archaic & & Mammalia (Small/medium) & Caudal vertebra & 1 \\
\hline 13 & 9 & 518 & IIIb & M. Archaic & & Mammalia (Small/medium) & Long bone & 1 \\
\hline 13 & 9 & 518 & IIII & M. Archaic & & Serpentes & Dorsal vertebra & 1 \\
\hline 13 & 9 & 518 & IIIb & M. Archaic & & Small vertebrate, class ind. & Distal phalange & 1 \\
\hline 13 & 9 & 518 & IIIb & M. Archaic & & Small/Medium Vertebrata & Long bone & 7 \\
\hline 13 & 9 & 518 & IIIb & M. Archaic & & Sylvilagus sp. & Calcaneus & 1 \\
\hline 13 & 9 & 518 & IIIlb & M. Archaic & & Testudinata & Carapace fragment ind. & 4 \\
\hline
\end{tabular}




\begin{tabular}{|c|c|c|c|c|c|c|c|c|}
\hline Square & Level & Lot & Unit & Cultural Affinity & Feature & Taxon & Element & No. \\
\hline 13 & 9 & 518 & IIIb & M. Archaic & & Vertebrata & Indeterminate & 49 \\
\hline 13 & $10 \mathrm{~A}$ & 543 & IIIIb & M. Archaic & & Carnivora & Permanent tooth & 1 \\
\hline 13 & $10 \mathrm{~A}$ & 543 & IIIIb & M. Archaic & & Colubridae & Dorsal vertebra & 1 \\
\hline 13 & $10 \mathrm{~A}$ & 543 & IIIb & M. Archaic & & Lepus californicus & Astragalus & 1 \\
\hline 13 & $10 \mathrm{~A}$ & 543 & IIIlb & M. Archaic & & Lepus californicus & Permanent tooth & 1 \\
\hline 13 & $10 \mathrm{~A}$ & 543 & IIIlb & M. Archaic & & Lepus californicus & Radius & 1 \\
\hline 13 & $10 \mathrm{~A}$ & 543 & IIIIb & M. Archaic & & Mammalia (Large) & Indeterminate & 1 \\
\hline 13 & $10 \mathrm{~A}$ & 543 & IIIIb & M. Archaic & & Mammalia (Large) & Long bone & 1 \\
\hline 13 & $10 \mathrm{~A}$ & 543 & IIIlb & M. Archaic & & Mammalia (Medium) & Radius & 3 \\
\hline 13 & $10 \mathrm{~A}$ & 543 & IIIIb & M. Archaic & & Mammalia (Medium/large) & Indeterminate & 10 \\
\hline 13 & $10 \mathrm{~A}$ & 543 & IIIIb & M. Archaic & & Mammalia (Medium/large) & Long bone & 3 \\
\hline 13 & $10 \mathrm{~A}$ & 543 & IIIlb & M. Archaic & & Mammalia (Small) & Humerus & 1 \\
\hline 13 & $10 \mathrm{~A}$ & 543 & IIIlb & M. Archaic & & Small/Medium Vertebrata & Long bone & 4 \\
\hline 13 & $10 \mathrm{~A}$ & 543 & IIIb & M. Archaic & & Sylvilagus sp. & Permanent tooth & 1 \\
\hline 13 & $10 \mathrm{~A}$ & 543 & IIIlb & M. Archaic & & Testudinata & Shell fragment & 8 \\
\hline 13 & $10 \mathrm{~A}$ & 543 & IIIlb & M. Archaic & & Vertebrata & Indeterminate & 12 \\
\hline 13 & $10 \mathrm{~B}$ & 560 & IIIb & M. Archaic & 213 & Colubridae & Dorsal vertebra & 1 \\
\hline 13 & $10 \mathrm{~B}$ & 560 & IIIlb & M. Archaic & 213 & Lepus californicus & Permanent tooth & 1 \\
\hline 13 & $10 \mathrm{~B}$ & 560 & IIIIb & M. Archaic & 213 & Mammalia (Medium) & Proximal phalange & 1 \\
\hline 13 & 10B & 560 & IIItb & M. Archaic & 213 & Medium/Large Vertebrata & Indeterminate & 1 \\
\hline 13 & 10B & 560 & IIIlb & M. Archaic & 213 & Vertebrata & Indeterminate & 2 \\
\hline 13 & $11 \mathrm{~A}$ & 563 & IIIlb & Early/M. Archaic & & Carnivora & Accessory carpal bone & 1 \\
\hline 13 & $11 \mathrm{~A}$ & 563 & IIIb & Early/M. Archaic & & Colubridae & Dorsal vertebra & 1 \\
\hline 13 & $11 \mathrm{~A}$ & 563 & IIIlb & Early/M. Archaic & & Leporidae & Scapula & 1 \\
\hline 13 & $11 \mathrm{~A}$ & 563 & IIIlb & Early/M. Archaic & & Mammalia (Large) & Indeterminate & 2 \\
\hline 13 & $11 \mathrm{~A}$ & 563 & IIIIb & Early/M. Archaic & & Mammalia (Medium) & Proximal phalange & 1 \\
\hline 13 & $11 \mathrm{~A}$ & 563 & IIIb & Early/M. Archaic & & Mammalia (Medium/large) & Cranium & 2 \\
\hline 13 & $11 \mathrm{~A}$ & 563 & mb & Early/M. Archaic & & Mammalia (Medium/large) & Indeterminate & 1 \\
\hline 13 & $11 \mathrm{~A}$ & 563 & IIIb & Early/M. Archaic & & Mammalia (Medium/large) & Long bone & 1 \\
\hline 13 & $11 \mathrm{~A}$ & 563 & IIIb & Early/M. Archaic & & Mammalia (Small) & Calcaneus & 1 \\
\hline 13 & $11 \mathrm{~A}$ & 563 & IIIlb & Early/M. Archaic & & Mammalia (Small/medium) & Caudal vertebra & 1 \\
\hline 13 & $11 \mathrm{~A}$ & 563 & IIIlb & Early/M. Archaic & & Mammalia (Small/medium) & Long bone & 1 \\
\hline 13 & $11 \mathrm{~A}$ & 563 & IIIlb & Early/M. Archaic & & Mammalia (Small/medium) & Vertebra & 1 \\
\hline 13 & $11 \mathrm{~A}$ & 563 & IIIb & Early/M. Archaic & & Medium vertebrate, class ind. & Middle phalange & 1 \\
\hline 13 & $11 \mathrm{~A}$ & 563 & IIIIb & Early/M. Archaic & & Medium/Large Vertebrata & Indeterminate & 5 \\
\hline 13 & $11 \mathrm{~A}$ & 563 & IIIIb & Early/M. Archaic & & Rodentia (Medium) & Permanent tooth & 2 \\
\hline 13 & $11 \mathrm{~A}$ & 563 & IIIb & Early/M. Archaic & & Serpentes & Dorsal vertebra & 1 \\
\hline 13 & $11 \mathrm{~A}$ & 563 & IIIb & Early/M. Archaic & & Sigmodon hispidus & Mandible & 1 \\
\hline 13 & $11 \mathrm{~A}$ & 563 & IIIlb & Early/M. Archaic & & Sigmodon hispidus & Permanent tooth & 1 \\
\hline 13 & $11 \mathrm{~A}$ & 563 & IIIb & Early/M. Archaic & & Small/Medium Vertebrata & Long bone & 4 \\
\hline 13 & $11 \mathrm{~A}$ & 563 & IIIlb & Early/M. Archaic & & Sylvilagus sp. & Astragalus & 1 \\
\hline 13 & $11 \mathrm{~A}$ & 563 & IIIIb & Early/M. Archaic & & Testudinata & Shell fragment & 4 \\
\hline 13 & $11 \mathrm{~A}$ & 563 & IIIlb & Early/M. Archaic & & Vertebrata & Indeterminate & 61 \\
\hline 13 & 11B & 586 & mb & Early/M. Archaic & 213 & Lepus californicus & Permanent tooth & 1 \\
\hline 13 & 11B & 586 & IIIIb & Early/M. Archaic & 213 & Small/Medium Vertebrata & Long bone & 2 \\
\hline 13 & $11 \mathrm{~B}$ & 586 & IIIb & Early/M. Archaic & 213 & Vertebrata & Indeterminate & 9 \\
\hline 13 & $12 \mathrm{~A}$ & 628 & IIIa/b & E. Archaic & & Mammalia (Medium/large) & Indeterminate & 10 \\
\hline 13 & $12 \mathrm{~A}$ & 628 & Ша/b & E. Archaic & & Mammalia (Micro) & Permanent tooth & 1 \\
\hline 13 & $12 \mathrm{~A}$ & 628 & IIIa/b & E. Archaic & & Mammalia (Small) & Calcaneus & 1 \\
\hline 13 & $12 \mathrm{~A}$ & 628 & IIIa/b & E. Archaic & & Mammalia (Small) & Distal phalange & 1 \\
\hline 13 & $12 \mathrm{~A}$ & 628 & ШІа/b & E. Archaic & & Neotoma sp. & Permanent tooth & 1 \\
\hline 13 & $12 \mathrm{~A}$ & 628 & IIIIa/b & E. Archaic & & Serpentes & Dorsal vertebra & 2 \\
\hline 13 & $12 \mathrm{~A}$ & 628 & IIITa/b & E. Archaic & & Small/Medium Vertebrata & Long bone & 4 \\
\hline 13 & $12 \mathrm{~A}$ & 628 & IIIa/b & E. Archaic & & Sylvilagus sp. & Third tarsal & 1 \\
\hline 13 & $12 \mathrm{~A}$ & 628 & IIIa/b & E. Archaic & & Testudinata & Shell fragment & 1 \\
\hline 13 & $12 \mathrm{~A}$ & 628 & IIIIa/b & E. Archaic & & Vertebrata & Indeterminate & 32 \\
\hline 13 & 13 & 655 & IIIIa/b & E. Archaic & & Colubridae & Dorsal vertebra & 1 \\
\hline 13 & 13 & 655 & Ша/b & E. Archaic & & Mammalia (Medium/large) & Indeterminate & 4 \\
\hline 13 & 13 & 655 & IIIa/b & E. Archaic & & Vertebrata & Indeterminate & 11 \\
\hline 14 & 2 & 147 & IIIc/FILL & Unassigned & & Vertebrata & Indeterminate & 1 \\
\hline 14 & 3 & 187 & |Wc & L. Archaic/L. Prehist. & & Mammalia (Large) & Indeterminate & 35 \\
\hline 14 & 3 & 187 & IIIIc & L. Archaic/L. Prehist. & & Mammalia (Medium/large) & Indeterminate & 2 \\
\hline 14 & 3 & 187 & IIIIc & L. Archaic/L. Prehist. & & Odocoileus sp. & Astragalus & 1 \\
\hline 14 & 3 & 187 & IIII & L. Archaic/L. Prehist. & & Odocoileus sp. & Tooth, perm./decid. ind. & 1 \\
\hline 14 & 3 & 187 & IIII & L. Archaic/L. Prehist. & & Small/Medium Vertebrata & Long bone & 7 \\
\hline 14 & 3 & 187 & IIIIc & L. Archaic/L. Prehist. & & Testudinata & Shell fragment & 1 \\
\hline 14 & 3 & 187 & IIIC & L. Archaic/L. Prehist. & & Vertebrata & Indeterminate & 64 \\
\hline
\end{tabular}




\begin{tabular}{|c|c|c|c|c|c|c|c|c|}
\hline Square & Level & Lot & Tunit & Cultural Affinity & Feature & Taxon & Element & No. \\
\hline 14 & 3 & 229 & IIIc & L. Archaic/L. Prehist. & & Mammalia (Medium/large) & Indeterminate & 4 \\
\hline 14 & 3 & 229 & IIIc & L. Archaic/L. Prehist. & & Odocoileus sp. & Tibia & 1 \\
\hline 14 & 4 & 306 & IIIc & L. Archaic/L. Prehist. & 202 & AntilocapralOdocoileus & Metapodial & 1 \\
\hline 14 & 4 & 306 & IIIIc & L. Archaic/L. Prehist. & 202 & AntilocapralOdocoileus & Proximal axial sesamoid & 1 \\
\hline 14 & 4 & 306 & III & L. Archaic/L. Prehist. & 202 & Colubridae & Dorsal vertebra & 1 \\
\hline 14 & 4 & 306 & IIIc & L. Archaic/L. Prehist. & 202 & Mammalia (Large) & Long bone & 1 \\
\hline 14 & 4 & 306 & IIIc & L. Archaic/L. Prehist. & 202 & Mammalia (Medium/large) & Indeterminate & 26 \\
\hline 14 & 4 & 306 & IIIc & L. Archaic/L. Prehist. & 202 & Mammalia (Medium/large) & Long bone & 10 \\
\hline 14 & 4 & 306 & IIIc & L. Archaic/L. Prehist. & 202 & Mammalia (Small) & Femur & 1 \\
\hline 14 & 4 & 306 & IIIc & L. Archaic/L. Prehist. & 202 & Odocoileus sp. & Tooth, perm./decid. ind. & 3 \\
\hline 14 & 4 & 306 & IIIC & L. Archaic/L. Prehist. & 202 & Serpentes & Dorsal vertebra & 1 \\
\hline 14 & 4 & 306 & IIIc & L. Archaic/L. Prehist. & 202 & Small/Medium Vertebrata & Long bone & 7 \\
\hline 14 & 4 & 306 & IIIc & L. Archaic/L. Prehist. & 202 & Testudinata & Shell fragment & 1 \\
\hline 14 & 4 & 306 & IIIC & L. Archaic/L. Prehist. & 202 & Vertebrata & Indeterminate & 84 \\
\hline 14 & 4 & 347 & IIIc & L. Archaic/L. Prehist. & 202 & Odocoileus sp. & Permanent tooth & 6 \\
\hline 14 & 5 & 368 & IIIc & L. Archaic/L. Prehist. & & Emydidae & Carapace fragment ind. & 1 \\
\hline 14 & 5 & 368 & IIIC & L. Archaic/L. Prehist. & & Geomys sp. & Permanent tooth & 1 \\
\hline 14 & 5 & 368 & IIIc & L. Archaic/L. Prehist. & & Leporidae & Permanent tooth & 2 \\
\hline 14 & 5 & 368 & IIIc & L. Archaic/L. Prehist. & & Mammalia (Large) & Vertebra & 1 \\
\hline 14 & 5 & 368 & IIIc & L. Archaic/L. Prehist. & & Mammalia (Medium) & Patella & 1 \\
\hline 14 & 5 & 368 & IIIc & L. Archaic/L. Prehist. & & Mammalia (Medium/large) & Indeterminate & 36 \\
\hline 14 & 5 & 368 & IIIC & L. Archaic/L. Prehist. & & Mammalia (Medium/large) & Long bone & 12 \\
\hline 14 & 5 & 368 & IIIIc & L. Archaic/L. Prehist. & & Mammalia (Medium/large) & Tooth, perm./decid. ind. & 2 \\
\hline 14 & 5 & 368 & IIIc & L. Archaic/L. Prehist. & & Mammalia (Small) & Caudal vertebra & 1 \\
\hline 14 & 5 & 368 & IIIc & L. Archaic/L. Prehist. & & Odocoileus sp. & Middle phalange & 1 \\
\hline 14 & 5 & 368 & IIIIc & L. Archaic/L. Prehist. & & Odocoileus sp. & Tooth, perm./decid. ind. & 2 \\
\hline 14 & 5 & 368 & IIIc & L. Archaic/L. Prehist. & & Testudinata & Shell fragment & 1 \\
\hline 14 & 5 & 368 & IIIIc & L. Archaic/L. Prehist. & & Vertebrata & Indeterminate & 171 \\
\hline 14 & $6 \mathrm{~A}$ & 408 & IIIIc & L. Archaic & & Antilocapra/Odocoileus & Radial carpal bone & 1 \\
\hline 14 & $6 \mathrm{~A}$ & 408 & IIIc & L. Archaic & & Colubridae & Dorsal vertebra & 3 \\
\hline 14 & $6 \mathrm{~A}$ & 408 & IIIc & L. Archaic & & Emydidae & Shell fragment & 8 \\
\hline 14 & $6 \mathrm{~A}$ & 408 & IIIIc & L. Archaic & & Lepus californicus & Metatarsal 3 & 1 \\
\hline 14 & $6 \mathrm{~A}$ & 408 & IIIc & L. Archaic & & Mammalia (Medium) & Cranium & 1 \\
\hline 14 & $6 \mathrm{~A}$ & 408 & IIIC & L. Archaic & & Mammalia (Medium/large) & Indeterminate & 30 \\
\hline 14 & $6 \mathrm{~A}$ & 408 & IIIc & L. Archaic & & Mammalia (Medium/large) & Long bone & 4 \\
\hline 14 & $6 \mathrm{~A}$ & 408 & IIIIc & L. Archaic & & Mammalia (Medium/large) & Tooth, perm./decid. ind. & 2 \\
\hline 14 & $6 \mathrm{~A}$ & 408 & IIIc & L. Archaic & & Mammalia (Small) & Cranium & 1 \\
\hline 14 & $6 \mathrm{~A}$ & 408 & IIIc & L. Archaic & & Mammalia (Small/medium) & Alveolar ridge fragment & 1 \\
\hline 14 & $6 \mathrm{~A}$ & 408 & IIIC & L. Archaic & & Mammalia (Small/medium) & Metapodial & 1 \\
\hline 14 & $6 \mathrm{~A}$ & 408 & IIIC & L. Archaic & & Medium/Large Vertebrata & Long bone & 1 \\
\hline 14 & $6 \mathrm{~A}$ & 408 & IIIc & L. Archaic & & Neotoma sp. & Permanent tooth & 1 \\
\hline 14 & $6 \mathrm{~A}$ & 408 & IIIC & L. Archaic & & Odocoileus sp. & Middle phalange & 1 \\
\hline 14 & $6 \mathrm{~A}$ & 408 & IIIC & L. Archaic & & Odocoileus sp. & Prox. phalange of paradigit & 1 \\
\hline 14 & $6 \mathrm{~A}$ & 408 & IIIc & L. Archaic & & Serpentes & Dorsal vertebra & 1 \\
\hline 14 & $6 \mathrm{~A}$ & 408 & IIIc & L. Archaic & & Small/Medium Vertebrata & Long bone & 11 \\
\hline 14 & $6 \mathrm{~A}$ & 408 & IIIC & L. Archaic & & Small/Medium Vertebrata & Phalange & 1 \\
\hline 14 & $6 \mathrm{~A}$ & 408 & IIIc & L. Archaic & & Small/Medium Vertebrata & Proximal phalange & 1 \\
\hline 14 & $6 \mathrm{~A}$ & 408 & IIIC & L. Archaic & & Testudinata & Carapace fragment ind. & 1 \\
\hline 14 & $6 \mathrm{~A}$ & 408 & IIIIC & L. Archaic & & Testudinata & Plastron fragment ind. & 1 \\
\hline 14 & $6 \mathrm{~A}$ & 408 & Wा & L. Archaic & & Testudinata & Shell fragment & 8 \\
\hline 14 & $6 \mathrm{~A}$ & 408 & IIIc & L. Archaic & & Vertebrata & Indeterminate & 203 \\
\hline 14 & $6 \mathrm{~B}$ & 421 & IIIc & L. Archaic & 207 & Mammalia (Large) & Indeterminate & 2 \\
\hline 14 & $6 \mathrm{~B}$ & 441 & IIIc & L. Archaic & 207 & Mammalia (Large) & Indeterminate & 3 \\
\hline 14 & $6 \mathrm{~B}$ & 441 & ШШc & L. Archaic & 207 & Mammalia (Large) & Long bone & 3 \\
\hline 14 & $6 \mathrm{~B}$ & 441 & IIIIc & L. Archaic & 207 & Mammalia (Medium/large) & Indeterminate & 5 \\
\hline 14 & $6 \mathrm{~B}$ & 441 & IIIIc & L. Archaic & 207 & Odocoileus sp. & Radius & 1 \\
\hline 14 & 7 & 488 & $\mathrm{mb} / \mathrm{c}$ & L. Archaic & & Lepus californicus & Metacarpal 3 & 1 \\
\hline 14 & 7 & 488 & $\mathrm{WL} / \mathrm{c}$ & L. Archaic & & Mammalia (Medium/large) & Indeterminate & 8 \\
\hline 14 & 7 & 488 & $\mathrm{IIJ} / \mathrm{c}$ & L. Archaic & & Medium/Large Vertebrata & Long bone & 1 \\
\hline 14 & 7 & 488 & $\Pi \Pi \mathrm{b} / \mathrm{c}$ & L. Archaic & & Odocoileus sp. & Tooth, perm./decid. ind. & 1 \\
\hline 14 & 7 & 488 & $\mathrm{IIb} / \mathrm{c}$ & L. Archaic & & Small/Medium Vertebrata & Long bone & 7 \\
\hline 14 & 7 & 488 & $\mathrm{IIll} \mathrm{b} / \mathrm{c}$ & L. Archaic & & Vertebrata & Indeterminate & 21 \\
\hline 14 & 8 & 506 & IIIb/c & L. Archaic & & Leporidae & Permanent tooth & 1 \\
\hline 14 & 8 & 506 & $\mathrm{mb} / \mathrm{c}$ & L. Archaic & & Mammalia (Medium) & Patella & 1 \\
\hline 14 & 8 & 506 & IIIb/c & L. Archaic & & Mammalia (Medium/large) & Indeterminate & 4 \\
\hline 14 & 8 & 506 & $\mathrm{IIlb} / \mathrm{c}$ & L. Archaic & & Mammalia (Small) & Caudal vertebra & 1 \\
\hline 14 & 8 & 506 & IIIb/c & L. Archaic & & Mammalia (Small) & Proximal phalange & 2 \\
\hline
\end{tabular}




\begin{tabular}{|c|c|c|c|c|c|c|c|c|}
\hline Square & Level & Lot & Unit & Cultural Affinity & Feature & Taxon & Element & No. \\
\hline 14 & 8 & 506 & $\mathrm{IIb} / \mathrm{c}$ & L. Archaic & & Odocoileus sp. & Tooth, perm./decid. ind. & 2 \\
\hline 14 & 8 & 506 & $\mathrm{IIIb} / \mathrm{c}$ & L. Archaic & & Rodentia (Medium) & Femur & \\
\hline 14 & 8 & 506 & $\mathrm{mb} / \mathrm{c}$ & L. Archaic & & Serpentes & Dorsal vertebra & 1 \\
\hline 14 & 8 & 506 & $\mathrm{mb} / \mathrm{c}$ & L. Archaic & & Small vertebrate, class ind. & Vertebra & \\
\hline 14 & 8 & 506 & $\mathrm{IIIb} / \mathrm{c}$ & L. Archaic & & Small/Medium Vertebrata & Long bone & 3 \\
\hline 14 & 8 & 506 & $\mathrm{mb} / \mathrm{c}$ & L. Archaic & & Sylvilagus sp. & Calcaneus & \\
\hline 14 & 8 & 506 & $\mathrm{IIIb} / \mathrm{c}$ & L. Archaic & & Sylvilagus sp. & Humerus & \\
\hline 14 & 8 & 506 & IIIIb/c & L. Archaic & & Vertebrata & Indeterminate & 34 \\
\hline 14 & 8 & 506 & $\mathrm{IIIb} / \mathrm{c}$ & L. Archaic & & Viperidae & Dorsal vertebra & 1 \\
\hline 14 & 9 & 512 & IIIIb & Middle/L. Archaic & & cf. Sigmodon hispidus & Calcaneus & \\
\hline 14 & 9 & 512 & IIIlb & Middle/L. Archaic & & Leporidae & Ulna & \\
\hline 14 & 9 & 512 & IIIlb & Middle/L. Archaic & & Lepus californicus & Metatarsal 4 & \\
\hline 14 & 9 & 512 & IIIIb & Middle/L. Archaic & & Lepus californicus & Permanent tooth & \\
\hline 14 & 9 & 512 & IIIlb & Middle/L. Archaic & & Mammalia (Large) & Long bone & \\
\hline 14 & 9 & 512 & IIIllb & Middle/L. Archaic & & Mammalia (Medium/large) & Indeterminate & \\
\hline 14 & 9 & 512 & IIIb & Middle/L. Archaic & & Mammalia (Micro) & Humerus & \\
\hline 14 & 9 & 512 & IIIlb & Middle/L. Archaic & & Medium/Large Vertebrata & Indeterminate & \\
\hline 14 & 9 & 512 & IIIlb & Middle/L. Archaic & & Sigmodon hispidus & Mandible & \\
\hline 14 & 9 & 512 & IIIb & Middle/L. Archaic & & Sigmodon hispidus & Permanent tooth & \\
\hline 14 & 9 & 512 & IIIlb & Middle/L. Archaic & & Small/Medium Vertebrata & Long bone & \\
\hline 14 & 9 & 512 & IIIlb & Middle/L. Archaic & & Sylvilagus sp. & Astragalus & \\
\hline 14 & 9 & 512 & IIIb & Middle/L. Archaic & & Testudinata & Shell fragment & \\
\hline 14 & 9 & 512 & IIIlb & Middle/L. Archaic & & Vertebrata & Indeterminate & 31 \\
\hline 14 & 10 & 537 & IIIlb & Middle/L. Archaic & & Antilocapra/Odocoileus & Fused central/fourth tarsal & \\
\hline 14 & 10 & 537 & IIIIb & Middle/L. Archaic & & Carnivora & Permanent tooth & \\
\hline 14 & 10 & 537 & IIIlb & Middle/L. Archaic & & Leporidae & Permanent tooth : & \\
\hline 14 & 10 & 537 & IIIlb & Middle/L. Archaic & & Leporidae & Radius & \\
\hline 14 & 10 & 537 & IIIlb & Middle/L. Archaic & & Mammalia (Medium) & Pelvis & \\
\hline 14 & 10 & 537 & IIIlb & Middle/L. Archaic & & Mammalia (Medium/large) & Indeterminate & \\
\hline 14 & 10 & 537 & IIIb & Middle/L. Archaic & & Small/Medium Vertebrata & Long bone & \\
\hline 14 & 10 & 537 & IIIlb & Middle/L. Archaic & & Vertebrata & Indeterminate & \\
\hline 14 & 11 & 551 & IIIlb & M. Archaic & & Geomys sp. & Permanent tooth & \\
\hline 14 & 11 & 551 & IIIb & M. Archaic & & Leporidae & Permanent tooth & \\
\hline 14 & 11 & 551 & IIIIb & M. Archaic & & Mammalia (Large) & Indeterminate & \\
\hline 14 & 11 & 551 & IIIlb & M. Archaic & & Mammalia (Medium/large) & Indeterminate & 17 \\
\hline 14 & 11 & 551 & IIIIb & M. Archaic & & Mammalia (Medium/large) & Tooth, perm./decid. ind. & 2 \\
\hline 14 & 11 & 551 & IIIIb & M. Archaic & & Neotoma sp. & Humerus & \\
\hline 14 & 11 & 551 & IIIIb & M. Archaic & & Small vertebrate, class ind. & Distal phalange & \\
\hline 14 & 11 & 551 & IIIb & M. Archaic & & Small/Medium Vertebrata & Long bone & 11 \\
\hline 14 & 11 & 551 & IIIIb & M. Archaic & & Sylvilagus sp. & Permanent tooth & \\
\hline 14 & 11 & 551 & IIIlb & M. Archaic & & Vertebrata & Indeterminate & 29 \\
\hline 14 & 12 & 561 & IIIa/b & M. Archaic & & Leporidae & Metacarpal 2 & 1 \\
\hline 14 & 12 & 561 & IIIIa/b & M. Archaic & & Mammalia (Large) & Indeterminate & 1 \\
\hline 14 & 12 & 561 & IIIa/b & M. Archaic & & Mammalia (Large) & Long bone & 2 \\
\hline 14 & 12 & 561 & IIIa/b & M. Archaic & & Mammalia (Medium/large) & Indeterminate & \\
\hline 14 & 12 & 561 & IIIa/b & M. Archaic & & Mammalia (Medium/large) & Long bone & \\
\hline 14 & 12 & 561 & IIIa/b & M. Archaic & & Mammalia (Medium/large) & Tooth, perm./decid. ind. & \\
\hline 14 & 12 & 561 & IШаa/b & M. Archaic & & Serpentes & Dorsal vertebra & 1 \\
\hline 14 & 12 & 561 & IIIIa/b & M. Archaic & & Small/Medium Vertebrata & Long bone & 4 \\
\hline 14 & 12 & 561 & IIIa/b & M. Archaic & & Small/Medium Vertebrata & Proximal phalange & \\
\hline 14 & 12 & 561 & IIIa/b & M. Archaic & & Sylvilagus sp. & Tibia & 1 \\
\hline 14 & 12 & 561 & IIIIa/b & M. Archaic & & Testudinata & Shell fragment & 1 \\
\hline 14 & 12 & 561 & IIIa/b & M. Archaic & & Vertebrata & Indeterminate & 44 \\
\hline 14 & 13 & 574 & IIIa/b & M. Archaic & & Antilocapra/Odocoileus & Phalange & 1 \\
\hline 14 & 13 & 574 & IIIIa/b & M. Archaic & & Leporidae & Permanent tooth & 1 \\
\hline 14 & 13 & 574 & IIIa/b & M. Archaic & & Mammalia (Medium/large) & Indeterminate & 4 \\
\hline 14 & 13 & 574 & IIIa/b & M. Archaic & & Mammalia (Medium/large) & Tooth, perm./decid. ind. & 1 \\
\hline 14 & 13 & 574 & IIIIa/b & M. Archaic & & Mammalia (Micro) & Tibia & 1 \\
\hline 14 & 13 & 574 & IIIa/b & M. Archaic & & Serpentes & Dorsal vertebra & 2 \\
\hline 14 & 13 & 574 & IIIa/b & M. Archaic & & Small/Medium Vertebrata & Long bone & 5 \\
\hline 14 & 13 & 574 & IIIIa/b & M. Archaic & & Testudinata & Carapace fragment ind. & 1 \\
\hline 14 & 13 & 574 & IIIa/b & M. Archaic & & Vertebrata & Indeterminate & 77 \\
\hline 14 & 14 & 590 & IIIIa & E. Archaic & & Medium/Large Vertebrata & Long bone & 1 \\
\hline 14 & 14 & 590 & IIIIa & E. Archaic & & Small/Medium Vertebrata & Long bone & 5 \\
\hline 14 & 14 & 590 & IIIIa & E. Archaic & & Small/Medium Vertebrata & Proximal phalange & 1 \\
\hline 14 & 14 & 590 & IIII & E. Archaic & & Vertebrata & Indeterminate & 11 \\
\hline 14 & 15 & 608 & IIIIa & E. Archaic & & Mammalia (Medium/large) & Indeterminate & 8 \\
\hline
\end{tabular}




\begin{tabular}{|c|c|c|c|c|c|c|c|c|}
\hline Square & Level & Lot & Unit & Cultural Affinity & Feature & Taxon & Element & No. \\
\hline 14 & 15 & 608 & $\overline{\mathrm{IIa}}$ & E. Archaic & & Mammalia (Medium/large) & Tooth, perm./decid. ind. & 3 \\
\hline 14 & 15 & 608 & IIIIa & E. Archaic & & Small/Medium Vertebrata & Long bone & 9 \\
\hline 14 & 15 & 608 & ШШа & E. Archaic & & Sylvilagus sp. & Metacarpal 3 & 1 \\
\hline 14 & 15 & 608 & ШШа & E. Archaic & & Sylvilagus sp. & Metapodial & 1 \\
\hline 14 & 15 & 608 & IIIIa & E. Archaic & & Testudinata & Shell fragment & 1 \\
\hline 14 & 15 & 608 & III & E. Archaic & & Vertebrata & Indeterminate & 42 \\
\hline 14 & 16 & 635 & IIIa & E. Archaic & & Mammalia (Medium/large) & Indeterminate & 1 \\
\hline 14 & 16 & 635 & IIIa & E. Archaic & & Mammalia (Small) & Calcaneus & 1 \\
\hline 14 & 16 & 635 & IIIIa & E. Archaic & & Small/Medium Vertebrata & Long bone & 4 \\
\hline 14 & 16 & 635 & IIIIa & E. Archaic & & Testudinata & Shell fragment & 2 \\
\hline 14 & 16 & 635 & IIIIa & E. Archaic & & Vertebrata & Indeterminate & 2 \\
\hline 15 & 3 & 217 & IIIc & L. Archaic/L. Prehist. & & Mammalia (Large) & Indeterminate & 1 \\
\hline 15 & 3 & 217 & IIIIc & L. Archaic/L. Prehist. & & Mammalia (Large) & Long bone & 2 \\
\hline 15 & 3 & 217 & IIIIc & L. Archaic/L. Prehist. & & Mammalia (Medium/large) & Indeterminate & 38 \\
\hline 15 & 3 & 217 & IIII & L. Archaic/L. Prehist. & & Mammalia (Medium/large) & Tooth, perm./decid. ind. & 1 \\
\hline 15 & 3 & 217 & IIIIc & L. Archaic/L. Prehist. & & Medium/Large Vertebrata & Indeterminate & 1 \\
\hline 15 & 3 & 217 & IIIIc & L. Archaic/L. Prehist. & & Odocoileus sp. & Antler & 3 \\
\hline 15 & 3 & 217 & IIIc & L. Archaic/L. Prehist. & & Odocoileus sp. & Radius & 1 \\
\hline 15 & 3 & 217 & IIIc & L. Archaic/L. Prehist. & & Vertebrata & Indeterminate & 114 \\
\hline 15 & $4 \mathrm{~A}$ & 235 & IIIc & L. Archaic & & AntilocapralOdocoileus & Humerus & 1 \\
\hline 15 & $4 \mathrm{~A}$ & 235 & IIIc & L. Archaic & & Cricetidae (Medium) & Tibia & 1 \\
\hline 15 & $4 \mathrm{~A}$ & 235 & IIIIc & L. Archaic & & Mammalia (Large) & Indeterminate & 1 \\
\hline 15 & $4 \mathrm{~A}$ & 235 & IIIIc & L. Archaic & & Mammalia (Medium/large) & Indeterminate & 33 \\
\hline 15 & $4 \mathrm{~A}$ & 235 & IIIc & L. Archaic & & Mammalia (Medium/large) & Long bone & 9 \\
\hline 15 & $4 \mathrm{~A}$ & 235 & IIIc & L. Archaic & & Mammalia (Medium/large) & Tooth, perm./decid. ind. & 2 \\
\hline 15 & $4 \mathrm{~A}$ & 235 & IIIIc & L. Archaic & & Odocoileus sp. & Middle phalange & 1 \\
\hline 15 & $4 \mathrm{~A}$ & 235 & IIIc & L. Archaic & & Odocoileus sp. & Tooth, perm./decid. ind. & 1 \\
\hline 15 & $4 \mathrm{~A}$ & 235 & IIIIc & L. Archaic & & Testudinata & Neural & 1 \\
\hline 15 & $4 \mathrm{~A}$ & 235 & IIIIc & L. Archaic & & Vertebrata & Indeterminate & 140 \\
\hline 15 & $4 \mathrm{~B}$ & 385 & IIIc & L. Archaic & & Artiodactyla & Tooth, perm./decid. ind. & 1 \\
\hline 15 & 4B & 385 & IIIIc & L. Archaic & & Colubridae & Dorsal vertebra & 3 \\
\hline 15 & 4B & 385 & IIIC & L. Archaic & & Geomys sp. & Ulna & 1 \\
\hline 15 & $4 \mathrm{~B}$ & 385 & IIIc & L. Archaic & & Lepus californicus & Permanent tooth & 1 \\
\hline 15 & 4B & 385 & IIIC & L. Archaic & & Mammalia (Medium/large) & Indeterminate & 50 \\
\hline 15 & 4B & 385 & IIII & L. Archaic & & Mammalia (Medium/large) & Rib & 1 \\
\hline 15 & $4 \mathrm{~B}$ & 385 & IIIc & L. Archaic & & Mammalia (Small) & Permanent tooth & 1 \\
\hline 15 & 4B & 385 & IIII & L. Archaic & & Mammalia (Small) & Proximal phalange & 1 \\
\hline 15 & 4B & 385 & IIIIc & L. Archaic & & Odocoileus sp. & Antler & 1 \\
\hline 15 & $4 \mathrm{~B}$ & 385 & IIII & L. Archaic & & Odocoileus sp. & Fused 3rd \& 4th metatarsal & 1 \\
\hline 15 & 4B & 385 & IIIc & L. Archaic & & Odocoileus sp. & Tooth, perm./decid. ind. & 1 \\
\hline 15 & 4B & 385 & IIIIc & L. Archaic & & Small/Medium Vertebrata & Long bone & 7 \\
\hline 15 & $4 \mathrm{~B}$ & 385 & IIII & L. Archaic & & Testudinata & Pleural & 1 \\
\hline 15 & $4 \mathrm{~B}$ & 385 & IIIIc & L. Archaic & & Vertebrata & Indeterminate & 261 \\
\hline 15 & $5 \mathrm{~A}$ & 387 & IIIc & L. Archaic & & Colubridae & Dorsal vertebra & 1 \\
\hline 15 & $5 \mathrm{~A}$ & 387 & IIIIc & L. Archaic & & Cricetidae (Medium) & Femur & 1 \\
\hline 15 & $5 \mathrm{~A}$ & 387 & IIIIc & L. Archaic & & Cricetidae (Medium) & Tibia & 1 \\
\hline 15 & $5 \mathrm{~A}$ & 387 & IIIIc & L. Archaic & & Leporidae & Metacarpal 2 & 1 \\
\hline 15 & $5 \mathrm{~A}$ & 387 & IIIIc & L. Archaic & & Mammalia (Large) & Long bone & 3 \\
\hline 15 & $5 \mathrm{~A}$ & 387 & IIIc & L. Archaic & & Mammalia (Medium/large) & Epiphysis & 1 \\
\hline 15 & $5 \mathrm{~A}$ & 387 & IIIIc & L. Archaic & & Mammalia (Medium/large) & Indeterminate & 28 \\
\hline 15 & $5 \mathrm{~A}$ & 387 & IIIIc & L. Archaic & & Mammalia (Medium/large) & Long bone & 5 \\
\hline 15 & $5 \mathrm{~A}$ & 387 & IIIc & L. Archaic & & Mammalia (Medium/large) & Permanent tooth & 1 \\
\hline 15 & $5 \mathrm{~A}$ & 387 & IIIIc & L. Archaic & & Mammalia (Medium/large) & Tooth, perm./decid. ind. & 4 \\
\hline 15 & $5 \mathrm{~A}$ & 387 & IIIIc & L. Archaic & & Medium/Large Vertebrata & Long bone & 1 \\
\hline 15 & $5 \mathrm{~A}$ & 387 & IIIIc & L. Archaic & & Odocoileus sp. & Tooth, perm./decid. ind. & 1 \\
\hline 15 & $5 \mathrm{~A}$ & 387 & IIIIc & L. Archaic & & Osteichthyes (Small) & Vertebra & 1 \\
\hline 15 & $5 \mathrm{~A}$ & 387 & IIIc & L. Archaic & & Small/Medium Vertebrata & Long bone & 6 \\
\hline 15 & $5 \mathrm{~A}$ & 387 & IIIc & L. Archaic & & Sylvilagus sp. & Permanent tooth & 1 \\
\hline 15 & $5 \mathrm{~A}$ & 387 & IIIc & L. Archaic & & Vertebrata & Indeterminate & 224 \\
\hline 15 & $6 \mathrm{~A}$ & 129 & IIIIc & Middle/L. Archaic & & Antilocapra/Odocoileus & Distal phalange & 1 \\
\hline 15 & $6 \mathrm{~A}$ & 129 & IIIc & Middle/L. Archaic & & Artiodactyla & Tooth, perm./decid. ind. & 2 \\
\hline 15 & $6 \mathrm{~A}$ & 129 & IIIc & Middle/L. Archaic & & Colubridae & Dorsal vertebra & 2 \\
\hline 15 & $6 \mathrm{~A}$ & 129 & IIIIc & Middle/L. Archaic & & Leporidae & Permanent tooth & 3 \\
\hline 15 & $6 \mathrm{~A}$ & 129 & IIIc & Middle/L. Archaic & & Leporidae & Radius & 1 \\
\hline 15 & $6 \mathrm{~A}$ & 129 & IIIc & Middle/L. Archaic & & Mammalia (Large) & Long bone & 6 \\
\hline 15 & $6 \mathrm{~A}$ & 129 & IIIIc & Middle/L. Archaic & & Mammalia (Medium/large) & Indeterminate & 37 \\
\hline 15 & $6 \mathrm{~A}$ & 129 & IIIIc & Middle/L. Archaic & & Mammalia (Medium/large) & Tooth, perm./decid. ind. & 8 \\
\hline
\end{tabular}




\begin{tabular}{|c|c|c|c|c|c|c|c|c|}
\hline Square & Level & Lot & Unit & Cultural Affinity & Feature & Taxon & Element & No. \\
\hline 15 & $6 \mathrm{~A}$ & 129 & IIIc & Middle/L. Archaic & & Mammalia (Small) & Femur & 1 \\
\hline 15 & $6 \mathrm{~A}$ & 129 & IIIIc & Middle/L. Archaic & & Mammalia (Small) & Mandible & 1 \\
\hline 15 & $6 \mathrm{~A}$ & 129 & IIIIc & Middle/L. Archaic & & Mammalia (Small) & Permanent tooth & 1 \\
\hline 15 & $6 \mathrm{~A}$ & 129 & IIIc & Middle/L. Archaic & & Odocoileus sp. & Permanent tooth & 1 \\
\hline 15 & $6 \mathrm{~A}$ & 129 & IIIc & Middle/L. Archaic & & Odocoileus sp. & Tooth, perm./decid. ind. & 2 \\
\hline 15 & $6 \mathrm{~A}$ & 129 & IIIIc & Middle/L. Archaic & & Rodentia (Medium) & Permanent tooth & 2 \\
\hline 15 & $6 \mathrm{~A}$ & 129 & IIIIc & Middle/L. Archaic & & Small vertebrate, class ind. & Proximal phalange & 1 \\
\hline 15 & $6 \mathrm{~A}$ & 129 & IIIc & Middle/L. Archaic & & Sylvilagus sp. & Femur & 1 \\
\hline 15 & $6 \mathrm{~A}$ & 129 & IIIIc & Middle/L. Archaic & & Testudinata & Pleural & 1 \\
\hline 15 & $6 \mathrm{~A}$ & 129 & IIIc & Middle/L. Archaic & & Vertebrata & Indeterminate & 335 \\
\hline 15 & $6 \mathrm{~A}$ & 460 & IIII & Middle/L. Archaic & & Mammalia (Medium/large) & Long bone & 1 \\
\hline 15 & $6 \mathrm{~A}$ & 461 & IIIIc & Middle/L. Archaic & & Mammalia (Large) & Indeterminate & 1 \\
\hline 15 & $6 \mathrm{~B}$ & 475 & IIIIc & Middle/L. Archaic & 206 & Mammalia (Medium/large) & Indeterminate & 1 \\
\hline 15 & $6 \mathrm{~B}$ & 475 & IIIc & Middle/L. Archaic & 206 & Medium/Large Vertebrata & Long bone & 1 \\
\hline 15 & 7 & 486 & $\mathrm{mim} / \mathrm{c}$ & Middle/L. Archaic & & Antilocapra/Odocoileus & Phalange & 1 \\
\hline 15 & 7 & 486 & IIIIb/c & Middle/L. Archaic & & Aves (Medium) & Tarsometatarsus & 1 \\
\hline 15 & 7 & 486 & $\mathrm{IIIb} / \mathrm{c}$ & Middle/L. Archaic & & Leporidae & Permanent tooth & 1 \\
\hline 15 & 7 & 486 & $\mathrm{mb} / \mathrm{c}$ & Middle/L. Archaic & & Lepus californicus & Permanent tooth & 1 \\
\hline 15 & 7 & 486 & $\mathrm{IIIb} / \mathrm{c}$ & Middle/L. Archaic & & Mammalia (Large) & Long bone & 2 \\
\hline 15 & 7 & 486 & $\mathrm{mb} / \mathrm{c}$ & Middle/L. Archaic & & Mammalia (Medium/large) & Indeterminate & 20 \\
\hline 15 & 7 & 486 & $\mathrm{mb} / \mathrm{c}$ & Middle/L. Archaic & & Mammalia (Medium/large) & Long bone & 1 \\
\hline 15 & 7 & 486 & $\mathrm{IIIb} / \mathrm{c}$ & Middle/L. Archaic & & Mammalia (Medium/large) & Permanent tooth & 1 \\
\hline 15 & 7 & 486 & $\mathrm{mb} / \mathrm{c}$ & Middle/L. Archaic & & Mammalia (Medium/large) & Tooth, perm./decid. ind. & 1 \\
\hline 15 & 7 & 486 & $\mathrm{mb} / \mathrm{c}$ & Middle/L. Archaic & & Mammalia (Small) & Tibia & 1 \\
\hline 15 & 7 & 486 & $\mathrm{mIllb} / \mathrm{c}$ & Middle/L. Archaic & & Mammalia (Small/medium) & Femur & 1 \\
\hline 15 & 7 & 486 & $\mathrm{mb} / \mathrm{c}$ & Middle/L. Archaic & & Odocoileus sp. & Antler & 1 \\
\hline 15 & 7 & 486 & $\mathrm{IIIb} / \mathrm{c}$ & Middle/L. Archaic & & Rodentia (Medium) & Permanent tooth & 1 \\
\hline 15 & 7 & 486 & $\mathrm{mlll} / \mathrm{c}$ & Middle/L. Archaic & & Small/Medium Vertebrata & Long bone & 25 \\
\hline 15 & 7 & 486 & $\mathrm{mb} / \mathrm{c}$ & Middle/L. Archaic & & Small/Medium Vertebrata & Phalange & 3 \\
\hline 15 & 7 & 486 & $\mathrm{mb} / \mathrm{c}$ & Middle/L. Archaic & & Small/Medium Vertebrata & Proximal phalange & 1 \\
\hline 15 & 7 & 486 & $\mathrm{milb} / \mathrm{c}$ & Middle/L. Archaic & & Small/Medium Vertebrata & Vertebra & 1 \\
\hline 15 & 7 & 486 & $\mathrm{mb} / \mathrm{c}$ & Middle/L. Archaic & & Sylvilagus sp. & Central tarsal bone & 1 \\
\hline 15 & 7 & 486 & $\mathrm{milb} / \mathrm{c}$ & Middle/L. Archaic & & Sylvilagus sp. & Permanent tooth & 1 \\
\hline 15 & 7 & 486 & $\mathrm{mb} / \mathrm{c}$ & Middle/L. Archaic & & Testudinata & Pleural & 1 \\
\hline 15 & 7 & 486 & $\mathrm{mb} / \mathrm{c}$ & Middle/L. Archaic & & Vertebrata & Indeterminate & 146 \\
\hline 15 & 8 & 507 & $\mathrm{mimb} / \mathrm{c}$ & M. Archaic & & Antilocapra americana & Permanent tooth & 1 \\
\hline 15 & 8 & 507 & $\mathrm{IIlm} / \mathrm{c}$ & M. Archaic & & Antilocapra/Odocoileus & 2nd or 4th metacarpal & 1 \\
\hline 15 & 8 & 507 & $\mathrm{IIIb} / \mathrm{c}$ & M. Archaic & & AntilocapralOdocoileus & Fused 3rd \& 4th metatarsal & 1 \\
\hline 15 & 8 & 507 & $\mathrm{mb} / \mathrm{c}$ & M. Archaic & & Artiodactyla & Tooth, perm./decid. ind. & 2 \\
\hline 15 & 8 & 507 & $\mathrm{IIIb} / \mathrm{c}$ & M. Archaic & & cf. Lepus californicus & Patella & 2 \\
\hline 15 & 8 & 507 & $\mathrm{mb} / \mathrm{c}$ & M. Archaic & & Lepus californicus & Ulna & 1 \\
\hline 15 & 8 & 507 & $\mathrm{mimb} / \mathrm{c}$ & M. Archaic & & Mammalia (Large) & Long bone & 2 \\
\hline 15 & 8 & 507 & $\mathrm{IIIb} / \mathrm{c}$ & M. Archaic & & Mammalia (Large) & Rib & 2 \\
\hline 15 & 8 & 507 & $\mathrm{mil \textrm {b }} / \mathrm{c}$ & M. Archaic & & Mammalia (Medium) & Metapodial & 1 \\
\hline 15 & 8 & 507 & $\mathrm{mb} / \mathrm{c}$ & M. Archaic & & Mammalia (Medium/large) & Alveolar ridge fragment & 1 \\
\hline 15 & 8 & 507 & IIIIb/c & M. Archaic & & Mammalia (Medium/large) & Indeterminate & 15 \\
\hline 15 & 8 & 507 & $\mathrm{mb} / \mathrm{c}$ & M. Archaic & & Mammalia (Medium/large) & Tooth, perm./decid. ind. & 1 \\
\hline 15 & 8 & 507 & $\mathrm{mim} / \mathrm{c}$ & M. Archaic & & Mammalia (Micro) & Humerus & 1 \\
\hline 15 & 8 & 507 & $\mathrm{IIlb} / \mathrm{c}$ & M. Archaic & & Medium/Large Vertebrata & Indeterminate & 1 \\
\hline 15 & 8 & 507 & $\mathrm{IIb} / \mathrm{c}$ & M. Archaic & & Odocoileus sp. & Astragalus & 1 \\
\hline 15 & 8 & 507 & $\mathrm{IImb} / \mathrm{c}$ & M. Archaic & & Odocoileus sp. & Calcaneus & 1 \\
\hline 15 & 8 & 507 & $\mathrm{IIIb} / \mathrm{c}$ & M. Archaic & & Odocoileus sp. & Mandible & 1 \\
\hline 15 & 8 & 507 & IIb/c & M. Archaic & & Odocoileus sp. & Permanent tooth & 2 \\
\hline 15 & 8 & 507 & $\mathrm{mb} / \mathrm{c}$ & M. Archaic & & Small/Medium Vertebrata & Middle phalange & 1 \\
\hline 15 & 8 & 507 & $\mathrm{IIIb} / \mathrm{c}$ & M. Archaic & & Small/Medium Vertebrata & Phalange & 1 \\
\hline 15 & 8 & 507 & $\mathrm{IIIb} / \mathrm{c}$ & M. Archaic & & Vertebrata & Indeterminate & 76 \\
\hline 15 & 9 & 526 & IIIb & M. Archaic & & Cricetidae (Medium) & Astragalus & 1 \\
\hline 15 & 9 & 526 & IIIlb & M. Archaic & & Cricetidae (Medium) & Humerus & 1 \\
\hline 15 & 9 & 526 & IIIb & M. Archaic & & Leporidae & Metatarsal 4 & 1 \\
\hline 15 & 9 & 526 & IIIb & M. Archaic & & Lepus californicus & Permanent tooth & 4 \\
\hline 15 & 9 & 526 & IIIlb & M. Archaic & & Mammalia (Medium/large) & Indeterminate & 7 \\
\hline 15 & 9 & 526 & IIIb & M. Archaic & & Mammalia (Medium/large) & Long bone & 4 \\
\hline 15 & 9 & 526 & IIIb & M. Archaic & & Mammalia (Medium/large) & Tooth, perm./decid. ind. & 2 \\
\hline 15 & 9 & 526 & IIIb & M. Archaic & & Mammalia (Small) & Permanent tooth & 1 \\
\hline 15 & 9 & 526 & IIIIb & M. Archaic & & Mammalia (Small) & Phalange & 1 \\
\hline 15 & 9 & 526 & IIIb & M. Archaic & & Mammalia (Small) & Proximal phalange & 1 \\
\hline 15 & 9 & 526 & IIIb & M. Archaic & & Mammalia (Small/medium) & Proximal phalange & 1 \\
\hline
\end{tabular}




\begin{tabular}{|c|c|c|c|c|c|c|c|c|}
\hline Square & Level & Lot & Unit & Cultural Affinity & Feature & Taxon & Element & No. \\
\hline 15 & 9 & 526 & IIlb & M. Archaic & & Rodentia (Medium) & Permanent tooth & 1 \\
\hline 15 & 9 & 526 & IIIlb & M. Archaic & & Serpentes & Dorsal vertebra & 1 \\
\hline 15 & 9 & 526 & IIIb & M. Archaic & & Small/Medium Vertebrata & Long bone & 9 \\
\hline 15 & 9 & 526 & IIIlb & M. Archaic & & Vertebrata & Indeterminate & 23 \\
\hline 15 & 10 & 542 & IIIb & M. Archaic & & Artiodactyla & Tooth, perm./decid. ind. & 1 \\
\hline 15 & 10 & 542 & IIItb & M. Archaic & & Emydidae & Peripheral & 1 \\
\hline 15 & 10 & 542 & IIIlb & M. Archaic & & Geomys sp. & Permanent tooth & 1 \\
\hline 15 & 10 & 542 & IIIb & M. Archaic & & Leporidae & Permanent tooth & 1 \\
\hline 15 & 10 & 542 & IIIb & M. Archaic & & Lepus californicus & Permanent tooth & 2 \\
\hline 15 & 10 & 542 & IIIlb & M. Archaic & & Mammalia (Medium/large) & Indeterminate & 8 \\
\hline 15 & 10 & 542 & IIlb & M. Archaic & & Mammalia (Small) & Distal phalange & 1 \\
\hline 15 & 10 & 542 & IIIb & M. Archaic & & Mammalia (Small) & Metapodial & 1 \\
\hline 15 & 10 & 542 & IIIlb & M. Archaic & & Medium/Large Vertebrata & Indeterminate & 2 \\
\hline 15 & 10 & 542 & IIIlb & M. Archaic & & Serpentes & Dorsal vertebra & 1 \\
\hline 15 & 10 & 542 & IIIb & M. Archaic & & Small/Medium Vertebrata & Long bone & 2 \\
\hline 15 & 10 & 542 & IIIlb & M. Archaic & & Sylvilagus sp. & Humerus & 1 \\
\hline 15 & 10 & 542 & IIIb & M. Archaic & & Sylvilagus sp. & Radius & 1 \\
\hline 15 & 10 & 542 & IIIb & M. Archaic & & Vertebrata & Indeterminate & 5 \\
\hline 15 & 11 & 549 & IIIIb & Early/M. Archaic & & Leporidae & Permanent tooth & 1 \\
\hline 15 & 11 & 549 & IIIb & Early/M. Archaic & & Lepus californicus & Permanent tooth & 1 \\
\hline 15 & 11 & 549 & IIIb & Early/M. Archaic & & Mammalia (Medium/large) & Indeterminate & 1 \\
\hline 15 & 11 & 549 & IIIlb & Early/M. Archaic & & Mammalia (Small) & Metapodial & 1 \\
\hline 15 & 11 & 549 & IIlb & Early/M. Archaic & & Mammalia (Small/medium) & Epiphysis & 1 \\
\hline 15 & 11 & 549 & IIIb & Early/M. Archaic & & Medium/Large Vertebrata & Indeterminate & 3 \\
\hline 15 & 11 & 549 & IIIlb & Early/M. Archaic & & Odocoileus sp. & Tooth, perm./decid. ind. & 1 \\
\hline 15 & 11 & 549 & IIIlb & Early/M. Archaic & & Serpentes & Dorsal vertebra & 1 \\
\hline 15 & 11 & 549 & IIIb & Early/M. Archaic & & Small/Medium Vertebrata & Long bone & 3 \\
\hline 15 & 11 & 549 & IIIlb & Early/M. Archaic & & Sylvilagus sp. & Cranium & 1 \\
\hline 15 & 11 & 549 & IIIlb & Early/M. Archaic & & Vertebrata & Indeterminate & 48 \\
\hline 15 & 12 & 568 & $\mathrm{III} \mathrm{a} / \mathrm{b}$ & Early/M. Archaic & & Geomys sp. & Permanent tooth & 1 \\
\hline 15 & 12 & 568 & $\mathrm{III} \mathrm{a} / \mathrm{b}$ & Early/M. Archaic & & Leporidae & Permanent tooth & 1 \\
\hline 15 & 12 & 568 & IIIa/b & Early/M. Archaic & & Lepus californicus & Astragalus & 1 \\
\hline 15 & 12 & 568 & IIIa/b & Early/M. Archaic & & Mammalia (Large) & Indeterminate & 1 \\
\hline 15 & 12 & 568 & IIIIa/b & Early/M. Archaic & & Mammalia (Medium) & Metapodial & 1 \\
\hline 15 & 12 & 568 & ШШа/b & Early/M. Archaic & & Mammalia (Medium/large) & Indeterminate & 3 \\
\hline 15 & 12 & 568 & ШІа/ & Early/M. Archaic & & Mammalia (Medium/large) & Tooth, perm./decid. ind. & 2 \\
\hline 15 & 12 & 568 & IIIa/b & Early/M. Archaic & & Mammalia (Small/medium) & Tibia & 1 \\
\hline 15 & 12 & 568 & IIIa/b & Early/M. Archaic & & Odocoileus sp. & Permanent tooth & 1 \\
\hline 15 & 12 & 568 & IIIa/b & Early/M. Archaic & & Odocoileus sp. & Tooth, perm./decid. ind. & 2 \\
\hline 15 & 12 & 568 & IIIa/b & Early/M. Archaic & & Rodentia (Medium) & Tibia & 1 \\
\hline 15 & 12 & 568 & IIIIa/b & Early/M. Archaic & & Small/Medium Vertebrata & Long bone & 5 \\
\hline 15 & 12 & 568 & IIIa/b & Early/M. Archaic & & Vertebrata & Indeterminate & 43 \\
\hline 15 & 13 & 596 & IIIa/b & E. Archaic & & Mammalia (Large) & Long bone & 2 \\
\hline 15 & 13 & 596 & IIIa/b & E. Archaic & & Mammalia (Medium/large) & Indeterminate & 14 \\
\hline 15 & 13 & 596 & IIIa/b & E. Archaic & & Mammalia (Medium/large) & Long bone & 2 \\
\hline 15 & 13 & 596 & $\mathrm{ma} / \mathrm{b}$ & E. Archaic & & Mammalia (Medium/large) & Tooth, perm./decid. ind. & 2 \\
\hline 15 & 13 & 596 & $\mathrm{IIIa} / \mathrm{b}$ & E. Archaic & & Small vertebrate, class ind. & Distal phalange & 1 \\
\hline 15 & 13 & 596 & IIIa/b & E. Archaic & & Small/Medium Vertebrata & Long bone & 5 \\
\hline 15 & 13 & 596 & IIIa/b & E. Archaic & & Sylvilagus sp. & Permanent tooth & 2 \\
\hline 15 & 13 & 596 & III a/b & E. Archaic & & Testudinata & Shell fragment & 2 \\
\hline 15 & 13 & 596 & IIIa/b & E. Archaic & & Vertebrata & Indeterminate & 26 \\
\hline 15 & 14 & 640 & IIIa/b & E. Archaic & & Leporidae & Permanent tooth & 2 \\
\hline 15 & 14 & 640 & IIIa/b & E. Archaic & & Mammalia (Large) & Indeterminate & 1 \\
\hline 15 & 14 & 640 & IIIa/b & E. Archaic & & Mammalia (Medium/large) & Indeterminate & 13 \\
\hline 15 & 14 & 640 & IIIa/b & E. Archaic & & Mammalia (Medium/large) & Tooth, perm./decid. ind. & 5 \\
\hline 15 & 14 & 640 & IIIa/b & E. Archaic & & Odocoileus sp. & Permanent tooth & 1 \\
\hline 15 & 14 & 640 & IIIIa/b & E. Archaic & & Serpentes & Dorsal vertebra & 1 \\
\hline 15 & 14 & 640 & IIIa/b & E. Archaic & & Small/Medium Vertebrata & Long bone & 4 \\
\hline 15 & 14 & 640 & IIIa/b & E. Archaic & & Vertebrata & Indeterminate & 21 \\
\hline 16 & 3 & 168 & IIIIc & L. Archaic/L. Prehist. & & Colubridae & Dorsal vertebra & 1 \\
\hline 16 & 3 & 168 & IIIIc & L. Archaic/L. Prehist. & & Emydidae & Peripheral & 1 \\
\hline 16 & 3 & 168 & IIIIc & L. Archaic/L. Prehist. & & Mammalia (Large) & Long bone & 8 \\
\hline 16 & 3 & 168 & IIIIc & L. Archaic/L. Prehist. & & Mammalia (Medium/large) & Indeterminate & 61 \\
\hline 16 & 3 & 168 & IIIc & L. Archaic/L. Prehist. & & Mammalia (Medium/large) & Long bone & 2 \\
\hline 16 & 3 & 168 & IIIIc & L. Archaic/L. Prehist. & & Mammalia (Medium/large) & Tooth, perm./decid. ind. & 4 \\
\hline 16 & 3 & 168 & IIIIC & L. Archaic/L. Prehist. & & Odocoileus sp. & Antler & 1 \\
\hline 16 & 3 & 168 & IIIIc & L. Archaic/L. Prehist. & & Odocoileus sp. & Tibia & 1 \\
\hline
\end{tabular}




\begin{tabular}{|c|c|c|c|c|c|c|c|c|}
\hline Square & Level & Lot & Unit & Cultural Affinity & Feature & Taxon & Element & No. \\
\hline 16 & 3 & 168 & IIIc & L. Archaic/L. Prehist. & & Odocoileus sp. & Tooth, perm./decid. ind. & 5 \\
\hline 16 & 3 & 168 & IIII & L. Archaic/L. Prehist. & & Testudinata & Shell fragment & 3 \\
\hline 16 & 3 & 168 & IIIC & L. Archaic/L. Prehist. & & Vertebrata & Indeterminate & 146 \\
\hline 16 & 4 & 120 & IIIIC & L. Archaic/L. Prehist. & & Antilocapra/Odocoileus & Astragalus & 1 \\
\hline 16 & 4 & 120 & IIIIC & L. Archaic/L. Prehist. & & Antilocapra/Odocoileus & Proximal phalange & 1 \\
\hline 16 & 4 & 120 & IIIIc & L. Archaic/L. Prehist. & & Colubridae & Dorsal vertebra & 2 \\
\hline 16 & 4 & 120 & IIIIc & L. Archaic/L. Prehist. & & Mammalia (Large) & Indeterminate & 1 \\
\hline 16 & 4 & 120 & IIII & L. Archaic/L. Prehist. & & Mammalia (Large) & Tooth, perm./decid. ind. & 1 \\
\hline 16 & 4 & 120 & IIIc & L. Archaic/L. Prehist. & & Mammalia (Medium/large) & Indeterminate & 225 \\
\hline 16 & 4 & 120 & IIIIc & L. Archaic/L. Prehist. & & Mammalia (Medium/large) & Tooth, perm./decid. ind. & 1 \\
\hline 16 & 4 & 120 & IIIIc & L. Archaic/L. Prehist. & & Neotoma sp. & Permanent tooth & 1 \\
\hline 16 & 4 & 120 & IIIIc & L. Archaic/L. Prehist. & & Odocoileus sp. & Tooth, perm./decid. ind. & 1 \\
\hline 16 & 4 & 120 & IIIIc & L. Archaic/L. Prehist. & & Testudinata & Shell fragment & 3 \\
\hline 16 & 4 & 120 & IIII & L. Archaic/L. Prehist. & & Vertebrata & Indeterminate & 225 \\
\hline 16 & 4 & 120 & IIIC & L. Archaic/L. Prehist. & & Viperidae & Dorsal vertebra & 1 \\
\hline 16 & 5 & 391 & IIIIc & L. Archaic & & Antilocapra/Odocoileus & Metapodial & 1 \\
\hline 16 & 5 & 391 & IIIIc & L. Archaic & & Antilocapra/Odocoileus & Proximal phalange & 1 \\
\hline 16 & 5 & 391 & IIIC & L. Archaic & & cf. Odocoileus sp. & Cranium & 1 \\
\hline 16 & 5 & 391 & IIIIc & L. Archaic & & Kinosternidae & Peripheral & 1 \\
\hline 16 & 5 & 391 & IIIIc & L. Archaic & & Leporidae & Permanent tooth & 1 \\
\hline 16 & 5 & 391 & IIIIc & L. Archaic & & Lepus californicus & Permanent tooth & 1 \\
\hline 16 & 5 & 391 & IIIIc & L. Archaic & & Mammalia (Large) & Long bone & 8 \\
\hline 16 & 5 & 391 & IIIc & L. Archaic & & Mammalia (Medium) & Proximal phalange & 1 \\
\hline 16 & 5 & 391 & IIIIc & L. Archaic & & Mammalia (Medium/large) & Indeterminate & 38 \\
\hline 16 & 5 & 391 & IIIIc & L. Archaic & & Mammalia (Medium/large) & Long bone & 6 \\
\hline 16 & 5 & 391 & IIIIc & L. Archaic & & Mammalia (Medium/large) & Patella & 1 \\
\hline 16 & 5 & 391 & IIIC & L. Archaic & & Mammalia (Medium/large) & Permanent tooth & 1 \\
\hline 16 & 5 & 391 & IIIIc & L. Archaic & & Mammalia (Medium/large) & Rib & 1 \\
\hline 16 & 5 & 391 & IIIIc & L. Archaic & & Mammalia (Medium/large) & Tooth, perm./decid. ind. & 14 \\
\hline 16 & 5 & 391 & IIIIc & L. Archaic & & Mammalia (Small) & Femur & 1 \\
\hline 16 & 5 & 391 & IIIIc & L. Archaic & & Mammalia (Small) & Tibia & 1 \\
\hline 16 & 5 & 391 & IIIIc & L. Archaic & & Mammalia (Small/medium) & Metapodial & 1 \\
\hline 16 & 5 & 391 & IIIIc & L. Archaic & & Mammalia (Small/medium) & Proximal phalange & 2 \\
\hline 16 & 5 & 391 & IIII & L. Archaic & & Odocoileus sp. & Middle phalange & 1 \\
\hline 16 & 5 & 391 & IIII & L. Archaic & & Osteichthyes (Small) & Vertebra & 2 \\
\hline 16 & 5 & 391 & IIIIc & L. Archaic & & Rodentia (Medium) & Permanent tooth & 1 \\
\hline 16 & 5 & 391 & IIIIc & L. Archaic & & Serpentes & Dorsal vertebra & 3 \\
\hline 16 & 5 & 391 & IIIIc & L. Archaic & & Small/Medium Vertebrata & Long bone & 9 \\
\hline 16 & 5 & 391 & IIIc & L. Archaic & & Testudinata & Pleural & 1 \\
\hline 16 & 5 & 391 & IIIIc & L. Archaic & & Testudinata & Shell fragment & 2 \\
\hline 16 & 5 & 391 & IIIc & L. Archaic & & Vertebrata & Indeterminate & 487 \\
\hline 16 & $6 \mathrm{~A}$ & 448 & IIIIc & L. Archaic & & Antilocapra/Odocoileus & Mandible & 1 \\
\hline 16 & $6 \mathrm{~A}$ & 448 & IIIIc & L. Archaic & & Mammalia (Large) & Cranium & 2 \\
\hline 16 & $6 \mathrm{~A}$ & 448 & IIIc & L. Archaic & & Mammalia (Large) & Indeterminate & 2 \\
\hline 16 & $6 \mathrm{~A}$ & 448 & IIIIc & L. Archaic & & Mammalia (Large) & Long bone & 4 \\
\hline 16 & $6 \mathrm{~A}$ & 448 & IIII & L. Archaic & & Mammalia (Medium/large) & Indeterminate & 15 \\
\hline 16 & $6 \mathrm{~A}$ & 448 & IIIc & L. Archaic & & Mammalia (Medium/large) & Tooth, perm./decid. ind. & 2 \\
\hline 16 & $6 \mathrm{~A}$ & 448 & IIIIc & L. Archaic & & Mammalia (Micro) & Metapodial & 1 \\
\hline 16 & $6 \mathrm{~A}$ & 448 & IIII & L. Archaic & & Mammalia (Small) & Cranium & 1 \\
\hline 16 & $6 \mathrm{~A}$ & 448 & IIIC & L. Archaic & & Medium/Large Vertebrata & Long bone & 1 \\
\hline 16 & $6 \mathrm{~A}$ & 448 & IIIc & L. Archaic & & Odocoileus sp. & Tooth, perm./decid. ind. & 1 \\
\hline 16 & $6 \mathrm{~A}$ & 448 & IIIC & L. Archaic & & Rodentia (Small) & Femur & 1 \\
\hline 16 & $6 \mathrm{~A}$ & 448 & IIII & L. Archaic & & Testudinata & Peripheral & 1 \\
\hline 16 & $6 \mathrm{~A}$ & 448 & IIII & L. Archaic & & Vertebrata & Indeterminate & 10 \\
\hline 16 & $6 \mathrm{~A}$ & 448 & IIII & L. Archaic & & Viperidae & Dorsal vertebra & 1 \\
\hline 16 & $6 \mathrm{~A}$ & 455 & IIIIc & L. Archaic & & Aves (Large) & Distal phalange & 1 \\
\hline 16 & $6 \mathrm{~A}$ & 455 & IIIc & L. Archaic & & cf. Odocoileus sp. & Permanent tooth & 1 \\
\hline 16 & $6 \mathrm{~A}$ & 455 & IIIc & L. Archaic & & Colubridae & Dorsal vertebra & 2 \\
\hline 16 & $6 \mathrm{~A}$ & 455 & IIII & L. Archaic & & Leporidae & Permanent tooth & 1 \\
\hline 16 & $6 \mathrm{~A}$ & 455 & IIIc & L. Archaic & & Mammalia (Medium/large) & Indeterminate & 12 \\
\hline 16 & $6 \mathrm{~A}$ & 455 & IIII & L. Archaic & & Mammalia (Medium/large) & Long bone & 10 \\
\hline 16 & $6 \mathrm{~A}$ & 455 & IIII & L. Archaic & & Mammalia (Medium/large) & Rib & 1 \\
\hline 16 & $6 \mathrm{~A}$ & 455 & IIIIc & L. Archaic & & Mammalia (Medium/large) & Tooth, perm./decid. ind. & 4 \\
\hline 16 & $6 \mathrm{~A}$ & 455 & IIIIc & L. Archaic & & Mammalia (Small) & Metapodial & 1 \\
\hline 16 & $6 \mathrm{~A}$ & 455 & IIIIc & L. Archaic & & Mammalia (Small) & Radius & 1 \\
\hline 16 & $6 \mathrm{~A}$ & 455 & IIII & L. Archaic & & Rodentia (Medium) & Permanent tooth & 1 \\
\hline 16 & $6 \mathrm{~A}$ & 455 & IIIc & L. Archaic & & Serpentes & Dorsal vertebra & 1 \\
\hline
\end{tabular}




\begin{tabular}{|c|c|c|c|c|c|c|c|c|}
\hline Square & Level & Lot & Unit & Cultural Affinity & Feature & Taxon & Element & No. \\
\hline 16 & $6 \mathrm{~A}$ & 455 & IIIc & L. Archaic & & Small/Medium Vertebrata & Long bone & 12 \\
\hline 16 & $6 \mathrm{~A}$ & 455 & III & L. Archaic & & Sylvilagus sp. & Mandible & 1 \\
\hline 16 & $6 \mathrm{~A}$ & 455 & IIIIc & L. Archaic & & Testudinata & Plastron fragment ind. & 1 \\
\hline 16 & $6 \mathrm{~A}$ & 455 & IIIC & L. Archaic & & Vertebrata & Indeterminate & 117 \\
\hline 16 & $6 \mathrm{~A}$ & 455 & IIIC & L. Archaic & & Viperidae & Dorsal vertebra & 1 \\
\hline 16 & $6 \mathrm{~B}$ & 452 & IIIIc & L. Archaic & 206 & Odocoileus sp. & Mandible & 1 \\
\hline 16 & $6 \mathrm{~B}$ & 452 & IIIc & L. Archaic & 206 & Odocoileus sp. & Permanent tooth & 2 \\
\hline 16 & $7 \mathrm{~A}$ & 480 & $\mathrm{IIIb} / \mathrm{c}$ & L. Archaic & & Antilocapra/Odocoileus & Phalange & 1 \\
\hline 16 & $7 \mathrm{~A}$ & 480 & $\mathrm{IIIb} / \mathrm{c}$ & L. Archaic & & Canis sp. & Permanent tooth & 1 \\
\hline 16 & $7 \mathrm{~A}$ & 480 & $\mathrm{IIIb} / \mathrm{c}$ & L. Archaic & & cf. Canis sp. & Cranium & 2 \\
\hline 16 & $7 \mathrm{~A}$ & 480 & $\mathrm{IIIb} / \mathrm{c}$ & L. Archaic & & Cricetidae (Small) & Mandible & 1 \\
\hline 16 & $7 \mathrm{~A}$ & 480 & $\mathrm{IIIb} / \mathrm{c}$ & L. Archaic & & Cricetidae (Small) & Permanent tooth & 3 \\
\hline 16 & $7 \mathrm{~A}$ & 480 & $\mathrm{IITb} / \mathrm{c}$ & L. Archaic & & Geomys sp. & Permanent tooth & 1 \\
\hline 16 & $7 \mathrm{~A}$ & 480 & $\mathrm{IITb} / \mathrm{c}$ & L. Archaic & & Leporidae & Permanent tooth & 3 \\
\hline 16 & $7 \mathrm{~A}$ & 480 & $\mathrm{IIIb} / \mathrm{c}$ & L. Archaic & & Mammalia (Medium/large) & Indeterminate & 22 \\
\hline 16 & $7 \mathrm{~A}$ & 480 & $\mathrm{IIIb} / \mathrm{c}$ & L. Archaic & & Mammalia (Medium/large) & Long bone & 12 \\
\hline 16 & $7 \mathrm{~A}$ & 480 & $\mathrm{IITb} / \mathrm{c}$ & L. Archaic & & Mammalia (Medium/large) & Tooth, perm./decid. ind. & 1 \\
\hline 16 & $7 \mathrm{~A}$ & 480 & $\mathrm{IIIb} / \mathrm{c}$ & L. Archaic & & Mammalia (Small/medium) & Alveolar ridge fragment & 1 \\
\hline 16 & $7 \mathrm{~A}$ & 480 & $\mathrm{IIlb} / \mathrm{c}$ & L. Archaic & & Odocoileus sp. & Tooth, perm./decid. ind. & 2 \\
\hline 16 & $7 \mathrm{~A}$ & 480 & $\mathrm{IITb} / \mathrm{c}$ & L. Archaic & & Serpentes & Dorsal vertebra & 2 \\
\hline 16 & $7 \mathrm{~A}$ & 480 & IIIb/c & L. Archaic & & Small/Medium Vertebrata & Long bone & 9 \\
\hline 16 & $7 \mathrm{~A}$ & 480 & $\mathrm{IIIb} / \mathrm{c}$ & L. Archaic & & Small/Medium Vertebrata & Phalange & 1 \\
\hline 16 & $7 \mathrm{~A}$ & 480 & $\mathrm{IITb} / \mathrm{c}$ & L. Archaic & & Sylvilagus sp. & Calcaneus & 2 \\
\hline 16 & $7 \mathrm{~A}$ & 480 & $\mathrm{IITb} / \mathrm{c}$ & L. Archaic & & Sylvilagus sp. & Metacarpal 4 & 1 \\
\hline 16 & $7 \mathrm{~A}$ & 480 & $\mathrm{IIIb} / \mathrm{c}$ & L. Archaic & & Vertebrata & Indeterminate & 90 \\
\hline 16 & 8 & 511 & $\mathrm{IITb} / \mathrm{c}$ & Middle/L. Archaic & & Antilocapra/Odocoileus & Fused 3rd \& 4th metatarsal & 1 \\
\hline 16 & 8 & 511 & $\mathrm{IIIb} / \mathrm{c}$ & Middle/L. Archaic & & Mammalia (Medium/large) & Indeterminate & 5 \\
\hline 16 & 8 & 511 & $\mathrm{IIIb} / \mathrm{c}$ & Middle/L. Archaic & & Mammalia (Medium/large) & Long bone & 1 \\
\hline 16 & 8 & 511 & $\mathrm{IIIb} / \mathrm{c}$ & Middle/L. Archaic & & Mammalia (Medium/large) & Tooth, perm./decid. ind. & 2 \\
\hline 16 & 8 & 511 & IIIlb/c & Middle/L. Archaic & & Mammalia (Small) & Metapodial & 1 \\
\hline 16 & 8 & 511 & $\mathrm{IIIb} / \mathrm{c}$ & Middle/L. Archaic & & Medium/Large Vertebrata & Indeterminate & 4 \\
\hline 16 & 8 & 511 & IIIb/c & Middle/L. Archaic & & Sigmodon hispidus & Mandible & 1 \\
\hline 16 & 8 & 511 & IIIb/c & Middle/L. Archaic & & Sigmodon hispidus & Permanent tooth & 4 \\
\hline 16 & 8 & 511 & $\mathrm{IIb} / \mathrm{c}$ & Middle/L. Archaic & & Small/Medium Vertebrata & Long bone & 7 \\
\hline 16 & 8 & 511 & $\mathrm{~m} \mathrm{mb} / \mathrm{c}$ & Middle/L. Archaic & & Vertebrata & Indeterminate & 37 \\
\hline 16 & 9 & 530 & $\mathrm{IIIb} / \mathrm{c}$ & M. Archaic & & Colubridae & Dorsal vertebra & 1 \\
\hline 16 & 9 & 530 & $\mathrm{IIIb} / \mathrm{c}$ & M. Archaic & & Leporidae & Permanent tooth & 1 \\
\hline 16 & 9 & 530 & $\mathrm{IIIb} / \mathrm{c}$ & M. Archaic & & Lepus californicus & Permanent tooth & 3 \\
\hline 16 & 9 & 530 & IIIb/c & M. Archaic & & Mammalia (Medium/large) & Indeterminate & 6 \\
\hline 16 & 9 & 530 & $\mathrm{IIIb} / \mathrm{c}$ & M. Archaic & & Mammalia (Medium/large) & Tooth, perm./decid. ind. & 3 \\
\hline 16 & 9 & 530 & $\mathrm{IIb} / \mathrm{c}$ & M. Archaic & & Mammalia (Small) & Calcaneus & 1 \\
\hline 16 & 9 & 530 & $\mathrm{IIIb} / \mathrm{c}$ & M. Archaic & & Mammalia (Small) & Ulna & 1 \\
\hline 16 & 9 & 530 & $\mathrm{IIlb} / \mathrm{c}$ & M. Archaic & & Small/Medium Vertebrata & Long bone & 9 \\
\hline 16 & 9 & 530 & $\mathrm{IITb} / \mathrm{c}$ & M. Archaic & & Vertebrata & Indeterminate & 34 \\
\hline 16 & $10 \mathrm{~A}$ & 573 & IIIb & M. Archaic & & Mammalia (Large) & Long bone & 1 \\
\hline 16 & $10 \mathrm{~A}$ & 573 & IIIb & M. Archaic & & Mammalia (Small) & Femur & 2 \\
\hline 16 & $10 \mathrm{~A}$ & 573 & IIIb & M. Archaic & & Rodentia (Medium) & Astragalus & 2 \\
\hline 16 & $10 \mathrm{~B}$ & 609 & IIIb & M. Archaic & 214 & Geomys sp. & Permanent tooth & 1 \\
\hline 16 & $10 \mathrm{~B}$ & 609 & IIIb & M. Archaic & 214 & Leporidae & Permanent tooth & 2 \\
\hline 16 & $10 \mathrm{~B}$ & 609 & IIIb & M. Archaic & 214 & Lepus californicus & Metatarsal 2 & 1 \\
\hline 16 & $10 \mathrm{~B}$ & 609 & IIIb & M. Archaic & 214 & Lepus californicus & Metatarsal 4 & 1 \\
\hline 16 & $10 \mathrm{~B}$ & 609 & IIIb & M. Archaic & 214 & Lepus californicus & Permanent tooth & 1 \\
\hline 16 & $10 \mathrm{~B}$ & 609 & IIIb & M. Archaic & 214 & Mammalia (Medium) & Calcaneus & 1 \\
\hline 16 & $10 \mathrm{~B}$ & 609 & IIIb & M. Archaic & 214 & Mammalia (Medium) & Middle phalange & 1 \\
\hline 16 & $10 \mathrm{~B}$ & 609 & IIIIb & M. Archaic & 214 & Mammalia (Medium/large) & Indeterminate & 1 \\
\hline 16 & $10 \mathrm{~B}$ & 609 & IIIb & M. Archaic & 214 & Mammalia (Medium/large) & Tooth, perm./decid. ind. & 1 \\
\hline 16 & $10 \mathrm{~B}$ & 609 & IIIb & M. Archaic & 214 & Mammalia (Small) & Femur & 1 \\
\hline 16 & $10 \mathrm{~B}$ & 609 & IIIIb & M. Archaic & 214 & Mammalia (Small) & Proximal phalange & 1 \\
\hline 16 & $10 \mathrm{~B}$ & 609 & IIIb & M. Archaic & 214 & Mammalia (Small/medium) & Cranium & 1 \\
\hline 16 & $10 \mathrm{~B}$ & 609 & IIIb & M. Archaic & 214 & Neotoma sp. & Permanent tooth & 4 \\
\hline 16 & 10B & 609 & IIIlb & M. Archaic & 214 & Serpentes & Vertebra & 2 \\
\hline 16 & $10 \mathrm{~B}$ & 609 & IIIb & M. Archaic & 214 & Small/Medium Vertebrata & Long bone & 3 \\
\hline 16 & $10 \mathrm{~B}$ & 609 & IIIb & M. Archaic & 214 & Sylvilagus sp. & Humerus & 1 \\
\hline 16 & $10 \mathrm{~B}$ & 609 & IIIb & M. Archaic & 214 & Testudinata & Plastron fragment ind. & 1 \\
\hline 16 & $10 \mathrm{~B}$ & 609 & IIIb & M. Archaic & 214 & Testudinata & Shell fragment & 2 \\
\hline 16 & $10 \mathrm{~B}$ & 609 & IIIb & M. Archaic & 214 & Vertebrata & Indeterminate & 51 \\
\hline 16 & $11 \mathrm{~A}$ & 580 & IIIb & M. Archaic & & Leporidae & Permanent tooth & 1 \\
\hline
\end{tabular}




\begin{tabular}{|c|c|c|c|c|c|c|c|c|}
\hline Square & Level & Lot & Unit & Cultural Affinity & Feature & Taxon & |Element & No. \\
\hline 16 & $11 \mathrm{~A}$ & 580 & $\overline{l i l b}$ & M. Archaic & & Mammalia (Large) & Long bone & 1 \\
\hline 16 & $11 \mathrm{~A}$ & 580 & IIIlb & M. Archaic & & Mammalia (Medium/large) & Indeterminate & 6 \\
\hline 16 & $11 \mathrm{~A}$ & 580 & IIIb & M. Archaic & & Mammalia (Small/medium) & Alveolar ridge fragment & 1 \\
\hline 16 & $11 \mathrm{~A}$ & 580 & IIIb & M. Archaic & & Small/Medium Vertebrata & Long bone & 8 \\
\hline 16 & $11 \mathrm{~A}$ & 580 & IIIlb & M. Archaic & & Sylvilagus sp. & Metapodial & 1 \\
\hline 16 & $11 \mathrm{~A}$ & 580 & IIIb & M. Archaic & & Sylvilagus sp. & Metatarsal 3 & 1 \\
\hline 16 & $11 \mathrm{~A}$ & 580 & IIIb & M. Archaic & & Vertebrata & Indeterminate & 61 \\
\hline 16 & 11B & 581 & IIIlb & M. Archaic & $214 ?$ & Mammalia (Medium) & Metapodial & 1 \\
\hline 16 & 111B & 581 & IIIb & M. Archaic & $214 ?$ & Serpentes & Dorsal vertebra & 1 \\
\hline 16 & 111B & 581 & IIIb & M. Archaic & $214 ?$ & Small/Medium Vertebrata & Long bone & 2 \\
\hline 16 & 11B & 581 & IIIIb & M. Archaic & $214 ?$ & Vertebrata & |Indeterminate & 14 \\
\hline 16 & $12 \mathrm{~A}$ & 651 & IIIlb & Early/M. Archaic & & Colubridae & Dorsal vertebra & 3 \\
\hline 16 & $12 \mathrm{~A}$ & 651 & IIIb & Early/M. Archaic & & Leporidae & Permanent tooth & 1 \\
\hline 16 & $12 \mathrm{~A}$ & 651 & IIIIb & Early/M. Archaic & & Mammalia (Large) & Indeterminate & 1 \\
\hline 16 & $12 \mathrm{~A}$ & 651 & IIIIb & Early/M. Archaic & & Mammalia (Large) & Long bone & 1 \\
\hline 16 & $12 \mathrm{~A}$ & 651 & IIIb & Early/M. Archaic & & Mammalia (Medium/large) & Indeterminate & 16 \\
\hline 16 & $12 \mathrm{~A}$ & 651 & IIIIb & Early/M. Archaic & & Mammalia (Medium/large) & Tooth, perm./decid. ind. & 3 \\
\hline 16 & $12 \mathrm{~A}$ & 651 & IIIIb & Early/M. Archaic & & Mammalia (Small) & Metapodial & 2 \\
\hline 16 & $12 \mathrm{~A}$ & 651 & IIIb & Early/M. Archaic & & Neotoma sp. & Permanent tooth & 2 \\
\hline 16 & $12 \mathrm{~A}$ & 651 & IIIb & Early/M. Archaic & & Odocoileus sp. & Permanent tooth & 1 \\
\hline 16 & $12 \mathrm{~A}$ & 651 & IIIlb & Early/M. Archaic & & Odocoileus sp. & Tooth, perm./decid. ind. & 5 \\
\hline 16 & $12 \mathrm{~A}$ & 651 & IIIb & Early/M. Archaic & & Small vertebrate, class ind. & Middle phalange & 1 \\
\hline 16 & $12 \mathrm{~A}$ & 651 & IIIb & Early/M. Archaic & & Small/Medium Vertebrata & Long bone & 9 \\
\hline 16 & $12 \mathrm{~A}$ & 651 & IIIlb & Early/M. Archaic & & Sylvilagus sp. & Calcaneus & 1 \\
\hline 16 & $12 \mathrm{~A}$ & 651 & IIIb & Early/M. Archaic & & Sylvilagus sp. & Ulna & 1 \\
\hline 16 & $12 \mathrm{~A}$ & 651 & IIIIb & Early/M. Archaic & & Testudinata & Shell fragment & 2 \\
\hline 16 & $12 \mathrm{~A}$ & 651 & IIIIb & Early/M. Archaic & & Vertebrata & |Indeterminate & 102 \\
\hline 16 & 13 & 685 & IIIa/b & Early/M. Archaic & & Anura & Humerus & 1 \\
\hline 16 & 13 & 685 & IIIa/b & Early/M. Archaic & & Anura & Indeterminate & 5 \\
\hline 16 & 13 & 685 & IIIIa/b & Early/M. Archaic & & Anura & |Tibiofibula & 1 \\
\hline 16 & 13 & 685 & $\mathrm{III} / \mathrm{b}$ & Early/M. Archaic & & cf. Leporidae & Distal phalange & 1 \\
\hline 16 & 13 & 685 & III $/ \mathrm{b}$ & Early/M. Archaic & & Colubridae & Dorsal vertebra & 1 \\
\hline 16 & 13 & 685 & IIIa/b & Early/M. Archaic & & Mammalia (Medium/large) & Indeterminate & 11 \\
\hline 16 & 13 & 685 & $\mathrm{IIa} / \mathrm{b}$ & Early/M. Archaic & & Mammalia (Medium/large) & Tooth, perm./decid. ind. & 1 \\
\hline 16 & 13 & 685 & III $/ \mathrm{b}$ & Early/M. Archaic & & Mammalia (Micro) & Permanent tooth & 4 \\
\hline 16 & 13 & 685 & IIII/b & Early/M. Archaic & & Mammalia (Small) & Metapodial & 1 \\
\hline 16 & 13 & 685 & II $/ \mathrm{b}$ & Early/M. Archaic & & Medium/Large Vertebrata & Indeterminate & 2 \\
\hline 16 & 13 & 685 & IIIIa/b & Early/M. Archaic & & Small/Medium Vertebrata & Long bone & 3 \\
\hline 16 & 13 & 685 & IIIIa/b & Early/M. Archaic & & Sylvilagus sp. & Permanent tooth & 1 \\
\hline 16 & 13 & 685 & IIIa/b & Early/M. Archaic & & Testudinata & Shell fragment & 1 \\
\hline 16 & 13 & 685 & III $/ \mathrm{b}$ & Early/M. Archaic & & Vertebrata & Indeterminate & 90 \\
\hline 17 & 0 & 436 & $?$ & Unassigned & & Vertebrata & Indeterminate & 2 \\
\hline 17 & 1 & 110 & FILL & Unassigned & & Mammalia (Large) & Long bone & 2 \\
\hline 17 & 3 & 194 & IIII & L. Archaic/L. Prehist. & & Antilocapra/Odocoileus & Proximal abaxial sesamoid & 1 \\
\hline 17 & 3 & 194 & IIII & L. Archaic/L. Prehist. & & Artiodactyla & Tooth, perm./decid. ind. & 1 \\
\hline 17 & 3 & 194 & IIIc & L. Archaic/L. Prehist. & & Colubridae & Dorsal vertebra & 1 \\
\hline 17 & 3 & 194 & IIIC & L. Archaic/L. Prehist. & & Mammalia (Large) & Indeterminate & 6 \\
\hline 17 & 3 & 194 & IIII & L. Archaic/L. Prehist. & & Mammalia (Medium/large) & Indeterminate & 26 \\
\hline 17 & 3 & 194 & IIIC & L. Archaic/L. Prehist. & & Mammalia (Medium/large) & Long bone & 1 \\
\hline 17 & 3 & 194 & IIIc & L. Archaic/L. Prehist. & & Mammalia (Medium/large) & Tooth, perm./decid. ind. & 3 \\
\hline 17 & 3 & 194 & IIIc & L. Archaic/L. Prehist. & & Vertebrata & Indeterminate & 94 \\
\hline 17 & 4 & 119 & IIIc & L. Archaic/L. Prehist. & & Mammalia (Large) & Indeterminate & 2 \\
\hline 17 & 4 & 258 & IIIc & L. Archaic/L. Prehist. & & Antilocapra/Odocoileus & Metapodial & 1 \\
\hline 17 & 4 & 258 & IIIC & L. Archaic/L. Prehist. & & Antilocapra/Odocoileus & Phalange & 2 \\
\hline 17 & 4 & 258 & IIIc & L. Archaic/L. Prehist. & & Antilocapra/Odocoileus & Proximal phalange & 1 \\
\hline 17 & 4 & 258 & IIIc & L. Archaic/L. Prehist. & & Antilocapra/Odocoileus & Tibia & 1 \\
\hline 17 & 4 & 258 & IIII & L. Archaic/L. Prehist. & & Artiodactyla & Tooth, perm./decid. ind. & 1 \\
\hline 17 & 4 & 258 & IIIc & L. Archaic/L. Prehist. & & cf. Odocoileus sp. & Mandible & 1 \\
\hline 17 & 4 & 258 & IIIc & L. Archaic/L. Prehist. & & Colubridae & Dorsal vertebra & 5 \\
\hline 17 & 4 & 258 & IIIc & L. Archaic/L. Prehist. & & Leporidae & Permanent tooth & 1 \\
\hline 17 & 4 & 258 & IIIC & L. Archaic/L. Prehist. & & Mammalia (Large) & Long bone & 9 \\
\hline 17 & 4 & 258 & IIIc & L. Archaic/L. Prehist. & & Mammalia (Medium/large) & Indeterminate & 96 \\
\hline 17 & 4 & 258 & IIIc & L. Archaic/L. Prehist. & & Mammalia (Medium/large) & Long bone & 7 \\
\hline 17 & 4 & 258 & IIIc & L. Archaic/L. Prehist. & & Mammalia (Medium/large) & Rib & 4 \\
\hline 17 & 4 & 258 & WIIc & L. Archaic/L. Prehist. & & Mammalia (Medium/large) & Tooth, perm./decid. ind. & 10 \\
\hline 17 & 4 & 258 & WI & L. Archaic/L. Prehist. & & Mammalia (Small) & Alveolar ridge fragment & 1 \\
\hline 17 & 4 & 258 & IIIIc & L. Archaic/L. Prehist. & & Mammalia (Small) & Cranium & 1 \\
\hline
\end{tabular}




\begin{tabular}{|c|c|c|c|c|c|c|c|c|}
\hline Square & Level & Lot & Unit & Cultural Affinity & Feature & Taxon & Element & No. \\
\hline 17 & 4 & 258 & IIIc & L. Archaic/L. Prehist. & & Mammalia (Small/medium) & Scapula & 1 \\
\hline 17 & 4 & 258 & IIII & L. Archaic/L. Prehist. & & Medium vertebrate, class ind. & Long bone & 1 \\
\hline 17 & 4 & 258 & IIIc & L. Archaic/L. Prehist. & & Odocoileus sp. & Antler & 1 \\
\hline 17 & 4 & 258 & IIIc & L. Archaic/L. Prehist. & & Odocoileus sp. & Distal fibula & 1 \\
\hline 17 & 4 & 258 & IIIc & L. Archaic/L. Prehist. & & Odocoileus sp. & Permanent tooth & 2 \\
\hline 17 & 4 & 258 & IIIc & L. Archaic/L. Prehist. & & Odocoileus sp. & Tooth, perm./decid. ind. & 5 \\
\hline 17 & 4 & 258 & IIIIc & L. Archaic/L. Prehist. & & Odocoileus sp. & Ulna & 1 \\
\hline 17 & 4 & 258 & IIIc & L. Archaic/L. Prehist. & & Serpentes & Dorsal vertebra & 1 \\
\hline 17 & 4 & 258 & IIIc & L. Archaic/L. Prehist. & & Sigmodon hispidus & Mandible & 1 \\
\hline 17 & 4 & 258 & IIIIc & L. Archaic/L. Prehist. & & Sigmodon hispidus & Permanent tooth & 2 \\
\hline 17 & 4 & 258 & IIIc & L. Archaic/L. Prehist. & & Small/Medium Vertebrata & Long bone & 10 \\
\hline 17 & 4 & 258 & IIIc & L. Archaic/L. Prehist. & & Sylvilagus sp. & Metatarsal 3 & 1 \\
\hline 17 & 4 & 258 & IIIIc & L. Archaic/L. Prehist. & & Testudinata & Neural & 2 \\
\hline 17 & 4 & 258 & IIII & L. Archaic/L. Prehist. & & Testudinata & Shell fragment & 1 \\
\hline 17 & 4 & 258 & IIII & L. Archaic/L. Prehist. & & Vertebrata & Indeterminate & 380 \\
\hline 17 & 4 & 264 & IIIIc & L. Archaic/L. Prehist. & & Odocoileus sp. & Proximal phalange & 1 \\
\hline 17 & 4 & 292 & IIII & L. Archaic/L. Prehist. & & Mammalia (Large) & Long bone & 1 \\
\hline 17 & 4 & 309 & IIII & L. Archaic/L. Prehist. & & Mammalia (Medium/large) & Indeterminate & 1 \\
\hline 17 & 4 & 309 & IIIIc & L. Archaic/L. Prehist. & & Mammalia (Medium/large) & Long bone & 1 \\
\hline 17 & 4 & 310 & IIII & L. Archaic/L. Prehist. & & Mammalia (Medium/large) & Indeterminate & 1 \\
\hline 17 & 5 & 344 & IIIIc & L. Archaic & & Antilocapra/Odocoileus & Phalange & 1 \\
\hline 17 & 5 & 344 & IIIIc & L. Archaic & & Emydidae & Carapace fragment ind. & 1 \\
\hline 17 & 5 & 344 & IIII & L. Archaic & & Geomys sp. & Permanent tooth & 1 \\
\hline 17 & 5 & 344 & IIII & L. Archaic & & Leporidae & Permanent tooth & 1 \\
\hline 17 & 5 & 344 & IIIIc & L. Archaic & & Leporidae & Tooth, perm./decid. ind. & 1 \\
\hline 17 & 5 & 344 & IIII & L. Archaic & & Lepus californicus & Permanent tooth & 1 \\
\hline 17 & 5 & 344 & IIII & L. Archaic & & Mammalia (Large) & Long bone & 1 \\
\hline 17 & 5 & 344 & IIIIc & L. Archaic & & Mammalia (Medium) & Proximal phalange & 1 \\
\hline 17 & 5 & 344 & IIII & L. Archaic & & Mammalia (Medium) & Radius & 1 \\
\hline 17 & 5 & 344 & IIIIc & L. Archaic & & Mammalia (Medium/large) & Indeterminate & 32 \\
\hline 17 & 5 & 344 & IIIIc & L. Archaic & & Mammalia (Medium/large) & Long bone & 19 \\
\hline 17 & 5 & 344 & IIII & L. Archaic & & Mammalia (Medium/large) & Rib & 1 \\
\hline 17 & 5 & 344 & IIIIc & L. Archaic & & Mammalia (Medium/large) & Tooth, perm./decid. ind. & 5 \\
\hline 17 & 5 & 344 & IIIIC & L. Archaic & & Mammalia (Small) & Alveolar ridge fragment & 1 \\
\hline 17 & 5 & 344 & IIIIc & L. Archaic & & Odocoileus sp. & Tooth, perm./decid. ind. & 2 \\
\hline 17 & 5 & 344 & IIII & L. Archaic & & Small/Medium Vertebrata & Long bone & 7 \\
\hline 17 & 5 & 344 & IIIIc & L. Archaic & & Vertebrata & Indeterminate & 150 \\
\hline 17 & 6 & 390 & IIIIc & L. Archaic & & Antilocapra americana & Permanent tooth & 1 \\
\hline 17 & 6 & 390 & IIII & L. Archaic & & Antilocapra/Odocoileus & Intermediate carpal bone & 1 \\
\hline 17 & 6 & 390 & IIIC & L. Archaic & & Artiodactyla & Tooth, perm./decid. ind. & 4 \\
\hline 17 & 6 & 390 & IIIc & L. Archaic & & Carnivora & Permanent tooth & 1 \\
\hline 17 & 6 & 390 & IIII & L. Archaic & & Emydidae & Neural & 1 \\
\hline 17 & 6 & 390 & IIII & L. Archaic & & Emydidae & Peripheral & 1 \\
\hline 17 & 6 & 390 & IIIIc & L. Archaic & & Geomys sp. & Permanent tooth & 1 \\
\hline 17 & 6 & 390 & IIIIc & L. Archaic & & Lepus californicus & Astragalus & 1 \\
\hline 17 & 6 & 390 & IIII & L. Archaic & & Lepus californicus & Calcaneus & 1 \\
\hline 17 & 6 & 390 & IIIIc & L. Archaic & & Mammalia (Large) & Alveolar ridge fragment & 2 \\
\hline 17 & 6 & 390 & IIII & L. Archaic & & Mammalia (Large) & Indeterminate & 1 \\
\hline 17 & 6 & 390 & IIIc & L. Archaic & & Mammalia (Large) & Long bone & 8 \\
\hline 17 & 6 & 390 & IIIIc & L. Archaic & & Mammalia (Medium) & Proximal phalange & 1 \\
\hline 17 & 6 & 390 & IIIIc & L. Archaic & & Mammalia (Medium/large) & Indeterminate & 29 \\
\hline 17 & 6 & 390 & IIII & L. Archaic & & Mammalia (Medium/large) & Long bone & 12 \\
\hline 17 & 6 & 390 & IIIC & L. Archaic & & Mammalia (Medium/large) & Tooth, perm./decid. ind. & 2 \\
\hline 17 & 6 & 390 & IIIIc & L. Archaic & & Mammalia (Medium/large) & Vertebra & 1 \\
\hline 17 & 6 & 390 & IIIc & L. Archaic & & Mammalia (Small/medium) & Middle phalange & 1 \\
\hline 17 & 6 & 390 & IIII & L. Archaic & & Odocoileus sp. & Permanent tooth & 2 \\
\hline 17 & 6 & 390 & IIIc & L. Archaic & & Odocoileus sp. & Tooth, perm./decid. ind. & 1 \\
\hline 17 & 6 & 390 & IIIc & L. Archaic & & Small/Medium Vertebrata & Long bone & 8 \\
\hline 17 & 6 & 390 & IIIc & L. Archaic & & Sylvilagus sp. & Calcaneus & 1 \\
\hline 17 & 6 & 390 & IIIc & L. Archaic & & Sylvilagus sp. & Permanent tooth & 1 \\
\hline 17 & 6 & 390 & IIIIc & L. Archaic & & Testudinata & Shell fragment & 1 \\
\hline 17 & 6 & 390 & IIIc & L. Archaic & & Vertebrata & Indeterminate & 116 \\
\hline 17 & 6 & 437 & IIIc & L. Archaic & & Mammalia (Very large) & Long bone & 1 \\
\hline 17 & $7 \mathrm{~A}$ & 454 & $\mathrm{IIIlb} / \mathrm{c}$ & L. Archaic & & AntilocapralOdocoileus & Fused 3rd \& 4th metatarsal & 1 \\
\hline 17 & $7 \mathrm{~A}$ & 454 & $\mathrm{IIIb} / \mathrm{c}$ & L. Archaic & & Antilocapra/Odocoileus & Metapodial & 1 \\
\hline 17 & $7 \mathrm{~A}$ & 454 & $\mathrm{mb} / \mathrm{c}$ & L. Archaic & & Artiodactyla & Tooth, perm./decid. ind. & 3 \\
\hline 17 & $7 \mathrm{~A}$ & 454 & $\mathrm{IIIb} / \mathrm{c}$ & L. Archaic & & Canis sp. & Permanent tooth & 1 \\
\hline
\end{tabular}




\begin{tabular}{|c|c|c|c|c|c|c|c|c|}
\hline Square & Level & Lot & Unit & Cultural Affinity & Feature & Taxon & Element & No. \\
\hline 17 & $7 \mathrm{~A}$ & 454 & IIIb/c & L. Archaic & & Mammalia (Large) & Indeterminate & 3 \\
\hline 17 & $7 \mathrm{~A}$ & 454 & $\mathrm{IIIb} / \mathrm{c}$ & L. Archaic & & Mammalia (Large) & Long bone & 6 \\
\hline 17 & $7 \mathrm{~A}$ & 454 & $\mathrm{mb} / \mathrm{c}$ & L. Archaic & & Mammalia (Large) & Tooth, perm./decid. ind. & 1 \\
\hline 17 & $7 \mathrm{~A}$ & 454 & $\mathrm{IIIb} / \mathrm{c}$ & L. Archaic & & Mammalia (Medium/large) & Indeterminate & 28 \\
\hline 17 & $7 \mathrm{~A}$ & 454 & $\mathrm{IIl} / \mathrm{c}$ & L. Archaic & & Mammalia (Medium/large) & Long bone & 6 \\
\hline 17 & $7 \mathrm{~A}$ & 454 & $\mathrm{IIIb} / \mathrm{c}$ & L. Archaic & & Mammalia (Medium/large) & Permanent tooth & 1 \\
\hline 17 & $7 \mathrm{~A}$ & 454 & $\mathrm{IIIb} / \mathrm{c}$ & L. Archaic & & Mammalia (Medium/large) & Tooth, perm./decid. ind. & 2 \\
\hline 17 & $7 \mathrm{~A}$ & 454 & $\mathrm{IIIb} / \mathrm{c}$ & L. Archaic & & Mammalia (Medium/large) & Vertebra & 1 \\
\hline 17 & $7 \mathrm{~A}$ & 454 & $\mathrm{mb} / \mathrm{c}$ & L. Archaic & & Odocoileus sp. & Proximal phalange & 1 \\
\hline 17 & $7 \mathrm{~A}$ & 454 & $\mathrm{mb} / \mathrm{c}$ & L. Archaic & & Small/Medium Vertebrata & Long bone & 10 \\
\hline 17 & $7 \mathrm{~A}$ & 454 & $\mathrm{IIIb} / \mathrm{c}$ & L. Archaic & & Testudinata & Shell fragment & 1 \\
\hline 17 & $7 \mathrm{~A}$ & 454 & $\mathrm{IIIb} / \mathrm{c}$ & L. Archaic & & Vertebrata & Indeterminate & 95 \\
\hline 17 & $8 \mathrm{~A}$ & 462 & $\mathrm{IIIb} / \mathrm{c}$ & Middle/L. Archaic & & Antilocapra americana & Tooth, perm./decid. ind. & 2 \\
\hline 17 & $8 \mathrm{~A}$ & 462 & $\mathrm{IIIb} / \mathrm{c}$ & Middle/L. Archaic & & Colubridae & Dorsal vertebra & 1 \\
\hline 17 & $8 \mathrm{~A}$ & 462 & $\mathrm{mb} / \mathrm{c}$ & Middle/L. Archaic & & Leporidae & Permanent tooth & 1 \\
\hline 17 & $8 \mathrm{~A}$ & 462 & $\mathrm{mb} / \mathrm{c}$ & Middle/L. Archaic & & Mammalia (Large) & Indeterminate & 1 \\
\hline 17 & $8 \mathrm{~A}$ & 462 & $\mathrm{IIIb} / \mathrm{c}$ & Middle/L. Archaic & & Mammalia (Large) & Long bone & 2 \\
\hline 17 & $8 \mathrm{~A}$ & 462 & $\mathrm{IIIb} / \mathrm{c}$ & Middle/L. Archaic & & Mammalia (Large) & Rib & 1 \\
\hline 17 & $8 \mathrm{~A}$ & 462 & $\mathrm{mb} / \mathrm{c}$ & Middle/L. Archaic & & Mammalia (Medium) & Patella & 1 \\
\hline 17 & $8 \mathrm{~A}$ & 462 & $\mathrm{IIIb} / \mathrm{c}$ & Middle/L. Archaic & & Mammalia (Medium/large) & Indeterminate & 10 \\
\hline 17 & $8 \mathrm{~A}$ & 462 & $\mathrm{IIIb} / \mathrm{c}$ & Middle/L. Archaic & & Mammalia (Medium/large) & Tooth, perm./decid. ind. & 3 \\
\hline 17 & $8 \mathrm{~A}$ & 462 & $\mathrm{IIIb} / \mathrm{c}$ & Middle/L. Archaic & & Mammalia (Small/medium) & Phalange & 1 \\
\hline 17 & $8 \mathrm{~A}$ & 462 & $\mathrm{IIIb} / \mathrm{c}$ & Middle/L. Archaic & & Small/Medium Vertebrata & Long bone & 3 \\
\hline 17 & $8 \mathrm{~A}$ & 462 & $\mathrm{IIIb} / \mathrm{c}$ & Middle/L. Archaic & & Sylvilagus sp. & Metacarpal 3 & 1 \\
\hline 17 & $8 \mathrm{~A}$ & 462 & $\mathrm{mb} / \mathrm{c}$ & Middle/L. Archaic & & Sylvilagus sp. & Metatarsal 4 & 1 \\
\hline 17 & $8 \mathrm{~A}$ & 462 & $\mathrm{IIIb} / \mathrm{c}$ & Middle/L. Archaic & & Testudinata & Shell fragment & 1 \\
\hline 17 & $8 \mathrm{~A}$ & 462 & $\mathrm{mb} / \mathrm{c}$ & Middle/L. Archaic & & Vertebrata & Indeterminate & 92 \\
\hline 17 & 9 & 544 & IIIb & M. Archaic & & Antilocapra/Odocoileus & Fused 3rd \& 4th metatarsal & 1 \\
\hline 17 & 9 & 544 & IIIlb & M. Archaic & & Anura & Pelvis & 1 \\
\hline 17 & 9 & 544 & IIIb & M. Archaic & & Colubridae & Dorsal vertebra & 1 \\
\hline 17 & 9 & 544 & IIIb & M. Archaic & & Geomys sp. & Permanent tooth & 1 \\
\hline 17 & 9 & 544 & IIIlb & M. Archaic & & Leporidae & Permanent tooth & 1 \\
\hline 17 & 9 & 544 & IIIb & M. Archaic & & Lepus californicus & Astragalus & 1 \\
\hline 17 & 9 & 544 & IIIlb & M. Archaic & & Lepus californicus & Radius & 1 \\
\hline 17 & 9 & 544 & IIIlb & M. Archaic & & Mammalia (Medium/large) & Indeterminate & 4 \\
\hline 17 & 9 & 544 & IIIlb & M. Archaic & & Mammalia (Medium/large) & Long bone & 1 \\
\hline 17 & 9 & 544 & IIIlb & M. Archaic & & Mammalia (Micro) & Permanent tooth & 1 \\
\hline 17 & 9 & 544 & IIIlb & M. Archaic & & Medium/Large Vertebrata & Indeterminate & 1 \\
\hline 17 & 9 & 544 & IIIlb & M. Archaic & & Rodentia (Small) & Tibia & 1 \\
\hline 17 & 9 & 544 & IIIlb & M. Archaic & & Serpentes & Dorsal vertebra & 1 \\
\hline 17 & 9 & 544 & IIIlb & M. Archaic & & Small vertebrate, class ind. & Distal phalange & 1 \\
\hline 17 & 9 & 544 & IIIb & M. Archaic & & Small/Medium Vertebrata & Long bone & 17 \\
\hline 17 & 9 & 544 & IIIlb & M. Archaic & & Vertebrata & Indeterminate & 34 \\
\hline 17 & 9 & 544 & IIIlb & M. Archaic & & Viperidae & Dorsal vertebra & 1 \\
\hline 17 & 10 & 595 & IIIb & M. Archaic & & Antilocapra/Odocoileus & Proximal axial sesamoid & 1 \\
\hline 17 & 10 & 595 & IIItb & M. Archaic & & Colubridae & Dorsal vertebra & 1 \\
\hline 17 & 10 & 595 & IIIlb & M. Archaic & & Mammalia (Medium/large) & Indeterminate & 2 \\
\hline 17 & 10 & 595 & IIIlb & M. Archaic & & Mammalia (Medium/large) & Tooth, perm./decid. ind. & 1 \\
\hline 17 & 10 & 595 & IIIlb & M. Archaic & & Mammalia (Small) & Phalange & 1 \\
\hline 17 & 10 & 595 & IIIlb & M. Archaic & & Medium/Large Vertebrata & Indeterminate & 1 \\
\hline 17 & 10 & 595 & IIIb & M. Archaic & & Small/Medium Vertebrata & Long bone & 6 \\
\hline 17 & 10 & 595 & IIIb & M. Archaic & & Sylvilagus sp. & Permanent tooth & 1 \\
\hline 17 & 10 & 595 & IIIlb & M. Archaic & & Vertebrata & Indeterminate & 32 \\
\hline 17 & 11 & 652 & IIIb & M. Archaic & & Lepus californicus & Permanent tooth & 1 \\
\hline 17 & 11 & 652 & IIIlb & M. Archaic & & Mammalia (Medium/large) & Tooth, perm./decid. ind. & 2 \\
\hline 17 & 11 & 652 & IIIlb & M. Archaic & & Mammalia (Micro) & Tooth, perm./decid. ind. & 1 \\
\hline 17 & 11 & 652 & IIIlb & M. Archaic & & Mammalia (Small) & Distal phalange & 1 \\
\hline 17 & 11 & 652 & IIIb & M. Archaic & & Mammalia (Small) & Metapodial & 1 \\
\hline 17 & 11 & 652 & IIIlb & M. Archaic & & Small/Medium Vertebrata & Long bone & 6 \\
\hline 17 & 11 & 652 & IIIb & M. Archaic & & Sylvilagus sp. & Humerus & 1 \\
\hline 17 & 11 & 652 & IIIb & M. Archaic & & Vertebrata & Indeterminate & 25 \\
\hline 17 & 12 & 676 & IIIlb & Early/M. Archaic & & Leporidae & Permanent tooth & 2 \\
\hline 17 & 12 & 676 & IIIb & Early/M. Archaic & & Mammalia (Medium) & Alveolar ridge fragment & 1 \\
\hline 17 & 12 & 676 & IIIb & Early/M. Archaic & & Mammalia (Medium/large) & Indeterminate & 11 \\
\hline 17 & 12 & 676 & IIIb & Early/M. Archaic & & Mammalia (Medium/large) & Long bone & 2 \\
\hline 17 & 12 & 676 & IIIlb & Early/M. Archaic & & Mammalia (Small) & Cranium & 1 \\
\hline 17 & 12 & 676 & IIIb & Early/M. Archaic & & Mammalia (Small) & Patella & 1 \\
\hline
\end{tabular}




\begin{tabular}{|c|c|c|c|c|c|c|c|c|}
\hline Square & Level & Lot & Unit & Cultural Affinity & Feature & Taxon & Element & No. \\
\hline 17 & 12 & 676 & $\overline{\mathrm{IIb}}$ & Early/M. Archaic & & Small/Medium Vertebrata & Long bone & 13 \\
\hline 17 & 12 & 676 & IIIlb & Early/M. Archaic & & Vertebrata & Indeterminate & 48 \\
\hline 17 & 13 & 703 & ШШа/ & E. Archaic & & Leporidae & Permanent tooth & 1 \\
\hline 17 & 13 & 703 & Ша/b & E. Archaic & & Mammalia (Large) & Long bone & 1 \\
\hline 17 & 13 & 703 & IIIa/b & E. Archaic & & Mammalia (Large) & Tooth, perm./decid. ind. & 2 \\
\hline 17 & 13 & 703 & IIIa/b & E. Archaic & & Mammalia (Medium) & Vertebra & 2 \\
\hline 17 & 13 & 703 & IIIa/b & E. Archaic & & Mammalia (Medium/large) & Indeterminate & 5 \\
\hline 17 & 13 & 703 & IIIa/b & E. Archaic & & Mammalia (Medium/large) & Long bone & 1 \\
\hline 17 & 13 & 703 & $\mathrm{IIa} / \mathrm{b}$ & E. Archaic & & Medium/Large Vertebrata & Indeterminate & 4 \\
\hline 17 & 13 & 703 & IIIa/b & E. Archaic & & Odocoileus sp. & Middle phalange & 1 \\
\hline 17 & 13 & 703 & IIIa/b & E. Archaic & & Serpentes & Dorsal vertebra & 5 \\
\hline 17 & 13 & 703 & IIIa/b & E. Archaic & & Small/Medium Vertebrata & Long bone & 3 \\
\hline 17 & 13 & 703 & IIa/b & E. Archaic & & Vertebrata & Indeterminate & 25 \\
\hline 18 & 8 & 188 & IIIc/FILL & Unassigned & & Mammalia (Large) & Indeterminate & 1 \\
\hline 18 & 8 & 188 & IIc/FILL & Unassigned & & Mammalia (Large) & Long bone & 1 \\
\hline 18 & 8 & 188 & IIIc/FILL & Unassigned & & Mammalia (Medium/large) & Permanent tooth & 1 \\
\hline 18 & 8 & 188 & IIII/FILL & Unassigned & & Odocoileus sp. & Humerus & 1 \\
\hline 18 & 8 & 188 & Шc/FILL & Unassigned & & Small/Medium Vertebrata & Long bone & 2 \\
\hline 18 & 8 & 188 & IIIc/FILL & Unassigned & & Vertebrata & Indeterminate & 1 \\
\hline 18 & 9 & 371 & IIIb/c/FILL & Middle/L. Archaic & & Antilocapra/Odocoileus & Fused 3rd \& 4th metatarsal & 1 \\
\hline 18 & 9 & 371 & IIb/c/FILL & Middle/L. Archaic & & Leporidae & Permanent tooth & 1 \\
\hline 18 & 9 & 371 & $\mathrm{mb} / \mathrm{c} / \mathrm{FILL}$ & Middle/L. Archaic & & Mammalia (Large) & Long bone & 3 \\
\hline 18 & 9 & 371 & IIIb/c/FILL & Middle/L. Archaic & & Mammalia (Medium/large) & Indeterminate & 13 \\
\hline 18 & 9 & 371 & $\mathrm{IIb} / \mathrm{c} / \mathrm{FLL}$ & Middle/L. Archaic & & Mammalia (Medium/large) & Tooth, perm./decid. ind. & 2 \\
\hline 18 & 9 & 371 & $\mathrm{Imb} / \mathrm{c} / \mathrm{FILL}$ & Middle/L. Archaic & & Serpentes & Dorsal vertebra & 1 \\
\hline 18 & 9 & 371 & IIIb/c/FILL & Middle/L. Archaic & & Small/Medium Vertebrata & Long bone & 2 \\
\hline 18 & 9 & 371 & $\mathrm{IIIb} / \mathrm{c} / \mathrm{FILL}$ & Middle/L. Archaic & & Vertebrata & Indeterminate & 62 \\
\hline 18 & 9 & 394 & $\mathrm{IIb} / \mathrm{c} / \mathrm{FILL}$ & Middle/L. Archaic & & Odocoileus sp. & Tibia & 1 \\
\hline 18 & 10 & 412 & |IIIb/c & Middle/L. Archaic & & AntilocapralOdocoileus & Mandible & 1 \\
\hline 18 & 10 & 412 & $\mathrm{IIb} / \mathrm{c}$ & Middle/L. Archaic & & Anura & Humerus & 1 \\
\hline 18 & 10 & 412 & $\mathrm{IIIb} / \mathrm{c}$ & Middle/L. Archaic & & Geomys sp. & Femur & 1 \\
\hline 18 & 10 & 412 & IIIIb/c & Middle/L. Archaic & & Geomys sp. & Permanent tooth & 2 \\
\hline 18 & 10 & 412 & $\mathrm{IIIb} / \mathrm{c}$ & Middle/L. Archaic & & Leporidae & Permanent tooth & 2 \\
\hline 18 & 10 & 412 & $\mathrm{IIJb} / \mathrm{c}$ & Middle/L. Archaic & & Mammalia (Medium/large) & Indeterminate & 20 \\
\hline 18 & 10 & 412 & $\mathrm{IITb} / \mathrm{c}$ & Middle/L. Archaic & & Mammalia (Medium/large) & Long bone & 2 \\
\hline 18 & 10 & 412 & IIIIb/c & Middle/L. Archaic & & Mammalia (Small) & Alveolar ridge fragment & 1 \\
\hline 18 & 10 & 412 & $\mathrm{IIIb} / \mathrm{c}$ & Middle/L. Archaic & & Mammalia (Small) & Tibia & 1 \\
\hline 18 & 10 & 412 & $\mathrm{IITb} / \mathrm{c}$ & Middle/L. Archaic & & Mammalia (Small/medium) & Alveolar ridge fragment & 1 \\
\hline 18 & 10 & 412 & IIIb/c & Middle/L. Archaic & & Medium vertebrate, class ind. & Middle phalange & 1 \\
\hline 18 & 10 & 412 & $\mathrm{IIIb} / \mathrm{c}$ & Middle/L. Archaic & & Medium/Large Vertebrata & Long bone & 1 \\
\hline 18 & 10 & 412 & IIIIb/c & Middle/L. Archaic & & Rodentia (Medium) & Permanent tooth & 1 \\
\hline 18 & 10 & 412 & $\mathrm{IIIb} / \mathrm{c}$ & Middle/L. Archaic & & Small/Medium Vertebrata & Long bone & 15 \\
\hline 18 & 10 & 412 & $\mathrm{mb} / \mathrm{c}$ & Middle/L. Archaic & & Small/Medium Vertebrata & Middle phalange & 1 \\
\hline 18 & 10 & 412 & $\mathrm{IITb} / \mathrm{c}$ & Middle/L. Archaic & & Sylvilagus sp. & Permanent tooth & 1 \\
\hline 18 & 10 & 412 & IIIb/c & Middle/L. Archaic & & Testudinata & Shell fragment & 6 \\
\hline 18 & 10 & 412 & $\mathrm{IIb} / \mathrm{c}$ & Middle/L. Archaic & & Vertebrata & Indeterminate & 118 \\
\hline 18 & 10 & 429 & $\mathrm{Imb} / \mathrm{c}$ & Middle/L. Archaic & & Mammalia (Medium/large) & Indeterminate & 4 \\
\hline 18 & 11 & 2171 & $\mathrm{IIb} / \mathrm{c}$ & M. Archaic & & Antilocapra/Odocoileus & Proximal axial sesamoid & 1 \\
\hline 18 & 11 & 2171 & $\mathrm{IIb} / \mathrm{c}$ & M. Archaic & & Leporidae & Permanent tooth & 1 \\
\hline 18 & 11 & 2171 & $\mathrm{mb} / \mathrm{c}$ & M. Archaic & & Lepus californicus & Calcaneus & 1 \\
\hline 18 & 11 & 2171 & $\mathrm{IIIb} / \mathrm{c}$ & M. Archaic & & Lepus californicus & Permanent tooth & 1 \\
\hline 18 & 11 & 2171 & $\mathrm{IIIb} / \mathrm{c}$ & M. Archaic & & Mammalia (Medium) & Distal phalange & 1 \\
\hline 18 & 11 & 2171 & $\mathrm{IIJb} / \mathrm{c}$ & M. Archaic & & Mammalia (Medium) & Middle phalange & 1 \\
\hline 18 & 11 & 2171 & $\mathrm{IIIb} / \mathrm{c}$ & M. Archaic & & Mammalia (Medium/large) & Indeterminate & 6 \\
\hline 18 & 11 & 2171 & $\mathrm{IIb} / \mathrm{c}$ & M. Archaic & & Mammalia (Medium/large) & Tooth, perm./decid. ind. & 4 \\
\hline 18 & 11 & 2171 & $\mathrm{mb} / \mathrm{c}$ & M. Archaic & & Mammalia (Small) & Distal phalange & 1 \\
\hline 18 & 11 & 2171 & IIIIb/c & M. Archaic & & Mammalia (Small) & Proximal phalange & 1 \\
\hline 18 & 11 & 2171 & $\mathrm{IIb} / \mathrm{c}$ & M. Archaic & & Neotoma sp. & Permanent tooth & 1 \\
\hline 18 & 11 & 2171 & $\mathrm{IImb} / \mathrm{c}$ & M. Archaic & & Odocoileus sp. & Permanent tooth & 1 \\
\hline 18 & 11 & 2171 & IIIJb/c & M. Archaic & & Serpentes & Dorsal vertebra & 1 \\
\hline 18 & 11 & 2171 & IIIb/c & M. Archaic & & Small/Medium Vertebrata & Long bone & 10 \\
\hline 18 & 11 & 2171 & $\mathrm{IIb} / \mathrm{c}$ & M. Archaic & & Testudinata & Carapace fragment ind. & 4 \\
\hline 18 & 11 & 2171 & IIIIb/c & M. Archaic & & Vertebrata & Indeterminate & 222 \\
\hline 18 & 12 & 607 & IIIlb & M. Archaic & & Leporidae & Cranium & 1 \\
\hline 18 & 12 & 607 & IIIb & M. Archaic & & Mammalia (Medium/large) & Indeterminate & 6 \\
\hline 18 & 12 & 607 & IIIlb & M. Archaic & & Mammalia (Medium/large) & Long bone & 2 \\
\hline 18 & 12 & 607 & IIIb & M. Archaic & & Mammalia (Micro) & Femur & 1 \\
\hline
\end{tabular}




\begin{tabular}{|c|c|c|c|c|c|c|c|c|}
\hline Square & Level & Lot & Unit & Cultural Affinity & Feature & Taxon & Element & No. \\
\hline 18 & 12 & 607 & IIIb & M. Archaic & & Small/Medium Vertebrata & Long bone & 10 \\
\hline 18 & 12 & 607 & IIIIb & M. Archaic & & Vertebrata & Indeterminate & 44 \\
\hline 18 & 13 & 653 & IIIIb & M. Archaic & & Colubridae & Dorsal vertebra & 1 \\
\hline 18 & 13 & 653 & IIIb & M. Archaic & & Mammalia (Medium/large) & Indeterminate & 3 \\
\hline 18 & 13 & 653 & IIIIb & M. Archaic & & Mammalia (Medium/large) & Long bone & 6 \\
\hline 18 & 13 & 653 & IIIb & M. Archaic & & Medium/Large Vertebrata & Indeterminate & 7 \\
\hline 18 & 13 & 653 & IIIb & M. Archaic & & Small/Medium Vertebrata & Long bone & 1 \\
\hline 18 & 13 & 653 & IIIIb & M. Archaic & & Vertebrata & Indeterminate & 26 \\
\hline 18 & 14 & 662 & ШШ口 & M. Archaic & & Mammalia (Medium/large) & Indeterminate & 9 \\
\hline 18 & 14 & 662 & IIIIb & M. Archaic & & Small/Medium Vertebrata & Long bone & 5 \\
\hline 18 & 14 & 662 & IIIb & M. Archaic & & Vertebrata & Indeterminate & 16 \\
\hline 19 & 7 & 230 & IIIc/FILL & Unassigned & & Mammalia (Large) & Indeterminate & 1 \\
\hline 19 & 7 & 230 & IIIc/FILL & Unassigned & & Mammalia (Medium/large) & Indeterminate & 2 \\
\hline 19 & 7 & 230 & IIIc/FILL & Unassigned & & Odocoileus sp. & Permanent tooth & 1 \\
\hline 19 & 7 & 230 & IIIc/FILL & Unassigned & & Small/Medium Vertebrata & Long bone & 2 \\
\hline 19 & 7 & 230 & IIIc/FILL & Unassigned & & Vertebrata & Indeterminate & 12 \\
\hline 19 & $8 \mathrm{~A}$ & 262 & $\mathrm{ITb} / \mathrm{c} / \mathrm{FILL}$ & Unassigned & & Leporidae & Metatarsal 3 & 1 \\
\hline 19 & $8 \mathrm{~A}$ & 262 & IIIb/c/FILL & Unassigned & & Mammalia (Medium/large) & Indeterminate & 10 \\
\hline 19 & $8 \mathrm{~A}$ & 262 & IIIb/c/FILL & Unassigned & & Mammalia (Medium/large) & Tooth, perm./decid. ind. & 2 \\
\hline 19 & $8 \mathrm{~A}$ & 262 & IIIb/c/FILL & Unassigned & & Mammalia (Small/medium) & Alveolar ridge fragment & 1 \\
\hline 19 & $8 \mathrm{~A}$ & 262 & IIIJ/c/FILL & Unassigned & & Medium/Large Vertebrata & Long bone & 2 \\
\hline 19 & $8 \mathrm{~A}$ & 262 & IIIb/c/FILL & Unassigned & & Odocoileus sp. & Permanent tooth & 1 \\
\hline 19 & $8 \mathrm{~A}$ & 262 & IIIb/c/FILL & Unassigned & & Odocoileus sp. & Tooth, perm./decid. ind. & 1 \\
\hline 19 & $8 \mathrm{~A}$ & 262 & IIIb/c/FILL & Unassigned & & Small/Medium Vertebrata & Long bone & 3 \\
\hline 19 & $8 \mathrm{~A}$ & 262 & IIIb/c/FILL & Unassigned & & Small/Medium Vertebrata & Vertebra & 1 \\
\hline 19 & $8 \mathrm{~A}$ & 262 & $\mathrm{IIb} / \mathrm{c} / \mathrm{FILL}$ & Unassigned & & Vertebrata & Indeterminate & 88 \\
\hline 19 & $8 \mathrm{~A}$ & 287 & IIIb/c/FILL & Unassigned & & Mammalia (Large) & Indeterminate & 1 \\
\hline 19 & $8 \mathrm{~A}$ & 287 & IIIb/c/FILL & Unassigned & & Mammalia (Medium/large) & Indeterminate & 7 \\
\hline 19 & $8 \mathrm{~A}$ & 329 & $\mathrm{IIIb} / \mathrm{c} / \mathrm{FLL}$ & Unassigned & & Mammalia (Large) & Long bone & 1 \\
\hline 19 & $8 \mathrm{~A}$ & 340 & IIIb/c/FILL & Unassigned & & Odocoileus sp. & Permanent tooth & 1 \\
\hline 19 & $8 \mathrm{~A}$ & 343 & IIIb/c/FILL & Unassigned & & Mammalia (Medium/large) & Indeterminate & 2 \\
\hline 19 & $8 \mathrm{~A}$ & 353 & IIIb/c/FILL & Unassigned & & Mammalia (Large) & Long bone & 1 \\
\hline 19 & $9 \mathrm{~A}$ & 365 & $\mathrm{IIb} / \mathrm{c}$ & Middle/L. Archaic & & AntilocapralOdocoileus & Fused 3rd \& 4th metatarsal & 1 \\
\hline 19 & $9 \mathrm{~A}$ & 365 & $\mathrm{IIb} / \mathrm{c}$ & Middle/L. Archaic & & AntilocapralOdocoileus & Phalange & 1 \\
\hline 19 & $9 \mathrm{~A}$ & 365 & $\mathrm{IIIb} / \mathrm{c}$ & Middle/L. Archaic & & Colubridae & Dorsal vertebra & 1 \\
\hline 19 & $9 \mathrm{~A}$ & 365 & IIIb/c & Middle/L. Archaic & & Leporidae & Permanent tooth & 4 \\
\hline 19 & $9 \mathrm{~A}$ & 365 & $\mathrm{IIb} / \mathrm{c}$ & Middle/L. Archaic & & Lepus californicus & Permanent tooth & 2 \\
\hline 19 & $9 \mathrm{~A}$ & 365 & $\mathrm{mb} / \mathrm{c}$ & Middle/L. Archaic & & Mammalia (Large) & Long bone & 11 \\
\hline 19 & $9 \mathrm{~A}$ & 365 & IIIb/c & Middle/L. Archaic & & Mammalia (Medium/large) & Caudal vertebra & 1 \\
\hline 19 & 9A & 365 & IIIb/c & Middle/L. Archaic & & Mammalia (Medium/large) & Indeterminate & 19 \\
\hline 19 & 9A & 365 & $\mathrm{IITb} / \mathrm{c}$ & Middle/L. Archaic & & Mammalia (Medium/large) & Long bone & 15 \\
\hline 19 & $9 \mathrm{~A}$ & 365 & IIIb/c & Middle/L. Archaic & & Mammalia (Medium/large) & Mandible & 1 \\
\hline 19 & 9A & 365 & $\mathrm{Imb} / \mathrm{c}$ & Middle/L. Archaic & & Mammalia (Medium/large) & Tooth, perm./decid. ind. & 4 \\
\hline 19 & 9A & 365 & $\mathrm{IITb} / \mathrm{c}$ & Middle/L. Archaic & & Mammalia (Small) & Middle phalange & 2 \\
\hline 19 & 9A & 365 & IIIb/c & Middle/L. Archaic & & Odocoileus sp. & Fused second \& third carpal & 1 \\
\hline 19 & 9A & 365 & $\mathrm{IIb} / \mathrm{c}$ & Middle/L. Archaic & & Small vertebrate, class ind. & Distal phalange & 1 \\
\hline 19 & 9A & 365 & $\mathrm{IITb} / \mathrm{c}$ & Middle/L. Archaic & & Small/Medium Vertebrata & Long bone & 12 \\
\hline 19 & $9 \mathrm{~A}$ & 365 & $\mathrm{IIb} / \mathrm{c}$ & Middle/L. Archaic & & Testudinata & Shell fragment & 3 \\
\hline 19 & 9A & 365 & $\mathrm{IIb} / \mathrm{c}$ & Middle/L. Archaic & & Vertebrata & Indeterminate & 279 \\
\hline 19 & $9 \mathrm{~A}$ & 427 & $\mathrm{IIIb} / \mathrm{c}$ & Middle/L. Archaic & & Antilocapra/Odocoileus & Calcaneus & 1 \\
\hline 19 & $9 \mathrm{~A}$ & 427 & IIIb/c & Middle/L. Archaic & & Mammalia (Medium/large) & Indeterminate & 3 \\
\hline 19 & $9 \mathrm{~A}$ & 618 & IIIb/c & Middle/L. Archaic & & Mammalia (Large) & Long bone & 3 \\
\hline 19 & 9B & 450 & $\mathrm{IIb} / \mathrm{c}$ & Middle/L. Archaic & 203 & Mammalia (Medium/large) & Indeterminate & 1 \\
\hline 19 & 9B & 450 & IIIb/c & Middle/L. Archaic & 203 & Odocoileus sp. & Metapodial of paradigit & 1 \\
\hline 19 & 9B & 450 & IIIb/c & Middle/L. Archaic & 203 & Odocoileus sp. & Tooth, perm./decid. ind. & 1 \\
\hline 19 & 9B & 450 & $\mathrm{IIJb} / \mathrm{c}$ & Middle/L. Archaic & 203 & Small/Medium Vertebrata & Long bone & 2 \\
\hline 19 & 9B & 450 & IIIb/c & Middle/L. Archaic & 203 & Vertebrata & Indeterminate & 21 \\
\hline 19 & 10 & 487 & $\mathrm{IIb} / \mathrm{c}$ & Middle/L. Archaic & & Leporidae & Permanent tooth & 1 \\
\hline 19 & 10 & 487 & $\mathrm{mb} / \mathrm{c}$ & Middle/L. Archaic & & Mammalia (Medium) & Cranium & 1 \\
\hline 19 & 10 & 487 & IIIb/c & Middle/L. Archaic & & Mammalia (Medium/large) & Indeterminate & 16 \\
\hline 19 & 10 & 487 & $\mathrm{IIb} / \mathrm{c}$ & Middle/L. Archaic & & Mammalia (Medium/large) & Mandible & 1 \\
\hline 19 & 10 & 487 & $\mathrm{IIb} / \mathrm{c}$ & Middle/L. Archaic & & Mammalia (Medium/large) & Tooth, perm./decid. ind. & 4 \\
\hline 19 & 10 & 487 & $\mathrm{IIIb} / \mathrm{c}$ & Middle/L. Archaic & & Mammalia (Small/medium) & Tooth, perm./decid. ind. & 2 \\
\hline 19 & 10 & 487 & $\mathrm{IIIb} / \mathrm{c}$ & Middle/L. Archaic & & Medium/Large Vertebrata & Long bone & 2 \\
\hline 19 & 10 & 487 & $\mathrm{IIb} / \mathrm{c}$ & Middle/L. Archaic & & Odocoileus sp. & Antler & 1 \\
\hline 19 & 10 & 487 & $\mathrm{IIIb} / \mathrm{c}$ & Middle/L. Archaic & & Odocoileus sp. & Permanent tooth & 2 \\
\hline 19 & 10 & 487 & $\mathrm{IIIb} / \mathrm{c}$ & Middle/L. Archaic & & Small/Medium Vertebrata & Long bone & 20 \\
\hline
\end{tabular}




\begin{tabular}{|c|c|c|c|c|c|c|c|c|}
\hline Square & Level & Lot & Unit & Cultural Affinity & Feature & Taxon & Element & No. \\
\hline 19 & 10 & 487 & $\overline{\mathrm{m}} \mathrm{II} / \mathrm{c}$ & Middle/L. Archaic & & Testudinata & Shell fragment & 1 \\
\hline 19 & 10 & 487 & IIIb/c & Middle/L. Archaic & & Vertebrata & Indeterminate & 162 \\
\hline 19 & 11 & 513 & IIIb & M. Archaic & & AntilocapralOdocoileus & |Proximal axial sesamoid & 1 \\
\hline 19 & 11 & 513 & IIItb & M. Archaic & & Artiodactyla & Tooth, perm./decid. ind. & 1 \\
\hline 19 & 11 & 513 & IIIlb & M. Archaic & & Geomys sp. & Permanent tooth & 1 \\
\hline 19 & 11 & 513 & IIIb & M. Archaic & & Leporidae & Permanent tooth & 4 \\
\hline 19 & 11 & 513 & IIItb & M. Archaic & & Leporidae & Ulna & 1 \\
\hline 19 & 11 & 513 & IIIlb & M. Archaic & & Lepus californicus & Patella & 1 \\
\hline 19 & 11 & 513 & IIIlb & M. Archaic & & Lepus californicus & Third tarsal & 1 \\
\hline 19 & 11 & 513 & IIIlb & M. Archaic & & Mammalia (Medium/large) & Indeterminate & 7 \\
\hline 19 & 11 & 513 & IIIlb & M. Archaic & & Mammalia (Medium/large) & Tooth, perm./decid. ind. & 3 \\
\hline 19 & 11 & 513 & IIIlb & M. Archaic & & Mammalia (Micro) & Permanent tooth & 1 \\
\hline 19 & 11 & 513 & $\mathrm{IIIb}$ & M. Archaic & & Mammalia (Small) & Proximal phalange & 1 \\
\hline 19 & 11 & 513 & IIIIb & M. Archaic & & Medium/Large Vertebrata & Indeterminate & 2 \\
\hline 19 & 11 & 513 & IIIlb & M. Archaic & & Small/Medium Vertebrata & Long bone & 8 \\
\hline 19 & 11 & 513 & IIIb & M. Archaic & & Sylvilagus sp. & Astragalus & 1 \\
\hline 19 & 11 & 513 & IIIIb & M. Archaic & & Sylvilagus sp. & Distal phalange & 1 \\
\hline 19 & 11 & 513 & IIIlb & M. Archaic & & Sylvilagus sp. & Permanent tooth & 2 \\
\hline 19 & 11 & 513 & IIIb & M. Archaic & & Sylvilagus sp. & Scapula & 1 \\
\hline 19 & 11 & 513 & IIIlb & M. Archaic & & Testudinata & Shell fragment & 1 \\
\hline 19 & 11 & 513 & IIIb & M. Archaic & & Vertebrata & |Indeterminate & 216 \\
\hline 19 & 12 & 626 & IIIb & M. Archaic & & cf. Microtus sp. & Mandible & 1 \\
\hline 19 & 12 & 626 & IIIb & M. Archaic & & cf. Microtus sp. & Permanent tooth & 1 \\
\hline 19 & 12 & 626 & IIIb & M. Archaic & & Colubridae & Dorsal vertebra & 1 \\
\hline 19 & 12 & 626 & IIIb & M. Archaic & & Leporidae & Metapodial & 1 \\
\hline 19 & 12 & 626 & IIIIb & M. Archaic & & Lepus californicus & Metatarsal 4 & 1 \\
\hline 19 & 12 & 626 & IIIlb & M. Archaic & & Mammalia (Medium/large) & Indeterminate & 2 \\
\hline 19 & 12 & 626 & IIIb & M. Archaic & & Mammalia (Medium/large) & Long bone & 3 \\
\hline 19 & 12 & 626 & IIIb & M. Archaic & & Small vertebrate, class ind. & Distal phalange & 1 \\
\hline 19 & 12 & 626 & IIIIb & M. Archaic & & Small/Medium Vertebrata & Long bone & 15 \\
\hline 19 & 12 & 626 & IIIb & M. Archaic & & Testudinata & Shell fragment & 2 \\
\hline 19 & 12 & 626 & IIIb & M. Archaic & & Vertebrata & Indeterminate & 81 \\
\hline 19 & 13 & 654 & IIIIb & M. Archaic & & Mammalia (Large) & Long bone & 1 \\
\hline 19 & 13 & 654 & IIIb & M. Archaic & & Mammalia (Medium/large) & Indeterminate & 7 \\
\hline 19 & 13 & 654 & IIIb & M. Archaic & & Mammalia (Medium/large) & Long bone & 2 \\
\hline 19 & 13 & 654 & IIIlb & M. Archaic & & Mammalia (Medium/large) & Tooth, perm./decid. ind. & 1 \\
\hline 19 & 13 & 654 & IIIb & M. Archaic & & Small vertebrate, class ind. & Proximal phalange & 1 \\
\hline 19 & 13 & 654 & IIIb & M. Archaic & & Small/Medium Vertebrata & Long bone & 4 \\
\hline 19 & 13 & 654 & IIIb & M. Archaic & & Testudinata & Shell fragment & 1 \\
\hline 19 & 13 & 654 & IIIb & M. Archaic & & Vertebrata & Indeterminate & 40 \\
\hline 19 & $14 \mathrm{~A}$ & 663 & IIIb & M. Archaic & & Mammalia (Medium) & Middle phalange & 1 \\
\hline 19 & $14 \mathrm{~A}$ & 663 & IIIb & M. Archaic & & Mammalia (Medium/large) & Indeterminate & 11 \\
\hline 19 & $14 \mathrm{~A}$ & 663 & IIIlb & M. Archaic & & Mammalia (Medium/large) & Tooth, perm./decid. ind. & 3 \\
\hline 19 & $14 \mathrm{~A}$ & 663 & IIIb & M. Archaic & & Mammalia (Micro) & Humerus & 1 \\
\hline 19 & $14 \mathrm{~A}$ & 663 & $\mathrm{IIlb}$ & M. Archaic & & Mammalia (Small) & Long bone & 1 \\
\hline 19 & $14 \mathrm{~A}$ & 663 & IIllb & M. Archaic & & Odocoileus sp. & Permanent tooth & 1 \\
\hline 19 & $14 \mathrm{~A}$ & 663 & IIIb & M. Archaic & & Serpentes & Dorsal vertebra & 1 \\
\hline 19 & $14 \mathrm{~A}$ & 663 & IIlb & M. Archaic & & Small vertebrate, class ind. & Middle phalange & 1 \\
\hline 19 & $14 \mathrm{~A}$ & 663 & IIIb & M. Archaic & & Small/Medium Vertebrata & Long bone & 10 \\
\hline 19 & $14 \mathrm{~A}$ & 663 & IIIb & M. Archaic & & Vertebrata & Indeterminate & 31 \\
\hline 20 & 7 & 203 & IIIc & L. Archaic & & Vertebrata & Indeterminate & 2 \\
\hline 20 & $13 \mathrm{~A}$ & 489 & IIIlb & M. Archaic & & Vertebrata & Indeterminate & 2 \\
\hline 20 & $16 \mathrm{~A}$ & 562 & $\mathrm{III} / \mathrm{b}$ & Early/M. Archaic & & Small/Medium Vertebrata & Long bone & 1 \\
\hline 21 & 1 & 154 & FILL & Unassigned & & Mammalia (Large) & Indeterminate & 1 \\
\hline 21 & 5 & 175 & IIIc/FILL & Unassigned & & Mammalia (Large) & Indeterminate & 2 \\
\hline 21 & 5 & 175 & IIIc/FILL & Unassigned & & Mammalia (Medium/large) & Indeterminate & 5 \\
\hline 21 & 5 & 175 & IIIc/FILL & Unassigned & & Mammalia (Medium/large) & Long bone & 2 \\
\hline 21 & 5 & 175 & IIIc/FILL & Unassigned & & Odocoileus sp. & Distal fibula & 1 \\
\hline 21 & 5 & 175 & IIIC/FILL & Unassigned & & Vertebrata & Indeterminate & 6 \\
\hline 21 & $6 \mathrm{~A}-\mathrm{B}$ & 209 & IIIc/FILL & Unassigned & 201/NO & Mammalia (Large) & Long bone & 1 \\
\hline 21 & $6 \mathrm{~A}-\mathrm{B}$ & 209 & IIIc/FILL & Unassigned & $201 / \mathrm{NO}$ & Mammalia (Medium/large) & Indeterminate & 9 \\
\hline 21 & $6 \mathrm{~A}-\mathrm{B}$ & 209 & IIII/FILL & Unassigned & $201 / \mathrm{NO}$ & Vertebrata & Indeterminate & 27 \\
\hline 21 & $6 \mathrm{~B}$ & 227 & IIIc/FILL & Unassigned & 201 & Mammalia (Large) & Long bone & 1 \\
\hline 21 & $6 \mathrm{~B}$ & 253 & IIC/FILL & Unassigned & 201 & Mammalia (Medium/large) & Long bone & 1 \\
\hline 21 & $7 \mathrm{~A}$ & 254 & IIIc & L. Archaic & & Medium/Large Vertebrata & Long bone & 2 \\
\hline 21 & $7 \mathrm{~A}$ & 260 & IIIc & L. Archaic & & Mammalia (Large) & Long bone & 1 \\
\hline 21 & $7 \mathrm{~A}$ & 260 & IIIc & L. Archaic & & Mammalia (Large) & Tooth, perm./decid. ind. & 1 \\
\hline
\end{tabular}




\begin{tabular}{|c|c|c|c|c|c|c|c|c|}
\hline Square & Level & Lot & Unit & Cultural Affinity & Feature & Taxon & Element & No. \\
\hline 21 & $7 \mathrm{~A}$ & 260 & IIIc & L. Archaic & & Mammalia (Medium/large) & Indeterminate & 18 \\
\hline 21 & $7 \mathrm{~A}$ & 260 & IIII & L. Archaic & & Mammalia (Medium/large) & Long bone & 3 \\
\hline 21 & $7 \mathrm{~A}$ & 260 & IIII & L. Archaic & & Mammalia (Small) & Ulna & 1 \\
\hline 21 & $7 \mathrm{~A}$ & 260 & IIIIc & L. Archaic & & Small/Medium Vertebrata & Long bone & 2 \\
\hline 21 & $7 \mathrm{~A}$ & 260 & IIII & L. Archaic & & Sylvilagus sp. & Permanent tooth & 1 \\
\hline 21 & $7 \mathrm{~A}$ & 260 & IIIIc & L. Archaic & & Vertebrata & Indeterminate & 40 \\
\hline 21 & $7 \mathrm{~A}$ & 326 & IIIIc & L. Archaic & & Antilocapra/Odocoileus & Ulnar carpal bone & 1 \\
\hline 21 & 7B & 367 & IIII & L. Archaic & 201 & Mammalia (Medium/large) & Indeterminate & 1 \\
\hline 21 & $7 \mathrm{~B}$ & 381 & IIIC & L. Archaic & 201 & Mammalia (Medium/large) & Indeterminate & 3 \\
\hline 21 & 7B & 383 & IIIIc & L. Archaic & 201 & Mammalia (Medium/large) & Indeterminate & 1 \\
\hline 21 & 7B & 438 & |IIC & L. Archaic & 201 & Mammalia (Medium) & Middle phalange & 1 \\
\hline 21 & $7 \mathrm{~B}$ & 438 & IIII & L. Archaic & 201 & Mammalia (Medium/large) & Indeterminate & 40 \\
\hline 21 & 7B & 438 & |IIIC & L. Archaic & 201 & Mammalia (Medium/large) & Long bone & 2 \\
\hline 21 & 7B & 438 & |III & L. Archaic & 201 & Mammalia (Medium/large) & Tooth, perm./decid. ind. & 2 \\
\hline 21 & 7B & 438 & IIIc & L. Archaic & 201 & Mammalia (Small/medium) & Vertebra & 1 \\
\hline 21 & 7B & 438 & IIIIc & L. Archaic & 201 & Neotoma sp. & Permanent tooth & 1 \\
\hline 21 & 7B & 438 & ШШс & L. Archaic & 201 & Odocoileus sp. & Tooth, perm./decid. ind. & 2 \\
\hline 21 & 7B & 438 & IIIc & L. Archaic & 201 & Rodentia (Medium) & Permanent tooth & 3 \\
\hline 21 & 7B & 438 & IIIIC & L. Archaic & 201 & Small/Medium Vertebrata & Long bone & 14 \\
\hline 21 & 7B & 438 & WI & L. Archaic & 201 & Testudinata & Shell fragment & 2 \\
\hline 21 & 7B & 438 & IIII & L. Archaic & 201 & Vertebrata & Indeterminate & 172 \\
\hline 21 & 8 & 431 & IIIIb/c & L. Archaic & & Canis sp. & Permanent tooth & 1 \\
\hline 21 & 8 & 431 & $\mathrm{IIb} / \mathrm{c}$ & L. Archaic & & Leporidae & Distal phalange & 1 \\
\hline 21 & 8 & 431 & $\mathrm{mb} / \mathrm{c}$ & L. Archaic & & Lepus californicus & Calcaneus & 1 \\
\hline 21 & 8 & 431 & $\mathrm{IIIb} / \mathrm{c}$ & L. Archaic & & Mammalia (Large) & Indeterminate & 3 \\
\hline 21 & 8 & 431 & $\mathrm{mb} / \mathrm{c}$ & L. Archaic & & Mammalia (Large) & Long bone & 4 \\
\hline 21 & 8 & 431 & $\mathrm{IITb} / \mathrm{c}$ & L. Archaic & & Mammalia (Medium/large) & Cranium & 1 \\
\hline 21 & 8 & 431 & $\mathrm{IIb} / \mathrm{c}$ & L. Archaic & & Mammalia (Medium/large) & Indeterminate & 54 \\
\hline 21 & 8 & 431 & $\mathrm{IIb} / \mathrm{c}$ & L. Archaic & & Mammalia (Medium/large) & Long bone & 5 \\
\hline 21 & 8 & 431 & $\mathrm{ml} b / \mathrm{c}$ & L. Archaic & & Mammalia (Medium/large) & Permanent tooth & 1 \\
\hline 21 & 8 & 431 & $\mathrm{IIIb} / \mathrm{c}$ & L. Archaic & & Mammalia (Medium/large) & Tooth, perm./decid. ind. & 5 \\
\hline 21 & 8 & 431 & $\mathrm{IIb} / \mathrm{c}$ & L. Archaic & & Mammalia (Small) & Femur & 1 \\
\hline 21 & 8 & 431 & $\mathrm{IIIb} / \mathrm{c}$ & L. Archaic & & Mammalia (Small/medium) & Metapodial & 1 \\
\hline 21 & 8 & 431 & $\mathrm{IIIb} / \mathrm{c}$ & L. Archaic & & Mammalia (Very large) & Long bone & 4 \\
\hline 21 & 8 & 431 & $\mathrm{mb} / \mathrm{c}$ & L. Archaic & & Odocoileus sp. & Proximal phalange & 1 \\
\hline 21 & 8 & 431 & $\mathrm{IIIb} / \mathrm{c}$ & L. Archaic & & Small/Medium Vertebrata & Middle phalange & 2 \\
\hline 21 & 8 & 431 & $\mathrm{IIb} / \mathrm{c}$ & L. Archaic & & Small/Medium Vertebrata & Phalange & 1 \\
\hline 21 & 8 & 431 & $\mathrm{IIlb} / \mathrm{c}$ & L. Archaic & & Sylvilagus sp. & Permanent tooth & 2 \\
\hline 21 & 8 & 431 & IIIb/c & L. Archaic & & Testudinata & Shell fragment & 2 \\
\hline 21 & 8 & 431 & $\mathrm{mb} / \mathrm{c}$ & L. Archaic & & Vertebrata & Indeterminate & 491 \\
\hline 21 & 8 & 431 & $\mathrm{IIb} / \mathrm{c}$ & L. Archaic & & Vertebrata & Long bone & 12 \\
\hline 21 & 8 & 435 & $\mathrm{IIlb} / \mathrm{c}$ & L. Archaic & & Antilocapra/Odocoileus & Femur & 1 \\
\hline 21 & 8 & 484 & $\mathrm{Imb} / \mathrm{c}$ & L. Archaic & & Mammalia (Large) & Long bone & 1 \\
\hline 21 & 9 & 503 & $\mathrm{IIIb} / \mathrm{c}$ & Middle/L. Archaic & & Geomys sp. & Permanent tooth & 1 \\
\hline 21 & 9 & 503 & $\mathrm{IIlb} / \mathrm{c}$ & Middle/L. Archaic & & Geomys sp. & Ulna & 1 \\
\hline 21 & 9 & 503 & $\mathrm{mb} / \mathrm{c}$ & Middle/L. Archaic & & Leporidae & Permanent tooth & 2 \\
\hline 21 & 9 & 503 & $\mathrm{IIIb} / \mathrm{c}$ & Middle/L. Archaic & & Mammalia (Medium/large) & Indeterminate & 21 \\
\hline 21 & 9 & 503 & IIIb/c & Middle/L. Archaic & & Mammalia (Medium/large) & Long bone & 1 \\
\hline 21 & 9 & 503 & $\mathrm{IIIb} / \mathrm{c}$ & Middle/L. Archaic & & Mammalia (Medium/large) & Tooth, perm./decid. ind. & 5 \\
\hline 21 & 9 & 503 & $\mathrm{IIIb} / \mathrm{c}$ & Middle/L. Archaic & & Mammalia (Small) & Distal phalange & 1 \\
\hline 21 & 9 & 503 & $\mathrm{IIb} / \mathrm{c}$ & Middle/L. Archaic & & Mammalia (Small) & Humerus & 1 \\
\hline 21 & 9 & 503 & $\mathrm{IIb} / \mathrm{c}$ & Middle/L. Archaic & & Mammalia (Small) & Metapodial & 2 \\
\hline 21 & 9 & 503 & $\mathrm{IIIb} / \mathrm{c}$ & Middle/L. Archaic & & Mammalia (Small) & Metatarsal & 1 \\
\hline 21 & 9 & 503 & $\mathrm{IIb} / \mathrm{c}$ & Middle/L. Archaic & & Mammalia (Small) & Permanent tooth & 2 \\
\hline 21 & 9 & 503 & $\mathrm{IIb} / \mathrm{c}$ & Middle/L. Archaic & & Mammalia (Small) & Radius & 1 \\
\hline 21 & 9 & 503 & $\mathrm{IIb} / \mathrm{c}$ & Middle/L. Archaic & & Mammalia (Small/medium) & Alveolar ridge fragment & 1 \\
\hline 21 & 9 & 503 & $\mathrm{IIIb} / \mathrm{c}$ & Middle/L. Archaic & & Mammalia (Small/medium) & Vertebra & 1 \\
\hline 21 & 9 & 503 & $\mathrm{IIIb} / \mathrm{c}$ & Middle/L. Archaic & & Odocoileus sp. & Proximal phalange & 2 \\
\hline 21 & 9 & 503 & $\mathrm{IIIb} / \mathrm{c}$ & Middle/L. Archaic & & Rodentia (Medium) & Femur & 1 \\
\hline 21 & 9 & 503 & $\mathrm{IIIb} / \mathrm{c}$ & Middle/L. Archaic & & Rodentia (Medium) & Permanent tooth & 1 \\
\hline 21 & 9 & 503 & $\mathrm{IIlb} / \mathrm{c}$ & Middle/L. Archaic & & Serpentes & Dorsal vertebra & 3 \\
\hline 21 & 9 & 503 & $\mathrm{IIIb} / \mathrm{c}$ & Middle/L. Archaic & & Small vertebrate, class ind. & Vertebra & 1 \\
\hline 21 & 9 & 503 & $\mathrm{IIIb} / \mathrm{c}$ & Middle/L. Archaic & & Small/Medium Vertebrata & Long bone & 4 \\
\hline 21 & 9 & 503 & $\mathrm{IIb} / \mathrm{c}$ & Middle/L. Archaic & & Sylvilagus sp. & Metatarsal 3 & 2 \\
\hline 21 & 9 & 503 & $\mathrm{IIIlb} / \mathrm{c}$ & Middle/L. Archaic & & Sylvilagus sp. & Scapula & 1 \\
\hline 21 & 9 & 503 & $\mathrm{IIL} / \mathrm{c}$ & Middle/L. Archaic & & Vertebrata & Indeterminate & 156 \\
\hline 21 & 10 & 522 & IIIb & Middle/L. Archaic & & Artiodactyla & Tooth, perm./decid. ind. & 1 \\
\hline
\end{tabular}




\begin{tabular}{|c|c|c|c|c|c|c|c|c|}
\hline Square & Level & Lot & Unit & Cultural Affinity & Feature & Taxon & Element & No. \\
\hline 21 & 10 & 522 & IIIlb & Middle/L. Archaic & & Colubridae & Dorsal vertebra & 1 \\
\hline 21 & 10 & 522 & IIIIb & Middle/L. Archaic & & Geomys sp. & Cranium & 1 \\
\hline 21 & 10 & 522 & IIIIb & Middle/L. Archaic & & Leporidae & Permanent tooth & 1 \\
\hline 21 & 10 & 522 & IIIIb & Middle/L. Archaic & & Lepus californicus & Humerus & 2 \\
\hline 21 & 10 & 522 & IIIIb & Middle/L. Archaic & & Lepus californicus & Permanent tooth & 1 \\
\hline 21 & 10 & 522 & IIIb & Middle/L. Archaic & & Mammalia (Large) & Indeterminate & 2 \\
\hline 21 & 10 & 522 & IIIIb & Middle/L. Archaic & & Mammalia (Medium) & Distal phalange & 1 \\
\hline 21 & 10 & 522 & IIIlb & Middle/L. Archaic & & Mammalia (Medium/large) & Indeterminate & 14 \\
\hline 21 & 10 & 522 & IIIlb & Middle/L. Archaic & & Mammalia (Medium/large) & Long bone & 1 \\
\hline 21 & 10 & 522 & IIIIb & Middle/L. Archaic & & Mammalia (Small) & Distal phalange & 1 \\
\hline 21 & 10 & 522 & IIIlb & Middle/L. Archaic & & Mammalia (Small) & Epiphysis & 1 \\
\hline 21 & 10 & 522 & IIIb & Middle/L. Archaic & & Mammalia (Small) & Long bone & 1 \\
\hline 21 & 10 & 522 & IIIb & Middle/L. Archaic & & Mammalia (Small) & Permanent tooth & 2 \\
\hline 21 & 10 & 522 & IIIIb & Middle/L. Archaic & & Mammalia (Small) & Proximal phalange & 1 \\
\hline 21 & 10 & 522 & IIItb & Middle/L. Archaic & & Mammalia (Small) & Radius & 1 \\
\hline 21 & 10 & 522 & IIIIb & Middle/L. Archaic & & Neotoma sp. & Humerus & 1 \\
\hline 21 & 10 & 522 & IIIlb & Middle/L. Archaic & & Neotoma sp. & Permanent tooth & 1 \\
\hline 21 & 10 & 522 & IIIlb & Middle/L. Archaic & & Odocoileus sp. & Fused second \& third carpal & 1 \\
\hline 21 & 10 & 522 & IIIlb & Middle/L. Archaic & & Small/Medium Vertebrata & Long bone & 25 \\
\hline 21 & 10 & 522 & IIIlb & Middle/L. Archaic & & Small/Medium Vertebrata & Rib & 1 \\
\hline 21 & 10 & 522 & IIIIb & Middle/L. Archaic & & Sylvilagus sp. & Metatarsal 3 & 1 \\
\hline 21 & 10 & 522 & IIIlb & Middle/L. Archaic & & Sylvilagus sp. & Metatarsal 5 & 1 \\
\hline 21 & 10 & 522 & IIIlb & Middle/L. Archaic & & Vertebrata & Indeterminate & 175 \\
\hline 21 & 11 & 555 & IIIlb & M. Archaic & & Colubridae & Dorsal vertebra & 1 \\
\hline 21 & 11 & 555 & IIIlb & M. Archaic & & Leporidae & Cranium & 1 \\
\hline 21 & 11 & 555 & IIIIb & M. Archaic & & Leporidae & Femur & 1 \\
\hline 21 & 11 & 555 & IIIb & M. Archaic & & Leporidae & Permanent tooth & 3 \\
\hline 21 & 11 & 555 & IIIlb & M. Archaic & & Lepus californicus & Permanent tooth & 3 \\
\hline 21 & 11 & 555 & IIIlb & M. Archaic & & Mammalia (Large) & Indeterminate & 2 \\
\hline 21 & 11 & 555 & IIIlb & M. Archaic & & Mammalia (Large) & Long bone & 1 \\
\hline 21 & 11 & 555 & IIIlb & M. Archaic & & Mammalia (Medium) & Tarsal & 1 \\
\hline 21 & 11 & 555 & IIIlb & M. Archaic & & Mammalia (Medium/large) & Indeterminate & 5 \\
\hline 21 & 11 & 555 & IIIb & M. Archaic & & Mammalia (Medium/large) & Long bone & 4 \\
\hline 21 & 11 & 555 & IIIlb & M. Archaic & & Mammalia (Medium/large) & Tooth, perm./decid. ind. & 1 \\
\hline 21 & 11 & 555 & IIIlb & M. Archaic & & Mammalia (Micro) & Calcaneus & 1 \\
\hline 21 & 11 & 555 & IIIlb & M. Archaic & & Mammalia (Small) & Permanent tooth & 1 \\
\hline 21 & 11 & 555 & IIIb & M. Archaic & & Rodentia (Small) & Permanent tooth & 1 \\
\hline 21 & 11 & 555 & IIIb & M. Archaic & & Small vertebrate, class ind. & Phalange & 1 \\
\hline 21 & 11 & 555 & IIIlb & M. Archaic & & Small/Medium Vertebrata & Long bone & 14 \\
\hline 21 & 11 & 555 & IIIb & M. Archaic & & Vertebrata & Indeterminate & 69 \\
\hline 21 & 12 & 584 & IIIlb & M. Archaic & & Leporidae & Permanent tooth & 4 \\
\hline 21 & 12 & 584 & IIIlb & M. Archaic & & Leporidae & Scapula & 1 \\
\hline 21 & 12 & 584 & IIIb & M. Archaic & & Mammalia (Large) & Long bone & 1 \\
\hline 21 & 12 & 584 & IIIlb & M. Archaic & & Mammalia (Large) & Vertebra & 1 \\
\hline 21 & 12 & 584 & IIIlb & M. Archaic & & Mammalia (Medium/large) & Indeterminate & 4 \\
\hline 21 & 12 & 584 & IIIlb & M. Archaic & & Mammalia (Medium/large) & Tooth, perm./decid. ind. & 4 \\
\hline 21 & 12 & 584 & IIIlb & M. Archaic & & Mammalia (Small) & Phalange & 1 \\
\hline 21 & 12 & 584 & IIIb & M. Archaic & & Neotoma sp. & Permanent tooth & 1 \\
\hline 21 & 12 & 584 & IIIb & M. Archaic & & Serpentes & Dorsal vertebra & 1 \\
\hline 21 & 12 & 584 & IIIlb & M. Archaic & & Small/Medium Vertebrata & Long bone & 9 \\
\hline 21 & 12 & 584 & IIIlb & M. Archaic & & Sylvilagus sp. & Calcaneus & 1 \\
\hline 21 & 12 & 584 & IIIb & M. Archaic & & Vertebrata & Indeterminate & 68 \\
\hline 21 & 13 & 594 & IIIlb & M. Archaic & & Mammalia (Large) & Indeterminate & 1 \\
\hline 21 & 13 & 594 & IIIlb & M. Archaic & & Mammalia (Medium/large) & Indeterminate & 2 \\
\hline 21 & 13 & 594 & IIIb & M. Archaic & & Medium/Large Vertebrata & Indeterminate & 2 \\
\hline 21 & 13 & 594 & IIIb & M. Archaic & & Osteichthyes & Dental bearing element & 1 \\
\hline 21 & 13 & 594 & IIIlb & M. Archaic & & Small/Medium Vertebrata & Long bone & 9 \\
\hline 21 & 13 & 594 & IIIlb & M. Archaic & & Vertebrata & Indeterminate & 15 \\
\hline 21 & 14 & 649 & IIIb & M. Archaic & & cf. Geomys sp. & Cranium & 1 \\
\hline 21 & 14 & 649 & IIIlb & M. Archaic & & Geomys sp. & Permanent tooth & 1 \\
\hline 21 & 14 & 649 & IIIlb & M. Archaic & & Mammalia (Medium/large) & Indeterminate & 4 \\
\hline 21 & 14 & 649 & IIIlb & M. Archaic & & Mammalia (Medium/large) & Long bone & 1 \\
\hline 21 & 14 & 649 & IIIlb & M. Archaic & & Mammalia (Medium/large) & Tooth, perm./decid. ind. & 1 \\
\hline 21 & 14 & 649 & IIIlb & M. Archaic & & Rodentia (Medium) & Permanent tooth & 1 \\
\hline 21 & 14 & 649 & IIIlb & M. Archaic & & Serpentes & Dorsal vertebra & 1 \\
\hline 21 & 14 & 649 & IIIb & M. Archaic & & Small/Medium Vertebrata & Long bone & 2 \\
\hline 21 & 14 & 649 & IIIb & M. Archaic & & Sylvilagus sp. & Radius & 1 \\
\hline
\end{tabular}




\begin{tabular}{|c|c|c|c|c|c|c|c|c|}
\hline Square & Level & Lot & Unit & Cultural Affinity & Feature & Taxon & Element & No. \\
\hline 21 & 14 & 649 & $\overline{\mathrm{IIb}}$ & M. Archaic & & Vertebrata & Indeterminate & 14 \\
\hline 22 & 4 & 179 & FILL & Unassigned & & Mammalia (Medium/large) & Indeterminate & 2 \\
\hline 22 & 5 & 183 & IIIc/FILL & Unassigned & & Antilocapra/Odocoileus & Calcaneus & 1 \\
\hline 22 & 5 & 208 & IIIc/FILL & Unassigned & & Artiodactyla & Tooth, perm./decid. ind. & 2 \\
\hline 22 & 5 & 208 & IIIc/FILL & Unassigned & & Mammalia (Large) & Indeterminate & 1 \\
\hline 22 & 5 & 208 & IIII/FILL & Unassigned & & Mammalia (Large) & Long bone & 1 \\
\hline 22 & 5 & 208 & IIIc/FILL & Unassigned & & Mammalia (Large) & Vertebra & 1 \\
\hline 22 & 5 & 208 & IIIc/FILL & Unassigned & & Mammalia (Medium/large) & Epiphysis & 1 \\
\hline 22 & 5 & 208 & IIII/FILL & Unassigned & & Mammalia (Medium/large) & Indeterminate & 23 \\
\hline 22 & 5 & 208 & IIIc/FILL & Unassigned & & Mammalia (Medium/large) & Tooth, perm./decid. ind. & 3 \\
\hline 22 & 5 & 208 & IIIc/FILL & Unassigned & & Odocoileus sp. & Tooth, perm./decid. ind. & 1 \\
\hline 22 & 5 & 208 & IIII/FILL & Unassigned & & Small/Medium Vertebrata & Long bone & 4 \\
\hline 22 & 5 & 208 & III $/$ FILL & Unassigned & & Vertebrata & Indeterminate & 61 \\
\hline 22 & 6 & 226 & |IIIc & L. Archaic & & Artiodactyla & Tooth, perm./decid. ind. & 13 \\
\hline 22 & 6 & 226 & IIIIc & L. Archaic & & cf. Leporidae & Lumbar vertebra & 1 \\
\hline 22 & 6 & 226 & IIIC & L. Archaic & & Mammalia (Medium/large) & Indeterminate & 28 \\
\hline 22 & 6 & 226 & IIIC & L. Archaic & & Mammalia (Medium/large) & Long bone & 1 \\
\hline 22 & 6 & 226 & IIIIc & L. Archaic & & Mammalia (Small/medium) & Alveolar ridge fragment & 1 \\
\hline 22 & 6 & 226 & IIIC & L. Archaic & & Small/Medium Vertebrata & Long bone & 5 \\
\hline 22 & 6 & 226 & IIII & L. Archaic & & Sylvilagus sp. & Permanent tooth & 1 \\
\hline 22 & 6 & 226 & IIIIc & L. Archaic & & Vertebrata & Indeterminate & 120 \\
\hline 22 & 6 & 233 & IIIIc & L. Archaic & & Mammalia (Large) & Femur & 1 \\
\hline 22 & 7 & 286 & IIII & L. Archaic & & Leporidae & Mandible & 1 \\
\hline 22 & 7 & 286 & IIIIc & L. Archaic & & Lepus californicus & Patella & 1 \\
\hline 22 & 7 & 286 & IIII & L. Archaic & & Lepus californicus & Permanent tooth & 1 \\
\hline 22 & 7 & 286 & IIIc & L. Archaic & & Mammalia (Large) & Long bone & 1 \\
\hline 22 & 7 & 286 & IIIIc & L. Archaic & & Mammalia (Medium/large) & Indeterminate & 24 \\
\hline 22 & 7 & 286 & IIII & L. Archaic & & Mammalia (Medium/large) & Tooth, perm./decid. ind. & 7 \\
\hline 22 & 7 & 286 & IIIc & L. Archaic & & Mammalia (Medium/large) & Vertebra & 1 \\
\hline 22 & 7 & 286 & IIIIc & L. Archaic & & Mammalia (Small) & Alveolar ridge fragment & 1 \\
\hline 22 & 7 & 286 & IIII & L. Archaic & & Neotoma sp. & Humerus & 1 \\
\hline 22 & 7 & 286 & IIIlc & L. Archaic & & Odocoileus sp. & Tooth, perm./decid. ind. & 2 \\
\hline 22 & 7 & 286 & IIIlc & L. Archaic & & Serpentes & Dorsal vertebra & 1 \\
\hline 22 & 7 & 286 & IIII & L. Archaic & & Small/Medium Vertebrata & Long bone & 14 \\
\hline 22 & 7 & 286 & IIII & L. Archaic & & Sylvilagus sp. & Permanent tooth & 1 \\
\hline 22 & 7 & 286 & IIIIc & L. Archaic & & Vertebrata & Indeterminate & 353 \\
\hline 22 & 7 & 328 & IIII & L. Archaic & & Mammalia (Medium/large) & Indeterminate & 2 \\
\hline 22 & 7 & 331 & IIIc & L. Archaic & & Mammalia (Large) & Indeterminate & 1 \\
\hline 22 & $7-10$ & 650 & IIIIc & L. Archaic & & Mammalia (Large) & Indeterminate & 1 \\
\hline 22 & $7-10$ & 650 & IIII & L. Archaic & & Mammalia (Large) & Long bone & 1 \\
\hline 22 & $7-10$ & 650 & IIII & L. Archaic & & Mammalia (Medium/large) & Indeterminate & 1 \\
\hline 22 & $7-10$ & 650 & IIIIc & L. Archaic & & Medium/Large Vertebrata & Indeterminate & 3 \\
\hline 22 & $7-10$ & 650 & IIIc & L. Archaic & & Small/Medium Vertebrata & Long bone & 1 \\
\hline 22 & $7-10$ & 650 & IIIIc & L. Archaic & & Vertebrata & Indeterminate & 7 \\
\hline 22 & 8 & 399 & $\mathrm{IIIb} / \mathrm{c}$ & L. Archaic & 205 & Antilocapra americana & Permanent tooth & 1 \\
\hline 22 & 8 & 399 & $\mathrm{IIIb} / \mathrm{c}$ & L. Archaic & 205 & Leporidae & Permanent tooth & 1 \\
\hline 22 & 8 & 399 & $\mathrm{milb} / \mathrm{c}$ & L. Archaic & 205 & Mammalia (Medium/large) & Indeterminate & 24 \\
\hline 22 & 8 & 399 & $\mathrm{IIIIb} / \mathrm{c}$ & L. Archaic & 205 & Mammalia (Medium/large) & Long bone & 1 \\
\hline 22 & 8 & 399 & IIIIb/c & L. Archaic & 205 & Mammalia (Medium/large) & Tooth, perm./decid. ind. & 6 \\
\hline 22 & 8 & 399 & $\mathrm{mb} / \mathrm{c}$ & L. Archaic & 205 & Mammalia (Small) & Radius & 1 \\
\hline 22 & 8 & 399 & $\mathrm{IIIb} / \mathrm{c}$ & L. Archaic & 205 & Mammalia (Small/medium) & Metapodial & 1 \\
\hline 22 & 8 & 399 & $\mathrm{IIIb} / \mathrm{c}$ & L. Archaic & 205 & Mammalia (Small/medium) & Permanent tooth & 1 \\
\hline 22 & 8 & 399 & $\mathrm{milm} / \mathrm{c}$ & L. Archaic & 205 & Mammalia (Small/medium) & Proximal phalange & 1 \\
\hline 22 & 8 & 399 & $\mathrm{IIIIb} / \mathrm{c}$ & L. Archaic & 205 & Odocoileus sp. & Tooth, perm./decid. ind. & 2 \\
\hline 22 & 8 & 399 & IIIIb/c & L. Archaic & 205 & Rodentia & Permanent tooth & 1 \\
\hline 22 & 8 & 399 & $\mathrm{mb} / \mathrm{c}$ & L. Archaic & 205 & Small/Medium Vertebrata & Long bone & 17 \\
\hline 22 & 8 & 399 & $\mathrm{IIIT} / \mathrm{c}$ & L. Archaic & 205 & Vertebrata & Indeterminate & 283 \\
\hline 22 & 8 & 428 & IIIb/c & L. Archaic & 205 & Mammalia (Large) & Indeterminate & 2 \\
\hline 22 & 8 & 428 & $\mathrm{mb} / \mathrm{c}$ & L. Archaic & 205 & Odocoileus sp. & Middle phalange & 1 \\
\hline 22 & 8 & 428 & $\mathrm{IIIb} / \mathrm{c}$ & L. Archaic & 205 & Odocoileus sp. & Permanent tooth & 1 \\
\hline 22 & $8-10$ & 2183 & $\mathrm{IIIb} / \mathrm{c}$ & Middle/L. Archaic & & Artiodactyla & Tooth, perm./decid. ind. & 2 \\
\hline 22 & $8-10$ & 2183 & $\mathrm{mb} / \mathrm{c}$ & Middle/L. Archaic & & Lepus californicus & Permanent tooth & 1 \\
\hline 22 & $8-10$ & 2183 & $\mathrm{IIIb} / \mathrm{c}$ & Middle/L. Archaic & & Small/Medium Vertebrata & Long bone & 1 \\
\hline 22 & $8-10$ & 2183 & $\mathrm{IIIIb} / \mathrm{c}$ & Middle/L. Archaic & & Vertebrata & Indeterminate & 12 \\
\hline 22 & $8 \mathrm{~B}$ & 404 & $\mathrm{IIIb} / \mathrm{c}$ & L. Archaic & 205 & Antilocapra/Odocoileus & Ulna & 1 \\
\hline 22 & $8 \mathrm{~B}$ & 404 & $\mathrm{mim} / \mathrm{c}$ & L. Archaic & 205 & Mammalia (Medium/large) & Long bone & 1 \\
\hline 22 & $9 \mathrm{~A}$ & 521 & IIIIb/c & Middle/L. Archaic & & Antilocapra/Odocoileus & Axis & 1 \\
\hline
\end{tabular}




\begin{tabular}{|c|c|c|c|c|c|c|c|c|}
\hline Square & Level & Lot & Unit & Cultural Affinity & Feature & Taxon & Element & No. \\
\hline 22 & $9 \mathrm{~A}$ & 521 & IIIb/c & Middle/L. Archaic & & Colubridae & Dorsal vertebra & 1 \\
\hline 22 & $9 \mathrm{~A}$ & 521 & $\mathrm{IITb} / \mathrm{c}$ & Middle/L. Archaic & & Leporidae & Astragalus & 1 \\
\hline 22 & $9 \mathrm{~A}$ & 521 & $\mathrm{IIIb} / \mathrm{c}$ & Middle/L. Archaic & & Leporidae & Permanent tooth & 2 \\
\hline 22 & $9 \mathrm{~A}$ & 521 & $\mathrm{IITb} / \mathrm{c}$ & Middle/L. Archaic & & Leporidae & Scapula & 1 \\
\hline 22 & $9 \mathrm{~A}$ & 521 & $\mathrm{IIIb} / \mathrm{c}$ & Middle/L. Archaic & & Lepus californicus & Third tarsal & 1 \\
\hline 22 & $9 \mathrm{~A}$ & 521 & $\mathrm{IIlb} / \mathrm{c}$ & Middle/L. Archaic & & Mammalia (Large) & Long bone & 2 \\
\hline 22 & $9 \mathrm{~A}$ & 521 & $\mathrm{IIIb} / \mathrm{c}$ & Middle/L. Archaic & & Mammalia (Medium/large) & Indeterminate & 18 \\
\hline 22 & $9 \mathrm{~A}$ & 521 & $\mathrm{IIIb} / \mathrm{c}$ & Middle/L. Archaic & & Mammalia (Medium/large) & Tooth, perm./decid. ind. & 5 \\
\hline 22 & $9 \mathrm{~A}$ & 521 & $\mathrm{IIIb} / \mathrm{c}$ & Middle/L. Archaic & & Mammalia (Small) & Metapodial & 1 \\
\hline 22 & $9 \mathrm{~A}$ & 521 & $\mathrm{IIIb} / \mathrm{c}$ & Middle/L. Archaic & & Mammalia (Small) & Permanent tooth & 3 \\
\hline 22 & $9 \mathrm{~A}$ & 521 & $\mathrm{IIIb} / \mathrm{c}$ & Middle/L. Archaic & & Mammalia (Small/medium) & Phalange & 1 \\
\hline 22 & $9 \mathrm{~A}$ & 521 & $\mathrm{IIIb} / \mathrm{c}$ & Middle/L. Archaic & & Micro vertebrate, class ind. & Mandible & 1 \\
\hline 22 & $9 \mathrm{~A}$ & 521 & $\mathrm{IIIb} / \mathrm{c}$ & Middle/L. Archaic & & Serpentes & Dorsal vertebra & 1 \\
\hline 22 & $9 \mathrm{~A}$ & 521 & $\mathrm{IIIb} / \mathrm{c}$ & Middle/L. Archaic & & Small/Medium Vertebrata & Long bone & 3 \\
\hline 22 & $9 \mathrm{~A}$ & 521 & $\mathrm{IIIb} / \mathrm{c}$ & Middle/L. Archaic & & Sylvilagus sp. & Humerus & 1 \\
\hline 22 & $9 \mathrm{~A}$ & 521 & $\mathrm{IIIb} / \mathrm{c}$ & Middle/L. Archaic & & Sylvilagus sp. & Metatarsal 3 & 1 \\
\hline 22 & $9 \mathrm{~A}$ & 521 & $\mathrm{IIIb} / \mathrm{c}$ & Middle/L. Archaic & & Vertebrata & Indeterminate & 136 \\
\hline 22 & 9B & 558 & $\mathrm{IIIb} / \mathrm{c}$ & Middle/L. Archaic & 210 & Leporidae & Permanent tooth & 1 \\
\hline 22 & 9B & 558 & $\mathrm{IIb} / \mathrm{c}$ & Middle/L. Archaic & 210 & Mammalia (Large) & Vertebra & 1 \\
\hline 22 & 9B & 558 & $\mathrm{IIIb} / \mathrm{c}$ & Middle/L. Archaic & 210 & Medium/Large Vertebrata & Indeterminate & 3 \\
\hline 22 & 9B & 558 & $\mathrm{IIIb} / \mathrm{c}$ & Middle/L. Archaic & 210 & Serpentes & Dorsal vertebra & 1 \\
\hline 22 & $9 \mathrm{~B}$ & 558 & $\mathrm{IIIb} / \mathrm{c}$ & Middle/L. Archaic & 210 & Vertebrata & Indeterminate & 20 \\
\hline 22 & $10 \mathrm{~A}$ & 538 & IIIb & Middle/L. Archaic & & Colubridae & Dorsal vertebra & 2 \\
\hline 22 & $10 \mathrm{~A}$ & 538 & IIIb & Middle/L. Archaic & & Mammalia (Medium/large) & Indeterminate & 6 \\
\hline 22 & $10 \mathrm{~A}$ & 538 & IIIb & Middle/L. Archaic & & Mammalia (Medium/large) & Long bone & 2 \\
\hline 22 & $10 \mathrm{~A}$ & 538 & IIIb & Middle/L. Archaic & & Mammalia (Medium/large) & Tooth, perm./decid. ind. & 4 \\
\hline 22 & $10 \mathrm{~A}$ & 538 & IIIb & Middle/L. Archaic & & Mammalia (Micro) & Permanent tooth & 2 \\
\hline 22 & $10 \mathrm{~A}$ & 538 & IIIb & Middle/L. Archaic & & Mammalia (Micro) & Tibia & 1 \\
\hline 22 & $10 \mathrm{~A}$ & 538 & IIIb & Middle/L. Archaic & & Mammalia (Small) & Alveolar ridge fragment & 2 \\
\hline 22 & $10 \mathrm{~A}$ & 538 & IIIb & Middle/L. Archaic & & Mammalia (Small) & Mandible & 2 \\
\hline 22 & $10 \mathrm{~A}$ & 538 & IIIb & Middle/L. Archaic & & Mammalia (Small) & Tarsal & 1 \\
\hline 22 & $10 \mathrm{~A}$ & 538 & IIIb & Middle/L. Archaic & & Neotoma sp. & Permanent tooth & 1 \\
\hline 22 & $10 \mathrm{~A}$ & 538 & IIIb & Middle/L. Archaic & & Serpentes & Dorsal vertebra & 1 \\
\hline 22 & $10 \mathrm{~A}$ & 538 & IIIb & Middle/L. Archaic & & Small/Medium Vertebrata & Long bone & 12 \\
\hline 22 & $10 \mathrm{~A}$ & 538 & IIIb & Middle/L. Archaic & & Sylvilagus sp. & Metacarpal 2 & 1 \\
\hline 22 & $10 \mathrm{~A}$ & 538 & IIIb & Middle/L. Archaic & & Sylvilagus sp. & Permanent tooth & 2 \\
\hline 22 & $10 \mathrm{~A}$ & 538 & IIIb & Middle/L. Archaic & & Sylvilagus sp. & Scapula & 1 \\
\hline 22 & $10 \mathrm{~A}$ & 538 & IIIb & Middle/L. Archaic & & Testudinata & Shell fragment & 4 \\
\hline 22 & $10 \mathrm{~A}$ & 538 & IIIb & Middle/L. Archaic & & Vertebrata & Indeterminate & 147 \\
\hline 22 & $10 \mathrm{~B}$ & 566 & IIIb & Middle/L. Archaic & 210 & Leporidae & Permanent tooth & 1 \\
\hline 22 & $10 \mathrm{~B}$ & 566 & IIIb & Middle/L. Archaic & 210 & Lepus californicus & Permanent tooth & 1 \\
\hline 22 & 10B & 566 & IIIb & Middle/L. Archaic & 210 & Mammalia (Small) & Metapodial & 1 \\
\hline 22 & 10B & 566 & IIIb & Middle/L. Archaic & 210 & Medium/Large Vertebrata & Indeterminate & 1 \\
\hline 22 & $10 \mathrm{~B}$ & 566 & IIIb & Middle/L. Archaic & 210 & Small/Medium Vertebrata & Long bone & 10 \\
\hline 22 & $10 \mathrm{~B}$ & 566 & IIIb & Middle/L. Archaic & 210 & Sylvilagus sp. & Metatarsal 3 & 1 \\
\hline 22 & $10 \mathrm{~B}$ & 566 & IIIb & Middle/L. Archaic & 210 & Vertebrata & Indeterminate & 43 \\
\hline 22 & 11 & 572 & IIIb & M. Archaic & & Artiodactyla & Tooth, perm./decid. ind. & 1 \\
\hline 22 & 11 & 572 & IIIb & M. Archaic & & Chrysemys sensu lato & Peripheral & 1 \\
\hline 22 & 11 & 572 & IIIb & M. Archaic & & Colubridae & Dorsal vertebra & 1 \\
\hline 22 & 11 & 572 & IIIb & M. Archaic & & Geomys sp. & Permanent tooth & 1 \\
\hline 22 & 11 & 572 & IIIb & M. Archaic & & Leporidae & Permanent tooth & 2 \\
\hline 22 & 11 & 572 & IIIb & M. Archaic & & Lepus californicus & Permanent tooth & 1 \\
\hline 22 & 11 & 572 & IIIb & M. Archaic & & Mammalia (Medium/large) & Indeterminate & 12 \\
\hline 22 & 11 & 572 & IIIb & M. Archaic & & Mammalia (Medium/large) & Permanent tooth & 1 \\
\hline 22 & 11 & 572 & IIIb & M. Archaic & & Mammalia (Small/medium) & Middle phalange & 1 \\
\hline 22 & 11 & 572 & IIIb & M. Archaic & & Mammalia (Small/medium) & Phalange & 1 \\
\hline 22 & 11 & 572 & IIIb & M. Archaic & & Serpentes & Dorsal vertebra & 3 \\
\hline 22 & 11 & 572 & IIIb & M. Archaic & & Small/Medium Vertebrata & Distal phalange & 1 \\
\hline 22 & 11 & 572 & IIIb & M. Archaic & & Small/Medium Vertebrata & Phalange & 1 \\
\hline 22 & 11 & 572 & IIIb & M. Archaic & & Sylvilagus sp. & Femur & 1 \\
\hline 22 & 11 & 572 & IIIb & M. Archaic & & Sylvilagus sp. & Metacarpal 2 & 1 \\
\hline 22 & 11 & 572 & IIIb & M. Archaic & & Sylvilagus sp. & Permanent tooth & 2 \\
\hline 22 & 11 & 572 & IIIb & M. Archaic & & Vertebrata & Indeterminate & 208 \\
\hline 22 & $12 \mathrm{~A}$ & 610 & IIIb & M. Archaic & & Mammalia (Medium/large) & Indeterminate & 7 \\
\hline 22 & $12 \mathrm{~A}$ & 610 & IIIb & M. Archaic & & Mammalia (Medium/large) & Long bone & 3 \\
\hline 22 & $12 \mathrm{~A}$ & 610 & IIIb & M. Archaic & & Mammalia (Medium/large) & Tooth, perm./decid. ind. & 3 \\
\hline 22 & $12 \mathrm{~A}$ & 610 & IIIb & M. Archaic & & Mammalia (Small/medium) & Patella & 1 \\
\hline
\end{tabular}




\begin{tabular}{|c|c|c|c|c|c|c|c|c|}
\hline Square & Level & \begin{tabular}{|l|l|} 
Lot \\
\end{tabular} & Unit & \begin{tabular}{|l} 
Cultural Affinity \\
\end{tabular} & Feature & Taxon & Element & No. \\
\hline 22 & $12 \mathrm{~A}$ & 610 & III) & M. Archaic & & Medium/Large Vertebrata & Indeterminate & 3 \\
\hline 22 & $12 \mathrm{~A}$ & 610 & IIIlb & M. Archaic & & Small/Medium Vertebrata & Long bone & 9 \\
\hline 22 & $12 \mathrm{~A}$ & 610 & IIIlb & M. Archaic & & Sylvilagus sp. & Permanent tooth & 3 \\
\hline 22 & $12 \mathrm{~A}$ & 610 & IIIb & M. Archaic & & Sylvilagus sp. & Ulna & 1 \\
\hline 22 & $12 \mathrm{~A}$ & 610 & IIIIb & M. Archaic & & Testudinata & Shell fragment & 2 \\
\hline 22 & $12 \mathrm{~A}$ & 610 & IIIb & M. Archaic & & Vertebrata & Indeterminate & 65 \\
\hline 22 & 13 & 644 & IIIb & M. Archaic & & Mammalia (Medium/large) & Indeterminate & 8 \\
\hline 22 & 13 & 644 & IIIIb & M. Archaic & & Mammalia (Medium/large) & Long bone & 2 \\
\hline 22 & 13 & 644 & IIIb & M. Archaic & & Small/Medium Vertebrata & Long bone & 6 \\
\hline 22 & 13 & 644 & IIIb & M. Archaic & & Vertebrata & Indeterminate & 19 \\
\hline 22 & 14 & 675 & IIIIb & M. Archaic & & Geomys sp. & Permanent tooth & 2 \\
\hline 22 & 14 & 675 & IIIb & M. Archaic & & Mammalia (Medium/large) & Indeterminate & 16 \\
\hline 22 & 14 & 675 & IIIb & M. Archaic & & Mammalia (Medium/large) & Long bone & 1 \\
\hline 22 & 14 & 675 & IIIlb & M. Archaic & & Mammalia (Micro) & Long bone & 1 \\
\hline 22 & 14 & 675 & IIIb & M. Archaic & & Mammalia (Micro) & Permanent tooth & 2 \\
\hline 22 & 14 & 675 & IIIb & M. Archaic & & Small/Medium Vertebrata & Long bone & 8 \\
\hline 22 & 14 & 675 & IIIIb & M. Archaic & & Sylvilagus sp. & Metatarsal 2 & 1 \\
\hline 22 & 14 & 675 & IIIlb & M. Archaic & & Sylvilagus sp. & Ulna & 1 \\
\hline 22 & 14 & 675 & IIIb & M. Archaic & & Testudinata & Shell fragment & 1 \\
\hline 22 & 14 & 675 & IIIIb & M. Archaic & & Vertebrata & Indeterminate & 44 \\
\hline 25 & 14 & 697 & IIIb & M. Archaic & & Geomys sp. & Permanent tooth & 1 \\
\hline 25 & 14 & 697 & IIIIb & M. Archaic & & Mammalia (Medium/large) & Long bone & 1 \\
\hline 25 & 14 & 697 & IIIIb & M. Archaic & & Neotoma $\mathrm{sp}$. & Permanent tooth & 1 \\
\hline 25 & 14 & 697 & IIIlb & M. Archaic & & Odocoileus sp. & Middle phalange & 1 \\
\hline 25 & 14 & 697 & IIIlb & M. Archaic & & Small/Medium Vertebrata & Long bone & 4 \\
\hline 25 & 14 & 697 & IIIIb & M. Archaic & & Vertebrata & Indeterminate & 41 \\
\hline 25 & 15 & 724 & IIIb & Early/M. Archaic & & Leporidae & Permanent tooth & 1 \\
\hline 25 & 15 & 724 & IIIIb & Early/M. Archaic & & Mammalia (Small) & Epiphysis & 1 \\
\hline 25 & 15 & 724 & IIIIb & Early/M. Archaic & & Medium/Large Vertebrata & Indeterminate & 1 \\
\hline 25 & 15 & 724 & IIIb & Early/M. Archaic & & Rodentia (Small/Medium) & Permanent tooth & 2 \\
\hline 25 & 15 & 724 & IIIIb & Early/M. Archaic & & Small vertebrate, class ind. & Phalange & 1 \\
\hline 25 & 15 & 724 & IIIlb & Early/M. Archaic & & Small/Medium Vertebrata & Long bone & 6 \\
\hline 25 & 15 & 724 & IIIIb & Early/M. Archaic & & Vertebrata & Indeterminate & 40 \\
\hline 25 & 16 & 748 & IIIIb & Early/M. Archaic & & Mammalia (Medium/large) & Indeterminate & 2 \\
\hline 25 & 16 & 748 & IIIb & Early/M. Archaic & & Mammalia (Small) & Permanent tooth & 1 \\
\hline 25 & 16 & 748 & IIIb & Early/M. Archaic & & Small/Medium Vertebrata & Long bone & 1 \\
\hline 25 & 16 & 748 & IIItb & Early/M. Archaic & & Testudinata & Carapace fragment ind. & 1 \\
\hline 25 & 16 & 748 & IIIlb & Early/M. Archaic & & Testudinata & Shell fragment & 1 \\
\hline 25 & 16 & 748 & IIIb & Early/M. Archaic & & Vertebrata & Indeterminate & 23 \\
\hline 25 & 17 & 481 & IIIIb & Early/M. Archaic & & Mammalia (Medium/large) & Indeterminate & 1 \\
\hline 25 & 17 & 481 & IIlb & Early/M. Archaic & & Testudinata & Carapace fragment ind. & 1 \\
\hline 25 & 17 & 481 & IIIb & Early/M. Archaic & & Vertebrata & Indeterminate & 6 \\
\hline 25 & 18 & 823 & IIIb & Early/M. Archaic & & Vertebrata & Indeterminate & 7 \\
\hline 25 & 19 & 848 & Ша/b & E. Archaic & & Mammalia (Medium/large) & Indeterminate & 1 \\
\hline 25 & 19 & 848 & IIIa/b & E. Archaic & & Vertebrata & Indeterminate & 8 \\
\hline 25 & 20 & 871 & IIIa/b & E. Archaic & & Medium/Large Vertebrata & Indeterminate & 2 \\
\hline 25 & 20 & 871 & Ша/b & E. Archaic & & Small/Medium Vertebrata & Long bone & 2 \\
\hline 25 & 20 & 871 & IIIa/b & E. Archaic & & Vertebrata & Indeterminate & 6 \\
\hline 25 & 21 & 909 & IIIIa & E. Archaic & & Small/Medium Vertebrata & Long bone & 2 \\
\hline 25 & 21 & 909 & Ша & E. Archaic & & Vertebrata & Indeterminate & 12 \\
\hline 25 & 22 & 924 & III & E. Archaic & & Leporidae & Calcaneus & 1 \\
\hline 25 & 22 & 924 & IIIIa & E. Archaic & & Mammalia (Micro) & Femur & 1 \\
\hline 25 & 22 & 924 & ШШа & E. Archaic & & Medium/Large Vertebrata & Indeterminate & 3 \\
\hline 25 & 22 & 924 & IIIa & E. Archaic & & Small vertebrate, class ind. & Phalange & 1 \\
\hline 25 & 22 & 924 & IIIIa & E. Archaic & & Small/Medium Vertebrata & Long bone & 4 \\
\hline 25 & 22 & 924 & ШШа & E. Archaic & & Squamata & Dorsal vertebra & 1 \\
\hline 25 & 22 & 924 & IIIa & E. Archaic & & Vertebrata & Indeterminate & 24 \\
\hline 25 & 24 & 978 & IIIIa & E. Archaic & & Geomys sp. & Permanent tooth & 1 \\
\hline 25 & 24 & 978 & III & E. Archaic & & Mammalia (Medium/large) & Long bone & 1 \\
\hline 25 & 24 & 978 & IШа & E. Archaic & & Small/Medium Vertebrata & Long bone & 11 \\
\hline 25 & 24 & 978 & IIIIa & E. Archaic & & Vertebrata & Indeterminate & 46 \\
\hline 25 & 25 & 1040 & III & E. Archaic & & Lepus californicus & Tibia & 1 \\
\hline 25 & 25 & 1040 & ШШа & E. Archaic & & Mammalia (Medium) & Proximal phalange & 1 \\
\hline 25 & 25 & 1040 & IIIa & E. Archaic & & Mammalia (Small) & Permanent tooth & 1 \\
\hline 25 & 25 & 1040 & ШШа & E. Archaic & & Medium/Large Vertebrata & Indeterminate & 2 \\
\hline 25 & 25 & 1040 & IIIIa & E. Archaic & & Small/Medium Vertebrata & Long bone & 6 \\
\hline 25 & 25 & 1040 & IIIIa & E. Archaic & & Vertebrata & Indeterminate & 19 \\
\hline
\end{tabular}




\begin{tabular}{|c|c|c|c|c|c|c|c|c|}
\hline Square & Level & Lot & Unit & Cultural Affinity & Feature & Taxon & Element & No. \\
\hline$\frac{1}{25}$ & 26 & 1161 & $\bar{\pi} / \mathrm{IIIa}$ & L. Paleo./E. Archaic & & Geomys sp. & Permanent tooth & 1 \\
\hline 25 & 26 & 1161 & III/IIIa & L. Paleo./E. Archaic & & Leporidae & Permanent tooth & 2 \\
\hline 25 & 26 & 1161 & II/IIIa & L. Paleo./E. Archaic & & Mammalia (Medium) & Astragalus & 1 \\
\hline 25 & 26 & 1161 & III/IIIa & L. Paleo./E. Archaic & & Mammalia (Medium/large) & Long bone & 3 \\
\hline 25 & 26 & 1161 & III/IIIa & L. Paleo./E. Archaic & & Mammalia (Medium/large) & Tooth, perm./decid. ind. & 1 \\
\hline 25 & 26 & 1161 & II/IIIa & L. Paleo./E. Archaic & & Mammalia (Small) & Distal phalange & 2 \\
\hline 25 & 26 & 1161 & II/IIIIa & L. Paleo./E. Archaic & & Mammalia (Small) & Proximal phalange & 1 \\
\hline 25 & 26 & 1161 & II/IIIa & L. Paleo./E. Archaic & & Medium/Large Vertebrata & Indeterminate & 2 \\
\hline 25 & 26 & 1161 & II/IIIa & L. Paleo./E. Archaic & & Small/Medium Vertebrata & Long bone & 16 \\
\hline 25 & 26 & 1161 & II/IIIa & L. Paleo./E. Archaic & & Testudinata & Shell fragment & 3 \\
\hline 25 & 26 & 1161 & IIIIIIIa & L. Paleo./E. Archaic & & Vertebrata & Indeterminate & 60 \\
\hline 25 & 27 & 1196 & II/IIIIa & L. Paleo./E. Archaic & & Mammalia (Medium/large) & Indeterminate & 2 \\
\hline 25 & 27 & 1196 & II/IIIIa & L. Paleo./E. Archaic & & Mammalia (Medium/large) & Long bone & 1 \\
\hline 25 & 27 & 1196 & III/IIIa & L. Paleo./E. Archaic & & Mammalia (Small) & Caudal vertebra & 1 \\
\hline 25 & 27 & 1196 & II/IIIIa & L. Paleo./E. Archaic & & Mammalia (Small) & Pelvis & 1 \\
\hline 25 & 27 & 1196 & II/IIIIa & L. Paleo./E. Archaic & & Mammalia (Small) & Permanent tooth & 1 \\
\hline 25 & 27 & 1196 & IIIIIa & L. Paleo./E. Archaic & & Mammalia micro/small & Calcaneus & 1 \\
\hline 25 & 27 & 1196 & III/IIIa & L. Paleo./E. Archaic & & Mammalia micro/small & Permanent tooth & 1 \\
\hline 25 & 27 & 1196 & II/IIIIa & L. Paleo./E. Archaic & & Small/Medium Vertebrata & Long bone & 13 \\
\hline 25 & 27 & 1196 & II/IIIIa & L. Paleo./E. Archaic & & Testudinata & Carapace fragment ind. & 1 \\
\hline 25 & 27 & 1196 & IIIIIIa & L. Paleo./E. Archaic & & Vertebrata & Indeterminate & 34 \\
\hline 25 & 27 & 1196 & II/IIIa & L. Paleo./E. Archaic & & Viperidae & Dorsal vertebra & 1 \\
\hline 25 & 28 & 1236 & II/IIIa & L. Paleo./E. Archaic & & Colubridae & Dorsal vertebra & 1 \\
\hline 25 & 28 & 1236 & IIIIIIa & L. Paleo./E. Archaic & & Mammalia (Small) & Cranium & 1 \\
\hline 25 & 28 & 1236 & II/IIIIa & L. Paleo./E. Archaic & & Medium/Large Vertebrata & Indeterminate & 1 \\
\hline 25 & 28 & 1236 & IIIIIIa & L. Paleo./E. Archaic & & Serpentes & Dorsal vertebra & 1 \\
\hline 25 & 28 & 1236 & II/IIIIa & L. Paleo./E. Archaic & & Small/Medium Vertebrata & Long bone & 10 \\
\hline 25 & 28 & 1236 & II/IIIa & L. Paleo./E. Archaic & & Vertebrata & Indeterminate & 23 \\
\hline 25 & 29 & 1270 & III & L. Paleo. & & Mammalia (Medium/large) & Indeterminate & 2 \\
\hline 25 & 29 & 1270 & III & L. Paleo. & & Small/Medium Vertebrata & Long bone & 8 \\
\hline 25 & 29 & 1270 & III & L. Paleo. & & Vertebrata & Indeterminate & 22 \\
\hline 25 & 30 & 1316 & III & L. Paleo. & & Mammalia (Medium/large) & Long bone & 2 \\
\hline 25 & 30 & 1316 & III & L. Paleo. & & Mammalia (Small) & Metapodial & 1 \\
\hline 25 & 30 & 1316 & III & L. Paleo. & & Small/Medium Vertebrata & Long bone & 7 \\
\hline 25 & 30 & 1316 & III & L. Paleo. & & Testudinata & Shell fragment & 1 \\
\hline 25 & 30 & 1316 & III & L. Paleo. & & Vertebrata & Indeterminate & 23 \\
\hline 25 & 31 & 1377 & III & L. Paleo. & & Leporidae & Permanent tooth & 1 \\
\hline 25 & 31 & 1377 & III & L. Paleo. & & Medium/Large Vertebrata & Long bone & 2 \\
\hline 25 & 31 & 1377 & III & L. Paleo. & & Small/Medium Vertebrata & Long bone & 8 \\
\hline 25 & 31 & 1377 & III & L. Paleo. & & Vertebrata & Indeterminate & 32 \\
\hline 25 & 32 & 1411 & III & L. Paleo. & & Leporidae & Permanent tooth & 1 \\
\hline 25 & 32 & 1411 & III & L. Paleo. & & Lepus californicus & Metatarsal 4 & 1 \\
\hline 25 & 32 & 1411 & III & L. Paleo. & & Mammalia (Small) & Epiphysis & 1 \\
\hline 25 & 32 & 1411 & III & L. Paleo. & & Mammalia (Small) & Radius & 2 \\
\hline 25 & 32 & 1411 & III & L. Paleo. & & Small vertebrate, class ind. & Middle phalange & 1 \\
\hline 25 & 32 & 1411 & III & L. Paleo. & & Small/Medium Vertebrata & Long bone & 21 \\
\hline 25 & 32 & 1411 & III & L. Paleo. & & Sylvilagus sp. & Calcaneus & 1 \\
\hline 25 & 32 & 1411 & III & L. Paleo. & & Sylvilagus sp. & Metatarsal 3 & 1 \\
\hline 25 & 32 & 1411 & III & L. Paleo. & & Vertebrata & Indeterminate & 44 \\
\hline 25 & 33 & 1293 & III & L. Paleo. & & Geomys sp. & Permanent tooth & 1 \\
\hline 25 & 33 & 1293 & III & L. Paleo. & & Leporidae & Permanent tooth & 1 \\
\hline 25 & 33 & 1293 & III & L. Paleo. & & Mammalia (Medium) & Distal phalange & 1 \\
\hline 25 & 33 & 1293 & III & L. Paleo. & & Mammalia (Medium) & Vertebra & 2 \\
\hline 25 & 33 & 1293 & III & L. Paleo. & & Mammalia (Medium/large) & Indeterminate & 7 \\
\hline 25 & 33 & 1293 & III & L. Paleo. & & Mammalia (Medium/large) & Long bone & 4 \\
\hline 25 & 33 & 1293 & III & L. Paleo. & & Mammalia (Medium/large) & Permanent tooth & 1 \\
\hline 25 & 33 & 1293 & II & L. Paleo. & & Mammalia (Micro) & Permanent tooth & 1 \\
\hline 25 & 33 & 1293 & III & L. Paleo. & & Mammalia (Small) & Long bone & 1 \\
\hline 25 & 33 & 1293 & II & L. Paleo. & & Mammalia (Small) & Tibia & 1 \\
\hline 25 & 33 & 1293 & III & L. Paleo. & & Medium/Large Vertebrata & Indeterminate & 4 \\
\hline 25 & 33 & 1293 & II & L. Paleo. & & Osteichthyes (Small) & Spine & 1 \\
\hline 25 & 33 & 1293 & II & L. Paleo. & & Rodentia (Medium) & Permanent tooth & 1 \\
\hline 25 & 33 & 1293 & III & L. Paleo. & & Rodentia (Small) & Humerus & 1 \\
\hline 25 & 33 & 1293 & II & L. Paleo. & & Serpentes & Dorsal vertebra & 2 \\
\hline 25 & 33 & 1293 & III & L. Paleo. & & Small vertebrate, class ind. & Proximal phalange & 1 \\
\hline 25 & 33 & 1293 & III & L. Paleo. & & Small vertebrate, class ind. & Vertebra & 1 \\
\hline 25 & 33 & 1293 & II & L. Paleo. & & Small/Medium Vertebrata & Long bone & 45 \\
\hline
\end{tabular}




\begin{tabular}{|c|c|c|c|c|c|c|c|c|}
\hline Square & Level & Lot & Unit & Cultural Affinity & Feature & Taxon & Element & No. \\
\hline 25 & 33 & 1293 & III & L. Paleo. & & Sylvilagus sp. & Calcaneus & 1 \\
\hline 25 & 33 & 1293 & III & L. Paleo. & & Sylvilagus sp. & Metacarpal 2 & 1 \\
\hline 25 & 33 & 1293 & III & L. Paleo. & & Vertebrata & Indeterminate & 113 \\
\hline 25 & 34 & 1598 & III & L. Paleo. & & Geomys sp. & Permanent tooth & 1 \\
\hline 25 & 34 & 1598 & III & L. Paleo. & & Mammalia (Medium) & Caudal vertebra & 1 \\
\hline 25 & 34 & 1598 & III & L. Paleo. & & Mammalia (Medium) & Distal phalange & 1 \\
\hline 25 & 34 & 1598 & III & L. Paleo. & & Mammalia (Medium) & Proximal phalange & 1 \\
\hline 25 & 34 & 1598 & III & L. Paleo. & & Medium/Large Vertebrata & Indeterminate & 3 \\
\hline 25 & 34 & 1598 & III & L. Paleo. & & Small/Medium Vertebrata & Long bone & 10 \\
\hline 25 & 34 & 1598 & III & L. Paleo. & & Vertebrata & Indeterminate & 33 \\
\hline 25 & 35 & 1715 & III & L. Paleo. & & Mammalia (Small) & Permanent tooth & 3 \\
\hline 25 & 35 & 1715 & III & L. Paleo. & & Medium/Large Vertebrata & Indeterminate & 12 \\
\hline 25 & 35 & 1715 & III & L. Paleo. & & Small/Medium Vertebrata & Long bone & 13 \\
\hline 25 & 35 & 1715 & III & L. Paleo. & & Sylvilagus sp. & Calcaneus & 3 \\
\hline 25 & 35 & 1715 & III & L. Paleo. & & Sylvilagus sp. & Metapodial & 1 \\
\hline 25 & 35 & 1715 & III & L. Paleo. & & Sylvilagus sp. & Permanent tooth & 1 \\
\hline 25 & 35 & 1715 & III & L. Paleo. & & Sylvilagus sp. & Radius & 1 \\
\hline 25 & 35 & 1715 & III & L. Paleo. & & Vertebrata & Indeterminate & 24 \\
\hline 25 & 36 & 1619 & |Isi-c/II & L. Paleo. & & Medium/Large Vertebrata & Long bone & 1 \\
\hline 25 & 36 & 1619 & |Isi-c/II & L. Paleo. & & Small/Medium Vertebrata & Long bone & 4 \\
\hline 25 & 36 & 1619 & Isi-c/II & L. Paleo. & & Vertebrata & Indeterminate & 8 \\
\hline 25 & 36 & 1734 & Isi-c/II & L. Paleo. & & Vertebrata & Indeterminate & 5 \\
\hline 25 & 37 & 1634 & Isi-c/II & L. Paleo. & & Rodentia (Small/Medium) & Permanent tooth & 1 \\
\hline 25 & 37 & 1634 & Isi-c/II & L. Paleo. & & Small vertebrate, class ind. & Middle phalange & 1 \\
\hline 25 & 37 & 1634 & Isi-c/II & L. Paleo. & & Small/Medium Vertebrata & Long bone & 3 \\
\hline 25 & 37 & 1634 & Isi-c/II & L. Paleo. & & Sylvilagus sp. & Humerus & 1 \\
\hline 25 & 37 & 1634 & Isi-c/II & L. Paleo. & & Vertebrata & Indeterminate & 14 \\
\hline 25 & 38 & 1836 & Isi-c/II & L. Paleo. & & Leporidae & Permanent tooth & 1 \\
\hline 25 & 38 & 1836 & Isi-c/II & L. Paleo. & & Medium/Large Vertebrata & Indeterminate & 2 \\
\hline 25 & 38 & 1836 & Isi-c/II & L. Paleo. & & Medium/Large Vertebrata & Long bone & 1 \\
\hline 25 & 38 & 1836 & Isi-c/II & L. Paleo. & & Small/Medium Vertebrata & Long bone & 5 \\
\hline 25 & 38 & 1836 & Isi-c/II & L. Paleo. & & Vertebrata & Indeterminate & 14 \\
\hline 25 & 39 & 1891 & Isi-c & L. Paleo. & & Small/Medium Vertebrata & Long bone & 1 \\
\hline 25 & 39 & 1891 & Isi-c & L. Paleo. & & Vertebrata & Indeterminate & 6 \\
\hline 25 & $39-45$ & 2839 & Isi-c & L. Paleo. & & Mammalia (Medium/large) & Long bone & 1 \\
\hline 25 & $39-45$ & 2839 & Isi-c & L. Paleo. & & Small/Medium Vertebrata & Long bone & 2 \\
\hline 25 & $39-45$ & 2839 & Isi-c & L. Paleo. & & Sylvilagus sp. & Calcaneus & 1 \\
\hline 26 & 15 & 700 & IIIlb & Early/M. Archaic & & Colubridae & Dorsal vertebra & 1 \\
\hline 26 & 15 & 700 & IIIb & Early/M. Archaic & & Mammalia (Medium/large) & Long bone & 1 \\
\hline 26 & 15 & 700 & IIIlb & Early/M. Archaic & & Small/Medium Vertebrata & Long bone & 1 \\
\hline 26 & 15 & 700 & IIIIb & Early/M. Archaic & & Vertebrata & Indeterminate & 4 \\
\hline 26 & 16 & 714 & IIIa/b & E. Archaic & & Mammalia (Medium/large) & Tooth, perm./decid. ind. & 1 \\
\hline 26 & 16 & 714 & IIIa/b & E. Archaic & & Small/Medium Vertebrata & Long bone & 5 \\
\hline 26 & 16 & 714 & IIIa/b & E. Archaic & & Testudinata & Shell fragment & 2 \\
\hline 26 & 16 & 714 & IIIa/b & E. Archaic & & Vertebrata & Indeterminate & 9 \\
\hline 26 & 16 & 714 & IIIa/b & E. Archaic & & Viperidae & Dorsal vertebra & 1 \\
\hline 26 & 17 & 752 & IIIa/b & E. Archaic & & Small/Medium Vertebrata & Long bone & 4 \\
\hline 26 & 17 & 752 & IIIa/b & E. Archaic & & Vertebrata & Indeterminate & 6 \\
\hline 26 & 18 & 407 & IIIIa/b & E. Archaic & & Leporidae & Permanent tooth & 1 \\
\hline 26 & 18 & 407 & IIIa/b & E. Archaic & & Mammalia (Large) & Long bone & 3 \\
\hline 26 & 18 & 407 & IIIa/b & E. Archaic & & Mammalia (Medium/large) & Indeterminate & 7 \\
\hline 26 & 18 & 407 & WIa/b & E. Archaic & & Testudinata & Shell fragment & 2 \\
\hline 26 & 18 & 407 & IIIa/b & E. Archaic & & Vertebrata & Indeterminate & 8 \\
\hline 26 & 19 & 810 & IIIa/b & E. Archaic & & Testudinata & Carapace fragment ind. & 1 \\
\hline 26 & 19 & 810 & IIIa/b & E. Archaic & & Vertebrata & Indeterminate & 12 \\
\hline 26 & 20 & 835 & IIIIa/b & E. Archaic & & Mammalia (Medium) & Long bone & 1 \\
\hline 26 & 20 & 835 & Ш一a/b & E. Archaic & & Vertebrata & Indeterminate & 5 \\
\hline 26 & 21 & 855 & IIIa & E. Archaic & & Medium/Large Vertebrata & Long bone & 1 \\
\hline 26 & 21 & 855 & IIIIa & E. Archaic & & Vertebrata & Indeterminate & 11 \\
\hline 26 & 22 & 897 & IIIIa & E. Archaic & & Antilocapra/Odocoileus & Tooth, perm./decid. ind. & 1 \\
\hline 26 & 22 & 897 & IIIa & E. Archaic & & Mammalia (Medium/large) & Indeterminate & 2 \\
\hline 26 & 22 & 897 & IIIIa & E. Archaic & & Small/Medium Vertebrata & Long bone & 10 \\
\hline 26 & 22 & 897 & IIIa & E. Archaic & & Testudinata & Carapace fragment ind. & 1 \\
\hline 26 & 22 & 897 & IIIIa & E. Archaic & & Vertebrata & Indeterminate & 13 \\
\hline 26 & 24 & 938 & IIIIa & E. Archaic & & Mammalia (Large) & Indeterminate & 1 \\
\hline 26 & 24 & 938 & IIII & E. Archaic & & Mammalia (Large) & Long bone & 1 \\
\hline 26 & 24 & 938 & IIIa & E. Archaic & & Mammalia (Medium/large) & Indeterminate & 1 \\
\hline
\end{tabular}




\begin{tabular}{|c|c|c|c|c|c|c|c|c|}
\hline Square & Level & Lot & Unit & Cultural Affinity & Feature & Taxon & Element & No. \\
\hline 26 & 24 & 938 & IIIIa & E. Archaic & & Medium/Large Vertebrata & Indeterminate & 1 \\
\hline 26 & 24 & 938 & IIIIa & E. Archaic & & Small/Medium Vertebrata & Long bone & 1 \\
\hline 26 & 24 & 938 & IIIIa & E. Archaic & & Vertebrata & Indeterminate & 4 \\
\hline 26 & 25 & 1094 & IIIIa & E. Archaic & & Mammalia (Medium) & Proximal phalange & 1 \\
\hline 26 & 25 & 1094 & IIIIa & E. Archaic & & Mammalia (Medium) & Scapula & 1 \\
\hline 26 & 25 & 1094 & IIIa & E. Archaic & & Mammalia (Medium/large) & Indeterminate & 5 \\
\hline 26 & 25 & 1094 & IIIla & E. Archaic & & Mammalia (Small) & Permanent tooth & 1 \\
\hline 26 & 25 & 1094 & ШІа & E. Archaic & & Mammalia (Small) & Rib & 1 \\
\hline 26 & 25 & 1094 & IIIla & E. Archaic & & Medium/Large Vertebrata & Indeterminate & 1 \\
\hline 26 & 25 & 1094 & IIIIa & E. Archaic & & Small/Medium Vertebrata & Long bone & 8 \\
\hline 26 & 25 & 1094 & IIIa & E. Archaic & & Sylvilagus sp. & Calcaneus & 1 \\
\hline 26 & 25 & 1094 & IIIIa & E. Archaic & & Testudinata & Neural & 1 \\
\hline 26 & 25 & 1094 & IIIIa & E. Archaic & & Vertebrata & Indeterminate & 48 \\
\hline 26 & 26 & 1153 & IIIa & E. Archaic & & Geomys sp. & Permanent tooth & 1 \\
\hline 26 & 26 & 1153 & IIIIa & E. Archaic & & Leporidae & Permanent tooth & 3 \\
\hline 26 & 26 & 1153 & IIIIa & E. Archaic & & Leporidae & Ulna & 1 \\
\hline 26 & 26 & 1153 & IIIIa & E. Archaic & & Mammalia (Medium/large) & Indeterminate & 2 \\
\hline 26 & 26 & 1153 & IIIIa & E. Archaic & & Mammalia (Small) & Phalange & 1 \\
\hline 26 & 26 & 1153 & IIIIa & E. Archaic & & Osteichthyes (Small) & Sagitta otolith & 1 \\
\hline 26 & 26 & 1153 & IIIIa & E. Archaic & & Small/Medium Vertebrata & Long bone & 11 \\
\hline 26 & 26 & 1153 & IIIIa & E. Archaic & & Sylvilagus sp. & Permanent tooth & 2 \\
\hline 26 & 26 & 1153 & IIIa & E. Archaic & & Vertebrata & Indeterminate & 38 \\
\hline 26 & 27 & 1199 & IIIIIIa & L. Paleo./E. Archaic & & Ictalurus sp. & Pectoral spine & 1 \\
\hline 26 & 27 & 1199 & IIIIIa & L. Paleo./E. Archaic & & Mammalia (Medium) & Alveolar ridge fragment & 1 \\
\hline 26 & 27 & 1199 & II/IIIa & L. Paleo./E. Archaic & & Mammalia (Medium/large) & Long bone & 3 \\
\hline 26 & 27 & 1199 & II/IIIa & L. Paleo./E. Archaic & & Serpentes & Dorsal vertebra & 1 \\
\hline 26 & 27 & 1199 & II/IIIa & L. Paleo./E. Archaic & & Small/Medium Vertebrata & Long bone & 8 \\
\hline 26 & 27 & 1199 & II/IIIIa & L. Paleo./E. Archaic & & Sylvilagus sp. & Radius & 1 \\
\hline 26 & 27 & 1199 & II/IIIa & L. Paleo./E. Archaic & & Testudinata & Shell fragment & 1 \\
\hline 26 & 27 & 1199 & II/IIIa & L. Paleo./E. Archaic & & Vertebrata & Indeterminate & 31 \\
\hline 26 & 28 & 1260 & II/IIIa & L. Paleo./E. Archaic & & Mammalia (Small) & Metapodial & 1 \\
\hline 26 & 28 & 1260 & II/IIIa & L. Paleo./E. Archaic & & Small/Medium Vertebrata & Long bone & 8 \\
\hline 26 & 28 & 1260 & IIIIIIa & L. Paleo./E. Archaic & & Vertebrata & Indeterminate & 21 \\
\hline 26 & 29 & 1378 & $\Pi 1 \mathrm{IIIIa}$ & L. Paleo./E. Archaic & & Mammalia (Medium/large) & Tooth, perm./decid. ind. & 3 \\
\hline 26 & 29 & 1378 & II/IIIa & L. Paleo./E. Archaic & & Mammalia (Small) & Permanent tooth & 1 \\
\hline 26 & 29 & 1378 & IIIIIIa & L. Paleo./E. Archaic & & Medium/Large Vertebrata & Indeterminate & 3 \\
\hline 26 & 29 & 1378 & II/IIIa & L. Paleo./E. Archaic & & Serpentes & Dorsal vertebra & 1 \\
\hline 26 & 29 & 1378 & IIIIIIa & L. Paleo./E. Archaic & & Small/Medium Vertebrata & Long bone & 7 \\
\hline 26 & 29 & 1378 & II/IIIa & L. Paleo./E. Archaic & & Small/Medium Vertebrata & Vertebra & 1 \\
\hline 26 & 29 & 1378 & IIIIIIa & L. Paleo./E. Archaic & & Sylvilagus sp. & Metacarpal 2 & 1 \\
\hline 26 & 29 & 1378 & ПIIIIa & L. Paleo./E. Archaic & & Vertebrata & Indeterminate & 33 \\
\hline 26 & 30 & 1419 & III & L. Paleo. & & Geomys sp. & Permanent tooth & 1 \\
\hline 26 & 30 & 1419 & III & L. Paleo. & & Small/Medium Vertebrata & Long bone & 7 \\
\hline 26 & 30 & 1419 & II & L. Paleo. & & Vertebrata & Indeterminate & 23 \\
\hline 26 & 31 & 1467 & III & L. Paleo. & & Mammalia (Medium) & Caudal vertebra & 1 \\
\hline 26 & 31 & 1467 & III & L. Paleo. & & Mammalia (Medium/large) & Long bone & 1 \\
\hline 26 & 31 & 1467 & III & L. Paleo. & & Small vertebrate, class ind. & Phalange & 1 \\
\hline 26 & 31 & 1467 & III & L. Paleo. & & Small/Medium Vertebrata & Long bone & 11 \\
\hline 26 & 31 & 1467 & III & L. Paleo. & & Vertebrata & Indeterminate & 59 \\
\hline 26 & 32 & 1500 & III & L. Paleo. & & Leporidae & Permanent tooth & 1 \\
\hline 26 & 32 & 1500 & III & L. Paleo. & & Mammalia (Medium/large) & Indeterminate & 2 \\
\hline 26 & 32 & 1500 & III & L. Paleo. & & Mammalia (Medium/large) & Long bone & 3 \\
\hline 26 & 32 & 1500 & III & L. Paleo. & & Small/Medium Vertebrata & Long bone & 12 \\
\hline 26 & 32 & 1500 & III & L. Paleo. & & Sylvilagus sp. & Astragalus & 1 \\
\hline 26 & 32 & 1500 & III & L. Paleo. & & Vertebrata & Indeterminate & 35 \\
\hline 26 & 33 & 1667 & III & L. Paleo. & & Medium/Large Vertebrata & Indeterminate & 1 \\
\hline 26 & 33 & 1667 & III & L. Paleo. & & Small/Medium Vertebrata & Long bone & 4 \\
\hline 26 & 33 & 1667 & III & L. Paleo. & & Vertebrata & Indeterminate & 11 \\
\hline 26 & 34 & 1716 & III & L. Paleo. & & Mammalia (Medium/large) & Indeterminate & 3 \\
\hline 26 & 34 & 1716 & II & L. Paleo. & & Medium/Large Vertebrata & Indeterminate & 3 \\
\hline 26 & 34 & 1716 & III & L. Paleo. & & Medium/Large Vertebrata & Long bone & 1 \\
\hline 26 & 34 & 1716 & III & L. Paleo. & & Rodentia (Small) & Permanent tooth & 1 \\
\hline 26 & 34 & 1716 & III & L. Paleo. & & Small vertebrate, class ind. & Proximal phalange & 1 \\
\hline 26 & 34 & 1716 & III & L. Paleo. & & Vertebrata & Indeterminate & 27 \\
\hline 26 & 35 & 1618 & III & L. Paleo. & & Mammalia (Medium/large) & Indeterminate & 1 \\
\hline 26 & 35 & 1618 & III & L. Paleo. & & Small/Medium Vertebrata & Long bone & 3 \\
\hline 26 & 35 & 1618 & III & L. Paleo. & & Vertebrata & Indeterminate & 20 \\
\hline
\end{tabular}




\begin{tabular}{|c|c|c|c|c|c|c|c|c|}
\hline Square & Level & Lot & Unit & Cultural Affinity & Feature & Taxon & Element & No. \\
\hline 26 & 36 & 1629 & $\overline{I I}$ & L. Paleo. & & Mammalia (Medium/large) & Tooth, perm./decid. ind. & 1 \\
\hline 26 & 36 & 1629 & III & L. Paleo. & & Small/Medium Vertebrata & Long bone & 4 \\
\hline 26 & 36 & 1629 & II & L. Paleo. & & Vertebrata & Indeterminate & 14 \\
\hline 26 & 37 & 1821 & Id/II & L. Paleo. & & Mammalia (Large) & Indeterminate & 1 \\
\hline 26 & 37 & 1821 & $\mathrm{Id} / \mathrm{II}$ & L. Paleo. & & Small/Medium Vertebrata & Long bone & 2 \\
\hline 26 & 37 & 1821 & Id/II & L. Paleo. & & Sylvilagus sp. & Fourth tarsal & 1 \\
\hline 26 & 37 & 1821 & $\mathrm{Id} / \mathrm{II}$ & L. Paleo. & & Vertebrata & Indeterminate & 10 \\
\hline 26 & 38 & 1879 & Isi-c/Id/II & L. Paleo. & & Mammalia (Medium) & Tooth, perm./decid. ind. & 1 \\
\hline 26 & 38 & 1879 & Isi-c/Id/II & L. Paleo. & & Mammalia (Medium/large) & Indeterminate & 2 \\
\hline 26 & 38 & 1879 & Isi-c/Id/II & L. Paleo. & & Medium/Large Vertebrata & Indeterminate & 2 \\
\hline 26 & 38 & 1879 & Isi-c/Id/II & L. Paleo. & & Small/Medium Vertebrata & Long bone & 3 \\
\hline 26 & 38 & 1879 & Isi-c/Id/II & L. Paleo. & & Vertebrata & Indeterminate & 17 \\
\hline 26 & 39 & 1937 & Isi-c/Id & L. Paleo. & & Mammalia (Medium/large) & Indeterminate & 1 \\
\hline 26 & 39 & 1937 & Isi-c/Id & L. Paleo. & & Mammalia (Small) & Metapodial & 1 \\
\hline 26 & 39 & 1937 & Isi-c/Id & L. Paleo. & & Mammalia (Small/medium) & Long bone & 1 \\
\hline 26 & 39 & 1937 & Isi-c/Id & L. Paleo. & & Small/Medium Vertebrata & Long bone & 3 \\
\hline 26 & 39 & 1937 & Isi-c/Id & L. Paleo. & & Sylvilagus sp. & Calcaneus & 1 \\
\hline 26 & 39 & 1937 & Isi-c/Id & L. Paleo. & & Vertebrata & Indeterminate & 13 \\
\hline 26 & 40 & 1960 & Isi-c & L. Paleo. & & Small/Medium Vertebrata & Long bone & 2 \\
\hline 26 & 40 & 1960 & Isi-c & L. Paleo. & & Sylvilagus sp. & Calcaneus & 1 \\
\hline 26 & 40 & 1960 & Isi-c & L. Paleo. & & Sylvilagus sp. & Tibia & 1 \\
\hline 26 & 40 & 1960 & Isi-c & L. Paleo. & & Vertebrata & Indeterminate & 24 \\
\hline 26 & 41 & 2016 & Isi-c & L. Paleo. & & Mammalia (Medium/large) & Indeterminate & 6 \\
\hline 26 & 41 & 2016 & Isi-c & L. Paleo. & & Medium/Large Vertebrata & Indeterminate & 6 \\
\hline 26 & 41 & 2016 & Isi-c & L. Paleo. & & Small/Medium Vertebrata & Long bone & 8 \\
\hline 26 & 41 & 2016 & Isi-c & L. Paleo. & & Sylvilagus sp. & Astragalus & 1 \\
\hline 26 & 41 & 2016 & Isi-c & L. Paleo. & & Testudinata & Shell fragment & 1 \\
\hline 26 & 41 & 2016 & Isi-c & L. Paleo. & & Vertebrata & Indeterminate & 64 \\
\hline 26 & 42 & 2036 & Isi-c & L. Paleo. & & cf. Sylvilagus sp. & Ulna & 1 \\
\hline 26 & 42 & 2036 & Isi-c & L. Paleo. & & Mammalia (Medium/large) & Indeterminate & 19 \\
\hline 26 & 42 & 2036 & Isi-c & L. Paleo. & & Mammalia (Small) & Radius & 1 \\
\hline 26 & 42 & 2036 & Isi-c & L. Paleo. & & Small/Medium Vertebrata & Long bone & 7 \\
\hline 26 & 42 & 2036 & Isi-c & L. Paleo. & & Sylvilagus sp. & Calcaneus & 2 \\
\hline 26 & 42 & 2036 & Isi-c & L. Paleo. & & Sylvilagus sp. & Metapodial & 1 \\
\hline 26 & 42 & 2036 & Isi-c & L. Paleo. & & Sylvilagus sp. & Metatarsal 2 & 1 \\
\hline 26 & 42 & 2036 & Isi-c & L. Paleo. & & Sylvilagus sp. & Third tarsal & 1 \\
\hline 26 & 42 & 2036 & Isi-c & L. Paleo. & & Vertebrata & Indeterminate & 86 \\
\hline 26 & 43 & 2075 & Icl/Isi-c & Paleoindian & & Mammalia (Medium/large) & Indeterminate & 4 \\
\hline 26 & 43 & 2075 & Icl/Isi-c & Paleoindian & & Small/Medium Vertebrata & Long bone & 1 \\
\hline 26 & 43 & 2075 & Icl/Isi-c & Paleoindian & & Sylvilagus sp. & Calcaneus & 1 \\
\hline 26 & 43 & 2075 & $\mathrm{Icl} / \mathrm{Isi}-\mathrm{c}$ & Paleoindian & & Sylvilagus sp. & Metatarsal 2 & 1 \\
\hline 26 & 43 & 2075 & Icl/Isi-c & Paleoindian & & Vertebrata & Indeterminate & 14 \\
\hline 26 & 44 & 2808 & Icl//si-c & Paleoindian & & Mammalia (Medium/large) & Indeterminate & 2 \\
\hline 26 & 44 & 2808 & Icl/Isi-c & Paleoindian & & Small/Medium Vertebrata & Long bone & 5 \\
\hline 26 & 44 & 2808 & Icl/Isi-c & Paleoindian & & Vertebrata & Indeterminate & 11 \\
\hline 26 & 45 & 2831 & Icl/Isi-c & Paleoindian & & Mammalia (Medium/large) & Indeterminate & 1 \\
\hline 26 & 45 & 2831 & Icl/Isi-c & Paleoindian & & Vertebrata & Indeterminate & 2 \\
\hline 26 & 46 & 2660 & Icl/Isi-c & Paleoindian & & Mammalia (Medium/large) & Indeterminate & 1 \\
\hline 26 & 46 & 2660 & Icl/Isi-c & Paleoindian & & Mammalia (Medium/large) & Long bone & 1 \\
\hline 26 & 46 & 2660 & Icl/Isi-c & Paleoindian & & Medium/Large Vertebrata & Indeterminate & 1 \\
\hline 26 & 46 & 2660 & Icl/Isi-c & Paleoindian & & Small/Medium Vertebrata & Long bone & 3 \\
\hline 26 & 46 & 2660 & Icl/Isi-c & Paleoindian & & Vertebrata & Indeterminate & 10 \\
\hline 26 & 47 & 2662 & Icl & E. Paleoindian & & Mammalia (Small) & Permanent tooth & 1 \\
\hline 26 & 47 & 2662 & Icl & E. Paleoindian & & Sylvilagus sp. & Metatarsal 2 & 1 \\
\hline 26 & 47 & 2662 & Icl & E. Paleoindian & & Sylvilagus sp. & Permanent tooth & 1 \\
\hline 26 & 47 & 2662 & Icl & E. Paleoindian & & Vertebrata & Indeterminate & 1 \\
\hline 26 & 48 & 2273 & Icl & E. Paleoindian & & Mammalia (Medium/large) & Indeterminate & 3 \\
\hline 26 & 48 & 2273 & Icl & E. Paleoindian & & Small/Medium Vertebrata & Long bone & 3 \\
\hline 26 & 48 & 2273 & Icl & E. Paleoindian & & Vertebrata & Indeterminate & 2 \\
\hline 26 & 49 & 2602 & Icl & E. Paleoindian & & Mammalia (Medium/large) & Indeterminate & 1 \\
\hline 26 & 49 & 2602 & Icl & E. Paleoindian & & Medium/Large Vertebrata & Indeterminate & 4 \\
\hline 26 & 49 & 2602 & Icl & E. Paleoindian & & Small/Medium Vertebrata & Long bone & 4 \\
\hline 26 & 49 & 2602 & Icl & E. Paleoindian & & Vertebrata & Indeterminate & 6 \\
\hline 26 & 50 & 2589 & Isi/Icl & E. Paleoindian & & Leporidae & Permanent tooth & 1 \\
\hline 26 & 50 & 2589 & Isi/Icl & E. Paleoindian & & Mammalia (Medium) & Proximal phalange & 1 \\
\hline 26 & 50 & 2589 & Isi/Icl & E. Paleoindian & & Small/Medium Vertebrata & Long bone & 5 \\
\hline 26 & 50 & 2589 & Isi/Icl & E. Paleoindian & & Sylvilagus sp. & Permanent tooth & 1 \\
\hline
\end{tabular}




\begin{tabular}{|c|c|c|c|c|c|c|c|c|}
\hline Square & Level & Lot & Unit & Cultural Affinity & Feature & Taxon & Element & No. \\
\hline 26 & \begin{tabular}{|l|}
50 \\
\end{tabular} & 2589 & Isi/Icl & E. Paleoindian & & Vertebrata & Indeterminate & 6 \\
\hline 26 & 51 & 2447 & |Isi/Icl & E. Paleoindian & & Mammalia (Medium/large) & Indeterminate & 1 \\
\hline 26 & 51 & 2481 & Isi/Icl & E. Paleoindian & & Medium/Large Vertebrata & Indeterminate & 1 \\
\hline 26 & 51 & 2483 & |Isi/Icl & E. Paleoindian & & Mammalia (Medium/large) & Indeterminate & 1 \\
\hline 26 & 51 & 2484 & |Isi/Icl & E. Paleoindian & & Mammalia (Medium/large) & Indeterminate & 1 \\
\hline 26 & 51 & 2485 & |Isi/Icl & E. Paleoindian & & Leporidae & Permanent tooth & 2 \\
\hline 26 & 51 & 2485 & |Isi/Icl & E. Paleoindian & & Lepus californicus & Permanent tooth & 2 \\
\hline 26 & 51 & 2485 & |Isi/Icl & E. Paleoindian & & Mammalia (Medium/large) & Indeterminate & 1 \\
\hline 26 & 51 & 2485 & |Isi/Icl & E. Paleoindian & & Mammalia (Medium/large) & Tooth, perm./decid. ind. & 1 \\
\hline 26 & 51 & 2485 & |Isi/Icl & E. Paleoindian & & Mammalia (Small) & Middle phalange & 1 \\
\hline 26 & 51 & 2485 & |Isi/Icl & E. Paleoindian & & Medium/Large Vertebrata & Indeterminate & 4 \\
\hline 26 & 51 & 2485 & |Isi/Icl & E. Paleoindian & & Small/Medium Vertebrata & Long bone & 2 \\
\hline 26 & 51 & 2485 & |Isi/Icl & E. Paleoindian & & Vertebrata & Indeterminate & 32 \\
\hline 26 & 51 & 2486 & |Isi/Icl & E. Paleoindian & & Mammalia (Medium/large) & Indeterminate & 2 \\
\hline 26 & 51 & 2486 & |Isi/Icl & E. Paleoindian & & Vertebrata & Indeterminate & 3 \\
\hline 26 & 52 & 2509 & Igl/Isi/Icl & E. Paleoindian & & Mammalia (Medium) & Mandible & 1 \\
\hline 26 & 52 & 2510 & Igl/Isi/Icl & E. Paleoindian & & Mammalia (Large) & Indeterminate & 1 \\
\hline 26 & 52 & 2511 & Igl/Isi/Icl & E. Paleoindian & & Mammalia (Medium/large) & Indeterminate & 1 \\
\hline 26 & 52 & 2516 & |Igl//si//Icl & E. Paleoindian & & Bison sp. & Permanent tooth & 1 \\
\hline 26 & 52 & 2516 & Igl/Isi/Icl & E. Paleoindian & & Mammalia (Small) & Permanent tooth & 1 \\
\hline 26 & 52 & 2516 & Igl/Isi/Icl & E. Paleoindian & & Vertebrata & Indeterminate & 40 \\
\hline 26 & 53 & 2514 & Igl/Isi/Icl & E. Paleoindian & & Mammalia (Large) & Indeterminate & 1 \\
\hline 26 & 53 & 2515 & Igl/Isi/Icl & E. Paleoindian & & Mammalia (Medium/large) & Indeterminate & 1 \\
\hline 26 & 53 & 2569 & Igl//si/Icl & E. Paleoindian & & Mammalia (Very large) & Tooth, perm./decid. ind. & 1 \\
\hline 26 & 53 & 2569 & Igl/Isi/Icl & E. Paleoindian & & Vertebrata & Indeterminate & 1 \\
\hline 26 & 53 & 2570 & Igl/Isi/Icl & E. Paleoindian & & Mammalia (Very large) & Tooth, perm./decid. ind. & 1 \\
\hline 26 & 53 & 2571 & Igl//si/Icl & E. Paleoindian & & Mammalia (Large) & Long bone & 1 \\
\hline 26 & 53 & 2572 & Igl/Isi/Icl & E. Paleoindian & & Mammalia (Large) & Indeterminate & 1 \\
\hline 26 & 53 & 2574 & Igl/Isi/Icl & E. Paleoindian & & Leporidae & Permanent tooth & 8 \\
\hline 26 & 53 & 2574 & Igl//si/Icl & E. Paleoindian & & Mammalia (Medium/large) & Indeterminate & 10 \\
\hline 26 & 53 & 2574 & Igl/Isi/Icl & E. Paleoindian & & Small/Medium Vertebrata & Long bone & 2 \\
\hline 26 & 53 & 2574 & Igl/Isi/Icl & E. Paleoindian & & Sylvilagus sp. & Permanent tooth & 1 \\
\hline 26 & 53 & 2574 & Igl/Isi/Icl & E. Paleoindian & & Vertebrata & Indeterminate & 6 \\
\hline 26 & $54 \mathrm{~A}$ & 2761 & |Igl//si & E. Paleoindian & & Leporidae & Permanent tooth & 1 \\
\hline 26 & $54 \mathrm{~A}$ & 2761 & Igl/Isi & E. Paleoindian & & Mammalia (Medium/large) & Indeterminate & 4 \\
\hline 26 & $54 \mathrm{~A}$ & 2761 & |Igl/Isi & E. Paleoindian & & Mammalia (Small) & Vertebra & 1 \\
\hline 26 & $54 \mathrm{~A}$ & 2761 & |Igl//si & E. Paleoindian & & Small/Medium Vertebrata & Long bone & 2 \\
\hline 26 & 55 & 2779 & Igl/Isi & E. Paleoindian & & Testudinata & Shell fragment & 1 \\
\hline 26 & 56 & 2813 & |Igl & E. Paleoindian & & Leporidae & Permanent tooth & 1 \\
\hline 26 & 59 & 2814 & Igl & E. Paleoindian & & Vertebrata & Indeterminate & 1 \\
\hline 26 & 60 & 2674 & Igl & E. Paleoindian & & Mammalia (Medium/large) & Indeterminate & 1 \\
\hline 27 & 15 & 698 & IIIlb & Early/M. Archaic & & Mammalia (Large) & Indeterminate & 2 \\
\hline 27 & 15 & 698 & IIIb & Early/M. Archaic & & Mammalia (Large) & Long bone & 1 \\
\hline 27 & 15 & 698 & IIIlb & Early/M. Archaic & & Mammalia (Medium/large) & Long bone & 1 \\
\hline 27 & 15 & 698 & IIIlb & Early/M. Archaic & & Rodentia (Medium) & Permanent tooth & 1 \\
\hline 27 & 15 & 698 & IIIb & Early/M. Archaic & & Vertebrata & Indeterminate & 2 \\
\hline 27 & 16 & 715 & IIIIa/b & Early/M. Archaic & & Geomys sp. & Permanent tooth & 1 \\
\hline 27 & 16 & 715 & IIIa/b & Early/M. Archaic & & Odocoileus sp. & Tooth, perm./decid. ind. & 1 \\
\hline 27 & 16 & 715 & IIIa/b & Early/M. Archaic & & Vertebrata & Indeterminate & 7 \\
\hline 27 & 17 & 749 & IIIa/b & E. Archaic & & Mammalia (Medium) & Long bone & 1 \\
\hline 27 & 17 & 749 & IIIa/b & E. Archaic & & Mammalia (Medium) & Middle phalange & 1 \\
\hline 27 & 17 & 749 & ШШа/b & E. Archaic & & Vertebrata & Indeterminate & 8 \\
\hline 27 & 18 & 137 & IIIa/b & E. Archaic & & Leporidae & Permanent tooth & 1 \\
\hline 27 & 18 & 137 & IIIa/b & E. Archaic & & Mammalia (Small) & Permanent tooth & 1 \\
\hline 27 & 18 & 137 & IIa/b & E. Archaic & & Small/Medium Vertebrata & Long bone & 3 \\
\hline 27 & 18 & 137 & IIIa/b & E. Archaic & & Vertebrata & Indeterminate & 14 \\
\hline 27 & 19 & 796 & IIIIa & E. Archaic & & Mammalia (Medium/large) & Indeterminate & 3 \\
\hline 27 & 19 & 796 & Ша & E. Archaic & & Small/Medium Vertebrata & Long bone & 1 \\
\hline 27 & 19 & 796 & ШШа & E. Archaic & & Vertebrata & Indeterminate & 1 \\
\hline 27 & 20 & 865 & III & E. Archaic & 231 & Small/Medium Vertebrata & Long bone & 2 \\
\hline 27 & 20 & 865 & ШШа & E. Archaic & 231 & Vertebrata & Indeterminate & 2 \\
\hline 27 & 21 & 887 & Ша & E. Archaic & 231 & Kinosternon sp. & Peripheral & 1 \\
\hline 27 & 21 & 887 & IIIIa & E. Archaic & 231 & Mammalia (Medium) & Femur & 1 \\
\hline 27 & 21 & 887 & IIIa & E. Archaic & 231 & Medium/Large Vertebrata & Long bone & 1 \\
\hline 27 & 21 & 887 & III & E. Archaic & 231 & Neotoma sp. & Permanent tooth & 1 \\
\hline 27 & 21 & 887 & IIIIa & E. Archaic & 231 & Vertebrata & Indeterminate & 29 \\
\hline 27 & 22 & 952 & IIIIa & E. Archaic & 225 & Mammalia (Medium/large) & Indeterminate & 1 \\
\hline
\end{tabular}




\begin{tabular}{|c|c|c|c|c|c|c|c|c|}
\hline Square & Level & Lot & Unit & Cultural Affinity & Feature & Taxon & Element & No. \\
\hline 27 & 22 & 952 & IIIa & E. Archaic & 225 & Small/Medium Vertebrata & Long bone & 7 \\
\hline 27 & 22 & 952 & III & E. Archaic & 225 & Vertebrata & Indeterminate & 3 \\
\hline 27 & $24-25$ & 1027 & IIIन & E. Archaic & $231 / 245$ & Leporidae & Permanent tooth & 1 \\
\hline 27 & $24-25$ & 1027 & IIIIa & E. Archaic & $231 / 245$ & Mammalia (Medium) & Metapodial & 1 \\
\hline 27 & $24-25$ & 1027 & ШШа & E. Archaic & $231 / 245$ & Mammalia (Small) & Permanent tooth & 1 \\
\hline 27 & $24-25$ & 1027 & IIIIa & E. Archaic & $231 / 245$ & Medium/Large Vertebrata & Indeterminate & 6 \\
\hline 27 & $24-25$ & 1027 & IIIIa & E. Archaic & $231 / 245$ & Small vertebrate, class ind. & Alveolar ridge fragment & 1 \\
\hline 27 & $24-25$ & 1027 & IIII & E. Archaic & $231 / 245$ & Small vertebrate, class ind. & Middle phalange & 1 \\
\hline 27 & $24-25$ & 1027 & IIIIa & E. Archaic & $231 / 245$ & Small/Medium Vertebrata & Long bone & 19 \\
\hline 27 & $24-25$ & 1027 & III' & E. Archaic & $231 / 245$ & Sylvilagus sp. & Permanent tooth & 1 \\
\hline 27 & $24-25 \mid$ & 1027 & III & E. Archaic & $231 / 245$ & Testudinata & Shell fragment & 1 \\
\hline 27 & $24-25$ & 1027 & III & E. Archaic & $231 / 245$ & Vertebrata & Indeterminate & 90 \\
\hline 27 & 25 & 1261 & IIII & E. Archaic & $231 / 245$ & Small vertebrate, class ind. & Vertebra & 1 \\
\hline 27 & 25 & 1261 & ШШа & E. Archaic & $231 / 245$ & Vertebrata & Indeterminate & 4 \\
\hline 27 & 26 & 1289 & II/IIIa & L. Paleo./E. Archaic & $231 / 245$ & Colubridae & Dorsal vertebra & 1 \\
\hline 27 & 26 & 1289 & II/IIIa & L. Paleo./E. Archaic & $231 / 245$ & Geomys sp. & Permanent tooth & 1 \\
\hline 27 & 26 & 1289 & II/IIIa & L. Paleo./E. Archaic & $231 / 245$ & Mammalia (Medium/large) & Tooth, perm./decid. ind. & 1 \\
\hline 27 & 26 & 1289 & II/IIIa & L. Paleo./E. Archaic & $231 / 245$ & Mammalia (Small) & Astragalus & 1 \\
\hline 27 & 26 & 1289 & III/IIIa & L. Paleo./E. Archaic & $231 / 245$ & Mammalia (Small) & Permanent tooth & 1 \\
\hline 27 & 26 & 1289 & II/IIIa & L. Paleo./E. Archaic & $231 / 245$ & Small/Medium Vertebrata & Long bone & 12 \\
\hline 27 & 26 & 1289 & Ш/Ша & L. Paleo./E. Archaic & $231 / 245$ & Sylvilagus sp. & Permanent tooth & 2 \\
\hline 27 & 26 & 1289 & II/IIIa & L. Paleo./E. Archaic & $231 / 245$ & Vertebrata & Indeterminate & 27 \\
\hline 27 & $27 \mathrm{~A}$ & 1376 & II/IIIa & L. Paleo./E. Archaic & & Canis sp. & Permanent tooth & 1 \\
\hline 27 & $27 \mathrm{~A}$ & 1376 & II/IIIa & L. Paleo./E. Archaic & & Colubridae & Dorsal vertebra & 1 \\
\hline 27 & $27 \mathrm{~A}$ & 1376 & II/IIIa & L. Paleo./E. Archaic & & Mammalia (Medium/large) & Long bone & 2 \\
\hline 27 & $27 \mathrm{~A}$ & 1376 & II/IIIa & L. Paleo./E. Archaic & & Mammalia (Micro) & Permanent tooth & 1 \\
\hline 27 & $27 \mathrm{~A}$ & 1376 & II/IIIa & L. Paleo./E. Archaic & & Mammalia (Small) & Alveolar ridge fragment & 1 \\
\hline 27 & $27 \mathrm{~A}$ & 1376 & II/IIIa & L. Paleo./E. Archaic & & Small/Medium Vertebrata & Long bone & 10 \\
\hline 27 & $27 \mathrm{~A}$ & 1376 & II/IIIa & L. Paleo./E. Archaic & & Sylvilagus sp. & Calcaneus & 1 \\
\hline 27 & $27 \mathrm{~A}$ & 1376 & IIIIIa & L. Paleo./E. Archaic & & Sylvilagus sp. & Permanent tooth & 1 \\
\hline 27 & $27 \mathrm{~A}$ & 1376 & II/IIIa & L. Paleo./E. Archaic & & Vertebrata & Indeterminate & 34 \\
\hline 27 & $27 \mathrm{~B}-2$ & 1767 & II/IIIa & L. Paleo./E. Archaic & 240 & Small/Medium Vertebrata & Long bone & 1 \\
\hline 27 & $27 \mathrm{~B}-2$ & 1767 & IIIIIa & L. Paleo./E. Archaic & 240 & Vertebrata & Indeterminate & 16 \\
\hline 27 & $28 \mathrm{~A}$ & 1456 & II/IIIa & L. Paleo./E. Archaic & & Small/Medium Vertebrata & Long bone & 2 \\
\hline 27 & $28 \mathrm{~A}$ & 1456 & II/LIIa & L. Paleo./E. Archaic & & Vertebrata & Indeterminate & 38 \\
\hline 27 & $28 \mathrm{~B}$ & 1433 & II/Шаa & L. Paleo./E. Archaic & 240 & Mammalia (Medium/large) & Long bone & 1 \\
\hline 27 & $30-29$ & 1610 & III & L. Paleo./E. Archaic & & Mammalia (Medium/large) & Long bone & 1 \\
\hline 27 & $30-29$ & 1610 & III & L. Paleo./E. Archaic & & Rodentia (Medium) & Permanent tooth & 1 \\
\hline 27 & $30-29$ & 1610 & III & L. Paleo./E. Archaic & & Small/Medium Vertebrata & Long bone & 2 \\
\hline 27 & $30-29$ & 1610 & III & L. Paleo./E. Archaic & & Sylvilagus sp. & Calcaneus & 1 \\
\hline 27 & $30-29$ & 1610 & III & L. Paleo./E. Archaic & & Vertebrata & Indeterminate & 28 \\
\hline 27 & $30 \mathrm{~A}$ & 1617 & III & L. Paleo. & & Mammalia (Medium/large) & Indeterminate & 1 \\
\hline 27 & $30 \mathrm{~A}$ & 1617 & III & L. Paleo. & & Medium/Large Vertebrata & Indeterminate & 2 \\
\hline 27 & $30 \mathrm{~A}$ & 1617 & III & L. Paleo. & & Small/Medium Vertebrata & Long bone & 6 \\
\hline 27 & $30 \mathrm{~B}$ & 1623 & III & L. Paleo. & 240 & Small/Medium Vertebrata & Long bone & 6 \\
\hline 27 & $30 \mathrm{~B}$ & 1623 & III & L. Paleo. & 240 & Vertebrata & Indeterminate & 16 \\
\hline 27 & 31 & 1809 & III & L. Paleo. & & Mammalia (Medium) & Ulna & 1 \\
\hline 27 & 31 & 1809 & III & L. Paleo. & & Small/Medium Vertebrata & Long bone & 4 \\
\hline 27 & 31 & 1809 & III & L. Paleo. & & Vertebrata & Indeterminate & 9 \\
\hline 27 & 32 & 1835 & III & L. Paleo. & & Mammalia (Medium/large) & Indeterminate & 1 \\
\hline 27 & 32 & 1835 & III & L. Paleo. & & Mammalia (Medium/large) & Long bone & 1 \\
\hline 27 & 32 & 1835 & III & L. Paleo. & & Mammalia (Small) & Cranium & 1 \\
\hline 27 & 32 & 1835 & III & L. Paleo. & & Mammalia (Small) & Permanent tooth & 1 \\
\hline 27 & 32 & 1835 & III & L. Paleo. & & Medium/Large Vertebrata & Indeterminate & 1 \\
\hline 27 & 32 & 1835 & II & L. Paleo. & & Small/Medium Vertebrata & Long bone & 10 \\
\hline 27 & 32 & 1835 & II & L. Paleo. & & Vertebrata & Indeterminate & 30 \\
\hline 27 & 33 & 1902 & III & L. Paleo. & & cf. Sylvilagus sp. & Ulna & 2 \\
\hline 27 & 33 & 1902 & III & L. Paleo. & & Medium/Large Vertebrata & Indeterminate & 3 \\
\hline 27 & 33 & 1902 & III & L. Paleo. & & Small/Medium Vertebrata & Long bone & 9 \\
\hline 27 & 33 & 1902 & III & L. Paleo. & & Sylvilagus sp. & Calcaneus & 1 \\
\hline 27 & 33 & 1902 & III & L. Paleo. & & Sylvilagus sp. & Metatarsal 2 & 1 \\
\hline 27 & 33 & 1902 & III & L. Paleo. & & Sylvilagus sp. & Metatarsal 3 & 1 \\
\hline 27 & 33 & 1902 & III & L. Paleo. & & Vertebrata & Indeterminate & 33 \\
\hline 27 & 34 & 1994 & III & L. Paleo. & & Leporidae & Permanent tooth & 1 \\
\hline 27 & 34 & 1994 & III & L. Paleo. & & Mammalia (Small) & Humerus & 1 \\
\hline 27 & 34 & 1994 & III & L. Paleo. & & Rodentia (Medium) & Permanent tooth & 1 \\
\hline 27 & 34 & 1994 & II & L. Paleo. & & Small/Medium Vertebrata & Long bone & 3 \\
\hline
\end{tabular}




\begin{tabular}{|c|c|c|c|c|c|c|c|c|}
\hline Square & Level & Lot & Unit & Cultural Affinity & Feature & Taxon & Element & No. \\
\hline 27 & 34 & 1994 & II & L. Paleo. & & Vertebrata & Indeterminate & 48 \\
\hline 27 & 35 & 2015 & II & L. Paleo. & & Mammalia (Small) & Permanent tooth & 1 \\
\hline 27 & 35 & 2015 & II & L. Paleo. & & Small/Medium Vertebrata & Long bone & 8 \\
\hline 27 & 35 & 2015 & III & L. Paleo. & & Vertebrata & Indeterminate & 41 \\
\hline 27 & 36 & 2642 & II & L. Paleo. & & Geomys sp. & Permanent tooth & 1 \\
\hline 27 & 36 & 2642 & III & L. Paleo. & & Mammalia (Medium/large) & Indeterminate & 1 \\
\hline 27 & 36 & 2642 & III & L. Paleo. & & Small/Medium Vertebrata & Long bone & 3 \\
\hline 27 & 36 & 2642 & III & L. Paleo. & & Vertebrata & Indeterminate & 1 \\
\hline 27 & 37 & 2658 & Id/II & L. Paleo. & & Medium/Large Vertebrata & Indeterminate & 5 \\
\hline 27 & 37 & 2658 & Id/II & L. Paleo. & & Small/Medium Vertebrata & Long bone & 1 \\
\hline 27 & 37 & 2658 & Id/II & L. Paleo. & & Vertebrata & Indeterminate & 5 \\
\hline 27 & 38 & 2800 & IId/II & L. Paleo. & & Small/Medium Vertebrata & Long bone & 3 \\
\hline 27 & 38 & 2800 & IId/II & L. Paleo. & & Vertebrata & Indeterminate & 10 \\
\hline 27 & 39 & 2605 & Id & L. Paleo. & & Medium/Large Vertebrata & Indeterminate & 1 \\
\hline 27 & 39 & 2605 & Id & L. Paleo. & & Neotoma sp. & Permanent tooth & 1 \\
\hline 27 & 39 & 2605 & Id & L. Paleo. & & Small/Medium Vertebrata & Long bone & 5 \\
\hline 27 & 39 & 2605 & Id & L. Paleo. & & Testudinata & Shell fragment & 3 \\
\hline 27 & 39 & 2605 & Id & L. Paleo. & & Vertebrata & Indeterminate & 15 \\
\hline 27 & 39 & 2684 & Id & L. Paleo. & & Mammalia (Medium/large) & Indeterminate & 2 \\
\hline 27 & 39 & 2684 & Id & L. Paleo. & & Mammalia (Medium/large) & Tooth, perm./decid. ind. & 1 \\
\hline 27 & 39 & 2684 & Id & L. Paleo. & & Vertebrata & Indeterminate & 4 \\
\hline 27 & 40 & 2663 & Isi-c/Id & L. Paleo. & & Geomys sp. & Permanent tooth & 1 \\
\hline 27 & 40 & 2663 & Isi-c/Id & L. Paleo. & & Leporidae & Metatarsal 3 & 1 \\
\hline 27 & 40 & 2663 & Isi-c/Id & L. Paleo. & & Leporidae & Permanent tooth & 1 \\
\hline 27 & 40 & 2663 & Isi-c/Id & L. Paleo. & & Mammalia (Medium/large) & Indeterminate & 3 \\
\hline 27 & 40 & 2663 & Isi-c/Id & L. Paleo. & & Mammalia (Small) & Radius & 2 \\
\hline 27 & 40 & 2663 & Isi-c/Id & L. Paleo. & & Small/Medium Vertebrata & Long bone & 9 \\
\hline 27 & 40 & 2663 & Isi-c/Id & L. Paleo. & & Small/Medium Vertebrata & Middle phalange & 1 \\
\hline 27 & 40 & 2663 & Isi-c/Id & L. Paleo. & & Small/Medium Vertebrata & Proximal phalange & 1 \\
\hline 27 & 40 & 2663 & Isi-c/Id & L. Paleo. & & Vertebrata & Indeterminate & 29 \\
\hline 27 & 41 & 2652 & Isi-c & L. Paleo. & & Mammalia (Medium) & Proximal phalange & 1 \\
\hline 27 & 41 & 2652 & Isi-c & L. Paleo. & & Mammalia (Medium/large) & Indeterminate & 10 \\
\hline 27 & 41 & 2652 & Isi-c & L. Paleo. & & Mammalia (Medium/large) & Long bone & 1 \\
\hline 27 & 41 & 2652 & Isi-c & L. Paleo. & & Small/Medium Vertebrata & Long bone & 4 \\
\hline 27 & 41 & 2652 & Isi-c & L. Paleo. & & Sylvilagus sp. & Axis & 1 \\
\hline 27 & 41 & 2652 & Isi-c & L. Paleo. & & Vertebrata & Indeterminate & 13 \\
\hline 27 & 42 & 2851 & Isi-c & L. Paleo. & & Mammalia (Medium/large) & Indeterminate & 4 \\
\hline 27 & 42 & 2851 & Isi-c & L. Paleo. & & Medium/Large Vertebrata & Indeterminate & 2 \\
\hline 27 & 42 & 2851 & Isi-c & L. Paleo. & & Small/Medium Vertebrata & Long bone & 8 \\
\hline 27 & 42 & 2851 & Isi-c & L. Paleo. & & Sylvilagus sp. & Calcaneus & 1 \\
\hline 27 & 42 & 2851 & Isi-c & L. Paleo. & & Vertebrata & Indeterminate & 23 \\
\hline 27 & 43 & 2812 & Icl/Isi-c & Paleoindian & & Mammalia (Large) & Indeterminate & 1 \\
\hline 27 & 43 & 2812 & Icl/Isi-c & Paleoindian & & Small/Medium Vertebrata & Long bone & 2 \\
\hline 27 & 43 & 2812 & Icl/Isi-c & Paleoindian & & Small/Medium Vertebrata & Vertebra & 1 \\
\hline 27 & 43 & 2812 & Icl/Isi-c & Paleoindian & & Vertebrata & Indeterminate & 11 \\
\hline 27 & 44 & 2821 & Icl/Isi-c & Paleoindian & & Mammalia (Medium/large) & Indeterminate & 1 \\
\hline 27 & 44 & 2821 & Icl/Isi-c & Paleoindian & & Small/Medium Vertebrata & Long bone & 6 \\
\hline 27 & 44 & 2821 & Icl/Isi-c & Paleoindian & & Vertebrata & Indeterminate & 6 \\
\hline 27 & 45 & 2603 & Icl & E. Paleoindian & & Vertebrata & Indeterminate & 5 \\
\hline 27 & 46 & 2798 & Icl & E. Paleoindian & & Mammalia (Medium/large) & Indeterminate & 3 \\
\hline 27 & 46 & 2798 & Icl & E. Paleoindian & & Small/Medium Vertebrata & Long bone & 8 \\
\hline 27 & 46 & 2798 & Icl & E. Paleoindian & & Vertebrata & Indeterminate & 13 \\
\hline 27 & 47 & 2766 & Icl & E. Paleoindian & & Medium/Large Vertebrata & Indeterminate & 2 \\
\hline 27 & 47 & 2766 & Icl & E. Paleoindian & & Vertebrata & Indeterminate & 5 \\
\hline 27 & 48 & 2763 & Icl & E. Paleoindian & & Mammalia (Medium/large) & Indeterminate & 1 \\
\hline 27 & 48 & 2763 & Icl & E. Paleoindian & & Medium/Large Vertebrata & Indeterminate & 2 \\
\hline 27 & 48 & 2763 & Icl & E. Paleoindian & & Small/Medium Vertebrata & Long bone & 3 \\
\hline 27 & 48 & 2763 & Icl & E. Paleoindian & & Vertebrata & Indeterminate & 4 \\
\hline 27 & 49 & 2303 & Icl & E. Paleoindian & & Vertebrata & Indeterminate & 3 \\
\hline 27 & 49 & 2633 & Icl & E. Paleoindian & & Mammalia (Small) & Permanent tooth & 3 \\
\hline 27 & 49 & 2633 & Icl & E. Paleoindian & & Mammalia (Small/medium) & Alveolar ridge fragment & 1 \\
\hline 27 & 49 & 2633 & Icl & E. Paleoindian & & Small/Medium Vertebrata & Long bone & 4 \\
\hline 27 & 49 & 2633 & Icl & E. Paleoindian & & Vertebrata & Indeterminate & 11 \\
\hline 27 & 50 & 2435 & |Isi/Icl & E. Paleoindian & & Mammalia (Medium/large) & Long bone & 1 \\
\hline 27 & 50 & 2592 & |Isi/Icl & E. Paleoindian & & Small/Medium Vertebrata & Long bone & 5 \\
\hline 27 & 50 & 2592 & Isi/Icl & E. Paleoindian & & Vertebrata & Indeterminate & 8 \\
\hline 27 & 51 & 2624 & Isi/Icl & E. Paleoindian & & Medium/Large Vertebrata & Indeterminate & 1 \\
\hline
\end{tabular}




\begin{tabular}{|c|c|c|c|c|c|c|c|c|}
\hline Square & Level & \begin{tabular}{|l|} 
Lot \\
\end{tabular} & Unit & Cultural Affinity & Feature & Taxon & Element & No. \\
\hline 27 & 51 & 2624 & Isi/Icl & E. Paleoindian & & Small/Medium Vertebrata & Long bone & 2 \\
\hline 27 & 51 & 2624 & Isi/Icl & E. Paleoindian & & Vertebrata & Indeterminate & \\
\hline 27 & $51 \mathrm{~A}$ & 2625 & Isi/Icl & E. Paleoindian & & Leporidae & Permanent tooth & \\
\hline 27 & $51 \mathrm{~B}$ & 2445 & Isi/Icl & E. Paleoindian & 262 & Mammalia (Medium/large) & Indeterminate & \\
\hline 27 & $51 \mathrm{~B}$ & 2451 & Isi/Icl & E. Paleoindian & 262 & Mammalia (Large) & Indeterminate & \\
\hline 27 & $51 \mathrm{~B}$ & 2453 & Isi/Icl & E. Paleoindian & 262 & Medium/Large Vertebrata & Indeterminate & \\
\hline 27 & $51 \mathrm{~B}$ & 2454 & Isi/Icl & E. Paleoindian & 262 & Mammalia (Medium/large) & Indeterminate & \\
\hline 27 & $51 \mathrm{~B}$ & 2457 & Isi/Icl & E. Paleoindian & 262 & Medium/Large Vertebrata & Indeterminate & \\
\hline 27 & $51 \mathrm{~B}$ & 2535 & Isi/Icl & E. Paleoindian & 262 & Mammalia (Large) & Long bone & \\
\hline 27 & $51 \mathrm{~B}$ & 2538 & |Isi/Icl & E. Paleoindian & 262 & Medium/Large Vertebrata & Indeterminate & \\
\hline 27 & 52 & 2621 & |Isi/Icl & E. Paleoindian & & Mammalia (Medium/large) & Indeterminate & \\
\hline 27 & $52 \mathrm{~A}$ & 2622 & Isi/Icl & E. Paleoindian & & Small/Medium Vertebrata & Long bone & \\
\hline 27 & $52 \mathrm{~A}$ & 2622 & |Isi/Icl & E. Paleoindian & & Vertebrata & Indeterminate & \\
\hline 27 & $52 \mathrm{~B}$ & 2463 & |Isi/Icl & E. Paleoindian & 262 & Medium/Large Vertebrata & Indeterminate & \\
\hline 27 & $52 \mathrm{~B}$ & 2539 & Isi/Icl & E. Paleoindian & 262 & Leporidae & Permanent tooth & \\
\hline 27 & $52 \mathrm{~B}$ & 2539 & Isi/Icl & E. Paleoindian & 262 & Medium/Large Vertebrata & Indeterminate & \\
\hline 27 & $52 \mathrm{~B}$ & 2539 & |Isi/Icl & E. Paleoindian & 262 & Small/Medium Vertebrata & Long bone & \\
\hline 27 & $52 \mathrm{~B}$ & 2539 & Isi/Icl & E. Paleoindian & 262 & Vertebrata & Indeterminate & \\
\hline 27 & 53 & 2506 & Igl//si/Icl & E. Paleoindian & & Medium/Large Vertebrata & Indeterminate & \\
\hline 27 & 53 & 2506 & Igl/Isi/Icl & E. Paleoindian & & Vertebrata & Indeterminate & \\
\hline 27 & $53 \mathrm{~B}$ & 2534 & Igl/Isi/Icl & E. Paleoindian & & Medium/Large Vertebrata & Indeterminate & \\
\hline 27 & $53 \mathrm{~B}$ & 2534 & Igl//si/Icl & E. Paleoindian & & Small/Medium Vertebrata & Long bone & \\
\hline 27 & $53 \mathrm{~B}$ & 2534 & Igl/Isi/Icl & E. Paleoindian & & Vertebrata & Indeterminate & \\
\hline 27 & $54 \mathrm{~B}$ & 2526 & Igl/Isi/Icl & E. Paleoindian & & Mammalia (Medium/large) & Indeterminate & \\
\hline 27 & $54 \mathrm{~B}$ & 2526 & $\mathrm{Igl} / \mathrm{Isi} / \mathrm{Icl}$ & E. Paleoindian & & Medium/Large Vertebrata & Indeterminate & \\
\hline 27 & $55 \mathrm{~A}$ & 2573 & Igl & E. Paleoindian & & Vertebrata & Indeterminate & \\
\hline 27 & 57 & 2645 & Igl & E. Paleoindian & & Leporidae & Permanent tooth & \\
\hline 27 & 57 & 2645 & Igl & E. Paleoindian & & Mammalia (Medium/large) & Indeterminate & \\
\hline 27 & 58 & 2657 & Igl & E. Paleoindian & & Small/Medium Vertebrata & Long bone & \\
\hline 27 & 58 & 2657 & $\mathrm{Igl}$ & E. Paleoindian & & Vertebrata & Indeterminate & \\
\hline 27 & 60 & 2677 & $\mathrm{Igl}$ & E. Paleoindian & & Medium/Large Vertebrata & Indeterminate & \\
\hline 27 & 60 & 2677 & Igl & E. Paleoindian & & Vertebrata & Indeterminate & \\
\hline 28 & 15 & 701 & IIIlb & Early/M. Archaic & & Medium/Large Vertebrata & Indeterminate & \\
\hline 28 & 15 & 701 & IIIb & Early/M. Archaic & & Vertebrata & Indeterminate & \\
\hline 28 & 16 & 729 & IIIa/b & Early/M. Archaic & & Vertebrata & Indeterminate & \\
\hline 28 & 17 & 753 & IIIa/b & E. Archaic & & Mammalia (Medium/large) & Indeterminate & \\
\hline 28 & 17 & 753 & IIIa/b & E. Archaic & & Mammalia (Medium/large) & Long bone & \\
\hline 28 & 17 & 753 & IIIa/b & E. Archaic & & Small/Medium Vertebrata & Long bone & \\
\hline 28 & 17 & 753 & IIIa/b & E. Archaic & & Vertebrata & Indeterminate & \\
\hline 28 & 18 & 789 & $\mathrm{ma} / \mathrm{b}$ & E. Archaic & & Mammalia (Medium/large) & Indeterminate & \\
\hline 28 & 18 & 789 & $\mathrm{mIIa} / \mathrm{b}$ & E. Archaic & & Testudinata & Shell fragment & \\
\hline 28 & 18 & 789 & IIIa/b & E. Archaic & & Vertebrata & Indeterminate & \\
\hline 28 & 19 & 831 & IIIa & E. Archaic & 231 & Mammalia (Micro) & Proximal phalange & \\
\hline 28 & 19 & 831 & IIIIa & E. Archaic & 231 & Mammalia (Micro) & Tibia & \\
\hline 28 & 19 & 831 & IIIIa & E. Archaic & 231 & Small/Medium Vertebrata & Long bone & \\
\hline 28 & 19 & 831 & IIIIa & E. Archaic & 231 & Vertebrata & Indeterminate & \\
\hline 28 & 20 & 885 & IIIIa & E. Archaic & 231 & Geomys sp. & Permanent tooth & \\
\hline 28 & 20 & 885 & IIIа & E. Archaic & 231 & Mammalia (Medium/large) & Indeterminate & \\
\hline 28 & 20 & 885 & IIIa & E. Archaic & 231 & Mammalia (Small) & Metapodial & \\
\hline 28 & 20 & 885 & IIIIa & E. Archaic & 231 & Small/Medium Vertebrata & Long bone & \\
\hline 28 & 20 & 885 & IIIIa & E. Archaic & 231 & Vertebrata & Indeterminate & 3 \\
\hline 28 & 21 & 979 & |Па & E. Archaic & 231 & Mammalia (Medium/large) & Indeterminate & \\
\hline 28 & 21 & 979 & IIIIa & E. Archaic & 231 & Medium/Large Vertebrata & Long bone & \\
\hline 28 & 21 & 979 & IIIIa & E. Archaic & 231 & Small/Medium Vertebrata & Long bone & \\
\hline 28 & 21 & 979 & IIIIa & E. Archaic & 231 & Vertebrata & Indeterminate & 13 \\
\hline 28 & 22 & 1025 & IIIIa & E. Archaic & 231 & Mammalia (Medium/large) & Indeterminate & \\
\hline 28 & 22 & 1025 & IIIIa & E. Archaic & 231 & Mammalia (Medium/large) & Long bone & \\
\hline 28 & 22 & 1025 & IIIIa & E. Archaic & 231 & Mammalia (Small) & Permanent tooth & \\
\hline 28 & 22 & 1025 & IIIIa & E. Archaic & 231 & Neotoma sp. & Permanent tooth & \\
\hline 28 & 22 & 1025 & IIIIa & E. Archaic & 231 & Small/Medium Vertebrata & Long bone & \\
\hline 28 & 22 & 1025 & IIIIa & E. Archaic & 231 & Vertebrata & Indeterminate & 5 \\
\hline 28 & 22 & 1324 & IIIIa & E. Archaic & 231 & Vertebrata & Indeterminate & \\
\hline 28 & 24 & 1488 & IIIIa & E. Archaic & 245 & Leporidae & Permanent tooth & \\
\hline 28 & 24 & 1488 & IIIIa & E. Archaic & 245 & Small/Medium Vertebrata & Long bone & \\
\hline 28 & 24 & 1488 & IIIIa & E. Archaic & 245 & Testudinata & Shell fragment & \\
\hline 28 & 24 & 1488 & IIIIa & E. Archaic & 245 & Vertebrata & Indeterminate & \\
\hline 28 & 24 & 1957 & ШІа & E. Archaic & 245 & Artiodactyla & Tooth, perm./decid. ind. & \\
\hline
\end{tabular}




\begin{tabular}{|c|c|c|c|c|c|c|c|c|}
\hline Square & Level & Lot & Unit & Cultural Affinity & Feature & Taxon & Element & No. \\
\hline 28 & 24 & 1957 & $\overline{\mathrm{IIIa}}$ & E. Archaic & 245 & Small/Medium Vertebrata & Long bone & 5 \\
\hline 28 & 24 & 1957 & IIIIa & E. Archaic & 245 & Vertebrata & Indeterminate & 5 \\
\hline 28 & $24-27$ & 1764 & IIIIa & E. Archaic & 245 & Vertebrata & Indeterminate & 1 \\
\hline 28 & 25 & 1579 & Ша & E. Archaic & 245 & Leporidae & Permanent tooth & 1 \\
\hline 28 & 25 & 1579 & IIIIa & E. Archaic & 245 & Lepus californicus & Third tarsal & 1 \\
\hline 28 & 25 & 1579 & IIIIa & E. Archaic & 245 & Mammalia (Medium/large) & Long bone & 3 \\
\hline 28 & 25 & 1579 & IIIa & E. Archaic & 245 & Small/Medium Vertebrata & Long bone & 9 \\
\hline 28 & 25 & 1579 & IIIIa & E. Archaic & 245 & Testudinata & Shell fragment & 1 \\
\hline 28 & 25 & 1579 & III & E. Archaic & 245 & Vertebrata & Indeterminate & 17 \\
\hline 28 & 25 & 1978 & IIIIa & E. Archaic & 245 & Mammalia (Medium/large) & Indeterminate & 3 \\
\hline 28 & 25 & 1978 & IIIIa & E. Archaic & 245 & Mammalia (Small) & Metapodial & 1 \\
\hline 28 & 25 & 1978 & IIIIa & E. Archaic & 245 & Sciurus sp. & Humerus & 1 \\
\hline 28 & 25 & 1978 & III & E. Archaic & 245 & Vertebrata & Indeterminate & 29 \\
\hline 28 & 26 & 1655 & II/IIIIa & L. Paleo./E. Archaic & 245 & Geomys sp. & Permanent tooth & 1 \\
\hline 28 & 26 & 1655 & II/IIIa & L. Paleo./E. Archaic & 245 & Leporidae & Permanent tooth & 1 \\
\hline 28 & 26 & 1655 & II/IIIa & L. Paleo./E. Archaic & 245 & Medium/Large Vertebrata & Indeterminate & 2 \\
\hline 28 & 26 & 1655 & II/IIIIa & L. Paleo./E. Archaic & 245 & Small/Medium Vertebrata & Long bone & 10 \\
\hline 28 & 26 & 1655 & ШІІІІа & L. Paleo./E. Archaic & 245 & Sylvilagus sp. & Third tarsal & 1 \\
\hline 28 & 26 & 1655 & II/IIIa & L. Paleo./E. Archaic & 245 & Vertebrata & Indeterminate & 33 \\
\hline 28 & 26 & 2008 & II/IIIa & L. Paleo./E. Archaic & 245 & Leporidae & Permanent tooth & 1 \\
\hline 28 & 26 & 2008 & II/Ша & L. Paleo./E. Archaic & 245 & Mammalia (Small) & Radius & 1 \\
\hline 28 & 26 & 2008 & ШІ/IIIa & L. Paleo./E. Archaic & 245 & Small/Medium Vertebrata & Long bone & 2 \\
\hline 28 & 26 & 2008 & II/IIIa & L. Paleo./E. Archaic & 245 & Testudinata & Shell fragment & 2 \\
\hline 28 & 26 & 2008 & II/IIIa & L. Paleo./E. Archaic & 245 & Vertebrata & Indeterminate & 15 \\
\hline 28 & $27 \mathrm{~A}$ & 1627 & II/IIIa & L. Paleo./E. Archaic & & Small/Medium Vertebrata & Long bone & 5 \\
\hline 28 & $27 \mathrm{~A}$ & 1627 & II/IIIa & L. Paleo./E. Archaic & & Sylvilagus sp. & Humerus & 1 \\
\hline 28 & $27 \mathrm{~A}$ & 1627 & II/Wa & L. Paleo./E. Archaic & & Vertebrata & Indeterminate & 2 \\
\hline 28 & 27B & 781 & II/IIIa & L. Paleo./E. Archaic & 245 & Small/Medium Vertebrata & Long bone & 6 \\
\hline 28 & 27B & 781 & II/IIIa & L. Paleo./E. Archaic & 245 & Vertebrata & Indeterminate & 9 \\
\hline 28 & 27B & 1625 & II/IIIa & L. Paleo./E. Archaic & 245 & Small/Medium Vertebrata & Long bone & 2 \\
\hline 28 & $27 \mathrm{~B}$ & 1625 & II/IIIa & L. Paleo./E. Archaic & 245 & Vertebrata & Indeterminate & 2 \\
\hline 28 & 27B & 2091 & II/IIIIa & L. Paleo./E. Archaic & 245 & Mammalia (Small) & Vertebra & 1 \\
\hline 28 & 27B & 2091 & II/IIIa & L. Paleo./E. Archaic & 245 & Small/Medium Vertebrata & Long bone & 2 \\
\hline 28 & 27B & 2091 & II/IIIa & L. Paleo./E. Archaic & 245 & Vertebrata & Indeterminate & 10 \\
\hline 28 & 28 & 2095 & II/IIIa & L. Paleo./E. Archaic & & Leporidae & Permanent tooth & 1 \\
\hline 28 & 28 & 2095 & II/IIIa & L. Paleo./E. Archaic & & Mammalia (Medium/large) & Indeterminate & 1 \\
\hline 28 & 28 & 2095 & III/IIIa & L. Paleo./E. Archaic & & Mammalia (Medium/large) & Tooth, perm./decid. ind. & 1 \\
\hline 28 & 28 & 2095 & II/ШII & L. Paleo./E. Archaic & & Mammalia (Small) & Rib & 1 \\
\hline 28 & 28 & 2095 & II/ШII & L. Paleo./E. Archaic & & Mammalia (Small) & Vertebra & 1 \\
\hline 28 & 28 & 2095 & II/IIIa & L. Paleo./E. Archaic & & Small/Medium Vertebrata & Long bone & 5 \\
\hline 28 & 28 & 2095 & II/IIIa & L. Paleo./E. Archaic & & Vertebrata & Indeterminate & 21 \\
\hline 28 & $28 \mathrm{~A}$ & 1788 & II/IIIIa & L. Paleo./E. Archaic & & Mammalia (Medium/large) & Long bone & 1 \\
\hline 28 & $28 \mathrm{~A}$ & 1788 & II/IIIa & L. Paleo./E. Archaic & & Small/Medium Vertebrata & Long bone & 6 \\
\hline 28 & $28 \mathrm{~A}$ & 1788 & II/IIIa & L. Paleo./E. Archaic & & Vertebrata & Indeterminate & 9 \\
\hline 28 & $28 \mathrm{~B}$ & 1798 & II/IIIa & L. Paleo./E. Archaic & & Small/Medium Vertebrata & Long bone & 4 \\
\hline 28 & $28 \mathrm{~B}$ & 1798 & Шा/Ша & L. Paleo./E. Archaic & & Vertebrata & Indeterminate & 1 \\
\hline 28 & 29 & 2102 & II/IIIa & L. Paleo./E. Archaic & & Mammalia (Medium/large) & Vertebra & 1 \\
\hline 28 & 29 & 2102 & II/IIIa & L. Paleo./E. Archaic & & Vertebrata & Indeterminate & 1 \\
\hline 28 & $29 \mathrm{~A}$ & 1890 & II/IIIa & L. Paleo./E. Archaic & & Geomys sp. & Ulna & 1 \\
\hline 28 & $29 \mathrm{~A}$ & 1890 & II/IIIa & L. Paleo./E. Archaic & & Small/Medium Vertebrata & Long bone & 5 \\
\hline 28 & $29 \mathrm{~A}$ & 1890 & II/IIIa & L. Paleo./E. Archaic & & Squamata & Dorsal vertebra & 1 \\
\hline 28 & $29 \mathrm{~A}$ & 1890 & II/IIIa & L. Paleo./E. Archaic & & Vertebrata & Indeterminate & 9 \\
\hline 28 & 29B & 1894 & IIIIIa & L. Paleo./E. Archaic & & Small/Medium Vertebrata & Long bone & 1 \\
\hline 28 & 29B & 1894 & II/IIIa & L. Paleo./E. Archaic & & Vertebrata & Indeterminate & 3 \\
\hline 28 & $30 \mathrm{~A}$ & 1899 & II/IIIa & L. Paleo./E. Archaic & & Mammalia (Small) & Calcaneus & 1 \\
\hline 28 & $30 \mathrm{~A}$ & 1899 & ШІШІа & L. Paleo./E. Archaic & & Osteichthyes (Small) & Sagitta otolith & 1 \\
\hline 28 & $30 \mathrm{~A}$ & 1899 & II/IIIa & L. Paleo./E. Archaic & & Small/Medium Vertebrata & Long bone & 6 \\
\hline 28 & $30 \mathrm{~A}$ & 1899 & II/IIIa & L. Paleo./E. Archaic & & Vertebrata & Indeterminate & 10 \\
\hline 28 & $30 \mathrm{~A}$ & 2121 & II/IIIa & L. Paleo./E. Archaic & & Mammalia (Medium) & Metapodial & 1 \\
\hline 28 & $30 \mathrm{~A}$ & 2121 & II/IIIa & L. Paleo./E. Archaic & & Small/Medium Vertebrata & Long bone & 10 \\
\hline 28 & $30 \mathrm{~A}$ & 2121 & II/IIII & L. Paleo./E. Archaic & & Testudinata & Carapace fragment ind. & 1 \\
\hline 28 & $30 \mathrm{~A}$ & 2121 & IIIIIIa & L. Paleo./E. Archaic & & Vertebrata & Indeterminate & 39 \\
\hline 28 & 30B & 2120 & II/IIIIa & L. Paleo./E. Archaic & & Mammalia (Medium) & Femur & 1 \\
\hline 28 & 30B & 2120 & II/IIIa & L. Paleo./E. Archaic & & Vertebrata & Indeterminate & 1 \\
\hline 28 & $31 \mathrm{~A}$ & 2073 & III & L. Paleo. & & Small/Medium Vertebrata & Long bone & 1 \\
\hline 28 & $31 \mathrm{~A}$ & 2073 & III & L. Paleo. & & Vertebrata & Indeterminate & 3 \\
\hline 28 & $31 \mathrm{~A}$ & 2124 & III & L. Paleo. & & Lepus californicus & Third tarsal & 1 \\
\hline
\end{tabular}




\begin{tabular}{|c|c|c|c|c|c|c|c|c|}
\hline Square & Level & \begin{tabular}{|l|l|} 
Lot & \\
\end{tabular} & Unit & Cultural Affinity & Feature & Taxon & Element & No. \\
\hline 28 & $31 \mathrm{~A}$ & 2124 & $\overline{I I}$ & L. Paleo. & & Small/Medium Vertebrata & Long bone & 1 \\
\hline 28 & $31 \mathrm{~A}$ & 2124 & III & L. Paleo. & & Sylvilagus sp. & Calcaneus & 1 \\
\hline 28 & $31 \mathrm{~A}$ & 2124 & III & L. Paleo. & & Vertebrata & Indeterminate & 12 \\
\hline 28 & 31B & 2071 & III & L. Paleo. & 254 & Small/Medium Vertebrata & Long bone & 3 \\
\hline 28 & $31 \mathrm{~B}$ & 2123 & III & L. Paleo. & 254 & Mammalia (Medium/large) & Indeterminate & 4 \\
\hline 28 & $31 \mathrm{~B}$ & 2123 & III & L. Paleo. & 254 & Small/Medium Vertebrata & Long bone & 2 \\
\hline 28 & $31 \mathrm{~B}$ & 2123 & III & L. Paleo. & 254 & Vertebrata & Indeterminate & 8 \\
\hline 28 & 32 & 2130 & III & L. Paleo. & & cf. Leporidae & Alveolar ridge fragment & 1 \\
\hline 28 & 32 & 2130 & II & L. Paleo. & & cf. Leporidae & Metapodial & 1 \\
\hline 28 & 32 & 2130 & III & L. Paleo. & & Lepus californicus & Humerus & 1 \\
\hline 28 & 32 & 2130 & III & L. Paleo. & & Mammalia (Medium/large) & Indeterminate & 6 \\
\hline 28 & 32 & 2130 & III & L. Paleo. & & Mammalia (Small) & Humerus & 1 \\
\hline 28 & 32 & 2130 & II & L. Paleo. & & Small/Medium Vertebrata & Long bone & 8 \\
\hline 28 & 32 & 2130 & II & L. Paleo. & & Vertebrata & Indeterminate & 50 \\
\hline 28 & 33 & 2152 & II & L. Paleo. & & Mammalia (Medium/large) & Indeterminate & \\
\hline 28 & 33 & 2152 & III & L. Paleo. & & Mammalia (Medium/large) & Tooth, perm./decid. ind. & 1 \\
\hline 28 & 33 & 2152 & II & L. Paleo. & & Mammalia (Small) & Permanent tooth & \\
\hline 28 & 33 & 2152 & II & L. Paleo. & & Small/Medium Vertebrata & Long bone & 12 \\
\hline 28 & 33 & 2152 & II & L. Paleo. & & Sylvilagus sp. & Calcaneus & \\
\hline 28 & 33 & 2152 & II & L. Paleo. & & Sylvilagus sp. & Mandible & \\
\hline 28 & 33 & 2152 & II & L. Paleo. & & Sylvilagus sp. & Permanent tooth & \\
\hline 28 & 33 & 2152 & III & L. Paleo. & & Vertebrata & Indeterminate & 35 \\
\hline 28 & 34 & 2161 & III & L. Paleo. & & Geomys sp. & Permanent tooth & \\
\hline 28 & 34 & 2161 & II & L. Paleo. & & Mammalia (Micro) & Permanent tooth & \\
\hline 28 & 34 & 2161 & II & L. Paleo. & & Mammalia (Small) & Caudal vertebra & \\
\hline 28 & 34 & 2161 & II & L. Paleo. & & Mammalia (Small/medium) & Permanent tooth & \\
\hline 28 & 34 & 2161 & III & L. Paleo. & & Small/Medium Vertebrata & Long bone & \\
\hline 28 & 34 & 2161 & III & L. Paleo. & & Vertebrata & Indeterminate & \\
\hline 28 & 35 & 2268 & II & L. Paleo. & & cf. Leporidae & Metapodial & \\
\hline 28 & 35 & 2268 & II & L. Paleo. & & Leporidae & Calcaneus & \\
\hline 28 & 35 & 2268 & II & L. Paleo. & & Mammalia (Medium) & Middle phalange & \\
\hline 28 & 35 & 2268 & II & L. Paleo. & & Mammalia (Small) & Permanent tooth & \\
\hline 28 & 35 & 2268 & II & L. Paleo. & & Serpentes & Dorsal vertebra & \\
\hline 28 & 35 & 2268 & III & L. Paleo. & & Small/Medium Vertebrata & Long bone & \\
\hline 28 & 35 & 2268 & III & L. Paleo. & & Vertebrata & Indeterminate & 2 \\
\hline 28 & 36 & 2267 & $\mathrm{Id} / \mathrm{II}$ & L. Paleo. & & Vertebrata & Indeterminate & 1 \\
\hline 28 & 37 & 2823 & Id & L. Paleo. & & Mammalia (Medium/large) & Indeterminate & \\
\hline 28 & 37 & 2823 & Id & L. Paleo. & & Mammalia (Medium/large) & Tooth, perm./decid. ind. & \\
\hline 28 & 37 & 2823 & Id & L. Paleo. & & Small/Medium Vertebrata & Long bone & \\
\hline 28 & 37 & 2823 & Id & L. Paleo. & & Testudinata & Shell fragment & \\
\hline 28 & 37 & 2823 & Id & L. Paleo. & & Vertebrata & Indeterminate & \\
\hline 28 & 38 & 2653 & Isi-c/Id & L. Paleo. & & Medium/Large Vertebrata & Indeterminate & \\
\hline 28 & 38 & 2653 & Isi-c/Id & L. Paleo. & & Small/Medium Vertebrata & Long bone & \\
\hline 28 & 38 & 2653 & Isi-c/Id & L. Paleo. & & Vertebrata & Indeterminate & \\
\hline 28 & 39 & 2789 & Isi-c/Id & L. Paleo. & & Mammalia (Medium) & Long bone & \\
\hline 28 & 39 & 2789 & Isi-c/Id & L. Paleo. & & Mammalia (Medium/large) & Indeterminate & \\
\hline 28 & 39 & 2789 & Isi-c/Id & L. Paleo. & & Small/Medium Vertebrata & Long bone & \\
\hline 28 & 39 & 2789 & Isi-c/Id & L. Paleo. & & Vertebrata & Indeterminate & 10 \\
\hline 28 & 40 & 2765 & Isi-c & L. Paleo. & & Mammalia (Medium/large) & Long bone & \\
\hline 28 & 40 & 2765 & Isi-c & L. Paleo. & & Small/Medium Vertebrata & Long bone & \\
\hline 28 & 40 & 2765 & Isi-c & L. Paleo. & & Vertebrata & Indeterminate & \\
\hline 28 & 41 & 2294 & Isi-c & L. Paleo. & & Mammalia (Medium/large) & Indeterminate & \\
\hline 28 & 41 & 2338 & Isi-c & L. Paleo. & & Small/Medium Vertebrata & Long bone & \\
\hline 28 & 41 & 2338 & Isi-c & L. Paleo. & & Vertebrata & Indeterminate & 18 \\
\hline 28 & 42 & 2738 & Isi-c & L. Paleo. & & Lepus californicus & Second tarsal & \\
\hline 28 & 42 & 2738 & Isi-c & L. Paleo. & & Small/Medium Vertebrata & Long bone & \\
\hline 28 & 42 & 2738 & Isi-c & L. Paleo. & & Vertebrata & Indeterminate & 15 \\
\hline 28 & 43 & 2759 & Isi-c & L. Paleo. & & Mammalia (Medium/large) & Indeterminate & \\
\hline 28 & 43 & 2759 & Isi-c & L. Paleo. & & Serpentes & Dorsal vertebra & 1 \\
\hline 28 & 43 & 2759 & Isi-c & L. Paleo. & & Small/Medium Vertebrata & Long bone & 2 \\
\hline 28 & 43 & 2759 & Isi-c & L. Paleo. & & Vertebrata & Indeterminate & 15 \\
\hline 28 & 44 & 2460 & Icl/Isi-c & Paleoindian & & Geomys sp. & Permanent tooth & 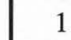 \\
\hline 28 & 44 & 2460 & Icl/Isi-c & Paleoindian & & Mammalia (Small) & Distal phalange & 1 \\
\hline 28 & 44 & 2460 & Icl/Isi-c & Paleoindian & & Small/Medium Vertebrata & Long bone & 1 \\
\hline 28 & 44 & 2460 & Icl/Isi-c & Paleoindian & & Vertebrata & Indeterminate & 15 \\
\hline 28 & 45 & 2630 & Icl/Isi-c & Paleoindian & & Medium/Large Vertebrata & Indeterminate & 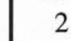 \\
\hline 28 & 45 & 2630 & Icl/Isi-c & Paleoindian & & Small/Medium Vertebrata & Long bone & \\
\hline
\end{tabular}




\begin{tabular}{|c|c|c|c|c|c|c|c|c|}
\hline Square & Level & Lot & Unit & Cultural Affinity & Feature & Taxon & Element & No. \\
\hline 28 & 45 & 2630 & $\mathrm{Icl} / \mathrm{Isi}-\mathrm{c}$ & Paleoindian & & Vertebrata & Indeterminate & 7 \\
\hline 28 & 46 & 2626 & Icl/Isi-c & Paleoindian & & Mammalia (Large) & Indeterminate & 1 \\
\hline 28 & 46 & 2626 & Icl/Isi-c & Paleoindian & & Small/Medium Vertebrata & Long bone & 9 \\
\hline 28 & 46 & 2626 & Icl/Isi-c & Paleoindian & & Vertebrata & Indeterminate & 11 \\
\hline 28 & 47 & 2776 & Icl/Isi-c & Paleoindian & & Medium/Large Vertebrata & Indeterminate & 1 \\
\hline 28 & 47 & 2776 & Icl/Isi-c & Paleoindian & & Small/Medium Vertebrata & Long bone & 7 \\
\hline 28 & 47 & 2776 & Icl/Isi-c & Paleoindian & & Vertebrata & Indeterminate & 20 \\
\hline 28 & 48 & 2593 & Icl/Isi-c & Paleoindian & & Mammalia (Small) & Metapodial & 1 \\
\hline 28 & 48 & 2593 & Icl/Isi-c & Paleoindian & & Medium/Large Vertebrata & Indeterminate & 3 \\
\hline 28 & 48 & 2593 & Icl/Isi-c & Paleoindian & & Small/Medium Vertebrata & Long bone & 8 \\
\hline 28 & 48 & 2593 & Icl/Isi-c & Paleoindian & & Vertebrata & Indeterminate & 7 \\
\hline 28 & 49 & 2163 & Icl & E. Paleoindian & & Leporidae & Permanent tooth & 1 \\
\hline 28 & 49 & 2163 & Icl & E. Paleoindian & & Small/Medium Vertebrata & Long bone & 13 \\
\hline 28 & 49 & 2163 & Icl & E. Paleoindian & & Sylvilagus sp. & Permanent tooth & 1 \\
\hline 28 & 49 & 2163 & Icl & E. Paleoindian & & Vertebrata & Indeterminate & 13 \\
\hline 28 & 50 & 2585 & Isi/Icl & E. Paleoindian & & Mammalia (Medium/large) & Tooth, perm./decid. ind. & 1 \\
\hline 28 & 50 & 2585 & Isi/Icl & E. Paleoindian & & Small/Medium Vertebrata & Long bone & 2 \\
\hline 28 & 50 & 2585 & Isi/Icl & E. Paleoindian & & Sylvilagus sp. & Calcaneus & 1 \\
\hline 28 & 50 & 2597 & Isi/Icl & E. Paleoindian & & Mammalia (Medium) & Long bone & 1 \\
\hline 28 & 50 & 2597 & Isi/Icl & E. Paleoindian & & Mammalia (Medium/large) & Indeterminate & 1 \\
\hline 28 & 50 & 2597 & Isi/Icl & E. Paleoindian & & Vertebrata & Indeterminate & 5 \\
\hline 28 & 51 & 2591 & Isi/Icl & E. Paleoindian & & Small/Medium Vertebrata & Long bone & 1 \\
\hline 28 & 51 & 2591 & Isi/Icl & E. Paleoindian & & Vertebrata & Indeterminate & 6 \\
\hline 28 & 52 & 2588 & Isi/Icl & E. Paleoindian & & Mammalia (Medium/large) & Indeterminate & 25 \\
\hline 28 & 52 & 2588 & Isi/Icl & E. Paleoindian & & Mammalia (Medium/large) & Tooth, perm./decid. ind. & 1 \\
\hline 28 & 52 & 2588 & Isi/Icl & E. Paleoindian & & Small/Medium Vertebrata & Long bone & 2 \\
\hline 28 & 52 & 2588 & Isi/Icl & E. Paleoindian & & Vertebrata & Indeterminate & 14 \\
\hline 28 & 53 & 2502 & Isi/Icl & E. Paleoindian & & Leporidae & Permanent tooth & 1 \\
\hline 28 & 53 & 2502 & Isi/Icl & E. Paleoindian & & Small/Medium Vertebrata & Long bone & 2 \\
\hline 28 & 53 & 2502 & Isi/Icl & E. Paleoindian & & Vertebrata & Indeterminate & 6 \\
\hline 28 & $54 \mathrm{~A}$ & 2587 & Igl/Isi//Icl & E. Paleoindian & & Vertebrata & Indeterminate & 2 \\
\hline 28 & $54 \mathrm{~B}$ & 2771 & Igl/Isi/Icl & E. Paleoindian & & Mammalia (Large) & Indeterminate & 2 \\
\hline 28 & $54 \mathrm{~B}$ & 2771 & Igl/Isi/Icl & E. Paleoindian & & Mammalia (Medium/large) & Indeterminate & 15 \\
\hline 28 & $54 \mathrm{~B}$ & 2771 & Igl/Isi/Icl & E. Paleoindian & & Vertebrata & Indeterminate & 1 \\
\hline 28 & 55 & 2810 & Igl/Isi & E. Paleoindian & & Vertebrata & Indeterminate & 1 \\
\hline 28 & 59 & 2680 & Igl & E. Paleoindian & & Vertebrata & Indeterminate & 2 \\
\hline 30 & 14 & 686 & IIIa & E. Archaic & & Aves (Small) & Distal phalange & 1 \\
\hline 30 & 14 & 686 & IIIa & E. Archaic & & Mammalia (Medium) & Alveolar ridge fragment & 1 \\
\hline 30 & 14 & 686 & IIIIa & E. Archaic & & Mammalia (Medium/large) & Indeterminate & 5 \\
\hline 30 & 14 & 686 & IIIa & E. Archaic & & Mammalia (Medium/large) & Long bone & 2 \\
\hline 30 & 14 & 686 & IIIa & E. Archaic & & Mammalia (Micro) & Permanent tooth & 1 \\
\hline 30 & 14 & 686 & IIIIa & E. Archaic & & Small/Medium Vertebrata & Long bone & 7 \\
\hline 30 & 14 & 686 & IIIa & E. Archaic & & Squamata & Vertebra & 1 \\
\hline 30 & 14 & 686 & IIIa & E. Archaic & & Testudinata & Shell fragment & 1 \\
\hline 30 & 14 & 686 & IIIa & E. Archaic & & Vertebrata & Indeterminate & 31 \\
\hline 30 & 15 & 716 & IIIa & E. Archaic & & Mammalia (Medium) & Proximal phalange & 1 \\
\hline 30 & 15 & 716 & IIIa & E. Archaic & & Mammalia (Medium/large) & Indeterminate & 1 \\
\hline 30 & 15 & 716 & IIIa & E. Archaic & & Mammalia (Medium/large) & Long bone & 3 \\
\hline 30 & 15 & 716 & IIa & E. Archaic & & Mammalia (Small) & Proximal phalange & 1 \\
\hline 30 & 15 & 716 & IIIa & E. Archaic & & Small/Medium Vertebrata & Long bone & 7 \\
\hline 30 & 15 & 716 & IIIa & E. Archaic & & Sylvilagus sp. & Calcaneus & 1 \\
\hline 30 & 15 & 716 & IIIa & E. Archaic & & Testudinata & Shell fragment & 1 \\
\hline 30 & 15 & 716 & IIa & E. Archaic & & Vertebrata & Indeterminate & 34 \\
\hline 30 & 16 & 744 & IIIa & E. Archaic & & Mammalia (Micro) & Metapodial & 1 \\
\hline 30 & 16 & 744 & IIIa & E. Archaic & & Mammalia (Small) & Middle phalange & 1 \\
\hline 30 & 16 & 744 & IIIa & E. Archaic & & Small/Medium Vertebrata & Long bone & 3 \\
\hline 30 & 16 & 744 & IIIa & E. Archaic & & Trionyx sp. & Shell fragment & 1 \\
\hline 30 & 16 & 744 & Ш一⿻ & E. Archaic & & Vertebrata & Indeterminate & 7 \\
\hline 30 & 17 & 765 & IIIa & E. Archaic & & Testudinata & Shell fragment & 3 \\
\hline 30 & 17 & 765 & IIIa & E. Archaic & & Vertebrata & Indeterminate & 2 \\
\hline 30 & 19 & 862 & ШІІІІа & L. Paleo./E. Archaic & & Mammalia (Medium/large) & Indeterminate & 2 \\
\hline 30 & 19 & 862 & IIII & L. Paleo./E. Archaic & & Mammalia (Small) & Permanent tooth & 1 \\
\hline 30 & 19 & 862 & II/IIIa & L. Paleo./E. Archaic & & Rodentia (Medium) & Permanent tooth & 1 \\
\hline 30 & 19 & 862 & II/II & L. Paleo./E. Archaic & & Small/Medium Vertebrata & Long bone & 6 \\
\hline 30 & 19 & 862 & IIIIIa & L. Paleo./E. Archaic & & Vertebrata & Indeterminate & 4 \\
\hline 30 & $20 \mathrm{~A}$ & 904 & II/IIIa & L. Paleo./E. Archaic & & Mammalia (Medium) & Fourth tarsal & 1 \\
\hline 30 & $20 \mathrm{~A}$ & 904 & II/IIIa & L. Paleo./E. Archaic & & Mammalia (Medium/large) & Tooth, perm./decid. ind. & 4 \\
\hline
\end{tabular}




\begin{tabular}{|c|c|c|c|c|c|c|c|c|}
\hline Square & Level & Lot & Unit & Cultural Affinity & Feature & Taxon & Element & No. \\
\hline 30 & $20 \mathrm{~A}$ & 904 & $\mathrm{II} / \mathrm{III}$ & L. Paleo./E. Archaic & & Mammalia (Micro) & Humerus & \\
\hline 30 & $20 \mathrm{~A}$ & 904 & II/IIIa & L. Paleo./E. Archaic & & Mammalia (Small) & Permanent tooth & 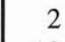 \\
\hline 30 & $20 \mathrm{~A}$ & 904 & II/IIIa & L. Paleo./E. Archaic & & Small/Medium Vertebrata & Long bone & 13 \\
\hline 30 & $20 \mathrm{~A}$ & 904 & II/IIIa & L. Paleo./E. Archaic & & Testudinata & Shell fragment & 1 \\
\hline 30 & $20 \mathrm{~A}$ & 904 & II/III & L. Paleo./E. Archaic & & Vertebrata & Indeterminate & 43 \\
\hline 30 & $21 \mathrm{~A}$ & 933 & III & L. Paleo. & & Geomys sp. & Permanent tooth & \\
\hline 30 & $21 \mathrm{~A}$ & 933 & III & L. Paleo. & & Leporidae & Tooth, perm./decid. ind. & \\
\hline 30 & $21 \mathrm{~A}$ & 933 & III & L. Paleo. & & Lepus californicus & Permanent tooth & \\
\hline 30 & $21 \mathrm{~A}$ & 933 & III & L. Paleo. & & Mammalia (Large) & Indeterminate & \\
\hline 30 & $21 \mathrm{~A}$ & 933 & III & L. Paleo. & & Mammalia (Medium) & Long bone & \\
\hline 30 & $21 \mathrm{~A}$ & 933 & III & L. Paleo. & & Mammalia (Medium) & Metapodial & \\
\hline 30 & $21 \mathrm{~A}$ & 933 & III & L. Paleo. & & Mammalia (Medium/large) & Tooth, perm./decid. ind. & \\
\hline 30 & $21 \mathrm{~A}$ & 933 & III & L. Paleo. & & Medium vertebrate, class ind. & Phalange & \\
\hline 30 & $21 \mathrm{~A}$ & 933 & III & L. Paleo. & & Small/Medium Vertebrata & Long bone & \\
\hline 30 & $21 \mathrm{~A}$ & 933 & III & L. Paleo. & & Squamata & Dorsal vertebra & \\
\hline 30 & $21 \mathrm{~A}$ & 933 & III & L. Paleo. & & Sylvilagus sp. & Metacarpal 2 & \\
\hline 30 & $21 \mathrm{~A}$ & 933 & III & L. Paleo. & & Vertebrata & Indeterminate & 28 \\
\hline 30 & $21 \mathrm{~B}$ & 941 & III & L. Paleo. & 227 & Leporidae & Permanent tooth & \\
\hline 30 & 21B & 941 & III & L. Paleo. & 227 & Mammalia (Micro) & Femur & \\
\hline 30 & 21B & 941 & III & L. Paleo. & 227 & Medium/Large Vertebrata & Long bone & \\
\hline 30 & 21B & 941 & III & L. Paleo. & 227 & Serpentes & Dorsal vertebra & \\
\hline 30 & 21B & 941 & III & L. Paleo. & 227 & Small vertebrate, class ind. & Proximal phalange & \\
\hline 30 & 21B & 941 & III & L. Paleo. & 227 & Small/Medium Vertebrata & Long bone & \\
\hline 30 & 21B & 941 & III & L. Paleo. & 227 & Vertebrata & Indeterminate & 24 \\
\hline 30 & $22 \mathrm{~A}$ & 962 & III & L. Paleo. & & Mammalia (Small/medium) & Alveolar ridge fragment & \\
\hline 30 & $22 \mathrm{~A}$ & 962 & III & L. Paleo. & & Small vertebrate, class ind. & Proximal phalange & \\
\hline 30 & $22 \mathrm{~A}$ & 962 & III & L. Paleo. & & Small/Medium Vertebrata & Long bone & 10 \\
\hline 30 & $22 \mathrm{~A}$ & 962 & III & L. Paleo. & & Sylvilagus sp. & Scapula & \\
\hline 30 & $22 \mathrm{~A}$ & 962 & III & L. Paleo. & & Vertebrata & Indeterminate & 21 \\
\hline 30 & $22 \mathrm{~B}$ & 988 & III & L. Paleo. & 227 & Lepus californicus & Permanent tooth & \\
\hline 30 & 22B & 988 & III & L. Paleo. & 227 & Mammalia (Micro) & Humerus & \\
\hline 30 & $22 \mathrm{~B}$ & 988 & III & L. Paleo. & 227 & Small vertebrate, class ind. & Proximal phalange & \\
\hline 30 & 22B & 988 & III & L. Paleo. & 227 & Small/Medium Vertebrata & Long bone & \\
\hline 30 & $22 \mathrm{~B}$ & 988 & III & L. Paleo. & 227 & Sylvilagus sp. & Calcaneus & \\
\hline 30 & $22 \mathrm{~B}$ & 988 & III & L. Paleo. & 227 & Vertebrata & Indeterminate & 25 \\
\hline 30 & 23 & 1022 & III & L. Paleo. & & Small/Medium Vertebrata & Long bone & \\
\hline 30 & 24 & 1029 & III & L. Paleo. & & Mammalia (Medium/large) & Indeterminate & \\
\hline 30 & 24 & 1029 & III & L. Paleo. & & Mammalia (Medium/large) & Tooth, perm./decid. ind. & \\
\hline 30 & 24 & 1029 & III & L. Paleo. & & Mammalia (Small) & Femur & \\
\hline 30 & 24 & 1029 & III & L. Paleo. & & Mammalia (Small) & Radius & \\
\hline 30 & 24 & 1029 & III & L. Paleo. & & Small/Medium Vertebrata & Long bone & \\
\hline 30 & 24 & 1029 & III & L. Paleo. & & Vertebrata & Indeterminate & 30 \\
\hline 30 & 25 & 1038 & III & L. Paleo. & & Mammalia (Medium/large) & Indeterminate & \\
\hline 30 & 25 & 1038 & III & L. Paleo. & & Mammalia (Small) & Proximal phalange & \\
\hline 30 & 25 & 1038 & III & L. Paleo. & & Vertebrata & Indeterminate & 11 \\
\hline 30 & 26 & 1121 & III & L. Paleo. & & Sylvilagus sp. & Permanent tooth & 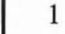 \\
\hline 30 & 27 & 1154 & III & L. Paleo. & & Mammalia (Micro) & Humerus & \\
\hline 30 & 27 & 1154 & III & L. Paleo. & & Mammalia (Micro) & Permanent tooth & \\
\hline 30 & 27 & 1154 & III & L. Paleo. & & Small/Medium Vertebrata & Long bone & \\
\hline 30 & 27 & 1154 & III & L. Paleo. & & Sylvilagus sp. & Metacarpal & \\
\hline 30 & 27 & 1154 & III & L. Paleo. & & Vertebrata & Indeterminate & \\
\hline 30 & 28 & 1070 & Isi-c/II & L. Paleo. & & Mammalia (Medium) & Permanent tooth & \\
\hline 30 & 28 & 1070 & |Isi-c/II & L. Paleo. & & Small vertebrate, class ind. & Middle phalange & \\
\hline 30 & 28 & 1070 & |Isi-c/II & L. Paleo. & & Small/Medium Vertebrata & Long bone & \\
\hline 30 & 28 & 1070 & |Isi-c/II & L. Paleo. & & Testudinata & Shell fragment & \\
\hline 30 & 28 & 1070 & Isi-c/II & L. Paleo. & & Vertebrata & Indeterminate & 24 \\
\hline 30 & 29B & 830 & Isi-c/II & L. Paleo. & 234 & Mammalia (Large) & Cranium & \\
\hline 30 & 29B & 830 & Isi-c/II & L. Paleo. & 234 & Mammalia (Medium/large) & Long bone & \\
\hline 30 & 29B & 830 & Isi-c/II & L. Paleo. & 234 & Small/Medium Vertebrata & Long bone & \\
\hline 30 & $29 \mathrm{~B}$ & 830 & |Isi-c/II & L. Paleo. & 234 & Vertebrata & Indeterminate & 10 \\
\hline 30 & 30 & 1200 & Isi-c/II & L. Paleo. & 234 & Geomys sp. & Permanent tooth & \\
\hline 30 & 30 & 1200 & |Isi-c/II & L. Paleo. & 234 & Mammalia (Small) & Permanent tooth & \\
\hline 30 & 30 & 1200 & Isi-c/II & L. Paleo. & 234 & Small vertebrate, class ind. & |Phalange : & \\
\hline 30 & 30 & 1200 & |Isi-c/II & L. Paleo. & 234 & Small/Medium Vertebrata & Long bone & \\
\hline 30 & 30 & 1200 & Isi-c/II & L. Paleo. & 234 & Vertebrata & Indeterminate & 24 \\
\hline 30 & $31 \mathrm{~B}$ & 1217 & Isi-c/II & L. Paleo. & 234 & Mammalia (Small) & Permanent tooth & 1 \\
\hline 30 & 31B & 1217 & Isi-c/II & L. Paleo. & 234 & Small/Medium Vertebrata & Long bone & 11 \\
\hline
\end{tabular}




\begin{tabular}{|c|c|c|c|c|c|c|c|c|}
\hline Square & Level & Lot & Unit & Cultural Affinity & Feature & Taxon & Element & No. \\
\hline 30 & $31 \mathrm{~B}$ & 1217 & Isi-c/II & L. Paleo. & 234 & Vertebrata & Indeterminate & 31 \\
\hline 30 & 32 & 1250 & Isi-c & L. Paleo. & & Mammalia (Medium) & Metapodial & 1 \\
\hline 30 & 32 & 1250 & Isi-c & L. Paleo. & & Small/Medium Vertebrata & Long bone & 10 \\
\hline 30 & 32 & 1250 & Isi-c & L. Paleo. & & Vertebrata & Indeterminate & 52 \\
\hline 30 & $33 \mathrm{~A}$ & 1294 & Isi-c & L. Paleo. & & Geomys sp. & Permanent tooth & 1 \\
\hline 30 & $33 \mathrm{~A}$ & 1294 & Isi-c & L. Paleo. & & Mammalia (Medium/large) & Indeterminate & 1 \\
\hline 30 & $33 \mathrm{~A}$ & 1294 & Isi-c & L. Paleo. & & Medium vertebrate, class ind. & Distal phalange & 3 \\
\hline 30 & $33 \mathrm{~A}$ & 1294 & Isi-c & L. Paleo. & & Small/Medium Vertebrata & Long bone & 12 \\
\hline 30 & $33 \mathrm{~A}$ & 1294 & Isi-c & L. Paleo. & & Testudinata & Shell fragment & 1 \\
\hline 30 & $33 \mathrm{~A}$ & 1294 & Isi-c & L. Paleo. & & Vertebrata & Indeterminate & 84 \\
\hline 30 & $33 \mathrm{~A}$ & 1294 & Isi-c & L. Paleo. & & Viperidae & Dorsal vertebra & 1 \\
\hline 30 & $33 \mathrm{~A}$ & 1314 & Isi-c & L. Paleo. & & Mammalia (Very large) & Long bone & 1 \\
\hline 30 & $34 \mathrm{~A}$ & 1348 & Isi-c & L. Paleo. & & Mammalia (Medium/large) & Tooth, perm./decid. ind. & 2 \\
\hline 30 & $34 \mathrm{~A}$ & 1348 & Isi-c & L. Paleo. & & Medium vertebrate, class ind. & Middle phalange & 1 \\
\hline 30 & $34 \mathrm{~A}$ & 1348 & Isi-c & L. Paleo. & & Medium/Large Vertebrata & Indeterminate & 6 \\
\hline 30 & $34 \mathrm{~A}$ & 1348 & Isi-c & L. Paleo. & & Small/Medium Vertebrata & Long bone & 6 \\
\hline 30 & $34 \mathrm{~A}$ & 1348 & Isi-c & L. Paleo. & & Squamata & Dorsal vertebra & 1 \\
\hline 30 & $34 \mathrm{~A}$ & 1348 & Isi-c & L. Paleo. & & Vertebrata & Indeterminate & 35 \\
\hline 30 & 34B & 1385 & Isi-c & L. Paleo. & 238 & Mammalia (Large) & Tooth, perm./decid. ind. & 1 \\
\hline 30 & 34B & 1385 & Isi-c & L. Paleo. & 238 & Medium/Large Vertebrata & Indeterminate & 1 \\
\hline 30 & $34 \mathrm{~B}$ & 1385 & Isi-c & L. Paleo. & 238 & Small/Medium Vertebrata & Long bone & 6 \\
\hline 30 & $34 \mathrm{~B}$ & 1385 & Isi-c & L. Paleo. & 238 & Vertebrata & Indeterminate & 27 \\
\hline 30 & 35 & 1426 & Isi/Isi-c & Paleoindian & & Geomys sp. & Permanent tooth & 1 \\
\hline 30 & 35 & 1426 & Isi/Isi-c & Paleoindian & & Medium/Large Vertebrata & Indeterminate & 5 \\
\hline 30 & 35 & 1426 & Isi/Isi-c & Paleoindian & & Serpentes & Dorsal vertebra & 1 \\
\hline 30 & 35 & 1426 & Isi/Isi-c & Paleoindian & & Small/Medium Vertebrata & Long bone & 1 \\
\hline 30 & 35 & 1426 & Isi/Isi-c & Paleoindian & & Vertebrata & Indeterminate & 31 \\
\hline 30 & 37 & 1549 & Isi/Isi-c & Paleoindian & & Mammalia (Medium/large) & Long bone & 1 \\
\hline 30 & 37 & 1549 & Isi/Isi-c & Paleoindian & & Mammalia (Medium/large) & Tooth, perm./decid. ind. & 1 \\
\hline 30 & 37 & 1549 & |Isi/Isi-c & Paleoindian & & Small/Medium Vertebrata & Long bone & 2 \\
\hline 30 & 37 & 1549 & Isi/Isi-c & Paleoindian & & Testudinata & Shell fragment & 1 \\
\hline 30 & 37 & 1549 & |Isi/Isi-c & Paleoindian & & Vertebrata & Indeterminate & 8 \\
\hline 30 & 38 & 1597 & Isi & E. Paleoindian & & Mammalia (Medium/large) & Indeterminate & 2 \\
\hline 30 & 38 & 1597 & Isi & E. Paleoindian & & Mammalia (Medium/large) & Tooth, perm./decid. ind. & 1 \\
\hline 30 & 38 & 1597 & Isi & E. Paleoindian & & Medium/Large Vertebrata & Indeterminate & 8 \\
\hline 30 & 38 & 1597 & Isi & E. Paleoindian & & Small/Medium Vertebrata & Long bone & 2 \\
\hline 30 & 38 & 1597 & Isi & E. Paleoindian & & Vertebrata & Indeterminate & 22 \\
\hline 30 & 40 & 1740 & Isi & E. Paleoindian & & Serpentes & Dorsal vertebra & 1 \\
\hline 30 & 40 & 1740 & Isi & E. Paleoindian & & Vertebrata & Indeterminate & 3 \\
\hline 30 & 42 & 1837 & Isi & E. Paleoindian & & Small/Medium Vertebrata & Long bone & 1 \\
\hline 30 & 42 & 1837 & Isi & E. Paleoindian & & Vertebrata & Indeterminate & 3 \\
\hline 30 & 43 & 1869 & Isi & E. Paleoindian & & Vertebrata & Indeterminate & 1 \\
\hline 32 & 14 & 683 & Ша & E. Archaic & & Mammalia (Medium/large) & Indeterminate & 9 \\
\hline 32 & 14 & 683 & IIIIa & E. Archaic & & Small/Medium Vertebrata & Long bone & 10 \\
\hline 32 & 14 & 683 & IIIIa & E. Archaic & & Testudinata & Carapace fragment ind. & 1 \\
\hline 32 & 14 & 683 & III & E. Archaic & & Vertebrata & Indeterminate & 4 \\
\hline 32 & 15 & 702 & IIIIa & E. Archaic & & Leporidae & Scapula & 1 \\
\hline 32 & 15 & 702 & IIIIa & E. Archaic & & Lepus californicus & Humerus & 1 \\
\hline 32 & 15 & 702 & IIIIa & E. Archaic & & Lepus californicus & Permanent tooth & 1 \\
\hline 32 & 15 & 702 & IIIa & E. Archaic & & Mammalia (Medium) & Middle phalange & 1 \\
\hline 32 & 15 & 702 & IIIIa & E. Archaic & & Mammalia (Medium/large) & Indeterminate & 2 \\
\hline 32 & 15 & 702 & IIIIa & E. Archaic & & Small/Medium Vertebrata & Long bone & 3 \\
\hline 32 & 15 & 702 & IIIa & E. Archaic & & Vertebrata & Indeterminate & 14 \\
\hline 32 & 16 & 717 & IIIIa & E. Archaic & & Kinosternidae & Peripheral & 1 \\
\hline 32 & 16 & 717 & IIIIa & E. Archaic & & Mammalia (Medium/large) & Indeterminate & 8 \\
\hline 32 & 16 & 717 & IIIIa & E. Archaic & & Serpentes & Dorsal vertebra & 1 \\
\hline 32 & 16 & 717 & IIIIa & E. Archaic & & Vertebrata & Indeterminate & 11 \\
\hline 32 & 17 & 743 & IIIIa & E. Archaic & & Mammalia (Micro) & Long bone & 1 \\
\hline 32 & 17 & 743 & III & E. Archaic & & Medium/Large Vertebrata & Indeterminate & 3 \\
\hline 32 & 17 & 743 & IIIa & E. Archaic & & Small/Medium Vertebrata & Long bone & 2 \\
\hline 32 & 17 & 743 & IIIIa & E. Archaic & & Vertebrata & Indeterminate & 10 \\
\hline 32 & 18 & 772 & IIIa & E. Archaic & & Mammalia (Medium/large) & Indeterminate & 10 \\
\hline 32 & 18 & 772 & IIIa & E. Archaic & & Mammalia (Small) & Alveolar ridge fragment & 1 \\
\hline 32 & 18 & 772 & IIIIa & E. Archaic & & Small/Medium Vertebrata & Long bone & 6 \\
\hline 32 & 18 & 772 & III & E. Archaic & & Testudinata & Shell fragment & 2 \\
\hline 32 & 18 & 772 & IIIa & E. Archaic & & Vertebrata & Indeterminate & 25 \\
\hline 32 & 19 & 863 & IIIIa & E. Archaic & & Mammalia (Small) & Proximal phalange & 1 \\
\hline
\end{tabular}




\begin{tabular}{|c|c|c|c|c|c|c|c|c|}
\hline Square & Level & Lot & Unit & Cultural Affinity & Feature & Taxon & Element & No. \\
\hline 32 & 19 & 863 & IIIa & E. Archaic & & Mammalia (Small) & Tooth, perm./decid. ind. & 1 \\
\hline 32 & 19 & 863 & IIIa & E. Archaic & & Small vertebrate, class ind. & Distal phalange & 1 \\
\hline 32 & 19 & 863 & IIIa & E. Archaic & & Small/Medium Vertebrata & Long bone & 5 \\
\hline 32 & 19 & 863 & IIIa & E. Archaic & & Vertebrata & Indeterminate & 16 \\
\hline 32 & $20 \mathrm{~A}$ & 908 & I/ШІШа & L. Paleo./E. Archaic & & Geomys sp. & Permanent tooth & 1 \\
\hline 32 & $20 \mathrm{~A}$ & 908 & II/IIIa & L. Paleo./E. Archaic & & Leporidae & Permanent tooth & \\
\hline 32 & $20 \mathrm{~A}$ & 908 & II/ШІа & L. Paleo./E. Archaic & & Lepus californicus & Permanent tooth & \\
\hline 32 & $20 \mathrm{~A}$ & 908 & Ш/Ша & L. Paleo./E. Archaic & & Mammalia (Medium/large) & Tooth, perm./decid. ind. & \\
\hline 32 & $20 \mathrm{~A}$ & 908 & II/IIIa & L. Paleo./E. Archaic & & Mammalia (Micro) & Permanent tooth & \\
\hline 32 & $20 \mathrm{~A}$ & 908 & II/IIIa & L. Paleo./E. Archaic & & Mammalia (Micro) & Tooth, perm./decid. ind. & \\
\hline 32 & $20 \mathrm{~A}$ & 908 & I/ШІІа & L. Paleo./E. Archaic & & Medium vertebrate, class ind. & Proximal phalange & \\
\hline 32 & $20 \mathrm{~A}$ & 908 & II/IIIa & L. Paleo./E. Archaic & & Small/Medium Vertebrata & Long bone & 19 \\
\hline 32 & $20 \mathrm{~A}$ & 908 & IIIIIIa & L. Paleo./E. Archaic & & Sylvilagus sp. & Metatarsal 2 & \\
\hline 32 & $20 \mathrm{~A}$ & 908 & IIIIIa & L. Paleo./E. Archaic & & Sylvilagus sp. & Permanent tooth & \\
\hline 32 & $20 \mathrm{~A}$ & 908 & П/ШІШа & L. Paleo./E. Archaic & & Testudinata & Humerus & \\
\hline 32 & $20 \mathrm{~A}$ & 908 & II/IIIa & L. Paleo./E. Archaic & & Testudinata & Shell fragment & \\
\hline 32 & $20 \mathrm{~A}$ & 908 & П/Ша & L. Paleo./E. Archaic & & Vertebrata & Indeterminate & 8 \\
\hline 32 & $20 \mathrm{~B}$ & 915 & П/ШІШа & L. Paleo./E. Archaic & & Small/Medium Vertebrata & Long bone & \\
\hline 32 & $20 \mathrm{~B}$ & 915 & II/IIIa & L. Paleo./E. Archaic & & Vertebrata & Indeterminate & \\
\hline 32 & 21 & 922 & ㅍ/ШІа & L. Paleo./E. Archaic & & Mammalia (Medium/large) & Indeterminate & \\
\hline 32 & 21 & 922 & I/IIIa & L. Paleo./E. Archaic & & Mammalia (Medium/large) & Tooth, perm./decid. ind. & \\
\hline 32 & 21 & 922 & IIIIIa & L. Paleo./E. Archaic & & Mammalia (Small) & Caudal vertebra & \\
\hline 32 & 21 & 922 & IIIIIa & L. Paleo./E. Archaic & & Mammalia (Small) & Permanent tooth & \\
\hline 32 & 21 & 922 & IIIIIIa & L. Paleo./E. Archaic & & Mammalia (Small) & Tooth, perm./decid. ind. & \\
\hline 32 & 21 & 922 & II/IIIa & L. Paleo./E. Archaic & & Small/Medium Vertebrata & Long bone & \\
\hline 32 & 21 & 922 & IIIIIa & L. Paleo./E. Archaic & & Vertebrata & Indeterminate & \\
\hline 32 & 22 & 932 & II/IIIa & L. Paleo./E. Archaic & & Mammalia (Medium) & Cranium & \\
\hline 32 & 22 & 932 & П/ШІІа & L. Paleo./E. Archaic & & Mammalia (Medium/large) & Long bone & \\
\hline 32 & 22 & 932 & I/IIIa & L. Paleo./E. Archaic & & Mammalia (Medium/large) & Tooth, perm./decid. ind. & \\
\hline 32 & 22 & 932 & П/111а & L. Paleo./E. Archaic & & Mammalia (Micro) & Tibia & \\
\hline 32 & 22 & 932 & ШІІІІа & L. Paleo./E. Archaic & & Mammalia (Small) & Epiphysis & \\
\hline 32 & 22 & 932 & П/IIIIa & L. Paleo./E. Archaic & & Mammalia (Small) & Humerus & \\
\hline 32 & 22 & 932 & II/IIIa & L. Paleo./E. Archaic & & Mammalia (Small) & Permanent tooth & \\
\hline 32 & 22 & 932 & I/IIIa & L. Paleo./E. Archaic & & Mammalia (Small) & Ulna & \\
\hline 32 & 22 & 932 & IIIIIa & L. Paleo./E. Archaic & & Medium vertebrate, class ind. & Vertebra & \\
\hline 32 & 22 & 932 & II/IIIa & L. Paleo./E. Archaic & & Small/Medium Vertebrata & Long bone & \\
\hline 32 & 22 & 932 & I/IIIa & L. Paleo./E. Archaic & & Testudinata & Shell fragment & \\
\hline 32 & 22 & 932 & П/IIIa & L. Paleo./E. Archaic & & Vertebrata & Indeterminate & \\
\hline 32 & 23 & 951 & II/IIIa & L. Paleo./E. Archaic & & Leporidae & Permanent tooth & \\
\hline 32 & 23 & 951 & П/Ша & L. Paleo./E. Archaic & & Lepus californicus & Permanent tooth & \\
\hline 32 & 23 & 951 & IIIIIIa & L. Paleo./E. Archaic & & Medium/Large Vertebrata & Indeterminate & \\
\hline 32 & 23 & 951 & II/IIIa & L. Paleo./E. Archaic & & Small/Medium Vertebrata & Long bone & 15 \\
\hline 32 & 23 & 951 & П/Ша & L. Paleo./E. Archaic & & Sylvilagus sp. & Metacarpal 3 & \\
\hline 32 & 23 & 951 & П/ШІІа & L. Paleo./E. Archaic & & Testudinata & Shell fragment & \\
\hline 32 & 23 & 951 & IIIIIIa & L. Paleo./E. Archaic & & Vertebrata & Indeterminate & 40 \\
\hline 32 & 24 & 973 & III & L. Paleo. & & cf. Sylvilagus sp. & Femur & \\
\hline 32 & 24 & 973 & III & L. Paleo. & & Geomys sp. & Permanent tooth & \\
\hline 32 & 24 & 973 & II & L. Paleo. & & Leporidae & Permanent tooth & \\
\hline 32 & 24 & 973 & III & L. Paleo. & & Mammalia (Large) & Long bone & \\
\hline 32 & 24 & 973 & III & L. Paleo. & & Mammalia (Medium/large) & Long bone & \\
\hline 32 & 24 & 973 & III & L. Paleo. & & Mammalia (Medium/large) & Tooth, perm./decid. ind. & \\
\hline 32 & 24 & 973 & II & L. Paleo. & & Medium/Large Vertebrata & Indeterminate & \\
\hline 32 & 24 & 973 & III & L. Paleo. & & Medium/Large Vertebrata & Long bone & \\
\hline 32 & 24 & 973 & II & L. Paleo. & & Small/Medium Vertebrata & Long bone & \\
\hline 32 & 24 & 973 & II & L. Paleo. & & Sylvilagus sp. & Calcaneus & \\
\hline 32 & 24 & 973 & II & L. Paleo. & & Testudinata & Shell fragment & \\
\hline 32 & 24 & 973 & III & L. Paleo. & & Vertebrata & Indeterminate & 12 \\
\hline 32 & 25 & 984 & III & L. Paleo. & & Mammalia (Medium/large) & Long bone & \\
\hline 32 & 25 & 984 & III & L. Paleo. & & Small/Medium Vertebrata & Long bone & \\
\hline 32 & 25 & 984 & II & L. Paleo. & & Vertebrata & Indeterminate & \\
\hline 32 & 26 & 1007 & II & L. Paleo. & & Mammalia (Small) & Proximal phalange & \\
\hline 32 & 26 & 1007 & III & L. Paleo. & & Small/Medium Vertebrata & Long bone & \\
\hline 32 & 26 & 1007 & III & L. Paleo. & & Vertebrata & Indeterminate & \\
\hline 32 & 26 & 1007 & II & L. Paleo. & & Viperidae & Dorsal vertebra & \\
\hline 32 & 27 & 1061 & II & L. Paleo. & & Medium/Large Vertebrata & Indeterminate & \\
\hline 32 & 27 & 1061 & III & L. Paleo. & & Odocoileus sp. & Antler & \\
\hline 32 & 27 & 1061 & II & L. Paleo. & & Small/Medium Vertebrata & Long bone & \\
\hline
\end{tabular}




\begin{tabular}{|c|c|c|c|c|c|c|c|c|}
\hline Square & Level & Lot & Unit & Cultural Affinity & Feature & Taxon & Element & No. \\
\hline 32 & 27 & 1061 & III & L. Paleo. & & Vertebrata & Indeterminate & 9 \\
\hline 32 & $28 \mathrm{~A}$ & 1213 & Isi-c/II & L. Paleo. & & Mammalia (Medium/large) & Indeterminate & 2 \\
\hline 32 & $28 \mathrm{~A}$ & 1213 & Isi-c/II & L. Paleo. & & Mammalia (Medium/large) & Long bone & 1 \\
\hline 32 & $28 \mathrm{~A}$ & 1213 & Isi-c/II & L. Paleo. & & Mammalia (Small) & Epiphysis & 1 \\
\hline 32 & $28 \mathrm{~A}$ & 1213 & Isi-c/II & L. Paleo. & & Small/Medium Vertebrata & Long bone & 14 \\
\hline 32 & $28 \mathrm{~A}$ & 1213 & Isi-c/II & L. Paleo. & & Sylvilagus sp. & Central tarsal bone & 1 \\
\hline 32 & $28 \mathrm{~A}$ & 1213 & Isi-c/II & L. Paleo. & & Vertebrata & Indeterminate & 29 \\
\hline 32 & $29 \mathrm{~A}$ & 1263 & Isi-c/II & L. Paleo. & & Leporidae & Permanent tooth & 1 \\
\hline 32 & $29 \mathrm{~A}$ & 1263 & Isi-c/II & L. Paleo. & & Small/Medium Vertebrata & Long bone & 10 \\
\hline 32 & $29 \mathrm{~A}$ & 1263 & Isi-c/II & L. Paleo. & & Vertebrata & Indeterminate & 30 \\
\hline 32 & 29B & 1259 & Isi-c/II & L. Paleo. & 235 & Small/Medium Vertebrata & Long bone & 5 \\
\hline 32 & $29 \mathrm{~B}$ & 1259 & Isi-c/II & L. Paleo. & 235 & Vertebrata & Indeterminate & 3 \\
\hline 32 & 30 & 1291 & Isi-c/II & L. Paleo. & & Leporidae & Permanent tooth & 1 \\
\hline 32 & 30 & 1291 & Isi-c/II & L. Paleo. & & Mammalia (Large) & Indeterminate & 1 \\
\hline 32 & 30 & 1291 & Isi-c/II & L. Paleo. & & Mammalia (Medium/large) & Long bone & 1 \\
\hline 32 & 30 & 1291 & Isi-c/II & L. Paleo. & & Mammalia (Micro) & Tooth, perm./decid. ind. & 1 \\
\hline 32 & 30 & 1291 & Isi-c/II & L. Paleo. & & Mammalia (Small) & Metapodial & 1 \\
\hline 32 & 30 & 1291 & Isi-c/II & L. Paleo. & & Medium/Large Vertebrata & Indeterminate & 2 \\
\hline 32 & 30 & 1291 & Isi-c/II & L. Paleo. & & Small vertebrate, class ind. & Phalange & 1 \\
\hline 32 & 30 & 1291 & Isi-c/II & L. Paleo. & & Small/Medium Vertebrata & Long bone & 20 \\
\hline 32 & 30 & 1291 & Isi-c/II & L. Paleo. & & Sylvilagus sp. & Tibia & 1 \\
\hline 32 & 30 & 1291 & Isi-c/II & L. Paleo. & & Vertebrata & Indeterminate & 38 \\
\hline 32 & 31 & 1305 & Isi-c/Id/II & L. Paleo. & & Leporidae & Permanent tooth & 1 \\
\hline 32 & 31 & 1305 & Isi-c/Id/II & L. Paleo. & & Mammalia (Medium/large) & Indeterminate & 1 \\
\hline 32 & 31 & 1305 & Isi-c/Id/II & L. Paleo. & & Mammalia (Medium/large) & Long bone & 4 \\
\hline 32 & 31 & 1305 & Isi-c/Id/II & L. Paleo. & & Medium/Large Vertebrata & Indeterminate & 1 \\
\hline 32 & 31 & 1305 & Isi-c/Id/II & L. Paleo. & & Small/Medium Vertebrata & Long bone & 5 \\
\hline 32 & 31 & 1305 & Isi-c/Id/II & L. Paleo. & & Sylvilagus sp. & Central tarsal bone & 1 \\
\hline 32 & 31 & 1305 & Isi-c/Id/II & L. Paleo. & & Vertebrata & Indeterminate & 17 \\
\hline 32 & 32 & 1317 & Isi-c/Id & L. Paleo. & & Leporidae & Permanent tooth & 2 \\
\hline 32 & 32 & 1317 & Isi-c/Id & L. Paleo. & & Mammalia (Medium/large) & Indeterminate & 14 \\
\hline 32 & 32 & 1317 & Isi-c/Id & L. Paleo. & & Mammalia (Medium/large) & Long bone & 2 \\
\hline 32 & 32 & 1317 & Isi-c/Id & L. Paleo. & & Mammalia (Medium/large) & Tooth, perm./decid. ind. & 3 \\
\hline 32 & 32 & 1317 & Isi-c/Id & L. Paleo. & & Medium/Large Vertebrata & Indeterminate & 5 \\
\hline 32 & 32 & 1317 & Isi-c/Id & L. Paleo. & & Small/Medium Vertebrata & Long bone & 18 \\
\hline 32 & 32 & 1317 & Isi-c/Id & L. Paleo. & & Sylvilagus sp. & Radius & 1 \\
\hline 32 & 32 & 1317 & Isi-c/Id & L. Paleo. & & Vertebrata & Indeterminate & 73 \\
\hline 32 & 33 & 1397 & Isi-c/Id & L. Paleo. & & Colubridae & Dorsal vertebra & 1 \\
\hline 32 & 33 & 1397 & Isi-c/Id & L. Paleo. & & Mammalia (Medium) & Vertebra & 1 \\
\hline 32 & 33 & 1397 & Isi-c/Id & L. Paleo. & & Mammalia (Medium/large) & Indeterminate & 10 \\
\hline 32 & 33 & 1397 & Isi-c/Id & L. Paleo. & & Mammalia (Medium/large) & Long bone & 1 \\
\hline 32 & 33 & 1397 & Isi-c/Id & L. Paleo. & & Mammalia (Medium/large) & Tooth, perm./decid. ind. & 1 \\
\hline 32 & 33 & 1397 & Isi-c/Id & L. Paleo. & & Mammalia (Small) & Permanent tooth & 1 \\
\hline 32 & 33 & 1397 & Isi-c/Id & L. Paleo. & & Mammalia (Small) & Tibia & 1 \\
\hline 32 & 33 & 1397 & Isi-c/Id & L. Paleo. & & Medium/Large Vertebrata & Indeterminate & 5 \\
\hline 32 & 33 & 1397 & Isi-c/Id & L. Paleo. & & Neotoma sp. & Permanent tooth & 1 \\
\hline 32 & 33 & 1397 & Isi-c/Id & L. Paleo. & & Serpentes & Dorsal vertebra & 1 \\
\hline 32 & 33 & 1397 & Isi-c/Id & L. Paleo. & & Small vertebrate, class ind. & Phalange & 3 \\
\hline 32 & 33 & 1397 & Isi-c/Id & L. Paleo. & & Small vertebrate, class ind. & Vertebra & 1 \\
\hline 32 & 33 & 1397 & Isi-c/Id & L. Paleo. & & Small/Medium Vertebrata & Long bone & 14 \\
\hline 32 & 33 & 1397 & Isi-c/Id & L. Paleo. & & Sylvilagus sp. & Central tarsal bone & 1 \\
\hline 32 & 33 & 1397 & Isi-c/Id & L. Paleo. & & Sylvilagus sp. & Radius & 1 \\
\hline 32 & 33 & 1397 & Isi-c/Id & L. Paleo. & & Vertebrata & Indeterminate & 96 \\
\hline 32 & 34 & 1401 & Isi-c/Id & L. Paleo. & & Carnivora & Tooth, perm./decid. ind. & 1 \\
\hline 32 & 34 & 1401 & Isi-c/Id & L. Paleo. & & Emydidae & Peripheral & 1 \\
\hline 32 & 34 & 1401 & Isi-c/Id & L. Paleo. & & Mammalia (Medium) & Metapodial & 1 \\
\hline 32 & 34 & 1401 & Isi-c/Id & L. Paleo. & & Mammalia (Medium/large) & Indeterminate & 5 \\
\hline 32 & 34 & 1401 & Isi-c/Id & L. Paleo. & & Mammalia (Medium/large) & Long bone & 1 \\
\hline 32 & 34 & 1401 & Isi-c/Id & L. Paleo. & & Medium vertebrate, class ind. & Phalange & 1 \\
\hline 32 & 34 & 1401 & Isi-c/Id & L. Paleo. & & Small vertebrate, class ind. & Caudal vertebra & 1 \\
\hline 32 & 34 & 1401 & Isi-c/Id & L. Paleo. & & Small/Medium Vertebrata & Long bone & 17 \\
\hline 32 & 34 & 1401 & Isi-c/Id & L. Paleo. & & Vertebrata & Indeterminate & 30 \\
\hline 32 & 35 & 1471 & Isi/Isi-c & Paleoindian & & Medium/Large Vertebrata & Indeterminate & 6 \\
\hline 32 & 35 & 1471 & Isi/Isi-c & Paleoindian & & Small/Medium Vertebrata & Long bone & 23 \\
\hline 32 & 35 & 1471 & Isi/Isi-c & Paleoindian & & Testudinata & Shell fragment & 1 \\
\hline 32 & 35 & 1471 & Isi/Isi-c & Paleoindian & & Vertebrata & Indeterminate & 53 \\
\hline 32 & 36 & 1689 & Isi/Isi-c & Paleoindian & & Aves (Medium) & Carpometacarpus & 1 \\
\hline
\end{tabular}




\begin{tabular}{|c|c|c|c|c|c|c|c|c|}
\hline Square & Level & Lot & Unit & Cultural Affinity & Feature & Taxon & Element & No. \\
\hline 32 & 36 & 1689 & Isi/Isi-c & Paleoindian & & Colubridae & Dorsal vertebra & 1 \\
\hline 32 & 36 & 1689 & Isi/Isi-c & Paleoindian & & Geomys sp. & Permanent tooth & 5 \\
\hline 32 & 36 & 1689 & Isi/Isi-c & Paleoindian & & Leporidae & Permanent tooth & 2 \\
\hline 32 & 36 & 1689 & Isi/Isi-c & Paleoindian & & Mammalia (Medium/large) & Long bone & 2 \\
\hline 32 & 36 & 1689 & Isi/Isi-c & Paleoindian & & Mammalia (Small) & Permanent tooth & 1 \\
\hline 32 & 36 & 1689 & Isi/Isi-c & Paleoindian & & Neotoma sp. & Permanent tooth & 1 \\
\hline 32 & 36 & 1689 & Isi/Isi-c & Paleoindian & & Serpentes & Dorsal vertebra & 1 \\
\hline 32 & 36 & 1689 & Isi/Isi-c & Paleoindian & & Small/Medium Vertebrata & Long bone & 20 \\
\hline 32 & 36 & 1689 & Isi/Isi-c & Paleoindian & & Testudinata & Shell fragment & 1 \\
\hline 32 & 36 & 1689 & Isi/Isi-c & Paleoindian & & Vertebrata & Indeterminate & 70 \\
\hline 32 & 36 & 1693 & Isi/Isi-c & Paleoindian & & Mammalia (Large) & Indeterminate & 1 \\
\hline 32 & 38 & 1806 & Isi/Isi-c & Paleoindian & & Colubridae & Dorsal vertebra & 1 \\
\hline 32 & 38 & 1806 & Isi/Isi-c & Paleoindian & & Geomys sp. & Permanent tooth & 1 \\
\hline 32 & 38 & 1806 & Isi/Isi-c & Paleoindian & & Mammalia (Medium/large) & Tooth, perm./decid. ind. & 1 \\
\hline 32 & 38 & 1806 & Isi/Isi-c & Paleoindian & & Serpentes & Dorsal vertebra & 1 \\
\hline 32 & 38 & 1806 & Isi/Isi-c & Paleoindian & & Small/Medium Vertebrata & Long bone & 3 \\
\hline 32 & 38 & 1806 & Isi/Isi-c & Paleoindian & & Sylvilagus sp. & Third tarsal & 1 \\
\hline 32 & 38 & 1806 & Isi/Isi-c & Paleoindian & & Vertebrata & Indeterminate & 27 \\
\hline 32 & 39 & 1844 & Isi/Isi-c & Paleoindian & & Mammalia (Medium/large) & Tooth, perm./decid. ind. & 1 \\
\hline 32 & 39 & 1844 & Isi/Isi-c & Paleoindian & & Mammalia (Small) & Metapodial & 1 \\
\hline 32 & 39 & 1844 & Isi/Isi-c & Paleoindian & & Serpentes & Dorsal vertebra & 1 \\
\hline 32 & 39 & 1844 & Isi/Isi-c & Paleoindian & & Small/Medium Vertebrata & Long bone & 25 \\
\hline 32 & 39 & 1844 & Isi/Isi-c & Paleoindian & & Small/Medium Vertebrata & Vertebra & 1 \\
\hline 32 & 39 & 1844 & Isi/Isi-c & Paleoindian & & Sylvilagus sp. & Calcaneus & 1 \\
\hline 32 & 39 & 1844 & Isi/Isi-c & Paleoindian & & Sylvilagus sp. & Ulna & 2 \\
\hline 32 & 39 & 1844 & Isi/Isi-c & Paleoindian & & Vertebrata & Indeterminate & 48 \\
\hline 32 & 40 & 1856 & Isi/Isi-c & Paleoindian & & Aves (Medium) & Distal phalange & 1 \\
\hline 32 & 40 & 1856 & Isi/Isi-c & Paleoindian & & Mammalia (Large) & Tooth, perm./decid. ind. & 1 \\
\hline 32 & 40 & 1856 & Isi/Isi-c & Paleoindian & & Medium/Large Vertebrata & Indeterminate & 23 \\
\hline 32 & 40 & 1856 & Isi/Isi-c & Paleoindian & & Small/Medium Vertebrata & Long bone & 11 \\
\hline 32 & 40 & 1856 & Isi/Isi-c & Paleoindian & & Vertebrata & Indeterminate & 58 \\
\hline 33 & 16 & 682 & IIIa & E. Archaic & & Colubridae & Dorsal vertebra & 1 \\
\hline 33 & 16 & 682 & IIIIa & E. Archaic & & Mammalia (Medium/large) & Tooth, perm./decid. ind. & 1 \\
\hline 33 & 16 & 682 & IIIIa & E. Archaic & & Serpentes & Dorsal vertebra & 1 \\
\hline 33 & 16 & 682 & IIIa & E. Archaic & & Small/Medium Vertebrata & Long bone & 4 \\
\hline 33 & 16 & 682 & IIIa & E. Archaic & & Vertebrata & Indeterminate & 19 \\
\hline 33 & $17 \mathrm{~A}$ & 695 & IIIIa & E. Archaic & & Vertebrata & Indeterminate & 3 \\
\hline 33 & $17 \mathrm{~B}$ & 712 & Ша & E. Archaic & 217 & Leporidae & Permanent tooth & 1 \\
\hline 33 & 17B & 712 & IIIIa & E. Archaic & 217 & Mammalia (Medium/large) & Indeterminate & 4 \\
\hline 33 & 17B & 712 & IIIa & E. Archaic & 217 & Mammalia (Medium/large) & Long bone & 1 \\
\hline 33 & $17 \mathrm{~B}$ & 712 & IIIa & E. Archaic & 217 & Mammalia (Medium/large) & Tooth, perm./decid. ind. & 1 \\
\hline 33 & 17B & 712 & IIIIa & E. Archaic & 217 & Mammalia (Small) & Radius & 1 \\
\hline 33 & 17B & 712 & Ша & E. Archaic & 217 & Odocoileus sp. & Proximal abaxial sesamoid & 1 \\
\hline 33 & $17 \mathrm{~B}$ & 712 & IIIa & E. Archaic & 217 & Serpentes & Dorsal vertebra & 1 \\
\hline 33 & 17B & 712 & IIIIa & E. Archaic & 217 & Small/Medium Vertebrata & Long bone & 3 \\
\hline 33 & 17B & 712 & IIIa & E. Archaic & 217 & Sylvilagus sp. & Calcaneus & 1 \\
\hline 33 & $17 \mathrm{~B}$ & 712 & IIIa & E. Archaic & 217 & Vertebrata & Indeterminate & 27 \\
\hline 33 & 19 & 912 & IIIIa & E. Archaic & 231 & Leporidae & Permanent tooth & 2 \\
\hline 33 & 19 & 912 & IIIIa & E. Archaic & 231 & Mammalia (Medium) & Distal phalange & 1 \\
\hline 33 & 19 & 912 & IIIa & E. Archaic & 231 & Mammalia (Medium) & Ulna & 1 \\
\hline 33 & 19 & 912 & IIIIa & E. Archaic & 231 & Mammalia (Medium/large) & Indeterminate & 2 \\
\hline 33 & 19 & 912 & III & E. Archaic & 231 & Mammalia (Medium/large) & Long bone & 1 \\
\hline 33 & 19 & 912 & IIIa & E. Archaic & 231 & Mammalia (Micro) & Permanent tooth & 1 \\
\hline 33 & 19 & 912 & IIIIa & E. Archaic & 231 & Small vertebrate, class ind. & Middle phalange & 1 \\
\hline 33 & 19 & 912 & IIIIa & E. Archaic & 231 & Small/Medium Vertebrata & Long bone & 5 \\
\hline 33 & 19 & 912 & IIIIa & E. Archaic & 231 & Testudinata & Shell fragment & 1 \\
\hline 33 & 19 & 912 & IIIIa & E. Archaic & 231 & |Vertebrata & Indeterminate & 34 \\
\hline 33 & 20 & 974 & IIIIa & E. Archaic & 231 & Geomys sp. & Permanent tooth & 1 \\
\hline 33 & 20 & 974 & III & E. Archaic & 231 & Lepus californicus & Permanent tooth & 1 \\
\hline 33 & 20 & 974 & IIIIa & E. Archaic & 231 & Mammalia (Medium/large) & Indeterminate & 3 \\
\hline 33 & 20 & 974 & IIIIa & E. Archaic & 231 & Mammalia (Medium/large) & Long bone & 1 \\
\hline 33 & 20 & 974 & ШШа & E. Archaic & 231 & Mammalia (Medium/large) & Tooth, perm./decid. ind. & 1 \\
\hline 33 & 20 & 974 & IIIIa & E. Archaic & 231 & Mammalia (Small) & Permanent tooth & 1 \\
\hline 33 & 20 & 974 & IIIIa & E. Archaic & 231 & Neotoma sp. & Permanent tooth & 1 \\
\hline 33 & 20 & 974 & Ша & E. Archaic & 231 & Small vertebrate, class ind. & Phalange & 1 \\
\hline 33 & 20 & 974 & IIIIa & E. Archaic & 231 & Small vertebrate, class ind. & Proximal phalange & 1 \\
\hline 33 & 20 & 974 & IIIIa & E. Archaic & 231 & Small/Medium Vertebrata & Long bone & 14 \\
\hline
\end{tabular}




\begin{tabular}{|c|c|c|c|c|c|c|c|c|}
\hline Square & Level & Lot & Unit & Cultural Affinity & Feature & Taxon & Element & No. \\
\hline 33 & 20 & 974 & IIIa & E. Archaic & 231 & Vertebrata & Indeterminate & 47 \\
\hline 33 & 21 & 995 & II/IIIa & L. Paleo./E. Archaic & & Carnivora & Permanent tooth & 1 \\
\hline 33 & 21 & 995 & II/IIIa & L. Paleo./E. Archaic & & Geomys sp. & Permanent tooth & 1 \\
\hline 33 & 21 & 995 & Ш/ШІІа & L. Paleo./E. Archaic & & Mammalia (Large) & Indeterminate & 1 \\
\hline 33 & 21 & 995 & III/IIIa & L. Paleo./E. Archaic & & Mammalia (Medium) & |Ulna & 1 \\
\hline 33 & 21 & 995 & II/III & L. Paleo./E. Archaic & & Mammalia (Medium/large) & Tooth, perm./decid. ind. & 1 \\
\hline 33 & 21 & 995 & II/IIIa & L. Paleo./E. Archaic & & Mammalia (Small) & Permanent tooth & 2 \\
\hline 33 & 21 & 995 & II/IIIa & L. Paleo./E. Archaic & & Medium vertebrate, class ind. & Middle phalange & 1 \\
\hline 33 & 21 & 995 & II/IIIa & L. Paleo./E. Archaic & & Small vertebrate, class ind. & Phalange & 1 \\
\hline 33 & 21 & 995 & II/IIIa & L. Paleo./E. Archaic & & Small/Medium Vertebrata & Long bone & 11 \\
\hline 33 & 21 & 995 & III/IIIa & L. Paleo./E. Archaic & & Small/Medium Vertebrata & Vertebra & 1 \\
\hline 33 & 21 & 995 & ШІШІа & L. Paleo./E. Archaic & & Sylvilagus sp. & Astragalus & 1 \\
\hline 33 & 21 & 995 & III/IIIa & L. Paleo./E. Archaic & & Sylvilagus sp. & Central tarsal bone & 1 \\
\hline 33 & 21 & 995 & III/IIIa & L. Paleo./E. Archaic & & Sylvilagus sp. & Femur & 1 \\
\hline 33 & 21 & 995 & II/IIIa & L. Paleo./E. Archaic & & Sylvilagus sp. & Humerus & 2 \\
\hline 33 & 21 & 995 & II/IIIa & L. Paleo./E. Archaic & & Testudinata & Shell fragment & 1 \\
\hline 33 & 21 & 995 & III/IIIa & L. Paleo./E. Archaic & & Vertebrata & Indeterminate & 57 \\
\hline 33 & 22 & 1023 & ШІІІІа & L. Paleo./E. Archaic & & Leporidae & Permanent tooth & 1 \\
\hline 33 & 22 & 1023 & ШIIIIa & L. Paleo./E. Archaic & & Mammalia (Small) & Middle phalange & 1 \\
\hline 33 & 22 & 1023 & III/IIIa & L. Paleo./E. Archaic & & Mammalia (Small) & Ulna & 1 \\
\hline 33 & 22 & 1023 & II/ШІа & L. Paleo./E. Archaic & & Small vertebrate, class ind. & Distal phalange & 1 \\
\hline 33 & 22 & 1023 & II/IIIa & L. Paleo./E. Archaic & & Small/Medium Vertebrata & Long bone & 6 \\
\hline 33 & 22 & 1023 & II/IIIa & L. Paleo./E. Archaic & & Vertebrata & Indeterminate & 20 \\
\hline 33 & 23 & 1045 & Ш/Ша & L. Paleo./E. Archaic & & Lepus californicus & Fourth tarsal & 1 \\
\hline 33 & 23 & 1045 & Ш/ШIIa & L. Paleo./E. Archaic & & Mammalia (Medium/large) & Indeterminate & 4 \\
\hline 33 & 23 & 1045 & III/IIIa & L. Paleo./E. Archaic & & Mammalia (Medium/large) & Tooth, perm./decid. ind. & 1 \\
\hline 33 & 23 & 1045 & ШI/IIIa & L. Paleo./E. Archaic & & Mammalia (Small) & Permanent tooth & 1 \\
\hline 33 & 23 & 1045 & II/IIIa & L. Paleo./E. Archaic & & Small/Medium Vertebrata & Long bone & 8 \\
\hline 33 & 23 & 1045 & II/IIIa & L. Paleo./E. Archaic & & Sylvilagus sp. & Calcaneus & 1 \\
\hline 33 & 23 & 1045 & II/IIIa & L. Paleo./E. Archaic & & Vertebrata & Indeterminate & 18 \\
\hline 33 & 24 & 1099 & IIIIIIa & L. Paleo./E. Archaic & & Lepus californicus & Permanent tooth & 1 \\
\hline 33 & 24 & 1099 & IIIIIIa & L. Paleo./E. Archaic & & Mammalia (Small) & Distal phalange & 1 \\
\hline 33 & 24 & 1099 & II/IIIa & L. Paleo./E. Archaic & & Mammalia (Small) & Permanent tooth & 1 \\
\hline 33 & 24 & 1099 & II/IIIa & L. Paleo./E. Archaic & & Small/Medium Vertebrata & Long bone & 21 \\
\hline 33 & 24 & 1099 & II/IIIa & L. Paleo./E. Archaic & & Sylvilagus sp. & Astragalus & 1 \\
\hline 33 & 24 & 1099 & IIIIIIa & L. Paleo./E. Archaic & & Vertebrata & Indeterminate & 36 \\
\hline 33 & 25 & 1133 & IIIIIIa & L. Paleo./E. Archaic & & Leporidae & Permanent tooth & 3 \\
\hline 33 & 25 & 1133 & III/IIIa & L. Paleo./E. Archaic & & Mammalia (Medium/large) & Indeterminate & 1 \\
\hline 33 & 25 & 1133 & IIIIIIa & L. Paleo./E. Archaic & & Mammalia (Micro) & Femur & 1 \\
\hline 33 & 25 & 1133 & IIIIIIa & L. Paleo./E. Archaic & & Small/Medium Vertebrata & Long bone & 14 \\
\hline 33 & 25 & 1133 & II/IIIa & L. Paleo./E. Archaic & & Sylvilagus sp. & Metapodial & 1 \\
\hline 33 & 25 & 1133 & III/IIIa & L. Paleo./E. Archaic & & Sylvilagus sp. & Permanent tooth & 1 \\
\hline 33 & 25 & 1133 & IIIIIIa & L. Paleo./E. Archaic & & Vertebrata & Indeterminate & 42 \\
\hline 33 & 26 & 1177 & II/IIIa & L. Paleo./E. Archaic & & Medium/Large Vertebrata & Indeterminate & 4 \\
\hline 33 & 26 & 1177 & II/IIIa & L. Paleo./E. Archaic & & Small/Medium Vertebrata & Long bone & 3 \\
\hline 33 & 26 & 1177 & II/IIIa & L. Paleo./E. Archaic & & Vertebrata & Indeterminate & 8 \\
\hline 33 & 27 & 1198 & III & L. Paleo. & & Leporidae & Permanent tooth & 1 \\
\hline 33 & 27 & 1198 & III & L. Paleo. & & Mammalia (Medium/large) & Indeterminate & 1 \\
\hline 33 & 27 & 1198 & III & L. Paleo. & & Mammalia (Medium/large) & Long bone & 5 \\
\hline 33 & 27 & 1198 & III & L. Paleo. & & Small/Medium Vertebrata & Long bone & 9 \\
\hline 33 & 27 & 1198 & III & L. Paleo. & & Sylvilagus sp. & Ulna & 1 \\
\hline 33 & 27 & 1198 & II & L. Paleo. & & Vertebrata & Indeterminate & 37 \\
\hline 33 & 28 & 1215 & III & L. Paleo. & & Mammalia (Large) & Long bone & 1 \\
\hline 33 & 28 & 1215 & III & L. Paleo. & & Mammalia (Medium/large) & Indeterminate & 1 \\
\hline 33 & 28 & 1215 & III & L. Paleo. & & Mammalia (Small) & Metapodial & 1 \\
\hline 33 & 28 & 1215 & III & L. Paleo. & & Mammalia (Small) & Tibia & 1 \\
\hline 33 & 28 & 1215 & III & L. Paleo. & & Small/Medium Vertebrata & Long bone & 11 \\
\hline 33 & 28 & 1215 & III & L. Paleo. & & Vertebrata & Indeterminate & 11 \\
\hline 33 & 29 & 1231 & III & L. Paleo. & & Medium/Large Vertebrata & Indeterminate & 1 \\
\hline 33 & 29 & 1231 & III & L. Paleo. & & Small/Medium Vertebrata & Long bone & 12 \\
\hline 33 & 29 & 1231 & III & L. Paleo. & & Vertebrata & Indeterminate & 9 \\
\hline 33 & $30 \mathrm{~A}$ & 1408 & III & L. Paleo. & & Leporidae & Permanent tooth & 1 \\
\hline 33 & $30 \mathrm{~A}$ & 1408 & III & L. Paleo. & & Mammalia (Medium/large) & Indeterminate & 3 \\
\hline 33 & $30 \mathrm{~A}$ & 1408 & III & L. Paleo. & & Mammalia (Medium/large) & Long bone & 5 \\
\hline 33 & $30 \mathrm{~A}$ & 1408 & III & L. Paleo. & & Small/Medium Vertebrata & Long bone & 6 \\
\hline 33 & $30 \mathrm{~A}$ & 1408 & III & L. Paleo. & & Sylvilagus sp. & Calcaneus & 1 \\
\hline 33 & $30 \mathrm{~A}$ & 1408 & III & L. Paleo. & & Sylvilagus sp. & Femur & 1 \\
\hline
\end{tabular}




\begin{tabular}{|c|c|c|c|c|c|c|c|c|}
\hline Square & Level & Lot & Unit & Cultural Affinity & Feature & Taxon & Element & No. \\
\hline 33 & $30 \mathrm{~A}$ & 1408 & $\overline{I I}$ & L. Paleo. & & Vertebrata & Indeterminate & 22 \\
\hline 33 & 30B & 1431 & II & L. Paleo. & 236 & Small/Medium Vertebrata & Long bone & 1 \\
\hline 33 & $31 \mathrm{~A}$ & 1414 & Id/III & L. Paleo. & & Geomys sp. & Permanent tooth & 2 \\
\hline 33 & $31 \mathrm{~A}$ & 1414 & Id/III & L. Paleo. & & Mammalia (Large) & Tooth, perm./decid. ind. & 1 \\
\hline 33 & $31 \mathrm{~A}$ & 1414 & Id/II & L. Paleo. & & Mammalia (Medium/large) & Indeterminate & 5 \\
\hline 33 & $31 \mathrm{~A}$ & 1414 & Id/III & L. Paleo. & & Mammalia (Medium/large) & Long bone & 1 \\
\hline 33 & $31 \mathrm{~A}$ & 1414 & $\mathrm{Id} / \mathrm{II}$ & L. Paleo. & & Mammalia (Medium/large) & Tooth, perm./decid. ind. & 3 \\
\hline 33 & $31 \mathrm{~A}$ & 1414 & Id/II & L. Paleo. & & Mammalia (Small) & Femur & 1 \\
\hline 33 & $31 \mathrm{~A}$ & 1414 & Id/II & L. Paleo. & & Mammalia (Small) & Permanent tooth & 1 \\
\hline 33 & $31 \mathrm{~A}$ & 1414 & $\mathrm{Id} / \mathrm{II}$ & L. Paleo. & & Mammalia (Small/medium) & Alveolar ridge fragment & 1 \\
\hline 33 & $31 \mathrm{~A}$ & 1414 & Id/II & L. Paleo. & & Small/Medium Vertebrata & Long bone & 23 \\
\hline 33 & $31 \mathrm{~A}$ & 1414 & Id/II & L. Paleo. & & Sylvilagus sp. & Calcaneus & 2 \\
\hline 33 & $31 \mathrm{~A}$ & 1414 & Id/III & L. Paleo. & & Sylvilagus sp. & Permanent tooth & 2 \\
\hline 33 & $31 \mathrm{~A}$ & 1414 & Id/II & L. Paleo. & & Sylvilagus sp. & Radius & 1 \\
\hline 33 & $31 \mathrm{~A}$ & 1414 & $\mathrm{Id} / \mathrm{II}$ & L. Paleo. & & Vertebrata & Indeterminate & 66 \\
\hline 33 & 32 & 1592 & $\mathrm{Id} / \mathrm{II}$ & L. Paleo. & & Leporidae & Permanent tooth & 1 \\
\hline 33 & 32 & 1592 & $\mathrm{Id} / \mathrm{II}$ & L. Paleo. & & Mammalia (Medium/large) & Long bone & 2 \\
\hline 33 & 32 & 1592 & Id/II & L. Paleo. & & Mammalia (Small) & Middle phalange & 1 \\
\hline 33 & 32 & 1592 & Id/II & L. Paleo. & & Mammalia (Small) & Radius & 1 \\
\hline 33 & 32 & 1592 & $\mathrm{Id} / \mathrm{II}$ & L. Paleo. & & Small/Medium Vertebrata & Long bone & 10 \\
\hline 33 & 32 & 1592 & Id/II & L. Paleo. & & Sylvilagus sp. & Calcaneus & 1 \\
\hline 33 & 32 & 1592 & $\mathrm{Id} / \mathrm{II}$ & L. Paleo. & & Sylvilagus sp. & Radius & 1 \\
\hline 33 & 32 & 1592 & $\mathrm{Id} / \mathrm{II}$ & L. Paleo. & & Vertebrata & Indeterminate & 40 \\
\hline 33 & 33 & 1665 & Id & L. Paleo. & & Leporidae & Permanent tooth & 1 \\
\hline 33 & 33 & 1665 & Id & L. Paleo. & & Mammalia (Medium/large) & Long bone & 5 \\
\hline 33 & 33 & 1665 & Id & L. Paleo. & & Mammalia (Small) & Caudal vertebra & 1 \\
\hline 33 & 33 & 1665 & Id & L. Paleo. & & Mammalia (Small) & Scapula & 1 \\
\hline 33 & 33 & 1665 & Id & L. Paleo. & & Mammalia (Very large) & Tooth, perm./decid. ind. & 1 \\
\hline 33 & 33 & 1665 & Id & L. Paleo. & & Medium vertebrate, class ind. & Proximal phalange & 2 \\
\hline 33 & 33 & 1665 & Id & L. Paleo. & & Neotoma sp. & Permanent tooth & 1 \\
\hline 33 & 33 & 1665 & Id & L. Paleo. & & Small/Medium Vertebrata & Long bone & 11 \\
\hline 33 & 33 & 1665 & Id & L. Paleo. & & Sylvilagus sp. & Astragalus & 1 \\
\hline 33 & 33 & 1665 & Id & L. Paleo. & & Sylvilagus sp. & Metatarsal 4 & 1 \\
\hline 33 & 33 & 1665 & Id & L. Paleo. & & Vertebrata & Indeterminate & 72 \\
\hline 33 & 34 & 1782 & Isi-c/Id & L. Paleo. & & Vertebrata & Indeterminate & 3 \\
\hline 33 & 34 & 1819 & Isi-c/Id & L. Paleo. & & Mammalia (Micro) & Tibia & 1 \\
\hline 33 & 34 & 1819 & Isi-c/Id & L. Paleo. & & Mammalia (Small) & Femur & 1 \\
\hline 33 & 34 & 1819 & Isi-c/Id & L. Paleo. & & Medium vertebrate, class ind. & Distal phalange & 1 \\
\hline 33 & 34 & 1819 & Isi-c/Id & L. Paleo. & & Medium/Large Vertebrata & Indeterminate & 1 \\
\hline 33 & 34 & 1819 & Isi-c/Id & L. Paleo. & & Small/Medium Vertebrata & Long bone & 14 \\
\hline 33 & 34 & 1819 & Isi-c/Id & L. Paleo. & & Sylvilagus sp. & Calcaneus & 1 \\
\hline 33 & 34 & 1819 & Isi-c/Id & L. Paleo. & & Vertebrata & Indeterminate & 90 \\
\hline 33 & 35 & 1889 & Isi-c/Id & L. Paleo. & & Mammalia (Medium/large) & Tooth, perm./decid. ind. & 1 \\
\hline 33 & 35 & 1889 & Isi-c/Id & L. Paleo. & & Medium vertebrate, class ind. & Proximal phalange & 1 \\
\hline 33 & 35 & 1889 & Isi-c/Id & L. Paleo. & & Medium/Large Vertebrata & Indeterminate & 4 \\
\hline 33 & 35 & 1889 & Isi-c/Id & L. Paleo. & & Small/Medium Vertebrata & Long bone & 9 \\
\hline 33 & 35 & 1889 & Isi-c/Id & L. Paleo. & & Vertebrata & Indeterminate & 18 \\
\hline 34 & 15 & 672 & IIIIa & E. Archaic & & Leporidae & Permanent tooth & 2 \\
\hline 34 & 15 & 672 & IIIIa & E. Archaic & & Mammalia (Medium/large) & Indeterminate & 2 \\
\hline 34 & 15 & 672 & ШІа & E. Archaic & & Mammalia (Medium/large) & Mandible & 1 \\
\hline 34 & 15 & 672 & ШІ丨а & E. Archaic & & Mammalia (Micro) & Permanent tooth & 2 \\
\hline 34 & 15 & 672 & IIIa & E. Archaic & & Mammalia (Small) & Metapodial & 1 \\
\hline 34 & 15 & 672 & IIIa & E. Archaic & & Medium vertebrate, class ind. & Middle phalange & 1 \\
\hline 34 & 15 & 672 & IIIa & E. Archaic & & Serpentes & Dorsal vertebra & 2 \\
\hline 34 & 15 & 672 & IIIIa & E. Archaic & & Small/Medium Vertebrata & Long bone & 12 \\
\hline 34 & 15 & 672 & IIII & E. Archaic & & Testudinata & Shell fragment & 4 \\
\hline 34 & 15 & 672 & ШІа & E. Archaic & & Vertebrata & Indeterminate & 83 \\
\hline 34 & 16 & 693 & IIIIa & E. Archaic & & Mammalia (Medium/large) & Indeterminate & 1 \\
\hline 34 & 16 & 693 & ШІІа & E. Archaic & & Mammalia (Micro) & Calcaneus & 1 \\
\hline 34 & 16 & 693 & ШІІа & E. Archaic & & Small/Medium Vertebrata & Long bone & 9 \\
\hline 34 & 16 & 693 & IIIa & E. Archaic & & Testudinata & Shell fragment & 1 \\
\hline 34 & 16 & 693 & IIII & E. Archaic & & Vertebrata & Indeterminate & 29 \\
\hline 34 & 17 & 737 & ШІа & E. Archaic & & Mammalia (Large) & Indeterminate & 1 \\
\hline 34 & 17 & 737 & ШІа & E. Archaic & & Mammalia (Micro) & Permanent tooth & 1 \\
\hline 34 & 17 & 737 & IIIа & E. Archaic & & Mammalia (Small) & Calcaneus & 1 \\
\hline 34 & 17 & 737 & ШІа & E. Archaic & & Mammalia (Small) & Caudal vertebra & 1 \\
\hline 34 & 17 & 737 & IIIa & E. Archaic & & Medium/Large Vertebrata & Indeterminate & 4 \\
\hline
\end{tabular}




\begin{tabular}{|c|c|c|c|c|c|c|c|c|}
\hline Square & Level & Lot & Unit & Cultural Affinity & Feature & Taxon & Element & No. \\
\hline 34 & 17 & 737 & IIIa & E. Archaic & & Small vertebrate, class ind. & Distal phalange & 1 \\
\hline 34 & 17 & 737 & IIIIa & E. Archaic & & Small/Medium Vertebrata & Long bone & 2 \\
\hline 34 & 17 & 737 & IIIIa & E. Archaic & & Vertebrata & Indeterminate & 7 \\
\hline 34 & 18 & 785 & IIIIa & E. Archaic & & Leporidae & Calcaneus & 1 \\
\hline 34 & 18 & 785 & IIIIa & E. Archaic & & Leporidae & Permanent tooth & 1 \\
\hline 34 & 18 & 785 & III & E. Archaic & & Mammalia (Medium) & Middle phalange & 1 \\
\hline 34 & 18 & 785 & IIIIa & E. Archaic & & Mammalia (Medium/large) & Indeterminate & 3 \\
\hline 34 & 18 & 785 & IIII & E. Archaic & & Medium/Large Vertebrata & Indeterminate & 2 \\
\hline 34 & 18 & 785 & III & E. Archaic & & Serpentes & Dorsal vertebra & 1 \\
\hline 34 & 18 & 785 & IIIIa & E. Archaic & & Small/Medium Vertebrata & Long bone & 6 \\
\hline 34 & 18 & 785 & IIIIa & E. Archaic & & Testudinata & Neural & 1 \\
\hline 34 & 18 & 785 & IIIIa & E. Archaic & & Testudinata & Shell fragment & 3 \\
\hline 34 & 18 & 785 & IIIIa & E. Archaic & & Vertebrata & Indeterminate & 16 \\
\hline 34 & $19 \mathrm{~A}$ & 845 & IIIIa & E. Archaic & & Vertebrata & Indeterminate & 4 \\
\hline 34 & 19B & 872 & IIIIa & E. Archaic & 223 & Leporidae & Permanent tooth & 1 \\
\hline 34 & 19B & 872 & IIIa & E. Archaic & 223 & Medium/Large Vertebrata & Indeterminate & 4 \\
\hline 34 & 19B & 872 & IIIIa & E. Archaic & 223 & Small/Medium Vertebrata & Long bone & 2 \\
\hline 34 & 19B & 872 & IIIa & E. Archaic & 223 & Testudinata & Shell fragment & 3 \\
\hline 34 & 19B & 872 & IIIIa & E. Archaic & 223 & Vertebrata & Indeterminate & 24 \\
\hline 34 & 20 & 985 & IIII & E. Archaic & 231 & Antilocapra/Odocoileus & Fused 3rd \& 4th metatarsal & 1 \\
\hline 34 & 20 & 985 & IIIa & E. Archaic & 231 & Mammalia (Medium/large) & Indeterminate & 3 \\
\hline 34 & 20 & 985 & IIIa & E. Archaic & 231 & Small/Medium Vertebrata & Long bone & 3 \\
\hline 34 & 20 & 985 & IIIIa & E. Archaic & 231 & Vertebrata & Indeterminate & 12 \\
\hline 34 & 21 & 1115 & ШШа & E. Archaic & 231 & Colubridae & Dorsal vertebra & 1 \\
\hline 34 & 21 & 1115 & IIIIa & E. Archaic & 231 & Mammalia (Large) & Indeterminate & 1 \\
\hline 34 & 21 & 1115 & IIIIa & E. Archaic & 231 & Mammalia (Large) & Long bone & 3 \\
\hline 34 & 21 & 1115 & IIIa & E. Archaic & 231 & Mammalia (Medium/large) & Indeterminate & 3 \\
\hline 34 & 21 & 1115 & IIIIa & E. Archaic & 231 & Mammalia (Small) & Proximal phalange & 2 \\
\hline 34 & 21 & 1115 & IIIIa & E. Archaic & 231 & Neotoma sp. & Permanent tooth & 1 \\
\hline 34 & 21 & 1115 & IIIa & E. Archaic & 231 & Osteichthyes (Small) & Vertebra & 1 \\
\hline 34 & 21 & 1115 & IIIIa & E. Archaic & 231 & Small/Medium Vertebrata & Long bone & 13 \\
\hline 34 & 21 & 1115 & IIIIa & E. Archaic & 231 & Vertebrata & Indeterminate & 55 \\
\hline 34 & 22 & 1162 & ІІ/Ша & L. Paleo./E. Archaic & 231 & Leporidae & Permanent tooth & 1 \\
\hline 34 & 22 & 1162 & II/IIIa & L. Paleo./E. Archaic & 231 & Lepus californicus & Humerus & 1 \\
\hline 34 & 22 & 1162 & ПI/III & L. Paleo./E. Archaic & 231 & Mammalia (Medium) & Proximal phalange & 1 \\
\hline 34 & 22 & 1162 & II/IIIa & L. Paleo./E. Archaic & 231 & Mammalia (Medium/large) & Indeterminate & 5 \\
\hline 34 & 22 & 1162 & II/IIIa & L. Paleo./E. Archaic & 231 & Mammalia (Small) & Calcaneus & 1 \\
\hline 34 & 22 & 1162 & II/IIIa & L. Paleo./E. Archaic & 231 & Mammalia (Small) & Metapodial & 1 \\
\hline 34 & 22 & 1162 & II/IIIa & L. Paleo./E. Archaic & 231 & Mammalia (Small) & Proximal phalange & 1 \\
\hline 34 & 22 & 1162 & II/II & L. Paleo./E. Archaic & 231 & Medium/Large Vertebrata & Indeterminate & 1 \\
\hline 34 & 22 & 1162 & П/Ша & L. Paleo./E. Archaic & 231 & Serpentes & Dorsal vertebra & 1 \\
\hline 34 & 22 & 1162 & ПI/III & L. Paleo./E. Archaic & 231 & Small/Medium Vertebrata & Long bone & 15 \\
\hline 34 & 22 & 1162 & II/IIIa & L. Paleo./E. Archaic & 231 & Sylvilagus sp. & Astragalus & 1 \\
\hline 34 & 22 & 1162 & II/IIIa & L. Paleo./E. Archaic & 231 & Vertebrata & Indeterminate & 37 \\
\hline 34 & $23 \mathrm{~A}$ & 1245 & П/IIIa & L. Paleo./E. Archaic & 231 & Carnivora & Accessory carpal bone & 1 \\
\hline 34 & $23 \mathrm{~A}$ & 1245 & II/IIIa & L. Paleo./E. Archaic & 231 & Lepus californicus & Permanent tooth & 1 \\
\hline 34 & $23 \mathrm{~A}$ & 1245 & II/IIIa & L. Paleo./E. Archaic & 231 & Mammalia (Medium/large) & Indeterminate & 3 \\
\hline 34 & $23 \mathrm{~A}$ & 1245 & II/IIIa & L. Paleo./E. Archaic & 231 & Osteichthyes (Small) & Vertebra & 1 \\
\hline 34 & $23 \mathrm{~A}$ & 1245 & II/IIIa & L. Paleo./E. Archaic & 231 & Small/Medium Vertebrata & Long bone & 22 \\
\hline 34 & $23 \mathrm{~A}$ & 1245 & II/IIIa & L. Paleo./E. Archaic & 231 & Sylvilagus sp. & Astragalus & 2 \\
\hline 34 & $23 \mathrm{~A}$ & 1245 & II/IIIa & L. Paleo./E. Archaic & 231 & Sylvilagus sp. & Calcaneus & 1 \\
\hline 34 & $23 \mathrm{~A}$ & 1245 & П/ШІІа & L. Paleo./E. Archaic & 231 & Testudinata & Peripheral & 1 \\
\hline 34 & $23 \mathrm{~A}$ & 1245 & П/ШІа & L. Paleo./E. Archaic & 231 & Testudinata & Shell fragment & 1 \\
\hline 34 & $23 \mathrm{~A}$ & 1245 & II/IIIa & L. Paleo./E. Archaic & 231 & Vertebrata & Indeterminate & 49 \\
\hline 34 & 24 & 1292 & II/IIIa & L. Paleo./E. Archaic & 231 & Lepus californicus & Permanent tooth & 1 \\
\hline 34 & 24 & 1292 & II/IIIa & L. Paleo./E. Archaic & 231 & Mammalia (Large) & Long bone & 1 \\
\hline 34 & 24 & 1292 & П/ШाIа & L. Paleo./E. Archaic & 231 & Mammalia (Micro) & Permanent tooth & 1 \\
\hline 34 & 24 & 1292 & II/IIIa & L. Paleo./E. Archaic & 231 & Small/Medium Vertebrata & Long bone & 23 \\
\hline 34 & 24 & 1292 & II/IIIa & L. Paleo./E. Archaic & 231 & Sylvilagus sp. & Calcaneus & 1 \\
\hline 34 & 24 & 1292 & П/Шाа & L. Paleo./E. Archaic & 231 & Vertebrata & Indeterminate & 39 \\
\hline 34 & $25 \mathrm{~A}$ & 1346 & II & L. Paleo. & & Geomys sp. & Permanent tooth & 1 \\
\hline 34 & $25 \mathrm{~A}$ & 1346 & II & L. Paleo. & & Leporidae & Mandible & 1 \\
\hline 34 & $25 \mathrm{~A}$ & 1346 & III & L. Paleo. & & Leporidae & Permanent tooth & 3 \\
\hline 34 & $25 \mathrm{~A}$ & 1346 & III & L. Paleo. & & Mammalia (Medium) & Radius & 1 \\
\hline 34 & $25 \mathrm{~A}$ & 1346 & III & L. Paleo. & & Mammalia (Medium/large) & Indeterminate & 3 \\
\hline 34 & $25 \mathrm{~A}$ & 1346 & III & L. Paleo. & & Mammalia (Micro) & Permanent tooth & 1 \\
\hline 34 & $25 \mathrm{~A}$ & 1346 & III & L. Paleo. & & Serpentes & Dorsal vertebra & 1 \\
\hline
\end{tabular}




\begin{tabular}{|c|c|c|c|c|c|c|c|c|}
\hline Square & Level & Lot & Unit & Cultural Affinity & Feature & Taxon & Element & No. \\
\hline 34 & $25 \mathrm{~A}$ & 1346 & III & L. Paleo. & & Small/Medium Vertebrata & Long bone & 11 \\
\hline 34 & $25 \mathrm{~A}$ & 1346 & III & L. Paleo. & & Sylvilagus sp. & Astragalus & 1 \\
\hline 34 & $25 \mathrm{~A}$ & 1346 & III & L. Paleo. & & Sylvilagus sp. & Femur & 1 \\
\hline 34 & $25 \mathrm{~A}$ & 1346 & III & L. Paleo. & & Vertebrata & Indeterminate & 19 \\
\hline 34 & $25 \mathrm{~B}$ & 1382 & III & L. Paleo. & 239 & Small/Medium Vertebrata & Long bone & 4 \\
\hline 34 & $25 \mathrm{~B}$ & 1382 & III & L. Paleo. & 239 & Vertebrata & Indeterminate & 8 \\
\hline 34 & $26 \mathrm{~A}$ & 1421 & III & L. Paleo. & & Mammalia (Medium/large) & Tooth, perm./decid. ind. & 1 \\
\hline 34 & $26 \mathrm{~A}$ & 1421 & III & L. Paleo. & & Mammalia (Micro) & Tibia & 1 \\
\hline 34 & $26 \mathrm{~A}$ & 1421 & III & L. Paleo. & & Serpentes & Dorsal vertebra & 1 \\
\hline 34 & $26 \mathrm{~A}$ & 1421 & III & L. Paleo. & & Small vertebrate, class ind. & Proximal phalange & 1 \\
\hline 34 & $26 \mathrm{~A}$ & 1421 & II & L. Paleo. & & Small/Medium Vertebrata & Long bone & 10 \\
\hline 34 & $26 \mathrm{~A}$ & 1421 & III & L. Paleo. & & Sylvilagus sp. & Calcaneus & 1 \\
\hline 34 & $26 \mathrm{~A}$ & 1421 & III & L. Paleo. & & Vertebrata & Indeterminate & 29 \\
\hline 34 & $26 \mathrm{~B}$ & 1442 & III & L. Paleo. & 239 & Vertebrata & Indeterminate & 16 \\
\hline 34 & $27 \mathrm{~A}$ & 1466 & III & L. Paleo. & & Mammalia (Medium) & Calcaneus & 1 \\
\hline 34 & $27 \mathrm{~A}$ & 1466 & III & L. Paleo. & & Mammalia (Medium) & Femur & 1 \\
\hline 34 & $27 \mathrm{~A}$ & 1466 & III & L. Paleo. & & Mammalia (Medium/large) & Long bone & 2 \\
\hline 34 & $27 \mathrm{~A}$ & 1466 & III & L. Paleo. & & Mammalia (Medium/large) & Phalange & 1 \\
\hline 34 & $27 \mathrm{~A}$ & 1466 & III & L. Paleo. & & Mammalia (Micro) & Astragalus & 1 \\
\hline 34 & $27 \mathrm{~A}$ & 1466 & III & L. Paleo. & & Mammalia (Micro) & Tibia & 1 \\
\hline 34 & $27 \mathrm{~A}$ & 1466 & III & L. Paleo. & & Osteichthyes (Small) & Vertebra & 1 \\
\hline 34 & $27 \mathrm{~A}$ & 1466 & III & L. Paleo. & & Small vertebrate, class ind. & Phalange & 2 \\
\hline 34 & $27 \mathrm{~A}$ & 1466 & III & L. Paleo. & & Small/Medium Vertebrata & Long bone & 13 \\
\hline 34 & $27 \mathrm{~A}$ & 1466 & III & L. Paleo. & & Sylvilagus sp. & Calcaneus & 1 \\
\hline 34 & $27 \mathrm{~A}$ & 1466 & III & L. Paleo. & & Vertebrata & Indeterminate & 39 \\
\hline 34 & 27B & 1473 & III & L. Paleo. & 239 & Leporidae & Permanent tooth & 1 \\
\hline 34 & $27 \mathrm{~B}$ & 1473 & III & L. Paleo. & 239 & Medium/Large Vertebrata & Indeterminate & 1 \\
\hline 34 & $27 \mathrm{~B}$ & 1473 & III & L. Paleo. & 239 & Medium/Large Vertebrata & Long bone & 4 \\
\hline 34 & $27 \mathrm{~B}$ & 1473 & III & L. Paleo. & 239 & Small/Medium Vertebrata & Long bone & 3 \\
\hline 34 & $27 \mathrm{~B}$ & 1473 & III & L. Paleo. & 239 & Sylvilagus sp. & Tibia & 1 \\
\hline 34 & $27 \mathrm{~B}$ & 1473 & III & L. Paleo. & 239 & Vertebrata & Indeterminate & 7 \\
\hline 34 & 28 & 1531 & III & L. Paleo. & & Colubridae & Dorsal vertebra & 1 \\
\hline 34 & 28 & 1531 & III & L. Paleo. & & Leporidae & Permanent tooth & 1 \\
\hline 34 & 28 & 1531 & III & L. Paleo. & & Mammalia (Medium/large) & Indeterminate & 3 \\
\hline 34 & 28 & 1531 & III & L. Paleo. & & Mammalia (Small) & Permanent tooth & 1 \\
\hline 34 & 28 & 1531 & III & L. Paleo. & & Medium/Large Vertebrata & Indeterminate & 1 \\
\hline 34 & 28 & 1531 & III & L. Paleo. & & Rodentia (Medium) & Permanent tooth & 1 \\
\hline 34 & 28 & 1531 & III & L. Paleo. & & Small/Medium Vertebrata & Long bone & 7 \\
\hline 34 & 28 & 1531 & III & L. Paleo. & & Sylvilagus sp. & Humerus & 1 \\
\hline 34 & 28 & 1531 & III & L. Paleo. & & Vertebrata & Indeterminate & 10 \\
\hline 34 & 29 & 1551 & III & L. Paleo. & & Mammalia (Small) & Patella & 1 \\
\hline 34 & 29 & 1551 & III & L. Paleo. & & Rodentia (Medium) & Femur & 1 \\
\hline 34 & 29 & 1551 & III & L. Paleo. & & Small/Medium Vertebrata & Long bone & 13 \\
\hline 34 & 29 & 1551 & III & L. Paleo. & & Small/Medium Vertebrata & Phalange & 1 \\
\hline 34 & 29 & 1551 & III & L. Paleo. & & Sylvilagus sp. & Astragalus & 2 \\
\hline 34 & 29 & 1551 & III & L. Paleo. & & Vertebrata & Indeterminate & 27 \\
\hline 34 & 30 & 1666 & III & L. Paleo. & & Small/Medium Vertebrata & Long bone & 7 \\
\hline 34 & 30 & 1666 & III & L. Paleo. & & Vertebrata & Indeterminate & 24 \\
\hline 34 & $31 \mathrm{~A}$ & 1697 & III & L. Paleo. & & Small/Medium Vertebrata & Long bone & 5 \\
\hline 34 & $31 \mathrm{~A}$ & 1697 & III & L. Paleo. & & Sylvilagus sp. & Ulna & 2 \\
\hline 34 & $31 \mathrm{~A}$ & 1697 & III & L. Paleo. & & Vertebrata & Indeterminate & 8 \\
\hline 34 & $31 \mathrm{C}$ & 1612 & III & L. Paleo. & 247 & Small/Medium Vertebrata & Long bone & 1 \\
\hline 34 & $32 \mathrm{~A}$ & 1786 & Id/II & L. Paleo. & & Leporidae & Permanent tooth & 1 \\
\hline 34 & $32 \mathrm{~A}$ & 1786 & Id/II & L. Paleo. & & Mammalia (Medium) & Metapodial & 1 \\
\hline 34 & $32 \mathrm{~A}$ & 1786 & $\mathrm{Id} / \mathrm{II}$ & L. Paleo. & & Mammalia (Medium/large) & Indeterminate & 2 \\
\hline 34 & $32 \mathrm{~A}$ & 1786 & Id/II & L. Paleo. & & Small/Medium Vertebrata & Long bone & 12 \\
\hline 34 & $32 \mathrm{~A}$ & 1786 & Id/II & L. Paleo. & & Vertebrata & Indeterminate & 36 \\
\hline 34 & 33 & 1850 & Id/II & L. Paleo. & & Leporidae & Permanent tooth & 1 \\
\hline 34 & 33 & 1850 & Id/II & L. Paleo. & & Mammalia (Medium/large) & Indeterminate & 2 \\
\hline 34 & 33 & 1850 & Id/II & L. Paleo. & & Osteichthyes (Small) & Sagitta otolith & 1 \\
\hline 34 & 33 & 1850 & Id/II & L. Paleo. & & Small/Medium Vertebrata & Long bone & 7 \\
\hline 34 & 33 & 1850 & Id/II & L. Paleo. & & Vertebrata & Indeterminate & 53 \\
\hline 35 & 14 & 709 & IIIa/b & E. Archaic & & Carnivora & Tooth, perm./decid. ind. & 1 \\
\hline 35 & 14 & 709 & IIIa/b & E. Archaic & & Colubridae & Dorsal vertebra & 1 \\
\hline 35 & 14 & 709 & $\mathrm{IIa} / \mathrm{b}$ & E. Archaic & & Leporidae & Permanent tooth & 1 \\
\hline 35 & 14 & 709 & IIIa/b & E. Archaic & & Mammalia (Large) & Tooth, perm./decid. ind. & 5 \\
\hline 35 & 14 & 709 & IIIa/b & E. Archaic & & Mammalia (Medium/large) & Indeterminate & 6 \\
\hline
\end{tabular}




\begin{tabular}{|c|c|c|c|c|c|c|c|c|}
\hline Square & Level & Lot & Unit & Cultural Affinity & Feature & Taxon & Element & No. \\
\hline 35 & 14 & 709 & $\Pi \Pi \mathrm{II} / \mathrm{b}$ & E. Archaic & & Mammalia (Medium/large) & Tooth, perm./decid. ind. & 1 \\
\hline 35 & 14 & 709 & Шаa/b & E. Archaic & & Mammalia (Small) & Cranium & 1 \\
\hline 35 & 14 & 709 & IIIa/b & E. Archaic & & Medium/Large Vertebrata & Indeterminate & 4 \\
\hline 35 & 14 & 709 & ШШаa/b & E. Archaic & & Odocoileus sp. & Tooth, perm./decid. ind. & 1 \\
\hline 35 & 14 & 709 & IIIa/b & E. Archaic & & Serpentes & Dorsal vertebra & 1 \\
\hline 35 & 14 & 709 & IIIa/b & E. Archaic & & Sigmodon hispidus & Cranium & 1 \\
\hline 35 & 14 & 709 & Ша/b & E. Archaic & & Sigmodon hispidus & Permanent tooth & 3 \\
\hline 35 & 14 & 709 & ПIIa/b & E. Archaic & & Small/Medium Vertebrata & Long bone & 3 \\
\hline 35 & 14 & 709 & IIIIa/b & E. Archaic & & Vertebrata & Indeterminate & 59 \\
\hline 35 & 15 & 756 & Ша & E. Archaic & & Mammalia (Medium) & Proximal phalange & 1 \\
\hline 35 & 15 & 756 & IIIIa & E. Archaic & & Mammalia (Medium/large) & Indeterminate & 4 \\
\hline 35 & 15 & 756 & IIIIa & E. Archaic & & Mammalia (Medium/large) & Tooth, perm./decid. ind. & 5 \\
\hline 35 & 15 & 756 & III & E. Archaic & & Mammalia (Micro) & Tibia & 1 \\
\hline 35 & 15 & 756 & IIIa & E. Archaic & & Neotoma sp. & Permanent tooth & 1 \\
\hline 35 & 15 & 756 & IIIIa & E. Archaic & & Rodentia (Medium) & Permanent tooth & 1 \\
\hline 35 & 15 & 756 & ІІІа & E. Archaic & & Small/Medium Vertebrata & Long bone & 8 \\
\hline 35 & 15 & 756 & ШШа & E. Archaic & & Vertebrata & Indeterminate & 82 \\
\hline 35 & 16 & 803 & IIIIa & E. Archaic & & Colubridae & Dorsal vertebra & 1 \\
\hline 35 & 16 & 803 & IIIIa & E. Archaic & & Mammalia (Small) & Metapodial & 1 \\
\hline 35 & 16 & 803 & ШШа & E. Archaic & & Mammalia (Small) & Middle phalange & 1 \\
\hline 35 & 16 & 803 & IIIIa & E. Archaic & & Serpentes & Dorsal vertebra & 1 \\
\hline 35 & 16 & 803 & IIIa & E. Archaic & & Small/Medium Vertebrata & Long bone & 5 \\
\hline 35 & 16 & 803 & IIIa & E. Archaic & & Vertebrata & Indeterminate & 16 \\
\hline 35 & $17 \mathrm{~A}$ & 828 & IIIIa & E. Archaic & & Leporidae & Permanent tooth & 2 \\
\hline 35 & $17 \mathrm{~A}$ & 828 & IIIIa & E. Archaic & & Mammalia (Medium/large) & Indeterminate & 1 \\
\hline 35 & $17 \mathrm{~A}$ & 828 & IIIa & E. Archaic & & Mammalia (Medium/large) & Long bone & 1 \\
\hline 35 & $17 \mathrm{~A}$ & 828 & IIIIa & E. Archaic & & Medium/Large Vertebrata & Indeterminate & 1 \\
\hline 35 & $17 \mathrm{~A}$ & 828 & IIIIa & E. Archaic & & Small vertebrate, class ind. & Middle phalange & 1 \\
\hline 35 & $17 \mathrm{~A}$ & 828 & IIIa & E. Archaic & & Small/Medium Vertebrata & Long bone & 8 \\
\hline 35 & $17 \mathrm{~A}$ & 828 & IIIIa & E. Archaic & & Squamata & Vertebra & 1 \\
\hline 35 & $17 \mathrm{~A}$ & 828 & IIIIa & E. Archaic & & Vertebrata & Indeterminate & 27 \\
\hline 35 & 18 & 844 & IIIa & E. Archaic & & Mammalia (Medium/large) & Indeterminate & 1 \\
\hline 35 & 18 & 844 & IIIIa & E. Archaic & & Small/Medium Vertebrata & Long bone & 5 \\
\hline 35 & 18 & 844 & IIIIa & E. Archaic & & Sylvilagus sp. & Metatarsal 3 & 1 \\
\hline 35 & 18 & 844 & IIIa & E. Archaic & & Testudinata & Shell fragment & 1 \\
\hline 35 & 18 & 844 & Ша & E. Archaic & & Vertebrata & Indeterminate & 13 \\
\hline 35 & 19 & 866 & IIIa & E. Archaic & 231 & Leporidae & Permanent tooth & 1 \\
\hline 35 & 19 & 866 & IIa & E. Archaic & 231 & Mammalia (Small) & Calcaneus & 1 \\
\hline 35 & 19 & 866 & IIIa & E. Archaic & 231 & Mammalia (Small) & Proximal phalange & 1 \\
\hline 35 & 19 & 866 & IIIIa & E. Archaic & 231 & Mammalia (Small) & Ulna & 1 \\
\hline 35 & 19 & 866 & IIIa & E. Archaic & 231 & Small/Medium Vertebrata & Long bone & 8 \\
\hline 35 & 19 & 866 & IIIa & E. Archaic & 231 & Vertebrata & Indeterminate & 24 \\
\hline 35 & 20 & 894 & IIIIa & E. Archaic & 231 & Geomys sp. & Permanent tooth & 1 \\
\hline 35 & 20 & 894 & IIIa & E. Archaic & 231 & Mammalia (Medium/large) & Long bone & 2 \\
\hline 35 & 20 & 894 & IIa & E. Archaic & 231 & Neotoma sp. & Permanent tooth & 1 \\
\hline 35 & 20 & 894 & IIIa & E. Archaic & 231 & Rodentia (Medium) & Permanent tooth & 1 \\
\hline 35 & 20 & 894 & IIIa & E. Archaic & 231 & Small vertebrate, class ind. & Distal phalange & 1 \\
\hline 35 & 20 & 894 & Ша & E. Archaic & 231 & Small/Medium Vertebrata & Long bone & 13 \\
\hline 35 & 20 & 894 & IIIIa & E. Archaic & 231 & Testudinata & Shell fragment & 1 \\
\hline 35 & 20 & 894 & IIIIa & E. Archaic & 231 & Vertebrata & Indeterminate & 45 \\
\hline 35 & 21 & 996 & IIIa & E. Archaic & 231 & Leporidae & Permanent tooth & 1 \\
\hline 35 & 21 & 996 & IIIa & E. Archaic & 231 & Mammalia (Medium/large) & Indeterminate & 2 \\
\hline 35 & 21 & 996 & IIIIa & E. Archaic & 231 & Small/Medium Vertebrata & Long bone & 10 \\
\hline 35 & 21 & 996 & IIIIa & E. Archaic & 231 & Testudinata & Neural & 1 \\
\hline 35 & 21 & 996 & IIIa & E. Archaic & 231 & Testudinata & Shell fragment & 1 \\
\hline 35 & 21 & 996 & IIIa & E. Archaic & 231 & Vertebrata & Indeterminate & 28 \\
\hline 35 & 22 & 1041 & II/IIIa & L. Paleo./E. Archaic & 231 & Mammalia (Medium) & Proximal phalange & 1 \\
\hline 35 & 22 & 1041 & II/IIIa & L. Paleo./E. Archaic & 231 & Mammalia (Medium/large) & Indeterminate & 1 \\
\hline 35 & 22 & 1041 & II/IIIa & L. Paleo./E. Archaic & 231 & Mammalia (Medium/large) & Long bone & 2 \\
\hline 35 & 22 & 1041 & II/IIIa & L. Paleo./E. Archaic & 231 & Small/Medium Vertebrata & Long bone & 12 \\
\hline 35 & 22 & 1041 & II/IIIa & L. Paleo./E. Archaic & 231 & Sylvilagus sp. & Astragalus & 1 \\
\hline 35 & 22 & 1041 & II/IIIa & L. Paleo./E. Archaic & 231 & Vertebrata & Indeterminate & 64 \\
\hline 35 & 23 & 1226 & II/IIIa & L. Paleo./E. Archaic & & Geomys sp. & Permanent tooth & 1 \\
\hline 35 & 23 & 1226 & II/Ша & L. Paleo./E. Archaic & & Mammalia (Medium) & Metapodial & 1 \\
\hline 35 & 23 & 1226 & II/IIIa & L. Paleo./E. Archaic & & Mammalia (Medium) & Tooth, perm./decid. ind. & 1 \\
\hline 35 & 23 & 1226 & II/IIIIa & L. Paleo./E. Archaic & & Mammalia (Medium/large) & Indeterminate & 8 \\
\hline 35 & 23 & 1226 & II/IIIa & L. Paleo./E. Archaic & & Mammalia (Micro) & Mandible & 1 \\
\hline
\end{tabular}




\begin{tabular}{|c|c|c|c|c|c|c|c|c|}
\hline Square & Level & Lot & Unit & Cultural Affinity & Feature & Taxon & Element & No. \\
\hline 35 & 23 & 1226 & II/IIa & L. Paleo./E. Archaic & & Mammalia (Small) & Radius & 1 \\
\hline 35 & 23 & 1226 & II/IIIa & L. Paleo./E. Archaic & & Small vertebrate, class ind. & Phalange & 1 \\
\hline 35 & 23 & 1226 & II/IIIa & L. Paleo./E. Archaic & & Small/Medium Vertebrata & Long bone & 24 \\
\hline 35 & 23 & 1226 & II/Ша & L. Paleo./E. Archaic & & Sylvilagus sp. & Astragalus & 1 \\
\hline 35 & 23 & 1226 & II/IIIa & L. Paleo./E. Archaic & & Vertebrata & Indeterminate & 50 \\
\hline 35 & 24 & 1300 & ІІ/IIIa & L. Paleo./E. Archaic & & Geomys sp. & Permanent tooth & 1 \\
\hline 35 & 24 & 1300 & II/IIIa & L. Paleo./E. Archaic & & Leporidae & Permanent tooth & 1 \\
\hline 35 & 24 & 1300 & II/IIIa & L. Paleo./E. Archaic & & Mammalia (Micro) & Permanent tooth & 1 \\
\hline 35 & 24 & 1300 & П/ШІІа & L. Paleo./E. Archaic & & Mammalia (Small) & Femur & 1 \\
\hline 35 & 24 & 1300 & ПI/Ша & L. Paleo./E. Archaic & & Odocoileus sp. & Tooth, perm./decid. ind. & 1 \\
\hline 35 & 24 & 1300 & П/Шान & L. Paleo./E. Archaic & & Small vertebrate, class ind. & Proximal phalange & 1 \\
\hline 35 & 24 & 1300 & II/IIIIa & L. Paleo./E. Archaic & & Small/Medium Vertebrata & Long bone & 22 \\
\hline 35 & 24 & 1300 & ІІ/Ша & L. Paleo./E. Archaic & & Sylvilagus sp. & Ulna & 1 \\
\hline 35 & 24 & 1300 & II/1/a & L. Paleo./E. Archaic & & Vertebrata & Indeterminate & 38 \\
\hline 35 & 25 & 1398 & II & L. Paleo. & & Mammalia (Large) & Tooth, perm./decid. ind. & 1 \\
\hline 35 & 25 & 1398 & II & L. Paleo. & & Mammalia (Medium) & Caudal vertebra & 1 \\
\hline 35 & 25 & 1398 & II & L. Paleo. & & Mammalia (Micro) & Permanent tooth & 1 \\
\hline 35 & 25 & 1398 & II & L. Paleo. & & Medium/Large Vertebrata & Indeterminate & 3 \\
\hline 35 & 25 & 1398 & II & L. Paleo. & & Small/Medium Vertebrata & Long bone & 19 \\
\hline 35 & 25 & 1398 & III & L. Paleo. & & Sylvilagus sp. & Permanent tooth & 1 \\
\hline 35 & 25 & 1398 & II & L. Paleo. & & Sylvilagus sp. & Radius & 1 \\
\hline 35 & 25 & 1398 & II & L. Paleo. & & Sylvilagus sp. & Tibia & 1 \\
\hline 35 & 25 & 1398 & III & L. Paleo. & & Testudinata & Humerus & 1 \\
\hline 35 & 25 & 1398 & II & L. Paleo. & & Vertebrata & Indeterminate & 15 \\
\hline 35 & $26 \mathrm{~A}$ & 1104 & III & L. Paleo. & & Geomys sp. & Permanent tooth & 1 \\
\hline 35 & $26 \mathrm{~A}$ & 1104 & II & L. Paleo. & & Leporidae & Permanent tooth & 1 \\
\hline 35 & $26 \mathrm{~A}$ & 1104 & II & L. Paleo. & & Mammalia (Medium/large) & Indeterminate & 1 \\
\hline 35 & $26 \mathrm{~A}$ & 1104 & II & L. Paleo. & & Mammalia (Small) & Caudal vertebra & 1 \\
\hline 35 & $26 \mathrm{~A}$ & 1104 & II & L. Paleo. & & Osteichthyes (Small) & Vertebra & 3 \\
\hline 35 & $26 \mathrm{~A}$ & 1104 & II & L. Paleo. & & Rodentia (Medium) & Permanent tooth & 1 \\
\hline 35 & $26 \mathrm{~A}$ & 1104 & II & L. Paleo. & & Small/Medium Vertebrata & Long bone & 24 \\
\hline 35 & $26 \mathrm{~A}$ & 1104 & III & L. Paleo. & & Sylvilagus sp. & Humerus & 1 \\
\hline 35 & $26 \mathrm{~A}$ & 1104 & II & L. Paleo. & & Testudinata & Peripheral & 1 \\
\hline 35 & $26 \mathrm{~A}$ & 1104 & III & L. Paleo. & & Vertebrata & Indeterminate & 105 \\
\hline 35 & 27 & 1463 & III & L. Paleo. & & Leporidae & Permanent tooth & 1 \\
\hline 35 & 27 & 1463 & III & L. Paleo. & & Mammalia (Large) & Indeterminate & 1 \\
\hline 35 & 27 & 1463 & II & L. Paleo. & & Mammalia (Medium/large) & Indeterminate & 2 \\
\hline 35 & 27 & 1463 & II & L. Paleo. & & Mammalia (Medium/large) & Long bone & 3 \\
\hline 35 & 27 & 1463 & II & L. Paleo. & & Mammalia (Small) & Caudal vertebra & 1 \\
\hline 35 & 27 & 1463 & III & L. Paleo. & & Mammalia (Small) & Metapodial & 1 \\
\hline 35 & 27 & 1463 & III & L. Paleo. & & Small/Medium Vertebrata & Long bone & 10 \\
\hline 35 & 27 & 1463 & III & L. Paleo. & & Sylvilagus sp. & Astragalus & 1 \\
\hline 35 & 27 & 1463 & II & L. Paleo. & & Sylvilagus sp. & Radius & 1 \\
\hline 35 & 27 & 1463 & III & L. Paleo. & & Vertebrata & Indeterminate & 53 \\
\hline 35 & 28 & 1562 & III & L. Paleo. & & Geomys sp. & Permanent tooth & 1 \\
\hline 35 & 28 & 1562 & III & L. Paleo. & & Mammalia (Medium/large) & Indeterminate & 6 \\
\hline 35 & 28 & 1562 & II & L. Paleo. & & Mammalia (Medium/large) & Long bone & 1 \\
\hline 35 & 28 & 1562 & II & L. Paleo. & & Mammalia (Small) & Permanent tooth & 1 \\
\hline 35 & 28 & 1562 & II & L. Paleo. & & Mammalia (Small) & Radius & 1 \\
\hline 35 & 28 & 1562 & II & L. Paleo. & & Small/Medium Vertebrata & Long bone & 19 \\
\hline 35 & 28 & 1562 & II & L. Paleo. & & Vertebrata & Indeterminate & 76 \\
\hline 35 & 29 & 1685 & II & L. Paleo. & & Mammalia (Medium/large) & Long bone & 1 \\
\hline 35 & 29 & 1685 & II & L. Paleo. & & Medium/Large Vertebrata & Indeterminate & 2 \\
\hline 35 & 29 & 1685 & II & L. Paleo. & & Small/Medium Vertebrata & Long bone & 7 \\
\hline 35 & 29 & 1685 & II & L. Paleo. & & Vertebrata & Indeterminate & 31 \\
\hline 35 & $30 \mathrm{~A}$ & 1698 & II & L. Paleo. & & Geomys sp. & Permanent tooth & 2 \\
\hline 35 & $30 \mathrm{~A}$ & 1698 & II & L. Paleo. & & Leporidae & Permanent tooth & 1 \\
\hline 35 & $30 \mathrm{~A}$ & 1698 & II & L. Paleo. & & Mammalia (Small) & Permanent tooth & 1 \\
\hline 35 & $30 \mathrm{~A}$ & 1698 & II & L. Paleo. & & Rodentia (Small) & Permanent tooth & 1 \\
\hline 35 & $30 \mathrm{~A}$ & 1698 & II & L. Paleo. & & Small vertebrate, class ind. & Phalange & 1 \\
\hline 35 & $30 \mathrm{~A}$ & 1698 & II & L. Paleo. & & Small/Medium Vertebrata & Long bone & 8 \\
\hline 35 & $30 \mathrm{~A}$ & 1698 & II & L. Paleo. & & Sylvilagus sp. & Calcaneus & 1 \\
\hline 35 & $30 \mathrm{~A}$ & 1698 & II & L. Paleo. & & Vertebrata & Indeterminate & 38 \\
\hline 35 & $30 \mathrm{~B}$ & 1712 & II & L. Paleo. & 247 & Vertebrata & Indeterminate & 1 \\
\hline 35 & $31 \mathrm{~A}$ & 1743 & II & L. Paleo. & & Medium/Large Vertebrata & Indeterminate & 1 \\
\hline 35 & $31 \mathrm{~A}$ & 1743 & II & L. Paleo. & & Medium/Large Vertebrata & Long bone & 1 \\
\hline 35 & $31 \mathrm{~A}$ & 1743 & II & L. Paleo. & & Small/Medium Vertebrata & Long bone & 2 \\
\hline
\end{tabular}




\begin{tabular}{|c|c|c|c|c|c|c|c|c|}
\hline Square & Level & Lot & Unit & Cultural Affinity & Feature & Taxon & Element & No. \\
\hline 35 & $31 \mathrm{~A}$ & 1743 & II & L. Paleo. & & Vertebrata & Indeterminate & 5 \\
\hline 35 & $31 \mathrm{~B}$ & 1613 & III & L. Paleo. & 247 & Small/Medium Vertebrata & Long bone & 1 \\
\hline 35 & 31B & 1613 & III & L. Paleo. & 247 & Vertebrata & Indeterminate & 1 \\
\hline 35 & 32 & 1614 & III & L. Paleo. & & Mammalia (Small) & Distal phalange & 1 \\
\hline 35 & 32 & 1614 & III & L. Paleo. & & Medium vertebrate, class ind. & Proximal phalange & 1 \\
\hline 35 & 32 & 1614 & III & L. Paleo. & & Small/Medium Vertebrata & Long bone & 11 \\
\hline 35 & 32 & 1614 & III & L. Paleo. & & Sylvilagus sp. & Calcaneus & 1 \\
\hline 35 & 32 & 1614 & III & L. Paleo. & & Vertebrata & Indeterminate & 29 \\
\hline 35 & 33 & 1810 & Id/II & L. Paleo. & & Leporidae & Permanent tooth & 1 \\
\hline 35 & 33 & 1810 & Id/II & L. Paleo. & & Mammalia (Small) & Epiphysis & 1 \\
\hline 35 & 33 & 1810 & Id/II & L. Paleo. & & Medium vertebrate, class ind. & Phalange & 1 \\
\hline 35 & 33 & 1810 & Id/II & L. Paleo. & & Small/Medium Vertebrata & Long bone & 8 \\
\hline 35 & 33 & 1810 & Id/II & L. Paleo. & & Vertebrata & Indeterminate & 36 \\
\hline 35 & 34 & 1924 & Id/II & L. Paleo. & & Mammalia (Large) & Ulna & 1 \\
\hline 35 & 34 & 1924 & Id/II & L. Paleo. & & Mammalia (Medium/large) & Tooth, perm./decid. ind. & 1 \\
\hline 35 & 34 & 1924 & Id/II & L. Paleo. & & Medium/Large Vertebrata & Indeterminate & 2 \\
\hline 35 & 34 & 1924 & Id/II & L. Paleo. & & Rodentia (Medium) & Permanent tooth & 1 \\
\hline 35 & 34 & 1924 & Id/II & L. Paleo. & & Small/Medium Vertebrata & Indeterminate & 2 \\
\hline 35 & 34 & 1924 & Id/II & L. Paleo. & & Small/Medium Vertebrata & Long bone & 3 \\
\hline 35 & 34 & 1924 & $\mathrm{Id} / \mathrm{II}$ & L. Paleo. & & Sylvilagus sp. & Humerus & 1 \\
\hline 35 & 34 & 1924 & Id/II & L. Paleo. & & Sylvilagus sp. & Metatarsal 3 & 1 \\
\hline 35 & 34 & 1924 & Id/II & L. Paleo. & & Vertebrata & Indeterminate & 12 \\
\hline 35 & 35 & 1942 & Id/II & L. Paleo. & & Leporidae & Permanent tooth & 1 \\
\hline 35 & 35 & 1942 & Id/II & L. Paleo. & & Mammalia (Small) & Epiphysis & 1 \\
\hline 35 & 35 & 1942 & Id/II & L. Paleo. & & Medium/Large Vertebrata & Indeterminate & 6 \\
\hline 35 & 35 & 1942 & Id/II & L. Paleo. & & Small/Medium Vertebrata & Long bone & 5 \\
\hline 35 & 35 & 1942 & Id/II & L. Paleo. & & Vertebrata & Indeterminate & 22 \\
\hline 35 & 36 & 1982 & Isi-c/Id & L. Paleo. & & Leporidae & Permanent tooth & 1 \\
\hline 35 & 36 & 1982 & Isi-c/Id & L. Paleo. & & Mammalia (Medium) & Rib & 1 \\
\hline 35 & 36 & 1982 & Isi-c/Id & L. Paleo. & & Mammalia (Medium/large) & Vertebra & 1 \\
\hline 35 & 36 & 1982 & Isi-c/Id & L. Paleo. & & Small/Medium Vertebrata & Long bone & 3 \\
\hline 35 & 36 & 1982 & Isi-c/Id & L. Paleo. & & Vertebrata & Indeterminate & 17 \\
\hline 35 & 37 & 2001 & Isi-c/Id & L. Paleo. & & Mammalia (Medium) & Rib & 1 \\
\hline 35 & 37 & 2001 & Isi-c/Id & L. Paleo. & & Mammalia (Medium/large) & Permanent tooth & 1 \\
\hline 35 & 37 & 2001 & Isi-c/Id & L. Paleo. & & Mammalia (Small) & Femur & 1 \\
\hline 35 & 37 & 2001 & Isi-c/Id & L. Paleo. & & Mammalia (Small) & Tibia & 1 \\
\hline 35 & 37 & 2001 & Isi-c/Id & L. Paleo. & & Small/Medium Vertebrata & Long bone & 11 \\
\hline 35 & 37 & 2001 & Isi-c/Id & L. Paleo. & & Testudinata & Carapace fragment ind. & 1 \\
\hline 35 & 37 & 2001 & Isi-c/Id & L. Paleo. & & Testudinata & Shell fragment & 2 \\
\hline 35 & 37 & 2001 & Isi-c/Id & L. Paleo. & & Vertebrata & Indeterminate & 35 \\
\hline 35 & 38 & 2020 & Isi-c/Id & L. Paleo. & & Geomys sp. & Permanent tooth & 1 \\
\hline 35 & 38 & 2020 & Isi-c/Id & L. Paleo. & & Mammalia (Medium) & Long bone & 1 \\
\hline 35 & 38 & 2020 & Isi-c/Id & L. Paleo. & & Medium/Large Vertebrata & Indeterminate & 3 \\
\hline 35 & 38 & 2020 & Isi-c/Id & L. Paleo. & & Medium/Large Vertebrata & Vertebra & 1 \\
\hline 35 & 38 & 2020 & Isi-c/Id & L. Paleo. & & Neotoma sp. & Permanent tooth & 1 \\
\hline 35 & 38 & 2020 & Isi-c/Id & L. Paleo. & & Serpentes & Dorsal vertebra & 1 \\
\hline 35 & 38 & 2020 & Isi-c/Id & L. Paleo. & & Small/Medium Vertebrata & Long bone & 7 \\
\hline 35 & 38 & 2020 & Isi-c/Id & L. Paleo. & & Testudinata & Shell fragment & 1 \\
\hline 35 & 38 & 2020 & Isi-c/Id & L. Paleo. & & Vertebrata & Indeterminate & 20 \\
\hline 35 & 39 & 2056 & Isi-c & L. Paleo. & & Mammalia (Medium/large) & Indeterminate & 1 \\
\hline 35 & 39 & 2056 & Isi-c & L. Paleo. & & Small/Medium Vertebrata & Long bone & 2 \\
\hline 35 & 39 & 2056 & Isi-c & L. Paleo. & & Sylvilagus sp. & Metatarsal 5 & 1 \\
\hline 35 & 39 & 2056 & Isi-c & L. Paleo. & & Testudinata & Shell fragment & 1 \\
\hline 35 & 39 & 2056 & Isi-c & L. Paleo. & & Vertebrata & Indeterminate & 21 \\
\hline 35 & 40 & 2074 & Isi-c & L. Paleo. & & Leporidae & Permanent tooth & 1 \\
\hline 35 & 40 & 2074 & Isi-c & L. Paleo. & & Mammalia (Small) & Femur & 1 \\
\hline 35 & 40 & 2074 & Isi-c & L. Paleo. & & Medium/Large Vertebrata & Indeterminate & 1 \\
\hline 35 & 40 & 2074 & Isi-c & L. Paleo. & & Serpentes & Dorsal vertebra & 2 \\
\hline 35 & 40 & 2074 & Isi-c & L. Paleo. & & Small/Medium Vertebrata & Long bone & 7 \\
\hline 35 & 40 & 2074 & Isi-c & L. Paleo. & & Testudinata & Shell fragment & 2 \\
\hline 35 & 40 & 2074 & Isi-c & L. Paleo. & & Vertebrata & Indeterminate & 28 \\
\hline 35 & 41 & 2692 & Isi-c & L. Paleo. & & Mammalia (Medium/large) & Indeterminate & 4 \\
\hline 35 & 41 & 2692 & Isi-c & L. Paleo. & & Mammalia (Small) & Radius & 1 \\
\hline 35 & 41 & 2692 & Isi-c & L. Paleo. & & Small/Medium Vertebrata & Long bone & 2 \\
\hline 35 & 41 & 2692 & Isi-c & L. Paleo. & & Vertebrata & Indeterminate & 20 \\
\hline 35 & 42 & 2118 & Icl/Isi-c & Paleoindian & & Leporidae & Cranium & 1 \\
\hline 35 & 42 & 2118 & Icl/Isi-c & Paleoindian & & Medium/Large Vertebrata & Indeterminate & 7 \\
\hline
\end{tabular}




\begin{tabular}{|c|c|c|c|c|c|c|c|c|}
\hline Square & Level & Lot & \begin{tabular}{|l|} 
Unit \\
\end{tabular} & Cultural Affinity & Feature & Taxon & Element & No. \\
\hline 35 & 42 & 2118 & $\mathrm{Icl} / \mathrm{Isi}-\mathrm{c}$ & Paleoindian & & Small/Medium Vertebrata & Long bone & 11 \\
\hline 35 & 42 & 2118 & Icl/Isi-c & Paleoindian & & Testudinata & Shell fragment & 1 \\
\hline 35 & 42 & 2118 & Icl/Isi-c & Paleoindian & & Vertebrata & Indeterminate & 11 \\
\hline 35 & 43 & 2786 & $\mathrm{Icl} / \mathrm{Isi}-\mathrm{c}$ & Paleoindian & & Mammalia (Large) & Cranium & 1 \\
\hline 35 & 43 & 2786 & $\mathrm{Icl} / \mathrm{Isi}-\mathrm{c}$ & Paleoindian & & Mammalia (Medium/large) & Indeterminate & 10 \\
\hline 35 & 43 & 2786 & Icl/Isi-c & Paleoindian & & Medium/Large Vertebrata & Indeterminate & 1 \\
\hline 35 & 43 & 2786 & $\mathrm{Icl} / \mathrm{Isi}-\mathrm{c}$ & Paleoindian & & Small/Medium Vertebrata & Long bone & 3 \\
\hline 35 & 43 & 2786 & $\mathrm{Icl} / \mathrm{Isi}-\mathrm{c}$ & Paleoindian & & Vertebrata & Indeterminate & 2 \\
\hline 35 & 44 & 2659 & $\mathrm{Icl} / \mathrm{Isi}-\mathrm{c}$ & Paleoindian & & Medium/Large Vertebrata & Indeterminate & 11 \\
\hline 35 & 44 & 2659 & $\mathrm{Icl} / \mathrm{Isi}-\mathrm{c}$ & Paleoindian & & Small/Medium Vertebrata & Long bone & 18 \\
\hline 35 & 44 & 2659 & Icl/Isi-c & Paleoindian & & Vertebrata & Indeterminate & 30 \\
\hline 35 & 45 & 2729 & Isi/Icl & E. Paleoindian & & Mammalia (Medium/large) & Indeterminate & 3 \\
\hline 35 & 45 & 2729 & Isi/Icl & E. Paleoindian & & Mammalia (Small) & Radius & 1 \\
\hline 35 & 45 & 2729 & Isi/Icl & E. Paleoindian & & Medium/Large Vertebrata & Indeterminate & 1 \\
\hline 35 & 45 & 2729 & Isi/Icl & E. Paleoindian & & Small/Medium Vertebrata & Long bone & 8 \\
\hline 35 & 45 & 2729 & Isi/Icl & E. Paleoindian & & Vertebrata & Indeterminate & 13 \\
\hline 35 & 46 & 2683 & Isi/Icl & E. Paleoindian & & Geomys sp. & Permanent tooth & 1 \\
\hline 35 & 46 & 2683 & Isi/Icl & E. Paleoindian & & Mammalia (Large) & Phalange & 1 \\
\hline 35 & 46 & 2683 & Isi/Icl & E. Paleoindian & & Mammalia (Medium/large) & Indeterminate & 1 \\
\hline 35 & 46 & 2683 & Isi/Icl & E. Paleoindian & & Small/Medium Vertebrata & Long bone & 6 \\
\hline 35 & 46 & 2683 & Isi/Icl & E. Paleoindian & & Vertebrata & Indeterminate & 20 \\
\hline 35 & 47 & 2636 & Isi/Icl & E. Paleoindian & & Mammalia (Medium/large) & Indeterminate & 3 \\
\hline 35 & 47 & 2636 & Isi/Icl & E. Paleoindian & & Medium/Large Vertebrata & Indeterminate & 9 \\
\hline 35 & 47 & 2636 & Isi/Icl & E. Paleoindian & & Small/Medium Vertebrata & Long bone & 2 \\
\hline 35 & 47 & 2636 & Isi/Icl & E. Paleoindian & & Vertebrata & Indeterminate & 29 \\
\hline 35 & 48 & 2370 & Isi/Icl & E. Paleoindian & 259 & Vertebrata & Indeterminate & 8 \\
\hline 35 & 48 & 2380 & Isi/Icl & E. Paleoindian & & Mammalia (Medium/large) & Indeterminate & 1 \\
\hline 35 & 48 & 2391 & Isi/Icl & E. Paleoindian & & Vertebrata & Indeterminate & 2 \\
\hline 35 & 48 & 2747 & Isi/Icl & E. Paleoindian & & Small/Medium Vertebrata & Long bone & 1 \\
\hline 35 & 48 & 2747 & Isi/Icl & E. Paleoindian & & Testudinata & Shell fragment & 1 \\
\hline 35 & 48 & 2747 & Isi/Icl & E. Paleoindian & & Vertebrata & Indeterminate & 14 \\
\hline 35 & 49 & 2426 & Isi/Icl & E. Paleoindian & & Testudinata & Shell fragment & 4 \\
\hline 35 & 49 & 2426 & Isi/Icl & E. Paleoindian & & Vertebrata & Indeterminate & 3 \\
\hline 35 & 49 & 2745 & Isi/Icl & E. Paleoindian & & Mammalia (Small/medium) & Long bone & 1 \\
\hline 35 & 49 & 2745 & Isi/Icl & E. Paleoindian & & Medium/Large Vertebrata & Indeterminate & 2 \\
\hline 35 & 49 & 2745 & Isi/Icl & E. Paleoindian & & Testudinata & Shell fragment & 1 \\
\hline 35 & 49 & 2745 & Isi/Icl & E. Paleoindian & & Vertebrata & Indeterminate & 5 \\
\hline 35 & 50 & 2425 & Isi/Icl & E. Paleoindian & & Mammalia (Large) & Indeterminate & 1 \\
\hline 35 & 50 & 2427 & Isi/Icl & E. Paleoindian & & Mammalia (Large) & Indeterminate & 1 \\
\hline 35 & 50 & 2595 & Isi/Icl & E. Paleoindian & & Medium/Large Vertebrata & Indeterminate & 2 \\
\hline 35 & 50 & 2595 & Isi/Icl & E. Paleoindian & & Vertebrata & Indeterminate & 15 \\
\hline 35 & 51 & 2739 & Isi & E. Paleoindian & & Medium/Large Vertebrata & Indeterminate & 11 \\
\hline 35 & 51 & 2739 & Isi & E. Paleoindian & & Vertebrata & Indeterminate & 19 \\
\hline 35 & 53 & 2583 & Isi & E. Paleoindian & & Mammalia (Medium/large) & Indeterminate & 1 \\
\hline 35 & 53 & 2583 & Isi & E. Paleoindian & & Small/Medium Vertebrata & Long bone & 1 \\
\hline 35 & 53 & 2583 & Isi & E. Paleoindian & & Vertebrata & Indeterminate & 1 \\
\hline 37 & 10 & 520 & $\mathrm{IIIb} / \mathrm{c}$ & M. Archaic & & Antilocapra/Odocoileus & Fused central/fourth tarsal & 1 \\
\hline 37 & 10 & 520 & $\mathrm{IIIb} / \mathrm{c}$ & M. Archaic & & Colubridae & Dorsal vertebra & 2 \\
\hline 37 & 10 & 520 & $\mathrm{IIIb} / \mathrm{c}$ & M. Archaic & & Leporidae & Patella & 1 \\
\hline 37 & 10 & 520 & $\mathrm{IIIb} / \mathrm{c}$ & M. Archaic & & Leporidae & Permanent tooth & 1 \\
\hline 37 & 10 & 520 & $\mathrm{IIIb} / \mathrm{c}$ & M. Archaic & & Leporidae & Ulna & 1 \\
\hline 37 & 10 & 520 & $\mathrm{IIIb} / \mathrm{c}$ & M. Archaic & & Lepus californicus & Permanent tooth & 1 \\
\hline 37 & 10 & 520 & $\mathrm{IIIb} / \mathrm{c}$ & M. Archaic & & Mammalia (Medium/large) & Indeterminate & 1 \\
\hline 37 & 10 & 520 & $\mathrm{IIIb} / \mathrm{c}$ & M. Archaic & & Mammalia (Medium/large) & Long bone & 3 \\
\hline 37 & 10 & 520 & IIIIb/c & M. Archaic & & Mammalia (Small) & Calcaneus & 1 \\
\hline 37 & 10 & 520 & $\mathrm{IIIb} / \mathrm{c}$ & M. Archaic & & Mammalia (Small) & Podial & 1 \\
\hline 37 & 10 & 520 & $\mathrm{IIIb} / \mathrm{c}$ & M. Archaic & & Mammalia (Small) & Proximal phalange & 1 \\
\hline 37 & 10 & 520 & $\mathrm{IIIb} / \mathrm{c}$ & M. Archaic & & Medium/Large Vertebrata & Indeterminate & 1 \\
\hline 37 & 10 & 520 & $\mathrm{IIIb} / \mathrm{c}$ & M. Archaic & & Serpentes & Dorsal vertebra & 2 \\
\hline 37 & 10 & 520 & $\mathrm{IIIb} / \mathrm{c}$ & M. Archaic & & Small/Medium Vertebrata & Long bone & 18 \\
\hline 37 & 10 & 520 & IIIb/c & M. Archaic & & Sylvilagus sp. & Humerus & 1 \\
\hline 37 & 10 & 520 & $\mathrm{III} / \mathrm{c}$ & M. Archaic & & Sylvilagus sp. & Metatarsal 3 & 1 \\
\hline 37 & 10 & 520 & $\mathrm{IIIb} / \mathrm{c}$ & M. Archaic & & Sylvilagus sp. & Permanent tooth & 4 \\
\hline 37 & 10 & 520 & $\mathrm{IIIJ} / \mathrm{c}$ & M. Archaic & & Vertebrata & Indeterminate & 138 \\
\hline 37 & 11 & 532 & IIIb & M. Archaic & & Anura & Humerus & 1 \\
\hline 37 & 11 & 532 & IIIb & M. Archaic & & cf. Procyon lotor & Permanent tooth & 1 \\
\hline 37 & 11 & 532 & IIIb & M. Archaic & & Colubridae & Dorsal vertebra & 2 \\
\hline
\end{tabular}




\begin{tabular}{|c|c|c|c|c|c|c|c|c|}
\hline Square & Level & Lot & Unit & Cultural Affinity & Feature & Taxon & Element & No. \\
\hline 37 & 11 & 532 & IIIb & M. Archaic & & Leporidae & Patella & 1 \\
\hline 37 & 11 & 532 & IIIlb & M. Archaic & & Leporidae & Permanent tooth & 3 \\
\hline 37 & 11 & 532 & IIIb & M. Archaic & & Lepus californicus & Metapodial & 1 \\
\hline 37 & 11 & 532 & $\mathrm{IIllb}$ & M. Archaic & & Mammalia (Medium) & Long bone & 1 \\
\hline 37 & 11 & 532 & IIIlb & M. Archaic & & Mammalia (Medium) & Tooth, perm./decid. ind. & 1 \\
\hline 37 & 11 & 532 & IIIlb & M. Archaic & & Mammalia (Medium/large) & Indeterminate & 18 \\
\hline 37 & 11 & 532 & IIIlb & M. Archaic & & Mammalia (Medium/large) & Tooth, perm./decid. ind. & 1 \\
\hline 37 & 11 & 532 & IIIlb & M. Archaic & & Mammalia (Micro) & Tooth, perm./decid. ind. & 3 \\
\hline 37 & 11 & 532 & IIIlb & M. Archaic & & Mammalia (Small) & Metapodial & 1 \\
\hline 37 & 11 & 532 & IIIlb & M. Archaic & & Mammalia (Small) & Middle phalange & 1 \\
\hline 37 & 11 & 532 & IIIlb & M. Archaic & & Mammalia (Small) & Phalange & 1 \\
\hline 37 & 11 & 532 & IIIlb & M. Archaic & & Mammalia (Small) & Proximal phalange & 1 \\
\hline 37 & 11 & 532 & IIIlb & M. Archaic & & Mammalia (Small) & Radius & 1 \\
\hline 37 & 11 & 532 & IIIlb & M. Archaic & & Procyon lotor & Permanent tooth & 1 \\
\hline 37 & 11 & 532 & IIIlb & M. Archaic & & Serpentes & Dorsal vertebra & 1 \\
\hline 37 & 11 & 532 & IIIlb & M. Archaic & & Small/Medium Vertebrata & Long bone & 36 \\
\hline 37 & 11 & 532 & IIIlb & M. Archaic & & Sylvilagus sp. & Axis & 1 \\
\hline 37 & 11 & 532 & IIIb & M. Archaic & & Sylvilagus sp. & Humerus & 1 \\
\hline 37 & 11 & 532 & IIIlb & M. Archaic & & Testudinata & Shell fragment & 2 \\
\hline 37 & 11 & 532 & IIIlb & M. Archaic & & Vertebrata & Indeterminate & 126 \\
\hline 37 & $12 \mathrm{~A}$ & 557 & IIIlb & M. Archaic & & Colubridae & Dorsal vertebra & 1 \\
\hline 37 & $12 \mathrm{~A}$ & 557 & IIIlb & M. Archaic & & Lepus californicus & Permanent tooth & 1 \\
\hline 37 & $12 \mathrm{~A}$ & 557 & IIIlb & M. Archaic & & Mammalia (Medium/large) & Indeterminate & 3 \\
\hline 37 & $12 \mathrm{~A}$ & 557 & IIIlb & M. Archaic & & Mammalia (Medium/large) & Long bone & 2 \\
\hline 37 & $12 \mathrm{~A}$ & 557 & IIIlb & M. Archaic & & Mammalia (Medium/large) & Tooth, perm./decid. ind. & 1 \\
\hline 37 & $12 \mathrm{~A}$ & 557 & IIIlb & M. Archaic & & Mammalia (Micro) & Calcaneus & 1 \\
\hline 37 & $12 \mathrm{~A}$ & 557 & IIIlb & M. Archaic & & Small/Medium Vertebrata & Indeterminate & 3 \\
\hline 37 & $12 \mathrm{~A}$ & 557 & IIIlb & M. Archaic & & Small/Medium Vertebrata & Long bone & 3 \\
\hline 37 & $12 \mathrm{~A}$ & 557 & IIIlb & M. Archaic & & Vertebrata & Indeterminate & 18 \\
\hline 37 & $12 \mathrm{~B}$ & 588 & IIIb & M. Archaic & 212 & Vertebrata & Indeterminate & 6 \\
\hline 37 & $13 \mathrm{~A}$ & 592 & IIIlb & M. Archaic & & Carnivora & Tooth, perm./decid. ind. & 1 \\
\hline 37 & $13 \mathrm{~A}$ & 592 & IIIb & M. Archaic & & Leporidae & Permanent tooth & 1 \\
\hline 37 & $13 \mathrm{~A}$ & 592 & IIIb & M. Archaic & & Mammalia (Medium/large) & Indeterminate & 10 \\
\hline 37 & $13 \mathrm{~A}$ & 592 & IIIlb & M. Archaic & & Small vertebrate, class ind. & Vertebra & 1 \\
\hline 37 & $13 \mathrm{~A}$ & 592 & IIIlb & M. Archaic & & Sylvilagus sp. & Ulna & 1 \\
\hline 37 & $13 \mathrm{~A}$ & 592 & IIIb & M. Archaic & & Testudinata & Shell fragment & 1 \\
\hline 37 & $13 \mathrm{~A}$ & 592 & IIIlb & M. Archaic & & Vertebrata & Indeterminate & 69 \\
\hline 37 & 13B & 634 & IIIlb & M. Archaic & 212 & Mammalia (Medium) & Long bone & 1 \\
\hline 37 & $13 \mathrm{~B}$ & 634 & IIIlb & M. Archaic & 212 & Mammalia (Medium/large) & Indeterminate & 1 \\
\hline 37 & $13 \mathrm{~B}$ & 634 & IIIb & M. Archaic & 212 & Mammalia (Small) & Permanent tooth & 1 \\
\hline 37 & 13B & 634 & IIIlb & M. Archaic & 212 & Medium/Large Vertebrata & Long bone & 7 \\
\hline 37 & 13B & 634 & IIIlb & M. Archaic & 212 & Neotoma sp. & Permanent tooth & 1 \\
\hline 37 & 13B & 634 & IIIIb & M. Archaic & 212 & Vertebrata & Indeterminate & 29 \\
\hline 37 & 14 & 673 & ШIIa/b & Early/M. Archaic & & Antilocapra/Odocoileus & Proximal axial sesamoid & 1 \\
\hline 37 & 14 & 673 & IIIa/b & Early/M. Archaic & & Mammalia (Large) & Permanent tooth & 1 \\
\hline 37 & 14 & 673 & IIIa/b & Early/M. Archaic & & Mammalia (Medium/large) & Indeterminate & 12 \\
\hline 37 & 14 & 673 & IIIa/b & Early/M. Archaic & & Mammalia (Micro) & Permanent tooth & 5 \\
\hline 37 & 14 & 673 & IIIa/b & Early/M. Archaic & & Mammalia (Micro) & Tooth, perm./decid. ind. & 1 \\
\hline 37 & 14 & 673 & IIIa/b & Early/M. Archaic & & Odocoileus sp. & Tooth, perm./decid. ind. & 1 \\
\hline 37 & 14 & 673 & III $\mathrm{a} / \mathrm{b}$ & Early/M. Archaic & & Small/Medium Vertebrata & Long bone & 11 \\
\hline 37 & 14 & 673 & IIIa/b & Early/M. Archaic & & Sylvilagus sp. & Distal phalange & 1 \\
\hline 37 & 14 & 673 & IIIa/b & Early/M. Archaic & & Sylvilagus sp. & Permanent tooth & 2 \\
\hline 37 & 14 & 673 & $\mathrm{IIIa} / \mathrm{b}$ & Early/M. Archaic & & Vertebrata & Indeterminate & 112 \\
\hline 37 & 15 & 692 & IIIa/b & Early/M. Archaic & & Carnivora & Permanent tooth & 1 \\
\hline 37 & 15 & 692 & IIIa/b & Early/M. Archaic & & Colubridae & Dorsal vertebra & 1 \\
\hline 37 & 15 & 692 & $\mathrm{III} \mathrm{a} / \mathrm{b}$ & Early/M. Archaic & & Mammalia (Medium/large) & Indeterminate & 7 \\
\hline 37 & 15 & 692 & IIIa/b & Early/M. Archaic & & Mammalia (Small) & Tarsal & 1 \\
\hline 37 & 15 & 692 & IIIa/b & Early/M. Archaic & & Medium vertebrate, class ind. & Middle phalange & 1 \\
\hline 37 & 15 & 692 & IIIa/b & Early/M. Archaic & & Medium/Large Vertebrata & Indeterminate & 4 \\
\hline 37 & 15 & 692 & IIIa/b & Early/M. Archaic & & Serpentes & Dorsal vertebra & 3 \\
\hline 37 & 15 & 692 & $\mathrm{mlla} / \mathrm{b}$ & Early/M. Archaic & & Small/Medium Vertebrata & Long bone & 14 \\
\hline 37 & 15 & 692 & IIIa/b & Early/M. Archaic & & Sylvilagus sp. & Astragalus & 1 \\
\hline 37 & 15 & 692 & IIIa/b & Early/M. Archaic & & Testudinata & Shell fragment & 2 \\
\hline 37 & 15 & 692 & $\mathrm{IIa} / \mathrm{b}$ & Early/M. Archaic & & Vertebrata & Indeterminate & 70 \\
\hline 37 & $16 \mathrm{~A}$ & 778 & IIIa & E. Archaic & & Mammalia (Medium/large) & Indeterminate & 1 \\
\hline 37 & $16 \mathrm{~A}$ & 778 & IIIa & E. Archaic & & Small/Medium Vertebrata & Long bone & 4 \\
\hline 37 & $16 \mathrm{~A}$ & 778 & IIIa & E. Archaic & & Vertebrata & Indeterminate & 4 \\
\hline
\end{tabular}




\begin{tabular}{|c|c|c|c|c|c|c|c|c|}
\hline Square & Level & Lot & Unit & Cultural Affinity & Feature & Taxon & Element & No. \\
\hline 37 & $16 \mathrm{~B} \&$ & 851 & IIIa & E. Archaic & 222 & Vertebrata & Indeterminate & 1 \\
\hline 37 & $17 \mathrm{~A}$ & 825 & IIIa & E. Archaic & & Medium/Large Vertebrata & Indeterminate & 4 \\
\hline 37 & $17 \mathrm{~A}$ & 825 & IIIa & E. Archaic & & Small/Medium Vertebrata & Long bone & 2 \\
\hline 37 & $17 \mathrm{~A}$ & 825 & IIIa & E. Archaic & & Vertebrata & Indeterminate & 16 \\
\hline 37 & 18 & 852 & III & E. Archaic & & Leporidae & Permanent tooth & 2 \\
\hline 37 & 18 & 852 & IIIa & E. Archaic & & Mammalia (Medium/large) & Indeterminate & 5 \\
\hline 37 & 18 & 852 & IIIIa & E. Archaic & & Small/Medium Vertebrata & Long bone & 3 \\
\hline 37 & 18 & 852 & IIIIa & E. Archaic & & Vertebrata & Indeterminate & 46 \\
\hline 37 & 19 & 893 & IIIa & E. Archaic & 231 & Colubridae & Dorsal vertebra & 1 \\
\hline 37 & 19 & 893 & IIIIa & E. Archaic & 231 & Small/Medium Vertebrata & Long bone & 2 \\
\hline 37 & 19 & 893 & IIIa & E. Archaic & 231 & Vertebrata & Indeterminate & 28 \\
\hline 37 & 20 & 937 & IIIa & E. Archaic & 231 & Mammalia (Medium) & Radius & 1 \\
\hline 37 & 20 & 937 & IIIa & E. Archaic & 231 & Mammalia (Medium/large) & Indeterminate & 1 \\
\hline 37 & 20 & 937 & IIIa & E. Archaic & 231 & Mammalia (Small) & Femur & 1 \\
\hline 37 & 20 & 937 & $\mathrm{ma}$ & E. Archaic & 231 & Mammalia (Small) & Radius & 1 \\
\hline 37 & 20 & 937 & IIIa & E. Archaic & 231 & Small/Medium Vertebrata & Long bone & 5 \\
\hline 37 & 20 & 937 & IIIIa & E. Archaic & 231 & Sylvilagus sp. & Calcaneus & 1 \\
\hline 37 & 20 & 937 & II & E. Archaic & 231 & Vertebrata & Indeterminate & 35 \\
\hline 37 & 21 & 1017 & IIIIa & E. Archaic & 231 & Mammalia (Medium) & Proximal phalange & 1 \\
\hline 37 & 21 & 1017 & IIIIa & E. Archaic & 231 & Mammalia (Medium/large) & Tooth, perm./decid. ind. & 1 \\
\hline 37 & 21 & 1017 & IIIa & E. Archaic & 231 & Small/Medium Vertebrata & Long bone & 4 \\
\hline 37 & 21 & 1017 & IIIa & E. Archaic & 231 & Sylvilagus sp. & Permanent tooth & 1 \\
\hline 37 & 21 & 1017 & IIIIa & E. Archaic & 231 & Testudinata & Shell fragment & 1 \\
\hline 37 & 21 & 1017 & IIIIa & E. Archaic & 231 & Vertebrata & Indeterminate & 15 \\
\hline 37 & 22 & 1159 & IIIIa & E. Archaic & 231 & Mammalia (Medium/large) & Indeterminate & 2 \\
\hline 37 & 22 & 1159 & IIIa & E. Archaic & 231 & Small vertebrate, class ind. & Proximal phalange & 1 \\
\hline 37 & 22 & 1159 & IIIa & E. Archaic & 231 & Small/Medium Vertebrata & Long bone & 12 \\
\hline 37 & 22 & 1159 & IIIa & E. Archaic & 231 & Testudinata & Shell fragment & 2 \\
\hline 37 & 22 & 1159 & IIIa & E. Archaic & 231 & Vertebrata & Indeterminate & 16 \\
\hline 37 & 23 & 1345 & IIIa & E. Archaic & 231 & Geomys sp. & Permanent tooth & 1 \\
\hline 37 & 23 & 1345 & III। & E. Archaic & 231 & Leporidae & Humerus & 1 \\
\hline 37 & 23 & 1345 & -11а & E. Archaic & 231 & Leporidae & Mandible & 1 \\
\hline 37 & 23 & 1345 & IIIa & E. Archaic & 231 & Leporidae & Permanent tooth & 1 \\
\hline 37 & 23 & 1345 & IIIIa & E. Archaic & 231 & Mammalia (Medium/large) & Indeterminate & 3 \\
\hline 37 & 23 & 1345 & IIIIa & E. Archaic & 231 & Mammalia (Medium/large) & Long bone & 3 \\
\hline 37 & 23 & 1345 & IIIa & E. Archaic & 231 & Medium vertebrate, class ind. & Middle phalange & 1 \\
\hline 37 & 23 & 1345 & IIIIa & E. Archaic & 231 & Medium/Large Vertebrata & Indeterminate & 1 \\
\hline 37 & 23 & 1345 & IIIIa & E. Archaic & 231 & Medium/Large Vertebrata & Long bone & 1 \\
\hline 37 & 23 & 1345 & Шाа & E. Archaic & 231 & Odocoileus sp. & Tooth, perm./decid. ind. & 1 \\
\hline 37 & 23 & 1345 & IIIIa & E. Archaic & 231 & Small/Medium Vertebrata & Long bone & 18 \\
\hline 37 & 23 & 1345 & IIIa & E. Archaic & 231 & Vertebrata & Indeterminate & 45 \\
\hline 37 & $24 \mathrm{~A}$ & 1474 & |II/IIIa & L. Paleo./E. Archaic & & Geomys sp. & Permanent tooth & 1 \\
\hline 37 & $24 \mathrm{~A}$ & 1474 & 4 II/IIIa & L. Paleo./E. Archaic & & Small/Medium Vertebrata & Long bone & 6 \\
\hline 37 & $24 \mathrm{~A}$ & 1474 & - & L. Paleo./E. Archaic & & Vertebrata & Indeterminate & 27 \\
\hline 37 & 25 & 1561 & II/Ша & L. Paleo./E. Archaic & & Mammalia (Medium) & Alveolar ridge fragment & 1 \\
\hline 37 & 25 & 1561 & II/IIIa & L. Paleo./E. Archaic & & Mammalia (Medium) & Metapodial & 1 \\
\hline 37 & 25 & 1561 & II/IIIa & L. Paleo./E. Archaic & & Mammalia (Medium/large) & Indeterminate & 1 \\
\hline 37 & 25 & 1561 & II/IIIa & L. Paleo./E. Archaic & & Mammalia (Medium/large) & Long bone & 3 \\
\hline 37 & 25 & 1561 & IIIIIIIa & L. Paleo./E. Archaic & & Mammalia (Small) & Caudal vertebra & 1 \\
\hline 37 & 25 & 1561 & IIIIIIa & L. Paleo./E. Archaic & & Mammalia (Small) & Permanent tooth & 1 \\
\hline 37 & 25 & 1561 & 1 II/ШІа & L. Paleo./E. Archaic & & Small/Medium Vertebrata & Long bone & 11 \\
\hline 37 & 25 & 1561 & | & L. Paleo./E. Archaic & & Testudinata & Neural & 1 \\
\hline 37 & 25 & 1561 & IIIIIIIa & L. Paleo./E. Archaic & & Vertebrata & Indeterminate & 48 \\
\hline 37 & 26 & 1571 & ||II & L. Paleo. & & |Leporidae & Permanent tooth & 1 \\
\hline 37 & 26 & 1571 & I|II & L. Paleo. & & Mammalia (Medium) & Distal phalange & 1 \\
\hline 37 & 26 & 1571 & I|II & L. Paleo. & & Mammalia (Medium/large) & Indeterminate & 2 \\
\hline 37 & 26 & 1571 & II & L. Paleo. & & Small/Medium Vertebrata & Long bone & 10 \\
\hline 37 & 26 & 1571 & I|II & L. Paleo. & & Sylvilagus sp. & Metacarpal 2 & 1 \\
\hline 37 & 26 & 1571 & I|II & L. Paleo. & & Vertebrata & Indeterminate & 35 \\
\hline 37 & 28 & 1787 & 7|II & L. Paleo. & & Mammalia (Medium) & Femur & 1 \\
\hline 37 & 28 & 1787 & III & L. Paleo. & & Mammalia (Medium) & Metapodial & 1 \\
\hline 37 & 28 & 1787 & 7II & L. Paleo. & & Mammalia (Medium/large) & Tooth, perm./decid. ind. & 1 \\
\hline 37 & 28 & 1787 & 7II & L. Paleo. & & Mammalia (Micro) & Middle phalange & 1 \\
\hline 37 & 28 & 1787 & 7|II & L. Paleo. & & Mammalia (Micro) & Permanent tooth & 2 \\
\hline 37 & 28 & 1787 & 7|II & L. Paleo. & & Small/Medium Vertebrata & Long bone & 38 \\
\hline 37 & 28 & 1787 & 7|II & L. Paleo. & & Sylvilagus sp. & Humerus & 1 \\
\hline 37 & 28 & 1787 & 7II & L. Paleo. & & Sylvilagus sp. & Third tarsal & 1 \\
\hline
\end{tabular}




\begin{tabular}{|c|c|c|c|c|c|c|c|c|}
\hline Square & Level & Lot & Unit & Cultural Affinity & Feature & Taxon & Element & No. \\
\hline 37 & 28 & 1787 & III & L. Paleo. & & Vertebrata & Indeterminate & $\overline{123}$ \\
\hline 37 & 28 & 1787 & III & L. Paleo. & & Viperidae & Dorsal vertebra & 1 \\
\hline 37 & 29 & 1822 & III & L. Paleo. & & Small/Medium Vertebrata & Long bone & 27 \\
\hline 37 & 29 & 1822 & III & L. Paleo. & & Testudinata & Shell fragment & 1 \\
\hline 37 & 29 & 1822 & III & L. Paleo. & & Vertebrata & |Indeterminate & 23 \\
\hline 37 & 30 & 1832 & III & L. Paleo. & & Small vertebrate, class ind. & Proximal phalange & 1 \\
\hline 37 & 30 & 1832 & III & L. Paleo. & & Small/Medium Vertebrata & Long bone & 17 \\
\hline 37 & 30 & 1832 & III & L. Paleo. & & Sylvilagus sp. & Astragalus & 1 \\
\hline 37 & 30 & 1832 & III & L. Paleo. & & Vertebrata & Indeterminate & 36 \\
\hline 37 & 31 & 1860 & III & L. Paleo. & & Mammalia (Medium/large) & Tooth, perm./decid. ind. & 1 \\
\hline 37 & 31 & 1860 & III & L. Paleo. & & Mammalia (Small) & Cranium & 1 \\
\hline 37 & 31 & 1860 & III & L. Paleo. & & Mammalia (Small) & Permanent tooth & 1 \\
\hline 37 & 31 & 1860 & III & L. Paleo. & & Small/Medium Vertebrata & Indeterminate & 1 \\
\hline 37 & 31 & 1860 & III & L. Paleo. & & Small/Medium Vertebrata & Long bone & 15 \\
\hline 37 & 31 & 1860 & III & L. Paleo. & & Vertebrata & Indeterminate & 24 \\
\hline 37 & 32 & 1897 & III & L. Paleo. & & Mammalia (Medium/large) & Long bone & 1 \\
\hline 37 & 32 & 1897 & III & L. Paleo. & & Medium/Large Vertebrata & Long bone & 1 \\
\hline 37 & 32 & 1897 & III & L. Paleo. & & Small/Medium Vertebrata & Long bone & 17 \\
\hline 37 & 32 & 1897 & III & L. Paleo. & & Sylvilagus sp. & Astragalus & 1 \\
\hline 37 & 32 & 1897 & III & L. Paleo. & & Sylvilagus sp. & Calcaneus & 1 \\
\hline 37 & 32 & 1897 & III & L. Paleo. & & Vertebrata & Indeterminate & 29 \\
\hline 37 & 33 & 1923 & III & L. Paleo. & & Artiodactyla & Tooth, perm./decid. ind. & 1 \\
\hline 37 & 33 & 1923 & III & L. Paleo. & & Mammalia (Medium) & Rib & 1 \\
\hline 37 & 33 & 1923 & III & L. Paleo. & & Mammalia (Medium/large) & Indeterminate & 6 \\
\hline 37 & 33 & 1923 & III & L. Paleo. & & Mammalia (Medium/large) & Long bone & 6 \\
\hline 37 & 33 & 1923 & III & L. Paleo. & & Mammalia (Medium/large) & Tooth, perm./decid. ind. & 1 \\
\hline 37 & 33 & 1923 & III & L. Paleo. & & Mammalia (Small) & Metapodial & 1 \\
\hline 37 & 33 & 1923 & III & L. Paleo. & & Medium/Large Vertebrata & Vertebra & 1 \\
\hline 37 & 33 & 1923 & III & L. Paleo. & & Serpentes & Dorsal vertebra & 1 \\
\hline 37 & 33 & 1923 & III & L. Paleo. & & Small vertebrate, class ind. & Vertebra & 1 \\
\hline 37 & 33 & 1923 & III & L. Paleo. & & Small/Medium Vertebrata & Long bone & 5 \\
\hline 37 & 33 & 1923 & III & L. Paleo. & & Testudinata & Peripheral & 1 \\
\hline 37 & 33 & 1923 & III & L. Paleo. & & Vertebrata & Indeterminate & 52 \\
\hline 38 & 9 & 509 & $\mathrm{IIIb} / \mathrm{c}$ & Middle/L. Archaic & & Mammalia (Medium/large) & Indeterminate & 2 \\
\hline 38 & 9 & 509 & $\mathrm{mb} / \mathrm{c}$ & Middle/L. Archaic & & Small/Medium Vertebrata & Long bone & 1 \\
\hline 38 & 9 & 509 & $\mathrm{IIb} / \mathrm{c}$ & Middle/L. Archaic & & Vertebrata & Indeterminate & 5 \\
\hline 38 & 10 & 515 & IIIlb & M. Archaic & & Kinosternidae & Neural & 1 \\
\hline 38 & 10 & 515 & IIIlb & M. Archaic & & Mammalia (Large) & Long bone & 1 \\
\hline 38 & 10 & 515 & IIItb & M. Archaic & & Mammalia (Large) & Rib & 1 \\
\hline 38 & 10 & 515 & IIIlb & M. Archaic & & Mammalia (Medium) & Patella & 1 \\
\hline 38 & 10 & 515 & IIIb & M. Archaic & & Mammalia (Medium/large) & Indeterminate & 5 \\
\hline 38 & 10 & 515 & IIIlb & M. Archaic & & Small/Medium Vertebrata & Long bone & 12 \\
\hline 38 & 10 & 515 & IIItb & M. Archaic & & Vertebrata & Indeterminate & 15 \\
\hline 38 & 11 & 527 & IIIlb & M. Archaic & & Colubridae & Dorsal vertebra & 1 \\
\hline 38 & 11 & 527 & IIIb & M. Archaic & & Cricetidae & Tibia & 1 \\
\hline 38 & 11 & 527 & IIIlb & M. Archaic & & Geomys sp. & Permanent tooth & 1 \\
\hline 38 & 11 & 527 & IIIb & M. Archaic & & Lepus californicus & Metatarsal 2 & 1 \\
\hline 38 & 11 & 527 & IIIlb & M. Archaic & & Mammalia (Medium/large) & Long bone & 5 \\
\hline 38 & 11 & 527 & IIIIb & M. Archaic & & Mammalia (Small) & Alveolar ridge fragment & 1 \\
\hline 38 & 11 & 527 & IIIlb & M. Archaic & & Mammalia (Small) & Proximal phalange & 3 \\
\hline 38 & 11 & 527 & IIIb & M. Archaic & & Mammalia (Small/medium) & Epiphysis & 1 \\
\hline 38 & 11 & 527 & IIIIb & M. Archaic & & Odocoileus sp. & Permanent tooth & 1 \\
\hline 38 & 11 & 527 & IIIlb & M. Archaic & & Small/Medium Vertebrata & Long bone & 12 \\
\hline 38 & 11 & 527 & IIIlb & M. Archaic & & Sylvilagus sp. & Permanent tooth & 3 \\
\hline 38 & 11 & 527 & IIIb & M. Archaic & & Sylvilagus sp. & Ulna & 1 \\
\hline 38 & 11 & 527 & IIIlb & M. Archaic & & Vertebrata & Indeterminate & 56 \\
\hline 38 & $12 \mathrm{~A}$ & 535 & IIIlb & M. Archaic & & Antilocapra/Odocoileus & Accessory carpal bone & 1 \\
\hline 38 & $12 \mathrm{~A}$ & 535 & IIIIb & M. Archaic & & Geomys sp. & Tibia & 1 \\
\hline 38 & $12 \mathrm{~A}$ & 535 & IIIlb & M. Archaic & & Lepus californicus & Astragalus & 1 \\
\hline 38 & $12 \mathrm{~A}$ & 535 & IIIlb & M. Archaic & & Lepus californicus & Calcaneus & 1 \\
\hline 38 & $12 \mathrm{~A}$ & 535 & IIIb & M. Archaic & & Lepus californicus & Permanent tooth & 2 \\
\hline 38 & $12 \mathrm{~A}$ & 535 & IIIlb & M. Archaic & & Lepus californicus & Tibia & 1 \\
\hline 38 & $12 \mathrm{~A}$ & 535 & IIIlb & M. Archaic & & Mammalia (Large) & Indeterminate & 4 \\
\hline 38 & $12 \mathrm{~A}$ & 535 & IIIlb & M. Archaic & & Mammalia (Medium/large) & Indeterminate & 22 \\
\hline 38 & $12 \mathrm{~A}$ & 535 & IIIIb & M. Archaic & & Mammalia (Medium/large) & Tooth, perm./decid. ind. & 3 \\
\hline 38 & $12 \mathrm{~A}$ & 535 & IIIlb & M. Archaic & & Mammalia (Micro) & Permanent tooth & 1 \\
\hline 38 & $12 \mathrm{~A}$ & 535 & IIIlb & M. Archaic & & Medium/Large Vertebrata & Indeterminate & 6 \\
\hline
\end{tabular}




\begin{tabular}{|c|c|c|c|c|c|c|c|c|}
\hline Square & Level & Lot & Unit & Cultural Affinity & Feature & Taxon & Element & No. \\
\hline 38 & $12 \mathrm{~A}$ & 535 & IIllb & M. Archaic & & Small/Medium Vertebrata & Long bone & 19 \\
\hline 38 & $12 \mathrm{~A}$ & 535 & IIIb & M. Archaic & & Testudinata & Shell fragment & 1 \\
\hline 38 & $12 \mathrm{~A}$ & 535 & IIItb & M. Archaic & & Vertebrata & Indeterminate & 75 \\
\hline 38 & $13 \mathrm{~A}$ & 550 & IIIlb & M. Archaic & & Artiodactyla & Tooth, perm./decid. ind. & 1 \\
\hline 38 & $13 \mathrm{~A}$ & 550 & IIIlb & M. Archaic & & Leporidae & Permanent tooth & 1 \\
\hline 38 & $13 \mathrm{~A}$ & 550 & IIItb & M. Archaic & & Mammalia (Medium) & Epiphysis & 1 \\
\hline 38 & $13 \mathrm{~A}$ & 550 & IIIlb & M. Archaic & & Mammalia (Medium/large) & Indeterminate & 5 \\
\hline 38 & $13 \mathrm{~A}$ & 550 & IIIb & M. Archaic & & Mammalia (Medium/large) & Tooth, perm./decid. ind. & 2 \\
\hline 38 & $13 \mathrm{~A}$ & 550 & IIItb & M. Archaic & & Mammalia (Small) & Proximal phalange & 1 \\
\hline 38 & $13 \mathrm{~A}$ & 550 & IIItb & M. Archaic & & Mammalia (Small/medium) & Epiphysis & 1 \\
\hline 38 & $13 \mathrm{~A}$ & 550 & IIIIb & M. Archaic & & Odocoileus sp. & Tooth, perm./decid. ind. & 2 \\
\hline 38 & $13 \mathrm{~A}$ & 550 & IIIIb & M. Archaic & & Small/Medium Vertebrata & Long bone & 2 \\
\hline 38 & $13 \mathrm{~A}$ & 550 & IIIb & M. Archaic & & Sylvilagus sp. & Permanent tooth & 4 \\
\hline 38 & $13 \mathrm{~A}$ & 550 & IIIb & M. Archaic & & Testudinata & Shell fragment & 2 \\
\hline 38 & $13 \mathrm{~A}$ & 550 & IIItb & M. Archaic & & Vertebrata & Indeterminate & 75 \\
\hline 38 & 13B & 571 & IIIlb & M. Archaic & 212 & Artiodactyla & Tooth, perm./decid. ind. & 4 \\
\hline 38 & 13B & 571 & IIIb & M. Archaic & 212 & Mammalia (Medium/large) & Long bone & 1 \\
\hline 38 & 13B & 571 & IIIb & M. Archaic & 212 & Vertebrata & Indeterminate & 6 \\
\hline 38 & 14 & 583 & IIIIb & M. Archaic & & Geomys sp. & Permanent tooth & 2 \\
\hline 38 & 14 & 583 & IIIb & M. Archaic & & Leporidae & Permanent tooth & 5 \\
\hline 38 & 14 & 583 & IImb & M. Archaic & & Lepus californicus & Permanent tooth & 1 \\
\hline 38 & 14 & 583 & IIIlb & M. Archaic & & Mammalia (Medium) & Long bone & 3 \\
\hline 38 & 14 & 583 & IIIb & M. Archaic & & Mammalia (Medium/large) & Indeterminate & 13 \\
\hline 38 & 14 & 583 & IIIb & M. Archaic & & Mammalia (Medium/large) & Long bone & 1 \\
\hline 38 & 14 & 583 & IIIb & M. Archaic & & Mammalia (Small) & Permanent tooth & 2 \\
\hline 38 & 14 & 583 & IIIb & M. Archaic & & Mammalia (Small) & Phalange & 1 \\
\hline 38 & 14 & 583 & IIItb & M. Archaic & & Mammalia (Small) & Proximal phalange & 1 \\
\hline 38 & 14 & 583 & IIIlb & M. Archaic & & Medium/Large Vertebrata & Indeterminate & 4 \\
\hline 38 & 14 & 583 & IIIlb & M. Archaic & & Rodentia (Medium) & Femur & 1 \\
\hline 38 & 14 & 583 & IIIIb & M. Archaic & & Serpentes & Dorsal vertebra & 1 \\
\hline 38 & 14 & 583 & IIIlb & M. Archaic & & Small/Medium Vertebrata & Long bone & 16 \\
\hline 38 & 14 & 583 & IIIlb & M. Archaic & & Testudinata & Shell fragment & 1 \\
\hline 38 & 14 & 583 & IIIlb & M. Archaic & & Vertebrata & Indeterminate & 71 \\
\hline 38 & 15 & 593 & IIIa/b & Early/M. Archaic & & Antilocapra/Odocoileus & Fused central/fourth tarsal & 1 \\
\hline 38 & 15 & 593 & IIIa/b & Early/M. Archaic & & Colubridae & Dorsal vertebra & 1 \\
\hline 38 & 15 & 593 & IIIa/b & Early/M. Archaic & & Leporidae & Permanent tooth & 2 \\
\hline 38 & 15 & 593 & IIIIa/b & Early/M. Archaic & & Leporidae & Ulna & 1 \\
\hline 38 & 15 & 593 & IIIa/b & Early/M. Archaic & & Mammalia (Medium/large) & Indeterminate & 6 \\
\hline 38 & 15 & 593 & IIIa/b & Early/M. Archaic & & Mammalia (Medium/large) & Long bone & 1 \\
\hline 38 & 15 & 593 & IIIIa/b & Early/M. Archaic & & Odocoileus sp. & Fused 3rd \& 4th metatarsal & 1 \\
\hline 38 & 15 & 593 & IIIa/b & Early/M. Archaic & & Small/Medium Vertebrata & Long bone & 6 \\
\hline 38 & 15 & 593 & IIIIa/b & Early/M. Archaic & & Vertebrata & Indeterminate & 53 \\
\hline 38 & 16 & 639 & IIIa/b & Early/M. Archaic & & Mammalia (Large) & Long bone & 8 \\
\hline 38 & 16 & 639 & ШІІа/b & Early/M. Archaic & & Mammalia (Medium/large) & Indeterminate & 6 \\
\hline 38 & 16 & 639 & IIIa/b & Early/M. Archaic & & Serpentes & Dorsal vertebra & 1 \\
\hline 38 & 16 & 639 & IIIa/b & Early/M. Archaic & & Small/Medium Vertebrata & Long bone & 2 \\
\hline 38 & 16 & 639 & IIIa/b & Early/M. Archaic & & Testudinata & Shell fragment & 3 \\
\hline 38 & 16 & 639 & IIIa/b & Early/M. Archaic & & Vertebrata & Indeterminate & 32 \\
\hline 38 & $17 \mathrm{~A}$ & 667 & IIIIa & E. Archaic & & Mammalia (Medium/large) & Tooth, perm./decid. ind. & 1 \\
\hline 38 & $17 \mathrm{~A}$ & 667 & ШІІа & E. Archaic & & Serpentes & Vertebra & 2 \\
\hline 38 & $17 \mathrm{~A}$ & 667 & IIIIa & E. Archaic & & Small/Medium Vertebrata & Long bone & 3 \\
\hline 38 & $17 \mathrm{~A}$ & 667 & IIIIa & E. Archaic & & Vertebrata & Indeterminate & 32 \\
\hline 38 & 17B & 816 & IIIa & E. Archaic & & Vertebrata & Indeterminate & 1 \\
\hline 38 & 19 & 919 & IIIIa & E. Archaic & & Mammalia (Medium/large) & Long bone & 1 \\
\hline 38 & 19 & 919 & IIIIa & E. Archaic & & Small/Medium Vertebrata & Long bone & 4 \\
\hline 38 & 19 & 919 & IIIa & E. Archaic & & Testudinata & Shell fragment & 1 \\
\hline 38 & 19 & 919 & IIIIa & E. Archaic & & Vertebrata & Indeterminate & 48 \\
\hline 38 & 20 & 963 & IIIIa & E. Archaic & 231 & Geomys sp. & Permanent tooth & 2 \\
\hline 38 & 20 & 963 & IIIIa & E. Archaic & 231 & Mammalia (Large) & Long bone & 2 \\
\hline 38 & 20 & 963 & IIIIa & E. Archaic & 231 & Mammalia (Medium/large) & Indeterminate & 2 \\
\hline 38 & 20 & 963 & IIIIa & E. Archaic & 231 & Mammalia (Medium/large) & Tooth, perm./decid. ind. & 2 \\
\hline 38 & 20 & 963 & IIIa & E. Archaic & 231 & Mammalia (Small) & Permanent tooth & 1 \\
\hline 38 & 20 & 963 & IIIа & E. Archaic & 231 & Small/Medium Vertebrata & Long bone & 9 \\
\hline 38 & 20 & 963 & IIIIa & E. Archaic & 231 & Sylvilagus sp. & Calcaneus & 1 \\
\hline 38 & 20 & 963 & ШШа & E. Archaic & 231 & Testudinata & Shell fragment & 1 \\
\hline 38 & 20 & 963 & IIIa & E. Archaic & 231 & Vertebrata & Indeterminate & 38 \\
\hline 38 & $21 \mathrm{~A}$ & 173 & IIIIa & E. Archaic & 231 & Cricetidae (Medium) & Tibia & 1 \\
\hline
\end{tabular}




\begin{tabular}{|c|c|c|c|c|c|c|c|c|}
\hline Square & Level & Lot & Unit & Cultural Affinity & Feature & Taxon & Element & No. \\
\hline 38 & $21 \mathrm{~A}$ & 173 & $\overline{\mathrm{III}}$ & E. Archaic & 231 & Mammalia (Medium/large) & Indeterminate & 3 \\
\hline 38 & $21 \mathrm{~A}$ & 173 & IIIa & E. Archaic & 231 & Mammalia (Micro) & Tooth, perm./decid. ind. & 1 \\
\hline 38 & $21 \mathrm{~A}$ & 173 & IIIIa & E. Archaic & 231 & Small/Medium Vertebrata & Long bone & 1 \\
\hline 38 & $21 \mathrm{~A}$ & 173 & ШШа & E. Archaic & 231 & Vertebrata & Indeterminate & 11 \\
\hline 38 & $21 \mathrm{~B}$ & 1002 & IIIIa & E. Archaic & 228 & Lepus californicus & Permanent tooth & 1 \\
\hline 38 & 21B & 1002 & IIIIa & E. Archaic & 228 & Vertebrata & Indeterminate & 10 \\
\hline 38 & 22 & 1064 & III & E. Archaic & 231 & Kinosternidae & Peripheral & 1 \\
\hline 38 & 22 & 1064 & IIIIa & E. Archaic & 231 & Mammalia (Medium/large) & Indeterminate & 2 \\
\hline 38 & 22 & 1064 & IIII & E. Archaic & 231 & Mammalia (Medium/large) & Long bone & 2 \\
\hline 38 & 22 & 1064 & IIIa & E. Archaic & 231 & Mammalia (Medium/large) & Tooth, perm./decid. ind. & 1 \\
\hline 38 & 22 & 1064 & IIIIa & E. Archaic & 231 & Small/Medium Vertebrata & Long bone & 4 \\
\hline 38 & 22 & 1064 & III & E. Archaic & 231 & Vertebrata & Indeterminate & 42 \\
\hline 38 & 23 & 1354 & IIIIa & E. Archaic & 231 & Leporidae & Permanent tooth & 2 \\
\hline 38 & 23 & 1354 & IIIIa & E. Archaic & 231 & Mammalia (Medium/large) & Indeterminate & 3 \\
\hline 38 & 23 & 1354 & IIII & E. Archaic & 231 & Medium/Large Vertebrata & Long bone & 1 \\
\hline 38 & 23 & 1354 & ПII & E. Archaic & 231 & Serpentes & Dorsal vertebra & 1 \\
\hline 38 & 23 & 1354 & ПII & E. Archaic & 231 & Small/Medium Vertebrata & Long bone & 13 \\
\hline 38 & 23 & 1354 & IIII & E. Archaic & 231 & Vertebrata & Indeterminate & 36 \\
\hline 38 & 24 & 2315 & ШI/IIIa & L. Paleo./E. Archaic & 231 & cf. Lepus californicus & Tibia & 1 \\
\hline 38 & 24 & 2315 & II/IIIa & L. Paleo./E. Archaic & 231 & Lepus californicus & Astragalus & 1 \\
\hline 38 & 24 & 2315 & ШІШІІа & L. Paleo./E. Archaic & 231 & Mammalia (Medium/large) & Indeterminate & 3 \\
\hline 38 & 24 & 2315 & ПI/ШІІа & L. Paleo./E. Archaic & 231 & Mammalia (Micro) & Permanent tooth & 2 \\
\hline 38 & 24 & 2315 & ШI/IIIa & L. Paleo./E. Archaic & 231 & Small/Medium Vertebrata & Long bone & 11 \\
\hline 38 & 24 & 2315 & ШІ/ІІа & L. Paleo./E. Archaic & 231 & Small/Medium Vertebrata & Proximal phalange & 1 \\
\hline 38 & 24 & 2315 & ПI/IIIa & L. Paleo./E. Archaic & 231 & Testudinata & Shell fragment & 1 \\
\hline 38 & 24 & 2315 & II/IIIa & L. Paleo./E. Archaic & 231 & Vertebrata & Indeterminate & 62 \\
\hline 38 & $24 \mathrm{~A}$ & 1961 & Ш/Ша & L. Paleo./E. Archaic & & Small/Medium Vertebrata & Long bone & 1 \\
\hline 38 & $24 \mathrm{~A}$ & 1961 & III/IIIa & L. Paleo./E. Archaic & & Vertebrata & Indeterminate & 16 \\
\hline 38 & 24B\& & 1951 & II/IIIa & L. Paleo./E. Archaic & $181 / 231$ & Mammalia (Small/medium) & Vertebra & 1 \\
\hline 38 & 24B\& & 1951 & II/IIIa & L. Paleo./E. Archaic & $181 / 231$ & Small/Medium Vertebrata & Long bone & 5 \\
\hline 38 & 24B\& & 1951 & ПI/IIIa & L. Paleo./E. Archaic & $181 / 231$ & Vertebrata & Indeterminate & 6 \\
\hline 38 & $25 \mathrm{~A}$ & 1964 & II/IIIa & L. Paleo./E. Archaic & & cf. Lepus californicus & Metapodial & 1 \\
\hline 38 & $25 \mathrm{~A}$ & 1964 & ПI/ШІІа & L. Paleo./E. Archaic & & cf. Sylvilagus sp. & Ulna & 1 \\
\hline 38 & $25 \mathrm{~A}$ & 1964 & III/IIIa & L. Paleo./E. Archaic & & Lepus californicus & Permanent tooth & 1 \\
\hline 38 & $25 \mathrm{~A}$ & 1964 & III/IIIa & L. Paleo./E. Archaic & & Mammalia (Medium/large) & Long bone & 1 \\
\hline 38 & $25 \mathrm{~A}$ & 1964 & ІІ/ІІІа & L. Paleo./E. Archaic & & Mammalia (Small) & Long bone & 1 \\
\hline 38 & $25 \mathrm{~A}$ & 1964 & ШІ/IIIa & L. Paleo./E. Archaic & & Mammalia (Small) & Tibia & 1 \\
\hline 38 & $25 \mathrm{~A}$ & 1964 & III/IIIa & L. Paleo./E. Archaic & & Mammalia (Small) & Vertebra & 1 \\
\hline 38 & $25 \mathrm{~A}$ & 1964 & II/IIIIa & L. Paleo./E. Archaic & & Medium/Large Vertebrata & Indeterminate & 3 \\
\hline 38 & $25 \mathrm{~A}$ & 1964 & ШІ/Ша & L. Paleo./E. Archaic & & Rodentia (Small) & Humerus & 1 \\
\hline 38 & $25 \mathrm{~A}$ & 1964 & III/IIIa & L. Paleo./E. Archaic & & Rodentia (Small) & Permanent tooth & 1 \\
\hline 38 & $25 \mathrm{~A}$ & 1964 & ПI/IIIa & L. Paleo./E. Archaic & & Small/Medium Vertebrata & Long bone & 1 \\
\hline 38 & $25 \mathrm{~A}$ & 1964 & ШШ/Ша & L. Paleo./E. Archaic & & Vertebrata & Indeterminate & 36 \\
\hline 38 & $25 \mathrm{~B}$ & 2339 & II/IIIa & L. Paleo./E. Archaic & $181 / 231$ & Mammalia (Medium/large) & Indeterminate & 1 \\
\hline 38 & $25 \mathrm{~B}$ & 2339 & II/IIIa & L. Paleo./E. Archaic & $181 / 231$ & Mammalia (Small) & Permanent tooth & 1 \\
\hline 38 & $25 \mathrm{~B}$ & 2339 & ШІ/IIIa & L. Paleo./E. Archaic & $181 / 231$ & Small/Medium Vertebrata & Long bone & 4 \\
\hline 38 & $25 \mathrm{~B}$ & 2339 & II/IIIa & L. Paleo./E. Archaic & $181 / 231$ & Vertebrata & Indeterminate & 9 \\
\hline 38 & $25 \mathrm{C}$ & 2358 & II/IIIa & L. Paleo./E. Archaic & 258 & Vertebrata & Indeterminate & 3 \\
\hline 38 & $26 \mathrm{~A}$ & 1972 & ШІШІа & L. Paleo./E. Archaic & & Carnivora & Permanent tooth & 1 \\
\hline 38 & $26 \mathrm{~A}$ & 1972 & II/IIIa & L. Paleo./E. Archaic & & Mammalia (Medium/large) & Indeterminate & 1 \\
\hline 38 & $26 \mathrm{~A}$ & 1972 & II/IIIa & L. Paleo./E. Archaic & & Mammalia (Small) & Caudal vertebra & 1 \\
\hline 38 & $26 \mathrm{~A}$ & 1972 & II/IIIa & L. Paleo./E. Archaic & & Rodentia (Small) & Permanent tooth & 1 \\
\hline 38 & $26 \mathrm{~A}$ & 1972 & II/IIIa & L. Paleo./E. Archaic & & Serpentes & Dorsal vertebra & 1 \\
\hline 38 & $26 \mathrm{~A}$ & 1972 & II/IIIa & L. Paleo./E. Archaic & & Small/Medium Vertebrata & Long bone & 4 \\
\hline 38 & $26 \mathrm{~A}$ & 1972 & ІІ/Ша & L. Paleo./E. Archaic & & Testudinata & Shell fragment & 2 \\
\hline 38 & $26 \mathrm{~A}$ & 1972 & II/IIIa & L. Paleo./E. Archaic & & Vertebrata & Indeterminate & 5 \\
\hline 38 & $26 \mathrm{~A}$ & 2784 & II/IIIa & L. Paleo./E. Archaic & 231 & Mammalia (Medium/large) & Indeterminate & 2 \\
\hline 38 & $26 \mathrm{~A}$ & 2784 & ШІШІШа & L. Paleo./E. Archaic & 231 & Small/Medium Vertebrata & Long bone & 5 \\
\hline 38 & $26 \mathrm{~A}$ & 2784 & II/IIIa & L. Paleo./E. Archaic & 231 & Vertebrata & Indeterminate & 7 \\
\hline 38 & $26 \mathrm{~B}$ & 1965 & II/IIIa & L. Paleo./E. Archaic & 231 & Small/Medium Vertebrata & Long bone & 1 \\
\hline 38 & $26 \mathrm{~B}$ & 1965 & ШІІ/IIa & L. Paleo./E. Archaic & 231 & Vertebrata & Indeterminate & 3 \\
\hline 38 & 27 & 2012 & III & L. Paleo. & & Mammalia (Medium/large) & Tooth, perm./decid. ind. & 1 \\
\hline 38 & 27 & 2012 & III & L. Paleo. & & Mammalia (Small) & Metapodial & 1 \\
\hline 38 & 27 & 2012 & III & L. Paleo. & & Mammalia (Small/medium) & Podial & 1 \\
\hline 38 & 27 & 2012 & III & L. Paleo. & & Small/Medium Vertebrata & Long bone & 4 \\
\hline 38 & 27 & 2012 & III & L. Paleo. & & Vertebrata & Indeterminate & 14 \\
\hline 38 & $27 \mathrm{~A}$ & 2540 & III & L. Paleo. & & Mammalia (Medium) & Ulna & 1 \\
\hline
\end{tabular}




\begin{tabular}{|c|c|c|c|c|c|c|c|c|}
\hline Square & Level & Lot & Unit & Cultural Affinity & Feature & Taxon & Element & No. \\
\hline 38 & $27 \mathrm{~A}$ & 2540 & III & L. Paleo. & & Mammalia (Medium/large) & Indeterminate & 1 \\
\hline 38 & $27 \mathrm{~A}$ & 2540 & II & L. Paleo. & & Small/Medium Vertebrata & Long bone & 4 \\
\hline 38 & $27 \mathrm{~A}$ & 2540 & II & L. Paleo. & & Sylvilagus sp. & Intermediate carpal bone & 1 \\
\hline 38 & $27 \mathrm{~A}$ & 2540 & III & L. Paleo. & & Sylvilagus sp. & Radius & 1 \\
\hline 38 & $27 \mathrm{~A}$ & 2540 & II & L. Paleo. & & Vertebrata & Indeterminate & 9 \\
\hline 38 & 28 & 2032 & III & L. Paleo. & & Mammalia (Small) & Permanent tooth & 1 \\
\hline 38 & 28 & 2032 & III & L. Paleo. & & Small/Medium Vertebrata & Long bone & 8 \\
\hline 38 & 28 & 2032 & III & L. Paleo. & & Vertebrata & Indeterminate & 5 \\
\hline 38 & $28 \mathrm{~A}$ & 2533 & II & L. Paleo. & & Lepus californicus & Calcaneus & 1 \\
\hline 38 & $28 \mathrm{~A}$ & 2533 & II & L. Paleo. & & Mammalia (Medium/large) & Indeterminate & 1 \\
\hline 38 & $28 \mathrm{~A}$ & 2533 & III & L. Paleo. & & Mammalia (Medium/large) & Long bone & 1 \\
\hline 38 & $28 \mathrm{~A}$ & 2533 & III & L. Paleo. & & Small/Medium Vertebrata & Long bone & 9 \\
\hline 38 & $28 \mathrm{~A}$ & 2533 & II & L. Paleo. & & Sylvilagus sp. & Third tarsal & 1 \\
\hline 38 & $28 \mathrm{~A}$ & 2533 & III & L. Paleo. & & Vertebrata & Indeterminate & 20 \\
\hline 38 & 29 & 2051 & II & L. Paleo. & & Mammalia (Large) & Long bone & 1 \\
\hline 38 & 29 & 2061 & II & L. Paleo. & & Small/Medium Vertebrata & Long bone & 3 \\
\hline 38 & 29 & 2061 & III & L. Paleo. & & Vertebrata & Indeterminate & 12 \\
\hline 38 & 30 & 2065 & II & L. Paleo. & & Rodentia (Medium) & Tibia & 1 \\
\hline 38 & 30 & 2065 & II & L. Paleo. & & Small/Medium Vertebrata & Long bone & 7 \\
\hline 38 & 30 & 2065 & III & L. Paleo. & & Sylvilagus sp. & Ulna & 1 \\
\hline 38 & 30 & 2065 & III & L. Paleo. & & Vertebrata & Indeterminate & 18 \\
\hline 39 & $15 \mathrm{~A}$ & 722 & IIIa/b & E. Archaic & & Mammalia (Medium) & Metapodial & 1 \\
\hline 39 & $15 \mathrm{~A}$ & 722 & ma/b & E. Archaic & & Mammalia (Medium/large) & Indeterminate & 1 \\
\hline 39 & $15 \mathrm{~A}$ & 722 & IIIa/b & E. Archaic & & Mammalia (Small) & Permanent tooth & 1 \\
\hline 39 & $15 \mathrm{~A}$ & 722 & IIIa/b & E. Archaic & & Mammalia (Small) & Proximal phalange & 1 \\
\hline 39 & $15 \mathrm{~A}$ & 722 & IIa/b & E. Archaic & & Small/Medium Vertebrata & Long bone & 14 \\
\hline 39 & $15 \mathrm{~A}$ & 722 & IIIa/b & E. Archaic & & Vertebrata & Indeterminate & 23 \\
\hline 39 & $15 \mathrm{C}$ & 757 & Шаa/b & E. Archaic & 221 & Small/Medium Vertebrata & Long bone & 1 \\
\hline 39 & $16 \mathrm{~A}$ & 826 & IIa/b & E. Archaic & & Kinosternidae & Peripheral & 1 \\
\hline 39 & $16 \mathrm{~A}$ & 826 & IIIa/b & E. Archaic & & Mammalia (Large/very large) & Indeterminate & 1 \\
\hline 39 & $16 \mathrm{~A}$ & 826 & Шаa/b & E. Archaic & & Mammalia (Medium) & Metapodial & 1 \\
\hline 39 & $16 \mathrm{~A}$ & 826 & Wa/b & E. Archaic & & Medium/Large Vertebrata & Indeterminate & 7 \\
\hline 39 & $16 \mathrm{~A}$ & 826 & IIIa/b & E. Archaic & & Small/Medium Vertebrata & Long bone & 3 \\
\hline 39 & $16 \mathrm{~A}$ & 826 & $\mathrm{ma} / \mathrm{b}$ & E. Archaic & & Testudinata & Humerus & 1 \\
\hline 39 & $16 \mathrm{~A}$ & 826 & $\mathrm{ma} \mathrm{a} / \mathrm{b}$ & E. Archaic & & Vertebrata & Indeterminate & 20 \\
\hline 39 & 18 & 861 & $\mathrm{III} \mathrm{a} / \mathrm{b}$ & E. Archaic & & Mammalia (Medium/large) & Tooth, perm./decid. ind. & 1 \\
\hline 39 & 18 & 861 & $\mathrm{ma} / \mathrm{b}$ & E. Archaic & & Mammalia (Small) & Middle phalange & 1 \\
\hline 39 & 18 & 861 & IIIa/b & E. Archaic & & Small/Medium Vertebrata & Long bone & 3 \\
\hline 39 & 18 & 861 & $\mathrm{III} \mathrm{a} / \mathrm{b}$ & E. Archaic & & Testudinata & Shell fragment & 2 \\
\hline 39 & 18 & 861 & IIIa/b & E. Archaic & & Vertebrata & Indeterminate & 34 \\
\hline 39 & 19 & 874 & ma & E. Archaic & & Mammalia (Medium/large) & Tooth, perm./decid. ind. & 1 \\
\hline 39 & 19 & 874 & IIIIa & E. Archaic & & Small vertebrate, class ind. & Phalange & 1 \\
\hline 39 & 19 & 874 & ШІа & E. Archaic & & Small/Medium Vertebrata & Long bone & 5 \\
\hline 39 & 19 & 874 & IIIIa & E. Archaic & & Testudinata & Shell fragment & 2 \\
\hline 39 & 19 & 874 & IIIIa & E. Archaic & & Vertebrata & Indeterminate & 21 \\
\hline 39 & 20 & 896 & ШІа & E. Archaic & 231 & Colubridae & Dorsal vertebra & 1 \\
\hline 39 & 20 & 896 & IIIa & E. Archaic & 231 & Mammalia (Medium) & Permanent tooth & 1 \\
\hline 39 & 20 & 896 & IIIIa & E. Archaic & 231 & Mammalia (Medium/large) & Indeterminate & 2 \\
\hline 39 & 20 & 896 & ШІа & E. Archaic & 231 & Mammalia (Medium/large) & Tooth, perm./decid. ind. & 2 \\
\hline 39 & 20 & 896 & IIIa & E. Archaic & 231 & Small/Medium Vertebrata & Long bone & 2 \\
\hline 39 & 20 & 896 & IIIIa & E. Archaic & 231 & Sylvilagus sp. & Humerus & 1 \\
\hline 39 & 20 & 896 & ШІа & E. Archaic & 231 & Vertebrata & Indeterminate & 19 \\
\hline 39 & $21 \mathrm{~A}$ & 1008 & ШIIa & E. Archaic & 231 & Mammalia (Medium/large) & Indeterminate & 2 \\
\hline 39 & $21 \mathrm{~A}$ & 1008 & IIIIa & E. Archaic & 231 & Small/Medium Vertebrata & Long bone & 2 \\
\hline 39 & $21 \mathrm{~A}$ & 1008 & IIIIa & E. Archaic & 231 & Testudinata & Shell fragment & 1 \\
\hline 39 & $21 \mathrm{~A}$ & 1008 & Ша & E. Archaic & 231 & Vertebrata & Indeterminate & 22 \\
\hline 39 & $21 \mathrm{~B}$ & 1173 & IIIIa & E. Archaic & 230 & Mammalia (Medium/large) & Indeterminate & 1 \\
\hline 39 & $21 \mathrm{~B}$ & 1173 & IIIa & E. Archaic & 230 & Medium/Large Vertebrata & Indeterminate & 1 \\
\hline 39 & $22 \mathrm{~A}$ & 1156 & IIIa & E. Archaic & 231 & Colubridae & Dorsal vertebra & 1 \\
\hline 39 & $22 \mathrm{~A}$ & 1156 & IIIa & E. Archaic & 231 & Mammalia (Medium/large) & Indeterminate & 1 \\
\hline 39 & $22 \mathrm{~A}$ & 1156 & IIIIa & E. Archaic & 231 & Mammalia (Small) & Permanent tooth & 1 \\
\hline 39 & $22 \mathrm{~A}$ & 1156 & IIIa & E. Archaic & 231 & Mammalia (Small) & Ulna & 1 \\
\hline 39 & $22 \mathrm{~A}$ & 1156 & IIIa & E. Archaic & 231 & Medium/Large Vertebrata & Indeterminate & 4 \\
\hline 39 & $22 \mathrm{~A}$ & 1156 & IIIIa & E. Archaic & 231 & Medium/Large Vertebrata & Long bone & 2 \\
\hline 39 & $22 \mathrm{~A}$ & 1156 & IIIa & E. Archaic & 231 & Small/Medium Vertebrata & Long bone & 7 \\
\hline 39 & $22 \mathrm{~A}$ & 1156 & IIIa & E. Archaic & 231 & Sylvilagus sp. & Humerus & 1 \\
\hline 39 & $22 \mathrm{~A}$ & 1156 & IIIa & E. Archaic & 231 & Vertebrata & Indeterminate & 32 \\
\hline
\end{tabular}




\begin{tabular}{|c|c|c|c|c|c|c|c|c|}
\hline Square & Level & Lot & Unit & Cultural Affinity & Feature & Taxon & Element & No. \\
\hline 39 & $22 \mathrm{~B}$ & 1074 & IIIa & E. Archaic & 230 & Vertebrata & Indeterminate & 4 \\
\hline 39 & 23 & 1320 & IIIIa & E. Archaic & 231 & Colubridae & Dorsal vertebra & 1 \\
\hline 39 & 23 & 1320 & III' & E. Archaic & 231 & Leporidae & Permanent tooth & 1 \\
\hline 39 & 23 & 1320 & IIIa & E. Archaic & 231 & Mammalia (Medium/large) & Indeterminate & 4 \\
\hline 39 & 23 & 1320 & IIIIa & E. Archaic & 231 & Mammalia (Medium/large) & Long bone & 1 \\
\hline 39 & 23 & 1320 & IIIIa & E. Archaic & 231 & Medium/Large Vertebrata & Indeterminate & 3 \\
\hline 39 & 23 & 1320 & IIIIa & E. Archaic & 231 & Small/Medium Vertebrata & Long bone & 6 \\
\hline 39 & 23 & 1320 & IIIIa & E. Archaic & 231 & Vertebrata & Indeterminate & 42 \\
\hline 39 & 24 & 1529 & IIIIa & E. Archaic & $231 / 245$ & Lepus californicus & Tibia & 1 \\
\hline 39 & 24 & 1529 & IIIIa & E. Archaic & $231 / 245$ & Mammalia (Medium) & Radius & 1 \\
\hline 39 & 24 & 1529 & IIIIa & E. Archaic & $231 / 245$ & Mammalia (Medium/large) & Indeterminate & 6 \\
\hline 39 & 24 & 1529 & IIII & E. Archaic & $231 / 245$ & Mammalia (Medium/large) & Long bone & 2 \\
\hline 39 & 24 & 1529 & IIIIa & E. Archaic & $231 / 245$ & Mammalia (Medium/large) & Tooth, perm./decid. ind. & 2 \\
\hline 39 & 24 & 1529 & III & E. Archaic & $231 / 245$ & Mammalia (Small) & Calcaneus & 1 \\
\hline 39 & 24 & 1529 & IIIIa & E. Archaic & $231 / 245$ & Mammalia (Small) & Permanent tooth & 1 \\
\hline 39 & 24 & 1529 & IIIIa & E. Archaic & $231 / 245$ & Mammalia (Small) & Proximal phalange & 1 \\
\hline 39 & 24 & 1529 & IIIIa & E. Archaic & $231 / 245$ & Neotoma sp. & Permanent tooth & 1 \\
\hline 39 & 24 & 1529 & IIIa & E. Archaic & $231 / 245$ & Osteichthyes (Small) & Sagitta otolith & 3 \\
\hline 39 & 24 & 1529 & IIIIa & E. Archaic & $231 / 245$ & Sigmodon hispidus & Permanent tooth & 2 \\
\hline 39 & 24 & 1529 & IIIIa & E. Archaic & $231 / 245$ & Small/Medium Vertebrata & Long bone & 14 \\
\hline 39 & 24 & 1529 & IIIa & E. Archaic & $231 / 245$ & Testudinata & Shell fragment & 3 \\
\hline 39 & 24 & 1529 & IIIIa & E. Archaic & $231 / 245$ & Vertebrata & Indeterminate & 105 \\
\hline 39 & 25 & 1595 & II/ШІа & L. Paleo./E. Archaic & $231 / 245$ & Geomys sp. & Permanent tooth & 1 \\
\hline 39 & 25 & 1595 & II/IIIa & L. Paleo./E. Archaic & $231 / 245$ & Mammalia (Large) & Axis & 1 \\
\hline 39 & 25 & 1595 & II/IIIa & L. Paleo./E. Archaic & $231 / 245$ & Mammalia (Medium) & Middle phalange & 1 \\
\hline 39 & 25 & 1595 & III/III & L. Paleo./E. Archaic & $231 / 245$ & Mammalia (Medium/large) & Indeterminate & 1 \\
\hline 39 & 25 & 1595 & II//IIIa & L. Paleo./E. Archaic & $231 / 245$ & Mammalia (Medium/large) & Long bone & 2 \\
\hline 39 & 25 & 1595 & II/IIIa & L. Paleo./E. Archaic & $231 / 245$ & Mammalia (Medium/large) & Permanent tooth & 1 \\
\hline 39 & 25 & 1595 & II/IIIa & L. Paleo./E. Archaic & $231 / 245$ & Rodentia (Small/Medium) & Permanent tooth & 1 \\
\hline 39 & 25 & 1595 & II/IIIa & L. Paleo./E. Archaic & $231 / 245$ & Serpentes & Dorsal vertebra & 1 \\
\hline 39 & 25 & 1595 & II/IIIa & L. Paleo./E. Archaic & $231 / 245$ & Small/Medium Vertebrata & Indeterminate & 1 \\
\hline 39 & 25 & 1595 & II/IIIa & L. Paleo./E. Archaic & $231 / 245$ & Small/Medium Vertebrata & Long bone & 22 \\
\hline 39 & 25 & 1595 & III/IIa & L. Paleo./E. Archaic & $231 / 245$ & Testudinata & Shell fragment & 1 \\
\hline 39 & 25 & 1595 & II/IIIa & L. Paleo./E. Archaic & $231 / 245$ & Vertebrata & Indeterminate & 64 \\
\hline 39 & 26 & 1859 & II/Ша & L. Paleo./E. Archaic & & Vertebrata & Indeterminate & 7 \\
\hline 39 & 26 & 1880 & ШII/Ша & L. Paleo./E. Archaic & & Geomys sp. & Permanent tooth & 1 \\
\hline 39 & 26 & 1880 & III/IIIa & L. Paleo./E. Archaic & & Mammalia (Micro) & Permanent tooth & 1 \\
\hline 39 & 26 & 1880 & II/ШІа & L. Paleo./E. Archaic & & Osteichthyes (Small) & Sagitta otolith & 1 \\
\hline 39 & 26 & 1880 & III/IIIa & L. Paleo./E. Archaic & & Osteichthyes (Small) & Vertebra & 1 \\
\hline 39 & 26 & 1880 & III/IIIa & L. Paleo./E. Archaic & & Small/Medium Vertebrata & Long bone & 8 \\
\hline 39 & 26 & 1880 & II/IIIa & L. Paleo./E. Archaic & & Testudinata & Humerus & 1 \\
\hline 39 & 26 & 1880 & II/ШІа & L. Paleo./E. Archaic & & Vertebrata & Indeterminate & 27 \\
\hline 39 & 27 & 1901 & III & L. Paleo. & & cf. Lepus californicus & Ulna & 1 \\
\hline 39 & 27 & 1901 & III & L. Paleo. & & Leporidae & Permanent tooth & 1 \\
\hline 39 & 27 & 1901 & III & L. Paleo. & & Rodentia (Small) & Permanent tooth & 1 \\
\hline 39 & 27 & 1901 & III & L. Paleo. & & Small/Medium Vertebrata & Long bone & 10 \\
\hline 39 & 27 & 1901 & III & L. Paleo. & & Small/Medium Vertebrata & Phalange & 1 \\
\hline 39 & 27 & 1901 & III & L. Paleo. & & Vertebrata & Indeterminate & 26 \\
\hline 39 & 28 & 1949 & III & L. Paleo. & & Leporidae & Tooth, perm./decid. ind. & 1 \\
\hline 39 & 28 & 1949 & III & L. Paleo. & & Mammalia (Medium/large) & Indeterminate & 2 \\
\hline 39 & 28 & 1949 & II & L. Paleo. & & Mammalia (Small) & Radius & 1 \\
\hline 39 & 28 & 1949 & III & L. Paleo. & & Small/Medium Vertebrata & Long bone & 9 \\
\hline 39 & 28 & 1949 & III & L. Paleo. & & Sylvilagus sp. & Permanent tooth & 1 \\
\hline 39 & 28 & 1949 & III & L. Paleo. & & Vertebrata & Indeterminate & 41 \\
\hline 39 & 29 & 1980 & III & L. Paleo. & & Mammalia (Medium/large) & Long bone & 1 \\
\hline 39 & 29 & 1980 & III & L. Paleo. & & Mammalia (Small) & Vertebra & 2 \\
\hline 39 & 29 & 1980 & III & L. Paleo. & & Medium/Large Vertebrata & Indeterminate & 3 \\
\hline 39 & 29 & 1980 & III & L. Paleo. & & Small/Medium Vertebrata & Long bone & 10 \\
\hline 39 & 29 & 1980 & III & L. Paleo. & & Testudinata & Shell fragment & 1 \\
\hline 39 & 29 & 1980 & III & L. Paleo. & & Vertebrata & Indeterminate & 22 \\
\hline 39 & 30 & 1997| & III & L. Paleo. & & Medium/Large Vertebrata & Indeterminate & 2 \\
\hline 39 & 30 & 1997 & III & L. Paleo. & & Small vertebrate, class ind. & |Vertebra & 1 \\
\hline 39 & 30 & 1997| & III & L. Paleo. & & Small/Medium Vertebrata & Long bone & 13 \\
\hline 39 & 30 & 1997 & III & L. Paleo. & & Vertebrata & Indeterminate & 26 \\
\hline 39 & 31 & 2018 & III & L. Paleo. & & Leporidae & Vertebra & 1 \\
\hline 39 & 31 & 2018 & III & L. Paleo. & & Mammalia (Small) & Caudal vertebra & 1 \\
\hline 39 & 31 & 2018 & III & L. Paleo. & & Mammalia (Small) & Permanent tooth & 1 \\
\hline
\end{tabular}




\begin{tabular}{|c|c|c|c|c|c|c|c|c|}
\hline Square & Level & Lot & Unit & Cultural Affinity & Feature & Taxon & Element & No. \\
\hline 39 & 31 & 2018 & II & L. Paleo. & & Small/Medium Vertebrata & Long bone & 21 \\
\hline 39 & 31 & 2018 & III & L. Paleo. & & Sylvilagus sp. & Humerus & 2 \\
\hline 39 & 31 & 2018 & III & L. Paleo. & & Testudinata & Shell fragment & 1 \\
\hline 39 & 31 & 2018 & III & L. Paleo. & & Vertebrata & Indeterminate & 56 \\
\hline 39 & 32 & 2035 & III & L. Paleo. & & Carnivora & Metapodial & 1 \\
\hline 39 & 32 & 2035 & III & L. Paleo. & & Mammalia (Medium/large) & Indeterminate & 1 \\
\hline 39 & 32 & 2035 & III & L. Paleo. & & Medium/Large Vertebrata & Indeterminate & 2 \\
\hline 39 & 32 & 2035 & III & L. Paleo. & & Small/Medium Vertebrata & Long bone & 16 \\
\hline 39 & 32 & 2035 & III & L. Paleo. & & Sylvilagus sp. & Permanent tooth & 1 \\
\hline 39 & 32 & 2035 & II & L. Paleo. & & Sylvilagus sp. & Scapula & 1 \\
\hline 39 & 32 & 2035 & III & L. Paleo. & & Testudinata & Shell fragment & 1 \\
\hline 39 & 32 & 2035 & III & L. Paleo. & & Vertebrata & Indeterminate & 49 \\
\hline 39 & 33 & 2094 & III & L. Paleo. & & Carnivora & Tooth, perm./decid. ind. & 1 \\
\hline 39 & 33 & 2094 & II & L. Paleo. & & Leporidae & Permanent tooth & 1 \\
\hline 39 & 33 & 2094 & III & L. Paleo. & & Medium/Large Vertebrata & Indeterminate & 1 \\
\hline 39 & 33 & 2094 & II & L. Paleo. & & Small/Medium Vertebrata & Long bone & 6 \\
\hline 39 & 33 & 2094 & III & L. Paleo. & & Sylvilagus sp. & Permanent tooth & 1 \\
\hline 39 & 33 & 2094 & III & L. Paleo. & & Testudinata & Shell fragment & 1 \\
\hline 39 & 33 & 2094 & III & L. Paleo. & & Vertebrata & Indeterminate & 15 \\
\hline 39 & 34 & 2112 & III & L. Paleo. & & Mammalia (Medium/large) & Indeterminate & 6 \\
\hline 39 & 34 & 2112 & III & L. Paleo. & & Mammalia (Small) & Permanent tooth & 1 \\
\hline 39 & 34 & 2112 & II & L. Paleo. & & Mammalia (Small) & Radius & 1 \\
\hline 39 & 34 & 2112 & III & L. Paleo. & & Medium/Large Vertebrata & Indeterminate & 3 \\
\hline 39 & 34 & 2112 & III & L. Paleo. & & Rodentia (Medium) & Permanent tooth & 1 \\
\hline 39 & 34 & 2112 & III & L. Paleo. & & Small/Medium Vertebrata & Long bone & 15 \\
\hline 39 & 34 & 2112 & III & L. Paleo. & & Vertebrata & Indeterminate & 42 \\
\hline 39 & 35 & 2122 & Id/II & L. Paleo. & & Geomys sp. & Permanent tooth & 1 \\
\hline 39 & 35 & 2122 & Id/II & L. Paleo. & & Mammalia (Medium/large) & Indeterminate & 3 \\
\hline 39 & 35 & 2122 & Id/II & L. Paleo. & & Mammalia (Small) & Scapula & 1 \\
\hline 39 & 35 & 2122 & Id/II & L. Paleo. & & Small/Medium Vertebrata & Long bone & 6 \\
\hline 39 & 35 & 2122 & Id/II & L. Paleo. & & Vertebrata & Indeterminate & 31 \\
\hline 39 & 36 & 2275 & Id/II & L. Paleo. & & Vertebrata & Indeterminate & 1 \\
\hline 39 & $36 \mathrm{~A}$ & 2276 & Id/II & L. Paleo. & & Small/Medium Vertebrata & Long bone & 3 \\
\hline 39 & $36 \mathrm{~A}$ & 2276 & Id/II & L. Paleo. & & Vertebrata & Indeterminate & 14 \\
\hline 39 & 36B & 2277 & Id/II & L. Paleo. & & Mammalia (Medium/large) & Indeterminate & 2 \\
\hline 39 & $36 \mathrm{~B}$ & 2277 & Id/II & L. Paleo. & & Vertebrata & Indeterminate & 4 \\
\hline 39 & 36B-3 & 2258 & IId/II & L. Paleo. & & Mammalia (Large/very large) & Indeterminate & 1 \\
\hline 39 & 37 & 2804 & IId/II & L. Paleo. & & Mammalia (Medium/large) & Indeterminate & 2 \\
\hline 39 & 37 & 2804 & Id/II & L. Paleo. & & Small/Medium Vertebrata & Long bone & 1 \\
\hline 39 & 37 & 2804 & Id/II & L. Paleo. & & Vertebrata & Indeterminate & 4 \\
\hline 39 & $38 \mathrm{~A}$ & 2792 & Isi-c/Id & L. Paleo. & & Mammalia (Medium/large) & Indeterminate & 1 \\
\hline 39 & $38 \mathrm{~A}$ & 2792 & Isi-c/Id & L. Paleo. & & Odocoileus sp. & Antler & 1 \\
\hline 39 & $38 \mathrm{~A}$ & 2792 & Isi-c/Id & L. Paleo. & & Small/Medium Vertebrata & Indeterminate & 1 \\
\hline 39 & $38 \mathrm{~A}$ & 2792 & Isi-c/Id & L. Paleo. & & Vertebrata & Indeterminate & 11 \\
\hline 39 & 39 & 2748 & Isi-c/Id & L. Paleo. & & Small/Medium Vertebrata & Long bone & 2 \\
\hline 39 & 39 & 2748 & Isi-c/Id & L. Paleo. & & Vertebrata & Indeterminate & 3 \\
\hline 39 & 40 & 2737 & |Isi-c & L. Paleo. & & Leporidae & Permanent tooth & 1 \\
\hline 39 & 40 & 2737 & Isi-c & L. Paleo. & & Medium/Large Vertebrata & Indeterminate & 1 \\
\hline 39 & 40 & 2737 & Isi-c & L. Paleo. & & Vertebrata & Indeterminate & 7 \\
\hline 39 & 41 & 2459 & Isi-c & L. Paleo. & & Small/Medium Vertebrata & Long bone & 2 \\
\hline 39 & 41 & 2459 & |Isi-c & L. Paleo. & & Sylvilagus sp. & Permanent tooth & 1 \\
\hline 39 & 41 & 2459 & Isi-c & L. Paleo. & & Vertebrata & Indeterminate & 13 \\
\hline 39 & 42 & 2431 & Isi-c & L. Paleo. & 260 & Mammalia (Large) & Long bone & 1 \\
\hline 39 & 42 & 2752 & Isi-c & L. Paleo. & & Mammalia (Large) & Tooth, perm./decid. ind. & 1 \\
\hline 39 & 42 & 2752 & Isi-c & L. Paleo. & & Mammalia (Medium/large) & Indeterminate & 4 \\
\hline 39 & 42 & 2752 & Isi-c & L. Paleo. & & Small/Medium Vertebrata & Long bone & 6 \\
\hline 39 & 42 & 2752 & Isi-c & L. Paleo. & & Vertebrata & Indeterminate & 8 \\
\hline 39 & 43 & 2615 & Icl/Isi-c & Paleoindian & & Mammalia (Medium/large) & Indeterminate & 1 \\
\hline 39 & 43 & 2615 & Icl/Isi-c & Paleoindian & & Mammalia (Medium/large) & Tooth, perm./decid. ind. & 1 \\
\hline 39 & 43 & 2615 & Icl/Isi-c & Paleoindian & & Mammalia (Small) & Permanent tooth & 2 \\
\hline 39 & 43 & 2615 & Icl/Isi-c & Paleoindian & & Neotoma sp. & Permanent tooth & 1 \\
\hline 39 & 43 & 2615 & Icl/Isi-c & Paleoindian & & Small/Medium Vertebrata & Long bone & 2 \\
\hline 39 & 43 & 2615 & Icl/Isi-c & Paleoindian & & Testudinata & Shell fragment & 1 \\
\hline 39 & 43 & 2615 & Icl/Isi-c & Paleoindian & & Vertebrata & Indeterminate & 14 \\
\hline 39 & 44 & 2590 & Icl/Isi-c & Paleoindian & & Small/Medium Vertebrata & Long bone & 2 \\
\hline 39 & 44 & 2590 & Icl/Isi-c & Paleoindian & & Vertebrata & Indeterminate & 5 \\
\hline 39 & 45 & 2496 & Icl/Isi-c & Paleoindian & & Geomys sp. & Permanent tooth & 1 \\
\hline
\end{tabular}




\begin{tabular}{|c|c|c|c|c|c|c|c|c|}
\hline Square & Level & Lot & Unit & Cultural Affinity & Feature & Taxon & Element & No. \\
\hline 39 & 45 & 2496 & $\mathrm{Icl} / \mathrm{Isi}-\mathrm{c}$ & Paleoindian & & Small/Medium Vertebrata & Long bone & 12 \\
\hline 39 & 45 & 2496 & Icl//si-c & Paleoindian & & Vertebrata & Indeterminate & 3 \\
\hline 39 & 46 & 2523 & $\mathrm{Icl} / \mathrm{Isi}-\mathrm{c}$ & Paleoindian & & Mammalia (Medium) & Phalange & 1 \\
\hline 39 & 46 & 2523 & Icl/Isi-c & Paleoindian & & Mammalia (Medium/large) & Indeterminate & 2 \\
\hline 39 & 46 & 2523 & Icl/Isi-c & Paleoindian & & Small/Medium Vertebrata & Long bone & 5 \\
\hline 39 & 46 & 2523 & Icl/Isi-c & Paleoindian & & Vertebrata & Indeterminate & 12 \\
\hline 39 & 47 & 2567 & Icl/Isi-c & Paleoindian & & Small/Medium Vertebrata & Long bone & 1 \\
\hline 39 & 47 & 2567 & Icl/Isi-c & Paleoindian & & Vertebrata & Indeterminate & 4 \\
\hline 39 & 48 & 2582 & Icl & E. Paleoindian & & Mammalia (Medium/large) & Tooth, perm./decid. ind. & 1 \\
\hline 39 & 48 & 2582 & Icl & E. Paleoindian & & Small/Medium Vertebrata & Long bone & 2 \\
\hline 39 & 48 & 2582 & Icl & E. Paleoindian & & Vertebrata & Indeterminate & 6 \\
\hline 39 & 49 & 2758 & Icl & E. Paleoindian & & Medium/Large Vertebrata & Indeterminate & 1 \\
\hline 39 & 49 & 2758 & Icl & E. Paleoindian & & Vertebrata & Indeterminate & 6 \\
\hline 39 & 50 & 2856 & Icl & E. Paleoindian & & Mammalia (Medium/large) & Indeterminate & 1 \\
\hline 39 & 50 & 2856 & Icl & E. Paleoindian & & Vertebrata & Indeterminate & 14 \\
\hline 39 & 51 & 2815 & Icl & E. Paleoindian & & Vertebrata & Indeterminate & 7 \\
\hline 39 & 52 & 2807 & Icl & E. Paleoindian & & Mammalia (Medium/large) & Indeterminate & 1 \\
\hline 39 & 52 & 2807 & Icl & E. Paleoindian & & Medium/Large Vertebrata & Indeterminate & 7 \\
\hline 39 & 52 & 2807 & Icl & E. Paleoindian & & Vertebrata & Indeterminate & 11 \\
\hline 39 & 53 & 2806 & Isi/Icl & E. Paleoindian & & Mammalia (Medium/large) & Indeterminate & 16 \\
\hline 39 & 53 & 2806 & Isi/Icl & E. Paleoindian & & Medium/Large Vertebrata & Indeterminate & 9 \\
\hline 39 & 53 & 2806 & Isi/Icl & E. Paleoindian & & Vertebrata & Indeterminate & 31 \\
\hline 39 & 54 & 2773 & $\operatorname{Igl} / / \operatorname{Isi}$ & E. Paleoindian & & Mammalia (Medium/large) & Indeterminate & 38 \\
\hline 39 & 54 & 2773 & Igl/Isi & E. Paleoindian & & Vertebrata & Indeterminate & 17 \\
\hline 39 & 55 & 2782 & $\operatorname{Igl} / / \operatorname{Isi}$ & E. Paleoindian & & Vertebrata & Indeterminate & 1 \\
\hline 39 & 56 & 2834 & Igl/Isi & E. Paleoindian & & Medium/Large Vertebrata & Long bone & 1 \\
\hline 41 & 20 & 906 & $\mathrm{ma} / \mathrm{b}$ & E. Archaic & & Vertebrata & Indeterminate & 2 \\
\hline 41 & 21 & 923 & IIIa & E. Archaic & & Geomys sp. & Permanent tooth & 1 \\
\hline 41 & 21 & 923 & IIIa & E. Archaic & & Vertebrata & Indeterminate & 2 \\
\hline 41 & 22 & 957 & Ш一a & E. Archaic & & Vertebrata & Indeterminate & 4 \\
\hline 41 & 24 & 1033 & IIIa & E. Archaic & & Mammalia (Medium/large) & Indeterminate & 2 \\
\hline 41 & 24 & 1033 & IIIa & E. Archaic & & Small/Medium Vertebrata & Long bone & 1 \\
\hline 41 & 24 & 1033 & IIIa & E. Archaic & & Vertebrata & Indeterminate & 3 \\
\hline 41 & 25 & 1130 & IIIIa & E. Archaic & & Sylvilagus sp. & Permanent tooth & 1 \\
\hline 41 & 25 & 1130 & IIIa & E. Archaic & & Vertebrata & Indeterminate & 5 \\
\hline 41 & 26 & 1152 & ПI/Ша & L. Paleo./E. Archaic & & Medium/Large Vertebrata & Indeterminate & 4 \\
\hline 41 & 26 & 1152 & ПШШІа & L. Paleo./E. Archaic & & Small/Medium Vertebrata & Long bone & 3 \\
\hline 41 & 26 & 1152 & II/IIIa & L. Paleo./E. Archaic & & Vertebrata & Indeterminate & 5 \\
\hline 41 & 28 & 1216 & ІІ/Ша & L. Paleo./E. Archaic & & Small/Medium Vertebrata & Long bone & 2 \\
\hline 41 & 28 & 1216 & ПI/Ша & L. Paleo./E. Archaic & & Vertebrata & Indeterminate & 2 \\
\hline 41 & 29 & 1262 & III & L. Paleo. & & Vertebrata & Indeterminate & 3 \\
\hline 42 & 17 & 764 & IIIa/b & E. Archaic & & Vertebrata & Indeterminate & 1 \\
\hline 42 & 18 & 204 & $\mathrm{ma} / \mathrm{b}$ & E. Archaic & & Vertebrata & Indeterminate & 1 \\
\hline 42 & 21 & 856 & IIIa & E. Archaic & & Mammalia (Medium/large) & Indeterminate & 1 \\
\hline 42 & 21 & 856 & IIIa & E. Archaic & & Medium/Large Vertebrata & Indeterminate & 2 \\
\hline 42 & 21 & 856 & IIIa & E. Archaic & & Testudinata & Shell fragment & 1 \\
\hline 42 & 22 & 928 & IIIa & E. Archaic & & Medium/Large Vertebrata & Indeterminate & 1 \\
\hline 42 & 22 & 928 & IIIa & E. Archaic & & Small/Medium Vertebrata & Long bone & 1 \\
\hline 42 & 22 & 928 & IIIa & E. Archaic & & Vertebrata & Indeterminate & 4 \\
\hline 42 & 24 & 947 & IIIa & E. Archaic & & Vertebrata & Indeterminate & 4 \\
\hline 42 & 26 & 1096 & IIIa & E. Archaic & & Mammalia (Medium) & Distal phalange & 1 \\
\hline 42 & 26 & 1096 & ШІа & E. Archaic & & Medium/Large Vertebrata & Indeterminate & 1 \\
\hline 42 & 26 & 1096 & IIIa & E. Archaic & & Small/Medium Vertebrata & Long bone & 3 \\
\hline 42 & 26 & 1096 & IIIa & E. Archaic & & Vertebrata & Indeterminate & 16 \\
\hline 42 & 27 & 1073 & ІІ/Ша & L. Paleo./E. Archaic & & Lepus californicus & Permanent tooth & 1 \\
\hline 42 & 27 & 1073 & II/IIa & L. Paleo./E. Archaic & & Small/Medium Vertebrata & Long bone & 2 \\
\hline 42 & 27 & 1073 & II/IIа & L. Paleo./E. Archaic & & Vertebrata & Indeterminate & 8 \\
\hline 42 & 28 & 1247 & ПI/Ша & L. Paleo./E. Archaic & & Mammalia (Micro) & Permanent tooth & 1 \\
\hline 42 & 28 & 1247 & II/Ша & L. Paleo./E. Archaic & & Small vertebrate, class ind. & Distal phalange & 1 \\
\hline 42 & 28 & 1247 & II/IIa & L. Paleo./E. Archaic & & Vertebrata & Indeterminate & 3 \\
\hline 42 & 29 & 1360 & П/Ша & L. Paleo./E. Archaic & & Mammalia (Medium/large) & Long bone & 1 \\
\hline 42 & 29 & 1360 & II/Ша & L. Paleo./E. Archaic & & Mammalia (Medium/large) & Tooth, perm./decid. ind. & 1 \\
\hline 42 & 35 & 1709 & II & L. Paleo. & & Mammalia (Medium/large) & Indeterminate & 1 \\
\hline 42 & 50 & 2774 & Isi/Icl & E. Paleoindian & & Mammalia (Medium/large) & Indeterminate & 3 \\
\hline 42 & 50 & 2774 & Isi/Icl & E. Paleoindian & & Vertebrata & Indeterminate & 4 \\
\hline 42 & 51 & 2676 & Isi/Icl & E. Paleoindian & & Mammalia (Medium/large) & Indeterminate & 1 \\
\hline 42 & 51 & 2847 & Isi/Icl & E. Paleoindian & & Leporidae & Permanent tooth & 2 \\
\hline
\end{tabular}




\begin{tabular}{|c|c|c|c|c|c|c|c|c|}
\hline Square & Level & Lot & Unit & Cultural Affinity & Feature & Taxon & Element & No. \\
\hline 42 & 51 & 2847 & Isi/Icl & E. Paleoindian & & Mammalia (Medium/large) & Indeterminate & 21 \\
\hline 42 & 51 & 2847 & Isi/Icl & E. Paleoindian & & Small/Medium Vertebrata & Long bone & 1 \\
\hline 42 & 51 & 2847 & Isi/Icl & E. Paleoindian & & Sylvilagus sp. & Permanent tooth & 1 \\
\hline 42 & 51 & 2847 & Isi/Icl & E. Paleoindian & & Vertebrata & Indeterminate & 40 \\
\hline 42 & 52 & 2842 & $\operatorname{Igl} / \operatorname{Icl}$ & E. Paleoindian & & Leporidae & Permanent tooth & 2 \\
\hline 42 & 52 & 2842 & $\operatorname{Igl} / \operatorname{Icl}$ & E. Paleoindian & & Mammalia (Medium/large) & Indeterminate & 8 \\
\hline 42 & 52 & 2842 & Igl/Icl & E. Paleoindian & & Sylvilagus sp. & Permanent tooth & 3 \\
\hline 42 & 52 & 2842 & $\operatorname{Igl} / \mathrm{Icl}$ & E. Paleoindian & & Vertebrata & Indeterminate & 10 \\
\hline 42 & $53 \mathrm{~A}$ & 2705 & $\operatorname{Igl} / \operatorname{Icl}$ & E. Paleoindian & & Mammalia (Medium) & Vertebra & 1 \\
\hline 42 & $53 \mathrm{~A}$ & 2705 & $\mathrm{Igl} / \mathrm{Icl}$ & E. Paleoindian & & Medium/Large Vertebrata & Indeterminate & 8 \\
\hline 42 & $53 \mathrm{~A}$ & 2705 & $\operatorname{Igl} / \operatorname{Icl}$ & E. Paleoindian & & Serpentes & Dorsal vertebra & 1 \\
\hline 42 & $53 \mathrm{~A}$ & 2705 & $\operatorname{Igl} / \mathrm{Icl}$ & E. Paleoindian & & Vertebrata & Indeterminate & 1 \\
\hline 42 & 53B & 2849 & $\operatorname{Igl} / \operatorname{Icl}$ & E. Paleoindian & & Vertebrata & Indeterminate & 1 \\
\hline 42 & $54 \mathrm{~B}$ & 2840 & Igl & E. Paleoindian & & Vertebrata & Indeterminate & 1 \\
\hline 42 & 55 & 2790 & Igl & E. Paleoindian & & Vertebrata & Indeterminate & 1 \\
\hline 43 & 0 & 2153 & $?$ & Unassigned & & Medium/Large Vertebrata & Indeterminate & 1 \\
\hline 43 & 18 & 795 & IIIa/b & E. Archaic & & Vertebrata & Indeterminate & 1 \\
\hline 43 & 20 & 822 & IIIa & E. Archaic & 231 & Vertebrata & Indeterminate & 1 \\
\hline 43 & 21 & 939 & IIII & E. Archaic & 231 & Vertebrata & Indeterminate & 2 \\
\hline 43 & 22 & 1006 & IIIa & E. Archaic & 231 & Mammalia (Medium/large) & Indeterminate & 2 \\
\hline 43 & 22 & 1006 & IIIIa & E. Archaic & 231 & Mammalia (Small) & Astragalus & 1 \\
\hline 43 & 22 & 1006 & IIIIa & E. Archaic & 231 & Medium/Large Vertebrata & Indeterminate & 1 \\
\hline 43 & 22 & 1006 & IIIa & E. Archaic & 231 & Small/Medium Vertebrata & Long bone & 3 \\
\hline 43 & 22 & 1006 & IIIIa & E. Archaic & 231 & Vertebrata & Indeterminate & 6 \\
\hline 43 & 24 & 1129 & IIIIa & E. Archaic & 231 & Small/Medium Vertebrata & Long bone & 1 \\
\hline 43 & 24 & 1129 & IIIa & E. Archaic & 231 & Testudinata & Shell fragment & 1 \\
\hline 43 & 24 & 1129 & IIIIa & E. Archaic & 231 & Vertebrata & Indeterminate & 7 \\
\hline 43 & 25 & 1248 & IIIIa & E. Archaic & 231 & Small/Medium Vertebrata & Long bone & 2 \\
\hline 43 & 25 & 1248 & IIIIa & E. Archaic & 231 & Vertebrata & Indeterminate & 8 \\
\hline 43 & 26 & 1319 & II/IIIa & L. Paleo./E. Archaic & & Mammalia (Medium/large) & Long bone & 1 \\
\hline 43 & 26 & 1319 & II/IIIa & L. Paleo./E. Archaic & & Small/Medium Vertebrata & Long bone & 2 \\
\hline 43 & 26 & 1319 & II/IIIa & L. Paleo./E. Archaic & & Vertebrata & Indeterminate & 3 \\
\hline 43 & 27 & 1399 & II/IIIa & L. Paleo./E. Archaic & & Small/Medium Vertebrata & Long bone & 7 \\
\hline 43 & 27 & 1399 & II/Wa & L. Paleo./E. Archaic & & Vertebrata & Indeterminate & 5 \\
\hline 43 & 28 & 1412 & II/IIIa & L. Paleo./E. Archaic & & Small/Medium Vertebrata & Long bone & 3 \\
\hline 43 & 28 & 1412 & II/IIIa & L. Paleo./E. Archaic & & Vertebrata & Indeterminate & 13 \\
\hline 43 & 29 & 1647 & II/IIIa & L. Paleo./E. Archaic & & Mammalia (Medium/large) & Indeterminate & 1 \\
\hline 43 & 29 & 1647 & II/III & L. Paleo./E. Archaic & & Vertebrata & Indeterminate & 3 \\
\hline 43 & 50 & 2816 & Isi/Icl & E. Paleoindian & & Medium/Large Vertebrata & Indeterminate & 1 \\
\hline 43 & 51 & 2668 & Isi/Icl & E. Paleoindian & & Medium/Large Vertebrata & Indeterminate & 6 \\
\hline 43 & 51 & 2668 & |Isi/Icl & E. Paleoindian & & Vertebrata & Indeterminate & 2 \\
\hline 43 & 51 & 2853 & Isi/Icl & E. Paleoindian & & Mammalia (Medium/large) & Indeterminate & 15 \\
\hline 43 & 51 & 2853 & Isi/Icl & E. Paleoindian & & Medium/Large Vertebrata & Indeterminate & 11 \\
\hline 43 & 51 & 2853 & Isi/Icl & E. Paleoindian & & Vertebrata & Indeterminate & 78 \\
\hline 43 & 52 & 2690 & Isi/Icl & E. Paleoindian & & Mammalia (Large/very large) & Indeterminate & 1 \\
\hline 43 & 52 & 2838 & Isi/Icl & E. Paleoindian & & Vertebrata & Indeterminate & 6 \\
\hline 43 & $53 \mathrm{~A}$ & 2696 & Igl/Isi/Icl & E. Paleoindian & & Small/Medium Vertebrata & Long bone & 1 \\
\hline 43 & $53 \mathrm{~A}$ & 2696 & Igl/Isi//cl & E. Paleoindian & & Vertebrata & Indeterminate & 7 \\
\hline 43 & $54 \mathrm{~A}$ & 2704 & Igl/Isi/Icl & E. Paleoindian & & Small/Medium Vertebrata & Long bone & 1 \\
\hline 43 & $54 \mathrm{~A}$ & 2704 & Igl/Isi/Icl & E. Paleoindian & & Vertebrata & Indeterminate & 2 \\
\hline 43 & $55 \mathrm{~A}$ & 2780 & Igl & E. Paleoindian & & Medium/Large Vertebrata & Indeterminate & 1 \\
\hline 43 & $56 \mathrm{~B}$ & 2874 & Igl & E. Paleoindian & & Mammalia (Medium/large) & Indeterminate & 5 \\
\hline 44 & 17 & 760 & $?$ & E. Archaic & & Small/Medium Vertebrata & Long bone & 1 \\
\hline 44 & 18 & 788 & IIIa/b & E. Archaic & & Vertebrata & Indeterminate & 5 \\
\hline 44 & 19 & 818 & IIIa & E. Archaic & 231 & Vertebrata & Indeterminate & 2 \\
\hline 44 & 20 & 972 & Ша & E. Archaic & 231 & Mammalia (Medium/large) & Long bone & 1 \\
\hline 44 & 20 & 972 & IIIa & E. Archaic & 231 & Small/Medium Vertebrata & Long bone & 3 \\
\hline 44 & 20 & 972 & IIIIa & E. Archaic & 231 & Vertebrata & Indeterminate & 2 \\
\hline 44 & 21 & 1079 & IIII & E. Archaic & 231 & Mammalia (Medium/large) & Indeterminate & 1 \\
\hline 44 & 21 & 1079 & IIIIa & E. Archaic & 231 & Vertebrata & Indeterminate & 2 \\
\hline 44 & 22 & 1080 & IIII & E. Archaic & 231 & Mammalia (Medium/large) & Indeterminate & 1 \\
\hline 44 & 22 & 1080 & IIIa & E. Archaic & 231 & Mammalia (Small) & Alveolar ridge fragment & 1 \\
\hline 44 & 22 & 1080 & IIIIa & E. Archaic & 231 & Small/Medium Vertebrata & Long bone & 2 \\
\hline 44 & 22 & 1080 & IIIIa & E. Archaic & 231 & Vertebrata & Indeterminate & 6 \\
\hline 44 & 24 & 1486 & IIIa & E. Archaic & 245 & Small/Medium Vertebrata & Long bone & 3 \\
\hline 44 & 24 & 1486 & IIIIa & E. Archaic & 245 & Testudinata & Shell fragment & 1 \\
\hline 44 & 24 & 1486 & IIIa & E. Archaic & 245 & Vertebrata & Indeterminate & 4 \\
\hline
\end{tabular}




\begin{tabular}{|c|c|c|c|c|c|c|c|c|}
\hline Square & Level & Lot & Unit & Cultural Affinity & Feature & Taxon & Element & No. \\
\hline 44 & 25 & 1567 & IIIa & E. Archaic & 245 & Geomys sp. & Permanent tooth & 1 \\
\hline 44 & 25 & 1567 & IIIa & E. Archaic & 245 & Mammalia (Medium) & Permanent tooth & 1 \\
\hline 44 & 25 & 1567 & ШШа & E. Archaic & 245 & Small/Medium Vertebrata & Long bone & 4 \\
\hline 44 & 25 & 1567 & IIII & E. Archaic & 245 & Sylvilagus sp. & Astragalus & 1 \\
\hline 44 & 25 & 1567 & IIIIa & E. Archaic & 245 & Vertebrata & Indeterminate & 4 \\
\hline 44 & 26 & 1651 & ПI/IIIa & L. Paleo./E. Archaic & 245 & Leporidae & Permanent tooth & 2 \\
\hline 44 & 26 & 1651 & II/ШІа & L. Paleo./E. Archaic & 245 & Small/Medium Vertebrata & Long bone & 1 \\
\hline 44 & 26 & 1651 & II/IIIa & L. Paleo./E. Archaic & 245 & Vertebrata & Indeterminate & 4 \\
\hline 44 & 27 & 1766 & II/IIIa & L. Paleo./E. Archaic & & Mammalia (Medium) & Long bone & 1 \\
\hline 44 & 27 & 1766 & II/IIIa & L. Paleo./E. Archaic & & Medium/Large Vertebrata & Indeterminate & 1 \\
\hline 44 & 27 & 1766 & II/IIIa & L. Paleo./E. Archaic & & Vertebrata & Indeterminate & 8 \\
\hline 44 & $28 \mathrm{~A}$ & 1824 & II/IIIa & L. Paleo./E. Archaic & & Mammalia (Small) & Metapodial & 1 \\
\hline 44 & $28 \mathrm{~A}$ & 1824 & III/IIIa & L. Paleo./E. Archaic & & Small/Medium Vertebrata & Long bone & 1 \\
\hline 44 & $28 \mathrm{~A}$ & 1824 & II/IIIa & L. Paleo./E. Archaic & & Vertebrata & Indeterminate & 2 \\
\hline 44 & $28 \mathrm{~B}$ & 1800 & IIIIIIa & L. Paleo./E. Archaic & 248 & Mammalia (Medium/large) & Long bone & 1 \\
\hline 44 & 28B & 1800 & II/IIIIa & L. Paleo./E. Archaic & 248 & Small/Medium Vertebrata & Long bone & 1 \\
\hline 44 & $28 \mathrm{~B}$ & 1800 & II/IIIa & L. Paleo./E. Archaic & 248 & Vertebrata & Indeterminate & 2 \\
\hline 44 & $29 \mathrm{~A}$ & 1855 & ШI/IIIa & L. Paleo./E. Archaic & & Vertebrata & Indeterminate & 5 \\
\hline 44 & 29B & 1898 & II/ШІІа & L. Paleo./E. Archaic & 248 & Vertebrata & Indeterminate & 1 \\
\hline 44 & 41 & 2320 & ? & |Unassigned & & Medium/Large Vertebrata & Indeterminate & 2 \\
\hline 44 & 41 & 2320 & ? & Unassigned & & Small/Medium Vertebrata & Long bone & 1 \\
\hline 44 & 41 & 2320 & $?$ & Unassigned & & Vertebrata & Indeterminate & 10 \\
\hline 44 & 50 & 2850 & Isi/Icl & E. Paleoindian & & Leporidae & Permanent tooth & 1 \\
\hline 44 & 50 & 2850 & Isi/Icl & E. Paleoindian & & Vertebrata & Indeterminate & 6 \\
\hline 44 & 51 & 2852 & Isi/Icl & E. Paleoindian & & Leporidae & Permanent tooth & 1 \\
\hline 44 & 51 & 2852 & Isi//Icl & E. Paleoindian & & Mammalia (Medium/large) & Indeterminate & 9 \\
\hline 44 & 51 & 2852 & Isi/Icl & E. Paleoindian & & Small/Medium Vertebrata & Long bone & 1 \\
\hline 44 & 51 & 2852 & Isi/Icl & E. Paleoindian & & Vertebrata & Indeterminate & 6 \\
\hline 44 & 52 & 2855 & Isi/Icl & E. Paleoindian & & Vertebrata & Indeterminate & 2 \\
\hline 44 & 52 & 2863 & Isi/Icl & E. Paleoindian & & Vertebrata & Indeterminate & 4 \\
\hline 44 & 53 & 2706 & Isi/Icl & E. Paleoindian & & Lepus californicus & Permanent tooth & 1 \\
\hline 44 & 53 & 2706 & Isi/Icl & E. Paleoindian & & Mammalia (Medium/large) & Indeterminate & 1 \\
\hline 44 & 53 & 2706 & Isi/Icl & E. Paleoindian & & Mammalia (Medium/large) & Long bone & 9 \\
\hline 44 & 53 & 2706 & Isi/Icl & E. Paleoindian & & Mammalia (Small) & Permanent tooth & 1 \\
\hline 44 & 53 & 2706 & Isi/Icl & E. Paleoindian & & Small/Medium Vertebrata & Long bone & 2 \\
\hline 44 & 53 & 2706 & Isi/Icl & E. Paleoindian & & Vertebrata & Indeterminate & 3 \\
\hline 44 & $54 \mathrm{~A}$ & 2708 & Igl/Isi/Icl & E. Paleoindian & & Lepus californicus & Mandible & 1 \\
\hline 44 & $54 \mathrm{~A}$ & 2708 & Igl/Isi/Icl & E. Paleoindian & & Mammalia (Medium/large) & Indeterminate & 3 \\
\hline 44 & $54 \mathrm{~A}$ & 2708 & Igl/Isi/Icl & E. Paleoindian & & Vertebrata & Indeterminate & 5 \\
\hline 44 & $55 \mathrm{~A}$ & 2843 & |Igl/Isi & E. Paleoindian & & Medium/Large Vertebrata & Indeterminate & 2 \\
\hline 44 & $55 \mathrm{~A}$ & 2843 & Igl/Isi & E. Paleoindian & & Small/Medium Vertebrata & Long bone & 1 \\
\hline 44 & 56 & 2791 & Igl & E. Paleoindian & & Vertebrata & Indeterminate & 2 \\
\hline 45 & 17 & 811 & IIIIa & E. Archaic & & Small/Medium Vertebrata & Long bone & 3 \\
\hline 45 & 17 & 811 & IIIIa & E. Archaic & & Vertebrata & Indeterminate & 8 \\
\hline 45 & 18 & 838 & III/II & L. Paleo./E. Archaic & & Geomys sp. & Permanent tooth & 1 \\
\hline 45 & 18 & 838 & II/IIIa & L. Paleo./E. Archaic & & Mammalia (Small) & Permanent tooth & 1 \\
\hline 45 & 18 & 838 & II/IIIIa & L. Paleo./E. Archaic & & Vertebrata & Indeterminate & 6 \\
\hline 45 & 19 & 879 & II/IIIIa & L. Paleo./E. Archaic & & Mammalia (Medium/large) & Tooth, perm./decid. ind. & 1 \\
\hline 45 & 19 & 879 & II/IIIIa & L. Paleo./E. Archaic & & Rodentia (Small) & Permanent tooth & 1 \\
\hline 45 & 19 & 879 & II/IIIIa & L. Paleo./E. Archaic & & Small/Medium Vertebrata & Long bone & 5 \\
\hline 45 & 19 & 879 & II/IIIa & L. Paleo./E. Archaic & & Vertebrata & Indeterminate & 9 \\
\hline 45 & 20 & 895 & IIIIIIa & L. Paleo./E. Archaic & & Vertebrata & Indeterminate & 11 \\
\hline 45 & 20 & 895 & II/IIIa & L. Paleo./E. Archaic & & Vertebrata & Long bone & 1 \\
\hline 45 & 21 & 927 & III & L. Paleo. & & Mammalia (Small) & Permanent tooth & 1 \\
\hline 45 & 21 & 927 & III & L. Paleo. & & Small/Medium Vertebrata & Long bone & 7 \\
\hline 45 & 21 & 927 & III & L. Paleo. & & Sylvilagus sp. & Calcaneus & 1 \\
\hline 45 & 21 & 927 & III & L. Paleo. & & Vertebrata & Indeterminate & 15 \\
\hline 45 & 21 & 927 & III & L. Paleo. & & Viperidae & Dorsal vertebra & 1 \\
\hline 45 & 22 & 958 & III & L. Paleo. & & Leporidae & Permanent tooth & 2 \\
\hline 45 & 22 & 958 & III & L. Paleo. & & Medium vertebrate, class ind. & Phalange & 1 \\
\hline 45 & 22 & 958 & III & L. Paleo. & & Small vertebrate, class ind. & Proximal phalange & 1 \\
\hline 45 & 22 & 958 & III & L. Paleo. & & Small/Medium Vertebrata & Long bone & 5 \\
\hline 45 & 22 & 958 & III & L. Paleo. & & Squamata & Dorsal vertebra & 1 \\
\hline 45 & 22 & 958 & III & L. Paleo. & & Vertebrata & Indeterminate & 11 \\
\hline 45 & 23 & 1009 & III & L. Paleo. & & Mammalia (Medium/large) & Indeterminate & 2 \\
\hline 45 & 23 & 1009 & III & L. Paleo. & & Small/Medium Vertebrata & Long bone & 2 \\
\hline 45 & 23 & 1009 & II & L. Paleo. & & Vertebrata & Indeterminate & 2 \\
\hline
\end{tabular}




\begin{tabular}{|c|c|c|c|c|c|c|c|c|}
\hline Square & Level & Lot & Unit & Cultural Affinity & Feature & Taxon & Element & No. \\
\hline 45 & 24 & 1058 & III & L. Paleo. & & Mammalia (Medium/large) & Indeterminate & 1 \\
\hline 45 & 24 & 1058 & II & L. Paleo. & & Mammalia (Small) & Calcaneus & 1 \\
\hline 45 & 24 & 1058 & II & L. Paleo. & & Small/Medium Vertebrata & Long bone & 2 \\
\hline 45 & 24 & 1058 & II & L. Paleo. & & Vertebrata & Indeterminate & 13 \\
\hline 45 & 26 & 1105 & II & L. Paleo. & & Small/Medium Vertebrata & Long bone & 3 \\
\hline 45 & 26 & 1105 & III & L. Paleo. & & Vertebrata & Indeterminate & 4 \\
\hline 45 & 27 & 1141 & III & L. Paleo. & & Medium/Large Vertebrata & Indeterminate & 1 \\
\hline 45 & 27 & 1141 & III & L. Paleo. & & Osteichthyes (Small) & Vertebra & 1 \\
\hline 45 & 27 & 1141 & II & L. Paleo. & & Sylvilagus sp. & Metatarsal 5 & 1 \\
\hline 45 & 27 & 1141 & II & L. Paleo. & & Vertebrata & Indeterminate & 6 \\
\hline 45 & 28 & 1155 & II & L. Paleo. & & Vertebrata & Indeterminate & 1 \\
\hline 45 & 29 & 1287 & III & L. Paleo. & & Small/Medium Vertebrata & Long bone & 1 \\
\hline 45 & 29 & 1287 & II & L. Paleo. & & Vertebrata & Indeterminate & 4 \\
\hline 45 & 39 & 1653 & Isi & E. Paleoindian & & Medium/Large Vertebrata & Indeterminate & 1 \\
\hline 46 & 17 & 773 & IIIa & E. Archaic & & Colubridae & Dorsal vertebra & 1 \\
\hline 46 & 17 & 773 & IIIa & E. Archaic & & Kinosternon sp. & Peripheral & 1 \\
\hline 46 & 17 & 773 & IIIIa & E. Archaic & & Mammalia (Small) & Permanent tooth & 1 \\
\hline 46 & 17 & 773 & III & E. Archaic & & Small/Medium Vertebrata & Long bone & 4 \\
\hline 46 & 17 & 773 & IIIa & E. Archaic & & Vertebrata & Indeterminate & 21 \\
\hline 46 & 18 & 791 & IIIIa & E. Archaic & & Mammalia (Medium/large) & Indeterminate & 2 \\
\hline 46 & 18 & 791 & ШІа & E. Archaic & & Small/Medium Vertebrata & Long bone & 4 \\
\hline 46 & 18 & 791 & IIIa & E. Archaic & & Testudinata & Shell fragment & 2 \\
\hline 46 & 18 & 791 & IIIa & E. Archaic & & Vertebrata & Indeterminate & 20 \\
\hline 46 & 19 & 824 & IIIIIa & L. Paleo./E. Archaic & & Mammalia (Large) & Long bone & 1 \\
\hline 46 & 19 & 824 & II/IIIa & L. Paleo./E. Archaic & & Mammalia (Medium/large) & Indeterminate & 2 \\
\hline 46 & 19 & 824 & Ш/ШІШа & L. Paleo./E. Archaic & & Mammalia (Small) & Distal phalange & 1 \\
\hline 46 & 19 & 824 & I/IIIa & L. Paleo./E. Archaic & & Small/Medium Vertebrata & Long bone & 2 \\
\hline 46 & 19 & 824 & II/IIIa & L. Paleo./E. Archaic & & Vertebrata & Indeterminate & 14 \\
\hline 46 & $20 \mathrm{~A}$ & 1290 & Ш/Ша & L. Paleo./E. Archaic & & Lepus californicus & Mandible & 1 \\
\hline 46 & $20 \mathrm{~A}$ & 1290 & П/ШाI & L. Paleo./E. Archaic & & Mammalia (Medium/large) & Tooth, perm./decid. ind. & 1 \\
\hline 46 & $20 \mathrm{~A}$ & 1290 & ПI/IIIa & L. Paleo./E. Archaic & & Small/Medium Vertebrata & Long bone & 1 \\
\hline 46 & $20 \mathrm{~A}$ & 1290 & П/Ша & L. Paleo./E. Archaic & & Vertebrata & Indeterminate & 4 \\
\hline 46 & $21 \mathrm{~A}$ & 911 & ПI/11а & L. Paleo./E. Archaic & & Mammalia (Medium/large) & Tooth, perm./decid. ind. & 1 \\
\hline 46 & $21 \mathrm{~A}$ & 911 & ПI/IIIa & L. Paleo./E. Archaic & & Mammalia (Micro) & Permanent tooth & 1 \\
\hline 46 & $21 \mathrm{~A}$ & 911 & Ш/Ша & L. Paleo./E. Archaic & & Small/Medium Vertebrata & Long bone & 7 \\
\hline 46 & $21 \mathrm{~A}$ & 911 & П/ШІа & L. Paleo./E. Archaic & & Vertebrata & Indeterminate & 18 \\
\hline 46 & $21 \mathrm{~B}$ & 925 & П/ШाIа & L. Paleo./E. Archaic & 226 & Sylvilagus sp. & Scapula & 1 \\
\hline 46 & $21 \mathrm{~B}$ & 925 & Ш/ШІІа & L. Paleo./E. Archaic & 226 & Vertebrata & Indeterminate & 1 \\
\hline 46 & 22 & 934 & Ш/Ша & L. Paleo./E. Archaic & & Mammalia (Medium/large) & Long bone & 1 \\
\hline 46 & 22 & 934 & IIIIIa & L. Paleo./E. Archaic & & Small/Medium Vertebrata & Long bone & 6 \\
\hline 46 & 22 & 934 & П/Ша & L. Paleo./E. Archaic & & Vertebrata & Indeterminate & 5 \\
\hline 46 & 23 & 949 & П/Шाа & L. Paleo./E. Archaic & & Mammalia (Micro) & Permanent tooth & 1 \\
\hline 46 & 23 & 949 & ПIIIIa & L. Paleo./E. Archaic & & Micro vertebrate, class ind. & Vertebra & 1 \\
\hline 46 & 23 & 949 & Ш/Ша & L. Paleo./E. Archaic & & Neotoma sp. & Permanent tooth & 1 \\
\hline 46 & 23 & 949 & П/Шाँ & L. Paleo./E. Archaic & & Small/Medium Vertebrata & Long bone & 16 \\
\hline 46 & 23 & 949 & П/IIIa & L. Paleo./E. Archaic & & Vertebrata & Indeterminate & 42 \\
\hline 46 & 24 & 1097 & II & L. Paleo. & & Mammalia (Medium/large) & Indeterminate & 1 \\
\hline 46 & 24 & 1097 & III & L. Paleo. & & Small/Medium Vertebrata & Long bone & 1 \\
\hline 46 & 24 & 1097 & II & L. Paleo. & & Vertebrata & Indeterminate & 12 \\
\hline 46 & 25 & 1112 & III & L. Paleo. & & Mammalia (Medium/large) & Indeterminate & 2 \\
\hline 46 & 25 & 1112 & II & L. Paleo. & & Mammalia (Small) & Permanent tooth & 1 \\
\hline 46 & 25 & 1112 & III & L. Paleo. & & Medium/Large Vertebrata & Indeterminate & 3 \\
\hline 46 & 25 & 1112 & III & L. Paleo. & & Small/Medium Vertebrata & Long bone & 23 \\
\hline 46 & 25 & 1112 & III & L. Paleo. & & Sylvilagus sp. & Metacarpal 2 & 1 \\
\hline 46 & 25 & 1112 & III & L. Paleo. & & Vertebrata & Indeterminate & 25 \\
\hline 46 & 26 & 1134 & II & L. Paleo. & & Small/Medium Vertebrata & Long bone & 7 \\
\hline 46 & 26 & 1134 & III & L. Paleo. & & Vertebrata & Indeterminate & 15 \\
\hline 46 & $27 \mathrm{~A}$ & 1158 & III & L. Paleo. & & Mammalia (Medium/large) & Indeterminate & 2 \\
\hline 46 & $27 \mathrm{~A}$ & 1158 & II & L. Paleo. & & Testudinata & Shell fragment & 1 \\
\hline 46 & $27 \mathrm{~A}$ & 1158 & III & L. Paleo. & & Vertebrata & Indeterminate & 4 \\
\hline 46 & $28 \mathrm{~A}$ & 2174 & III & L. Paleo. & & Mammalia (Medium/large) & Indeterminate & 5 \\
\hline 46 & $28 \mathrm{~A}$ & 2174 & III & L. Paleo. & & Small/Medium Vertebrata & Long bone & 2 \\
\hline 46 & $28 \mathrm{~A}$ & 2174 & III & L. Paleo. & & Vertebrata & Indeterminate & 10 \\
\hline 46 & 29 & 1207 & Isi-c/II & L. Paleo. & & Medium/Large Vertebrata & Long bone & 1 \\
\hline 46 & 29 & 1207 & Isi-c/II & L. Paleo. & & Small/Medium Vertebrata & Long bone & 3 \\
\hline 46 & 29 & 1207 & Isi-c/II & L. Paleo. & & Vertebrata & Indeterminate & 4 \\
\hline 46 & 30 & 1288 & Isi-c/II & L. Paleo. & & Small vertebrate, class ind. & Phalange & 1 \\
\hline
\end{tabular}




\begin{tabular}{|c|c|c|c|c|c|c|c|c|}
\hline Square & Level & Lot & Unit & Cultural Affinity & Feature & Taxon & Element & No. \\
\hline 46 & 30 & 1288 & Isi-c/II & L. Paleo. & & Vertebrata & Indeterminate & 18 \\
\hline 46 & 31 & 1318 & Isi-c/II & L. Paleo. & & Mammalia (Medium) & Long bone & 1 \\
\hline 46 & 31 & 1318 & Isi-c/II & L. Paleo. & & Small/Medium Vertebrata & Long bone & 7 \\
\hline 46 & 31 & 1318 & Isi-c/II & L. Paleo. & & Vertebrata & Indeterminate & 3 \\
\hline 46 & 32 & 1337 & Isi-c & L. Paleo. & & Mammalia (Large) & Long bone & 1 \\
\hline 46 & 32 & 1337 & Isi-c & L. Paleo. & & Mammalia (Medium) & Metapodial & 1 \\
\hline 46 & 32 & 1337 & Isi-c & L. Paleo. & & Mammalia (Medium/large) & Long bone & 5 \\
\hline 46 & 32 & 1337 & Isi-c & L. Paleo. & & Small/Medium Vertebrata & Long bone & 7 \\
\hline 46 & 32 & 1337 & Isi-c & L. Paleo. & & Sylvilagus sp. & Humerus & 1 \\
\hline 46 & 32 & 1337 & Isi-c & L. Paleo. & & Vertebrata & Indeterminate & 8 \\
\hline 46 & 33 & 1387 & Isi-c & L. Paleo. & & Lepus californicus & Calcaneus & 1 \\
\hline 46 & 33 & 1387 & Isi-c & L. Paleo. & & Mammalia (Medium/large) & Indeterminate & 1 \\
\hline 46 & 33 & 1387 & Isi-c & L. Paleo. & & Mammalia (Medium/large) & Long bone & 1 \\
\hline 46 & 33 & 1387 & Isi-c & L. Paleo. & & Medium/Large Vertebrata & Indeterminate & 5 \\
\hline 46 & 33 & 1387 & Isi-c & L. Paleo. & & Medium/Large Vertebrata & Long bone & 2 \\
\hline 46 & 33 & 1387 & Isi-c & L. Paleo. & & Small/Medium Vertebrata & Long bone & 13 \\
\hline 46 & 33 & 1387 & Isi-c & L. Paleo. & & Sylvilagus sp. & Femur & 1 \\
\hline 46 & 33 & 1387 & Isi-c & L. Paleo. & & Vertebrata & Indeterminate & 17 \\
\hline 46 & 34 & 1285 & Isi-c & L. Paleo. & & Leporidae & Permanent tooth & 2 \\
\hline 46 & 34 & 1285 & Isi-c & L. Paleo. & & Leporidae & Tibia & 1 \\
\hline 46 & 34 & 1285 & Isi-c & L. Paleo. & & Mammalia (Medium/large) & Indeterminate & 2 \\
\hline 46 & 34 & 1285 & Isi-c & L. Paleo. & & Serpentes & Dorsal vertebra & 2 \\
\hline 46 & 34 & 1285 & Isi-c & L. Paleo. & & Small/Medium Vertebrata & Long bone & 8 \\
\hline 46 & 34 & 1285 & Isi-c & L. Paleo. & & Testudinata & Shell fragment & 1 \\
\hline 46 & 34 & 1285 & Isi-c & L. Paleo. & & Vertebrata & Indeterminate & 24 \\
\hline 46 & 35 & 1441 & Isi/Isi-c & Paleoindian & & Leporidae & Permanent tooth & 1 \\
\hline 46 & 35 & 1441 & Isi/Isi-c & Paleoindian & & Mammalia (Medium/large) & Indeterminate & 4 \\
\hline 46 & 35 & 1441 & Isi/Isi-c & Paleoindian & & Mammalia (Medium/large) & Long bone & 2 \\
\hline 46 & 35 & 1441 & Isi/Isi-c & Paleoindian & & Mammalia (Medium/large) & Tooth, perm./decid. ind. & 2 \\
\hline 46 & 35 & 1441 & Isi/Isi-c & Paleoindian & & Mammalia (Micro) & Femur & 1 \\
\hline 46 & 35 & 1441 & Isi/Isi-c & Paleoindian & & Mammalia (Micro) & Permanent tooth & 1 \\
\hline 46 & 35 & 1441 & Isi/Isi-c & Paleoindian & & Mammalia (Micro) & Tibia & 1 \\
\hline 46 & 35 & 1441 & Isi/Isi-c & Paleoindian & & Medium/Large Vertebrata & Indeterminate & 4 \\
\hline 46 & 35 & 1441 & Isi/Isi-c & Paleoindian & & Serpentes & Dorsal vertebra & 4 \\
\hline 46 & 35 & 1441 & Isi/Isi-c & Paleoindian & & Small/Medium Vertebrata & Long bone & 26 \\
\hline 46 & 35 & 1441 & Isi/Isi-c & Paleoindian & & Sylvilagus sp. & Radius & 1 \\
\hline 46 & 35 & 1441 & Isi/Isi-c & Paleoindian & & Testudinata & Shell fragment & 1 \\
\hline 46 & 35 & 1441 & Isi/Isi-c & Paleoindian & & Vertebrata & Indeterminate & 60 \\
\hline 46 & 36 & 1723 & Isi/Isi-c & Paleoindian & & Leporidae & Permanent tooth & 1 \\
\hline 46 & 36 & 1723 & Isi/Isi-c & Paleoindian & & Mammalia (Medium/large) & Indeterminate & 1 \\
\hline 46 & 36 & 1723 & Isi/Isi-c & Paleoindian & & Mammalia (Small) & Femur & 1 \\
\hline 46 & 36 & 1723 & Isi/Isi-c & Paleoindian & & Mammalia (Small) & Permanent tooth & 3 \\
\hline 46 & 36 & 1723 & Isi/Isi-c & Paleoindian & & Mammalia (Small/medium) & Alveolar ridge fragment & 1 \\
\hline 46 & 36 & 1723 & Isi/Isi-c & Paleoindian & & Medium/Large Vertebrata & Indeterminate & 9 \\
\hline 46 & 36 & 1723 & Isi/Isi-c & Paleoindian & & Serpentes & Dorsal vertebra & 1 \\
\hline 46 & 36 & 1723 & Isi/Isi-c & Paleoindian & & Small/Medium Vertebrata & Long bone & 15 \\
\hline 46 & 36 & 1723 & Isi/Isi-c & Paleoindian & & Sylvilagus sp. & Humerus & 1 \\
\hline 46 & 36 & 1723 & Isi/Isi-c & Paleoindian & & Sylvilagus sp. & Ulna & 1 \\
\hline 46 & 36 & 1723 & Isi/Isi-c & Paleoindian & & Testudinata & Shell fragment & 2 \\
\hline 46 & 36 & 1723 & Isi/Isi-c & Paleoindian & & Vertebrata & Indeterminate & 50 \\
\hline 46 & 37 & 1797 & Isi/Isi-c & Paleoindian & & Medium/Large Vertebrata & Indeterminate & 6 \\
\hline 46 & 37 & 1797 & Isi/Isi-c & Paleoindian & & Serpentes & Dorsal vertebra & 1 \\
\hline 46 & 37 & 1797 & Isi/Isi-c & Paleoindian & & Small vertebrate, class ind. & Proximal phalange & 1 \\
\hline 46 & 37 & 1797 & Isi/Isi-c & Paleoindian & & Small/Medium Vertebrata & Long bone & 5 \\
\hline 46 & 37 & 1797 & Isi/Isi-c & Paleoindian & & Sylvilagus sp. & Permanent tooth & 1 \\
\hline 46 & 37 & 1797 & Isi/Isi-c & Paleoindian & & Vertebrata & Indeterminate & 29 \\
\hline 46 & 37 & 1797 & Isi/Isi-c & Paleoindian & & Viperidae & Dorsal vertebra & 1 \\
\hline 46 & 38 & 1857 & Isi/Isi-c & Paleoindian & & Colubridae & Dorsal vertebra & 1 \\
\hline 46 & 38 & 1857 & Isi/Isi-c & Paleoindian & & Mammalia (Small) & Patella & 1 \\
\hline 46 & 38 & 1857 & Isi/Isi-c & Paleoindian & & Serpentes & Dorsal vertebra & 1 \\
\hline 46 & 38 & 1857 & Isi/Isi-c & Paleoindian & & Small/Medium Vertebrata & Long bone & 6 \\
\hline 46 & 38 & 1857 & Isi/Isi-c & Paleoindian & & Vertebrata & Indeterminate & 27 \\
\hline 46 & 39 & 1925 & Isi/Isi-c & Paleoindian & & Mammalia (Small) & Permanent tooth & 1 \\
\hline 46 & 39 & 1925 & Isi/Isi-c & Paleoindian & & Medium/Large Vertebrata & Indeterminate & 4 \\
\hline 46 & 39 & 1925 & Isi/Isi-c & Paleoindian & & Medium/Large Vertebrata & Long bone & 1 \\
\hline 46 & 39 & 1925 & Isi/Isi-c & Paleoindian & & Serpentes & Dorsal vertebra & 1 \\
\hline 46 & 39 & 1925 & Isi/Isi-c & Paleoindian & & Small/Medium Vertebrata & Long bone & 4 \\
\hline
\end{tabular}




\begin{tabular}{|c|c|c|c|c|c|c|c|c|}
\hline Square & Level & Lot & Unit & Cultural Affinity & Feature & Taxon & Element & No. \\
\hline 46 & 39 & 1925 & Isi/Isi-c & Paleoindian & & Vertebrata & Indeterminate & 23 \\
\hline 46 & 40 & 2109 & Isi/Isi-c & Paleoindian & & Leporidae & Cranium & 1 \\
\hline 46 & 40 & 2109 & Isi/Isi-c & Paleoindian & & Mammalia (Medium/large) & Indeterminate & 5 \\
\hline 46 & 40 & 2109 & Isi/Isi-c & Paleoindian & & Mammalia (Medium/large) & Long bone & 1 \\
\hline 46 & 40 & 2109 & Isi/Isi-c & Paleoindian & & Mammalia (Medium/large) & Tooth, perm./decid. ind. & 1 \\
\hline 46 & 40 & 2109 & Isi/Isi-c & Paleoindian & & Mammalia (Small) & Calcaneus & 1 \\
\hline 46 & 40 & 2109 & Isi/Isi-c & Paleoindian & & Mammalia (Small) & Permanent tooth & 1 \\
\hline 46 & 40 & 2109 & Isi/Isi-c & Paleoindian & & Small/Medium Vertebrata & Long bone & 6 \\
\hline 46 & 40 & 2109 & Isi/Isi-c & Paleoindian & & Vertebrata & Indeterminate & 33 \\
\hline 46 & 41 & 2111 & Isi/Isi-c & Paleoindian & & Mammalia (Medium/large) & Cranium & 1 \\
\hline 46 & 41 & 2111 & Isi/Isi-c & Paleoindian & & Mammalia (Medium/large) & Indeterminate & 4 \\
\hline 46 & 41 & 2111 & Isi/Isi-c & Paleoindian & & Mammalia (Medium/large) & Long bone & 1 \\
\hline 46 & 41 & 2111 & Isi/Isi-c & Paleoindian & & Mammalia (Medium/large) & Tooth, perm./decid. ind. & 1 \\
\hline 46 & 41 & 2111 & Isi/Isi-c & Paleoindian & & Small/Medium Vertebrata & Long bone & 5 \\
\hline 46 & 41 & 2111 & Isi/Isi-c & Paleoindian & & Sylvilagus sp. & Humerus & 1 \\
\hline 46 & 41 & 2111 & Isi/Isi-c & Paleoindian & & Testudinata & Shell fragment & 1 \\
\hline 46 & 41 & 2111 & Isi/Isi-c & Paleoindian & & Vertebrata & Indeterminate & 15 \\
\hline 46 & $42 \mathrm{~A}$ & 2608 & Isi & E. Paleoindian & & Vertebrata & Indeterminate & 4 \\
\hline 46 & 43 & 2149 & Isi & E. Paleoindian & & Small/Medium Vertebrata & Long bone & 1 \\
\hline 46 & 44 & 2828 & Isi & E. Paleoindian & & Mammalia (Medium/large) & Long bone & 1 \\
\hline 46 & 44 & 2828 & Isi & E. Paleoindian & & Mammalia (Medium/large) & Tooth, perm./decid. ind. & 2 \\
\hline 46 & 44 & 2828 & Isi & E. Paleoindian & & Vertebrata & Indeterminate & 2 \\
\hline 46 & 45 & 2700 & Isi & E. Paleoindian & & Small/Medium Vertebrata & Long bone & 1 \\
\hline 46 & 45 & 2700 & Isi & E. Paleoindian & & Sylvilagus sp. & Calcaneus & 1 \\
\hline 46 & 45 & 2700 & Isi & E. Paleoindian & & Vertebrata & Indeterminate & 2 \\
\hline 46 & 46 & 2601 & Isi & E. Paleoindian & & Vertebrata & Indeterminate & 2 \\
\hline 46 & 48 & 2306 & Isi & E. Paleoindian & & Mammalia (Medium/large) & Long bone & 1 \\
\hline 46 & 48 & 2796 & Isi & E. Paleoindian & & Ondatra zibethicus & Permanent tooth & 1 \\
\hline 46 & 48 & 2796 & Isi & E. Paleoindian & & Vertebrata & Indeterminate & 1 \\
\hline 46 & 49 & 2637 & Isi & E. Paleoindian & & Vertebrata & Indeterminate & 2 \\
\hline 46 & 50 & 2744 & Isi & E. Paleoindian & & Vertebrata & Indeterminate & 3 \\
\hline 47 & 14 & 786 & IIIIa & E. Archaic & & Mammalia (Medium/large) & Indeterminate & 1 \\
\hline 47 & 14 & 786 & ШІа & E. Archaic & & Small/Medium Vertebrata & Long bone & 2 \\
\hline 47 & 14 & 786 & IIIIa & E. Archaic & & Sylvilagus sp. & Ulna & 1 \\
\hline 47 & 14 & 786 & IIIIa & E. Archaic & & Vertebrata & Indeterminate & 2 \\
\hline 47 & 18 & 829 & ШIIIa & E. Archaic & & Mammalia (Small) & Femur & 1 \\
\hline 47 & 18 & 829 & ПIIIa & E. Archaic & & Small/Medium Vertebrata & Long bone & 2 \\
\hline 47 & 18 & 829 & IIIIa & E. Archaic & & Vertebrata & Indeterminate & 11 \\
\hline 47 & 19 & 875 & ШІІа & E. Archaic & & Small/Medium Vertebrata & Long bone & 2 \\
\hline 47 & 19 & 875 & IIIa & E. Archaic & & Vertebrata & Indeterminate & 4 \\
\hline 47 & $20 \mathrm{~A}$ & 878 & II/IIIa & L. Paleo./E. Archaic & & Mammalia (Medium/large) & Indeterminate & 2 \\
\hline 47 & $20 \mathrm{~A}$ & 878 & Ш/IIIa & L. Paleo./E. Archaic & & Vertebrata & Indeterminate & 6 \\
\hline 47 & $20 \mathrm{~B}$ & 898 & IIIIIa & L. Paleo./E. Archaic & & Small/Medium Vertebrata & Long bone & 1 \\
\hline 47 & $20 \mathrm{~B}$ & 898 & II/IIIa & L. Paleo./E. Archaic & & Vertebrata & Indeterminate & 3 \\
\hline 47 & 21 & 903 & II/IIIa & L. Paleo./E. Archaic & & Mammalia (Medium/large) & Indeterminate & 2 \\
\hline 47 & 21 & 903 & II/IIIa & L. Paleo./E. Archaic & & Small/Medium Vertebrata & Long bone & 2 \\
\hline 47 & 21 & 903 & II/IIIa & L. Paleo./E. Archaic & & Vertebrata & Indeterminate & 9 \\
\hline 47 & 22 & 930 & II/IIIa & L. Paleo./E. Archaic & & Mammalia (Micro) & Permanent tooth & 1 \\
\hline 47 & 22 & 930 & II/IIIa & L. Paleo./E. Archaic & & Serpentes & Dorsal vertebra & 1 \\
\hline 47 & 22 & 930 & II/IIIa & L. Paleo./E. Archaic & & Small/Medium Vertebrata & Long bone & 4 \\
\hline 47 & 22 & 930 & II/III & L. Paleo./E. Archaic & & Sylvilagus sp. & Mandible & 1 \\
\hline 47 & 22 & 930 & II/IIIa & L. Paleo./E. Archaic & & Testudinata & Shell fragment & 1 \\
\hline 47 & 22 & 930 & $\mathrm{II} / \mathrm{III} \mathrm{a}$ & L. Paleo./E. Archaic & & Vertebrata & Indeterminate & 6 \\
\hline 47 & 23 & 943 & II/IIIa & L. Paleo./E. Archaic & & Leporidae & Permanent tooth & 1 \\
\hline 47 & 23 & 943 & II/IIIa & L. Paleo./E. Archaic & & Small/Medium Vertebrata & Long bone & 5 \\
\hline 47 & 23 & 943 & II/IIIa & L. Paleo./E. Archaic & & Vertebrata & Indeterminate & 7 \\
\hline 47 & 24 & 964 & II & L. Paleo. & & Osteichthyes (Small) & Vertebra & 1 \\
\hline 47 & 24 & 964 & II & L. Paleo. & & Small vertebrate, class ind. & Vertebra & 1 \\
\hline 47 & 24 & 964 & III & L. Paleo. & & Small/Medium Vertebrata & Indeterminate & 2 \\
\hline 47 & 24 & 964 & II & L. Paleo. & & Vertebrata & Indeterminate & 3 \\
\hline 47 & 25 & 983 & III & L. Paleo. & & Small/Medium Vertebrata & Long bone & 1 \\
\hline 47 & 25 & 983 & III & L. Paleo. & & Vertebrata & Indeterminate & 8 \\
\hline 47 & 26 & 1004 & II & L. Paleo. & & Mammalia (Medium/large) & Indeterminate & 1 \\
\hline 47 & 26 & 1004 & III & L. Paleo. & & Small/Medium Vertebrata & Long bone & 6 \\
\hline 47 & 26 & 1004 & III & L. Paleo. & & Vertebrata & Indeterminate & 12 \\
\hline 47 & 27 & 559 & III & L. Paleo. & & Medium/Large Vertebrata & Indeterminate & 1 \\
\hline 47 & 27 & 559 & III & L. Paleo. & & Small/Medium Vertebrata & Long bone & 1 \\
\hline
\end{tabular}




\begin{tabular}{|c|c|c|c|c|c|c|c|c|}
\hline Square & Level & Lot & Unit & Cultural Affinity & Feature & Taxon & Element & No. \\
\hline 47 & 27 & 559 & III & L. Paleo. & & Vertebrata & Indeterminate & 1 \\
\hline 47 & 28 & 1218 & Isi-c/II & L. Paleo. & & Medium vertebrate, class ind. & Proximal phalange & 1 \\
\hline 47 & 28 & 1218 & Isi-c/II & L. Paleo. & & Small/Medium Vertebrata & Long bone & 2 \\
\hline 47 & 28 & 1218 & Isi-c/II & L. Paleo. & & Vertebrata & Indeterminate & 5 \\
\hline 47 & 29 & 1286 & Isi-c/II & L. Paleo. & & Leporidae & Permanent tooth & 1 \\
\hline 47 & 29 & 1286 & Isi-c/II & L. Paleo. & & Mammalia (Small) & Metacarpal 2 & 1 \\
\hline 47 & 29 & 1286 & Isi-c/II & L. Paleo. & & Medium/Large Vertebrata & Indeterminate & 1 \\
\hline 47 & 29 & 1286 & Isi-c/II & L. Paleo. & & Small/Medium Vertebrata & Long bone & 6 \\
\hline 47 & 29 & 1286 & Isi-c/II & L. Paleo. & & Vertebrata & Indeterminate & 12 \\
\hline 47 & 35 & 1449 & Isi/Isi-c & Paleoindian & & Leporidae & Humerus & 1 \\
\hline 47 & 35 & 1449 & Isi/Isi-c & Paleoindian & & Mammalia (Large) & Indeterminate & 1 \\
\hline 47 & 35 & 1449 & Isi/Isi-c & Paleoindian & & Mammalia (Large) & Middle phalange & 1 \\
\hline 47 & 35 & 1449 & Isi/Isi-c & Paleoindian & & Small/Medium Vertebrata & Long bone & 1 \\
\hline 47 & 35 & 1449 & Isi/Isi-c & Paleoindian & & Vertebrata & Indeterminate & 41 \\
\hline 48 & 17 & 492 & III। & E. Archaic & & Mammalia (Medium/large) & Indeterminate & 1 \\
\hline 48 & 17 & 492 & III & E. Archaic & & Small/Medium Vertebrata & Long bone & 5 \\
\hline 48 & 17 & 492 & IIIIa & E. Archaic & & Vertebrata & Indeterminate & 9 \\
\hline 48 & 18 & 837 & III। & E. Archaic & 231 & Mammalia (Medium/large) & Indeterminate & 1 \\
\hline 48 & 18 & 837 & IIIa & E. Archaic & 231 & Vertebrata & Indeterminate & 2 \\
\hline 48 & 19 & 917 & IIIIa & E. Archaic & 231 & Carnivora & Permanent tooth & 1 \\
\hline 48 & 19 & 917 & IIIa & E. Archaic & 231 & Mammalia (Medium/large) & Indeterminate & 1 \\
\hline 48 & 19 & 917 & III & E. Archaic & 231 & Small/Medium Vertebrata & Long bone & 5 \\
\hline 48 & 19 & 917 & III। & E. Archaic & 231 & Vertebrata & Indeterminate & 5 \\
\hline 48 & 20 & 991 & III & E. Archaic & 231 & Mammalia (Medium) & Radius & 1 \\
\hline 48 & 20 & 991 & ШШа & E. Archaic & 231 & Medium/Large Vertebrata & Indeterminate & 2 \\
\hline 48 & 20 & 991 & IIIIa & E. Archaic & 231 & Small vertebrate, class ind. & Distal phalange & 1 \\
\hline 48 & 20 & 991 & IIIIa & E. Archaic & 231 & Small/Medium Vertebrata & Long bone & 4 \\
\hline 48 & 20 & 991 & IIIIa & E. Archaic & 231 & Vertebrata & Indeterminate & 11 \\
\hline 48 & 21 & 1005 & II/III & L. Paleo./E. Archaic & & Colubridae & Dorsal vertebra & 1 \\
\hline 48 & 21 & 1005 & II/IIIa & L. Paleo./E. Archaic & & Mammalia (Micro) & Permanent tooth & 1 \\
\hline 48 & 21 & 1005 & IIIIIIa & L. Paleo./E. Archaic & & Small/Medium Vertebrata & Long bone & 4 \\
\hline 48 & 21 & 1005 & ІІ/ІІа & L. Paleo./E. Archaic & & Vertebrata & Indeterminate & 18 \\
\hline 48 & 22 & 1056 & II/IIIa & L. Paleo./E. Archaic & & Mammalia (Small) & Scapula & 1 \\
\hline 48 & 22 & 1056 & IIIIIIa & L. Paleo./E. Archaic & & Medium/Large Vertebrata & Indeterminate & 1 \\
\hline 48 & 22 & 1056 & II/IIIa & L. Paleo./E. Archaic & & Small/Medium Vertebrata & Long bone & 7 \\
\hline 48 & 22 & 1056 & II/IIIa & L. Paleo./E. Archaic & & Vertebrata & Indeterminate & 26 \\
\hline 48 & 23 & 1095 & IIIIIIa & L. Paleo./E. Archaic & & Mammalia (Medium/large) & Indeterminate & 25 \\
\hline 48 & 23 & 1095 & II/IIIa & L. Paleo./E. Archaic & & Small/Medium Vertebrata & Long bone & 2 \\
\hline 48 & 23 & 1095 & III/IIIa & L. Paleo./E. Archaic & & Vertebrata & Indeterminate & 5 \\
\hline 48 & 24 & 1137 & II/III & L. Paleo./E. Archaic & & Leporidae & Permanent tooth & 1 \\
\hline 48 & 24 & 1137 & II/IIIa & L. Paleo./E. Archaic & & Mammalia (Medium) & Phalange & 1 \\
\hline 48 & 24 & 1137 & II/IIIa & L. Paleo./E. Archaic & & Mammalia (Medium/large) & Long bone & 2 \\
\hline 48 & 24 & 1137 & II/IIIa & L. Paleo./E. Archaic & & Small/Medium Vertebrata & Long bone & 6 \\
\hline 48 & 24 & 1137 & II/IIIa & L. Paleo./E. Archaic & & Testudinata & Shell fragment & 1 \\
\hline 48 & 24 & 1137 & II/IIIa & L. Paleo./E. Archaic & & Vertebrata & Indeterminate & 8 \\
\hline 48 & 25 & 1157 & II/IIIa & L. Paleo./E. Archaic & & Leporidae & Permanent tooth & 1 \\
\hline 48 & 25 & 1157 & IIIIIa & L. Paleo./E. Archaic & & Serpentes & Dorsal vertebra & 1 \\
\hline 48 & 25 & 1157 & II/IIIa & L. Paleo./E. Archaic & & Small/Medium Vertebrata & Long bone & 1 \\
\hline 48 & 25 & 1157 & II/IIIa & L. Paleo./E. Archaic & & Vertebrata & Indeterminate & 8 \\
\hline 48 & 26 & 1166 & Ш/IIIa & L. Paleo./E. Archaic & & Leporidae & Calcaneus & 1 \\
\hline 48 & 26 & 1166 & II/IIIa & L. Paleo./E. Archaic & & Vertebrata & Indeterminate & 3 \\
\hline 48 & 27 & 1062 & III & L. Paleo. & & Vertebrata & Indeterminate & 2 \\
\hline 48 & 28 & 1208 & III & L. Paleo. & & Geomys sp. & Permanent tooth & 1 \\
\hline 48 & 28 & 1208 & III & L. Paleo. & & Small/Medium Vertebrata & Long bone & 2 \\
\hline 48 & 28 & 1208 & III & L. Paleo. & & Vertebrata & Indeterminate & 14 \\
\hline 48 & 29 & 1264 & III & L. Paleo. & 236 & Small/Medium Vertebrata & Long bone & 4 \\
\hline 48 & 29 & 1264 & III & L. Paleo. & 236 & Vertebrata & Indeterminate & 7 \\
\hline 48 & $30 \mathrm{~A}$ & 1303 & III & L. Paleo. & & Vertebrata & Indeterminate & 2 \\
\hline 48 & $31 \mathrm{~A}$ & 1390 & Id/II & L. Paleo. & & Colubridae & Dorsal vertebra & 1 \\
\hline 48 & $31 \mathrm{~A}$ & 1390 & $\mathrm{Id} / \mathrm{II}$ & L. Paleo. & & Vertebrata & Indeterminate & 19 \\
\hline 49 & 17 & 761 & IIIIa & E. Archaic & & Colubridae & Dorsal vertebra & 1 \\
\hline 49 & 17 & 761 & IIIIa & E. Archaic & & Mammalia (Small) & Proximal phalange & 1 \\
\hline 49 & 17 & 761 & |IIIa & E. Archaic & & Vertebrata & Indeterminate & 5 \\
\hline 49 & 18 & 815 & |IIIa & E. Archaic & & Vertebrata & Indeterminate & 6 \\
\hline 49 & 19 & 864 & IIIIa & E. Archaic & 231 & Leporidae & Metacarpal 2 & 1 \\
\hline 49 & 19 & 864 & IIIIa & E. Archaic & 231 & Mammalia (Medium/large) & Indeterminate & 1 \\
\hline 49 & 19 & 864 & IIIIa & E. Archaic & 231 & Small vertebrate, class ind. & Ulna & 1 \\
\hline
\end{tabular}




\begin{tabular}{|c|c|c|c|c|c|c|c|c|}
\hline Square & Level & Lot & Unit & Cultural Affinity & Feature & Taxon & Element & No. \\
\hline 49 & 19 & 864 & IIIa & E. Archaic & 231 & Small/Medium Vertebrata & Long bone & 2 \\
\hline 49 & 19 & 864 & IIIa & E. Archaic & 231 & Vertebrata & Indeterminate & 20 \\
\hline 49 & 20 & 1021 & |IIIa & E. Archaic & 231 & Mammalia (Medium) & Permanent tooth & 1 \\
\hline 49 & 20 & 1021 & IIIIa & E. Archaic & 231 & Mammalia (Medium/large) & Indeterminate & 1 \\
\hline 49 & 20 & 1021 & IIIa & E. Archaic & 231 & Medium/Large Vertebrata & Long bone & 1 \\
\hline 49 & 20 & 1021 & IIIa & E. Archaic & 231 & Small/Medium Vertebrata & Long bone & 4 \\
\hline 49 & 20 & 1021 & IIIIa & E. Archaic & 231 & Vertebrata & Indeterminate & 9 \\
\hline 49 & 21 & 1132 & IIIa & E. Archaic & 231 & Mammalia (Medium/large) & Long bone & 4 \\
\hline 49 & 21 & 1132 & Шाँ & E. Archaic & 231 & Small/Medium Vertebrata & Long bone & 2 \\
\hline 49 & 21 & 1132 & IIIIa & E. Archaic & 231 & Vertebrata & Indeterminate & 9 \\
\hline 49 & 22 & 1143 & II/IIIa & L. Paleo./E. Archaic & 231 & Colubridae & Dorsal vertebra & 1 \\
\hline 49 & 22 & 1143 & Шा/ाа & L. Paleo./E. Archaic & 231 & Mammalia (Medium) & Permanent tooth & 1 \\
\hline 49 & 22 & 1143 & II/IIIa & L. Paleo./E. Archaic & 231 & Mammalia (Medium/large) & Indeterminate & 1 \\
\hline 49 & 22 & 1143 & II/IIIa & L. Paleo./E. Archaic & 231 & Mammalia (Medium/large) & Tooth, perm./decid. ind. & 1 \\
\hline 49 & 22 & 1143 & Шा/Ша & L. Paleo./E. Archaic & 231 & Mammalia (Small) & Ulna & 1 \\
\hline 49 & 22 & 1143 & II/IIIIa & L. Paleo./E. Archaic & 231 & Medium/Large Vertebrata & Indeterminate & 4 \\
\hline 49 & 22 & 1143 & Ш/Ша & L. Paleo./E. Archaic & 231 & Small/Medium Vertebrata & Long bone & 7 \\
\hline 49 & 22 & 1143 & ПI/ШІа & L. Paleo./E. Archaic & 231 & Vertebrata & Indeterminate & 28 \\
\hline 49 & 23 & 1221 & II/IIIa & L. Paleo./E. Archaic & 231 & Small/Medium Vertebrata & Long bone & 14 \\
\hline 49 & 23 & 1221 & ШІІІШа & L. Paleo./E. Archaic & 231 & Sylvilagus sp. & Radius & 1 \\
\hline 49 & 23 & 1221 & III/IIa & L. Paleo./E. Archaic & 231 & Vertebrata & Indeterminate & 16 \\
\hline 49 & 24 & 1278 & II/IIIa & L. Paleo./E. Archaic & 231 & Anura & Humerus & 1 \\
\hline 49 & 24 & 1278 & ШІ/Шаa & L. Paleo./E. Archaic & 231 & Mammalia (Medium) & Long bone & 2 \\
\hline 49 & 24 & 1278 & Шा/Ша & L. Paleo./E. Archaic & 231 & Mammalia (Medium/large) & Indeterminate & 1 \\
\hline 49 & 24 & 1278 & II/IIIa & L. Paleo./E. Archaic & 231 & Vertebrata & Indeterminate & 15 \\
\hline 49 & 25 & 2175 & Шा/Ша & L. Paleo./E. Archaic & & Mammalia (Small) & Proximal phalange & 2 \\
\hline 49 & 25 & 2175 & III/IIIa & L. Paleo./E. Archaic & & Mammalia (Small) & Radius & 1 \\
\hline 49 & 25 & 2175 & II/IIIa & L. Paleo./E. Archaic & & Small/Medium Vertebrata & Long bone & 6 \\
\hline 49 & 25 & 2175 & Ш/Ша & L. Paleo./E. Archaic & & Vertebrata & Indeterminate & 12 \\
\hline 49 & 26 & 1071 & III & L. Paleo. & & Small/Medium Vertebrata & Long bone & 7 \\
\hline 49 & 26 & 1071 & III & L. Paleo. & & Vertebrata & Indeterminate & 17 \\
\hline 49 & 27 & 1427 & III & L. Paleo. & & Mammalia (Medium/large) & Indeterminate & 2 \\
\hline 49 & 27 & 1427 & III & L. Paleo. & & Small/Medium Vertebrata & Long bone & 8 \\
\hline 49 & 27 & 1427 & III & L. Paleo. & & Vertebrata & Indeterminate & 15 \\
\hline 49 & 28 & 1472 & III & L. Paleo. & & Small/Medium Vertebrata & Long bone & 8 \\
\hline 49 & 28 & 1472 & III & L. Paleo. & & Sylvilagus sp. & Ulna & 1 \\
\hline 49 & 28 & 1472 & III & L. Paleo. & & Vertebrata & Indeterminate & 22 \\
\hline 49 & 29 & 1503 & III & L. Paleo. & & Small/Medium Vertebrata & Long bone & 6 \\
\hline 49 & 29 & 1503 & III & L. Paleo. & & Vertebrata & Indeterminate & 3 \\
\hline 49 & 30 & 1591 & III & L. Paleo. & & Small/Medium Vertebrata & Long bone & 1 \\
\hline 49 & 30 & 1591 & III & L. Paleo. & & Vertebrata & Indeterminate & 2 \\
\hline 49 & $32 \mathrm{~A}$ & 1785 & IId/II & L. Paleo. & & Mammalia (Small) & Proximal phalange & 1 \\
\hline 49 & $32 \mathrm{~A}$ & 1785 & Id/II & L. Paleo. & & Small/Medium Vertebrata & Long bone & 5 \\
\hline 49 & $32 \mathrm{~A}$ & 1785 & IId/II & L. Paleo. & & Sylvilagus sp. & Fourth tarsal & 1 \\
\hline 49 & $32 \mathrm{~A}$ & 1785 & Id/II & L. Paleo. & & Vertebrata & Indeterminate & 28 \\
\hline 50 & 16 & 812 & Ша & E. Archaic & & Vertebrata & Indeterminate & 4 \\
\hline 50 & 17 & 854 & IIIa & E. Archaic & & Vertebrata & Indeterminate & 3 \\
\hline 50 & 19 & 920 & IIIIa & E. Archaic & & Geomys sp. & Permanent tooth & 1 \\
\hline 50 & 19 & 920 & ШШа & E. Archaic & & Small vertebrate, class ind. & Proximal phalange & 1 \\
\hline 50 & 19 & 920 & IIIa & E. Archaic & & Small/Medium Vertebrata & Long bone & 3 \\
\hline 50 & 19 & 920 & IIIIa & E. Archaic & & Vertebrata & Indeterminate & 21 \\
\hline 50 & 20 & 965 & III & E. Archaic & 231 & Small/Medium Vertebrata & Long bone & 3 \\
\hline 50 & 20 & 965 & III' & E. Archaic & 231 & Vertebrata & Indeterminate & 4 \\
\hline 50 & 21 & 1088 & IIIIa & E. Archaic & 231 & Medium/Large Vertebrata & Indeterminate & 1 \\
\hline 50 & 21 & 1088 & IIIa & E. Archaic & 231 & Small/Medium Vertebrata & Long bone & 5 \\
\hline 50 & 21 & 1088 & ШШа & E. Archaic & 231 & Vertebrata & Indeterminate & 6 \\
\hline 50 & 22 & 1072 & IIIIa & E. Archaic & 231 & Small/Medium Vertebrata & Long bone & 3 \\
\hline 50 & 22 & 1072 & IIII & E. Archaic & 231 & Vertebrata & Indeterminate & 14 \\
\hline 50 & 23 & 1343 & ШШа & E. Archaic & 231 & Mammalia (Large) & Tooth, perm./decid. ind. & 1 \\
\hline 50 & 23 & 1343 & IIIIa & E. Archaic & 231 & Vertebrata & Indeterminate & 8 \\
\hline 50 & $24 \mathrm{~A}$ & 1596 & II/IIIa & L. Paleo./E. Archaic & & Mammalia (Medium) & Long bone & 1 \\
\hline 50 & $24 \mathrm{~A}$ & 1596 & II/Шаa & L. Paleo./E. Archaic & & Mammalia (Medium/large) & Long bone & 1 \\
\hline 50 & $24 \mathrm{~A}$ & 1596 & II/IIIa & L. Paleo./E. Archaic & & Mammalia (Small) & Caudal vertebra & 1 \\
\hline 50 & $24 \mathrm{~A}$ & 1596 & II/IIIa & L. Paleo./E. Archaic & & Testudinata & Peripheral & 1 \\
\hline 50 & $24 \mathrm{~A}$ & 1596 & II/IIIa & L. Paleo./E. Archaic & & Vertebrata & Indeterminate & 10 \\
\hline 50 & 24B & 1589 & II/IIIa & L. Paleo./E. Archaic & $181 / 231$ & Medium/Large Vertebrata & Indeterminate & 3 \\
\hline 50 & $24 \mathrm{~B}$ & 1589 & II/IIIIa & L. Paleo./E. Archaic & $181 / 231$ & Vertebrata & Indeterminate & 4 \\
\hline
\end{tabular}




\begin{tabular}{|c|c|c|c|c|c|c|c|c|}
\hline Square & Level & Lot & Unit & Cultural Affinity & Feature & Taxon & Element & No. \\
\hline 50 & $25 \mathrm{~A}$ & 1670 & II/IIIa & L. Paleo./E. Archaic & & Mammalia (Medium) & Cranium & 1 \\
\hline 50 & $25 \mathrm{~A}$ & 1670 & II/IIIa & L. Paleo./E. Archaic & & Mammalia (Medium/large) & Indeterminate & 1 \\
\hline 50 & $25 \mathrm{~A}$ & 1670 & IIIIIIa & L. Paleo./E. Archaic & & Small/Medium Vertebrata & Long bone & 6 \\
\hline 50 & $25 \mathrm{~A}$ & 1670 & III/IIIa & L. Paleo./E. Archaic & & Vertebrata & Indeterminate & 12 \\
\hline 50 & $25 \mathrm{~B}$ & 1671 & II/IIIa & L. Paleo./E. Archaic & $181 / 231$ & Mammalia (Large) & Indeterminate & 1 \\
\hline 50 & $25 \mathrm{~B}$ & 1671 & II/IIIa & L. Paleo./E. Archaic & $181 / 231$ & Small/Medium Vertebrata & Long bone & 1 \\
\hline 50 & $25 \mathrm{~B}$ & 1671 & III/IIIa & L. Paleo./E. Archaic & $181 / 231$ & Vertebrata & Indeterminate & 1 \\
\hline 50 & $26 \mathrm{~A}$ & 1701 & IIIIIIa & L. Paleo./E. Archaic & & Geomys sp. & Permanent tooth & 1 \\
\hline 50 & $26 \mathrm{~A}$ & 1701 & II/IIIa & L. Paleo./E. Archaic & & Osteichthyes (Small) & Vertebra & 1 \\
\hline 50 & $26 \mathrm{~A}$ & 1701 & II/IIIa & L. Paleo./E. Archaic & & Small/Medium Vertebrata & Long bone & 6 \\
\hline 50 & $26 \mathrm{~A}$ & 1701 & II/IIIa & L. Paleo./E. Archaic & & Vertebrata & Indeterminate & 16 \\
\hline 50 & $26 \mathrm{~B}$ & 1676 & IIIIIIa & L. Paleo./E. Archaic & $181 / 231$ & Mammalia (Medium/large) & Long bone & 1 \\
\hline 50 & $26 \mathrm{~B}$ & 1676 & III/IIIa & L. Paleo./E. Archaic & $181 / 231$ & Small/Medium Vertebrata & Long bone & 3 \\
\hline 50 & $26 \mathrm{~B}$ & 1676 & IIIIIIa & L. Paleo./E. Archaic & $181 / 231$ & Vertebrata & Indeterminate & 4 \\
\hline 50 & $27 \mathrm{~A}$ & 1745 & III & L. Paleo. & & Geomys sp. & Permanent tooth & 1 \\
\hline 50 & $27 \mathrm{~A}$ & 1745 & III & L. Paleo. & & Small/Medium Vertebrata & Long bone & 7 \\
\hline 50 & $27 \mathrm{~A}$ & 1745 & III & L. Paleo. & & Sylvilagus sp. & Permanent tooth & 1 \\
\hline 50 & $27 \mathrm{~A}$ & 1745 & III & L. Paleo. & & Testudinata & Neural & 1 \\
\hline 50 & $27 \mathrm{~A}$ & 1745 & III & L. Paleo. & & Vertebrata & Indeterminate & 21 \\
\hline 50 & 27B & 1705 & III & L. Paleo. & & Colubridae & Dorsal vertebra & 1 \\
\hline 50 & $27 \mathrm{~B}$ & 1705 & III & L. Paleo. & & Mammalia (Medium/large) & Indeterminate & 1 \\
\hline 50 & 27B & 1705 & III & L. Paleo. & & Vertebrata & Indeterminate & 11 \\
\hline 50 & $27 \mathrm{C}$ & 1706 & III & L. Paleo. & $184 / 260$ & Small/Medium Vertebrata & Long bone & 6 \\
\hline 50 & $27 \mathrm{C}$ & 1706 & III & L. Paleo. & $184 / 260$ & Vertebrata & Indeterminate & 12 \\
\hline 50 & 28 & 1630 & III & L. Paleo. & & Mammalia (Small) & Caudal vertebra & 1 \\
\hline 50 & 28 & 1630 & III & L. Paleo. & & Small/Medium Vertebrata & Long bone & 9 \\
\hline 50 & 28 & 1630 & III & L. Paleo. & & Sylvilagus sp. & Calcaneus & 1 \\
\hline 50 & 28 & 1630 & III & L. Paleo. & & Vertebrata & Indeterminate & 8 \\
\hline 50 & 29 & 1803 & III & L. Paleo. & & Medium vertebrate, class ind. & Phalange & 1 \\
\hline 50 & 29 & 1803 & III & L. Paleo. & & Small/Medium Vertebrata & Long bone & 4 \\
\hline 50 & 29 & 1803 & III & L. Paleo. & & Vertebrata & Indeterminate & 12 \\
\hline 50 & $30 \mathrm{~A}$ & 1827 & III & L. Paleo. & & Leporidae & Permanent tooth & 1 \\
\hline 50 & $30 \mathrm{~A}$ & 1827 & III & L. Paleo. & & Mammalia (Medium/large) & Indeterminate & 1 \\
\hline 50 & $30 \mathrm{~A}$ & 1827 & III & L. Paleo. & & Vertebrata & Indeterminate & 21 \\
\hline 50 & 30B & 1825 & III & L. Paleo. & 249 & Small/Medium Vertebrata & Long bone & 1 \\
\hline 50 & $31 \mathrm{~A}$ & 1853 & III & L. Paleo. & & Mammalia (Medium) & Femur & 1 \\
\hline 50 & $31 \mathrm{~A}$ & 1853 & III & L. Paleo. & & Small/Medium Vertebrata & Long bone & 3 \\
\hline 50 & $31 \mathrm{~A}$ & 1853 & II & L. Paleo. & & Vertebrata & Indeterminate & 8 \\
\hline 50 & 31B & 1852 & III & L. Paleo. & 249 & Vertebrata & Indeterminate & 1 \\
\hline 50 & $32 \mathrm{~A}$ & 1896 & II & L. Paleo. & & Medium/Large Vertebrata & Indeterminate & 2 \\
\hline 50 & $32 \mathrm{~A}$ & 1896 & II & L. Paleo. & & Small/Medium Vertebrata & Long bone & 6 \\
\hline 50 & $32 \mathrm{~A}$ & 1896 & II & L. Paleo. & & Vertebrata & Indeterminate & 13 \\
\hline 50 & $32 \mathrm{~B}$ & 1877 & III & L. Paleo. & 249 & Osteichthyes (Small) & Vertebra & 1 \\
\hline 50 & $32 \mathrm{~B}$ & 1877 & III & L. Paleo. & 249 & Small/Medium Vertebrata & Long bone & 6 \\
\hline 50 & $32 \mathrm{~B}$ & 1877 & III & L. Paleo. & 249 & Testudinata & Humerus & 1 \\
\hline 50 & $32 \mathrm{~B}$ & 1877 & II & L. Paleo. & 249 & Vertebrata & Indeterminate & 8 \\
\hline 51 & 16 & 797 & IIIa/b & E. Archaic & & Mammalia (Medium) & Alveolar ridge fragment & 1 \\
\hline 51 & 16 & 797 & IIIa/b & E. Archaic & & Mammalia (Medium) & Permanent tooth & 1 \\
\hline 51 & 16 & 797 & ШIIa/b & E. Archaic & & Mammalia (Medium/large) & Indeterminate & 2 \\
\hline 51 & 16 & 797 & IIIa/b & E. Archaic & & Mammalia (Small) & Caudal vertebra & 1 \\
\hline 51 & 17 & 832 & IIIIa & E. Archaic & & Vertebrata & Indeterminate & 12 \\
\hline 51 & 19 & 942 & IIIIa & E. Archaic & & Antilocapra/Odocoileus & Proximal phalange & 1 \\
\hline 51 & 19 & 942 & IIIa & E. Archaic & & Mammalia (Micro) & Tibia & 1 \\
\hline 51 & 19 & 942 & IIIIa & E. Archaic & & Medium/Large Vertebrata & Indeterminate & 1 \\
\hline 51 & 19 & 942 & IIIIa & E. Archaic & & Small/Medium Vertebrata & Long bone & 4 \\
\hline 51 & 19 & 942 & IIIa & E. Archaic & & Vertebrata & Indeterminate & 13 \\
\hline 51 & 20 & 1049 & IIIa & E. Archaic & 231 & Mammalia (Medium/large) & Indeterminate & 4 \\
\hline 51 & 20 & 1049 & IIIIa & E. Archaic & 231 & Vertebrata & Indeterminate & 4 \\
\hline 51 & 21 & 1160 & ШШа & E. Archaic & $181 / 231$ & Leporidae & Permanent tooth & 1 \\
\hline 51 & 21 & 1160 & IIIa & E. Archaic & $181 / 231$ & Small/Medium Vertebrata & Long bone & 4 \\
\hline 51 & 21 & 1160 & IIIIa & E. Archaic & $181 / 231$ & Vertebrata & Indeterminate & 6 \\
\hline 51 & 22 & 1034 & IIIIa & E. Archaic & $181 / 231$ & Vertebrata & Indeterminate & 4 \\
\hline 51 & 24 & 1930 & IIIa & E. Archaic & $181 / 231$ & Vertebrata & Indeterminate & 6 \\
\hline 51 & 26 & 1971 & ПIIIIa & L. Paleo./E. Archaic & 231 & Small/Medium Vertebrata & Long bone & 1 \\
\hline 51 & 26 & 1971 & II/IIIa & L. Paleo./E. Archaic & 231 & Vertebrata & Indeterminate & 2 \\
\hline 51 & $27 \mathrm{~A}$ & 2006 & IIIIIa & L. Paleo./E. Archaic & & Rodentia (Small) & Permanent tooth & 1 \\
\hline 51 & $27 \mathrm{~A}$ & 2006 & Ш/Ша & L. Paleo./E. Archaic & & Small/Medium Vertebrata & Long bone & 1 \\
\hline
\end{tabular}




\begin{tabular}{|c|c|c|c|c|c|c|c|c|}
\hline Square & Level & Lot & Unit & Cultural Affinity & Feature & Taxon & Element & No. \\
\hline 51 & $27 \mathrm{~A}$ & 2006 & II/IIIa & L. Paleo./E. Archaic & & Vertebrata & Indeterminate & 3 \\
\hline 51 & $27 \mathrm{~A}$ & 2762 & II/IIIa & L. Paleo./E. Archaic & & Small/Medium Vertebrata & Long bone & 3 \\
\hline 51 & $27 \mathrm{~A}$ & 2762 & II/IIIa & L. Paleo./E. Archaic & & Vertebrata & Indeterminate & 6 \\
\hline 51 & $27 \mathrm{~B}$ & 2007 & IIIIIa & L. Paleo./E. Archaic & 249 & Mammalia (Medium/large) & Indeterminate & 1 \\
\hline 51 & $27 \mathrm{~B}$ & 2007 & II/IIIa & L. Paleo./E. Archaic & 249 & Vertebrata & Indeterminate & 4 \\
\hline 51 & $28 \mathrm{~A}$ & 2026 & $\Pi / \amalg \mathrm{II}$ & L. Paleo./E. Archaic & & Small/Medium Vertebrata & Long bone & 2 \\
\hline 51 & $28 \mathrm{~A}$ & 2026 & II/IIIa & L. Paleo./E. Archaic & & Vertebrata & Indeterminate & 1 \\
\hline 51 & $28 \mathrm{~B}$ & 2034 & II/IIIa & L. Paleo./E. Archaic & 249 & Vertebrata & Indeterminate & 1 \\
\hline 51 & $28 \mathrm{D}$ & 2499 & Шा/Iа & L. Paleo./E. Archaic & 249 & Carnivora & Distal phalange & 1 \\
\hline 51 & $28 \mathrm{E}$ & 2581 & IIIIIa & L. Paleo./E. Archaic & & Small/Medium Vertebrata & Long bone & 3 \\
\hline 51 & $29 \mathrm{~A}$ & 2062 & II/IIIa & L. Paleo./E. Archaic & & Mammalia (Medium/large) & Tooth, perm./decid. ind. & 1 \\
\hline 51 & $30 \mathrm{~A}$ & 2063 & II/IIIa & L. Paleo./E. Archaic & & Small/Medium Vertebrata & Long bone & 2 \\
\hline 51 & $30 \mathrm{~B}$ & 2064 & Ш/Шаa & L. Paleo./E. Archaic & 249 & Artiodactyla & Permanent tooth & 1 \\
\hline 51 & $30 \mathrm{~B}$ & 2064 & II/IIIIa & L. Paleo./E. Archaic & 249 & Small/Medium Vertebrata & Long bone & 1 \\
\hline 51 & $30 \mathrm{~B}$ & 2064 & II/IIIIa & L. Paleo./E. Archaic & 249 & Vertebrata & Indeterminate & 3 \\
\hline 51 & $31 \mathrm{~A}$ & 2069 & II & L. Paleo. & & Mammalia (Medium/large) & Long bone & 1 \\
\hline 51 & $31 \mathrm{~A}$ & 2078 & III & L. Paleo. & & Small/Medium Vertebrata & Long bone & 2 \\
\hline 51 & $31 \mathrm{~A}$ & 2078 & III & L. Paleo. & & Vertebrata & Indeterminate & 2 \\
\hline 51 & $31 \mathrm{~B}$ & 2079 & III & L. Paleo. & 249 & Sylvilagus sp. & Permanent tooth & 1 \\
\hline 51 & $31 \mathrm{~B}$ & 2079 & III & L. Paleo. & 249 & Vertebrata & Indeterminate & 4 \\
\hline 52 & $15 \mathrm{~A}$ & 711 & IIIa/b & E. Archaic & & Colubridae & Dorsal vertebra & 1 \\
\hline 52 & $15 \mathrm{~A}$ & 711 & IIIa/b & E. Archaic & & Geomys sp. & Permanent tooth & 1 \\
\hline 52 & $15 \mathrm{~A}$ & 711 & IIIa/b & E. Archaic & & Mammalia (Medium/large) & Indeterminate & 5 \\
\hline 52 & $15 \mathrm{~A}$ & 711 & IIIa/b & E. Archaic & & Mammalia (Small) & Proximal phalange & 1 \\
\hline 52 & $15 \mathrm{~A}$ & 711 & IIIa/b & E. Archaic & & Medium/Large Vertebrata & Indeterminate & 1 \\
\hline 52 & $15 \mathrm{~A}$ & 711 & IIIa/b & E. Archaic & & Small/Medium Vertebrata & Long bone & 6 \\
\hline 52 & $15 \mathrm{~A}$ & 711 & IIIa/b & E. Archaic & & Vertebrata & Indeterminate & 17 \\
\hline 52 & 15B & 138 & IIIa/b & E. Archaic & 220 & Small/Medium Vertebrata & Long bone & 1 \\
\hline 52 & 15B & 138 & IIIa/b & E. Archaic & 220 & Vertebrata & Indeterminate & 1 \\
\hline 52 & 15B & 774 & ШIIa/b & E. Archaic & 220 & Vertebrata & Indeterminate & 2 \\
\hline 52 & $16 \mathrm{~A}$ & 746 & IIIa/b & E. Archaic & & Mammalia (Medium/large) & Indeterminate & 4 \\
\hline 52 & $16 \mathrm{~A}$ & 746 & IIIa/b & E. Archaic & & Medium/Large Vertebrata & Long bone & 2 \\
\hline 52 & $16 \mathrm{~A}$ & 746 & IIIa/b & E. Archaic & & Vertebrata & Indeterminate & 9 \\
\hline 52 & $16 \mathrm{~A}$ & 770 & IIIa/b & E. Archaic & & Odocoileus sp. & Astragalus & 1 \\
\hline 52 & $16 \mathrm{~B}$ & 139 & IIIa/b & E. Archaic & 220 & Sylvilagus sp. & Astragalus & 1 \\
\hline 52 & $16 \mathrm{~B}$ & 139 & IIIa/b & E. Archaic & 220 & Vertebrata & Indeterminate & 1 \\
\hline 52 & 17 & 807 & IIIa/b & E. Archaic & & Small/Medium Vertebrata & Long bone & 2 \\
\hline 52 & 17 & 807 & IIIa/b & E. Archaic & & Vertebrata & Indeterminate & 7 \\
\hline 52 & 19 & 850 & IIIa & E. Archaic & & Testudinata & Shell fragment & 1 \\
\hline 52 & 19 & 850 & IIIa & E. Archaic & & Vertebrata & Indeterminate & 4 \\
\hline 52 & 20 & 877 & IIIIa & E. Archaic & 231 & Medium vertebrate, class ind. & Indeterminate & 1 \\
\hline 52 & 20 & 877 & Ша & E. Archaic & 231 & Small/Medium Vertebrata & Long bone & 1 \\
\hline 52 & 20 & 877 & IIIa & E. Archaic & 231 & Vertebrata & Indeterminate & 36 \\
\hline 52 & 21 & 910 & IIIIa & E. Archaic & 231 & Medium/Large Vertebrata & Indeterminate & 3 \\
\hline 52 & 21 & 910 & IIIa & E. Archaic & 231 & Small/Medium Vertebrata & Long bone & 2 \\
\hline 52 & 21 & 910 & IIIa & E. Archaic & 231 & Testudinata & Shell fragment & 1 \\
\hline 52 & 21 & 910 & IIIa & E. Archaic & 231 & Vertebrata & Indeterminate & 25 \\
\hline 52 & 22 & 950 & ШІа & E. Archaic & 231 & Leporidae & Permanent tooth & 1 \\
\hline 52 & 22 & 950 & IIIIa & E. Archaic & 231 & Mammalia (Medium/large) & Tooth, perm./decid. ind. & 1 \\
\hline 52 & 22 & 950 & IIIa & E. Archaic & 231 & Medium/Large Vertebrata & Indeterminate & 3 \\
\hline 52 & 22 & 950 & ШІа & E. Archaic & 231 & Small/Medium Vertebrata & Long bone & 5 \\
\hline 52 & 22 & 950 & IIIIa & E. Archaic & 231 & Vertebrata & Indeterminate & 34 \\
\hline 52 & 23 & 1098 & IIIa & E. Archaic & 231 & Geomys sp. & Tibia & 1 \\
\hline 52 & 23 & 1098 & ШІІа & E. Archaic & 231 & Lepus californicus & Calcaneus & 1 \\
\hline 52 & 23 & 1098 & IIIa & E. Archaic & 231 & Mammalia (Medium) & Metapodial & 1 \\
\hline 52 & 23 & 1098 & IIIIa & E. Archaic & 231 & Mammalia (Medium) & Middle phalange & 1 \\
\hline 52 & 23 & 1098 & IIIa & E. Archaic & 231 & Mammalia (Medium/large) & Indeterminate & 2 \\
\hline 52 & 23 & 1098 & IIIa & E. Archaic & 231 & Medium/Large Vertebrata & Long bone & 2 \\
\hline 52 & 23 & 1098 & IIIIa & E. Archaic & 231 & Small/Medium Vertebrata & Long bone & 8 \\
\hline 52 & 23 & 1098 & IIIa & E. Archaic & 231 & Testudinata & Shell fragment & 1 \\
\hline 52 & 23 & 1098 & IIIa & E. Archaic & 231 & Vertebrata & Indeterminate & 50 \\
\hline 52 & 24 & 1462 & II/IIIa & L. Paleo./E. Archaic & 245 & Medium/Large Vertebrata & Indeterminate & 1 \\
\hline 52 & 24 & 1462 & Ш/ШІІа & L. Paleo./E. Archaic & 245 & Osteichthyes (Small) & Spine & 1 \\
\hline 52 & 24 & 1462 & Ш/ШІа & L. Paleo./E. Archaic & 245 & Small/Medium Vertebrata & Long bone & 3 \\
\hline 52 & 24 & 1464 & II/IIIa & L. Paleo./E. Archaic & $231 / 245$ & Mammalia (Small) & Metapodial & 1 \\
\hline 52 & 24 & 1464 & II/IIIa & L. Paleo./E. Archaic & $231 / 245$ & Small/Medium Vertebrata & Long bone & 5 \\
\hline 52 & 24 & 1464 & П/Ша & L. Paleo./E. Archaic & $231 / 245$ & Vertebrata & Indeterminate & 9 \\
\hline
\end{tabular}




\begin{tabular}{|c|c|c|c|c|c|c|c|c|}
\hline Square & Level & Lot & Unit & Cultural Affinity & Feature & Taxon & Element & No. \\
\hline 52 & 24 & 1648 & II/IIIa & L. Paleo./E. Archaic & $231 / 245$ & Mammalia (Medium/large) & Indeterminate & 1 \\
\hline 52 & 24 & 1648 & ШІ/III & L. Paleo./E. Archaic & $231 / 245 \mid$ & Mammalia (Medium/large) & Tooth, perm./decid. ind. & 1 \\
\hline 52 & 24 & 1648 & II/IIIa & L. Paleo./E. Archaic & $231 / 245 \mid$ & Small/Medium Vertebrata & Long bone & 7 \\
\hline 52 & 24 & 1648 & II/IIIa & L. Paleo./E. Archaic & $231 / 245$ & Vertebrata & Indeterminate & 32 \\
\hline 52 & $25 \mathrm{~A}$ & 1578 & II/IIIa & L. Paleo./E. Archaic & & Small/Medium Vertebrata & Long bone & 3 \\
\hline 52 & $25 \mathrm{~A}$ & 1578 & II/IIIa & L. Paleo./E. Archaic & & Vertebrata & Indeterminate & 6 \\
\hline 52 & 25B & 1744 & ІІ/ШІа & L. Paleo./E. Archaic & $231 / 245$ & Leporidae & Permanent tooth & 1 \\
\hline 52 & $25 \mathrm{~B}$ & 1744 & II/IIIa & L. Paleo./E. Archaic & $|231 / 245|$ & Mammalia (Medium) & Phalange & 1 \\
\hline 52 & 25B & 1744 & III/IIIa & L. Paleo./E. Archaic & $231 / 245$ & Small/Medium Vertebrata & Long bone & 12 \\
\hline 52 & 25B & 1744 & II/IIIa & L. Paleo./E. Archaic & $|231 / 245|$ & Sylvilagus sp. & Permanent tooth & 1 \\
\hline 52 & $25 \mathrm{~B}$ & 1744 & II/ШIIa & L. Paleo./E. Archaic & $231 / 245$ & Testudinata & Carapace fragment ind. & 1 \\
\hline 52 & $25 \mathrm{~B}$ & 1744 & ПI/IIIа & L. Paleo./E. Archaic & $231 / 245$ & Testudinata & Pleural & 1 \\
\hline 52 & $25 \mathrm{~B}$ & 1744 & ШI/IIIa & L. Paleo./E. Archaic & $|231 / 245|$ & Testudinata & Shell fragment & 1 \\
\hline 52 & $25 \mathrm{~B}$ & 1744 & II/IIIa & L. Paleo./E. Archaic & $231 / 245$ & Vertebrata & Indeterminate & 23 \\
\hline 52 & $26 \mathrm{~A}$ & 1678 & ПI/IIIa & L. Paleo./E. Archaic & & Mammalia (Medium/large) & Indeterminate & 1 \\
\hline 52 & $26 \mathrm{~A}$ & 1678 & ШI/IIIa & L. Paleo./E. Archaic & & Mammalia (Medium/large) & Long bone & 1 \\
\hline 52 & $26 \mathrm{~A}$ & 1678 & II/IIIa & L. Paleo./E. Archaic & & Small/Medium Vertebrata & Long bone & 3 \\
\hline 52 & $26 \mathrm{~A}$ & 1678 & ПI/IIIa & L. Paleo./E. Archaic & & Vertebrata & Indeterminate & 5 \\
\hline 52 & $26 \mathrm{~A}$ & 1826 & II/IIIa & L. Paleo./E. Archaic & & Mammalia (Micro) & Humerus & 1 \\
\hline 52 & $26 \mathrm{~A}$ & 1826 & III/IIIa & L. Paleo./E. Archaic & & Mammalia (Small) & Calcaneus & 1 \\
\hline 52 & $26 \mathrm{~A}$ & 1826 & II/IIIa & L. Paleo./E. Archaic & & Mammalia (Small) & Cranium & 1 \\
\hline 52 & $26 \mathrm{~A}$ & 1826 & ШI/IIIa & L. Paleo./E. Archaic & & Mammalia (Small) & Femur & 2 \\
\hline 52 & $26 \mathrm{~A}$ & 1826 & ШІ/ШІа & L. Paleo./E. Archaic & & Medium/Large Vertebrata & |Indeterminate & 1 \\
\hline 52 & $26 \mathrm{~A}$ & 1826 & III/IIIa & L. Paleo./E. Archaic & & Serpentes & Dorsal vertebra & 1 \\
\hline 52 & $26 \mathrm{~A}$ & 1826 & ШI/ШІа & L. Paleo./E. Archaic & & Small/Medium Vertebrata & Long bone & 10 \\
\hline 52 & $26 \mathrm{~A}$ & 1826 & II/IIIa & L. Paleo./E. Archaic & & Sylvilagus sp. & Metatarsal 3 & 1 \\
\hline 52 & $26 \mathrm{~A}$ & 1826 & ПI/IIIа & L. Paleo./E. Archaic & & Vertebrata & Indeterminate & 17 \\
\hline 52 & $26 \mathrm{~B}$ & 1654 & ШI/ШІа & L. Paleo./E. Archaic & 245 & Mammalia (Small) & Calcaneus & 1 \\
\hline 52 & $26 \mathrm{~B}$ & 1654 & ПІШа & L. Paleo./E. Archaic & 245 & Small/Medium Vertebrata & Long bone & 4 \\
\hline 52 & $26 \mathrm{~B}$ & 1831 & ПI/IIIa & L. Paleo./E. Archaic & 231 & Mammalia (Large) & Indeterminate & 1 \\
\hline 52 & $26 \mathrm{~B}$ & 1831 & ШІ/ШІІа & L. Paleo./E. Archaic & 231 & Small/Medium Vertebrata & Long bone & 2 \\
\hline 52 & $26 \mathrm{~B}$ & 1831 & ш/111а & L. Paleo./E. Archaic & 231 & Vertebrata & Indeterminate & 5 \\
\hline 52 & $26 \mathrm{C}$ & 1830 & II/IIIa & L. Paleo./E. Archaic & 245 & Mammalia (Medium/large) & Indeterminate & 1 \\
\hline 52 & $26 \mathrm{C}$ & 1830 & II/ШІа & L. Paleo./E. Archaic & 245 & Medium/Large Vertebrata & Indeterminate & 1 \\
\hline 52 & $26 \mathrm{C}$ & 1830 & II/IIIa & L. Paleo./E. Archaic & 245 & Small/Medium Vertebrata & Long bone & 1 \\
\hline 52 & $26 \mathrm{C}$ & 1830 & ШI/IIIa & L. Paleo./E. Archaic & 245 & Vertebrata & Indeterminate & 1 \\
\hline 52 & 27 & 1684 & II/IIIa & L. Paleo./E. Archaic & & Lepus californicus & Calcaneus & 1 \\
\hline 52 & 27 & 1684 & ШІ/Іа & L. Paleo./E. Archaic & & Mammalia (Small) & Permanent tooth & 1 \\
\hline 52 & 27 & 1684 & II/IIIa & L. Paleo./E. Archaic & & Medium/Large Vertebrata & Indeterminate & 2 \\
\hline 52 & 27 & 1684 & II/IIIa & L. Paleo./E. Archaic & & Medium/Large Vertebrata & Long bone & 2 \\
\hline 52 & 27 & 1684 & ШІШІа & L. Paleo./E. Archaic & & Small/Medium Vertebrata & Long bone & 8 \\
\hline 52 & 27 & 1684 & II/IIIa & L. Paleo./E. Archaic & & Testudinata & Humerus & 1 \\
\hline 52 & 27 & 1684 & II/IIIa & L. Paleo./E. Archaic & & Vertebrata & Indeterminate & 17 \\
\hline 52 & $27 \mathrm{~A}$ & 1878 & ПI/IIIa & L. Paleo./E. Archaic & & Medium/Large Vertebrata & Long bone & 1 \\
\hline 52 & $27 \mathrm{~A}$ & 1878 & II/IIIa & L. Paleo./E. Archaic & & Small/Medium Vertebrata & Long bone & 1 \\
\hline 52 & 28 & 1893 & III & L. Paleo. & & Geomys sp. & Permanent tooth & 1 \\
\hline 52 & 28 & 1893 & II & L. Paleo. & & Leporidae & Permanent tooth & 1 \\
\hline 52 & 28 & 1893 & II & L. Paleo. & & Mammalia (Medium/large) & Indeterminate & 2 \\
\hline 52 & 28 & 1893 & III & L. Paleo. & & Mammalia (Micro) & Permanent tooth & 1 \\
\hline 52 & 28 & 1893 & III & L. Paleo. & & Medium/Large Vertebrata & Indeterminate & 2 \\
\hline 52 & 28 & 1893 & II & L. Paleo. & & Osteichthyes & Vertebra & 1 \\
\hline 52 & 28 & 1893 & III & L. Paleo. & & Small/Medium Vertebrata & Long bone & 13 \\
\hline 52 & 28 & 1893 & III & L. Paleo. & & Vertebrata & Indeterminate & 48 \\
\hline 52 & $28 \mathrm{~A}$ & 1741 & III & L. Paleo. & & Small vertebrate, class ind. & Distal phalange & 1 \\
\hline 52 & $28 \mathrm{~A}$ & 1741 & III & L. Paleo. & & Small/Medium Vertebrata & Long bone & 1 \\
\hline 52 & $28 \mathrm{~A}$ & 1741 & III & L. Paleo. & & Sylvilagus sp. & Permanent tooth & 1 \\
\hline 52 & $28 \mathrm{~A}$ & 1741 & III & L. Paleo. & & Vertebrata & Indeterminate & 24 \\
\hline 52 & $28 \mathrm{~B}$ & 1742 & III & L. Paleo. & 248 & Mammalia (Micro) & Proximal phalange & 1 \\
\hline 52 & $28 \mathrm{~B}$ & 1742 & III & L. Paleo. & 248 & Vertebrata & Indeterminate & 2 \\
\hline 52 & 29 & 2537 & III & L. Paleo. & & Small/Medium Vertebrata & Long bone & 7 \\
\hline 52 & 29 & 2537 & III & L. Paleo. & & Vertebrata & Indeterminate & 16 \\
\hline 52 & $29 \mathrm{~A}$ & 1873 & III & L. Paleo. & & Medium/Large Vertebrata & Indeterminate & 1 \\
\hline 52 & $29 \mathrm{~A}$ & 1873 & III & L. Paleo. & & Small/Medium Vertebrata & Long bone & 2 \\
\hline 52 & $29 \mathrm{~A}$ & 1873 & III & L. Paleo. & & Testudinata & Shell fragment & 1 \\
\hline 52 & $29 \mathrm{~A}$ & 1873 & III & L. Paleo. & & Vertebrata & Indeterminate & 14 \\
\hline 52 & 29B & 1881 & III & L. Paleo. & 248 & Vertebrata & Indeterminate & 4 \\
\hline 52 & 30 & 1984 & III & L. Paleo. & & Mammalia (Medium/large) & Indeterminate & 4 \\
\hline
\end{tabular}




\begin{tabular}{|c|c|c|c|c|c|c|c|c|}
\hline Square & Level & Lot & Unit & Cultural Affinity & Feature & Taxon & Element & No. \\
\hline 52 & 30 & 1984 & III & L. Paleo. & & Mammalia (Small) & Caudal vertebra & 1 \\
\hline 52 & 30 & 1984 & III & L. Paleo. & & Serpentes & Dorsal vertebra & 1 \\
\hline 52 & 30 & 1984 & III & L. Paleo. & & Small/Medium Vertebrata & Long bone & 9 \\
\hline 52 & 30 & 1984 & III & L. Paleo. & & Sylvilagus sp. & Metapodial & 1 \\
\hline 52 & 30 & 1984 & III & L. Paleo. & & Sylvilagus sp. & Ulna & 1 \\
\hline 52 & 30 & 1984 & III & L. Paleo. & & Testudinata & Peripheral & 1 \\
\hline 52 & 30 & 1984 & III & L. Paleo. & & Vertebrata & Indeterminate & 44 \\
\hline 52 & 31 & 2017 & III & L. Paleo. & & Mammalia (Small) & Calcaneus & 1 \\
\hline 52 & 31 & 2017 & III & L. Paleo. & & Medium/Large Vertebrata & Indeterminate & 1 \\
\hline 52 & 31 & 2017 & III & L. Paleo. & & Small vertebrate, class ind. & Phalange & 1 \\
\hline 52 & 31 & 2017 & III & L. Paleo. & & Small/Medium Vertebrata & Long bone & 14 \\
\hline 52 & 31 & 2017 & III & L. Paleo. & & Sylvilagus sp. & Central tarsal bone & 1 \\
\hline 52 & 31 & 2017 & III & L. Paleo. & & Vertebrata & Indeterminate & 28 \\
\hline 52 & 32 & 2039 & III & L. Paleo. & & Lepus californicus & Permanent tooth & 1 \\
\hline 52 & 32 & 2039 & III & L. Paleo. & & Mammalia (Medium/large) & Indeterminate & 3 \\
\hline 52 & 32 & 2039 & III & L. Paleo. & & Mammalia (Medium/large) & Tooth, perm./decid. ind. & 1 \\
\hline 52 & 32 & 2039 & II & L. Paleo. & & Mammalia (Small) & Permanent tooth & 1 \\
\hline 52 & 32 & 2039 & III & L. Paleo. & & Mammalia (Small/medium) & Ulna & 1 \\
\hline 52 & 32 & 2039 & III & L. Paleo. & & Neotoma sp. & Permanent tooth & 1 \\
\hline 52 & 32 & 2039 & III & L. Paleo. & & Small/Medium Vertebrata & Long bone & 17 \\
\hline 52 & 32 & 2039 & III & L. Paleo. & & Sylvilagus sp. & Astragalus & 1 \\
\hline 52 & 32 & 2039 & III & L. Paleo. & & Sylvilagus sp. & Calcaneus & 1 \\
\hline 52 & 32 & 2039 & III & L. Paleo. & & Sylvilagus sp. & Third tarsal & 1 \\
\hline 52 & 32 & 2039 & III & L. Paleo. & & Vertebrata & Indeterminate & 41 \\
\hline 52 & 33 & 2080 & III & L. Paleo. & & Carnivora & Tooth, perm./decid. ind. & 1 \\
\hline 52 & 33 & 2080 & III & L. Paleo. & & Leporidae & Permanent tooth & 2 \\
\hline 52 & 33 & 2080 & III & L. Paleo. & & Lepus californicus & Fused central/fourth tarsal & 1 \\
\hline 52 & 33 & 2080 & III & L. Paleo. & & Mammalia (Medium/large) & Long bone & 1 \\
\hline 52 & 33 & 2080 & II & L. Paleo. & & Mammalia (Medium/large) & Tooth, perm./decid. ind. & 2 \\
\hline 52 & 33 & 2080 & III & L. Paleo. & & Small/Medium Vertebrata & Long bone & 14 \\
\hline 52 & 33 & 2080 & II & L. Paleo. & & Testudinata & Shell fragment & 1 \\
\hline 52 & 33 & 2080 & III & L. Paleo. & & Vertebrata & Indeterminate & 70 \\
\hline 52 & 34 & 2769 & III & L. Paleo. & & Mammalia (Medium/large) & Indeterminate & 3 \\
\hline 52 & 34 & 2769 & III & L. Paleo. & & Mammalia (Medium/large) & Long bone & 3 \\
\hline 52 & 34 & 2769 & II & L. Paleo. & & Mammalia (Small) & Ulna & 1 \\
\hline 52 & 34 & 2769 & II & L. Paleo. & & Small/Medium Vertebrata & Long bone & 8 \\
\hline 52 & 34 & 2769 & II & L. Paleo. & & Vertebrata & Indeterminate & 17 \\
\hline 52 & 35 & 2801 & Id/II & L. Paleo. & & Small/Medium Vertebrata & Long bone & 1 \\
\hline 52 & 35 & 2801 & $\mathrm{Id} / \mathrm{II}$ & L. Paleo. & & Vertebrata & Indeterminate & 3 \\
\hline 52 & 36 & 2613 & Id/II & L. Paleo. & & Mammalia (Medium/large) & Indeterminate & 1 \\
\hline 52 & 36 & 2613 & Id/II & L. Paleo. & & Medium/Large Vertebrata & Indeterminate & 2 \\
\hline 52 & 36 & 2613 & Id/II & L. Paleo. & & Rodentia (Medium) & Permanent tooth & 1 \\
\hline 52 & 36 & 2613 & Id/II & L. Paleo. & & Small/Medium Vertebrata & Long bone & 5 \\
\hline 52 & 36 & 2613 & Id/II & L. Paleo. & & Vertebrata & Indeterminate & 20 \\
\hline 52 & $36 \mathrm{~B}$ & 2138 & Id/II & L. Paleo. & & Vertebrata & Indeterminate & 3 \\
\hline 52 & 37 & 2794 & Isi-c/Id & L. Paleo. & & Mammalia (Medium) & Long bone & 3 \\
\hline 52 & 37 & 2794 & Isi-c/Id & L. Paleo. & & Small/Medium Vertebrata & Long bone & 1 \\
\hline 52 & 37 & 2794 & Isi-c/Id & L. Paleo. & & Vertebrata & Indeterminate & 7 \\
\hline 52 & 38 & 2767 & |Isi-c/Id & L. Paleo. & & Mammalia (Medium/large) & Indeterminate & 5 \\
\hline 52 & 38 & 2767 & Isi-c/Id & L. Paleo. & & Mammalia (Medium/large) & Tooth, perm./decid. ind. & 1 \\
\hline 52 & 38 & 2767 & Isi-c/Id & L. Paleo. & & Small/Medium Vertebrata & Long bone & 3 \\
\hline 52 & 38 & 2767 & Isi-c/Id & L. Paleo. & & Vertebrata & Indeterminate & 17 \\
\hline 52 & 39 & 2207 & Isi-c/Id & L. Paleo. & & Antilocapra/Odocoileus & Phalange & 1 \\
\hline 52 & 39 & 2207 & Isi-c/Id & L. Paleo. & & Mammalia (Medium/large) & Tooth, perm./decid. ind. & 2 \\
\hline 52 & 39 & 2207 & Isi-c/Id & L. Paleo. & & Small/Medium Vertebrata & Long bone & 2 \\
\hline 52 & 39 & 2207 & Isi-c/Id & L. Paleo. & & Testudinata & Shell fragment & 1 \\
\hline 52 & 39 & 2207 & Isi-c/Id & L. Paleo. & & Vertebrata & Indeterminate & 20 \\
\hline 52 & 40 & 2638 & Isi-c & L. Paleo. & & Lepus californicus & Permanent tooth & 1 \\
\hline 52 & 40 & 2638 & Isi-c & L. Paleo. & & Mammalia (Medium) & Long bone & 1 \\
\hline 52 & 40 & 2638 & Isi-c & L. Paleo. & & Mammalia (Medium/large) & Indeterminate & 2 \\
\hline 52 & 40 & 2638 & Isi-c & L. Paleo. & & Mammalia (Medium/large) & Permanent tooth & 1 \\
\hline 52 & 40 & 2638 & Isi-c & L. Paleo. & & Mammalia (Small) & Middle phalange & 1 \\
\hline 52 & 40 & 2638 & Isi-c & L. Paleo. & & Medium/Large Vertebrata & Indeterminate. & 3 \\
\hline 52 & 40 & 2638 & Isi-c & L. Paleo. & & Small/Medium Vertebrata & Long bone & 15 \\
\hline 52 & 40 & 2638 & Isi-c & L. Paleo. & & Sylvilagus sp. & Humerus & 1 \\
\hline 52 & 40 & 2638 & Isi-c & L. Paleo. & & Vertebrata & Indeterminate & 38 \\
\hline 52 & 41 & 2635 & Isi-c & L. Paleo. & & Geomys sp. & Permanent tooth & 1 \\
\hline
\end{tabular}




\begin{tabular}{|c|c|c|c|c|c|c|c|c|}
\hline Square & Level & Lot & Unit & Cultural Affinity & Feature & Taxon & Element & No. \\
\hline 52 & 41 & 2635 & Isi-c & L. Paleo. & & Kinosternidae & Peripheral & 1 \\
\hline 52 & 41 & 2635 & Isi-c & L. Paleo. & & Leporidae & Permanent tooth & 3 \\
\hline 52 & 41 & 2635 & Isi-c & L. Paleo. & & Mammalia (Medium/large) & Indeterminate & 10 \\
\hline 52 & 41 & 2635 & Isi-c & L. Paleo. & & Mammalia (Small) & Femur & 3 \\
\hline 52 & 41 & 2635 & Isi-c & L. Paleo. & & Mammalia (Small) & Middle phalange & 1 \\
\hline 52 & 41 & 2635 & Isi-c & L. Paleo. & & Mammalia (Small) & Ulna & 1 \\
\hline 52 & 41 & 2635 & Isi-c & L. Paleo. & & Medium/Large Vertebrata & Indeterminate & 2 \\
\hline 52 & 41 & 2635 & Isi-c & L. Paleo. & & Neotoma sp. & Permanent tooth & 1 \\
\hline 52 & 41 & 2635 & |Isi-c & L. Paleo. & & Rodentia (Medium) & Permanent tooth & 2 \\
\hline 52 & 41 & 2635 & Isi-c & L. Paleo. & & Small/Medium Vertebrata & Long bone & 18 \\
\hline 52 & 41 & 2635 & Isi-c & L. Paleo. & & Sylvilagus sp. & Ulna & 1 \\
\hline 52 & 41 & 2635 & Isi-c & L. Paleo. & & Vertebrata & Indeterminate & 25 \\
\hline 52 & 42 & 2749 & Isi-c & L. Paleo. & & Mammalia (Medium/large) & Indeterminate & 1 \\
\hline 52 & 42 & 2749 & Isi-c & L. Paleo. & & Small/Medium Vertebrata & Long bone & 5 \\
\hline 52 & 42 & 2749 & Isi-c & L. Paleo. & & Vertebrata & Indeterminate & 21 \\
\hline 52 & $42 B$ & 2406 & Isi-c & L. Paleo. & 260 & Small/Medium Vertebrata & Long bone & 1 \\
\hline 52 & 43 & 2594 & Isi-c & L. Paleo. & & Geomys sp. & Permanent tooth & 1 \\
\hline 52 & 43 & 2594 & Isi-c & L. Paleo. & & Lepus californicus & Permanent tooth & 1 \\
\hline 52 & 43 & 2594 & Isi-c & L. Paleo. & & Mammalia (Medium/large) & Indeterminate & 1 \\
\hline 52 & 43 & 2594 & Isi-c & L. Paleo. & & Mammalia (Small) & Permanent tooth & 1 \\
\hline 52 & 43 & 2594 & Isi-c & L. Paleo. & & Small/Medium Vertebrata & Long bone & 4 \\
\hline 52 & 43 & 2594 & Isi-c & L. Paleo. & & Vertebrata & Indeterminate & 16 \\
\hline 52 & 44 & 2559 & Icl/Isi-c & Paleoindian & & Small/Medium Vertebrata & Long bone & 2 \\
\hline 52 & 44 & 2559 & Icl/Isi-c & Paleoindian & & Vertebrata & Indeterminate & 6 \\
\hline 52 & 45 & 2467 & Icl/Isi-c & Paleoindian & & Small/Medium Vertebrata & Long bone & 4 \\
\hline 52 & 45 & 2467 & Icl/Isi-c & Paleoindian & & Testudinata & Pleural & 1 \\
\hline 52 & 45 & 2467 & Icl/Isi-c & Paleoindian & & Vertebrata & Indeterminate & 13 \\
\hline 52 & 46 & 2340 & Icl/Isi-c & Paleoindian & & Vertebrata & Indeterminate & 2 \\
\hline 52 & 46 & 2618 & Icl/Isi-c & Paleoindian & & Medium/Large Vertebrata & Indeterminate & 4 \\
\hline 52 & 46 & 2618 & Icl/Isi-c & Paleoindian & & Small/Medium Vertebrata & Long bone & 2 \\
\hline 52 & 46 & 2618 & Icl/Isi-c & Paleoindian & & Vertebrata & Indeterminate & 22 \\
\hline 52 & 47 & 2505 & Icl/Isi-c & Paleoindian & & Leporidae & Permanent tooth & 1 \\
\hline 52 & 47 & 2505 & Icl/Isi-c & Paleoindian & & Mammalia (Medium/large) & Indeterminate & 6 \\
\hline 52 & 47 & 2505 & Icl/Isi-c & Paleoindian & & Small/Medium Vertebrata & Long bone & 2 \\
\hline 52 & 47 & 2505 & Icl/Isi-c & Paleoindian & & Vertebrata & Indeterminate & 10 \\
\hline 52 & 48 & 2500 & Icl & E. Paleoindian & & Leporidae & Permanent tooth & 7 \\
\hline 52 & 48 & 2500 & Icl & E. Paleoindian & & Mammalia (Medium/large) & Indeterminate & 9 \\
\hline 52 & 48 & 2500 & Icl & E. Paleoindian & & Mammalia (Small) & Femur & 1 \\
\hline 52 & 48 & 2500 & Icl & E. Paleoindian & & Small/Medium Vertebrata & Indeterminate & 1 \\
\hline 52 & 48 & 2500 & Icl & E. Paleoindian & & Small/Medium Vertebrata & Long bone & 1 \\
\hline 52 & 48 & 2500 & Icl & E. Paleoindian & & Vertebrata & Indeterminate & 10 \\
\hline 52 & 49 & 2517 & Icl & E. Paleoindian & & Medium/Large Vertebrata & Indeterminate & 2 \\
\hline 52 & 49 & 2517 & Icl & E. Paleoindian & & Vertebrata & Indeterminate & 2 \\
\hline 52 & 49 & 2565 & Icl & E. Paleoindian & & cf. Leporidae & Permanent tooth & 3 \\
\hline 52 & 49 & 2565 & Icl & E. Paleoindian & & Mammalia (Medium/large) & Indeterminate & 1 \\
\hline 52 & 49 & 2565 & Icl & E. Paleoindian & & Medium/Large Vertebrata & Indeterminate & 3 \\
\hline 52 & 49 & 2565 & Icl & E. Paleoindian & & Small/Medium Vertebrata & Long bone & 7 \\
\hline 52 & 49 & 2565 & Icl & E. Paleoindian & & Vertebrata & Indeterminate & 14 \\
\hline 52 & 50 & 2566 & |Isi/Icl & E. Paleoindian & & Mammalia (Small) & Permanent tooth & 1 \\
\hline 52 & 50 & 2566 & |Isi/Icl & E. Paleoindian & & Small/Medium Vertebrata & Long bone & 2 \\
\hline 52 & 50 & 2566 & |Isi/Icl & E. Paleoindian & & Vertebrata & Indeterminate & 8 \\
\hline 52 & 51 & 2575 & |Isi/Icl & E. Paleoindian & & Geomys sp. & Permanent tooth & 1 \\
\hline 52 & 51 & 2575 & |Isi/Icl & E. Paleoindian & & Medium/Large Vertebrata & Indeterminate & 5 \\
\hline 52 & 51 & 2575 & Isi/Icl & E. Paleoindian & & Small/Medium Vertebrata & Epiphysis & 1 \\
\hline 52 & 51 & 2575 & |Isi/Icl & E. Paleoindian & & Small/Medium Vertebrata & Long bone & 5 \\
\hline 52 & 51 & 2575 & Isi/Icl & E. Paleoindian & & Testudinata & Carapace fragment ind. & 1 \\
\hline 52 & 51 & 2575 & Isi/Icl & E. Paleoindian & & Testudinata & Plastron fragment ind. & 1 \\
\hline 52 & 51 & 2575 & |Isi/Icl & E. Paleoindian & & Vertebrata & Indeterminate & 4 \\
\hline 52 & 52 & 2578 & |Isi/Icl & E. Paleoindian & & Mammalia (Large) & Indeterminate & 1 \\
\hline 52 & 52 & 2579 & Isi/Icl & E. Paleoindian & & Mammalia (Medium/large) & Indeterminate & 1 \\
\hline 52 & 52 & 2580 & |Isi/Icl & E. Paleoindian & & Mammalia (Medium/large) & Indeterminate & 2 \\
\hline 52 & 52 & 2586 & |Isi/Icl & E. Paleoindian & & Geomys sp. & Permanent tooth & 2 \\
\hline 52 & 52 & 2586 & |Isi/Icl & E. Paleoindian & & Medium/Large Vertebrata & Indeterminate & 6 \\
\hline 52 & 52 & 2586 & |Isi/Icl & E. Paleoindian & & Small/Medium Vertebrata & Long bone & 6 \\
\hline 52 & 52 & 2586 & Isi/Icl & E. Paleoindian & & Vertebrata & Indeterminate & 16 \\
\hline 52 & 53 & 2600 & |Isi/Icl & E. Paleoindian & & Mammalia (Large) & Indeterminate & 12 \\
\hline 52 & 53 & 2600 & Isi/Icl & E. Paleoindian & & Mammalia (Large) & Long bone & 1 \\
\hline
\end{tabular}




\begin{tabular}{|c|c|c|c|c|c|c|c|c|}
\hline Square & Level & Lot & Unit & Cultural Affinity & Feature & Taxon & Element & No. \\
\hline 52 & 53 & 2750 & Isi/Icl & E. Paleoindian & & Mammalia (Large) & Indeterminate & 1 \\
\hline 52 & 53 & 2750 & |Isi/Icl & E. Paleoindian & & Mammalia (Medium/large) & Indeterminate & 1 \\
\hline 52 & 53 & 2750 & |Isi/Icl & E. Paleoindian & & Small/Medium Vertebrata & Long bone & 1 \\
\hline 52 & 53 & 2750 & |Isi/Icl & E. Paleoindian & & Vertebrata & Indeterminate & 4 \\
\hline 52 & 54 & 2650 & |Isi/Icl & E. Paleoindian & & Vertebrata & Indeterminate & 2 \\
\hline 52 & 55 & 2772 & |Igl/Isi & E. Paleoindian & & Mammalia (Medium) & Humerus & 1 \\
\hline 52 & 55 & 2772 & Igl/Isi & E. Paleoindian & & Medium/Large Vertebrata & Indeterminate & 2 \\
\hline 52 & 55 & 2772 & Igl//si & E. Paleoindian & & Small/Medium Vertebrata & Long bone & 1 \\
\hline 52 & 56 & 2865 & $\mathrm{Ig} 1 / \mathrm{Isi}$ & E. Paleoindian & & Mammalia (Medium/large) & Indeterminate & 1 \\
\hline 52 & 57 & 2709 & Igl/Isi & E. Paleoindian & & Vertebrata & Indeterminate & 1 \\
\hline 52 & 59 & 2869 & $\operatorname{Ig} 1 / \operatorname{Isi}$ & E. Paleoindian & & Mammalia (Small) & Femur & 1 \\
\hline 52 & 59 & 2869 & Igl/Isi & E. Paleoindian & & Vertebrata & Indeterminate & 1 \\
\hline 52 & 60 & 2848 & | Igl/Isi & E. Paleoindian & & Small/Medium Vertebrata & Long bone & 1 \\
\hline 53 & 19 & 873 & IIIa & E. Archaic & & Vertebrata & Indeterminate & 5 \\
\hline 53 & 20 & 899 & IIIIa & E. Archaic & 231 & Small/Medium Vertebrata & Long bone & 1 \\
\hline 53 & 20 & 899 & ШШа & E. Archaic & 231 & Vertebrata & Indeterminate & 2 \\
\hline 53 & 23 & 1151 & IIIIa & E. Archaic & 231 & Small/Medium Vertebrata & Long bone & 1 \\
\hline 53 & 23 & 1151 & IIIIa & E. Archaic & 231 & Vertebrata & Indeterminate & 5 \\
\hline 53 & 24 & 1460 & Ш/Ша & L. Paleo./E. Archaic & $231 / 245$ & Vertebrata & Indeterminate & 5 \\
\hline 53 & 25 & 1543 & II/IIIa & L. Paleo./E. Archaic & & Mammalia (Small) & Cervical vertebra & 1 \\
\hline 53 & 25 & 1543 & ПI/IIIa & L. Paleo./E. Archaic & & Vertebrata & Indeterminate & 1 \\
\hline 53 & $26 \mathrm{~A}$ & 1669 & II/IIIa & L. Paleo./E. Archaic & & Mammalia (Medium/large) & Long bone & 1 \\
\hline 53 & $26 \mathrm{~A}$ & 1669 & Шा/II & L. Paleo./E. Archaic & & Sylvilagus sp. & Permanent tooth & 1 \\
\hline 53 & $26 \mathrm{~A}$ & 1669 & II/IIIa & L. Paleo./E. Archaic & & Vertebrata & Indeterminate & 3 \\
\hline 53 & $26 \mathrm{~B}$ & 1652 & II/IIIa & L. Paleo./E. Archaic & 245 & Leporidae & Permanent tooth & 4 \\
\hline 53 & 26B & 1652 & II/IIIa & L. Paleo./E. Archaic & 245 & Small/Medium Vertebrata & Long bone & 2 \\
\hline 53 & 26B & 1652 & ШІШІІа & L. Paleo./E. Archaic & 245 & Vertebrata & Indeterminate & 4 \\
\hline 53 & 27 & 1683 & Ш/Шаa & L. Paleo./E. Archaic & & Vertebrata & Indeterminate & 6 \\
\hline 53 & 28 & 1707 & III & L. Paleo. & 248 & Mammalia (Small) & Metapodial & 1 \\
\hline 53 & 28 & 1707 & III & L. Paleo. & 248 & Vertebrata & Indeterminate & 2 \\
\hline 53 & $38 \mathrm{ID}$ & 2756 & Isi-c/Id & L. Paleo. & & Small/Medium Vertebrata & Long bone & 2 \\
\hline 53 & $38 \mathrm{ID}$ & 2756 & Isi-c/Id & L. Paleo. & & Vertebrata & Indeterminate & 3 \\
\hline 53 & $39 \mathrm{~A}$ & 2754 & Isi-c/Id & L. Paleo. & & Small/Medium Vertebrata & Long bone & 1 \\
\hline 53 & $39 \mathrm{~A}$ & 2754 & Isi-c/Id & L. Paleo. & & Vertebrata & Indeterminate & 2 \\
\hline 53 & 41 & 2536 & |Isi-c & L. Paleo. & & Mammalia (Medium/large) & Long bone & 1 \\
\hline 53 & 50 & 2825 & Isi/Icl & E. Paleoindian & & Small/Medium Vertebrata & Long bone & 1 \\
\hline 53 & 50 & 2825 & |Isi/Icl & E. Paleoindian & & Vertebrata & Indeterminate & 2 \\
\hline 53 & 51 & 2788 & Isi/Icl & E. Paleoindian & & Mammalia (Medium/large) & Indeterminate & 2 \\
\hline 53 & 51 & 2788 & Isi/Icl & E. Paleoindian & & Small/Medium Vertebrata & Long bone & 1 \\
\hline 53 & 51 & 2788 & |Isi/Icl & E. Paleoindian & & Vertebrata & Indeterminate & 6 \\
\hline 53 & 52 & 2667 & |Isi/Icl & E. Paleoindian & & Medium/Large Vertebrata & Indeterminate & 3 \\
\hline 53 & 52 & 2667 & |Isi/Icl & E. Paleoindian & & Small/Medium Vertebrata & Long bone & 2 \\
\hline 53 & 52 & 2667 & |Isi/Icl & E. Paleoindian & & Vertebrata & Indeterminate & 3 \\
\hline 53 & 53 & 2859 & |Isi/Icl & E. Paleoindian & & Vertebrata & Indeterminate & 2 \\
\hline 53 & 54 & 2864 & |Isi/Icl & E. Paleoindian & & Mammalia (Medium/large) & Indeterminate & 2 \\
\hline 53 & 54 & 2864 & |Isi/Icl & E. Paleoindian & & Vertebrata & Indeterminate & 8 \\
\hline 53 & 55 & 2860 & | Igl/Isi & E. Paleoindian & & Mammalia (Medium/large) & Indeterminate & 3 \\
\hline 53 & 55 & 2860 & |Igl//si & E. Paleoindian & & Small/Medium Vertebrata & Long bone & 1 \\
\hline 53 & 55 & 2860 & |Igl//si & E. Paleoindian & & Vertebrata & Indeterminate & 2 \\
\hline 54 & 44 & 1892 & Isi & E. Paleoindian & & Small/Medium Vertebrata & Long bone & 1 \\
\hline 54 & 44 & 1892 & Isi & E. Paleoindian & & Vertebrata & Indeterminate & 3 \\
\hline 54 & 45 & 1895 & Isi & E. Paleoindian & & Mammalia (Medium) & Caudal vertebra & 1 \\
\hline 54 & 45 & 1895 & Isi & E. Paleoindian & & Vertebrata & Indeterminate & 1 \\
\hline 54 & 46 & 1833 & Isi & E. Paleoindian & & Vertebrata & Indeterminate & 2 \\
\hline 54 & 47 & 1834 & Isi & E. Paleoindian & & Vertebrata & Indeterminate & 1 \\
\hline 54 & 51 & 2809 & Isi & E. Paleoindian & & Vertebrata & Indeterminate & 1 \\
\hline 54 & 53 & 2125 & Isi & E. Paleoindian & & Vertebrata & Indeterminate & 2 \\
\hline 55 & 41 & 1915 & Isi/Isi-c & Paleoindian & & Artiodactyla & Tooth, perm./decid. ind. & 3 \\
\hline 55 & 41 & 1915 & Isi/Isi-c & Paleoindian & & Mammalia (Medium/large) & Tooth, perm./decid. ind. & 2 \\
\hline 55 & 41 & 1915 & Isi/Isi-c & Paleoindian & & Mammalia (Small) & Proximal phalange & 1 \\
\hline 55 & 41 & 1915 & Isi/Isi-c & Paleoindian & & Mammalia (Small) & Vertebra & 1 \\
\hline 55 & 41 & 1915 & Isi/Isi-c & Paleoindian & & Small/Medium Vertebrata & Long bone & 6 \\
\hline 55 & 41 & 1915 & Isi/Isi-c & Paleoindian & & Testudinata & Carapace fragment ind. & 2 \\
\hline 55 & 41 & 1915 & Isi/Isi-c & Paleoindian & & Vertebrata & Indeterminate & 25 \\
\hline 55 & 41 & 1921 & Isi/Isi-c & Paleoindian & & Sylvilagus sp. & Calcaneus & 1 \\
\hline 55 & 41 & 1921 & Isi/Isi-c & Paleoindian & & Sylvilagus sp. & Permanent tooth & 1 \\
\hline 55 & 42 & 1938 & Isi/Isi-c & Paleoindian & & Chondrichthyes & Tooth & 1 \\
\hline
\end{tabular}




\begin{tabular}{|c|c|c|c|c|c|c|c|c|}
\hline Square & Level & Lot & Unit & Cultural Affinity & Feature & Taxon & Element & No. \\
\hline 55 & 42 & 1938 & Isi/Isi-c & Paleoindian & & Mammalia (Medium/large) & Tooth, perm./decid. ind. & 3 \\
\hline 55 & 42 & 1938 & Isi/Isi-c & Paleoindian & & Mammalia (Small) & Vertebra & 1 \\
\hline 55 & 42 & 1938 & Isi/Isi-c & Paleoindian & & Medium/Large Vertebrata & Indeterminate & 5 \\
\hline 55 & 42 & 1938 & Isi/Isi-c & Paleoindian & & Small/Medium Vertebrata & Long bone & 7 \\
\hline 55 & 42 & 1938 & Isi/Isi-c & Paleoindian & & Vertebrata & Indeterminate & 40 \\
\hline 55 & $43 \mathrm{~A}$ & 2854 & Isi/Isi-c & Paleoindian & & Small/Medium Vertebrata & Long bone & 4 \\
\hline 55 & $43 \mathrm{~A}$ & 2854 & Isi/Isi-c & Paleoindian & & Vertebrata & Indeterminate & 2 \\
\hline 55 & 45 & 2751 & Isi & E. Paleoindian & & Mammalia (Medium/large) & Indeterminate & 1 \\
\hline 55 & 45 & 2751 & Isi & E. Paleoindian & & Medium/Large Vertebrata & Indeterminate & 4 \\
\hline 55 & 45 & 2751 & Isi & E. Paleoindian & & Vertebrata & Indeterminate & 8 \\
\hline 55 & 46 & 2610 & Isi & E. Paleoindian & & Serpentes & Dorsal vertebra & 1 \\
\hline 55 & 46 & 2610 & Isi & E. Paleoindian & & Small/Medium Vertebrata & Long bone & 2 \\
\hline 55 & 46 & 2610 & Isi & E. Paleoindian & & Vertebrata & Indeterminate & 6 \\
\hline 55 & 48 & 2799 & Isi & E. Paleoindian & & Small/Medium Vertebrata & Long bone & 1 \\
\hline 55 & 48 & 2799 & Isi & E. Paleoindian & & Vertebrata & Indeterminate & 2 \\
\hline 55 & 49 & 2768 & Isi & E. Paleoindian & & Mammalia (Medium/large) & Indeterminate & 1 \\
\hline 55 & 49 & 2768 & Isi & E. Paleoindian & & Medium/Large Vertebrata & Indeterminate & 4 \\
\hline 55 & 49 & 2768 & Isi & E. Paleoindian & & Vertebrata & Indeterminate & 12 \\
\hline 55 & 50 & 2639 & Isi & E. Paleoindian & & Small/Medium Vertebrata & Long bone & 4 \\
\hline 55 & 50 & 2639 & Isi & E. Paleoindian & & Vertebrata & Indeterminate & 1 \\
\hline 56 & 36 & 1903 & Isi-c/Id & L. Paleo. & & Mammalia (Medium/large) & Indeterminate & 3 \\
\hline 56 & 36 & 1903 & Isi-c/Id & L. Paleo. & & Mammalia (Medium/large) & Long bone & 1 \\
\hline 56 & 36 & 1903 & Isi-c/Id & L. Paleo. & & Mammalia (Small) & Humerus & 1 \\
\hline 56 & 36 & 1903 & Isi-c/Id & L. Paleo. & & Medium/Large Vertebrata & Indeterminate & 1 \\
\hline 56 & 36 & 1903 & Isi-c/Id & L. Paleo. & & Small/Medium Vertebrata & Long bone & 13 \\
\hline 56 & 36 & 1903 & Isi-c/Id & L. Paleo. & & Sylvilagus sp. & Distal phalange & 1 \\
\hline 56 & 36 & 1903 & Isi-c/Id & L. Paleo. & & Sylvilagus sp. & Permanent tooth & 1 \\
\hline 56 & 36 & 1903 & Isi-c/Id & L. Paleo. & & Testudinata & Shell fragment & 1 \\
\hline 56 & 36 & 1903 & Isi-c/Id & L. Paleo. & & Vertebrata & Indeterminate & 46 \\
\hline 56 & 37 & 1918 & Isi-c/Id & L. Paleo. & & Leporidae & Permanent tooth & 1 \\
\hline 56 & 37 & 1918 & Isi-c/Id & L. Paleo. & & Mammalia (Medium/large) & Indeterminate & 1 \\
\hline 56 & 37 & 1918 & Isi-c/Id & L. Paleo. & & Neotoma sp. & Permanent tooth & 1 \\
\hline 56 & 37 & 1918 & Isi-c/Id & L. Paleo. & & Small/Medium Vertebrata & Long bone & 15 \\
\hline 56 & 37 & 1918 & Isi-c/Id & L. Paleo. & & Sylvilagus sp. & Calcaneus & 1 \\
\hline 56 & 37 & 1918 & Isi-c/Id & L. Paleo. & & Sylvilagus sp. & Ulna & 1 \\
\hline 56 & 37 & 1918 & Isi-c/Id & L. Paleo. & & Testudinata & Peripheral & 2 \\
\hline 56 & 37 & 1918 & Isi-c/Id & L. Paleo. & & Vertebrata & Indeterminate & 90 \\
\hline 56 & 38 & 1941 & Isi-c/Id & L. Paleo. & & Artiodactyla & Tooth, perm./decid. ind. & 1 \\
\hline 56 & 38 & 1941 & Isi-c/Id & L. Paleo. & & cf. Leporidae & Permanent tooth & 1 \\
\hline 56 & 38 & 1941 & Isi-c/Id & L. Paleo. & & Leporidae & Permanent tooth & 4 \\
\hline 56 & 38 & 1941 & Isi-c/Id & L. Paleo. & & Mammalia (Large) & Radius & 1 \\
\hline 56 & 38 & 1941 & Isi-c/Id & L. Paleo. & & Mammalia (Medium/large) & Indeterminate & 1 \\
\hline 56 & 38 & 1941 & Isi-c/Id & L. Paleo. & & Mammalia (Medium/large) & Long bone & 1 \\
\hline 56 & 38 & 1941 & Isi-c/Id & L. Paleo. & & Mammalia (Medium/large) & Tooth, perm./decid. ind. & 5 \\
\hline 56 & 38 & 1941 & Isi-c/Id & L. Paleo. & & Mammalia (Small) & Radius & 3 \\
\hline 56 & 38 & 1941 & Isi-c/Id & L. Paleo. & & Mammalia (Small/medium) & Long bone & 1 \\
\hline 56 & 38 & 1941 & Isi-c/Id & L. Paleo. & & Medium/Large Vertebrata & Indeterminate & 8 \\
\hline 56 & 38 & 1941 & Isi-c/Id & L. Paleo. & & Small/Medium Vertebrata & Long bone & 13 \\
\hline 56 & 38 & 1941 & Isi-c/Id & L. Paleo. & & Squamata & Dorsal vertebra & 1 \\
\hline 56 & 38 & 1941 & Isi-c/Id & L. Paleo. & & Sylvilagus sp. & Calcaneus & 1 \\
\hline 56 & 38 & 1941 & Isi-c/Id & L. Paleo. & & Sylvilagus sp. & Mandible & 1 \\
\hline 56 & 38 & 1941 & Isi-c/Id & L. Paleo. & & Sylvilagus sp. & Permanent tooth & 3 \\
\hline 56 & 38 & 1941 & Isi-c/Id & L. Paleo. & & Vertebrata & Indeterminate & 58 \\
\hline 56 & 39 & 1962 & Isi-c & L. Paleo. & & Artiodactyla & Tooth, perm./decid. ind. & 1 \\
\hline 56 & 39 & 1962 & Isi-c & L. Paleo. & & Geomys sp. & Permanent tooth & 1 \\
\hline 56 & 39 & 1962 & Isi-c & L. Paleo. & & Mammalia (Medium) & Tooth, perm./decid. ind. & 1 \\
\hline 56 & 39 & 1962 & Isi-c & L. Paleo. & & Mammalia (Medium/large) & Indeterminate & 2 \\
\hline 56 & 39 & 1962 & Isi-c & L. Paleo. & & Mammalia (Medium/large) & Tooth, perm./decid. ind. & 1 \\
\hline 56 & 39 & 1962 & Isi-c & L. Paleo. & & Mammalia (Small) & Pelvis & 1 \\
\hline 56 & 39 & 1962 & Isi-c & L. Paleo. & & Medium/Large Vertebrata & Long bone & 1 \\
\hline 56 & 39 & 1962 & Isi-c & L. Paleo. & & Serpentes & Dorsal vertebra & 1 \\
\hline 56 & 39 & 1962 & Isi-c & L. Paleo. & & Small/Medium Vertebrata & Long bone & 11 \\
\hline 56 & 39 & 1962 & Isi-c & L. Paleo. & & Vertebrata & Indeterminate & 38 \\
\hline 56 & 40 & 1989 & Isi/Isi-c & Paleoindian & & Mammalia (Medium/large) & Vertebra & 1 \\
\hline 56 & 40 & 1990 & Isi/Isi-c & Paleoindian & & Geomys sp. & Permanent tooth & 1 \\
\hline 56 & 40 & 1990 & Isi/Isi-c & Paleoindian & & Mammalia (Medium/large) & Indeterminate & 2 \\
\hline 56 & 40 & 1990 & Isi/Isi-c & Paleoindian & & Mammalia (Small) & Radius & 1 \\
\hline
\end{tabular}




\begin{tabular}{|c|c|c|c|c|c|c|c|c|}
\hline Square & Level & Lot & Unit & Cultural Affinity & Feature & Taxon & Element & No. \\
\hline 56 & 40 & 1990 & Isi/Isi-c & Paleoindian & & Medium/Large Vertebrata & Indeterminate & 4 \\
\hline 56 & 40 & 1990 & Isi/Isi-c & Paleoindian & & Serpentes & Dorsal vertebra & 2 \\
\hline 56 & 40 & 1990 & Isi/Isi-c & Paleoindian & & Small/Medium Vertebrata & Long bone & 6 \\
\hline 56 & 40 & 1990 & Isi/Isi-c & Paleoindian & & Testudinata & Long bone & 1 \\
\hline 56 & 40 & 1990 & Isi/Isi-c & Paleoindian & & Testudinata & Shell fragment & 3 \\
\hline 56 & 40 & 1990 & Isi/Isi-c & Paleoindian & & Vertebrata & Indeterminate & 31 \\
\hline 56 & 40 & 1998 & Isi/Isi-c & Paleoindian & & Mammalia (Medium/large) & Indeterminate & 1 \\
\hline 56 & 40 & 1999 & Isi/Isi-c & Paleoindian & & Mammalia (Medium/large) & Indeterminate & 1 \\
\hline 56 & 41 & 2021 & Isi/Isi-c & Paleoindian & & Small/Medium Vertebrata & Long bone & 10 \\
\hline 56 & 41 & 2021 & Isi/Isi-c & Paleoindian & & Vertebrata & Indeterminate & 31 \\
\hline 56 & 42 & 2046 & Isi/Isi-c & Paleoindian & & Leporidae & Permanent tooth & 2 \\
\hline 56 & 42 & 2046 & Isi/Isi-c & Paleoindian & & Mammalia (Small) & Permanent tooth & 1 \\
\hline 56 & 42 & 2046 & Isi/Isi-c & Paleoindian & & Mammalia (Small/medium) & Alveolar ridge fragment & 1 \\
\hline 56 & 42 & 2046 & Isi/Isi-c & Paleoindian & & Small/Medium Vertebrata & Long bone & 4 \\
\hline 56 & 42 & 2046 & Isi/Isi-c & Paleoindian & & Vertebrata & Indeterminate & 30 \\
\hline 56 & 42 & 2046 & Isi/Isi-c & Paleoindian & & Vertebrata & Tooth, perm./decid. ind. & 1 \\
\hline 56 & 43 & 2082 & Isi/Isi-c & Paleoindian & & cf. Leporidae & Alveolar ridge fragment & 1 \\
\hline 56 & 43 & 2082 & Isi/Isi-c & Paleoindian & & Mammalia (Medium/large) & Indeterminate & 6 \\
\hline 56 & 43 & 2082 & Isi/Isi-c & Paleoindian & & Mammalia (Medium/large) & Tooth, perm./decid. ind. & 1 \\
\hline 56 & 43 & 2082 & Isi/Isi-c & Paleoindian & & Rodentia (Small) & Femur & 1 \\
\hline 56 & 43 & 2082 & Isi/Isi-c & Paleoindian & & Small/Medium Vertebrata & Long bone & 8 \\
\hline 56 & 43 & 2082 & Isi/Isi-c & Paleoindian & & Vertebrata & Indeterminate & 48 \\
\hline 56 & 44 & 2110 & Isi/Isi-c & Paleoindian & & Medium/Large Vertebrata & Indeterminate & 2 \\
\hline 56 & 44 & 2110 & Isi/Isi-c & Paleoindian & & Small/Medium Vertebrata & Long bone & 6 \\
\hline 56 & 44 & 2110 & Isi/Isi-c & Paleoindian & & Vertebrata & Indeterminate & 36 \\
\hline 56 & 45 & 2148 & Isi/Isi-c & Paleoindian & & Mammalia (Large) & Indeterminate & 1 \\
\hline 56 & 45 & 2148 & Isi/Isi-c & Paleoindian & & Vertebrata & Indeterminate & 2 \\
\hline 56 & 46 & 2656 & Isi & E. Paleoindian & & Mammalia (Medium/large) & Indeterminate & 1 \\
\hline 56 & 46 & 2656 & Isi & E. Paleoindian & & Medium/Large Vertebrata & Indeterminate & 1 \\
\hline 56 & 46 & 2656 & Isi & E. Paleoindian & & Vertebrata & Indeterminate & 1 \\
\hline 56 & 47 & 2270 & Isi & E. Paleoindian & & Bison sp. & Permanent tooth & 1 \\
\hline 56 & 47 & 2655 & Isi & E. Paleoindian & & Mammalia (Medium/large) & Indeterminate & 1 \\
\hline 56 & 47 & 2655 & Isi & E. Paleoindian & & Medium/Large Vertebrata & Indeterminate & 2 \\
\hline 56 & 47 & 2655 & Isi & E. Paleoindian & & Testudinata & Shell fragment & 1 \\
\hline 56 & 47 & 2655 & Isi & E. Paleoindian & & Vertebrata & Indeterminate & 4 \\
\hline 56 & 48 & 2612 & Isi & E. Paleoindian & & Geomys sp. & Permanent tooth & 1 \\
\hline 56 & 48 & 2612 & Isi & E. Paleoindian & & Medium/Large Vertebrata & Indeterminate & 3 \\
\hline 56 & 48 & 2612 & Isi & E. Paleoindian & & Testudinata & Shell fragment & 1 \\
\hline 56 & 48 & 2612 & Isi & E. Paleoindian & & Vertebrata & Indeterminate & 21 \\
\hline 56 & 49 & 2271 & Isi & E. Paleoindian & & Medium/Large Vertebrata & Indeterminate & 1 \\
\hline 56 & 49 & 2271 & Isi & E. Paleoindian & & Vertebrata & Indeterminate & 1 \\
\hline 56 & 50 & 2641 & Isi & E. Paleoindian & & Vertebrata & Indeterminate & 4 \\
\hline 56 & 51 & 2760 & Isi & E. Paleoindian & & Vertebrata & Indeterminate & 3 \\
\hline 56 & 52 & 2560 & Isi & E. Paleoindian & & Vertebrata & Indeterminate & 4 \\
\hline 56 & 53 & 2623 & Isi & E. Paleoindian & & Medium/Large Vertebrata & Indeterminate & 1 \\
\hline 56 & 53 & 2623 & Isi & E. Paleoindian & & Vertebrata & Indeterminate & 2 \\
\hline 56 & 54 & 2617 & Isi & E. Paleoindian & & Medium/Large Vertebrata & Long bone & 1 \\
\hline 57 & 34 & 1871 & $\mathrm{Id} / \mathrm{II}$ & L. Paleo. & & Colubridae & Dorsal vertebra & 1 \\
\hline 57 & 34 & 1871 & $\mathrm{Id} / \mathrm{II}$ & L. Paleo. & & Leporidae & Permanent tooth & 1 \\
\hline 57 & 34 & 1871 & Id/II & L. Paleo. & & Mammalia (Large) & Tooth, perm./decid. ind. & 3 \\
\hline 57 & 34 & 1871 & $\mathrm{Id} / \mathrm{II}$ & L. Paleo. & & Mammalia (Small) & Permanent tooth & 1 \\
\hline 57 & 34 & 1871 & $\mathrm{Id} / \mathrm{II}$ & L. Paleo. & & Medium vertebrate, class ind. & Proximal phalange & 1 \\
\hline 57 & 34 & 1871 & $\mathrm{Id} / \mathrm{II}$ & L. Paleo. & & Small/Medium Vertebrata & Long bone & 10 \\
\hline 57 & 34 & 1871 & $\mathrm{Id} / \mathrm{II}$ & L. Paleo. & & Vertebrata & Indeterminate & 42 \\
\hline 57 & 35 & 1904 & Id & L. Paleo. & & Leporidae & Permanent tooth & 1 \\
\hline 57 & 35 & 1904 & Id & L. Paleo. & & Small/Medium Vertebrata & Long bone & 8 \\
\hline 57 & 35 & 1904 & Id & L. Paleo. & & Sylvilagus sp. & |Ulna & 1 \\
\hline 57 & 35 & 1904 & Id & L. Paleo. & & Vertebrata & Indeterminate & 32 \\
\hline 57 & 36 & 1917 & Isi-c/Id & L. Paleo. & & Mammalia (Medium) & Metacarpal & 1 \\
\hline 57 & 36 & 1917 & Isi-c/Id & L. Paleo. & & Mammalia (Medium/large) & Tooth, perm./decid. ind. & 1 \\
\hline 57 & 36 & 1917 & Isi-c/Id & L. Paleo. & & Medium/Large Vertebrata & Indeterminate & 8 \\
\hline 57 & 36 & 1917 & Isi-c/Id & L. Paleo. & & Medium/Large Vertebrata & Long bone & \\
\hline 57 & 36 & 1917 & Isi-c/Id & L. Paleo. & & Sylvilagus sp. & Permanent tooth & \\
\hline 57 & 36 & 1917 & Isi-c/Id & L. Paleo. & & Testudinata & Shell fragment & 1 \\
\hline 57 & 36 & 1917 & Isi-c/Id & L. Paleo. & & Vertebrata & Indeterminate & 43 \\
\hline 57 & 37 & 1954 & Isi-c & L. Paleo. & & Mammalia (Medium/large) & Indeterminate & \\
\hline 57 & 37 & 1954 & Isi-c & L. Paleo. & & Mammalia (Small) & Humerus & \\
\hline
\end{tabular}




\begin{tabular}{|c|c|c|c|c|c|c|c|c|}
\hline Square & Level & Lot & Unit & Cultural Affinity & Feature & Taxon & Element & No. \\
\hline 57 & 37 & 1954 & Isi-c & L. Paleo. & & Mammalia (Small) & Middle phalange & 1 \\
\hline 57 & 37 & 1954 & Isi-c & L. Paleo. & & Medium/Large Vertebrata & Indeterminate & 2 \\
\hline 57 & 37 & 1954 & Isi-c & L. Paleo. & & Serpentes & Dorsal vertebra & 2 \\
\hline 57 & 37 & 1954 & Isi-c & L. Paleo. & & Small/Medium Vertebrata & Long bone & 9 \\
\hline 57 & 37 & 1954 & Isi-c & L. Paleo. & & Squamata & Dorsal vertebra & 1 \\
\hline 57 & 37 & 1954 & Isi-c & L. Paleo. & & Sylvilagus sp. & Proximal phalange & 1 \\
\hline 57 & 37 & 1954 & Isi-c & L. Paleo. & & Testudinata & Peripheral & 1 \\
\hline 57 & 37 & 1954 & Isi-c & L. Paleo. & & Testudinata & Shell fragment & 1 \\
\hline 57 & 37 & 1954 & Isi-c & L. Paleo. & & Vertebrata & Indeterminate & 82 \\
\hline 57 & 38 & 1991 & Isi-c & L. Paleo. & & Aves (Large) & Vertebra & 1 \\
\hline 57 & 38 & 1991 & Isi-c & L. Paleo. & & cf. Geomys sp. & Permanent tooth & 1 \\
\hline 57 & 38 & 1991 & Isi-c & L. Paleo. & & cf. Spermophilus mexicanus & Humerus & 1 \\
\hline 57 & 38 & 1991 & Isi-c & L. Paleo. & & Mammalia (Medium/large) & Indeterminate & 4 \\
\hline 57 & 38 & 1991 & Isi-c & L. Paleo. & & Mammalia (Small) & Caudal vertebra & 1 \\
\hline 57 & 38 & 1991 & Isi-c & L. Paleo. & & Mammalia (Small) & Proximal phalange & 1 \\
\hline 57 & 38 & 1991. & Isi-c & L. Paleo. & & Mammalia (Small) & Radius & 1 \\
\hline 57 & 38 & 1991 & Isi-c & L. Paleo. & & Medium/Large Vertebrata & Indeterminate & 2 \\
\hline 57 & 38 & 1991 & Isi-c & L. Paleo. & & Neotoma sp. & Permanent tooth & 1 \\
\hline 57 & 38 & 1991 & Isi-c & L. Paleo. & & Serpentes & Dorsal vertebra & 2 \\
\hline 57 & 38 & 1991 & Isi-c & L. Paleo. & & Small/Medium Vertebrata & Long bone & 8 \\
\hline 57 & 38 & 1991 & Isi-c & L. Paleo. & & Sylvilagus sp. & |Ulna & 1 \\
\hline 57 & 38 & 1991 & Isi-c & L. Paleo. & & Testudinata & Shell fragment & 2 \\
\hline 57 & 38 & 1991 & Isi-c & L. Paleo. & & Vertebrata & Indeterminate & 37 \\
\hline 57 & 39 & 2029 & Isi-c & L. Paleo. & & Blarina sp. & Mandible & 1 \\
\hline 57 & 39 & 2029 & Isi-c & L. Paleo. & & Blarina sp. & Permanent tooth & 1 \\
\hline 57 & 39 & 2029 & Isi-c & L. Paleo. & & Leporidae & Permanent tooth & 2 \\
\hline 57 & 39 & 2029 & Isi-c & L. Paleo. & & Mammalia (Small) & Femur & 1 \\
\hline 57 & 39 & 2029 & Isi-c & L. Paleo. & & Mammalia (Small) & Radius & 1 \\
\hline 57 & 39 & 2029 & Isi-c & L. Paleo. & & Mammalia (Small) & Vertebra & 1 \\
\hline 57 & 39 & 2029 & Isi-c & L. Paleo. & & Medium/Large Vertebrata & Indeterminate & 3 \\
\hline 57 & 39 & 2029 & Isi-c & L. Paleo. & & Rodentia (Small) & Permanent tooth & 1 \\
\hline 57 & 39 & 2029 & Isi-c & L. Paleo. & & Serpentes & Dorsal vertebra & 1 \\
\hline 57 & 39 & 2029 & Isi-c & L. Paleo. & & Small/Medium Vertebrata & Long bone & 21 \\
\hline 57 & 39 & 2029 & Isi-c & L. Paleo. & & Sylvilagus sp. & Astragalus & 1 \\
\hline 57 & 39 & 2029 & Isi-c & L. Paleo. & & Sylvilagus sp. & Calcaneus & 1 \\
\hline 57 & 39 & 2029 & Isi-c & L. Paleo. & & Sylvilagus sp. & Humerus & 1 \\
\hline 57 & 39 & 2029 & Isi-c & L. Paleo. & & Testudinata & Shell fragment & 2 \\
\hline 57 & 39 & 2029 & Isi-c & L. Paleo. & & Vertebrata & Indeterminate & 77 \\
\hline 57 & 39 & 2058 & Isi-c & |L. Paleo. & & Medium/Large Vertebrata & |Indeterminate & 7 \\
\hline 57 & 40 & 2090 & Isi/Isi-c & Paleoindian & & Serpentes & Dorsal vertebra & 1 \\
\hline 57 & 40 & 2090 & Isi/Isi-c & Paleoindian & & Small/Medium Vertebrata & Long bone & 10 \\
\hline 57 & 40 & 2090 & Isi/Isi-c & Paleoindian & & Sylvilagus sp. & Ulna & 1 \\
\hline 57 & 40 & 2090 & Isi/Isi-c & Paleoindian & & Testudinata & Shell fragment & 1 \\
\hline 57 & 40 & 2090 & Isi/Isi-c & Paleoindian & & Vertebrata & Indeterminate & 29 \\
\hline 57 & 41 & 2100 & Isi/Icl/Isi-c & Paleoindian & & Mammalia (Medium/large) & Vertebra & 1 \\
\hline 57 & 41 & 2100 & Isi/Icl/Isi-c & Paleoindian & & Mammalia (Small) & Caudal vertebra & 1 \\
\hline 57 & 41 & 2100 & Isi/Icl/Isi-c & Paleoindian & & Mammalia (Small) & Permanent tooth & 1 \\
\hline 57 & 41 & 2100 & Isi/Icl/Isi-c & Paleoindian & & Neotoma sp. & Permanent tooth & 1 \\
\hline 57 & 41 & 2100 & Isi/Icl/Isi-c & Paleoindian & & Odocoileus sp. & Permanent tooth & 1 \\
\hline 57 & 41 & 2100 & Isi/Icl/Isi-c & Paleoindian & & Rodentia (Medium) & Femur & 1 \\
\hline 57 & 41 & 2100 & Isi/Icl//Isi-c & Paleoindian & & Rodentia (Medium) & Permanent tooth & 1 \\
\hline 57 & 41 & 2100 & |Isi/Icl/Isi-c & Paleoindian & & Serpentes & Dorsal vertebra & 1 \\
\hline 57 & 41 & 2100 & Isi/Icl/Isi-c & Paleoindian & & Small/Medium Vertebrata & Long bone & 11 \\
\hline 57 & 41 & 2100 & |Isi/Icl/Isi-c & Paleoindian & & Sylvilagus sp. & Calcaneus & 2 \\
\hline 57 & 41 & 2100 & |Isi/Icl/Isi-c & Paleoindian & & Sylvilagus sp. & Permanent tooth & 1 \\
\hline 57 & 41 & 2100 & |Isi/Icl/Isi-c & Paleoindian & & Testudinata & Shell fragment & 1 \\
\hline 57 & 41 & 2100 & |Isi/Icl/Isi-c & Paleoindian & & Vertebrata & Indeterminate & 115 \\
\hline 57 & 42 & 2646 & |Isi/Icl/Isi-c & Paleoindian & & Leporidae & Permanent tooth & 1 \\
\hline 57 & 42 & 2646 & |Isi/Icl/Isi-c & Paleoindian & & Mammalia (Medium/large) & Indeterminate & 3 \\
\hline 57 & 42 & 2646 & Isi/Icl/Isi-c & Paleoindian & & Mammalia (Micro) & Tooth, perm./decid. ind. & 2 \\
\hline 57 & 42 & 2646 & Isi/Icl/Isi-c & Paleoindian & & Serpentes & Dorsal vertebra & 1 \\
\hline 57 & 42 & 2646 & |Isi/Icl/Isi-c & Paleoindian & & Small/Medium Vertebrata & Long bone & 8 \\
\hline 57 & 42 & 2646 & |Isi/Icl/Isi-c & Paleoindian & & Testudinata & Carapace fragment ind. & 1 \\
\hline 57 & 42 & 2646 & |Isi/Icl/Isi-c & Paleoindian & & Vertebrata & Indeterminate & 14 \\
\hline 57 & 43 & 2777 & Isi/Isi-c & Paleoindian & & Mammalia (Medium/large) & Indeterminate & 2 \\
\hline 57 & 43 & 2777 & Isi/Isi-c & Paleoindian & & Small/Medium Vertebrata & Long bone & 4 \\
\hline 57 & 43 & 2777 & Isi/Isi-c & Paleoindian & & Vertebrata & Indeterminate & 16 \\
\hline
\end{tabular}




\begin{tabular}{|c|c|c|c|c|c|c|c|c|}
\hline Square & Level & Lot & Unit & Cultural Affinity & Feature & Taxon & Element & No. \\
\hline 57 & 44 & 2686 & Isi/Isi-c & Paleoindian & & Mammalia (Medium/large) & Indeterminate & 5 \\
\hline 57 & 44 & 2686 & Isi/Isi-c & Paleoindian & & Mammalia (Medium/large) & Long bone & 1 \\
\hline 57 & 44 & 2686 & Isi/Isi-c & Paleoindian & & Mammalia (Medium/large) & Permanent tooth & 1 \\
\hline 57 & 45 & 2797 & Isi/Isi-c & Paleoindian & & Small/Medium Vertebrata & Long bone & 1 \\
\hline 57 & 45 & 2797 & Isi/Isi-c & Paleoindian & & Vertebrata & Indeterminate & 10 \\
\hline 57 & 46 & 2141 & Isi/Isi-c & Paleoindian & & Medium/Large Vertebrata & Indeterminate & 1 \\
\hline 57 & 46 & 2607 & Isi/Isi-c & Paleoindian & & Mammalia (Large) & Tooth, perm./decid. ind. & 4 \\
\hline 57 & 46 & 2607 & Isi/Isi-c & Paleoindian & & Mammalia (Medium/large) & Tooth, perm./decid. ind. & 1 \\
\hline 57 & 46 & 2607 & Isi/Isi-c & Paleoindian & & Medium/Large Vertebrata & Indeterminate & 1 \\
\hline 57 & 46 & 2607 & Isi/Isi-c & Paleoindian & & Small/Medium Vertebrata & Long bone & 1 \\
\hline 57 & 46 & 2607 & Isi/Isi-c & Paleoindian & & Sylvilagus sp. & Calcaneus & 1 \\
\hline 57 & 46 & 2607 & Isi/Isi-c & Paleoindian & & Testudinata & Shell fragment & 1 \\
\hline 57 & 46 & 2607 & Isi/Isi-c & Paleoindian & & Vertebrata & Indeterminate & 26 \\
\hline 57 & 47 & 2832 & Isi/Isi-c & Paleoindian & & Mammalia (Medium/large) & Indeterminate & 2 \\
\hline 57 & 47 & 2832 & Isi/Isi-c & Paleoindian & & Mammalia (Medium/large) & Tooth, perm./decid. ind. & 3 \\
\hline 57 & 47 & 2832 & Isi/Isi-c & Paleoindian & & Mammalia (Micro) & Femur & 1 \\
\hline 57 & 47 & 2832 & Isi/Isi-c & Paleoindian & & Medium/Large Vertebrata & Indeterminate & 2 \\
\hline 57 & 47 & 2832 & Isi/Isi-c & Paleoindian & & Small/Medium Vertebrata & Long bone & 4 \\
\hline 57 & 47 & 2832 & Isi/Isi-c & Paleoindian & & Sylvilagus sp. & Metatarsal 2 & 1 \\
\hline 57 & 47 & 2832 & Isi/Isi-c & Paleoindian & & Vertebrata & Indeterminate & 3 \\
\hline 57 & 48 & 2857 & Isi & E. Paleoindian & & Medium/Large Vertebrata & Indeterminate & 1 \\
\hline 57 & 48 & 2857 & Isi & E. Paleoindian & & Vertebrata & Indeterminate & 1 \\
\hline 57 & 49 & 2732 & Isi & E. Paleoindian & & Mammalia (Medium/large) & Tooth, perm./decid. ind. & 1 \\
\hline 57 & 49 & 2732 & Isi & E. Paleoindian & & Medium/Large Vertebrata & Indeterminate & 3 \\
\hline 57 & 49 & 2732 & Isi & E. Paleoindian & & Small/Medium Vertebrata & Long bone & 1 \\
\hline 57 & 49 & 2732 & Isi & E. Paleoindian & & Sylvilagus sp. & Calcaneus & 1 \\
\hline 57 & 49 & 2732 & Isi & E. Paleoindian & & Sylvilagus sp. & Permanent tooth & 1 \\
\hline 57 & 49 & 2732 & Isi & E. Paleoindian & & Testudinata & Shell fragment & 1 \\
\hline 57 & 49 & 2732 & Isi & E. Paleoindian & & Vertebrata & Indeterminate & 23 \\
\hline 57 & 50 & 2746 & Isi & E. Paleoindian & & Mammalia (Medium) & Tooth, perm./decid. ind. & 1 \\
\hline 57 & 50 & 2746 & Isi & E. Paleoindian & & Mammalia (Small) & Caudal vertebra & 1 \\
\hline 57 & 50 & 2746 & Isi & E. Paleoindian & & Vertebrata & Indeterminate & 37 \\
\hline 57 & 51 & 2755 & Isi & E. Paleoindian & & Mammalia (Medium/large) & Indeterminate & 1 \\
\hline 57 & 51 & 2755 & Isi & E. Paleoindian & & Medium/Large Vertebrata & Indeterminate & 4 \\
\hline 57 & 51 & 2755 & Isi & E. Paleoindian & & Small/Medium Vertebrata & Long bone & 1 \\
\hline 57 & 51 & 2755 & Isi & E. Paleoindian & & Vertebrata & Indeterminate & 1 \\
\hline 57 & 52 & 2868 & Isi & E. Paleoindian & & Vertebrata & Indeterminate & 1 \\
\hline 57 & 53 & 2584 & Isi & E. Paleoindian & & Vertebrata & Indeterminate & 2 \\
\hline 58 & 40 & 1927 & Isi-c & L. Paleo. & & Small/Medium Vertebrata & Long bone & 2 \\
\hline 58 & 40 & 1927 & Isi-c & L. Paleo. & & Vertebrata & Indeterminate & 4 \\
\hline 58 & 41 & 1959 & Isi-c & L. Paleo. & & Leporidae & Permanent tooth & 1 \\
\hline 58 & 41 & 1959 & Isi-c & L. Paleo. & & Mammalia (Small/medium) & Permanent tooth & 1 \\
\hline 58 & 41 & 1959 & Isi-c & L. Paleo. & & Vertebrata & Indeterminate & 4 \\
\hline 58 & 42 & 1983 & Isi-c & L. Paleo. & & Geomys sp. & Permanent tooth & 1 \\
\hline 58 & 42 & 1983 & Isi-c & L. Paleo. & & Mammalia (Small) & Phalange & 1 \\
\hline 58 & 42 & 1983 & Isi-c & L. Paleo. & & Vertebrata & Indeterminate & 6 \\
\hline 58 & 43 & 1993 & Icl/Isi-c & Paleoindian & & Vertebrata & Indeterminate & 5 \\
\hline 58 & 44 & 2028 & Icl/Isi-c & Paleoindian & & Leporidae & Permanent tooth & 1 \\
\hline 58 & 44 & 2028 & Icl/Isi-c & Paleoindian & & Mammalia (Medium/large) & Tooth, perm./decid. ind. & 1 \\
\hline 58 & 44 & 2028 & Icl/Isi-c & Paleoindian & & Small/Medium Vertebrata & Long bone & 2 \\
\hline 58 & 44 & 2028 & Icl/Isi-c & Paleoindian & & Vertebrata & Indeterminate & 4 \\
\hline 58 & 45 & 2066 & Icl/Isi-c & Paleoindian & & Mammalia (Small) & Permanent tooth & 1 \\
\hline 58 & 45 & 2066 & Icl/Isi-c & Paleoindian & & Vertebrata & Indeterminate & 3 \\
\hline 58 & 46 & 2833 & Icl/Isi-c & Paleoindian & & Medium/Large Vertebrata & Indeterminate & 1 \\
\hline 58 & 46 & 2833 & Icl/Isi-c & Paleoindian & & Small/Medium Vertebrata & Long bone & 1 \\
\hline 58 & 46 & 2833 & Icl/Isi-c & Paleoindian & & Vertebrata & Indeterminate & 1 \\
\hline 58 & 47 & 2116 & Icl & E. Paleoindian & & Vertebrata & Indeterminate & 1 \\
\hline 58 & 48 & 2140 & Isi/Icl & E. Paleoindian & & Mammalia (Medium/large) & Indeterminate & 1 \\
\hline 58 & 48 & 2140 & |Isi/Icl & E. Paleoindian & & Small/Medium Vertebrata & Long bone & 3 \\
\hline 58 & 48 & 2140 & Isi/Icl & E. Paleoindian & & Vertebrata & Indeterminate & 6 \\
\hline 58 & 49 & 2151 & |Isi/Icl & E. Paleoindian & & Medium/Large Vertebrata & Indeterminate & 3 \\
\hline 58 & 49 & 2160 & Isi/Icl & E. Paleoindian & & Mammalia (Medium/large) & Indeterminate & 1 \\
\hline 58 & 49 & 2604 & Isi/Icl & E. Paleoindian & & Medium/Large Vertebrata & Indeterminate & 3 \\
\hline 58 & 49 & 2604 & Isi/Icl & E. Paleoindian & & Small/Medium Vertebrata & Long bone & 4 \\
\hline 58 & 49 & 2604 & Isi/Icl & E. Paleoindian & & Vertebrata & Indeterminate & 6 \\
\hline 58 & 50 & 2817 & |Isi/Icl & E. Paleoindian & & Geomys sp. & Permanent tooth & 1 \\
\hline 58 & 50 & 2817 & Isi/Icl & E. Paleoindian & & Mammalia (Large) & Indeterminate & 3 \\
\hline
\end{tabular}




\begin{tabular}{|c|c|c|c|c|c|c|c|c|}
\hline Square & Level & Lot & Unit & Cultural Affinity & Feature & Taxon & Element & No. \\
\hline 58 & 50 & 2817 & Isi/Icl & E. Paleoindian & & Medium/Large Vertebrata & Long bone & 1 \\
\hline 58 & 50 & 2817 & |Isi/Icl & E. Paleoindian & & Vertebrata & Indeterminate & 2 \\
\hline 58 & 52 & 2844 & Isi & E. Paleoindian & & Mammalia (Medium/large) & Indeterminate & 5 \\
\hline 58 & 52 & 2844 & Isi & E. Paleoindian & & Sylvilagus sp. & Permanent tooth & 3 \\
\hline 58 & 52 & 2844 & Isi & E. Paleoindian & & Vertebrata & Indeterminate & 10 \\
\hline 58 & 53 & 2862 & Isi & E. Paleoindian & & Medium/Large Vertebrata & Indeterminate & 1 \\
\hline 58 & 53 & 2862 & Isi & E. Paleoindian & & Vertebrata & Indeterminate & 2 \\
\hline 58 & $54 \mathrm{~A}$ & 2701 & Igl/Isi & E. Paleoindian & & Vertebrata & Indeterminate & 1 \\
\hline 58 & 55 & 2703 & Igl/Isi & E. Paleoindian & & Leporidae & Permanent tooth & 1 \\
\hline 58 & 55 & 2703 & Igl/Isi & E. Paleoindian & & Mammalia (Medium/large) & Indeterminate & 4 \\
\hline 58 & 55 & 2703 & Igl/Isi & E. Paleoindian & & Mammalia (Medium/large) & Tooth, perm./decid. ind. & 1 \\
\hline 58 & 55 & 2703 & Igl/Isi & E. Paleoindian & & Vertebrata & Indeterminate & 1 \\
\hline 58 & 56 & 2822 & Igl & E. Paleoindian & & Mammalia (Medium/large) & Indeterminate & 1 \\
\hline 59 & 34 & 2084 & Id/II & L. Paleo. & & Leporidae & Permanent tooth & 1 \\
\hline 59 & 34 & 2084 & Id/II & L. Paleo. & & Mammalia (Medium/large) & Indeterminate & 1 \\
\hline 59 & 34 & 2084 & Id/II & L. Paleo. & & Mammalia (Medium/large) & Tooth, perm./decid. ind. & 2 \\
\hline 59 & 34 & 2084 & Id/II & L. Paleo. & & Mammalia (Small) & Alveolar ridge fragment & 1 \\
\hline 59 & 34 & 2084 & Id/II & L. Paleo. & & Mammalia (Small) & Vertebra & 1 \\
\hline 59 & 34 & 2084 & Id/II & L. Paleo. & & Medium/Large Vertebrata & Indeterminate & 1 \\
\hline 59 & 34 & 2084 & Id/II & L. Paleo. & & Small/Medium Vertebrata & Long bone & 6 \\
\hline 59 & 34 & 2084 & Id/II & L. Paleo. & & Sylvilagus sp. & Permanent tooth & 1 \\
\hline 59 & 34 & 2084 & Id/II & L. Paleo. & & Sylvilagus sp. & Radius & 1 \\
\hline 59 & 34 & 2084 & Id/II & L. Paleo. & & Vertebrata & Indeterminate & 51 \\
\hline 59 & 35 & 2103 & Id/II & L. Paleo. & & Mammalia (Medium/large) & Tooth, perm./decid. ind. & 1 \\
\hline 59 & 35 & 2103 & Id/II & L. Paleo. & & Mammalia (Small) & Alveolar ridge fragment & 1 \\
\hline 59 & 35 & 2103 & Id/II & L. Paleo. & & Rodentia (Medium) & Permanent tooth & 1 \\
\hline 59 & 35 & 2103 & Id/II & L. Paleo. & & Small/Medium Vertebrata & Long bone & 4 \\
\hline 59 & 35 & 2103 & Id/II & L. Paleo. & & Sylvilagus sp. & Femur & 1 \\
\hline 59 & 35 & 2103 & Id/II & L. Paleo. & & Sylvilagus sp. & Metapodial & 1 \\
\hline 59 & 35 & 2103 & Id/II & L. Paleo. & & Vertebrata & Indeterminate & 46 \\
\hline 59 & 36 & 2811 & Id/II & L. Paleo. & & Medium/Large Vertebrata & Indeterminate & 1 \\
\hline 59 & 36 & 2811 & Id/II & L. Paleo. & & Small/Medium Vertebrata & Long bone & 3 \\
\hline 59 & 36 & 2811 & Id/II & L. Paleo. & & Testudinata & Shell fragment & 1 \\
\hline 59 & 36 & 2811 & Id/II & L. Paleo. & & Vertebrata & Indeterminate & 4 \\
\hline 59 & 37 & 2611 & Id & L. Paleo. & & Leporidae & Permanent tooth & 1 \\
\hline 59 & 37 & 2611 & Id & L. Paleo. & & Mammalia (Small) & Permanent tooth & 1 \\
\hline 59 & 37 & 2611 & Id & L. Paleo. & & Medium/Large Vertebrata & Indeterminate & 2 \\
\hline 59 & 37 & 2611 & Id & L. Paleo. & & Small/Medium Vertebrata & Long bone & 1 \\
\hline 59 & 37 & 2611 & Id & L. Paleo. & & Vertebrata & Indeterminate & 3 \\
\hline 59 & 38 & 2606 & Isi-c/Id & L. Paleo. & & Small/Medium Vertebrata & Long bone & 7 \\
\hline 59 & 38 & 2606 & Isi-c/Id & L. Paleo. & & Vertebrata & Indeterminate & 15 \\
\hline 59 & 39 & 2693 & Isi-c/Id & L. Paleo. & & Mammalia (Medium) & Podial & 1 \\
\hline 59 & 39 & 2693 & Isi-c/Id & L. Paleo. & & Small/Medium Vertebrata & Long bone & 9 \\
\hline 59 & 39 & 2693 & Isi-c/Id & L. Paleo. & & Testudinata & Shell fragment & 1 \\
\hline 59 & 39 & 2693 & Isi-c/Id & L. Paleo. & & Vertebrata & Indeterminate & 13 \\
\hline 59 & 40 & 2278 & Isi-c & L. Paleo. & & Mammalia (Medium/large) & Indeterminate & 2 \\
\hline 59 & 40 & 2278 & Isi-c & L. Paleo. & & Mammalia (Medium/large) & Long bone & 1 \\
\hline 59 & 40 & 2278 & Isi-c & L. Paleo. & & Mammalia (Small) & Permanent tooth & 1 \\
\hline 59 & 40 & 2278 & Isi-c & L. Paleo. & & Small/Medium Vertebrata & Long bone & 13 \\
\hline 59 & 40 & 2278 & Isi-c & L. Paleo. & & Vertebrata & Indeterminate & 34 \\
\hline 59 & 41 & 2269 & Isi-c & L. Paleo. & & Mammalia (Small) & Permanent tooth & 1 \\
\hline 59 & 41 & 2269 & Isi-c & L. Paleo. & & Small/Medium Vertebrata & Long bone & 8 \\
\hline 59 & 41 & 2269 & Isi-c & L. Paleo. & & Vertebrata & Indeterminate & 24 \\
\hline 59 & $42 \mathrm{~A}$ & 2272 & Isi-c & L. Paleo. & & Small/Medium Vertebrata & Long bone & 5 \\
\hline 59 & $42 \mathrm{~A}$ & 2272 & Isi-c & L. Paleo. & & Vertebrata & Indeterminate & 4 \\
\hline 59 & 43 & 2735 & Icl/Isi-c & Paleoindian & & |Leporidae & Permanent tooth & 1 \\
\hline 59 & 43 & 2735 & Icl/Isi-c & Paleoindian & & Medium/Large Vertebrata & Long bone & 1 \\
\hline 59 & 43 & 2735 & Icl/Isi-c & Paleoindian & & Small/Medium Vertebrata & Long bone & 3 \\
\hline 59 & 43 & 2735 & Icl/Isi-c & Paleoindian & & Testudinata & Shell fragment & 1 \\
\hline 59 & 43 & 2735 & Icl/Isi-c & Paleoindian & & Vertebrata & Indeterminate & 24 \\
\hline 59 & 44 & 2640 & Icl/Isi-c & Paleoindian & & Mammalia (Medium/large) & Indeterminate & 3 \\
\hline 59 & 44 & 2640 & Icl/Isi-c & Paleoindian & & Medium/Large Vertebrata & Indeterminate & 3 \\
\hline 59 & 44 & 2640 & Icl/Isi-c & Paleoindian & & Small/Medium Vertebrata & Long bone & 2 \\
\hline 59 & 44 & 2640 & Icl/Isi-c & Paleoindian & & Vertebrata & Indeterminate & 11 \\
\hline 59 & 45 & 2733 & Icl/Isi-c & Paleoindian & & Leporidae & Metacarpal 2 & 1 \\
\hline 59 & 45 & 2733 & Icl/Isi-c & Paleoindian & & Small/Medium Vertebrata & Long bone & 5 \\
\hline 59 & 45 & 2733 & Icl/Isi-c & Paleoindian & & Sylvilagus sp. & Metatarsal 2 & 1 \\
\hline
\end{tabular}




\begin{tabular}{|c|c|c|c|c|c|c|c|c|}
\hline Square & Level & Lot & Unit & Cultural Affinity & Feature & Taxon & Element & No. \\
\hline 59 & 45 & 2733 & Icl/Isi-c & Paleoindian & & Vertebrata & Indeterminate & 18 \\
\hline 59 & 46 & 2740 & Icl & E. Paleoindian & & Small/Medium Vertebrata & Long bone & 2 \\
\hline 59 & 47 & 2634 & Icl & E. Paleoindian & & Mammalia (Medium/large) & Indeterminate & 12 \\
\hline 59 & 47 & 2634 & Icl & E. Paleoindian & & Small/Medium Vertebrata & Long bone & 2 \\
\hline 59 & 47 & 2634 & Icl & E. Paleoindian & & Vertebrata & Indeterminate & 5 \\
\hline 59 & 48 & 2632 & Icl & E. Paleoindian & & Mammalia (Medium) & Long bone & 1 \\
\hline 59 & 48 & 2632 & Icl & E. Paleoindian & & Vertebrata & Indeterminate & 5 \\
\hline 59 & 49 & 2631 & Isi/Icl & E. Paleoindian & & Leporidae & Permanent tooth & 2 \\
\hline 59 & 49 & 2631 & Isi/Icl & E. Paleoindian & & Mammalia (Medium/large) & Indeterminate & 6 \\
\hline 59 & 49 & 2631 & Isi/Icl & E. Paleoindian & & Small/Medium Vertebrata & Long bone & 1 \\
\hline 59 & 49 & 2631 & Isi/Icl & E. Paleoindian & & Vertebrata & Indeterminate & 6 \\
\hline 59 & 50 & 2627 & Isi/Icl & E. Paleoindian & & Mammalia (Large) & Indeterminate & 1 \\
\hline 59 & 50 & 2627 & Isi/Icl & E. Paleoindian & & Mammalia (Medium/large) & Indeterminate & 3 \\
\hline 59 & 50 & 2627 & Isi/Icl & E. Paleoindian & & Small/Medium Vertebrata & Long bone & 2 \\
\hline 59 & 50 & 2627 & Isi/Icl & E. Paleoindian & & Vertebrata & Indeterminate & 3 \\
\hline 59 & 51 & 2387 & Isi/Icl & E. Paleoindian & & Medium/Large Vertebrata & Indeterminate & 1 \\
\hline 59 & 51 & 2775 & Isi/Icl & E. Paleoindian & & Mammalia (Large) & Indeterminate & 1 \\
\hline 59 & 51 & 2775 & Isi/Icl & E. Paleoindian & & Mammalia (Medium/large) & Indeterminate & 6 \\
\hline 59 & 51 & 2775 & Isi/Icl & E. Paleoindian & & Medium/Large Vertebrata & Indeterminate & 2 \\
\hline 59 & 51 & 2775 & Isi/Icl & E. Paleoindian & & Vertebrata & Indeterminate & 4 \\
\hline 59 & 52 & 2493 & Isi & E. Paleoindian & & Mammalia (Medium/large) & Indeterminate & 5 \\
\hline 59 & 52 & 2495 & Isi & E. Paleoindian & & Mammalia (Large) & Long bone & 1 \\
\hline 59 & 52 & 2503 & Isi & E. Paleoindian & & Mammalia (Medium/large) & Indeterminate & 12 \\
\hline 59 & 52 & 2503 & Isi & E. Paleoindian & & Medium/Large Vertebrata & Indeterminate & 1 \\
\hline 59 & 52 & 2503 & Isi & E. Paleoindian & & Vertebrata & Indeterminate & 14 \\
\hline 59 & 52 & 2508 & Isi & E. Paleoindian & & Vertebrata & Indeterminate & 6 \\
\hline 59 & 53 & 2529 & Isi & E. Paleoindian & & Mammalia (Medium/large) & Indeterminate & 2 \\
\hline 59 & 53 & 2568 & Isi & E. Paleoindian & & Mammalia (Medium/large) & Indeterminate & 8 \\
\hline 59 & 53 & 2568 & Isi & E. Paleoindian & & Mammalia (Small) & Permanent tooth & 1 \\
\hline 59 & 53 & 2568 & Isi & E. Paleoindian & & Sylvilagus sp. & Calcaneus & 1 \\
\hline 59 & 53 & 2568 & Isi & E. Paleoindian & & Sylvilagus sp. & Humerus & 1 \\
\hline 59 & 53 & 2568 & Isi & E. Paleoindian & & Vertebrata & Indeterminate & 33 \\
\hline 59 & 54 & 2734 & Isi & E. Paleoindian & & Medium/Large Vertebrata & Indeterminate & 1 \\
\hline 59 & 54 & 2734 & Isi & E. Paleoindian & & Vertebrata & Indeterminate & 12 \\
\hline 59 & 55 & 2648 & Isi & E. Paleoindian & & Mammalia (Very large) & Long bone & 1 \\
\hline 59 & 55 & 2654 & Isi & E. Paleoindian & & Medium/Large Vertebrata & Indeterminate & 3 \\
\hline 59 & 55 & 2654 & Isi & E. Paleoindian & & Vertebrata & Indeterminate & 5 \\
\hline 59 & 56 & 2781 & Isi & E. Paleoindian & & Medium/Large Vertebrata & Indeterminate & 1 \\
\hline 60 & 56 & 2697 & Igl/Isi & E. Paleoindian & & Medium/Large Vertebrata & Indeterminate & 4 \\
\hline 60 & 56 & 2697 & Igl/Isi & E. Paleoindian & & Testudinata & Carapace fragment ind. & 1 \\
\hline 100 & 2 & 1206 & IIIc & L. Archaic/L. Prehist. & BRM 1 & Antilocapra/Odocoileus & Metapodial & 1 \\
\hline 100 & 2 & 1206 & IIIc & L. Archaic/L. Prehist. & BRM 1 & Antilocapra/Odocoileus & Middle phalange & 1 \\
\hline 100 & 2 & 1206 & IIIc & L. Archaic/L. Prehist. & BRM 1 & Antilocapra/Odocoileus & Phalange & 2 \\
\hline 100 & 2 & 1206 & IIIC & L. Archaic/L. Prehist. & BRM 1 & AntilocapralOdocoileus & Radius & 1 \\
\hline 100 & 2 & 1206 & IIIc & L. Archaic/L. Prehist. & BRM 1 & Colubridae & Dorsal vertebra & 2 \\
\hline 100 & 2 & 1206 & IIIc & L. Archaic/L. Prehist. & BRM 1 & Geomys sp. & Ulna & 1 \\
\hline 100 & 2 & 1206 & IIII & L. Archaic/L. Prehist. & BRM 1 & Leporidae & Permanent tooth & 1 \\
\hline 100 & 2 & 1206 & IIII & L. Archaic/L. Prehist. & BRM 1 & Lepus californicus & Permanent tooth & 1 \\
\hline 100 & 2 & 1206 & IIIc & L. Archaic/L. Prehist. & BRM 1 & Mammalia (Large) & Cranium & 1 \\
\hline 100 & 2 & 1206 & IIIc & L. Archaic/L. Prehist. & BRM 1 & Mammalia (Large) & Indeterminate & 1 \\
\hline 100 & 2 & 1206 & IIIC & L. Archaic/L. Prehist. & BRM 1 & Mammalia (Large) & Long bone & 3 \\
\hline 100 & 2 & 1206 & IIIc & L. Archaic/L. Prehist. & BRM 1 & Mammalia (Medium) & Femur & 1 \\
\hline 100 & 2 & 1206 & IIIc & L. Archaic/L. Prehist. & BRM 1 & Mammalia (Medium/large) & Indeterminate & 75 \\
\hline 100 & 2 & 1206 & IIIc & L. Archaic/L. Prehist. & BRM 1 & Mammalia (Medium/large) & Long bone & 51 \\
\hline 100 & 2 & 1206 & IIIc & L. Archaic/L. Prehist. & BRM 1 & Mammalia (Medium/large) & Permanent tooth & 1 \\
\hline 100 & 2 & 1206 & IIIc & L. Archaic/L. Prehist. & BRM 1 & Mammalia (Medium/large) & Tooth, perm./decid. ind. & 18 \\
\hline 100 & 2 & 1206 & IIII & L. Archaic/L. Prehist. & BRM 1 & Mammalia (Medium/large) & Vertebra & 1 \\
\hline 100 & 2 & 1206 & IIIc & L. Archaic/L. Prehist. & BRM 1 & Mammalia (Micro) & Permanent tooth & 1 \\
\hline 100 & 2 & 1206 & IIIc & L. Archaic/L. Prehist. & BRM 1 & Mammalia (Small) & Metapodial & 1 \\
\hline 100 & 2 & 1206 & IIII & L. Archaic/L. Prehist. & BRM 1 & Mammalia (Small) & Tibia & 1 \\
\hline 100 & 2 & 1206 & IIIc & L. Archaic/L. Prehist. & BRM 1 & Odocoileus sp. & Fused second \& third carpal & 2 \\
\hline 100 & 2 & 1206 & IIIc & L. Archaic/L. Prehist. & BRM 1 & Odocoileus sp. & Fused second \& third tarsal & 1 \\
\hline 100 & 2 & 1206 & IIII & L. Archaic/L. Prehist. & BRM 1 & Odocoileus sp. & Permanent tooth & 7 \\
\hline 100 & 2 & 1206 & IIIc & L. Archaic/L. Prehist. & BRM 1 & Odocoileus sp. & Phalange & 1 \\
\hline 100 & 2 & 1206 & IIIc & L. Archaic/L. Prehist. & BRM 1 & Odocoileus sp. & Proximal axial sesamoid & 1 \\
\hline 100 & 2 & 1206 & IIII & L. Archaic/L. Prehist. & BRM 1 & Odocoileus sp. & Proximal phalange & 1 \\
\hline 100 & 2 & 1206 & IIIc & L. Archaic/L. Prehist. & BRM 1 & Odocoileus sp. & Tooth, perm./decid. ind. & 3 \\
\hline
\end{tabular}




\begin{tabular}{|c|c|c|c|c|c|c|c|c|}
\hline Square & Level & Lot & Unit & Cultural Affinity & Feature & Taxon & Element & No. \\
\hline 100 & 2 & 1206 & IIIc & L. Archaic/L. Prehist. & $\overline{B R M} 1$ & Small/Medium Vertebrata & Long bone & 10 \\
\hline 100 & 2 & 1206 & IIII & L. Archaic/L. Prehist. & BRM 1 & Sylvilagus sp. & Radius & 2 \\
\hline 100 & 2 & 1206 & IIIIc & L. Archaic/L. Prehist. & BRM 1 & Testudinata & Carapace fragment ind. & 1 \\
\hline 100 & 2 & 1206 & IIIIc & L. Archaic/L. Prehist. & BRM 1 & Testudinata & Shell fragment & 2 \\
\hline 100 & 2 & 1206 & IIIIc & L. Archaic/L. Prehist. & BRM 1 & Vertebrata & Indeterminate & 860 \\
\hline 100 & 3 & 1265 & IIIc & L. Archaic & BRM 1 & Antilocapra/Odocoileus & Fused 3rd \& 4th metatarsal & 1 \\
\hline 100 & 3 & 1265 & IIIIc & L. Archaic & BRM 1 & Antilocapra/Odocoileus & Middle phalange & 1 \\
\hline 100 & 3 & 1265 & IIIIc & L. Archaic & BRM 1 & Antilocapra/Odocoileus & Phalange & 2 \\
\hline 100 & 3 & 1265 & IIIIc & L. Archaic & BRM 1 & Colubridae & Dorsal vertebra & 1 \\
\hline 100 & 3 & 1265 & IIIIc & L. Archaic & BRM 1 & Geomys sp. & Permanent tooth & 1 \\
\hline 100 & 3 & 1265 & IIIIc & L. Archaic & BRM 1 & Mammalia (Large) & Long bone & 2 \\
\hline 100 & 3 & 1265 & IIIIc & L. Archaic & BRM 1 & Mammalia (Medium) & Metapodial & 1 \\
\hline 100 & 3 & 1265 & IIIIc & L. Archaic & BRM 1 & Mammalia (Medium) & Third tarsal & 1 \\
\hline 100 & 3 & 1265 & IIII & L. Archaic & BRM 1 & Mammalia (Medium/large) & Alveolar ridge fragment & 1 \\
\hline 100 & 3 & 1265 & IIIIc & L. Archaic & BRM 1 & Mammalia (Medium/large) & Indeterminate & 138 \\
\hline 100 & 3 & 1265 & IIIIc & L. Archaic & BRM 1 & Mammalia (Medium/large) & Long bone & 59 \\
\hline 100 & 3 & 1265 & IIIIc & L. Archaic & BRM 1 & Mammalia (Medium/large) & Mandible & 1 \\
\hline 100 & 3 & 1265 & IIIIc & L. Archaic & BRM 1 & Mammalia (Medium/large) & Rib & 1 \\
\hline 100 & 3 & 1265 & IIIIc & L. Archaic & BRM 1 & Mammalia (Medium/large) & Tooth, perm./decid. ind. & 7 \\
\hline 100 & 3 & 1265 & IIIIc & L. Archaic & BRM 1 & Mammalia (Micro) & Mandible & 1 \\
\hline 100 & 3 & 1265 & IIIIc & L. Archaic & BRM 1 & Medium/Large Vertebrata & Indeterminate & 1 \\
\hline 100 & 3 & 1265 & IIIIc & L. Archaic & BRM 1 & Odocoileus sp. & Middle phalange & 1 \\
\hline 100 & 3 & 1265 & IIIIc & L. Archaic & BRM 1 & Odocoileus sp. & Tibia & 1 \\
\hline 100 & 3 & 1265 & IIII & L. Archaic & BRM 1 & Odocoileus sp. & Tooth, perm./decid. ind. & 5 \\
\hline 100 & 3 & 1265 & IIII & L. Archaic & BRM 1 & Serpentes & Dorsal vertebra & 1 \\
\hline 100 & 3 & 1265 & IIIIc & L. Archaic & BRM 1 & Small vertebrate, class ind. & Phalange & 1 \\
\hline 100 & 3 & 1265 & IIII & L. Archaic & BRM 1 & Small/Medium Vertebrata & Long bone & 25 \\
\hline 100 & 3 & 1265 & IIIc & L. Archaic & BRM 1 & Sylvilagus sp. & Central tarsal bone & 1 \\
\hline 100 & 3 & 1265 & IIIIc & L. Archaic & BRM 1 & Testudinata & Carapace fragment ind. & 2 \\
\hline 100 & 3 & 1265 & IIIIc & L. Archaic & BRM 1 & Testudinata & Shell fragment & 3 \\
\hline 100 & 3 & 1265 & IIIIc & L. Archaic & BRM 1 & Vertebrata & Indeterminate & 359 \\
\hline 100 & 3 & 1265 & IIIIc & L. Archaic & BRM 1 & Viperidae & Dorsal vertebra & 2 \\
\hline 100 & 4 & 1295 & IIIIc & L. Archaic & BRM 1 & Antilocapra/Odocoileus & Fused 3rd \& 4th metatarsal & 1 \\
\hline 100 & 4 & 1295 & IIIIc & L. Archaic & BRM 1 & Colubridae & Dorsal vertebra & 1 \\
\hline 100 & 4 & 1295 & IIII & L. Archaic & BRM 1 & Lepus californicus & Permanent tooth & 1 \\
\hline 100 & 4 & 1295 & IIIc & L. Archaic & BRM 1 & Mammalia (Large) & Indeterminate & 2 \\
\hline 100 & 4 & 1295 & IIIIc & L. Archaic & BRM 1 & Mammalia (Medium) & Femur & 1 \\
\hline 100 & 4 & 1295 & IIIIc & L. Archaic & BRM 1 & Mammalia (Medium/large) & Indeterminate & 20 \\
\hline 100 & 4 & 1295 & IIIIc & L. Archaic & BRM 1 & Mammalia (Medium/large) & Long bone & 3 \\
\hline 100 & 4 & 1295 & IIIc & L. Archaic & BRM 1 & Mammalia (Medium/large) & Tooth, perm./decid. ind. & 6 \\
\hline 100 & 4 & 1295 & IIII & L. Archaic & BRM 1 & Mammalia (Small) & Patella & 1 \\
\hline 100 & 4 & 1295 & IIIIc & L. Archaic & BRM 1 & Small vertebrate, class ind. & Distal phalange & 1 \\
\hline 100 & 4 & 1295 & IIIc & L. Archaic & BRM 1 & Small/Medium Vertebrata & Long bone & 17 \\
\hline 100 & 4 & 1295 & IIIIc & L. Archaic & BRM 1 & Sylvilagus sp. & Humerus & 1 \\
\hline 100 & 4 & 1295 & IIIIc & L. Archaic & BRM 1 & Testudinata & Shell fragment & 2 \\
\hline 100 & 4 & 1295 & IIIIc & L. Archaic & BRM 1 & Vertebrata & Indeterminate & 70 \\
\hline 100 & 5 & 1308 & IIIIc & L. Archaic & BRM 1 & Small/Medium Vertebrata & Long bone & 1 \\
\hline 100 & 5 & 1315 & IIIc & L. Archaic & BRM 1 & Mammalia (Medium/large) & Indeterminate & 4 \\
\hline 100 & 5 & 1315 & IIIc & L. Archaic & BRM 1 & Mammalia (Medium/large) & Tooth, perm./decid. ind. & 2 \\
\hline 100 & 5 & 1315 & IIIIC & L. Archaic & BRM 1 & Mammalia (Micro) & Metapodial & 1 \\
\hline 100 & 5 & 1315 & IIIIc & L. Archaic & BRM 1 & Medium/Large Vertebrata & Indeterminate & 1 \\
\hline 100 & 5 & 1315 & IIIC & L. Archaic & BRM 1 & Small/Medium Vertebrata & Long bone & 10 \\
\hline 100 & 5 & 1315 & IIIC & L. Archaic & BRM 1 & Testudinata & Carapace fragment ind. & 1 \\
\hline 100 & 5 & 1315 & IIIIc & L. Archaic & BRM 1 & Vertebrata & Indeterminate & 44 \\
\hline 100 & 6 & 1349 & IIIIc & Archaic & BRM 1 & Mammalia (Medium/large) & Indeterminate & 2 \\
\hline 100 & 6 & 1349 & IIIC & Archaic & BRM 1 & Mammalia (Medium/large) & Tooth, perm./decid. ind. & 2 \\
\hline 100 & 6 & 1349 & IIIIc & Archaic & BRM 1 & Serpentes & Dorsal vertebra & 1 \\
\hline 100 & 6 & 1349 & IIIIc & Archaic & BRM 1 & Small/Medium Vertebrata & Long bone & 14 \\
\hline 100 & 6 & 1349 & IIIIc & Archaic & BRM 1 & Sylvilagus sp. & Permanent tooth & 1 \\
\hline 100 & 6 & 1349 & IIIIc & Archaic & BRM 1 & Testudinata & Shell fragment & 1 \\
\hline 100 & 6 & 1349 & IIIc & Archaic & BRM 1 & Vertebrata & Indeterminate & 69 \\
\hline 100 & 6 & 1353 & IIIIc & Archaic & BRM 1 & Vertebrata & Indeterminate & 1 \\
\hline 100 & 7 & 1384 & IIIIc & Archaic & BRM 1 & Anura & Long bone & 1 \\
\hline 100 & 7 & 1384 & IIIc & Archaic & BRM 1 & Carnivora & Permanent tooth & 1 \\
\hline 100 & 7 & 1384 & IIIc & Archaic & BRM 1 & Mammalia (Medium) & Metapodial & 1 \\
\hline 100 & 7 & 1384 & IIIIc & Archaic & BRM 1 & Mammalia (Medium/large) & Indeterminate & 3 \\
\hline 100 & 7 & 1384 & IIIIc & Archaic & BRM 1 & Mammalia (Medium/large) & Long bone & 2 \\
\hline
\end{tabular}




\begin{tabular}{|c|c|c|c|c|c|c|c|c|}
\hline Square & Level & Lot & Unit & Cultural Affinity & Feature & Taxon & Element & No. \\
\hline 100 & 7 & 1384 & IIIc & Archaic & $\overline{\text { BRM } 1}$ & Mammalia (Micro) & Permanent tooth & 1 \\
\hline 100 & 7 & 1384 & IIIC & Archaic & BRM 1 & Small/Medium Vertebrata & Long bone & 14 \\
\hline 100 & 7 & 1384 & IIIIc & Archaic & BRM 1 & Vertebrata & Indeterminate & 41 \\
\hline 100 & 8 & 1422 & IIIIc & Archaic & BRM 1 & Colubridae & Dorsal vertebra & 1 \\
\hline 100 & 8 & 1422 & IIIc & Archaic & BRM 1 & Mammalia (Medium) & Proximal phalange & 1 \\
\hline 100 & 8 & 1422 & IIIIc & Archaic & BRM 1 & Mammalia (Micro) & Calcaneus & 1 \\
\hline 100 & 8 & 1422 & IIIIc & Archaic & BRM 1 & Small/Medium Vertebrata & Long bone & 20 \\
\hline 100 & 8 & 1422 & IIIIc & Archaic & BRM 1 & Sylvilagus sp. & Metatarsal 4 & 1 \\
\hline 100 & 8 & 1422 & IIIIc & Archaic & BRM 1 & Testudinata & Shell fragment & 2 \\
\hline 100 & 8 & 1422 & IIIIc & Archaic & BRM 1 & Vertebrata & Indeterminate & 55 \\
\hline 100 & 9 & 1505 & $\mathrm{Y} / \mathrm{III} \mathrm{c}$ & Archaic & & Mammalia (Medium) & Alveolar ridge fragment & 1 \\
\hline 100 & 9 & 1505 & $\mathrm{Y} / \mathrm{III} \mathrm{c}$ & Archaic & & Mammalia (Micro) & Calcaneus & 2 \\
\hline 100 & 9 & 1505 & $\mathrm{Y} / \mathrm{III} \mathrm{c}$ & Archaic & & Medium/Large Vertebrata & Indeterminate & 2 \\
\hline 100 & 9 & 1505 & $\mathrm{Y} / \mathrm{III} \mathrm{c}$ & Archaic & & Odocoileus sp. & Proximal phalange & 1 \\
\hline 100 & 9 & 1505 & $\mathrm{Y} / \mathrm{III} \mathrm{c}$ & Archaic & & Osteichthyes (Small) & Vertebra & 1 \\
\hline 100 & 9 & 1505 & $\mathrm{Y} / \mathrm{IIIc}$ & Archaic & & Small/Medium Vertebrata & Long bone & 14 \\
\hline 100 & 9 & 1505 & $\mathrm{Y} / \mathrm{III} \mathrm{c}$ & Archaic & & Testudinata & Plastron fragment ind. & 1 \\
\hline 100 & 9 & 1505 & $\mathrm{Y} / \mathrm{IIIc}$ & Archaic & & Testudinata & Shell fragment & 2 \\
\hline 100 & 9 & 1505 & $\mathrm{Y} / \mathrm{III} \mathrm{c}$ & Archaic & & Vertebrata & Indeterminate & 69 \\
\hline 100 & 10 & 1560 & Y & E. Archaic & & Antilocapra/Odocoileus & Proximal phalange & 1 \\
\hline 100 & 10 & 1560 & Y & E. Archaic & & Colubridae & Dorsal vertebra & 3 \\
\hline 100 & 10 & 1560 & Y & E. Archaic & & Leporidae & Permanent tooth & 1 \\
\hline 100 & 10 & 1560 & Y & E. Archaic & & Mammalia (Large) & Indeterminate & 1 \\
\hline 100 & 10 & 1560 & Y & E. Archaic & & Mammalia (Medium/large) & Long bone & 1 \\
\hline 100 & 10 & 1560 & Y & E. Archaic & & Mammalia (Micro) & Mandible & 1 \\
\hline 100 & 10 & 1560 & Y & E. Archaic & & Small vertebrate, class ind. & Vertebra & 1 \\
\hline 100 & 10 & 1560 & Y & E. Archaic & & Small/Medium Vertebrata & Long bone & 26 \\
\hline 100 & 10 & 1560 & Y & E. Archaic & & Testudinata & Shell fragment & 3 \\
\hline 100 & 10 & 1560 & Y & E. Archaic & & Vertebrata & Indeterminate & 105 \\
\hline 100 & 10 & 1563 & Y & E. Archaic & & Small vertebrate, class ind. & Phalange & 1 \\
\hline 100 & 10 & 1563 & Y & E. Archaic & & Small vertebrate, class ind. & Proximal phalange & 1 \\
\hline 100 & 10 & 1563 & Y & E. Archaic & & Vertebrata & Indeterminate & 2 \\
\hline 100 & 11 & 1668 & Y & E. Archaic & & Mammalia (Medium/large) & Indeterminate & 1 \\
\hline 100 & 11 & 1668 & Y & E. Archaic & & Mammalia (Medium/large) & Long bone & 4 \\
\hline 100 & 11 & 1668 & Y & E. Archaic & & Mammalia (Medium/large) & Tooth, perm./decid. ind. & 1 \\
\hline 100 & 11 & 1668 & Y & E. Archaic & & Mammalia (Small) & Permanent tooth & 1 \\
\hline 100 & 11 & 1668 & Y & E. Archaic & & Small vertebrate, class ind. & Phalange & 1 \\
\hline 100 & 11 & 1668 & Y & E. Archaic & & Small/Medium Vertebrata & Long bone & 12 \\
\hline 100 & 11 & 1668 & Y & E. Archaic & & Vertebrata & Indeterminate & 59 \\
\hline 101 & 12 & 2083 & Y & E. Archaic & & Lepus californicus & Astragalus & 1 \\
\hline 101 & 12 & 2083 & Y & E. Archaic & & Mammalia (Medium/large) & Tooth, perm./decid. ind. & 3 \\
\hline 101 & 12 & 2083 & Y & E. Archaic & & Mammalia (Small) & Radius & 1 \\
\hline 101 & 12 & 2083 & $Y$ & E. Archaic & & Medium/Large Vertebrata & Indeterminate & 4 \\
\hline 101 & 12 & 2083 & Y & E. Archaic & & Serpentes & Dorsal vertebra & 2 \\
\hline 101 & 12 & 2083 & Y & E. Archaic & & Small/Medium Vertebrata & Long bone & 11 \\
\hline 101 & 12 & 2083 & Y & E. Archaic & & Testudinata & Shell fragment & 4 \\
\hline 101 & 12 & 2083 & Y & E. Archaic & & Vertebrata & Indeterminate & 112 \\
\hline 101 & 13 & 2858 & Y & E. Archaic & & Serpentes & Dorsal vertebra & 1 \\
\hline 101 & 13 & 2858 & Y & E. Archaic & & Small/Medium Vertebrata & Long bone & 2 \\
\hline 101 & 13 & 2858 & Y & E. Archaic & & Vertebrata & Indeterminate & 2 \\
\hline 101 & 15 & 2651 & $X$ & E. Archaic & & Leporidae & Mandible & 1 \\
\hline 101 & 15 & 2651 & $\mathrm{X}$ & E. Archaic & & Leporidae & Permanent tooth & 1 \\
\hline 101 & 15 & 2651 & $\mathrm{X}$ & E. Archaic & & Lepus californicus & Permanent tooth & 1 \\
\hline 101 & 15 & 2651 & $\mathrm{X}$ & E. Archaic & & Mammalia (Small) & Alveolar ridge fragment & 1 \\
\hline 101 & 15 & 2651 & $\mathrm{X}$ & E. Archaic & & Serpentes & Dorsal vertebra & 1 \\
\hline 101 & 15 & 2651 & $\mathrm{X}$ & E. Archaic & & Small/Medium Vertebrata & Long bone & 6 \\
\hline 101 & 15 & 2651 & $\mathrm{X}$ & E. Archaic & & Vertebrata & Indeterminate & 8 \\
\hline 101 & 16 & 2805 & $\mathrm{X}$ & E. Archaic & & Medium/Large Vertebrata & Indeterminate & 7 \\
\hline 101 & 16 & 2805 & $\mathrm{X}$ & E. Archaic & & Small/Medium Vertebrata & Long bone & 2 \\
\hline 101 & 16 & 2805 & $\mathrm{X}$ & E. Archaic & & Vertebrata & Indeterminate & 19 \\
\hline 101 & 17 & 2827 & $\mathrm{X}$ & E. Archaic & & Leporidae & Permanent tooth & 1 \\
\hline 101 & 17 & 2827 & $\mathrm{X}$ & E. Archaic & & Mammalia (Large) & Indeterminate & 1 \\
\hline 101 & 17 & 2827 & $\mathrm{X}$ & E. Archaic & & Mammalia (Medium/large) & Indeterminate & 2 \\
\hline 101 & 17 & 2827 & $\mathrm{X}$ & E. Archaic & & Mammalia (Medium/large) & Tooth, perm./decid. ind. & 1 \\
\hline 101 & 17 & 2827 & $\mathrm{X}$ & E. Archaic & & Mammalia (Micro) & Cranium & 1 \\
\hline 101 & 17 & 2827 & $\mathrm{X}$ & E. Archaic & & Mammalia (Small) & Radius & 1 \\
\hline 101 & 17 & 2827 & $\mathrm{X}$ & E. Archaic & & Small/Medium Vertebrata & Long bone & 2 \\
\hline
\end{tabular}




\begin{tabular}{|c|c|c|c|c|c|c|c|c|}
\hline Square & Level & Lot & Unit & Cultural Affinity & Feature & Taxon & Element & No. \\
\hline 101 & 17 & 2827 & $\mathrm{X}$ & E. Archaic & & Vertebrata & Indeterminate & 13 \\
\hline 101 & 18 & 2688 & $\mathrm{X}$ & L. Paleo./E. Archaic & & Leporidae & Permanent tooth & 1 \\
\hline 101 & 18 & 2688 & $\mathrm{x}$ & L. Paleo./E. Archaic & & Mammalia (Medium/large) & Indeterminate & 2 \\
\hline 101 & 18 & 2688 & $\mathrm{x}$ & L. Paleo./E. Archaic & & Small/Medium Vertebrata & Long bone & 3 \\
\hline 101 & 18 & 2688 & $\mathrm{x}$ & L. Paleo./E. Archaic & & Vertebrata & Indeterminate & 19 \\
\hline 101 & 19 & 2795 & $\mathrm{x}$ & L. Paleo./E. Archaic & & Vertebrata & Indeterminate & 1 \\
\hline 101 & 21 & 2147 & $\mathrm{x}$ & L. Paleo./E. Archaic & & Vertebrata & Indeterminate & 2 \\
\hline 101 & 22 & 2291 & $\mathrm{x}$ & L. Paleo./E. Archaic & & Vertebrata & Indeterminate & 1 \\
\hline 101 & 24 & 2731 & $\mathrm{X}$ & Paleoindian & & Vertebrata & Indeterminate & 1 \\
\hline 101 & 26 & 2629 & $\mathrm{x}$ & Paleoindian & & Vertebrata & Indeterminate & 1 \\
\hline 101 & 27 & 2727 & $\mathrm{X}$ & Paleoindian & & Vertebrata & Indeterminate & 1 \\
\hline B & 1 & 297 & Isi & E. Paleoindian & & Small/Medium Vertebrata & Long bone & 2 \\
\hline B & 1 & 297 & Isi & E. Paleoindian & & Sylvilagus sp. & Permanent tooth & 1 \\
\hline B & 1 & 297 & Isi & E. Paleoindian & & Vertebrata & Indeterminate & 2 \\
\hline B & 2 & 136 & Isi & E. Paleoindian & & Vertebrata & Indeterminate & 9 \\
\hline B & 3 & 143 & Igl/Isi & E. Paleoindian & & Mammalia (Medium/large) & Long bone & 1 \\
\hline B & 3 & 143 & Igl/Isi & E. Paleoindian & & Sylvilagus sp. & Ulna & 1 \\
\hline B & 3 & 143 & $\mathrm{Igl} / \mathrm{Isi}$ & E. Paleoindian & & Vertebrata & Indeterminate & 1 \\
\hline Unknown & 0 & 1489 & $?$ & Unassigned & & Mammalia (Large) & Pelvis & 1 \\
\hline Unknown & 0 & 2446 & ? & Unassigned & & Mammalia (Large) & Indeterminate & 5 \\
\hline Unknown & $39-45$ & 2785 & ? & Unassigned & & Leporidae & Permanent tooth & 1 \\
\hline Unknown & 43 & 2261 & ? & Unassigned & & Mammalia (Medium/large) & Indeterminate & 1 \\
\hline
\end{tabular}


ISBN 1-887072-29-2 (Volume V)

ISBN 1-887072-24-1 (5 Volume Set) 